


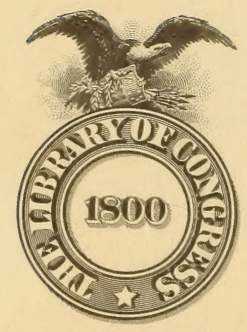








\section{HANDBOOK OF BIRDS}

OF EASTERN NORTH AMERICA 


\section{By FRANK M. CHAPMAN}

Curator of Ornithology in the American Museum of Natural History

HANDBOOK OF BIRDS OF EASTERN NORTH AMERICA

Revised Edition. With Keys to the Species, Descriptions of their Plumages, Nests, etc., and their Distribution and Migrations. With over 200 Illustrations. I2mo.

Library Edition, \$3.50 net. Postpaid, \$3.64.

Pocket Edition, flexible covers, $\$ 400$ net. Postpaid, \$4.10.

BIRD=LIFE. A Guide to the Study of Our Common Birds

Popular EDition in colors, \$2.00 net. Postpaid, \$2. I6.

BIRD STUDIES WITH A CAMERA. With Introductory Chapters on the Outfit and Methods of the Bird Photographer

Illustrated with over IOO Photographs from Nature by the Author. I2mo. Cloth, \$1.75, postpaid.

\section{THE WARBLERS OF NORTH AMERICA}

With Contributions from other Ornithologists and 24 full-page Colored Plates illustrating every Species, from Drawings by L. A. Fuertes and B. Horsfall, and Half-tones of Nests and Eggs. 8vo. Cloth, \$3.00 net. Postpaid, \$3.20.

\section{CAMPS AND CRUISES OF AN ORNITHOLOGIST}

With 250 Photographs from Nature by the Author. 8vo. Cloth, \$3.00 net. Postpaid, \$3.24.

D. APPLETON AND COMPANY, NEW YORK 



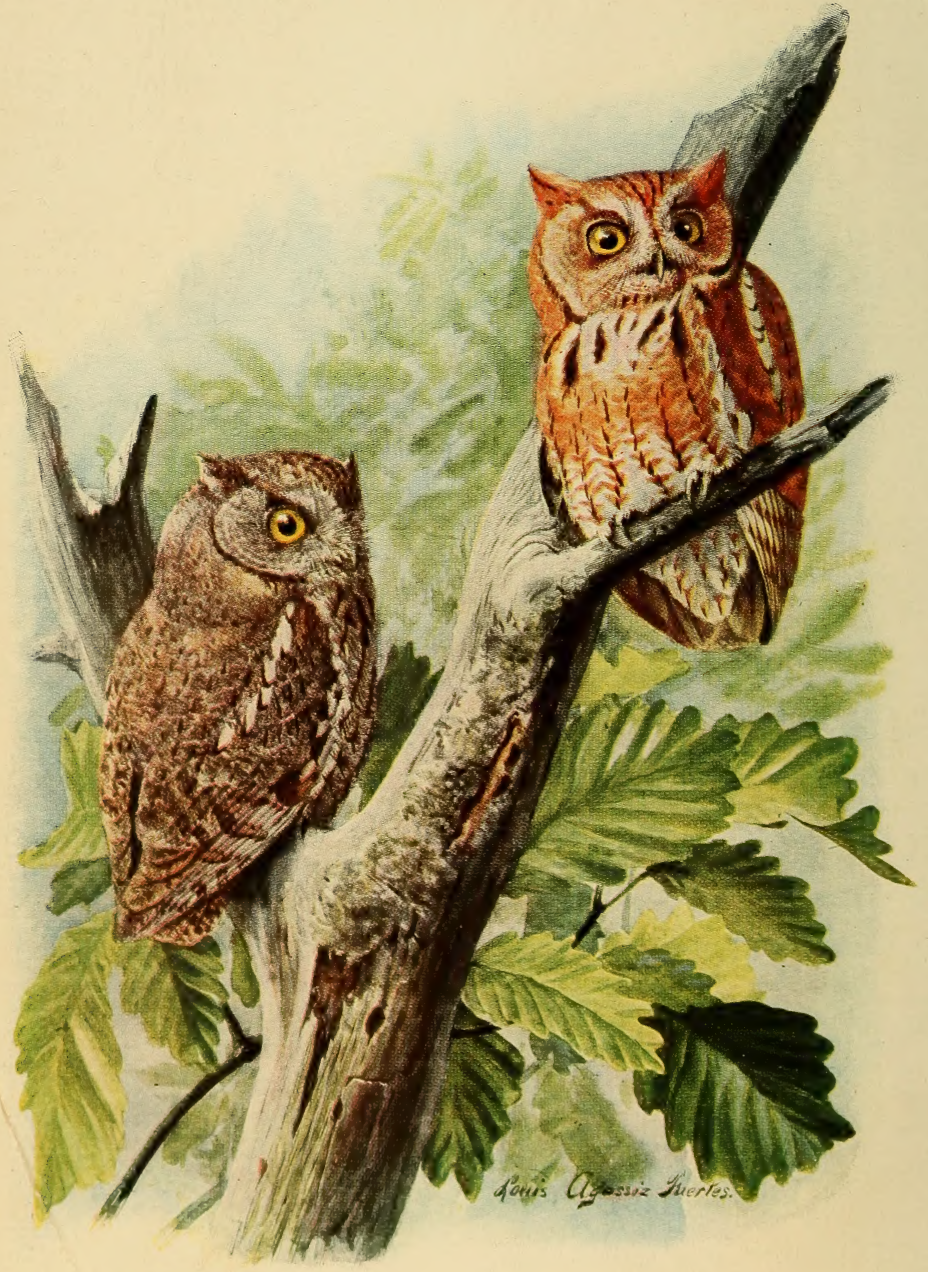

Screech OWL

Gray and rufous phases of plumage 


\title{
HANDBOOK OF BIRDS OF EASTERN NORTH AMERICA
}

WITH INTRODUCTORY CHAPTERS ON THE STUDY OF BIRDS IN NATURE

\author{
BY \\ FRANK M. CHAPMAN
}

CURATOR OF ORNITHOLOGY IN THE AMERICAN MUSEUM OF NATURAL HISTORY FELLOW OF THE AMERICAN ORNITHOLOGISTS' UNION FOREIGN MEMBER OF THE BRITISH ORNITHOLOGISTS' UNION, ETC.

WITH FULL-PAGE PLATES IN OOLORS AND BLAOK AND WHITE BY LOUIS AGASSIZ FLERTES

AND TEXT-OUTS BY TAPPAN ADNEY AND ERNEST THOMPSON SETON

REVISED EDITION

NEW YORK AND LONDON

D. APPLETON AND COMPANY 


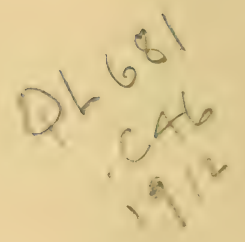

COPYRIGHT, 1895, 1912

By D. APPLETON AND COMPANY

Published May, 1912

Printed in the United States of America 


\section{TO MY MOTHER}

WHO HAS EVER ENCOURAGED HER SON IN HIS NATURAL HISTORY STUDIES

THIS BOOK IS AFFECTIONATELY DEDICATED 



\section{PLAN OF THE WORK}

Introduction.-The Introduction to the present edition of the "Handbook" is wholly new, and is designed to meet the wants of a class of bird-students which was almost unknown when the first edition of the "Handbook" was written. Field work in eastern North America then meant chiefly collecting. Now it means chiefly observing. The observation blind, the camera, the note-book to record prolonged, consecutive, definitely directed studies, were then used rarely, if at all. Now they form part of the equipment of all serious students of birds in nature, and it is to them that this Introduction is addressed.

Nomenclature.-The nomenclature of the American Ornithologists' Union's "Check-List of North American Birds" (third edition, 1910) has been adopted. The number preceding the name of each species is its permanent number in the Union's "Check-List."

Through an oversight, trinomials were not employed in the "CheckList" for certain races, of which only the one first described occurs in North America, and such species are here entered under their proper trinomial designation.

I have not, however, followed this plan for species of wholly accidental occurrence, with which a re-examination of the specimen or specimens on which the records are based might be essential to their correct subspecific determination.

With the object of encouraging uniformity in the use of common or vernacular names of our birds, I have given in the body of the book only one such name for each species - that adopted for it in the "CheckList" of the American Ornithologists' Union. Other common names, which have been or are in more or less general use, are given in the index, with a cross reference to the name with which they are synonymous.

In some instances, I have taken the common names of the earlier, rather than of the last, edition of the "Check-List," in which abbreviations have been made with consequent loss of definir ess. Examples are "Scaup," "Scoter," "Crossbill," and other instances where two or more species, having the same general name, are found in the same locality. In such cases, it is evident that, to avoid ambiguity, each one should have some qualifying title.

Definition of Terms.- The accompanying figure, with its named parts, will explain the meaning of the terms used in the following descriptions of birds. The words upperparts and underparts, mentioned so frequently, refer respectively to the whole upper or under surfaces of the body of the bird, from the base of the bill to the root of the tail, but are not applied to either wings or tail. 
xiv

There are infinite variations in the markings of feathers, and those figured present only the patterns most frequently met with. The

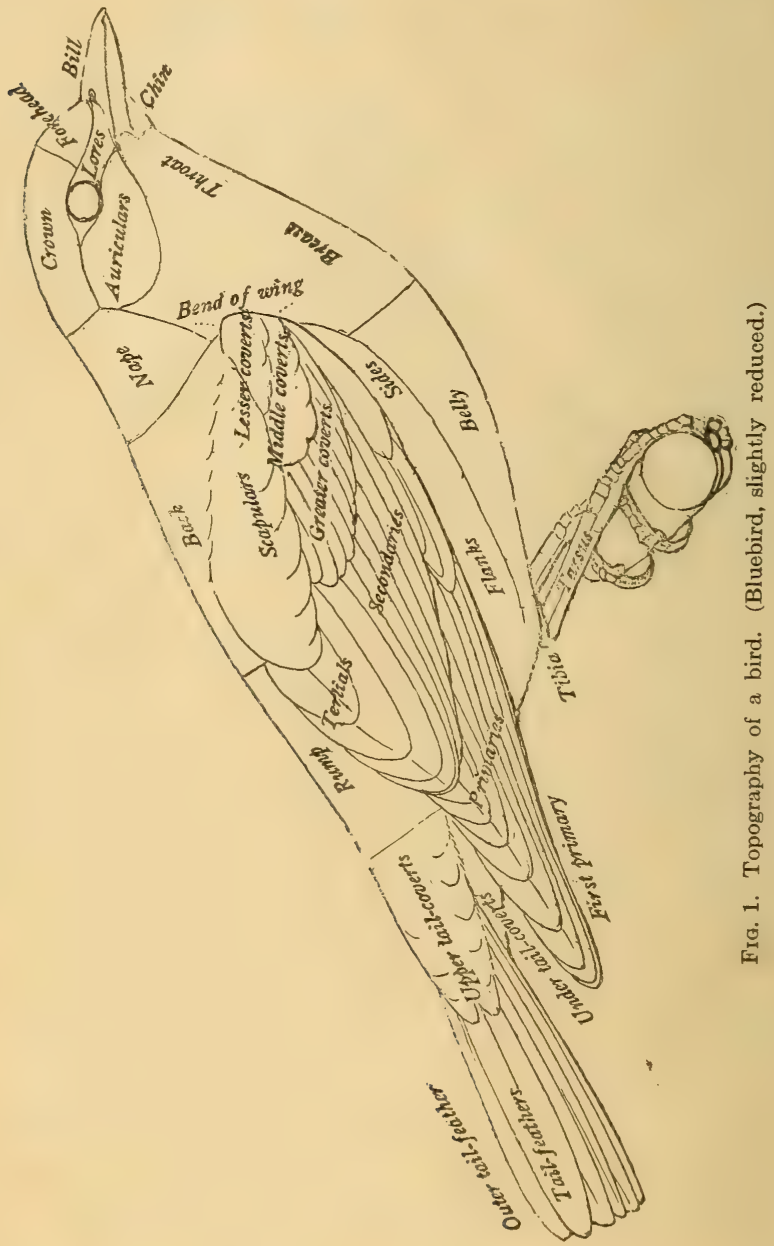

shaft of the feather is the midrib, to either side of which the vanes, or webs, are attached. (See Fig. 2.)

The Keys.-It is of the utmost importance thoroughly to under- 


\section{PREFACE TO THE REVISED EDITION}

In preparing a revised edition of the "Handbook," it was decided that any increase in size which would remove it from the ranks of true handbooks was not to be considered for a moment. The question, then, with which I have been confronted, was, how, within given limits, to meet the wants of the bird student of today, who demands, primarily, information concerning the bird in nature. To add materially to the space given to each of the species contained in the first edition would result in widely overstepping the bounds set by necessity. But, if it were not possible to present a complete biography of every bird, at least a suggestive biography of the bird could be given, and the expansion in size permitted has been largely used for this purpose.

This added material will be found in the introductory pages, which number 116, as compared with 31 in the original edition.

Here I have dealt with those phases of bird-life which, to a greater or less extent, enter into the existence of every species. These chapters on migration, song, nesting habits, color, structure and function, food, etc., may be read not only alone, but they are intended to be a guide to the study in life of any bird to which we may devote our attention. In short, they are designed to arouse an interest in the bird in relation to its environment, and to stimulate and direct original observations.

Aside from this Introduction, which constitutes both the largest and most important addition to the new "Handbook," the balance of the book has been thoroughly revised, much of it has been rewritten, and not a little of it is wholly new. The nomenclature is that of the last (1910) edition of the A. O. U. Check-List. 'The Ranges have also been taken from this same authoritative souree, and are a vast improvement over those of the first edition of the "Handbook." In addition to the migration notes given in preceding editions, data are now also included for northern ()hio, Glen Ellyn, Illinois, and southeastern Minnesota. A new feature, which we believe will prove helpful, is the series of nesting dates from localities often covering the breeding range of the species.

If space has prohibited giving all that is known about a bird, at least one may say where recent information concerning it may be found, and to this end I have added many referenees not contained in earlier editions. This bibliographical feature of the new "IIandbook" is best shown in the Appendix giving referenees to the more important faunal lists of birds in Eastern North America, a knowledge of which is believed to be of the utmost importance to the local student. 


\section{viii PREFACE TO THE REVISED EDITION}

In the preparation of the first edition of this book, the author gratefully acknowledged assistance which he had received from Florence Merriam Bailey, J. A. Allen, and Ernest Thompson Seton, and he now desires to express his indebtedness to Waldron DeWitt Miller for aid in reading the proof of the present edition, and to Henry W. Henshaw, Chief of the Biological Survey, for permission to reproduce the faunal map appearing on the cover pages.

It is proper, in closing this preface, for the author to express the pleasure and gratification which the reception of the first edition of the "Handbook" has given him. So far as circumstances permit, he has endeavored to make this new "Handbook" worthy of the praise which has so generously been accorded its predecessor.

Frank M. Chapman.

American Museum of Natural History, New York City, October 1, 1911. 


\section{HISTORICAL REVIEW}

A review of the progress which has been made in the study of North American birds during the eighteen years since the first edition of the "Handbook" was published must impress one with the fact that it is our knowledge of living rather than of dead birds which has increased.

A more exact discrimination, larger and better collections, and gradually changed standards as to the degree of differentiation which deserves recognition by name, have added many forms to our "CheckList," and rendered more definite our knowledge of the relationships of others. Particularly is this true of the birds of the Pacific coast region. This systematic work has appeared in various special papers and monographs, the most thorough of which, not only for the period under consideration, but for any preceding period in the history of North American ornithology, is Ridgway's "Birds of North and Middle America," of which five volumes have thus far been issued.

Thanks to the American Ornithologists' Union, our nomenclature has been revised with the utmost care and, while the numerous resulting changes in names may be annoying to present-day students, those who follow us will enjoy, in greater measure, that stability which is the ideal of the biologist. The third (1910) edition of the Union's "Check-List" contains this modern nomenclature; but it is worthy of note that the classification employed in this work is the same as that used in the first (1886) edition of the "Check-List." So little advance has been made in this branch of ornithology that no system of classification proposed since 1886 was considered sufficiently satisfactory to warrant adoption by the Committee of the Union having in charge the preparation of the 1910 edition.

The studies of Dwight and others have made far more definite our knowledge of the molt of birds, the times and manner of featherloss and renewal having been determined for many species, with an exactness made possible only by the collecting of specimens for this special purpose. At the same time, Beebe, by experiments on captive birds, has attacked the problem of the causes of molt, while Strong's histological work on the feather has increased our understanding of its growth and development.

In laboratory experiment on living birds, Beche has shown certain effects of humidity upon the colors of feathers; Davenport has used Canaries and domestic fowls in working on the laws of heredity; Porter and others have conducted psychological investigations upon certain species; and Watson has pursued similar studies upon the Noddy and the Sooty Tern in nature. The highly original researches of Thayer 
have greatly stimulated interest in the study of the colors of birds in relation to their environment.

Dealing still with the more technical branches of ornithology, the investigations of Fisher, Beal, and other members of the Biological Survey of the United States Department of Agriculture, of Forbush in Massachusetts, and of other state ornithologists, have supplied by far the larger part of our exact knowledge of the food-habits of our birds and determined for the first time the economic status of many species. This work constitutes one of the most pronounced and important phases of research during the period under consideration. While based, primarily, on field work in observing as well as in collecting, special training in laboratory methods is required to make the analyses of stomach contents, from which, in the main, the nature of a bird's food is ascertained.

Field, as well as laboratory work, has also been required to produce the faunal papers and books which, in volume, form the greatest addition to the ornithological literature of the past decade and a half. From the pioneer explorations of Merriam, Fisher, Nelson, Bailey, Preble, Osgood, and other members of the Biological Survey, in new or but little-known regions, to the almost final reports of Brewster and others on the bird-life of localities which have been studied for years by many observers, these publications have added enormously to our knowledge of the distribution of North American birds. This is particularly true of western North America, especially of the Pacific coast region, where Grinnell, W. K. Fisher, Swarth, and other members of the Cooper Ornithological Club, have placed on record a vast amount of data concerning the birds of this area.

Besides furnishing material for the more philosophic phases of faunal work, these monographs and local lists often treat also of the migration of the birds with which they deal. Most important contributions to this subject have been made by the large and widely distributed corps of observers acting under the direction of the Biological Survey, which, under the authorship of Cooke, has published several important bulletins on migration. Here also should be mentioned the significant experiments of Watson upon the homing instincts of Terns, which are referred to beyond (p. 54).

Possibly, in no other branch of definitely directed ornithological research has greater advance been made than in the study of the nesting habits of birds. For the first time in the history of ornithology, trained biologists have devoted an entire nesting season to the continuous study of certain species, and the results obtained by Watson, Herrick, Finley, and others, have, in a high degree, both scientific value and popular interest.

No small part of the educational value of work of this kind is due to the photographic illustrations by which it is usually accompanied, and bird study with a camera may be said to be the most novel and, in many respects, the most important development in ornithological 
field work during the past fifteen years. Not only has the fascination of camera hunting itself stimulated the bird photographer, but the results he has obtained have at times had a commercial value, which has enabled him to pursue his labors in before unexplored fields. In consequence, in the books of Job, Finley, Dugmore, and others, and in numerous magazine articles, we now have thousands of graphic records, not one of which existed fifteen years ago, depicting the home-life of some of our rarest as well as commonest birds, and possessed of a power for conveying and diffusing information with which the written word cannot compare.

Here, too, should be mentioned the work of the ornithological artists who, lead by Fuertes, have given us an unsurpassed series of faithful and beautiful portraits of our birds, to the educational value of which, in no small measure, is to be attributed the existing widespread interest in bird study.

It is the growth of this interest which has chiefly distinguished the past two decades; for, much as they have been marked by activity in various branches of ornithology, it is less as an exponent of natural laws than as a most attractive form of wild life that the bird has made its appeal. In the history of North American ornithology, therefore,this period may well stand as the Epoch of Popular Bird Study. Where, in 1895, there was one person who could claim acquaintance with our commoner birds, today there are hundreds; and the plea for the development of our inherent love of birds, which was made in the first edition of the "Handbook," has been answered with an effectiveness few would have predicted.

Opportunity alone was needed to bring to its fulfilment this inborn interest in creatures which have such manifold claims to our attention, and with which we may become so intimately associated. This opportunity has come in popular manuals of bird study, which, in the aggregate, have been sold by hundreds of thousands; in the introduction of nature study in the schools, in the formation of bird clubs and classes, through the far-reaching and important work of the National and State Audubon Societies, through popular lectures, through magazines devoted to bird study, and the greater attention of the press in general to bird studies-particularly such as are illustrated by photographs, through increased museum facilities, and through the closer relation everywhere existing between the professional or advanced student and the amateur, a relation which must be attributed primarily to the influence exerted by the American Ornithologists' Union.

It is the diffusion of this widespread knowledge of the economic, as well as the esthetic importance of birds, which has made it possible to secure the passage and enforcement of effective laws for their protection; and it is in this continued and increasing interest in birds, not alone as our efficient co-workers in garden, field, orchard and forest, but as the most eloquent expression of nature's beauty, joy and freedom, that we shall doubtless find a true measure of their greatest value to man. 


\section{LIST OF ABBREVIATIONS}

Ad. Adult; a fully matured bird.

A. V. Accidental visitant (see page 33).

B. Bill.

B. from N. Bill from nostril.

\& The sign employed to designate female sex (see page 20).

$\sigma^{7}$ The sign employed to designate male sex (see page 20).

Im. Immature; the term is generally applied to birds lese than a year old, or to those in first winter plumage.

L. Total length.

P. R. Permanent resident (see page 32).

S. R. Summer resident (see page, 32 ).

T. Tail.

Tar. Tarsus $=$ Metatarsus.

T. V. Transient visitant (see page 33).

W. Wing.

W. V. Winter visitant (see page 33). 
stand the use of the keys. At first sight they will, no doubt, appear confusing, but in reality they are exceedingly simple. The system upon which they are arranged may be mastered in a few minutes, and you will then be surprised at the ease and rapidity with which, even in large families, you can "run a bird down."

The Key to Families.-The scheme of this key which, since its appearance in the first edition of the "Handbook," has been so widely adopted, originated with Ernest Thompson Seton. The key here presented is, with some modifications and expansions, based on one contributed by Mr. Seton at a time when he was expected to be a joint author of this work. Strictly speaking this is not one key but a series of keys, one under each order. The orders are placed in a natural sequence,- that is, we begin with the oldest, or lowest, forms of birds, Loons, Grebes, etc., and end with the most highly developed ones, Thrushes, Bluebirds, etc. Two main divisions are given: first, Water Birds; second, Land Birds. In no case will it be difficult to decide in which of these groups a bird belongs. Now glance over the illustrations, and select the one which you think most nearly resemb!es the bird you are identifying. At each step, test your decision by reading the brief diagnoses of orders and families. In this way you may readily place your bird in its proper family.

The Keys to Species.-If a bird always wore the same plumage, it would be a comparatively easy matter to place it in a certain section of a key and keep it there. But, unfortunately, not only are the males and females of the same species frequently quite unlike, and the young different from either, but their plumages may vary with the season. Furthermore, an individual of a given species may not only wear two very different costumes, but, in doffing one for another, he does it gradually, and, in the meantime, appears in changing or transition plumage.

For this reason it has been customary to base keys on only adult males. Such keys do very well in the nesting season, when birds are in song, and when males constitute probably nine-tenths of the birds one sees. But at other times of the year young birds outnumber the old ones, and the adults themselves may lose their breeding plumage and wear quite a different one. I have, therefore, attempted to make keys which will identify a bird in any plumage. To do this, it was necessary to use many more specimens than there were species. For example, the key to our some 40 species of Warblers is based on 110 specimens, representing as many phases of plumage.

With identification as the sole end in view, I have, in the keys, abandoned all attempts to follow the current system of elassification, and, taking color as the most tangible character, have to a great extent arranged the species on this character alone. The result, from the systematist's standpoint, is most unnatural. Species of different genera are brought into the same subsections, and the more variable species may be placed in several widely separated sections. 
The maker of keys, however, should not try to serve two masters. If the keys will identify, they will have accomplished their purpose. The classification of our birds is shown in the body of the book, where the species are arranged according to the system adopted by the American Ornithologists' Union. The keys proper are dichotomous, but I have not hesitated to divide the larger families into three, or even four, primary sections, the characters of which are placed together at the head of the keys to permit of direct comparison. The heading of a group or section applies to all the species included in it. Thus, if I does not apply to the bird you are identifying, you must pass at once to II, or III, or IV, as the case may be. Even should the first section describe your bird, it is well to read the sections which are contrasted with it.

As a model to show how the keys are used, let us identify a male English Sparrow, a bird which has a black patch on the throat and breast, a slate-colored crown, chestnut marks on the sides of the head, and a streaked back. Turning to the key to the family Fringillidæ, or Finches, Sparrows, etc., we read first the headings to the main divisions, which are placed at the beginning of the key in order that they may be more readily compared.

"I. Underparts with red.

"II. Underparts with no red, and without distinct streaks; throat or breast sometimes with a patch or spot.

"III. Underparts without red, and with numerous streaks."

Our bird evidently belongs in Section II. Under this section we read first: "1. Tail with white spots, bars or patches." Our bird has no white in the tail, so we go to "2" and read: "Tail without large white spots or patches." The first subsection here is: "A. Back plain, without distinct streaks." Our bird is unquestionably streaked, so we therefore go to "B. Back distinctly streaked." Under B we have " $a$. Bend of the wing yellow," and "b. Bend of the wing not yellow." Our bird has no yellow on the wing, and we therefore place it in subsection " $b$. ." This subsection is subdivided into " $b$. Crown bright reddish brown," etc., and "c1. Crown not bright reddish brown." Evidently our bird belongs in the group headed " $c$," which is further divided into " $c$. Crown streaked or spotted with black or black and white" and " $d^{2}$. Crown mixed grayish brown, and rufous, ashy or slate-color, without black streaks." It is clear that our bird with its slate-colored crown, belongs in the second of these sections. This, we observe, contains four species, and we soon discover that " $\mathrm{d}$. Crown slate-color; a chestnut patch behind the eye; throat black," fits our bird, and to prove the identification we turn to the detailed deseription beyond.

If this more than usually complicated case has been clearly demonstrated, you should have no difficulty in using the keys, so far as their construction goes. One has only to remember that if the deseriptive matter following I does not fit, one should try II; similarly 1 is contrasted with 2 , A with $\mathrm{B}$, $a$ with $b, a^{1}$ with $b^{1}, b^{2}$ with $c^{2}$, etc. 
Descriptions of Plumage.-The descriptions, with quoted exceptions, are from specimens in the American Museum of Natural History, and my thanks are due the authorities of that instutition for permission to use its valuable collections. I have tried to make them as concise and simple and, at the same time, as detailed, as seemed necessary for the purpose of identification.

It has not always been possible to describe in detail all the plumages assumed by a species at various ages and seasons, but at least the more important plumage changes, and the differences due to sex, age, and season are indicated. It should be explained that, where the sexes are alike, they are described under the subheading " $A d s$. ." meaning adult specimens in breeding dress. The subheading "Im.," in the light
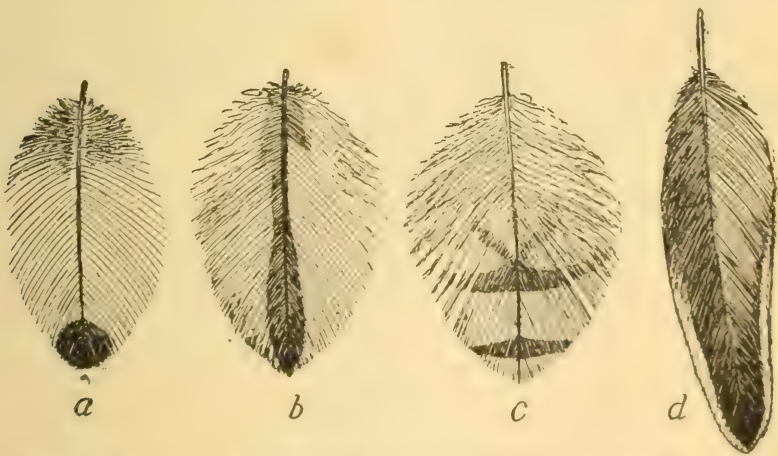

FIG. 2. Spotted (a), streaked (b), barred (c) and margined (d) feathers.

of our present more exact knowledge, is somewhat indefinite; but, as has just been said, absolute exactness in this connection is not possible in a book of this size, where deseriptions are intended primarily for the purpose of identification. It may be said, however, that, with but fow exceptions, "Im." signifies a bird in first winter plumage, or the one following that (the juvenal) in which the bird leaves the nest. Where, however, the juvenal plumage is worn for some time, as with the Snipe, in which it largely takes the place of a first winter plumage, then it is described under the term "Juv."

Measurements. - All the measurements given are in English inches and hundredths. Those of birds are average meisurements, taken for the most part from specimens in the Americin Museum of Natural History. I have also, with the author's permission, made use of the excellent series of measurements in Dr. F. A. Mearn's Birds of the IIudson Highlands. A variation of about ten per eent from the figures given may be expected.

The total length (= L.) of a bird is found by gently stretching the specimen, laying it on its back, and measuring the distance from the 
end of its bill to the tip of its longest tail-feather. The length of the wing (=W.) is the distance from the "bend of the wing" to the end of the longest primary. The length of the tail $(=\mathrm{T}$.) is the distance from the base, or insertion of the middle feathers, to the end of the longest feather. The length of the tarsus (= Tar.) is the distance from the base, or insertion of the toes, to the end of the tibia, or what in reality is the heel. The "tarsus" is therefore the true foot of the bird, while the part to which this name is generally applied consists only of the toes. The length of the bill (= B.), or "culmen," is the distance from the base of the feathers on the forehead to the tip of the upper mandible in a straight line. With the exception of total length, these measurements are generally taken with a pair of dividers.

Range.-The paragraphs under this heading are taken from the "Check-List" (third edition, 1910) of the American Ornithologists' Union. In some few instances I have abridged, and in others expanded or emended the original. Based primarily on the unexampled series of records on file in the Biological Survey of the United States Department of Agriculture, these outlines of distribution are more accurate and detailed than any we have before had of North American birds.

Following the paragraphs on range are exact, concise statements of the birds' status, manner and times of occurrence, at various localities from the District of Columbia northward to Cambridge, Mass., and thence westward to southeastern Minnesota. Each locality is treated by a recognized authority, from notes based on observations extending over many years. The statement in italics in the first edition of the "Handbook," that the dates given represent the "usual times of migration" appears, by some readers, to have been overlooked. It may be well, therefore, to emphasize it here.

The data from Washington, D. C., were supplied by Dr. C. W. Richmond of the United States National Museum. Not only has Dr. Richmond had a prolonged personal experience in this field, but he has had access to the notes of other local ornithologists.

The water birds of Long Island are treated by William Dutcher, who for years made our coast birds a subject of special investigation. Sportsmen, lighthouse keepers, and ornithologists have all contributed to his splendid series of notes on the movements of waterfowl and bay birds. In more recent years, Mr. Dutcher's work has been continued by Dr. W. C. Braislin, from whose paper on the Birds of Long Island (Abst. Proc. Linnæan Society, Nos. 17-19, 1904-7) I have supplemented or emended Mr. Dutcher's notes.

Dr. A. K. Fisher supplied the notes from Ossining, New York. This locality formed the field of his ornithological labors for fifteen years. Within the limits of the town of Ossining, he has observed no less than 236 species of birds. I doubt if any other one person in northeastern America has recorded so large a number from so small an area.

Cambridge, Massachusetts, is historic ground in the annals of ornithology. From the time of Nuttall, its bird-life has been studied 
by an ever-increasing number of enthusiastic field students, whose acknowledged leader for the past forty odd years has been William Brewster. Mr. Brewster contributed to the first edition of the "Handbook" data on Cambridge birds of much value; but, since that time, he has fortunately embodied his life studies in his "Birds of the Cambridge Region" (Memoir No. 4, Nutt. Orn. Club), beyond question the most important local work on American birds which has as yet been published. The data from the Cambridge region given in this edition of the "Handbook" are quoted, by permission, from Mr. Brewster's book, where the exact limits of the area covered will be found stated.

None of the additional records were contained in the first edition of the "Handbook." Those from Ohio were supplied by Professor Lynds Jones, of Oberlin, long the authority on the birds of that State. They cover Lorain and Erie Counties. The dates, Professor Jones states, are "median dates of first arrival."

B. T. Gault, who has contributed the notes from Glen Ellyn, writes: "The dates given are extreme [thus contrary to the plan followed by other contributors], excepting in isolated cases of extra-limital species. My observations really cover the township of Milton, but every bird listed, except Gallinula galeata, Strix varia, and Aquila chrysaëtos, has been noted within the corporate limits of the village of Glen Ellyn."

The records from southeastern Minnesota were supplied by Dr. Thomas S. Roberts, for many years the leading authority on the birds of Minnesota. They are based, in the main, on observations made in the vicinity of Minneapolis.

Nests and Eggs. - The brief descriptions of nests and eggs are based on the collections of the American Museum of Natural History, supplemented by the use of Baird, Brewer, and Ridgway's "History of North American Birds," Davie's "Nests and Eggs of North American Birds," Ridgway's "Manual," and Bendire's "Life Histories of North American Birds." In describing the eggs, the color chart was used when possible; but it was designed with particular reference to the plumages of our birds, and is of less assistance in describing their eggs. The measurements of eggs are mostly from series of measurements made by Mr. H. B. Bailey, accompanying the Bailey eollection in the American Museum, supplemented by reference to the works mentioned above.

Nesting Dates.-The dates following the descriptions of nest and eggs are designed to indicate when the nesting seuson of the species in question begins at various localities. They are the earliest dat es I have found for the taking of full sets of (presumably) fresh eggs of the first laying. These records were compiled chiefly from the data accompranying the collections of the United States National Muscum (to which I have kindly been given access by Dr. C. Wr. Richmond), those of the American Museum of National History, and the collection of Mr. J. P. Norris, Jr., to whom I gratefully express my indebtedness. The "Cambridge" records are all extracted, by permission, from Brewster's "Birds of the Cambridge Region," while for those from "SE. Minn." 
I have to thank my friend Dr. Thomas S. Roberts. The Charleston and South Carolina coast records are from Wayne's excellent work on "The Birds of South Carolina."

Biographies.-After devoting separate paragraphs to the bird's general range, its manner of occurrence, comparative numbers, times of migration at several specific points, and its nest and eggs, the space remaining is given to a brief sketch of its haunts, notes, and disposition, with the particular object of aiding in its identification in the field.

In preparing these biographical sketches, I have aimed to secure the best material possible, using my own notes only when I felt they were based on adequate observations. Not only have I carefully examined the literature relating to the habits of our birds, selecting what seemed to be the most trustworthy accounts of their appearance in life, but, through the generous coöperation of fellow-students of living birds, I am able to present character sketches of some of our birds, written by observers who are everywhere known for their sympathy with birds out-of-doors. Thus, I have to thank Mrs. Miller, Mrs. Bailey, Mr. Bicknell, Mr. Brewster, Dr. Dwight, Mr. Seton, and Mr. Torrey, for pen pictures of birds with which they are especially familiar, each sketch being signed by its author.

Illustrations.-Tappan Adney's pen-and-ink drawings, which have added so much to the value of the preceding editions of the "Handbook," appear in the present edition. To them have been added others by Ernest Thompson Seton, from "Bird-Life."

In the matter of illustrations, the present edition of the "Handbook" is chiefly distinguished from its predecessors by the inclusion of fifteen full-page plates by America's foremost painter of birds, Louis Agassiz Fuertes. Of those in color, some are designed to aid in identifying the more difficult species of birds, like Flycatchers and Thrushes, while others are intended to illustrate various phenomena in connection with the plumage of birds.

The Color Chart.-It must not be supposed for a moment that the colors on this chart represent the colors of all the birds of eastern North America. It does not do so any more than an artist's palette shows all the colors of his picture; in fact, I have called this plate my mental palette, and have frequently used two, and even three, terms to describe a given shade or tint.

It should be clearly understood, therefore, that when grayish brown, for example, is mentioned, it does not follow that the feathers to which the term is applied are of exactly the same color as the plate, but that they are nearer to this color than to any other in the plate. Used even in this general way, the plate will prove a far more definite basis for description than if every one were left to form his own idea of the colors named. 


\section{CONTENTS}

Historical Review.

List of Abbreviations. . . . . . . . . . xii

Plan of the Work. . . . . . . . . . . xiii

INTRODUCTION . . . . . . . . 1

Chapter I.-Why We Shodld Study Birds • • • 1

Chapter II.-A Word to the Beginner . . . . 3

Finding and Naming Birds . . . . . . . 3

The Equipment of the Field Student $\quad$. $\quad$ $\quad$. 9

Collecting Birds, Their Nests and Eggs . . . . 15

American Ornithological Societies . . . . . . 23

Current Ornithological Magazines . . . . . 24

Chapter III.-The Study of Birds in Nature a $\quad$ • 26

The Distribution of Birds . . . . . . 27

The Migration of Birds a . . . . . 32

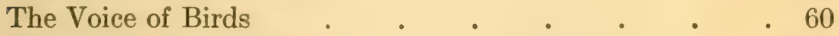

The Nesting Season . $\quad . \quad$. .666

The Plumage of Birds . $\quad$. $\quad$. $\quad$. $\quad$. 84

The Food of Birds . . . . . . . 98

General Activities of the Adult Bird . . . . 103

THE BIRDS OF NORTH AMERICA EAST OF THE NINETIETH MERIDIAN . . . . . 118

Key to Orders and Families . . . . . . 118

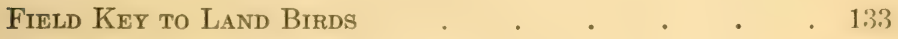

I. Order Pygopodes: Diving Birds . . . . 138

1. Family Colymbidæ: Grebes . . . . 138

2. Family Gaviidæ: Loons . . . . . 142

3. Family Alcidæ: Auks, Murres, and Puffins @ 145 
II. Order Longipennes: Long-winged Swimmers

4. Family Stercorariidæ: Jaegers and Skuas

5. Family Lridm: Gulls and Terns

5. Family Laridæ. Gulls and Terns • • • 152

6. Family Rynchopidæ: Skimmers . . . 172

III. Order Tubinares: Tube-Nosed Swimmers $\quad . \quad 172$

7. Family Diomedeidæ: Albatrosses . . . . 172

8. Family Procellariidæ: Fulmars, Shearwaters, and

Petrels . . . . . 173

IV. Order Steganopodes: Totipalmate Swimmers $\quad 178$

9. Family Phaëthontidæ: Tropic-birds . . . 178

10. Family Sulidæ: Gannets . . . . 179

11. Family Anhingidæ: Darters . . . . 181

12. Family Phalacrocoracidæ: Cormorants . . 182

13. Family Pelecanidæ: Pelicans . . . . 183

14. Family Fregatidæ: Man-o'-war-birds . . 185

V. Order Anseres: Lamellirostral Swimmers a 186

15. Family Anatidæ: Ducks, Geese, and Swans 186

Vi. Order Odontogloss e: Lamelitrostral Grallatores 216 16. Family Phœnicopteridæ: Flamingoes . . 216

VII. Order Herodiones: Herons, Storks, Ibises, etc. 217

17. Family Plataleidæ: Spoonbills . . . 217

18. Family Ibididæ: Ibises . . . . . . 218

19. Family Ciconiidæ: Storks . . . . 219

20. Family Ardeidæ: Herons and Bitterns . . 219

ViII. Order Paludicolæ: Cranes, Rails, etc. . . 229

21. Family Gruidæ: Cranes . . . . . 229

22. Family Aramidæ: Courlans . . . . 230

23. Family Rallidæ: Rails, Gallinules, and Coots . 230

IX. Order Limicole: Shore Birds . . . . 238

24. Family Phalaropodidæ: Phalaropes . . . 239

25. Family Recurvirostridæ: Stilts and Avocets . 241

26. Family Scolopacidx: Snipes, Sandpipers, etc. . 242

27. Family Charadriidæ: Plovers . . . . 263

28. Family Aphrizidæ: Surf-birds and Turnstones . 268

29. Family Hæmatopodidæ: Oyster-catchers . . 268 
X. Order Galline: Gallinaceous Birds

Gallina: GalliNaceous BIRds 269

30. Family Odontophoridæ: American Quail . . 269

31. Family Tetraonidæ: Grouse . . . . 272

32. Family Meleagridæ: Turkeys _ . . 278

XI. Order Colcmbe: Pigeons and Doves . . . 281

33. Family Columbidæ: Pigeons and Doves . . 281

XII. Order Raptores: Birds of Prey a . . . 286

34. Family Cathartidæ: American Vultures . . 286

35. Family Buteonidæ: Hawks, Eagles, Kites, etc. . 287

36. Family Falconidæ: Falcons, Caracaras, ete. . 303

37. Family Pandionidæ: Ospreys . . . . 307

38. Family Aluconidæ: Barn Owls . . . 308

39. Family Strigidæ: Horned Owls, Hoot Owls, etc. . 309

XIII. Order Psittaci: Parrots, Macaws, Paroquets,

\section{Cockatoos}

40. Family Psittacidæ: Parrots and Paroquets

XIV. Order Coccyges: Cuckoos, Kingfishers, etc.

318

41. Family Cuculidæ: Cuckoos, Anis, etc. - . 318

42. Family Alcedinidæ: Kingfishers . . . 320

XV. Order Pici: Woodpeckers, Wrynecks, etc.

322

43. Family Picidæ: Woodpeckers

XVI. Order Macrochires: Goatsuckers, Swifts, IIt mmingBIRDS, ETC. .

44. Family Caprimulgidx: Nighthawks, Whip-poorwills, etc.

45. Family Micropodidæ: Swifts . . . . 334

46. Family Trochilidæ: Hummingbirds . . . 335

XVII. Order Passeres: Perching Birds

47. Family Tyrannidæ: Flycatchers . . . 338

48. Family Alaudidæ: Larks . . . . . 347

49. Family Corvidæ: Crows, Jays, etc. . . . . 350

50. Family Sturnidæ: Starlings . . . . 355

51. Family Icterido: Blacklirds, Orioles, etc. . . 355

52. Family Fringilliclæ: Finches, Sparrows, ete. . 369

53. Family Tangaridæ: Tanagers . . . 413

54. Family Hirundinidæ: Swallows _ . . 415 
55. Family Bombycillidæ: Waxwings

56. Family Laniidæ: Shrikes . . . . 422

57. Family Vireonidæ: Vireos . . . . 424

58. Family Mniotiltidæ: Wood Warblers . . 430

59. Family Motacillidæ: Wagtails and Pipits . . 470

60. Family Mimidæ: Thrashers, Mockingbirds, etc. . 472

61. Family Troglodytidæ: Wrens . . . 475

62. Family Certhiidæ: Creepers . . . . 481

63. Family Sittidæ: Nuthatches . . . . 482

64. Family Paridæ: Titmice . . . . . 485

65. Family Sylviidæ: Old-World Warblers, Kinglets, and Gnatcatchers . . . . . 488

66. Family Turdidæ: Thrushes, Bluebirds, etc. . 491

Bibliographical Appendix . $\quad$ • . . . 501

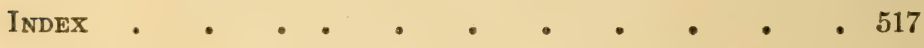




\title{
LIST OF ILLUSTRATIONS
}

\author{
FLLL-PAGE PLATES
}

PLATE

FACING PAGE

I. Screech Owl. (In color.) L. A. Fuertes. Frontispiece.

Color Chart. (Double page in color.)

II. Nests of Red-winged Blackbird and of Pheasant. Photographed by F.M. C.

III. Eggs of Meadowlark, Upland Plover, and Common Tern. Photographed by F.M. C.

IV. Plumages of the Scarlet Tanager. (In color.) $L . A$. Fuertes.

V. Adult Male Wood Duck in 'Eclipse' Plumage. (In color.) L. A. Fuertes.

VI. Red-winged Blackbirds and Chickadees in Juvenal

Plumage. Photographed by F.M. C.

VII. Song Sparrows. (In color.) L. A. Fuertes. .

VIII. Woodcock on Nest. Photographed by E. Van Altena. Black Skimmer on Nest. Photographed by F. M. C.

IX. Gannet, Murres, Puffins, and Razor-billed Auks. Photographed by F.M.C.

X. Gulls and Petrels. L. A. Fuertes.

XI. Terns AND Skimmers. From Habitat Group in the American Museum of Natural History.

XII. HEADs of Ducks. Photographed from Specimens in the American Museum of Natural History.

XIII. Ducks and Geese. L. A. Fuertes.

XIV. Clapper Rail. From Group in the American Musenum of Natural History.

XV. Spotted Sandpiper and Young. Photographed from Specimens in the American Museum of Natural History

XVI. Passenger Pigeon. L. A. Fuertes.

XVII. Flying Hawks. L. A. Fuertes.

XVIII. Heads of Owls. L. A. Fuertes.

XIX. Flycatchers. (In color.) L. A. Fuertes.

XX. Plumages of the Bobolink. (In color.) L. A. Fuertes.

XXI. Plumages of the Orchard Oriole. (In color.) $L . \Lambda$. Fuertes. 
XXII. Pine Siskin, Redpoll, Tree Sparrow, Snow Bunting. L. A. Fuertes.

XXIII. Bachman's, Swainson's, and Worm-eating Warblers. L. A. Fuertes.

XXIV. Thrushes of the Genus Hylocichla. (In color.) L. A. Fuertes.

PAGE xiv

1. Topography of a bird

2. Spotted $(a)$, streaked $(b)$, barred $(c)$, margined $(d)$ feathers. - xvii

3. The Umbrella blind

4. A completed bird skin

5. Migration of the Blackpoll Warbler

6. Migration of the Mourning Warbler .

7. Migration of the Bobolink

8. Migration of the Redstart

9. Migration of the Golden Plover

10. Feathers of Snow Bunting

11. Bill of Woodcock

12. Bill of Avocet .

13. Wing and foot of Tree Swallow

14. Wing and foot of Little Black Rail

15. Man-o'-war-bird

16. Wing of Woodcock .

17. Tail of (a) Downy Woodpecker, (b) Brown Creeper

18. Flamingo

19. Toes of Ruffed Grouse

20. Foot of Osprey

21. Feet of (a) Phalarope, (b) Coot

22. Feet of $(a)$ Pied-billed Grebe, (b) Loon, (c) Puffin

23. (a) Bill of Parasitic Jaeger; (b) bill and foot of Laughing Gull

24. Bill of Common Tern

25. Bill of Skimmer

26. (a) Bill and foot of Black-footed Albatross; (b) bill and foot of Fulmar

27. Bill of Gannet

29. Bill of Yellow-billed Tropic Bird

29. Foot of Cormorant

30. Bill of Anhinga

31. Bill of Cormorant

32. Bill of Man-o'-war-bird

33. Bill of Merganser

31. ( 1 ) Bill and foot of Mallard; (b) foot of Canvasback

35. Bill of Flamingo
11

19

42

43

44

45

47

87

104

105

105

105

106

106

107

107

108

108

109

118

118

119

119

119

120

120

120

120

120

120

121

121

122 
36. Bill and toe-nail of Green Heron

37. Bill of White Ibis.

38. Bill of Roseate Spoonbill .

39. (a) Bill and foot of Clapper Rail; bills of (b) Yellow Rail, (c) Sora, (d) Florida Gallinule; (e) bill and foot of Coot

40. Bill of Sandhill Crane

41. Bill of Limpkin

42. Bllls of (a) Dowitcher, (b) Knot, (c) Black-bellied Plover, (d) Semipalmated Plover

43. Feet of (a) Red Phalarope, (b) Knot, (c) Dowitcher, (d) Black-bellied Plover, (e) Semipalmated Plover

44. Bill of Ruffed Grouse

45. Bill of Wild Pigeon

46. Feet of $(a)$ Barred Owl, (b) Red-shouldered Hawk . . 125

47. Head of Barn Owl

48. Head of Barred Owl

49. Head of Turkey Vulture

50. Head of Red-shouldered Hawk

51. Bill and foot of Carolina Paroquet . . . . . . . $\quad$. 126

52. Bill and foot of Belted Kingfisher . . . . . . . 126

53. Bill and foot of Yellow-billed Cuckoo

126

54. (a) Bill and foot of Hairy Woodpecker, (b) foot of Arctic Three-toed Woodpecker

55. Bill and foot of Nighthawk

56. Bill and tail-feather of Chimney Swift . . . . 127

57. Bill of Hummingbird

58. Foot of Robin

59. Bill and wing of Phœbe

60. Bill and hind-toe of Horned Lark

61. (a) Bill and wing of Blue Jay, (b) bill of Crow . . . 128

62. Bill and wing of Starling

63. (a) Bill and wing of Baltimore Oriole; bills of (b) Meadowlark, (c) Purple Grackle

64. Bills of (a) Cardinal, (b) Pine Grosheak, (c) Purple Finch, (d) Am. Crossbill, (e) Seaside Finch, ( $f$ ) Goldfinch .

65. Bill of Scarlet Tanager

66. Bill and foot of Cliff Swallow

67. Head of Cedar Waxwing

68. Bill of Loggerhead Shrike

70. (a) Bill of Tennessee Warbler; (b) bill, wing, and hind-toe of Pine Warbler; bills of (c) Redstart, (d) Water-Thrush;

(e) Chat

71. Bill and hind-toe of Amerioen Pipit

72. (a) Bill of Brown Thrasher, (b) bill and wing of Catbird; bills of (c) Carolina Wren, (d) House Wren 
73. Bill and tail of Brown Creeper

74. (a) Bill of White-breasted Nuthatch, (b) bill and wing of Chickadee

75. Bill and wing of Golden-crowned Kinglet, $(b)$ bill of Bluegray Gnatcatcher

76. (a) Bill of Robin, (b) bill and wing of Bluebird

77. Great Auk

78. First primaries of (a) Herring Gull, (b) Ring-billed Gull, (c) Laughing Gull, $(d)$ Franklin's Gull, (e) Bonaparte's Gull.

79. First primaries of (a) Caspian Tern, $(b)$ Royal Tern, $(c)$ Common Tern, $(d)$ Arctic Tern, (e) Roseate Tern .

80. Head of Least Sandpiper

81. Head of Red-backed Sandpiper

82. Wing of Solitary Sandpiper

83. Head of Semipalmated Plover .

84. Head of Wilson's Plover .

85. Tail of Sharp-shinned Hawk .

266

267

293

86. Tail of Cooper's Hawk

294

87. Primaries of Red-shouldered Hawk .

88. Primaries of Broad-winged Hawk .

89. Foot of Golden Eagle

90. Foot of Bald Eagle

91. Tail-feathers of Yellow-billed Cuckoo

92. Tail-feathers of Black-billed Cuckoo

93. Tongue of Pileated Woodpecker

94. Whip-poor-will

95. Head of Crested Flycatcher

96. Head of Prairie Horned Lark

97. Starling;- Summer plumage

98. Starling;-Winter plumage

99. Head of Cowbird

100. Head of Purple Finch

101. Head of Redpoll

102. Hind-toe of Lapland Longspur

103. Tail-feathers of Vesper Sparrow

104. Tail of Grasshopper Sparrow

105. Head of Seaside Sparrow

106. Head of Lark Sparrow

107. Head of Chipping Sparrow

108. Head of Fox Sparrow

109. Head of Dickcissel .

110. Barn, Cliff, Tree, and Bank Swallows

297

298

301

302

319

320

327

332

341

349

355

356

360

377

381

385

386

389

393

395

398

405

412

415

420

111. Seretion of primary of Rough-winged Swallow

425

113. Wing of Warbling Vireo . 


\section{LIST OF ILLUSTRATIONS}

xxix

FIGURE

PAGE

114. Head, of Black and White Warbler . . . 445

115. Head of Worm-eating Warbler . . . . . 445

116. Head of Biue-winged Warbler . . . . . . . 445

117. Head of Golden-winged Warbler . . . . . 445

118. Head of Parula Warbler . . . . . . . 445

119. Head of Myrtle Warbler . . . . . . . 445

120. Head of Magnolia Warbler . . . . . . 445

121. Head of Chestnut-sided Warbler . . . . . 445

122. Black-throated Blue Warbler . . . . . . . 449

123. Head of Blackpoll Warbler . • . • • . 462

124. Head of Prairie Warbler . . . . . . . 462

125. Head of Ovenbird . . . . . . . . . . 462

126. Head of Kentucky Warbler . . . . . . . 462

127. Head of Maryland Yellow-throat . . . . . . 462

128. Head of Wilson's Warbler . . . . . . 462

129. Head of Hooded Warbler . • . . . . . 462

130. Head of Canadian Warbler . . . . . . . . 462

131. Head of Yellow-breasted Chat . . . . . . 467

132. Head of Short-billed Marsh Wren . . . • . 479

133. Head of Long-billed Marsh Wren . . • • . 480

134. Head of Red-breasted Nuthatch . . . • . 484

135. Head of Tufted Titmouse . . . . . . . . 486

136. Head of Golden-crowned Kinglet . 489 



\section{A HANDBOOK OF THE BIRDS OF EASTERN NORTH AIERICA}

\section{INTRODUCTION}

WHY WE SHOULD STUDY BIRDS

A WORD TO THE BEGINNER

THE STUDY OF BIRDS IN NATURE

\section{CHAPTER I}

\section{WHY WE SHOULD STUDY BIRDS}

Birds occupy a fourfold relation to man: an economic, esthetic, what may be termed a mythological or symbolic, and a scientific relation.

Birds are Nature's most potent checks upon the undue increase of noxious insects and harmful rodents; they devour the seeds of weeds and act as scavengers. The more we learn of their food habits, the greater becomes the realization of our indebtedness to them, and economic ornithologists now agree that, without the services rendered by birds, the ravages of the animals they prey upon would render the earth uninhabitable.

Birds, however, not only make life upon the globe possible, but they may add immeasurably to our enjoyment of it. Where in all animate nature shall we find so marvelous a combination of beauty of form and color, of grace and power of motion, of musical ability and intelligence, to delight our eyes, charm our ears and appeal to our imagination?

To the birds' mastery of the air, to their mysterious appearances and disappearances oceasioned by migration, to the weird or peculiar character of their notes, as well as to their human-like characteristic's, we may doubtless attribute the influence they have exerted on the mind of primitive man. This is shown in a thousand myths and legends investing the bird with supernatural powers, and in savage art and symbolism, and is reflected in the folk-lore of a later day. It is not surprising, therefore, that civilized man should derote esperial attention to creatures possessed of such unusual interest, studying their origin and relationships, their distribution in time and spacee, their migrations, their nesting habits, their form and color, and all the details 
of their structure and life which go to make up the science of ornithology. The claims of birds to our attention may then be formally summarized as follows:

First, because, as the natural enemies of harmful insects and rodents, as destroyers of weed seeds and as scavengers, birds are of inestimable value in the economics of nature.

Second, because birds are sensitively arganized creatures, and respond so readily to the influences of their surroundings that in their structure, distribution, migration and habits they furnish naturalists with numerous and imporiant clews to the workings of natural laws.

Third, because birds, more effectively than any other forms of life, arouse our inborn iriterest in animals, not only through their abundance and familiarity, but because their form, color and power of flight stimulate our love of beauty and of grace; because their songs appeal to us as the most eloquent of nature's voices; because their migrations excite our wonder and continually renew our interest in the bird-life of the same locality, and because the human-like traits displayed during their nesting season emphasize our kinship with them. Hence it follows that birds, more than any other animals, may serve as bonds between man and nature. 


\title{
CHAPTER II
}

\section{A WORD TO THE BEGINNER}

\author{
Finding and Naming Birds \\ The Eqdipment of the Field Student \\ Collecting Birds, Their Nests and Eggs \\ American Ornithological Societies \\ Current Ornithological Magazines
}

\section{Finding and Naming Birds \\ How to Find Birds \\ How to Identify Birds \\ How Birds Are Named}

How to Find Birds.- The best times of the day in which to look for birds are early morning and late afternoon. After a night of fasting and resting, birds are active and hungry. When their appetites are satisfied, they may rest quietly until hunger again sends them forth in search of food.

Experience will soon show you where birds are most abundant. The more varied the nature of the country the greater number of species you may expect to find inhabiting it. An ideal locality would be a bit of tree-dotted meadow with a reed-bordered pond or stream, surrounded by woods, rolling uplands and orchards.

Common sense will tell you how to act in the field. Birds are generally shy creatures and must be approached with caution. You must not, therefore, go observing or collecting dressed in flaming red, but in some inconspicuous garb and as quietly as a cat. Furthermore, go alone and keep the sun at your back-two apparently unrelated but equally important bits of advice.

The naturalist generally has the instincts of the hunter, and practice will develop them. The 'squeak' is one of his most valuable aids. It is made by placing the lips to the back of the hand or finger and kissing vigorously. The sound produced bears some resemblanee to the cries of a wounded or young bird. In the nesting seatson its utteranee? frequently creates much excitement in the bird-world, and at all times it is useful as a means of drawing bush- or reed-haunting spereies from their retreats. One may enter an apparently deserted thicket, and, after a few minutes' squeaking, find himself surrounded by an anxious or curious group of its feathered inhabitants.

The observer of birds will find that by far the best way to study 
their habits is to take a sheltered seat in some favored locality and become a part of the background. Your passage through the woods is generally attended by sufficient noise to warn birds of your coming long before you see them. They are then suspicious and ill at ease, but secrete yourself near some spot loved by birds, and it may be your privilege to learn the secrets of the forest. In this connection I cannot too highly recommend the observation blind described beyond. Adequate natural cover cannot always be found and at best, rarely permits of much freedom of movement. In it, one therefore becomes so cramped and tired that what should be a pleasure becomes hard labor. Whereas, I have passed as much as eight consecutive hours in a blind without undue fatigue; and, it may be added that, although I was in an open field only twenty feet from a Meadowlark's nest, the birds had not the slightest suspicion of my proximity.*

How to Identify Birds. - Whether your object be to study birds as a scientist or simply as a lover of Nature, the first step is the same-you must learn to know them. This problem of identification has been given up in despair by many would-be ornithologists. We can neither pick, press, net, nor impale birds; and here the botanist and the entomologist have a distinct advantage. Even if we have the desire to resort to a gun, its use is not always possible. But with patience and practice the identification of birds is comparatively an easy matter, and in the end you will name them with surprising ease and certainty. There is generally more character in the flight of a bird than there is in the gait of a man. Both are frequently indescribable but perfectly diagnostic, and you learn to recognize bird friends as you do human ones-by experience.

If you confine your studies to one locality, probably not more than one-third of the species described in this volume will come within the field of your observation. To aid you in learning which species should be included in this third, the paragraphs on Range are followed by a statement of the bird's standing at several localities distributed throughout the Eastern United States. Take the list of birds from the point nearest your home.as an index of those you may expect to find. This may be abridged for a given season by considering the times of the year at which a bird is present. Often you can secure a published list of the birds of your state, county, or immediate vicinity, and publications of this nature are of such exceptional value and interest to the local student that a list of the more important ones has been prepared as an appendix to this edition of the "Handbook."

After this slight preparation, you may take to the field with a much clearer understanding of the situation. Two quite different ways of identifying birds are open to you. Either you may shoot them, or study them through a field- or opera-glass. (See beyond, under Collecting.) A bird in the hand is a definite object whose structure and color can be studied to such advantage that in most cases you will afterward recog-

*See "Camps and Cruises," pp. 15-19. 
nize it at sight. After learning the names of its parts, its identity is simply a question of keys and descriptions.

If you would "name the birds without a gun," by all means first visit a museum, and, with text-book in hand, study those species which you have previously found are to be looked for near your home. This preliminary introduction will serve to ripen your acquaintance in the field. A good field- or opera-glass is absolutely indispensable. (See beyond, under Equipment.) Study your bird as closely as circumstances will permit, and write, on the spot, a comparative description of its size, the shape of its bill, tail, etc., and a detailed description of its colors. In describing form, take a Robin, Chipping Sparrow, or any bird you know, which best serves the purpose, as a basis for comparison. A bird's bill is generally its most diagnostic external character. A sketch of it in your note-book will frequently give you a good clue to its owner's family. It is of the utmost importance that descriptions and sketches should be made in the field. Not only do our memories sometimes deceive us, but we really see nothing with exactness until we attempt to describe it. Haunts, actions, and notes should also be carefully recorded.

Even better than a description is a figure colored with crayons or water-colors. It may be the crudest outline and in ridiculous pose, but at least it is definite. There is no possibility of error through the wrong use of terms; the observer draws or charts what he sees. Neither art nor skill is required. Anyone can learn to make the outline of the normal bird figure as readily as he can learn to make the letters of the alphabet, and a little practice will enable one to give the shape of bill, wings and tail, and even a hint of characteristic form and position. Typical, passerine outline figures may be made in advance in one's field note-book, and the shape of the bill and color may be added while the bird is under observation. A collection of diagrams or sketches of this kind will be found to possess far greater individuality and value than mere written descriptions. If the sketch cannot be completed, if essential details are lacking, it is obvious that the subject has not been seen with that definiteness upon which satisfactory field identification should rest. With this deseription or sketch you may now proceed to use the 'Keys' as explained on an earlier page.

How Birds Are Named.-Nine years have passed since an actually new species of bird was discovered in Vorth Amorica, while no new eastern North American bird has been found for twenty-five years. It is extremely doubtful, therefore, if from our Mexican boundary to the Arctic Ocean there remains a single unknown species of bird. (Of ge()graphical races, or climatic varieties or subspecies, a gradually decreasing number will be deseribed from at least western North Ameriea for years to come, but in eastern North America we have practically reached, if indeed we have not passed, the point whore such forms may be profitably named.

The bird student in this area may be reasonably certain, therefore, 
that every bird he sees has a name, and in the preceding section having suggested ways in which this name may be learned, the somewhat obscure details of nomenclature may be made clearer by explaining how the bird got it. In doing so I draw freely from a similar effort in the "Color Key to North American Birds."

Birds have two kinds of names. One is a common, vernacular or popular name; the other is a technical or scientific name. The first is usually given to the living bird by the people of the country it inhabits. The second is applied to specimens of birds by ornithologists who classify them. Common names in their origin and use know no law. Technical names are bestowed under the system of binomial nomenclature established by Linnæus in 1758, and their formation and adoption are governed by certain definite, generally accepted rules. The Linnæan system, as it is now employed by most ornithologists, provides that a bird, in addition to being grouped in a certain Order, Family, etc., shall have a generic, a specific, and, often, a subspecific name which, together, shall not be applied to any other animal.

Generally speaking, Orders and Families are based on skeletal, muscular, and visceral, or what may be termed internal characters; while genera are based on the form of bill, wings, feet and tail, and sometimes on pattern of markings, and species and subspecies on color and size, or external characters. Thus, all the members of an Order agree in major internal characters; those of a Family further agree in minor internal characters; those of a Genus, in addition, resemble one another in external characters, while species and subspecies differ only in color and in size.

Frequently it happens that a bird may possess some of the characters of one group in connection with some of the characters of another group, and such birds, collectively, create intergrading groups known as Suborders, Subfamilies, Subgenera, or Subspecies. With the last, the student is especially concerned since they figure in the name by which a bird is known.

In pre-Darwinian days it was generally believed that a species was a distinct creation whose characters did not vary from a certain type. But in later years comparison of many specimens of a species from throughout the region it inhabits, shows that specimens from one part of a bird's range may differ in size and color, or both, from those taken in another part of its range. At intervening localities, however, intermediate specimens will be found connecting the extremes. (See beyond, under Color and Climate.).

Variations of this kind are termed geographic, racial or subspecific and the hirds exhibiting them are known as subspecies. In naming them, a third name, or trinomial is employed, and the possession of such a name indicates, at onee, that the bird is a geographic or racial representative of a species with one or more representatives of which it intergrades.

In illustration let us now trace the history of a trinominal designa- 
tion; for example, that of our Robin, Planesticus migratorius migratorius (Linn.). The first account of this bird appears in Catesby (1731) and it was later classified by Linnæus in the twelfth edition (1766) of his epoch-making "Systema Naturæ" as Turdus migratorius. By this name the Robin or 'Migratory Thrush' was known for over one hundred years, when that finer discrimination, which has increasingly characterized systematic ornithology, showed that the genus Turdus of Linnæus contained species which, in the light of this more modern view, were generically separable. The type of the genus having been determined to be Turdus viscivorus Linn., the Mistle Thrush of Europe, the name Turdus was restricted to that bird and its congeneric allies, and the genus Merula of Leach was accepted for our Robin and the species with which it is generically related. The bird's name then became Merula migratoria (Linn.), the termination of the specific name being changed from us to $a$ in order that it might conform to the gender of the generic name with which it was associated; and the parentheses enclosing the abbreviation for the name of Linnæus, indicating that while Linnæus described the species migratoria, he did not place it in the genus Merula.

Now, by one of those unfortunate coincidences which have done so much to create confusion in zoölogical nomenclature, it was discovered, in 1907, that the generic name Merula of Leach was 'preoceupied' by the Merula of Koch, proposed by the latter for a genus of Starlings, and, under the ruling of the 'Law of Priority,' the name. Merula could therefore no longer be applied to the Robin and its congeners, and the next available name proved to be Planesticus of Bonaparte. 'There the case stands, though it is by no means impossible that in some obseure publication Planesticus itself may be found to be preoceupied or perhaps antedated by some other name proposed before that of Bonapurte. Such cases, however, are the inevitable result of the rigid enforement of now universally accepted laws of zoölogical nomenclature, which, if they had been in existence and observed from the time of Linnarus, would have prevented these seemingly unneressary changes in the technical names of animals. Fach change, however, means the diseovery of an error, and brings us nearer to that stability in numes which some day we shall unquestionably reach.

So much for the Robin's generic designation. Passing now to its specific name, migratorius, which being again associated with a masculine generic name resumes ite original tormination of $u s$, this name wats applied to the bird throughout its entire Vorth Americun range until 1877, when Ridgway proposed the name propinqums for the Rohin of western North America on the ground that in this race the out rer tailfeather had little or no white, and on other characters, and this western bird, after sharing the various generic experienees of out rastern form, is now known as Plomestirus migmalorius propinumus (Rihlgw.).

After the recognition of a western rare of the Rebsin under a trinosmial name, it would be obviously inconsistent to apply a binomial to 
our eastern bird, the former being no more a subspecies of the latter, than the latter is of the former. In other words, to continue to apply only generic and specific names to the Eastern Robin would imply that it was a species, while the use of a trinomial for the Western Robin would imply that it was a subspecies. As a matter of fact, we know that there is but one species of true Robin in North America, consequently, in accordance with the logical and now generally accepted method, we apply to that species the name Planesticus migratorius, and this is equally applicable to Robins from the West and from the East. The eastern subspecies is, therefore, known by the trinomial Planesticus migratorius migratorius, the western subspecies by the exact nomenclatural equivalent, Planesticus migratorius propinquus, and the more recently described small, pale Southern Robin, as Planesticus migratorius achrusterus. Thus we have one Robin which is represented by three subspecies. It may be asked, why give names to these geographical races? Why not call Eastern, Western and Southern Robins by one name without regard to their climatic variations? To which it may be replied, that subspecies often differ more from each other than do species. For example, it would clearly be inadvisable to apply the same name to the small, pale Song Sparrow of Arizona, and the large dark Song Sparrow of Alaska. (See figures beyond.) Seen without the connecting forms from the intervening regions and they apparently are specifically distinct, but the application to each of a subspecific name, or trinomial, not only indicates that they are different, but it shows also that they are representative forms which are joined by a series of intergrades; a contribution of the first importance to the study of evolution.

For much the same reason, we should recognize by name those birds, which, like the Robin, show less pronounced climatic variations. Here we have species in the earliest stages of development from a common ancestor, and in naming them we are, in effect, giving ' $a$ handle to the fact' of their evolution by environment. The study of the distribution and migration of birds and the mapping of natural life-areas are also intimately connected with this recognition by name of geographical variations.

Since it is evident that a species may vary much or little according to the extent of its range, the governing conditions, and its tendency to respond to them, no fixed rule can be drawn which shall state just what degrees of difference are deserving a name. It follows, therefore, that in some cases ornithologists do not agree upon the validity of a bird's claims to subspecific rank.*

In North America, however, questions of this kind are referred to a Committee of the American Ornithologists' Union, and its decisions establish a nomenclature which is accepted as the standard by other American ornithologists and which is adopted in this volume.

Finally, the student should be warned not to permit this matter of *See Allen, Auk, 1890, pp. 1-9. 
names to have an undue significance. A species is not an entity or distinct creation, but merely one link in the chain of bird-life, which, because of the loss of the adjoining link or links, appears to stand by itself. Nor should he allow himself to think of a subspecies as materially different from the species which it represents, simply because it has received a distinctive name. Nomenclature gives undue emphasis to differences, whereas, it is equally important to emphasize resemblances.

\title{
The Equipment of the Field Student
}

\author{
The Glass \\ Note-books and Journals \\ The Observation Blind \\ Photographic Outfit \\ Collector's Outfit
}

Glass.-A good field-glass is necessary, not alone as an aid in identifying birds, but in observing their actions. When one is working in fields and woods where the birds are comparatively near, a low-power glass with good illumination can be used more quickly and to better advantage than the higher-power glasses which require more frequent adjustment of focus, with consequent loss of time. But on the shore, or over the water, where birds are seen at great distances and where there is an abundance of light, the high-power glasses are much more serviceable. There is, however, a limit to the magnification which can be used effectively; the 8-power prism binocular of any one of half-a-dozen makes proving, in practice, to be best adapted to the bird student's needs. Beyond this power, the increased precision required in focussing, and the need for greater steadiness when in use, do not compensite one for the larger size of the image it is possible to obtain. For a lowpower glass I know of none better than the Lemaire pocket field-glass, which has a magnification of about four diameters.

Note-Books and Journals.-The necessity for a well-kept journal and full field-notes eannot be too strongly urged. Specimens may be duplicated, but no one can ever see with your eyes. Do not trust your memory-a willing servant too frequently imposed on. It maty receive and retain one impression clearly, but as others are added the earlier ones lose their distinetness or become entirely effaced.

The system adopted for recording notes should be simple to keep and easy of reference. In the field, I use a pocket note-book arranged to hold perforated leaves. In such a book one enters deseriptions of birds' appearance and of their calls and song, and of her memoranda which it is desired to commit at onee to writing. No leaf should eontain notes relating to more than one species, and the leaves, properly headed, may then be filed for reference, either alphabetically, or according to the classification of the American Ornithologists' Union. 
For a journal I use a college lecture note-book, also arranged to hold perforated loose leaves, which measure $6 \frac{1}{2}$ by $8 \frac{1}{2}$ inches. The first half-dozen leaves (others can be inserted when needed) should be ruled in small squares, leaving a space wide enough to enter birds' names at the left-hand page, with only horizontal lines. A portion of such a page is appended:

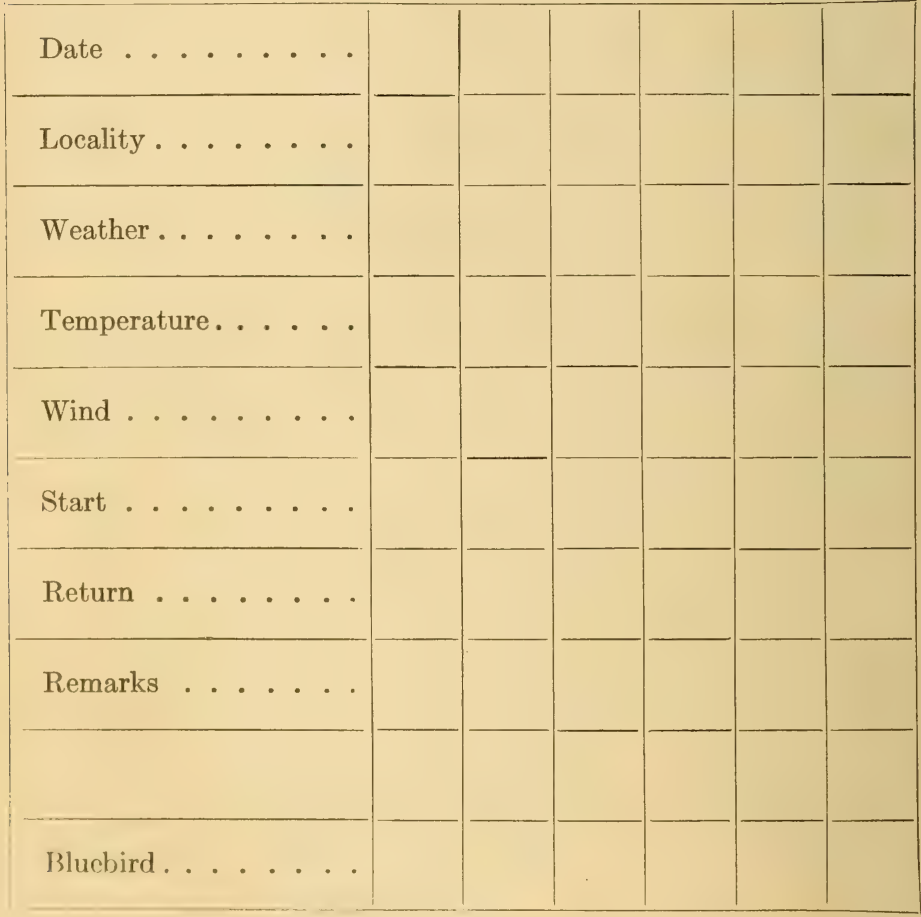

After returning from the field, I enter on these roll-call sheets a record of weather, temperature, direction and force of the wind, route, time of starting and returning and incidental observations on the blooming of flowers, appearance of certain insects, calling of frogs, ete.

After filling in these preliminary data, I write after the name of mach hird rither the exact or approximate number of individuals seen, or clse the letters " $\Lambda$.," "C.," or "T.C.," meaning abundant, common, or tolerably common. This is accompanied by an "s" if the bird is in song, or "calls" if it is simply heard calling. The possibilities of abbreviation are unlimited, but use no abbreviation which is not fully 
explained. If you wish to make a record of some length concerning a certain species, place a cross or asterisk in its square. This refers to your journal of the same date which is entered on the horizontally ruled sheets following those used for the roll-call.

Read from left to right, such a roll-call gives in a graphic, condensed form the standing of a species during the period of observation. Read from the top to the bottom of the page, it gives, in an easily comparable way, the complete record of each day, and, at the same time, it becomes an index to the bird-notes in the journal, which follows.

To prevent needlessly multiplying these roll-call sheets, the series of birds' names should be made to last at least during an entire season. To this end do not completely fill the right-hand page, but when you have used all of it but a space equal in width to the space occupied by the column of birds' names on the left side of the left page, cut this part of the page - the extreme right-off; the part remaining will, when turned over to the left, just meet the column of names, and the lines of this column and of the new page will thus run conlinuously. As before remarked, the roll-book should be attended to immediately on returning from the field, while your impressions are fresh. The journal may if necessary wait, when a reference to the roll-call will aid in recalling the day's experiences. Only one cover, with clasps for the retention of the perforated sheets, will be needed, and at the end of a trip or season the sheets may be removed and bound. This is essentially the method of note-keeping described in the first edition of the "Handbook" and which, after seventeen years' additional use, I still unreservedly recommend.

The Observation Blind.-The observation blind which, during the past ten years, has met the demands of many and varied situations, is in brief an umbrella opened within a bag long enough to conceal one. It is described in my "Camps and Cruises of an Ornithologist" (p. xiii) as follows:

"The umbrella employed in making an observation blind is known to the trade as a 'sign' umbrella. It agrees with the normal variety in size but differs from it in having a large hole in the center. This permits a current of air to pass through the blind-a matter of the first import-

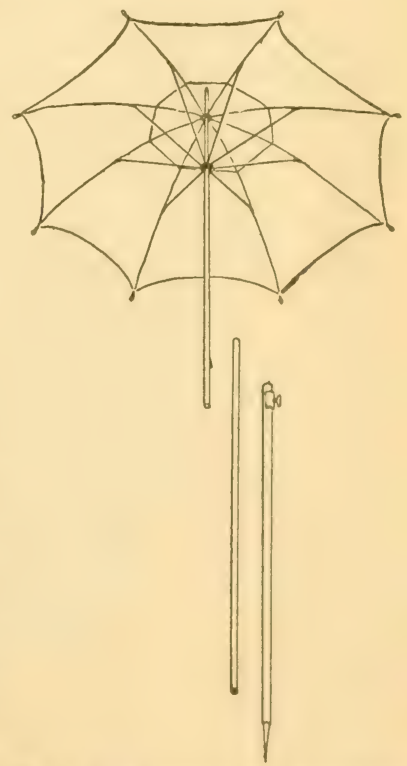

Fir. 3. The umbrell:t amel +mpporling rods of the umbrella blind. 
ance when one spends hours in the little structure on beach or marsh, where it is fully exposed to the sun. The 'stick' of this umbrella is a metal tube without the usual wooden handle.

"The umbrella is supported by two brass tubes each of the same length as the umbrella, or thirty-two inches. The larger is shod with a steel point, by the insertion of a small cold chisel or nail-punch, which is brazed in position. The rod can then be readily driven into the ground. At the upper end a thumb-screw is placed. The smaller tube should enter the larger snugly, and should in turn be just large enough to receive the umbrella-rod which will enter it as far as the spring "catch." The height of the umbrella may, therefore, be governed by the play of the smaller tube in the larger, while the thumb-screw will permit one to maintain any desired adjustment; as one would fix the height of a music rack.

"If the blind is to be used about home, a light denim may be employed; if it is to see the harder service of travel and camp-life, a heavier grade of the same material will be found more serviceable. In the former case the denim may be sewed to the edge of the umbrella, which then has only to be opened and placed in the brass tube, the latter have been thrust into the ground, when the blind is erected; an operation requiring less than a minute.

"When traveling, it seems more desirable not to attach the walls of the blind to the umbrella. The covering then consists of several strips of material sewed together to make a piece measuring ten and a half feet wide by six and a half feet high. The two ends of this piece are sewed together at what then becomes the top of the blind, for about two feet. The unjoined portion below becomes the door of the blind. Openings should be cut in the opposite side for the lens and for observation. A strong draw cord is then run about the top edge of the cloth, so that, before inserting and opening the umbrella, one can draw it up as one would the neck of a bag, until the opening corresponds in size to that of the umbrella. The draw cord should be long enough to serve as a guy or stay. This covering places less strain on the umbrella and may be packed in smaller space than one which is sewed to the umbrella, and, when in camp, it may be used to sleep on, as a covering, as a shelter tent or in a variety of ways.

"The color of the umbrella should be leaf-green. The covering should be sand- or earth-colored and should be dyed leaf-green on its upper third whence it should gradually fade to the original cloth color at about the center. Such a color scheme conforms to Abbott Thayer's law that animals are darkest where they receive the most light, and palest where they are most in shadow; and renders the blind much less conspicuous than if it were uniformly green or gray. It is not amiss to run belts of braid about the covering, sewing them to it at intervals and thus forming loops in which, when desired, reeds or branches may be thrust.

"In erecting the blind, if circumstances permit, it is desirable to 
place the 'door' toward the wind to insure better ventilation. When the situation is exposed, an additional stay or two may be required. If the camera box is not strong enough to sit on, a collapsible, artist's camp-stool should be added to the outfit. One cannot spend half a day in such close quarters and observe and record to advantage unless one is comfortably seated."

Photographic Outfit.-The camera has unquestionably won its place as the most important item in the field student's outfit; not merely because it enables one to record facts in a graphic, communicable form, but also because it supplies an incentive for definitely directed study, by satisfying the hunting instinct and gratifying the desire for some tangible return for effort expended. Photographs can be made not alone of birds, their nests and eggs, but of haunts and of vegetation, showing its condition at certain dates as it develops in the spring or dies in the autumn.

The naturalist photographer should seek the advice and instruction of some one with experience; or, when this is not possible, the books on the subject should be consulted. Much may be done in the study of nest-life with a camera and lens costing between thirty and forty dollars. Select a strong, not too light, $4 \times 5$ camera, having a bellows-length of not less than 16 inches and fitted with a trade shutter; and a lens of about 7-inch focus, convertible in type, in order that either the front or rear half of the lens can be used alone, giving an image about double the size of that produced by both combined.

Such a camera should be used from a tripod, and under favorable conditions of light and time it will do excellent work. It cannot be employed to photograph flying birds or to do many other things which require the most rapid lenses and special apparatus; but, from a blind, with the nest, food, or decoys to act as a lure, bringing birds within range, one may secure an endless number of valuable and interesting photographic records of bird-life.

By using one of the modern, very rapid multi-speed, lens-shutters and guessing at the focus, such a camera may be used in photographing birds in flight; but the best results are attained in this somewhat difficult field with a reflecting camera of the 'Graflex' type, equipped with a focal-plane shutter. Satisfactory flight photographs, at close range, require an exposure of not more than $\frac{1}{800}$ part of a second. This necessitates the use of a high-class, rapid lens and the outfit becomes too costly to be within the reach of many. However, except under the conditions which sometimes prevail in large bird rookeries, one can do far more and better work from a blind with inexpensive apparatus, than with a high-priced hand-camera in the open, while the notes on birds' habits obtained from the blind are incomparably more valuable.

Telephoto lenses require too great care in focusing, and too much time when exposing, to be of much service in bird photography. Nor indeed is it desirable to have a lens which too greatly increases the 
distance from one's subject. We are not out merely to get birds' pictures, but to record their habits with a camera, and the nearer we can get to the bird without disturbing it, the better we can accomplish our object.

The Collector's Outfit.-Individual preference will always play a part in the selection of a gun. My own choice for general collecting is a 16-bore equipped with a 0.32 auxiliary barrel. In general collecting in a more or less wooded region, fully 80 per cent of your shots will be fired from the auxiliary - or 'aux' as it is commonly termed-while there will be but few occasions in the remaining 20 per cent when the 16-bore, if properly held (!) will permit a specimen to escape.

Crude but effective auxiliary barrels may be made with a 16gauge brass shell and a brass tube about ten inches long and having an opening the diameter of a 0.32 Ideal shell. Enlarge the cap-opening of the 16-gauge shell until it will exactly receive the brass tube; stand the shell on a level surface squarely on its base, place the tube upright in it with its end in the enlarged cap-hole and flush with the base of the shell; now, using extreme care to have the tube exactly in the center of the shell, fill the shell about the sides of the tube with molten lead. When it has cooled, counter-sink a shoulder in the base of the tube of sufficient size and depth to receive the rim of the 0.32 shell, file a narrow slot to enable one to remove with an awl or properly sharpened nail the exploded shell, and your 'aux' is made.

A gunsmith could do a better job and give you a barrel with an extractor which will work automatically with that of your gun, and such barrels may sometimes be purchased from natural history dealers; but the one I have described can be made by any one and will answer every purpose. In any event, test your 'aux' thoroughly until you have learned its range and what load will give the best pattern and penetration. I use about three-fifths fine smokeless powder with a cardboard and felt or leather wad, and two-fifths shot with a cardboard wad. In loading a large number of shells for a prolonged collecting trip, the wad over the shot may be dipped lightly in liquid paraffine, which, in hardening, will tend to keep the wad from slipping.

Since the 'aux' is used almost exclusively for birds no larger than a Blue Jay, the shells for it should be loaded with No. 12 shot. For the 16-bore, one should carry variously loaded shells, as the nature of the collecting directs.

A hunting-coat with large pockets, a fisherman's creel, or a gamebag, for carrying specimens, a bottle of corn-meal for cleaning them, non-absorbent cotton for 'plugging' them, stiff paper for wrapping them, and a mixture of equal parts powdered alum and arsenic for preserving them, are all part of the collector's outfit.

The hird skinner's outfit, in its simplest form, consists of one or more scalpels having blades with well-rounded ends, and one, at least, with a handle small enough to be used as a spoon in removing brains; three pairs of scissors, one with short, heavy blades for bone-crushing, 
one with sharp points and long handles, and one of medium size with blunt ends; one medium size, flat-end 'eye-forceps'; thread, pins and needles. This outfit, which can be purchased of a dealer in naturalists' supplies or surgical instruments, can be enlarged as circumstances require or taste directs.

Any cotton will do for filling skins, but for use in wrapping them, procure the best cotton batting that money will buy. Usually it will be found that absorbent cotton, such as may be purchased at drug stores, will be as good as if not better than any which is available.

Large birds may be filled with excelsior or a body made of crumpled newspaper, possibly covered with a thin sheet of cotton.

\section{REFERENCES}

1900. Prnchon, W. H. C., A Method of Recording Observations, Bird-Lore, II, 19-22.-1900. Chapman, F. M., Bird Studies with a Camera, 12 mo., 218 pp., illus. (Appleton). -1901. Herrick, F. H., The Home Life of Wild Birds, rev. ed., 1905, 8vo., 255 pp. (Putnam's).-1902. Barley, F. M. Handbook of Birds of Western United States, introduction (Houghton, Mifflin \& Co.).-1902. Dugmore, A. R., Nature and the Camera, 8vo., 126 pp. (Doubleday).-1902. Felger, A. H., A Plan for Recording in a Condensed Form the Life History Notes of Birds, Auk, XIX, 189-195.1904. Brownell, Photography for the Sportsman Naturalist (Macmillan). 1910. Job, H. K., How to Study Birds, (Outing Co.).-1911. Beetham, B., Photography for Bird Lovers, 12mo., 126 pp., illus. (Witherby, London.)

\section{Collecting Birds, Their Nests and Eggs}

Collecting Birds

Care of the Bird in the Field

Making Birdskins

Sexing

Cataloguing and Labeling

Care of a Collection

Collecting and Preserving Nests and Eggs

Collecting Birds.-When one goes to a country whose birds are unknown or but little known, the first thing to do is to collect and preserve them in order that they may be properly named and classified, and that our records of their distribution may rest on the tangible ground of specimens.

This is the essential procedure in beginning the study of bird-life the world over, but once thoroughly done, it is neither necessary nor desirable to repeat it indefinitely.

To say that one cannot become an ornithologist without first having been a collector of bird's skins, is to confess ignorance of the advance which has been made in the methods and possibilities of bird study.

The non-collector will possibly never have that intimate, personal, first-hand knowledge of specific differences which has been gainerl by the man who has handled many birds of his own killing, nor will he 
have added as many 'records' of the occurrence of species beyond the normal limits of their range; but in regions whose birds have been adequately collected, he will unquestionably render ornithology a far higher service by devoting himself to a study of biographic problems than by collecting specimens which, however much they may gratify his desire for acquisition and increase his personal acquaintance with birds, will add but little or nothing to the fund of ornithological knowledge.

The student with some definite problem in view is always justified in taking the specimens which are required to aid in prosecuting his researches, nor can there be any reasonable objection to collecting for purposes of identification; but there can be no doubt that throughout the greater part of eastern North America there is no longer need for general, indiscriminate collecting. No better proof of the truth of this statement can be required than the fact that, as our introductory 'Historical Review' shows, some of the most important additions to our knowledge of birds in this area, during the past fifteen years, have been made by men who are not collectors.

There is no question of the destruction of life involved here. In only two or three instances has the collecting of birds for specimens appreciably affected the numbers of a species; and, as every one familiar with the facts involved kniows, the results of general amateur collecting are absolutely inappreciable. Therefore, it is the student, rather than the bird, I have in mind, when I discourage further collecting in regions whose bird-life is already well-known. In most cases the time which he can give to bird study is limited, and the question is, shall he devote it to doing exactly what ornithologists for generations before him have done, or shall he, by concentrating on a definite probblem, do what no one has done? Can he not well afford to forego a general superficial knowledge of a large number of birds, such as many have had, for a special knowledge of some few birds such as no one has had? For the real student, imbued with the true spirit of research, there can be only one answer to this question.

After this protest against unnecessary collecting, and the waste of opportunity it occasions, I add a description of the technique of birdskin making, for the use of those who may properly employ it.

Care of the Bird in the Field.-On killing a bird, pick it up by the bill or feet, and at once sprinkle meal or dry earth on any blood which may be visible. When this is saturated, scrape it off with a knife-blade and repeat the operation until all the blood is absorbed. Sprinkle some meal at the base of the feathers about the shot-holes from which the blood appears, or, if necessary, plug these holes with bits of cotton. Place a large plug of cotton in the mouth and force it well down the throat to prevent bleeding at the mouth from an internal wound. In some cases it is necessary to also plug the nostrils. Now make a cornucopia of stiff paper, drop the bird in it head foremost, taking care that the bill is not turned forward on to the throat, and, if the bird is 
not too large, fold in the edges of the cornucopia and place the specimen in your bag or basket. In the case of very large specimens-Hawks, Owls, etc.-it is advisable to skin out the body in the field, when they can be packed in much smaller space.

Making Birdskins.-With proper instruction it is not difficult to learn to skin birds. I have known beginners, who had closely watched experts at work, make fair skins at their first attempt-better skins, indeed, than the person who learns only from written directions may ever make. I am speaking from experience. Only too clearly do I remember my own first attempts at skinning birds and their hopelessly wretched results. In despair I at last sought the assistance of a distant ornithological friend. In one lesson he made the process so clear to me that I was at once enabled to make skins twice as quickly and twice as well. However, we unfortunately are not all blessed with ornithological friends to whom we can turn for advice, and I therefore append the following directions for making birdskins:

Let us begin with a bird, say, the size of a Robin: 1 . Plug the bird's throat and nostrils tightly with fresh cotton. If the eyeball is ruptured, pull it out with the forceps and fill the cavity with meal. 2. Lay the bird before you on its back, its bill pointing to the left; place your open left hand lengthwise on it, so that the base of your first and second fingers rests on the middle of the breastbone; use these fingers and the handle of the scalpel to separate the feathers from near the end of the breastbone to the vent, and when the parting is made use the same fingers to hold the feathers aside. 3. With the scalpel make an incision in the skin from just in front of the end of the breastbone, or at the base of the $\mathrm{V}$ formed by the spread fingers, to the vent, being careful not to cut through into the abdomen. 4. Sprinkle a pinch of meal along the cut. 5. Lift the skin at the front end of the cut and insert the end of the scalpel handle between it and the breastbone. If you try to do this lower down on the cut, over the belly, you will find it difficult to separate the skin on which the feathers grow from the immediately underlying skin which covers the abdomen. Separate the skin from the body the whole length of the eut and as far down toward the backbone as possible, thus exposing the bare knee. 6. Take hold of the foot and push the knee farther up into view, then take the blunt-ended scissors and, on the inside of the skin, clip the leg entirely in two. 7. Repeat. operations 5 and 6 on the other side of the body. 8. Press away the skin as much as possible on either side of the rump, and plare the thumb at the left side (left, seen from above) of the base of the tail or 'pope's nose,' with the first finger on the other side (both inside the skin) and the second finger behind (above) on the rump; now with the blunt. scissors cut through the flesh between the thumb and first finger toward the second finger, which serves the purpose of a guard to prevent you from cutting through the skin. 9. Stand the bird on its breastbone, the belly toward you, and with both thumbs press the tail and skin of the rump over and down off the stump from which you have just 
cut it. 10. When the stump is free from the skin, take hold of it with the right hand and with the fingers of the left gently press the skin from the body, keeping it constantly turned inside out and using an abundance of meal. 11. Soon the wing-bones (humeri) will appear. Clip them off at either side close to the body, and resume skinning as before. 12. The skin will slip easily over the neck, and you will then meet with an obstruction in the head. 13. Work the skin carefully over the head, using the tips of the first two fingers of either hand, placing the thumbs as a brace farther forward over the eyes.* 14. Pull the ears carefully from their sockets. 15 . The eyes will now appear; carefully cut the membrane joining the skin and eyeball, making the incision as far back as possible, in order to avoid cutting the skin, which should be pulled forward until it is entirely free of the eyeball. 16. Remove the eyes with the forceps. 17. With the sharp-pointed scissors make an incision directly across the roof of the mouth, inside the branches of the lower mandible, just back of the skin, and below the eye-sockets. 18. With the sharp-pointed scissors make incisions from either end of this cut back along the branches of the lower mandible through the base of the skull on either side of the neck at its junction with the skull. 19. Connect these cuts by a fourth, which passes through the base of the skull just above the neck, and pull the body and neck from the skull. 20. Scoop out what brains remain with the handle of the scalpel. 21. Pull the end of the wingbone (humerus) inward, skinning the feathers off the bones of the forearm (radius and ulna), and remove the flesh. 22. Do the same thing for the legs, but, after cleaning, do not in either case pull the bones back. 23. Remove as much flesh as possible from the base of the tail, including the oil-gland at the base of the tail above. 24. Hold the skin over the arsenic and alum box, and with a bit of fluffy cotton at the end of a stick, or held in the forceps, dust it choroughly with the poison, giving an extra allowance to the base of the tail and bones of the skull, wings, and legs. 25. Pull the legs back into place. 26. Place a fluff of cotton on the end of a wire and roll it into a firm, smooth ball, placing one in each eye-socket. 27. Coax the skin back over the head, using the first two fingers of each hand and placing the thumbs at the base of the skull. When the tip of the bill appears through the feathers, use the fingers outside, on the feathers, pressing the skin back over the head, and keeping the thumbs in the same position. When the bill is free, take it with the right hand, and use the fingers of the left to urge the skin over the skull, being careful to get it in its former place so that the feathers of the head will lie smoothly. 28. Dress the feathers of the head, particularly those about the eye. 29. Take hold of the tip of the bill and shake the skin gently but vigorously to aid in settling the plumage. 30. Lay the skin on its back, the bill pointing from you, and turn back the

*In large-headed birds, like Ducks and Woodpeckers, this is impossible, and it is neecsuary to slit the skin down the back of the neck and push the skull through the opening. 
feathers about the opening on the belly. 31. See that the wing-bones lie flat on the back of the skin, with their ends touching each other.* 32. Take a bit of fluffy cotton, press it lightly together, and draw out one end to form a neck. When released from your grasp this cotton body should be but little larger than the body you have removed from the skin. 33. Take the end of the neck with the forceps and insert it gently into the neck of the skin, working the skin down onto it in order to avoid stretching the neck, until the points of the forceps appear in the mouth, then hold the cotton there and withdraw the forceps. 34. Carefully fit the cotton body into the skin. 35. Put one or two stitches in the incision on the belly. 36. Ascertain the sex of the bird (see beyond). 37. Cross the legs, and at the point of intersection attach a label (see beyond). 38. Squeeze the wing-bones together until you feel the tips of your fingers meet over the bird's back. 39 Prepare a sheet of cotton about five inches square and as thin as you can make it; lay the bird on this on its right side, the bill pointing to your right hand. 40. Put the left wing in place and dress the feathers about it. 41. Take hold of the sheet of cotton, and turn the bird over in it in order that you may dress the right wing. 42. Roll the bird on to its belly, holding the wings in position with the thumb and first finger

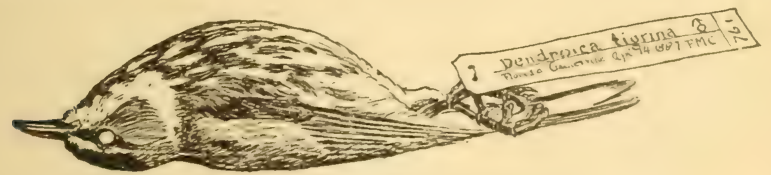

Fig. 4. A completed birdskin (reduced).

of the left hand, and with the right hand bring the tips of the wingfeathers into their proper place over the back. 43. Roll the bird back on to its back, the bill pointing to your right hand; take the end of the sheet of cotton farthest from you and draw it lighlly over the bird to the side nearest you. 44. Draw the end nearest you in the opposite direction. 45. See that the feet, tail, and tips of the wings are in their proper position, and place your specimen out of harm's way to dry.

It will doubtless take you from half an hour to an hour to make your first birdskin. It will probably be a sorry-looking object, perhaps minus a head or tail or half its feathers; but do not let this dis-

*The most difficult part in making a birdskin is to induer the wings to atsume anything like their natural position when closed. This is because the artificial cotton body is apt to force them outward on to the sides rather than on the buck, where they belong.

In the bird in the flesh the wings are held in place by being atturherd to the bodly; in the skin they are loose and hanging. To remerly this, after alraw ing the wing-hones in to remove the flesh from them, they should be pushed hack only far emongh to enable one to see plainly the elbow or bend of the wing cutside of the skin. This prevents the wings from hanging, and, to further kerp them in place, it will be well at first to tie the ends of the bones (humeri) together. 
courage you. An expert can make ten birdskins an hour, and you need only practice to approach this.

Sexing.-A specimen without a sex mark on its label is of comparatively little value. The sexes in many birds can of course be distinguished by their color, but the young male frequently resembles the female, while in some instances the female has been known to assume the plumage of the male. Dissection, therefore, is the only safe way to determine sex. Upon reaching stage 36 , in the operation of making a birdskin, cut through the left side of the body from the vent to the neck, taking care not to disturb the internal organs. Force the edges of the opening apart, and, pressing the intestines gently to one side, look for the sexual organs, which will be found on the walls of the small of the back very near to the backbone. The male organs (testes), two in number, are usually dull-white, elongate bodies lying side by side. The female organs (ovary) are composed of numerous round bodies lying in a mass or cluster. In the breeding season the sexual organs of birds become much enlarged, and at this season the testes of a male Chipping Sparrow are about the size of a pea, while the ovary of the female has been likened to a bunch of grapes, the largest being the size of the yolk of the egg of this species. After the breeding season the sexual organs decrease in size, and in adults in the winter and young birds are sometimes difficult to find. The testes of a male Chipping Sparrow at that season are about as large as a small pinhead, while a hand-lens is required to plainly distinguish the ovary of the female. The arrow of Mars $\left(\sigma^{\pi}\right)$ is used to indicate the male sex; the mirror of Venus ( $q$ ) the female sex.

Cataloguing and Labeling.-Before skinning your birds you should catalogue them. The catalogue should have columns giving (1) the date, (2) your serial collection number, (3) name of the bird, (4) sex and condition of the sexual organs, (5) place of capture, (6) name of collector, and (7) remarks. In the last column enter any notes on the color of the eyes, or parts which will change color when drying, contents of the stomach, and other notes. In addition to this 'day-book' or 'blotter' some ornithologists open a ledger account with their collection and devote a folio to each species, on which are posted the entries made in the collection register.

Labels should be of strong bond paper, two inches and a half long and half an inch wide. They are attached to the crossed legs of the bird by linen thread strung through their left end. The face of the label bears the name and sex of the bird, place and date of capture, name of collector, and serial collection number. The label shown in Fig. 4 is small, but will illustrate the appearance and manner of attachment. The name of the owner of the collection is printed on the back of the label, preceded by the words "Collection of."

Many collectors prefer to use as a field label a small jeweler's tag upon which the collection number, sex and date are written. The large label is added after the specimen is dry. 
Care of a Collection.-The best cases in which to keep a collection of birdskins are known as "Cambridge cans." They are made of tin, with covers which fit into grooves lined with rubber tubing, and are practically air-tight. The smaller sizes cost from five dollars to seven dollars and a half each, and can be obtained of Müller and Wood, of New York City.

A wooden cabinet with tight-fitting drawers and door is less expensive, and with ordinary care will preserve specimens for a practically indefinite period. The drawers should be thirty inches long by sixteen inches in width. For birds the size of a Robin a depth of one inch and three-quarters is sufficient, while drawers four inches deep will take the largest Hawks or Owls. These drawers will hold about thirty birds the size of a Robin, eighty the size of a Chickadee, and eight to ten Hawks and Owls.

Well cleaned and thoroughly poisoned specimens of small birds are not likely to be attacked by the moth (Tinea) or beetles (Dermestes and Anthrenus) which so often infest poorly prepared or nonpoisoned skins. Naphthaline crystals or camphor gum should be placed in each drawer of the cabinet, the door of which should not be left open needlessly. If a specimen falls a victim to insects, the better plan is to discard it at once. If, however, it is rare, it may be taken out-of-doors and placed in an air-tight box with a few tablespoonfuls of bisulphuret of carbon.

Collecting and Preserving Nests and Eggs.-The following quotation, from the late Major Bendire's Instructions for Collecting, Preparing, and Preserving Birds' Eggs and Nests* may be taken as authoritative: "Unless the would-be collector intends to make an especial study of oölogy and has a higher aim than the mere desire to take and accumulate as large a number of eggs as possible regardless of their proper identification, he had better not begin at all, but leave the nests and eggs of our birds alone and undisturbed. They have too many enemies to contend with, without adding the average egg collector to the number. The mere accumulation of specimens is the least important object of the true oölogist. His principal aim should be to make carcful observations on the habits, call notes, song, the character of the food, mode and length of incubation, and the actions of the speries generally, from the beginning of the mating season to the time the young are able to leave the nest. This period comprises the most interesting and instructive part of the life-history of our birds." Very heartily do I endorse every word of this, and to the concluding sentence I would add: and there can be no better way to atooid increasing our knowledge of a bird's domestie life than to rob it of its eggs, and destroy its home and our own opportunities at the same time. Studied from a local standpoint, I confess I can see only two points of interest in a bird's egg - one is what the egg is in, the other is what is in the egg.

Nevertheless, I can understand the pleasure attending the legiti*Part D. Bull. U. S. Nat. Mus., No. 39, 1891, pp. 3-10. 
mate formation of what Major Bendire has called "a small, thoroughly identified, well-prepared, and neatly cared for collection," which, as the same author adds, "is worth far more scientifically and in every other way than a more extensive one gained by exchange or purchase."

An egg collector's outfit consists of several drills, an embryo-hook, a blowpipe, forceps, and scissors. A fresh egg should be blown through a hole slightly larger than the tip of the blowpipe. Drill the hole in the side of the egg, and, after inserting the blowpipe about one-sixteenth of an inch, blow gently and steadily until the contents have been removed. Then rinse the egg thoroughly with water and lay it hole downward on corn-meal to drain.

In eggs containing embryos it is necessary to make a hole large enough to permit of the use of the embryo-hook, scissors, or forceps, as the case may be.

Each egg should be marked with the number of the species in the 'Check-List' of the American Ornithologists' Union, the number of the set in your collection, and the number of eggs in the set. Thus, if I were about to label my second set of four eggs of the Bluebird, I should write with a lead pencil on each egg, near the hole, $766 \frac{2}{4}$.

There are many ways of displaying collections of eggs. Some collectors place their eggs in little boxes or partitions filled with sawdust or cotton; Major Bendire used small pasteboard trays lined, bottom and sides, with cotton wadding, and divided into partitions for each egg by strips of cotton wadding set on edge. It is, however, very largely a matter of taste, and collectors generally have their own ideas on these matters.

A collection of birds' nests is a telling object lesson in the study of ornithology. Familiar as I am with them, I never see the nests of some birds without feeling the most intense admiration for the marvelous skill which has aided them in forming a structure man would find it difficult, if not impossible, to duplicate. A bird's nest in its original site is a concrete expression of the intelligence of its maker; for the foresight displayed in the choice of a situation, and the ingenuity shown in the construction of the nest, even if largely instinctive now, originated in the intelligence of a line of ancestors.

Nests may be collected before they have been used, when the birds will generally build again; or you may wait and take them after the birds have left them, labeling each nest with what you have learned of the history of its owners. For example: Time required for its construction; whether made by one or both sexes; notes on the laying of the eggs; period of incubation; whether both sexes assisted in incubation; care of the young; number of days they were in the nest, etc.

Some nests, for example the pendent "baskets" of Vireos or such as are placed in crotches, should be taken with the crotch or branch to which they are attached.

With others it is obviously impossible to do this. They should therefore be placed in a frame of wire and wrapped about with fine wire 
thread. To make this frame, twist two pieces of annealed wire, painted brown, into the shape of a letter $\mathrm{X}$. About midway from the point of intersection and the end of the arm, bend the wires upward at right angles. Now take the fine hair or thread wire and wind it about the four horizontal arms of the frame until its bottom looks like a spider's web; place the nest in this half-formed basket, bend the upright wires inward or outward as the case requires, and continue winding until the nest is bound firmly. The size of the frame and the wire used in its construction may be varied to suit the nest.

\section{REFERENCES}

1891. Honnaday, W. T., Taxidermy and Zoölogical Collecting, 8vo., 362 pp., ills. (Scribners).-1898. Rowley, J., The Art of Taxidermy, 12mo., 244 pp., ills. (Appleton.)

\section{American Ornithological Societies}

The bird student, particularly if, as so often happens, he be isolated from others of kindred tastes, should, if possible, affiliate himself with one or more of the ornithological societies in this country. In any event, he should aim to secure election to Associate Membership in the American Ornithologists' Union, not alone because this is the first step toward becoming a Fellow in this organization, "the highest honor to which an American ornithologist can attain," but also because he will be brought into communication with the leading bird students of this country, who, he may be assured, will never fail to respond to his requests for information or advice. A list of the principal ornithological societies together with one of their official organs is therefore appended.

American Ornithologists' Union.-Founded 1884. This is the leading as well as the largest ornithological organization in the country. Membership is divided into the following classes: Fellows (limited to 50, contains* 49), Honorary Fellows (limited to 25, contains 12), Corresponding Fellows (limited to 100, contains 61), Members (limited to 100 , contains 79), Associates (unlimited in number, contains 738). All bird students are eligible as eandidates for election to associate membership. Annual Congresses are hold, usually in November, in Washington, Philadelphia, New York, or Cambridge.

Official organ, The Auk; free to all members. Address, American Ornithologists' Union, eare of the American Museum of Natural History, New York City, N. Y. (For a history of the Union, see J. A. Allen in Bird-Lore, 1899, pp. 143-148.)

Delaware Valley Ornithological Cluh).-Founderd, 1890. Organ, Cassinia, published annually. Address, eare of the Academy of Natural Sciences, Philadelphia, Penna. (For a history of the Club, see S. N. Rhoads in Bird-Lore, 1902, pp. 57-61.) 
Cooper Ornithological Club.-Founded, 1893. Organ, The Condor. Address, care of the University of California, Berkeley, Cal.

Linncean Society of New York.-Founded, 1878. While devoted to Natural History in general, the active membership of the Linnæan Society is composed chiefly of bird students. Organ, Abstract of Proceedings, issued annually. Address, care of the American Museum of Natural History, New York City, N. Y.

The Maine Ornithological Society.-Founded, 1893. Organ, Journal of the Maine Ornithological Society. Address, Portland, Maine. (For a history of the Society, see J. Merton Swain, Bird-Lore, 1907, pp. 65-68.)

National Association of Audubon Societies.-Founded, 1902. Organ, Bird-Lore. Issues educational leaflets for teachers and literature relating to bird conservation. Address, 1974 Broadway, New York City, N. Y. (A list of the some forty State Audubon Societies may be obtained from the National Association.)

Nebraska Ornithologists' Union.-Founded, 1899. Organ, Proceedings, issued at irregular intervals. Address care of the University of Nebraska, Lincoln, Neb.

Nuttall Ornithological Club.-Founded, 1873. The oldest ornithological organization in America. From it sprung the American Ornithologists' Union. Official organ, occasional Memoirs. Address, Cambridge, Mass. (For a history of the Nuttall Club, see F. H. Allen, in Bird-Lore, 1902, pp. 12-17.)

Wilson Ornithological Club.-Founded, 1888. Organ, Wilson Bulletin. Address, Oberlin, Ohio.

\section{Current Ornithological Magazines}

The Auk.-Organ of the American Ornithologists' Union. Quarterly. Established as the Bulletin of the Nuttall Ornithological Club in 1876, taking its present name with the organization of the A. O. U. in 1884. Each volume contains about 500 pages, a number of half-tones and, occasionally, colored plates. Subscription, $\$ 3$ per annum (free to members of the A. O. U.). Address, care of the Academy of Natural Sciences, Philadelphia, Penna.

Bird-Lore.-Organ of the National Association of Audubon Societies. Bi-monthly. Established in 1899. Each volume contains about 400 pages, many half-tones, and 12 colored plates. Annual subseription $\$ 1$ (free to members of the N. A. A. S.). Address, D. Appleton \& Co., New York City, N. Y.

The ('ondor.-Organ of the Cooper Ornithological Club. Bi-monthly. Established in 1899. Each volume contains about 250 pages and numcrous half-tones. Annual subseription $\$ 1.50$ (free to members of the C. O. C.). Address, Pasadena, Cal.

Journal of the Maine Ornithological Society.-Quarterly. Established in 1899. Each volume contains about 150 pages and occasional half- 


\section{ORNITHOLOGICAL MAGAZINES}

tones. Annual subscription $\$ 1$ (free to members of the M. O. S.). Address, Portland, Maine.

The Oölogist.-Monthly. Established in 1884. Each volume contains about 160 pages and a number of half-tones. Annual subscription 50 cents. Address, Lacon, Ill.

Wilson Bulletin.-Quarterly. Organ of the Wilson Ornithological Club. Established in 1889. Each volume contains about 225 pages and a number of half-tones. Annual subscription, $\$ 1$ (free to members of the W. O. C.). Address, Oberlin, Ohio. 


\title{
CHAPTER III
}

\section{THE STUDY OF BIRDS IN NATURE}

\author{
The Distribution of Birds \\ The Migration of Birds \\ The Votce of Birds \\ The Nesting Season \\ The Plumage of Birds \\ THE Food of Birds \\ General Activities of the Addut Bird
}

For one person with the time and equipment essential to research in systematic ornithology, there are hundreds, equally ambitious, but handicapped by limited opportunity and inadequate material. To what problems can these amateur students turn their attention? How can they gratify their ambition to make some noteworthy contribution to the science of birds?

Large collections and museum facilities are within reach of comparatively few, but living birds are everywhere; even the Sparrow of our streets is worthy of our attention, and anyone who can get out-of-doors has the opportunity to add to our knowledge of birds. Indeed, observations of real value have been made from a window or from an invalid's chair.

It is proposed, therefore, to present here at least an outline of those branches of ornithology which relate to the habits of birds, with the object of suggesting some field to which the student may devote his attention. To do this at great length, however, would require a volume alone, and I have therefore dwelt fully on only those two branches of bird study which especially interest the field student-migration and nesting - treating other phases of the subject in less detail.

The importance of specialization, with a definite end in view, cannot be too strongly emphasized. Select a subject for investigation, or a species, preferably the most common one in your vicinity, for continued observation, and your studies will acquire a character, importance, and interest which they lacked before. Not only will you pursue your field work with renewed pleasure and enthusiasm, but your researehes will lead to the reading of publications which before secmerl unattractive, and your search for information will develop a correspondence with fellow students throughout the country, widening your horizon and leading to those delightful associations born of kindred tastes.

It must not, however, be supposed that one cannot enjoy an 


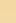



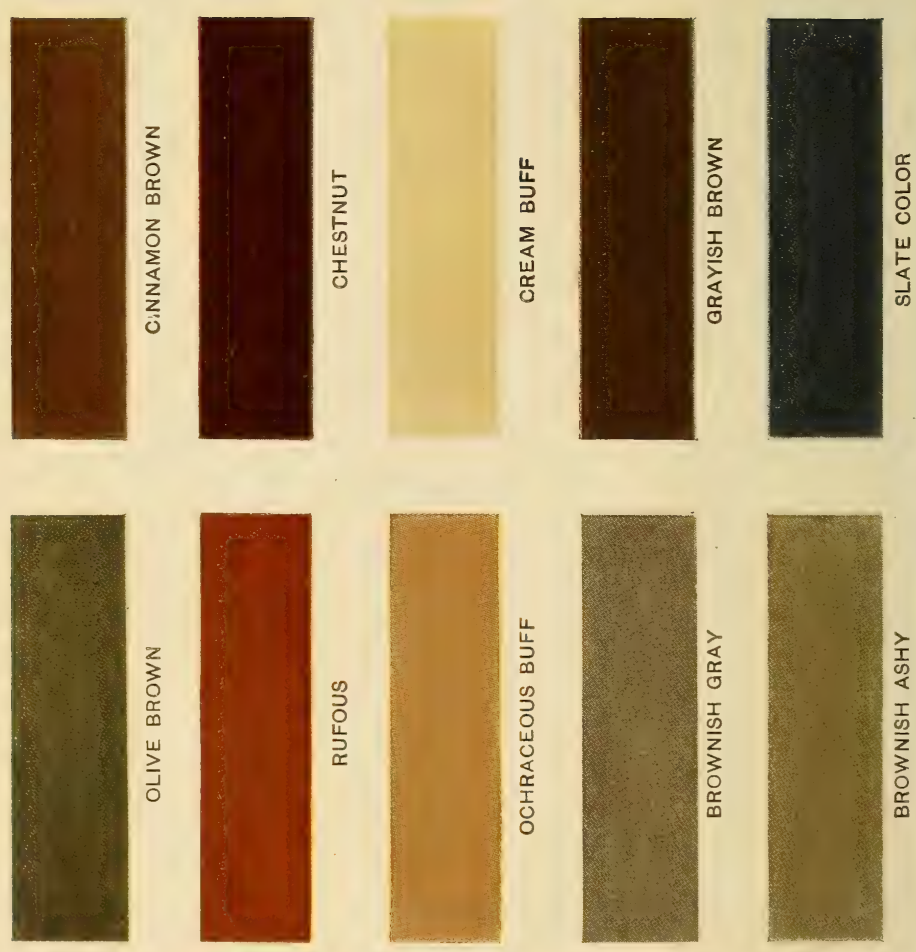

$\frac{1}{1}$
0
4
$\frac{1}{0}$
$\frac{D}{z}$
3
0
$\frac{x}{\infty}$
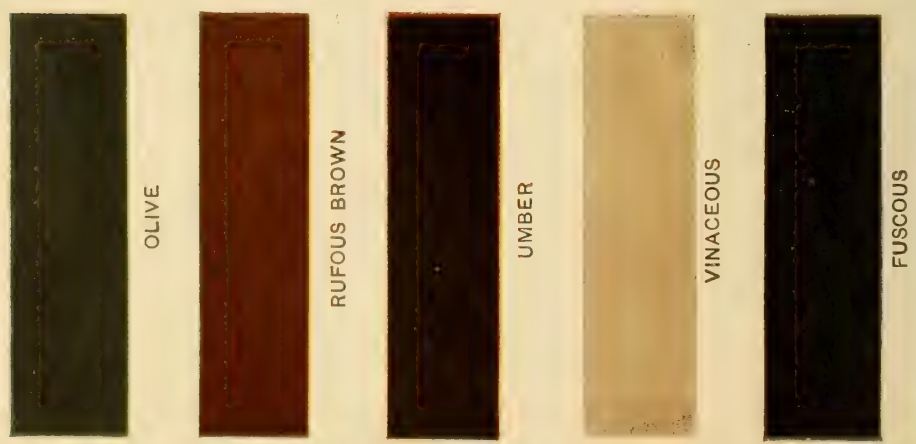


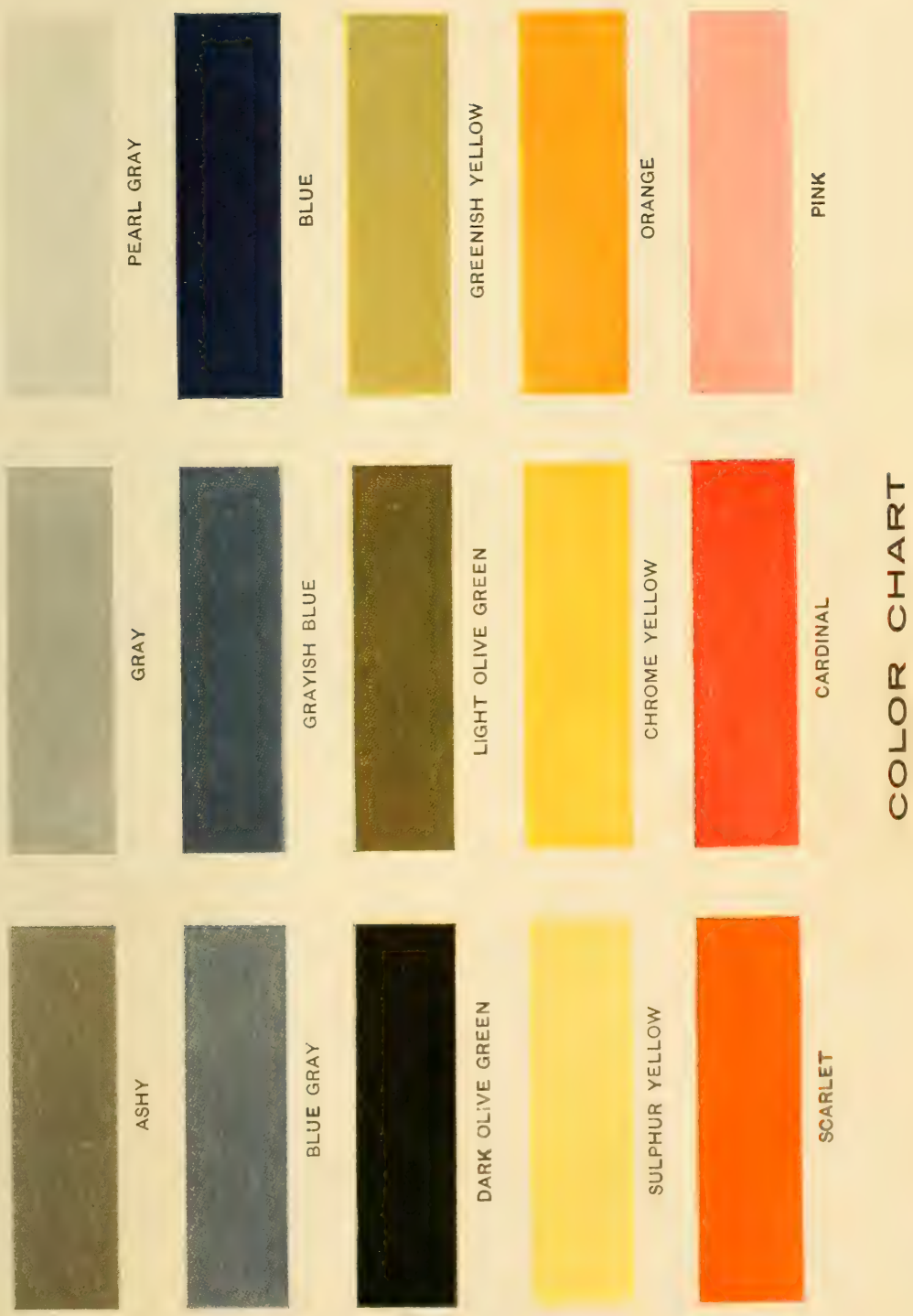

acquaintance with birds without a formal attempt to add to our knowledge of them. Bird study may not necessarily be anything so serious as a study; it may be merely a recreation, a pastime, even a 'fad,' if you like; but so long as our interest in birds is sufficient to take us to their haunts, or so long as the voice of a bird expresses for us that joy in nature which is the rightful heritage of every human being, just so long will it repay us to add to our sources of pleasure that knowledge of birds which will permit us to "come at these enchantments."

\section{The Distribution of Birds}

\section{Factors Influencing Distribution \\ Faunal Areas \\ Zones of the Boreal Region \\ Zones of the Austral Region \\ Floridian Fauna}

Factors Influencing Distribution.-Possessed of a space-defying means of locomotion, birds are more widely distributed than any other vertebrates; but in spite of their unexcelled mobility their sensitive organizations respond quickly to those influences which determine the distribution of life. Consequently we find that while some species have an almost world-wide range, others are confined to surprisingly restricted areas. The factors determining the boundaries of the region inhabited by any given bird may be classed primarily under the heads of Past and Present. Past factors include those great earth-forming forces which, through a series of profoundly important changes, have brought about the now long-standing inter-relation of land areas-in other words, the world as we know it. The land bridges which connected Great Britain with the Continent, or Alaska with siberia, and the strait which separated the American continents at Panama are factors of this kind. In their time they obviously exercised a powerful influenee on the distribution of life. Were we equally sure of all the land connections and water separations which have existed since lifo appeared on the earth, we might hope to solve many at present inexplicable problems in distribution.

Of far-reaching importance also has been the evolution of climates which this globe has witnessed, and which, through the last. (iliteial Period, has introduced the climate under which we now live. Reforenee to page 57 will explain how the distribution of White Pelicans, for example, is believed to have been affected by such past climatic changes.

Climate, of course, has never ecased to exert its influenee on the distribution of life and we find it the most active present-day factor. It is expressed mainly through temperature, and, to a lesser extent, through rainfall. Thus the boundaries of the three transeontinental zones forming the Austral Region (sce cover map) conform more or 
less closely to certain isotherms, or lines of equal temperature, but their eastern and western faunal subdivisions are determined by the annual precipitation of rain. Any factors such as altitude, exposure in relation to the sun, or proximity to water, which affect temperature exert a marked influence on the boundaries of faunas and must of course be considered in mapping faunal areas.

Outside of purely tropical regions, as Merriam ('94) has shown, temperature is not active throughout the year, but only at certain seasons. Merriam has therefore formulated the following Laws of Temperature Control: First, "Animals and plants are restricted in northward distribution by the total quantity of heat during the season of growth and reproduction." Second, "Animals and plants are restricted in southward distribution by the mean temperature of a brief period covering the hottest part of the year." With birds, of course, it should be understood that the southern as well as northern limits of the breeding range are here referred to.

Faunal Areas.-It is not possible for us to treat, even in outline, this absorbing and important subject, but for practical purposes, if for no other reasons, the student should become familiar with the boundaries of the faunal areas of North America, as well as the names of the birds which characterize them. This is the study of faunal geography, or zoögeography, as compared with that of political geography.

Examination of maps showing (1) the ranges of the families, (2) the genera, and (3) the species of birds, reveals the fact that many families, genera and species are distributed, respectively, over essentially the same parts of the earth's surface. It will also be found that these areas are occupied by other families, genera and species of animals as well as of plants. Such areas are therefore called natural life areas, and their rank conforms more or less closely to the systematic standing of the groups of animals inhabiting them. While the faunal terms employed are not always used in the same sense (see Merriam '92, and Allen '93), it may be said that families are distributed through regions, genera through zones, and species in faunas.

North America, it will be observed on the cover map, here reproduced by courtesy of the Biological Survey, is divided primarily into three Regions, ${ }^{*}$ the Boreal, the Austral and the Tropical. The last, occupying only the southern extremities of Florida and Lower California, has in these limits no zonal subdivisions.

Zones of the Boreal Region.-The Boreal Region includes three transcontinental zones, the Arctic, the Hudsonian, and the Canadian. The first-named extends southward to the northern limit of forests, and not only crosses this continent but is circumpolar; the uniform climatic conditions of the Arctic portions of both hemispheres, in connection with their comparative proximity, being responsible for essen-

*For detailed consideration of the characteristics of these Regions consult Merriam '98. 
tially similar faunas. Consequently, Ptarmigan, Gyrfalcons, Snowy Owls, Snow Buntings, and numerous species of water birds are found in northern Eurasia as well as in northern North America. In fact, as Allen ('93) has shown, 60 of the 65 genera of birds occurring in the American Arctic are circumpolar. The parts of the Rocky Mountains and Sierras reaching above timberline, where, at the border of perpetual snow, Leucostictes, the Pipit and White-tailed Ptarmigan nest, should, it seems, also be included in the Arctic zone, altitude rather than latitude here giving the required low temperature.

The Hudsonian zone marks the northern limit of forest growth of firs and spruces. It will be observed that on both the Atlantic and Pacific coasts, as well as along the Mackenzie River, its northern limits are considerably extended; while southward it pushes a spur down the crest of the Rocky Mountains with outlying 'islands' as far south as Colorado and New Mexico. The Rough-legged Hawk, Great Gray Owl, Pine Grosbeak, Northern Shrike and Alice's Thrush are characteristic birds of this zone.

The Canadian zone is distinguished by the high development of its coniferous forests. Its extension southward along the Alleghanies will be noted, its altitude increasing as the latitude decreases. Thus, where primeval coniferous forests have not been destroyed, the Canadian zone appears in Massachusetts at an elevation of 1,800 feet (Howe and Allen), in Pennsylvania at 2,000 feet (Dwight), and in North Carolina at 4,500 feet (Brewster).

Reference to the Biological Survey map will show how numerous are the Canadian zone 'islands' on the higher portions of our western mountain systems. Evidences of this zone should also be shown at least as far south as the southern end of the Mexican tableland, where, at an elevation of from 8,000 to 13,000 feet in heavy forests of pine and spruce, such characteristic Canadian species as the Red Crossbill, Evening Grosbeak, Junco, Siskin, and Brown Creeper are represented by closely allied forms which breed there in abundance.

In addition to the species just named, the Canadian zone is characterized by the presence in the nesting season of the Spruec Partridge, Hawk Owl, Goshawk, Three-toed Woodpeckers, Yellow-bellied Flycatcher, Canada Jay, White-throated Sparrow, Tennessere, Myrtle, Blackpoll, Bay-breasted, Blackburnian, Magnolia, and Canadian Warblers, Winter Wren, Red-breasted Nuthatch, Ruby-and Golden-crowned Kinglets, Bicknell's, Olive-backed, and Hermit Thrushes.

The Zones of the Austral Region.-The Transition, Ipper Austral, and Lower Austral zones, as has been before remarked, are transeont inental, but differenees in rainfall separate them into rastern humicl, western arid, and Pacific coast humid divisions.

The eastern humid and western arid divisions morge into one another at about the one-hundredth meridian, or, approximately, where, in going westward, the prairies pass into the plains. To the 
eastward of this meridian the annual rainfall exceeds 25 inches; to the westward, except on the Pacific coast, it is below this amount.

In the present connection we may restrict our statements concerning the three zones of the Austral Region to their eastern or humid portions, which have long been known as the Alleghanian, Carolinian, and Austroriparian or Louisianian faunas (see Allen '71).

The Alleghanian, as will be observed on the map, extends at sealevel only as far south as Long Island, where, in response to conditions which produce scrub oak and pitch pines, it occupies the southern portion of the island, while the Carolinian element is restricted to the more fertile northern shore.

Crossing northern New Jersey and northeastern Pennsylvania, the Alleghanian fauna extends southwestward along the Alleghanies to northern Georgia, appearing at an ever increasing altitude. Thus in western Maryland its lower limit is 1,200-1,300 feet (Preble), in North Carolina 2,500 feet (Brewster), and in Georgia 3,500 feet (Howell).

The following species are characteristic of the Alleghanian fauna: Virginia Rail, Sora, Bob-white, Mourning Dove, Black-billed and Yellow-billed Cuckoos, Kingbird, Crested Flycatcher, Bobolink, Cowbird, Meadowlark, Baltimore and Orchard Orioles, Chipping and Field Sparrows, Towhee, Indigo Bunting, Yellow-throated and Blueheaded Vireos, Golden-winged and Pine Warblers, Catbird, Brown Thrasher, House Wren, Long-billed Marsh Wren, White-breasted Nuthatch, Wood Thrush and Wilson's Thrush.

The Carolinian fauna, or humid division of the Upper Austral zone, reaches the Atlantic seaboard only between Virginia and southeastern New York. Westward it ascends the Alleghanies to an altitude of 1,200 feet in Maryland (Preble), 2,500 feet in North Carolina (Brewster), and 3,500 feet in extreme northeastern Georgia (Howell). At this point it sweeps around the extreme southern extension of the Alleghanian fauna and expands toward the north and west as indicated by the map. In the Atlantic States a tinge of the Carolinian fauna is present at least as far east as Saybrook, Connecticut, and as far north as Portland in the Connecticut Valley, and Fishkill in the Hudson Valley.

Characteristic Carolinian birds are Acadian Flycatcher, Fish Crow, Cardinal, Prothonotary, Worm-eating and Blue-winged Warblers, Louisiana Water-Thrush, Kentucky and Hooded Warblers, Chat, Carolina Wren, and Tufted Titmouse.

The Austroriparian fauna, or humid division of the Lower Austral zone, as its name implies, occupies the South Atlantic States from the vicinity of Cape Charles, Virginia, to the tropical portions of southern Florida, thenee westward through the Gulf States and northward in the Mississippi Valley to southern Illinois and southern Kansas. Among its characteristic birds are the Water-Turkey, Louisiana Heron, Black Vulture, Ground Dove, Carolina Paroquet (now extinct in this 
fauna), Ivory-billed Woodpecker, Chuck-will's-widow, Nonpareil, Bachman's Sparrow, Boat-tailed Grackle, Yellow-throated Warbler, and Brown-headed Nuthatch.

The Floridian Fauna.-To the three faunas above named may be added the Floridian fauna, a name applied to that part of the Tropical Region which occupies southern Florida as far north as Lake Worth on the Atlantic Coast and the mouth of the Caloosahatchie River on the Gulf Coast, which is approximately the northern limit of cocoanut palms. The species which characterize this fauna are mainly West Indian and a number of them are confined to the Florida Keys. They are the Noddy and Sooty Terns, Great White Heron (Ardea occidentalis), Reddish Egret, Caracara, Everglade Kite, White-crowned Pigeon, Mangrove Cuckoo, and Black-whiskered Vireo.

\section{Suggestions For the Student}

What group of animals is most widely distributed? Mention several wide-ranging species of birds and outline their distribution. Mention several having a restricted range on continental areas. Mention several which are confined to islands. What factors have exerted an influence on the distribution of birds? Illustrate with definite instances. Mention several islands which were formerly connected with continents. Compare their bird-life with that of the adjoining part of the continent from which they have been separated. Describe the probable influence of the Glacial Period on the distribution of the White Pelicans (see beyond, under Mimration). Mention other groups of birds which have probalbly been similarly affected. What are the factors now controlling the distribution of birds? Compare the effect of temperature with that produced by humidity. What is Merriam's Law of Temperature Control? How may altitude and slope exposure influence distribution? Compare political with zoölogical geography. How are the boundaries of natural life areas determined? What are the primary life areas of North America? Name and outline the three zones of the Boreal Region and mention several species characteristic of each. Describe the general characters of each zone; topography, climate, forest-growth, etc. Treat in a similar manner the humid portions of the Austral Region, and the Floridian fauna of the Tropical Region, tracing their extent in the map, mentioning some characteristic trees, plants and crops as well as birds, and discussing their general topographic and climatic features in relation to their effect on the distribution of life.

\section{REFERENCES}

1871. Allen, J. A., A Sketch of the Bird Faunæ of Fastern North America, Bull. Mus. Comp. Zoöl., II, pp. 375-425.-1892. ALLw, J. A., The Geographical Distribution of North American Mammals, Bull. Am. Mus. Nat. Hist., IV, pp. 199-244; maps.-1892. Merria., C. H., The Geographic Distribution of Life in North Ameriea with Sperial Reference to the Mammalia, Proc. Biol. Soc. Wash., VII, pp) 1-6.4, one map.-1893. Allen, J. A., The Geographical Origin and Distribution of North Ameriran Birds Considered in Relation to the Faunal Areas of North America, The Auk, X, pp. 97-150, 2 maps.-1894. Merriam, ( Control of the Geographical Distribution of Terrestrial Animals and Plants, Nat. Geog. Mag., VI, pp. 229-238, 3 maps.-1895. Merriam, C. H., The Geographic Distribution of Animals and Plants in North America, Yearbook U. S. Dep't of Agriculture, for 1894, pp). 2(1)? 214.-1898. M вrriaм, C. H., Life Zones and Crop Zones of the United States, Bull. No. 10, Biolog- 
ical Survey, pp. 1-79, one map.-1904. Russell, I. C., North America, Chap. III, Climate, pp. 184-203 (Appleton).

Note.-Discussion of the faunal affinities of the region in question will frequently be found as introductory matter in 'local' or state bird lists; see especially (in the Bibliographical Appendix) under Georgia, 1909, Howell; Illinois, 1890, Ridgway; Iowa, 1907, Anderson; Kentucky, 1910, Howell; Maine, 1908, Knight; Maryland, 1900, Merriam and Preble; Massachusetts, 1901, Howe and Allen; Nebraska, 1909, Wolcott; New Hampshire, 1904, Allen; New Jersey, 1894, 1909, Stone; New York, 1910, Eaton; North Carolina, 1886, Brewster; Ohio, 1903, Jones; Pennsylvania, Stone, 1891, 1894; Dwight, 1892; Todd, 1893, 1904. South Carolina, 1890, 1891, Loomis; Tennessee, 1910, Howell; Virginia, 1890, Rives; West Virginia, 1890, 1898, Rives.

\section{The Migration of Birds}

Times of Migration

Extent of Migration

Routes of Migration

How Birds Migrate

Why Do'Birds Migrate?

Migration is the most distinctive phase of bird-life. Certain mammals, fishes, and even insects migrate, but no animals approach birds in the extent of their migrations. Wholly aside from the interest which is attached to a study of bird migration in the broader aspects, as we attempt to determine its origin and extent and the various factors which govern the times and manner of a bird's journeys, there is a fascination and excitement for the student in observing the arrival and passage of the great army of feathered travelers which ever renews itself when birds

\footnotetext{
"Part loosely wing the region; part more wise,

In common, ranged in figure, wedge their way

Intelligent of seasons, and set forth

Their aëry caravan, high over seas."
}

To the nature lover birds are a living calendar. "What was that sound that came on the softened air? It was the warble of the Bluebird from the scraggy orchard yonder. When this is heard, then has spring arrived."

Times of Migration.-According to the nature of their occurrence the birds of temperate regions may be grouped seasonally as follows:

1. Permanent Residents.-Includes species that are represented in the same locality throughout the year. In temperate and boreal Eastern North America few species are permanently resident as individuals. Possibly Ruffed Grouse and Bob-whites pass their lives in a comparatively restricted area. But the winter Crows, Jays, and Nuthatches of a certain locality are probably not the ones that nested there.

2. Summer Residents.-Includes species that come to us from farther south in the spring, rear their young, and return to the south in the fall. As a rule, the first species to come in the spring are the last 
to leave in the fall, while the later arrivals are among the first departures. With this group should also be placed a small number of what may be called Summer Visitants, composed of birds which, like the Little Blue Heron and White Egrets, after breeding in more southern latitudes may wander as far as several hundred miles northward. The term Summer Visitant may also be applied to Shearwaters and Petrels, which, having bred in the Southern Hemisphere during our winter, pass the summer off our coasts.

3. Transient Visitants.-Includes species which, nesting north of a given locality and wintering south of it, consequently pass through it when migrating. Most transient visitants may be found at a certain locality on both their spring and fall migrations, but a small number occur at only one season. In the Mississippi Valley, for example, the Golden Plover is found in the spring but much less frequently in the fall; while on the Atlantic Coast the Black Tern appears during the fall migration but is unknown in the spring. The earlier Transient Visitants, for example the Fox Sparrow and Hermit Thrush, may remain in the latitude of New York City for a month or more, but the later arrivals pass by in a week or ten days.

4. Winter Residents.--Includes species which come to us in the fall and remain until the spring. Some, like the Junco, are of regular occurrence. Others, like the Pine Grosbeak, may be abundant some winters and rare or wanting other winters. To these four groups may be added a fifth of birds of accidental occurrence.

Let us now review the bird-life of the vicinity of New York City for the year as it is affected by migration. I here abridge from "Bird-Life."

January.-Probably during no other month is there less movement among our birds than in January. The regular winter residents have come; the fall migrants, which may have lingered until December, have gone, and the earliest spring migrants will not arrive before the latter part of February or early March. January, in fact, is the only month in the year in which as a rule some birds do not arrive or depart. This rule, however, may be broken by such irregular birds as the Snowy Owl, Pine Grosbeak, or Redpoll, which wander southward in search of food. Food, indeed, is now the one concern of birds and their movements are largely governed by its supply. Snow may fall and blizzards rage, but so long as birds find sufficient to eat they apparently are not affected by the weather. Where seed-bearing weeds are accessible there we may look for Juncos and Tree Sparrows; cedar trees bearing berries often tempt Waxwings, Robins and Bluebirds to winter near them. When bayberries are abundant we may expect Myrtle Warblers to remain through the winter. I recall a sheltered pile of buckwheat chaff at Englewood, N. J., which furnished food for a small flock of Mourning Doves all one winter. In Central Park, New York City, a Mockingbird, which had evidently eseaped from a cage, was under daily observation from Octoher to January, and thrived during: the exceptionally severe winter while nourished by the berries of a privet 
tree. Food, therefore, rather than temperature is the all important factor in a bird's life at this season.

February.-The conditions prevailing during January will be practically unchanged until the latter half of February. Then, should there be a period of mild weather, we may expect to hear the Meadowlark, Song Sparrow, and Bluebird, inaugurate the season of song, and note the appearance of Robins, Purple Grackles, and Red-winged Blackbirds, which pass the winter such a short distance south that they appear at the first sign of returning spring. It is probable that in most cases the first individuals of our summer resident species to arrive remain to nest. (See beyond, under Nesting.)

March.-While March is certain to witness a general northward movement among the birds, the date of their arrival is as uncertain as the weather of the month itself. Continued severe weather prevents the advance, which a higher temperature as surely occasions. When ice leaves the bays, ponds and rivers we may look for Ducks and Geese. When successive thaws have made the ground soft enough to probe, we may expect the Woodcock. With the advent of insects their enemy the Phœebe will appear.

The weather which hastens the arrival of birds from the south, also prompts certain of our winter residents to begin their northward journey.

A pril.-The developments in the plant world, in early April, which are apparent to the least observant, are accompanied by corresponding but less noticed activities in the world of birds. The migratory movement now gains strength rapidly and during the latter part of the month one may expect new arrivals daily.

It will be noted that the earlier migrants of the month are largely seed-eaters, while those which come later are insectivorous, particularly those insect-eaters, which like the Swallows, Swift and Nighthawk feed upon the wing.

May.-As the season advances, marked changes in temperature are less likely to occur, and the migration becomes more regular and continuous. In February and March there may be two weeks or more variation in the times of arrival of the same species in different years; in May birds usually arrive within a day or two of a certain date. Nevertheless the force of the migratory current is still closely dependent on meteorologic conditions, and under the encouragement of high temperature may reach the proportions of a 'wave,' which when dammed by a sudden return of cold weather, floods the woods with migrants. Birds are then doubtless more abundant than at any other season. The arrival of ten or a dozen species may be noted on the same date, and a total of as many as 144 species has been recorded by a single observer during one day. (Iynds Jones at Oberlin, O., May 13, 1907.)

After the middle of the month birds begin to decrease in numbers as the transient visitants pass northward, and by the first week in June our bird-life is composed of permanent residents and summer residents. 
It will be noticed that with but few exceptions the birds arriving in May are insectivorous; particularly those insect-eating birds which obtain their food from vegetation. Thus, no sooner are the unfolding leaves and opening blossoms exposed to the attack of insects than the Vireos and Warblers appear to protect them, and the abundance of these small birds is the distinctive feature of the bird-life of the month.

June.-June is the home month of the year. Nest-building, egglaying, incubating, and the care of the young now make constant and exceptional demands on the birds, which, in response, exhibit traits shown only during the nesting season.

A feature of the month is the formation of roosts which are nightly frequented by the now fully grown young of such early-breeding birds as the Purple Grackle and Robin. When a second brood is reared, as with the Robin, the young may be accompanied to the roost by only the male parent, but in the one-brooded Grackle the roost is used by both adults and young.

July.-The full development of the bird's year is reached in June, and as early as the first week in July there are evidences of a preparation for the journey southward. The young of certain species which rear but one brood, accompanied by their parents, now wander about the country, and may be found in new localities. In some cases these families join others of their kind, forming small flocks, the nucleus of the great gatherings seen later. Examples are Grackles, Red-winged Blackbirds, Bobolinks, and Tree Swallows. The latter increase rapidly in number, and by July 10 we may see them, late each afternoon, flying to their roosts in the marshes.

It is during this and the following month that the postbreeding northward wanderings of certain more southern birds, notably Herons, occur.

August.-August is the month of molt, and when molting, bircls are less in evidence than at any other time. What becomes of many of our birds in August it is difficult to say. Baltimore ()rioles, for instince', are rare from the 1 st to the 20 th, but after that date are seen commonly. Possibly their apparent increase in numbers may in part be due to the fact that they have now in a measure regained their voices and often utter nearly their full song. However this may be, whether the seeming scarcity of birds in August is due to their silenee and inactivity or to their actual departure, certain it is that before the fall migration brings arrivals daily from the north, one may spend hours in the woods and see little besides Wood Pewees and Red-ryed Vireos, whose abundance may also be attributed to the fact that they are still in song.

After the middle of the month migrants from the north will be found in increasing numbers, but the characteristic bird-life of August will be found in the marshes. There the Swallows, Rerl-winged Blackbirds and Bobolinks, known now as Recl-birds, eome in increasing numbers to roost in the reeds, the last two with the Sora Rail attracted also by the ripening wild rice. 
September.-The first marked fall in the temperature will be followed by a flight of migrants which, because of the denser vegetation and absence of song, are much more difficult of observation than in May. Birds of the year, that is those born the preceding season, will outnumber the adults, and in most cases their plumage will be quite unlike that worn by their parents in May, while, in many instances, even the adults themselves will appear in a changed costume. Often this new dress will resemble that of the immature bird, a fact which in part accounts for the apparent scarcity of old birds in the fall migration.

In September more migrating birds are killed by striking lighthouses or illuminated towers than in any other month of the year. This is doubtless owing to the fact that stormy or foggy weather is more apt to prevail in September than during any other period of active migration; that the majority of migrants are young and inexperienced, and that probably more migrants pass in September than in any other month. It does not follow from this statement, however, that birds may be so abundant on any one day as they are under certain conditions in May, when, as before described, low temperature checks the northward movement and causes an overflow.

About September 25 the first winter residents arrive, and after that date birds rapidly decrease in numbers.

October--Early October generally brings the first killing frost, causing the leaves to fall in fluttering showers and depriving many insectivorous birds of their food and shelter. Flycatchers, Warblers, Vireos, as well as Swallows, now take their departure, and after the fifteenth of the month few insect-eating birds remain, except those which, like Woodpeckers, feed on insects' eggs or larvæ.

This is the season of Sparrows. In countless numbers they throng old stubble, potato and corn fields, doing untold good by destroying the seeds of noxious weeds. Song, Field, Chipping and Vesper Sparrows may be found in flocks, and with them will be the lately arrived Juncos, Tree and Fox Sparrows.

The diurnal migration of Crows and of Hawks, which in scattered companies string across the sky, the foraging flocks of Grackles, and, in recent years, the gatherings of European Starlings, are features of the bird-life of the month.

November. - It is an interesting fact that the first migrants to come in the spring are the last to leave in the fall. The bird-life of November, therefore, closely resembles that of March. Doubtless this is because both months furnish essentially the same kind of food. Thus Loons, Grebes, Ducks, Geese and Kingfishers remain until November or early December, when the forming of ice deprives them of food and forces them to seck open water. Woodeock and Snipe linger until they ean no longer probe the frost-hardened earth; but the thaws of March will bring all these birds back to us by restoring their food.

December.-The character of the bird-life of December depends 
largely upon the mildness or severity of the season. Should the ponds and streams remain open, the ground be unfrozen, and little or no snow fall, many of the migrant species of November will linger into December. They rarely are found, however, after the middle of the month, when our bird-life is again reduced to its simplest terms of permanent residents and winter visitants.

Similarity of feeding habits now brings certain species into loose bands whose movements are governed largely by the presence or absence of food. Their wanderings may lead them over large areas, and our orchards and dooryards may now be visited by species which will eagerly partake of our bounty. Crumbs and seeds will bring Juncos, Tree Sparrows and Purple Finches; an old seed-filled sunflower head may prove a feast for Goldfinches, while bits of meat, suet, or ham bone will be welcomed by Chickadees, Nuthatches and Downy Woodpeckers. (On this subject of winter feeding consult the publications of the National Association of Audubon Societies.)

The flight of Crows to and from their roosts is one of the characteristic sights of the bird-life of this season.

This outline of changes in the bird-life of the year occasioned by migration, may be summarized by presenting a list of the commoner permanent residents of the vicinity of New York City and adding chronological tables of migration.

\section{PERMANENT RESIDENTS}

Bob-white, Ruffed Grouse, Red-shouldered Hawk, Red-tailed Hawk, Broad-winged Hawk,* Marsh Hawk,* Sparrow Hawk, Duck Hawk, * Sharp-shinned Hawk, Cooper's Hawk, Bald Eagle, * Screech Owl, Long-eared Owl, Short-eared Owl, Barred Owl, Great Horned Owl, Downy Woodpecker, Hairy Woodpecker, Red-headed Woodpecker,* Flicker, American Crow, Fish Crow, Blue Jay, Starling, Meadowlark, Song Sparrow, House Sparrow, American Groldfinch, European Goldfinch, Purple Finch, Cardinal, Cedar Waxwing, ${ }^{*}$ Carolina Wren, Chickadee, Tufted Titmouse, White-breasted Nuthatch, Robin,* Bluebird.

To complete the possible winter avifauna, a list of winter resident land birds and of the commoner winter water birds is ardeded.

\section{WINTER RESIDENTS}

Black-backed Gull, Herring Gull, Kittiwake, Bonaparte's Gull, Old Squaw, Surf Scoter, White-winged Scotor, Saw-whet Owl, ${ }^{*}$ Horned Lark, Prairie Horned Lark, Juneo, Tree Sparrow, Pine Siskin,* Red-poll,* Snowflake, Lapland Longspur,* Red Crossbill, ${ }^{*}$ Whitewinged Crossbill, * Pine Grosbeak, ${ }^{*}$ Northern Shrike, ${ }^{*}$ Winter Wren, Brown Creeper, Red-breasted Nuthatch,* Golden-crowned Kinglet. 


\section{SPRING MIGRATION}

Arrival of Summer Residents and Transients* from the south.

February 15-March 10.-Canada Goose (April 20-30), Pintail (April), Scaup Duck (April 20-30), Purple Grackle, Rusty Blackbird (May 1-10), Red-winged Blackbird, Robin, Bluebird.

March 10-20.-Woodcock, Phøbe, Meadowlark, Cowbird, Fox Sparrow (April 1-15).

March 20-31.- Red-breasted Merganser (May 1-10), Wilson's Snipe (May 1-10), Kingfisher, Mourning Dove, Swamp Sparrow, Whitethroated Sparrow (May 15-30), Field Sparrow.

April 1-10.-Great Blue Heron, Black-crowned Night Heron, Fish Hawk, Purple Finch, Vesper Sparrow, Savanna Sparrow (May 1-15), Chipping Sparrow, Tree Swallow (May 15-31), Myrtle Warbler (May 10-20), Pipit (April 15-25), Hermit Thrush (April 25-May 5).

A pril 10-20.-Bittern, Green Heron, Clapper Rail, Yellow-bellied Sapsucker (April 20-30), Barn Swallow, Yellow Palm Warbler (April 25-May 10), Pine Warbler, Louisiana Water-Thrush, Ruby-crowned Kinglet (May 1-15).

April 20-30.-Virginia Rail, Sora, Spotted Sandpiper, Whip-poorwill, Chimney Swift, Least Flycatcher, Seaside Sparrow, Sharp-tailed Sparrow, Towhee, Blue-headed Vireo (May 10-15), Purple Martin, Cliff Swallow, Bank Swallow, Rough-winged Swallow, Black and White Warbler, Black-throated Green Warbler (May 15-25), Ovenbird, House Wren, Brown Thrasher, Catbird, Wood Thrush.

May 1-10.-Least Bittern, Solitary Sandpiper (May 15-25), Semipalmated Sandpiper (June 1-10), Yellow-billed Cuckoo, Black-billed Cuckoo, Nighthawk, Ruby-throated Hummingbird, Crested Flycatcher, Kingbird, Baltimore Oriole, Orchard Oriole, Bobolink, Grasshopper Sparrow, Lincoln's Sparrow, (May 15-25), Indigo Bunting, Rose-breasted Grosbeak, Scarlet Tanager, Red-eyed Vireo, Warbling Vireo, Yellow-throated Vireo, White-eyed Vireo, Nashville Warbler (May 15-25), Blue-winged Warbler, Parula Warbler, Yellow Warbler, Black-throated Blue Warbler (May 15-30), Magnolia Warbler (May 15-30), Chestnut-sided Warbler, Prairie Warbler, Maryland Yellowthroat, Worm-eating Warbler, Northern Water-Thrush (May 10-30), Hooded Warbler, Chat, Redstart, Veery.

May 10-20.-Wood Pewee, Acadian Flycatcher, Alder Flycatcher, Yollow-bellied Flycatcher (May 20-30), White-crowned Sparrow (May 20-30), Golden-winged Warbler (May 15-30), Tennessee Warbler (May 15-30), Cape May Warbler (May 15-30), Blackburnian Warbler (May 15-30), Bay-breasted Warbler (May 15-30), Black-poll Warbler (May 25-June 5), Mourning Warbler (May 20-30), Wilson's Warbler (May 20-30), Canadian Warbler (May 25-June 5), Long-billed Marsh Wren, Short-billed Marsh Wren, Olive-backed Thrush (May 20-30),

\footnotetext{
*The date of departure for the north is given for transient visitants; the omission of this date indicates a summer resident.
} 
Gray-cheeked Thrush (May 25-June 5), Bicknell's Thrush (May 25June 5).

\section{FALL MIGRATION}

I. Departure of Summer Residents for the south.

September 1-10.-Acadian Flycatcher, Orchard Oriole, Roughwinged Swallow, Worm-eating Warbler, Blue-winged Warbler. Chat.

September 10-20.-Baltimore Oriole, Purple Martin, Yellow Warbler,

September 20-30.-Hummingbird, Kingbird, Crested Flycatcher, Wood Pewee, Seaside Sparrow, Rose-breasted Grosbeak, Yellowthroated Vireo, Warbling Vireo, Hooded Warbler, Louisiana WaterThrush, Veery.

October 1-10.-Clapper Rail, Yellow-billed Cuckoo, Black-billed Cuckoo, Chimney Swift, Least Flycatcher, Bobolink, Grasshopper Sparrow, Indigo Bunting, Scarlet Tanager, Barn Swallow, Cliff Swallow, White-eyed Vireo, Chestnut-sided Warbler, Redstart, Ovenbird, Wood Thrush.

October 10-20.-Whip-poor-will, Nighthawk, Sharp-tailed Sparrow, Red-eyed Vireo, Black and White Warbler, Maryland Yellow-throat, Long-billed Marsh Wren, Short-billed Marsh Wren, House Wren, Brown Thrasher, Catbird.

October 20-31.-Phocbe, Towhee, Tree Swallow.

November 1-30*.-Woodeock, Mourning Dove, Kingfisher, Redwinged Blackbird, Purple Grackle, Cowbird, Vesper Sparrow, Field Sparrow, Chipping Sparrow, Swamp Sparrow.

II. Arrival of Transients and Winter Visitants from the north.

August 1-15.-Black Tern (September 25-October 10), Sora (October 15-31), Yellow-bellied Flycatcher (September 20-30), Golden-winged Warbler (September 1-10), Canadian Warbler (September 20-30), Northern Water-Thrush (September 25-October 5).

August 15-31.-Olive-sided Flyeatcher (September 10-20), Migrant Shrike (September), Tennessee Warbler (September 25-October 5), Nashville Warbler (September 25-Oetober 5), Cape May Warbler (September 25-October 5), Black-throated Blue Withler (()etoher 1525), Black-throated Green Warbler (October 15-31), Magnolia Warbler (October 10-20), Blackburnian Warbler (September 20-30), Wilson's Warbler (September 20-30), Rerl-breasted Nuthat ch (November 1-30).

September 1-10.-Seaup Duck (April), Lincoln's Syarrow (Xovember 15-30), Blackpoll Warbler (Oetober 15-25), Connerticut Warbler (September 20-30).

September 10-20.-Wilson's Snipe (()ctober 1.5-30), Bluc-hrated Vireo (Oetober 15-25), Philaulelphia Vires (Sepumber 20)-30), ()livebacked Thrush (October 20-:30), Bicknell's Thrush (()etober 20)-3(0).

*Should the season be exceptionally milcl, some of these birds may remain until late December. 
September 20-30.-Herring Gull (May), Yellow-bellied Sapsucker (October 20-30), Junco (May 1-10), White-throated Sparrow (May 1-20), White-crowned Sparrow (October 15-30), Myrtle Warbler (May 5-20), Yellow Palm Warbler (October 15-30), Brown Creeper (April), Goldencrowned Kinglet (April), Ruby-crowned Kinglet (October 20-30), Winter Wren (April), Gray-cheeked Thrush (October 15-25).

October 1-10.-Bronzed Grackle (December), Rusty Blackbird (December), Pipit (October 25-November 5), Hermit Thrush (November).

October 10-31.-Horned Lark (April), Pine Finch (April), Snow Bunting (March), Redpoll (April), Tree Sparrow (April), Fox Sparrow (November 25-December 10), Northern Shrike (April). bill.

November.-Pine Grosbeak, White-winged Crossbill, Red Cross-

The Extent of Migration.-After this glimpse of the swing of the pendulum of migration, from a local point of view, we may extend our inquiry by following the birds to their winter quarters, with the object of learning where they go and the routes they travel.

Generally speaking, the extent of a bird's migration is related to the character of its food; insect-eating birds journey much farther than seed-eaters, many of which travel but a short distance south of their birthplace. There are, however, some marked exceptions to this statement. The Bobolink, for instance, is in part granivorous, but it winters south of the Amazon, while the Golden-crowned Kinglet is insectivorous and winters as far north as New England. Again, of two insectivorous birds, one, the Short-billed Marsh Wren, does not winter north of the Gulf or South Atlantic States, while the other, the Winter Wren, is found northward to New England in winter. Numerous similar instances might be cited, all indicating that some cause other than food has determined the extent of the journeys made by many migratory birds. It will be observed that of the species just mentioned, the Bobolink and Short-billed Marsh Wren are American types of austral origin, while the Golden-crowned Kinglet and Winter Wren are European types and of boreal origin. Further inquiry will show that among land-birds the migrants which go farthest south belong in the first class, while those which winter farthest north belong in the second class. It is not improbable, therefore, that the extent of a bird's migrations may give some indication of its place of origin as a migrant.

In the western states the migration of birds is not so pronounced as it is east of the Rocky Mountains, and the latitudinal movement is eomplieated by an altituilinal one. The migrants of this region, which winter south of the Inited States, pass this season largely in Mexien. Comparatively fow land-birds go beyond Guatemala and practically none cross the Isthmus of Panama.

In eastern North America, not only are migrants proportionally more abundant, but their movements are more clearly defined, and 
the journeys of those birds that leave the United States are far more extended than those performed by the birds of the western portion of the continent.

Of our thirty-nine species of Warblers, twenty-seven winter entirely south of the United States, twenty of them reaching South America, the Yellow Warbler and Blackpoll having been recorded from as far south as Peru. The shortest journey of any Blackpoll, as Cooke points out, is 3,500 miles, "while those that nest in Alaska have 7,000 miles to travel to their probable winter home in Brazil." ("Warblers of North America," p. 15; see also his admirable "Distribution and Migration of Warblers," Bull. No. 18, Biological Survey.)

Of our ten species of Flycatchers, nine leave the United States for the winter (the Crested Flycatcher is of rare occurrence in southern Florida at this season), and all of them reach South America, the Kingbird (Tyrannus tyrannus) going as far south as Bolivia.

Two of our eight Vireos remain in Florida during the winter, five winter in Central America, and one, the Red-eye, extends its winter journey to Bolivia and southwestern Brazil.

Even more extended migrations are performed by certain Sandpipers and Plovers which nest within the Arctic Circle and winter as far south as the southern extremity of South America.

Routes of Migration.-Lying within those regions climatically most favorable for the human race, the boundaries of the summer ranges of most of our migrating birds are known with more or less definiteness; but when they leave the temperate zone to enter tropical wilds, our knowledge of their distribution is far less satisfactory. The data now available show, however, that a ficld of exceptional interest awaits the investigator who, with adequate information, traces the routes of migration followed by birds in journeying between their summer and winter homes.

In Eastern North America some migrant land birds leave the United States by passing through Texas into Mexico and are unknown in the southeastern Atlantic States (e.g. the Mourning Warbler); others leave through Florida and are unknown in Texiss and Mexico (e.g. the Bobolink and Blackpoll Warbler). Others still (e.g. the Redstart), travel through both Texas and Florida into Mexico as well as to the West Indies. There is also a route which appears to cross the Gulf of Mexico from the region at the mouth of the Mississippi, though no species is confined to it.

It was at one time supposed that the hirds which left the United States by way of Florida all erosserl direretly to ('uba, but, aceording to Cooke ('03), "The main traveled highway is that which st reterhes from northwestern Florida across the (iulf, entinuing the southwest direction which most of the birds of the Atlintie Const follow in patsing to Florida. A larger or smaller proportion of mearly all the speecies bound for South Ameriea take this roundabout course, quite regardless of the 700-mile flight over the Gulf of Mexico." 
The observations of Scott* and Bennett $\dagger$ in the Tortugas show that these islets evidently lie in a migratory highway, and we know as yet too little about the birds of western Cuba to be sure that many of the birds which pass over them do not pause on that island. But,

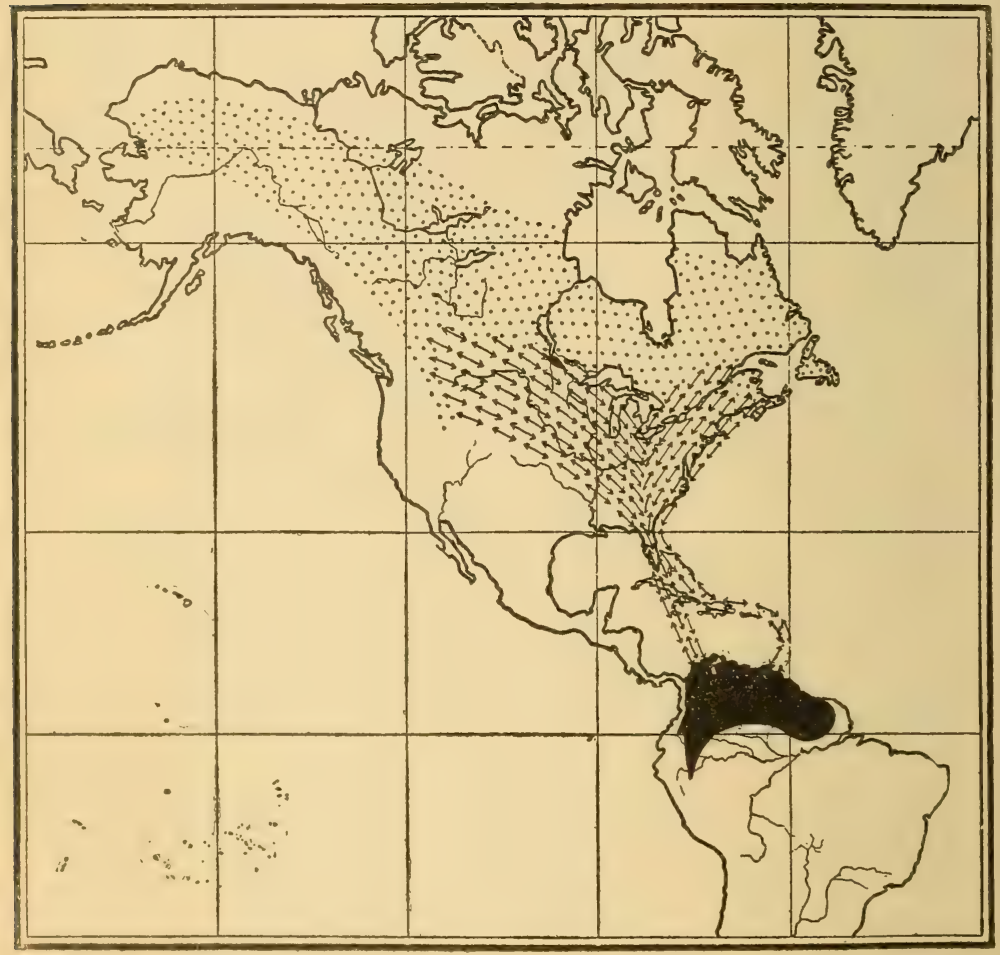

Fic. 5. Migration of the Blackpoll Warbler. A species which breeds as far northwrit as Alaska, but leaves North America through Florida, and reaches South Amerien through the West Indies, avoiding Mexico and Central America. route.

I otted arca-Breeding range. Black area-Winter range. Arrows-Migration

in any event, it is evident that, whether to or from western Cuba and Juratan, there is a clirect flight across the Culf to or from western Floridit, and, as Cooke ('(0.5) remarks, it is this route which is followed by most of our migrant land-birds which winter in South America. He sums the matter up as follows:

*The Auk, VII, 1S90, pp. 301-311. † †ird-Lore, XI, 1909, pp. 110-113. 
Species that reach South America or Panama:

By way of the West Indies............... 10

By an unknown route................... 7

By way of the Gulf of Mexico.............. 49

There is apparently, also, a small off-shore or southeastward flight to the eastward of Florida leading into and through the Bahamas, and possibly even farther east.

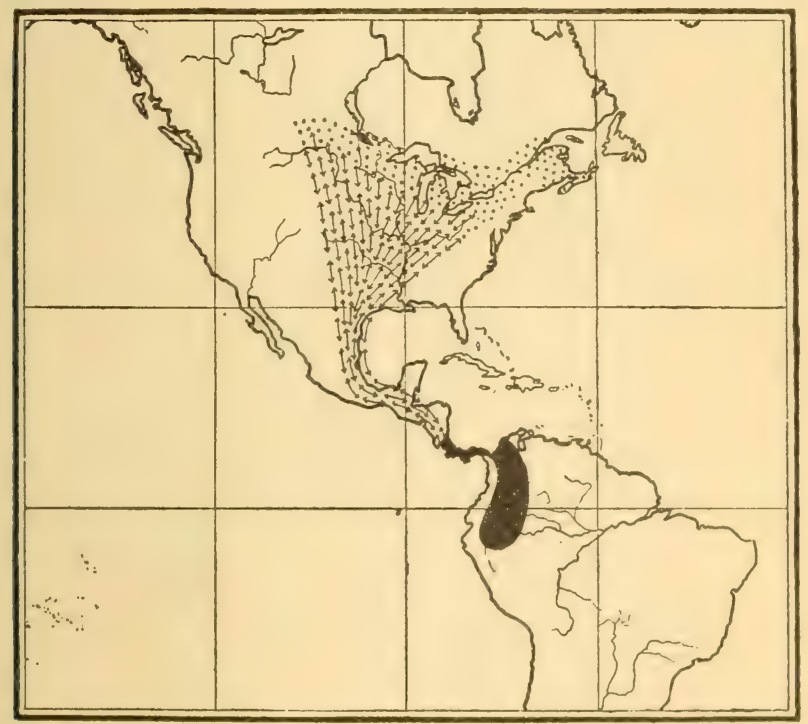

F1G. 6. Migration of the Mourning Warbler. A species whirh breeds as far northeast as Nova Scotia, but migrates southwestwarl, reaching fouth . Imericat through Mexico and Central America, and avoirling thr South Atlantic sitates atul West Indies. route.

Dotted area-Breeding range. Black area-Winter range. Arrows-Migration

According to Reid, the migrant land-hirds which visit the Bormudas with more or less regularity are the Belted Kingfisher, Yellow-billed Cuckoo, Bobolink, and Northern Water-Thrush. The last two were recorded by Julien* during a short stay on Sombrere, at the northern extremity of the Lesser Antilles; and in Gramada, the most southern island of this chain, Wellst has found the Kingfisher, Bobolink, and Water-Thrush.

Possibly these birds may have reached the Insser Antilles through *Ann. Lyc. Nat. Hist., New York, VIII, 1864, p. 93.

†Proc. U. S. Nat. Mus., IX, 1886, p. 609. 
Porto Rico from the westward. This route, however, is followed by only a small portion of the birds which migrate southward, through Florida and the Bahamas, into the Greater Antilles. If they continue their journey to South America, most of them do so through Jamaica, the 400 miles of water separating this island from northern South

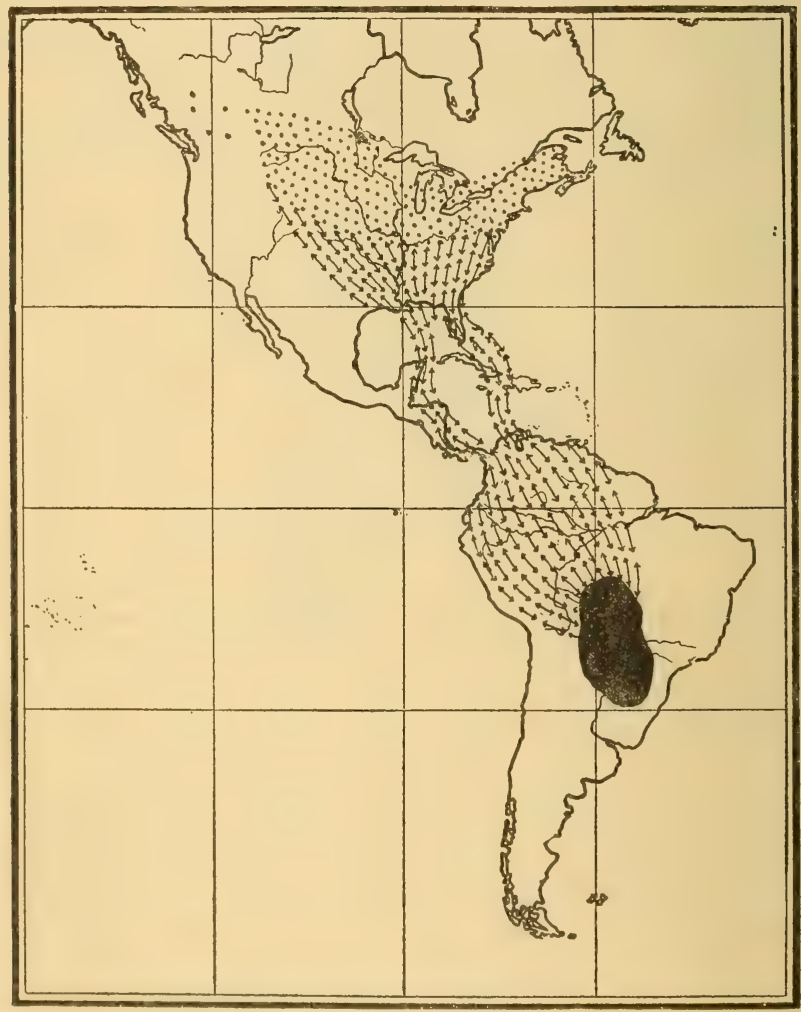

FIG. 7. Migration of the Bobolink. A species which breeds west of the Rocky Mountains, but migrates through the southeastern United States, reaching South America through the Greater Antilles and Central America. route.

Dotted area-Breeding range. Black area-Winter range. Arrows-Migration

America being cvidently no barrier to such great travelers as the Bobolink and Blackpoll Warbler.

Within the limits of the I'nited States, coast-lines, mountain chatins, and the larger river valleys, appear to be followed by birds in their migrations; nevertheless, there is a more or less pronounced 
highway of migration which crosses the southern Alleghanies from northwest to southeast. This is evidently followed by Kirtland's Warbler, which nests in northern Michigan and winters in the Bahamas, and it brings to our southeast Atlantic Coast, with more or less regularity, birds which are practically unknown in our North Atlantic States.

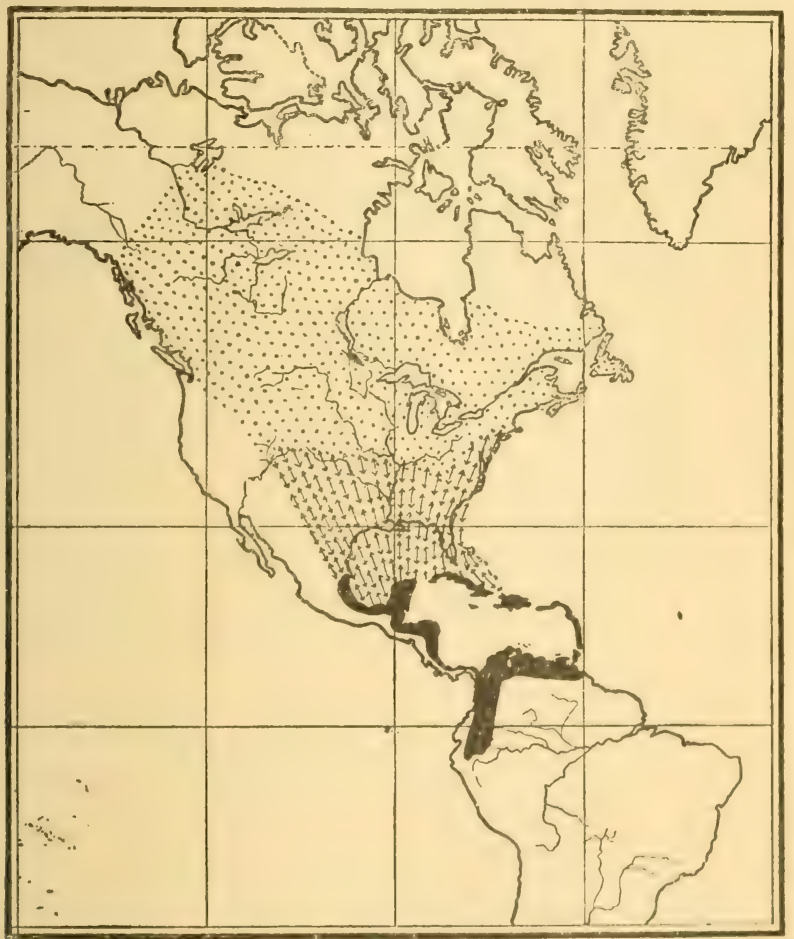

Fig. 8. Migration of the Revlstart. A species which brecels thromelume the greater part of temperate North Americas, and migrates through the Wirat lublios. Mexico and Central America. route.

Dotted area-Breeding range. Black area-Winter range:. Arrown-Mligration

There are also minor routes or paths of migration formerl, gencrally, by favorable local eonditions, but in some instanees diffienlt to mplatin. I have seen Tree Swallows, in the spring, on the (indf en:sit of Floridte, migrating northward low over the great explanse of mul moken marshese, but evidently following a definite track. Ther seattrered flockis were often separated by several miles, but each one followerl in llare wake of its invisible predecessor as though guided by the marks of wingbeats in the air. 
Most birds appear to return to their summer homes over much the same route by which they left them. There are, however, a few marked exceptions to this rule. Among our land-birds, the Connecticut Warbler enters the United States through Florida and journeys thence northwestward along the Alleghanies, and west to Missouri, to the Upper Mississippi Valley and Manitoba. At this season it is unknown on the Atlantic Coast north of Florida; but during its return migration, in September and October, it is often not uncommon from Massachusetts southward and, at this season, is rare or unknown in the Mississippi Valley south of Chicago. (See Cooke, '04.')

Among our water-birds, cases of this kind are more frequent. The fall migration often brings to the Atlantic Coast species which are rarely if ever seen there in the spring. The Black Tern, for example, occurs near New York City in numbers, from August to October, but is not found there in the spring.

The Golden Plover, as has been shown by Cooke ('93), after breeding in June on the shores of the Arctic Ocean, in August migrates southeastward to Labrador, where it feeds on the crowberry ( $\mathrm{Em}$ petrum), laying on a supply of fat as fuel for the remarkable voyage which follows. From Labrador the birds fly south to Nova Scotia and thence lay their course for northern South America in a direct line across the Atlantic.

Under favorable conditions they may pass the Bermudas without stopping, but should they encounter storms they rest in these islands and are also driven to our coast. Their first stop may be made in the Lesser Antilles, through or over which they proceed to South America, en route to their winter quarters in southwestern Brazil and the La Plata region.

In returning to their Arctic home these Plover pass northward through Central America and the Mississippi Valley, the main line of their fall and spring routes, therefore, being separated by as much as 1,500 miles.

The explanations advanced to account for the gradual development of migration routes, over which birds in the fall retrace the path followed in the spring, are inadequate to account for the origin of these phenomenal journeys, on which the pioneer voyagers must apparantly have embarked unguided by either inherited or acquired experience. Nor do we understand how birds have learned to cross regularly over bodies of water, hundreds or even thousands of miles in width.

European hirds cross the Mediterranean, to and from Africa, at a point where soundings indicate that a much closer land relation formerly existerl but the 100-mile flight from Jamaica to northern South Amerisa, the fo(o)-mile flight from the nearest land to the Bermudas, or the journey regularly made by the Turnstone and Golden Plover to Hawaii, 2,000 miles from the nearest land, are evidently not to be explained in this way. 


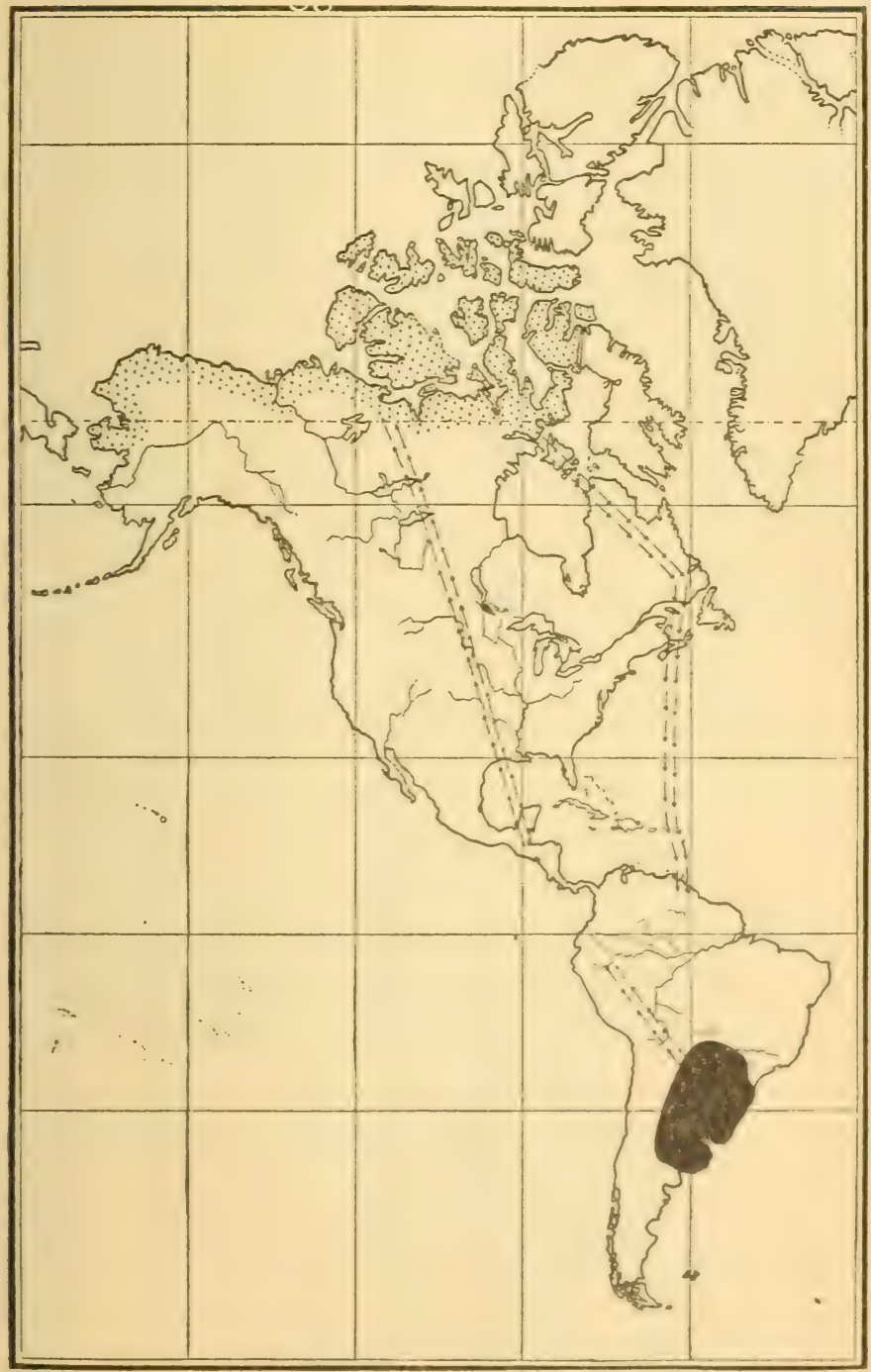

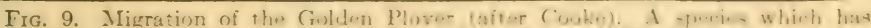

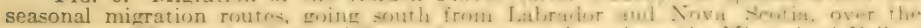

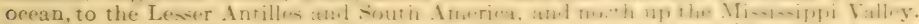

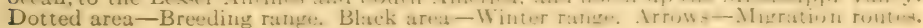


How Birds Migrate.--The more we learn of the marvelous semiannual journeys made with such surprising regularity by many birds, the greater becomes our interest in the manner by which they are performed. It is well enough to point out on the map the routes of nigration followed by Bobolink or Blackpoll, but how do the feathered mites traverse the thousands of miles which separate their summer and winter homes?

It is evidently essential that the bird be prepared for the journey. Fall migration usually follows the annual post-breeding molt, and the birds, in fresh plumage, proceed slowly, often lingering in favorable feeding-grounds, as does the Golden Plover among the crowberries of Labrador, or the Bobolink in the rice-fields of our south Atlantic Coast, until they are in physical condition to endure the strain of prolonged flight.

In the spring, they have had months' exemption from family cares, with no other duty than to wander where food was most abundant; excellent preparation for the return journey to the nesting-ground. We know less, however, about birds' movements at this season than when, after breeding, they prepare to leave us.

Some species begin to flock immediately after the nesting season and, as a preliminary to actual migration, develop regular and definitely directed movements in their daily returns to and departure from a certain roosting-place. Such roosting-places form stations on the migratory journey and are focal points for small bodies of birds which, later, take flight in one great company. Red-winged Blackbirds, Grackles, and the various species of Swallows inaugurate their southward migrations in this way.

Less gregarious birds, at the conclusion of their post-breeding molt or even before it is completed, simply disappear without our knowing when they go.

The adult birds, either alone or accompanied by birds of the year, migrate first. Later, the adults decrease in number and the last flights may be composed entirely of young birds. In the fall the sexes appear to travel together, but in the spring the males usually precede the females.

Some birds migrate only by day, others only during the night, while a smaller number travel both by day and night. In his now classic Memoir on "Bird Migration" Brewster ('86) puts the matter clearly as follows:

"1. Species which migrate exclusively by night habitually feed in or near the shelter of trees, hushes, rank herbage or grass, and when not migrating are birds of limited powers of flight and sedentary habits, restricting their daily excursions to the immediate vicinity of their chosen haunts. As a rule they are of timid, or at least retiring disposition, and when alarmed or pursued seek safety in concealment rather than by extended flights.

"2. Species which migrate chiefly or very freely by day, habitually 
feed in open, exposed situations, and in their daily excursions for food often cover considerable distances. As a rule they are of bold, restless disposition, and when alarmed or pursued seek safety in long flights rather than by concealment.

"3. Species which migrate exclusively by day habitually feed either on the wing or over very extensive areas. In disposition they are either trustful and unsuspecting, or wary and self-reliant. Without exception they are birds of strong, easy flight, and rely solely on their wings for escape from danger."

A wedge of honking Geese, a close-massed flock of chattering Grackles or Red-wings, a straggling train of Crows or Hawks, are familiar evidences of diurnal migration; while the passage, by day, of the Wild Pigeon was one of the most pronounced and impressive of daylight travels by migrating birds of which we have any record.

Other of our land-birds "which migrate freely, chiefly or exclusively by day" (Brewster, l.c.) are the Hummingbird, Chimney Swift, Horned Larks, Blue Jay, Waxwing, Shrikes, Swallows, Pipit, Robin and Bluebird. To this list may be added certain gregarious Finches, like Crossbills, Siskins, Redpolls, Pine and Evening Grosbeaks, Purple Finches and Snow Buntings. I have also seen Dickcissels, high in the air, traveling in compact bodies by day, though they apparently also migrate by night.

Ducks, Shore-birds (Limicolæ) and Sea-birds (Alcidæ, Longipennes, and Tubinares) migrate both by day and by night. The sportsman is first made aware of the passage of Plover or Yellow-legs by their mellow calls, as they journey through the air beyond the reach of unaided vision.

An interesting note on the diurnal migration of birds at an apparently high altitude, is supplied by R. A. Bray ('95) who reecords a flight of birds observed through a trelescope, directed toward the sun, at 3 P. M. on September 30, 1894, at shere, England. Every few seconds a bird was seen to pass slowly across the sun, and there wais no decrease? in their numbers during the ten minutes of observation. The birds were flying in a southerly direction and were invisible to the naked eye.

The daily flight of vast numbers of Sea-birds along the Pareifie coast is recorded in detail by $\mathrm{I}$. MI. Loomis' ('06, 3). 2.S(0) who stiters that on one occasion (S'p)tember 2?3, 1s96i) "not less than a (puarter of a inillion" Dark-bodied shearwaters "passed in review during two hours and a half." "There were several divisions-eateh a sollid phal:uns about an eighth of a mile derp-following closely one upen the of here," low, over the water.

Loons may be seen migrating by day, but the weaker winged (irebes, relying on their diving powers for safoty, evidently travel by night. Other water-birds, like the Bitterns, Woodeork, Wilson's Snipe, Rails, Coots, and Gallinules, whose habits do not lead them over the seat or its shores, migrate, as Brewster has siaid, by night. 
Our knowledge of the nocturnal migration of birds is based on evidence supplied by the call-notes of passing birds, on data from light-houses, on observations through telescopes and on field-work on days succeeding flights.

It is a common experience, during the season of migration, to hear the notes of birds which are passing overhead. From an elevation in a line of flight, or where the city lights may attract birds, such notes, when birds are moving in numbers, are almost continuous. O. G. Libby ('99) states that on the night of September 14, 1896, on "a small elevation west of the city of Madison, Wisconsin," a total of 3,800 bird-calls were recorded. The average was twelve per minute, but the rate "varied greatly, sometimes running as high as two or three per second, and again falling to about the same number per minute. The great space of air above swarmed with life. Singly, or in groups, large and small, or more seldom in a great throng, the hurrying myriads passed southward."

Lighthouses, because of their location on the coast, on promontories or outlying islets, are often situated in the path of migrating birds. This fact, in connection with the fatal attraction which the rays of the light possess for migrating birds during stormy weather, has supplied an extended and definite series of records, which also emphasize the high mortality often prevailing in the ranks of night-migrating birds. Shortly after its erection, 1,400 dead birds are said to have been picked up at the base of the Bartholdi statue, in New York harbor, which had been killed by striking the statue the preceding night.

For years light-keepers have reported to the Biological Survey at Washington on the birds seen about or striking the lights in their care and, in not a few instances, our knowledge of the migration of a species rests largely on this class of data. (Allen, '80, p. 131.)

We have also the testimony of ornithologists who have visited lighthouses especially for the purpose of observing the nocturnal journeys of birds. Brewster (l.c. p. 7), who visited Point LePreaux Lighthouse, in the Bay of Fundy, for this purpose, gives an impressive picture of observations made there on the night of September 4 .

Observations through telescopes, though limited in number, when one considers how easily they are made and how interesting and valuable are the results to be obtained, supply probably our most satisfactory data on nocturnal migration. They can be made only on clcar, moonlight nights, when the current of migration, flowing smoothly through the air above, is viewed under wholly normal conditions.

A low-power telescope is focused on the moon, the glowing surface of which forms a background against which the birds, in passing, are elcarly silhouetted. On September 3, 1886, at Tenafly, N. J., with the aid of a $6 \frac{1}{2}$ inch equatorial glass, 262 birds were seen to cross the narrow angle subtended by the limits of the moon between the hours of eight and cleven (Chapman, '88). Subsequent observations from the observiatory of Columbia University and at Englewood, N. J., have revealed 
the vast numbers of birds which throng the upper air during nights of active migration.

At Madison, Wisconsin, on the nights of September 11-13, 1897, Libby $(l . c$.) saw 583 birds through a 6 -inch glass, the largest number counted during a fifteen minute period being forty-five. Additional data of this nature are included in a paper by H. A. Winkenwerder ('02), while Stone's ('06) observations on birds seen migrating at night by the light of a great conflagration in Philadelphia have exceptional interest.

The height at which migrating birds fly has been variously estimated. Many diurnal migrants may be seen traveling from a few yards (e. g. Shearwaters) to several hundred yards (e.g. Geese) above the earth, but Shore-birds evidently seek a greater altitude, and the experience of Bray, referred to above, hints at a diurnal flight of which we know practically nothing.

Our knowledge of the height at which nocturnal migrants journey is based on the telescopic observations already mentioned. As intimated in the article itself $(l . c$.), the conclusions presented in my paper on birds seen flying over Tenafly, were not satisfactory. More recently, the problem has been attacked by F. W. Carpenter ('06) and Stebbins* with results which seem far more worthy of acceptance. Their calculations show that while an altitude of 4,000 to 5,000 yards may occasionally be reached, the greater number of birds observed were not over 1,600 yards above the earth, while many passed considerably below this elevation. The ease with which the calls of night-flying birds may be heard also argues for a lower altitude than has been commonly accredited to them.

The speed at which migrating birds fly has also been greatly overrated. Two observations with theodolites give to migrating Duckis a speed of 47.8 , and to migrating Geese a speed of 44.3 miles an hourt. Homing Pigeons do not often exceed forty to forty-five miles an hour. It is a common experience, when traveling in a train at a rate of thirt $y$ five to forty-five miles an hour, to pass birds which are flying parallel to the track. I have had this occur repeatedly with such compariatively large and swift birds as the Mourning Dove. It seems probable, therefore, that our smaller birds do not average more than thirty miles an hour when migrating.

Gätke's estimate of 212 miles per hour as the speed of the (iolden Plover when migrating, is based wholly on the assumption that fifterm hours is "the longest spell during which a bird is able to remain on the wing without taking sustenance of any kind." The Plover, however, does not fly from "Labrador to northern Brazil," as he statrid, but, from Nova Scotia to the Lesser Antilles; as we have seen, it makes special preparation for the journey, is extremely fat, when it starts and thin when it arrives.

*'"Popular Astronomy," XIV, 1906, pp. 65-70.

†Clayton, Science, 1897, pp. 26, 585. 
The rate at which a bird migrates, however, is of course not to be considered its limit of speed. The migrating bird, like the long-distance runner, must adopt a pace which will enable it to reach the goal without danger of exhaustion by the way. Should necessity arise, it doubtless, for a time, could more than double the speed at which it normally travels.

The rate of progress of the individual must not be confused with that at which the species advances. Nocturnal migrants probably cover 200 to 400 miles in a single night's journey; but, as Cooke ('03) has shown, "The average speed of migration from New Orleans to southern Minnesota for all species is close to 23 miles per day." From this latitude northward, however, in response to the more rapid development of the season, the speed is constantly accelerated until the breeding-place is reached. Thus, the same author remarks, "Sixteen species maintain a daily average of forty miles from southern Minnesota to southern Manitoba, and from this point twelve species travel to Lake Athabasca at an average speed of seventy-two miles a day, five others to Great Slave Lake at 116 miles a day, and five more to Alaska at 150 miles a day."

The slow rate at which a species moves, when compared with that at which the individuals composing it travel, is evidence that its migration is not performed continuously, night after night, until the haven is reached, but that after a flight birds pause to rest, to await favorable weather conditions, and the further seasonal change which such conditions hasten. The observations of Wright ('09) in the Boston Public Garden, where, as in other city parks, local conditions are exceptionally favorable for the correct interpretation of migration phenomena, also confirm this view, if indeed further confirmation be required.

The impelling motive being more powerful, the object more definite, and the seasonal influences more pronounced, the spring migration of birds is a more orderly and regular movement than the return in the fall. Clear nights and a rising thermometer are most likely to induce birds to travel, a 'wave' of migrants coming often on the crest of a 'wave' of warmer temperature. When such a movement is checked by cold or stormy weather, the result is an overflow of migrants which flood the woods. Ordinarily rare species may then become comparatively common, and the impression is produced of an actual increase in bird-life. In the fall, when physiological factors incident to reproduction are not potent and seasonal changes are less marked, birds travel more leisurely. Clear nights and a falling thermometer are then most favorable for a general movement.

The high mortality in the ranks of migrating birds occasioned by the storms they encounter is evidence of their inability to anticipate changes in the weather. On the coast of Texas I have known birds to migrate northward in great numbers directly into the face of a 'norther,' with evidently no warning of the unfavorable conditions toward which they were hastening. Again, under the influence of exceptionally 
warm weather, Tree Swallows have been induced to travel northward and appear near New York City in numbers late in December.

And now we ask the question to which any consideration of the phenomena of migration inevitably leads, "How do birds find their way?" What faculty directs them over thousands of miles of land and water through the darkness of the night with a regularity and accuracy that brings them to the same locality, even the same nest-site, on essentially the same date year after year?

Granted that in birds, sight, hearing, and the power of association are exceptionally developed; that the chirping and calling of night migrants is an effective means of holding them to the main traveled way; that diurnal migrants are guided by prominent topographical features; still something far more potent than eye, ear, and memory is evidently required to lead birds over journeys where landmarks are wanting.

While at sea on May 24, 1905, a Curlew (Numenius sp.) boarded the steamer when we were 140 miles south of Fastnet Light. While photographing the bird, I alarmed it, when it took wing and headed for Ireland with as much confidence as though land had been visible, and was soon far beyond us. There was here no established line of flight in which to join, no evident external guiding influence; nevertheless the bird set its course without hesitation.

Terns, Murres, and other sea-birds go out to feed and return to their breeding-grounds through dense fog and with unfailing precision. Tropic-birds reach Bermuda, 600 miles from the nearest land, regularly each spring; Turnstones and Pacific Golden Plover travel twice each year over at least 2,000 miles of water in their journey to and from Hawaii. The Eastern Golden Plover strikes boldly out over the Atlantic bound from Nova Scotia to the Lesser Antilles; vast numbers of birds of many species cross the Gulf of Mexico, others fly from Jamaic:a to South America.

This power of 'distant orientation' is apparently only to be explained through the bird's possession of a 'homing instinct' or 'sense of direretion' which, when the impulse to migrate is active, automatically induces them to follow a certain route.

The experiments of Reynaud ('00) and others with IIoming Pigeons appear to have definitely established the existenee of the sense of direction in this species, and more recently Watson ('09) hats demonstrated in a most noteworthy manner its evident possession by footy and Noddy Terns. Among other tests, Reymated tramsported five Pigeons, under the influence of chloroform, from ()rleans to Evrrux, France, a locality which they had not visited before. Two ditys later, having evidently recovered from the effects of the drug, they were? released and all returned to Orleans. While the senses of sight, smell, taste, touch, and hearing were not functional during the time when the birds were under the influenee of chloroform, Reynatud expresses his belief that "the sense of direction, on the contrary, whose artion 
is based on the automatic and mechanical registration of the road followed, continued to work, in spite of the chloroform, absolutely like other mechanical functions - the circulation of the blood, the digestive organs, and respiration-in some way, without the knowledge of the animal."

Watson's experiments were made with Sooty and Noddy Terns, among which he passed the breeding season of 1907 on their nestingground on Bird Key, Dry Tortugas. He first captured and marked six Noddies, and had them released at distances varying from 19.5 to 65.8 miles from the Key. All returned within from one and three-quarters to about three and a half hours after being released.

July 8, two Noddies and two Sooties were captured and marked and sent to Havana (108 miles) where they were released early on the morning of the 11th; all returned to the Key on the 12th.

None of these birds, however, were sent beyond the normal range of their species and it may be claimed that they were simply traveling over a route with which they were familiar. In any event, the journey was made unassisted by any trend of migration or established migratory movement which they had simply to join. When breeding, these birds are closely confined to the vicinity of their homes. Watson found that they rarely went further than 15 knots from Bird Key. Some of the birds returned alone, evidently dependent only on themselves for guidance.

A third test, in which the surrounding conditions were ideal, was made with three Noddies and two Sooties which were captured and marked on June 13, and sent from Bird Key to Key West. Here they were transferred to the hold of the steamship 'Denver' where they were both watered and fed while en route. On June 16, the birds were released about 12 miles east of Cape Hatteras, approximately 1,081 miles by water from Bird Key. Both the Sooties were found on their respective nests on the morning of June 21, and one of the Noddies was observed several days later.

Neither the Noddy nor Sooty Tern range, as a rule, north of the Florida Keys. There is small probability, therefore, that the individuals released off Hatteras had ever been over the route before and, for the same reason, they could not have availed themselves of the experience or example of migratory individuals of their own species; nor, since the birds were released at the height of the nesting season, was there any marked southward movement of birds in the line of which they might follow.

Even had there been such a movement, it is not probable that it would have taken the birds southwest to the Florida Keys and thence west to the Tortugas. This marked change in direction, due to the fact that the birds' maritime habits would force tham to take a course over the water, removes the direction of the wind as a possible guiding ageney, while the birds' unfamiliarity with the coast-line makes it improbable that sight was of service to them in finding their way. In 
short, we cannot but feel that this experiment constitutes the strongest argument for the existence of a sense of direction as yet derived from the study of wild birds; with this established, the so-called 'mystery of migration' becomes no more a mystery than any other instinctive, functional activity.

Why Do Birds Migrate?-Any attempt to reply to this question should be prefaced by the statement that birds have been migrating for an incalculable period. The existing phenomena are not therefore to be explained solely by observable causes, but they may often have their origin in influences which have long ceased to be potent. In other words, the migration of birds, as well as the birds themselves, is an outcome of those gradual adjustments between an organism and its environment which has led, on the one hand, to activities which existing causes only in part explain, and on the other to the evolution of certain types of form and color the reason for which we cannot now wholly determine. We observe that bird migration is most highly developed in those parts of the world which are subjected to marked seasonal changes. In endeavoring, therefore, to ascertain the factors governing migration either north or south of subtropical regions, we find our problem greatly complicated by questions of temperature and food which seem to exert a powerful influence on the movement of birds.

Fortunately we are not obliged to begin our examination of the subject in this, its most complex form, but in the tropies may find perfectly well-defined instances of bird migration in which the matters of food and temperature seem to play no part.

With tropical land-birds there is, as a rule, no well-marked migration; while their numbers may fluctuate in response to an increasing or diminishing supply of food, they make no journeys to a nestingground.

Tropical sea-birds, however, are often great wanderers and, during the year, many cover vast distances, within the tropic zone, in their search for food. They cannot, however, nest on the water, and when the season of reproduction approaches, they are, of necessity, forced to go to the land. Now it is of the highest importance for us to know that their visits to their breeding resorts are made with the same regularity which attends the journey of Oriole, Bobolink or Warbler. They return each year to the same place and they all reach it, almost to the day, at the same time. The Brown Pelicans of eastern Florida come in thousands to Pelican Island the first weck in November; Boobies and Man-o'war-birds return to certain Bahama key's in January; the Noddy and Sooty Terns appear on Bird Key in the Tortugas, the last week in April.

Temperature, obviously, has nothing to do with these journeys, since with the Pclicans the average daily temperature is dercoising, with the Terns increasing, while the Boobies and Man-o'-war Birds have probably experienced no change of temperature. Nor are the 
birds induced to travel by a more abundant supply of food. Incieed, the focusing of so large a number of individuals in a comparatively limited area doubtless increases the severity of the competition for subsistence. As I have said in discussing the return of the Brown Pelicans, " "The immediate cause of the journey is doubtless physiological and the prompting comes from within. With birds, the season of reproduction is periodic, and with migratory species, whether the journey be to a nearby islet or to another zone, the return to the breeding ground is only one phenomenon in a cycle of events which includes, in regular order, migration, courtship, nest-building, egg-laying, incubation, the care of the young, the molt, and the retreat to winter quarters"-or, as might be better said of these tropical and subtropical birds, the desertion of the nesting-ground.

The yearly life-cycle in the vegetable world parallels, in a sense, that which exists in the world of birds. In orderly succession the plant develops leaf, blossom and fruit, sheds its foliage, and, after a period of rest, the phenomena are repeated. With birds it is the return of the season of physical fruition which arouses not only the sexual but also the homing instinct under the guidance of which these mobile creatures repair to the place of their birth.

Migration, then, in its simplest form, is merely a journey to the nesting-ground, made without apparent relation to either food or temperature.

When, now, we turn from these birds which migrate only a few miles to others which travel thousands, there is no reason to doubt that with both the initial impulse to migrate is in the annual recurrence of the period of reproduction. The migration of fish to their spawningground, and of seals to their 'rookeries,' are further examples of journeys made solely to reach certain breeding-grounds.

It is not difficult for us to understand why the Pelicans, Boobies, Terns and other birds return to certain isolated islets within the area of their winter wanderings, but the reasons why birds travel beyond subtropical zones to the shores of the Arctic or Antarctic seas are less evident. Temperature, as it affects environment and particularly as it controls the food-supply, is, with these, a powerful factor. Not only must we consider existing climates, but we must take into account those profound climatic changes incident to the development and passing of the Glacial Period, and which have apparently exerted so great an influence on the distribution of life in the northern parts of the world that Allen believes we have here the origin of bird migration itself. He writes ('80, p. 151): "Nothing is doubtless more thoroughly established than that a warm temperate or sub-tropical climate prevailed down to the close of the Tertiary Epoch nearly to the Northern P'sle, and that climate was previously everywhere so far equable that the neressity for migration can hardly be supposed to have existed. With the later refrigeration of the northerr regions, bird life must * "Camps and Cruises of an Ornithologist," p. 88. 
have been crowded thence toward the tropics; and the struggle for life thereby greatly intensified. The less yielding forms may have become extinct; those less sensitive to climatic changes would seek to extend the boundaries of their range by slight removal northward during the milder intervals of summer, only, however, to be forced back again by the recurrence of winter. Such migration must have been at first 'incipient and gradual,' extending and strengthening as the cold-wave Ice Age receded and opened up a wider area within which existence in summer became possible. What was at first a forced migration would become habitual, and through the heredity of habit give rise to the wonderful faculty which we call migration."

While it is by no means certain that "the necessity of migration" did not exist prior to the Glacial Period, it seems probable that, whether or not this period actually gave rise to bird migration, it affected the movements of birds much as Allen has suggested.

It is to the influence of the Glacial Period that we must attribute the presence, in the warmer parts of the globe, today, of such physically closely related, but geographically widely separated birds as Ibises, Spoonbills, Pelicans, Frigate Birds, Anhingas and Flamingoes.

It is out of the question to believe that birds, so like each other and so unlike other birds, can have originated independently in the old world and in the new; whence it follows, of course, that they have descended from a common ancestor, or, in other words, that their ranges were at one time continuous. This time we may well believe to have been that portion of the Tertiary Period preceding the Glacial Epoch, when the warm climate of the polar regions was adapted to their wants. With the climatic change which culminated in the Ice Age, their boreal representatives either became extinct or were forced southward, some in the Old World, some in the New, and the territory thus deserted has never been reacquired. The White Pelicans, and many other species closely related to Old World forms, and now breeding north of the most southern limit of the great Ice Field (for instance, the Eared Grebe, Gannet, Great Blue Heron, Gallinule, Oyster-eatcher, Crossbill and Brown Creeper), have, however, evidently extended their summer ranges to the northward of the area which they occupied during the maximum development of the Ice Age. To spreak of only the White Pelican, the reasons have just been stated for believing this species to have formerly inhabited the shores of the Aretie Ocean, whence it was foreerl southward, bolow possibly the forticth degrees of latitude, by the rigors of the climate of the Iere Age. Nerertheless it now breeds regularly as far north ats latitude $61^{\circ}$, and hats therefore regained at least a thousand miles in latitule, of the region from which it has been foreed; but cach year the individual repeats the history of the speeies, by retreating before what may he tromed a seasonal Ice Age, as winter seals the lakes and rivers on which it has passed the summer.

In a similar manner the migrations of cach of our birds may be 
studied with reference to its distribution, relationships and the climatic influences to which it has probably been subjected, opening a most suggestive and instructive field for speculation on the origin of existing conditions.

\section{Suggestions FOR the StUdent}

Returning now to the more practical and personal side of bird migration, I append here a few hints to the local student for observing and recording it.

Too much time cannot be spent in the field during the migration season. If possible, one should go out both in the early morning and late afternoon, visiting as great a variety of ground as opportunity permits. It is desirable also to follow the same route daily, in order that changes in bird-life, other than the first arrival of certain species (for example, increase or decrease, flocking, roosting, pairing, etc., of species which have already been noted), may be more readily and definitely ascertained.

Weather conditions should be observed as closely as the migration itself and the charts issued by the Weather Bureau at Washington should he studied. Examine also published tables of migration. One's chances of finding a given species are greatly increased if one knows where to look for it.

The blooming of plants, shrubs and trees and the advance of vegetation in general, together with the appearance of various forms of insect life, calling of hylas, etc., should all be recorded.

The record of each species of bird should show its date of arrival, with the number and, if possible, sex of the individuals observed, if migrating singly, in scattered companies or in flocks. Succeeding records of the same species should be entered with as much detail as the first one, in order that the whole record may show the rise and fall of its migration.

Try to observe closely the movements of the same birds-a certain flock of Robins, for example, which is found day after day near the same place, or an isolated Red-winged Blackbird or two, which appear to remain in some small marsh -with the object of learning whether the first individuals to come, among summer resident species, are the birds which nest with us, or those which continue their journey northward.

Note the movements of winter birds-Juncos, Tree Sparrows, and others-indicating that their migration is under way. Do the winter resident individuals of these species start before their ranks receive additions from the South?

Observe the connection between the time of a bird's arrival and the character of its food; for example, water-fowl appearing when the ice breaks; Woodcock when frost leaves the ground and worms can be secured; Phœbes when aërial insects appear.

At night listen for the calls of birds passing overhead as evidence of a gen ral movement, or use a low-power telescope in the manner before described.

By day note the extended migratory flights of such birds as Hawks, Crows, and other diurnal migrants. Are they dependent on the direction of the wind? Do they follow certain routes regularly?

Olserve also the more restrieted movements of such night-fliers as Warblers and Vireos, which as they feed still move toward their goal.

I uring the summer note the gathering of birds in flocks and the formation of regularly freiuented roosts, as a first step in their southward migration. Be on the lookout also for certain more southern species, which may wander northward after their breeding season has closed.

('lose ofservation is required to detect the arrival of the first Warblers, Vireos and Flyeatchers from the North; as well as to determine when our earlier departing summer residents leave us. 
When possible, the age of first comers from the North should be recorded; but the plumage of adult and young are now often alike, and a bird's age can be ascertained with exactness only by dissection, the condition of the bones of the cranium furnishing one of the most deperidable clues.

\section{REFERENCES}

1836. Bachman, J., On the Migration of the Birds of North America, Sillim. Am. Journ. Sci., XXX, pp. \$1-100. Reprinted in The Warbler II, 1907, 24.-1866. BAIRD, S. F., The Distribution and Migration of North American Birds, Am. Journ. Sci., XLI, pp. 78-90; 184-192, 339-347.-1880 Allen, J. A., Destruction of Birds by Lighthouses, Bull. Nutt. Orn. Club, V, pp, 131-138.-1880. Allen, J. A., Origin of the Instinct of Migration in Birds, Ibid, 151-154.-1881. Allen, J. A., The Migration of Birds. Scribner's Mag., XXII, pp. 932-938.-1881. Scotт, W. E. D., Some Observations on the Nocturnal Migration of Birds, Bull. Nutt. Orn. Club, VI, pp. 97-100.-1884. Dutcher, W., Migration at L. I. Lighthouses, Auk, I, pp. 174-179.-1885. Merrial, C. H., Preliminary Rep. of the A. O. U. Comm. on Bird Migration, Auk, II, pp. 53-64.-1886. Brewster, W., Bird Migration, Mem. Nutt. Orn. Club, I, 22 pp.-1888. Chapman, F. M., The Nocturnal Migration of Birds, Auk, V, pp. 37-39.-1888. Cooke, W. W., Bird Migration in the Mississippi Valley, Bull. 2, Biol. Surv., $313 \mathrm{pp}$ - - 1889 Stone, W., Graphic Representation of Bird MIigration, Auk, VI, pp. 139-144. VIII, 1891, pp. 194-108.-1892-1894. Looms, L. M., Observations on Migration in South Carolina, Auk, IX, pp. 28-39; XI, 1894, 26-39, 94-117.1893. Mackay, G. H., Fly Lines, Auk, X, pp. 245-249.-1894. Chapman, F. M., Remarks on the Origin of Bird Migration, Auk, XI, pp. 12-17.1894. Stone, W., Bird Migration in the Vicinity of Philadelphia, Birds E. Pa. and N. J., pp. 15-28.-1895. BRAY, R. S., A Remarkable Flight of Birds, Nature, LII, p. 45.-1895. Jones, L., Bird Migration at Grinncll, Ia., Auk, XII, pp. 117-134; 231-244.-1895-1900. Looms, L. M., California Water Birds, Proc. Acad. Sci., 2d ser., V, pp. 177-224; VI, 1896, 1-30; 353-366; 3d ser., 1900; 277-322; 349-363.-1896. Allen, J. A., The Migration of Birds, Papers Presented to the World's Congress of Ornithology pp. 31-38.-1898. Stone, W., Methods of Recording and Using Iird Migration Data, Proc. Acad. Nat. Sci., Phila., pp. 128-156.-1899. Lrisy, O. G., The Nocturnal Flight of Migratory Birds, Auk, XVI, pl). 140-146. 1900. ReYnaUd, G., The Orientation of Birds, Bird-Lore, II, pp. 101-108; 141-147.-1901. Cole, L. J., Suggestions for a Mrthod of Studying the Migration of Birds, 3d. Rep. Mich. Arad. Sci., pp. (77-70.-1902. Winkevwerder, H. A., The Migration of Birds with Sipecial Referenee to Noceturnal Flight, Bull. Wis. Nat. Hist. Sor., II, pp. 177-26i3.-1903. Bonmots, J. I.., Bird Migration at Some of the Bahama Lighthouses, Auk, XX, p). 1(i9-17?. -1903. Cooke, W. W., Some New Facts about the Migration of IBirds, Yearbook, Dept. of Agric., pp. 371-3x6.-1904. ('OOKE, W. W., I)istribution and Migration of N. A. Warblers, Bull. 18, Biol. Surv., 142 yj). S(er also pp. 14-20, Warblers of N. A., 1904. ('OOKE, W. W., The IEfferet of Altiturle

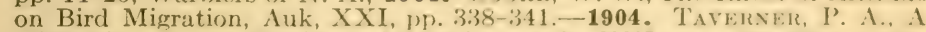
Discussion of the Origin of Migration, Auk, XXI, Mu. 32.2 3333.-1905. Allen, J. A. (Review), Auk, XXII, pp. 325 328.-1905. BIsHop, L. I3., The Direction of Flight in the Fall Migration at Vew Haven, (onn., Auk, XXII, pp. 372-377.-1905. (cooke, W. W.., Rontes of Bird Migration,

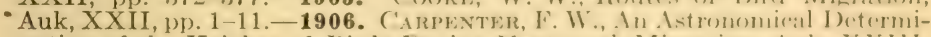
nation of the Heights of Birds During Norturnal Migration, Iuk, XXIII, pp. 210-217.-1906. ('oOKE, W. W. Distribution and Mligration of N. A.

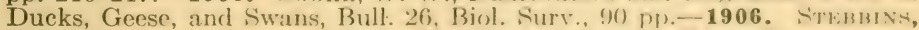
J., A Method of Determining the Heights of Migrating Birels, Poj). Astronomy, XIV, pp. 65-70.-1906. SToNe, W., Some Light on Night Migration, Auk, XXIII, pp. 249-252. Fxecptionally interesting.-1908. ('о)к E, II. II., Bird Migration in the District of Columbia, Proc. Biol. Soc., XXI, 1) 10. 107- 
118.-1909. Watson, J. B., Some Experiments on Distant Orientation. Papers from the Tortugas Lab. of the Carnegie Inst., II, pp. 227-230.1909. Wright, H. W., Birds of the Boston Public Garden. A Study in Migration, $229 \mathrm{pp}$. (Houghton, Mifflin \& Co.).-1910. Henshaw, H. W., Migration of the Pacific Plover to and from the Hawaiian Islands, Auk, XXVII, pp. 246-262.-1911. Cooke, W. W., Our Greatest Travelers, Natl. Geog. Mag., XXII, pp. 346-365, 12 maps.

\section{The Voice of Birds}

\section{Call-Notes}

Song

The gift of song is the bird's most appealing and charming attribute; but, wholly aside from their esthetic importance, the notes of birds have an especial interest for every one who would attempt to interpret and ascertain their significance. The weird cries and enraptured warbles which are often so strangely expressive of nature itself and which so strongly appeal to the wild and primitive within us constitute, in truth, the language of birds, to understand which is to bring one to a new and intimate knowledge of bird-life. It is out of the question to present here anything like an adequate essay on the calls and songs of birds, but the subject is so attractive, and its investigation is so well within reach of the local or isolated student, that it must at least be treated in sufficient detail to suggest lines of study.

Call-Notes.-The term call-notes is somewhat loosely applied to a great variety of bird utterances, including true call notes as well as notes or 'calls' of alarm, anger, etc.

The student may first consider the origin of voice in birds, beginning with silent species, like the Man-o'-war-bird and Brown Pelican (though the young of both are noisy enough), through others, like the Cormorant, Water-Turkey, or Black Vulture, which utter only the most rudimentary sounds, to those which have acquired an extended vocabulary, like the Crow or Jay. Then may follow a study of the calls of young birds. With altricial birds, which are reared in the nest, the hunger or food-call with which the returning parent is greeted is the most characteristic, and is common to such unlike birds as Thrushes and other Oscines, Swifts, Pelicans and Herons, in fact, doubtless, to all birds which are fed in the nest.

()n the other hand, with prococial birds which follow the parent shortly after birth, what may be termed the 'lost' or 'location' call is the most important. IIere the chick is quickly taught to feed itself, and its life depends chiefly on its ability to keep up with the flesk and recrive parental eare and guidanee. The peep of a chick or duckling will be readily recalled as a note of this kind.

When threatened by danger, both altricial and præcocial young, as a rule, try to atooid observation by squatting and remaining motionless, but young Vultures hiss in the most curious manner; young Pelicans 
and young Boobies scream; young Man-o'-war-birds squeal and rattle their bills; and all three species strike at one most viciously. Possibly the size and snowy plumage of these young birds renders them so conspicuous that they cannot expect to escape observation by remaining motionless, and therefore adopt a more direct and aggressive means of self-preservation.

As the young bird develops, its range of calls increases until finally we have the full vocabulary of maturity. This varies widely with different species, and it may, I think, be truly said that no exhaustive study has as yet been made of the calls of a single species of wild bird.

When the young bird is old enough to care for itself, the language of the nursery is forgotten, and the recognition call, by which individuals of the same species are brought together in flocks or companies, is doubtless its most valuable and most frequently employed vocal asset. This is particularly true with migratory species, whose oft-repeated notes, while winging their way through the night, serve to mark the line of flight and keep stragglers in line. The pink of the Bobolink, the liquid purt of the Olive-backed Thrush, the fine but far-carrying cheep of Warblers, are familiar illustrations.

Calls of this nature, by which a bird simply announces its presence, together with those of alarm, are uttered by most birds, and it is probable that they constitute a common language, the significance of which is generally understood. That is, a migrating bird may be guided by the notes of other species, without necessarily knowing to what species the call it follows belongs, just as it will recognize as an alarm call the warning note of a bird of a different species, which has been the first to see and give notice of the presence of a Hawk or Owl or other form of danger.

Crows, however, immediately recognize the hoot of a Barred Owl as such, and on hearing it at once utter a certain caw-caw which may be termer their 'rally call,' and which is so quickly responded to by other Crows that within a few minutes a throng of them has surrounded the cause of the disturbance. This example serves well to illustrate the difference between the common or charactoristic call of a ecrtain species, its simple "I am here" or "This is I," and others possessing a special significance. That the rally eall of the Crow is clearly understend by all the Crows that hear it, no one will doubt, who has observed its effect; while further attention to Crow couss will reveal a surprising variation in their character and the manner in which they are ut tereel; all of which doubtless possesses an exact significance to Crows and may some day be intelligible to man.

The Robin also supplies a familiar illustration of a birl possessing a wide variety of ealls, each one of which has its own meaning, and indered one need go no further than the hen-yard to find opporortunities for the study of bird language and to be eonvineed of the possibilitics which may arise from close, sympathetic observation of this phase of the bird's life. 
Each species will offer its own problem, but in every instance the greatest interest will center about the life of the nest, where the complex relations of parent with parent and of both with offspring, supply occasions for the utterance of notes heard under no other conditions. Not the least interesting of these will be the warning calls by which the adult conveys to her inexperienced, or even blind, young, knowledge of a threatening danger, in the presence of which they must betray no sign of life. Perhaps no one case more strongly illustrates the importance of a means of exact communication among birds, for failure to understand and obey may here be followed by death.

Song.-As a rule, the songs of birds are uttered by the male alone and mainly or only during the nesting season. It is true that in rare cases the female sings; the female Cardinal and Rose-breasted Grosbeak, for example, sometimes sing to a limited extent, and the female of a certain tropical American Wren (Pheugopedius rutilus) sings a delightful duet with her mate. It is also true that some birds sing more or less throughout the year, while many have a short, second songseason after the postnuptial molt. But song in its full development, and with its real significance, is restricted to the nesting-season. It is, therefore, a secondary sexual character, an irrepressible manifestation of the greatly increased vitality of the bird during the period of reproduction.

The systematist classifies as Oscines, or true singing birds, those species which have the "syrinx with four or five distinct pairs of intrinsic muscles, inserted at ends of three upper bronchial half-rings and thus constituting a highly complex and effective musical apparatus" (Coues); but while this group contains the most gifted singers, it does not by any means contain all our song birds, many species having a less highly developed syrinx with fewer muscles, which are inserted into the middle, not the ends, of the bronchial half-rings, still being able to produce both pleasing and complex vocal sounds. Note, for example, the songs of certain Snipe and Plover or of Goatsuckers. On the other hand, some true Oscines, like Crows, Magpies, and Jays, with a highly developed vocal apparatus, are practically songless, while the Cactus Wren, a member of a family of noted songsters utters only harsh squawks.

Song, therefore, is not restricted solely to the Oscines, but in a broad sense is the attribute of every species of birds which gives expression to the cmotions inspired by the nesting-period. The whistling of Grehes, the 'bleating' of Snipe, the 'booming' of Bitterns, the 'trumpeting' of Cranes, the 'whinny' of Soras or 'cooing' of Doves, the hooting of the ()wls, are, therefore, types of songs, and we may even include here such mechanical forms of hird music as the 'drumming' of Grouse, tapping of Woodpeckers or 'booming' of Nighthawks.

Through the exercise of these vocal and instrumental gifts, which so dolightfully voice the joys and hopes of spring, the male bird replies to the challenge in kind of a rival, and what is of far more importance, informs the female of his presence. 
It does not follow that he deliberately woos her in musical terms, since not only caged birds but those species in which the males arrive in advance of the female, sing with or without an audience.

Recall, as example, a solitary captive whose notes day after day, and possibly spring after spring, never arouse response from others of his species, or the more pleasing picture of a flock of male Redwings, chanting their gurgling chorus with no streaked female to hear them. Even when the flock has broken and its individuals have taken possession of their own special bit of marsh or swamp-land, they sing alone until their notes attract the later migrating females and the match is made.

Attention is often called to the fact that the best songsters are dull in color, while brightly plumaged birds are poor singers, but the musical standard here adopted is wholly human, and so far as we know harsh tones may be just as effective in winning a mate as sweet ones. (See also, under Color.)

While the main object of song is now accomplished, fortunately for the nature lover the singer continues to voice his passion during the period of nest-building, while his mate is incubating, and rarely (e.g. the Warbling Vireo and Rose-breasted Grosbeak) while he himself sits upon the nest.

With the appearance of the young the song wanes, and with onebrooded species it now soon ceases, but the excess vitality possessed by those birds which rear a second brood is manifested also in their renewed vocal efforts, and their song season is prolonged to midsummer or early August.

As has been said, many species have a second song-period, at the conclusion of the annual post breeding molt, but it lasts only for a few days and the song rarely reaches the fullness of springtime. As diminishing vigor of the later nesting-season ceases to demand full expression, the song may decrease in volume and, at times, is uttered solto voce with closed bill, when, though perfect in form, it may be heard only at. close range.

The time of the day, as well as the time of the year in which a species sings, is also to be noted. Farly morning and late afternoon are the periods of greatest activity in the bird's day, and it is then that most species are heard singing, but each species will be found to be more or less regular in regard to the time of its singing. Some begin carlier and sing later, some sing more or less throughout the diay, ot hers only before sunrise and after sunset, others still by night as well ats by daty.

- In recording a bird's biography one should also learn the duration of the song itself, noting whether it is a short, definite effort, like, for example, that of the Meadowlark or House IIren, or a more or less continuous performance like that of the Red-ryed Vireo, Mockinghird or Robin. Nothing so stimulates song as song, and the freculeney of song in its relation to the abundane of the spreins should be observed. The partial or complete cessation of song during periods of cold or 
inclement weather will further illustrate the connection between song and the bird's physical condition.

Singing usually claims all a bird's attention. Some birds, it is true, like the Red-eyed Vireo or Black and White Warbler, sing as they work, but in most instances the bird seeks a point of vantage from which to deliver his message. The Brown Thrasher mounts to the topmost twig of the tallest tree, the Mocker often takes his stand on a chimney, Bob-white mounts to a fence-post, while most of the song birds of prairie and plain, like the Horned Larks, Pipits, Longspurs and Lark Bunting, for lack of other perch, deliver their songs from the air.

Other birds, like the Bobolink and Rose-breasted Grosbeak, sing while flying as well as while perching, and observation will show that each species of bird has a more or less well-defined taste in the selection of its song-perch.

The flight-song of birds inhabiting treeless regions must not be confused with the exceptional and infrequent flight-or ecstasy-song of certain birds, like the Ovenbird, Water-Thrushes, and Maryland Yellow-throat, which usually sing from a perch, but which, on occasion, bound into the air, rising only a few feet in the case of the Yellowthroat, but a hundred or more with the Seiuri, and on trembling wing utter a hurried, ecstatic outburst of twittering notes wholly unlike their normal song. The Meadowlark has such a flight-song, but in my experience the bird of the plains (Sturnella neglecta) utters it far more frequently than does our eastern Sturnella magna, a variation possibly due to the difference in the nature of their haunts.

A further study of Meadowlark songs opens the subject of geographical variation in the songs of the same species. Its widely different song is one of the Western Meadowlark's best claims to specific distinctness from the eastern bird, but even among the slightly differentiated forms of Sturnella magna, there are striking variations in voice. The songs of some Florida Meadowlarks are scarcely recognizable to one familiar only with the Meadowlark in the north, while the Meadowlark of Cuba would not be known to him by its notes.

The 'musical' ear will detect more or less pronounced variations in the voices of other widely distributed species, as they are heard in the various parts of their range, and, in addition to this geographical variation, a variation with age may be detected. This is obvious enough with species like the Song Sparrow, the young of which, while still wearing in whole or part their nestling plumage, sing an evidently immature song; and is still apparent with birds like the Orchard Oriole or Indigo Bunting, whose first spring plumage betrays their age and explains why their songs are less finished, less developed than those of the adults of their kind.

Birds inherit at least the calls they utter when in the nest, just as a child cries instinctively, but they apparently do not inherit their songs any more than the child inherits the language of its parents, and in many recorded instances they have learned the notes of the birds 
within sound of whose voices they have been reared. There are, for example, a number of cases in which young House or English Sparrows when reared with Canaries have learned the Canary's song. Two Baltimore Orioles, reared by W. E. D. Scott ('04) apart from all other birds, developed a song of their own which was wholly unlike that of their species, and this song was learned by four other Baltimore Orioles which were subsequently reared in the companionship of the first two.

It is this strong tendency to imitate which has given rise to the theory of the mimetic origin of bird song, and which is no doubt largely responsible for much of the individual variation so prevalent in birds' songs. There is, for example, a Maryland Yellow-throat now (May, 1910) living near my home, the first half of whose song is that of the Yellow Warbler, while the remainder resembles that of its own species, evidence that the inherent predisposition toward the acquisition of the song of its ancestors was not sufficiently strong to prevent its song from being modified by the notes of another species.

It would be interesting to determine just when this presumably inherent tendency is active. Is the nestling unconsciously influenced by the song of its parent during the period of its infancy? Single-brooded birds may not hear the song of their species from the time they leave the nest until the following spring song again announces the opening of the nesting-season. It seems probable, therefore, that their song is acquired during the formative period of immaturity and before they come into contact with other species whose notes their strong mimetic gifts might lead them to adopt as their own, as doubtless did the Mary land Yellow-throat mentioned above.

With some species the tendency to imitate is functional long after it has served its universal purpose of giving them the notes characteristic of their species. Among our birds the Mockingbird takes first rank as a mimie, and L. M. Loomis tells me of one with a repertoire containing no less than thirty-two songs of other species of birds; but on the other hand some Mockingbirds sing only their own song. The Catbird, White-eyed Vireo, Blue Jay and introduced Starling are also to be numbered among the mimics.

\section{Suggestions for the Student}

What North American birds are voiceless? Which possess rudimentary voices? Trace the development of voice. Define the difference between call-notes and song. Note the development of call-notes in the young of præcocial birds; of altricial birds. Interpret, as far as possible, the call-notes of certain species. Give illustrations of different types of anger calls $(\rho . g$. spitting of brooding (hickadee, snapping of bill by sicreech ()wl, hiss of Duck, etc.); of alarm notes; of scolcling notes. How are call-notes used by migrating birds? Do birds understand the call-notes of other than their own species? Do the young understand the note's of their parents? What

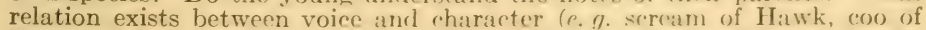
Dove)? Define Oscines. Give instanees of soner in non-Oscines; in the female. Define the song season. What speciess hate beren heard singing in the fall or winter? What is the relation between song and the advance of 
the nesting-season? Among single-brooded species? Among double-brooded species? Mention types of mechanical and other forms of bird music. What is the function of song? What are the earliest and latest dates on which certain species have been heard singing? What species arrive in song? What is the relation between song and the color of a bird's plumage? What birds sing sotto voce? Note the hours at which certain birds sing. What relation exists between the song-perch, haunt and habit (terrestrial or arboreal)? What birds sing at night? What birds sing on the wing or have a true flight-song? Give instances of individual variation in song; of variation with age; of geographical variation. Do young birds sing their first fall? Do birds inherit the call-notes and songs? When does the young bird acquire its song? Give instances of mimicry in birds.

\section{References}

1871. Darwin, C., The Descent of Man.-1884-5. Bicknell, E. P., A Study of the Singing of Our Birds, The Auk, I, pp. 60-71, 126-140, 209218, 322-332; II, pp. 144-154, 249-262.-1889. RHoAds, S. N., The Mimetic Origin and Development of Bird Language, Am. Nat. XXIII, pp. 91-102.1895. Shaler, N. S., Domesticated Animals, 155 pp, 8vo., (Scribner's).1896. Witchell, C. A., The Evolution of Bird-Song, 10mo., 253 pp., (Black, London).-1901. Sсотт, W. E. D., Data on Song in Birds, Science, N. S., XIV, p. 522.-1904. MAтнews, F. S., Field Book of Wild Birds and Their Music, 16mo., 262 pp., illus., (Putnam's).-1904. Scotr, W. E. D., Inheritance of Song in Passerine Birds, Science, N. S., XIX, p. 154; XX, p. 282.-1908. Craig, W., The Voices of Pigeons Regarded as a Means of Social Control, Am. Journ. Sociology, XIV, pp. 86-100.

\section{The Nesting Season}

Date

Number of Broods

Courtship

The Nest

Enemies of Nesting Birds

Nesting-site

Material

Construction

Character of the Nest

Inheritance

Parasitism

The Egg

Number Laid

Size
The Egg, continued

Colors

Shape

Variations

Incubation

The Young Bird

Condition at Birth

Food

Nest Sanitation

Defence of the Young

Voice

Nest Exercises

Fear

Flight

Date.- Why should a bird build its nest at a certain time of the year? Some variation in nesting dates, it is true, is shown by all birds, but this does not affect the truth of the statement that most species have a definite nesting season.

In a general way it may be answered that the nesting period, as a whole, is determined by those climatic changes, which, independent of latitude, divide the year into seasons. In the extreme north, where it is possible for birds to nest only during a small portion of the year, the 
relation between nesting time and season is obvious enough. But in the south, so far as climate is concerned, birds might rear their young any month in the year; nevertheless, even in the tropics most species appear to have a more or less well-defined nesting-season.

So we look for a deeper reason why there should be this regular, annual, nesting period, and we apparently find it in the bird itself. In the bird-world as in the plant-world there exist cycles of physiological development. The tree buds, leaves, blossoms, fruits, loses its foliage and rests; then, all in due time, the same events are repeated in proper order. Thus the bird migrates (if it be migratory), mates, builds its nest, lays its eggs, incubates, rears its young, molts, and retreats to winter quarters. There are exceptions to this program, as where a bird raises more than one brood, or has more than one molt, but they are only the results of variations in the underlying physiological processes which, through a regular series of events, prepare the bird for the nesting season.

Insect-, seed- or fruit-eating birds require an abundant supply of food during the nesting-season, when, within a comparatively limited area, they must find sustenance for their young as well as for themselves. Now while it is true that in the tropies food is to be had throughout the year, it is far more abundant and varied during the spring or early summer. There, with the coming of rains, the trees renew their foliage, then insects become more numerous, and coincidentally the instincts of the nesting-season become active in birds.

Confining our attention to our own birds, we observe that some species nest early and some late in the nesting-season. Why is this? The character of the food of the young is the most obvious cause determining the exact date of a bird's nesting. Hence those birds of prey which feed their offspring on mammals or birds are the first birds to nest, while those birds that rear their brood on insects or fruit nest later.

But is not a bird's nesting-time also dependent on whether it be migratory or resident? This is a difficult question to answer, since it is by no means easy to determine whether or not a species is resident, in the strict sense of the word. Among resident species of not dissimilar feeding habits, there is often much difference in nesting dates. The White-breasted Nuthatch near New York City, for instance, nests in the middle of April, while the Downy Woodpecker waits until a month later. The Bluebird nests in the first half of April, the Cedar Waxwing the latter half of June. Possibly a study of the food of their young may explain this difference in dates.

- Some migratory birds which arrive at about the same time also nest on widely different dates. Robins and Red-winged Blackbirds, for instance, reach New York City in late February or early March, but the Robin nests nearly a month earlier than the Redwing. Haunts may here exert some influence. The early nesting Robins find favorable sites in evergreens, long before the vegetation in the marshes the Red- 
wings frequent affords concealment for their nests. The Woodcock, on the other hand, nests shortly after its arrival; possibly because a site is at once available.

Consequently, in addition to those physiological factors which induce an annual nesting-season as one of the phenomena in the cycle of the bird's year, the exact date of a bird's nesting appears to be governed by (1) the nature of the food of its young; (2) whether it is resident or migratory, though this remains to be determined; and (3) the condition of its nesting haunts. To these will doubtless be added other causes, as we become more intimate with the facts involved.

Number of Broods.-Why do some birds raise only one brood and others two or even three? We should look for a partial answer to this question in the length of time required by a species to rear a brood. If the period from the beginning of the nest-building to the date when the resulting young are able to care for themselves is so short that the parents are still in the physiological condition incident to reproduction, a second family may be expected, and under similar circumstances a third may follow. The eggs of the English Sparrow hatch in about twelve days, the young remain in the nest only about a week, and the species is reported to have reared six broods in a season near New York City, but this number is doubtless exceptional. Robins' eggs hatch in thirteen days; the young leave the nest when about two weeks old, and the species raises two or even three broods. But the eggs of Fish Hawks, for example, require four weeks' incubation; the young do not fly until about six weeks old, and the species is one-brooded. These facts, however, fail to explain why many birds in which the periods of incubation and rearing of the young are quite as short as those of the Robin, should have only one brood. The time of a bird's arrival on the nesting-ground doubtless has some bearing on the question, and we should also take into account the time of return to its winter haunts, without in the least being able to say why it should come and go at a certain time. Still, among permanent residents and migrants, which arrive and depart at about the same season, some are single-brooded while others raise two or even three broods. For instance, of the former, the Song Sparrow rears two and on occasions, three broods, while the Chickadee has but one. Here size of the brood may be a factor. Among migrants, the Robin is two- or rarely three-brooded, while the Purple Grackle, which comes just as early and remains nearly as long, is onebrooded. Possibly there are here temperamental differences not to be explained by observable influences.

The question, not infrequently asked, whether any of our migrant birds nest in their winter homes, makes it necessary to add that a bird has only one nesting-season, and with those species which rear more than one brood there is no appreciable interval of rest between the first and succeeding broods.

A table of dates showing when one may expect to find full sets of birds' eggs of the first laying near New York City is appended: 
Feb. 28. Great Horned Owl.

Mar. 12. Barred Owl.

28. Carolina Wren.

30. Duck Hawk.

Apl. 1. Woodcock.

3. Red-shouldered Hawk.

3. Screech Owl.

6. Red-tailed Hawk.

9. American Crow.

9. Long-eared Owl.

10. Bluebird.

17. White-breasted Nuthatch.

18. Broad-winged Hawk.

20. Robin.

25. Mourning Dove.

25. Purple Grackle.

28. Phœbe.

29. Song Sparrow.

May 1. Black-crowned Night Heron.

1. Cooper's Hawk.

1. Kingfisher.

2. Osprey.

3. Cardinal.

5. Cowbird.

6. Wood Duck.

6. Green Heron.

7. Flicker.

8. Barn Swallow.

10. Clapper Rail.

10. Ruffed Grouse.

10. Sparrow Hawk.

10. Vesper Sparrow.

11. Louisiana Water-Thrush.

12. Ruby-throated Hummingbird.

13. Red-headed Woodpecker.

14. Acadian Flycatcher.

14. Blue Jay.

14. Chipping Sparrow.

14. Towhee.

15. Virginia Rail.

15. Meadowlark.

15. Field Sparrow.

15. Swamp Sparrow.

15. Hooded Warbler.

16. Blue-winged Warbler.

16. Brown Thrasher.

17. Fish Crow.

17. Redstart.

17. Catbird.
May 17. Wood Thrush.

18. Red-winged Blackbird.

18. Black and White Warbler.

18. House Wren.

19. Tree Swallow.

19. Bank Swallow.

19. Chickadee.

20. Rose-breasted Grosbeak.

20. Worm-eating Warbler.

20. Oven-bird.

20. Veery.

21. Sharp-shinned Hawk.

21. Downy Woodpecker.

21. Least Flycatcher.

22. Northern Parula Warbler.

23. Hairy Woodpecker.

23. Chat.

24. Spotted Sandpiper.

25. Chimney Swift.

25. Baltimore Oriole.

25. Purple Martin.

25. White-eyed Vireo.

25. Maryland Yellow-throat.

26. Bob-white.

26. Marsh Hawk.

28. Grasshopper Sparrow.

28. Red-eyed Vireo.

28. Yellow-throated Vireo.

29. Black-billed Cuckoo.

29. Kingbird.

29. Bobolink.

29. Indigo Bunting.

29. Chestnut-sided Warbler.

30. Yellow-billed Cuckoo.

30. Orchard Oriole.

30. Seaside Sparrow.

30. Sharp-tailed Sparrow.

30. Rough-winged Swallow.

30. Cliff Swallow.

30. Warbling Vireo.

31. Long-billed Marsh Wren.

31. Least Bittern.

June 1. Nighthawk.

1. Kentucky Warbler.

3. Whip-poor-will.

3. Crested Flycatcher.

3. Scarlet Tanager.

5. Wood Pewee.

7. Short-billed Marsh Wren.

19. Cedar Waxwing.

20. American Goldfinch. 
Courtship.-The first evidence of the near approach of the nestingseason among birds is furnished by the phenomena of courtship. Chief among these are song and the sounds produced in various ways which take the place of song; display of plumage, fighting, dancing, and other often remarkable activities through which birds give vent to their emotions at this period of maximum vitality. As a rule, these vocal or physical exhibitions are given by the male; and the question at issue is, are they simply expressions of irrepressible vigor or are they designed to attract the attention or stimulate the interest of the female and thus aid the bird to win a mate.

The function of song is discussed in another chapter, but in fighting for a mate, action and cause are so closely connected that the development of spurs, for instance, is generally considered a result of that form of natural selection which awards success to the strongest, bestarmed fighter and enables it to transmit its own desirable characters to its offspring. This matter is, however, primarily to be settled by the males. Two or more males meet, battle, and the victor gets the prize of a mate; but has this mate any voice in the matter? In those more peaceful contests where rival males attempt to outdo one another through display of plumage or violent actions, it is even more difficult to decide to what extent the female is influenced, but it seems probable that there is less actual selection than passive acceptance on her part of the male which is most active in battle or display.

It is much less difficult to make observations in this field than to interpret them. What, for example, is the significance of the squabbles, struttings and irrepressible vociferousness of the English Sparrow when courting?

Most of our birds are monogamous and doubtless take a new mate for each nesting season; but some of the larger birds, notably among the Hawks and Owls, are known to be more constant and are believed to be mated for life. In either case, however, the mate, if lost, is usually soon replaced, at least in the earlier stages of the nesting-season.

Exceptions to the rule of monogamy are shown by the Anis (Crotophaga) which are communistic, and by certain species which are polygamous. The Anis live in small flocks throughout the year. The females lay in a common nest and all share the family duties.

Among our North American birds the Wild Turkey is polygamous, though all association with the female ceases after incubation begins, while the male of the Prairie Hen and of some other members of the Grouse family are said to have more than one mate. The Great-tailed Grackle in Mexico has, at least, as many as five or six wives, and our Red-winged Blackbird has been suspected of Mormonism.

The males of our Cowbirds are believed to outnumber the females, and as this parasitic species apparently never pairs, its sexual relations may be described as representing a kind of promiscuous polygamy. 


\section{The Nest}

Enemies of Nesting Birds.-It will add to our appreciation of a bird's resources and most assuredly to our sympathy with birds, if before discussing their nesting habits we merely mention some of the enemies and dangers which threaten birds at this season. These are of two kinds; first, the elements; second, predatory animals including parasites. High winds, heavy rains, prolonged wet or cool periods and hail-storms are among the weather phenomena often fatal to the life of the nest; while chief among the animals that prey upon the eggs or young of our birds, are Crows, Jays, Grackles, cats, squirrels, opossums, minks, weasels, skunks, snakes, and man, who either directly, as an egg collector for the table or cabinet, or indirectly, in mowing fields, clearing hedgerows and in other ways, has won a prominent place among the enemies of nest-life.

With such an array of adverse conditions and relentless foes, the bird which reaches maturity may be said to have escaped nine-tenths of the dangers to which bird-flesh is heir. One realizes, therefore, how important it is for birds to select a site, build a nest, and care for their young in a way which has proved to be most desirable for their species; and how readily imperfect inheritance of the proper activities or inability to conform to new conditions may mean failure to rear a brood, and in the end extinction of the species.

Nesting Site.-The nature of a bird's nesting site appears to be determined by (1) the necessity for protection; (2) condition of the young at birth; (3) temperament, whether social or solitary; (4) habit, whether arboreal, terrestrial or aquatic; (5) haunt, whether in woodland, field, marsh, etc.

Protection may be secured by hiding the nest, by placing it in more or less inaccessible situations in trees or on cliffs, or by frequenting some isolated islet uninhabited by predatory animals. As I have elsewhere said ("Camps and Cruises of an Ornithologist," pp. 35-37), "So far as my experience goes, all colonial ground-nesting birds breed only on islands." Auks, Murres, Skimmers, Petrels, Tropic Birds, Gannets, Cormorants, Pelicans and Flamingoes are examples among North Amcrican birds, with which Bank Swallows appear to be the only execption. It is less to their terrestrial habit than to their gregariousness that we must attribute the necessity of an island home for these birds. When nesting, all the individuals of a given species, which at other seasons are seattered over a wide area, are focused in a small space. To find one nest is to find all, and to a large degree the fortune of one nest is also the fate of its neighbor.

Even when arboreal, colonial birds like Herons, Spoonbills, Anhingas, and Cormorants usually hreecl in trees growing in water and which are thus insulated. The birds just mentioned are all exeeptions to the rule that terrestrial feeding birds usually nest on the ground, while arboreal feeders nest in trees. But here the condition of the young at birth exerts 
an influence. The young of Herons, Spoonbills, Anhingas, Cormorants and Ibises are altricial, hence require the protection of a more or less inaccessible nest during the comparatively long period they are confined to it. On the other hand, the Whip-poor-will is, in feeding habit, a bird of the air, but the eggs are laid on the ground, the præcocial young apparently not requiring the shelter of a nest.

Exceptions to the rule that exclusively terrestrial feeding birds usually nest upon the ground have already been referred to under Herons, Ibises, Spoonbills, etc., whose gregariousness in connection with the condition of the young at birth evidently demands an arboreal site; but the reasons why such terrestrial birds as the Quail and Grouse, Snipe and Plover or the Loons and Grebes nest on the ground are obvious. It is equally to be expected that birds, like the Catbird, which live among bushes, should nest among them, and that arboreal species, like Tanagers, should nest in trees, though we shall always find interesting variations or departures from the normal; as, for example, the nesting of the Solitary Sandpiper in the old homes of such arboreal species as the Robin, or of the Wood Duck and Golden-eye in trees, while such purely individual variations as a Wild Goose occupying a Fish Hawk's nest or a Mallard laying in a Rough-leg's nest, occur without number.

It is to be expected, too, that the character of a bird's haunts should be reflected in its nesting-site, and as a result we have some most interesting variations in site among birds of the same family but which live in unlike haunts. Many Hawks, for example, are wood-dwellers, and the ideal Hawk's nest is placed in a tree; but the Marsh Hawk lives in treeless areas and nests upon the ground. So the Burrowing Owl of the prairies nests in holes in the ground; while the forest-haunting members of its family usually select hollow trees. Consequently it follows that when there is a marked difference in the range of the same species there is apt to be a corresponding variation in the nature of its nestingsite. The Red-winged Blackbirds living in reedy marshes weave their nests to the reed-stems, while those Redwings of the adjoining alder growths place their nests in alder bushes. Mourning Doves nest in trees in the East, and on the ground in treeless areas of the West. Night Herons, which in the East may build seventy or eighty feet from the ground, in the West build at water-level among reeds. Even more surprising is it to find the Great Blue Heron in treeless areas nesting on the bare ground or on rocks, rarely, or never, however, using a terrestrial site except upon islands. While many birds show little or no variation in the character of their nesting-sites, others place their nests in many and widely different situations, even under the same conditions. Robins, for example, aside from nesting in trees at varying heights, place their nests on window-sills, in arbors, summer-houses or barns, on fence-rails, etc., and in cases of this kind it is interesting to learn the fate of those nests which in site depart from the prevailing type.

Civilization, which while it has added the cat to the Robin's enemies, 
has also decreased the number of its natural foes, is no doubt responsible for much of this variation; few of our native birds have so prospered through the change from forest to farm; though even more marked departure from feral nesting habit has been shown by the Chimney Swift, Barn and Cliff Swallows, Martin, House Wren and Bluebird; not to mention the irrepressible English Sparrow. Herring Gulls, on the same islet, build in trees as well as on the ground, and as Dutcher and Baily have shown, the tree nests have a solid foundation of sticks and twigs which is lacking in those nests built on the ground. (The Auk, XX, 1903, p. 419.)

On Gardiner's Island, where there are no predatory mammals, and, with the exception of Crows, practically no enemies of nesting birds, Robins build their nests in almost any situation, even on the ground, with apparently equal chances of rcaring their young. Here too Fish Hawks nest, not only in trees, but also in the most exposed situations on the beach; and because of the protection afforded by an insular home, their eggs and young are as safe as those of the tree-nesting individuals of their kind.

As I have elsewhere said ("Camps and Cruises," p. 37, also pp. 38-61; and Bird-Lore, V, 1903, p. 59), it is not probable that in instances of this kind certain birds have with deliberate intent abandoned the customs of their species, but the tendeney to vary, being unchecked, finds tangible expression under conditions where new habits may be successfully formed. Doubtless the same tendency exists in the Fish Hawks nesting on the mainland; but there the struggle for existence is so much more intense that any wide departure from the standard may be attended by disastrous results. Environment is thus the mold in which habit is cast.

Through these generalizations we come to the more practical, definite side of the question of nesting-site, and ask which sex selects it. With some species it is known to be the female, with others the male, and with others still the situation must evidently be satisfactory to them both; but exact observations on this subject are few.

More difficult it will be to learn whether the same individual occupies the same site and even the same nest season after season. Fish Hawks and birds which return! to the same islet year after year are known to do this, and the habit is probably common to many species. Doubtless the present-day practice of banding birds with numbered metal tags will, in time, yield much valuable information in this field.

With birds which have more than one brood in a season, a new nest is usually built. It is then of interest to compare its site with that chosen for the earlier nest, to ascertain how much variation in site-selection the same individuals may exhibit.

Material.-The material of which a bird builds its nest depends in most cases upon the nature of the bird's haunts. The nests of marshhaunting birds are usually made of reeds or woven of wet marsh grasses; 
woodland birds generally employ twigs, rootlets, bark, leaves, mosses, etc., while field-inhabiting species, as a rule, use chiefly dried grasses. It follows, therefore, that a change in the nature of a bird's haunts often causes more or less variation in the character of its nesting material. In the North, for example, the Acadian Flycatcher builds its nest of plant-stems, grasses, and dried blossoms, but in Florida it uses the Spanish or Tillandsia 'moss,' a material, by the way, which enters into the nests of many birds. In the East, Night Herons, building in trees, use sticks; in the West, where they nest in marshes, the nest is composed of reeds. There are many similar instances.

A familiar case of local variation, due to change in environment, is furnished by the Baltimore Oriole, which gathers string, worsteds, etc., in place of plant fibers; and experimenters have tried to determine the bird's choice of colors by supplying it with worsteds of varied hues, without, however, other result than a demonstration of range in choice among different individuals, since some selected gay and others dull colors.

The use by birds of rags, paper, horse-hair, etc., also clearly illustrates the influence of civilization on the bird's selection of material with which to build a nest.

The necessity for concealment is, in some cases, a potent influence in the choice of nesting material. What is generally spoken of as 'nest decoration,' if it have any significance, is assuredly not designed to make the nest conspicuous through display, but inconspicuous by matching it with its surroundings. The lichen-covered nests of the Wood Pewee, Blue-gray Gnatcatcher, and Hummingbird are examples of this class.

The Great-crested Flycatcher introduces a bit of cast-off snakeskin into its nest, it has been said, to serve the purpose of a scare-crow. The explanation is important if true but lacks evidence to support it.

The student should try to observe the methods employed by birds in gathering and carrying the material for their nests, noting, for example, Robins, Barn and Eave Swallows picking up billfuls of mud, a. Chimney Swift breaking off dead twigs with bill or feet, a Hummingbird collecting lichens from a tree-trunk, an Oriole tugging at a plant fiber, etc.

Construction.-Then follows a study of nest-construction, from the simple method of the Skimmer which by squatting low and turning around again and again hollows a nest in the sand, to the more complex activities of Swallows, Swifts and Orioles, which respectively exhibit the arts of the muson, joiner and weaver. Herrick's detailed and, so far as I am aware, unique study of a pair of Robins while nest-building, should be rearl in this connection. The work may be performed by one or both sexes. In the former case the female is usually the builder when the male maly assist by hringing material. The nest may be completed in a day and oecupied at onee, or a longer time may be required and it may apparently be deserted for days after its completion. The weather, 

Plate II

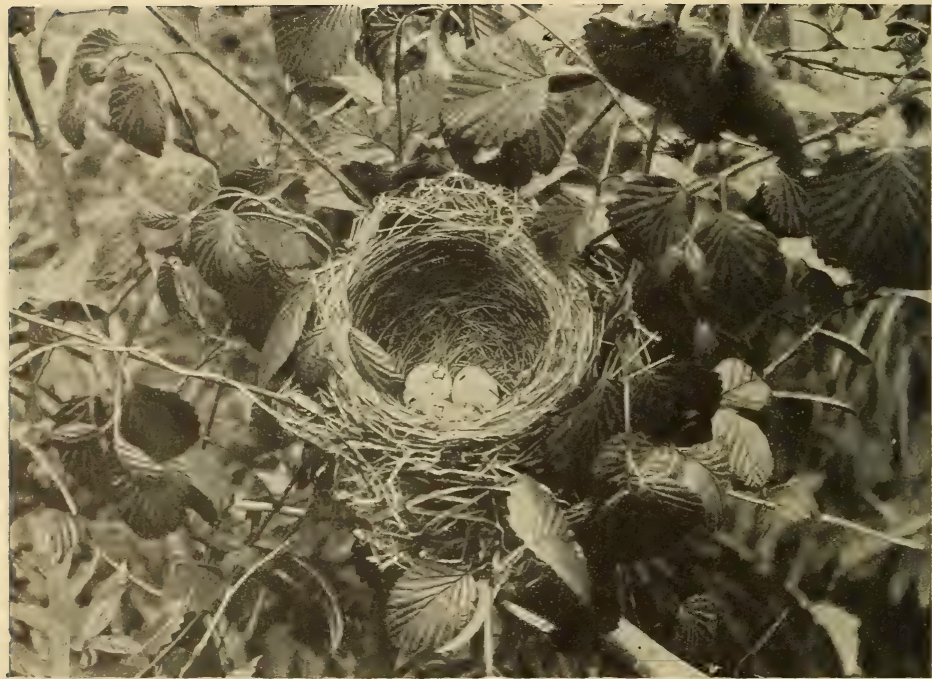

Well-formed Nest of Red-winged Blackbird-an Altricial Species Englewood, N. J.

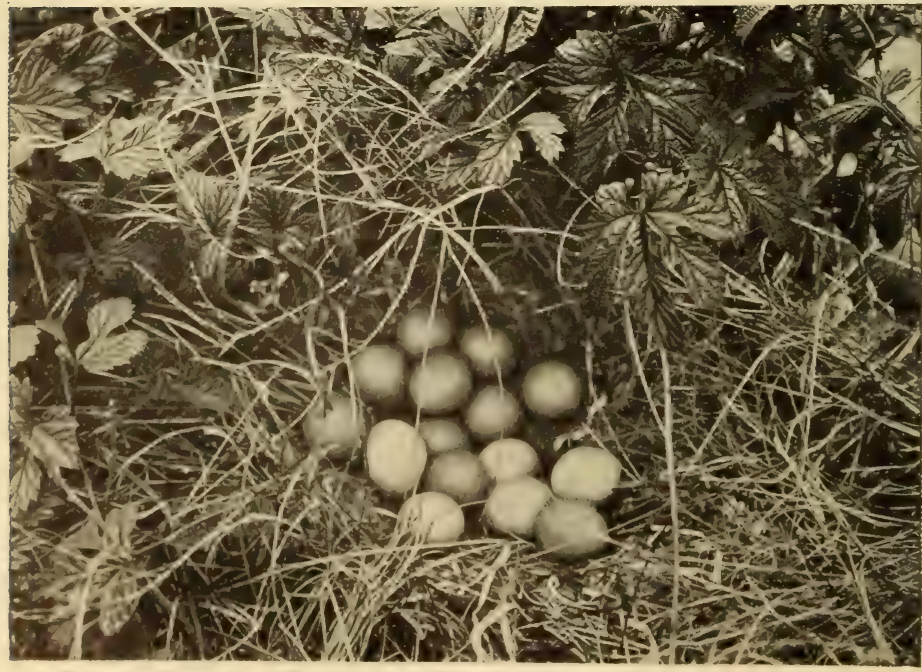

Simple Nest of Pheasant (Phasianus) -a Precocial Species Gardiner's Island, L. I. 
particularly if the temperature is much below the average, is a factor here. In some species, notably the Long-billed Marsh Wren, the nestbuilding instinct does not seem to be satisfied by the making of a single structure, and the male continues his work after the female is sitting, building one or more additional homes in which possibly he may sleep, and which are sometimes called 'cock-nests.'

Character of the Nest.-From an architectural point of view, nests may differ greatly even when the material of which they are composed is the same. The tools (bill and feet) with which a bird is provided do not often bear any relation to the character of the home their owner builds. A Swallow, it is true, could not construct a Woodpecker's dwelling; but a momentary comparison of the widely different kinds of nests built by various species of Swallows and Swifts (which so far as nesting tools are concerned may be classed with Swallows), readily shows how little the structure of the bird has to do with nest architecture.

Most of the causes determining the nature of site and material are also more or less active in shaping the nest itself, but of them all by far the most important is the condition of the young bird at birth. Indeed in considering this question we are brought very near to an inquiry concerning the origin of birds' nests.

As regards their condition when leaving the egg, birds may be roughly classified in two groups: First, those which leave the nest shortly after hatching; second, those which are reared in the nest. Birds of the first class are termed præcocial; those of the second, altricial. Compare the newly hatched young of a Grouse and a Robin and we have two excellent examples of præcocialism and altricialism; while a further comparison of the Grouse's simple bed of leaves with the Robin's firm, deep cup of mud and grasses equally well illustrates the difference in the nests of præcocial and altricial birds. The former serve only to hold the egge, the latter perform not only this function but must also house the young during their period of helplessness.

The significance of the condition of the young at birth is doubtless far-reaching, but unfortunately, it is not as yet understood. It appears that most of the older or lower forms of birds - that is, those which most elosely approach the reptilian types, whence it is believed birds have descended-are prococial. On the other hand, all the higher birds, that is those farthest removed from reptilian ancestors, are altricial. For example, among North American birds the Grebes, Loons, Gulls, Terns, Ducks, Rail, Coots, Snipe, Plover, Quail, and Grouse, are præcocial, and build, as a rule, nests of the most rudimentary kind, while the great group of Perehing Birds (Passeres), containing half the known birds, are altricial, and all builil more or less complex nests.

It is possible, therefore, that as altricialism has been evolved from præcocialism, so the type of nest has changed, keeping pace with the demands which the young birds make upon it. There are, however, 
some exceptional cases of birds, like Pelicans, Water-Turkeys, and Cormorants, which, while low in the evolutionary scale, have altricial young, and in consequence build well-formed, complex nests. The Noddy Tern, sole tree nest-builder of its group, usually constructs in bushes a nest of sufficient strength to harbor the young for two months. (Thompson, Bird-Lore, V, 1903, p. 81.)

Other low types of altricial birds secure shelter for their helpless young without actually building a nest, but by using a natural cavity in tree or cliff, or by making a burrow, and we doubtless have here a primitive type of bird home.

It is impracticable to go into further detail here, but the study of birds' nests may be indefinitely extended by taking up certain "species of birds and considering their nesting-habits in the light of what appears in this chapter.

Inheritance.-There is no reason to doubt that nest-building is as much an instinctive activity with birds as it is with bees or wasps. Some writers would have us believe that the young bird in the nest makes mental notes of its surroundings for use the following spring; but even man himself could not tell how certain birds' nests were built merely by looking at them. The young bird, therefore, builds its first nest without ever having seen one made and with no other experience with nests than is implied by having lived in one.

There can be no question that the impulse to build is as much the result of a physiological prompting as the impulse to mate which precedes it, or the impulse to lay which follows it. Inherited habit directs the impulse in normal channels and, allowing for the range of individuality present in a greater or less degree in all birds, the bird, in its proper environment, selects a site and constructs a home after the manner of its species. When, however, the environment is changed and new conditions of site or material are introduced, the nest-building impulse, unchecked, and inevitably demanding an outlet, finds expression through new media. Possibly it is governed to some extent by intelligence, but any departure from type is usually an experiment, and the progressive individual pays the price or gains the reward of the pioneer by dire failure on the one hand, or exceptional success on the other.

It is not unusual to observe evidences of sexual activity among hirds in the fall-a mere reflection of the instincts of the nesting scason-and among them is what might be called 'play' at site-hunting and material gathering. So I have seen Tree Swallows, in August, investigate the openings in piles and pick up bits of dried grass only to drop them after a flight of fifty yards or more; and in this connection it is of significance to learn that they were all birds of the year ("Bird Studies with a Camera," p. 103; see also Brewster, The Auk, 1898, p. 194).

P'arasitism.- - In a comparatively few cases, the instinct to build a nest is wanting, when the bird entrusts its egg to the care of another species. The European Cuckoo and our own Cowbird are examples of 
this kind of parasitism. The former lays its egg in some convenient place and, taking it in its bill, inserts it into the foreign nest; but the Cowbird, as far as is known, lays its egg in the nest selected.

Of the nearly one hundred species of North American birds in whose nests the egg of the Cowbird has been found, one fourth are Warblers, indicating how often the Cowbird chooses as a foster parent a bird smaller than itself. The Warbler may nest upon the ground, or eighty feet above it, and still be preyed upon by the Cowbird, which never having had a home of its own has formed no attachment for any particular site. Many theories have been advanced to account for the lack of the nest-building instinct in the Cowbird, but none is conclusive (see, however, Herrick '11). In any consideration of the subject, however, it should be remembered that some of our Cowbird's seven tropical American relatives have advanced toward the prevalent custom of monogamy, Molothrus badius of Argentina always incubating its own eggs and sometimes building a nest. (See Bendire, "The Cowbirds," Rep. U. S. N. M. for 1893, pp. 587-624.)

\section{The Egg}

Number Laid.-The number of eggs comprising a full 'set' or 'clutch' ranges from one to as many as twenty. No law governing this number is known, though birds of temperate zones usually lay more eggs than their representatives in the tropics. Our northern Terns (Common, Roseate, Arctic), for example, usually lay three eggs, while southern Terns (Noddy, Sooty, Bridled) lay but one. Our Thrushes lay normally four eggs, but tropical Thrushes lay only two or three.

Generally speaking, birds of the same family lay approximately the same number of eggs, but there is much variation between birds of closely related families (e.g. Loons and Grebes, Thrushes and Wrens), while birds of similar nesting-site may not lay the same number of eggs (e.g. Bob-white and Meadowlark).

The young of præcocial birds require less care than do those which are wholly dependent on their parents, and among Grouse, Quail, and Ducks we find the largest families. But, on the other hand, the eminently prococial Snipe and Plover have but four young. These birds, however, are too small to cover more than four of their disproportionatcly large eggs, while the gallinaceous birds can readily cover a dozen or more. Therefore, size of the parent, as well as condition of the young at birth, is here a governing factor.

The number of eggs laid is no indication of the fecundity of the bird. At the time of laying, the ovary contains a large number of partly formed eggs, of which, normally, only the required number will become fully developed. But if the nest be robbed, the stolen exges will frequently be replaced. The oft-cited case of the Flicker which laid seventy-one eggs in seventy-three days is in point, while the long con- 
tinued laying of our domestic fowls is a familiar illustration of the results following unnatural stimulation of the ovaries caused by persistent robbing.

Size of the Eggs.-Primarily, the size of the egg depends upon the size of the bird that lays it. Hummingbirds, the smallest birds, lay the smallest eggs, while Ostriches, the largest birds, lay the largest eggs. This scale, however, is not always maintained, the eggs of præcocial birds being relatively larger than those of altricial birds of the same size, obviously because of the more advanced, larger young they hold. Compare, for example, the eggs of a Meadowlark with those of an Upland Plover, or a Robin's eggs with those of a Spotted Sandpiper.

The Colors of Eggs.-The colors of eggs are due to pigments deposited by ducts while the egg is receiving its shell in the lower or uterine dilation of the oviduct. One or all the layers of the shell may be pigmented, and variation in color may be caused by a superimposed stratum of carbonate of lime, producing lilac tints and 'clouded' or 'shell' markings. In the earlier stages of their descent from reptilian ancestors all birds doubtless laid white eggs, as do all reptiles, and color is believed to have been acquired for purposes of protection, as the bird has departed from the reptilian habit of covering its eggs or laying them in covered situations and has adopted a more or less open nest. Hence, where the eggs are still placed in holes or hollowed trees, they as a rule are white, and where they are laid in exposed situations they are usually protectively marked. Compare, for example, the eggs of Kingfishers, Woodpeckers, and Owls, with those of Terns, Snipe, or Plover. There are, however, numerous exceptions to this rule; for instance, Doves lay white eggs in frail, open nests. But here both sexes incubate and the eggs are rarely exposed. Again, Grebes lay white or whitish eggs in flat, open nests, but they generally cover them with nest material before leaving the nest.

While we cannot so readily explain why Chickadees or Cliff Swallows lay pigmented eggs, it is obvious that the significance of the colors of eggs can be ascertained only by a study of them where they were laid.

Shape of Eggs.-Birds' eggs are usually ovate, but may be elliptical, spherical, pyriform or conical. The pyriform egg of the Murre, when moved slowly, describes a circle about its own point, and is therefore less apt to roll over the narrow, rocky ledges on which Murres usually lay, than an oval egg. The conical eggs of Snipe and Plover are placed in the nest point downward or inward, thus fitting together so closely that they can be easily covered by the comparatively smallbodied parent. Thus with form, as with color, it is clear that the egg should be studied where the bird placed it.

Variations.-Although, generally speaking, the eggs of the same species resemble one another, there is a wide range of variation in color, size and shape, and to a lesser degree in number. Doubtless these variations are in the main an index of the physical condition of the bird 


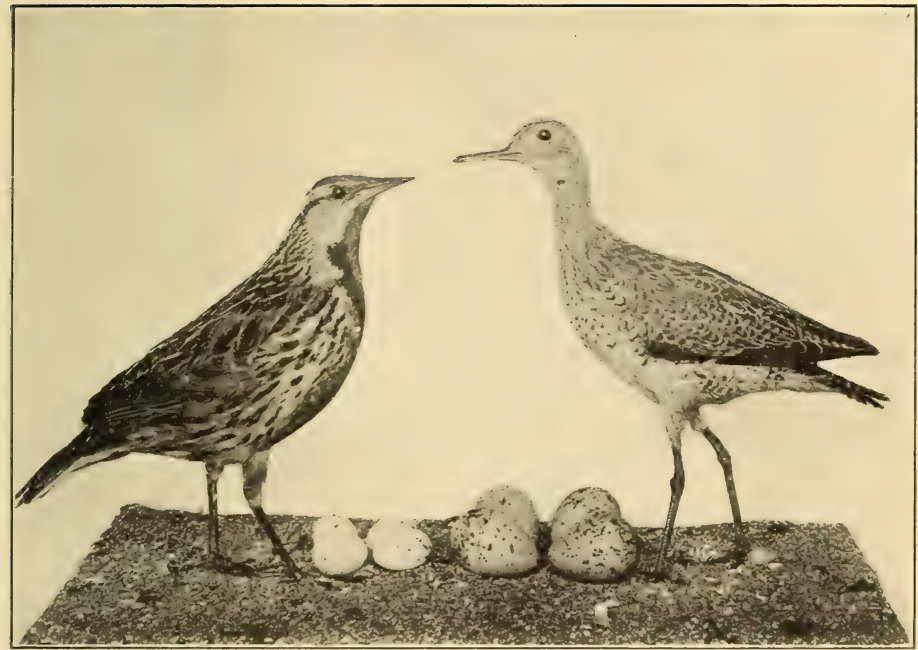

Eggs of Meadowlark and Upland Plover

Size of eggs in relation to condition of young birds when hatched. Note that, while the birds are of about the same size, the eggs of the Meadowlark, an altricial bird, are much smaller than those of the Upland Plover, a præcocial bird.
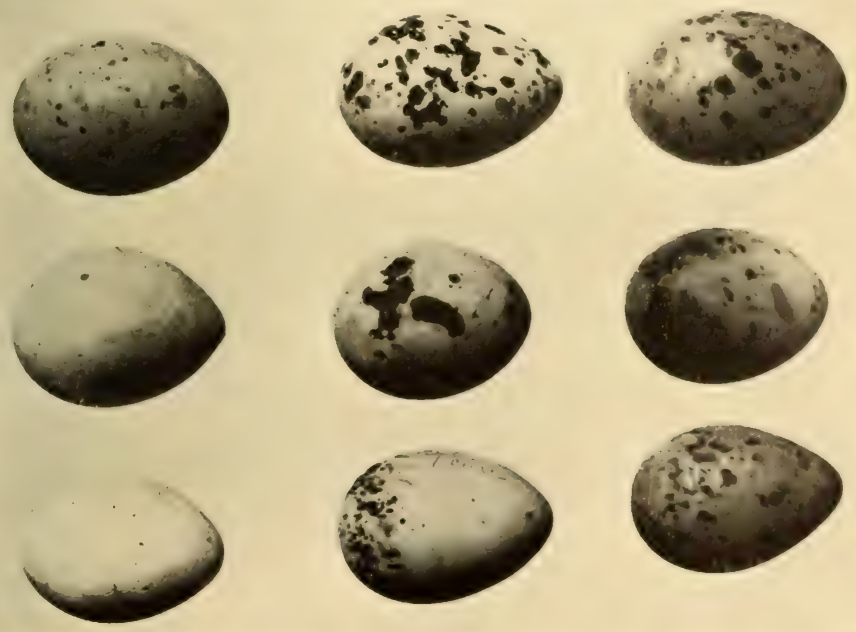

EGgS of Common Tern

Collected in a small colony on an island in Shoal Lake, Man., to whow variation in color and pattern. 

concerned. Fully adult, vigorous birds probably lay larger and more heavily pigmented eggs and more of them than their younger or weaker fellows. Again, the first eggs of a set, as well as those of first sets, where more than one is laid, may be more strongly pigmented or larger than those laid later. But whatever their cause, the cataloguing of these variations constitutes no small part of the labors of the oölogist, whose delight in finding an unusually large set, or one containing 'runt' eggs, or colored eggs which should be plain, or plain eggs which should be colored, is somewhat out of proportion to the scientific value of the 'discovery.'

Incubation.-The period of incubation is more or less closely related to the size of the egg. With the Chipping Sparrow it is twelve days, but with the Ruby-throated Hummingbird fourteen; the English Sparrow requires twelve or thirteen, the Robin thirteen or fourteen, the Fish Hawk about twenty-eight, but the exact period has been ascertained for comparatively few of our birds.

Incubation is usually performed by the female and is sometimes equally shared by the male; or the male may merely cover the eggs during the female's absence; or again, as with the Ruby-throated Hummingbird, he may not be seen near the nest after the eggs are laid. With the Phalaropes the male alone incubates.

The treatment of their eggs by sitting birds is a subject concerning which we have not much information, though some birds are known to turn them with their feet and others with their bills. I have seen a Least Bittern calmly eat two of her five eggs which had been punctured by a Marsh Wren, and then settle herself on the remaining three. ("Bird Studies with a Camera," p. 75.)

The disposal of the egg-shell is also a matter of interest. Most birds carry it some distance from the nest before dropping it, but young Flamingoes eat it!

\section{The Young Bird}

Condition at Birth.-The treatment of the young bird during its period of dependence on parental care is determined primarily by its state on leaving the egg. If it be præcocial and hence runs or swims with the parent the day it is born, its early life will differ greatly from that of the altricial bird, which hatched naked, blind and helpless, is reared in the nest.

In either case, the act which in natural succession follows incubating is brooding. Præcocial birds are usually hatched within a few hours of each other, and are as a rule brooded in the nest only until the waterproof sheath, in which their natal down is enclosed, is dry and slits, transforming the nestling from an apparently scantily haired little creature to one thickly covered with down. After that they are brooded only at night or when, tired, they are permitted to 'snuggle' beneath the parental breast. 
But altricial birds which may be hatched at longer intervals are brooded more or less constantly for days or until their own feathers are sufficiently grown to protect them. Even then, when exposed to rain or sun, the parent may stand above them with half-spread wings.

Food.-The young of præcocial birds feed themselves, but either learn by experience or are taught by their parents what they shall eat. Recall a Hen clucking to her chicks and picking up and dropping bits of food she desires them to have. Even the act of drinking is not instinctive. (See especially Lloyd Morgan's "Habit and Instincts.")

The young of altricial birds, not only when they are in the nest, but as long as a month after leaving it, are fed by the parents. The nature of the food and the manner in which it is given are subjects of far too great import to be adequately treated here. The food, at first, is usually more or less digested in the crop or stomach of the parent whence it is regurgitated into the mouth of the young. With Passerine birds, this method, when employed, is soon abandoned, and food in a more or less natural state is captured and given directly to the open-mouthed offspring; but the Flicker, Hummingbirds, and Doves, for example, feed only by regurgitation, inserting their bill far into the mouth of their young.

Young Pelicans, Cormorants, Water Turkeys, Spoonbills, and Ibises thrust their bill down the throat of their parents. Flamingoes introduce the tip of their great bill into that of their single chick, giving it, by regurgitation, a few drops of predigested liquid food, an exceptional method of feeding among præcocial birds; young Herons grasp the bill of their parent at the base with their own, as one would with a pair of scissors, when the old bird either disgorges food into the nest or skillfully into the mouth of the young. Hawks tear the food into bits and give it to their young, and larger insects are beaten or pulled apart by Passerine birds, both parents sometimes working together at the task.

The young of Passerine birds are fed every few minutes throughout a greater part of the day, but the young of larger birds are waited on less frequently, hours often elapsing between meals, at which, however, they receive large portions.

The rate of growth of young birds, particularly of young perching birds, is little short of marvelous. Herrick ('0s, p. 187) writes of a young Cedar Waxwing the weight of which "doubled on the first day, more than trebled on the second, and nearly quadrupled on the third. On the twelfth day, when it weighed approximately one and one-fifth ounces, and had increased in weight thirteen-fold, it left the nest." "At a corresponding rate of growth," he adds, "a ten-pound baby when one day old would weigh twenty-one pounds, and at the age of twelve days one hundred and thirty-four pounds." A young Song Sparrow, studied by Owen, weighed, on hatching, 2.9 grams, and when at the age of seven days it left the nest, 16 grams. (The Auk, 1899, p. 222.) 
Herrick ('05, p. 181), whose continued, systematic studies have added so greatly to our knowledge of the life of the nest, was among the first to discover that admirable adjustment of the young bird's nervous system which prevents it from being overfed. He writes: "The food is placed not simply in the mouth of the young bird but well down the sensitive throat, and if the bird does not immediately respond, it is withdrawn and passed to another, and often to a third, until a throat is found which has the proper reaction time. If the gullet is already full, the swallowing reflex is inhibited, and the bird must wait."

Nest Sanitation.-Second only in importance to the subject of food is that of nest-sanitation. The young of altricial birds as unlike as Hawks and Hummingbirds void their excreta far over the edge of the nest, but with probably all our Passerine birds, and with some others, it is enclosed in a membranous sac, which is removed and, in some cases, devoured by the parent.

Defence of the Young.- Just how birds defend their young from their natural enemies we cannot always say, but before man as a possible nest-robber, some species (e.g. Pelicans, Flamingoes, Cormorants, Ibises, Spoonbills, Herons, and most Raptores) desert the nest without protest; others (Gulls, Terns, some Raptores) protest loudly and dart at the enemy, sometimes actually hitting him; the Passeres, with some exceptions (e.g. Crows and Jays), utter loud alarm or call notes, which more often betray their secret than conceal it, and the Thrasher will occasionally strike the intruder; while many ground-nesting birds (e.g. Ducks, Snipe, Grouse, Nighthawks, Doves) seek to draw attention from their nest or young, by feigning partial helplessness and fluttering painfully before the marauder, always, however, keeping just beyond his reach; a wonderful exhibition of parental devotion the origin and development of which it is difficult to explain.

Voice.-Some suggestions for a study of the notes of young birds are made in the chapter on the "Voice of Birds." Their instinctive obedience to parental command is also mentioned. Observe, for example, how young Gulls, Terns or Grouse squat and remain perfectly motionless in response to a certain alarm note; and how, under the same stimulus, a brood of young Ducks scatters.

Certain birds have a fecding note which induces the young bird to open its mouth in preparation for the eoming morsel. ()n leaving the nest some young birds (e. \%. Baltimore ()riole, Yellow-headed Blarkbird) develop a food-call, which is lost when they hatve learned to care for themselves.

Nest Exercises. - While in the nest, young birrls devote much attention to their newly grown feathers, preening them carefully and repeatedly. The parasites which infest some hirds, notal)ly Phoreces, while in the nest, also give the young bird much oecupation. The frequent stretching of the wing is a characteristic nest aretivity, and, according to Seott, the grasping of the nest-lining with the toes is an important, nest exercise. 
Fear.-Herrick (l.c. p. 227) considers the instinct of fear to be inherited, but it apparently is often wanting in birds which have never known parental care. I have seen young Wild Geese, which were hatched from eggs taken from a wild bird's nest and placed under a hen, so devoid of the sense of fear that when two weeks old they would attempt to crowd into a hand basin when it was being used; while innumerable instances of birds raised from the nest, which have never developed a sense of fear, could be mentioned. In a state of nature, the young bird does not evince fear until it has acquired sufficient strength to respond to the impulses born of fear; in other words, until it can run, swim, or flutter in the first attempts at flight.

Flight.- Some young birds remain in the nest only a week (e.g. Song Sparrow, House Sparrow), while the wandering Albatross is said not to leave its nest until forced to by the parents at the beginning of the nesting season succeeding its birth.

It is of interest to note the stimulus which finally induces flight; whether supplied by the parent, for example, through a refusal to bring further food to the nest, or through increasing strength which prompts the bird to make its initial venture in the world. The first flight may be a mere flutter to an adjoining limb, or so well directed that the young bird (e.g. Swallows) directs its movements with the ease, grace, and precision of the adult.

The nest may now be used as a roosting place; and the young remain under the care of the parents for as much as a month. With the Robin, the male is said to frequent the summer roosts formed by these birds, with the young, while the female incubates the second set of eggs.

\section{Suggestions for the Student}

Necessity for Concealment.-If one would study the habits of birds under natural conditions, it is of the first importance that they be unalarmed by one's presence. With birds, as with man, the consciousness of being under observation induces more or less artificiality of behavior, and if one would gain true insight into either bird-life or human life one's subject should be unaware that it is an object of scrutiny.

Some nests may be built within range of already existing hiding-places, but in the end it will be found desirable to employ a portable blind such as has been described. During ten years' experience this blind has met many and widely different demands, and whether one uses a camera or only a notebook it will enalsle one to reach a point of vantage from which either photographs or observations can be satisfactorily made. It is unnecessary to speak of the value of the camera as a means of securing graphic, communicable records of the life of the nest, but in any event I cannot too strongly urge the use of a blind. When one wishes to have several nests under observation, a blind may be placed and left near each one, and with extremely wary species it may be ereeted at night. It is then not associated with any cause of alarm, and is more quickly accepted than if the birds were disturbed when it was being set up). It will usually save much time to have a companion aceompany you to the blind and depart as you enter it. The impression of fear eaused by your approach will be largely dispelled by his withdrawal, since birds do not distineuish between two and one.

Professor Herrick's plan of cutting off the limb containing the nest 
and removing it to the blind may be employed by careful, conscientious students, who are in a position to assume the responsibilities involved and who desire not merely to photograph but to see at close range the details of the later phases of nest-life, but it is not a method to be recommended to the general public. In the beginning, at any rate, one will find abundant opportunity afforded by nests which can be studied without moving them or unduly disturbing their surroundings.

Do not imagine that the most thorough history of the life of one nest completes your studies of that species. It may serve for the individuals concerned, but the behavior of many individuals must be learned before one can assert what are the habits of the species. Again I emphasize the need for specialization. Better a mass of data which permit one to judge of the significance of the facts involved, than an accumulation of isolated, unrelated observations.

The preceding annotated outline of the principal phases of bird study in the nesting season will be of greater value to the student if read with the nesting habits of some particular species in mind, and as a further guide to the study of nest life there is appended a summary of the more important problems confronting the local student.

Date.-What species are among the first to nest? Why? How long after its arrival does a migratory species nest? Are there any relations between the development of foliage and nesting-date? Between food and nesting-date? What appear to be the local factors governing the nestingdate? What species raise more than one brood? Do you know of any definite cases of third broods? Why are some birds single- and others doublebrooded?

Courtship.-Does the male arrive in advance of the female? Do the birds ever arrive mated? What evidences of courtship are noted? Does the male display before the female? Does the female appear to be interested? Does she select or accept a mate? Does the sexual display continue after mating? Does display precede a second brood?

Nest Enemies. - To what forms of danger are nesting birds subjected in your vicinity?

Nesting-site. - What factors influence the choice of nesting-site? Which of them are potent in your vicinity? Why do gregarious ground-builders nest on islands? What variations in site have been noted? How are they to be accounted for? With what species has civilization affected the nature of the nesting-site? Which sex selects the site? Is the same site used for the nests of second broods? or in succeeding years?

Material. - What factors govern the hird in the choies of material? What variations have been noted? What birds use artificial material, string, etc.? How is it gathered? How far from the nest? By one or both sexes? How is so-called "nest decoration" to be explained?

Nest-Building. - Is the nest made by one or both sexes? If the male does not build, does he bring material? How is the nest constructed? How much time is required for its completion? Is it delayod hy inclement weather? Is more than one nest built? If the ne'st is abandoned, state why.

The Nest. - What relation exists betwern the uest and the strueture of its builder? What eauses determine the appearance of the nest? What variations in form have been noterl? How are they to be explained? Which nests are of the most primitive kind? Which nests are most advancerl? How do new conditions change the characeter of the nest? Do birds inherit their nest-building abilities? I) second nests rescmble those built for the first brood?

The Egg.-How long after the complotion of the nest is the first eng laid? Are the egress laid at regular intervals? At certain hours? How many are laid? What factors appear to govern the number? the size? the shape? the color? What variations have been noterl? If an exge should be removed will the bird replace it". Will a ("owhird's eger be rejereted? How"?

Incubation.-When does incubation begin? How long does it continue? 
Is it performed by one or both sexes? Is there any regularity in the daily periods of sitting? Does one sex ever feed the other while on the nest? Will the sitting bird permit a near approach? Does the bird return to the nest directly or with much caution? Are the eggs turned in the nest? Are they covered when left? How is the egg-shell disposed of after hatching?

The Young Bird.-What is the condition of the young bird at birth? If blind, when do the eyes open? What notes does it utter? How long is it in the nest? How is it fed? on what? how often? Is the food prepared? What prevents the young bird from being over-fed? At what rate does it increase in weight? How is it brooded? How is the nest cleaned? Do the young obey the parent? When is fear first shown? Is it instinctive? What nest exercises are manifested? How long after leaving the nest is the young bird dependent on the parents? What induces it to leave the nest? Does it fly at once? Does it return to the nest? Does it frequent roosts? Does it flock with other young or with adults or both? How do the parents protect the young?

\title{
REFERENCES
}

(Restricted largely to the more recent studies of the nesting habits of birds.)

1844. Rennie, J., Bird Architecture (London).-1878. Allen, J. A., An Inadequate Theory of Birds' Nests, Bull. Nutt. Orn. Club, III, pp. 2232.-1900. Chapman, F. M., Bird Studies with a Camera, 12 mo., 218 pp. ills., (Appleton). - 1900. Dugmore, A. R., Bird Homes, 4to., 183 pp., ills., (Doubleday).-1902. Jов, H. K., Among the Water-Fowl, 12mo., 224 pp., ills., (Doubleday). -1905. Jов, H. K., Wild Wings, 8vo., 341 pp., ills., (Houghton, Mifflin).-1905. Herrick, F. H., Home Life of Wild Birds, rev. ed., 255 pp., ills., (Putnam's). (Important.) - 1907. FrnLey, W. L., American Birds, 12 mo., 256 pp., ills., (Scribner's).-1907. Chapman, F. M., Camps and Cruises of an Ornithologist, 8 vo., 432 pp., illus., (Appleton).-1908. Watson. J. B., The Behavior of the Noddy and Sooty Terns, Papers from Tortugas Lab. of Carn. Inst., II, pp. 189-255, (Important). -1910. Herrick, F. H., Instinct and Intelligence in Birds, Pop. Sci. Monthly, June, July, and August. - 1911. Herrick, F. H., Nests and Nest-building in Birds, Journ. of Animal Behavior, Vol I, (Holt).

\section{The Plumage of Birds}

\author{
The Molt \\ Plumage Wear \\ The Colors of Plumage \\ Color and Age \\ Color and Season \\ Color and Sex \\ Color and Climate \\ Color and Concealment \\ Banner Marks \\ Albinism and Dichromatism
}

Feathers are the only character which birds do not share with other forms of life. No other animals are feathered and no birds are featherless.

It is apart from our ohject to deseribe here the development and structure of feathers, but rather to discuss their function, as in their 


$$
\text { . }
$$




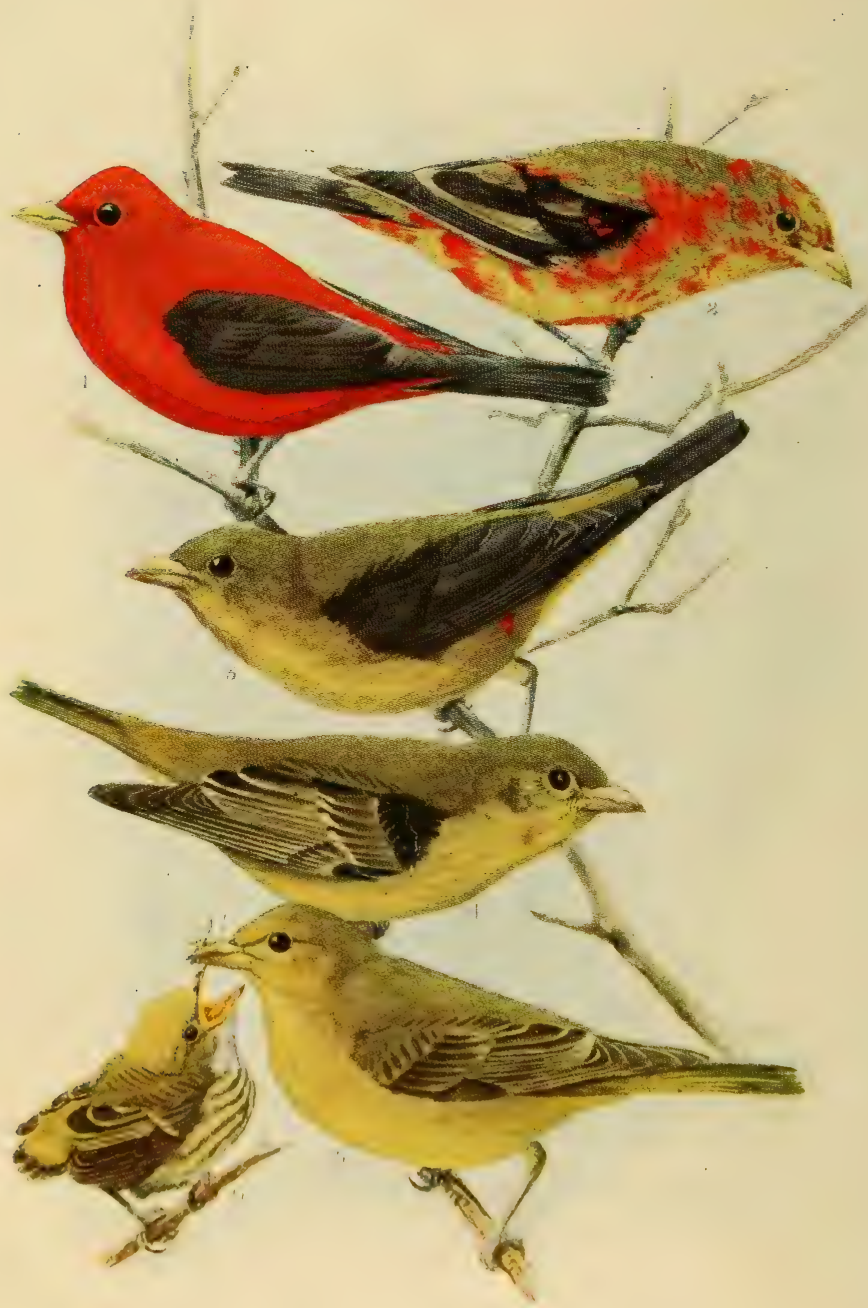

Plumages of the Scarlet Tanager

1. Adult male, summer. 2. Adult male in post-nuptial (fall) molt, by which it passes into (3) winter plumage. 4. Young male, first winter. 5. Female, which, after the post-juvenal molt, undergoes no changes in color. 6. Juvenal, or nestling plumage, which. in the male, is followed by plumage No. 4, and, in the female, by plumage No. 5 . 
form they fit the bird for locomotion (see beyond, under Uses of the Wing and Tail) or in color adapt it to the special needs of its haunts and habits. In the first place, however, the field student should have some knowledge of the laws of feather change included under the general term of molt.

The Molt.-When hatched, a Passerine bird is naked except for a scanty growth of filmy down on the feather tracts of the upper half of the body. This is the 'natal down' of Dwight ('00) whose terminology I adopt. The natal down is quickly succeeded by the 'juvenal' or nestling plumage, which is sufficiently grown in from eight to fourteen days to enable the bird to leave the nest. The tail is still only about halfgrown and the wings, as a rule, barely large enough to permit of short, uncertain flight.

Some birds (e.g. Sharp-tailed and Seaside Sparrows) wear this juvenal or nestling plumage between two and three months, but most species lose it shortly after leaving the nest. In either case, it is followed by the first winter plumage, which is acquired by molt (postjuvenal) of all the body feathers, most of those of the wings and tail usually being retained. If the young bird now resembles its parent, their plumage changes are thenceforth the same.

In the fall all birds molt, but in the spring there is no regularity as to feather renewal, even among closely related species. The Bobolink and the Sharp-tailed Sparrow have a complete spring molt (prenuptial), even to the wings and tail; the Scarlet Tanager and Goldfinch molt only the body feathers; other species acquire some new feathers about the head and chin, and with many there is no feather growth at this season, the differences between the winter and breeding plumages being due to wear or fading.

After the breeding season, all adult birds pass through a complete molt (postnuptial), and the bird is again in winier plumage.

In its simplest form, and ignoring the comparatively few cases in which an essentially adult plumage is not acquired at or before the first prenuptial (spring) molt, the molt among the Passeres may be summarized as follows: (1) Natal down, lost by postnatal molt which brings the (2) juvenal or nestling plumage; lost by postjuvenal molt which brings the (3) first winter plumage; lost to a greater or less extent in some species by prenuptial molt which brings the (t) nuptial plumage; lost by postnuptial molt which brings the (.5) second and subsequent winter plumages.

With some minor variations this is the general order of molt among other than Passerine birds. Exeept the Ducks and Ptarmigan all birds have a complete postnuptial molt, and with many Snipe the spring or prenuptial molt is complete. Some Snipe wear the juvenal plumage until winter or even until the prenuptial molt, the postjuvenal molt being omitted.

Among the præcocial Gulls, Terns, Ducks, Shore-birds and Gallinaceous birds the natal down thickly eovers the body and the chick 
swims or runs about in it shortly after hatching. In the Gallinæ the wing-quills are large enough to permit of short flights while the body of the chick is still in the downy plumage. They are lost at the succeeding postnatal molt, which is entire, new wing- and tail-feathers, as well as body feathers, being acquired.

Ptarmigan unmistakably demonstrate the need of a protective coloration by undergoing only a limited instead of complete molt at the close of the nesting season. It affects solely the upperparts and breast, or exposed surfaces, and is obviously a transition plumage, of neutral browns and grays, designed to prevent the acquisition of the wholly white winter dress until the coming of snow, at which time a complete molt follows and the bird becomes as white as its surroundings.

Male Ducks have a not dissimilar supplementary or partial postnuptial molt which is apparently also acquired for protective purposes. It affects chiefly the scapulars, head, neck and breast, and is worn only while the bird is deprived of the power of flight through the loss, in the postnuptial molt, of its wing-quills. In this 'eclipse' plumage, as it is called, the male resembles the female, but when the new wing-quills are grown and the power of flight returns, this eclipse plumage is shed and the male plumage regained. (See Plate V.)

The simultaneous loss of the flight-feathers is common to swimming birds which have a secondary means of locomotion in their natatorial powers, but with other birds the wing-quills are molted slowly and symmetrically from the middle of the wing both inwardly and outwardly. As the old feathers are lost new ones grow, and the bird can therefore fly during the whole period of feather renewal.

In other feather tracts, also, normal molt follows an orderly sequence, feather succeeding feather and plumage plumage throughout the life of the individual. The minor variations of molt within the limits above outlined for the Passeres are endless, but they can be considered adequately only by treating of each species separately. For further details the student is therefore referred to the succeeding descriptions of plumage, and pa icularly to the papers of Dwight ('00) cited beyond.

Plumage Wear.-Molt, wear and fading are the only processes by which the color of a bird's plumage is changed. The claim that a feather may be repigmented, and that eonsequently a bird's plumage may undergo radical changes in eolor without the growth of new feathers and without the aid of wear and fading, has never been substantiated, and by students of the development of the feather from germ to maturity such a change is declared to be impossible. (See, especially, Strong.)

Striking changes are, however, effected by wear, chiefly of the tips or margins. These differ in color from that of the base of the feather which is wholly or in part concealed. The loss of these margins may completely alter the bird's appearance, as where the brown Snow 


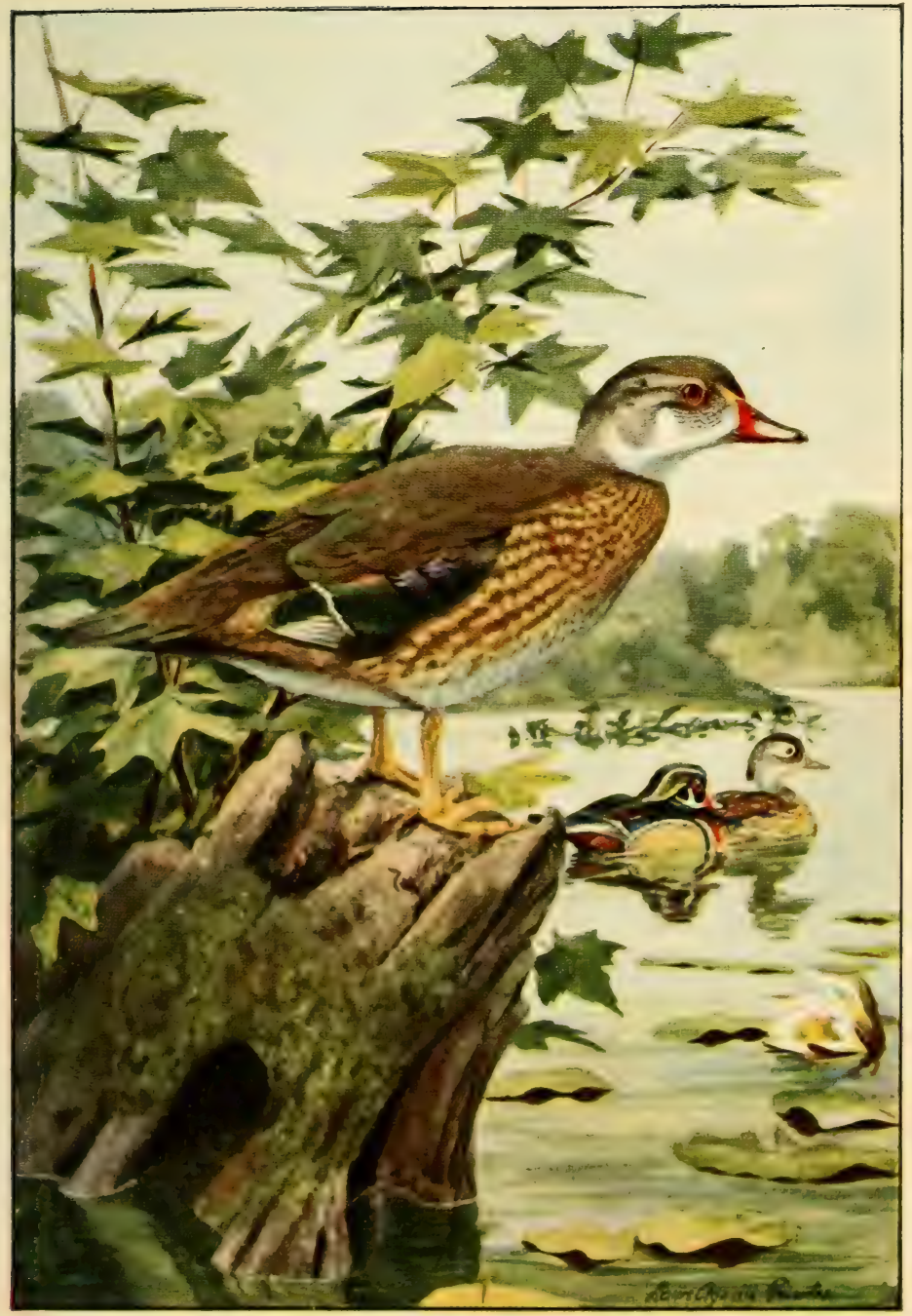

Adult Male Wood Deck in 'Eclipse' Plumage

Note the absence of primaries, indirating inability to fly. From :t specimen mollerted by E. A. Mearns, at Fort Snellitg, Minn., July 24, $18 \times 8$. 

Bunting of October is transformed to the black and white bird of June, and this without the acquisition of a feather. (Fig. 10.) The Bobolink, Red-winged and Rusty Blackbirds also illustrate color change by wear.

With the Purple Finch and Indigo Bunting, as Dwight ('00) has shown, wear increases the brightness of the bird's colors.

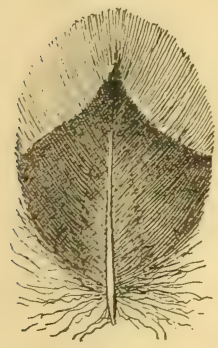

October

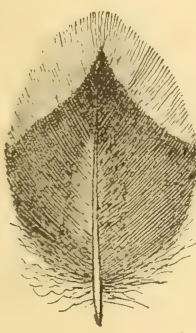

January

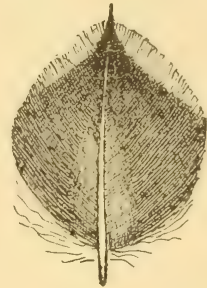

March

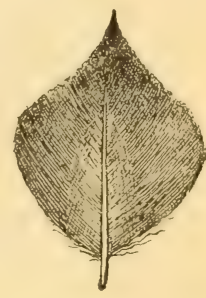

June

FIG. 10. Feathers from back of Snow Bunting, showing seasonal changes in form and color due to wearing off of tips. (Natural size.)

The Colors of Plumage.-Color is nature's last touch in adapting a bird to the needs of its own special environment. In many instances it apparently has been given during the prevalence of existing conditions of haunt and habit; consequently, in studying color, there is a greater possibility of associating cause and effect than exists when we attempt to determine the origin of the older, more stable characters of form. One, therefore, may reasonably ask what is the significance of the manifold shades and tints, marks and patterns, not to mention various appendages found in the plumage of birds? But before a reply is justified, the bird must be studied in nature, its food, its foes, its general habits and special actions learned; and at all times the student should avoid the human viewpoint, but imagine himself in the position of food or foe, an individual of the same species or one of a species with which the bird under consideration may come in contact.

It is not to be expected that any color character should invariably achieve its end; if it does so more than half the time, it will in the aggregate prove beneficial to the species. (See A. H. Thayer, "Concealing Coloration," p. 8.)

In the study of color, there is a wide field for laboratory experiment on captive birds to determine the laws of molt, the effects of food, humidity, hybridizing, artificial selection, ete., into which it is not possible to enter here. (See Beebe, '08.)

Color and Age.-Most passerine birds acquire an essentially adult plumage not later than their first prenuptial (spring) molt. Prominent exceptions are the Orchard Oriole, Crossbills and Redstart, which breed 
in a plumage more like that of the female than of the adult male and acquire their mature plumages at the first postnuptial (fall) molt.

Less striking instances of failure to acquire a fully adult plumage at the first spring molt are shown by birds like the Scarlet Tanager, which at its first prenuptial molt retains most if not all the brownish wingquills and some of their coverts of its first winter plumage, the black wing-quills of maturity not appearing until the first postnuptial molt; or the American Goldfinch, which does not gain the yellow shoulder patch until after the first breeding season. (Plate IV.)

When the adults of both sexes are alike in color, the young in juvenal plumage more or less closely resembles them (e.g. Flycatchers, Jays, Crows, most Sparrows, Chickadees, Thrushes); when the male differs from the female, the young in juvenal plumage more nearly resembles its mother (e.g. Red-winged Blackbirds, Orioles, Purple Finches, Goldfinches, Hooded Warblers, Redstarts). (Plate VI.)

The juvenal plumage often gives interesting clues to relationships and ancestry. The nestlings of the Blackpoll and Bay-breasted Warblers, for instance, are almost indistinguishable, as are indeed the first winter costume of these species; while the spotted breasts of nestling Robins and Bluebirds betray their relationship with the Thrushes.

Color and Season.-Dull or inconspicuously colored birds, having once acquired the plumage of maturity, exchange it only for another of the same kind at their respective molts; but birds of striking colors frequently change their bright breeding costume for one less likely to expose them to danger while migrating. The male Scarlet Tanager, for instance, at the postnuptial molt takes the olive-green body plumage of his mate, only the black wings and tail coming in the same color as before. At the same molt, the male Bobolink assumes a plumage practically indistinguishable from that of his mate. With both birds this dull plumage is worn until the prenuptial molt the following spring. Other examples are the American Goldfinch, Bay-breasted, Blackpoll, and Myrtle Warblers. (Plates IV, XX.)

Among Gallinaceous birds the Ptarmigan alone have marked seasonal changes in plumage, but in the Shore-birds, Gulls, Terns, and Grebes, they are more or less pronounced.

Here should be mentioned the various appendages like the plumes of the Night Heron and Egrets, and crests or other head decorations in the White Pelican and Grebe, which are usually acquired at the prenuptial molt and are worn only during the nesting season.

Color and Sex.-When there is a sexual difference in color among hirds, with few exceptions the male is the brighter. In North America the exceptions are the three species of Phalaropes. No conclusive reason why the male should be brighter than the female has been advaneed. Darwin's theory of sexual selection endows the female with an esthetic sense, making the most brightly plumed male more acceptable in her eyes than his less effectively attired rivals. No one who has watched a bird display its charms before the female (and this is done 


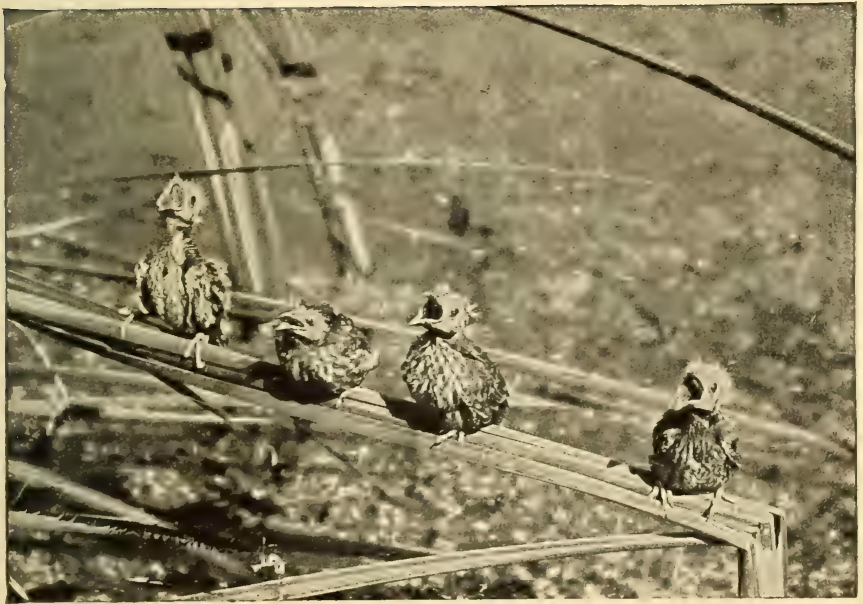

Red-winged Blackbirds in Juvenal Plumage

Illustrating the law that when the adults differ in color the young of both sexes ' usually resemble the female.
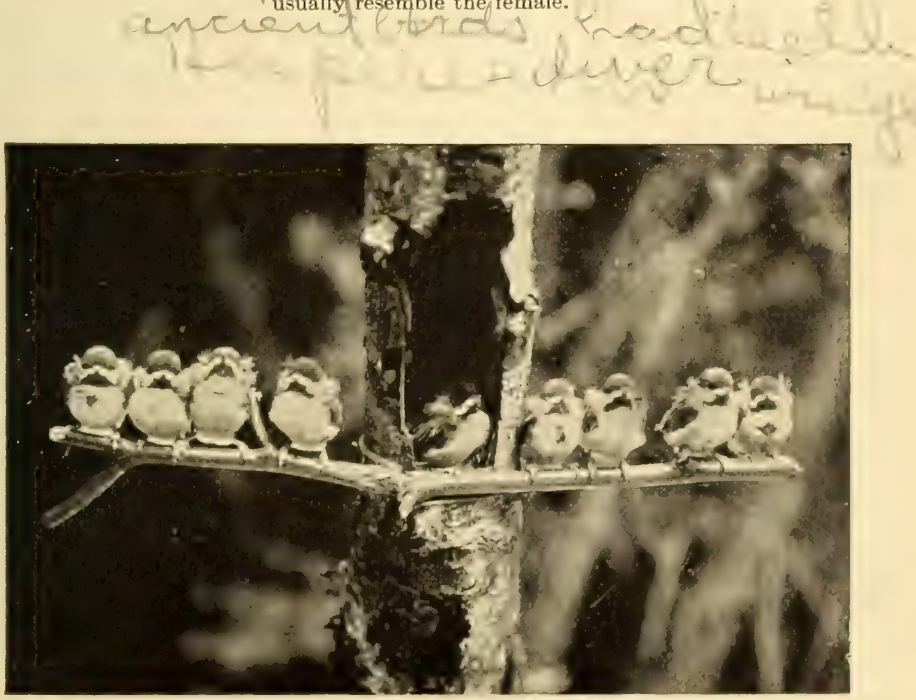

Chickadees in Juvenal Pudmage

Illustrating the law that when the adults are alike the young resemble them. 

more commonly than is generally supposed, and by species which do not possess pronounced sexual characters of color or plume), will doubt the ardor or objects of the suitor; but it seems probable that the effect of such display is to stimulate the female to the point of accepting rather than of selecting a mate. It should not be forgotten, however, that if this theory be true the male which breeds in immature plumage (e. g. Orchard Oriole; Redstart) is placed at a distinct disadvantage.

Wallace ('91) attributes gay colors and showy plumes to the action of the surplus vital energy which, because of a bird's perfect adaptation to its environment, can expend itself in the production of brilliant colors and ornamental appendages without endangering their owner; but in this connection we should recall that when, as with the Phalaropes, the male plays the part of the female, incubating unaided by her, then it is the female that wears the brighter colors.

Thayer, without positively committing himself on the subject of sexual coloration, contends that, whaterer be the minor uses of the distinctively male costumes, their main function is for the purposes of concealment; but it is difficult to believe that the male of the Redwinged Blackbird, Bobolink, Scarlet Tanager or Lark Bunting, for example, is as protectively colored as his dull-plumaged mate, which lives in the same environment. If, however, his brighter colors increase his chances of death, there must be born a greater number of males than females, to offset the higher mortality.

Again, it has been suggested that it is only the female's plumage which has an especial significance, the task of incubation requiring in her a concealing coloration which will protect the contents of the nest as well as herself. The whole subject is as attractive as it is difficult. It should be studied in connection with other secondary sexual characters of which a synopsis from "Bird-Life" is appended:

\section{Synopsis of the Secondary Sexual Characters of Birds}

\section{StructURAL}

Size $\ldots \ldots\left\{\begin{array}{l}\text { Male larger than female (usual). } \\ \text { Female larger than male (rare). }\end{array}\right.$

Plumage ... $\left\{\begin{array}{l}\text { Color }\left\{\begin{array}{l}\text { Male brighter than female. } \\ \text { Female brienter than male (rare). }\end{array}\right. \\ \text { Form. }\left\{\begin{array}{l}\text { Assumption of plumes, ruffs, erests, trains, etc.; } \\ \text { special modification of wing- and tail-feathers. } \\ \text { a. Worn by male alone. } \\ \text { b. Worn by both sexes. }\end{array}\right.\end{array}\right.$ Of the body. $\left\{\begin{array}{c}\text { Sole or greater development in male of brightly colored } \\ \text { bare tracts of shin, combs, wattles, caruncles, and other } \\ \text { fleshy or horny appendages. }\end{array}\right.$

Of the feet.. . Sole or greater development in male of spurs.

Of the bill. ...Male with more highly colored or larger bill than female. 


\section{Functional}

Pursuit ... $\{$ By male when similar to or brighter than female.

. By female when brighter than male.

Display .......By male of accessory plumes and other appendages.

Battle ......By male using spurs, wings, bill, etc.

Music ..... \{ Vocal, by male and rarely female.

Mechanical, by male and sometimes female.

(Dances, mock fights, aërial evolutions, construction of Special $\left\{\begin{array}{l}\text { bowers, decoration of play-grounds, attitudinizing, strut- } \\ \text { ting, etc. }\end{array}\right.$ habits ....

a. By male before the female.

b. Among the males alone.

Color and Climate.-The immediate effect of climate on a bird's plumage is to increase or decrease its general tone of color; thus, those representatives of a species living in arid regions are paler than representatives of the same species living in humid regions. The degree of difference is closely related to the annual rainfall, as it indicates relative humidity; and where there are no abrupt changes in climate, these climatic variations change as gradually as the conditions which cause them. At first so slight that only the expert systematic ornithologist, with access to large series of specimens, can detect them, they become, in some instances, so pronounced that not only the general tone of color but pattern itself is affected. It is on such variations that most subspecies or geographical races of birds are based. (See Allen, '77.)

Among North American birds, they are best illustrated by the oftcited case of the Song Sparrow. (See Diagram A and Plate VII.) Twentythree races of this exceedingly plastic species are recognized. They are distributed from the Valley of Mexico northward throughout the United States and a large part of Canada to the Aleutian Islands. Note, however, that only two of them are found east of the Rocky Mountains, where climatic conditions are comparatively uniform; while California alone has ten resident races, an indication of its great diversity of climate.

The Desert Song Sparrow (Diagram A. 8; Plate VII) the palest race, inhabits the Colorado desert region where the average rainfall is about six inches; the Sooty Song Sparrow (Diagram A. 19; Plate VII) the darkest race, is found on the northwest Pacific Coast where the annual rainfall averages over ninety inches.

Again, observe that the Mexican Song Sparrow (Diagram A. 1) at the southern extremity of the range of the species is one of the smallest races, measuring some six inches in length, and that there is a gradual increase in size northward until the maximum is reached at the northern extremity of the range of the species, where the Aleutian Song Sparrow (Diagram A. 23; Plate VII) attains a length of nearly nine inches. 


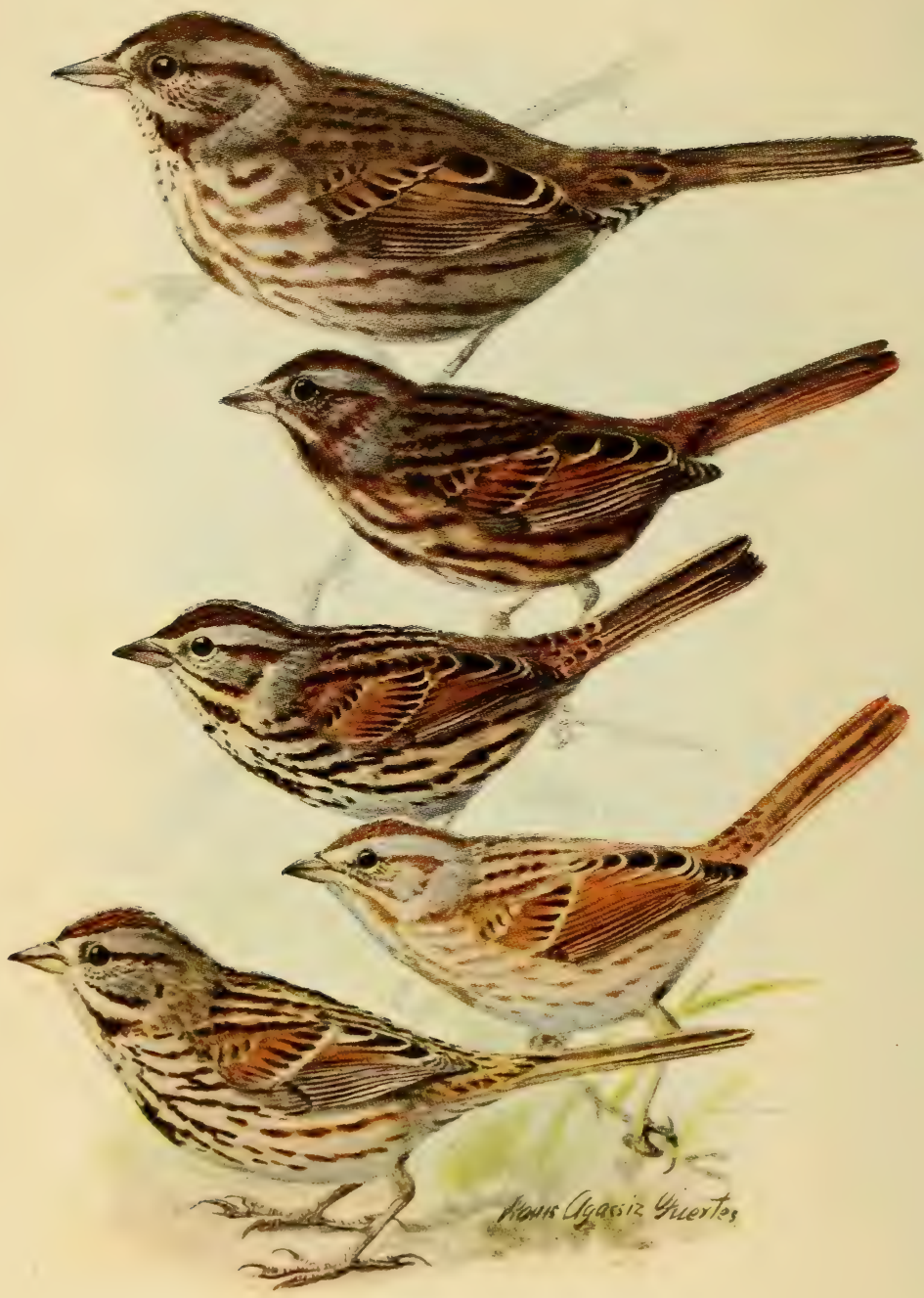

Song Sparrows

1. Aleutian Song Sparrow. 2. Sooty Song Sparrow.
3. Samuels's Song Sparrow.

4. Desert Song Sparrow. 


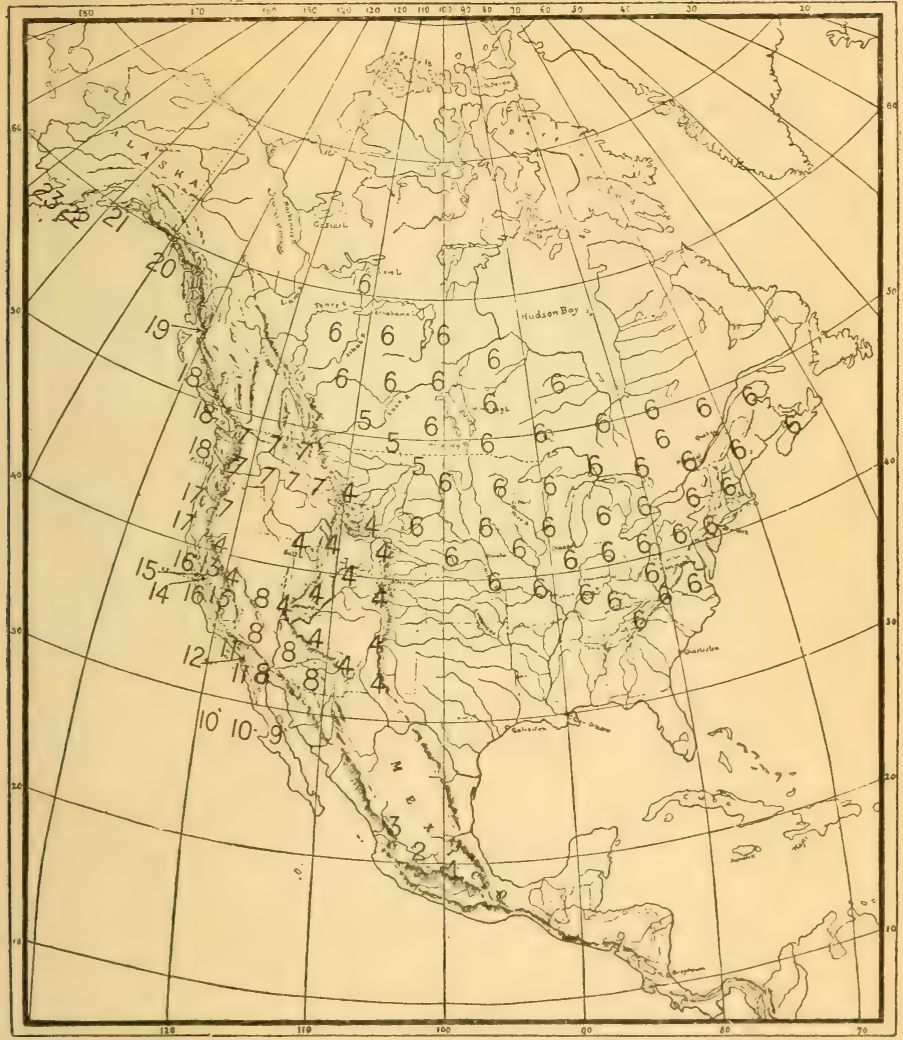

\section{DIAGRAM A. ILLUSTRATING THE DISTRIBUTION OF SONG SPARROWS.}

1. Mexican Song Sparrow.

2. Michoacan Song Sparrow.

3. Durango Song Sparrow.

4. Mountain Song Sparrow.

5. Dakota Song Sparrow.

6. Eastern Song Sparrow.

7. Merrill's Song Sparrow.

8. Desert Song Sparrow.

9. Brown's Song Sparrow.

10. San Clemente Song Sparrow.

11. Santa Barbara Song Sparrow.

12. Cooper's Song Sparrow.
13. Herrmann's Song Sparrow.

14. Alameda Song Sparrow.

15. Suisun Song Sparrow.

16. Samuel's Song Sparrow.

17. Mendocino Song Sparrow.

18. Rusty Song Sparrow.

19. Sooty Song Sparrow.

20. Yakutat Song Sparrow.

21. Kenai Song Sparrow.

22. Bischoff's Song Sparrow.

23. Aleutian Song Sparrow. 
If we compared only the palest Song Sparrow with the darkest, we might well believe, so unlike are they, that each form represents a distinct species; but when we include in our comparison representatives of all the twenty-three races of Song Sparrows we find complete intergradation in color and in size. Nowhere can one draw the line. As the climatic conditions under which the birds live change, the birds keep pace. Cause and effect go hand in hand. Here we have a species in flower, as it were, a single Song Sparrow stalk with its twenty-three blossoms, any one of which might make an independent growth as a species it if were separated from the parent stem. Doubtless some day the separation will come, when we shall have several species of Song Sparrow, each with its group of races, but at present we have only one species, divided into some twenty-three sub-species, or species in process of formation.

A variety of reasons may be advanced to account for the pronounced geographical variations shown by the Song Sparrow. Its wide range indicates physical adaptability and ready adjustment to differences in food and habitat. Its variations in size, while they conform to the general law of increase in size northward, are exceptionally marked, and are not equalled by those of any other North American bird-a further indication of an inherent plasticity.

The species is comparatively non-migratory. Several races, notably in California, are permanently resident in contiguous and restricted areas. Such strictly non-migratory species are continuously subjected to the influences of their environment, which are heightened by permanent isolation. But even the most migratory forms come early and stay late, and are thus in the breeding area for a much greater part of the year than, for example, many Warblers which come in May and leave in August.

But, suggest as we may the various factors which appear to be active in producing such geographic variations as the Song Sparrows exhibit, they are not potent with all birds, even when other things are equal, and it seems probable that some species are in an active state of development and readily respond to the influences of their surroundings, while others are fixed and make no such response. The latter represent older types of birds, which are, so to speak, near to or a part of the trunk of the bird's family tree, while the former class includes the birds at the terminal branches of this tree.

Color and Concealment.- - It is clear that the life of the individual bird, and hence the continued existence of its species, depends primarily on its success in securing food and in escaping from its foes. The colors of predaceous species must, therefore, tend to conceal them from their prey (aggressive or deceptive colors), while the colors of those that are preyed on are designed to conceal them from their enemies (protective colors).

When, however, a bird's food may be secured without the exercise of caution, when it apparently is not preyed upon, or when it is protected 
by the character of its haunts, its colors, unchecked by any need for concealment, may make it conspicuous.*

Inconspicuousness is achieved primarily, not alone in birds but also in most other animals, by that disposition of color which makes them darkest where they receive the most light, and palest where they are most in shadow. This is the far-reaching principle of countershading discovered by Abbott $\mathrm{H}$. Thayer and announced by him in 1896 (The Auk, 1896, pp. 124,318). Of it Poulton remarks: "For ages the artist has known how to produce the appearance of solid objects standing out on his canvas, by painting in the likeness of the shadows. It has remained for this great artist-naturalist to realize the logical antithesis, and show how solid objects may be made to fade away and become ghost-like, or even invisible, by painting out the shadows."

Thayer's experiments in conclusive demonstration of this law may be repeated, even if crudely, by taking, say, four bits of wood shaped to resemble a bird's body, or, failing these, several symmetrical potatoes of about the same size. Run a stout wire rod through these objects, leaving intervals of about eight or ten inches and, selecting a spot not in direct sunlight, support the rod at both ends, on uprights which will raise it six or eight inches from the ground. The models should be uniformly colored to resemble the earth against which they are seen, and the resemblance may be heightened by sprinkling some of the earth upon them.

If the secret of protective coloration is an exact likeness in color between an animal and its background, these models should be essentially invisible, whereas they are exceedingly conspicuous. Now, in imitation of nature, paint out the shadow on the lower half of two of the models by grading through earth color laterally, to pure white on the lower median line, when it will be seen that at a distance of thirty feet or more these white-bottomed models have, in a magical manner, become nearly if not quite invisible, although they are still the same color on the upper half as the untouched models, which are plainly visible at a distance of at least forty or fifty yards.

To prove that this result is due to the disposition of color, as regards light and shade, rather than to color alone, turn the models so that the white is uppermost, thus reversing nature's law, and thereby rendering the two models which before were indistinguishable even more prominent than those which are uniformly colored.

Such, in briefest outline, is an explanation of Thayer's law of counter-shading, for a fuller description of which, as well as of its various modifications, the student is referred to Thayer's work on "Concealing Coloration." Thayer's law of obliterative markings is also presented in this book. This explains the pattern of eoloration or markings of counter-shaded birds which bear on their plumage a picture of the background against which they are most commonly seen by their

*In this connection see Reighard on the colors of coral-reef fishes. Papers from Tortugas Lab. of Carn. Inst. Wash., 1908, pp. 261-325. 
prey or by their enemies. Or, as Gerald Thayer puts it: the object's "obliteratively-shaded surface must bear a picture of such background as would be seen through it, if it were transparent." (l.c. p. 31.) Thus our Woodcock is said to bear a picture of "dead leaves, twigs and grasses, variously disposed over shadow-holes," while the plumage of Wilson's Snipe represents "sticks, grasses, etc., with their shadows at various distances." The plumage of the Upland Plover shows a "grass" pattern, a type common to many field or upland species. Certain of the Plover and Sandpipers wear this plumage during the summer, when they live among weeds and grasses, but lose it for one of pure and simple counter-shading when they winter along the shores and beaches.

From these more obvious instances of obliterative picture patterns, Thayer leads us to an interpretation of the brilliantly colored and intricately marked plumage of birds like the male Wood Duck, Peacock, and Paradise Bird (Paradisea), or of such special markings and appendages as the speculum in Ducks, gorget in Hummingbirds, tail-coverts in the Resplendent Trogon, etc., all of which, under certain vital conditions, are considered by him to make or to aid in making their wearers inconspicuous. The use of no pattern, mark or appendage is left unexplained by the proposer of this law, and while naturalists recognize the importance of his studies, Thayer's contention "that patterns and utmost contrasts of color (not to speak of appendages) of animals make wholly for their 'obliteration,' " finds few supporters.

Flamingoes, Crows, Ravens and Turkey Vultures, for example, are seemingly from any point of view conspicuous. The nature of their food and their excessive wariness or absence of foes apparently remove them from the action of the laws producing a true concealing coloration.

Protected primarily by the character of their haunts, it is not improbable that the striking and endlessly varied colors of Tanagers, Honey Creepers, Cotingas, Toucans, Trogons, Parrots and other brilliantly marked arboreal birds may be explained in a similar manner. It is important to remember in this connection that many birds of such habits are dull as well as brightly colored, and we may suggest that among tree-haunting, and to a less extent thicket-haunting birds, the actual physical causes of color, uncontrolled by natural selection, have run riot. When, however, the nature of a bird's haunts affords it less adequate means of concealment, then color plays a more important part in protecting it, and there is consequently less variation from the type of color which presumably has proved to have the highest concealing value.

Thrushes, Ovenbirds and Doves, for example, which feed on the ground, may frequent the tree-tops without unduly exposing themselves to danger, but let a male Scarlet Tanager or other brightly-colored arboreal bird alight upon the ground and, even when motionless, it is conspicuous.

This illustration may serve also to remind us that the protective 



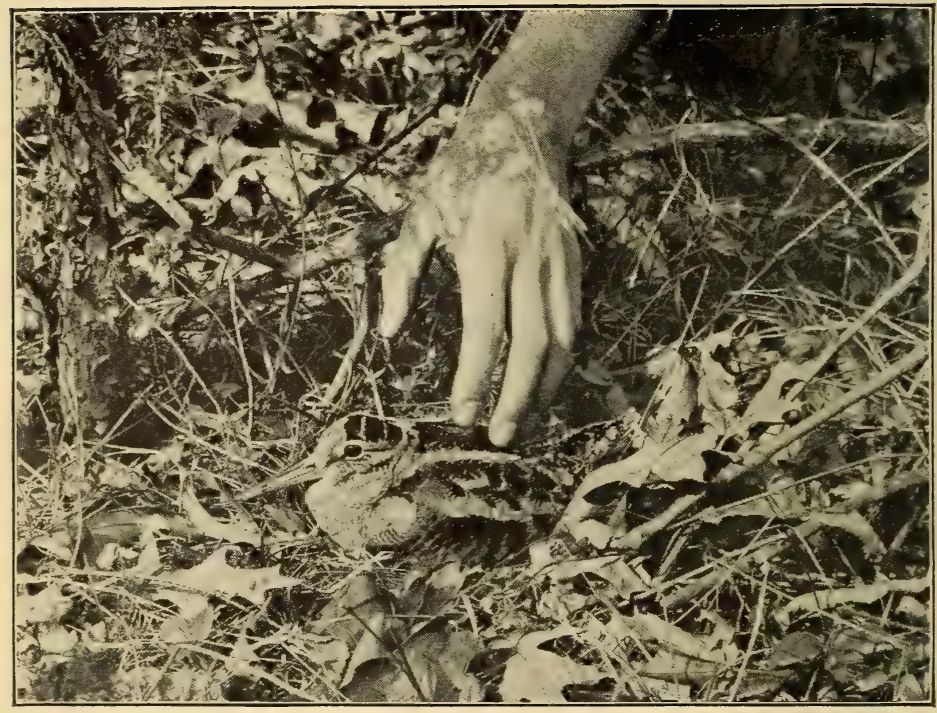

\section{WOODCOCK ON NEST}

A protectively colored bird which, relying on its color to escape detection, may sometimes be touched before it takes wing.

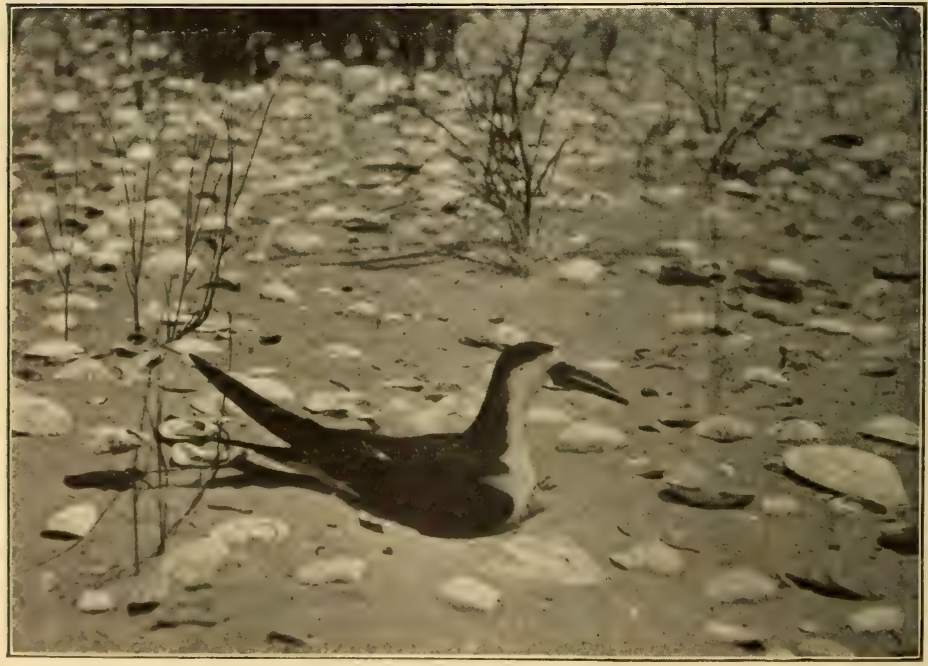

Black Skimmer on Nest

A conspicuously colored bird which is so shy that it leaves its nest at the first indication of danger. 
value of any color scheme or pattern of marking is active only when the animal bearing it is at rest. Without regard to color, movement at once reveals, and bearing this in mind, the action of a bird in the presence of danger is a supreme test of the protective or non-protective value of its colors.

If the bird is wary and can be approached only with difficulty, we may feel assured that it realizes its conspicuousness and consequently it relies for safety on its watchfulness and its wings. But if the bird attempts to hide and flies only when convinced that it has been discovered, then we may believe that it relies primarily on the nature of its coloring to escape observation, when we are evidently justified in assuming that its colors are truly protective. Compare the colors and actions of such 'wild' birds as Gulls, Terns, Skimmers, Ducks, Geese, Cormorants, Cranes, Herons, Flamingoes, Stilts, Avocets, and Crows, with those of birds which take wing only to avoid being stepped on (e. g. Bitterns, Rails, Woodcock, Wilson Snipe, Quails, Grouse, Whippoor-wills) to appreciate how closely color is here correlated with habit.

Compare further the colors and habits of the flightless young of Gulls, Terns, Skimmers, Stilts or Avocets with those of their parents to observe how there may be both a protective and a conspicuous plumage in the same species. Enter the breeding resorts of any of these birds and the conspicuously colored adults at once take wing while the protectively colored young, squatting motionless, make no attempt to escape, even by running, until they are actually touched.

Obviously, then, the significance of the colors of birds is to be learned only by the study of species by species in nature. The whole subject is preëminently within the domain of the field naturalist. Only when our knowledge of a bird's haunts and habits, its food and foes, and its actions in the presence of danger is reasonably complete are we in a position to determine to what factors we may attribute its particular colors and markings. This is the ground taken by Theodore "oosevelt in his extended criticism ('11) of Abbott Thayer's theories, and while one may argue that Mr. Roosevelt underrates the necessity of concealing coloration in animals, one must commend his admirable plea for the accumulation of further evidence from nature before giving a verdict.

Banner Marks. - The plumage of many birds contains marks which are usually conspicuous only when the bird is in motion. White outer tail-feathers (e.g. Junco, Vesper Sparrow, Meadowlark), or wingpatches (e.g. Mockinghird), or a white rump (e.g. Flicker), are markings of this type and to them the term 'banner', 'recognition' or 'directive' marks have been applied.

Some authors would have us believe that such flight-revealed markings have a directive value which assists birds of the same species in keeping together (see Tracy, '10) but the ease with which dull-eyed man learns to recognize birds, even at a great distance, makes it difficult to believe that birds require some conspicuous mark to distinguish others of their own kind, as Abbott Thayer has well shown (The Auk, 
1900, p. 108). On the other hand, there seems better ground for belief in the theory, advanced by Dr. C. Hart Merriam, that these so-called banner marks protect their possessors by being so strikingly evident when their wearers are in flight that their sudden and complete effacement when the creature takes to cover, tends to puzzle the pursuer, which, looking in vain for a victim conspicuously marked with white, soon abandons the chase.

The subject is a fascinating one and is to be especially commended to field students, who alone can supply the data on which a solution of the problems involved can be based.

Albinism.-Albinism is not infrequent among birds and may occur in any species. I have seen a white Crow and a white Turkey Vulture. It is, however, rarely complete but more frequently affects a part of the plumage, when it is usually symmetrical, that is, if a feather in one wing be white the corresponding feather in the other wing will also be white.

The presence of an albino bird always excites interest. When, because of its markings, the history of the individual may be learned, and possibly its return to a certain locality noted year after year, albinism permits of the making of observations of real value. But albinism in itself is a matter calling for no special record or comment. It is due to an absence of pigment in the part affected and may indicate a more or less degenerate condition in the individual exhibiting it. Albinistic English Sparrows are not uncommon, a fact which may be due to the abundance of the species and ease with which it is observed, or to excessive inbreeding among a comparatively limited number of very local individuals.

Melanism, or undue blackness, implies an excess of pigment, while xanthochroism and erythrism are terms applied respectively to abnormally yellow or red birds. These three phases of color are, as a rule, shown only in caged-birds and are then evidently due to unnatural diet or other conditions. (See Beebe, '07.)

Dichromatism.-Dichromatism implies the existence of two phases of color in the same species. It is well illustrated by our Screech Owl, some individuals of which are gray and others rufous. (See frontispiece.) This difference in color is not dependent upon age, sex or season; indeed, gray and rufous birds may be found in the same family. It appears, however, to be connected with locality, since a species may be dichromatic in one part of its range and less so or not at all in another part of its range. The rufous phase of the Screech Owl, for example, is rare in Florida, just as the black phase of the gray squirrel is rare in Florida. Beyond this relation between dichromatism and locality its causes are not understood.

\section{Suggestions for the Student}

The processes of molt and feather-growth may be studied in captive hirds provided they be kept under proper conditions. Change in conditions may advance or retard molt. (See Beebe, '08.) 
Describe condition of a Passerine bird at birth and its subsequent plumages and molts. About how long is it in the nest? How long does it wear the juvenal plumage? What plumage follows? What feathers are usually retained at the postjurenal molt? When does the prenuptial molt occur? Is it usually complete? What molt is complete? How does the natal down of præcocial birds differ from that of altricial birds? How long do some Snipe wear the postjuvenal plumage? What variation in the law of molt is shown by Ptarmigan and most swimming birds? Describe changes in color due to wear or fading. Give illustrations of the acquisition by molt of nuptial plumes. Describe differences in color due to age. When do most birds acquire their mature plumage? Mention several species which do not reach full plumage until at least their second year. Describe the plumage changes of the Scarlet Tanager, American Goldfinch, and Bobolink. When the adults are unlike in color, which is usually the brighter? Which parent does the nestling usually resemble? What may be inferred from the spotted juvenal plumage of the Bluebird? What is Darwin's theory of sexual selection? What is Wallace's theory? Describe what is meant by secondary sexual characters and give cases in illustration. What relations exist between the degree of intensity of a bird's color and the climatic conditions under which it lives? Describe the case of the Song Sparrows. Is it believed that their changes in color are due to the direct influence of environment rather than to the influence of natural selection in establishing protective colors? Why are concealing colors necessary? To what factors other than color may a bird owe its comparative immunity from its foes? Are they required by all species? How may we account for the wide range of color in arboreal birds? What is Thayer's principle of counter-shading? Demonstrate this theory with the aid of decoys. What are 'obliterative' markings? What are 'banner' or 'directive' marks? What theories have been advanced to account for their significance? Mention all the birds you know which reveal white marks in flight. What is allinism? melanism? xanthrochroism? erythrism? Describe an albino which you have seen. Dirl it act like normally colored birds of its own species? What may be learnerd from observing albinoes or other birds so marked that they may be recognized? Have you ever known a caged-bird to change in color?

\section{References}

1871. Darwin, C., The Descent of Man, Chaps. XIII-XVI.-1877. Alzen, J. A., The Influence of Physical Conditions on the Genesis of Specie's, Radical Review, I, pp. 108-140. Reprinted in Smithsonian Rep. 1905, pp. 375-402.-1891. Wallace, A. R., Darwinism, Chaps. VIII-XI, (Macmillan).-1890. Poulton, E. B., The Colours of Animals, (Appleton).-1893. Newton and Gadow, Colors of Birds, in Dictionary of Birds, (Macmillan). -1896. Stone, W., The Molting of Birds, Proc. Acad. Nat. Sci., Phila., pp. 108-167.-1900. Dwight, J., JR., Sequence of Plumages and Moults of the Passerine Birds of New York, Annals, A cad. S'ci., XIII, pp. 7:3-360). See also Auk, XVII, pp. 34, 143, 368.-1907. Befrise, ('. W., Generraphic Variation in Birds with Especial Reference to the Eiffects of Humidity, Zoölogiea, I, pp. 1-41.-1908. BeEre, C. W., Scasonal ('hanges of ("olor in Birds, Am. Nat., XLII, pp. 34-38.-1909. ThAYER, G. H., Concealing ('oloration in the Animal Kingdom, 4to., 260 pu., ills., (Macmillan).-1910. Trac'Y, H. C., Significance of White Markings in Birds of the ()rder Passeriformes, Univ. Cal. Pub. in Zoöl., VI, pp. 285-312.-1910. Pyстағт, W. P., A IIstory of Birds, (London: Methuen \& (o.).-1911. Barrot:ar, T., and PhitLIPS, J. C., Concealing Coloration Again, Auk, XXVIII, 179-188.-1911. Thayer, A. H., Concealing Coloration, Pop. Ści. Monthly, July, pp). 20-35. -1911. Roosevelt, Theodore, Revealing and Concealing Coloration in Birds and Mammals, Bull. Am. Mus. Nat. His., XXX, pp. 119-2'31. 


\title{
The Food of Birds
}

\author{
Food and Distribution \\ Food and Habit \\ Economic Value of Birds \\ Birds and Insects \\ Birds and Weeds \\ Birds and Rodents \\ Birds as Scavengers
}

Food and Distribution.-Birds consume a large amount of food and they rarely store it. No one factor, therefore, exercises a greater or more constant influence on their activities than the ever-present necessity of securing a sufficient amount of the proper kind of nourishment.

Not only are a bird's daily movements more or less governed by the search for food, with pronounced local variations in numbers, due to the ripening of fruits, unusual abundance of insects, supply of carrion, etc., but the presence or absence of the species during certain seasons may depend directly on the abundance or scarcity of a certain kind of food. Given bayberries, and one may expect Myrtle Warblers to winter in numbers near New York City; buckwheat in a pile of chaff induced a flock of Mourning Doves to pass the winter at Englewood, N. J.; the failure of the coniferous seed crop is evidently the reason for the irregular occurrence of great numbers of Crossbills south of their usual winter range, to cite only a few of the innumerable instances showing how both the local and general movements of birds are influenced by the food-supply.

Food and Habit.-From the Swifts, coursing the sky almost beyond the reach of vision, to the Diver beneath the waters, birds neglect no spot containing food. The result is not only great diversity of fare, but a correspondingly wide range in the methods, or feeding habits, by which it is secured. (See under Uses of the Bill and Feet.)

Economic Value of Birds.-Interesting as we shall find the study of a bird's food in relation to its distribution and habits, it is of even greater importance for us to learn in what way or ways the nature of its food determines its economic relations to man.

In no branch of American ornithology has greater advance been made, during the past twenty years, than in the study of the value of birds to man based on a knowledge of their food. This is due chiefly to the investigations of the Biological Survey of the United States Department of $\Lambda$ griculture, and also to the researches conducted by certain states, notably Massachusetts, New Hampshire, and Pennsylvania. The subject is too wide and too important to be treated adequately here and the student is referred to the many valuable papers listed beyond, particularly to those issued by the Department of Agriculture (many of which can be secured from the Superintendent of Documents at Washington) and to Forbush's "Useful Birds." 
The nature of a bird's food can be determined by observing what it eats and by an examination of what it has eaten. It is, of course, often impossible to see just what a bird is eating or, even having seen, one still may not recognize the particular kind of insect, fruit or seed which has been swallowed. Expert analysis of the contents of the digestive tract is therefore essential to an accurate knowledge of the character of a bird's food. The conclusions drawn from laboratory work should, however, be checked by studies in nature, to which the field ornithologist may make valuable contributions.

Looking from my window as I write, I see five Starlings (Sturnus) running actively about the lawn beneath a cherry tree, picking up fallen fruit. An examination of the contents of their stomachs would unquestionably reveal the presence of cherries, but I see this groundfeeder gather fallen cherries far more frequently than growing ones, and stomach analysis alone might, therefore, in a case of this kind, lead to a false estimate of a bird's destructiveness. (On the study of food habits in the field, see especially Forbush's "Useful Birds.")

Equally true is it that verdicts based only on casual observations of the bird in nature are far from the truth; and it is this kind of hasty conclusion that the economic ornithologist finds the greatest difficulty in combating. A Cooper's Hawk may be seen to catch a chicken or scatter a flock of Bob-whites; Robins may be noted in the cherry trees or Catbirds in the strawberry bed, and without further evidence all Hawks are declared to be destroyers of poultry and game, and small birds generally devourers of fruit. But thanks to the investigations made by federal and state governments, as already mentioned, we are now in possession of accurate, incontrovertible data, and there is no excuse for signing a bird's death warrant on false or insufficient observation. It has thus been determined that birds are of inestimalle value to man (1) by eating harmful insects, their eggs and larra; (2) by destroying the seeds of noxious weeds; (3) by devouring field mice and other small mammals which injure crops; and (4) by acting as scavengers.

Birds and Insects.-Dr. L. C. Marlatt, of the United States Department of Agriculture, estimates that in the year 1904t the loss to our agricultural interests occasioned by insects amounted to $\$ 795,000$,000 (Yearbook, U. S. Dept. Agr., 1904, p. 46.4). Dr. A. D. Hopkins, also of the Department of Agriculture, estimates that insects cause an annual loss to our forestry and timber interests of $\$ 100,000,000$. It is difficult for us to comprehend fully the significance of these figures, but at least they may serve to impress us with the value of any form of life which in turn preys upon insects, and in the front rank of insect enemies stand the birds.

It is possible here only to give referenees (see beyond) to the now extensive literature containing exact statistics of this battle of the birds and the bugs. In these papers, for example, it will be found stated that the stomach of a single Cedar Waxwing contained 100 canker worms, 
that one Cuckoo had eaten 250 caterpillars, that 454 plant-lice were found in the stomach of one Chickadee, that a Nighthawk had made a meal on 60 grasshoppers, that a Flicker had devoured 1,000 chinch bugs, that a Scarlet Tanager was seen to eat 630 gypsy moth caterpillars in eighteen minutes, or at the rate of 2,100 an hour; while a Maryland Yellow-throat ate 3,500 plant-lice in forty minutes, or at the rate of 5,270 an hour!

As the destroyers of insects that breed disease, birds stand in an even closer economic relation to man. Five hundred mosquitos, for example, were found in the stomach of a single Nighthawk; Swallows and other wing-feeding birds also feed upon this pest, which, in the larval form, is eaten by various marsh-inhabiting birds. It is probable, therefore, that as our knowledge of the history of various diseases to which man is subject through insect attack increases, birds will here be found to be correspondingly valuable.

In spite of the immense amount of authoritative data, of which we are now in possession, we are far from beginning to realize the profoundly important part played by insectivorous birds in holding in check the insects injurious to vegetation and to man. We may, however, accept without question the opinion of Henry W. Henshaw, Chief of the Biological Survey, who states as his conviction that without the services of insect-eating birds "it is more than likely-nay, it is almost certainthat within a limited time not only would successful agriculture become impossible, but the destruction of the greater part of vegetation would follow." (Nat. Geog. Mag., 1908, p. 89.)

Birds and Weeds.--It is not, however, only as a scourge to insects that the bird is of value to the farmer, but also as a destroyer of the seeds of weeds it performs a service of incalculable importance. Again we must turn to the researches of the economic ornithologist for those definite daca (see especially papers by Judd) without which satisfactory conclusions cannot be reached. In passing we may merely state that 700 seeds of the pigeon grass were taken from the stomach of a Tree Sparrow by Professor Beal, who estimates that this species destroys no less than 875 tons of weed-seed annually in the single state of Iowa; that 1,000 pigweed seeds were found in the stomach of a Snow Bunting; that a Bob-white contained 5,000 seeds of pigeon grass, while a Mourning Dove had eaten the enormous number of 7,500 seeds of the yellow wood sorrel.

Birds and Rodents. - Still we have not given the birds all the credit due them as powerful allies of the agriculturist. Every farmer knows all too well how seriously small rodents, particularly field mice, can damage his crops in the field as well as in the storehouse or granary; but few farmers know that Hawks and Owls, birds they have aways believed should be killed on sight, are among nature's most potent checks on the undue increase of these destructive little creatures.

The loss which may follow ignorance of the economic value of Hawks and Owls has never been more clearly shown than by Dr. 
Merriam, who as early as 1886 made the following comments on the then recently passed 'Scalp Act' of the State of Pennsylvania, and subsequent investigations have confirmed his views:

"On the 23d of June, 1885, the Legislature of Pennsylvania passed an act known as the 'scalp act,' ostensibly 'for the benefit of agriculture,' which provides a bounty of fifty cents each on Hawks, Owls, weasels and minks killed within the limits of the State, and a fee of twenty cents to the notary or justice taking affidavit.

"By virtue of this act about $\$ 90,000$ has been paid in bounties during the year and a half that has elapsed since the law went into effect. This represents the destruction of at least 128,571 of the abovementioned animals, most of which were Hawks and Owls.

"Granting that 5,000 chickens are killed annually in Pennsylvania by Hawks and Owls, and that they are worth twenty-five cents each (a liberal estimate in view of the fact that a large portion of them are killed when very young), the total loss would be $\$ 1,250$, and the poultry killed in a year and a half would be worth $\$ 1,875$. Hence it appears that during the past eighteen months the State of Pennsylvania has expended $\$ 90,000$ to save its farmers a loss of $\$ 1,875$. But this estimate by no means represents the actual loss to the farmer and the taxpayer of the State. It is within bounds to say that in the course of a year every Hawk and Owl destroys at least a thousand mice or their equivalent in insects, and that each mouse or its equivalent so destroyed would cause the loss of two cents per annum. Therefore, omitting all reference to the enormous increase in the numbers of these noxious animals when nature's means of holding them in check has been removed, the lowest possible estimate of the value to the farmer of each Hawk, Owl, and weasel would be $\$ 20$ a year, or $\$ 30$ in a year and a half.

"Hence, in addition to the $\$ 90,000$ actually expended by the State in destroying 128,571 of its benefactors, it has incurred a loss to its agricultural interests of at least $\$ 3,857,130$, or a total loss of $\$ 3,947,130$ in a year and a half, which is at the rate of $\$ 2,631,420$ per annum. In other words, the State has thrown away $\$ 2,105$ for every dollar saved! And even this does not represent fairly the full loss, for the slaughter of such a vast number of predaceous birds and mammals is almost certain to be followed by a correspondingly enormous increase in the numbers of mice and insects formerly held in check by them, and it will take many years to restore the balance thus blindly destroyed through ignorance of the economic relations of our common birds and mammals."

Birds as Scavengers.-Besides destroying various species of insects inimical to the health of the human race, birds further increase the healthfulness of the world by acting as scavengers. It would be difficult to overestimate the value of Buzzards, Vultures, and other offaleating birds to the countries in which they live. In most instances the economic importance of these birds is too obvious to be overlooked, and they are, therefore, protected by law, and by what is far more powerful than law, public sentiment. 
In our southern States the Turkey 'Buzzard' and Black Vulture, or 'Carrion Crow,' have become so numerous and tame as a result of the protection there given them that they walk around the streets of the towns and cities in great numbers, and with no more evidence of fear than is shown by poultry. Every one realizes that a living Buzzard is of infinitely more value than a dead one, and in many years' experience in the South I have never seen a Buzzard molested.

The value of Gulls as scavengers was forcibly impressed on my mind when, some years ago, I visited the lower harbor of New York Bay to see the Gulls which were attracted by the scows of the Street-cleaning Department of New York City. The number of Gulls present on this occasion was beyond calculation, but certainly exceeded three hundred thousand. Before the scows began to discharge their cargo most of the birds were resting on the water, but at the sound of the whistle giving the signal to dump, they arose in clouds and clustered thickly over the wake of each of the eleven scows to feed on the vegetable and animal matter thrown overboard. It was a most impressive object lesson in the economic value of these birds, which until recently have been destroyed in enormous numbers for millinery purposes.

\section{Suggestions for the Student}

How may a bird's local or seasonal distribution be governed by the food supply? Give instances. Group our land birds under general headings according to the nature of their food. How is the nature of a bird's food determined? Give instances illustrating the importance of field observation; of laboratory examination. To what extent are insects believed to injure our agricultural and forestry interests annually? Give definite instances based on personal observation in which insectivorous birds were seen to destroy injurious insects. How may birds aid in preventing disease? What birds are known to feed on mosquitos? Is it probable that agriculture would be possible without the service rendered by birds? Describe the feeding habits of aërial, arboreal, scansorial and terrestrial insectivorous birds. Is the food of young birds like that of their parents? Why are insectivorous birds particularly valuable in the winter? Describe the value of birds as weed-seed eaters and give statistics of their destructive powers. What birds are the natural enemies of small rodents? Give the results of stomach analyses of various species of Hawks and Owls (see body of book). Which are considered beneficial? Which injurious? What birds are known to act as scavengers?

\section{REFERENCES}

1880. Forbes, S. A., The Food of Birds, Bull. 3, Ills. State Lab. Nat. Hist., pp. 80-149. See also Bull. 6, pp. 3-32.-1883. KInG, F. H., Economic Relations of Wisconsin Birds, Geol. Wisc., I, pp. 441-610.-1886-1909. Merriam, C. Hart, Chief and others. Reports on Investigations of the Biological Survey of the U. S. Dept. of Agriculture. Some of these papers are cited here, others under the species to which they refer.-1888. WARREN, B. H., Birds of Pennsylvania with Special Reference to their Food Habits, 266 pp.-1889. Barrows, W. B., The English Sparrow in North America, Bull. No. 1, Biol. Surv., 405 pp.-1893. Fisher, A. K., Hawks and Owls of the U. S. in their Relation to Agriculture, 209 pp.-1895. Barrows, W. B., and Schwarz, E. A., The Common Crow, 98 pp.-1895. Forbush, E. H., 
Birds as Protectors of Orchards, Bull. 3, Mass. Board Agric., pp. 20-32.1895. Beal, F. E. L., The Food of Toodpeckers, Bull. 7, 39 pp.-1896. Palmer, T. S., Extermination of Noxious Animals by Bounties, Yearbook, U. S., Dept. Agr., pp. 55-68.-1897. BEAL, F. E. L., Some Common Birds in their Relation to Agriculture, Farmer's Bull., No. 54, 40 pp.-1898. Forbush, E. H., Nature's Foresters, Bull. No. 1, Mass. Board Agric., pp. 27-40.-1898. PAlmer, T. S., The Danger of Introducing Noxious Animals and Birds, Yearbook, pp. 87-110.-1898. NAsH, C. W., Birds of Ontario in Relation to Agric., Rep. Farmer's Inst. Ont., Dept. Agric., pp. 1-32.-1898. JCDD, S. D., Birds as Weed Destroyers, Yearbook, pp. 221-232.-1899. Palmer, T. S., Review of Economic Orn. in U. S., Yearbook, pp. 259-292.1900. BEAL, F. E. L., How Birds Affect the Orchard, Yearbook, pp. 291304.-1900. Chapman, F. M., The Talue of Birds to the Commonwealth, Rep. Board Agric. Conn., 41 pp.-1901. Brtwer; L., Birds in their Relation to Agriculture, Proc. Neb. Orn. Union, 18-29-1901. JCDD, S. D., Relation of Sparrows to Agriculture, Bull. 15, Biol. Surv., 98 pp.-1902. Judd, Sylvester D., Birds of a Maryland Farm, Biol. Surv. Bull. 17, 116 pp.-1902. Forbesh, E. H., Two Years With the Birds on a Farm, Mass. State Board Agric., 2nd.Ed.-1903. ChApuAn, F. M., The Economic Value of Birds to the State, Seventh Rep. N. Y. Forest, Fish and Game Comm., 66 pp. With bibliography.-1903. WeED, C. M., and DEARBORN, NED, Birds in Their Relations to Man. A Manual of Economic Ornithology for the U. S. and Canada. $380 \mathrm{pp}$. With bibliography.-1905. Hexshaw, H. W., Does it Pay the Farmer to Protect Birds. Yearbook, 165-178. -1906. Howell, A. H., Birds that Eat the Cotton Boll Weevil, Biol. Surv. Bull. 25, 22 pp.; Bull. 29, 30 pp.; Circ. 64, 5 pp.-1906. McAtee, W. L., Birds that Eat Scale Insects, Yearbook, pp. 189-198.-1906. BEAL, F. E. L., Birds as Conservators of the Forests, Rep. N. Y. Forest, Fish and Game Comm., 1902, 3 pp. 235-274.-1907. Forbesh, E. H., Useful Birds and Their Protection, Mass. State Board Agric., 437 pages. Comprehensive.-1907. Henshaw, H. W., Value of Swallows as Insect Destroyers, Circ. 56, Biol. Surv., 4 pp.-1907. Hexshaw, H. W., Birds Useful in the War Against the Cotton Boll Weevil, Circ. 57, Biol. Surv., 4 pp.-1908. Hexshaw, H. W., The Policemen of the Air, Natl. Geog. Mag., pp. 79-118.-1911. BEAL, F. E. L., Food of the Woodpeckers of the United States, Bull. 37, Biol. Surv., 64 pp.

\section{General Activities of the Adult Bird}

Habitat
Habit and Structure
The Bill
The Wing
The Tail
The Feet

The Senses

Intelligence

Status of the Species

Having devoted the larger part of the space allotted to this Introduction to those features of bird sturly in nature which secm most important from the field student's point of riew, our outline of a bird's life may be enmpleted by briefly calling attention to certain other subjects, each of which must be considered if we would approach anything like a complete local biography of a given species.

Habitat.-The range or geographical distribution of a species is 
ascertained only by compiling the data of many workers, but its local distribution, or habitat, can be determined by a single observer. Wonderful as it is that the range of so mobile a creature as a bird should have more or less well defined boundaries, beyond which it rarely advances, even more remarkable is it that within the limits of this range the bird often should have still more sharply marked haunts. Thus, shore, salt and fresh marshes, meadow, upland, bush, deciduous or coniferous forests, all have birds which, when nesting, are restricted to them, and the mapping of the habitats of the birds in one's locality is one of the interesting duties of the local ornithologist. The rarer birds will often be found confined to certain areas where perhaps a small colony may be established, and one should note whether it increases or decreases and attempt to learn the reasons for its success or failure.

Vegetation as it influences the food-supply or offers suitable nesting sites, will be found to be the chief factor in controlling the distribution of birds locally; and it is important to record, during the course of years, those fluctuations in the numbers of a species due to changes in the character of the country incident to man's presence as he fells

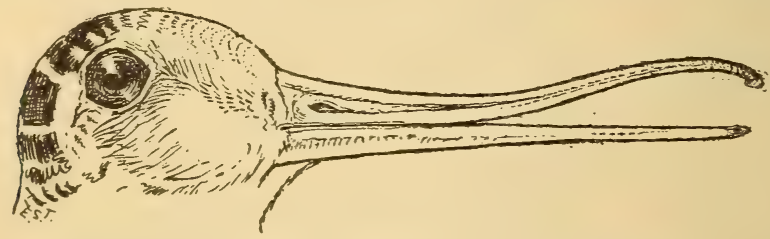

FIG. 11. Probelike bill of Woodcock, showing extent to which upper mandible can be moved. (One-half natural size.)

forests, drains marshes, permits the growth of scrub on fallow land, introduces new types or sources of food, furnishes new nesting-sites, etc. (See, especially, the Introduction to Brewster's "Birds of the Cambridge Region.")

It is interesting, too, to observe the distribution of a bird during the day; where does it feed? where does it sleep? does it have regular flyways between feeding-ground and roost?

Habit and Structure.-The relation between form and function is in most cases so obvious that even the casual observer is impressed by the admirable adjustment existing between a bird's habits and its structure. The subject has been dealt with at length by Headley, Becbe and others, and offers far less opportunity for original investigation by the local student than is found, for example, in a study of nesting habits. Nevertheless he should learn from personal observation, when possible, the part that bill, wings, feet and tail play in a bird's life.

Uses of the Bill.-Birds' bills usually take the form of forceps or probes rivaling in variety of shape the combined outfits of the sur- 
geon and dentist; but spears, awls, chisels, picks, hooks, crackers, trowels, needles, scoops and strainers are also represented in the bird's equipment. Primarily these instruments or weapons are designed to secure food for the adult and to feed its young, but the bill is also of

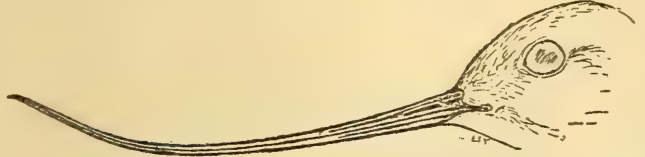

FIG. 12. Recurved bill of Avocet. (Two-thirds natural size.) service in preening, in gathering and placing nesting material or excavating nesting - sites, and as a weapon of attack or defence in the usually harmless struggles of birds. Woodpeckers use it as a drumstick. Owls rattle their mandibles threateningly, and Pelicans snap theirs in loud defiance.

With some birds, the bill is the seat of some special growth or color during the breeding season. The White Pelican then wears a keellike knob on the upper mandible, and the bills of Auks, Puffins and some Ducks are brightly colored or modified in form.

Uses of the Wing.-The student should observe the relation between the shape of a bird's wing and the character of its flight and the further relation between the manner of its flight and its general habits.

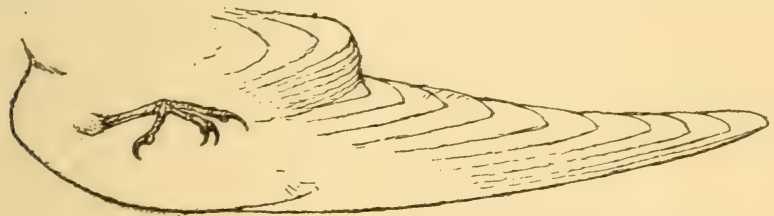

FIG. 13. Long, pointed wing and small foot of Tree Swallow, an aërial bird. (Natural size.)

Compare, for example, the wing of a Turkey Vulture with that of a Quail or Partridge; one aërial, the other terrestrial in habit. Note the lengthened flight-feathers and broad expanse of the Vulture's wing, its comparative slowness in getting under way, its ability to soar indefinitely, in short, to remain in the air with the least possible expenditure of effort; while the rounded wing of the Quail, although incapable of prolonged flight and requiring great exertion for effective use, can nevertheless be employed at highest speed so quickly that the bird is in full flight almost the moment it leaves the ground. Continue the comparison through your list of birds, noting not only the power but the rhythm of the wing-stroke, whether it be regular or varied, whether the flight be direct or undulating, etc.

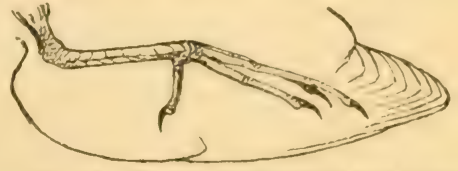

Fig. 14. Short, rounded wing and large foot of Little Black Rail, a terrestrial bird. (Natural size.) 
Auks and other members of their family fly under water and some Ducks also use their wings when diving, while the true Divers use both feet and wings. (See Townsend, The Auk, and "A Labrador Spring," pp. 180-205.) The loss by molting, depriving birds of all their flightfeathers at the same time, has already been mentioned (see Molt),

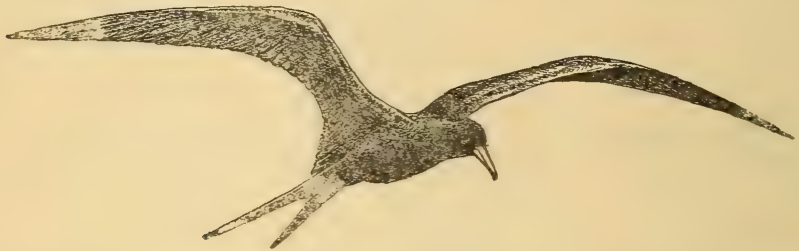

Frg. 15. Man-'o-war-bird; a species in which the wings have been developed at the expense of the feet.

and it will be interesting to learn whether at this time the Auks use their feet when progressing under water or whether a wing devoid of its quills supplies sufficient power. Young birds rest upon their wings as they would upon fore-feet and in some instances $(e . g$. Grebes and Gallinules) they are employed in climbing about among reeds, etc., or with young Herons, among branches. Adult Grebes and Loons, like the flightless Penguins, rely on their wings to aid them when on land.

The whistling or humming of wings may be the accompaniment of regular flight, as with the Mourning Dove, certain Ducks, or the Hummingbirds; it may be the result of an especial evolution, as with

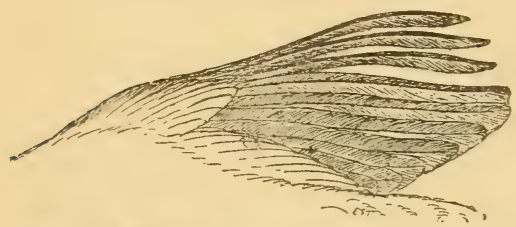

FIG. 16. The wing as a musical organ. Wing of Woodcock, showing outer attenuate feathers which produce the 'whistling' sound in flight. the swooping Nighthawk, or it may proceed from some special structure, as with the narrowed outer primaries of the Woodcock. The drumming of Grouse and the 'clapping' of Roosters, before crowing, are further illustrations of the use of the wing as a musical organ.

Sitting Hens threaten with their wings, Swans and Pigeons strike with them, Herons use the wing as a shield, altricial birds protect their roung from sun or rain by standing over them with spread wings, and they shelter præcocial birds; fledglings flutter the wings tremulously when begging for food.

The Tail.-A hird's tail is primarily a rudder. Compare the direct line of flight of a short-tailed bird, for example, a Duck or Quail, with the darting, erratie morements of a Tern or Barn Swallow. Soaring birrls spread the tail as an additional means of support and balance; and when spread and thrown downward and forward it serves as a brake for the bird when alighting. 
With Woodpeckers, Creepers and Chimney Swift the tail is modified for use as a prop.

The tail is exceedingly variable in form and is the seat of many interesting marks and colors which are displayed intentionally or when

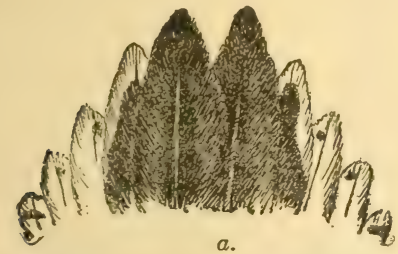

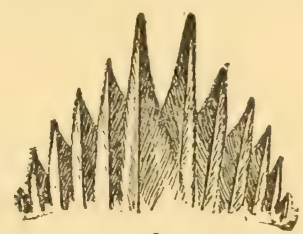

$b$.

FrG. 17. Tip of tail of (a) Downy Woodpecker and of (b) Brown Creeper, to show the pointed shape in tails of climbing birds of different families. (Natural size.)

the bird is in motion. Turkeys, Sage Cocks, Woodcock, spread the tail when strutting; with a host of birds white on the outer tail-feathers is conspicuously shown in flight or when the tail is nervously 'jetted' or twitched by the hopping bird (see Color). Some birds not closely related wag the tail (e.g. Spotted Sandpiper, Water-Thrush, Palm Warbler, Pipit), though why they should so do does not appear to be known.

The Feet.-Birds' feet serve a greater variety of uses than any of the four organs whose uses we are considering. Primarily they are of value as aids to locomotion, and the student should first note their length in wading birds like Flamingoes, Herons, and Stilts, and the relation between length of foot and length of neck. Aside from its length, the foot is variously modified by the development of webs and lobes and lengthening of the toes and nails, for swimming, running, hopping, climbing and perching. The growth in the fall of horn-like marginal fringes on the toes of the Ruffed Grouse and of feathers on the toes of Ptarmigan, presents an unusual case of seasonal adaptation in structure.

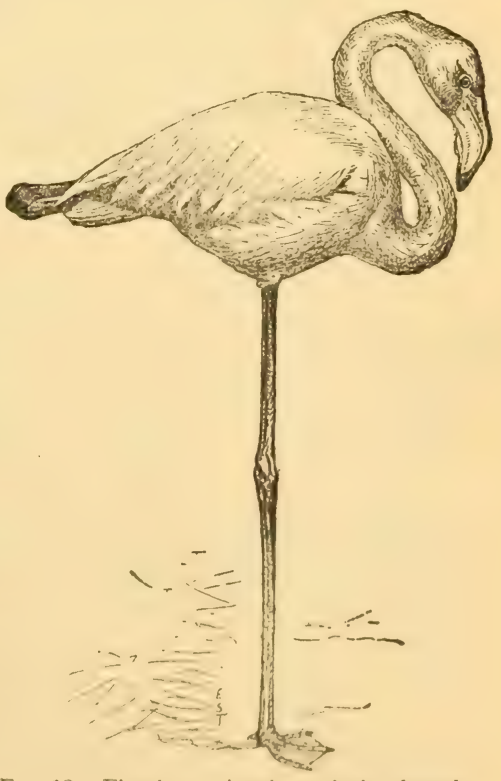

FIg. 18. Flamingo, showing relative length of legs and neck in a wading bird. 
In short-tailed birds like Murres, the feet, when extended backward, act as rudders in flight. It may be added that all the Water-birds, the Gallinæ, Columbæ and Raptores, carry the feet extended backward in flight, while all the Passeres, or Perching Birds, carry them drawn up forward. In the intermediate groups (Cuckoos, Trogons, Woodpeckers, Swifts, Hummingbirds and Parrots) the manner in which the
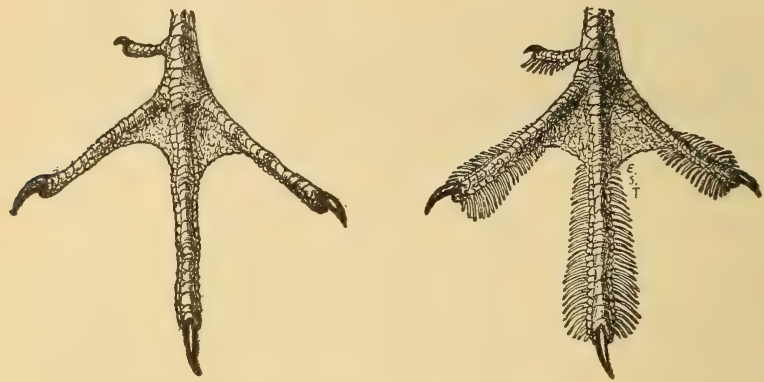

Fig. 19. Toes of Ruffed Grouse. Naked in summer, fringed in winter to serve as snowshoes. Illustrating seasonal adaptation in structure.

feet are held in flight does not appear to be definitely known, though it seems probable that they are drawn up as in the Passeres. (See Townsend, "A Labrador Spring," pp. 180-205.)

The longer-winged diving birds, like Cormorants and Water-Turkeys, use only the feet to propel them when under water; Grebes and Loons also use the feet for a similar purpose, and to a lesser extent the wings.

The relation between the two organs of locomotion, wings and feet,

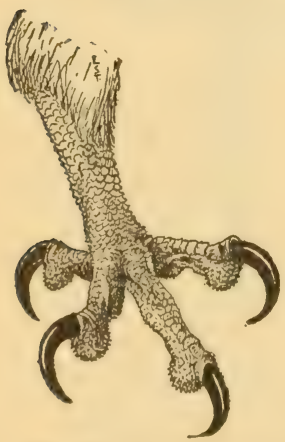

Fir. 20. Foot of Osprev; to show large, apposed claws and spicules on under surface of toes. should be observed, when it will be found that when the former are greatly developed the feet are correspondingly small (e.g. Man-o'war-bird; Swallows), while when the feet are large the wings are proportionately short and weak (e.g. the Rails and Gallinules).

In securing food, feet are of service in scratching (e.g. Gallinæ; Fox Sparrows), while in predaceous birds long, recurved talons and grasping power reach their maximum among birds.

Parrots use the foot as a hand, and many birds employ it to gather and place nesting material. With gallinaceous birds, particularly those that have spurs, the foot is a weapon. In Iferons and Coatsuckers, the middle-toe has a lateral terminal comb or pectination the function of which is unknown. 
It should be repeated, as we close this short section on structure and habit, that the species mentioned in connection with the functions of bill, wings, tail and feet have been restricted mainly to North American birds, in order that the student may verify, by personal observation, the close relation existing between the form of an organ and the manner in which it is employed.

The Senses.-In order that we may more nearly take the birds' point of view

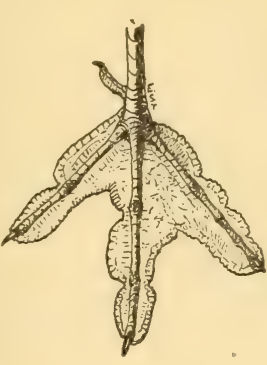

a.

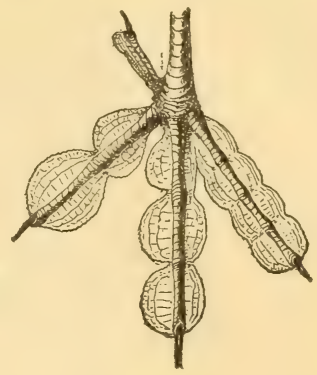

$b$.

Fig. 21. Lobed feet (a) Phalarope and (b) Coot, swimming birds of the Snipe and Rail families. and appreciate the significance of their actions, it is essential that we should have some knowledge of the development of their senses. Briefly, it is believed that in birds the senses of smell, taste and touch are inferior to our own, but that in sight and hearing they are immeasurably our superiors.

There do not appear to be on record any well-defined illustrations of the sense of smell in birds. Vultures are believed to find their food by the exercise of sight alone, and it is by no means certain that probing birds are attracted to their prey by its scent.

To what extent birds taste their food it is difficult for us to determine. That certain things are pleasant and others disagreeable will be obvious to any one who has seen a bird vigorously wipe its bill after attempting to eat an ill-tasting bug; but it is also clear that the bird's standard of gustation is not to be measured by our cwn. The experiments of Judd ( $A m$. Nat., 1899, p. 474) showed that many insects, which to man are both nauseating and foul-smelling, are relished by birds, while others are refused. It is, however, certain that the bird's restricted sense of smell in a large degree limits its ability to deteet finer differences in taste.

The bird's sense of touch is evidently more highly developed than either the sense of smell or that of taste. It is seated mainly in the tip of the bill, and the precision and delicacy with which this organ is used in picking up the smallest seeds, dislodging insects, their rgges and larva from the crevices in bark, grasping worms or grubs out of sight in the ground, or eatehing minute forms of life in mudly water, demonstrates the degree of ability with which it is employed.

When we reach the sense of hearing, we must at onere coneede that the bird is so far beyond us that we probably do not fully realize the extent of its powers. A Barred $\mathrm{Ow}$, which alighted with his back toward 
me, at a distance of about fifty yards, turned his head instantly in response to the slightest 'squeak' made to test its hearing. The same sound will often turn a passing Hawk when he might be thought to be beyond its reach. The snapping of the smallest twig throws a whole Heron colony into wildest commotion. Woodpeckers locate the grubs of boring beetles, and Robins apparently listen for crawling worms.

That birds not only have incredibly acute hearing, but can also distinguish minor differences in sound, is implied by the wide range of sounds which birds themselves produce and which, in the economy of their lives, are obviously not intended to fall on deaf or inappreciative ears; as other writers have before remarked.

A colony of Roseate Spoonbills which I have lately studied from a blind, were not alarmed by various noises made in manipulating a camera, but at a single word, spoken in a low voice, every bird sprang into the air.

White Egrets, in Florida, have acquired so great a fear of a gun that the birds of a rookery in which my blind was placed left their nests with a rush at the faint report of a gun fired by a guide a mile and a half away.

Crows immediately respond to an imitation of the call of the Barred Owl, and though this may be uttered but once, they come from some distance directly to the spot whence the hoot proceeded.

In default of definite experiments, it is on casual observations of this nature that our knowledge of the comparative power of a bird's hearing is based. There is much need for further data here.

With eyes, the relation between cause and action is more apparent, and without knowing exactly how well a bird can see, we have at least seen enough to be impressed by its marvelous power of vision. Recall a quietly observant Loggerhead Shrike leaving its lookout and flying so directly to a grasshopper in the grass a hundred feet away, that it is clear the insect was seen before starting; or again, Gulls and Petrels picking up small bits of food from waves so boisterous that a man would be lost to sight in them. "Observe," says Coues ('Key,' 5th Ed., p. 18.5), "an Eagle soaring aloft until he seems to us but a speck in the blue expanse. He is far-sighted; and scanning the earth below, descries an object much smaller than himself, which would be invisible to us at that distance. He prepares to pounce upon his quarry; in the moment required for the deadly plunge, he becomes near-sighted, seizes his victim with unerring aim, and sees well how to complete the bloody work begun. A Hummingbird darts so quickly that our eyes cannot follow him, yet instantaneously settles as light as a feather upon a tiny twig. How far off it was, when first perceived, we do not know; but in the intervening fraction of a second the twig has rushed into the focus of distinct vision, from many yards away. A Woodeock tears through the thickest eover as if it were clear space, avoiding every obstacle. The only things to the accurate perception of which birds' eyes appear not to have accommodated themselves are tele- 
graph wires and lighthouses; thousands of birds are annually hurled against these objects to their destruction."

A probable sense of direction has already been considered in the chapter on 'Migration.'

Intelligence.-It is the human side of bird-life which in recent years has most attracted bird students and has been most emphasized by popular writers. With the bird's already pronounced human-like traits to build on, it has required only imagination, unrestrained by scientific method or analysis, to make of the bird a creature of marvelous mental endowment, whose reasoning powers, within the limits of its normal activities, are equal if not superior to those of man.

Such treatment finds favor with those whose love of birds exceeds their knowledge of ornithology, but it is strongly resented by others who, yielding nothing in their appreciation of the birds' claims to our attention, would still have them regarded as birds rather than as feathered human beings. But in attempting to administer a corrective, the critics of the ultra-human point of view have given an overdose. They not only deny the bird ability to reason, but assert that all its mental activities are wholly instinctive; in short, that the bird is a feathered automaton.

It is not possible here to discuss this question in the light of all the available evidence, but only to record my own views as they are based mainly on personal observations. These lead me to belicve that neither point of view is wholly right nor wholly wrong; in other words, that there is a measure of truth in both contentions. In each case, however, it would appear that a fundamental error is made in speaking of the "mind of birds" collectively, or as a unit. We would not attempt thus to consider the mind of mammals, and while there is not, it is true, so wide a range of mental development in birds as there is in mammals, the difference between the least intelligent and the most intelligent is far too great for us to diseuss the mind of the Class Aves without distinction as to species and even individuals.

For example, a prolonged, intimate study of Pelicans seems to emphasize the low order of their intelligence. Perfectly as they are adipted to their own environment, they exhibit, when confronted by new conditions, what, judged by human standards, ean only be ealled stupidity.

On the other hand, the Blue Jays, Crows, Jackdaws, and others of their near kin, often exhibit so high a degree of intelligence that the bird-lover, unmindful of exact definitions, is tempted to assert that they show ability to reason.

The Herons of Cuthbert Rookery were alarmed into hurried flight by the firing of a gun a mile and a half away, but the Crows which were with them paid no attention to the report. The Herons' experience with firearms has developed an unreasoning foar, while Crows show the nicest judgment in cstimating the range of a gun.

The Herons of this rookery permitted the Crows to rob them of their eggs by the hundred without the slightest indication of protest or 
resentment, but Kingbirds attack every Crow which ventures near their nest, often pursuing them for several hundred yards.

Similar instances, illustrating the wide range of intelligence among birds of different species, might be multiplied endlessly, but any consideration of the subject renders this variation so evident that it is assuredly unnecessary to present further proof.

Variation in intelligence is not confined to these differences between species, but within narrower limits is shown by the individual. To those who study birds as individuals rather than as species, this statement will seem superfluous, but advocates of automatic bird-life would have us believe that, in the same species, one bird is essentially the duplicate of another. Birds which nest, closely associated in colonies, where a certain standard of behavior is developed by similarity of environment and imitation, show less individuality than those species of more solitary habits; but it requires only intimate experience with representatives of either class to convince one that pronounced characteristics are often shown by certain individuals, and indeed one rarely finds in the latter group two birds which act exactly alike. It is the range of intelligence among the individuals which, in the end, determines the degree of success of the species. It is among the Passerine birds that we shall find birds possessing the highest intelligence, and the Passeres are the birds of the day, the dominant group in the Class Aves, outnumbering the members of all other orders combined.

Admitting then that some species of birds exhibit barely a glimmer of intelligence, and are indeed very near to being feathered automata, are there not at the other end of the scale birds which possess the power to reason?

By reason, accepting Lloyd Morgan's definition, is meant the "process of drawing a logical inference," the ability "to think the therefore." We can of course determine the bird's mental status only on the basis of its actions. Birds' notes, so far as we understand them, express only primary emotions. If birds then can draw an inference, we can be aware of it only through its effect on their behavior. Those direct responses to conditions which lead to change of action, or of habit, as where a bird becomes shy through persecution or tame through protection, are not to be attributed to reason, as the term is here used, but are unreasoning exhibitions prompted by sense associations which occasion no sequence of thought on the part of the bird, no drawing of conclusions or performance of acts made with such indubitable reference to other following, dependent acts, that it is evident the latter were conceived of as the logical consequence of the former. The bird, with truly wonderful quickness, learns to associate a certain thing with danger, another thing with safety. The Pelieans of Pelican Island, Florida, for the first time in their known history, failed to return to their island because a sign had been erected on it. This illustrates the keenness of the birds' perception, but it also demonstrates their inability to infer that a piece of board was harmless. 
A pair of Blue Jays, after an absence of nearly two hours, immediately returned to their nest and fed their young, their suspicions completely allayed by the presence of a mounted Jay in the nest tree. Here was a response so quick and satisfactory that it might be considered evidence of the bird's ability to draw an inference, but the bird's failure to distinguish a poorly mounted, discarded museum specimen of its own kind, and later of an $\mathrm{Owl}$, from the living bird, indicates its inability to reason. (See "Camps and Cruises," pp. 5-14.)

Using the word reason, therefore, as psychologists commonly define it, I may say at once that I have seen no conclusive evidence of reasoning power in my study of birds. But in place of this characteristic of the human mind, one finds in birds certain other senses and faculties so much more highly developed than they are in man that we doubtless have but a faint conception of their value. Birds exhibit a truly surprising power of memory-implying also association of experiences - while in their hearing, sight, and probable sense of direction, they are incomparably our superiors. In my judgment, then, it is to the keenness of these powers rather than to an alleged gift of reason that the bird owes its success in life. Before their manifestation, reason, following the slower channels of logical inference, may often well stand aghast. What form of reason would lead a bird night after night on a journey of thousands of miles with such nice precision of movement that the goal is reached on a certain day? For men, with only the bird's physical equipment, the feat would be impossible.

In thus denying the bird's power to reason, we add rather than detract from the interest with which we study the evidences of its own peculiar and remarkable gifts; and our interest is intensified by the wide range of variation in the mental development among individuals as well as groups, which often renders it uncertain just what response will follow a certain stimulus.

Nor, in denying the birds close association with us on the higher planes of intelligence, should we lose our feeling of kinship with them. We have distanced them in the race of mental development; but that should not render us any the less eager to discover in some of their traits those which characterized the childhood of our race.

Status of the Species. - The measure of a bird's success in life is determined not alone by its powers as a migrant (if it be migratory); its attractiveness when wooing a mate; its skill as a nest-builder; its devotion and courage as a parent; the nature of its physical and mental endowment, or the degree of its intelligence, but also by the extent of its adaptability and the character of its temperament. When, therefore, we ask why some birds are abundant and others rare, all these factors are to be considered in connection with all the conditions under which the bird lives; and to do this with due attention to the many influences involved, is one of the ultimate objects of the study of ornithology; for, to determine the causes of the success and failure of life is second only to determining the origin of life itself. 
Species which are the direct object of man's unbridled greed, must succumb to an enemy before which neither swiftness of flight nor excessive wariness avail. Thus the Wild Pigeon and White Egrets, however well they were fitted to contend with nature, could not escape man.

But when man enters the bird's life only indirectly, altering its environment without actually killing the bird itself, the species in undiminished numbers is left to face the problem; and its ability to adjust itself to new conditions is now put to a vital and immediate test.

The Pileated and Ivory-billed Woodpeckers have decreased with the forests; but the Crow and the Robin, both naturally forest-inhabiting species, have more than held their own. Both, in different ways, have adapted themselves to the new order of things; the Crow meets the distinctly hostile if not actively aggressive attitude of man by wariness and more than average intelligence; the Robin, through its fearlessness, has won man's friendship and protection. Near his dwellings its natural enemies have been reduced in number, and the normal food supply greatly augmented by fruits of various kinds, a more accessible supply of worms on close-cropped lawns, and various insects which also thrive on man's bounty.

The introduction into this country of the House or English Sparrow has, from a biological point of view, been an overwhelming success. Not only did the bird fill an unoccupied place in our cities, but when brought into competition with native species, its hardiness, general adaptability, pugnacity and continuous presence have all been in its favor. When the migratory Bluebirds or Purple Martins returned, they often found the Sparrows in possession of their nesting-boxes, and the decrease in the numbers of both these species is unquestionably to be attributed to their inability to compete with the Sparrow.

In the changes wrought by man, directly or indirectly, we may find many similar illustrations of sudden alterations in the bird's environment, and the manner in which they are met demonstrates what is meant by adaptability. In nature, equally great changes may occur, but they take place more slowly, and the adjustment between them and the bird, while not the less essential, is not so severe and sudden a tax on the bird's resources.

But aside from these external influences, which may remain unchanged and hence inactive for long periods of time, there are certain internal influences which are constantly potent. Chief among these is temperament as it is expressed in sociability or desire for solitude. It is obvious that only birds of social, or at least peaceable, disposition could live in such close juxtaposition as do colonial birds, like Gannets, Murres, Flamingoes, Cliff Swallows and many others, where nests or nesting birds almost touch one another. Such social species are usually represented by numerous individuals, while on the other hand the relative abundance of solitary species is related to the extent of the area over which they claim guardianship while nesting, to the exclusion only of other birds of their own kind. Hence, Hawls and Owls, for 
example, which resent the intrusion of other individuals of the species into their nesting area, are comparatively rare; while Robins and Chipping Sparrows, which, though not colonial, often nest near others of their kind, are comparatively abundant. The abundance of a species is, therefore, doubtless more dependent upon the number of nests which, under favorable conditions of environment, constitute the normal number for a given area, than upon the supply of food in that area.

On this subject, Brewster ("Birds of the Cambridge Region," pp. 62, 63) remarks, "In my opinion the desire for exclusive possession so conspicuously shown by the male, and often by him alone, is usually the direct result of sexual jealousy. This, as is natural, makes him intolerant, during the breeding season, of the near presence of rival males. If his concern were chiefly in respect to the food supply, it would be equally manifested at every season and towards all birds who subsist on the same food that he and his mate require, which is certainly not the case."

When in possession of all the essential facts, we may, therefore, in many instances, present more or less conclusive reasons for the success or failure of a species; but there will remain many others which are apparently inexplicable. Species will be observed, practically alike in structure and habits, some of which in incalculable numbers flood the land, while others are represented by but a few individuals scattered here and there in small colonies or concentrated in a narrow area.

All other explanations failing, such cases tempt the belief that species as well as individuals have a life, that some full of the vigor of youth are advancing, while others past their prime are declining; that some in short are dominant, and others decadent. Dominant species are possessed of the vitality which admits of adaptiveness and power to overcome unfavorable conditions to which decadent species would succumb.

Thus we may think of a dominant species as an expansive force which is preëminently fitted to fill, with the utmost precision of adjustment, its own place in nature, and is also constantly pressing against all the governing influences which go to make up its environment, to increase its number and extend its range. Up to a certain point it meets a degree of success in proportion to its mental and physical endowment; beyond that it advances or retreats only after a struggle.

In February, 1895, the South Atlantic States were visited by a blizzard which practically annihilated the Bluebirds wintering or resident in them, and the following spring the species was absent from large areas, where the preceling year it harl been eommon. The loss of a beautiful bird, so intimately associated with man, was deplored as irreparable, but within three years the spocies was as abunclant as ever, so quickly did the expansive fores of the speceies bring it to the limit where contact with environment ehecks further advanee.

Less evident, but in the end of greater signifie:anee, is the Bluebird's struggles with the English Sparrow and the European Starling, both 
growing, expansive species. The conflict is not over food, for all the species are of different feeding habits, but over the nesting-site. We cannot imagine that the Bluebird will, even through force of circumstances, exhibit the Sparrow's adaptability, and, in default of a normal site, build in branches, vines, electric light hoods - in short, any place which will hold nest-material-nor has it strength to compete successfully with the Starling.

Let us, therefore, join forces with this gentle-voiced messenger of sky and earth, by providing it with suitable homes in which these enemies, for whose presence we are responsible, shall not be permitted to abide.

\section{Suggestions For the Student}

Habitat.-Define the difference between 'Range' and 'Habitat.' Describe the habitat of a given species. What are the more important factors in determining the nature of a bird's habitat? Can you mention an instance where a change in the character of the habitat has been followed by a change in the character of the bird-life? Give instances of daily change in habitat.

Habit and Structure.-Name the principal functions of the bill, and give illustrations of each. Describe the feeding habits of Woodpeckers, of Hawks, of the Woodcock, of Flycatchers, of Sparrows in relation to the character of their bill. What birds use the bill when climbing? In what birds is the bill adorned by bright colors or appendages in the breeding season? Name the functions of the wing. Describe the flight of Ducks, Quail, Hawks, Vultures, Woodpeckers, Purple Finches, Swallows, etc. Describe the relation between the shape of their wings and their manner of flight. What relation exists between the size of the wing and foot? What North American bird was flightless? What North American birds use their wings as muscial instruments? Which use them under water? How are they used in defence? Describe their use in sheltering the young.

Name the functions of the tail. Which of our birds use it in display? Which as a prop? Describe its relation to manner of flight.

What are the functions of the feet? Describe the various means of locomotion employed by birds. What birds use only the feet under water? In what way is a Coot's (Fulica) adapted to its wants? Why is a Phalarope's foot webbed? In what birds does the structure of the foot change with season? How is the foot held in flight by various birds? What is the relation of length of foot to length of neck? (There is almost no limit to the questions which may be asked in regard to the form and function of birds, and the student is urged to draw largely on local material to stimulate his powers of observation in this direction.)

The Senses.- How do the senses of birds compare with those of man? Is the sense of smell well developed in birds? Can you mention any instances illustrating the bird's power of taste? Its powers of touch? Is the power of hearing well developed in birds? Mention several instances. Do birds learn quickly the significance of certain sounds? Mention several instances illustrating the bird's power of sight. Define what is meant by intelligence in birds. Are some species more intelligent than others? What is the difference between intelligence and reason? What is Lloyd Morgan's definition of "reason"? Have you found any evidence illustrating the bird's ability to reason? Why is it desirable to base stories of bird-life presented as "true" on known facts in their habits?

Status of the Species. - What are the most important factors in determining whether a bird is rare or common? How may man directly or indirectly affect the members of a species? Give illustrations. Why does the English Sparrow present an interesting biological problem? How may 


\section{REFERENCES}

a bird's temperament affect its numbers? Give illustrations. When were Bluebirds destroyed by a blizzard? How long before their numbers reached normal? What is the probable reason of their sudden increase?

\section{REFERENCES}

1883. Martin and Moale, How to Dissect a Bird (Macmillan).-1884. Coues, E., Key to North American Birds (Dana Estes) rev. ed. 1902, Vol. I, pp. 59-233 (important).-1893-1896. NewTon, A. and others, A Dictionary of Birds, 1 vol., 1088 pp. (Macmillan).-1894. Morgan, C. L., An Introduction to Comparative Psychology, 12mo., $382 \mathrm{pp}$. (Scribner's).1895. Headley, F. W., The Structure and Life of Birds, 12mo. 412 pp., ills. (Macmillan), -1898. BEDdARD, F. E., Structure and Classification of Birds, 8vo., 548 pp., ills. (Longmans).-1 1897. BASKET, J. N., The Story of the Birds, 12mo., 263 pp., ills. (Appleton).-1906. BeEBe, C. W., The Bird. Its Form and Function, 8vo., 496 pp., ills. (Holt).-1910. Pycraft, W. P., A History of Birds, 8vo., 458 pp., ills. (Methuen, London). -1910. Herrick, F. H., Instinct and Intelligence in Birds, Pop. Sci. Monthly, June, July, and August.-1911. Various Authors, Journ. of Animal Behavior (Holt). 


\title{
THE BIRDS OF NORTH AMERICA EAST OF THE NINETIETH MERIDIAN
}

\author{
KEY TO ORDERS AND FAMILIES
}

\section{THE WATER BIRDS}

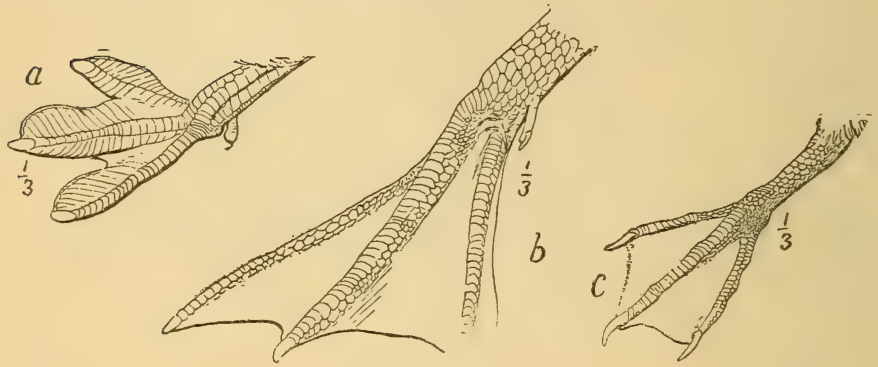

FIG. 22.

Order I. Pygopodes.-Grebes, Loons, and AuKs.

Ducklike birds, but with the bill usually pointed, never feathered and wider than high; never with flutings, 'gutters,' or serrations on its sides; wings short, never with a bright-colored patch or speculum; tail insignificant; feet placed far back (most species, when standing, usually rest on their entire length, thus including the tarsus); tarsus flattened to present least resistance when swimming; toes webbed or lobed. Color, usually blackish above, white below, the throat often dark. Grebes and Loons, when pursued, usually dive; Auks generally fly.

A. Toes four, nail $\mathrm{fla}^{\mathrm{L}}$ or rounded.

a. Toes with lobate webs; tail absent. (Fig. 22, a.) ... Family Colymbida: Grebes, p. 138.

b. Toes webbed, tail present. (Fig. 22, b.)

......... Family Gaviidae: Loons, p. 142.

B. Toes three, webbed, nails sharply pointed; tail present. (Fig. 22, c)... Family Alcida: AuKs, Murres, and Puffins, p. 145.
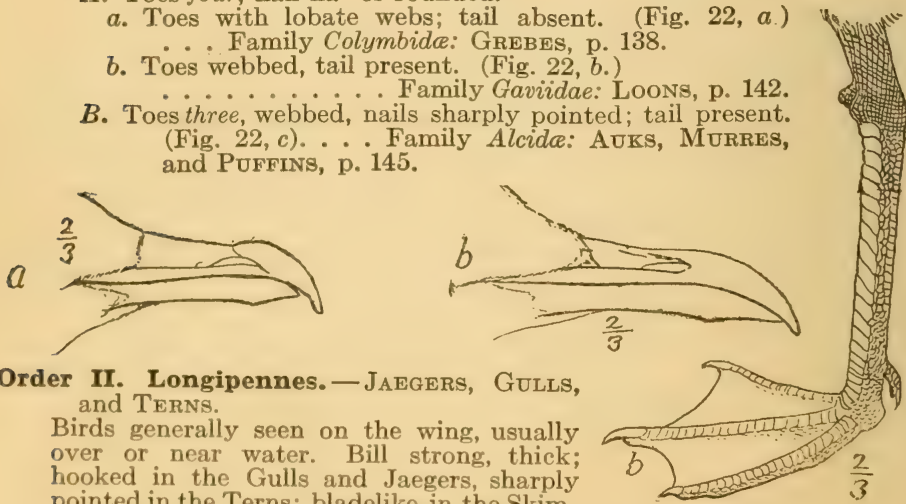

and Tengipennes.-JAEGERS, GULLS,

Birds generally seen on the wing, usually over or near water. Bill strong, thick; hooked in the Gulls and Jaegers, sharply pointed in the Terns; bladelike in the Skimmers; often in part yellow or red; wings

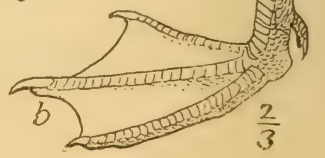

FIG. 23. 
very long and pointed, the outer feathers being much the longest; toes webbed. Adult Gulls and Terns are usually pearl-gray above, white below; Jaegers and most young Gulls are dark.

A. Bill hooked and hawklike.

a. Bill with a naillike hook, its base with a scaly shield; plumage dark; central tail-feathers longest. (Fig. 23, a). . . . Family Stercorariida: SKuAS and 'JAEGERS, p. 150.

$b$. Hook continuous with bill, no scaly shield, tail-feathers usually of about equal length (Fig. $23, \bar{b}$ ) .... Subfamily Larina: GULLS, p. 152.

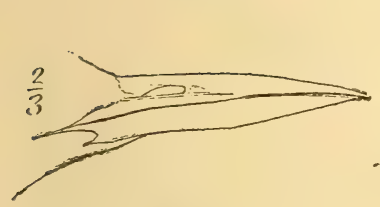

Fí. 24 .

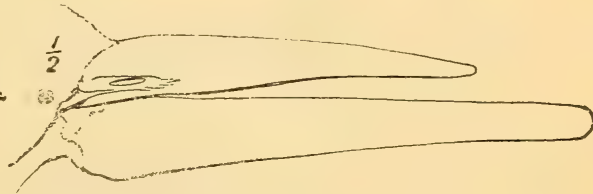

Fig. 25.

B. Bill not hooked.

a. Bill straight, usually slender and sharply pointed; tail usually more or less forked. . . . Subfamily Sternince: Terns (Fig. 24), p. 162.

b. Bill thin and bladelike, the lower mandible longer than the upper (Fig. 25). . . . Family Rynchopida: Skrmmers, p. 172.
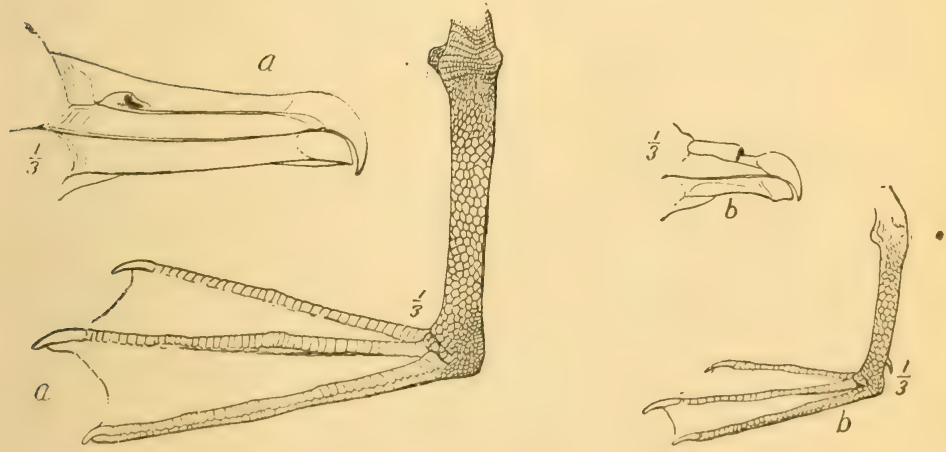

FIG. 26.

Order III. Tubinares.-Albatrosses, Petrels, and Fulmars.

Gray, sooty, or black and white sea-birds; living, except when nesting, well off shore; flying low, often skimming the waves. Nostril-openings tubelike; bill hawklike, its 'hook' often prominent; front-toes webbed, hind-toe small or absent; wings long and pointed; tail short.

A. Size very large, nostril-tubes separated, on sides of hill (Fig. 26, a).

. . Family Diomedeida: Albatrosses, p. 172.

B. Size smaller, nostril-tubes joined on top of bill (Fig. 26, b) . . . Family Procellariida: Petrels, Fulmars, Shearwaters, p. 173. 


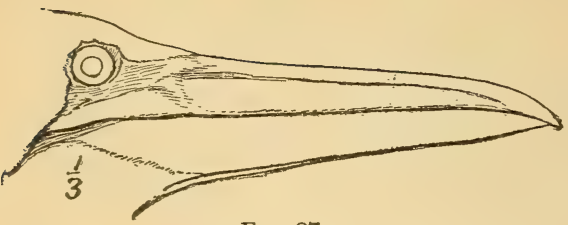

Fig. 27.

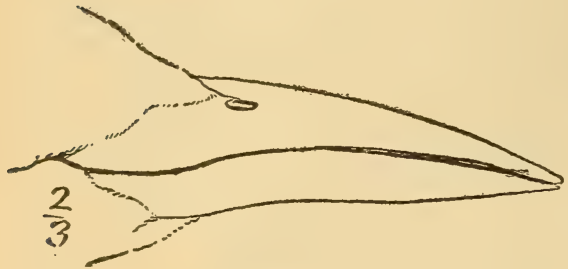

FIG. 28.

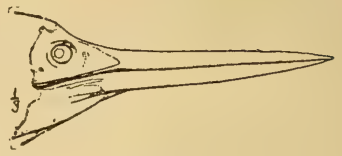

FIG. 30

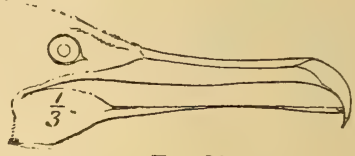

FIG. 31 .

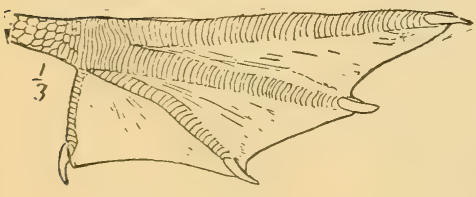

FIG. 29.

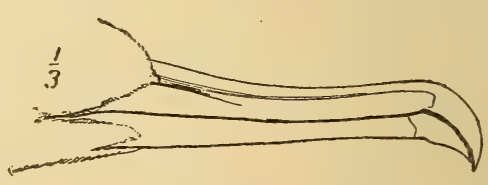

FIG. 32.

Order IV. Steganopodes.-Gannets, Cormorants, Pelicans, etc. Large birds, two feet or more in length, differing widely in appearance and habits; in external structure agreeing in having all four toes connected by webs (Fig. 29), though in the Fregatida and Phaëthontida this character is poorly developed.

A. Bill unhooked, more or less sharply pointed (Figs. 27, 28, 30).

a. Chin feathered, adult with very long central tail-feathers; maritime; general appearance ternlike; rarely enters United States. . . Family Phaëthontida: Tropic Birds (Fig. 28), p. 178.

$b$. Chin bare; central tail-feathers not greatly lengthened.

$b^{1}$. Sea-birds with thick necks and stout bills, central tailfeathers without transverse flutings. . . Family Sulida: Gannets (Fig. 27), p. 179.

$b^{2}$. In whole or part black or blackish; fresh-water or coast birds, with straight, slender bills (Fig. 30), central tailfeathers fluted. . . . Family Anhingida: DARTERs. p. 181.

B. Bill hooked (Figs. 31,32 ).

a. Lores bare, tail not forked.

$a^{1}$. Bill over $12 \cdot 00$, with a large pouch. . . Family Pelicanida: Pelicans, p. 183.

$a^{2}$. Bill under $4 \cdot 00$ (Fig. 31), no large pouch; black or blackish birds. . . . Family Phalacrocoracida: Cormorants, p. 182.

b. Lores feathered; tail deeply forked (Fig. 32). . . Family Fregatida: MAN-o'-WAR-BIRDs, p. 185. 
Order V. Anseres.-Ducks, Geese, and Swans.

Toes four; tarsus rounded not flattened as in the Grebes; tail well developed; bill rounded and with tooth-like projections, or flattened and with fluted ridges. Unlike the Grebes, most Ducks when pursued fly rather than dive.

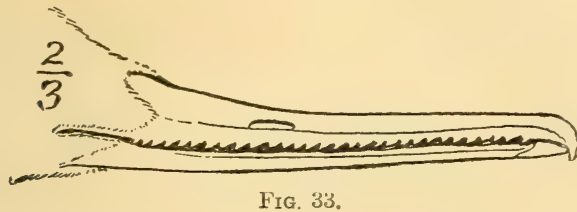

1. Bill, long, narrow and rounded, with tooth-like projections (Fig. 33). . . . Subfamily Mergince: Mergansers, p. 187.

2. Bill more or less flattened and ducklike.

A. Lores feathered.

a. True Ducks; tarsus shorter than the middle-toe without nail; scales on its front transverse more or less square (Fig. 34, $a, b$ ).

$a^{1}$. Hind-toe without a flap or lobe (Fig. $34, a$ ) . . . Subfamily Anatina: RIVER DUCKs, p. 190.

$a^{2}$. Hind-toe lobed (Fig. 34, b) . . . Subfamily Fuligulina:

SeA and Bay Ducks, p. 198.
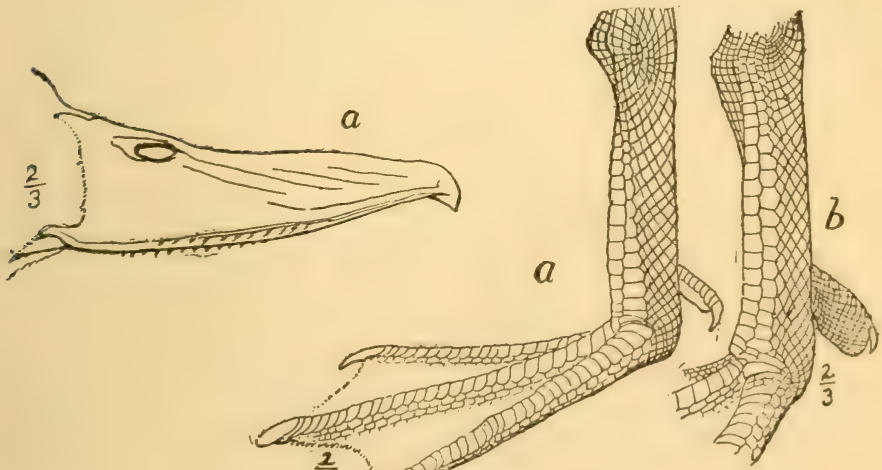

FIG. 34

b. Tarsus generally longer than middle-toc, without nail; scales on its front rounded. . . Subfamily Anserina: Geese, p. 210.

B. Lores bare. . . Subfamily Cygnince: Swans, p. 215. 
Order VI. Odontoglossæ.Flamingoes.

Long-legged, long-necked, red or pink - and - white birds; bill bent downward, with lateral ridges (Fig. $35)$; toes four, front ones webbed. With the characters of the Order..... Family Phonicopterida: Flamingoes, p. 216.

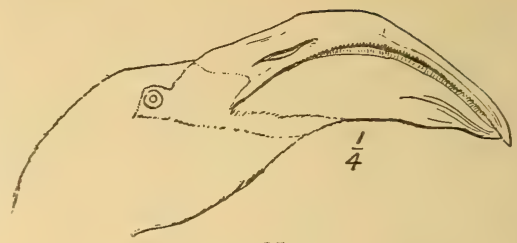

Fig. 35.

Grder VII. Herodiones.-Herons, Storks, Ibises, etc.

Long-legged, wading birds usually found along shores, on muddy flats or in marshes. Herons and Bitterns fly with a fold in the neck; Ibises and Spoonbills with the neck straight. Toes four, slightly or not webbed, all on the same level; lores bare.

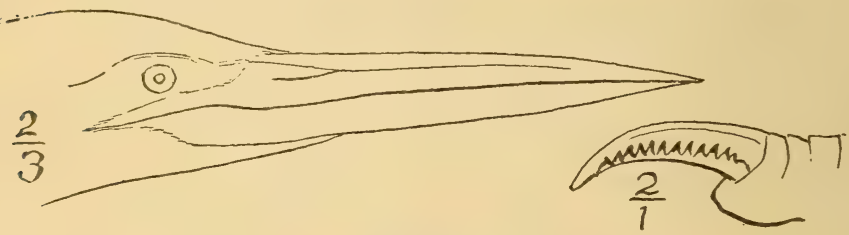

Fig. 36.

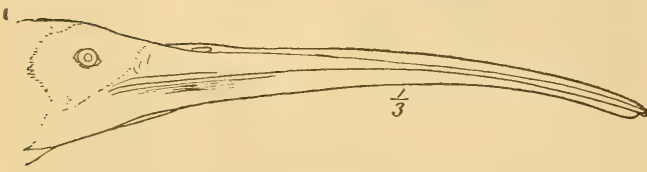

Fig. 37.

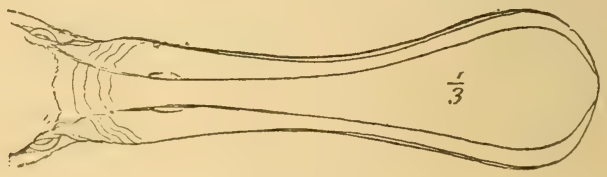

FIG. 38.

$A$. Bill straight and sharply pointed; inner border of middle toenail with a comblike edge (Fig. 36); neck curved in flight. . . . Family Ardeida: Herons, Egrets, Bitterns, p. 219.

$B$. Bill not sharply pointed, cylindrical or flattened (Figs. 37,38 ); no comb on toe-nail; neck straight in flight.

a. Bill rounded, more or less curved downward.

$a^{1}$. Size large, tarsus over $5^{\circ} 00$; whole head bare in adult. . . . Family Ciconiida: STORKs and Wood IBISEs, p. 219.

$a^{2}$. Size smaller, tarsus under 5.00; face bare (Fig. 37). . . . Family Ibidida: Ibises, p. 218.

b. Bill flattened and much broadened at the end (Fig. 38), our species pink. ... Family Plataleida: Spoonbills, p. 217. 

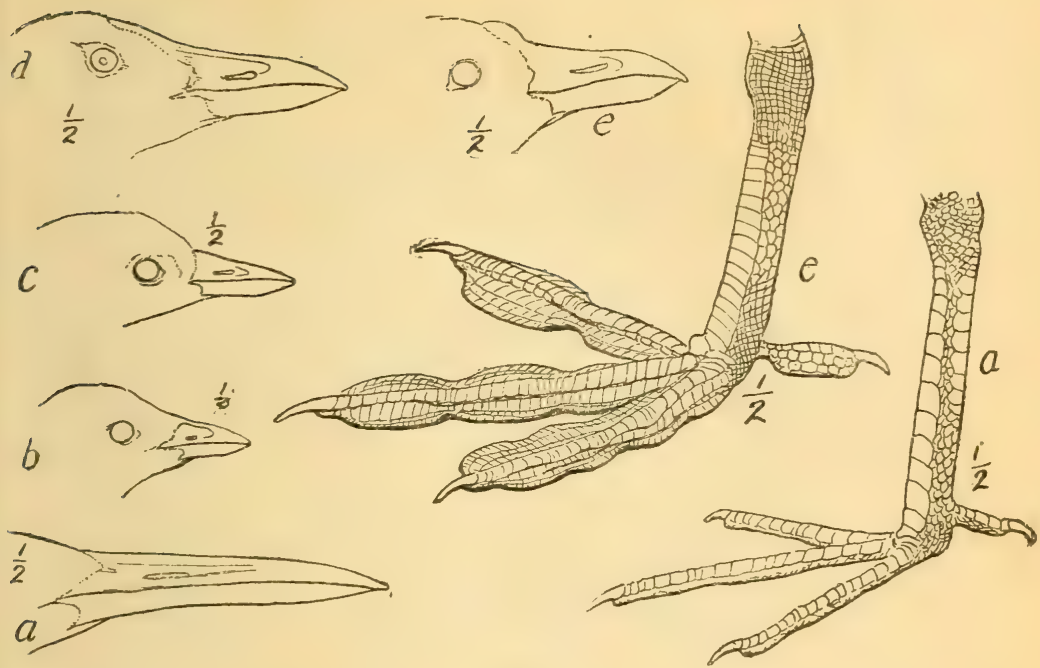

Frg. 39

Order VIII. Paludicolæ.-Cranes, Rails, Gallindles, etc.

Neck extended in flight; toes four without webs (except in lobate Coot, Fig. 39,e) or a comb on toe-nail; hind-toe generally small and higher than the front one; or if on the same level (Gallinules and Coots only), the bill is then comparatively short (Fig. 39, $d, e$ ) and the forehead bare; lores feathered or (Cranes) with hairlike bristles.

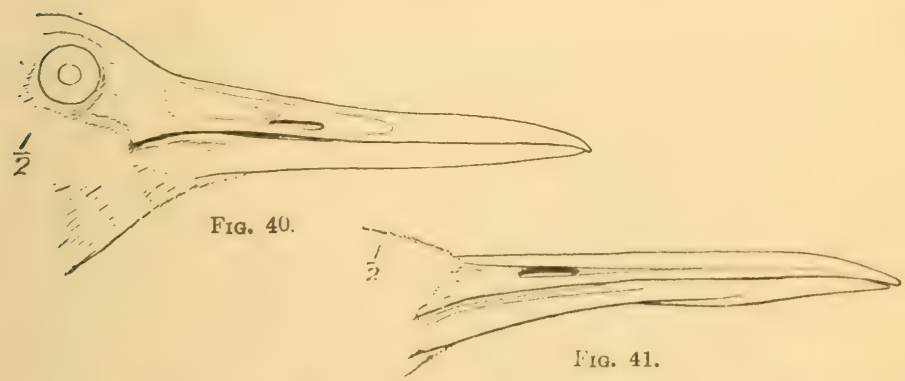

A. Smaller, bill under 3*00 (Fig. 39). . . Family Rallida: Raits, Gallinules, Coots, p. 230.

B. Larger, bill over $3^{\circ} 00$ (Figs. 40,41 ).

a. Tarsus over $\left(f^{\circ}\right) 0$ (Fig. H1).). . Family Gruila: CR.1.NEs, 1). 229.

b. Tarsus under $6^{\circ} 00$ (Fir. 11) . . . Family Aramida: Courlans, ๖. 230. 

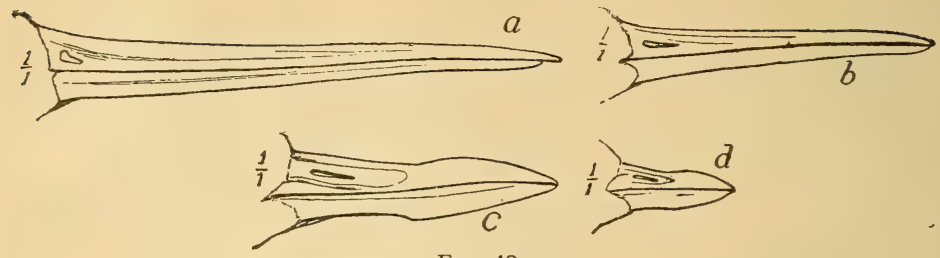

FIG. 42.

Order IX. Limicolæ.-Phalaropes, Snipes, Plovers, etc.

Long-legged, often slender-billed 'Shore-birds,' usually less than a foot in length, which frequently utter piping whistles in flight or as they take wing; toes four or (Plovers) three; the hind-toe, when present, less than half the length of the inner, and always elevated; bill soft; nostrils opening through slits or grooves; wings long and pointed, tertials much elongated.

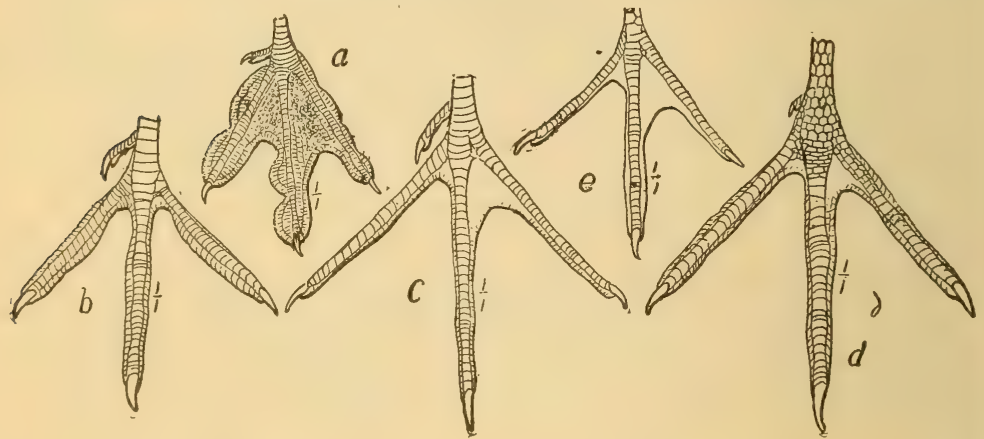

FIG. 43.

1. Tarsus over $3 \cdot 50$; noisy, conspicuous, black and white or black, and white and brown birds. .. Family Recuvirostrida: Avocets (Fig. 12) and Struts, p. 241.

2. Tarsus under $3 \cdot 50$.

A. Toes lobate (Fig. 43 a). . . Family Phalaropodida: PranarOPES, p. 239.

B. Toes not lobate (Fig. $43, b, c, d, e$ ).

a. Front of tarsus with square, transverse scales (Fig. 43, b, c); toes four' except in the Sanderling.

$a^{1}$. Whole lower back white, a black band across the rump; bill short, stout and slightly recurved. . . Family Aphrizida: Surf Birds and Turnstones, p. 268.

$b^{1}$. Whole lower back not white; bill a probe, softer, proportionately longer, not recurved (Fig. 42, $a, b$ ). . . Family Scolopacida: SNIPES, SANDPIPERS, ete., p. 242.

b. Front of tarsus with rounded scales; toes three (except in Black-bellied Plover). (Fig. 43, d, e.)

$b^{1}$. Bill under $2 \cdot 00$ (Fig. $42, c, d$ ). . . . Family Charadriida: Plovers, p. 263.

$b^{2}$. Bill over 2*00. . Fämily Hamatopodida: OxsterCATchers, p. 268. 


\section{THE LAND BIRDS}

Order $\mathbf{X}$. Gallinæ.-Turkeys, Grouse, Bob-Whites, etc.

Terrestrial, scratching birds of henlike form; bill stout and short, its culmen rounded (Fig. 44); wings short and rounded, the primaries stiffened and producing a whirring sound in flight; tail variable, feet strong, hind-toe short, elevated.

$A$. Smaller than a Turkey.

a. Tarsus unfeathered. . . Family Odontophorida: BOB-WHITES and NEW WORLd QUaILs, p. 269.

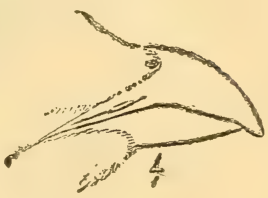

FIG. 44.

b. Tarsus more or less feathered . . . Family Tetraonidae: Grouse. Ptarmigans, etc., p. 272.

B. Size of a Turkey. . . . Family Meleagrida: Turkeys, p. 278.

\section{Order XI. Columbæ.-Pigeons and Doves.}

Toes four, all on the samelevel; the hind-toe about as long as the shortest front one; bill (Fig. 45) ( slender, deeply grooved, the nostrils opening in a soft, fleshy membrane.

Characters those of the Order. ... Family Columbida: Pigeons and Doves, p. 281

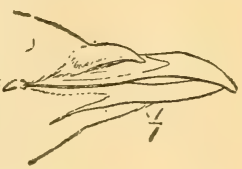

FIG. 45

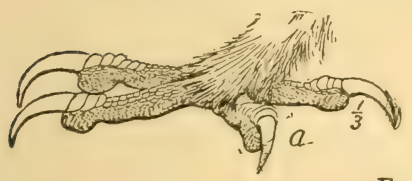

FIG. 46.

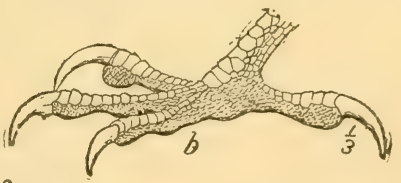

Order XII. Raptores.-Vultures, Hawks, and Owls.

Generally large birds with hooked bill; feet strong with long curved nails. (Fig. 46.)

A. Eyes set in a feathered disk (Figs. 47,48 ), tarsus generally feathered; plumage soft and fluffy.

a. Middle-toe with a comblike edge. ... Family Aluconida: BARN OWls, p. 308.

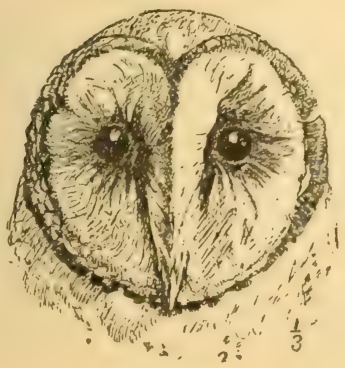

FIa. 47.

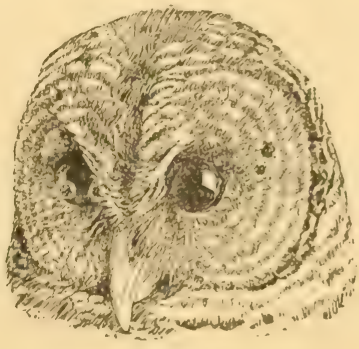

KIG. 45. 


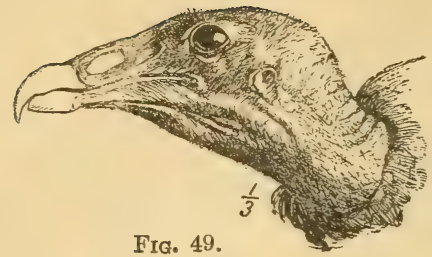

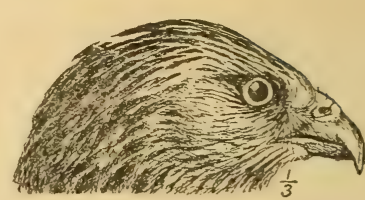

FIG. 50.

b. Midsle-toe without a comblike edge. .. Family Strigida, p. 309.

$B$. Eyes not set in a feathered disk, tarsus largely bare; plumage firm and close.

a. Front of tarsus with square scales.

$a^{1}$. Bill not strongly hooked; toe-nails comparatively weak; nostrils large, piercing the bill; head and more or less of neck bare (Fig. 49). . . . Family Cathartida: AMERICAN VULTURES, p. 286.

$a^{2}$. Bill strongly hooked (Fig. 50); hind-toe generally as long as or longer than the shortest front one; claws large; head not bare. . . . Family Buteonida: Hawks, Eagles, Kites, p. 287.

b. Front of tarsus with rounded scales.

$b^{1}$. Soles of feet thickly set with sharp spicules (Fig. 20). . . Family Pandionida: Ospreys, p. 307.

$b^{2}$. Soles of feet without spicules. ... Family Falconida: Falcons, Caracaras, etc., p. 303.

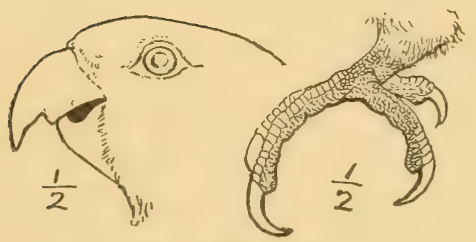

Order XIII. Psittaci.-PARRots, Paroquets, etc.

Toes four, two in front, two behind; bill strong, hooked, with a cere; lower mandible scoop-shaped (Fig. 51).... Family Psittacida: PArrots; PAROQUets, p. 317.

FIG. 51.
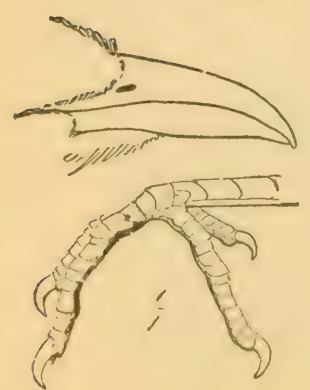

Fra. 53.

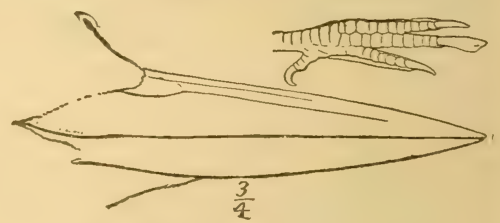

FIG. 52.

Order XIV. Coceyges. - Cucroos, KingFISHERS, etc.

Toes four, the middie and the outer ones joined for half their length (Fig. 52) or two in front and two behind (Fig. 53); bill without a cere; tail-feathers not stiff and pointed. 
A. Middle and outer toes joined for half their length (Fig. 52). . . Family Alcedinida: Kingrishers, p. 320.

B. Two toes in front and two behind (Fig. 53). . . F Family Cuculida: Cuckoos, p. 318.

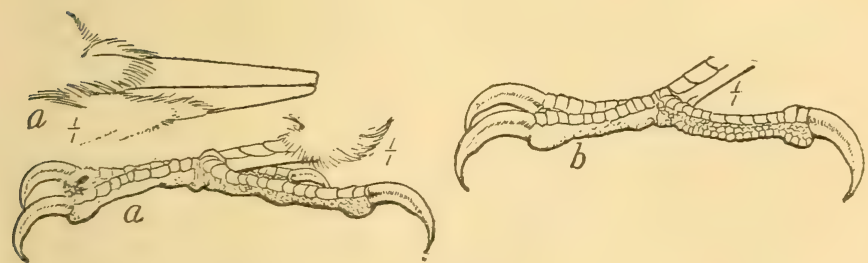

FrG. 54.

\section{Order XV. Pici.-Woodpeckers.}

Climbing birds with stout, pointed bills, bristly nostrils, pointed, stiffened tail-feathers; strong feet and nails; toes four, two in front, two behind, or three, two in front, one behind (Fig. 54). Prevailing colors black and white, the male usually with red on the head.

Characters those of the Order. . . Family Picida: Woodpeckers, p. 322 .

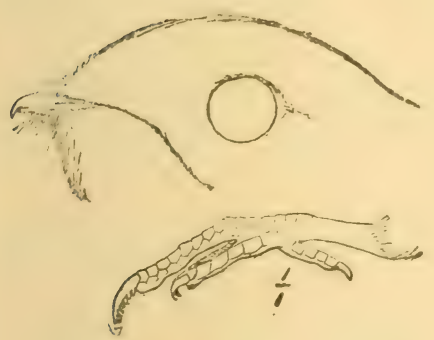

Fra. 55.
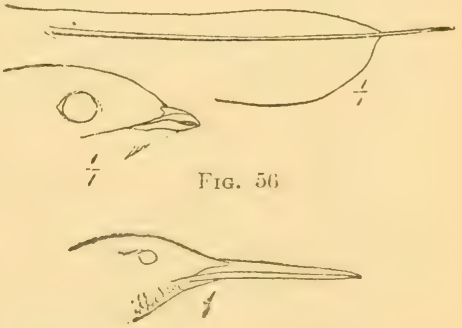

FIG. 57.

Order XVI. Machrochires.-Goatsuckers, Swifts, and Hummingimis. An obsolete group to which, for the present, the A. (). U. continues to refer our American (ioatsuckers, swifts, and Humminglirds with more obvious external characters as below.

A. Size comparatively large, plumage soft, variogated black, brown, and buff; middle-toe with a eomblike edge (Fig. 55). . . .

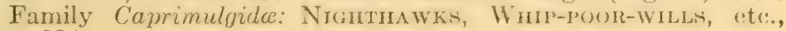
p. 331 .

$B$. Size medium, plumage close, firm, sooty llack; tips of tailfeathers with spines (Fig. 56). ... Family Micropodide: SwifTs, p. 334.

C. Size very small, upperparts shining green; bill long and slender (Fig. 57). . . . Fumily Trochilida: Humancibirds, p. 335. 
Order XVII. Passeres.-Perching Birds: Flycatchers, Blackbirds, Jays, Orioles, Sparrows, Finches, Swallows, Vireos, Warblers, Wrens, Thrushes, etc.

Toes four, without webs, all on the same level; hindtoe as large as the middle one, its nail generally longer than that of the middle one; tail of twelve feathers. (Fig. 58.)

[The following synoptical table of the characters of the twenty families which we have in this order seems more satisfactory than an artificial key.]

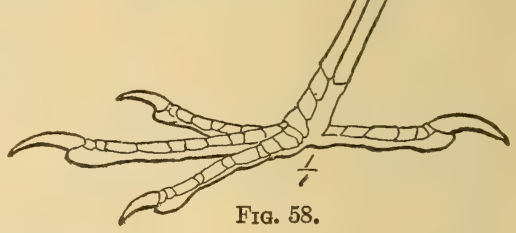

Family 1. Tyrannida.-Flycatchers (Fig. 59).
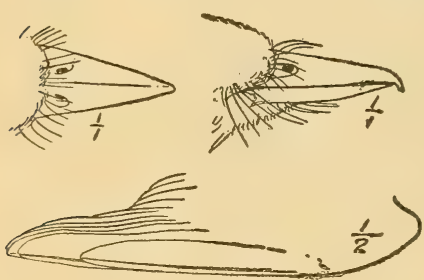

FIG。 59.

Family 2. Alaudida. - L A RKS (Fig. 60).

Bill rather stout and rounded; nostrils with bristly tufts; nail of hind-toe much lengthened, as long as the middle-toe without nail; back of the tarsus rounded like the front, p. 347.

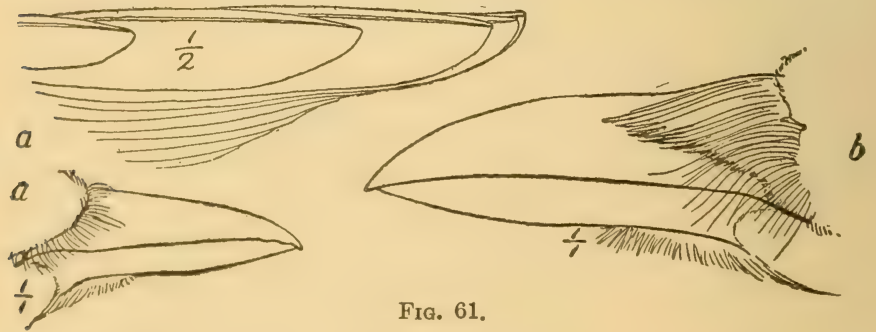

Family 3. Corvida.-Crows and JAYS (Fig. 61).

Large birds, over 10.00 in length; bill stout, the nostrils concealed by tufts of bristly feathers; fourth to fifth primary the longest, the first about half as long; outer tail-feathers shortest; feet and legs stout, p. 350. 
Family 4. Sturnida.-STARLINGS (Fig. 62).

Bill flattened, wider than high at the base; tail short and square; wings long and pointed, second primary longest, the first very small, less than half an inch in length, p. 355.

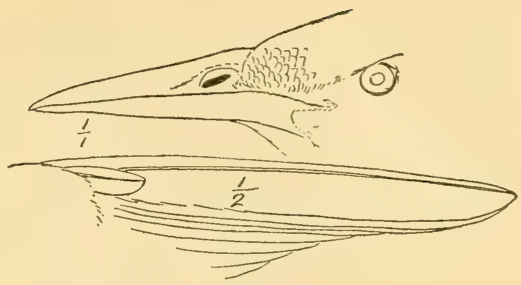

FIG. 62 .
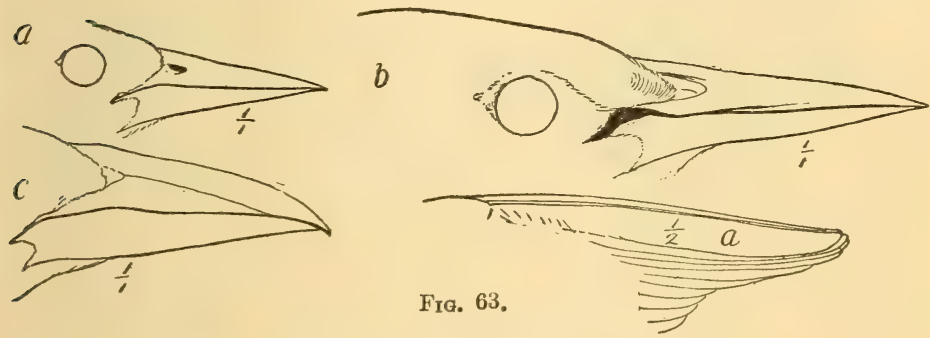

Family 5. Icterida.-Blackbirds, Orioles, etc. (Fig 63).

Length $7 \cdot 00-17 \cdot 00$; base of the bill, between the nostrils, extending backward and dividing the feathers of the forehead; nostrils not concealed by bristles; first three primaries of about equal length; outer tail-feathers generally shortest, p. 357 .

Family 6. Fringillida.-SPARrows, Finches, GrosBEAKS, etc. (Fig. 64).

Length $4 \cdot 75-9 \cdot 00$, generally under 8.00 ; bill short, stout, and conical, admirably fitted to crush seeds; third and fourth primaries generally about the same length, the first never more than half an inch shorter than the longest, p. 369 .

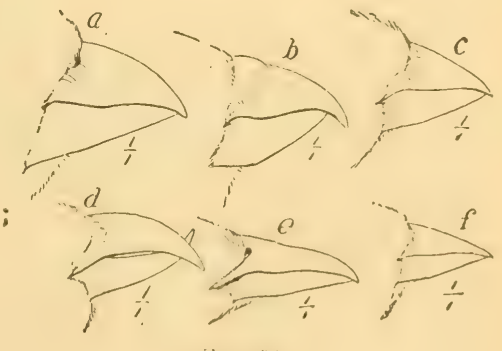

ilis. (i.1.

Family 7. Tangarida.-TANAGERs (Fig. 65).

Length about $7 \cdot 00$; the males of our species mostly red; bill finchlike, but less conical, somewhat swollen, the outline of the upper mandible curved, its sides with a slight but generally evident 'tooth' near the middle; tail-feathers of equal length, p. 413.

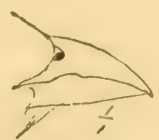

Fia. 65. 
Family 8. Hirundinida.-Swallows (Fig. 66).

Bill short and flattened, much wider than high at the base; no bristles at the base of the bill; wings long and pointed, tips, when closed, generally reaching beyond the end of the tail; first primary the longest; outer tailfeathers longest; feet small, tarsus short, round in front, narrower and sharper in the back, p. 415.
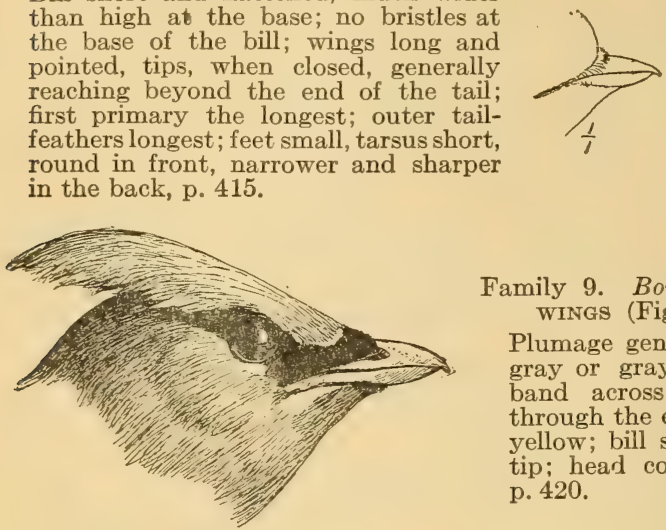

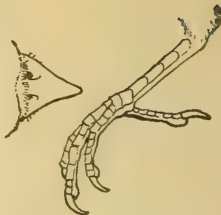

FIG. 66.

Family 9. Bombycillida. - W A XWINGS (Fig. 67).

Plumage generally soft, brownish gray or grayish brown; a black band across the forehead and through the eyes; tail tipped with yellow; bill short, notched at the tip; head conspicuously crested, p. 420 .

FIG. 6..

Family 10. Laniida.-Shrikes (Fig. 68).

Grayish birds, 8.00-9.00 in length, most of the tail-feathers tipped with white; bill hooked and hawklike, p. 422.

Family 11. Vireondia.-Vireos (Fig. 69).

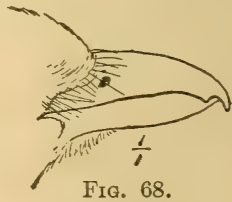

Small birds, $5 \cdot 00-7 \cdot 00$ in length, with generally olive-green backs; tailfeathers without white spots; bill rather stout, higher than broad at the base,
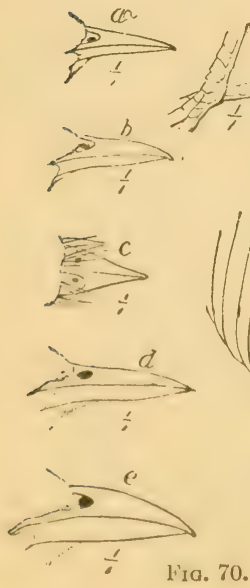

lis. 70. the tip of the upper mandible notched and hooked, bristles at the base of the bill barely evident; tarsi scaled, round in front, narrower and sharper behind; toes united at the base, p. 424.

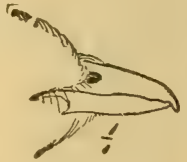

Fig. 69.
Family 12. Mniotiltida.-Wood WARBLERS (Fig. 70).

Small birds, length generally under 6.00 , but in four species $6 \cdot 50-7 \cdot 50$, with, as a rule, brightly colored plumage, olive-green or yellow being the most frequent; bill various, never notched at the tip, usually slender and sharply pointed, without conspicuous bristles, but sometimes flattened and broader than high at the base, when the bristles are evident (thus resembling the bill of a true Flycatcher, but the back of the tarsus is always thin 
and narrow, and never rounded as in front); rarely the bill is heavier, more thrushlike or finchlike; second or third primary longest, the first little if any shorter; tail generally square, sometimes rounded, the outer feathers frequently blotched with white, p. 430.

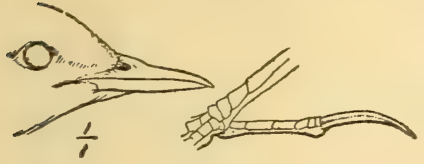

FIG. 71.

Family 13. Motacillido.-W -Watails and PipITs (Fig. 71).

No bristles over the nostrils; bill slender, much as in the preceding; hind toe-nail much lengthened, as long as or longer than the toe; first three primaries of equal length, p. 470.

Family 14. Mimida.-Thra Shers, Mockingbirds, and CATBIRDS (Fig. 72, $a, b$ ).

Length $8^{\circ} 00-12^{\circ} 00$; tarsus scaled; tail rounded, the outer feathers at least half an inch shorter than the middle ones, third to fifth primary longest, the first about half as long, p. 472.

Family 15. Troglodytide.-Wrens (Fig. $72, c, d)$.

Length $4 \cdot 00-6 \cdot 00$; bill moderate, the upper mandible slightly curved, no bristles at its base; third to fourth primary longest, first about half as long; tail short and rounded; brown or brownish birds with indistinctly barred wings and tail, p. 475 .

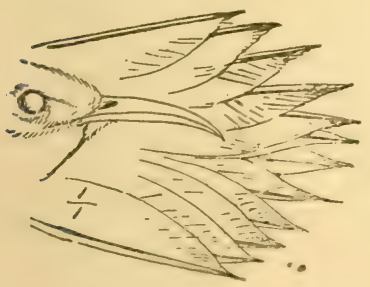

FIG. 73.

Family 17. Sittida.-Nuthatches (Fig. 74, $a, b)$.

Bill rather long and slender, the end of the lower mandible slanting slightly upward; wings long and pointed, the third or fourth primary the longest, the first very small, not an inch in length; tail short and square, the outer feathers blotched with white, p. 482 .

Family 18. Parida.-Tiтmce (Fig. $74, b$ ). Length $4.50-6.50$; bill short, stout, and rounded, less than half an inch in length;

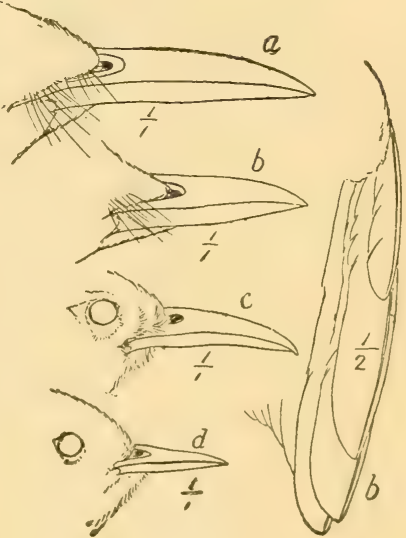

FIG. 72 . Bill slender and much curved; tail-feathers pointed and slightly stiffened, p. 481 .

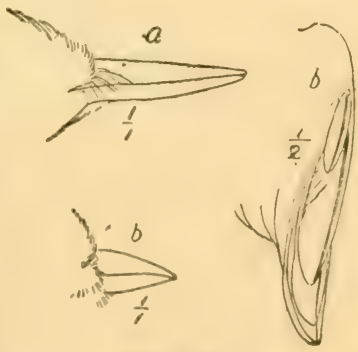

FIG. 74. 


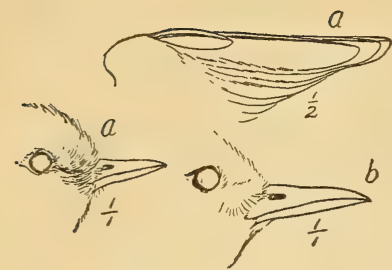

FrG. 75.

fourth or fifth primary longest, first very short, not more than one-third as long; tail rather long, dull, ashy gray without white blotches, p. 485 .

Family 19. Sylviida.-KINGLets and Gnatcatchers (Fig. 75).

Length 3.50-5.00; bill slender, resembling that of some Warblers, but the first primary is very short, only about one-third as long as the longest, p. 488.

Family 20. Turdida.Thrushes, Bluebirds, etc. (Fig. 76).

Length over 5.50 ; bill moderate, the tip of the upper mandible notched; tarsus smooth, the scales, if any, fused and indistinct; tail square; wings long and pointed, $3 \cdot 75$ or over, third primary the longest, the first very short, less than one inch in length, p. 491.

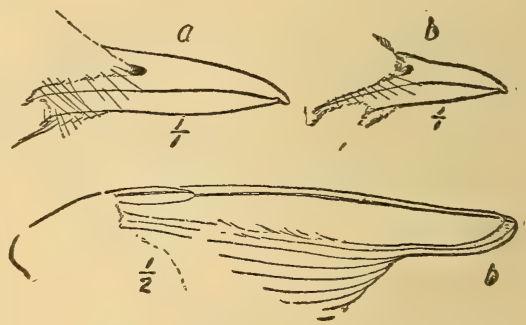

Fig. 76. 


\section{A FIELD KEY TO OUR COMMONER EASTERN LAND BIRDS}

The following is a field key to those birds which, either because of their abundance or conspicuous colors, most frequently attract our attention. With the object of making it as brief, and consequently as simple, as possible, I have omitted species which can be referred to their respective families without difficulty-for example, Hawks, Owls, Woodpeckers, and Swallows. It is designed simply as an aid to the first steps of the beginner, who will soon graduate from it to the more detailed keys in the body of the book. Like the field keys to Finches and Sparrows and Warblers, it is based largely upon adult males.

First Group.-With yellow or orange in the plumage.

Second Group.-With red in the plumage.

Third Group.-With blue in the plumage.

Fourth Group.-Plumage conspicuously black, or black and white.

Fifth Group.-Without either yellow, orange, red, or blue in the plumage; not conspicuously black, or black and white.

\section{First Group.-With yellow or orange in the plumage}

I. Throat yellow.

1. Throat and breast pure yellow, without streaks or spots.

$A$. Length $5^{\circ} 00$; cap, wings, and tail black; back yellow; song canarylike, sometimes uttered on the wing; flight undulating, frequently accompanied by the notes chic-o-ree, per-chic-o-ree.

B. 529. GoldFinch.

$B$. Length 5.50 ; lower belly and wing-bars white; back olive-green; frequents the upper branches, generally in woodland; actions deliberate; song loud and musical, uttered slowly, often with pauses: "See me? I'm here; where are you?"

628. Yellow-throated Vireo.

$C$. Length $5 \cdot 25$; cheeks and forehead black bordered by ashy; upper parts olive-green; no wing-hars; haunts thickets and undergrowth; movements nervous and active; call-note, pit or chack; song, a vigorous, rapid witch-e-wèe-o, wi'ch-e-wèe-o, witch-e-wèe-o.

681. Maryland Yellow-throat

$D$. Length $7 \cdot 25$; upperparts olive-green; no wing-bars; a white line before the eye; haunts thickets and undergrowth; song, a striking mixture of whistles, chucks, and caws, sometimes uttered on the wing. . . . . . . . . 683. Yellow-breasted Chat.

2. Underparts streaked or spotted.

$A$. Underparts streaked with rufous-brown; length 5.00 ; general appearance of a yellow bird; haunts shrubbery of lawns, orchards, second growths, and particularly willows near water; song, rather

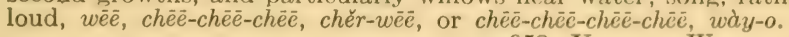

652. YelLOW WARBLER.

$B$. Breast yellow, with a conspicuous black crescent; length 10.00; fields and meadows, largely terrestrial; flight quail-like, outer white tail-feathers showing when on the wing; song, a loud, musical whistle ................. 501. Meadowlark. 
II. Throat not yellow.

1. Throat white.

$A$. With yellow on the sides.

a. Length 5.50; rump yellow; breast streaked or spotted with black; tail-feathers marked with white; note, a characteristic tchip; Sept. to May, usually rare or local in winter.

655. Myrtle Warbler.

b. Length 5*00; no streaks on underparts or white in the tail; yellow extending along the whole sides; back olive-green, iris white; haunts thickets; call, an emphatic "Who are you, eh?"

631. WHITE-EYED VIREO.

c. Length $5 \cdot 25$; tail and wings banded with yellow, showing conspicuously in flight; haunts woodland; movements active, much in the air, tail frequently spread . . . . . . . 687. RedstaRT.

$B$. No yellow on sides.

a. Length $6 \cdot 75$; a yellow line from the bill to the eye; crown black, with a white stripe through its center; haunts in and about thickets and bushy woodlands; song, a high, clear, musical whistle; call-note, chink.....558. WHITE-THROATED SPARROw.

$b$. Length 4:00; a yellow or yellow and orange crown-patch, bordered by black; flits restlessly about outer limbs of trees and bushes; note, a fine $t i$ - $t i$; Oct. to Apl...748. Golden-CROwned KingLet.

2. Throat not white.

A. Throat vinaceous; length 12.00 ; a black breast-patch; belly white, spotted with black; rump white, showing conspicuously in flight; linings of wings yellow; call-note, a loud kèe-yer . . 412. FuICKER.

$B$. Throat and head black; length $7 \cdot 50$; breast, belly, and lower back deep orange; an active inhabitant of fruit and shade trees; song, a loud, ringing whistle........ 507. Baltimore Oriole.

$C$. Throat and upper breast ashy; length 9.00 ; crested; belly yellow; tail-feathers largely pale rufous; haunts upper branches in woodland; note, a loud questioning, or grating whistle.

452. Crested Flycatcher.

$D$. Grayish brown; length $7^{\circ} 00$; crested; tip of tail yellow.

619. Cedar Waxwing.

\section{Second Group.-With red in the plumage}

I. With red on the underparts.

A. Throat red.

a. Length 7.00; wings and tail black; rest of plumage bright scarlet; call-note, chip-chirr . . . . . . . 608. SCARLET TANAGER.

b. Length 6.00; dull, pinkish red, wings and tail brownish; frequently seen fceding on buds or blossoms; call-note, a sharp chink, often uttered during flight; song, a sweet, flowing warble.

517. Purple Finch.

c. Length 6.00; dull red or green tinged with red; mandibles crossed; generally seen in flocks feeding on pine-cones. . 521. Am. Crossbill

$d$. Length 5.00; a red crown-cap; back streaked black and brown; breast rosy; feeds $\mathrm{n}$ seeds or catkins; Nov. to Mch. .528. Redpoll.

B. Throat black.

a. Length $8 \cdot 00$; breast rose-red, rest of plumage black and white; song loud and musical; call-note, peek. .595. ROSE-BREASTED GROSBEAK.

b. Length 8.00; a conspicuous erest; region about the base of the bill black; rest of the plumage and bill red; song, a clear whistle.

593. Cardinal.

c. Length 5.50; wings and tail banded with orange-red, showing conspicuously in flight; movements active; much in the air; tail frequently spread; haunts w odland....... 687. REDSTART. 
II. No red on the underparts.

A. Length 9.00; black; shoulders red; haunts marshes; migrates in flocks. 498. RED-WINGED BLACKBIRD.

$B$. Length $5 \cdot 25$; crown-cap red; chin black; rest of underparts streaked with blackish; feeds on seeds and catkins; Nov. to Mch.

528. Redpoll (Im.).

C. Length 4.00 ; underparts whitish; back olive-green; a ruby crownpatch; eye-ring white; movements restless, wings flitted nervously; call-note, cack; song remarkably loud and musical; Sept. and Oct.; Äl. and May. . . . . . . . . . 749. Ruby-Crowned Kinglet.

\section{Third Group.-With blue in the plumage}

A. Length 11.50 ; a conspicuous crest; upperparts dull blue; underparts whitish; a black patch on the breast ....... 477. BLUE JAY.

$B$. Length 7:00; upperparts bright blue; breast cinnamon-rufous.

C. Length 5.50; entire plumage indigo-blue..598. Indigo Bunting.

\section{Fourth Group.-Plumage conspicuously black, or black and white}

I. Black and white birds.

A. Throat black.

a. Length over $6^{\circ} 00$.

$a^{1}$. Entire underparts black; nape buffy; rump white; a musical dweller of fields and meadows; frequently sings on the wing.

494. Boвolink.

$a^{2}$. Breast rose-red; rest of the plumage black and white; song rapid, loud, and musical; call-note, peek; a tree dweller in rather open. woodland ........ 595. Rose-breasted Grosbeak.

$a^{3}$. Sides rufous; rest of the plumage black and white; call-note, chewink or towhee; inhabits the undergrowth . . 587. TowheE.

b. Length under 6.00.

$b^{1}$. Crown black; cheeks white; back ashy; unstreaked; call, chick-adee, or a musical, double-noted whistle ...735. Chickadee.

$b^{2}$. Conspicuously streaked with black and white; a tree creeper.

$B$. Underparts white or whitish.

636. Black and White Warbler.

a. Length 8.00; upperparts grayish slate-color; tail tipped with white; a bird of the air, catching its insert food on the wing, and occasionally sallying forth from its exposed perch in pursuit of a passing Crow; note, an unmusical, steely chatter ... 444. KingBind.

$b$. Length 5.75; crown black; back bluish gray; a tree ereeper; (all-note, yank, yank ...... 727. White-Breasted Nuthatch.

c. Length 6;50; upper parts washed with rusty; generally seen in flocks; terrestrial; Nov.-Mch. ......... 534. Snow Bunting

II. No white in the plumage.

A. Length $19 \cdot 00$; jet-black . . . . . . . . . . 488. Am. Crow.

$B$. Length $12 \cdot 00$; black with metallic reflections; iris yellowish; migrates in flock:; nests usually in colonies in eoniferous trees; voice cratcked and reedy; tail "keeled" in short flights; a walker.

511. Purple Grackle. $511 b$. Bronzed Grackle.

C. Length 9.50; shoulders red; haunts narshes; call, lioney-quér-rée.

498. RED-WINGED BLACKBIRD.

D. Length 7:50; head and neck coffee-brown; frequently seen on the ground near cattle . . . . . . . . 495. Cowbird. 
Fifth Group.-Without either yellow, orange, red, or blue in the plumage; not conspicuously black, or black and white

I. Underparts all one color, without streaks or spots.

1. Back without streaks or spots.

$A$. Underparts white or whitish.

a. Length under 7:50.

$a^{1}$. Back olive, olive-green, or slaty fuscous.

$a^{2}$. No white line over the eye; flycatchers, capturing their prey on the wing and returning to their perch, where they sit quietly until making a fresh sally.

$a^{3}$. Crown blackish; frequently found nesting under bridges or about buildings; tail wagged nervously; note, pewit-phobe.

456. Рнавве.

$a^{4}$. Wing-bars whitish; haunts orchards, lawns, and open woodland; note, chebèc, chebèc . 467. LEAst Firycatcher.

$a^{5}$. Haunts woodlands; generally frequents the upper branches; note, a plaintive pee-a-wee. . ... 461. Wood PEwEe.

$b^{2}$. A white line over the eye, or wing-bars white; gleaners; patiently exploring the foliage for food or flitting about the outer branches.

$b^{3}$. White line over the eye bordered by a narrow black one; cap gray; iris red; song, a rambling recitative: "You see it -you know it-do you hear me?" etc.

624. RED-EYED VIREO.

b4 $^{4}$ White line over the eye not bordered by black; prefers the upper branches of rows of elms and other shade trees; song a rich, unbroken warble with an alto undertone.

627. WARBLING Vireo.

$\mathbf{b}^{5}$. No white line over the eye; eye-ring and wing-bars white; length 4.00; a tiny, unsuspicious bird; flits about the outer branches of trees and shrubs; wings twitched nervously; note, cack; song, a remarkably loud, musical whistle.

31. Back not olive-green, or slaty fuscous.

749. Ruby-CRowned Kinglet.

$b^{2}$. Back gray or bluish gray.

$b^{3}$. Crown black; cheeks white; a tree creeper; note, yank, yank. 727. WHITE-BREASTED NUTHATCH.

$b^{4}$. A gray, crested bird; forehead black; no white in the tail; note, a whistled peto, peto, or hoarse de-de-de-de.

731. Tufted TrT.

$c^{2}$. Back cinnamon-brown; length 4.75; a nervous, restless, excitable bird; tail carried erect; song, sweet, rapid and rippling, delivered with abandon ....... 721. House Wren.

b. Length over $7 \cdot 50$.

$b^{1}$. Upperparts grayish slate-color; a white band at the end of the tail; a concealed orange-red crest; a bird of the air, catching its insect food on the wing, and occasionally sallying forth from its exposed perch in pursuit of a passing Crow; note, an unmusical, steely chatter......... 444. KingBird.

$b^{2}$. Length 12.00 ; slim, brownish birds with long tails; flight short and noiseless; perch in a tree, not in an exposed position; note tut-tut, cluck-cluck, and cow-cow.

387. Yellow-Billed Cuckoo. 388. Black-Billed Cuckoo. B. Underparts not white.

a. Slate-color; cap and tail black; inhabits the lower growth; call-note, nasal; song highly musical and varied; length 8.50 .

704. Catbird.

b. Grayish brown; conspicuously crested; a black line through the eye; tail tipped with yellow; generally seen in small flocks; note thin and weak; length $7 \cdot 00 \ldots . .619$. Cedar Waxwing. 
c. Underparts cream-buff; a conspicuous whitish line over the eye; upperparts rufous-brown; movements active; tail carried erect; haunts lower growth; notes loud and striking; length 5.50.

2. Back streaked.

718. Carolina Wren.

$A$. Crown rufous or chestnut without streaks.

a. Length $5 \cdot 25$; bill black; a whitish line over the eye; a familiar bird of lawns and dooryards; song, a monotonous chippychippy-chippy. ......... 560. Chipping Sparrow.

b. Length 5.50; bill reddish brown, back rufous, or rufous-brown; wing-bars and eye-ring whitish; haunts dry, bushy fields and pastures; song, a musical, plaintive cher-wee, cher-wee, cher-wee, cheeo, dee-dee-dee-dee......... 563. Field Sparrow.

c. Length 5.50; forehead black; crown and wings chestnut-rufous; flanks pale grayish brown; haunts marshes; song, a rapidly repeated weet-weet-weet, etc. . . . . 584. Swamp Sparrow.

$B$. Crown not rufous or chestnut.

a. Length 6.75; crown, blackish with a central whitish stripe; throat white; breast gray; a yellow spot before the eye; haunts in and about thickets and bushy woodlands; song, a high, clear, musical whistle; call-note, chink . . 558. White-throated Sparrow.

b. Length 5.50; crown finely streaked; a tree climber, winding patiently up tree trunks in search of food; tail-feathers pointed.

726. BROWN CREEPER.

c. Length 5.50; bill slender; a white line over the eye; tail carried erect; haunts reedy marshes; call-note scolding; song, rippling.

725. Long-BILled Marsh Wren.

II. Underparts not all one color.

1. Underparts white or whitish, streaked or spotted.

$A$. Back streaked.

a. Crown streaked; underparts conspicuously streaked.

$a^{1}$. Outer tail-feathers white, showing conspicuously when the bird flies; length 6.00; haunts dry fields and roadsides; song loud and musical ........ 540. Vesper Sparrow.

$b^{1}$. Outer tail-feathers not white.

$b^{2}$. Length 6.00; plumage with a rufous-brown cast; spots on the breast tending to form one large spot in its center; haunts on or near the ground, generally in the vicinity of bushes; call-note, a characteristic chimp; song musical....581. Song Sparrow.

$b^{3}$. Length $6.00 ;$ no rufous in the plumage; streaks on the underparts evenly distributed; frequently seen feeding on buds or blossoms; call-note, a sharp chink, often uttered during flight; song, a sweet, flowing warble. . 517. PURPLE FINCH (Im.).

b. Crown not streaked, rufous-brown; underparts whitish with an indistinct blackish spot in the center of the breast; Oct. to Apl. . . . . . . . . . . 559. Tree Sparrow.

$B$. Back not streaked.

a. Upperparts rufous, olive-brown, or cinnamon-brown.

$a^{1}$. Bill slender and thrushlike; breast spotted with blackish.

$a^{2}$. Length $11^{\circ} 00$; tail 5.00; wing-hars white; upperparts, wings, and tail uniform rufous; haunts undergrowth; sings from an exposed and generally elevated position; song loud, striking and continuous. ....... 705. BROWN THRAsher.

$b^{2}$. Length under $9 \cdot 00$; tail under 300 ; no wing-bars.

$b^{3}$. Breast and sides heavily marked with large, round, black sp ts; head and upper back brighter than lower back and tail; call-note, a sharp pit or liquid quirt. 755. WOOD THRUsh.

$b^{4}$ : Breast with wedge-shaped black spots; sides unspotted, washed with brownish ashy; tail rufous, brighter than back; call-note, a low chuck ... . . 7593, Hermit Throsh. 
$b^{5}$. Upper breast lightly spotted with small, wedge-shaped, blackish spots; tail the same color as the back; sides white; callnote, a clearly whistled whèeu. . . . . . . 756. VEERY.

$b^{1}$. Bill short and stout; breast and sides heavily spotted with rufous; length $7 \cdot 00$; haunts on or near the ground, generally in or about shrubbery; call-note, tseep; song loud, ringing, and musical .

585. Fox Sparrow.

b. Back olive-green; center of crown pale rufous, bordered by black; length 6.00 ; haunts on or near the ground in woodland; a walker; song, a ringing teacher, teacher, TEACHER, TEACHER, TEACHER.

674. OVEN-BIRD.

Underparts not white or whitish.

$A$. Throat and upper breast black or slate-color, very different from the white or chestnut belly.

a. Throat black.

$a^{1}$. Belly and rump chestnut; head, wings and tail black; haunts orchards, shade trees, etc.; song highly musical.

506. Orchard ORIOLE.

$a^{2}$. Belly white; sides rufous; tail black and white; haunts undergrowths; call-note, chewink or towhee. . . . . 587. TowHEE.

h. Throat slate-color.

$b^{1}$. Back and wings slate-color; outer tail-feathers and belly white; haunts generally on or near the ground about shrubbery; Oct. to Apl. . . . . . . . . . . 567. Junco.

$B$. Throat streaked with black and white; rest of underparts rufous; upperparts grayish slate-color; length $10^{\circ} 00 . . . .761$. RoBIN.

\section{ORDER PYGOPODES. DIVING BIRDS}

\section{Family Colymbid As. Grebes. (Fig. 22a.)}

The Grebes, or lobe-footed divers, are of world-wide distribution. Of the twenty-five known species, six are North American. When nesting, Grebes usually frequent reed-grown ponds or sloughs, but during their migrations they are found in more open water and some species pass the winter well off the coast.

When on the water, Grebes bear a general resemblance to Ducks, but where the Duck would fly the Grebe usually dives. A few surface foot-strokes are the usual prelude to flight and, when in the air, the Grebe's smaller wings and shorter tail are evident, while when one is near enough to see their pointed bill no doubt is left of their family relationship.

Grebes are eminently aquatic birds, and rarely venture far on land, where their slow and awkward progress is more or less assisted by their wings, used as forefeet, though they can go a short distance aided by feet alone. When on shore, Grebes either lie flat on their breasts or sit erect on their tails and entire foot or tarsus.

The surprising rapidity with which Grebes dive, and the ease with which, formerly at least, they escaped the shot of the fowler, won for them such descriptive numes as 'Hell-diver,' 'Water-witch,' etc.; but the cartridges of the modern breech-loader do not give the warning of the discarded flint-lock or percussion cap, and to "dive at the flash" 
is now an obsolete expression. In diving, Grebes spring partly from the water and plunge downward, headfirst, or sink quietly backward, leaving scarce a ripple behind. Returning, they may pop suddenly from beneath the surface, or rise slowly and expose only the bill above the water, a habit which accounts for many apparently mysterious disappearances. When under water, Grebes progress usually by aid of the feet. With other diving birds, they control their specific gravity by inhaling or exhaling air, and it has lately been suggested (Townsend, "Labrador Spring," p. 191) that, by compressing their feathers and expelling the air between them, the birds become less buoyant when diving.

Grebes' nests are usually rafts or islands of water-soaked vegetation. They lay from three to nine dull white eggs, which they generally cover with the nest-material before leaving. The young are born covered with down, which, in most species, has a boldly striped pattern. They swim soon after hatching, using the back of the parent as a resting-place.

Grebes feed chiefly on fish, but eat also various small forms of aquatic life and some vegetable matter. Their stomachs usually contain feathers, often in astonishing numbers. I have found 331 body feathers of the adult Western Grebe in the stomach of a young bird of this species not more than three days old. This feather-eating habit has not, I believe, ever been explained. The close-plumed, satiny breasts of Grebes have long been used for turbans, muffs, capes, etc., and their slaughter for commercial purposes, added to the shrinkage in the area of their haunts, due to draining and land reclamation, has greatly reduced their numbers.

KEY TO THE SPECIES

A. Depth of bill at nostril over 35 .

a. Wing over $6.00 \ldots \ldots . . . . .2$. Holbell's Grebe. b. Wing under $6.00 \ldots \ldots \ldots \ldots$. Pied-BIlled GreBe. B. Depth of bill at nostril less than $35 \ldots \ldots . . .3$. Horned Grebe.

1. Aechmophorus occidentalis (Lawr.). WeSTERN Grebe. Neck long and slender; no seasonal difference in plumage. Ads.-Crown and hindneck black; back brownish gray; underparts satiny white; inner-web, of wingquills more or less white. L., 26.00; W., 7.50; B., '2.60.

Range.-W. N. A. Breeds from B. C., s. Sask, and s. Man. s. to n. Calif., Utah, and n. N. D.; winters from s. B. ( $\therefore$ s. to cen. Mex., casual e. to Nebr., Kans., Wisc., Minn., and Que.

Nest, in colonies of the stems and leaves of aquatic plants; an attached but floating raft, or an island. Eggss, 3-5, pale bluish overlaid with chalky white, $2 \cdot 39 \times 1.55$. Date, Devil's Lake, N. D., June 1 .

The long, slender neck gives to this species a singularly stately and swanlike appearance. It is an exquisitoly graceful creature, and there is to me more beauty in the satiny white and shining black of its neck and head than in the ornate breeding enstumes of some other Grebes. While preening their plumage they often lie on one side in the water, when the light flashes from their glistening breasts as it would from a mirror. Their call is a loud, double-toned, grating, whistle? $c-r-r-e e, c-r-r-e e$ - which can be clearly heard when the bird is out of 
sight on the open waters of the lake. They nest in colonies often containing hundreds of pairs, and I have known them voluntarily to spend much time away from their nests, leaving the eggs uncovered. I have also seen the bird while standing nearly erect in the nest place some covering over the eggs before sliding into the water at my approach. Thousands of these birds have been killed for their breasts by millinery collectors.

1902. Јов, H. K., Among the Water-Fowl, 15-28.-1908. Chapman, F. M., Camps and Cruises, 302, 330, 348.

2. Colymbus holbœllii (Reinh.). HolbæLl's Grebe. Ads. in summer.-Top of head, small crest, and back of neck, slossy black; back blackish; throat and sides of head silvery white; front and sides of neck rufous, changing gradually over breast into the silvery white belly; sides tinged with rufous. Ads. in winter. - Upperparts blackish brown; throat and underparts whitish; front and sides of neck pale rufous. Im.-Upperparts blackish; throat and underparts silvery white; neck and sides grayish. L., 19.00; W., 7·50; Tar., 2*20; B., $1 \cdot 90$.

Range.-N. N. A. and e. Asia. Breeds from nw. Alaska, n. Mackenzie, and n. Ungava s. to n. Wash., n. Mont., and sw. Minn.; winters from s. B. C., s. Wisc., s. Ont., and Maine s. to s. Calif., s. Colo., the Ohio Valley, and N. C.; casual in Ga. and Greenland.

Washington, uncommon W. V., Sept. 30-Mch. or Apl. Long Island, W. V., Nov. 11-Apl. 7. Ossining, rare T. V., Oct.-Dec. Cambridge, rare T. V. and W. V. N. Ohio, occasional in winter.

Nest, of water-soaked, decaying vegetation, an island or floating among rushes in a slough, generally attached to its surroundings. Eggs, 3-8, dull white, more or less soiled, $2 \cdot 25 \times 1 * 35$. Date, Grant Co., Minn., May 28.

Although this large Grebe breeds in reed-grown lake borders, at other seasons it frequents large bodies of open water, and in winter resorts to the sea, where I have seen it fifty miles from land. So far as my experience goes it thoroughly covers its eggs, even when frightened from the nest, and although making every effort to avoid being seen, remains near its home, uttering a sharp explosive cluck of protest. Brewster describes its call as deliberately uttered and exceedingly loud and harsh, not unlike the voice of an angry Crow, but with much greater volume.

1903. Srm, R. J., Wilson Bull., 67-74, (habits in captivity).

3. Colymbus auritus Linn. Horned GreBe. Ads. in summer.Top of head, hindneck, and throat, glossy blackish; lores pale chestnut; stripe, and plumes behind eye, buffy ochraceous, deeper posteriorly; back and wings blackish; secondaries white; foreneck, upper breast and sides chestnut; lower breast and belly white. Ads. in winter and Im.-Upperparts grayish black; underparts silvery white, sometimes washed with grayish on the throat and breast; white of cheeks nearly meeting on hindneck. L., 13.50; W., 5*40; Tar., 1.75; B. .90.

Remarks.-Differs from $P$. podicrps, in more pointed bill, more white in wing, and, in winter, has no brown below.

Range.-N. mart of N. Hemisphere. Breeds from the lower Yukon, n. Markenzie, een. Keewatin, sw. Ungava, and Magdalen Islands, s. to s. B. C., n. Utah, n. Nebr., cen. Minn., s. Ont., and ne. Maine; winters from s. B. C., s. Ont., and Maine s. to s. Calif., the Gulf coas', and Fla.; casual in Greenland. 
Washington, common W. V., Aug. 20-Apl. 28. Long Island, common W. V., Oct. 15-May 15. Ossining, common T. V., Oct.-Dec.; Mch. Cambridge, T. V. uncommon in fall, very rare in spring. N. Ohio, not common T. V., Apl. 4-May 6; Oct. 1-Nov. 25; occasional in winter. Glen Ellyn, rare, Mch. 31-Sept. 6. SE. Minn., common T. V. Apl. 13.

Nest, of water-soaked, decaying vegetation, an island or raft-floating among rushes in a slough, generally attached to its surroundings. Eggs, 2-7, dull white, more or less soiled, $1.74 \times 1 \cdot 15$. Date, Grant Co., Minn., May 28.

This species and the next are probably frequently mistaken for each other in life, and the same common names are in some instances applicable to both. In breeding costume it is easily identifiable, but in the winter it is a grayish bird. In flight the white margin to its secondaries is clearly displayed. It then suggests a Gallinule, but is smaller and paler. Ernest Seton writes of a captive individual: "When ordinarily swimming, the feet strike out alternately, and the progression is steady; but sometimes both feet struck together, and then the movement was by great bounds, and was evidently calculated to force the bird over an expanse of very weedy water, or through any tangle of weeds or rushes in which it might have found itself. When lifted out of the water, the feet worked so fast as to be lost to the eye in a mere haze of many shadowy feet with one attachment. When placed on the ground, it was perfectly helpless." ("Birds of Manitoba," p. 466.) H. K. Job writes of a pair of Horned Grebes which alighted in a brook and could not fly out "because with their small wings they require a lot of room to flutter and patter over the water in getting started." ("Sport of Bird Study," p. 272.) The same author writes of the notes of this species as "a quick chatter ending with several prolonged notes I can only describe as yells." ("Among the Water-Fowl," p. 33.)

4. Colymbus nigricollis californicus (Heerm.). Eared Grebe. Smaller than $C$. auritus, bill wider than high at base; adult blacker above, foreneck black, not chestnut; in winter, cheeks grayer. L., 12.50; W., E*20; $1 \cdot 70 ;$ B., $\cdot 80$.

Range.-W. N. A. Breeds from cen. B. C., Great Slave Lake, and Man. s. to s. Calif., n. Ariz., n. Nebr., and n. Iowa.; winters from cen. Calif. to Cape San Lucas and Guatemala; e. to Kans. in migration; casual in Mo., Ind., and Ont.

Nest, in colonies, of water-soaked vegetation, an island or floating raft, when usually attached. E'ggs, 3-9, dull white more or less soiled, 1.73 $\times 1 \cdot 19$. Date, Meckling, N. D., May 27.

The Eared Grebe barely comes within our limits. It nests in colonies often containing hundreds of birds. They cover their eggs, even when frightened from the nest, and Job observed some slipping back to complete the work. Eggs from which Job removed the eovering placed on them by the bird, were soon eaten by a Franklin's Gull, evidence that the birds cover their egg to prevent their being seen. Experience on Crane Lake, Saskatchewan, suggests that the call of this bird resembles that of the Pied-billed Grebe.

6. Podilymbus podiceps (Linn.). Pien-Billed Grebe. (Fig. 22a.) Ads. in summer.-Upperparts glossy, brownish black; throat black; upper 
lreast, front and sides of neck, and sides of body, washed with brownish and indistinctly mottled with blackish; lower breast and belly white; a black band across bill. Ads. in winter and Im.-Much like the above, but throat white and no black band on bill. L., 13.50; W., 5.10; Tar., 1.45; B., 85 .

Range.-N. and S. A. Breeds from B. C., s. Mackenzie, s. Keewatin, Que., and N. B., s. to Chile and Argentina, but often rare or local; winters from Wash., Tex., Miss., and Potomac Valley southward.

Washington, common W. V., Aug. 27-Apl. 24. Long Island, probably P. R., rare, most common in Sept. Ossining, common T. V., Apl. 6-Apl. 20; Sept. 3-Oct. 28; a few summer. Cambridge, T. V., common in fall, formerly bred in one locality; Apl. 6-Nov. 10. N. Ohio, often common T. V., rare S. R. Apl. 1-May 10; Sept. 1-Oct. 25. Glen Ellyn, not common S. R., Mch. 20-Nov.4. SE. Minn., common S. R., Apl. 2-Nov. 9.

Nest, of water-soaked, decaying vegetation, sometimes built up from the bottom in shallow water, sometimes floating among rushes in a slough, when it is generally attached to its surroundings. Eggs, 4-8, dull white, more or less soiled or stained, $1 \cdot 74 \times 1 \cdot 19$. Date, Cambridge, Apl. 23; Seneca River Marshes, N. Y., June 3; Winnebago, Ill., May 13; se. Minn., May 15.

Any Grebe found breeding in the eastern United States will probably prove to be this species which, generally speaking, is the best known of our Grebes. From the Eared Grebe, with which it shares various names indicative of its natatorial powers, it may be known by its brown breast, and the absence of a white wing-patch. Its notes, as I have heard them in the Montezuma marshes, are very loud and sonorous with a cuckoolike quality, and may be written cow-cow-cow-cow-cow-cowcow-cow-cow-uh, cow-uh, cow-uh-cow-uh. These notes vary in number, and are sometimes followed by prolonged wailing cows or uhs, almost human in their expressiveness of pain and fear. This is apparently the love song of the male in which his mate sometimes joins with a cuk$c u k-c u k$-followed by a slower ugh, ugh, ugh. ("Bird Studies with a Camera," p. 70.)

On Heron Lake, Minnesota, in early October, I have seen Piedbilled Grebes in close-massed flocks, containing a hundred or more birds, cruising about in open water.

\section{Family Gavinde. Loons. (Fig. 22b.)}

A family containing only five species, inhabiting the northern half of the Northern Hemisphere. The Loons are scarcely less aquatic than the Grebes, and are their equals as divers and swimmers. When nesting, they inhabit fresh-water lakes and ponds, but during the winter are maritime, often living fifty miles or more from land. They migrate by day (and doubtless also by night), and are strong fliers. Being larger than Ducks, and smaller or with shorter necks than Geese, they should not be mistaken for either. They visit the land rarely, when their clumsy progress is assisted by the use of bill and wings. The nest is usually a mere depression on a mud-lump, or so near the shore that the bird ean slide quickly into and under the water, to come to the surface some distance away. Two eggs are laid and the young are 
præcocial. Loons feed chiefly on fish, which they procure by diving, progressing when under water usually by aid of the feet alone.

\section{KEY TO THE SPECIES}

1. Throat black or gray.

A. Throat black.

a. Head black .................. 7. Loon.

b. Head ashy ............ 9. Black-throated Loon. B. Throat gray, foreneck chestnut ..... 11. Red-throated Loon.

2. Throat not black or gray.

A. Throat white or whitish; back fuscous, margined with grayish.

a. Wing over $13^{\circ} 00$; base of bill to anterior end of nostril $\cdot 75$ or over.

7. LooN (Im.).

b. Wing under $13 \cdot 00$; base of bill to anterior end of nostril less than 75 .

9. Black-THROATED LOON (Im.).

$B$. Throat white or whitish; back fuscous, spotted with white.

11. RED-THROATED LOON (Im.).

7. Gavia immer (Brunn.). Loon. (Fig. 22b.) Ads. in summer.$\mathrm{U}^{\top}$ pperparts, wings, tail, and neck black with bluish or greenish reflections; spaces on the throat and sides of neck streaked with white; back and wings spotted and barred with white; breast and belly white; sides and a band at base of under tail-coverts black spotted with white. Ads. in winter and Im.Upperparts, wings and tail blackish margined with grayish, not spotted with white; underparts white; throat sometimes washed with grayish. L., $32 \cdot 00$; W., $14^{\circ} 00$; Tar., $3 \cdot 40 ;$ B., $2 \cdot 80$.

Range.-N. part of N. Hemisphere. Breeds in Am. from Kotzebue Sound, Banks Land, Barrow Strait, an 1 n. Greenland s. to n. Calif., n. Iowa, n. Ill. (at least formerly), n. Ind., n. Ohio, n. N. Y., Pa. (casually), N. H., Mass. (rarely), and N. S.; winters from s. B. C., the Great Lakes, and s. New England to s. L. Calif., the Gulf coast, and Fla.

Washington, common W. V., Sept.-June. Long Island, common W. V., Aug. 10-May 31. Ossining, common T. V., Mch. and Oct. Cambridge, rare T. V., Apl. to early May; Sept.-Nov. N. Ohio, not common T. V., Mch. 17-Apl. 30; Oct. 15-30. Glen Ellyn, irregular, uncommon T. V., Apl. 2 -June 17. SE. Minn., common S. R., Apl. 1-Nov. 9.

Nest, a slight depression in the ground within a few feet of the water, sometimes on a mud lump or muskrat house. Eggs, 2, grayish olive-brown, thinly spotted with blackish, $3.50 \times 2.20$. Date, Upton, Maine, June 15; Mitchell's Bay, Ont., May 31; Pewaukee, Wisc., May 7; se. Minn., May 12.

This wild inhabitant of our northern lakes and ponds possesses all the characteristic traits of the Divers. Its remarkable notes are thus described by J. H. Langille:

"Beginning on the fifth note of the scale, the voice slides through the eighth to the third of the scale above in loud, clear, sonorous tones, which on a dismal evening before a thunderstorm, the lightning already playing along the inky sky, are anything but musical. He has also another rather soft and pleasing utterance, sounding like who-whowho-who, the syllables being so rapidly pronounced as to sound almost like a shake of the voice-a sort of weird laughter."

Loons may be seen migrating by day singly or in small companies, generally at a considerable height. Their flight is strong, rapid and direct. They winter in large numbers some distance off the Coast. 
I have seen several thousand in a day (March 9, 1907) east of Hatteras when sailing from New York to Florida.

1899. Mead, J. C., Journ. Me. Orn. Soc., I, 21-24 (habits).

The Yellow-Billed Loon ( 8 Gavia adamsi) of northwest Alaska and northern Siberia is of accidental occurrence in Greenland. It closely resembles $G$. immer but has the bill yellow.

9. Gavia arctica (Linn.).-Black-THROATEd Loon. Ads. in summer.Throat, foreneck, back, wings, and tail black, with purplish and bluish reflections; a band of white streaks on throat; sides of neck, back, and wings streaked, barred, or spotted with white; top of head and nape gray; breast and belly white; a blackish band at the base of the under tail-coverts. Ads. in winter and Im.- Similar in color to $U$. immer, not spotted above 'with white. L., $27 \cdot 00$; W., 11*00; Tar., $2 \cdot 60$; B., $2 * 00$.

Remarks.-Immature and winter birds may be distinguished from the corresponding stage of immer by their small size; from stellata by grayish margins instead of white spots, bars, or margins on the upperparts.

Range.-N. part of N. Hemisphere. Breeds from Kotzebue Sound, Alaska, w. along n. coast of Siberia, on islands north of Europe, and from Cumberland Sound south to Ungava; winters in the s. Canadian Provinces; casually s. to Colo., Nebr., Iowa, n. Ohio, and Long Island, N. Y.

Long Island, A. V., one record. N. Ohio, casual on Lake Erie in winter.

Nest, a slight depression in the ground within a few feet of the water. Eggs, 2, grayish olive-brown, spotted or scrawled with blackish, $3 \cdot 20 \times 2 \cdot 10$. Date, St. Michael's, Alaska, June 6.

This species is a very rare winter visitant to the northern border of the United States. The most southern record of its occurrence is April 29, 1893, Sandpoint lighthouse, Long Island Sound. (Dutcher, Auk, X, p. 265.)

11. Gavia stellata (Pont.). Red-THROAted Loon. Ads. in summer.Back, wings, and tail fuscous, more or less spotted with white; head and neck ashy gray; foreneck chestnut; back of the neck black, streaked with white; breast and belly white; longer under tail-coverts and band at the base of shorter ones fuscous. Ads. in winter and Im. - Similar to G. immer, but back spotted with white. L., $25^{\circ} 00 ;$ W., $11^{*} 00$; Tar., $2 \cdot 60$; B., 2*00.

Range. $-\mathrm{N}$. part of N. Hemisphere. In Am. breeds from cen. Keewatin, cen. Que., N. B., and N. F. and n.; winters from s. B. C. to s. Calif., and from Maine, and the Great Lakes to Fla.; casual in interior to Mont., Mo., Nebr., and Ariz.; hreeds also throughout Arctic Europe and Asia, and winters s. to the Mediterranean and s. China.

Washington, rare W. V., Oct. 20 to spring. Long Island, common T. V., Sept. 14-Dec. 30; Mch. 30-May 11. Ossining, casual T. V. Cambridge, one instance, Oct. N. Ohio, casual on Lake Erie, in winter. Glen Ellyn, very rare T. V. spring only, Apl. 14-17. SE. Minn., rare W. R.

Nest, a slight depression in the ground within a few feet of the water. Eggs, 2, grayish olive-brown, sometimes tinged with green and spotted with blackish, 2.80 × 1.75. Date, Resolution Is., H. B., June 9; Iceland, May 23.

In the United States we know this bird only as a winter visitant when it occurs along our coasts, and, less commonly, on the larger bodies of water inland. At this season it resembles the Loon in habits. Nelson describes its notes as a harsh $g r-r-g a, g r-r, g r-r-g a, g r-r$. 

Plate IX

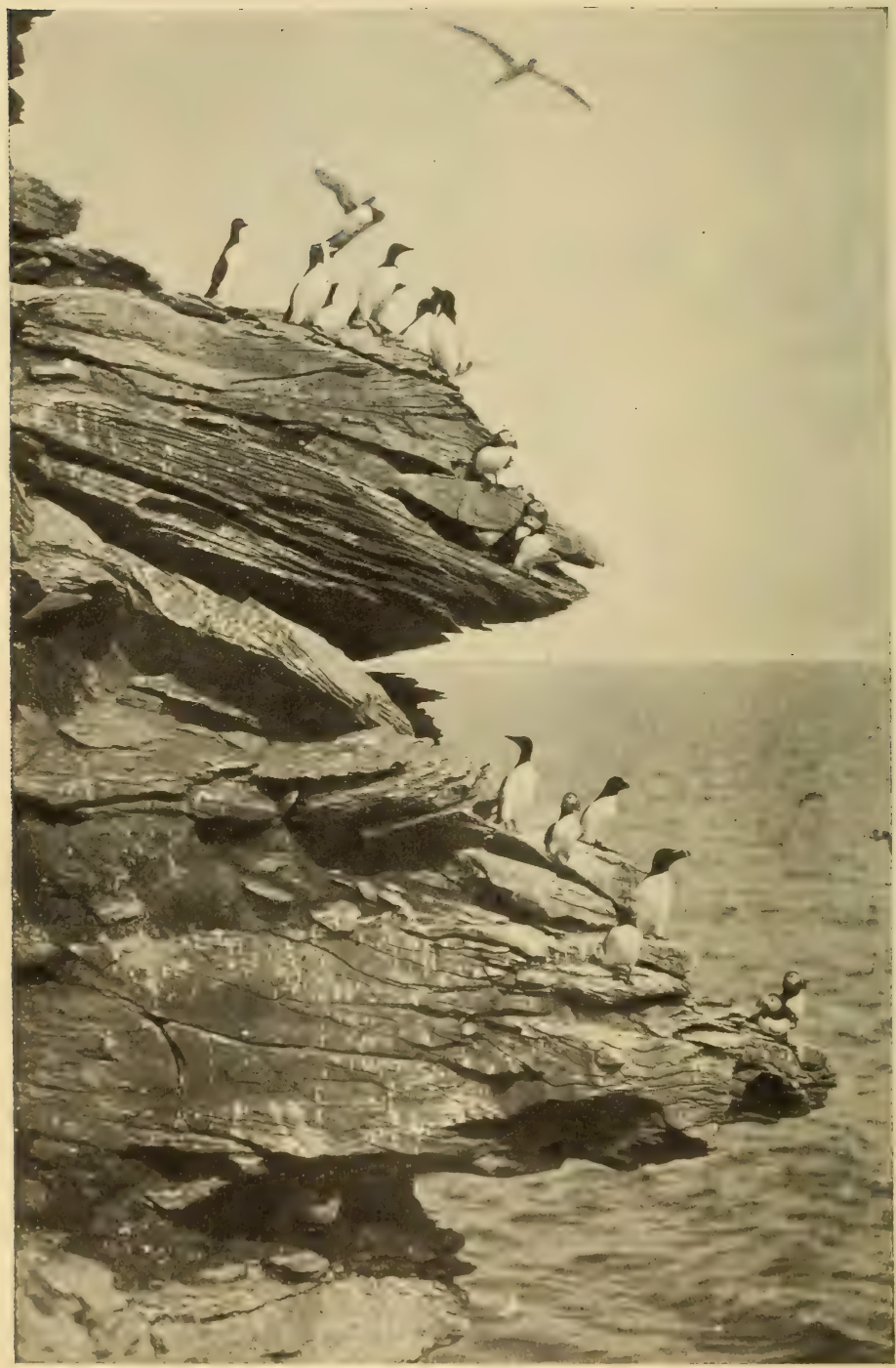

Gannet (flying over), Murres, Puffins, and Razor-billed Auks From a photograph made on Bird Rock, Gulf of St. Lawrence, July 24, 1898. 


\section{Family Alcide. Aurs, Murres, and Puffins. (Fig. 22c.)}

Twenty-four of the twenty-five species contained in this family are North American, and all are confined to the northern parts of the Northern Hemisphere. Only seven species are found in the North Atlantic, where none nests south of Maine. They are, without exception, maritime birds, visiting our bays and harbors at certain seasons, but passing much of their lives on the open sea. They go ashore, as a rule, only to nest, when they gather on islets, often rocky and difficult of access, in vast numbers. Puffins stand on the toes and run about freely, but the other species rest, like Grebes, on the whole foot and tail, and their progress is more awkward. Unlike the Grebes and Loons, they use their wings rather than their feet when swimming under water. In the air, their flight is direct and rapid, suggesting, in some instances, that of a Duck, but the shorter neck should prevent confusion here.

The Alcidce feed on fish, crustacea, sand-eels, and other forms of sea life.

1900. Chapman, F. M., Bird Studies with a Camera, 152-190. (Appleton's). - 1902. JoB, H. K., Among the Water-Fowl, 50-96. (Doubleday).1905. Wild Wings, 153-170. (Houghton, Mifflin.)

KEY TO THE SPECIES

I. Bill under $\cdot 75$

II. Bill over 75 .

1. Depth of bill at nostril over 60 .

A. Bill yellowish, depth at nostril over $1^{\cdot} 00$.

13. Puffin. 13a. Large-billed Puffin.

B. Bill black, depth at nostril under 1.00 . 32. RAzor-BILled AUK.

2 Depth of bill at nostril under 60 .

A. Wing-coverts white or tipped with white.

a. Greater wing-coverts entirely white . . 28. Mandt's Gilllemot.

b. Basal half of greater wing-coverts black. . 27. Black GuIllemot.

$B$. No white on wing-coverts.

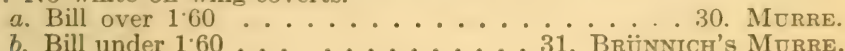

13. Fratercula aretica arctica (Linn.). PuFfix. (Fig. 22, c). Ads.Upperparts, wings, tail and foreneck blackish, browner on the head and foreneck; nape with a narrow grayish collar; sides of the head and throat white, sometimes washed with urayish; breast and belly white. (Breeding birds have the bill larger and brighter, and a horny spine over the eye.) L., 13.00; W., 6.10; Tar., 1.05; I3., 1.5.5; depth of B. at hase (in winter), 1.50.

Range.-Coasts and islands of $\mathrm{n}$. Atlantic. Breeds in $\mathrm{N}$. Am., from Ungava s. to Bay of Fundy and Maine; winters s. to Mass., casually to

L. I. and Delaware Bay.

Long Island, A. V. in winter.

Nest, in a burrow in the ground or in crevices among rocks. Egg, 1, dull white, sometimes with obscure markings, $2.49 \times 1.68$. Date, Bird Rock, Que., May 26; Cape Whittle, Lab,, June 11.

One has only to see a Puffin to realize why it is eommonly known as 'Sea Parrot;' and when the bird on outstretehed, short, rounded wings hovers for a moment before alighting, it bears the strongest resemblance 
to a Japanese bird-kite. In flight the Puffin's wings move more rapidly than those of the Murre and Razorbill, and unlike those birds it stands only on its toes, and can run about easily and rapidly.

While Murres and Razorbills usually resort to rocky islets whose ledges and crannies afford nesting-sites, Puffins may.use low-lying, flat islands in the turf of which they excavate their burrows. It was a surprising experience, in crossing an apparently deserted bit of ground on the Farne Islands, to have at nearly every step dozens of Puffins burst from the earth at my feet. The only note I have heard from a Puffin is a hoarse grunt or groan. Puffins can infliet serious wounds with their powerful bill, which they use ferociously.

1883. Brewster, W., Proc. Bost. Soc. Nat. Hist., XXII, 407 (habits).

13a. F. a. naumanni (Norton). LARge-BILled PUffiN. Similar to the preceding, but larger. W., 6*80-7.40; B., 2.00-2.30 (B., B., and R.).

Range.-Coasts and islands of Arctic Ocean, from n. and w. Greenland to Nova Zembla.

The TuFted Puffin (12 Lunda cirrhata) inhabits the North Pacific from California to Alaska. The specimen figured by Audubon was said by him to have been procured at the mouth of the Kennebec River, Maine. It has also been recorded from Greenland.

The Ancient Murrelet (21 Synthliboramphus antiquus) of the North Pacific has been once recorded from Wisconsin.

27. Cepphus grylle (Linn.). BlaCK Guillemot. Ads. in summer.Sooty black, lighter below and with slight greenish reflections above; lesser wing-coverts and terminal half of the-greater wing-coverts white, the basal half of the greater coverts black; linings of the wings white. Ads. in winter.Upperparts gray or black, the feathers all more or less tipped with white; wings as in summer; underparts white. Im.-Upperparts as in winter adults; underparts white, mottled with black; wing-coverts tipped with black. L., $13 \cdot 00$; W., 6.25; Tar., 1*25; B., 1.20.

Range.-Coasts of e. N. Am. and nw. Europe. In Am. breeds from s. Greenland and Ungava to Maine; winters from Cumberland Sound s. to Cape Cod and casually to N. J.; accidental in Pa.

Long Island, A. V. in winter, one reoord.

Nest, in the crevices and fissures of cliffs and rocky places. Eggs, 2-3, dull white, sometimes with a greenish tinge, more or less heavily spotted with clear and obscure dark chocolate markings, more numerous, and sometimes confluent at the larger end. $2 \cdot 18 \times 1.40$. Date, Grand Menan, N. B., June 14 .

Whether in black summer or grayish winter plumage, the Guillemot's white wing-coverts on a black wing are a conspicuous and unmistakable identification mark, whether the bird is swimming or flying.

Guillemots (in England this name is applied to the Murre, Lomvia) are not usually found in the great colonies of Murres and Puffins, but nest apart by themselves. They stand on the whole foot or tarsus and often sit or lic comfortably on their lower parts. When approached they emit a high, squealing whistle, opening wide their coral-lined mouths. They feed their young largely on sand-eels, and it is a common sight to see them with a number of these fish hanging from the sides of their 
bill, flying low over the water to the base of the breeding-cliff, then rising abruptly to the nest in the rocks above.

28. Cepphus mandti (Mandt). Mandt's Guillemot. Resembles the preceding, but the bases of the greater wing-coverts are white instead of black.

Range.-Arctic regions of both continents. Breeds on Arctic islands s. to n. Hudson Bay and mainland of Siberia; winters in Arctic Ocean and casually s. to Norton Sound and Lake Ontario; n. in migration to lat. $84^{\circ}$.

Nest, in crevices and fissures of cliffs and rocky places. Eggs, 2-3, not distinguishable from those of C. grylle, $2 \cdot 34 \times 1 \cdot 15$.

A more northern species than the preceding, which it doubtless resembles in habits.

30. Uria troille troille (Linn.). MurRe. Ads. in summer.-Upperparts, wings, tail and neck all around, dark sooty brown, blacker on back, wings and tail; tips of secondaries, breast and belly white, sides more or less streaked with blackish. Ads. in winter and Im.-Upperparts, wings, and tail much as in summer; underparts white, throat more or less washed with sooty brown, flanks sometimes streaked with brownish, and feathers of belly more or less lightly margined with blackish. L., 16.00; W., 8.00; Tar., 1.40; B., 1.75; depth of B. at nostril, 50 .

Remarks.-Some specimens have a white ring around the eye and a white stripe behind it. They have been named $U$. ringvia (Brün.), but are generally believed to represent merely an individual variation. The case is unusual.

Range.-Coasts and islands of N. Atlantic. Breeds in N. Am. from s. Greenland and s. Ungava s. to N.F. and Magdalen Islands; winters s. to Maine.

Nests in communities, side by side on the bare ledges of rocky cliffs. $E g g, 1$, pyriform, pale blue or greenish blue to whitish or buffy, singularly spotted, scrawled, or streaked with shades of chocolate, rarely unmarked, $3 \cdot 25 \times 2 \cdot 00$. Date, Bird Rock, Que., May 15 .

When on the water, Murres bear a general resemblance to Ducks, but may be distinguished by their short, thick necks and pointed bill. Unlike the Razor-bill, they do not swim with upturned tail. When nesting, probably no other birds are more closely associated than Murres. They often gather on favorable ledges of rocky islets in such numbers that a newcomer finds an alighting place with difficulty, while the place vacated by a departing bird is immediately filled by pressure from all sides. Nevertheless the birds lay their single egg on the bare rock, and under these apparently unfavorable conditions rear their young. Long-continued studies of Murres on the coast of Yorkshire warrant the belief that, although the eggs of no'two Murres (or Guillemot as it is termed in England) are alike, those of the same individual more or less closely agree, and that the same bird lays year after year on the same ledge.

Murres perch on the entire foot or tarsus, and when undisturbed usually turn their back to the sea and hold their egg between their legs with its point outward. When alarmed they face about, bob and bow and utter their bass-voiced murre. 
31. Uria lomvia lomvia (Linn.). BrünNICH's Murre. Ads. in summer. - Upperparts, wings and tail sooty black; foreneck somewhat browner; tips of secondaries, breast and belly white; base of upper mandible greenish, rounded outward beyond edge of lower mandible. L., 16.50 W., 8.40; Tar., $1 \cdot 30$; B., 1*25; depth of B. at nostril $\cdot 47$.

Remarks. - Adults are to be distinguished from adults of $U$. t. troile by the darker color of the head, which in lomvia is darker than the throat, by the size of the bill and thickening of its cutting edge at the base. Winter and immature birds can be distinguished from those of $U$.t. troile only by the size of the bill, which, as the measurements show, is longer in that species.

Range.-Coasts and islands of the n. Atlantic. Breeds from s. Ellesmere Land and n. Greenland to n. Hudson Bay and Gulf of St. Lawrence; resident in Greenland and Hudson Bay; s. casually in winter on Atlantic coast from Maine to S. C., and in interior to n. Ohio, cen. Ind., and cen. Iowa.

Washington, A. V., several, Dec. 1896. Long Island, W. V. Nov. 22Mch. 24. Ossining, A. V. Cambridge, two records, Nov., Dec. N. Ohio, casual on Lake Erie in winter.

Nests in communities, side by side on the bare ledges of rocky cliffs. Egg, 1 , not distinguishable from that of U.t. troile. Date, Bird Rock, Que., June 17.

Brünnich's Murre often nests in the same colonies with the Common Murre, which it resembles in habits, and from which, at close range, it may be distinguished by its shorter, heavier bill and swollen, whitish margin of the base of the mandible. The downy young of the two species can "be distinguished by the somewhat hairy, gray-streaked back of troile as compared with the more downy, brown mottled back of lomvia. Both utter the characteristic screech of young Murres while young Razor-bills whistle. This species sometimes invades the interior in numbers.

1905. Fleming, J. H., Proc. 4th Int. Orn. Cong., 528-543.-1910. Eaton, E. H., Birds of New York, 108, 109.

32. Alca torda Linn. RAzor-BILled AuK. Ads. in summer.-Upperparts, wings and tail sooty black; foreneck somewhat browner; tips of econdaries, a line from eye to bill, breast, and belly white; bill black, crossed by a white band. Ads. in winter. - Similar, but with sides and front of neck white. Im.- Similar to ad. in winter, but with bill smaller and without white bar. L., 16:50; W., 7·90; Tar., 1·35; B., 1*25.

Range.-Coasts and islands of the n. Atlantic. Breeds on American side of $\mathrm{s}$. Greenland to N. F. and N. B.; winters from N. B. and Ont. to L. I. and casually to N. C.

Long Island, W. V., Nov. 2-Feb. 6.

Nest, in the crevices and fissures of cliffs and rocky places Eggs, 1-2, pale bluish white or buffy, thickly spotted and speckled with chocolate markings most numerous and sometimes confluent at the larger end, $3^{*} 00 \times$ 1:90. Date, Bird Rock, Que., May 24.

"When brooding, it crouches along, not across, the egg, its mate often standing near; and both sexes incubate, though the male may be seen bringing food to the sitting female. . . . The young flutter from the rocks to the sea, or are taken by the neck and carried down by the parents. They are at first very loath to follow the old bird in diving, and remain crying plaintively on the surface of the water. The Razor-bill utters a peculiar grunting or groaning, especially when sitting. On the water it may be distinguished from the Guillemot, [=Murre] at a distance, by its upturned tail." (Saunders.) 


\section{AUKS, MURRES, AND PUFFINS}

33. Plautus impennis (Linn.). GREAT AUK. Upperparts fuscousblack, a large white spot before the eye; secondaries tipped with white; sides of the neck and throat seal-brown, rest of the underparts silvery white. L., $28 \cdot 00-30.00$; W., 5.75; B., 3.15-3.50; greatest depth of B., 1.50 (Ridgw.).

Range.-Formerly coasts and islands of the n. Atlantic, from near the Arctic Circle s. to Mass. and Ireland, and probably s. casually to S. C. and Fla.; now extinct.

$E g g, 1$, pyriform-ovate, pale olive buffy, variously marked with brown and black, $4.67 \times 2.91$ (Ridgw.).

The Great Auk was flightless. Like other birds of this family, it frequented certain localities in large numbers each year to breed. Early voyagers and fishermen visited its nesting-grounds, killing the helpless birds in enormous numbers for their flesh, feathers and oil. The result was extinction, and no living Great Auk has been observed since 1842. About seyenty specimens are known to be preserved in collections.

In 1902, two humeri of the Great Auk, both from the left side, were found in a shell-mound at Ormond, Fla. (Hay, Auk, XIX, p. 255), where their discovery gives new meaning to Catesby's statements that the "Penguin"

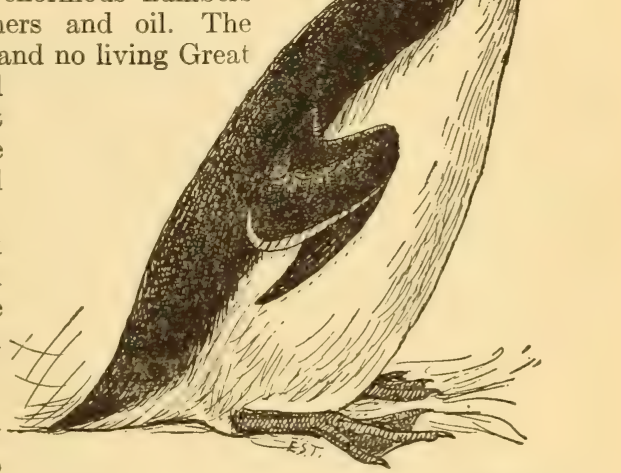

FIG. 77. Great Auk. Note the short wings of a flightless bird. (Much reduced.)

was a winter visitant to South Carolina.

1888. Lucas, F. A., Auk, V, 278-28.3.-1887-8, Rep. U. S. Nat. Mus., 493-529.-1891. Ibid., 709-728 (history').-1 1893. Newton, A., Dictionary of Birds (history, bibliography).

34. Alle alle (Linn.). Doverif. Ads. in summer.-Upperparts, wings and tail sooty black; sides and front of neck and upper breast somewhat browner; secondaries tipped and seapulars streaked with white; lower breast and belly white. Ads. in winter and Im. - Similar, but throat whiter or washed with dusky, and sometimes a gray collar on nape. L., 8.00; W., 4.50; Tar., '70; B., '50.

Range.-Coasts and islands of the $\mathrm{n}$. Atlantic. Breeds from Kane Basin and Baffin Bay east to Franz Josef Land; winters from s. Greenland s. to L. I., and casually to Delaware Bay and N. C.; accidental near Melville Island, and in Wisc., Mich., Ont., and Bermuda.

Long Island, Nov. 18-Mch. 24. Ossining, A. V. Cambridge, irregular T. V., late fall or winter.

Nest, on the ledges and in the crevices of rocky cliffs. Egg, 1, pale, bluish white, $1.85 \times 1 \cdot 27$. Date, Disco Bay, Greenland, June 28 ,

"On the approach of a vessel this bird has a peculiar way of splash- 
ing along the surface of the water, as if unable to fly, and then diving through the crest of an advancing wave; it swims rather deep and very much 'by the stern.' . . ." (Saunders).

"Its wings are small, but they are moved almost as rapidly as a Hummingbird's, and propel the bird through the air with great rapidity. This bird is an expert diver too, and, though awkward on land, swims with ease and grace. . . ." (Chamberlain).

1900-02. Figgins, J. D., Abst. Proc. Linn. Soc., 61-63 (use of, for food).

\section{ORDER LONGIPENNES. LONG-WINGED SWIMMERS}

\section{Family Stercoraritde. Jaegers and Skuas. (Fig. 23a.)}

Three of the seven known members of this family are birds of Antarctic seas; the remaining four nest in the northern parts of the Northern Hemisphere, but at other seasons are widely distributed. Except when nesting, they are maritime, but at times are found on large bodies of water inland.

The Jaegers are the pirates among birds of the high seas. With strong and dashing flight, they successfully pursue Gulls and Terns, forcing them to disgorge their prey. They carry their predaceous habits to their nesting-grounds on the tundras, where they feed upon the young of other birds and even upon mice and lemmings.

\section{KEY TO THE SPECIES}

A. Bill over $1 \cdot 35$; tarsus over $1 \cdot 70$; middle tail-feathers never pointed.

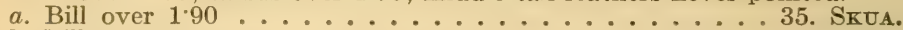
b. Bill under $1.90 \ldots \ldots \ldots \ldots 36.3_{3}$. Pomarine JeGER. $B$. Bill uncier $1 \cdot 35$; tarsus under $1 \cdot 70$; middle tail-feathers generally pointed.

$a$. Scaly shield on the bill longer than the distance from its end to the tip of the bill ...................... Parasitic JaEger.

$b$. Scaly shicld on the bill shorter than the distance from its end to the tip of the bill ............... 38. Long-Tailed JaEger.

35. Megalestris skua (Brunn.). SKUA. Ads.-Upperparts, tail, and wings dark, dirty brown; shafts of the wing and tail-feathers white, except at the tip; outer wing-feathers with inner vanes white at the base; underparts somewhat lighter; neck more or less streaked with whitish. Im."Similar to adult, but more distinctly" streaked with ycllowish, especially on the head and neck." L., 22.00 ; W., 15.91; Tar., 2.63; B., 2.06 (Ridgw.).

Range.-Coasts and islands of the $\mathrm{n}$. Atlantic. Breeds on Lady Franklin Island (Hudson Strait), in Iceland, on the Faroe and Shetland islands; winters on fishing banks off N. F. and N. S.; casually to L. I., in Europe s. to Gibraltar.

Long Island, one record.

Nest, of grass, on the ground. Eggs, 2, pale olive-brown or greenish gray spotted with chocolate, $2 \cdot 80 \times 1 \cdot 90$. Date, Greenland, May 5.

36. Stercorarius pomarinus $(T \mathrm{~cm}$. ). Pomarine Jaeger. Ads. light phase.-Very similar in color to corresponding phase of $S$. parasiticus, 
but with the upperparts darker, nearly black. Ads. dark phase and Im.Similar in color to corresponding stages of S. parasiticus. L., 22.00; W., 13.50; T., Ad., 8.00; Im., 5.40; Tar., 2.00; B., 1.55.

Remarks. - This species is to be distinguished from the two following by its larger size and the rounded ends of its central tail-feathers.

Range. $-\mathrm{N}$. part of $\mathrm{N}$. Hemisphere. Breeds from Melville Island and cen. Greenland s. to n. Alaska, n. Mackenzie, Melville Peninsula, and Baffin Land, and also on Arctic islands of E. Hemisphere; winters off Atlantic coast, s. to N. J.; common fall migrant on coast of Calif.; winters s. to Galapagos, Peru, Africa, and Australia; accidental in Nebr.

Long Island, regular from June 1j-Oct. 30 (Dutcher). Ossining, A. V. N. Ohio, casual on Lake Erie.

Nest, on the ground. Eggs, 2-3, deep olive-drab sparingly spotted with slate color, and light and dark raw-umber markings and black dots, chiefly at the larger end, where confluent, $2.25 \times 1.70$ (Brewer). Date, Cape Lisburne, Alaska, June 10.

37. Stercorarius parasiticus (Linn.). PARASITIC JAEGER (Fig. 23a). Ads. light phase.-Back, wings and tail slaty fuscous; top of head and lores nearly black; sides of head and back of neck straw-yellow, this color sometimes spreading down sides of neck and on throat; breast and belly white; sides of breast, flanks, lower belly, and crissum slaty fuscous; tarsi and feet (in dried specimens) black; middle tail-feathers pointed and extending about 3.00 beyond the others. Ads., darli phase.-Entire plumage dark, slaty brown, darker on top of head; underparts slightly lighter; sometimes a trace of straw-yellow on sides and back of neck; tarsi, feet and tail as in preceding. Im., light phase.-L Lperparts, wings and tail fuscous; feathers of back, neck and head more or less hordered, tipped or barred with buffy; hindneck and head sometimes buffy, streaked or barred with fuscous, and varying from this color to plain fuscous; longer, lateral upper tail-coverts barred with buffy; tail buffy, whitish at base; under wing-coverts barred with buffy; underparts white, washed with buffy, and irregularly barred with sooty fuscous; these bars sometimes very numerous when the underparts look as if washed with sooty fuscous; again, they may be less numerous and confined to breast and sides, leaving the belly white; central tail-feathers pointed, projecting more or less beyond rest. I $m$., dark phase.-Sooty fuscous feathers, particularly on underparts, more or less marked with ochraceous-buff. L., $17^{\circ} 00$; W., 13.00; T., Ad., 8*60; Im., 6*40; B., 1.15.

Remarks. - This species closely resembles $S$. longicaudus. Adults of both species, whether in the dark or light phase of plumage, may always be distinguished from each other by the difference in the length of their central tail-feathers, in addition to the characters given in the key. Young birds can not be distinguished by color, but may be identified by the differenees in relative proportions of the bill. Eaton calls attention to the fact that in parasiticus the shafts of all the primaries are white, while in longicaudus only the outer two or three are white, the rest being abruptly brownish.

Range. $-\mathcal{N}$. part of $\$$. Hemisphere. Breeds from nw. Alaska, Mreille Island, and n. Greenland s. to Alentian Islands, een. Machenzic (Great Slave Lake), and cen. Keewatin, and on Arctic islands of Siberia and of $n$. Europe s. to Seotland; winters from the Aleutian Islands s. to ('alif., from New England coast s. to Brazil, in Australia, and from coast of Europe s. to (ape of Good Hope; casual in interior to the (ireat Lakes, MIo., Kans. and Colo. Erie.

Long Island, regular, Apl. 30; Aug. 6-Nov. 9. N. Ohio, casual on Lake

Nest, on the morors or tundras, a slight depression in the ground seantily lined with grasses, ete., or on rocks he the sea. Ekgs, 22 4, light olive-hrown, with frequently a strong greenish tinge and chocolate markings, more numerous and sometimes confluent at the larger end, $2 \cdot 25 \times 1.65$. Date, Iceland, May 23; Bering Island, Kamchatka, May 29. 
38. Stercorarius Iongicaudus Vieill. LONG-TAILED JAEGER. Ads. light phase.-Back, wings and tail slaty fuscous; top of head and lores nearly black; sides of head, back and sides of neck straw-yellow; throat sometimes washed with same color; underparts white; sides, lower belly, and crissum slaty fuscous; central tail-feathers extending about 7.00 beyond the others, the projecting ends narrow and pointed. (No dark phase of this species has been described.) Im.-Similar in plumage to im. of $S$. parasiticus, but differing otherwise as pointed out under that species. L., 21.00 ; W., 12.50 ; T., Ad., 12.00., Im., 5.50; B., 1.08.

Range.-N. part of the N. Hemisphere. Breeds on Arctic islands of Europe and Asia, and coasts of Kotzebue and Norton sounds, n. Mackenzie, and n. Hudson Bay to n. Greenland; winters s. to Gibraltar and Japan; not rare in migration off New England; casual on the Pacific coast s. to Calif.; accidental in Man., Iowa, Ill., and Fla.

Long Island, casual, Oct.

Nest, a slight depression in the ground, sometimes scantily lined with grasses. Eggs, 2-3, similar in color to those of the preceding, $2.10 \times 1.50$. Date, Southern Greenland, June 1.

\section{Family Laride. Gulls and Terns. (Figs. 23b, 24.)}

This family contains about 100 species, divided equally between subfamily Larince (Gulls) and subfamily Sternince (Terns). They are distributed throughout the world. Some forty species inhabit North America. With few exceptions, they agree in possessing the marked characters of their respective subfamilies, under which they may be more conveniently treated.

\section{Subfamily Larinæ. Gulls. (Fig. 23b.)}

The fifty odd members of this subfamily are distributed throughout the world; twenty-five of them have been recorded from North America, where the greater number nest north of the United States; in Eastern North America, the Laughing Gull being the only species which nests south of latitude $41^{\circ}$.

Franklin's Gull is a bird of the Mississippi Valley, and many of the maritime species nest on the islands of inland lakes, where, indeed, they may be represented throughout the year; but, as a family, Gulls are true birds of the sea and its bays. They throng our harbors from early fall to late spring, and during this season are ever in attendance on coast-wise craft, and are not wanting in mid-ocean.

Gulls average larger and stockier than Terns, and have less pointed, broader wings, and, as a rule, square tails. They procure their food largely by picking it from the surface of the water with their strong, hooked bills, not by plunging or darting, as do the Terns. They are among nature's scavengers of the water, and perform a service of great value to man by devouring various forms of aquatic animals which, in dying, come to the surface. They also aid in freeing the waters of our harbors from the garbage which inevitably finds its way there. Although feeding thus on offal, most Gulls are highly predaceous and 
Plate X

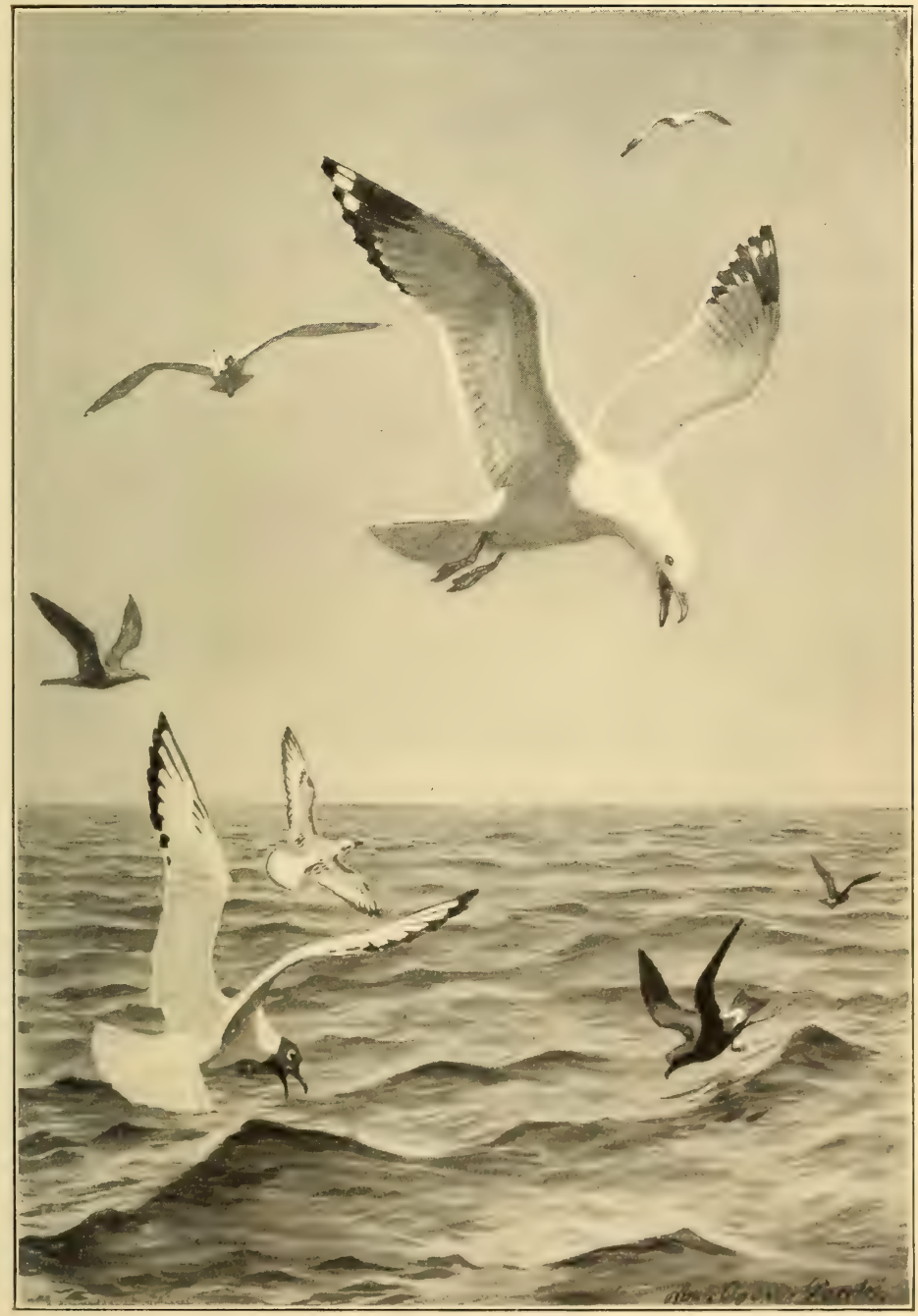

Gulls and Petrels

Laughing Gull. Herring Gull.

Wilscn's Petrel. 

feed upon the eggs and young of the other birds among which they nest, rarely, however, preying on their own species.

Gulls are buoyant swimmers, and, unlike Terns, rest and roost on the water, often gathering in close-massed "beds." They nest in colonies on islands. The young are born covered with down of mottled pattern, and though they may leave the nest in their natal dress, are dependent on their parents until they acquire the power of flight. The voices of Gulls possess a certain, indescribable human quality which adds in no small degree to the impression created when storms rule and these wild cries are heard above the tumult of wind and wave.

I. Wing over $15^{\circ} 00$.

KEY TO THE SPECIES

1. Back dark slaty black. ....... 47. Black-Backed Gull.

2. Back not dark slaty black.

A. Back pearl-gray.

a. Outer primaries marked with black ... 51. Herring Gult.

$b$. No black on primaries.

$b^{1}$. Bill under $2 \cdot 00$.

$b^{2}$. Primaries light pearl-gray, fading gradually into white at their tips ............ 43. ICELAND GULL.

$b^{3}$ Primaries pearl gray, tipped with white, and with well-defined gray spaces on the outer webs of the outer two primaries and on both webs of the third and fourth primaries. ......... 45. KuMLien's GulL.

$c^{l}$. Bill over 2.00 . . . . . . . 42. Gladcous Gull.

B. Back grayish, whitish, or brownish, or mottled or spotted with grayish or brownish.

a. Tail black or blackish, with or without irregular white markings. $a^{1}$. Wing over $17 \cdot 50$; depth of bill at nostril over 70 .

47. Black-Backed GUll (Im.). $a^{2}$. Wing under $17 \cdot 50$; depth of bill at nostril under 70 .

51. Herring Gull (Im.).

b. Tail white or whitish or grayish brown, with or without black markings.

$b^{1}$. Bill under 2.00 . . . . . 43. ICeland Gull (Im.).

$b^{2}$. Bill over $200 \ldots \ldots$. . . 42. Glaucous Gull (Im.).

II. Wing under $15^{\circ} 00$.

1. Tail white.

A. Head and throat slaty black.

a. Outer primary black or mostly black.

$a^{1}$. Outer primary entirely black ..... 58. Ladghing Gull. $a^{2}$. Inner half of inner weh of first primary white.

b. Outer primary mostly white.

62. SABINE's GULl. $b^{1}$. Tip of first primary white. . . . 59. FrankLin's Goll. $b^{2}$. Tip of first primary black. . . . 60. Bonafarte's Gull.

$B$. Head white, sometimes washed with pearl-gray.
a. Wings white . . . . . . . 39. Ivory Gulu.
b. Primaries with more or less black.
$b^{1}$. Wing over $11^{\circ} 00$.
$b^{2}$. Hind-toe very small, without a nail . . . 40. KiтTIWAKe. -
$b^{3}$. Hind-toe normal, with a nail ...54. Ring-BILLEI) (fitL. $c^{1}$. Wing under $11.00 \ldots \ldots$. . Ross's GuLL 
2. Tail marked with black.

A. Wing over $13 \cdot 25$.

a. Primaries mostly white ...... 39. Ivory GuLL (Im.).

b. Primaries black or mostly black .. 54. RING-BILled GuLL (Im.). $B$. Wing under $13 \cdot 25$.

a. Hind-toe very small, without a nail . . . 40. Kittiwake (Im.).

$b$. Hind-toe normal, with a nail.

$b^{1}$. Tarsus 1.50 or over . . . . . 58. Ladghing Gull (Im.). $c^{1}$. Tarsus under $1: 50$.

$c^{2}$. Secondaries pearl color, tail square.

60. Bonaparte's Gull (Im.). $c^{3}$. Secondaries mostly white, tail rounded.

61. Ross's Gull (Im.)
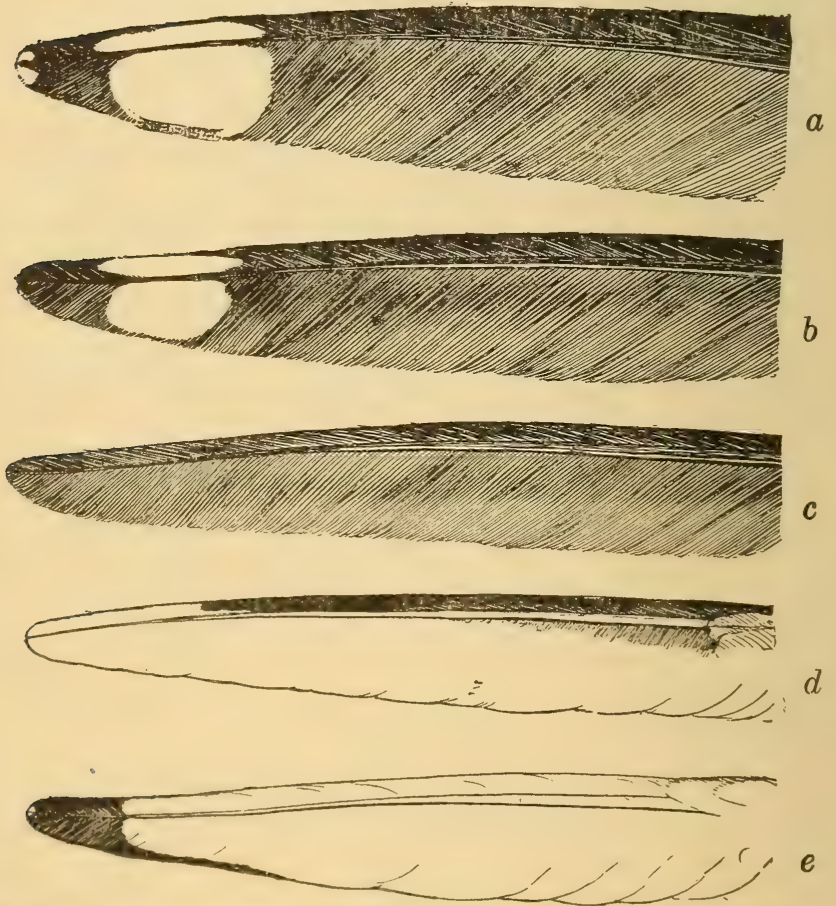

FIG. 78. First primaries of adult Gulls, seen from below: (c) Herring Gull; (b) Ringbilled Gull; (c) Laughing Gull; (d) Franklin's Gull; $(e)$ Bonaparte's Gull.

39. Pagophila alba (Gunn.). Irory Gull. Ads.-Entire plumage pure white; hill yellow, foet black. Im. - Similar to ad., but wing and tailfeathers, and sometims wing-eoverts, with a black spot at their tips. L., $17 \cdot 00 ; W ., 13 \cdot 25 ;$ T., 5*50; $13 ., 1 \cdot 35$.

Range.-Arctic seas. Breeds in high Arctic latitudes from Melville 
Island and n. Baffin Land to n. Greenland, and on Arctic islands of E. Hemisphere; winters in the Arctic regions and casually s. to B. C., Lake Ont., and L. I. ; in Europe, s. to France.

Long Island, A. V., one record, Jan.

Nest, of grass, moss, and feathers on rocky cliffs. Eggs, light yellowish olive, marked with small blotches of brown and larger cloudings of lilac, $2.45 \times 1.70$ (Brewer). Date, Prince Patrick's Island, Arctic. Ocean, June 18.

"The Ivory Gulls appear to spend most of the time amid the packice, often at a long distance from land" (Chamberlain).

40. Rissa tridactyla tridactyla (Linn.). Kittiwake. Ads. in summer.-Head, neck, tail and underparts pure white; back and wings pearlgray; outer web of first primary and 3.00 of the ends of first and second primaries black; third to fifth primaries black at ends and with white tips; hind-toe very small, a mere hnob without a nail; bill yellowish, feet black. Ads. in winter. - Similar to above, but top of head and back of neck washed with pearl-gray, and a dark spot about eye. Im.- Similar to winter adults, but with the back of the neck, lesser wing-coverts, and part of the tertials black; tail, except outer pair of feathers, with a black band at its tip; four outer primaries black, except the inner half or more of their inner webs; fifth and sixth tipped with black and white; bill black, feet yellowish. L., 16.00 ; W., 12.00; T., 4.50; B., 1.30.

Remarks. - This species can always be distinguished by the small size of the hind-toe.

Range.-Arctic regions. Breeds from Wellington Channel and $\mathrm{n}$. Greenland, s. to Gulf of St. Lawrence, and from Arctic islands of Europe and $w$. Siberia to s. France; winters from Gulf of St. Lawrence s. to N. J., and casually to Va., Bermuda, and the Great Lakes; accidental in Mo., Colo., and Wyo.

Long Island, common W. V., Nov. 4-Feb. 27.

Nest, of grass, moss, and seaweed in colonies on the ledges of rocky cliffs. Eggs, 3-5, varying from shades of buffy to grayish brown, distinctly and obscurely marked with chocolate, $2 \cdot 25 \times 1 \cdot 60$. Date, Bird Rock, Que., May 23.

"Our bird differs but little in its habits from other oceanic Gulls. Feeding chiefly on fish, but accepting any diet that drifts within range of its keen sight; drinking salt-water in preference to fresh; breasting a gale with ease and grace soaring in midair, skimming close above the crested waves, or swooping into the trough for a coveted morsel; resting upon the rolling billows, and sleeping serenely as they roll, with head tucked snugly under a wing; wandering in loose flocks, and making comrades of other wanderers; devoted to mate and young, and attached to all its kin-wherever seen or however employed, the Kittiwake is revealed as a typical gleaner of the sea.

"The name is derived from the bird's singular ery, which resembles the syllables kitti-aa, kitti-aa" (Chamberlain).

42. Larus hyperboreus Gumn. (ildavouts Give. Ads. in summer. Back and wings pale pearl-eray; primaries lightly tinted with pearl, inner half of their inner webs and tips fadling gradually into white: rest of phlumage pure white. Ads. in winter.- - similar, hut with hearl and nerek lightly streaked with grayish. I $m$.- Upperparts varying from ashy gray to white, feathers widely barred, mottled, or streaked with buffy or ashy gray; primaries varying from pale smoky gray to pure white; tail ashy or brownish gray; underparts varying from dirty whitish to ashy gray, generally darker on belly, sometimes mottled with buffy or grayish. (Birds of the second year 
are said to be pure white.) L., $28 \cdot 00$; W., $17 \cdot 10$; B., $2 \cdot 35$; depth of B. at projection on the lower mandible 75 to $1 \cdot 00$; Tar., $2 \cdot 60$.

Range.-Arctic regions. Breeds from nw. Alaska, Melville Island, and n. Greenland s. to Aleutian Islands, n. Mackenzie, cen. Ungava, and on Arctic islands of E. Hemisphere; winters from the Aleutians and Greenland s. to Monterey, Calif., the Great Lakes, and L. I., and casually to Bermuda, N. C., and Tex.; in Europe and Asia s. to the Mediterranean, Black, and Caspian seas, and Japan. Apl.

Long Island, rare, W. V., Jan. 2-May 1. Cambridge, rare W. V., Nov.-

Nest, of grasses, moss, etc., on the ground. Eggs, 2-3, varying from pale olive-brown to grayish white, spotted or speckled with shades of chocolate, $3 \cdot 10 \times 2 \cdot 20$. Date, Cumberland Sound, June 8 .

Mr. Chamberlain remarks that this species combines "with some gull-like traits many of the coarse characteristics of both Falcon and Vulture."

"Some observers have reported that flocks are at times very noisy, particularly when settling for the night; but those I have met with in winter have been rather silent. Their cry is harsh and at times very loud; it sounds something like the syllables $k u k-l a k$. I have seen it written cut-leek."

43. Larus leucopterus Faber. ICELANd Goll. Resembles the preceding but is much smaller; specimens in juvenal plumage more frequently have white or brownish shafts untinged with yellow, as in hyperboreus; others are mottled with black rather than brownish (Dwight, $A u k, 1906,34$ ). W., $15.40-16.50$; B., 1.65-1.90; depth of B. at projection on the lower mandible, '60-70; Tar., 2.05-2'20 (B., B., and R.).

Range.-Arctic regions. Breeds from Victoria Land (Cambridge Bay) and Boothia Peninsula to cen. Greenland and e. to Nova Zembla; winters from s. Greenland s. to L. I.; casual on the Great Lakes; accidental in Nebr. and Md.; in Europe s. to the British Isles, Scandinavia, and Baltic Sea.

Long Island, very rare W. V. Cambridge, rare W. V. N. Ohio, casual on Lake Erie in winter.

Nest, of grasses, moss, etc., on the ground. Eggs, 2-3, clay-color with numerous chocolate markings, $279 \times 1.89$. Date, Julianshaab, Greenland, June 1.

"It is not particularly difficult for the trained observer to distinguish the White-winged Gulls in the field from the Herring Gull; but as between $L$. hyperboreus and $L$. leucopterus a positive identification is not so easy. . . One soon gets to recognize the white-winged species flying, even at a considerable distance, and the smaller size of the Iceland Gull is seen perhaps more distinctly on the wing than when the bird is sitting. The bill, when it can be seen, is an excellent ficld-mark, the Iccland Gull's like that of Kumlien's Gull, being much smaller in proportion. . . ." (Allen, F. H., Auk, 1908, p. 300, status near Boston.)

45. Larus kumlieni Brewst. KumLien's Gull. Very similar in general color to the two preerding species, but differs from them in the color of the primaries. These, instead of being uniformly pure white or but lightly tinted with gray, are marked with sharply defined spaces of ashy gray. The first yrimary is tipped with white and marked with ashy gray on the outer web and shaft part of the inner web; the second primary is ashy gray on only 
part of the outer web; the third and fourth primaries have smaller white tips and are marked with ashy gray near their ends on both webs. W., 15.5017.00 ; B., $1.65-1.88$; depth of B., at projection on the lower mandible, 60-66; Tar., 2.10-2.35 (Brewster).

Remarks.-For a plate and detailed discussion of the status of this and related species see Dwight, Auk, XXIII, 1906, pp. 26-43.

Range.-N. Atlantic coast of N. Am., breeding in Cumberland Sound; s. in winter to N. Y. and Conn.

Long Island, one record, Mch. 8.

Nest, on "the shelving rocks of high cliffs." Eggs, resembling those of L. glaucescens (Kumlien). Date, Weyprecht Islands, Ellesmere Land, June 15 (Thayer Coll.).

Kumlien found this bird breeding in considerable numbers near the head of Cumberland Gulf, and it is now known to winter south regularly, if rarely, to Massachusetts and casually farther. The adult "when seen under favorable conditions, is easily distinguished from $L$. hyperboreus and $L$. leucopterus, for the spots on the primaries cannot fail to be noticed whether the bird is sitting or flying" (Allen, F. H., $A u k, 1908$, pp. 296-300, status near Boston).

47. Larus marinus Linn. GreAt BLACK-BACKed Gull. Ads. in summer.-Back and wings slaty black; wing-feathers tipped with white; rest of plumage white; tail sometimes mottled with dusky. Ads. in winter.Similar, but with head and neck streaked with grayish. Im.-Head and nape whitish, streaked with grayish; back and wings, except primaries, brownish, the feathers margined and irregularly marked with pale buffy; primaries dark brownish black, inner ones with small white tips; tail mottled with black and white; underparts whitish, more or less streaked or barred with grayish. L., $29 \cdot 00 ;$ W., $18.50 ;$ T., 8.00; B., 2.50 .

Range.-Coasts of the N. Atlantic. Breeds from North Devon Island and cen. Greenland s. to N. S. and to lat. $50^{\circ}$ on European coasts; winters from s. Greenland s. to the Great Lakes and Delaware Bay (casually to Fla.) and the Canaries; accidental in Bermuda.

Long Island, common W. V., Nov. 3-Mch. 13. Cambridge, common W. V., Dec. 1-Apl. 15.

Nest, of grasses, seaweed, etc., on the ground. Eggs, 2-3, clay-color, brownish ashy or buffy, rather evenly spotted with chocolate, $3.00 \times 2.15$. Date, Kings Co., N. S., May 23.

A more northern species than the Herring Gull. Mr. Brewster, who observed it in numbers in the island of Anticosti in July, writes:

"The Black-backs are exceedingly noisy birds, especially when their young are in danger, as well as toward evening. . . . I identified four distinct cries: a braying ha-ha-ha, a deep keow, keow, a short barking note, and a long-drawn groan, very loud and decidedly impressive. - . At all times of the year, during the breeding season as well as in winter, it is by far the wariest bird that I have ever met."

The Siberian Gull (50. Larus affinis) - a large Gull inhabiting northern Asia and Europe-is accidental in Greenland.

51. Larus argentatus Pont. Herring Gult. Ads. in summer.Back and wings deep pearl-gray; first primary tipped with white, then crossed by a small hlack mark, then a much larger white one; this is followed by a black space; the black runs down the outer weh of the feather to near its base and the shaft part of the inner web nearly as far, leaving the inner 
two-thirds of the web below the black mark white (Fig. 78, a); second primary similar, but second white mark is a round spot on inner web and black occupies a greater space near tip, but does not continue so far down on feather; third to sixth primaries tipped with white, which is succeeded by a gradually diminishing black band which extends farther down on the outer web of the feather than on the inner; rest of plumage pure white. Ads. in winter. - Similar, but with head and neck streaked and spotted with grayish. Im.-Upperparts ashy fuscous; head and nape more or less streaked with pale buffy; back and wings margined or irregularly marked with same color; primaries brownish black; tail the same, sometimes tipped or margined with buffy; underparts ashy fuscous, sometimes lightly barred or streaked. L., $24 \cdot 00 ;$ W., $17 \cdot 50 ;$ T., $7 \cdot 50 ;$ B., $2 \cdot 30$.

Range.-N. Hemisphere. In Am. breeds from s. cen. Alaska, Melville Island, s. Ellesmere Land, and Cumberland Sound s. to s. B. C., s. Alberta, n. N. D., cen. Wisc., s. Ont., n. N. Y., and Maine, and in Europe s. to n. France and e. to White Sea; winters from s. B. C. s. to L. Calif., and w. Mex., and from Gulf of St. Lawrence and the Great Lakes s. to the Bahamas, Cuba, Yucatan, and eoast of Tex., and, in Europe, to Mediterranean and Caspian Seas.

Washington, common W. V., Oct.-May 10. Long Island abundant W. V., Oct.-Apl., a few summer. Ossining, common T. V., Sept. 21-May 9; common W. V. when river is open. Cambridge, abundant W. V., Oct. 15-May 8. N. Ohio, common P. R. on Lake Erie. Glen Ellyn, T. V. chiefly spring, occasional W. V., Dec. 4-Apl. 7. SE. Minn., occasional in summer, Apl. 1.

Nest, of grasses, moss, seaweed, etc., on the ground, but, where the birds have been persistently robbed, it is more compactly built and placed in trees sometimes fifty feet or more from the ground. Eggs, 2-3, grayish olive-brown, rarely whitish, spotted, blotched, and scrawled with distinct and obscure chocolate markings, $2 \cdot 85 \times 1.90$. Date, Midriff Lake, N. Y., May 3; Isle Royal, Mich., May 20.

This species is by far the most abundant winter Gull along the coasts of the Middle and Southern States. Unlike the more pelagic species, it frequents our rivers and harbors, feeding about piers and wharves, and near the cities where as a scavenger it is of the highest value. Sometimes one may see them 'bedded' in flocks on the water where they alight to rest. It is generally this species which follows in the wake of our coastwise vessels, sailing astern, when the wind is from ahead, without the slightest perceptible movement of the wings.

1902. Mackay, G. H., Auk, IX, 221-228.-1903. Dutcher, W. and Baily, W. L., Auk, XX, 417-431 (nesting).-1900. Chapman, F. M., Bird-Lore, II, 10, 11 (value as scavengers).

54. Larus delawarensis $O r d$. RING-BILLED GULL. Ads. in summer.Back and wings pearl-gray; first primary black, with a white spot near tip, base of inner half of inner web pearl-gray (Fig. 78, b); second primary black, basal half of inner web pearl-gray; on the third to sixth primaries the black decreases rapidly, and each one is tipped with white; rest of plumage pure white; bill greenish yellow with a black band in front of the nostril. Ads. in winter. - Similar to above, but head and nape streaked with grayish. Im.- I ${ }^{\mathrm{I}} \mathrm{pperparts}$ varying from ashy fuscous, the feathers margined with whitish, to pearl-eray, the feathers more or less mottled, spotted, or, on head and nock, struaked with ashy fuscous; outer primaries black, tail varying from pearl-eray, more or less mottled with blackish, to white, and crossed near rnd hy a wide band of black; basal half of bill yellowish, end black. L., $18.50 ; \dot{W} ., 14.00 ;$ T., 6.00; B., 1.60.

Range.-N. America. Breeds from s. B. C., Great Slave Lake, s. Keewatin, and s. Ungava s. to s. Ure., s. Colo., n. N. D., cen. Wisc., cen. Ont., 
n. N. Y. (casually), and n. Que.; winters from B. C., the Great Lakes, and Mass. s. to Bermuda, the Gulf coast, Cuba, and s. Mex.

Washington, very common T. V., Feb.-Apl. 5; Oct.-Nov.; rare in winter. Long Island, regular T. V., abundant in fall; casual in winter and summer; Sept. 5-Nov. 12; Mch. 27-May 15. Ossining, casual T. V. SE. Minn., T. V., Mch. 23, Oct. 10.

Nest, of grasses, etc., on the ground. Eggs, 2-3, clay-color, buffy, or whitish, rather evenly spotted with chocolate, $230 \times 1.65$. Date, Stump Lake, N. D., May 31.

The coast-inhabiting individuals of this species resemble the Herring Gull in habits, and are not easily identifiable from that species unless the two be seen together, when the smaller size of the Ring-bill is noticeable.

In the interior, where the species is locally common, it feeds in part on insects, which it catches both on the ground and in the air.

The Short-Billed Goll (55. Larus brachyrhynchus) of Western North America, is accidental in Quebec.

The Mew Gull (56. Larus canus)-a European species-has been reported once from Labrador.

58. Larus atricilla Linn. LAJGHing GUll. (Fig. 23, b). Ads. in summer.-Back and wings dark pearl-gray; primaries black, inner ones with small white tips (Fig. 78, c); whole head and throat deep slate-color; rest of plumage, including nape, pure white, breast sometimes suffused by a delicate peach-blossom tint; bill dark reddish brighter at the tip. Ads. in winter.- Resemble above, but have the head and throat white, crown and sides of head and sometimes nape spotted or streaked with grayish. Im.Upperparts light ashy fuscous, the feathers margined with whitish; primaries black; forehead and underparts white, sometimes washed in places with dusky; tail dark pearl-gray, broadly tipped with black. L., 16.50; W., $12.50 ;$ T., 4.90 ; B., 1.65 .

Range.-Tropical and temperate coasts. Breeds from Maine (rarely) and Mass. (abundantly but locally) s. on the Atlantic and Gulf coasts to Tex., the Lesser Antilles and Venezuela; winters from Ga. and Gulf coast s. to w. Mex., Chile, and Brazil; casual in Colo., Nebr., Wisc., Ont., and Iowa.

Washington, irregular in Sept. Long Island, rare S. R., irregular S. V., Apl.-Sept. (Dutcher).

Nest, of grasses, seaweed, etc., in grassy marshes. Eggs, 3-4, varying from grayish olive-brown to greenish gray, spotted, blotched, and scrawled with chocolate, $2.15 \times 1.55$. Date, Corpus Christi, Tex., Apl. 8; Cobb's Is., Va., May 26; Muskeget Is., Mass., June 7.

This is the only Gull nesting on our Atlantic coast south of Maine. It was formerly abundant and generally distributed but is now found only locally, the colonies on Western Egg Rock in Maine and Muskeget Island, Massachusetts, being the only ones north of southern New Jersey.

When nesting, the Laughing Gull is an inhabitant of the salt marshes. On Cobb's Island, Virginia, the sitting birds were so conspicuous that from a distance they looked like white flowers dotting the marsh. The downy young, however, are much darker than young Terns, the general tone of their plumage resembling that of the reeds of which the nest is made. 
The resemblance of its call to wild, maniacal laughter has won for this species its common name.

1895. Mackay, G. H., Auk, X, 332-336 (habits in Mass.).

59. Larus franklini Rich. Frankin's Gull. Ads. in summer.Whole head and throat sooty black, nape, sides of neck, and underparts, except throat, white, generally suffused (in fresh specimens) with an exquisite peach-blossom tint; tail white; back and wings pearl-gray; first primary white, outer web black, except at the tip, shaft part of the inner web grayish on basal half (Fig. 78, $d$ ); second primary white, with a black mark on inner web and a black stripe on outer web near the tip, rest of outer web and shaft part of inner web pearl-gray; third to sixth primaries tipped with white, then banded with gradually diminishing bars of black, which are succeeded by a whitish space, while the rest of the feather is pearl-gray; bill dark coral-red. Ads. in winter.-"Similar, but head and neck white, the occiput, with orbital and auricular regions, grayish dusky; bill and feet dusky, the former tipped with orange reddish." Young, first plumage.-"Top and sides of the head (except forehead and lores), back and scapulars grayish brown, the longer scapulars bordered terminally with pale grayish buff; wing-coverts bluish gray tinged with grayish brown; secondaries dusky, edged with pale grayish blue and broadly tipped with white; primaries dusky, the inner more plumbeous, all broadly tipped with white. Ceritral portion of the rump uniform light bluish gray; lateral and posterior portions of the rump, upper tail-coverts, entire lower parts, forehead, lores, and eyelids white. Bill brownish, dusky terminally; feet brown (in skin)." W., 11.25; B., 1.30; depth through nostrils, 35: Tar., 1.60 (B., B., and R.).

Range.-Interior N. Am. Breeds from sw. Sask. and sw. Keewatin to S. D., Iowa, and s. Minn.; winters from Gulf coast of La. and Tex. to Peru and Chile.; accidental in Utah, Ont., Ohio, Va., and the Lesser Antilles.

Nest, of grasses, etc., in reedy marshes. Eggs, 2-3, varying from dark chocolate to creamy brown and sooty white, irregularly marked with small spots or large blotches of umber, and with obsolete lilac shell markings, $2.12 \times 1.40$ (Preston). Date, Heron Lake, Minn., May 8 .

Many Gulls nest in the interior, but of them all Franklin's has rarely been found on either our Atlantic or Pacific coasts, though it reaches the seashore in its winter quarters.

Pausing in its billowy flight over the prairies to circle about one curiously; hovering over the plowman, or exploring the furrow in his wake; eagerly chasing grasshoppers, like a flock of pearl-plumaged hens; gathered in thousands in the reeds where it nests or in vast flocks prior to its fall migration, Franklin's Gull is one of the most interesting, as it is unexpected, forms of bird-life of our interior.

1886. Preston, J. W., Orn. and Oöl., XI, 54, 55.-1900. Roberts, T. S., Auk, XVII, 272-283 (one of the first as well as one of the best of American bird studies with a camera).-1902. JoB, H. K., Among the Water-Fowl, 159-165.-1910. Ed. Leaflet, No. 44, Natl. Assoc. Aud. Soc., Bird-Lore, XII, 124-127.

60. Larus philadelphia (Ord). Bonaparte's Gull. Ads. in summer. -Whole head and throat dark, sooty slate-color; nape and sides of the neck, underparts, except throat, and tail white; back and wings pearl-gray; first primary, secn from above, white, outer web and tip black (Fig. 78, e); second and third primaries white, tipped with black; third to sixth primaries with small whitish tips, then large black spaces, the rest of feather white or pearl-gray; hill black. Ads. in winter.-Similar, but head and throat white, back and sides of head washed with grayish. Im.-Top of the head and 
nape and a spot on the auriculars more or less washed with grayish; back varying from brownish gray to pearl-gray; lesser wing-coverts grayish brown, secondaries mostly pearl-gray; first primary with outer web, tip, and most of shaft part of inner web black; inner margin of inner web at end of feather narrowly bordered with black; second and third primaries much the same, but with slightly more black at ends; tail white, banded with black and narrowly tipped with white; underparts white. L., 14.00; W., 10.30; T., 4.00; B., 1.15.

Range.-N. Am. Breeds from nw. Alaska and n. Mackenzie s. to s. B. C. and s. Keewatin; winters from Maine to Fla. and on the Gulf coast to Tex. and Yucatan, and on the Pacific coast from s. B. C. s. to L. Calif. and w. Mex. (Jalisco); in migration w. to Kotzebue Sound and e. to Ungava; casual in Bermuda and the Bahamas.

Washington, common T. V., Mch.-May 30; Oct. and Nov. Long Island, regular W. V., Nov. 18-May 11. Ossining, rather rare T. V., Apl. and Oct. Cambridge, rare T. V. in spring. N. Ohio, regular but not common T. V., Apl. 10-May 20; Sept. 1-20. SE. Minn., common T. V., Apl. 23.

Nest, of sticks lined with grasses, etc., on stumps, in bushes or trees four to twenty feet from the ground. Eggs, 3-4, grayish olive with a greenish tint and small clove-brown spots, chiefly about the larger end, 1.97 $\times 1.40$ (B., B., and R.). Date, Anderson River, June 6.

"This little Gull is more often found in flocks than our other species, and is frequently seen flying over swamps and plowed fields searching for worms and insects; but it is usually met with on the lakes and rivers hunting its food like the Herring Gull. It is far less wary than that species" (Eaton).

It may sometimes be seen in active, fluttering groups feeding in our harbors.

The Little Gull (60.1. Larus minutus), a European species, has been taken once on Long Island, in September, 1887 (Dutcher, Auk, V, 1888, p. 171), and once in Maine, July 20, 1910 (Norton, $A u k, 1910,447$ ), and also in Bermuda.

61. Rhodostethia rosea (Macg.). Ross's GuLL. Middle tail-feathers longest. Ads. summer.-Head, neck and underparts exquisite rosy shellpink; a black ring around the neck; back and wings pearl-gray, outer margin of outer primary black above except at tip; tail white pink tirıged. Ads. in winter. - Similar but without black collar and with less pink (Saunders). Im.-No collar, no pink tint; central tail-feathers tipped with blackish; crown and back pearl-gray; rump barred; ear-coverts dusky, region around eye streaked with dusky; below white; outer primar: s blackish, white on the inner webs, increasing to nearly white inner primar. aries; tertials and coverts, blackish, white tipped. In a succeeding plumage the tail is white and the collar evident. L., $13.50 ;$ W., $10.50 ;$ T., $5.25 ; \mathrm{B}$. 75 .

Range.-Arctic regions. Breeds in delta of Kolyma River ne. Siberia; migrates to Kamchatka, n. coast of Alaska, Melville Peninsula, w. coast of Greenland, and Arctic islands of Europe; casual in England, Faroe Islands, and Helgoland.

Nest, on the ground of dry grass and Carices, sometimes with a few Betula or Salix leaves, or of reindeer moss. Eggs, 2-3, "beautiful deep rich olivegreen without any of the grayish or sandy shade, spotted, especially near the large end, with chocolate-brown, 1.65 × 1.22." Date, June 13. (See Buturlin, Ibis, 1906, 131-139; 333-337).

In 1905 Ross's Gull was discovered by Buturlin breeding in numbers in the delta of the Kolyma River, northeast Siberia. His obser- 
vations are given in the Ibis as above. (See also a review of his paper in The Auk, 1906, p. 348.)

62. Xema sabini (Sab.). Sabine's Gull. Ads. in summer.-Whole head and throat slate-color, bordered posteriorly by black, back and sides of neck, underparts, except throat, and slightly forked tail pure white; back and wings dark pearl-gray; secondaries tipped with white; first primary black, inner half of inner web, except at end, white; second to fourth primaries similar, but tipped with white; bill black, end yellow. Ads. in winter."Similar to the summer plumage, but the head and neck white, except occiput, nape, and auricular region, which are dull, dusky plumbeous" (B., B., and R.). Im.-Forehead and lores white, rest of upperparts ashy brown, feathers slightly tipped with whitish; tail white, broadly tipped with blackish; underparts white. L., 14.00; W., 10.50; T., 4.50; B., 95.

Range.-Arctic regions to S. Am. Breeds on the coast of Alaska from Kuskokwim River to Norton Sound and in n. Mackenzie, n. Keewatin, and n. Greenland, and on Arctic islands of Europe and Asia; in migration on both coasts of U. S. and casual in the interior; winters in Peru.

Long Island, A. V. two records; July; Oct.

Nest, of grasses, etc., on the ground. Eggs, 2-5, deep olive (varying in intensity, however), rather indistinctly spotted or blotched with brown, $1.78 \times 1.26$ (Ridgw.). Date, Hooker Bay, Alaska, July 1 (Thayer Coll.).

This boreal species is of rare occurrence in the Northern United States, there being but three records for Massachusetts and the same number for New York.

\section{Subfamily Sternince. Terns. (Fig. 24.)}

The Terns number some fifty species, distributed throughout the world, ten being found in North America. They are more southern than the Gulls, only two species nesting north of Maine, in Eastern North America. They are also more migratory, none wintering on our coasts north of the Carolinas.

Terns are littoral, not pelagic, and, although characteristic of our sea-coasts, like the Gulls, several species nest in the interior, the Black Tern breeding only on bodies of fresh water. Beautiful as pearls, graceful and active as Swallows, Terns are a constant delight to the eye. They capture their prey of small fish by darting toward it like a living arrow, plunging recklessly into the water, and, in some cases, swimming a few feet beneath the surface. When looking for food they usually fly with the bill pointed downward, a habit which will aid in distinguishing them from the Gulls, whose bill is carried more nearly in a line with the body.

Terns nest in colonies on islands and when disturbed are much bolder than most Gulls, hovering elose overhead and swooping toward one fearlessly. The young are born covered with down, mottled in pattern like that of Gulls. This plumage is both countershaded and obliteratively marked; further proof of its protective value being furnished by the birds themselves, which, in obedience to the warning note of their parent, squat flat and become almost invisible so long as they remain motionless. Like the young of Gulls, young Terns are de- 
Plate XI

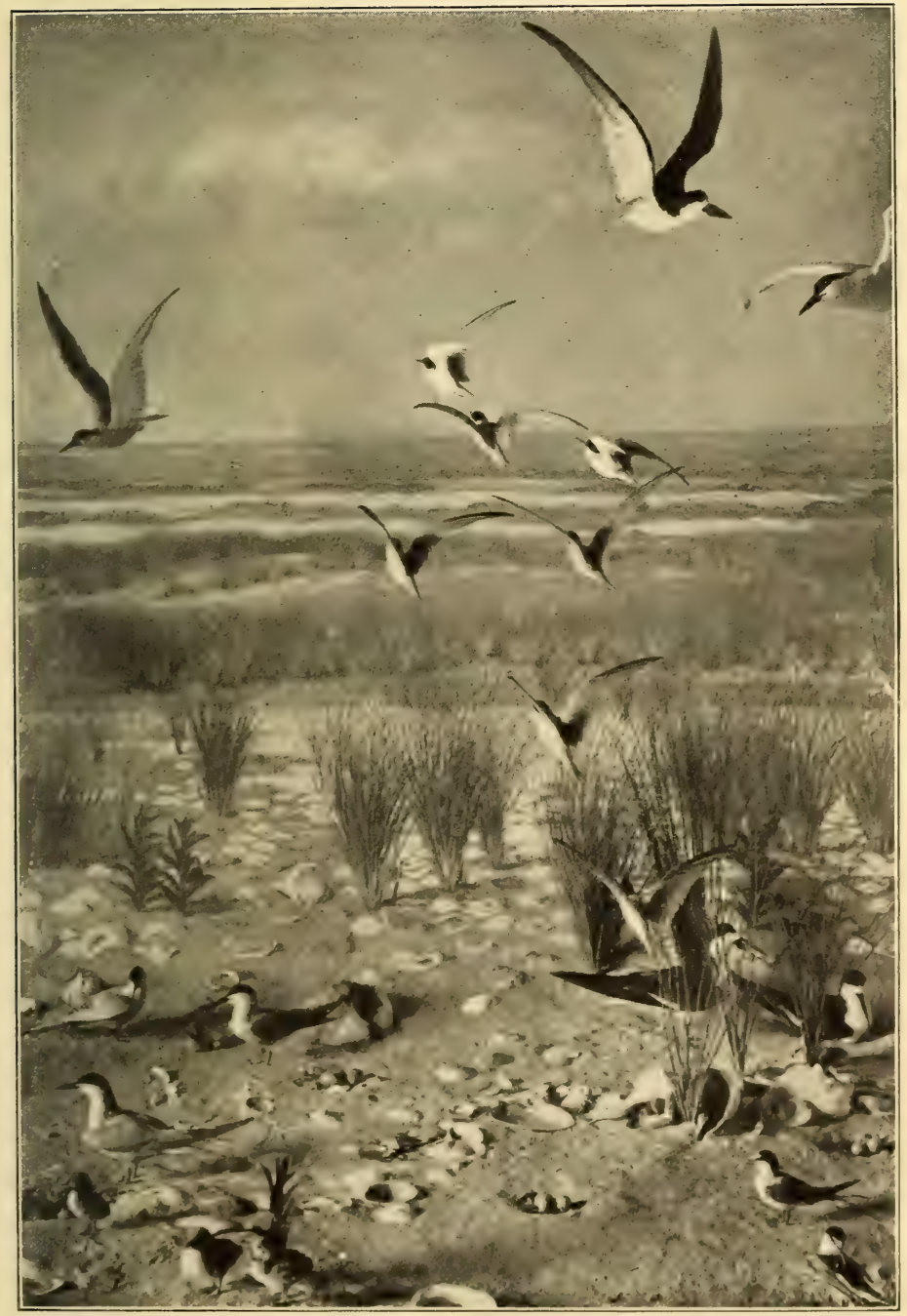

Common Terns

TerNS AND SKIMMERS

Least Terns.

Black Skimmers.

From the Habitat Group of Cobb's Island in the American Museum of Natural History. 

pendent on their parents until they acquire the power of flight. During this period, the young of some, possibly of all, species, enter the water of their own volition and swim freely, a habit in which the adult rarely, if ever, indulges.

\section{Subfamily Sternince. Terns}

I. Wing under $13 \cdot 00$.

$$
\text { KEY TO THE SPECIES }
$$

1. Entire top of the head jet-black.

A. Bill black, or mostly black.

a. Feet black or blackish.

$a^{1}$. Underparts black or blackish ....... 77. Black TerN.

$a^{2}$. Underparts white; bill black ... 63. Gull-BIlled Tern.

$a^{3}$. Underparts white; bill black, broadly tipped with yellow.

b. Feet yellowish or orange.

67. Cabot's Tern.

$b^{1}$. Outer tail-feathers pure white; outer web of first primary black.

72. Roseate Tern.

$b^{2}$. Inner web of outer tail-feather gray; outer web of first primary gray . . . . . . . . 69. Forster's TerN.

$B$. Bill mostly or entirely yellowish, reddish, brownish, or orange.

$a$. Underparts tinged with grayish; outer web of outer tail-feather gray; inner web white.

$a^{1}$. Bill broadly tipped with blackish; tarsus generally over 70 .

70. COMMON TERN. $a^{2}$. Bill without a distinct black tip; tarsus generally under 70 .

71. Arctic Tern.

b. Underparts pure white; inner web of outer tail-feather gray; outer web white.........69. Forster's Tern.

2. Entire top of head not jet-black.

$A$. Forehead white; lores black; crown jet-black or silvery.

a. Wing under 8.00; back pearl-gray ....... 74. LeAst TerN.

$b$. Wing over 8.00; back grayish brown or blackish.

$b^{1}$. Back grayish brown; a white stripe from the forehead over the eye. ................. 76. BRIDLEd Tern.

$b^{2}$. Back blackish; white of forehead not reaching over the eye.

75. SoOtY TERN.

$b^{3}$. Crown silvery, rest of plumage sooty . . . . 79. Noddy.

$B$. Forehead or crown white or grayish, sometimes speckled with black; lores not entirely black.

a. Wing pearl-gray.

$a^{1}$. Outer tail-feather entirely pure white.

$a^{2}$. Bill over 1.75, tipped with yellowish. . 67. CABOT's TERN.

$\boldsymbol{a}^{3}$. Bill under $1 \cdot 75$, without a yellow tip.

$b^{1}$. Outer tail-feather not pure white.

72. Roseate Tern (Im.).

$b^{2}$. Inner web of outer tail-feather darker than outer web; outer weh mostly or entirely white; a black space generally on the side of the head inclosing the eye.

69. Forster's Tern (Im.).

$b^{3}$. Outer web of outer tail-feather darker than inner web; tarsus over $70 \ldots \ldots . . .70$. Common Tern (Im.).

$b^{4}$. Outer web of outer tail-feather darker than inner web; tarsus under $70 \ldots \ldots . . .71$. Arctic Tern (Im.).

$b^{5}$. Tail wholly gray, not deeply forked, wing under $9^{\circ} 00$; belly white or mottled with black. . . 77. BLACK TERN (Im.).

$b$. Wing blackish.

$b^{1}$. Underparts blackish . . . . . . 75. Sooty Tern (Im.).

$b^{2}$. Underparts white $\ldots \ldots \ldots \ldots$ 76. BRIdLED Tern (Im.). 
II. Wing over $13^{\circ} 00$.

A. Wing 15.00 or over; outer primary mostly gray. 64. Caspian Tern.

$B$. Wing under 15.00 ; inner half of inner web of first primary white.

65. Royal Tern.
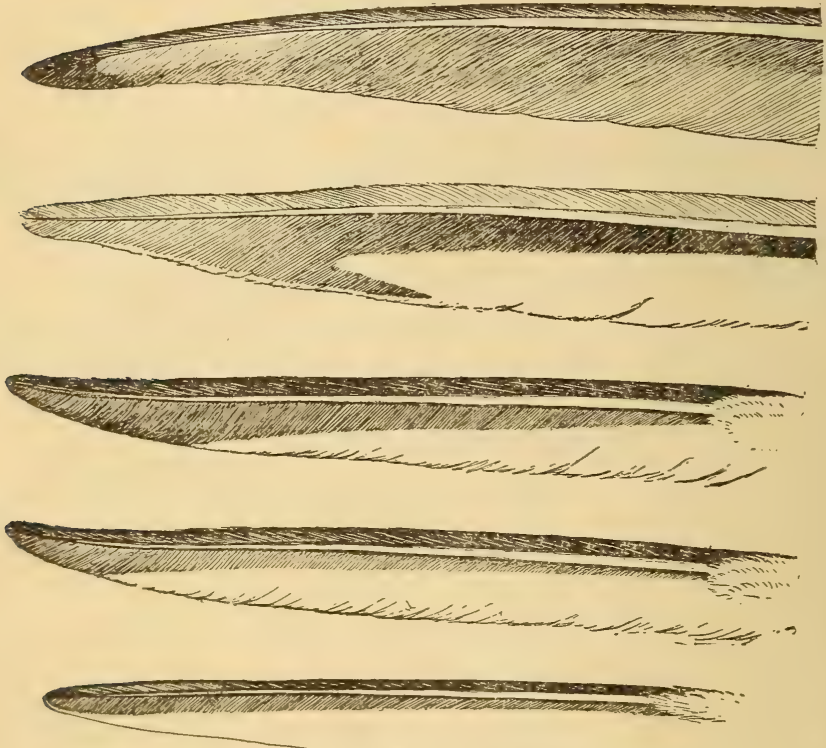

FIG. 79. First primaries of adult Terns, seen from below: (a) Caspian Tern; (b) Royal Tern; (c) Common Tern; (d) Arctic Tern; (e) Roseate Tern.

63. Gelochelidon nilotica (Linn.). GULL-BILLED TERN. Ads. in summer.--Top of head and nape black; back and wings pale pearl-gray; outer web of outer primaries silvery; tip and shaft part of inner web darker; inner part of inner web, except for a narrow margin at end of feather, white; tail white, slightly forked, the middle feathers grayish; underparts white; bill and feet black, the former rather short and stout. Ads. in winter.-Similar to the above, but top of the head white, auriculars grayish, and a space in front of the eye blackish. L., $14.50 ;$ W., $12.00 ;$ T., $5.50 ;$ B., 1.40 ; depth of B. at base, 50 .

Range.-Nearly cosmopolitan. Breeds in N. Am. on coasts of Tex., La., N. C., Va. (formerly to N. J.), and in the Bahamas; wanders casually to Maine and Ohio); winters in s. Mex., s. Guatemala, and from Brazil s. to Patagonia and Chile. Brceds also in Europe, Asia, and Australia, and winters s. to n. Africa.

Washington, casual in autumn, no recent records. Long Island, A. V. in summer.

Irsi, of shells and pehbles, on beaches. Eggs, 3-5, rather uniform buffy white, with numerous distinct and olsscure chocolate markings, $1.80 \times 1.30$. Date, Corpus Christi, Tex., Apl. 30; Cobb's Is., Va., May 30. 
The Gull-billed Tern has greatly decreased in numbers during recent years, and it now breeds only locally and in small numbers from Cobb's Island, Virginia, southward. It is a less excitable bird than the Common Tern, from which and its near allies it may be known by its short, comparatively heavy, black bill and short, less-forked tail. Its notes are a high, reedy tee-tee-tee, sometimes suggesting those of a weak-voiced katydid.

64. Sterna caspia Pallas. Caspian Tern. Ads. in spring.-Top and back of head shining black, the feathers lengthened to form a crest; back of neck, underparts, and tail white; back and wings pearl-gray; primaries dark slaty, silvery on the outer web (Fig. 79, a); bill coral-red, darker near tip; feet black. Ads. after he breeding season and in winter. - Similar to the above, but top of the head streaked with black. Im.-Top of head streaked with black and white; back of neck and underparts white; back, wingcoverts, and tertials pearl-gray, spotted or barred with brownish black; primaries dark slaty, silvery on the outer web; tail pearl-gray, more or less barred with brownish black; bill orange-red; feet blackish brown. L., $21 \cdot 00 ;$ W., $16 \cdot 20 ;$ T., $6.00 ;$ B., $2 \cdot 80$.

Range.-Nearly cosmopolitan. Breeds in N. Am. at Great Slave Lake, Ore., on islands of $\mathrm{n}$. Lake Michigan, on coast of $\mathrm{s}$. Lab., and also on coasts of Tex., La., Miss., S. C., and (formerly) Va.; winters from coast of cen. Calif. to L. Calif. and w. Mex. (Colima), and on s. Atlantic and Gulf coasts; casual in migration north to Alaska, James Bay, and N. F.

Washington, casual, Sept., Oct., 1896. Long Island, uncommon T. V. May and Sept. SE. Minn., uncommon T. V., Apl. 25.

Eggs, 2-3, grayish white or buffy white, with rather small, distinct, and obscure chocolate markings, $2 \cdot 70 \times 1.83$. Date, Corpus Christi, Tex., Apl. 8, 1885; Gravel Is., Wis., June 10.

The singularly interrupted distribution of this, the largest of our Terns, indicates that it was once a far more abundant bird. It resembles the smaller red-billed Terns in general habits, but its large size prevents it from being confused with any other species except the Royal Tern. From Gulls it may be known by its red, pointed bill and forked tail.

1908. Chapman, F. M., Camps and Cruises, 301 (nesting).

65. Sterna maxima Bodd. Royal TERN. Ads. in spring.-Top and back of head shining black, feathers lengthened to form a crest; back of neck, underparts, and tail white; back and wings pearl-gray; inner web of primaries, except at tip, white; outer web, and shaft part of inner web dark, silvery slate-color (Fig. 79, b). Ads. after the bresding season and in winter.-Similar but top of head streaked with black and white. Im.-Rescmbling young of S. caspia, but smaller and with the inner half of the inner web of the primaries white. L., 19.00; W., $14^{\circ} 00 ;$ T., 7.00 ; B., 2.50.

Range.-Tropical coasts n. to U. S. Breeds in W. Indies and on $\mathrm{s}$. Atlantic and Gulf coasts n. to $V a$. and w. to Tex.; wanders casually to Mass.; not rare in summer from San Francisco Bay s. to w. Mex.; winters from Monterey, Calif. and Gulf of Mex., s. to Peru and Brazil, and on w. coast of Africa from Gibraltar to Angola.

Long Island, one record, Aug. 27.

Eggs, 2-4, more pointed than those of the preceding, gravish white, with rather small, distinct, and obscure chorolate markings, $2.65 \times 1.75$. Date, Corpus Christi, Tex., Apl. 8, 1885; near Charleston S. C., May 15.

A common species on our southern coasts. During the winter it is about the only Tern one sees in Florida waters. It is a strong, active 
bird on the wing, and a reckless, dashing diver, frequently disappearing beneath the surface in catching its prey. The slow-flying Pelicans are at its mercy, and it sometimes deftly robs them of their well-earned gains.

67. Sterna sandvicensis acuflavida (Cabot). CABOT's TERN. Ads, in spring.-Whole top of head and crest black; back and wings light pearlgray; primaries silvery gray; the shaft part of the inner web white except at the tip; rest of the plumage white; feet and bill black, the latter with a conspicuous yellowish tip. Ads. after breeding season and in winter.- Similar, but crown white, sometimes spotted with black; back of head and crest more or less streaked with white. Im.- Similar, but back spotted with blackish; tail slaty gray and much shorter; bill slightly if at all tipped with yellow. L., $16 \cdot 00 ;$ W., $10.50 ;$ T., 5.50; B., $2 \cdot 05$.

Range.-N. and S. Am. Breeds from N. C. to Fla., Tex., and Mex.; winters from the Bahamas, Fla., and La. to Cen. Am. (both coasts), the Greater Antilles, Colombia, and Brazil; accidental in Ont., Mass., N. J., and the Lesser Antilles.

Eggs, 2-3, buffy white, spotted, speckled, and scrawled with distinct and obscure chocolate markings, 2.05 × 1.40. Date, Tampa, Fla., Apr. 10; coast of S. C., second week in June.

Cabot's Tern was formerly abundant along the coasts of Florida, but it now breeds only locally. There is a small breeding colony in Pamlico Sound, North Carolina (Pearson), and in Bull's Bay, South Carolina (Wayne). The bird winters from the Florida Keys southward. Its black, yellow-tipped bill is a good field mark.

Trudead's Tern (68. Sterna trudeaui) is a South American species which has been taken once on Long Island and once on the New Jersey coast.

69. Sterna forsteri $N u t t$. Forster's TERn. Ads. in summer.-Whole top of head black; back and wings pearl-gray; inner border of inner web of outer primaries white, except at the tip; rump and entire underparts white; tail light pearl-gray, the outer feather darker toward the end, where the inner web is always darker than the outer; bill dull orange, the end third blackish; feet orange. Ads. in winter.- Similar to the above, but head white, more or less washed with grayish or spotted with black, a large black spot on the side of the head inclosing the eye; bill mostly black; feet brownish. Im.- Similar to the preceding, but the back and wings more or less mottled or washed with light brownish, and the tail much shorter. L., 15.00; W., 10.25; T., 7*00; Tar., '90; B., 1.50 .

Range.-N. Am. Breeds on interior lakes of Calif., s. Ore., and Nev., and from sw. Sask. and Man. s. to n. Colo., n. Nebr., ne. Ills., and s. Ont., and on coasts of Tex., La., and Va.; winters from s. Calif., Gulf of Mex., and S. C. to s. Guatemala; in migration occurs on the Atlantic coast, casually as far $\mathrm{n}$. as Mass.; casual in Brazil.

Washington, irregular T. V. Long Island, casual. Glen Ellyn, very rare T.-V., May. SE. Minn., common T. V., uncommon S. R., Apl. 29Aug. 21.

Nest, of seaweed, flags, or weeds on a slight elevation in grassy marshes. lings, 3, very variahle, olive-gray, or olive brownish ashy, more rarely whitish or buff, heavily marked with chocolate, $1.80 \times 1: 30$. Date, Corpus Christi, Tex., Apr. 29; Cobb's Is., Va., June 1; Swan Lake, Minn., June 13.

Forster's Tern, although so like the Common Tern in appearance, differs materially from it in hahits. It is not dependent on sandy beaches for a nest-site, but is a marsh inhabitant, laying on a platform 
nest in the grasses. I have never found it in large colonies, but in scattered pairs. Its notes are a long-drawn, reedy cackle and a tweet-tweettweet-tweet.

70. Sterna hirundo Linn. Common Tern (Fig. 24). Ads. in summer. -Whole top of head black; back and wings pearl-gray; inner border of inner web of outer primaries white, except at tip (Fig. 79, c); throat white; breast and belly pale pearl-gray; tail white, the outer webs of the outer feathers gray or pearl-gray; bill red at the base, the end third black; feet orange-red. Ads. in winter. - Similar, but front part of head and underparts white; bill mostly black. Im. - Similar, but back more or less washed or mottled with light brownish; lesser wing-coverts slaty gray, and tail much shorter. L., $15 \cdot 00$; W., $10 \cdot 25$; T., $5 \cdot 50$; Tar., $\cdot 75$; B., $1 \cdot 40$.

Range.-N. Hemisphere, n. S. Am., and Africa. Breeds from Great Slave Lake, cen. Keewatin, and s. Ungava s. to sw. Sask., n. N. D., s. Wisc., n. Ohio, and N. C.; winters from Fla. to Brazil; casual in migration on Pacific coast from B. C. to L. Calif. In E. Hemisphere breeds in Europe and Asia and winters in India and s. Africa.

Washington, irregular T. V., sometimes common. Long Island, common S. R. on Gardiner's Is., May 20-Oct. 15., Ossining, casual in late summer. Cambridge, very rare T. V. N. Ohio, S. R. in large colonies on islands in Lake Erie, May 5-Sept. 20. Glen Ellyn, irregular, uncommon T. V. May 15-Sept. 9. SE. Minn., T. V.

Remarks.-The Common Tern is closely related to Forster's Tern and also to the Arctic Tern. From the former it is to be distinguished by the color of the long outer tail-feathers. In the Common Tern the outer web of these feathers is always darker than the inner web; in Forster's Tern the inner web is always darker than the outer one. Adult Common Terns have the breast and belly washed with pearl-gray, while in Forster's Tern these parts are pure white.

The Common Tern differs from the Arctic Tern in having the bill tipped with black instead of being entirely red; in having longer tarsi, and in the color of the primaries.

Nest, a slight depression in the sand, scantily lined with sea-weed or grasses. Eggs, 3-4, not distinguishable with certainty from those of the preceding, but averaging paler and greener, and less heavily marked, 1.60 × 1.20. Date, Cobb's Is., Va., May 28; Muskeget Is., Mass., May 28.

It is many years since I visited my first breeding colony of Common Terns (on Gull Island, L. I.), but I can close my eyes and still feel the air vibrate with the harsh, half-threatening, half-pleading chorus of nearly two thousand excited voices. There is a dull, heavy, hopeless monotone, broken only by the seream of some half-maddened bird who fearlessly darts downward to protect its nest at my feet. A shot is fired; there is a moment of awe-struck silence, then, with renewerl violence, the screaming is resumed. Pandemonium reigns: tearr, tearr, swish! the air is full of darting, diving, crying Terns. It was useless to attempt to secrete myself. At no time during my stay did the outery cease or hovering flock disperse.

It was only after I had exchangerl a gun for a eamera that I learned how quickly Terns will go back to their nest if one will eoneral oneself in a blind, which in itself may be conspicuous enough, if it be motionless. Then one learns that the tearrr note of alarm and protest gives way to a great variety of calls incident to the activities of the birds when not disturbed; for example, a sharp chirp not unlike that of a 
White-throated Sparrow, and a tue, tue, tue, uttered by a bird in pursuit of another. The young are fed on fish which they take from the bill of the parent. They promptly and instinctively squat at the parent's warning note and remain motionless until touched. They enter the water of their own volition and swim freely, while the parents, which rarely swim, stand on the shore and watch them; webbed feet, therefore, apparently being of use to young Terns although practically functionless in the adult.

Thanks to the movement for the protection of our birds, Terns, which fifteen years ago seemed to be doomed to extinction, are now increasing, and there is reason to hope that our shores may again be enlivened by these beautiful, graceful creatures.

1879. Brewster, WM., Bull. Nutt. Orn. Club. IV, 13-22 (habits).1895-99. MackaY, G. H., Auk, XIII, 32-48, 178; XIV, 21, 22, 278-284, 383-390; XVI, 168-172; XVII, 259-266 (on Muskeget and Penikese Islands, Mass.) - 1900. Chapman, F. M., Bird Studies with a Camera, 106-127.1902. JoNes, L., Wilson Bull., XV, 94-100.-1906. XVIII, 35-47 (on Weepeckets).

71. Sterna paradisæa Brünn. ARCTIC TERN. Very similar in color to the Common Tern, from which it differs in having less gray on the shaft part of the inner web of the outer primaries (Fig. 79, d); in having the tail somewhat longer, the tarsi and bill shorter, while the latter, in the adult, is generally without a black tip. L., $15 \cdot 50$; W., 10.25; T., 7.50; Tar., '65; B., $1 \cdot 30$.

Range.-Nearly cosmopolitan. Breeds from n. Alaska, Melville Island, and n. Greenland, s. to Commander and Aleutian Islands, n. B. C., Great Slave Lake, cen. Keewatin, Maine, and (formerly) Mass., and in entire Arctic regions of Europe and Asia; winters in Antarctic Ocean, s. to lat. $74^{\circ}$; in migration, Pacific coast s. to s. Calif., and Atlantic coast s. to L. 1. accidental in Colo.

Long Island, one record, July 1.

Nest, as in preceding. Eggs, 3-4, not distinguishable with certainty from those of the preceding, $1.62 \times 1 \cdot 15$. Date, Seal Is., Maine, June 17, 1875 .

Comparing the notes of this bird with those of the Common Tern, Mr. Brewster writes: "Their notes are similar, but several of them can be distinguished. The usual cry of S. macrura [= paradisca] corresponds to the tearr of $S$. hirundo, but is shriller, ending in a rising inflection, and sounding very like the squeal of a pig. The bird also has a short, harsh note similar to that of Forster's Tern. At any distance within fair gun-range I could usually separate it from Wilson's [=Common] Tern by its longer tail, and by the uniform and deeper color of the bill. In flight and habits the two seemed to me identical" (Proc. Bost. Soc. Nat. Hist., XXII, 1883, p. 402).

72. Sterna dougalli Montag. Roseate Tern. Ads. in summer.Top of head black; back and wings pearl-gray; outer web of outer primaries and shaft part of the inner web slaty black (Fig. 79,e); underparts white, generally delicately tinted with pinkish; tail pure white; bill black, the base redlish; feet red. Ads. in winter. - Similar to the above, but front of the head white, more or less streaked or spotted with black; underparts pure white. Im., first plumage.- "Pileum and nape pale buffy grayish finely mottled or sprinkled with darker, and strcaked, especially on the crown, with 
dusky; orbital and auricular regions dusky blackish; remainder of the head, extreme lower part of the nape, and entire lowerparts white, the nape and sometimes the breast, finely mottled with buffy gray; back, scapulars, wingcoverts, rump, upper tail-coverts, and tail pale pearl-blue, the back and scapulars overlaid with pale buff irregularly mottled with dusky, each feather with a submarginal dusky V-shaped mark; primary coverts and primaries dark bluish gray edged with paler, the inner webs of the latter broadly edged with white; tail-feathers, marked near their ends much like the longer scapulars, their outer webs rather dark grayish; bill brownish dusky; feet dusky." L., 15.50; W., 9.50; T., 7.50; B., 1.50 (B., B., and R.).

Range.-Temperate and tropical regions. Breeds locally from Sable Island to L. I. and from the Bahamas to Lesser Antilles and Venezuela; formerly from Maine to Fla.; rare migrant in Cen. Am.; winters from the Bahamas to Brazil; accidental in Ohio; occurs on the coasts of a large part of the E. Hemisphere.

Long Islanc, formerly uncommon but regular S. R., May through Sept. (Dutcher). N. Ohio, casual T. V.

Nest, as in Common Tern. Eggs, 3, not distinguishable with certainty from those of $S$. forsteri or $S$. hirundo, but averaging paler and less heavily marked, 1.65 × 1.20. Date, Cobb's Is., Va., May 13, 1871; Muskeget Is., Mass., June 7.

This species is found in small numbers associated with colonies of Common Terns, apparently making its nest among theirs. It is a less excitable, wilder bird than hirundo, and its single harsh note, cack, may be distinctly heard above the the uproar of Common Terns, as it hovers somewhat in the background. Its white breast and long outer tail-feathers also aid in distinguishing it.

74. Sterna antillarum (Less.). Least Tern. Ads. in summer.Forehead white, lores and crown black; back, tail and wings pearl-gray; outer web of outer primaries and shaft part of inner web slaty black; underparts white; bill yellow, generally tipped with black; feet orange. Ads. in winter.-Top of head white, more or less spotted with black; back of head black; bill blackish. Im.-Upperparts and tail at end mottled with blackish and buffy, primaries as in adult, underparts white, bill blackish. L., 9.00; W., 6.90; T., 3.50; B., $1 \cdot 10$.

Range.-Tropical and temperate Am. Breeds on coast of s. Calif. and on Gulf coast from Tex. eastward; also n. to Mo. (formerly to Iowa) and nw. Nebr., has occurred in Wisc. and S. D.; breeds also from the coasts of Mass., Va., N. C., and Fla. s. to the Bahamas, W. Indies, British Honduras and Venezuela; now rare, but formerly abundant in the breeding season from Fla. to Maine, wandering to Lab. and N. F.; in migration occurs on the coasts of L. Calif. and w. Mex.; winters from the Gulf coast to Venezuela and Peru.

Washington, casual T. V.; Long Island, T. V., formerly abundant S. R., now rare. N. Ohio, common 'S. R. in Sandusky marshes, May 10-Sept. 25. SE. Minn., rare T. V., Aug. 29.

Nest, a slight depression in the sand. Eggs, 3-4, buffy white, speckled or spotted with chocolate, $1 \cdot 2.5 \times 90$. Date, Matanzas Inlet, Fla., May 18, 1894; Cobb's Is., Va., May 28, 1886.

The Least Tern was brought so near the verge of extinction by milliners' collectors that in spite of protection it has never recovered from the attack. There is a small colony on Martha's Vineyard, and they are found breeding locally in small numbers from North Carolina southward.

Small size is always a good character in identifying this species, and 
in breeding plumage its white forehead and largely yellow bill are distinctive. Its call, as described by Job, is "a shrill, staccato yip, yip, yip."

75. Sterna fuscata Linn. Sоотү TERN. Ads.-Forehead and a line reaching to the eye white, lores and rest of the head black; nape, back, and wings brownish black, nearly as dark as the head; outer tail-feathers white, brownish on the end half of the inner web; rest of tail-feathers of the same color as the back; underparts white; bill and feet black. Im., first plumage.Sooty slate-color; linings of the wings and under tail-coverts whitish; wingcoverts, scapulars, upper tail-coverts, and tail-feathers more or less tipped with white. L., $17 \cdot 00$; W., 11·50; T., 7·25; B., 1·75.

Range.-Tropical and subtropical coasts, except Pacific coast of S. Am. Breeds in Am. from s. Fla., La., and Tex. throughout the Bahamas, $\mathrm{W}$. Indies, and tropical islands of the Atlantic; wanders $\mathrm{n}$. rarely to Maine; winters from La. to Brazil and the Falkland Islands.

Long Island, one record, Sept.

Nest, a slight hollow in the sand. Egg, one, whitish or buff, speckled or spotted with chocolate, $2.00 \times 1 \cdot 45$. Date, Tortugas, Fla., May 7 .

So far as I am aware the Sooty Tern breeds in the Atlantic States only in the Dry Tortugas of Florida, where about 19,000 nested when Watson made his important studies of their habits in 1907. They reach the island the last week in April and remain until about September 1 . The period of incubation is twenty-six days. The warning note is a shrill $e-e-e-e$; they also utter a squeaky quack and a nasal ker-wackywak, and other calls, being very noisy birds.

Flocks of Terns seen darting actively and repeatedly into schools of small fish in West Indian waters are very apt to be of this species.

1903. Thомpson, J., Bird-Lore, V, 77-84.-1905. Јов, H. K., Wild Wings, 83-99.-1908. WATSON, J. B., Tortugas Lab. of Carnegie Inst., 189-255.-1908. Chapman, F. M., Camps and Cruises, 192-199.

The Bridled Tern (76. Sterna ancethetus), a tropical species, has been taken once in Florida, but may prove to be a regular summer visitant to some of the Florida Keys. It resembles the Sooty Tern, but has the back sooty gray and the white of the forehead extends backward over the eye.

77. Hydrochelidon nigra surinamensis ( $G m e l$.). Black Tern. Ads. in summer. - Whole head and underparts, except under tail-coverts, black; hack, wings, and tail slate-color; bill and feet black. Ads. in winter.-Forehead, nape, and underparts white; back of the head black mixed with white; back, wings, and tail deep pearl-gray. Im.-Similar to the preceding, but upperparts more or less washed and tipped with brownish; sides washed with grayish. L., 10*00; W., 8*30; T., 3 30; B., 1.00.

Range.-N. and S. Am. Breeds from sw. B. C., Great Slave Lake, s. Keewatin, and w. Ont. s. to inland lakes of Calif., Nev., Colo., n. Mo., and n. Ohio; winters from Mazatlan, Mex., to Panama, Peru, and Chile; e. coast of U. S. in autumn; arcidental in Alaska, N. S., and N. B.; casual in the W. Indies and Bahamas.

Washington, irregular T. V., Aug. 15-Sept. 22. Long Island, common T. V. July 21- hept. 14. Ossining, casual, Sept. SE. Minn., common S. R., May 1 -Sept. 1.

Nrst, of reerds, grasses, etc., an islet in marsh or slough. Eggs, 2-3, grayish olive-brown, rarely whitish, heavily spotted and blotched with chocolate markings, frequently confluent aliout the larger end, $1.35 \times 98$. Date, Dodge Co., Wisc., May 28; se. Minn., May 26. 
To one who associates all Terns with sandy beaches, it is a novel experience, when driving over the prairies, to be surrounded by an active flock of these birds, darting eagerly here and there in pursuit of the insects flushed by one's team from the grass. When on their nesting-grounds in the interior, Black Terns, indeed, appear to feed largely on insects, but when migrating southward along our coasts in late summer and autumn, in habits, and doubtless in food also, they more nearly resemble the coast-breeding members of their family.

It is difficult to recognize in the silent bird of this season the excitable, noisy Tern of June, which with its frequently repeated, sharp peek protests loudly against trespass on its haunts whether or not it has a nest there.

H. K. Job found "scores and scores" of Black Terns in full breeding plumage on an island at the mouth of Chesapeake Bay in late June, but there appears to be no record of their breeding on the Atlantic coast, where they are rarely seen before the fall migration.

1908. Chapman, F. M., Camps and Cruises, 324-329 (nesting).

The White-Winged Black Tern (78. Hydrochelidon leucoptera), an old World species, has been taken once in America-at Lake Koshkonong, Wisc., July 5, 1873 (Kumlien and Hollister, Bull., Wisc. Nat. Soc., III, 14).

79. Anoüs stolidus ( $\operatorname{Linn}$.). NoDDY. Ads.-Top of head silvery whitish, lores black; rest of plumage dark sooty brown; tail rounded, the central tail-feathers longest. Im.--Similar, but top of head like rest of plumage, silvery whitish appears as a line from bill to above eye. L., $15 \cdot 00$; W., $10 \cdot 25 ;$ T., $5.90 ;$ B., $1 \cdot 70$.

Range.-Tropical coasts. Brecds on the Tortugas, on the coast of La., and in the Bahamas and W. Indies; winters s. to Brazil and Tristan da Cunha Island.

Nest, of sticks, grasses, etc., on a bush, or low tree, sometimes on the ground or in crevices of rocks. Egg, 1, pale buffy white, sparingly marked with rufous, $2.05 \times 135$. Date, Tortugas, Fla., May 4.

In our Atlantic states the Noddly is known to nest only on Bird Key in the Tortugas of Florida, where, in 1907, Watson found about seven hundred pairs.

According to this author, whose exceptionally important paper on the habits of the Noddy and Sooty Terns should be read by every one interested in bird psychology, it arrives late in April and remains until September. The period of incubation is from thirty-two to thirty-five days, and the young, accorling to Thompson, are dependent upon their parents "until they are over three months old."

The Noddy's exceptional tameness is apparently temperamental rather than the result of ignorance of man, sinee the sooty and Bridled Terns, with which it often breeds, are far more shy.

As the only Tern with a rounder tail, the Norldy, as might be expected, differs widely in flight from other menbers of its subfamily. In the air it suggests a light-bodied Pigeon with long wings and tail. It flies rapidly and does not hover over its nesting-ground, as do the 
Sooty, Common, and other fork-tailed Terns. Its note is a low, reedy cack, at times increased to a rolling guttural $k-r-r-r-r$.

References to papers on the habits of this species will be found under the Sooty Tern.

\section{Family Rrnchopide. Skimmers. (Fig. 25.)}

The five closely allied species constituting this small but distinct group are found in the warmer parts of the earth. Three species inhabit the Western Hemisphere, of which one reaches North America. Skimmers nest in colonies on beaches. The black adults are conspicuous when incubating and correspondingly wary; but the sand-colored down of the young is obviously intended to picture their background, and, like young Terns and Gulls, they squat close and are then exceedingly difficult to discover. Skimmers are unique both in the form of the bill and in their manner of feeding. Opening the mouth, the bladelike lower mandible is dropped just beneath the surface of the water; then, flying rapidly, they may be said to literally "plow the main" in search of their food of small aquatic animals.

80. Rynchops nigra Linn. Black Skimmer. (Fig. 25.) Ads.-Forehead, sides of the head, underparts and tips of the secondaries white; upperparts and wings black; outer tail-feathers white, inner ones more or less brownish; base of bill red, end black. L., $18^{*} 00$; W., $14 \cdot 50$; T., 4.75 ; B., $2 \cdot 60$.

Range.-Tropical and temperate Am. Breeds from Va. (formerly N. J.) to the Gulf coast and Tex.; wanders casually n. to Bay of Fundy; winters from the Gulf coast to Colima, Mex. and Costa Rica; casual in the W. Indies.

Washington, A. V., Sept. 1858. Long Island, occasional in summer.

Nest, a slight hollow in the sand or shells of a beach. Eggs, 3-5, white or buffy white, heavily blotched with chocolate, $1.80 \times 1.35$. Date, Nueces Co., Tex., May 15; Cobb's Is., Va., June 6.

The Black Skimmer breeds in large colonies from Virginia southward. They make their nest-hollow by squatting on the sand and turning slowly around, boring with their bodies. They are exceedingly noisy when one invades their haunts, and, calling loudly, charge one repeatedly. They are evidently more or less nocturnal, and while feeding at this time utter their sharp yap, yap, like a pack of hounds on the trail.

1905. Jов, H. K., Wild Wings, 120.-1908. Chapman, F. M., Camps and Cruises, 64-75 (nesting in Va.).

\section{ORDER TUBINARES. TUBE-NOSED SWIMMERS}

\section{Family Dromederdx. Albatrosses. (Fig. 26a.)}

The Albatrosses, numbering seventeen species, are confined chiefly to the seas of the Southern Hemisphere. Four species visit our Pacific coast after nesting farther south, but on the Atlantic coast of North 
America Albatrosses are almost unknown, and there are but few records of their occurrence. Albatrosses are among the most tireless and wideranging of ocean wanderers. The flight of the Wandering Albatross (Diomedea exulans), which Coleridge's "Rime of the Ancient Mariner" has made more widely known than all that naturalists have ever written about it, is thus described by Professor Hutton: "With outstretched, motionless wings, he sails over the surface of the sea, now rising high in the air, now with a bold sweep, and wings inclined at an angle with the horizon, descending until the tip of the lower one all but touches the crests of the waves as he skims over them." On the water "he is at home, breasting the waves like a cork. Presently he stretches out his neck, and with great exertion of his wings runs along the top of the water for seventy or eighty yards, until, at last, having got sufficient impetus, he tucks up his legs, and is once more fairly launched in the air."

Lucas writes, "The Albatross has that type of wing which best fulfils the conditions necessary for an aëroplane, being long and narrow, so that, while a full-grown Wandering Albatross may spread from ten to twelve feet from tip to tip, this wing is not more than nine inches wide."

The Yellow-nosed Albatross (83. Thalassogeron culminatus), a southern species, is said to have been taken once in Quebec (Chamberlain, Nuttall's Manual, 2d ed., II, p. 277).

\section{Family Procellaridde. Fulmars, Shearwaters, and} Petrels. (Fig. 26b.)

The about one hundred known members of this family are distributed over the seas of the world. Thirty-five species have been found in North America, of which only seven occur regularly on our Atlantic coast. Like their large relatives, the Albatrosses, they are strictly pelagic, and visit the land only to nest. The strong, swift scaling flight of Shearwaters, and the graceful swallow-like movements of the smaller "Mother Carey's Chickens," are familiar sights to those who go "down to the sea in ships." Living where storms attain their greatest power, where there is no shelter from the gale other than the troubled seat itself, Petrels are sometimes carried far out of their course by the wind, no less than seven of the seventeen species recorded from North Americia being of accidental occurrence.

The Fulmars (genus F'ulmarus) nest like Gulls, in vast numbers, on islets off the coasts of the North Atlantic and North Pacific. Comparatively little is known of the nesting-places of our Shearwaters, but it is probable that most of them breed in the southern hemisphere and migrate northward to pass their winter (our summer) off our coasts. One of our Petrels (Oceanites) has this habit, the other two nest in the North Atlantic.

All the birds of this group, so far as known, lay but a single egg. 
The young are hatched covered with down, usually sooty or gray in color, and are reared in the nest. When taken from the nest, both old and young usually disgorge a quantity of amber-colored oil, the strong odor of which always characterizes the burrows or cavities in which most of these birds nest.

1902. Јов, H. K., Among the Water-Fowl, 97-128 (Doubleday).1905. Wild Wings, 185-200, (Houghton, Mifflin Co.).

I. Wing over $10 \cdot 50$.

KEY TO THE SPECIES

A. Underparts dusky . . . . . . . . 94. Sooty Shearwater.

$B$. Underparts white.

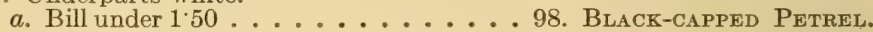

b. Bill over 1.50 .

$b^{1}$. Under tail-coverts white . . . . . 88. Cory's SHearwater.

II. Wing under 10.50.

$A$. Wing over $7 \cdot 25$.

a. Depth of bill at base over $50 \ldots \ldots \ldots . \ldots$. . . Fulmar.

b. Depth of bill at base under 50 .

$b^{1}$. Upperparts bluish gray . . . . . . . . 99. Scaled Petrel.

$b^{2}$. Upperparts sooty black . . . . 92. Addubon's Shearwater.

$B$. Wing under $7 \cdot 25$.

a. Upper tail-coverts more or less white.

$a^{1}$. Tail forked . . . . . . . . . . . 106. Leach's Petrel. $b^{1}$. Tail square.

$b^{2}$. Webs of feet marked with yellow; upper tail-coverts not tipped with black ............. 109. Wilson's Petrel.

$b^{3}$. Webs of feet without yellow; tail-coverts tipped with black.

$b$. Upper tail-coverts grayish or brownish.

104. Storm Petrel.

$b^{1}$. Entire underparts brownish . . . . . . 101 Bulwer's Petrel. $b^{2}$. Breast grayish . . . . . . . . 110. White-Bellied Petrel. $b^{3}$. Entire underparts white . . . . 111. White-faced Petrel.

86. Fulmarus glacialis glacialis (Linn.). FULMar. (Fig. 26, b.) Light phase.-Head, neck, and underparts white or whitish; back, wings, and tail slaty gray. Dark phase.-Entire plumage nearly uniform dark, slaty gray. L., 19.00 ; W., 13.04 ; B., 1.50 ; depth of B. at base, 75 .

Range.-N. Atlantic. Breeds from n. Greenland to Cumberland Sound and e. at least to Franz Josef Land; ranges n. to lat. $85^{\circ}$ and w. to Melville Island; winters s. of the Arctic Circle to the fishing-banks off N. F. and to George Bank off Mass., and casually to N. J.

Nest, on the ledges of rocky cliffs. Egg, 1, dull white, $2.85 \times 2.01$. Date, Iceland, May 10.

"The Fulmar is a constant attendant on whalers, sealers, etc.-who know it as the 'Mollimoke'-in order to obtain fatty substances and animal offal; but I never saw it take any while on the wing, and it always settles on the water to feed, like an Albatross. The pinions are often flapped slowly in an owl-like manner, but in scudding they are held very straight - a pecularity by which it may easily be distinguished from a Gull at a distance" (Saunders).

The Pintano Petrei, (10?. Daption capense) of the Southern Hemisphere has been one recorded from Maine (Purdie, "New England Bird-Life," p. 387 ; see also Knight's "Birds of Maine," p. 67). 
88. Puffinus borealis Cory. Cory's Shearwater. Ad.-Upperparts ashy fuscous, wings and tail darker; sides of head and neck slightly lighter; underparts white, sometimes washed with grayish on the breast; under wing-coverts and under tail-coverts white, the latter more or less mottled with grayish; bill yellowish. L., 21.00 ; W., 14.00; Tar., 2.20; B., 2*10.

Range.-Known only from off coasts of Mass., R. I., and L. I. (Aug.Nov.).

Long Island, probably regular S. R., Aug. 6.-Oct. 18.

Nesting, unknown.

Cory's Shearwater is not uncommon off our middle Atlantic Coast from August until November, but its entire range is unknown.

89. Puffinus gravis (O'Reilly.). Greater Shearwater. Ads.Upperparts fuscous, wings and tail slightly darker; longer upper tail-coverts tipped with whitish; underparts white; belly more or less ashy gray; under tail-coverts ashy gray; bill blackish. L., 20.00; W., 12.25; Tar., 2.20; B., 1.85. Range.-Atlantic Ocean, from Arctic Circle s. to Cape Horn and Cape of Good Hope; occurs off the e. coast of N. Am. from June to November.

Long Island, irregularly common, June-Nov.

Nesting, unknown.

"The long, narrow wings are set stiffly at right angles with the body, and the bird frequently glides half a mile at a time without moving them perceptibly. It usually follows a direct course, and invariably skims close over the waves. I know of no other sea-bird whose movements are as easy and graceful. Indeed, at times, especially during a gale, its evolutions will compare in grace and spirit with those of the Mississippi or Swallow-tailed Kites" (Brewster).

1905. Јов, H. K., Wild Wings, 198 (off Mass.).

Manx's Shearwater (90. Puffinus puffinus) resembles Audubon's Shearwater in color, but is larger. W., $8 \cdot 50-9 \cdot 25 ;$ B., $1 \cdot 35-1 \cdot 40$; depth of B. through base, 40-45; Tar., 1.70-1.80" (B., B., and R.). It occurs on the European coast of the North Atlantic and has been recorded from Greenland.

92. Puffinus lherminieri Less. A dedebon's Shearwater. Ads.Upperparts, wings and tail dark, sooty, brownish black; underparts white; sides of the breast grayish; a patch on the flanks and under tail-coverts sooty brownish black; inner side of tarsi yellowish, outer brownish; bill blackish. L., 12.00; W., 8.00; Tar., 1.60; B., 1.20.

Range.-Warmer parts of the Atlantic, n. rarely to L. I.; breeds in the Antilles and Bahamas, but not, so far as known, on our coasts.

Washington, A. V., two or three records but no specimens. Long Island, one record, Aug. 1.

Nest, in a hole, in the rocks. Egg, 1, chalky white, $2.05 \times 1.40$. Date, Ragged Is., Bahamas, Apl. 13.

This small Shearwater is an abundant West Indian species which breeds in Bermuda, the Bahamas and Antilles, and is doubtless not uncommon off our southern coasts. Its flight, low over the water, is strong and swift, five or six rapid wing-beats being followed by a short sail.

It is active about its nesting-ground only at night when the constant repetition of its uncanny see-saw notes is an indication of its before-unsuspected abundance. I have found either the male or female on the 
nest, and, when exposed by the removal of protecting rock, they made no attempt to fly but scuttled away into another hole or under the vegetation.

The Allied Shearwater (92.1. Puffinus assimilis) of Southern seas, has been found once on Sable Island, N. S. (Dwight, Pr. Biol. Soc. Wash., XI, 1897, 69).

95. Puffinus griseus (Gmel.). Sooty Shearwater. Ads.-Upperparts, wings and tail dark, sooty, brownish black; underparts somewhat grayer; bill blackish. L., 17•00; W., 12*00; Tar, 2*10; B., 1*65.

Range.-Oceans of $\mathrm{S}$. Hemisphere; occurs in summer on the Pacific coast from s. Alaska to L. Calif. and on Atlantic Coast from Gulf of St. Lawrence to S. C.; accidental in Ala.; breeds in the s. Pacific off New Zealand.

Long Island, rare in summer. (Buller).

Nest, in burrows. Egg, 1 , white, $2.60 \times 1.60$. Date, February and March

"Its flight and habits seem to be identical with those of major, but its uniform dark coloring gives it a very different appearance. At a distance it looks as black as a Crow" (Brewster).

98. Astrelata hasitata $(K u h l)$. Black-CAPPed Petrel. Ads.Upperparts and wings fuscous; forehead and nape whitish; upper tailcoverts white; tail fuscous, basally white, central feathers longest; below white. W., $11 \cdot 50 ;$ T., $5 \cdot 25 ;$ B., $1 \cdot 15$.

Range.-Warmer parts of the Atlantic Ocean. Bred formerly in the Lesser Antilles, straying to Haiti, Fla., Va., N. Y. (Ulster Co., Oneida Lake and L. I.), N. H., Ky., Ohio, and Ont., and also to England and France; probably now extinct.

The Scaled Petrel (99. Astrelata scalaris) is known from one individual which had wandered to western New York. Its true home has not been discovered, but is doubtless in the Antarctic Ocean. (Brewster, Auk, III, 1886,300 .) Its identity with $\mathscr{E}$. gularis has been suggested.

Peale's Petrel (Astrelata gularis), an Antarctic species, has been taken once in Bermuda (Bradlee, $A u k, 1906,217$ ).

Bulwer's Petrel (101. Bulweria bulweri) inhabits the north temperate portions of the Eastern Atlantic and the Pacific Oceans, and is of accidental occurrence in Greenland.

104. Thalassidroma pelagica (Linn.). Storm Petrel. Ads.-Upperparts, wings and tail sooty black; underparts slightly browner; upper tailcoverts white, the longer ones broadly tipped with black; under tail-coverts mixed with whitish; bill and feet black. L., 5.50 ; W., $4.80 ;$ T., $2.50 ;$ B., 45 .

Range.-The more easterly portions of the Atlantic Ocean s. to the Mediterranean and w. coast of Africa. Said to occur at times on the Newfoundland Banks and off the coast of N. S. Breeds on islands off Great Britain.

Nest, of a few bits of grasses and feathers in a burrow in the ground or bencath a rock. Egg, 1, dull white, sometimes with a wreath of minute or olscrure markings at the larger end, $1 \cdot 10 \times 80$. Date, Hebrides, G. B., May 29.

This is the common Petrel of the east side of the Atlantic. It nests in numbers on the small islands along the coast of Great Britain, but is only a transient visitant in our waters. It resembles the two following species in habits. 
106. Oceanodroma leucorhoa (Vieill.). Leach's Petrel. Ads.Upperparts, wings and tail sooty brown; underparts slightly browner; wing-coverts grayish brown; longer upper tail-coverts white, shorter ones mixed with sooty brownish; tail forked, outer feathers more than 50 longer than middle pair; bill and feet wholly black. L., 8.00; W., 6.20; T., 3.50; B., $\cdot 62$.

Range.-N. Pacific and N. Atlantic oceans. Breeds from the Aleutian and Copper Islands, Bering Sea, s. to Sitka, and from s. Greenland s. to Maine and the Hebrides; casual in migration s. to Va.

Washington, A. V., several records, most frequent in Aug. Long Island, rare T. V., May; July-Aug. Cambridge, rare T. V. in fall.

Nest, of a few bits of grasses and feathers in a burrow in the ground, or beneath a rock. Egg, 1, creamy white, sometimes with a wreath of minute or obscure markings at the larger end, $1 \cdot 34 \times 1 \cdot 00$. Date, Bird Rock, Que., May 29.

This is the only Petrel nesting on our Atlantic Coast, where from about May 1 it is locally abundant on islets or isolated headlands from Maine northward. It digs its own nesting-holes or uses, sometimes in common, those made by Puffins. During the day it apparently never leaves its nest, on which, prior to laying, both birds may be found, but later, only one, either the male or female, incubates or remains with the young. The absent one of the pair is presumably then at sea, from which it returns after nightfall.

On Bird Rock in the Magdalens, where not a Petrel was seen during the day, I was given the most surprising evidence of their activity during the night. From the ground at my feet and from every side there issued the uncanny little song of birds doubtless sitting at the mouths of their burrows. It was a distinctly enunciated call of eight notes with a certain crowing quality; such a call as might be uttered by elves or brownies. Occasionally I saw a blur of wings as a bird passed between me and the lighthouse.

1909. Chapman, F. M., Bird Studies with a Camera, 180.

The Hawairan Petrel (106.2 Oceanodroma castro) of southern oceans has been taken in the District of Columbia (two specimens Aug. 29, 1893) and in Indiana.

109. Oceanites oceanicus $(K u h l)$. Wilson's Petrel. Ads.-Upperparts, wings and tail sooty black; underparts somewhat lighter; under tailcoverts mixed with whitish, longer upper tail-eoverts white, shorter ones marked with sooty blark; wing-coverts grayish, margined with whitish; bill and feet black, toe-webs mostly yellow. L., 7.00; W., 5.90; T., 2.80; B., $\cdot 50$.

Range.-S. Polar regions n. to Lab. and British Isles. Breeds on Antarctic islands in Feb.; occurs off American coast from May-Sept.; accidental on Muskoka Lake, Ont.

Washington, A. V., one record. Long Island, common S. R., May-Sept. Nest, in burrows or the crevices of rocks. Egg, 1, white. Date, February.

It is generally known that some birds which nest in the northern parts of our continent in the winter migrate as far south as Patagonia; but comparatively few are aware that during the summer we receive several visitors from the southern parts of the Southern Hemissphere. They are all included in the family Procellariida, and Wil- 
son's Petrel is doubtless the most common. It breeds in the islands of the South Atlantic in February, and after the cares of the breeding season are over migrates northward to pass its winter off our coasts. At this season its home is the sea, and its occurrence on land is generally due to storms. For this reason, and because of its long migration, it is the Petrel most frequently observed in western Atlantic waters during the summer.

Under the name of "Stormy Petrel," or "Mother Carey's Chicken," these birds are familiar to most people who have made sea voyages. On tireless wing they follow in the track of a ship, coursing ceaselessly back and forth, now beneath the stern, now hovering over the foamflecked wake, reminding one of white-rumped Martins in their easy, graceful flight. If food be thrown overboard, they are at once attracted to it, and soon are left far behind, a little group of black, fluttering forms on the surface of the ocean. The meal disposed of, a few rapid wing-beats bring them to us, and again they resume their patient beating to and fro.

1905. Јов, H. K., Wild Wings, 191 (off Mass.).

The White-Bellied Petrel (110. Fregetta grallaria) is a tropical species which has been taken once in North America-at St. Marks, Fla.

The White-Faced Petrel (111. Pelagodroma marina) inhabits the S. Atlantic and southern seas. It is of accidental occurrence off the coast of Massachusetts. It may be distinguished from any of our small Petrels by its white underparts.

\section{ORDER STEGANOPODES. TOTIPALIMATE SWIMMIERS}

\section{Family Рhä̈thontid ж. Tropic-Birds. (Fig. 28.)}

The six species comprising this small but' distinct family are distributed through the tropical and subtropical seas of both hemispheres, but none regularly reach the United States. Tropic-birds frequent the high seas. They fly with quick, strong beats of the wing, quite unlike the more leisurely stroke of Gulls; and from Terns they may be known by the long, willowy tail-feathers which add greatly to their appearance when in the air. They hunt for food by beating back and forth over the water and plunging abruptly down upon it.

Tropic-birds lay their single brownish, purplish egg on the bare ground or rock, in a burrow or crevice often some height above the water. Incubation is said to be performed by both parents. When on the nest, they vigorously resent being disturbed, by screaming, biting and scratching.

112. Phä̈thon americanus Grant. Yellow-BILled Tropic-Bird. (Fig. 28.) Ads.-White; a mark hefore and through eye; outer web of primaries, lesser wing-coverts, and tertials black; flanks streaked with slate; bill yellow; tail tinged with salmon, shafts of feathers black. W., 10.75; T., 19.00; B. $2 \cdot 00$. 
Range-Fla. and Bermuda s. to W. Indies and Atlantic coast of Cen. Am., accidental in w. N. Y. and N. S.

Nest, in holes in rocks or cliffs. Egg, 1, heavily dotted or marked with chestnut, $2.10 \times 1 \% 45$. Date, Bermuda, May 5.

This species breeds abundantly in the Bermudas, but is of rare occurrence on our coasts.

The Red-Billed TropiC-Bird (113. Phaëthon athereus, Fig. 28) resembles the preceding species, but has the bill red and the upperparts finely barred with black. Its range in the Atlantic is more southern than that of the Yellow-billed Tropic-bird. The only record of its occurrence in eastern North America is off the Newfoundland Banks.

\section{Family Sulide. Gannets. (Figs. 27, 29.)}

The Gannets or Boobies number eleven species, of which one is northern while the remaining ten are distributed throughout the tropical and subtropical coasts of the world, five of them having been recorded from our southern borders. They are strictly maritime, but are more abundant near the coast than on the high seas. Their flight is strong and rapid, the vigorous strokes of the wing being interrupted at intervals by a short sail. They obtain their food of fish by plunging for it from the air. The northern species is migratory; the others are roving, but all return with regularity to their nesting-places, generally on some islet, where, during the breeding season, they may be found associated in large numbers. The young are born naked, but are soon covered with white down. In common with other members of the Order Steganopodes (except Phaëthon) they feed by thrusting their head down the parent's throat. They are wholly dependent on parental care until they acquire the power of flight.

115. Sula leucogastra (Bodd.). Bоовy. (Fig. 27.) Ads.-Breast and belly white, sometimes washed with grayish; rest of plumage brownish fuscous; head and neck sometimes streaked with grayish brown and white; bill and feet yellowish. Im.- Entire plumage brownish fuscous, lighter below; bill blackish, feet ycllow. L., 30.00); W., 15.50; T., 8.00; I3., 3.80.

Range.-Atlantic coasts of tropical Am., and Pacific and Indian Oreans; casual on s. Atlantic and Gulf coasts of U. S. from S. C. to La.; accidental on L. I. and in Mass.

Nest, on the ground of a barren islet. Eggs, 2, chalky white, $2.30 \times 1.55$. Date, Cay Verde, Bahamas, February.

This Booby breeds abundantly in Cay Verde, southeast of Ragged Island in the Bahamas, and on other Bahaman Keys, but is known on our coasts only as an irregular visitant, though off eastern Florida it is of probably more frequent occurrence than the actual records would indicate. Bangs ohserved it in numbers off the coast east of Micco on February 12, 1895 ( $A u k$, XIX, p. 395), and on March 11, 1907, I saw twelve at the mouth of the St. John's River.

On its nesting-grounds the bird is exceedingly tame and will often 
strike at one viciously rather than take wing. It feeds on squids and fish, which, like other birds of its genus, it catches by diving.

1908. Chapman, F. M., Papers from Tortugas Lab. of Carnegie Inst., II, 141-149; Camps and Cruises, 208-217 (nesting).

The Blue-FACed Boosy (114. Sula cyanops) a southern species, breeds as far north as the Bahamas and is of casual occurrence off southern Florida, but there are no recent records of its appearance there.

116. Sula piscator (Linn.). RED-FOOTED BоOBY. Wing-quills more or less frosty. Ads.-White more or less tinged with straw; wings hoary fuscous, their coverts and inner tertials like back; face blue, pouch slate, feet red. Young birds are nearly uniform brown, and in a later plumage the head, neck and underparts are white, but at all times the wing-quills are frosty. L., 29.00; W., 15.00; B., 3.30.

Range.-C Coasts and islands of tropical and subtropical seas, from Fla. and w. Mex. southward.

Bangs records the occurrence of great numbers of white, blackwinged Boobies, doubtless this species, off the east Florida coast, opposite Micco, on February 12, 1905 ( $A u k$, XIX, p. 395). The species is not known to nest nearer Florida than the Cayman islands south of Cuba, but I have elsewhere given reasons for believing that the Booby recorded by Audubon as nesting in the Tortugas was this species and not Sula leucogastra (see Papers from Tortugas Lab. of Carnegie Inst., 1908, II, p. 144).

117. Sula bassana (Linn.). GanNet. (Figs. 27, 29.) Ads.-White, head and neck tinged with pale straw-yellow; primaries fuscous. Im.Throat and upperparts, including wing-coverts, dark grayish brown, each feather with a small white wedge-shaped spot; breast and belly white, margined with grayish brown. L., 35.00; W., 19.00; T., 9.50; B., 4.00.

Range.-Coasts of N. Atlantic. Breeds on Bird Rock and Bonaventure Island in the Gulf of St. Lawrence, and on islets off British Islands; winters from N. C. coast s. to Gulf of Mex., and on coasts of n. Africa, Madeira, and the Canaries; occurs off e. U. S. in migration; casual n. to Greenland; accidental in Ind. and Ont.

Long Island, common T. V., Mch. 23-May 9; Oct. 5-Dec. 5.

Nest, of seaweed on rocky cliffs. Egg, 1, pale bluish white, overlaid by a chalky deposit, more or less soiled and stained, $3.20 \times 1.90$. Date, Bird Rock, Que., May 5.

The distribution of this, the only boreal member of its family, indicates that at one time it was found even farther north than it is at present, and that through a climatic change the more northern birds were either exterminated or forced southward, leaving only the widely separated existing colonies-two in the Gulf of St. Lawrence and about a dozen off the northern shores of the British Islands.

They reach their American nesting-grounds early in April, and a month later are massed in snowy banks on the broader ledges of the precipitous cliffs, laying or incubating. Where they are not frequently disturbed, they are so tame that they can be touched as they sit on their nests. Their call is a harsh gor-r-r-r-rok.

During their migrations they are found usually well off the coast, 
though I have seen them fishing in the surf at Virginia Beach. They are splendid birds and when on the wing exhibit a striking combination of power and grace. They are most impressive when diving, as with half-closed wings, like great spearheads they strike the water with a force which takes them wholly out of sight and splashes the spray ten feet or more into the air.

1900. Chapman, F. M., Bird Studies with a Camera, 139-145, 181, 189.-1908. Camps and Cruises, 408.

\section{Family Anhingidær. Darters. (Figs. 29, 30.)}

There are four species of Darters, Snakebirds or Water-Turkeys, one each in Africa, southern Asia, Australia, and tropical and subtropical America. They are silent birds, generally living in pairs or colonies on bodies of fresh water with wooded shores. They select a perch over the water, and when alarmed sometimes drop into the element below and disappear beneath its surface, or fly upward to a considerable height and circle about like sailing Hawks. They swim well, and when approached too closely, sink quietly backward, frequently leaving the long, thin neck and narrow, pointed head above the surface, when one at once observes the origin of the name "Snakebird." They obtain their food by pursuing it under water, and their finely serrated bill assists them in retaining their hold upon it. The young are born naked, but are soon covered with close, short, buff down. They obtain their food from the throat of the parent, and remain in or near the nest until they are able to fly.

118. Anhinga anhinga (Linn.). Water-Turkey. (Fig. 13.) Ad. $0^{7}$ in summer.- General plumage glossy black with greenish reflections; back of head and nerk with scattered grayish plumes; upper back with numerous elongated silvery white spots, which on the scapulars become streaks; lesser wing-coverts spotted like back; exposed portion of median and greater coverts silvery gray; tail tipped with whitish, outer wels of middle pair of feathers with transverse flutings. Ad. o in winter. - Similar, but without grayish plumes on head and neck. Ad. \&. - Similar to $\sigma^{\circ}$, but with whole head, nerk, and breast brownish, darker above. Im.- Similar to 8 , but with black parts of plumage brownish. L., 34.00; W., 13.50; T., $10.50 ;$ B., 3.25 .

Range.-Tropical Am. n. to w. Mex. (Tepic), Tex., Fla., s. Ills., and N. C., and casually to Kans.; accidental in N. Mex. and Ariz.

Nest, well formed, of sticks lined with moss, rootlets, ete., over the water in a low bush or high tree. Eggs, 2-5, bluish white with a chalky deposit, $2.15 \times 1.35$. Date, Tampa, Fla., Mch. 21 .

This singular bird is a permanent resident in Florida but migratory farther north. They nest in isolated pairs, or in eolonies of as many as two hundred birds. Although they soar with great ease they alight clumsily, tumbling on to their perches, with much flapping of wings before gaining their balanee. When not alarmed, they seem to take flight with much hesitation, opening and closing their wings repeatedly before they trust themselves to their support. When alighting near the 
nest, they utter harsh, grating calls, which, if another bird chances to be near, is replied to with threatening motions of the sharply pointed bill.

1908. Chapman, F. M., Camps and Cruises, 116-118 (nesting).

\section{Family Phalacrocoracid}

Cormorants are found in all parts of the world. Six of the forty known species inhabit North America. As a rule they are maritime, but they also frequent bodies of fresh water far from the seacoast. They are more or less gregarious at all seasons, and breed in colonies. Their flight is strong and ducklike, and they often fly in diagonal lines with a somewhat gooselike formation. They secure their food of fish by pursuing it under water, swimming with feet alone, their hooked bill assisting them in its capture. Unlike the Gannets, they do not dive from the air, but from the water or a low perch. They nest on the ground on islands, or on trees growing in water, building well-formed structures. The young are born naked, but are soon covered with a thick, short, black down, which is succeeded by the plumage of flight. They feed, as do the young of most Steganopodes, by thrusting their head and neck well down the parent's throat.

\section{KEY TO THE SPECIES}

A. Tail of 14 feathers, length over $33.00 \ldots \ldots$. . . 119. Cormorant. $B$. Tail of 12 feathers, length under $31^{\circ} 00$.

a. Feathers of back and scapulars rounded.

120. Double-Crested Cormorant.

b. Feathers of back and scapulars pointed . 121. MEXICAN Cormorant.

119. Phalacrocorax carbo (Linn.). Cormorant (Figs. 29, 32.) Ads. in breeding plumage.-Region about base of lower mandible white or whitish; head, upper neck, and throat glossy black, thickly sprinkled with white; rest of neck, underparts, and rump glossy black; a white patch on flank; upper back, scapulars, and wing-coverts light olive-brown, each feather bordered by glossy black; tail black, composed of fourteen feathers. Ads. in winter.-Similar, but without white on the head. Im.-Top of the head and hindneck brownish black; upper back, scapulars, and wing-coverts grayish brown, the feathers bordered by blackish; rump glossy black; throat and breast grayish brown, changing to white on belly; sides and under tail-roverts glossv black. L., 36.00; IV., 14.00; T., 7.00; B., 3.00.

Range.-N. Hemisphere. Breeds from cen. Greenland s. to N. S., and e. through Europe and Asia to Kamchatka; winters from s. Greenland s. to L. I., casually to Lake Ont. and S. C., and from the Mediterranean s. to s. Africa, Australia, and Malay Pen.

Long Island, regular T. V. in limited numbers (Dutcher).

Nest, of sticks and seaweed, in colonies, generally on the ledges of rocky cliffs. Eggs, 4-6, pale bluish white, more or less overlaid with a chalky deposit, $2.50 \times 1.50$. Date, s. Lab., June 19 .

120. Phalacrocorax auritus auritus (Swains.). DodBLE-CREsted Cormorant. Ads. in breeding plumage.-Head, neck, rump and underparts glossy blark; upper hack, scapulars, and wing-coverts light grayish brown, (ach frather margined with glossy black; tail black, composed of twelve feath- 
ers; a tuft of black feathers on either side of the head; a few white ones over the eye. Ads. in winter.-Similar, but without tufts on the head. Im.-Top of the head and back of the neck blackish brown; upper back, scapulars, and wing-coverts brownish gray, each feather margined with black; rump glossy black; sides of the head and foreneck grayish white, whiter on the breast and changing gradually to black on the lower belly. L., 30.00; W., 12.50 ; T., 6.20 ; B., $2 \cdot 30$.

Range.-E. N. Am. Breeds from cen. Sask. (casually Great Slave Lake), s. Keewatin, ne. Que., and N. F. s. to n. Utah, S. D., s. Minn., and Penobscot Bay, Maine; winters from N. C., (casually Mass.), s. to Gulf coast; casual in Bermuda.

Washington, casual, several records. Long Island, common T. V., in fall, Aug. 26-Nov. 5; Apl. 20-May 15. Ossining, A. V., June. Cambridge, casual, one instance, Sept. N. Ohio, casual T. V.

Nest, of sticks, seaweed, etc., on the ledges of cliffs, in trees or bushes, or on the ground. Eggs, 2-4, similar in color to those of the preceding, $2.40 \times 1.40$. Date, s. Lab., June 19; se. Minn., May 7.

This is the common Cormorant of the middle Eastern States. We see it chiefly as migrant when in flocks of varying size it passes far overhead, or pauses to rest on our shores. In migrating the flock is formed in a long line, comparatively few birds deep. On the wing they bear a general resemblance to large Ducks or to Geese.

1894. Mackay, G. H., Auk, XI, 18-25 (habits in R. I.).-1911. Sмітн, F., Auk, XXVIII, 16-19 (breeding in Ills.).

120a. P. a. floridanus (Aud.). Florida CoRmorant. Resembles the preceding species in color, but is smaller. W., $12 \cdot 00 ;$ T., $5 \cdot 50 ;$ B., $2 \cdot 10$.

Range.-Subtropical and temperate N. Am. Breeds from s. Ills., La., N. C., Bahamas, and Cuba s. to British Honduras and Yucatan; winters $\mathrm{n}$. to Tex. and S. C.; wanders to the Dismal Swamp, Va.

Nest, in bushes or trees, preferably mangroves or cypresses. Eggs, like those of preceding. Date, Walkulla, Fla., Mch. 20.

This is an abundant bird on the Florida coast and westward along the shores of the Gulf. Almost every buoy in the harbors of Florida is capped by a Cormorant.

121. Phalacrocorax vigua mexicanus (Brandt). MExicAN CorMorant. Scapulars and wing-coverts pointed. Resembling $P$. auritus but smaller, and feathers above more pointed. Ads. in breeding plumage with pouch and face bordered posteriorly by white. L., $25 \cdot 00 ;$ W., $10 \cdot 25 ; 13 ., 1 \cdot 80$.

Range.-New Mex., Kans., and s. Ills. s. to Gulf of Mex., Bahamas, Cuba, Mex., and Nicaraugua.

\section{Family Pelecanide. Pelicans. (Fig. 29.)}

The ten known species of Pelicans are distributed throughout the warmer parts of the world. Three species are North American, of which two are exclusively maritime and are found on our southern coasts, while the third nests well to the north, in the interior, and winters on the seacoasts southward. Pelicans are gregarious and nest in colonies. Their flight is strong but leisurely, six or seven wing-strokes being foliowed by a short sail, all the members of a flock flapping and sailing in unison. They often mount to great heights, there to soar 
majestically in broad circles, evidently for mere pleasure in the evolution. They feed on.fish, for which some species plunge from the air, while others capture small fry with their scooplike pouches while swimming. The young are born naked, but are shortly covered with white down which is followed by the plumage of flight. They procure their food of fish by plunging their heads far down the parental pouch.

125. Pelecanus erythrorhynchos Gmel. White Pelican. Ads. in nuptial plumage.- White, more or less straw-color on breast and wing-coverts; wing-quills chiefly black; occipital crest white or straw-color; a horny prominence on the culmen. Post-nuptial plumage.-Similar, but occiput of short gray feathers, no horny ridge on bill. Ads. in winter.-Similar, but occiput white. Im.- Similar, but lesser wing-coverts and top of the head brownish gray. L., 60*00; W., 22.00; Tar., 4.50; B., 14.00.

Range.-Temperate N. Am. Breeds from s. B. C., Great Slave Lake, and sw. Keewatin to Man. (formerly s. Minn. and S. D.), Utah and s. Calif.; winters from s. Calif., the Gulf States, Fla., and Cuba s. to w. Mex., and Costa Rica; casual e. in migration to the Atlantic coast, n. to New Brunswick.

Washington, casual, four records. Long Island, two records. N. Ohio. casual T. V.

Nest, in colonies, on the ground, a depression in a mound of pebbles, or of grasses, sticks or reeds. Eggs, 2-4, creamy or bluish white with a chalky deposit, more or less stained, $3.45 \times 2.30$. Date, Big Stick Lake, Sask., June 10, eggs hatching.

During the summer the White Pelican frequents only fresh water; in winter it lives chiefly on salt water. At this season it is not uncommon locally on the Gulf coast of Florida, and a few are usually seen each winter on the Mosquito Lagoon of the east coast. With a wing expanse of between eight and nine feet, and a weight of sixteen pounds, the White Pelican is one of the largest of American birds. Its snowy plumage renders it conspicuous at a great distance and a far-away Pelican may be mistaken for a sail. This species migrates by day. In mid-March I have seen flocks containing thousands of birds passing northward along the eastern face of the Sierras of Vera Cruz. Although they progresscd in wheeling circles, they moved on their course very rapidly. The habit of soaring, or sailing, is also common in the nesting season when the birds practically go up beyond the reach of vision.

The White Pelican does not dive but catches its food while swimming.

1908. Chapman, F. M., Camps and Cruises, 366-388 (biographical).

126. Pelecanus occidentalis Linn. Brown Pelican. Ads, in breed- 1 ing plumasfe. - Top of hearl white, sometimes straw-yellow like a spot on upper breast; line down either side of breast white; hindhead, neck and a spot on forencek seal-brown; sides and back silvery gray bordered by brownish black; scapulars, wing-coverts, seeondaries, and tail silvery gray; primaries black: underparts dark blackish brown narrowly streaked with white. Ads. after the breeding season.-Similar, but with hindhead and whole neck white, morc or less tinged with straw-yellow. Im.-Above grayish 
brown margined with paler; chest brownish, belly white. L., 50.00; W., 19.50; Tar., $2 \cdot 65 ;$ B., $11 \cdot 00$.

Range.-Gulf coast of U. S. and Atlantic coast of Cen. and S. Am. Breeds from S. C. and La. s. to Brazil; casual in N. C.; accidental in Wyo., Nebr., Iowa, Ills., Ind., Mass., and N. S.

Long Island, one record.

Nest, in colonies, of sticks or weed-stalks, etc., in mangrove bushes or on the ground. Eggs, 3, similar in color to those of the preceding species, $3.00 \times 1.95$. Date, Pelican Is., Fla., usually Dec. 1; Gulf Coast, Fla., Apl. 4; So. Car., May 23.

At all seasons the Brown Pelican is maritime. It is a permanent resident in Florida, but nevertheless migrates regularly to its ancestral nesting-grounds, those of the east coast reaching Pelican Island in Indian River about Norember 1. Eggs are laid by December. They hatch in about four weeks, and their young fly when about ten weeks old. They are exceedingly noisy but the adults are virtually silent.

The Pelicans of Pelican Island go fishing possibly fifty miles or more up or down the coast from their island home. With a favorable wind they travel high before it; with a head wind they skim low over the waves usually just outside the breakers. The usual flock-formation is a diagonal single file, and the birds progress by alternate flapping and sailing in unison. The first wing-stroke after a sail is generally given by the leader, not because he is in command, but because, being in advance, he encounters greater air-resistance and is the first to lose momentum when sailing.

Unlike the White Pelican, this species secures its prey by diving. Singly, in pairs, or in small flocks, they beat back and forth, generally about twenty feet above the water, and when opportunity offers, plunge downward with such force that the spray daskes high about them, and the resulting splash may be heard half a mile. They usually fish at sea and feed chiefly on menhaden.

1900. Chapmax, F. M., Bird Studies with a Camera, 191-214.-1908 Camps and Cruises, 8.3-112 (biographical).-1905. Jов, H. K., Wild Wings, $1-18$.

\section{Family Fregatide. Max-o'-War-birds. (Fig. 32.)}

Man-o'-war-birds, or Frigate-birds, are found throughout intertropical seas. One of the two known species occurs in America. They are strictly maritime, and, while sometimes observed at great distanees from the land, are met with in numbers only near the coasts. They have a greater expanse of wing in proportion to the weight of their body than any other bird, and in power of flight are unsurpassed. Facing the wind, they pass hours resting motionless on outstretched wings, sometimes ascending to great heights and calmly soaring far above storms. It is when feeding that their marvelous aerial powers are displayed to the best advantage. By swift, indeseribably graceful darts they secure fish which are near the surface, or capture those which have leaped from the water to escape some enemy below. They also 
pursue Gulls and Terns, and, forcing them to disgorge their prey, catch it in midair. As a rule they are gregarious at all seasons, and nest and roost on bushes near the shore. The feet are exceedingly small and of little use except in perching. The single young is born naked but is quickly clothed in long white down. The black scapulars appear at a very early age.

128. Fregata aquila (Linn.). MAN-o'-WAR-BIRD. (Figs. 19, 31.) Ad. $\sigma^{7}$. -Entire plumage black, more glossy above; dilatable gular pouch in breeding season orange-red or carmine. 9.- Similar, but browner; lesser wingcoverts grayish brown; breast and upper belly white. Im.-Similar to the o. but whole head and neck white. L., 40.00 ; W., 25.00; T., 17.00; B., 4.50 .

Range.-Tropical and subtropical coasts; in Am. n. to s. Calif., Tex., La., and Fla., and casually to Calif. (Humboldt Bay), Kans., Iowa, Wisc., Ohio, and N. S.

Long Island, one record, Aug.

Nest, of sticks, in colonies, on bushes or rocks. Egg, 1, chalky white, $2.65 \times 175$. Date, Atwood Key, Bahamas, Feb. 9 .

This species is found at all seasons in Florida, but I know of no authentic record of its nesting there. It becomes more common in late spring after its breeding season in the Bahamas.

1908. Chapman, F. M., Camps and Cruises, 217-221 (nesting).

\section{ORDER ANSERES. LAMELLIROSTRAL SWIMMMERS}

\section{Family Anatide. Ducks, Geese and Swans. (Figs. 33, 34.)}

The two hundred species included in this family are distributed throughout the world. One-fourth of this number occur in North America, and are grouped by the A. O. U. Check-List in the five subfamilies, Mergince, or Mergansers, Anatince, or River Ducks, Fuligulina, or Sea Ducks, Anserina, or Geese, and Cygnina, or Swans. The Anatidoe in common with other diving birds whose natatorial powers give them a secondary means of locomotion, lose all their wing-quills simultaneously during the annual postnuptial molt, and at this time cannot fly. Evidently to make them less conspicuous during this period, the males of many species acquire by molt a plumage more or less closely resembling that of the female. This 'eclipse plumage,' as it is called, is worn only until the wing-quills are regained, when it is lost and the distinctive male costume reacquired. This phenomenr $n$ is well illustrated in the preceding plate of the Wood Duck showing an adult male in 'breeding' as well as in 'eclipse' plumage. Incidently it may be remarked that the assumption of this concealing plumage at a time of comparative helplessness, is an indication that the breeding plumage is conspicuous. (See Stone, Pr. Acad. Nat. Sci., Phila., 1889, p. 467; Chapman, Bull. Am. Mus. Nat. Hist., 1899, p. 219.) 
Plate XII
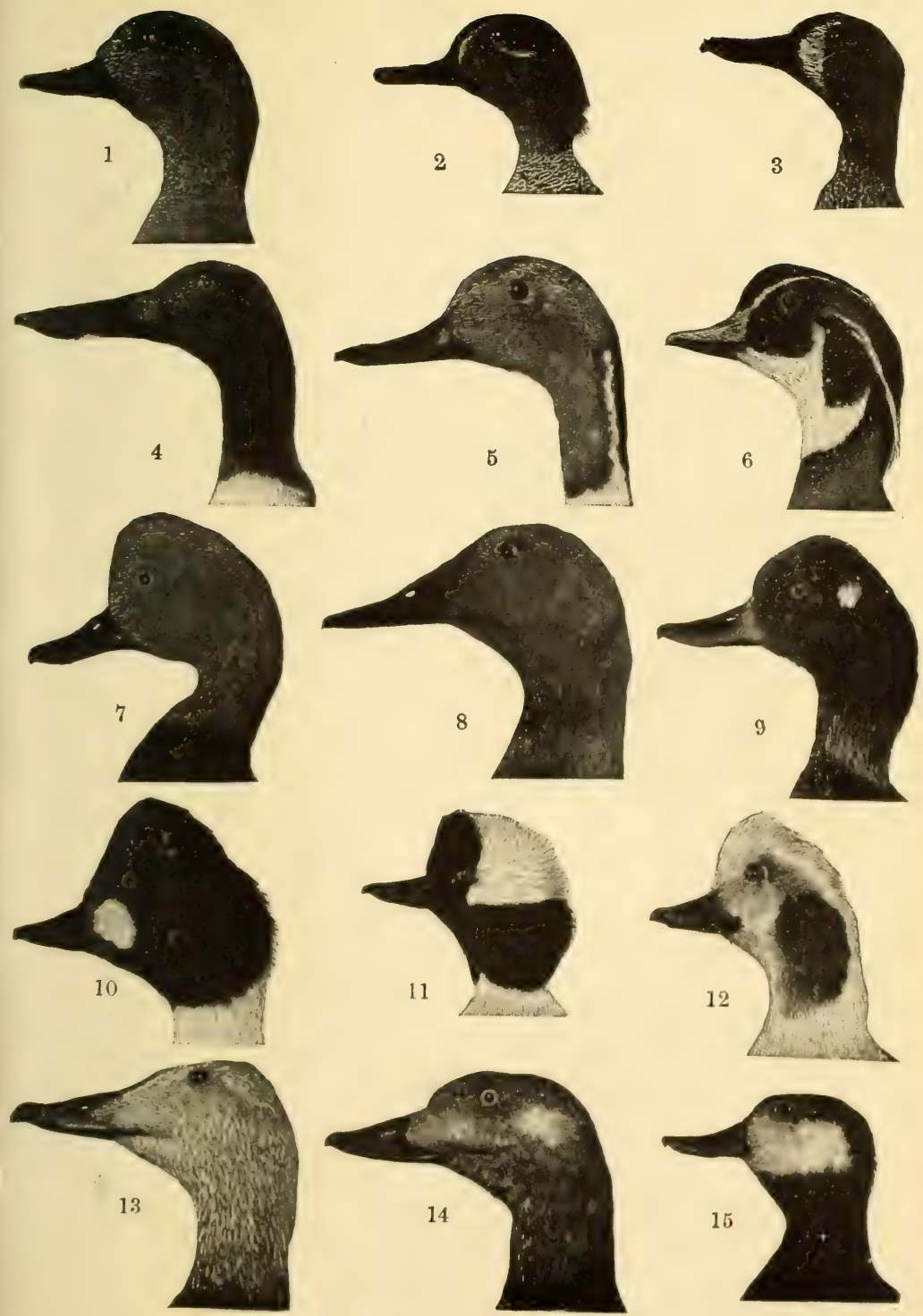

Heads of Ducks

1. Baldpate.

2. Green-winged Teal.

3. Blue-winged Teal.

4. Shoveller.

5. Pintail.
6. Wood Duck.

7. Redhead.

8. Canvasback.

9. Am. Scaup Duck. 10. Am. Golden-ye.
L-11. Bufflehead.

12. Old Squaw.

13. Greenland Eider.

14. White-winged Scoter

15. Ruddy Duck. 

Most of these birds breed north of the United States; in eastern North America, only five of our forty species nesting south of latitude $41^{\circ}$. We know them, therefore; as migrants and as winter visitants and to those who are so fortunate as to live near their haunts, their goings and comings are among the most important events in the birds' calendar. Strong of wing, hardy of body, many species pass the winter on the open sea, while the river and bay Ducks remain until ice forms, and return the first day of open water. How the eye is held by the sight of their swiftly moving forms silhouetted against the sky! Through them, bird-life makes its strongest appeal to our love of the wild and elemental in nature.

As the ancestors of our domesticated water-fowl and as game, the Anatidce are doubtless better known to man than any other birds. Of late years their numbers have been greatly reduced by excessive shooting for market and for sport, and by the reclamation for the agriculturist of vast areas in which formerly they bred. We have, consequently, only to examine the history of the past few decades to be assured that a further attempt to supply the unlimited and ever-growing demands of the game-dealer for wild-fowl means, ultimately, that both market hunters and sportsmen may lay aside their guns. Let us, therefore, look to our poultry yards for Ducks and Geese as food, and leave the wild birds as a lure to draw brain-weary toilers to marsh, bay and headland.

1896. Јов, H. K., Ducks of Plymouth Co., Mass., Auk, XIII, 197-204.1897. Cory, C. B., How to Know the Ducks, Geese and Swans, 8vo. pp. 94, many ills.-1898. Ellror, D. G., Wild-Fowl of United States and British Possessions, 8vo, pp. 316, plls. 63 (Francis Harper).-1901-2. Bent, A. C., Nesting Habits of Anatidæ in N. D., Auk, XVIII, 328-336; XIX, 1-12; 165-174.-1902. Jов, H. K., Among the Water-Fowl (Doubleday).-1903. Huntington, D. W., Our Feathered Game, 8vo, pp. 396, plls. 37.-1903. Sanford, L. C., Bishop, L. B., Van Dyke, T. S., The Water-Fowl Family, 12 mo. pp. ix-598, plls. 20 (Macmillan).-1906. Cooke, W. W., Dist. and Migr. of N. A. Ducks, Geese, and Swans, Bull. 26, Biol. Surv.-1907. Rich, W. H., Feathered Game of the Northeast, 8vo. pp. 432, pls. 87.-1909. DeHaven, I. N., Duck Shooting on N. J. Coast, Cassinia, 11-18. - 1910. Grinnell, G. B., American Game Bird Shooting, 8vo, pp. xviii-558 (Forest and Stream).-1910. Huntington, D. W., Our Wild Fowl and Waders, pp. 207 (N'w York City).-1911. Phillips, J. C., Ten Years' Migration of Anatidx at Wenham, Mass., Auk, XXVIII, 188-200; see also, 319-323.

\section{Subfamily Mergince. Mergansers. (Fig. 33.)}

The five subfamilies into which our Anatida fall are so well defined, it seems advisable to treat of each one separately. The first of these, the Shelldrakes or Sawbills, are fish-eating Ducks. They pursue and capture their prey under water, progressing by aid of the feet alone, and their serrate bills seem especially adapted to this mode of feeding. Three of the nine known specics are found in North America, and all may be recognized in life by their cylindrical bill. 


\section{KEY TO THE SPECIES}

1. Bill under 1.75, wing 8.00 or under ... 131. Hooded Merganser.

2. Bill over $1 \cdot 75$, wing over $8 \cdot 00$.

$A$. Head and throat black.

$a$. Breast and belly white, tinged with salmon.

129. Am. Merganser ( $\sigma^{\top}$ ad.).

b. Breast brownish, thickly streaked and spotted with black.

$B$. Head and throat not black.

130. Red-breasted Merganser (ơ ad.).

a. Head and sides of the neck rich rufous-brown; distance from nostril to end of bill less than 1:50 . 129. Am. Merganser ( $\%$ and im.).

$b$. Crown grayish brown, more or less washed with cinnamon-rufous: sides of the neck cinnamon-rufous; distance from nostril to end of bill over 1.50 .. 130. Red-breasted Merganser ( $\%$ and im.).

129. Mergus americanus (Cass.). American MErganser. (Fig. 33.) $A d . \sigma^{7}$.-Whole head and upper neck glossy greenish black; hindneck, secondaries, lesser wing-coverts, and ends of greater ones white; back black, rump and tail ashy gray; breast and belly white, delicately tinged with salmon. Ad. o and Im.-Chin and upper throat white; lower throat and entire top of the head rufous-brown; rest of upperparts and tail ashy gray; speculum* white; breast and belly white. L. $25^{\circ} 00$; w., 10.50; Tar., 1.85; B., from N. 1:50.

Range.-N. Am. Breeds from s. Alaska, s. Yukon, Great Slave Lake, cen. Keewatin, s. Ungava, and N. F. s. to cen. Ore., s. S. D., s. Minn., cen. Mich., Ohio (formerly), n. N. Y., Vt., N. H., and Maine, and in mountains, s. to n. Calif., cen. Ariz., n. N. Mex., and Pa. (formerly); winters from Aleutian Islands, B. C., Idaho, n. Colo., s. Wisc., s. Ont., n. New England, and N. B., s. to n. L. Calif., n. Mex. (Chihuahua), Tex., La., Fla., and Bermuda.

Washington, rare W. V., Oct. 13-May 26. L. I., uncommon W. V. Nov. 4-Dec. 30. Ossining, tolerably common T. V., Jan. 1-Mch. 8. Cambridge, rare T. V. and W. V. N. Ohio, W. V., Nov. 1-May. Glen Ellyn, T. V., spring only, May 7-12. SE. Minn., T. V., Mch. 9, casual W. R.

Nest, of leaves, grasses and moss, lined with down, in a hole in a tree or cliff. Eggs, 6-10, creamy buff, $2.65 \times 1 \cdot 75$. Date, Saginaw Is., Mich., May 26.

"This bird is fond of plunging beneath rushing currents for its food, and should it encounter a raft of floating rubbish, or an ice-cake, it will readily pass underneath it. It swims so deeply as to afford the gunner but a small mark, and dives so quickly at the snap or flash of his gun that he stands but a small chance of killing it.

"On being surprised, the Goosander may rise directly out of the water, but more commonly pats the surface with his feet for some yards and then rises to windward. A whole flock thus rising from some foaming current affords a spirited scene. Once on the wing, the flight is straight, strong, and rapid" (Langille).

130. Mergus serrator (Linn.). Red-breasted Merganser. Ad. $\sigma^{7}$. -Whole head and throat black, more greenish above; a white ring around neck; a broad cinnamon-rufous band with black streaks on upper breast and sides of lower neck; lesser wing-coverts, tips of greater ones, secondaries, breast and belly white; rump and sides finely barred with black and white.

*A patch in the wing formed by the end half of the secondaries, which in Ducks are generally of a different color from the rest of the wing-feathers. 
Ad. $\%$ and Im.- Top and back of head grayish brown washed with cinnamonrufous; sides of head and throat cinnamon-rufous, paler on throat; rest of underparts white; back and tail ashy gray; speculum white. L., $22^{\circ} 00$; W., 9.00; Tar., 1*70; B. from N., 1'80.

Remarks.-Adults of this and the preceding species may always be distinguished by the color of the breast; females and young, by the differently colored heads, while the position of the nostril is always diagnostic.

Range.-N. part of N. Hemisphere. Breeds in N. Am., from Arctic coast of Alaska, n. Mackenzie, Cumberland Sound, and Greenland (lat. $73^{\circ}$ ) s. to s. B. C., s. Alberta, s. Minn., cen. Wisc., n. N. Y., s. Maine, and Sable Island; winters in s. Greenland, the Commander Islands, and from s. British Columbia, Utah, Colo., s. Wisc., s. Ont., and Maine, s. to s. L. Calif., La., and Fla.; casual in Bermuda, Cuba, and Hawaii.

Washington, uncommon W. V. L. I., abundant T. V., Mch. 25-May 2; Oct. 15-Dec. 25; occasional in summer (and in winter). Ossining, common T. V., Dec.-Apl. 30. Cambridge, uncommon T. V., in late fall. N. Ohio, tolerably common T. V., Mch. 10-May 10; Dec. 1-29. SE. Minn., T. V., Apl. 1 ; casual W. R.

$N$ est, of leares, grasses, mosses, etc., lined with down, on the ground near water, among rocks or scrubby bushes. Eggs, $6-12$, creamy buff, $2.55 \times 1 \cdot 75$. Date, Seal Is., Magdalen Islands, June 24.

"These Mergansers are often observed to hunt in company, a large flock sometimes advancing with wide extended front, driving the fish before them and diving simultaneously, so that whichever way their prey may dart there is a serrated beak and capacious gullet ready to receive them" (Eaton).

1911. Townsend, C. W., Auk, XXVIII, 341-345 (courtship and migration).

131. Lophodytes cucullatus (Linn.). Hooded Merganser. Ad. o7. -Front part of large circular crest black; remaining part white, bordered by black; rest of head, the neck and back black; breast and belly white; sides cinnamon-rufous, finely barred with black. Ad. $\%$ - - Tpper throat white; head, neck and upper breast grayish brown, more or less tinged with cinnamon, especially on the small crest; lower breast and belly white; sides grayish brown; back fuscous. Im. o.-Similar, but throat blackish. L., $17 \cdot 50$ : W., $7 \cdot 50$; Tar., $1 \cdot 10$; B., $1 \cdot 45$.

Range.-N. Am. Breeds from cen. British Columbia, Great Slave Lake, cen. Keewatin, cen. Ungava, and N. F., s. to s. Ore., n. N. Mex., s. La., and cen. Fla.; winters from s. B. C., Utah, Colo., Nebr., Ills., Ind., Pa. and Mass. s. to L. Calif., Mex., the Gulf States, and Cuba; rare in ne. part of range; recorded from St. Michael, Alaska, and from Europe and Bermuda.

Washington, uncommon W. V., Sept. 11-Apl. 8. Long Island, common T. V. in fall, Nov. 5-Dec. 14 ; rare W. V. and in spring. Ossining, rare T. V., Meh. Cambridge, formerly common T. V., Now. 10-30. N. Ohio, not common T. V., Apl. 1-15; Nov. 1-30. (ilen Ellyn, rare T. V., spring only, Apl. 8-June 5. SE. Minn., common T. V., unconimon S. R., Mch. 24-Oct. 26.

Nest, of grasses, leaves, moss, ete., lined with down, in a hollow tree or stump near water. Eggs, 8-10, buffy white, $2.10 \times 1.75$. Date, Saranac, Mich., Apl. 22.

As Ernest Seton has pointed out, both the preceding species of Mergansers frequent chiefly 'living' or running water, while this bird prefers 'dead' waters, or quiet ponds and lakes. In Florida it lives in small ponds in the 'hummocks,' where one expects to find Wood Ducks, and feeds on roots, seeds, etc. It visits also the lakes frequented by 
Black Ducks, Mallards, and other Anatince. The male is a striking bird in life, and can not be mistaken for any other species.

The Smew (131.1 Mergellus albellus), an Old World species, has been once recorded from the Hudson Bay region. (Salvadori, Cat. B. M., XXVII, 468.)

\section{Subfamily Anatino. River and Pond Ducks. (Fig. 34a.)}

The Ducks of this subfamily are distinguished by the absence of a lobe on the hind-toe. They are, for the most part, northern breeding birds, and appear on our waters chiefly as migrants. At this time, they differ but little in habits, and, as a rule, frequent sluggish streams, shallow ponds, arms of bays, and marshes. In comparison with the deepwater Fuligulinœ, they might be called 'dabblers' or 'tip-ups,' and any one who has seen them dabbling along the shore, or with upturned tail and head immersed, probing the bottom in shallow water, like a flock of animated tenpins, will recognize the appropriateness of these terms. They dive but little and when under water are said to use both feet and wings. (They feed upon mollusks, crustaceans, insects and their larvæ, the seeds and roots of aquatic plants.) The 'gutters' on the sides of the bill act as strainers, and, after probing the bottom, the mere act of closing the bill forces out the mud and water taken in with the food. As a rule, they feed more commonly by night than by day. They do not gather in such large flocks as the Sea Ducks, and in our waters are generally found in groups of less than fifty. They spring from the water at a bound, and on whistling wing are soon beyond the fowler's reach. Their highest speed is variously estimated, for different species, at from one hundred to one hundred and sixty miles an hour. Doubtless the first-named distance is nearer the truth.

All our Anatina, but the Wood Duck, nest on the ground, lining a slight hollow with grasses, leaves, moss or rootlets, and with more or less down from the breast of the incubating bird, which is used to cover the eggs, doubtless for purposes of warmth, as well as concealment, during the absence of the sitter. The nesting-site is usually near water, but may be half a mile or more from the shore, and is sometimes in grass so scanty that the sitting bird may be plainly seen, but as a rule it is in denser vegetation or under bushes.

The generally greenish, cream, or buff eggs, number from six to fourteen or rarely more, and hatch within a surprisingly short time of one another. Incubation is performed by the female alone. She sits close and springs from the nest at one's feet in a most disconcerting manner, to flutter off through the grass or, with halting flight, make for the water, there to alight with much show of anxiety. The young are in the highest. degree prixeocial, leaving the nest almost as soon as they leave the egg, and under the guidance of their mother, at once taking to water. Few hirls show more concern for the safety of their offspring than do Wild Ducks. When danger threatens, the young, evidently 
acting under direction, scatter and seek cover in every direction, while the female gives a remarkable and courageous exhibition of partial helplessness.

I. Wing under 8.50.

$$
\text { KEY TO THE SPECIES }
$$

a. Lesser wing-coverts gray.

b. Lesser wing-coverts blue.

139. Green-Winged Teal. 138. European Teal.

$b^{1}$. Cheeks slate-color, a broad white mark near the front of the face.

$b^{2}$. Cheeks and underparts chestnut-rufous.

140. Blue-Winged Teal (ơ ad.).

$c^{1}$. Cheeks finely streaked with blackish.

141. Cinnamon teal (ơ ad.)

$c^{2}$. Underparts whitish, sometimes washed with brownish, streaked or spotted with blackish ...... 140. BLUE-WINGEd Teal o.

$c^{3}$. Underparts heavily washed with chestnut-rufous and mottled with black ...................... Cinnamon Teal.

II. Wing over 8.50 .

A. Belly white or grayish white, not conspicuously streaked or spotted.

a. Whole head shining dark green ...... 132. Mallard (o ad.).

$b$. Center of head white or whitish, a large streak behind the eye.

137. Baldpate (ox ad.).

c. Throat white, crown green or grayish green, tips of primaries greenish.

144. WoOD DUCK.

d. Throat blackish, center of crown buffy, rest of head rufous.

136. WIDGEON (ơ ad.).

$e$. Throat and sides of head olive-brown, darker on the crown.

143. Pintail (o ad.).

f. Throat, crown and sides of head more or less finely streaked with blackish.

$f^{1}$. Wing-coverts with more or less chestnut ... 135. Gadwall.

$g^{1}$. No chestnut in wing-coverts.

$g^{2}$. Axillars* and sides barred with black. . . . 143. Pintail o.

$g^{3}$. Axillars white or speckled with black, sides plain brownish.

137. Baldpate. $g^{4}$. Axillars white, sides thickly spotted or barred with black.

135. Gadwall o.

$B$. Underparts conspicuously mottled, spotted, or streaked, or feathers margined with chestnut-rufous-or belly chestnut.

a. With white conspicuous in wing-coverts.

$a^{1}$. Lesser wing-coverts ashy blue ........ 142. Shoveller.

$b^{1}$. Lesser wing-coverts brownish gray, bordered with white or tipped with black.

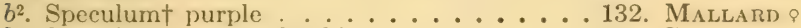

$b^{3}$. Speculum gray and white ......... 135. Gadwall \&

b. No conspicuous white in wing-coverts.

$b^{1}$. Throat fulvous or buffy, without streaks. . 134. Florida Durk.

$b^{2}$. Throat fincly streaked with black..... 133. BLACK DUCK

132. Anas platyrhynchos Linn. MALlard. (Fig. 34a.) Ad. $\pi^{*-}$ Whole head and throat glossy greenish or lbluish black; a white ring around the neck; breast rich chestnut; belly grayish white, finely markerl with way black lines; under tail-eoverts black; upper back dark grayish brown; rump and upper tail-coverts black; four middle tail feathers recurved; speculum rich purple, bordered at the base and tip by narrow bands of black and white. Ad. . - Top and sides of head streaked with fuscous and buffy; back fuscous, the feathers with internal rings or loops and sometimes borders of pale ochra- 
ceous buffy; speculum as in the preceding; breast and belly ochraceous buffy, mottled with dusky grayish brown. L., $23 \cdot 00$; W., 11.00; Tar., 1.75; B., 2.25.

Range.-N. Hemisphere. In N. Am. breeds from Pribilof Islands, nw. Alaska, n. Mackenzie, cen. Keewatin, and Greenland s. to L. Calif., s. N. Mex., s. Kans., cen. Mo., s. Ind., and Md. (rarely); winters from the Aleutian Islands, cen. Alaska, cen. Mont., Wyo., Nebr., s. Wisc., n. Ind., Ohio, Md., and N. S. (rarely) s. to Mex., the Lesser Antilles, and Panama; casual in Bermuda and Hawaii.

Washington, common W. V., Aug. 28-Mch. 19. Long Island, uncommon T. V., Oct. 3-Dec. 24; Mch., Apl. Ossining, rare T. V., Oct., Mch. Cambridge, rare but regular in fall. N. Ohio, tolerably common T. V., Mch. 1May 15; Oct. 1-Dec. 1. Glen Ellyn, regular but uncommon T. V., Mch. 10Apl. 7; Sept. 13-Nov. 23. SE. Minn., S. R., casual W. R., Meh. 4-Dec. 11.

Nest, on the ground, usually near water and among high grass or reeds. Eggs, 6-13, light greenish buff to light grayish buff, with very little luster, $2.27 \times 1 \cdot 61$. (Bent.) Date, Heron Lake, Minn., May 11.

The loud, resonant quacking of the female Mallard and much lower, less clearly enunciated quack of the drake are familiar sounds, though the loud notes are usually attributed to the male. When flying, the white under wing-coverts are sometimes conspicuous when the birds are too far away to distinguish the green head of the male. In Minnesota the Mallard is considered the wildest of wild Ducks.

133. Anas rubripes Brewst. Black DUcK. Ads.-Top of head rich fuscous, slightly streaked with pale buffy; sides of the head and throat pale buffy, thickly streaked with blackish; rest of underparts fuscous-brown, the feathers all bordered by ochraceous-buff; back slightly darker and narrowly margined with buffy; speculum rich purple, bordered by black, and, at the end only, narrowly by white. L., $22 \cdot 00$; W., 11.00; Tar., 1.75; B., $2 \cdot 20$.

Remarks. - Always to be distinguished from the female Mallard by its darker colors and smaller amount of white in the wing.

According to William Brewster (Auk, 1902, 184) the Black Duck is represented by two forms, the status of which, however, is considered doubtful by the A. O. U. Committee on Nomenclature. Should they be recognized, they will stand as Anas rubripes rubripes, the Red-legged Black Duck, and Anas rubripes tristis, which, for sake of distinction, may be called the Brown-legged Black Duck. A. r. rubripes is the larger of the two (o W., 10.99; Tar., 1.68 ; B., $2 \cdot 13$; \% W., $10^{\circ} 47$; Tar., 1.60; B., $2 \cdot 03$, as compared with the following measurements for A. r. tristis: or W., 10.52; Tar., 1.65; B., 2.05; o. W., 10.14; Tar., 1.61; B., 1.93) and has the sides of the head and the neck, chin, and throat more heavily streaked than in tristis in which the throat and chin are said to be unstreaked. In life the tarsi and toes are bright red, the bill yellow; while tristis has the tarsi and toes brownish, the bill olivaceous. The difference in the colors of the feet, while not apparent in museum specimens, form a readily observable field mark. The limits of the breeding ranges of these supposed forms have not been determined, but rubripes appears to be the more northern, not being known to breed south of the Gulf of St. Lawrence. During the migration and in winter both red-legged and brown-legged birds may be found in the same flock. (See also Brewster, Auk, 1909, 175-179; 1910, 323-333, and Dwight, Ibid, 1909, 422-426.)

Range.-E. N. Am. Breeds from cen. Keewatin and n. Ungava s. to n. Wisc., n. Ind., and s. Md.; winters from N. S. s. to s. La., and Colo.; w. in migration to Nebr. and cen. Kans.; casual in Bermuda; accidental in Jamaica.

Washington, common W. V. Aug. 1-Mch. 17. Long Island, abundant W. V., Sept.-May; a few breed. Ossining, tolerably common S. R., Mch. 6Nov. 13. Cambridge, very common T. V., and W. V.; a few breed. N. Ohio, 
tolerably common, Mch. 1-May 1; Sept. 1-Nov. 30. SE. Minn., uncommon T. V.

Nest, on the ground in grass or brush, often far from water. Eggs, 6-12, pale greenish or bluish white, or creamy buff, $2.43 \times 1 \cdot 75$. Date, Montauk Point, L. I., Apl. 5; Cambridge, Apl. 19; St. Croix River, Maine, Apl. 30.

Though not literally a black Duck, this bird appears so much darker in life than the female of its near relative Mallard, that it is sometimes known as Black Mallard. Its loud, resonant quack resembles that of the Mallard. It is more common in the Atlantic Coast States than inland, and when molested will sometimes pass the day at sea returning at night to feed in the ponds and marshes. It has won a deserved reputation for wariness.

The gullet and gizzard of a Black Duck shot by E. H. Eaton were found by him to contain 23,704 weed seeds. ("Birds of New York.") 1893. Allen, C. S., Auk, X, 53-59 (nesting).

134. Anas fulvigula Ridgw. FLORIDA DUCK. Ads.-Top of head streaked with black and buffy; sides of head and entire throat buffy, without streaks; rest of underparts rich buffy ochraceous, widely streaked with black; back black, the feathers broadly margined and sometimes internally striped with ochraceous-buff; speculum rich purple bordered by black; bill olive-yellow, its nail black. L., 20.00; W., 10.50; Tar., 1.65; B., 2.05.

Remarks.-Easily distinguished from $A$. rubripes by the absence of streaks on the throat.

Range.-Fla. and Gulf coast to Miss.

Eggs, 8-10, pale dull buff or pale grayish buff, $2 \cdot 15 \times 1 \cdot 61$ (Ridgw.).

Date, Caloosahatchie River, Fla., Apl. 16.

This southern representative of the Black Duck is permanently resident in Florida, where it has apparently decreased in numbers in recent years. It resembles the Black Duck in voice and feeding habits, but I have never known it to go out to sea.

135. Chaulelasmus streperus (Linn.). Gadwall. Ad. $0^{x}$-Top of head streaked with rufous-brown and black; sides of head and neck pale buffy, thickly streaked or spotted with black; breast and neck all around black, each feather with a border and an internal ring of white, giving the plumage a beautifully scaled appearance; belly white or grayish; rump, upper and under tail-coverts black; lesser wing-coverts chestnut. Ad. $9 .-$ Head and throat as in male; back fuscous margined with buffy; breast and sides ochraceous buffy, thickly spotted with blackish; belly and under tail-coverts white, more or less thickly spotted with blackish; little or no chestnut on wing-coverts; speculum ashy gray and white; axillars and under wing-coverts pure white. L., $19 \cdot 50$; W., 10.40; Tar., 1.55; B., 1.70.

Range.-Nearly cosmopolitan. In N. Am. breeds from s. B. C., cen. Alberta, and cen. Keewatin s. to s. Calif., s. Colo., n. Nel)r., and s. Wise.; winters from s. B. C., Ariz., Ark., s. Ill., and N. C. s. to s. L. Calif., cen. Mex. (Jalisco), and Fla.; accidental in Bermuda, Cuba, and Jamaica; rare in migration on the Atlantic coast of the Middle and New England States n. to N. F.

Washington, common W. V., Aug. 24-Apl. L. I., rare T. V. N. Ohio, occasional T. V. SE. Minn., common T. V., uncommon S. R., Apl. 3.

Nest, on the ground, near water, in short prairie grass or concealed bencath rose bushes. Eggs, 8-12, pale buff or buffy white, $2.09 \times 1.57$ (Ridgw.). Date, N. D., June 7. 
The Gadwall is common in the interior but rare on the Atlantic Coast, except in Florida. Its voice is a quack higher and with less volume than that of the Mallard. It is a surprising sight to see these birds in courtship flight, when the male pursues the female often high in the air and for some time, on a course as erratic as that of a Barn Swallow.

136. Mareca penelope (Linn.). European Widgeon. Ad. $o^{x}$ Crown creamy buff; throat blackish, rest of head and neck rufous-brown; upper breast vinaceous, lower breast and belly white; sides and back finely marked with wavy black and white lines. Ad. $\%$.- Head and throat deep ochraceous-buff, finely streaked and barred with black, darker above; upper breast and sides much the same color, but without black markings; lower breast and belly white; back grayish brown, the feathers with small ochraceous buffy bars; tertials fuscous, bordered by deep ochraceous buffy; greater wing-coverts brownish gray, usually whiter on the outer webs and tipped with black. W., $10 \cdot 50 ;$ B., 1*40.

Remarks. - The females of the European and American Widgeons bear a general resemblance to one another. Their distinguishing characters are mainly in the color of the head and throat, which are browner in the European species, and in the color of the greater wing-coverts, which are whiter in the American bird.

Range.-N. part of the E. Hemisphere. Occurs in N. Y., N. S., N. F., and Greenland s. to Nebr., Mo., Ind., Ohio, N. C., and Fla., and in Alaska, B. C., and Calif.

W'ashington, A. V., two records. Long Island, rare T. V.

Eggs, 5-8, buffy white, $2 \cdot 23 \times 1 \cdot 53$. Date, Iceland, June 2.

The European Widgeon is of rare but regular occurrence in Eastern North America. "The call-note of the male is a shrill, whistling whéeyoŭ, whence the local names 'Whew Duck' and 'Whewer'; but the female utters a low purr-ing growl. Both sexes, however, rise in silence." (Saunders.)

137. Mareca americana (Gmel.). Baldpate. Ad. $\sigma^{x}$--Middle of crown white or buffy; sides of crown, from eye to nape, glossy green, more or less sprinkled with black; lores, cheeks and throat buffy, finely barred with black: upper breast and sides vinaceous, the latter more or less finely barred with wavy black lines; lower breast and belly white; back grayish brown, more or less tinged with vinaceous and finely barred with black. $A d$. $\odot .-$ Head and throat white or pale, creamy buff, finely streaked and barred with black, darker above; upper breast and sides pale vinaceous washed with grayish; lower hreast and belly white; back grayish brown, the feathers with small creamy buff bars; tertials fuscous, bordered with whitish or creamy buff; greater wing-coverts brownish gray, their outer webs mostly or entirely white, their ends lilack, sometimes tipped with white. L., 19.00; W., 10.50; Tar., 1.50; B., 1.40.

Range.-N. Am. Brecds from nw. Alaska, n. Mackenzie, and cen. Keewatin s. to Ore., Nev., Utah, Colo., Kans., s. Wisc., and n. Ind.; winters from s. B. C., Ariz., s. Ills., MId., and Del. (casually Mass., and R. I.), s. to s. L. Calif., the Wrest Indies, and Costa Rica; rare in migration to $\mathbf{n}$. Ont., $\mathbf{n}$. Que., and N. F.; accidental in Hawaii, Bermuda, and Europe.

W ashington, common W. R., Oct.-Apl. Long Island, T. V., common, Oct. 10) Feh. ; less common Mch. 8-Apl. 16; a few winter. Ossining, common T. V., Mrh. 11-A pl. 12; ()c.t. $4-28$. Cambridge, rare T. V. in fall. N. Ohio, not common T. V., Meh. 10-Apl. 25. SE. Minn., common T. V., Mch. 17-Oct. 20.

$N e s t$, on the ground near water, sometines exposed, usually concealed in grass, weeds or bushes. Eggs, $7-12$, buffy white, 2.05 × 1.50. Date, N. D., May 31. 
N.S. Goss writes that, as a rule, Widgeons are "not shy, and their note, a sort of whew, whew, whew, uttered while feeding and swimming, enables the hunter to locate them in the thickest growth of water plants; and when in the air the whistling noise made by their wings heralds their approach." They are fond of wild celery, which they procure by robbing the Canvasback and other diving Ducks, "snatching their catch from their bills the moment their heads appear above the water." "The female utters a loud cry like the syllables kaow, kaow." (Eaton.)

The European Teal (138. Nettion crecca) is of casual occurrence in Eastern North America. The adult male resembles that of $N$. carolinense, but the white bar in front of the wing is lacking, and the inner scapulars are creamy buff, with a sharply defined black mark on their outer-webs. The female can not be distinguished from that of $N$. carolinense.

139. Nettion carolinense (Gmel.). Green-Winged Teal. Ad. o.Chin black, sides of head from eye to nape shining green, rest of head and neck rufous-chestnut; breast washed with vinaceous and spotted with black; belly white; sides finely marked with wavy black and white lines; middle under tail-coverts black, lateral ones creamy buff; upper back like sides, lower back grayish fuscous; a white bar in front of the bend of the wing; wing-coverts brownish gray, tipped with ochraceous buffy. Ad. ‥Top of head brownish fuscous, margined with cinnamon; throat and sides of neck white, finely spotted with black; breast and sides washed with cinnamon and spotted or barred with black; belly and under tailcoverts white, sometimes spotted with black; back fuscous, the feathers with crescent-shaped marks of ochraceous buffy, and bordered with grayish; wings as in the male. L., $14 \cdot 50 ; \mathrm{W} ., 7 \cdot 00$; Tar., $1 \cdot 10 ; \mathrm{B} ., 1 \cdot 35$.

Range.-N. Am. Breeds from nw. Alaska, n. Mackenzie, cen. Keewatin, n. Urigava, and N. F. s. to cen. Calif., n. N. Mex., n. Nebr., n. Ills., s. Ont., Que., and N. B.; winters from Alaska, B. C., Nev., s. Nebr., n. Ind., w. N. Y., and R. I. (casually N.S.) s. to s. L. Calif., the West Indies, and Honduras; accidental in Hawaii, Bermuda, Greenland, and Great Britain.

Washington, common W. V., Sept.-Apl. Long Island, uncommon T. V. and W. V., Oct.-Apl. Ossining, common T. V., Apl.; Sept. 11-Oct. 28. Cambridge, uncommon T. V., Apl.; Sept.-Dec. N. Ohio, occasional T. V. Glen Ellyn, quite regular T. V., Mch. 10-Apl. 14; Sept. 25-Oct. 19. SE. Minn., common T. V., Mch. 11.

Nest, on the ground near water. Eggs, 6-12, buffy white or creamy buff, $1.80 \times 1 \cdot 25$. Date, N. D., May 20 .

"The Green-wing is a noisier bird than the Blue-winged Teal, the male uttering a short, mellow whistle and the duck a quack after the fashion of a Black Duck, but small, high-pitched and often repeated." (Eaton. )

140. Querquedula discors (Linn.). BleE-Winged Teal. $A d$. $\sigma^{7}$ Crown fuscous, chin and sides of base of bill black; a broad white band across front of head, its hinder margin bordered by black; rest of head and throat dark ashy with purplish reflections; breast and belly (innamon-rufous, thickly spotted with black; back fuscous, the feathers with creserents of ochraceous-buff; lesser and median wing-coverts grayish blue, end half of greater ones white; speculum green. Ad. ?.-Crown fuscous, lightly margined with grayish; sides of the head and the nock whitish, fincly spotfed with blackish, except on the throat; breast and belly with less cinnamon wash than in the preceding: back and wings quite sinilar to the precedling, but ochraceous bars sometimes wanting, speculum darker and greater coverts with less white. L., 16*00; W., 7`25; Tar., 1*20; B., 1*60. 
Range.-W. Hemisphere. Breeds from cen. B. C., Great Slave Lake, cen. Ungava, and N. F. s. to cen. Ore., n. Nev., n. N. M., cen. Mo., s. Ind., n. Ohio., w. N. Y. (occasionally R. I.), and Maine; winters from s. B. C., Ariz., s. Ills., Md., and Del. s. to the West Indies and S. A. as far as Brazil and Chile; accidental in Bermuda and Europe.

Washington, common W. V., Aug. 18-June 2. Long Island uncommon T. V., Mch. 24-Apl. 21; Aug. 28-Oct. 25. Ossining, common T. V. in fall, Sept. 24-Oct. 17. Cambridge, rare in spring; very common (at least formerly) Aug.-Oct. N. Ohio, not common T. V. Apl. 20-May 4. Glen Ellyn, not common S. R., Apl. 2-Oct. 8. SE. Minn., common S. R., Mch. 29.

Nest, on ground, well concealed in grass, near water. Eggs, 6-12, buffy white or creamy buff, 1.85 × 1:30. Date, SE. Minn., May 10 .

The Blue-winged Teal is one of the swiftest of our Ducks. The white face-mark of the male can be discerned at some distance, and, in connection with the bird's small size, is a good field-mark. "The BlueWing's note is a whistling 'peep' repeated five or six times, but is seldom heard. The duck quacks less plainly and in a hoarser voice than the Green-wing" (Eaton).

The Cinnamon Teal (141. Querquedula cyanoptera), a species of western North America, sometimes occurs east of the Mississippi. It has been recorded from Illinois and Florida. The male has the underparts deep cinnamon; the female closely resembles the same sex of our $Q$. discors.

The RUdDy SHELdRAke (141.1 Casarca ferruginea), an Old World species, is of casual occurrence in Greenland. (See Allen, Auk, 1896, 243.)

142. Spatula clypeata (Linn.). Shoveller. Ad. $\sigma^{7}$.-Head and neck fuscous, glossed with bluish green; back and a broken line down back of lower neck fuscous; rest of lower neck and breast white; lower breast and belly rufous-chestnut; upper and under tail-coverts dark greenish; lesser wing-coverts grayish blue, greater ones brownish gray tipped with white; speculum green. Ad. . - Throat buffy white; head and neck streaked with buffy and black; rest of underparts more or less washed with buffy ochraceous, everywhere indistinctly spotted with fuscous except on middle of belly; back fuscous, the feathers with margins and internal crescents of whitish and buffy; wing-coverts and speculum much as in $\sigma^{7}$. Im.-The im. $\sigma^{7}$ is intermediate between the ad. $\sigma^{7}$ and $o$; the im. o resemble the ad. o, but the wing-coverts are slaty gray, the speculum with little or no green. L., $20^{\circ} 00$; W., 9.50; B., 2.50; greatest width of B., 1.20.

Range.-N. Hemisphere. In N. A. breeds from 'nw. Alaska, nw. Mackenzie, and s. Keewatin s. to s. Calif., cen. N. M., n. Tex., n. Mo., and n. Ind.; winters from s. B. C., Ariz., N. M., s. Mo., s. Ills., Md., and Del. s. to the W. Indies, Colombia and Hawaii; in migration occasional in Bermuda, and n. to N. S., and N. F.

Washington, not uncommon W. V. Long Island, rare T. V., Oct. 25Nov. 29. Ossining, A. V. Oct. Cambridge, one record. N. Ohio, not common T. V., Mch. 12-Apl. 6; Sept. 20-Nov. 1. Glen Ellyn, not common T. V., fall records only, Oct. 11-Nov. 8. SE. Minn., common T. V., uncommon S. R., Mch. 30 .

Nest, on the ground, well concealed in grass, sometimes near to, sometimes far from water. Eggs, 6-11, pale olive-buff or pale greenish gray similar to a Mallard's or Pintail's but smaller, $2.03 \times 1.42$ (Bent). Date, Heron Lake, Minn., May 9.

The Shoveller, like most of the members of this subfamily, is more common in the Mississippi Valley than on the coast. It is generally a silent bird, but its note in the breeding season is said to be took, took. It feeds largely by tipping in shallow water. 
143. Dafila acuta (Linn.). Pintail. Ad. $\sigma^{x}$.-Head and throat olivebrown; back of neck blackish, bordered by white stripes, which pass to breast; breast and belly white; the abdomen faintly and sides strongly marked with wavy lines of black and white; back somewhat darker than sides; scapulars black, bordered or streaked with buffy white; wing-coverts brownish gray, greater ones tipped with rufous; speculum green; central tail-feathers glossed with green and much elongated. Ad. o.- Throat white or whitish, crown and sides of head streaked with blackish and buffy ochraceous, darker above; breast washed with buffy ochraceous and spotted with blackish; belly white; abdomen more or less indistinctly mottled with blackish; sides with bars and lengthened black and white crescents; under wing-coverts fuscous, bordered with whitish; axillars barred or mottled with black; back fuscous, the feathers with borders, bars, or crescents of white or buffy; speculum grayish brown bordered with white. Im.-The im $\sigma^{\text {a }}$ is variously intermediate between the ad. $\sigma^{7}$ and $\%$, the im. $\%$ resembles the ad. \%, but the underparts are more heavily streaked or spotted. L., ơ , 28.00, ค, $22 \cdot 00$; W., $10^{\circ} 00$; T., $\sigma^{7}, 7 \cdot 50$, ᄋ, $3 \cdot 60 ;$ B., $2 \cdot 00$.

Remarks. - The female of this species is a rather obscure-looking bird, but may always be known by its broad, sharply pointed central tail-feathers and dusky under wing-coverts.

Range.-N. Hemisphere. In N. Am. breeds on the Arctic coast from Alaska to Keewatin and s. to s. Calif., s. Colo., n. Nebr., n. Iowa, and n. Ills.; winters from s. B. C., Nev., Ariz., s. Mo., s. Wisc., s. Ohio, Pa. (rarely), and Del., s. to Porto Rico and Panama, and in Hawaii; in migration occasional on the Atlantic coast to n. Ungava, Greenland, and N. F., and in Bermuda.

Washington, W. V., Sept. 13-Apl. 1. Long Island, common T. V., Sept. 15-Apl. 15; a few winter (Dutcher). Ossining, common T. V., Mch. 15-Apl. 10; Sept. 26-Dec. 4. Cambridge, rather rare T. V., Apl.; Oct.-Dec. N. Ohio, common T. V., Mch. 1-Apl. 7; Sept. 20-Dec. 1. Glen Ellyn, irregular, Mch. 19-Apl. 17. SE. Minn., common T. V., Mch. 3.

Nest, on the ground, often but little concealed, sometimes near to, at others far from water. Eggs, 8-10, pale olive-green or olive-buff, $2 \cdot 20 \times 1 \cdot 50$. Date, Minor Co., S. D, May 7.

"Its note is seldom heard by day, but while coming into the feedinggrounds at night with the Widgeons, Black Ducks and Mallards, the hoarse, muffled quack of the duck and the mellow whistle of the drake are heard mingled with the whistling of the Widgeon and the loud calls of the Black Duck. In the springtime the drake often gives utterance to low, soft notes which seem to flow from deep down in the throat, especially while performing curious courting antics in the presence of the ducks." (Eaton.) The Pintail's long, slender neck, and in the male the long tail-feathers, are good field-marks.

144. Aix sponsa (Linn.). Wood Duck. Ad. $\sigma^{7}-\mathrm{A}$ line from bill over eye, a similar line at base of side of crest, and some of elongated crestfeathers white; throat, a band from it up side of head, and a wider one to nape, white; rest of cheeks and ('rown green with purplish reflections; a white band in front of wings; breast and a spot at either side of the base of the tail purplish chestnut, the former spotted with white; bolly white; sides buffy ochraceous, finely barred with black, longer flank feathers tipped with wider bars of black and white; back greenish brown; scapulars blacker; speculum steel-blue; primaries tipped with greenish blue.-Ad. \&.- Throat and a stripe from the eye backward white; crown purplish brown; sides of the head ashy brown; breast and sides grayish brown streaked with buffy; belly white; back olive-brown glossed with greenish; inner primaries tipred with greenish blue. Im.-The im. of resembles the \&. L., 18.50; W., 9.00; Tar., 1:35; B., 1:30. 
Range.-Temperate N. A. Breeds from s. B. C., cen. Sask., n. Ont., N. B. and N. S. s. to cen. Calif., s. Tex., Fla. and Cuba; winters chiefly in U. S., from s. B. C., Kans., Ills., Ind., Pa., and N. J., s. to s. Calif., and the Gulf of Mex.; accidental in Bermuda, Mex., Jamaica, and Europe.

Washington, uncommon P. R. Long Island, rare S. R., May 2-Nov. 27. Ossining, tolerably common S. R. Cambridge, not common T. V., Apl. 1-30; Sept. 15-Oct. 20. N. Ohio, rare S. R., Mch. 20-Oct. 15. Glen Ellyn, rare, May records only. SE. Minn., uncommon S. R., Mch. 17Oct. 23.

Nest, of grasses, leaves, twigs, down, etc., in a hole in a tree or stump. Eggs, 8-14, pale buffy white, 2.05 × 1.50. Date, Chester Co., S. C., Mch. 10; Black Hawk Co., Iowa, May 4.

Woodland ponds and forest-bordered streams make a proper setting for the grace and beauty of these richly attired birds. I know of no sight in the bird world which so fully satisfies the eye as to see them in the unconscious enjoyment of their secluded homes. Alarm them, and with a frightened, plaintive whistle, "oo-eek," they spring from the water and make off through the woods. At other times they will swim ahead of one's canoe, and, rounding a bend in the stream, go ashore and walk rapidly away.

The Rufous-crested Duck (145. Netta mufina) is an Old World species which has been taken once in America. The record is based on an immature male found in Fulton Market, New York City, which was supposed to have been shot on Long Island. (Ridgw., Bull. U. S. Nat. Mus., 1881, 25.)

\section{Subfamily Fuligulince. Bay, Sea, or Diving Ducks. (Fig. 34b.)}

The members of this subfamily are to be distinguished from those of the preceding by the presence of a lobe or web on the hind-toe. They are open-water Ducks, frequenting our large lakes, bays and sea-coasts. Their food consists chiefly of mollusks, crustaceans, and the seeds and roots of aquatic plants. They obtain it principally by diving, sometimes descending one hundred and fifty feet or more. According to Townsend ("Labrador Spring," p.92), the Old Squaw, Scoters and Eiders use their wings when diving, while the Redhead, Canvasback, Bufflehead, Scaups and Golden-eyes use only their feet. The bill, as in the Anatino, acts as a sieve or strainer. As a rule they feed by day and pass the night at a distance from the shore or at sea. Some of the species occur in our waters in large flocks-indeed, our most abundant Ducks are members of this subfamily. With one exception, they are northern breeding birds, seldom nesting south of our northern tier of States. Their nest is composed of leaves, grasses, stems of aquatic plants, seaweed, ete., lined with down from the breast of the incubating bird, and is variously located.

\section{KEY TO THE SPECIES}

I. Frathers at the base of the bill not reaching 50 forward along its sides.

1. Wing over $7^{\circ} 00$.

A. Axillars and most, if not all, the linings of the wings white. a. Head and neck black, with greenish or purplish reflections. 
Plate XIII

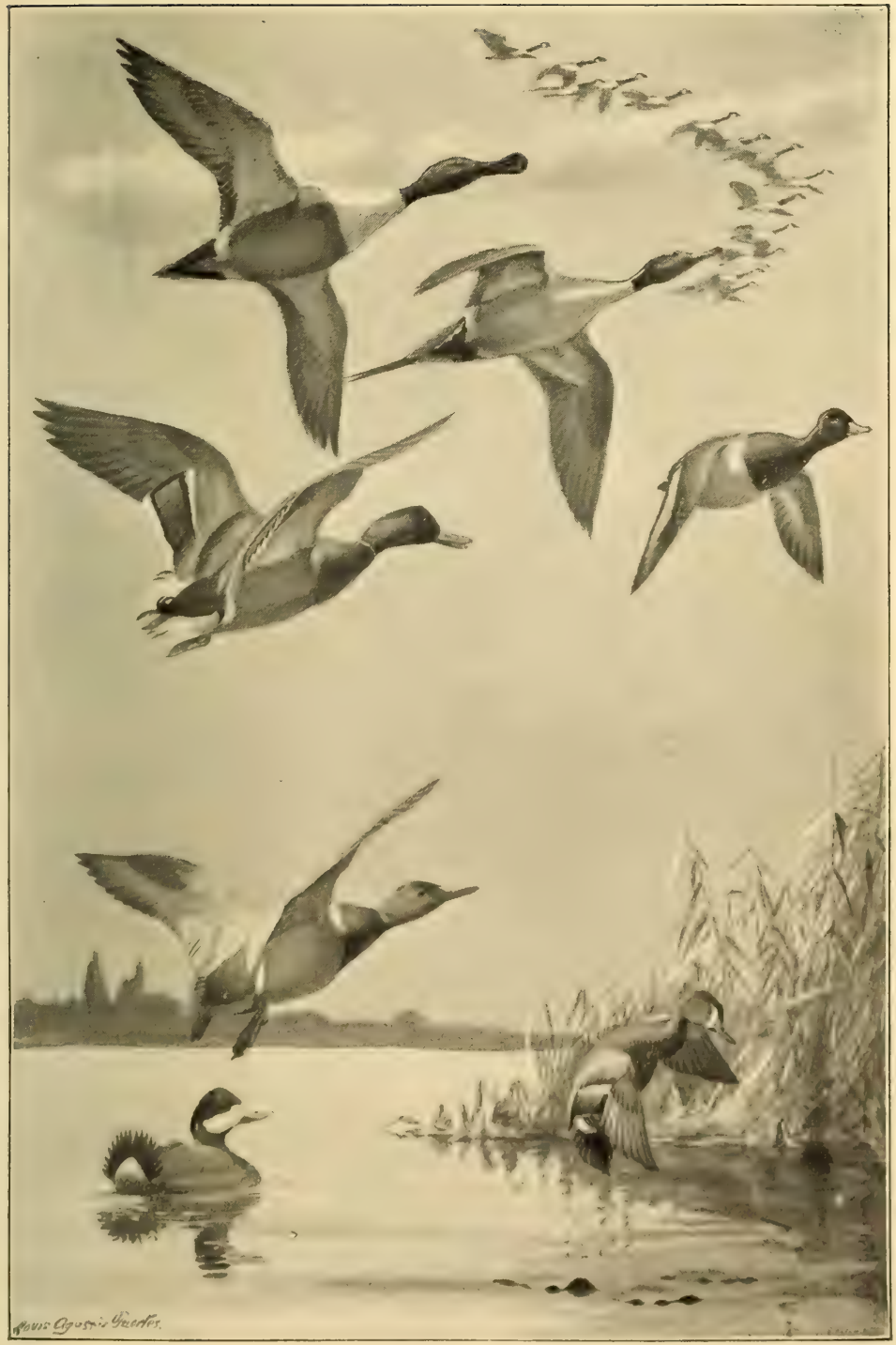

DUCKs AND Geese.

Shoveller.

Mallard.

Canvasback.

Ruddy Duck.
Canada Giecse.

Pintail.

Seaup Duck.

Blue-winged Teal. 

$a^{1}$. Back black; bill with a bluish band near its tip.

$b^{1}$. Back finely barred with black and white.

150. RING-NECKED DUCK $\sigma^{x}$.

$\iota^{2}$. Back of head generally with purplish reflections; wing generally under $8 \cdot 25$; nail of bill generally under $\cdot 25$ in width.

149. Lesser Scaup DUCK ot.

$b^{3}$. Back of head generally with greenish reflections; wing generally over $8 \cdot 25$; nail of bill over 25 in width.

148. Greater Scaup DuCK ot.

b. Head and neck not black.

$b^{1}$. Head and neck rufous or rufous-brown, sharply defined from the black breast.

$b^{2}$. Head and upper neck rich rufous; bill $2^{\circ} 00$ or under; flanks finely barred, like the back ...... 146. REDHEAD o'.

$b^{3}$. Head and neck rufous-brown; crown blackish; bill over 2.00 ; flanks very slightly if at all barred . . 147. CANVASBACK $\sigma^{7}$.

$c^{1}$. Head and neck brownish or grayish.

$c^{2}$. A white patch in the wing.

$c^{3}$. Feathers at base of bill white; wing generally under $8 \cdot 25$; nail of bill generally under ' 25 in width.

149. Lesser ScaUp DUCK o.

$c^{4}$. Feathers at base of bill white; wing generally over $8 * 25$; nail of bill generally over ${ }^{*} 25$ in width

$d^{2}$. No white in wing.

148. Greater Scaup Duck o.

$d^{3}$. An indistinct bluish band near the tip of bill; bill under $2 \cdot 00$. $d^{4}$. Wing under $8^{\circ} 00 \ldots . . .150$. RING-NECKED DUCK ㅇ. $d^{5}$. Wing over $8 \cdot 00 \ldots \ldots$. . . . Re . . . . . . $e^{3}$. No band on bill; bill over $2^{\circ} 00 \ldots$ 147. Canvasback $\%$.

B. Axillars and most, if not all, the under wing-coverts blackish.

$a$. Head and throat dark steel-blue or steel-green.

$a^{1}$. Head and throat steel-blue; white patch at base of bill $1^{\circ} 00$ or more in height ....... 152. BARROw's GOLdEN-EYE $\sigma^{7}$.

$a^{2}$. Head and throat steel-green; white patch at base of bill less than $1^{\circ} 00$ in height ..... 151. AM. Golden-Eye ơ

b. Head and throat not steel-blue.

$b^{1}$. Whole head and throat brown, sharply defined from the gray or white neck; a white patch (speculum) in the wing.

$b^{2}$. Nostril nearer the tip than the base of the bill.

$b^{3}$. Nostril in the middle of the bill.

151. AM. GOLdEN-EYE 오.

152. Barrow's Golden-EYE .

$c^{1}$. Head and throat not brown but with more or less black.

$c^{2}$. Whole head'and neck black.

$c^{3}$. Plumage black

$d^{2}$. Whole head and neck not black.

$d^{3}$. Crown-patch or cheeks white.

$d^{4}$. A white patch on the top of the head and another on

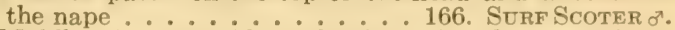

$d^{5}$. Middle of crown black, bordered by chestnut; front half of face white.... 155. Harlequin DUCK o".

$e^{3}$. Head and neck whitish, grayish, or brownish, no white in wing.

$e^{4}$. Bill over $1 \cdot 25$.

$e^{5}$. Feathers on culmen reaching much farther forward than those at sides of the bill . 166. Surf Scoter $\&$.

$e^{6}$. Feathers on culmen reaching little of any beyond those at sides of bill ... . 163. AM. Scoter .

$f^{4}$. Bill under $1 \cdot 25$. 
2. Wing under $7 \cdot 00$.

$f^{5}$. Central tail-feathers longest, sharply pointed, under
tail-coverts white. . . . . 154. OLD SQUAW.
$f^{6}$. Central tail-feathers not sharply pointed; under tail-
coverts grayish brown . . . 155. HARLEUIN DUCK.

$a$. Tail-feathers stiff and narrow; upper tail-coverts very short.

$a^{1}$. Upperparts mostly rich chestnut-rufous.

$a^{2}$. Cheeks white . . . . . . 167. RUDDY Duck on. $a^{3}$. Cheeks black ... . . . . . . 168. MASKED DUCK ơ $b^{1}$. Upperparts grayish or brownish, with sometimes rufous markings.

$b^{2}$. Lining of wing blackish; underparts grayish.

$b^{3}$. Lining of wing whitish; underparts grayish.

168. MASKed DUCK \&.

167. RUDDX DUCK ᄋ.

b. Tail-feathers normal; upper tail-coverts about half as long as tail. 153. BUFFLEHEAD.

II. Feathers at sides or top of bill extending forward generally as far as nostril.

A. Feathers on sides of bill not reaching nostril.

a. Nostril narrow, elongate; feathers on culmen extending forward in a narrow line, a V-shaped mark on throat . 162. KING EIDER.

$b$. Nostril large, rounded; feathers on culmen not extending forward in a narrow line ......... 165. WHITE-WINGED ScOTER.

$B$. Feathers on sides of bill extending as far as nostril.

a. Bare base of bill on top narrow, ending posteriorly in a sharp point.

b. Bare base of bill on top broad, the posterior end rounded.

159. Greenland Eider. 160. Am. Eider

146. Marila americana (Eyt.). REDHEAD. Ad. $\sigma^{3}$-- Head and throat bright rufous; lower neck, breast, back of neck and upper back black; rest of back and scapulars finely barred with wavy black and white lines of equal width; wing-coverts brownish gray; upper tail-coverts black; belly white, lower belly more or less finely barred with black; under tail-coverts black; sides like buck. Ad. \&.-Upperparts dark grayish brown, darker on rump, the feathers more or less margined with buffy or ashy; sides of head lighter; upper throat white; neck buffy ochraceous; breast and sides grayish brown, more or less washed or margined with buffy or buffy ochraceous; belly white; lower belly and under tail-coverts tinged with ochraceous; an indistinct bluish gray band across end of bill. L., $19^{\circ} 00$; T., 8.90; Tar., $1.55 ;$ B., 1.85.

Remarks. - This species is frequently confused with the Canvasback, from which it may be distinguished by the characters given under that species.

The female Redhead suggests the female Ring-neck in coloration, but the latter is browner, and they can be also distinguished with certainty by the difference in their size.

Range.-N. A. Breeds from s. B. C., cen. Alberta, cen. Sask. and sw. Keewatin s. to s. Calif., Utah, s. S. D., s. Minn., and s. Wisc.; winters from s. B. C., Utah, N. M., Kans., Ills., Md., Del., and Mass., s. to s. L Calif., cen. Mex., and Fla.; accidental in Jamaica; in migration casual in Alaska and regularly on the Atlantic coast n. to s. Lab.

Washington, common W. V. Long Island T. V., locally common, Sept. 30-Jan. 9; Feb. 15-Mch. 22. Ossining, common T. V., Apl. 1-Apl. 24; Oet. 12-Oct. 2s. Cambridge, rather rare T. V., in fall. N. Ohio, tolerably common T. V., Mch. 1-Apl. 25. SE. Mimn., uncommon T. V., Apl. 14.

Nest, of reeds, with more or less white down, in reeds, usually over water. Eggs, 6-18; light olive-huff to light eream-buff, $2 * 40 \times 1 \cdot 70$. Date, Dodge Co., Wisc., May 22, $18 s$; Heron Lake, Minn., May 19, 1887. 
The Ducks of the genus Marila possess to some extent the habits of both the River Ducks and true Sea Ducks. They are divers in deep water, but along the shores or in shallow water they are also 'dabblers.' On the Atlantic coast the Redhead is a Bay Duck, and feeds in salt and brackish water; but in the West it inhabits prairie sloughs and lakes. When feeding on wild celery its flesh is equal to that of the Canvasback, indeed, by the discriminating it is considered slightly superior, being as much finer as the bird is smaller than its more famous cousin.

147. Marila valisineria (Wils.). CANvASBACK. Ad. $0^{7}$.- -Head and neck rufous-brown, chin and crown generally blackish; breast and upper back black; rest of back and generally wing-coverts finely barred with wavy lines of black and white, white lines wider; belly white; lower belly more or less finely barred with hlack; upper and under tail-coverts black; sides white, much more lightly barred with wary black lines than back, or even entirely without bars. Ad. o.- - Head, neck, upper breast, and upper back cinnamon, throat lighter, and, with front parts of head, more or less washed with rufous; back grayish brown, feathers more or less barred with wary white lines; belly white or grayish white; sides the same or grayish brown, generally marked like back. L., $21^{\cdot} 00$; W., 9.00; Tar., 1·60; B., 2*40.

Remarks. - This species is sometimes mistaken for the Redhead, to which it bears a general resemblance. The males of the two species may be distinguished (1) by the color of the head and neck, which is rufous in the Redhead and rufous-brown in the Canvasback; (2) by the generally blackish chin and crown of the Canvashack, these parts in the Redhead being colored like the rest of the head; (3) by the difference in the markings of the back, wing-coverts, and sides; and (4) by the difference in the size and shape of the bill, as shown by the accompanying measurements. The females of the two species may be at once distinguished by the color of the back, which in the Canvasback is finely barred with wiry white lines, markings which do not appear on the back of the female Redhead.

Range.-N. A. Breerls from cen. B. C., Fort Yukon, Great Slave Lake, and sw. Keewatin s. to Ore., n. Nev., Colo. (rarely), Nebr., and s. Minn., winters from s. B. C., Nev., Colo., Ills., Pa., and w. N. Y. s. to cen. Mex. (Jaliseo) and the Gulf coast; in winter formerly abundant, now less so, in Md., Va., and N. C.; orcasional s. to Fla., and casual in the West Indies, Bermuda, and Guatemala; in migration n. rarely to N. B. and N. S.

Washington, rare W. V., (Oct. 1.5-MI.h. 25. L. I., rare T. V., Oct. 20Feb. 11. Ossining, rare T. V., Oct. Cambridge, rare T. V. N. Ohio, tolerably common T. V., Mch. 20-Apl. 10, Oct. 1-Nor. 25. SE. Minn., uncommon T. V.

Nest, of reeds, lined with gray down, in reeds, or tules over water. Eggs, 6-10, (often with eggs of the Ruddly Duck or Redhead added) "rich grayish olive or greenish drab of a darker shade than is usually seen in the egress of other species" of Ducks, $248 \times 1.75$ (Bent). Date, Heron Lake, Minn., May 9,1886 , adv.

While the fame of the Canvasback has no doubt been unduly sung by the epicure, there can be no question that from the sportsman's viewpoint it is king among the Ducks. Pursued for the market and as game, it has doereased alarmingly, but in recent years, thanks to more stringent and better enforeed laws, and particularly to the abolition of spring shooting, its numbers appear to be incrasing.

In October, 1910, ten thousand Canvashack were estimated to be on Heron Lake, Minnesota. They were feerling on the wild colery which nearly covers the bottom of this shallow body of water, and, 
as a rule, kept near the center of the lake (where shooting is prohibited) massed in one great body. On still mornings, the shining white backs of the males could be clearly seen, while at a distance of half a mile, one could hear distinctly a dabbling sound as they ate the celery brought to the surface

"The female Canvasback can quack almost as well as a Black Duck, and also gives voice to a screaming curr-row when startled. The males, when together, frequently utter a peeping or growling note." (Eaton.)

1910. FAY, S. P., Auk, XXVII, 369-381 (status in Mass.).

148. Marila marila (Linn.). Greater Scaup Duck. Ad. o.:-Head, neck, breast and upper back black, top and sides of head with generally green$i$ sh reflections; back and scapulars with wavy black and white bars; speculum white; upper and under tail-coverts black; belly white; lower belly strongly and sides faintly marked with wavy black bars. $A d$. $\%$.- Region around base of bill white; head, ncck, breast and upper back umber, margined with ochraceous on breast; back and scapulars fuscous-brown; sides dark grayish bromn, both generally marked with fine, wavy bars of white; speculum and belly white. o L., 18.50 ; W., 8.75 ; Tar., 1.40 ; B., 1.65 ; greatest width of B., 1.00. o L., $17 \cdot 50$; W., $8 \cdot 25$; Tar., $1 \cdot 36$; B., $1 \cdot 65$; greatest width of B., $1 \cdot 00$.

Range.-N. part of N. Hemisphere. In N. A., breeds from the Aleutian Islands, nw. Alaska, Great Slave Lake, and cen. Keewatin s. to s. B. C. and n. N. D.; has bred casually on Magdalen Islands and in Ont. and Mich.; winters from Maine to Fla., and the Bahamas, and from the Aleutian Islands, Nev., Colo., and Lake Ont., s. to s. Calif., s. N. M., and s. Tex.; in migration rare in cen. Ungava, N. F., and N. S.

TI ashington, rather common W. V. Long Island, abundant T. V., Sept. 1-Apl. 22, some winter. Ossining, common T. V., Mch. 22-Apl. 13; Oct. 4-Dec. 3. N. Ohio, common T. V., Mch. 10-May 1; Oct. 1-Dec. 10, breeds occasionally. Glen Ellyn, April records only. SE. Minn., T. V.

Vest, on the ground, near grassy sloughs or marshy lake sides. Eggs, 6-10, olive-buff, $2 \cdot 54 \times 1 \cdot 71$. Date, Bering Is., June 6 .

This is one of our most common Bay Ducks. While with us it seems to prefer salt and brackish water. It feeds largely on mollusks, which it obtains by diving. "Ducks of this species utter a soft, purring whistle when excited or calling to their mates, and rarely the discordant note described by Sechohm as resembling the word scaup, screamed out in an exceptionally harsh voice. On two or three occasions I have heard a flock of Scaups gire utterance to these notes, and the effect was the loudest and most discordant chorus of bird-notes to which I ever listened, coming as it did from scores of voices over silent water." (Eaton.)

149. Marila affinis (Eyt.). LEsser SCAUP DCC'K. Ad. $\sigma^{\top}$.-Similar to precerding spereins lut smaller, head, as a rule, glossed with purplish instead of errernish, and flanks strongly instead of faintly markerl with wavy black loars. A1. . - cimilar to of the precerling species, hut smaller. o L., 16.50;

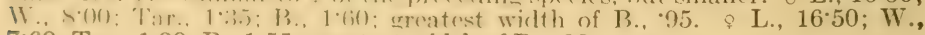
7.60; Tar., $1 \cdot 30$; B., 1.55; greatest width of B., 90

lirmorlis. - The (caup) Durkis resemble each other so closely that it is sometimes imposible to toll them apart, but they may generally be distinguished by the characters given above. 
Range.-N. Am. Breeds from the Yukon Valley, Alaska, and Fort Anderson, Mackenzie, s. to cen. B. C., s. Mont., Colo. (casually), n. Iowa, n. Ind., and w. Lake Erie; winters from s. B. C., Nev., Colo., Lake Erie, and N. J. s. to the Bahamas, Lesser Antilles, and Panama; rare in migration in N. F., N. B., and N. S.; accidental in Greenland and Bermuda.

Washington, not uncommon W. R., Sept. 25-May 30. Long Island, common T. V., Oct. 1-Apl. 28; a few winter. Ossining, common T. V., Jan. 28-Apl. 12; Aug. 31-Nov.* Cambridge, common in Oct. and Nov.; rare in spring. N. Ohio, common T. V., Mch. 15-May 10; Oct. 1-Dec. 1. Glen Ellyn, regular T. V., Mch. 10-Apl. 18; Oct. 23-Nov. 4. SE. Minn., T. V., Mch 9.

Nest, on the ground near grassy sloughs and marshy lake sides. Eggs, 6-11, "rich olive-buff," $2 \cdot 25 \times 1 \cdot 58$. Date, N. D., May 31 .

This species has much the same habits as the preceding, but is more southern in its distribution during the winter. It is by far the most abundant Duck in Florida waters at that season, where it occurs in enormous flocks in the rivers and bays along the coasts. When protected it soon becomes as tame as a domesticated Duck, but beyond the limits of protection at once exhibits its normal shyness. I have heard it utter a soft, purring note.

150. Marila collaris (Donov.). RING-NECKED DUCK. Ad. $\sigma^{7}$.-Chin white; head, neck, breast and upper back black, head with bluish reflections, neck with a not sharply defined chestnut collar; back and scapulars black, speculum gray; upper and under tail-coverts black, belly white, lower belly and sides finely harred with wavy black lines; bill black, base and a band across end bluish gray. Ad. ‥- Cpperparts fuscous-brown, more or less margined with ochraceous; speculum gray; sides of head and neck mixed grayish brown and white; breast, sides and lower belly grayish brown, more or less margined with ochraceous; upper belly white or whitish; bill blackish, an indistinet band of bluish gray across its end. L., 16.50; W., 7.50; Tar., $1 \cdot 25$; B., $1 \cdot 80$.

Remarks. - The male Ring-neck may be known from any of its allies by its chestnut collar and other excellent characters; the female resembles the female Redhead, but is smaller and generally browner.

Range.-N. A. Breeds from s. 13. (. to n. Calif., and from n. Alberta and Lake Winnipeg s. to N. D., n. Iowa., and s. Wisc.; wintrrs from s. B. C., N. M., n. Tex., s. Ills., and N. J. s. to Porto Rico and (illatemala; oreurs in migration n. to N. F., N. S., and (2ne.; recorded from Bcrmuda and England.

Washington, not rare, W. V., Oct. 6-M I h. 13. Long Island, two records Ossining, A. V., Apl. Cambridge, rare T. V. in fall. N. ()hio, not common T. V., Meh. 20-Apl. 15. Glen Ellyn, fairly common T. V., Mrch. 24-May 24; Oct. 12-Nov. 29. SE. Minn., common S., R., MIrh. 3-Noy. 30.

Nest, on the ground, near grassy sloughs or marshy lakesides. Eggs, $6-12$, similar in color to those of the two preceding species, $2 \cdot 28 \times 1 \cdot 63$ Date, SE. Minn., May 27.

This is more of a fresh-water bird than either of the preceding. It is not common in the Atlantic states north of Florida, where, during the winter, it is abundant on fresh-water lakes.

151. Clangula elangula americana Bonal). AMERICAN (')t,LN-EYE.

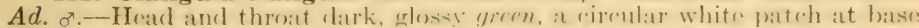
of bill measuring, akong hill, less than half an ineh in height: nerek all around,

*The presence or absence of Ducks in the winter depends upon whether the river is frozen or open. 
breast, belly, exposed part of wing-coverts, speculum, and most of the scapulars white; rest of plumage black. Ad. o.- Head and throat cinnamonbrown, foreneck white; upper breast, back, and sides ashy gray bordered with grayish; wing-coverts tipped with white; speculum, lower breast and belly white. L., $20^{\circ} 00 ;$ W., $9^{\circ} 00 ;$ B. from anterior margin of white patch to anterior margin of nostril, $1^{\circ} 00$; from anterior margin of nostril to tip, $\cdot 75$.

Range.-N. A. Breeds from cen. Alaska, n. Mackenzie, cen. Keewatin, n. Ungava, and N. F., s. to s. B. C., s. Mont., n. N. D., n. Mich., n. N. Y., and n. New England; winters from the Aleutian Islands, Utah, Nebr., Minn., Lake Erie, Maine, and N. B. s. to s. Calif., cen. Mex., and Fla.; occurs in Bermuda.

Washington, not rare, W. V., Oct. 8-Apl. 1. Long Island, common W. V., Dec. 5-Apl. Ossining, common T. V. and W. V., Nov.-May. Cambridge, rather common, T. V. and W. V., Nov. 15-Apl. 1. N. Ohio, not common T. V., Mch. 10-30; Oct. 5-Nov. 20. SE. Minn., uncommon T. V., Mch. 23.

Nest, in a stump or hollow tree. Eggs, 6-10, pale greenish, $2.35 \times 1 \cdot 75$. Date, Upton, Maine., May 10; Sweetwater Lake, N. D., May 14.

The rapidly moving wings of most Ducks make a whistling sound, but this species excels in wing music. As a diver it can also claim high rank. Brewster records a brood of young birds which, in response to the calls of their mother at the base of the nest-tree, jumped from the nest-opening to the water twelve feet below. (See his important paper, $A u k$, XVII, 1900, pp. 207-216.) "The note of the male Whistler is a single peep, accompanied by a kicking up of the feet, while the head is thrown far back toward the tail. The duck, when startled or lost, calls out a sharp cur-r-rew." (Eaton.)

1910. Townsend, C. W., Auk, XXVII, 177-181 (courtship).

152. Clangula islandica (Gmel.). BARROW's GoLdEN-EYE. Ad. o - Head and throat dark, glossy, purplish blue, an irregular, somewhat spreadwing-shaped white patch at the base of the bill measuring, along the bill, about one inch in height; neck all around, breast, belly, speculum, lesser wing-coverts, ends of greater ones, and the shaft part of the scapulars white; rest of plumage black. Ad. $\%$.- Resembles the $\%$ of the preceding species but has the bill shorter and more tapering, with more or less yellow instead of brown; brown of head and neck darker; ashy on chest broader and more pronounced; greater wing-coverts usually tipped with black. (W. Brewster, $A u k, 1909,158)$. W. $9 \cdot 25$; B., from anterior margin of white patch to anterior margin of nostril, ' 80 ; from anterior margin of nostril to tip, ${ }^{\bullet} 66$.

Range.-N. N. Am. Breeds from s. cen. Alaska and nw. Mackenzie to s. Ore., and s. Colo., and from n. Ungava to cen. Quebec; winters from se. Alaska, cen. Mont., the Great Lakes, and Gulf of St. Lawrence s. to cen. Calif., s. Colo., Nehr., and New England; accidental in Europe; breeds commonly in Iceland and is a rare visitor to Greenland.

Washington, A. V., one record. Long Island, one record. N. Ohio, casual T. V. SE. Minn., rare W. R.

Nest, in a stump or hollow tree. Eggs, 6-10, pale greenish, $2.40 \times 1 \cdot 70$. Date, Iceland, May 30; Flathead Valley, Mont., May 14.

A more northern species than the preceding, which it doubtless resembles in habits.

153. Charitonetta albeola (Linn.). Bufflehead. Ad. ơ-A broad white band passes aromul back of head from eye to eye; rest of head, upper nerk, and throat beantifully glossed with purple, greenish and bluish; lower nerk all around, breast, belly, winereoverts, speculum and outer scapulars white; back black: mp)er tail-eoverts and tail ashy grayish. Ad. $\%$. - A white patch on cither side of hoad, throat and entire upperparts fuscous- 
brown; speculum, breast and belly white. L., 14.75; W., 6.50; Tar., 1.25 B., $1^{\circ} 05$.

Range.-N. A. Breeds from the upper Yukon (rarely Yukon mouth), the lower Mackenzie, Great Slave Lake, and cen. Keewatin s. to B. C., n. Mont., and cen. Ont.; winters from the Aleutian Islands, B. C., Idaho, Colo., Mo., s. Mich., w. N. Y., and N. B. s. to n. L. Calif., cen. Mex. (Jalisco), and Fla.; recorded from Hawaii, Greenland, N. F., N. S., Bermuda, and Great Britain.

Washington, common W. V., Sept.-Apl. Long Island, rather common W. V., Dec. 8-Apl. 6. Ossining, tolerably common T. V. Cambridge, T. V. in autumn (W. V.?), Oct, 30-Nov. 15. N. Ohio, common, T. V., Mch. 25-May 1; Oct. 15-Nov. 30. Glen Ellyn, rare in April. SE. Minn., common T. V., Apl. 3.

Nest, in a stump or hollow tree. Eggs, 6-12, dull light buff, 1.98 $\times 1.46$ (Ridgw.). Date, Fort Simpson, Mack., May 25.

This small Duck has won deserved distinction through its powers as a diver. Like the Grebes, it "dives at the flash," though this wellworn expression has lost half its meaning since flintlocks and percussion caps have become things of the past. The Bufflehead feeds to some extent on small fish, which it pursues and catches under water.

154. Harelda hyemalis (Linn.). OLD SQUAw. Ad. o in winter.Sides of front of head washed with grayish brown; sides of back of head and sides of upper neck black, more or less margined with ochraceous; rest of head, neck all around, upper back, scapulars, and lower belly white; back, breast, and upper belly black; tail pointed, middle feathers very long and narrow; band across end of bill yellowish orange. Ad. $\sigma^{7}$ in summer.- Sides of the front of head white; rest of head, neck, throat, breast and upper belly black; back and scapulars black, the latter margined with dark buffy ochraceous; lower belly white; tail and bill as in preceding. \% in winter.-Upperparts black or fuscous; scapulars and upper back more or less margined with grayish or grayish brown; sides of head and neck and sometimes back of neck white or whitish; breast grayish; belly white; tail pointed, but without long feathers of male; under wing-coverts dark. Ad. o in summer.Generally similar to above, but sides of head and throat mostly blackish, and feathers of upperparts more or less margined with ochraceous. L., $\sigma$,

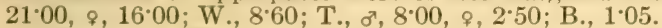

Remarks. - The male Old Squaw is too distinct to be confused with any other species, its long tail-feathers being its most striking character; the female bears some resemblance to the female of the Harlequin Duck, but has the belly pure white instead of grayish dusky.

Range.-N. Hemisphere. In N. A. breeds from islands of Bering Sea, Arctic coast of Alaska, Melville Island, Wellington Channel, Grinnell Land, and n. Greenland s. to Aleutian Islands, e. cen. Markenzie, n. Hudson Bay, and se. Ungava; winters from the Aleutian Islands s. regularly to Wash. rarely to San Diego Bay, Calif., and in s. Greenland, and from (iulf of St. Lawrence s. regularly to the Great Lakes and N. C., and rarely to Colo., Tex., La., and Fla.

Washington, rare W. V., Oct. 20-Apl. 20. Long Island, abundant W. V., Oct. 15-May 1. Ossining, tolerably common W. V., Dec. 4-Apl. 6. Cambridge, rather common in Oct. and Nov. N. Ohio, irregular W. V., Nov. 1-Apl. 16.

Nest, on the ground near water, under low bushes or tall grasses. Eggs, 6-12, pale bluish tinged with olive, $2 \cdot()_{5}^{5} \times 1.49$. Date, I)isen Bay, (ireenland, June 15.

In The Auk for 1892, pp. 330-337, ( account of the habits of this species in our waters. He speaks of them 
as the swiftest flying as well as the noisiest (in the spring) of all the sea-fowl which tarry with us, and gives their curious scolding or talking notes as o-onc-o-onc-ough, egh-ough-egh. Their flight is generally near the water, and when shot at while flying they sometimes dive from the wing. He also mentions their habit of towering, "usually in the afternoon, collecting in mild weather in large flocks if undisturbed, and going up in circles so high as to be scarcely discernible, often coming down with a rush and great velocity, a portion of the flock scattering and coming down in a zigzag course similar to the Scoters when whistled down."

155. Histrionicus histrionicus (Linn.). HARLeQUiN DUCK. Ad. $\sigma^{7}$. Center of the crown black, margined by white and rufous; front of sides of head, a spot on ear, a stripe back of it, and a collar around back and sides of neck white; rest of head and throat rich slaty blue; a band in front of the wing white, margined with black; inner scapulars white; back and breast bluish slate; belly fuscous; sides rufous-chestnut. Ad. o.--Front of head whitish; a white spot on ears; upperparts brownish fuscous; throat, breast and sides lighter; belly grayish brown, margined with whitish. L., 17'00: W., 7·80; Tar., $1 \cdot 50 ;$ B., 1.05.

Range.-N. N. Am., and E. Asia. Breeds from the Kowak and Yukon rivers, Alaska, Arctic coast, and Greenland s. to sw. B. C., cen. Mackenzie; n. Ungava, and N. F., and s. in the mts., to cen. Calif., sw. Colo., ne. Asia, and Iceland; occurs in summer in flocks near the Pribilof and Aleutian Islands and on the coast of Wash.; winters on the Pacific coast from the Aleutian Islands to Monterey, Calif., in the interior to Colo., Mo., Lake Michigan, and w. N. Y., and on the Atlantic coast from Gulf of St. Lawrence regularly to Maine, rarely to N. J., and accidentally to Fla.; accidental in Europe and not rare in Asia south to Japan.

Long Island, rare W. V.

Nest, near water, on the ground, "under rocks or driftwood," or in a hollow stump. Eggs, 6-8, yellowish buff or greenish yellow, 2"30 × 1.62 (Davie). Date, Holsteinborg, Greenland, June 24.

Unlike other members of this subfamily, this species passes the breeding season on rapid dashing streams, but during the winter it occurs as a Sea Duck off our more northern coasts.

1896. Norton, A. H., Auk, XIII, 229-234 (habits in Maine).

156. Camptorhynchus labradorius (Gmel.). LaBrador DUCK. Ad. 7.-Center of crown black; rest of head, throat and upper neck white; a black band around lower neck connected behind with the black back; primaries fuscous, rest of wing white; front and sides of upper breast white, lower breast and belly black. Ad. o.--Brownish gray, speculum white, Im. $0^{7}$ - - Like o, but with throat and ends of greater wing-coverts white. L., 20.00; W., 8*40; Tar., $1 \cdot 50 ;$ B., $1 \cdot 58$.

Range. - Formerly, n. Atlantic coasts of N. A.; supposed to have bred in Labrador; wintered from N. S. to N. J.; now extinct.

Nesting, unknown.

William Dutcher (1891) quotes the late George N. Lawrence, as follows: "I recollect that about forty or more years ago it was not unusual to see them in Fulton Market, and without doubt killed on Long Island; at one time I remember sering six fine males, which hung in the market until spoiled for want of a purchaser; they were not 
considered desirable for the table, and collectors had a sufficient number, at that time a pair being considered enough to represent a species in a collection."

The cause of this Duck's extinction is unknown. The last specimen, so far as known, was taken at Grand Menan in 1871. Forty-three specimens have been recorded as existing in collections.

1891. Dutcher, W., Auk, VIII, 201-216; 1894. XI, 4-12 (history).

Steller's Eider (15\%. Polysticta stelleri), a North Pacific species, is of accidental occurrence in Greenland and Quebec.

159. Somateria mollissima borealis (Brehm). NORTHERN EIDER. $A d$. o $^{7}$ - - Top of head black, a greenish white line on the crown; rest of head, throat, neck, upper breast, back, scapulars and lesser wing-coverts white, tinged with greenish on sides and back of head, and with vinaceous on breast; middle of rump, upper and under tail-coverts, lower breast and belly black. Ad. o. - Head, throat and neck buffy ochraceous, darker above and streaked with black; back black, feathers all widely margined, and sometimes partly barred with buffy ochraceous; breast buffy ochraceous, barred with black; belly grayish brown or olive-brown, indistinctly margined or barred with buffy. Im. - Similar, but distinctly marked with buffy. L., $23 \cdot 00$; W., $11 \cdot 00$; Tar., $1 \cdot 80 ;$ B., $2 \cdot 10$.

Range.-NE. N. Am. Breeds from Ellesmere Land and both coasts of Greenland s. to nw. Hudson Bay and s. Ungava; winters in s. Greenland and s. rarely to Mass.

Nest, on the ground, amid coarse herbage and rocks. Eggs, 5-8, pale bluish or greenish, tinged with olive, $2.95 \times 2.00$. Date, Shertook Is., Greenland, June 20.

This is the American representative of the Eider Duck of northern Europe, from which it differs only slightly. The highly prized Eider down is taken from the nest of this bird and its allies. As incubation progresses the sitting bird plucks the down from her breast to serve as a nest lining. In Iceland, according to Saunders, the average yield from each nest is about one-sixth of a pound. When the females begin to sit the males leave them, and, gathering in small flocks, live at sea.

160. Somateria dresseri Sharpe. American Eider. Resembles the preceding in color, but differs in the feathering of the base of the culmen. In both species the culmen is divided by a wedge of feathers reaching forward from the forehead. Looked at from the tip of the bill, the base of the culmen is thus $V$-shaped. In dresseri the arms of the $V$ are very broid and rounded at the ends, while in borculis they are much narrower and generally pointed at the ends. L., 23*00; W., 11*30; Tar., 1·70; B., 2*10.

Range.-NE. N. Am. Breeds from s. Ungava and N. F., to se. Maine, and on the s. half of Hudson Bay; winters from N. F., and (iulf of St. Lawrence s. on Atlantic roast, regularly to Mass., rarely to Va., and in interior rarely to Colo., Iowa, Wisc., Ohio, and w. N. Y.

Long Island, rare W. V. Ossining, A. V., Dec.

Nest, on the ground, generally sheltered by rocks. Eggs, 5-8, pale bluish or greenish, tinged with olive, $3 \cdot 00 \times 2 \cdot 00$. Date, Labrador, June 5.

This species nests from the coast of Maine northward, and is therefore a species of more southern distribution than the preceding, which it resembles in habits. During their visits to the coasts of the United States the Eiders are true Sea Ducks, living some distance off shore, 
generally over a bed of mussels, which they secure by diving, and which constitute their chief fooc.

1890. MackaY, G. H., Auk, VII, 315-319 (habits in Mass.). 1910. Townsend, C. W., Auk, XXVII, 177-181 (courtship).

162. Somateria spectabilis (Linn.). KING EIDER. Ad. o.-Region about base of upper mandible and a large $V$-shaped mark on throat black; top of head bluish gray; cheeks greenish; neck all around white; front and sides of breast creamy buff; upper back, sides of rump, and wing-coverts white; rest of plumage black. Ad. $\%$.- Head and throat buffy ochraceous, the former streaked with black; back black, the feathers widely margined with ochraceous or rufous; underparts varying from brownish gray to fuscous, more or less washed, especially on breast, with ochraceous or rufous. Im.-Paler and with less ochraceous. L., 23.00; W., 10.80; Tar., 1.80; B., $1: 30$.

Remarks.-The adult male of this species may at once be known by its bluish gray head and the V-shaped mark on its throat. Females and young birds resemble those of the two preceding species, but are to be distinguished by the generally unstreaked throat and the feathering of the side of the base of the bill, which in this species does not, as in the two preceding, reach to the nostril.

Range.-N. part of N. Hemisphere. Breeds along the whole coast of $\mathrm{n}$. Siberia, Bering Sea (St. Lawrence Island), and Arctic coast of Am. from Icy Cape e. to Melville Island, Wellington Channel, n. Greenland, nw. Hudson Bay, and $\mathrm{n}$. Ungava; winters on Pacific coast from Aleutian Islands to Kadiak Island, in the interior rarely to the Great Lakes, and from s. Greenland and Gulf of St. Lawrence s. regularly to Long Island, rarely to Ga.; accidental in Calif. and Iowa.

Long Island, rare but regular W. V., Nov. 13-Apl. 21. Cambridge, casual in early winter.

Nest, on the ground, among rocks or herbage. Eggs, 6-10, light olivegray to grayish green, $3.12 \times 1.92$ (Davie). Date, Pt. Barrow, Alaska, June 25.

While in our waters this species does not differ from the preceding in habits.

163. Oidemia americana Swains. AMERICAN SCOTER. Ad. $\sigma^{x}-$ Entire plumage black, feathers on side of bill extending little if any forward beyond corner of mouth; bill black; upper mandible orange or yellowish at the base. Ad. o and Im.-Above chest and sides grayish brown; cheeks whitish, sharply defined from crown; belly whitish faintly barred with dusky. L., 19.00; W., 9*00; Tar., 1*70; B. along culmen, 1*75; B. along side, $1 \cdot 85$.

Range.-N. N. Am. and E. Asia. Breeds in ne. Asia and Kotzebue Sound to Aleutian Islands, including Near Islands; also on w. shore of Hudson Bay, Ungava, and N. F.; winters on Asiatic coast to Japan and from islands of Bering Sea s. rarely to Santa Catalina Island, Calif.; in the interior not rare on the Great Lakes, and casual or accidental in Mo., La., Nebr., Colo., and Wyo.; on the Atlantic coast abundant during migration from N. F., and Maine, s. (rarely to Fla.).

Washington, casual W. V. Long Island, common W. V., Oct. through Apl. Ossining, rare T. V., Oct. Cambridge, occasional in fall.

Nest, on the ground, near water. Eggs, "6-10, pale dull buff or pale brownish buff, $2.55 \times 1.80$ " (Ridgw.). Date, Cape Lisburne, Alaska, June 15 .

All three species of Surf Scoters, or "Coots," are abundant winter residents off the coasts of the New England and Middle States. At this time their habits are practically alike-indeed, they are often found 
associated. As a rule, they frequent only the sea and its estuaries, where they live over beds of mussels, clams, or scallops, which they obtain by diving; but they are sometimes found in ponds near the coast where food of this nature is abundant.

The flight of the Surf Scoter "is marked by a shrill whistling, and when the birds are in large numbers this sound is heard a long distance off." (Sanford.)

1891. MACKAY, G. H., Auk, VIII, 279-290; IX, 292-294 (habits in Mass.).

The Velvet Scoter (164. Oidemia fusca), an Old World species, has been recorded from Greenland.

165. Oidemia deglandi Bonap. White-WINGed Scoter. Ad. $\sigma^{x}$.A spot below eye and speculum white, rest of plumage black; bill orange, black at base, the feathers on it reaching forward far beyond corners of mouth. Ad. o and Im. o.-Grayish or fuscous-brown, lighter below; speculum white, feathers at base of upper bill and a spot on the ears whitish. L., $22^{\circ} 00$; W., $11^{\circ} 00$; Tar., 2.00; B. along culmen, 1.50 ; B. along side, 1.55 .

Remarks.-The white speculum and feathering of the bill will always serve to distinguish this species from its allies.

Range.-N. A. Breeds from the coast of ne. Siberia, n. Alaska, n. Mackenzie, and n. Ungava s. to cen. B. C., Alberta, n. N. D., and s. Que.; winters on the Asiatic coast to Bering I., Japan, and China, and in N. A., from Unalaska Island to San Quintin Bay, L. Calif., the Great Lakes (casually to Colo., Nebr., and La.), and the Atlantic coast from the Gulf of St. Lawrence s. (rarely) to Fla.; non-breeding birds occur in summer as far s. as R. I., and Monterey, Calif.

Washington, casual W. V., Oct.-Apl. Long Island, common W. V., Oct. 15-A pl. 13. Ossining, tolerably common T. V. Cambridge, occasional in fall. SE. Minn., casual W. R.

Nest, on the ground, beneath bushes, or in high growth. Eggs, "6-14, pale dull buff, varying to cream-color, $2.68 \times 1.83$ "' (Ridgw.). Date, N. D., June 20.

166. Oidemia perspicillata (Linn.). SURF Scoter. Ad. o.-A square mark on crown and a triangular one on nape white, rest of plumage black; bill with white, red and ycllow, a black spot on its side at base; feathers on culmen extending nearly to a level with nostril, feathers on side of bill not extending forward. Ad. $\%$. and $I m$. - A whitish spot at base of the bill and on ears; upperparts fuscous-brown; throat, breast, sides and lower belly grayer, belly white. L., 20*00; W., 9*30; Tar., 1*60; B. along culmen, $1.55 ; \mathrm{B}$. along side $2: 30$.

Remarks. - The forward extension of the feathers on the culmen will always distinguish this species from $O$. americana, while it may be known from deglandi by the absence of white in the wings.

Range.-N. A. Breeds on the Pacific roast from Kotzebue Sound to Sitka, and from nw. Mackenzie: and Hudson Strait to (ireat Slave Lake, cen. Keewatin, and n. Quchee; non-breceling birds oceur in summer in ne. Siberia and s. on the Pacific (roast to L. ("alif., and in (ireonland and s. on the Atlantic coast to L. I.; winters on the Parific coast from the Aleutian Islands s. to San Quintin Bay, L. Calif., on the (ireat Lakes, and s. casually to Colo., Kans., Iowa, Ills., and La.; and on the Atlantic coast from N. S. to N. C., rarely to Fla.; casual in Bermuda; frequent in Europe.

Washington, casual W. V. until Apl. Long Island, common W. V., Sept. 1-Apl. 13. Ossining, common T. V., Oct. 7-()ct. 22. ('ambridge, occasional in fall. 
Nest, in tall grasses near water. Eggs, "5-8, pale buff or pale creamy buff, $2.47 \times 1 \cdot 70$ " (Ridgw.). Date, Fort Anderson, Mack., June 25.

167. Erismatura jamaicensis (Gmel.). RUDDy DUCK. Ad. $\sigma^{7}$ - -Top of head black, cheeks and chin white, throat and back rufous-chestnut, lower back blackish; breast and belly silvery white; upper tail-coverts very short, tail-feathers stiff and pointed; bill blue. Ad. $q$ and Im.-Upperparts dark grayish brown, the feathers marked with fine wavy bars of buffy; sides of head and upper throat whitish, lower throat grayish, rest of underparts silvery white. L., $15^{\circ} 00$; W., $5 \cdot 90$; Tar., $1 \cdot 15$; B., $1 \cdot 55$.

Remarks. - The short upper tail-coverts and stiff, pointed tail-feathers will always serve to identify this species.

Range.-N. A. Breeds from cen. B. C., Great Slave Lake, s. Keewatin, and n. Ungava s. to n. L. Calif., cen. Ariz., n. N. Mex., nw. Nebr., s. Minn., s. Mich., s. Ont., and Maine, and rarely and locally in s. L. Calif., Kans., Mass., Valley of Mex., Lake Dueñas, Guatemala, and in Cuba, Porto Rico, and Carriacou; winters from s. B. C., Ariz., N. Mex., s. Ills., Maine, Pa. and s. to the Lesser Antilles and Costa Rica; rare in migration to N. F. and Bermuda.

Washington, common W. V., Aug. 20-June 21. Long Island, irregular T. V. and W. V., Oct. 17-May 22. Ossining, common T. V., Mch. 14-Apl. 6; Oct. 5-Oct. 28. Cambridge, formerly very common in fall; Oct. 10-Nov. 8 . N. Ohio, common T. V., Apl. 1-May 15; Oct. 10-Nov. 20. Glen Ellyn, rare T. V., Mch. 21-May 21. SE. Minn., T. V., and uncommon S. R., Apl. 14.

Nest, of reeds, in reeds over water. Eggs, 6-10, white, $2.50 \times 1.80$. Date, N. D., June 10.

This plump little Duck swims jauntily with upturned tail. When pursued it dives, unless too hard pressed, and then, after pattering over the water, it takes to the air, with rapidly whirring wings and low, straight flight which suggests that of a great bumblebee. The male, in breeding plumage, is unmistakable and its bright, sky-blue bill is distinguishable from a distance.

The MASKED DUCK (168. Nomonyx dominicus) is a tropical species rare north of the Rio Grande. Single specimens have been taken in Wisconsin, Massachusetts, Vermont, and Maryland.

\section{ふubfamily Anserince. Geese.}

Excluding the members of the subfamilies Anseranatina and Plectropterince we have left the true Geese, numbering twenty-five species, which are included in the present subfamily. With Geese the sexes are alike in color. The male is the larger and he takes part in incubation and in the care of the young.

Geese are vegetarians. When on the water, they feed largely by tipping, as with head and neck immersed and tail pointing skyward, they search for the roots or seeds of aquatic plants. They are far more terrestrial than Ducks, and visit the land to nip the herbage, young corn, or ecreals. When wounded, they dive readily and, with their body just below the surface of the water and only the bill exposed, hearl for the shore, where they attempt to hide in the vegetation. In migrating, the flock is formed in a V-shaped wedge, the lead, it is said, being taken by an old gander. 
I. Whole head or forehead white.

A. Bill yellowish.

a. Forehead and feathers at the base of bill white.

171a. White-Fronted Goose (Ad.).

b. Head and neck white or grayish, sometimes tinged with rusty.

$b^{1}$. Primaries black, rest of plumage white.

169. Lesser Snow Goose. 169a. Greater Snow Goose.

$b^{2}$. Back grayish brown, rump and belly whitish, wing-coverts and tertials widely margined with white. 169. LESSER SNOw Goose (Im.). 169a. Greater Snow Goose (Im.).

$b^{3}$. Back grayish brown, rump, belly and wing-coverts gray, the latter not conspicuously margined with white.

169.1. Blue Goose(Ad.).

$B$. Bill black, throat and sides of the head white, lores black.

175. Barnacle Goose.

II. Head or forehead not white.

1. Head and neck brown, bill yellow or yellowish.

A. Nail of bill black, rump fuscous.

171a. White-Fronted Goose (Im.).

B. Nail of bill yellow, rump gray . . . 169.1. Blue Goose (Im.).

2. Head black or brownish black, bill black.

A. Throat white . 172. Canada Goose. 172a. Hutchins's Goose.

B. Throat black or brownish black, neck speckled with white.

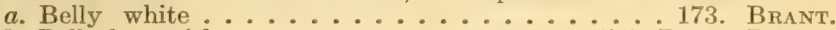

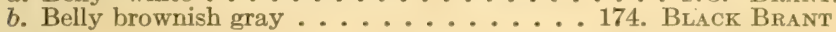

169. Chen hyperboreus hyperboreus (Pall.). Lesser SNow Goose. Ads.-Entire plumage, except primaries with their coverts, white; primaries black, their bases and coverts ashy. Im.- "Head, neck and upperpurts pale grayish, the feathers of the latter with whitish edges and (especially wing-coverts and tertials) striped medially with darker; rump, up)er tailcoverts, tail and lower parts plain white. L., 2:3*00-28.00; W., 14.50-17.00; B., 1*95-2:30; Tar., 2.80-3*25"' (Ridgw.).

Range.-N. A. Breeds from mouth of the Mackenzie e. probally to Coronation Gulf and Melville Island; oreurs on the Aretic coast of ne. Asia, but not known to breed there; winters from s. 13. C., s. Colo., and s. Ills. s. to n. L. Calif., cen Mex. (Jaliseo), Tex., and La., and on the Asiatic coast s. to Japan; generally rare in e. U. S.

SE. Minn., T. V.

Eggs, uniform dirty, chalky white, $3.40 \times 2.20$ (B., B., and R.). Date, Pt. Barrow, Alaska, June 18.

169a. C. h. nivalis (Forst.). Greater Snow Goose. Resembles the preceding in color, but is larger. L., $3(0 \cdot 0)\left(0-38^{\circ}(0)\right.$; W. $17 \cdot 3 \cdot 5-17 \cdot 5() ; 13 ., 2 \cdot 5.5-$ $2 \cdot 70$; Tar., 3·15-3.50 (Ridgw.).

Range.-E. N. Am. Has been found breeding at Whale Sound, n. Greenland, and Ellesmere Land; full breeding range not known; winters froms. Ills., Chesapeake Bay, and Mass. (rarely) s. to Lat., Flat., and Wot Indiesto) Porto Rioro; in migration rarely w. to ('olo., and e. to New Enerland and N. F.

Long Island, rare T. V., in fall, ()et.X-Jan. 30). ()ssinine, . . V., Apl.

Nesting date, Admiralty Bay, Alaska, June 17, 1898 (Norris); Mackonzic: Bay, June 15 (Thayer Coll.).

The Snow Goose does not appear to be a eommon birel on any part of the Atlantic coast. It migrates both by night and $1: 1 y$, and when on the wing its white plumage and black-tipped primarios ronder it easily identifiable. It is a noisior hird than the Cantuda Ciocse, and its voice is higher and more cackling. 
169.1. Chen crerulescens (Linn.). BLut Goose. Ads.-Head and upper neck white; middle of hindneck sometimes blackish, lower neck all around fuscous, rest of underparts brownish gray edged with buffy; lower belly generally paler, sometimes white; upper back and scapulars like breast; lower back, rump and upper tail-coverts gray; tail fuscous-gray edged with whitish; wing-coverts like the rump or slightly darker, with little or no whitish margins; wing-quills and tertials fuscous, the latter more or less margined with whitish. Im.- "Similar to adult, but head and neck uniform deep grayish brown, only the chin being white. L., $26^{\circ} 50-30^{\circ} 00$; W., $15^{\circ} 00$ 17'00; B., 2'10-2*30; Tar., 3*00-3*30' (Ridgw.).

Range.-E. N. Am. Breeding range unknown, but probably interior of $\mathrm{n}$. Ungava; winters from Nebr. and s. Ills. s. to coasts of Tex. and La.; rare or casual in migration in Calif., and from N. H. to Fla., Cuba, and the Bahamas.

Long Island, one record. N. Ohio, casual T. V.

Nest, in a depression on dried grass. Eggs, 4, "brownish buff, $2.50 \times$ 1.75" (Reed). Date, Cape Bathurst, June 29 (Thayer Coll.).

The fact that the summer home of the Blue Goose is in the far north while its winter range is remarkably restricted, has brought the bird to the attention of comparatively few ornithologists. In consequence it has until recently been considered a rare species. During the winter of 1910 , however, it was found in flocks of thousands at the delta of the Mississippi River by Job and by McAtee ( $A u k, 1910$, p. 337). Here they were doing great damage to pasture lands, through their destruction of various grasses.

171a. Anser albifrons gambeli $H a r t l$. White-Fronted Goose. Ads. -Forehead and region bordering base of bill white; upperparts and foreneck grayish brown, more or less margined on back with lighter; longer and lateral upper tail-coverts white; breast somewhat lighter than throat, more or less irregularly marked with black, and fading gradually into pure white on lower belly; sides like back. Im.- Similar, but no white at base of bill or black marks on breast; nail of the bill black. "L., $27^{\circ} 00-30$ "00; W., $14 \cdot 25-17 \cdot 50$; B., $1.80-2 \cdot 35$; depth of mandible at base, $90-1 \cdot 20$; width, .85-1.05; Tar., 2*60-3.20"'(Ridgw.).

Range.-Cen. and w. N. A. Breeds on and near the Arctic coast from ne. Siberia e. to ne. Mackenzie and s. to lower Yukon Valley; winters commonly from s. B. C. to s. L. Calif., and Jalisco, and rarely from s. Ills., s. Ohio, and N. J. s. to ne. Mex., s. Tex., and Cuba, and on the Asiatic coast to China and Japan; rare in migration on the Atlantic coast $\mathrm{n}$. to Ungava.

Long Island, rare T. V. Glen Ellyn, rare T. V., Mch. and Oct. SE. Minn., T. V., Apl. 1.

Nest, on the ground, of grasses lined with down. Eggs, 6-7, dull greenish ycllow with obscure darker tints, 3.10 × 2.07 (Davie). Date, Pt. Barrow, Alaska, June 19.

"These birds are rarely met with on the Atlantic coast, but are quite common in the Misissippi Valley and abundant on the Pacific slojee. They prefer low, wet grounds in the vicinity of timber, or where the prairic is dotted here and there with bushes; and, while they occasionally forage off the wheat fields and other grains on the bottom lands, they seldom visit the high, dry prairies like the Snow and Canada Geese." (Goss.)

The Furopenn Winte-Fronted Goose (171. Anser albifrons albifrons) resembles its American representative in color, but averages smaller. It is of doubtful record from Eastern Greenland. 
The Bean Goose (171.1 Anser fabalis) and the Pink-footed Goose (171.2 Anser brachyrhynchus), Old World species, have been recorded from Greenland.

172. Branta canadensis canadensis (Linn.). CANADA Goose. Ads. -Throat and a large patch on side of head behind eye white or whitish; chin and rest of head and neck black; back and wings grayish brown, more or less edged with lighter; tail and shorter upper tail-coverts black, longer and lateral ones white; breast and belly grayish, fading to white on lower belly; sides like back. Im.-Similar, but throat and cheeks sometimes mixed with blackish. "L., 35.00-43*00; W., 15.60-21.00; Tar., 2*45-3.70; B., 1.55-2:70" (Ridgw.).

Range.-N. A. Breeds from limit of trees in valley of the lower Yukon, nw. Mackenzie, and cen. Keewatin s. to s. Ore., n. Colo., Nebr., and Ind.; formerly bred casually s. to N. M., Kans., Tenn., and Mass.; winters from s. B. C., s. Colo., s. Wisc., s. Ills., and N. J. (rarely s. Ont. and N. F.), s. to s. Calif., Tex., and Fla.; accidental in Bermuda and Jamaica.

Washington, W. V. and rather common T. V., Oct.-Apl. Long Island., common T. V., Feb. 27-Apl. 28; Oct. 1-Dec. 31; some W. V. Ossining, tolerably common T. V., Mch. 11-May 21; Oct. Cambridge, not uncommon T. V., Mch.-Apl.; Nov. 1-30. N. Ohio, not common T. V., Mch. 1-30. Glen Ellyn, W. V., quite common in spring, Oct. 17-May 5. SE. Minn., T. V., Feb. 10 .

Nest, on the ground, often on an island, of twigs, grasses, or reeds and large quantity of down. Eggs, 4-7, white. Date, Kossuth Co., Iowa, May 7, 1883; Grant Co., Minn., Apl. 29, 1876.

Probably the migration of no bird attracts more universal interest than that of the Wild Goose. Ornithologists talk of "waves" and "flights" of migrants passing in the night, but the semiannual pilgrimage of the Canada Goose appeals to us all with the directness of a personal experience. We see the living wedge of long-necked birds passing high overhead; the unbroken sound-waves bring the sonorous "honks" with unexpected distinctness to our ears; and we receive an impressive lesson in the migration of birds. They are embarked on a journey of several thousand miles, but they come and go as surely as though they carried chart and compass.

1910. Phillips, J. C., Auk, XXVII, 263-271; XXVIII, 319-323 (migration in Mass.).

172a. B. c. hutchinsi (Rich.). Hutchrns's Goose. Resembles the precerling in color, but averages smaller. L., $25^{\circ} 00-34^{\circ} 00$; W., 14.7517'75; Tar., $2 \cdot 25-3 \cdot 20$; B., $1 \cdot 20-1 \cdot 90$ (Ridgw.).

Range.-W. N. Am. Breeds from Kowak Valley, Alaska, and from mouth of Mackenzie e. along Arctic: shores and islands from lat. $70^{\circ} \mathrm{s}$. to Melville Peninsula and nw. Hudlson Bay; winters from B. C., Nev., (oolo., and Mo., s. to San Rafael in L. ("alif., Tex., and La.; accidental in Vera Cruz; in migration rare e. of the Miss. Valley but recorded on the Atlantic coast from Maine to Va.

Long Island, A. V.

172c. B. c. minima Ridgw. Cackrrng Goose. To be distinguished from the two preceding by its smaller size and the much darker brownish gray color of the breast and upper belly. "W., 13.60-14.50; Tar., 2.40-2.75; B., '95-1.15"' (Ridgw.).

Range.-W. N. Am. Breeds in w. Aleutians and from Norton Sound s. to $\mathrm{n}$. coast of Alaska Peninsula; winters from B. C. s. to San Diego Co., Calif.; casual e. to Colo., Iowa, Wisc., and Ills. 
173. Branta bernicla glaucogastra $($ Brehm). Brant. Ads.-Head, neck, throat and upper breast black; sides of the neck speckled with white; back brownish gray, margined with grayish brown; longer and lateral upper tail-coverts white; lower breast ashy gray fading to white on lower belly; sides darker. Im.- Similar, but with less white on sides of neck and wingcoverts, and secondaries tipped with white. L., 26.00; W., 13•20; Tar., 2*20; B., $1: 35$.

Range.-N. Hemisphere. Breeds on Arctic islands n. of lat. $74^{\circ}$ and w. to about long. $100^{\circ}$, and on the whole w. coast of Greenland; winters on the Atlantic coast from Mass. s. to N. C., rarely to Fla., has been recorded in the interior from Man., Ont., Colo., Nebr., Wisc., Mich., Ind., and La.; accidental in B. C. and Barbados.

Washington, rare W. V. Long Island, common T. V., Nov. 18-Jan. 8; Mch. 6-May 10; a few winter. Ossining, A. V.

Nest, of grasses, moss, etc., lined with down, on the ground. Eggs, 4, smooth and creamy white in color, $2.70 \times 1.80$ (Saunders). Date, Buchanan Bay, Ellesmere Land, June 17 (Thayer Coll.).

"Its manner of flying is different from that of the Canada Goosemoving in more compact bodies, less rapidly, and without seeming to have a chosen leader-that marked characteristic in the flight of the latter.

"While in our bays it appears inactive, seldom taking to wing unless disturbed by a passing boat or the near report of a gun.

"The Brant rises slowly, and when on the wing moves sluggishly for a short distance, and, if not attracted by a distant flock, frequently returns to the place it had left. Its food consists of a marine plant (Zostera marina), commonly called 'eel grass.' At low water it is seen industriously at work tearing up its favorite plant. After the tide has risen to such a height as to compel it to relinquish its vocation, it is seen drifting with the current, feeding sumptuously on the fruits of its labor." (Giraud.)

174. Branta nigricans (Lawr.). BLACK BRANT. Bears a general resemblance to the preceding species, but may be readily distinguished by its much darker lower breast and upper belly, which are nearly as dark as the back, and by having white markings on the front as well as on the sides of the neck.

Range.-W. N. Am. Breeds on the Arctic coast and islands from Pt. Barrow e. to near mouth of Anderson River, n. probably to Melville Island; common on Siberian coast, Chukchi Peninsula, and w. to New Siberian Islands; winters on the Pacific coast from B. C. s. to San Quintin Bay, L. Calif., in the interior of Ore., and Nev., and on the Asiatic coast s. to Japan; recorded as a straggler to Mass., N. Ý., and N. J.

Long Island, A. V.

Nest, of grasses, moss, etc., lined with down, on the ground. Eggs, 5-7, dull ivory-white or grayish white, $2.85 \times 1.82$ (B., B., and R.). Date, Admiralty Bay, Alaska, June 19.

This is the western representative of the preceding species. It is of casual oceurrence on the Atlantic coast, about a dozen birds having been recorded from between Massachusetts and New Jersey.

1910. Fay, S. P., Auk, XXVII, 336.

The IBarnacle Goose (175. Branta leucopsis) is an Old World species which visits (ircenlatud regularly in the fall, and is sometimes found on our 
coasts. It differs from any of the preceding in having the forehead, sides of the head, throat and chin white, the lores being black.

The Fulvous TREe-DCCK (178. Dendrocygna bicolor) of the Southwestern United States and southward, is accidental in North Carolina.

\section{Subfamily Cygnina. Swans.}

A group containing eight species distributed throughout the world. Swans feed from the surface, either by 'tipping' or by simply immersing the long neck and head. Their food consists largely of vegetable matter, but they eat also small mollusks. They migrate in V-shaped flocks. When on the wing, and also when feeding, they utter at times loud, trumpeting notes. When pursued, they do not at once take flight, but swim rapidly away, and in this manner easily distance a strong rower. The sexes are alike in color and both share in the task of incubation and care of the young.

\section{KEY TO THE SPECIES}

$A$. With yellow on the lores; distance from the eye to the nostril greater than the distance from the nostril to the tip of the bill.

180. Whistling Swan. B. No yellow on the lores; distance from the eye to the nostril not greater than from the nostril to the end of the bill . . 181. Trumpeter Swan.

180. Olor columbianus (Ord). Whistling Swan. Ads.-White; bill and feet black; a small ycllow spot on the lores; tail usually with but 20 feathers. Im.- Head and neck brownish and rest of plumage more or less washed with grayish; bill and feet light. L., 55.00; W., 22*00; Tar., 4*00; Eye to N., $2 \cdot 40 ;$ N. to tip of B., $2 \cdot 25$.

Remarks.- Few unquestionably distinct species of birds resemble each other more closely, superficially, than do the Whistling and Trumpeter Swans. In freshly killed specimens, at least in the spring, the yellow on the bill of the former and red on the bill of the latter is wholly and sufficiently diagnostic. Lacking these characters, which are always wanting in old, dried skins, the birds can be distinguished by the larger size of buccinator in connection with the fact that its mostrils are nearer the center of the bill than in columbianus (which has them nearer the tip)) while buccinator usually has 24 , instead of the 20 tail-feathers of columbianus.

Range.-N. A. Breeds from n. Alaskat s. to Becharof Lake, Alaska Peninsula, and on Arctic islands from about lit. $74^{\circ} \mathrm{s}$. to n. Mackenzie and nw. Hudson Bay; in migration oceurs w. to Bering Islands; winters on the Pacific coast from s. B. C., rarcly s. to s. Calif., and in the interior from Lake Erie and s. Ills. to coast of La. and Tex., and on Atlantic coast from Del. and Md. to S. C., rarely n. to Mass., and s. to Fla.; casual in n. Mex.; accidental in Scotland and Bermuda.

Washington, rare W. V., ()ct. 15-Mch. 25. Long Island, rare T. V. Cambridge, A. V. in fall. N. Ohio, occusional T. V., Mrh., carly Apl. SE. Minn., T. V., Apl. 12.

Nest, of grasses, moss, ete., lined with down, on the ground near water Eggs, 2-5, soiled whitish, 4"25 $\times 2 \cdot 70$. Irate, Nt. Michacl's, Alaska, May 29.

This is a rare bird on the Atlantic coast north of Virginia. In the Currituck region, thanks to its excessive wariness, it is not uncommon in winter. "When feeling, or dressing thrir plumage, this Swan is usually very noisy, and at night their clamors may be heard to the 
distance of several miles. Their notes are varied, some resembling the lower ones made by the common tin horn, others running through the various modulations of the notes of the clarionet. These differences are presumed to be dependent upon age.". (B., B., and R.)

181. Olor buccinator (Rich.). Trumpeter Swan. Ads.-White, bill and feet black, no yellow on the lores; cutting edge of the lower mandible, at least in spring, reddish; tail usually with 24 feathers $I m$.- Head and neck brownish, rest of plumage more or less washed with grayish. L., $65^{\circ} 00$; W., $23^{\cdot} 00$; Tar., $4 \cdot 25$; Eye to N., $2 \cdot 70$; N. to tip of B., $2 \cdot 20$.

Range.-Interior and w. N. A. Breeds from the Rocky Mountains to w. shore of Hudson Bay and from the Arctic Ocean to about lat. $60^{\circ}$; formerly bred s. to Ind., Mo., Nebr., Mont., and Idaho, and casually w. to Fort Yukon and B. C.; winters from s. Ind. and s. Ills. s. to Tex., and from s. B. C. to s. Calif.; casual in migration in the Rocky Mt. region of U. S.; accidental in N. Y. and Del. Now of rare occurrence nearly everywhere.

Nest, of grasses and down, on the ground. Eggs, 2-6, soiled whitish, $4.40 \times 2 \cdot 80$. Date, Mackenzie Bay, June 17, 1900 (Thayer Coll.).

The Trumpeter Swan is now one of the rarest of American birds. I know of no recent records of its capture. Heard in captivity, its call has more of a clarion tone than that of the Whistling Swan.

The Whooping Swan (179. Olor cygnus) is an Old World species which sometimes is found in Greenland. It differs from either of our Swans in having the "basal portion of the bill and entire lores yellow in the adult."

\section{ORDER ODONTOGLOSSE. LAMELLIROSTRAL GRALLA- TORES}

\section{Family Phenicopterid ex. Flamingoes. (Fig. 35.)}

The six species included in this family are distributed throughout the tropics. Four species are American, of which one reaches southern Florida in winter. Flamingoes are gregarious at all seasons. Their favorite resorts are shallow bays and lakes or vast mud flats which are flooded at high water. In feeding, the bill is pressed downward into the mud, its peculiar shape making the point then turn upward. The ridges along its sides, as in the bills of Ducks, serve as strainers through which are forced the sand and mud taken in with the food. The wingquills are molted simultaneously, as with the Anatido, indicating relationship with that family.

182. Phonicopterus ruber (Linn.). Flamingo. (Figs. 17, 35.) $A d s$. -Beautiful rosy vermilion, scapulars and underparts somewhat paler; flanks carmine; primaries and secondaries black; bill red-tinged at base, black at the tip. Im.-A bove brownish gray, back with black shaft-streaks, scapulars basally pink-tinged; wing-quills black, primary and under wingcoverts pinkish; below paler than above fading to whitish, pink-tinged on the belly. L., $45^{\circ} 00$; W., 16.25; Tar, $12 \cdot 50 ;$ B., $5 \cdot 50$.

Range.-Atlantic coast of subtropical and tropical Am., from the Bahamas, and Yucatan to Brazil, and in the Galapagos; extremity of Fla. in winter; accidental in S. C. 
Nest, in colonies on mud flats, a truncate cone of mud 8-14 inches in height, hollowed on top. Egg, 1, whitish with a chalky deposit, $3.55 \times 2.20$. Date, Andros Is., Bahamas, May 5.

The Flamingo was formerly a regular winter visitant to the vast shoals at the extremity of Florida, but it is now of rare occurrence there. (Scott, Auk, VII, pp. 221-226; Ingraham, World's Congress in Orn., pp. 59-69.) There are probably two large breeding colonies on Andros Island, Bahamas. The nests are placed within a few feet of each other, 2,000 being counted in a space one hundred and thirty yards long. Both sexes incubate. The period of incubation is about four weeks. The young are hatched covered with down and leave the nest when two or three days old. They are fed by regurgitation on the partially digested juices of a small mollusk of the genus Cerithium, which forms apparently the only food of the adult. The note of the young is a shrill whistling, that of the adult a goose-like honking. In flight the neck is fully extended.

1902. Chapman, F. M., Bird-Lore, IV, 177-181. 1908. Camps and Cruises, 155-191 (nesting habits).

VII. ORDER HERODIONES. HERONS, STORKS, IBISES, ETC.

17. Family Plataleide. Spoonbills. (Fig. 38.)

The Spoonbills inhabit the warmer parts of the world. Only one of the six species is found in America. They frequent the shores both on the seacoast and in the interior. They are generally found in flocks and they nest in colonies. Spoonbills have the general habits of Ibises, but feed by immersing the bill and swinging it from side to side in their search for food. They fly with the neck fully extended, and with steady, uninterrupted wing-stroke.

183. Ajaia ajaja (Linn.). Roseate Spoonbill. (Fig. 38.) Ads.Head and throat bare, neck and upper back white, sometimes tinged with pink; sides of breast in front of the wings and end half of tail ochraceousbuff; rest of plumage pink; lengthened feathers at the base of the neck darker; lesser wing-coverts, upper and under tail-coverts carmine. Im.-Similar, but head and throat feathered, ochraceous-buff and carmine of the adult replaced by pink. L., 32*00; W., 14.50; Tar., 4*00; B., 6*25.

Range.-N. and S. A., from Tex., Lat., Fla., and Ga. s. to Patagonia and the Falkland Islands; formerly casual north to P'at. and the lower Ohio Valley (Ind. and Ills.); accidental in ('alif., Colo., Kans., and Wisc.

Nest, in colonies, a platform of sticks in small trees, usually about 10 feet up. Eggs, 3-5, white, spotted and speckled with shardes of olive-brown, $2.57 \times 1.73$. Date, Marruesas Kre, Fla., Jan. 11, 188:3; s. Fat., Mch. 11; Tamiahua Lagoon, Vera ('ruz, Apl. 17, second plumage well grown.

There are probably not more than a few hundred spoonbills existing in Eastern North America, and they are eonfincd to the southern part of Florida. The Spoonbill's flight is rather ibislike, the neck being fully extended, but the wing-strokes are not interrupted by short sails. The 
pink color is very evident at a great distance, either against sky or foliage.

1908. Chapman, F. M., Camps and Cruises, 141, 146 (Fla.).

\section{Family Ibidide. Ibises. (Fig. 37.)}

Ibises are distributed throughout the warmer parts of the globe; they number about thirty species, of which four occur in North America. They are usually silent birds, and live in flocks during the entire year. They feed along the shores of lakes, bays, and salt-water lagoons, and on mud flats over which the tide rises and falls. Their food consists principally of crustaceans, frogs, and small fish. They fly with the neck extended and their wing-strokes are often followed by a short sail.

KEY TO THE SPECIES

A. Plumage deep chestnut . . . . . . . . . . 186. Glossy IBis. B. Plumage scarlet . . . . . . . . 185. Scarlet IbIS (Ad.). C. Plumage white ......... . 184. White IbIS (Ad.). $D$. Back brown, belly white.

a. Rump white. . . . . . . . . . . . 184. White Iвis (Im.). b. Rump like the back.......... 185. Scarlet Ibis (Im.).

184. Guara alba (Linn.). White Ibis. (Fig. 37.). Ads.-White, the tips of the four outer primaries black; bare parts of the head orange-red. Im.-Head and neck white, streaked with grayish brown; upper back and wings grayish brown; rump, breast and belly white. L., 25.00; W., 11.00; Tar., $3 \cdot 40 ;$ B. from N., $4^{*} 60$.

Range.-N. and S. A., from L. Calif., Tex., and S. C., s. to West Indies, Brazil, and Peru, and casually to Great Salt Lake, S. Dak., Ills., Vt., Conn., and L. I.; winters from Gulf of Mex., southward.

Long Island, two records.

Nest, in colonies, of reeds and weed stalks, in trees, bushes and reedy marshes. Eggs, 3-5, pale greenish white, with chocolate markings generally most numerous at the larger end, $2 \cdot 25 \times 1 \cdot 50$. Date, s. Fla., Apl. 2 .

This locally abundant species is generally found in flocks of five or six to as many hundred birds which frequent mud flats, marshes, or the borders of lagoons. They fly in close rank, and when in large flocks, with their snowy plumage glistening in the sunlight and their wingstrokes accented by the black-tipped primaries, form a strikingly beautiful picture. They progress by alternate flapping and sailing, the neck being fully extended. Birds in the brown immature plumage may be seen in large flocks in the spring, indicating that the birds do not breed until at least their second spring.

The Scarlet Iris (185. Guara rubra), a South American species, has been recorded from Florida, Louisiana, New Mexico, Colorado and Arizona. (Sice Brewster, Bull. Nutt. Orn. Club., VIII, 1883, 185; also Scott, Auk, VI, 1889, 15.)

186. Plegadis autumnalis (Hasselq.). Glossy IBIs. Ads.--Rich chestmit, uypere and under tail-coverts, back, wings and front of the head with greenish and purplish reflections; lores (in skins) blackish. Im.-Head and neck fuscous-brown, the feathers laterally margined with white; rest of 
underparts dull fuscous-brown; back with greenish reflections. L., $24^{\circ} 00^{*}$ W., 11.50; Tar., 3.10; B., 5r00.

Range.-Tropical and subtropical regions, mainly of E. Hemisphere. Rare and local in se. U. S. from La. to Fla., and in the West Indies; casual n. to Mo., Wisc., Mich., Ont., and N. S.

Washington, two records. Long Island, two records. Cambridge, one record, May.

Nest, of rushes, plant stems, etc., in reedy swamps or low bushes. Eggs, 3 , rather deep, dull blue, 2*01 × 1*47. Date, Orange Lake, Fla., Apl.

Of this once doubtless widely distributed species comparatively few individuals remain, and in the New World it is of rare and irregular occurrence.

The White-faced Glossr Ibis (18\%. Plegadis guarauna), a locally common species from Texas westward and southward, has been recorded but once from east of the Mississippi, viz., at or near Lake Washington, Florida, where a female was shot on a nest containing three eggs (Brewster, $A u k$, III, 1886, 482). This species resembles the Glossy Ibis, but adults have the region about the base of the bill white.

\section{Family Ciconimde. Storks}

The nineteen known species of this family are distributed throughout the world, but only three are found in the Western Hemisphere, and of these but one occurs north of Mexico. The Common Stork (Ciconia ciconia) of Europe, the Adjutant (Leptoptilus dubius) of India, and Marabou ( $L$. crumeniferus) of Africa are the best known of the Old World species. The Marabou feathers of commerce are from the last-named species.

While terrestrial in feeding habit, Storks usually nest some distance above the ground. They perch readily in trees and in this respect differ from Cranes, with which, however, they agree in flying with the neck fully extended. The young are hatched with but a scanty covering of down and are reared in the nest, Storks, in this respect, resembling Herons rather than Cranes. They are essentially voiceless.

188. Mycteria americana Linn. WoOD IBIs. Ads.-Head and neck bare; primaries, secondaries and tail glossy greenish black, rest of plumage white. Im.-Head more or less feathered; heard and neck grayish brown, blacker on the nape; rest of plumage as in the adult, but more or less marked with grayish; wings and tail less greenish. L., 40*00; W., 18*00; Tar., 7*60; B. from N., 8*00.

Range.-Temperate and tropical Am. from s. Calif., Ariz., Tex., Ohio Valley, and S. C., s. to Argentina; casual n. to Mont., Wisc., N. Y. and Vt. Washington, casual in July. Long Island, one record.

Nesi, in colonies, a platform of sticks in trees. Eggs, 2-3, dull white with a soft calcarcous deposit, 2.75 × 1.75. Date, Brevard Co., Fla., Mch. 14 .

This is a locally common species in Florida.

20. Family Ardeide. Herons and Bitterns. (Fig. 36.)

This family contains about one hundred species distributed in most parts of the globe, but more numerously in the intertropical regions. 
Generally speaking, Herons are gregarious, nesting and roosting in flocks. While feeding they are more solitary, but each night they regularly return to roost with their kind in a "rookery." Bitterns do not associate in flocks, and are generally found singly or in pairs. As a rule, they feed in grassy marshes, while Herons more commonly resort to the shores of lakes, rivers, bays, or salt-water lagoons. Herons perch, and usually nest in trees; Bitterns rarely or never do. Some species secure their food of frogs, fish, small reptiles, etc., by standing rigidly motionless and waiting for it to come within striking distance, or by wading for it with the utmost caution. Others run rapidly and noisily through the water, trusting to their agility and the rapidity of their spearlike thrusts to supply their wants. Herons; unlike our Ibises and Cranes, fly with their folded neck drawn in between their shoulders. Their voice is a hoarse squawk. The young are born with a scanty covering of long, filamentous down and are reared in the nest. In feeding, young Herons, and possibly also young Bitterns, take a scissorlike grasp of the base of the parent's bill with their own, when the parent disgorges food into the nest or skillfully into the mouth of the young.

I. Wing over $13^{\circ} 00$.

\section{KEY TO THE SPECIES}

$A$. Plumage pure white.

a. Wing $17^{\circ} 00$ or over; feathers on the lower neck long, narrow.

b. Wing under $17^{\circ} 00$; neck-feathers not lengthened.

$B$. Upperparts generally slaty or grayish blue.

196. AM. Egret. 194b. Ward's Heron. 194. Great Blue Heron.

II. Wing under $13^{\circ} 00$.

1. Crown without streaks.

$A$. Crown white or whitish.

a. Wing over $11^{\circ} 00$.

$a^{1}$. Plumage entirely or mostly white. . . 198. Reddish Egret. $a^{2}$. Plumage gray streaked with black; throat and sides of neck. black . . . 203. Yellow-Crowned Night HeroN. b. Wing under $11 \cdot 00$.

$b^{1}$. Plumage pure white; legs and bill black; feet yellow.

197. SNOWY HERON.

$b^{2}$. Tips of primaries slate-color; plumage white, sometimes irregu-

$\boldsymbol{B}$. Crown not white or whitish.

larly marked with slaty blue . 200. Little Blue Heron (Im.)

a. Crown umber or reddish brown.

$a^{1}$. Head and neck reddish brown; body slate-color.

$a^{2}$. Neck conspicuously streaked; body variegated.

198. REDDISH EGRET.

b. Crown not umber or reddish brown.

190. Am. Bittern.

$b^{1}$. Crown slaty or slate-hlue with sometimes a purplish east.

$b^{2}$. Wing-coverts more or less margined with rufous.

$3^{3}$. Wing-coverts without 199. Loursiana Heron. $c^{1}$. Crown not slaty, but greenish or bluish black.

$c^{2}$. Wing over $10^{\circ} 00$; entire underparts pure white. 202. Black-Crowned Night Heron. 


\section{HERONS AND BITTERNS}

$d^{2}$. Wing under $10^{\circ} 00$.

$d^{3}$ Wing-coverts green . . . . 201. Little Green Heron. $e^{3}$. Wing-coverts rufous-chestnut and buff. $e^{4}$. Underparts buffy, more or less streaked.

$e^{5}$. Underparts rufous-chestnut.

191. Least Bittern.

2. Crown streaked.

191.1 Cory's Least Bittern.

$A$. Wing under 10.00; upperparts greenish 201. Little Green Heron.

$B$. Wing over $10^{\circ} 00$; upperparts brownish or blackish brown streaked with white.

a. Upperparts light brown; outer edge of primaries reddish.

202. Black-Crowned Night Heron (Im.).

b. Back dark brown; crown nearly black with white streaks; primaries dark slate-color.

203. Yellow-Crowned Night Heron (Im.).

190. Botaurus lentiginosus (Montag.). AMerican Bittern. Ads.A glossy black streak on each side of upper neck; top of head and back of neck bluish slate, more or less washed with buffy; back brown, bordered and irregularly mottled with buffy, and buffy ochraceous, wing-coverts similarly marked, but ground color grayer; underparts creamy buff, the feathers all widely streaked with buffy brown, which is finely speckled with buffy and narrowly margined by brownish gray. Im.- Similar, but buffy everywhere deeper and more ochraceous. L., 28.00; W., 10.50; Tar., 3.50; B., $3 \cdot 00$.

Range.-N. A. Breeds from cen. B. C., s. Mackenzie, cen. Keewatin, s. Ungava, and N. F., s. to s. Calif., n. Ariz., Kans., the Ohio Valley and N. C., and less frequently in s. U. S.; winters from Calif., Ariz. s. Tex., the Ohio Valley, and Va.s. to Cuba and Guatemala, and casually to the Bahamas, Porto Rico, Jamaica, and Great Britain.

Washington, rather' common W. V., July 15-Apl. 30. Long Island, common T. V., Apl. 16-May 5; Aug. 4-Dec. 11. Ossining, rare S. R., Apl. 11-Oct. 5. Cambridge, common T. V., breeds locally, Apl. 15-Oct. 20. N. Ohio, tolerably common S. R., Apl. 1-Oct. 1. Glen Ellyn, fairly common S. R., Apl. 9-Nov. 1. SE. Minn., common S. R., Apl. 8.

Nest, of grasses, etc., on the ground in marshes. Eggs, 3-5, pale olivebuff, 1.90 × 1.45. Date, Cambridge, May 5; Pewaukee, Wisc., May 23.

The Bittern makes its home in extensive grassy meadows with plenty of water, but in the season of migration may be found and heard "booming" in smaller and more accessible swampy places. Like the other members of its family, it excels in standing still, and will hold its head erect and motionless amid the tall grass till the watcher tires of looking and pronounces the suspicious object nothing but a stick after all. The Bittern's fame rests upon its vocal performance, or "boom." This is sometimes exactly like the working of an old-fashioned wooden pump, and sometimes-even with the same bird-like the driving of a stake in a bog. It can be heard for a long distance. The performance is best witnessed in spring, while the grass is still low. That it is not so very difficult at that season to steal a march upon the bird may perhaps be considered as established on the testimony of a man who has never lived near a Bittern mearlow, and yet has watched the performance at much length and at near range on several occasions. His first experience of this kind is described somewhat fully in The Auk, Vol. VI., page 1. The strange notes are delivered 
with equally strange contortions, as if the bird were horribly nauseated, and are preceded by a succession of quick snapping or gulping sounds"hiccoughs," one observer has called them. No water is employed in the operation, in spite of the circumstantial assertions of several persons who profess to have seen the bird swallowing and then ejecting it. BRADFORD TORREY.

Brewster, WM., Auk, 1911, 90-100 (display of plumes).

191. Ixobrychus exilis (Gmel.). Least BitTenn. Ad. $\sigma^{x}$-Top of head, back and tail shining black; back of neck chestnut-rufous; most of the greater wing-coverts and outer vanes of the secondaries darker; lesser wing-coverts and part of greater ones buffy; underparts, including under tail-coverts, washed with buffy; a blackish patch at each side of the breast. $A d$.. Similar, but head browner and back light, glossy umber; underparts darker and more or less streaked with brownish. Im. $\sigma^{3}$. - Similar to ad. $\sigma^{2}$, but the back washed and tipped with chestnut; underparts darker and lightly streaked with black. Im. ‥-Similar to ad. 오, but the back rufous, margined with buffy ochraceous. L., $13^{\circ} 00 ;$ W., $4^{*} 60$; Tar., 1*60; B., 1.80.

Range.-Temperate N. A., and n. S. A. Breeds from s. Ore., s. Sask. s. Man., s. Que., and N. S. s. to the West Indies and Brazil; winters from Fla. and Gulf of Mex., southward.

Washington, not very numerous S. R., May 5-Sept. 25. Long Island, common S. R., May-Sept. Ossining, tolerably common S. R., to Aug. 10 . Cambridge, local S. R., May 15-Aug. 1. N. Ohio, not common S. R., Apl. 20-Sept. 20. Glen Ellyn, local S. R., late spring and summer records only. SE. Minn., common S. R.

Nest, a platform of grasses, reeds, etc., in marshes among rushes, sometimes in a small bush, usually over water. Eggs, 3-6, pale bluish white, $1 \cdot 20 \times 92$. Date, Ft. Thompson, Fla., Mch. 25; Mt. Pleasant, S. C., May 1; Cambridge, June 1; Pewaukee, Wisc., May 27.

Wet, grassy marshes such as Rail love, or reed-grown ponds that Gallinules frequent, are the resorts of these retiring, secretive little birds. With outstretched necks and lowered heads they make their way without difficulty through the jungle of roots and stalks. Sometimes they climb up a slender reed, and, hanging on like Marsh Wrens, survey their surroundings. They take wing almost from beneath one's feet, and, with a low, frightened qua, fly slowly for a short distance and then drop back into the grass. During the breeding season one may hear what presumably is the voice of only the male-a soft, slowly repeated, dovelike $c 00, c 00, c 00, c 00, c 0 o$. It floats over the marsh like the voice of a spirit bird.

1900. Chapman, F. M., Bird Studies with a Camera, 62-75 (nesting).

191.1. Ixobrychus neoxenus (Cory). Cory's LeAst BitTern. Ad. o.-Above shining greenish black, tail the same; wings black, their coverts rich chestnut; underparts chestnut, sides black. $A d$. $\%$. - Similar but black area cluller, chestnut arcas slichtly paler. W., 4*30; Tar., 1•40; B., 1.80. (See Chapman, Auk, 1896, 11-19.)

Ramere.-Imperfectly known. Breeds in s. Ont. and s. Fla.; occurs casually in Mass., Mich., and Wise.

Nest, "of willow twigs, lined with maiden cane leaves; in a low bush two anrl a half feet aloove the water." Young two-thirds grown, Lake Flirt, Fla., June 8, 1890. (Scott, Auk, 1891, 309.) 
Twerty-four specimens of this species have been recorded, of which five are from Florida and sixteen from the vicinity of Toronto. It resembles the Least Bittern in haunts and habits, but I know of no description of its notes. Its rarity, sporadic distribution, and albinistic tendencies, indicative of physical degeneration, suggest that it is a decadent species on the verge of extinction.

1896. Chapman, F. M., Auk, XIII, 11-19 (historical). 1901. Fleming, J. H., Auk, XVIII, 106 (nesting); XIX, 77 (Toronto records).

192. Ardea occidentalis $A u d$. Great White Heron. Ads.-Entirely white; in breeding plumage, with long, narrow, stiffened feathers on the back and lower foreneck, and two narrow plumes on the back of the crown, "L., 45.00-54.00; W., 17.00-21.00; B., 6.00-7.00; Tar., 8.00-8.75" (Ridgw.). Range.-Region bordering Gulf of Mex. from s. Fla. s. to Cuba, Jamaica, and Yucatan; casual n. to Anclote River and Micco, Fla.

Nest, in small colonies, a platform of sticks usually in mangrove bushes. Eggs, 3-4, pale, dull blue, $2 \cdot 50 \times 10^{\circ} 80$. Date, Florida Keys, Jan. and Feb.

This is a common species on the coasts of southern Florida, particularly in the vicinity of Cape Sable. Rarely it is found as far north as the Anclote River on the west coast and Micco on the east coast. This bird is as large as the Great Blue Heron, and must not be confused with Herodias egretta, to which the name Great White Heron is frequently applied.

Ardea wuerdmanni Baird has been considered to be a color phase of this species, but its true standing is unknown. It may be described as a Ward's Heron with a whitish head and neck, and is thus intermediate between occidentalis and wardi. On March 27, 1908, on Clive Key, southeast of Cape Sable, I found two young Ward's Herons and one pure white bird in the same nest. One of the parents was Ardea occidentalis, the identity of the other was not ascertained.

1905. Јов, H. K., Wild Wings, 27.

194. Ardea herodias herodias Linn. Great Blof Heron. Ads. in breeding plumage. - Center of rrown and throat white, side's of (rown black, this color meeting on back of head, where the feathers are lengthened to form an occipital crest; neck pale grayish brown, a narrow black, white, and ochraceous line down the midclle of the foreneck; feathers of lower forenerk narrow and much lengthened, whitish with sometimes black streaks; back, wing-eoverts, and tail slaty gray, the scapulars paler, narrow and much lengthened; bend of wing chestnut-rufous; a batch of black and white feathers on side of hreast; breast and belly streaked with l, lack and white and sometimes pale rufous; feathers on legs dull rufous, leges and foet black, upper mandible colive-yellow, the culmen blackish; lower mandible yellow; lores blue. Im. - Similar, but entire ('rown black, throat white, neck brownish gray washed with buffy ochraceous; no black at sides of the breast or plumes on the lower nerk; underparts streaked with black, slaty, white and ochraceous; bend of wings and frathers on legs paler; batek slaty grayish

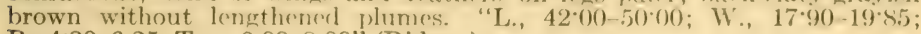
B., 4*30-6*25; Tar., 6*00-8*00" (Ridgw.).

Range.-W. Hemisphere. Breeds from se. B. C.. een. Alberta, een. Man., n. Ont., and Prince Erlward Island s. to s. T. Calif., n. Tex., and S. Atlantic States (except Fla.); winters from ()ro., Hhe ()hio Villey, and Middle States s. to the West Indies, Panama, and Venezucla. 
Washington, rather common, absent only in midwinter. Long Island, common T. V., Apl. and May; Aug.-Dec. (Dutcher). Ossining, common T. V., Apl. 4-Apl. 18; Aug. 16-Oct. 6. Cambridge, uncommon T. V., Apl. 1-May 1; Sept. 1-Oct. 20; occasional in winter. N. Ohio, tolerably common S. R., Mch. 20-Oct. 10. Glen Ellyn, not common T. V., Apl. 3-26; Aug. 3-Oct. 24. SE. Minn., common S. R., Mch. 26-Oct. 1.

Nest, a platform of sticks, generally in colonies, usually in tall trees, sometimes on the ground on islets. Eggs, 3-4, pale, dull blue, $2.50 \times 1.50$. Date, Coast S. C., Mch. 20; Oneida Co., N. Y., May 1; SE. Minn., Apl. 28.

Is it due to the influence of the artists of the Orient that these long-legged, long-necked birds are so frequently miscalled "Cranes?" With head drawn in and legs trailing on behind, they fiap slowly over the water, resembling, no doubt, the "Cranes" of fans, screens, and bronzes; nevertheless, they are Herons. With all a Heron's immovable alertness they watch patiently for passing fish, sometimes wading with extreme caution, placing one foot slowly after the other. They feed both by day and night. Fishes, frogs, reptiles, even small mice, all are welcome; and all are powerless to escape the lightning thrust of the spearlike bill. Their voice is harsh and rasping. When alarmed they utter a croak which is sometimes prolonged into a series of squawks. They nest and roost in colonies, but at other times are solitary birds.

194.b. A. h. wardi (Ridgw.). WARD's Heron. The Florida representative of $A$. $h$. herodias. The average differences in color between it and $A$. $h$. herodias consist in its whiter lower parts, darker neck, and olive instead of black legs. These differences, however, cannot always be relied upon, and size is the character by which the two birds can best be distinguished, wardi being the larger, as the following measurements show; L., 52.00; W., 19.75-20.50; B., 6*40-6.80; Tar., 8.00-8.50.

Range.-Fla. and the Gulf coast to Tex.

Nest, in colonies, a platform of sticks, usually in trees, sometimes bushes, generally over water. Eggs, 3-4, pale, dull blue, $2.65 \times 1.85$. Date, Tarpon Springs, Fla., Jan. 20.

This is the Florida form of the Great Blue Heron, which it resembles in habits.

1908. Chapman, F. M., Camps and Cruises, 119-122 (nesting).

The European Great Blue Heron (195. Ardea cinerea) is accidental in southern Greenland. It may be distinguished from our species by the white instead of rufous feathers on the legs.

196. Herodias egretta $(\mathrm{Gmel}$.). EGRET. Ads. in breeding plumage.Entire plumage pure white; about fifty straight 'aigrette' plumes grow from the interscapular region and reach beyond the tail; legs and feet black; bill yellow; lores orange, bordered below by greenish. Ads. after the breeding season and Im.-Without the interscapular plumes. L., $41^{\circ} 00$; W., $1^{\circ} 00$; Tar., 5.60; B., 4.50 .

Range.-Temperate and tropical Am. Breeds in Ore. and Calif., and from N. C., Fla., the Gulf coast, and Mex. s. to Patagonia; formerly bred n. to N. J. and Wise.; winters from the Gulf of Mex. southward; casual to Man., Que., N. Y., New England, and N. S.

Washington, not common and irregular S. R., May-Aug. Long Island, rare from July-Oct. Ossining, A. V. N. Ohio, tolerably common S. R., Mch. 20-Oct. 10. SE. Minn. A. V.

Nest, a platform of sticks, in colonies, in trees or bushes over water. 
Eggs, 3-5, dull blue, of a rather deeper shade than those of the preceding, $2.25 \times 1 \cdot 60$. Date, s. Fla., Feb.; Santee, S. C., Apl. 5.

Tourists who went to Florida prior to 1880 have told me of prairies white with Egrets, of bushy islands glistening in the sun like snow banks. Now you may look for miles along a lake shore and perhaps in the distance see a solitary Egret, which, as you approach, with a frightened squawk takes wing a rifle-shot away. The rapid extermination of these plume-bearing birds is startling evidence of man's power in the animal world. At his word a species is almost immediately wiped out of existence. I have heard a "plume-hunter" boast of killing three hundred Herons in a "rookery" in one afternoon. Another proudly stated that he and his companions had killed one hundred and thirty thousand birds-Herons, Egrets, and Terns-during one winter. The destruction of these birds is a blot on Florida's history.

1887. Sсотт, W. E. D., Auk, IV, 135 (destruction in Fla.). 1905. Јов, H. K., Wild Wings, 134-149 (habits, destruction).-1908. Chapman, F. M., Camps and Cruises, 122-134 (nesting).

197. Egretta candidissima candidissima (Gmel.). SNowr Egret. Ads. in breeding plumage.-Entire plumage pure white; about fifty recurved 'aigrette' plumes grow from the interscapular region and reach to or just beyond the end of the tail; legs black, feet ycllow, bill black, yellow at the base; lores orange-yellow. Ads. after the breeding season and Im.-Without the interscapular plumes. L., $24 \cdot 00$; W. , 9·75; Tar., $3 \cdot 80 ;$ B., $3 \cdot 20$.

Range.-Temperate and tropical Am. Formerly bred from Ore., Nebr., Ind., Ills., and N.J.s. to Chile and Argentina; now breeds locally in the U.' S. from N. C., to La.; winters from Fla., southward; casual in B. C., Ont., Mass., and N.S.

Washington, casual; irregular in fall. Long Island, rare S. R. MaySept. Ossining, A. V.

Nest, a platfom of sticks, in colonies, in bushes over water. Eggs, 3-5, pale, dull blue, 1.80 × 1*20. Date, s. Fla., March; Coast S. C., May 5.

The "curse of beauty" has numbered the days of this the most dainty and graceful of Herons. Formerly it was abundant in the South, now it is the rarest of its family. The delicate 'aigrettes' which it donned as a nuptial dress were its death warrant. Woman demanded from the bird its wedding plumes, and man has supplied the demand. The Florida Egrets are near the verge of extermination and now he is pursuing the helpless birds to the uttermost parts of the earth. Mercilessly they are shot down at their roosts or nesting-grounds, the coveted feathers are stripped from their backs, the carcasses are left to rot, while the young in the nest above are starving. Consular reports show that in 1898 the plumes of about 1,538,000 White Herons were shipped from Venezuela alone.

198. Dichromanassa rufescens (Gmel.). ReDDish EGRET. Ads. dark phase.-Hearl and neck rufous-chestnut, glossed with vinaceous; rest of plumage dark bluish slate-color; about thirty 'aigrette' plumes grow from interscapular region and reach beyond tail; lepgs and feet black. Im.- Similar, but without 'aigrette' plumes. White phase. - Similar in size and form, but entire plumage white, except tips of primaries, which are sometimes very 
finely speckled with grayish. Im.- Similar, but without 'aigrette' plumes, L., 29.00; W., $12 \cdot 50$; Tar., 5*40; B., $3 \cdot 60$.

Remarks.-The two color phases of this bird were supposed to represent two species, the white phase being called Ardea pealei Bonap. They have, however, been found mated together, and intermediates or parti-colored specimens are known.

Range.-S. N. Am. Breeds from L. Calif. and Gulf of Mex. to Jamaica and Guatemala; winters from s. Fla. southward; casual in Colo. and s. Ills.

Nest, a platform of sticks, singly or in colonies, in bushes generally over salt-water. Eggs, 2-4, pale, dull blue, 1.95 × 1*45. Date, Tampa Bay, Apl.

This is now a rare bird on the coasts of southern Florida and it is occasionally seen in the interior; the reddish phase prevailing. It is a graceful, active fisher and instead of waiting for its prey to come within spearing distance, pursues it rapidly through the shallow water.

199. Hydranassa tricolor ruficollis (Gosse). LoUISIANA Heron. $A d s$.-Upperparts dark bluish slate-color; back of head and upper neck with elongated chestnut-rufous and white feathers; back with pale brownish gray 'aigrette' plumes reaching to tail; lower back, rump and belly white; neck bluish slate-color; throat white, an indistinct rufous line down the middle of foreneck; legs blackish; base of bill and lores bluish. Im.-Throat, and an indistinct line down the foreneck, white; rest of head and neck brownish rufous; upper back and wings bluish slate-color, more or less washed with brownish rufous; no plumes; lower back, rump and belly white; breast with more or less slaty streaks; legs yellow behind, blackish before; lower mandible and lores orange; upper mandible black. L., 26.00; W., 10*00; Tar., 3•70; B., $3 \cdot 90$.

Range.-S. N. Am. Breeds from N. C., and the Gulf States to the West Indies, Mex. (both coasts), and Cen. Am.; winters from S. C. southward; casual in Ind., N. J., and L. I.

Long Island, one record.

Nest, a platform of sticks, in colonies, in bushes or small trees over water. Eggs, 3-4, pale, dull blue, 1.75 × 1.35. Date, s. Fla., Apl. 1; Santee, S. C., Apl. 20.

The Louisiana Heron has fortunately never found favor with the milliners and consequently is doubtless as abundant today as it ever was; rookeries containing thousands of birds being not uncommon in Florida. It flies with its neck less drawn in than do our other Herons, and its sharply defined white abdomen is a further excellent field-mark. It is very noisy and excitable when mating and nesting, and when challenging a rival the neck-feathers are so erected and ruffled that the bird seems to be wearing a feather boa. It is sometimes a slow, stealthy feeder, and at others dashes for its prey.

1908. Chapman, F. M., Camps and Cruises, 143.

200. Florida carulea carulea (Linn.). Little Blue Heron. Ads.Head and neck maroon-chestnut; rest of plumage dark bluish slate-color; intrrscapulars and lower neck feathers lengthened and narrowly pointed; lores hluc; legs and fert black. Im.-White, plumage sometimes more or less washed with slaty; tips of the primaries always bluish slate-color; legs, feet and lores greenish yellow. L., 22'(00; W., 10*25; Tar., 3*70; B., 3•00.

Remorks. - Between the young and adult there is every stage of intergrarlation of eolor, some specimens being irregularly marked with blue and white in alonut equal proportions. Young birds are sometimes mistaken for Surowy Hornns, but can always be distinguished by the greenish yellow legs and slaty tips of the primaries. They breed in the white plumage. 
Range.-N. and S. Am. Formerly bred from Mo., Ind., Ills., and N. J. to w. Mex. and s. to. Argentina and Peru; in the U. S. now breeds locally in the Gulf states and n. to S. C.; after breeding season wanders casually to Nebr., Wisc., Ont., New England, and N. S.; winters from S. C. southward.

Washington, casual in July and Aug.; sometimes quite common. Long Island, rare from Apl.-Sept. Cambridge, casual.

Nest, a platform of sticks, in colonies, in bushes or small trees over water. Eggs, 3-4, pale, dull blue, 170 × 1*30. Date, San Mateo, Fla., Apl. 1; coast S. C., Apl. 23.

Thanks to their lack of 'aigrette' plumes Little Blue Herons are one of the most common Herons in Florida today. They are generally found in flocks, sometimes composed entirely of blue adults, sometimes of white, immature birds, and at others both young and old are associated. I have seen a few white-plumaged birds nesting in colonies composed of blue adults. The white birds resemble $E$. candidissima, but the color of their legs and feet serves as a distinguishing character at some distance. They are silent when feeding, but when undisturbed in their rookeries, each bird seems to have something to say, and the result is a strange chorus of croaking voices. They feed by day, and generally wait for their prey to come within striking distance.

201. Butorides virescens virescens (Linn.). Littlle Green Heron. (Fig. 36.) Ads.-Crown and a short line below eye glossy greenish black; throat buffy white, this color extending down foreneck as a narrow line mixed with blackish, widening on breast; rest of head and neck rufouschestnut glossed with vinaceous; back, with lengthened interscapulars, green, more or less washed with bluish gray; wing-coverts green, margined with white or buffy; belly ashy gray, more or less washed with buffy. Im.Similar, but with neck and underparts streaked with blackish; back without lengthened feathers or wash of blue-gray; wing-coverts widely margined with buffy ochraceous. L., 17*00; W., 7*25; Tar., 1•90; B., 2*50.

Range.-E. N. Am. Breeds from s. S. D., n. Wisc., s. Ont., s. Que., and N.S. s. to the West Indies; winters from the West Indies southward, and rarely in se. U. S.; casual in Colo.

Washington, very common S. R., Apl. 9-Sept. 15. Long Island, common S. R., Apl. to Oct. Ossining, common S. R., Apl. 6-Sept. 26. Cambridge, common S. R., May 1-Sept. 30. N. Ohio, common s. R., Apl. 14-Nov. 15. Glen Ellyn, fairly common S. R., Apl. 25-Aug. 31 and doubtless later. SE. Minn., uncommon S. R., Apl. 23-Sept. 25.

Nest, a platform of sticks in a bush or low branch of a tree. Eggs, 3-6, pale, dull blue, $1.50 \times 1.14$. Date, San Mateo, Fla., Mch. 25; Chester ('o., Pa., Apl. 30; Cambridge, May 10.

The shores of wooded streams or ponds are frequented by this small Heron in preference to more exposed situations. It is most active in the early morning or at nightfall, during the day it rests quictly in some sheltered situation. When startled, it springs into the air with a frightened skeow or explosive whistle, and, alighting at a safe distance on a tree or on some elevated perch, with upstretched neek watches the intruder, betraying its apprehension by nervous twitchings of the tail. It is a solitary bird, and, unlike most Herons, is not found in flocks, and usually nests alone, though as many as a dozen pairs may sometimes $\mathrm{be}$ found associated. In the mating season it utters a surprising variety of hen-like notes and a hoarse, choking gulp. 
202. Nycticorax nycticorax næevius (Bodd.). BLACK-CROWNED Night Heron. Ads.-Forehead, lores, neck and underparts white or whitish; crown, upper back and scapulars glossy, greenish black; lower back, wings and tail ashy gray; legs and feet yellow; lores greenish; two or three white rounded occipital plumes about 8.00 in length. Im.-Upperparts grayish brown, the feathers streaked or with wedge-shaped spots of white or buffy; outer web of primaries pale rufous; underparts white, streaked with blackish. L., $24^{\circ} 00 ;$ W., $12^{\circ} 00$; Tar., $3{ }^{\circ} 20 ;$ B., $3^{*} 00$.

Range.-N. and S. Am. Breeds from n. Ore., s. Wyoming, s. Man., n. Que., and N. S. s. to Patagonia; winters from n. Calif. and Gulf States southward; casual in winter $\mathrm{n}$. to Mass. and s. Ills.

Washington, not uncommon S. R., occasional in winter. Long Island, S. R., Apl. 12-Sept. 29; a few winter. Ossining, common S. R., Apl. 6-Oct. 20. Cambridge, formerly P. R., now found sparingly chiefly in late summer and early fall; Apl. 10-Nov. 1. N. Ohio, occasional in summer. Glen Ellyn, quite common S. R., Apl. 8-Oct. 15. SE. Minn., uncommon S. R., May 15.

Nest, of sticks, in colonies, in the upperparts of tall trees, sometimes in bushes or on the ground. Eggs, 3-6, pale, dull blue, $2.00 \times 1.40$. Date, San Mateo, Fla., Mch. 29; Chester Co., Pa., May 3; Ossining, N. Y., May 7.

These birds live in colonies composed sometimes of thousands of pairs. Their day begins after sunset, when they leave their roosts and start for their feeding-grounds. Occasionally they utter a loud, hoarse quawk, the origin of their common name; and looking up we may catch a glimpse of them hurrying through the gloom. During the nesting-season the demands of the young force them to feed both by day and night. L. I.).

1900. Chapman, F. M., Bird Studies with a Camera, 76-85 (nesting on

203. Nyctanassa violacea (Linn.). Yellow-Crowned Night Heron. Ads.-Crown white, generally washed with buffy; ear-coverts white; rest of head and throat black; neck, breast and belly blue-gray; back the same; the lengthened interscapulars, scapulars and wing-coverts streaked with black; two or three black and white rounded occipital plumes; lores greenish yellow; legs greenish. Im.-Crown black, the feathers streaked with white or buffy; rest of upperparts, including wing-coverts, fuscous-brown with wedge-shaped buffy or white spots; primaries dark bluish slate-color without rufous; underparts white or buffy streaked with blackish. L., 23.00; W., 12.00; Tar., $3 \cdot 75$; B., 3*00.

Remarks. - Young birds bear a general resemblance to those of the preceding species, but differ in being darker, in having the head darker than the back, and the primaries without rufous.

Range--Warm temperate and tropical Am. Breeds from s. L. Calif., Kans., s. Ills., s. Ind., and S. C. s. to Brazil and Peru; casual n. to Colo., Ont., Mass., Maine, and N. S.; winters from s. L. Calif., and s. Fla., southward.

Washington, A. V., one record, Aug. 1901. Long Island, three records. Cambridge, A. V., one record, July.

Nest, a platform of sticks, in pairs or small colonies, generally on a hranch over water. Eggs, 4-5, pale dull blue, $1.95 \times 11^{\circ} 45$. Date, San Mateo, Fla., Apl. 2; coast, S. C., Apl. 20.

This is a less common species than the preceding. It nests in pairs along the borders of wooded streams and is also found nesting in association with other Herons. 


\section{ORDER PALUDICOLE. CRANES, RAILS, ETC.}

\section{Family Gruid ж. Cranes. (Fig. 40.)}

The Cranes number nineteen species, of which three are North American, while the remaining sixteen inhabit the Old World. They frequent plains and marshes, and are omnivorous feeders, eating frogs, lizards, field-mice, snakes, etc., and various kinds of vegetable food. Our species migrate in flocks, but are solitary rather than gregarious at other times of the year. Their voice is loud and resonant. Unlike the Herons, they fly with the neck fully extended. The nest is placed in the ground, and the eggs number two or, rarely, three. The young, again unlike Herons, are born covered with down and leave the nest shortly after birth.

204. Grus americana (Linn.). Whooping CRANe. Ad.-Top of head, lores and sides of the throat dull red, with a thin growth of black 'hairs'; primaries black, rest of the plumage white. Im.-Similar, but whole head feathered, and plumage more or less washed with buffy ochraceous. L., 50॰00; W., 25*00; Tar., $11 \cdot 50 ;$ B., 5•00.

Range.-N. Am. Bred formerly from N. Mackenzie s. to Ills. and Iowa; now mainly restricted to s. Mackenzie and n. Sask.; in migration, formerly not rare on the Atlantic coast from New England to Fla. and casual west to Colo. and Idaho; winters from the western Gulf States to cen. Mex.

SE. Minn., T. V., Mch 3.

Nest, an islet of grasses and weed stalks, in marshy places. Eggs, 2, olive-gray, spotted and blotched with distinct and obscure cinnamonbrown markings, $4.00 \times 2.50$. Date, Dubuque, Iowa, Apl. 25, 1868 .

This is now one of the rarest of North American birds. There are no recent records of its nesting. "In flight their long necks and stiltlike legs are stretched out in a line with the body to the full extent, moving strongly with slowly beating wings, but not swiftly, . . . often circling spiral-like to a great height. They occasionally bunch up, and I have seen them in triangular form; but as a rule they travel in single file, following their leader in a wavy line, croaking as they go, like hounds upon a cold trail." (Goss).

The Little Brown Crane (20\%. Grus canadensis) breeds from Hudson Bay to Alaska, and winters in Texas and Mexicos. There are but two instanees of its occurrence east of the Mississippi (Rhore Island and South Carolina). It resembles $G$. mexicana, but is smaller; W., 18*50; $13 ., 4 * 10$.

206. Grus mexicana (Müll.). Sandhill Crane. (Fig. 40.) Ad.Whole top of the head to below the eyes eovered with rough, minutely warty, dull reddish skin thinly grown with short, black 'hairs'; plumage brownish gray, with more or less silvery gray and buffy ochraceous. Im.Similar, but whole hearl feathered, and with more buffy ochraceous in the plumage. "L., 40*00-48.00; W., 21.83; Tar., 10*25; B., 5.47" (Rirlow.).

Range.-N. A. Resident in La. and lila.; bred, formerly, from s. B. C., Sask., Man., and w. Orit. s. to Calif., Colo., Nebr., Ills., and (Ohio; formerly in migration e. to New Lingland; now rare e. of the Miss., exeept in Fla., and rare as a breeder in the s. half of its former breeding range; winters from Calif., Tex., and La. s. to Mex.

Washington, A. V., one record. SE. Minn., T. V., Mch. 29. 
Nest, an islet, of roots, rushes, weed stalks, etc., in marshy places. Eggs, 2 , olive-gray, spotted and blotched with distinct and obscure cinnamonbrown markings, $3.90 \times 2.40$. Date, Lantana, Fla., Mch. 2; Dubuque, Iowa, May 11, 1865.

Thanks to the preserving influences of peninsulation, this splendid bird is still common in south-central Florida, where its loud, resonant trumpeting is one of the characteristic bird-notes. It feeds about the borders of sloughs in the prairies and pines and particularly over burned areas, and is one of the most wary of birds.

"During courtship and the early breeding season their actions and antics at times are ludicrous in the extreme, bowing and leaping high in the air, hopping, skipping, and circling about with drooping wings and croaking whoop, an almost indescribable dance and din, in which the females (an exception to the rule) join, all working themselves up into a fever of excitement only equaled by an Indian war dance, and, like the same, it stops only when the last one is exhausted"'(Goss).

\section{Family Aramide. Courlans. (Fig. 41.)}

Courlans might be called large Rails with some of the habits of Herons. Two species are known, Aramus scolopaceus of South America, and $A$. vociferus of Central America, Mexico, the West Indies, and Florida. They frequent the borders of wooded streams and swamps, and at times the uplands. Their flight is short, and when on the wing their legs dangle below them. Like the Herons, they perch in trees. Their prolonged, melancholy call has won for them the name "Cryingbird." Their usual note is a loud, rather high wah-ree-ow; the last syllable is drawn out into a wail, and the effect is most grewsome. Courlans feed to a large extent on land shells (Ampullaria), and, as Barrows has shown, the tip of the Courlan's bill is sometimes turned slightly to one side, an evident result of forcing it into the spiral opening of the shell to extract the animal.

207. Aramus vociferus (Lath.). Limpkin. (Fig. 41.) Ads.-Glossy olive-brown, the feathers of the head and neck narrowly, those of the body broadly, striped with white; wings and tail more bronzy. Im.-Similar, but paler and duller. L., 28*00; W., 13.00; Tar., 4.50; B., 4*25.

Range.-Fla. Greater Antilles, and both coasts of Cen. Am.; casual n. to S. C.; accidental in Tex.

Nest, of leaves, twigs, etc., in a bush or small tree. Eggs, 4-7, pale buffy white, blotched, stained and speckled with light cinnamon-brown, $2 \cdot 30 \times 1 \cdot 70$. Date, Ocklawhaha River, Fla., Mch. 6.

This is a locally common species in Florida. Its general habits are described in the remarks on the family Aramida.

23. Family Rallide. Rails, Gallindles, and Coots. (Fig. 39.)

The one hundred and eighty odd species contained in this family are distributed throughout the greater part of the world, fifteen species inhabiting North America. Rails and Gallinules are not strictly gre- 
garious, but are generally associated through a community of interests; Coots, however, are usually found in flocks. Rails inhabit grassy marshes, in which they seek safety by running or hiding, taking to wing, when pursued, only as a last resort. Their large, strong legs, therefore, have been developed at the expense of their weak, rounded wings. In several island species, this degeneracy of wing has been carried to such an extreme that the birds have lost the power of flight. At the best, their flight when flushed is short and labored, and with dangling legs they soon drop back into cover. Nevertheless, they perform extended migrations, traveling hundreds of miles without resting.

Gallinules live near the marshy borders of bodies of water, while the more aquatic Coots resemble some Ducks in habits. They are at times noisy birds and are more often heard than seen. All the forms nest on the ground, laying generally large sets of eggs, and the young are born covered with (usually black) down and can run soon after hatching.

\section{Bill over $1 \cdot 75$.}

\section{KEY TO THE SPECIES}

$A$. Cheeks below the eye einnamon-rufous, like the breast; flanks black barred with white; upperparts rich olive-brown streaked with black. 208. King RaIL.

$B$. Cheek below the eye gray; flanks generally gray or brownish, barred with white; upperparts generally grayish, streaked with black.

II. Bill under $1 \cdot 75$.

211. Clapper RaIl and races.

$A$. Wing over $6^{\circ} 00$.

a. General color blue, feet yellow . . . . 218. Purple Gallinule.

$b$. General color slaty, feet dark greenish.

$b^{1}$. Toes with large scalloped webs or flaps at the side . . . 221. Cоот. $b^{2}$. Toes without flaps or webs . . . 219. FLORIDA Gallindle.

$B$. Wing under $6^{\circ} 00$.

$a$. Wing under 3.50 .

$a^{1}$. Back blackish, with small round, white spots. 216. BlAck RAIL. $a^{2}$. Back blackish, barred with white and margined with buffy.

b. Wing over $3 \cdot 50$.

215. Yellow RaIL.

$b^{1}$. Bill over $1.00 \ldots \ldots \ldots \ldots$. . . . . . . . . . . $c^{1}$. Bill under $1^{\circ} 00$.

$c^{2}$. Wing over $4: 50$, lesser wing-coverts rufous 217 . CoRN CRAKE. $c^{3}$. Wing under $4 \cdot 50$, lesser wing-coverts olive ... 214. Sora.

208. Rallus elegans $A u d$. KING RAIL. Ads.-Upperparts varying from olive-brown to black, the back and scapulars widely margined with olive-gray; wings and tail olive-brown; wing-coverts rufous; throat white; neck and breast cinnamon-rufous; belly and sides fuscous, sharply barred with white. Downy Young.-Glossy black. L., 15.00; W., 6.50; Tar., 2*20; B., $2 \cdot 40$.

Range.-E. N. Am. Breeds from Nebr., s. Minn., Ont., N. Y., and Conn. s. to Tex., Fla., and Cuba; winters mainly in the s. part of its breeding range.

Washington, uncommon S. R., almost a P. R. Long Island, rare S. R. Cambridge, casual. N. Ohio, not common S. R., May 1-Sept. 5. Glen Ellyn, common S. R., Apl. 19-Sept. 16. SE. Minn., uncommon S. R., Apl. 15.

Nest, of grasses, on the ground in fresh-water marshes. Eggs, 7-12, buffy white, more heavily spotted and speckled with rufous-brown than 
those of the next species, $1.68 \times 1 \% 20$. Date, Mercer Co., Ill., May 5; Raleigh, N. C., May 31; se. Minn., June 6.

The King Rail is the fresh-water representative of the Clapper Rail. It is, however, a much less common bird, and less is known of its habits. Like other Rails, it is a skulker, and never flies when it can escape by running or hiding in the dense grass of its home. On three occasions I have heard what I am quite sure was the King Rail's call, a loud, startling bŭp, bŭp, bŭp, bŭp, bŭp, uttered with increasing rapidity until the syllables were barely distinguishable, then ending somewhat as it began. The whole performance occupied about five seconds.

211. Rallus erepitans crepitans Gmel. Clapper RatL. (Fig. 39, a.) Ad.-Upperparts very pale greenish olive, the feathers widely margined with gray; wings and tail grayish brown; wing-coverts pale cinnamon much washed with gray; throat white; neck and breast pale, between ochraceous and cream-buff, more or less washed with grayish; belly and sides gray or brownish gray, barred with white. Downy young-Glossy black. L., 14.50; W., 5*00; Tar., 2*00; B., $2 \cdot 50$.

Remarks. - The Clapper Rail may always be known from the King Rail by its generally grayish instead of brownish or blackish upperparts, and its much paler breast and flanks and paler wing-coverts.

Range. - Salt marshes of the Atlantic coast. Breeds from Conn. to N. C.; winters mainly s. of N. J.; casual n. to Maine.

Washington, A. V., one record. Long Island, common S. R., Apl.-Oct., a few winter. Ossining, A. V.

Nest, of grasses, near or on the ground, in grass-grown, salt-water marshes. Eggs, 8-12, buffy white, spotted and speckled with rufous-brown, $1 \cdot 72 \times 1 \cdot 20$. Date, Cobb's Islend, Va., May 19; Oyster Bay, N. Y., May 24.

The Clapper Rail is an inhabitant of grassy, salt-water marshes, and, in the southern parts of its range, of mangrove swamps. It is almost impossible to flush these birds unless their haunts are invaded by an unusually high tide, when a boat may be pushed through the meadows and the birds forced to take wing. I have heard birds calling in the tall grass within a few fect of me, and have made a wild rush in their direction, only to be mocked a moment later by apparently the same bird calling from a point almost within reach. They dodge about over well-traveled pathways like children in a game of blindman's buff.

While not strictly gregarious, they live in colonies, and the call of one bird is sometimes taken up and repeated by others until the marsh vibrates with their cries.

211a. R. c. saturatus Hensh. Lodistana Clapper Ratu. A local race of the Clapper Rail found in the marshes of Louisiana. It is much darker than crepitans, but not so dark as scottii. "W., 5*65; Tar., 1'97; B., 2.27" (Ridgw.).

Range.-Coast of Louisiana.

211b. R. c. scotti Senn. Florida Clapper Rail. Differs from crepitans in being black, fuscous or olive-brown above, with olive-gray margins to the feathers; in having the neck and breast cinnamon-rufous washed with brownish, and in having the belly and flanks black instead of gray. In fact, the general color of scottii suggests a King Rail, but the latter may 


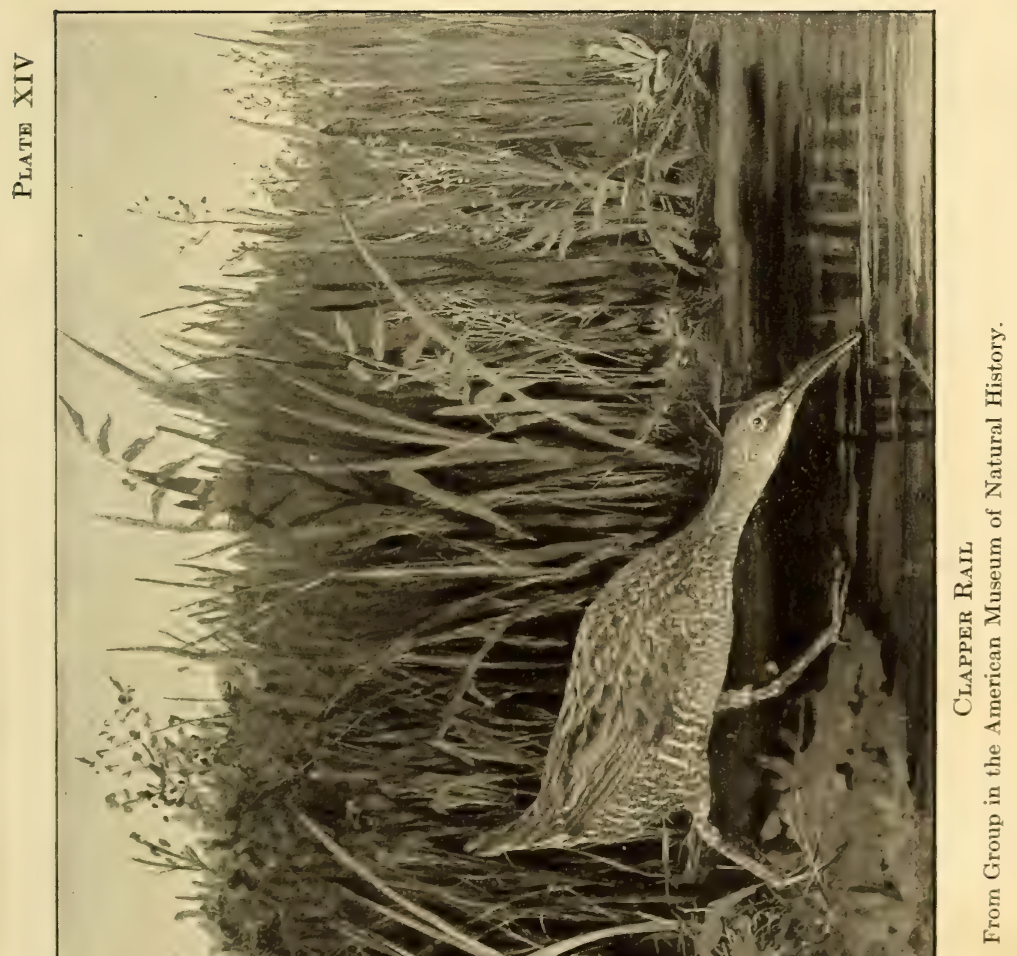



always be known by its mufous wing-coverts and clear cinnamon-rufous neck and breast. W., 5*50; Tar., $1 \cdot 90 ;$ B., $2 \cdot 40$.

Range.- Salt marshes of the Gulf coast of Florida.

Nesting date, Raccoon Pass, La., May 19.

211c. R. c. waynei (Brewst.). WAYNE'S ClapPeR RAIL. "Similar to R. crepitans, but the general coloring much darker, the underparts with more ashy, the under tail-coverts with fewer markings" (Brewst., Proc. N. E. Zoöl. Club, I, 1899, p. 50).

Range.-Salt marshes of the s. Atlantic coast from N. C. to Fla.

Nesting date, McIntosh, Ga., Mch. 29; Ft. Macon, N. C., May 9.

212. Rallus virginianus Linn. VIRGINIA RAIL. Ad.-Upperparts fuscous or black, the feathers bordered by pale grayish brown; wings and tail dark grayish brown; wing-coverts rufous, lores whitish, cheeks gray, throat white, rest of the underparts cinnamon-rufous; flanks and under tailcoverts barred or spotted with black and white. Downy young.-Glossy black. L., 9.50; W., 4:30; Tar., 1:30; B., 1:50.

Range.-N. A. Breeds from B. C., s. Sask., s. Keewatin, Ont., s. Que., and N. B. s. to s. Calif., Utah, Kans., Mo., Ills., N. J., and e. N. C., and in Toluca Valley, Mex.; winters from Ore., Utah, and Colo., to L. Calif. and Guatemala, also in the Lower Miss. States, and from N. C. (casually Mass.) to Fla.; occurs casually n. to n. Que. and N. F.

Washington, probably P. R. Long Island, rather common S. R., Apl.Oct.; a few winter. Ossining, tolerably common S. R., to Sept. 29. Cambridge, locally abundant S. R., Apl. 20-Sept. 25. N. Ohio, common S. R., Apl. 25Sept. 10. Glen Ellyn, not very common S. R., Apl. 25-Sept. 13. SE. Minn., common S. R., May 12.

Nest, of grasses, on the ground in marshes. Eggs, 6-12, pale buffy white, spotted and speckled with rufous-brown, $1.26 \times 96$. Date, Cambridge, May 15; Pewaukee, Wisc., May 20; se. Minn., May 28.

In almost any extensive fresh or brackish marsh, especially if it has beds of cat-tail flags or scattered thickets of low bushes and briers, one may hear in May and June, particularly in the early morning, late afternoon, or during cloudy weather, a succession of grunting sounds not unlike those of a hungry pig. Although by no means loud, they have a pentrating quality which makes them carry to a considerable distance; and they are apt to attract attention even when, as is usually the case, they mingle with the songs of innumerable Red-winged Blackbirds, Marsh Wrens, and other swamp-loving birds. It is no easy matter to trace them to their author, but if you are persevering and at the same time fortunate, you may at length discover him skulking under a bush or behind a tuft of grass. He is the Virginia Rail, an odd-looking bird about the size of a Snipe. If you remain motionless, he may presently come out into fairer view and walk slowly around the edge of some $\quad l$, lifting and putting down his large feet with curious deliberation, cocking up his absurdly short tail at each step, and every now and then stopping to thrust his bill deep into the ooze in search of food. As he pauses to look at you, you are struck by his half-quizzical, half-sinister expression, due, no doubt, to the fact that his eyes are blood-red and deeply sunk in their long, narrow head. Startle him by some sudden movement, and he will do one of three things-dart back into cover as swiftly as a frightened mouse, skip across the pool over 
the floating leaves of the water plants, using both wings and feet, or rise with feebly fluttering wings and hanging legs to fly only a few rods before dropping beyond some intervening screen of grass or bushes. In any case you are not likely to find him again on this occasion.

Besides the grunting sound, the Virginia Rail utters during the breeding season, especially at night and in lowering weather, a guttural cùt, cùtta-cùtta-cùtta, often repeated at brief intervals for hours in succession. This cry appears to be peculiar to the male, and is, no doubt, his love-song. When heard at a distance of only a few yards it has a vibrating, almost unearthly, quality, and seems to issue from the ground directly beneath one's feet. The female, when anxious about her eggs or young, calls $k i-k i-k i$ in low tones, and kiu much like a Flicker. The young of both sexes in autumn give, when startled, a short, explosive kep or kik, closely similar to that of the Carolina Rail.

William Brewster.

214. Porzana carolina (Linn.). SorA. (Fig. 39c.) Ad.-Region about the base of the bill, center of crown, and a line down the middle of the neck black; rest of the breast and throat, sides of the head, and front part of the crown pale blue-gray; rest of the upperparts olive-brown, most of the feathers with black centers, the scapulars and back streaked on each side with white; wings fuscous-brown, their coverts grayish cinnamon, outer edge of first primary white; lower belly white, flanks barred with black and white. Im.- Similar, but without black at the base of the bill or on the throat; breast washed with cinnamon and upperparts darker. L., 8.50; W., 4*30; Tar., 1·30; B., 80 .

Range.-N. A. Breeds from cen. B. C., s. Mackenzie, cen. Keewatin, and Gulf of St. Lawrence s. to s. Calif., Utah, Colo., Kans., Ills., and N. J.; winters from n. Calif., Ills., and S. C. through the West Indies and Cen. Am. to Venezuela and Peru; accidental in Bermuda, Greenland and England.

Washington, common T. V., Mch.-May; July-Nov. Long Island, common T. V., Apl. and May; Aug.-Oct.; rare S. R. Ossining, common T. V. May; Aug. 19-Oct. 24. Cambridge, locally abundant S. R., Apl. 15-Oct. 31. N' Ohio, common S. R., May 1-Oct. 23. Glen Ellyn, tolerably common S. R., Apl. 14-Oct. 17. SE. Minn., common S. R., Apl. 25-Dec. 5.

$N e s t$, of grasses, on the ground in or near marshes. Eggs, 8-15, buffy white or ochraceous-buff, spotted and speckled with rufous-brown, $1: 24 \times$ -90. Date, Cambridge, May 20; se. Minn., June 3; Pewaukee, Wisc., May 19.

The Soras' summer home is in fresh-water marshes, where, if it were not for their notes, the reeds and grasses would long keep the sceret of their presence. But knowing their calls, you have only to pass a May or June evening near a marsh to learn whether they inhahit it. If there, they will greet you late in the afternoon with a clear whistled ker-wee, which soon comes from dozens of invisible birds about you, and long after night has fallen it continues like a springtime chorus of piping hylas. Now and again it is interrupted by a high-roiecd, rolling whinmy which, like a call of alarm, is taken up and repeated by different birds all over the marsh.

They seem so ahsorberl by their musical devotions that even when calling continuously it requires endless patience and keen eyes to see 
the dull-colored, motionless forms in places where one would not suppose there was sufficient growth to conceal them.

Floating silently near the shore on my back in a canoe, I have seen them venture out to feed. With tails erect they step gingerly along, evidently aware of their exposed position, for on the least alarm they dart back to cover. Sometimes they cross small streams by swimming, and they are expert divers.

In the fall they gather in the wild-rice or wild-oat (Zizania aquatica) marshes, and a well-directed stone or unusual noise may bring a series of protesting interrogative kuks or peeps from the apparently deserted reeds. At this season "gunners" in small flat-bottomed boats are poled through the flooded meadows, and the Soras, waiting until the last moment, rise on feeble wing - a mark which few can miss. Numerous puffs of smoke float over the tall grasses, and the dull reports come booming across the marsh with fateful frequency.

The Spotted Crake (213. Porzana porzana)-an Old World representative of our Sora-is recorded as "occasional in Greenland."

215. Coturnicops noveboracensis (Gmel.). Yellow RaIL. (Fig. 39, b.) Ads. - Upperparts black, the feathers bordered with ochraceous-buff and with from one to three narrow white bars; breast ochraceous-buff; middle of the belly white; sides and lower belly black or brownish, barred with white. L., 7•00; W., 3*40; Tar., '95; B., '52.

Range.-Chiefly e. N. A. Breeds from s. Mackenzie, cen. Keewatin, and s. Ungava s. to Minn. and Maine; winters in the Gulf States, rarely in Calif., Ills, and N. C.; casual in Nev., Utah, and Bermuda.

Washington, rare T. V., Mch.-Apl. 14; Oct. 4-Nov. 12. Long Island, rare, probably S. R. Cambridge, rare T. V., in fall. N. Ohio, rare S. R. SE. Minn., rare, May 14-Sept. 24.

Nest, on the ground in grassy marshes. Eggs, 6-10, creamy buff, densely sprinkled and speckled on larger end with rusty brown, $1.12 \times \cdot 83$ (Ridgw.). Date, Winnebago, Ills., May 17.

This little Rail inhabits marshes with others of its family. It seems to know that it can escape its enemies much more easily by hiding in the tangled grasses of its home than by taking wing, and it flies only to avoid actual capture. It can be hunted successfully, therefore, only with dogs.

Nuttall describes its notes as "an abrupt and cackling cry, 'krèk, 'krèk, 'krèk, 'krèk, 'kuk, 'k'kh," and compares them to the croaking of the tree frog, while a captive bird in the possession of J. H. Ames uttered a scolding kik-kik-kik-kik-queah. (Auk, XIX, p. 94.)

216. Creciscus jamaicensis (Gmel.). Little Black RaIl. (Fig. 14.) Ads.-Head, breast and upper belly slate-color; lower belly and wings brownish black, barred or spotted with white; nape dark reddish brown. L., 5•00; W., 2•80; Tar., '80; B., '60.

Range.-E. N. Am. Breeds from s. Ont. and Mass. s. to Kans., Ills., and S. C.; winters from Tex. $c$. through the Gulf States and s. to Jamaica and Guatemala; casual in Bermuda.

Washington, rare, May, June, sept. Long Island, rare, probably S. R. N. Ohio, rare S. R.

Nest, of grasses, on the ground in marshes. Eggs, 8-10, white, thinly 
sprinkled with reddish brown dots, more numerous at the larger end, $1.00 \times$ -80 (Nelson, Bull. Nutt. Orn. Club, I, 1876, 43). Date, Saybrook, Conn., July 10; Garden City, Kans., June 6.

This bird is about as difficult to observe as a field-mouse. It is said to prefer grassy meadows, where it never flies when it can escape by running or hiding. Apparently it is not common. Wayne describes the call of the female as croo-croo-croo-o, like the beginning of the song of the Yellow-billed Cuckoo. To this the male responded kik, kik, kik, kik, or $k u k, k u k, k u k, k u k$.

1900. Allen, J. A., Auk, XVII, 1-8 (historical); Stone, W., Ibid, 171 (nesting).-1901. BREWSTER, W., Ibid, XVIII, 321-328 (in Mass.). - 1905. Wayne, A. T., The Warbler, No. 2.—1910. Bds. So. Car., 39 (nesting).

The Corn Crake (217. Crex crex), a bird of Europe and northern Asia, is casual in Greenland, Bermudas and eastern North America. It is about the size of a Clapper Rail, but has a bill no larger than that of the Sora. The general color of the upperparts is between ochraceous-buff and cream-buff, the feathers with black centers; the wing-coverts and most of the quills are pale rufous; the breast is pale ochraceous-buff; the sides are the same, barred with white; the middle of the belly is white.

218. Ionornis martinicus (Linn.). PURPle Gallindle. Ad.-Front of crown with a bare, bluish plumbeous plate; rest of head and underparts rich dark purplish blue; under tail-coverts white; back shining olive-green; wings light blue tinged with greenish; bill carmine, tipped with pale greenish (in skins, reddish orange, tipped with yellowish); legs yellow. Im.-Upperparts more or less washed with brownish; underparts more or less mottled with white; plate on the head smaller; bill without orange-red. Downy young. -Glossy black, head with numerous white, hairlike feathers; base of the bill yellowish, end black. L., 13*00; W., 7•10; Tar., 2*40; B., from posterior margin of nostril, ' 80 .

Range.-Tropical and subtropical Am. Breeds from Tex., Tenn., and S. C., s. through Mex. and the West Indies to Ecuador and Paraguay; winters from Tex., La., and Fla. southward; irregularly n. in summer to Ariz., Nebr., Wisc., Ont., Que., N. S., and N. B.; accidental in England and Bermuda.

Long Island, two records.

Nest, a platform of reed stalks built in rushes over the water or in grassy marshes. Eggs, 4-10, buffy white, finely speckled with rufous-brown $1 \cdot 60 \times$ 1•15. Date, Avery's Is., La., Apl. 15; Coast S. C., May 21.

This is a common species on ponds densely grown with yellow pondlilies (in Florida known as 'bonnets') and other aquatic plants, where it may be seen walking daintily over the leaves or swimming when occasion requires. It may be easily identified by its bright colors and conspicuous white under tail-coverts. The latter are especially evident when the bird takes wing.

219. Gallinula galeata galeata (Licht.). Florida Gallinule. $A d$. - Dark bluish slate-color; back and scapulars washed with olive-brown; holly whitish; flainks with a few conspicuous white streaks; under tail-coverts white; (rown with a hare, bright-red plate; bill the same color tipped with yollowish; logs loricht-rerl at the tibix. Im.- Similar, but underparts grayish white; (rown plate much snaller and with the bill brownish; no red on the legs. I) mmy youmg. - "Glossy black, the lowerparts sooty along the median line; throat and rherks interspersed with silvery white hairs" (Ridgw.). L., 13.50; W., 7*00; Tar., $2 \cdot 15$; B., from posterior margin of nostril, 80 . 
Range-Tropical and temperate Am. Breeds from cen. Calif., Ariz., Nebr., Minn., Ont., N. Y., and Vt. s. through the West Indies and Mex. to Chile and Argentina, and in the Galapagos and Bermuda; winters from s. Calif., Ariz., Tex., and Ga. southward; casual in Colo., Que., N. S., N. B., and Maine.

Washington, rare T. V., Apl.; Aug.-Oct. Long Island, uncommon T. V., May; Sept. and Oct.; a few breed. Ossining, rare S. R., June 5-Nor. 5. Cambridge, uncommon S. R., May 15-Oct. 25. N. Ohio, common S. R., Apl. 25Sept. 20. Glen Ellyn, rare ard local S. R., May 26. SE. Minn., common S. R.

Nest, of rushes on a bed of rushes or similar slight elevation in marshes, lagoons, or swampy lake sides. Eggs, 8-13, buffy white or ochraceous-buff, spotted and speckled with rufous-brown, $1.80 \times 1.25$. Date, Coast S. C., May 21; Cambridge, June 5; Pewaukee, Wisc., May 20.

There is something about the appearance and habits of Gallinules which always suggests to me the thought that they are chickens which for unknown reasons have been forced to adopt the ways of both Coots and Rails. Indeed, the names Water-hen and Moor-hen are applied to near relatives of our bird.

They frequent marshy, reed- or bush-grown shores of ponds and lakes, walking gracefully through the tangled vegetation. Their flight is short, and, like a Rail, with dangling legs they drop awkwardly to the ground. They swim readily, and when on the water resemble a Coot, though they are by no means so aquatic. Their notes are loud and varied, and during the nesting season they are unusually noisy. Their common note is an explosive chuck; other calls are suggestive of the barnyard, and remind one of the protest of a disturbed brooding hen or even the squawking of a struggling fowl.

Brewster, Wm., Auk, VII, 1-7 (nesting in Mass.).-1910. Miller, R. F., Auk, XXVII, 181-184 (nesting in Pa.).

The European CоOт (220. Fulica atra) inhabits the northern parts of the Old World, and sometimes occurs in Greenland. It closely resembles the American Coot, but lacks the white markings on the edge of the wing and under tail-coverts.

221. Fulica americana Gmel. Соот. (Figs. 21b; 39e.) Ads.-Head and neck blackish; rest of plumage dark, bluish slate-color, paler below; edge of wing, tips of secondaries, and under tail-coverts white; bill whitish, two spots near its tip and crown plate brownish; legs and feet greenish; tocs with scalloped flaps. Im.- Similar, but much whiter below, a slight brownish wash above; crown plate much smaller. Downy young.-Blackish, white below; throat and upperparts with numerous bright orange hairlike feathers; lores red; bill red, tipped with black. L., 15*00; W., 7*50; Tar., 2*25; I3. from posterior margin of nostril, $\cdot 80$.

Remarks. - The Coot bears a general resemblance to the Florida Gallinule, but, aside from the differences in color, the scalloped weblbed feet of the Coot will always serve to distinguish it.

Range.-N. A. Breeds from cen. B. (., s. Mackenzie, Man., Que., and N. B. s. to n. L. Calif., Tex., Tenn., and N. J., and also in s. Mex., s. West Indies, and Guatemala; winters from s. B. C., Nev., Utah, the (Ohio Valley, and Va., s. to Colombia; casual at Fort Yukon, Alaska, and in (irrenland, Lab. and Bermuda.

Washington, common T. V., Mch.-May; Sept. 1-Oct. 31. Long Island, uncommon, T. V., Apl.; not uncommon, Sept.-Nov. (Duteher). Ossining, common T. V., Apl. 28-May 16; Sept. 22-Nov. 13. Cambridge, T. V., rare in Apl.; not uncommon, Sept. 15-Oct. 25. N. Ohir, tolerably common T. 
V., Mch. 15-May 5; Sept. 1-Nov. 1. Glen Ellyn, not common S. R., Apl. 14-Oct. 4. SE. Minn., common S. R., Apl. 3-Oct. 14.

Nest, of reeds, grasses, etc., among reeds in fresh-water marshes. Eggs, 8-15, pale, buffy white, finely and uniformly speckled with chocolate or black, 1.85 × 1.25. Date, St. Clair Flats, Mich., May 17; se. Minn., May 27.

As one might imagine after seeing their lobed feet, Coots are more aquatic than either of the Gallinules. In the Middle States they are found in creeks and rivers with marshy and reed-grown shores, while in Florida they resort in enormous numbers to lakes covered with the yellow lilies locally known as 'bonnets' (Nymphoea); and in some of the large, shallow rivers, like Indian River, they may be found in myriads, associated with Lesser Scaup Ducks.

In my experience they are as a rule quite shy; but near the long railway pier at Titusville, Florida, where shooting is prohibited, they are as tame as domestic Ducks. They evidently know the boundary line between safety and danger, however, and when beyond the protected limits show their usual caution.

Coots swim easily, with a peculiar bobbing motion of the head and neck. When alarmed they patter over the water, using their feet as much as their wings. Both the sound produced and the wake left are characteristic.

They are noisy birds, and when alarmed break out into a great chorus of high, cackling notes which I have heard at a distance of half a mile. Their ivory-white bill is an excellent field-mark, and readily serves to distinguish Coots from Gallinules.

1902. Evermann, B. W., The Osprey, 57 (feeding habits).

\section{ORDER LIMICOLE. SHORE BIRDS}

Although placed in several well-defined family groups, the Limicolæ have many traits in common. Their center of abundance is in the northern parts of the Northern Hemisphere, a large number of species nesting in the Arctic zone. Many of these winter in the southern portions of the Southern Hemisphere, their migrations, therefore, being the most extended of those performed by birds. With the exception of the European Green Sandpiper and its American representative, our Solitary Sandpiper, the Limicolæ all nest on the ground, the nest being more or less simple in structure. The eggs, usually four in number, are large in proportion to the size of the bird, and are decidedly conical in shape, and some species, at least, arrange them in the nest, point down, in order that the exposed upper surface may be decreased in extent and thus be more easily and fully covered by the sitting bird. The young are born with a downy covering, usually of soft browns, grays and buffs, and with more or less pronounced markings, and can run about actively, shortly after hatching. This natal down is soon followed by the juvenal plumage, to the tips of which it may, in places, be seen adhering. 
With some species (e.g., Spotted and Solitary Sandpipers) there is no postjuvenal molt, the postjuvenal plumage being also the first winter plumage. The larger number, however, acquire a winter plumage by postjuvenal molt during the fall migration. At the postnuptial molt, which often occurs during migration, the adults assume a plumage similar to the first winter plumage of the immature bird, when, as a rule, old and young birds, males and females, are alike in color. The spring or prenuptial molt often begins in January or February, which involves all the body feathers, and, in some cases, also the wings and tail (see Dwight).

1888. SеЕвонм, H., Distribution of the Family Charadriidæ, 4to, pp. 524, plls. 21.-1895. ElLIOT, D. G., North American Shore Birds, 8vo, pp. 268; plls. 74 (Francis Harper).-1897. CorY, C. B., How to Know the Shore Birds, 8vo, pp. 89; many ills.-1900. Dwight, J., JR., The Moult of the North American Shore Birds, Auk, XVII, 368-385.-1903. HUNTINGTON, D. W., Our Feathered Game, 8vo, pp. 396, plls. 37. - 1903. Sanford, L. C., Bishop, L. B., Van Dyke, T. S., The Water-Fowl Family, 12 mo, pp. ix +598 , plls. 20 (Macmillan).-1905. Јов, H. K., Wild Wings, 203-255. (Houghton, Mifflin.)-1905. CLARK, A. H., Migrations of Certain Shore Birds, Auk, XXII, 134-140.-1907. RicH, W. H., Feathered Game of the Northeast, 8vo, pp. 432, plls. 87.-1910. CoOKE, W. W., Distribution and Migration of North American Shore Birds, Bull. 35, Biol. Surv. U. S. Dept. Agr., plls. 4, pp. 100.

\section{Family Phalaropodide. Phalaropes. (Fig. 43a.)}

There are three known members of this family: one is confined to the interior of North America, the other two may be called Sea Snipe, and are found in the northern parts of the Northern Hemisphere. The lobate feet of these pelagic species enable them to swim with ease, and during their migrations they may be found in flocks resting upon the sea, far from land. After nesting, their presence on land is largely dependent upon the weather, severe storms sometimes bringing them to our coasts in numbers. Contrary to the usual rule, the female in this family is the larger and more brightly colored -indeed, in the domestic economy of the Phalarope household, the female is male, except in the prime essentials of sex. She does the wooing, takes the lead in selecting the nesting-site, and, although she lays the eggs, the duties of incubation fall upon the male.

1908. Chapman, F. M., Camps and Cruises, 268-271; 321, 322.

KEY TO THE SPECIES

A. Bill over $1 \cdot 10$

224. Wilson's Phalarope.

$B$. Bill under $1 \cdot 10$.

a. Bill very slender; wing under 4.75 . . 223. Northern Phalarope. $b$. Bill stout; wing over 4.75 . . . . 222. Red Phalarope.

222. Phalaropus fulicarius ( $\operatorname{linn}$.). RED PhaLAROPE. Toes webbed at base and with scalloped lobes terminally; bill heavy, wider than deep. $A d$. o in summer.-Crown and chin fuscous; cheeks white; back black, the feathers bordered with cream-buff; wings gray; some of the secondaries and 
tips of greater coverts white; upper tail-coverts rufous; underparts dull, reddish brown, often with scattered white feathers. Ad. $\sigma^{c}$ in summer.Similar, but smaller, crown striped like back, little or no white in cheeks. Juv.-Similar to ads. in winter but upperparts margined with buff, chest washed with buff. Ads. and juv. in winter.-Top of head and underparts white; region about eye and back of neck fuscous; back and scapulars dark pearl-gray; wings grayish fuscous, the coverts and secondaries tipped with white; rump and tail fuscous. L., $8 \cdot 12$; W., $5 \cdot 37$; B., $\cdot 87$; Tar., $\bullet 82$.

Remarks. - The juvenal plumage is worn until October or November. Molting spring birds are strikingly pied below.

Range.-N. and S. Hemispheres. In N. A. breeds from n. Alaska, Melville Island, and n. Ellesmere Land s. to mouth of the Yukon, n. Mackenzie, cen. Keewatin, Hudson Strait, and s. Greenland; winter home unknown but probably on the oceans, at least as far s. as Falkland and Juan Fernandez Islands; migrates along both coasts of U. S.; casual in migration in interior s. to Colo., Kans. Ills., and Md.

Washington, casual, one record, Oct. Long Island, rare T. V., Apl. 30June 5; Sept. 24-Nov. 27. Cambridge, one record, Aug.

Nest, a slight hollow in the ground lined with a few bits of moss and grasses. Eggs, 3-4, similar to those of the following species, $1 \cdot 25 \times 90$. Date, Pt. Barrow, Alaska, June 14.

This pelagic species is found in numbers some distance off the coast; it occurs on our shores rarely, and generally only after storms.

223. Lobipes lobatus (Linn.). Northern Phalarope. Toes webbed at base and with scalloped lobes terminally; bill very slender and sharply pointed. $A d$. o in summer.-Upperparts slaty gray; back and scapulars edged with ochraceous-buff; sides and front of the neck rufous, more or less mixed with slaty gray; rest of underparts white. Ad. $\sigma^{7}$ in summer.- Similar, but upperparts black, and with more ochraceous; sides and front of the neck mixed with fuscous. Ads. in winter and juv.-Upperparts grayish, more or less mixed with white; tips of greater wing-coverts and sometimes part of the secondaries white, occasionally (in ads.) with traces of rufous on the sides of the neck; underparts white, more or less mottled with grayish on the breast. Juv.-Upperparts black, edged with straw-color; forehead white; underparts white, chest sometimes lightly washed with buffy. L., 7·75; W., $4 \cdot 50$; Tar., $\cdot 80$; B., $\cdot 85$.

Range. - N. and S. Hemispheres. In N. A. breeds from n. Alaska, Melville Island, and cen. Greenland s. to Aleutian Islands (including Near Islands), valley of the Upper Yukon, n. Mackenzie, cen. Keewatin, s. James Bay, and $n$. Ungava; winter home unknown, but probably the oceans $s$. of the equator; in migration occurs nearly throughout the U. S. and in Mex., Cen. Am., Bermuda, and Hawaii.

Washington, casual, one record, Sept. Long Island, uncommon, T. V., Ayl. 27-May 29; Aug. 5-Oct. 22. Cambridge, of rare occurrence in spring. SE. Minn., T. V.

Nest, a slight hollow in the ground lined with grass and mosses. Eggs, 3-4, pale olive-gray heavily blotched with deep chocolate, $1 \cdot 18 \times \cdot 83$. Date, Ft. Yukon, Alaska, June 7.

During its presence off our coasts this species resembles the preceding in habits. It is, however, more common, and under proper conditions sometimes occur: in larger flights. I have seen it in great numbers about one hundred miles off Barnegat, New Jersey, in May. For several hours the steamer jassed through flocks of these 'Sea Snipe,' which were swimming on the ocean. They arose in a body at our approach, and in close rank whirled away to the right or left in search 
of new feeding-grounds. On March 10, when sailing to Florida, I saw Phalaropes in numbers, doubtless of both this and the preceding species, off the coast of North Carolina.

224. Steganopus tricolor Vieill. Willon's Phalarope. Ad. o in summer.-Top of the head and middle of the back pearl-gray, nape white; a black streak passes through eye to side of neck, and, changing to rufouschestnut, continues down the sides of the back and on scapulars; neck and upper breast washed with pale, brownish rufous; rest of underparts and upper tail-coverts white. Ad. o in summer.-Upperparts fuscous-brown, bordered with grayish brown; upper tail-coverts, nape, and a line over the eye white or whitish; sides of the neck and hreast washed with rufous; rest of the underparts white. Ads. and juv. in winter.-Upperparts gray, margined with white; upper tail-coverts white; wings fuscous, their coverts margined with buffy; underparts white. Juv.- "Top of head, back, and scapulars dusky blackish, the feathers distinctly bordered with buff; wingcoverts also bordered with pale buff or whitish; upper tail-coverts, superciliary stripe, and lowerparts white, the neck tinged with buff" (Ridgw.). ơL., 8.75; W., 4.75; Tar., 1*20; B., 1·20. ㅇ L., 9.50; W., 5·25; Tar., 1·30; B., $1 \cdot 30$.

Range.-N. and S. A. Breeds from cen. Wash., cen. Alberta, and Lake Winnipeg s. to cen. Calif., s. Colo., s. Kans., n. Iowa, and nw. Ind.; winters from cen. Chile and cen. Argentina s. to Falkland Islands; casual in migration on Pacific coast from s. B. C. to L. Calif., and on Atlantic coast from Maine to N. C.

Long Island, three records, Aug., Sept. and Oct. N. Ohio, casual T. V. SE. Minn., common S. R., May 12-Sept. 13.

Nest, a shallow depression in soft earth lined with a thin layer of fragments of grass. Eggs, 3-4, cream-buff or buffy white, heavily blotched with deep chocolate, $1.28 \times 94$. (See Nelson, Bull. Nutt. Oin. Club, II, 1879, 38-43.) Date, Minor Co., S. D., May 25; s. Saskatchewan, June 15, downy young.

This beautiful bird is a common summer resident of our interior prairie sloughs, and ranges westward as far as the San Joaquin valley of California. It feeds about the shores and of ten swims gracefully with a nodding motion of the head. Although the female does not incubate, she appears to be keenly interested in the welfare of the nest, and when I have flushed a sitting male, he has soon been joined by his mate who seemed to share his anxicty. Pairs of birds which evidently had young would utter a soft qua or quoli and fly about me with a slow, jerky, halting flight and a peculiar sinuous stretching of the neck. Usually the female led.

\section{Family Recurvirostride. Avocets and Stilts.}

The twelve species comprising this family are distributed througnout the warmer parts of the world. They are generally found in flocks, and may be called Wading Snipe. They feed in shallow water, wading to their heels, and when necessary swim with case.

225. Recurvirostra americana Gmel. AmErican Avorft. (Fig. 12.) Bill slender, recurved. Ads. in summer.-Head and nerk rinnamon-rufous, back and tail white, scapulars and primaries black; middle eoverts, tips of the greater ones, and part of secondaries white; belly white, bill turned 
upward. Ads. in winter and juv.-Generally similar, but head and neck white or pearl-gray. L., 16.50 ; W., 9.00; Tar., 3.75; B., 3.75.

Range.-N. A. Breeds from e. Ore., cen. Alberta, and s. Man. (rarely n. to Great Slave Lake) s. to s. Calif., s. N. Mex., nw. Tex., n. Iowa, and cen. Wisc.; winters from s. Calif., and s. Tex. to s. Guatemala; casual from Ont. and N. B. to Fla. and the West Indies, but rare e. of the Miss. River.

Long Island, two records.

Nest, a slight depression in the ground, near water. Eggs, 3-4, pale olive or buffy clay-color, thickly spotted with chocolate, $1^{\circ} \cdot 95 \times 1 \cdot 35$. Date, Lovelana, Colo., June 3.

Avocets are common birds in parts of the interior, but are rare on the Atlantic coast. They frequent shores and shallow pools, and in searching for shells, crustaceans, etc., their peculiar recurved bill is used in a most interesting manner. Dropping it beneath the surface of the water until its convexity touches the bottom, they move rapidly forward, and with every step swing their bill from side to side, as a mower does his scythe. In this way they secure food which the muddy water would prevent them from seeing. They are very noisy when nesting and with a loud, sharp plee-eek charge bravely toward one, swinging aside only when a few feet away.

226. Himantopus mexicanus (Müll.). BlaCK-NECKed Stilt. $A d$. $0^{7}$.-A white spot above and another below eye; front of head, front of neck, lower back, rump, and underparts white; tail grayish; rest of plumage glossy, greenish black.' $A d$. \%.- Similar, but with back fuscous-brown. Juv.Similar, but whole upperparts margined with rusty. L., 15.00; W., 9.00; Tar., 4.15; B., 2*00.

Range.-Temperate N. A. and n. S. A. Breeds from cen. Ore., n. Utah. and s. Colo. to s. Calif., s. N. Mex., s. Tex., coast of La., and in Mex., and from cen. Fla., and Bahamas throughout the West Indies to n. Brazil and Peru; formerly bred to N. J.; winters from s. L. Calif., s. Tex., s. La., and s. Fla. s. through Cen. Am. and the West Indies to n. Brazil, Peru, and the Galapagos; casual north in migration to Nebr., Wisc., and N. B.

Long Isiand, two records.

Nest, near water, a slight depression in the ground lined with grasses. Eggs, 3-4, olive or buffy clay-color, thickly spotted with chocolate, 1.70 $\mathrm{X}$ 1.25. Date, Fla. Keys, Apl. 25; Brownsville, Tex., Apl. 26.

Stilts are fond of wading in shallow ponds in both fresh and salt marshes, and are graceful and alert in their movements. During the nesting season they become very noisy, and express their solicitude for their eggs or young by the most surprising demonstrations. After nightfall I have heard Stilts utter their sharp $i p$-ip-ip as they darted erratically about over the marshes.

1908. Chapman, F. M., Camps and Cruises, 288 (nesting).

26. Family Scolopacidæ. Snipes, Sandpipers, Etc. (Figs. $42 a, b, 43 b, c$.)

About one hundred species are considered as belonging to this family. They are distributed throughout the world, but during the breeding season are mostly confined to the northern parts of the Northern Hemisphere. Some forty-five species are found in North America. 
With the Plovers they constitute the great group known as Shore Birds or Bay Birds, and with few exceptions they are rarely found far from the vicinity of water. Generally speaking, they are more abundant on the coast than in the interior, but many species are quite as numerous inland as they are near the sea. As a rule, they migrate and pass the winter in flocks, but they are not gregarious during the nesting season.

Their long bills serve the purpose of both probes and forceps. Most of the species probe the soft mud for food, while some are known to have the power of moving the upper mandible independently of the lower one, curving it at the tip as one would a finger.

Snipes are not supposed to be song birds, but during the breeding season many species are highly and peculiarly musical, and at other times of the year they utter characteristic whistles, to an imitation of which the birds are quick to respond.

\section{Bill $2 \cdot 00$ or over.}

\section{KEY TO THE SPECIES}

A. Axillars* barred with black.

a. Bill curved downward.

$a^{1}$. Bill over $3 \cdot 00$, under $4 \cdot 50 \ldots 265$. Hudsonian Curlew.

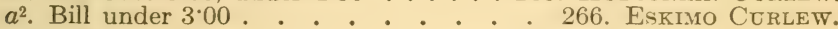

$a^{3}$. Bill over 450 . . . . 264. LONG-BILLEd CURLEW.

b. Bill straight or curved slightly upward.

$b^{1}$. Tail-feathers with numerous black bars.

$b^{2}$. Wing over $7^{\circ} 00$, primaries black or fuscous.

254. Greater Yellow-Legs.

$b^{3}$. Wing over $7^{\cdot} 00$, inner web of primaries buff or rufous.

$b^{4}$. Wing under $7 \cdot 00$, bill widened and pitted at the tip.

249. MaRBLED Godwit.

231. DOWITCHER. 232. LONG-BILLED DOWITCHER.

$c^{1}$. Tail black with a broad rufous tip or marked with rufous.

$c^{2}$. Outer web of primaries with rufous bars.

227. EUROPEAN WOODCOCK.

$B$. Axillars not barred.

227. EUROpEAN WoOdCOCK.
230. Wilson's SNipe.

a. Axillars rufous or ochraceous-buff.

$a^{1}$. Bill over $5^{\circ} 00$, much curved downward.

$a^{2}$. Bill nearly straight, between $3 \cdot 50$ and $5^{\circ} 00$.

264. Long-Billed CURlew.

249. Marbled Godwit.

$a^{3}$. Bill straight, under $3 \cdot 50$

228. AMERICAN WOODCOCK.

b. Axillars black.

$b^{1}$. Underparts chestnut-rufous, barred with black.

251. Hudsonian Godwit.
$b^{2}$. Underparts white, with or without blackish bars.
258 . WILLET. 258a. Western Willet.

II. Bill under $2^{\circ} 00$.

1. Tail with cross-bars.

$A$. Wing over $5^{\circ} 75$.

a. Outer tail-feathers white, more or less barred; outer primary without bars . . . . . 255. YELLOW-LEGS,

b. Outer primary with numerous black bars. 261. UpLand Plover. 
$B$. Wing under $5 \cdot 75$.

a. Underparts white, with numerous round blackish spots; upperparts brownish gray, barred with blackish.

263. SPOTTED SANDPIPER.

7 Underparts white, breast streaked with blackish; upperparts fuscous, spotted with white . . 256. Solitary SANDPIPER.

c. Underparts tinged with buffy, inner web of outer primary speckled with blackish . . . 262. BUFF-BREASTED SANDPIPER.

$d$. Underparts white, breast washed with grayish, inner primaries and secondaries with a concealed white patch.

2. Tail without cross-bars.

263. Spotted SANDPIPER (Im.).

A. Toes 4 .

a. Bill over $1 \cdot 10$.

$a^{1}$. Middle upper tail-coverts with cross-bars or streaks.

$a^{2}$. Tarsus over 1.50 . . . 233. STILT SANDPIPER.

$a^{3}$. Tarsus under 1.50 , wing under 6.00 244. CURLEW SANDPIPER.

$a^{4}$. Tarsus under 1.50 , wing over 6.00 . . . . 234. KNot.

$b^{1}$. Middle upper tail-coverts without cross-bars or streaks.

$b^{2}$. Middle upper tail-coverts black or fuscous, without bars; bill straight.

$b^{3}$. Tarsus under 150; upperparts blackish, more or less margined with gray . . . 235. PURPLE SANDPIPER.

$b^{4}$. Tarsus under 1.50 ; upperparts more or less margined with rufous. . . . . 239. PeCtORAL SANDPIPER.

$b^{5}$. Tarsus over $150 \ldots \ldots$. RUFF.

$c^{2}$. Middle upper tail-coverts grayish, bill curved slightly downward . . 243a. RED-BACKED SANDPIPER.

b. Bill under $1 \cdot 1 \dot{0}$.

$b^{1}$. Wing under $4 \cdot 00$.

$b^{2}$. Toes partly webbed.

246. Semipalmated Sandpiper. 247. Western Sandpiper.

$b^{3}$. Toes not webbed . . . . 242. LeAst SANDPIPER.

$c^{1}$. Wing over $4^{*} 00$.

$c^{2}$. Inner webs of primaries plain.

$c^{3}$. Breast white or whitish, streaked or spotted with blackish; middle upper tail-coverts white .

240. WHITE-RUMPED SANDPIPER.

$c^{4}$. Breast buffy, heavily spotted or streaked with blackish; middle upper tail-coverts black, slightly margined witt rufous. 239. Pectoral Sandpiper.

$c^{5}$. Breast buffy lightly spotted or streaked with black; middle upper tail-coverts fuscous, lightly margined with buffy.

$d^{2}$. Inner webs of primaries speckled. 241. BAIRD's SANDPIPER. 262. BUfF-BREASTED SANDPIPER.

B. Toes 3

228. Philohela minor (Gmel.). AMerican Woodcock. (Pl. VIII. Figs. 11, 15.) Ads.-Front of crown slaty, washed with buff, an indistinct blackish line in its center, and another from eye to bill; back of head black, with two or three bars of ochraceous-buff; rest of upperparts black, margined with slaty and barred and mottled with rufous or ochraceous-buff; tip of tail ashy gray above, silvery beneath; underparts between ochraceous buff and rufous; outer three primaries very narrow and much stiffened. L., 11.00; W., 5*40; Tar., 1*25; B., 2*90.

Range.-E. N. Am. Breeds from ne. N. D., s. Man., n. Mich., s. Que. and N. S. s. to s. Kans., s. La., and n. Fla.; winters from s. Mo., the Ohio Valley, and s. N. J. (rarely Mass.) s. to Tex. and s. Fla.; ranges casually to Sask., Keewatin, Colo., N. F., and Bermuda. 
Washington, rather common from Feb. to Nov.; a few winter. Long Island, rare S. R. Apl.-Nov., a few winter. Ossining, common S. R., Feb. 19-Dec. 2. Cambridge, rare S. R., uncommon T. V., Mch. 15-Nov. 10. N. Ohio, tolerably common, S. R., Mch. 10-Oct. 20. Glen Ellyn, not common S. R., May 17 (doubtless earlier) to Sept. 18. SE. Minn., Apl. 5-Oct. 18.

Nest, of a few dry leaves, on the ground in the woods. Eggs, 4, buffy, distinctly and obscurely spotted with shades of rufous, $1.60 \times 1.23$. Date, Caper's Is., S. C., Feb. 13; Lower Cedar Point, Md., Feb. 25; Cambridge, Apl. 15; Wheatland, Ind., Mch. 4; Petersburg, Mich., Apl. 16.

During the spring and early summer this Owl among Snipe haunts low, wooded bottom-lands; in August, while molting, it resorts to cornfields near woods, and in the fall migrating birds frequent wooded uplands. But at all times it requires a soft, moist earth in which it may easily probe with its long bill for its fare of earthworms. The holes it makes are known as 'borings.' They are generally found in little groups, and are, of course, certain evidence of the presence of Woodcock. Gurdon Trumbull discovered that the Woodcock can move the tip of its upper mandible independently of the lower one, and this organ is made to act as a finger to assist the bird in drawing its food from the ground. (Forest and Stream, XXXV, 1890, 412.)

The flight of the Woodcock is sometimes accompanied by a high, whistling sound produced by its narrow, stiffened primaries in beating the air. When flushed near its nest or young, the parent bird generally feigns lameness or a broken wing, and leads the intruder some distance from its treasures before taking wing.

The cloak of night alyvays lends a certain mystery to the doings of nocturnal birds, and more of ten than not their habits justify our unusual interest in them. Few of the mating evolutions of our birds are more remarkable than the sky dance of the Woodcock. He begins on the ground with a formal, periodic peent, peent, an incongruous preparation for the wild rush that follows. It is repeated several times before he springs from the ground, and on whistling wings sweeps out on the first loop of a spiral which may take him three hundred feet from the ground. Faster and faster he goes, louder and shriller sounds his wing-song; then, after a moment's pause, with darting, headlong flight, he pitches in zigzags to the earth, uttering as he falls a clear, twittering whistle. He generally returns to near the place from which he arose, and the peent is at once resumed as a preliminary to another round in the sky. In the gray of early morning this strange performance is repeated.

1894. Brewster, W., Auk, XI, 291-298 (song).

The European Woodcock (227. Scolopax misticola) hears a general resemblance to our Woodeock, but is murh larerer; the underparts are barred with black, the wings are barred with rufous, and the outror primarios are not emarginate. It is of accidental occurrence in eastern North Amcrica.

230. Gallinago delicata (Ord). Wilson's Snipe. Ads.-Upperparts black, barred, bordered, and mottlerl with different shades of cream-buff; wings fuscous; outer edge of outer prinary and tips of greater coverts white; throat white; neck and breast ochraceous-buff, indistinctly streaked with blackish; belly white, sides barred with black; under tail-coverts buffy, 
barred with black; outer tail-feathers barred with black and white, inner ones black, barred with rufous at their ends and tipped with whitish. L., 11.25; W., 5.00; Tar., 1*20; B., 2.50.

Range.-N. A. and n. S. A. Breeds from nw. Alaska, n. Mackenzie, cen. Keewatin, and n. Ungava s. to n. Calif., s. Colo., n. Iowa, n. Ills., Pa., and n. N. J.; winters from n. Calif., N. Mex., Ark., and N. C., through Cen. $\mathrm{Am}$. and West Indies to Colombia and s. Brazil; remains in winter casually and locally n. to Wash., Mont., Nebr., Ills., and N. S.; accidental in Hawaii, Bermuda, and Great Britain.

Washington, common T. V., Mch. 9-May 11; Aug. 30-Nov. 18, occasional in winter. Long Island, common T. V., Mch. and Apl.; Aug.-Oct., a few winter. Ossining, tolerably common T. V., Mch. 20-May 6; Oct. 6-Nov. 20. Cambridge, common T. V., Apl. 6-May 6; Sept. 12-Nov. 15. N. Ohio, common T. V., Mch. 19-May 15; Sept. 15-Oct. 30. Glen Ellyn, common T. V., Mch. 26-May 11; Sept. 1-Nov. 4. SE. Minn., common S. R., Mch. 11-Oct. 31 ., A. V. in winter.

Nest, of grasses, on the ground in marshy places. Eggs, 3-4, olive, claycolor, or brownish ashy, heavily marked with chocolate, principally at the larger end, 1.60 × 1'17. Date, Lake Co., Ills., Apl. 24; se. Minn., May 10.

Wilson's Snipe frequents fresh-water meadows and swamps, and in spring is often found in low-lying swales in meadows or mowing fields, but, excepting in very dry seasons, it seldom alights on salt marshes. At times, especially in winter or early spring, when the meadows are covered with snow or ice, it resorts to springy runs wooded with alders, birches, and maples, but as a rule it prefers open places. Two things are essential to its requirements-ground so thoroughly water-soaked as to afford slight resistance to its long and highly sensitive bill when probing, and such concealment as tussocks, hillocks, or long grass afford, for, unlike the Sandpipers, the Snipe rarely ventures out on bare mud flats, save under cover of darkness. Although less strictly nocturnal than the Woodcock, it feeds and migrates chiefly by night or in 'thick' weather. Its migratory movements are notoriously erratic, and meadows which one day are alive with birds may be quite deserted the next, or the reverse.

Dear to our sportsmen is Wilson's Snipe, partly because of the excellence of its flesh, but chiefly from the fact that it furnishes a mark which taxes their skill to the utmost, and which no mere novice need hope to hit, unless by accident; for the bird's flight is swift and tortuous, and it springs from the grass as if thrown by a catapult, uttering a succession of hoarse, rasping scaipes which have a peculiarly startling effect on inexperienced nerves.

In the springtime-and occasionally in autumn also-Wilson's Snipe mounts to a considerable height above his favorite meadows and darts downward with great velocity, making at each descent a low, yet penetrating, tremulous sound which suggests the winnowing of a domestic Pigeon's wings, or, if heard at a distance, the bleating of a goat, and which is thought to be produced by the rushing of the air through the wings of this Snipe. The performance may be sometimes witnessed in broad daylight when the weather is stormy, but ordinarily it is reserved for the morning and evening twilight and for moonlight nights, when it is often kept up for hours in succession. 
Besides this 'drumming' or 'bleating,' as it is called, the Snipe,

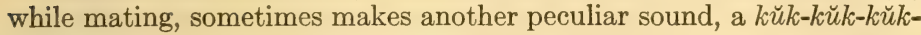

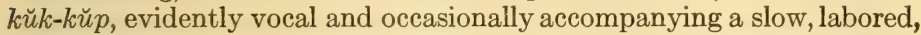
and perfectly direct flight, at the end of which the bird alights on a tree or fence-post for a few moments.

William Brewster.

1902. GaULt, B. T. Wilson Bull., 7-10 (food habits).

The European SNipe (229. Gallinago gallinago) inhabits the northern parts of the Old World, is of frequent occurrence in Greenland, and accidental in the Bermudas.

The Great Snipe (230.1 Gallinago media), an Old World species, has been taken once on Hudson Bay (Coues, Auk, XIV, 1897, 209).

231. Macrorhamphus griseus griseus (Gmel.). DowITCHER. (Figs. $42 a, 43 c$.) Ads. in summer. - Upperparts, tertials, and wing-coverts black, the feathers edged or barred with ochraceous-buff or rufous; rump, upper tail-coverts, and tail barred with black and more or less ochraceous-buff; primaries fuscous; underparts dull, pale rufous, whitish on belly, more or less spotted and barred with black. Ads. and Juv. in winter.-Upperparts brownish gray; rump and tail barred with black and white; throat and breast washed with ashy, belly white, sides and under tail-coverts barred with black. Juv.-Upperparts black, the feathers edged with rufous; rump and tail barred with black and white, and sometimes washed with rufous; secondaries widely edged with white; underparts more or less washed with ochraceous-buff and obscurely spotted with blackish. L., 10.50; W., 5.75; Tar., $1 * 30$; B., $2 \cdot 05-2 \cdot 50$.

Remarks.- The barred tail and tail-coverts, with the peculiar flattened, pitted tip of the bill, are characteristic of this species.

Range.-E. N. and S. Am. Breeding range unknown, but probably $\mathrm{n}$. Ungava; winters from Fla. and the West Indies s. to n. Brazil; in migration regularly on the Atlantic coast, and occasionally in Ills., Ind., and Ont.; accidental in Greenland, Bermuda, Great Britain, and France.

Washington, casual, one specimen, Sept. Long Island, common T. V., May 15-30; July 12-Sept. 29.

Eggs, 4, light buffy olive, distinctly spotted and speckled especially about the larger end, with deep brown, $1.65 \times 1.13$ (Ridgw.).

The Dowitchers are among our best-known Bay Birds. They migrate in compact flocks which are easily attracted to decoys by an imitiation of their call. Mud-flats and bars exposed by the falling tide are their chosen feeding-grounds. On the Gulf coast of Florida I have seen several hundred gathered in such close rank that they entirely concealed the sandbar on which they were resting.

232. M. g. scolopaceus (Say). LONG-BILLED Dowitcher. Ads. in summer. -Similar to the preceding, but averaging larger; the bill especially is longer, the underparts are more uniformly rufous, and the sides are more heavily barred with black. Ads. in winter and Juv.-To be distinguished from the corresponding stages of griseus only by their larger size. W., 6.00; Tar., 1.50; B., $2 \cdot 10-2 \cdot 90$.

Range.-W. N. and S. Am. Breeds from Point Barrow to mouth of the Yukon, e. to nw. Mackenzie; winters from La., Fla., and Mex. s., probably to S. A.; in migration most abundant in w. Miss. Valley; casual on the Atlantic coast from Mass. southward and on the $n$. coast of $e$. Siberia.

Washington, casual, seven shot in Apl. Long Island, rare T. V., in fall, July 23-Oct. 13; one record in spring. 
Eggs, 4, not distinguishable from those of the preceding species. Date, St. Michael's, Alaska, May 23.

This is a bird of the interior and Western States, and occurs on our coasts as a rare but regular late fall migrant. It resembles the preceding species in habits, but the baymen who 'gun' for Snipe say they can recognize it by its somewhat different notes. Like the Woodcock, Wilson's Snipe, and its near ally, $M . g$. griseus, the male utters a flight song in the nesting season. It is well described by Mr. E. W. Nelson in his Report on Collections made in Alaska, p. 101.

233. Micropalama himantopus (Bonap.). Stilt SANDPiper. Ads. in summer.-Upperparts black, bordered with grayish and buffy; earcoverts and an indistinct line around back of head rufous; secondaries grayish, edged with white; primaries fuscous; rump ashy; upper tail-coverts barred with black and white; outer tail-feathers with broken dusky bars, inner ones with central streaks or margins of brownish gray or white; underparts white, heavily barred with fuscous. Ads. and Juv. in winter.-Upperparts brownish gray; upper tail-coverts white; tail white, margined with brownish gray; underparts white; throat, neck and sides indistinctly streaked or washed with grayish. Juv.-Similar, but upperparts blackish, margined with ochraceous-buff. L., 8*25; W., 5.00; Tar., 1.60; B., 1.55.

Remarks. - The distinguishing characters of this species are the flattened, pitted tip of the bill, in connection with the very long tarsi.

Range.-N. and S. A. Breeds near the coast of Mackenzie and probably s. to cen. Keewatin; winters in S. A. s. to Uruguay and Chile; casual in winter in s. Tex., and Mex.; in migration occurs in w. Miss. Valley, West Indies, and Cen. Am.; less common on the Atlantic coast, and casual in B. C., N. F. and Bermuda.

Washington, casual, one record, Sept. Long Island, not uncommon T. V., May; July to Oct. 10 (Dutcher). SE. Minn., uncommon T. V., May 14Aug. 20.

Eggs, 3-4, pale grayish buff, or grayish buffy white, boldly spotted with rich vandyke-brown and purplish gray, 1*42 × 1.00 (Ridgw.). Date, Anderson River, Mack., June 23.

Colonel N. S. Goss, in his admirable "Birds of Kansas," writes that he has observed this species along the edges of old channels of rivers or muddy pools of water, in which it wades while feeding; immersing the head and feeling with its sensitive bill in the thin mud for food. It moves about rather slowly as compared with the true Sandpipers, and at times will try to avoid detection by squatting close to the ground, flying only as a last resort, and then darting swiftly away with a sharp tweet, tweet.

234. Tringa canutus Linn. Kлот. (See Figs. 42b, 43b.) $A d s$. in summer.-Upperparts barred and streaked with black and white and rufous; tail ashy gray, narrowly margined with whitish; underparts dull rufous; lower belly white or whitish, sides sometimes with black bars. (See Auk, X, 1893, p. 25.) Ads. and Juv. in winter.-Upperparts plain brownish gray; upper tail-coverts barred with black and white, tail brownish gray; breast and sides barred with black, belly white. Juv.-Upperparts pale brownish gray; head streaked with blackish; back, wing-coverts, and scapulars with distinct black and white borders; upper tail-coverts barred with blackish; tail ashy gray, narrowly margined with white; underparts white; lorcast finely streaked or spotted with blackish; flanks barred or streaked with blackish. L., 10.50; W., 6.75; Tar., 1.20; B., 1·30. 
Range.-N. and S. Hemispheres. Breeds from n. Ellesmere Land s. to Melville Peninsula and Iceland, and also on Taimyr Peninsula, Siberia; winters s. to s. Patagonia, and from the Mediterranean to S. Africa, India, Australia, N. Zealand; casual in winter on the Atlantic coast of U. S.; in migration occurs on the Atlantic coast of N. A., and over most of the E. Hemisphere; rare in the interior of $\mathrm{N}$. A., and on the Pacific coast.

Long Island, not uncommion T. V., May 15-June 10; July 15-Nov. (Dutcher). SE. Minn., uncommon T. V., Sept. 7.

Eggs, one specimen collected in the vicinity of Fort Conger by General Greely, is described as "light pea-green, closely spotted with brown in small specks about the size of a pinhead," $1.10 \times 1 \cdot 00$ (see Merriam, $A u k$, II, 1885, 313). A breeding-place of thirty pairs was discovered in northeast Greenland by the Danish expedition of 1906-8. (See Geog. Journ., XXXV, 541 and $I b i s, 1910,766$. )

Knots feed along the beaches on the small crustaceans and mollusca brought in by the waves, and they also frequent muddy places where, like the true Snipe, they probe the ground for food. They decoy with ease, 'bunching' so closely as they wheel into the stools that the entire flock is sometimes killed by a single discharge. Mr. George H. Mackay, in one of his careful and detailed studies of our Shore Birds, describes their notes as a soft wah-quoit and a little honk. The first is particularly noticeable when flocks are coming to the decoys (see $A u k, \mathrm{x}, 1893,25-35$ ).

235. Arquatella maritima maritima (Brünn.). PURPLE SANDPIPER. Ads. in summer.-Upperparts black, margined with ochraceous-buff and cream-buff; wings fuscous-gray, greater coverts margined with white and some secondaries entirely white; upper tail-coverts fuscous, outer tailfeathers ashy gray, inner ones fuscous; throat and breast brownish gray, streaked with black; belly white, sides and under tail-coverts streaked with brownish gray. Ads. and Juv. in winter.-Head, neck, breast, and sides ashy, the two latter margined with white; back fuscous, margined with ashy; wings fuscous, the coverts, secondaries, and tertials distinctly bordered with white; upper tail-coverts and middle tail-feathers black or fuscous, outer tail-feathers ashy; belly and linings of the wings white. L., 9.00; W., 5.00; Tar., 9.00; B., 1*40.

Remarks. - The brownish gray or ashy breast of this species is a good distinguishing character.

Range.-N. Hemisphere. Breeds from Melville Is., Ellesmere Land, and n. Greenland s. to Melville Peninsula, Cumberland Sound, and s. Greenland, and in Norway, Russia, Siberia, Iceland, and Faroe Islands; winters from s. Greenland and N. B., to L. I.; casual in migration to the Great Lakes, Ga., Fla., and Bermuda, and in the E. Hemisphere s. to Great Britain and the Mediterranean.

Long Island, uncommon W. V., Nov. 1-Mch. 1 (Dutcher). Cambridge, one instance, Oct.

Eggs, 3-4, olive clay-color or brownish ashy, heavily marked with rufousbrown, 1.45 × 1.08. Date, Umanak, Greenland, June 19; Faroe Ids., May 31.

This bird might be called Winter Snipe or Rock Snipe. Indeed, I find the latter name has been applied to it from its habit of frequenting rocky coasts, where it secures its food in the algae attached to rocks exposed by the falling tide.

239. Pisobia maculata (Vieill.). Pectoral Sandpiper. Ads. in summer.-Upperparts black, the feathers all heavily bordered with pale 
ochraceous-buff; rump and upper tail-coverts black, lightly tipped with ochraceous-buff; middle tail-feathers longest, pointed and margined with buffy; outer tail-feathers brownish gray, narrowly margined with white; throat white, neck and breast heavily streaked with black and buffy; rest of underparts white. Ads. and Juv. in winter. - Similar, but ochraceous-buff of upperparts replaced by rufous, and breast heavily washed with buffy. L. 9.00; W., 5*40; Tar., 1*10; B., 1*15.

Remarks. - This bird somewhat resembles both $P$. fuscicollis and $P$. bairdi, but it differs from them in its larger size, black instead of white or fuscous upper tail-coverts, and longer, more pointed middle tail-feathers.

Range. -N. and S. A. Breeds on the Arctic coast from n. Alaska to mouth of Yukon and ne. Mackenzie; winters in S. A. from Peru and Bolivia to n. Chile, Argentina, and cen. Patagonia; in migration very rare on Pacific coast south of B. C., except in L. Calif.; common in fall migration in Miss. Valley and on the Atlantic coast, rare in spring; casual in ne. Siberia, Unalaska, and Greenland; accidental in Hawaii and England.

Washington, common T. V., Apl.; Aug. 23-Oct. 22. Long Island, T. V., rare in May, common from July 15 to Nov. 1 . Ossining, rare T. V., Sept. 10-Oct. 16. Cambridge, uncommon T. V., Oct. 5-20. N. Ohio, common T. V., Apl. 1-May 5. Glen Ellyn, common T. V., Apl. 4-May 10; Aug. 5Sept. 28. SE. Minn., common T. V., Apl. 23; Sept. 15.

Eggs, 4, drab, sometimes with a greenish tinge, blotched with clear umber-brown markings, more numerous at the larger end, 1.50 × 1.09 (Murdoch). Date, Pt. Barrow, June 18.

The names Grass Snipe and Krieker describe with equal truth and conciseness the haunts and notes of this Snipe. It frequents wet, grassy meadows rather than beaches, and, although it flies in flocks, the birds scatter while feeding and take wing one or more at a time. They thus remind one of Wilson's Snipe. Their note is a squeaky, grating whistle. They will respond to an imitation of it, but do not decoy so readily as the larger Bay Birds. Mr. E. W. Nelson writes that during the breeding season the male inflates its breast and throat until they are double their normal size, and utters a deep, hollow, resonant note. (Rep. on Nat. Hist. Coll. made in Alaska, p. 108.)

240. Pisobia fuscicollis ( $V$ ieill.). White-RUMPED SANDPIPER. Ads. in summer.-Upperparts black, edged with rufous; rump grayish fuscous, margined with ashy; longer upper tail-coverts white, with sometimes brownish gray markings; central tail-feathers fuscous, outer ones brownish gray, upper throat white; neck, breast, and sides distinctly streaked and spotted with hlack and more or less washed with ochraceous-buff. Ads. and Juv. in winter. - "Upperparts plain brownish gray, with indistinct, narrow mesial streaks of dusky; otherwise as in summer, but streaks on chest, etc., less distinct" (Ridgw.). Juv.- Similar to summer examples, but the feathers of the upperparts with rounded whitish or ochraceous-buff tips; breast less distinctly streaked. L., 7•50; W., 4*90; Tar., 90 ; B., 95 .

Remarks. - The white upper tail-coverts distinguish this species.

Rangr.-N. and S. A. Brceds along the Arctic coast from nw. Mackenzie to (iumberland Is.; has occurred in summer w. to Point Barrow and e. to Greenlami; winters from Paraguay to s. Patagonia and the Falkland Islands; in migration most abundant in the Miss. Valley, less so on the Atlantic coast; (asual in Bermuda, Great Britain, the West Indies, and Cen. Am. T. V., Sept. N. Ohio, casual T. V.

Eigss, 34 , light olive, or olive brownish, spotted (usually rather finely) with decp brown and dull, purplish gray, 1.37 $\times{ }^{\circ} 94$ (Ridgw.). Date, Herschel Is., June 10 (Thayer Coll.). 
"They frequent the sandy beach as well as the marshy shores upon the coast, but inland seem to prefer the edges of pools of water upon the uplands. They move in small flocks, are very social, often associating with other waders, are not as a rule shy or timid, and, when startled, usually fly but a short distance, drop back, and run about in an unconcerned and heedless manner, picking up the minute forms of life that usually abound in such places, occasionally uttering a rather sharp, piping weet, weet. Their flight is swift and well sustained"' (Goss).

241. Pisobia bairdi (Coues). Baird's SANDPIPER. Ads. in summer.Upperparts fuscous; feathers of crown and nape margined laterally with pale buffy; back and scapulars tipped with pale buffy or brownish gray; middle upper tail-coverts fuscous, sometimes tipped with buffy; central tailfeathers fuscous, margined with whitish, outer ones pale brownish gray; throat white; breast washed with buffy and lightly spotted or streaked with fuscous sides and belly white. Juv.-Similar, but the back, scapulars, and wing-coverts with rounded white tips. (In the winter these tips are more or less worn off.) L., $7 \cdot 40$; W., 4.90; Tar., "90; B., "85.

Remarks. - This bird most closely resembles $P$. fuscicollis. In any plumage it may be known from that species by the fuscous instead of white middle upper tail-coverts. In summer it differs also in the absence of rufous above, the less heavily spotted throat, and the white instead of spotted sides. In winter the chief distinguishing marks of the two species, aside from the differently colored upper tail-coverts, are the buffy breast and generally paler upperparts of bairdi.

Range.-N. and S. A. Breeds along the Arctic coast from Point Barrow to $\mathrm{n}$. Keewatin; winters in Chile, Argentina, and Patagonia; occurs regularly in migration from the Rocky Mts. to the Miss. River, and in Cen. Am., and n. S. A., and irregularly in autumn on the Pacific coast from Alaska to L. Calif., and on the Atlantic coast from N. S. to N. J.; casual in summer in Guerrero, Mex.; accidental in England and S. Africa.

Washington, casual, one record, Sept. Long Island, rare T. V., in fall, Aug. 14-Oct. 31. N. Ohio, casual T. V. SE. Minn., T. V., May 10.

Eggs, 3-4, light, creamy buff, sometimes tinged with rusty, thickly speckled and spotted with deep reddish brown or chestnut, 1'30 ${ }^{\prime} 93$ (Ridgw.). Date, Pt. Barrow, June 20.

"In habits they are similar to the White-rumped (which they so closely resemble), but are more inclined to wander from the water's edge. I have flushed the birds on high prairie lands, at least a mile from the water" (Goss).

242. Pisobia minutilla (Vieill.). LEAst SANDPIPER. Ads. in summer.Upperparts black or fuscous, edged and tipped with buffy or rufous; rump and middle upper tail-coverts plain black or fuscous; central tail-feathers black or fuscous, outer ones ashy gray; upper throat white; neck and breast white or buffy, streaked with fuscous; belly and sides white. Juv. - Similar, but feathers of the back with rounded rufous or buffy tips; breast not distinctly streaked. Ads. and Juv, in winter.-Upperparts brownish gray, sometimes with more

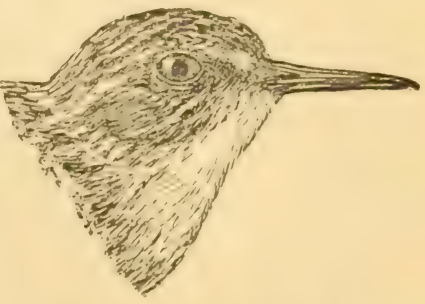

Fig. 80. Least Sandpiper. (Natural size.) 
or less black in the centers of the feathers; breast white or ashy, not distinctly streaked. L., $6 \cdot 00 ;$ W., $3 \cdot 50$; Tar., $\cdot 70$; B., $\cdot 75$.

Remarks. - This is the smallest of our Sandpipers, and can be confused only with Ereunetes pusillus, from which, however, it may always be distinguished by the absence of webs between the bases of the toes.

Range. $-\mathrm{N}$. and S. A. Breeds from nw. Alaska, s. Arctic islands, and n. Ungava to Yakutat Bay, Alaska, valley of the Upper Yukon, n. Mackenzie, cen. Keewatin, s. Ungava, N. S., and Sable Is.; winters from Calif., Tex., and N. C., through the West Indies and Cen. Am., to Brazil, Chile, and the Galapagos; in migration occurs throughout the U. S., and w. to ne. Siberia and the Commander Islands, n. to Greenland, and in Bermuda; accidental in Europe.

- Washington, uncommon T. V., May; Aug.-Oct. Long Island, abundant T. V., Apl. 25 through May; July through Sept. Ossining, tolerably common T. V., May 9-May 22; Oct. 3. Cambridge, very common T. V., May 15-May 28; July 20-Sept. 1. N. Ohio, common T. V., May 5-20; Sept. 1-30. Glen Ellyn, tolerably common T. V., May 4-15; Aug. 2-Sept. 5. SE. Minn., common T. V. May 9; Sept. 15.

Eggs, 3-4, pale, grayish buffy, varying to pale brownish, thickly spotted, speckled, or sprinkled with deep chestnut and dull, purplish gray, $1 \cdot 15 \times \cdot 83$ (Ridgw.). Date, Kadiak Islands, June 25 (Thayer Coll.).

This, the smallest of our Sandpipers, is frequently associated with its larger cousin, the Semipalmated Sandpiper, on the shores and beaches, but it also visits the grassy meadows, and for this reason is known by baymen as the 'Meadow Oxeye.'

243a. Pelidna alpina sakhalina ( $V$ ieill.). RED-BACKED SANDPIPER. $A d s$. in summer. - Uppernarts broadly margined with rufous, centers of the feathers black, wings brownish gray; breast whitish, lightly streaked with blackish; middle of the belly with a large black patch, lower belly white. Juv.

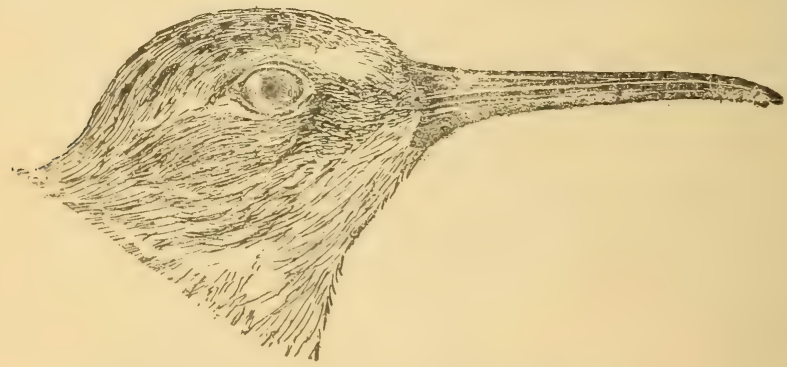

Fig. 81. Red-backed Sandpiper. (Natural size.)

- Trperparts blackish, the feathers with rounded tips of rufous or buffy; hreast washed with buffy and inclistinctly streaked with blackish; belly spotterl with black. Ads. and Juv. in winter.-Upperparts brownish gray; mirlelle up) we tail-coverts fuscous; wing-coverts brownish gray margined with buffy; throat white; brast ashy, inclistinctly strcaked; belly white, the sides semotimes spotted with blark. L., s.00; W., 4.75; Tar., 1.00; B., 1.50.

Remarlis. - There is, of course, every degree of intergradation between summer and winter plumage, but the species may always be known by its slightly curved bill.

Range.-N. A. and E. Asia. Breeds on the n. coast of Siberia w. to 
mouth of the Yenisei, and from Point Barrow to mouth of Yukon, and in Boothia and Melville Peninsulas and $\mathrm{n}$. Ungava; winters on the Pacific coast from Wash. to s. L. Calif., and from N. J. (rarely Mass.) s. to La. and s. Tex., and in Asia from China and Japan to the Malay Archipelago; rare in migration in the interior of the U. S. except about the s. end of Lake Michigan.

Washington, rare T. V., Apl.; Sept.-Nov. Long Island, T. V., uncommon in spring, Apl. 1-May 15; common in fall, Aug. 31 through Oct. (Dutcher). Ossining, tolerably common, T. V. in fall, Oct. 3-24. Cambridge, casual, one instance, Oct. N. Ohio, casual T. V. SE. Minn., T. V.,May 14..

Eggs, 3-4, varying from pale, bluish white to ochraceous-buff, heavily marked with chocolate, chiefly at the larger end, $1^{\circ} 43 \times 1^{\circ} 01$. Date, Pt. Barrow, Alaska, June 21.

Generally speaking, this is a shore or beach bird, though it also visits grassy marshes. It flies and feeds in flocks, and is an unsuspicious, rather stupid little Snipe, less active than most members of this family. The gray-plumaged fall birds are known as 'Leadbacks,' while in the spring they go by the names 'Blackbreast' or 'Redback.'

The Dunlin (243. Pelidna alpina alpina) is the Old World representative of our Red-backed Sandpiper, from which it differs only in being less brightly colored and somewhat smaller. L., about $7 \cdot 40 ; W^{*}, 4 \cdot 12-4{ }^{*} 50$; Tar., $\cdot 78-90$; B., $1 \cdot 05-1 \cdot 25$. It is of casual occurrence in North America.

244. Erolia ferruginea (Brünn.). CURLEw SANDPIPER. Bill slightly decurved. Ads. in summer.-Below reddish brown, ahove rusty and black. Juv.-Above brownish gray, margined with whitish, back blacker; below white. Ads. and Juv. in winter.-Above plain brownish gray; below white. L., $8 \cdot 00$; W., 5*00; B., 1.50; T., 1.10.

Range.-Chiefly E. Hemisphere; occasional in N. and S. A. Breeds in the Yenisei delta and on the Taimyr Peninsula, Siberia; winters in Africa, India, Malay Archipelago, and Australia; in migration occurs from Great Britain to China and the Philippines; occasional in N. A.; Alaska (Pt. Barrow), Ont., N. S., Maine., Mass., N. Y., and N. J., and in the West Indies and Patagonia.

246. Ereunetes pusillus (Linn.). Semipalmated Sandpiper. Ads. in summer.-Upperparts black or fuscous, margined with brownish gray and a small ariount of rufous; rump grayish brown; uppor tail-coverts blackish; tail-feathers brownish gray, central ones darkest; breast streaked or spotted with blackish. Juv.- Similar, but upperparts and wing-eoverts blackish, with rounded rufous or buffy tips to the feathers; breast unstreakerl, tinted with buffy. Ads. and Juv. in winter.-Upperparts brownish gray, with darker shaft streaks; upper tail-eoverts darker; underparts white, sometimes with faint streaks on the breast. L., 6:30; W., 3.75; Tar., 75 ; B., $\cdot(6.5-\cdot \$ 0$.

Remarlis. - The small size of this and the next species prevents their heing confused with any other except Pisolia minutilla, from which they may always be known by their partially wobled toes.

Range. -N. and S. A. Breeds from the Arctic coast of N. A. s. to mouth of Yukon and to s. Ungava; winters from Tex. and S. ( $\therefore$. through West Indies and Cen. Am. to Patagonia; migrate's mainly e. of the Rosky MIs.; casual in B. (.., Pribilof Islands, and ne. Siloria; adecidental in Europe.

Washington, rare: T. V., May; Aug. 10-Oct. 26. Iong Island, abundant T. V., May; July through Siept. Ossining, (ommon T. V., in fall, Aur. 14Oet. 20. Cambridge, T. V., in fall, Aug. 10-siopt. 15. N. Ohio, (common T. V., May 5-May 25; Sept. 1-25. Glen Ellyn, T. V., May; Aug. and Sept. SE. Minn., common T. V., May 22; Sept. 15.

Eggs, 3-4, pale, dull grayish.buff, sprinkled, speckled, or spotted with dark brown and purplish gray, $1.21 \times 85$ (Ridgw.). Date, Lab., June 12. 
The thought of these little Sandpipers always creates a mental picture of a long stretch of dazzling beach with its ever-changing surfline. I hear the oft-repeated booming of the rolling, tumbling breakers, and in the distance see a group of tiny forms hurrying to and fro over the sand smoothed by the frothy waves. With what nimble gracefulness they follow the receding waves, searching for treasures cast up by the sea! What contentment and good-fellowship are expressed by their cheery, conversational twitterings! Up and down the beach they run, now advancing, now retreating, sometimes, in their eagerness, venturing too far, when the waters threaten to engulf them, and in momentary confusion they take wing and hover back to a place of safety. Suddenly, as though at a signal, they are off; a compact flock moving as one bird, twisting and turning to right and left, now gleaming white as the sun strikes their snowy bodies, now dark again like a wisp of sunless cloud flying before the wind.

247. Ereunetes mauri (Cab.). WESTERN SANDPIPER. This bird closely resembles the preceding, from which, in summer plumage, it differs in having the upperparts conspicuously margined with rufous and the breast more heavily streaked. In fall and winter plumage the differences in coloration are not so apparent, but the birds are to be distinguished at any season by the size of the bill, which in the western species is always longer. W., $3 \cdot 80$; Tar., 80 ; B., $85-1 \cdot 20$.

Range.-N. and S. A. Breeds along the Alaska coast from Kotzebue Sound to mouth of Yukon; winters from N. C. to Fla., and from s. L. Calif. to Venezuela; in migration occurs mainly w. of the Rocky Mts., but also on the Atlantic coast as far n. as Mass., and in the West Indies.

Washington, rare T. V., Aug.-Sept. Long Island, uncommon T. V., in fall, occurring with $E$. pusillus.

Eggs, 3-4, deep cinnamon buffy, sprinkled, speckled, or thickly spotted with bright rusty brown or chestnut, the general aspect decidedly rusty, $1.24 \times \cdot 87$ (Ridgw.). Date, St. Michael's, Alaska, May 28.

This western representative of the preceding species is found on our coasts associated with its eastern relative. According to Wayne (Birds So. Car.) this is the most abundant winter wader on the South Carolina coast.

248. Calidris leucophra (Pall.). SANDERLING. Ads. in summer.Feathers of upperparts with generally black centers, bordered and sometimes barred with pale rufous and tipped with ashy white; wings fuscous, basal half of outer web of inner primaries white; wing-coverts grayish fuscous, greater ones, broadly tipped with white; tail brownish gray, narrowly margined with white; throat and upper breast washed with pale rufous and spotted with blackish; rest of the underparts pure white. Juv.-Similar, but upperparts without rufous, glossy black, the feathers sometimes bordered with white, but generally with two white spots at their tips separated by the black of the central part of the feather; nape grayish white, lightly streaked with blackish; underparts mure white, with occasionally a few spots on the breast. Ads. and Jux. in winter.-Upperparts pale brownish gray, wings as in the preceding; underparts pure white. L., 8.00; W., 5.00; Tar., $1 \cdot 00 ;$ B., 1.00.

Remarlis. - The Sanderling is the only one of our Snipes or Sandpipers having three toes, and it may always bn known by this character in combination with its transversely scaled tarsi. 
Range.-N. and S. Hemispheres. Breeds from Melville Is., Ellesmere Land, and n. Greenland to Pt. Barrow, Alaska, n. Mackenzie, Iceland, and in n. Siberia; winters from cen. Calif., Tex., Va., and Bermuda to Patagonia, and casually to Mass., and Wash.; also from the Mediterranean, Burma, and Japan to S. Africa and various Pacific islands, including Hawaii.

Washingıon, rare T. V., Sept.-Oct. Long Island, common T. V., Mch. 15 through May; July 20-Oct. 1 . Ossining, tolerably common T. V. to June 5; Sept. 9-Oct. 5. Cambridge, casual, one instance, Sept. N. Ohio, common T. V., May 1-20; Sept. 1-Oct. 10. SE. Minn., T. V., May 14.

Eggs, 3-4, light olive-brown, finely spotted or speckled with darker, the markings larger and more blended on the larger end, $1{ }^{*} 41 \times \cdot 91$ (Ridgw.). Date, Anderson River, Mack., June 27.

This is a true beach bird, and is usually found on shores washed by the sea. It frequently associates with the Semipalmated Sandpiper, or Oxeye, which it resembles in habits, but its larger size and lighter colors distinguish it from that species.

249. Limosa fedoa (Linn.). Marbled Godwit. Ads. in summer.Upperparts black, the head and neck streaked with buffy, back barred or the feathers spotted on the sides and sometimes tipped with buffy or ochraceous-buff; inner web of outer primaries and both webs of inner ones ochraceous-buff or pale buffy, speckled with black; tail ochraceous-buff barred with black; throat white, rest of underparts pale buffy, spotted or barred with black; bill curved slightly upward, yellowish at the base, black at the end. Juv.-Similar, but underparts with few or no bars except on flanks and under tail-coverts. L., $18 \cdot 00 ;$ W., $8 \cdot 75$; Tar., $2 \cdot 75 ;$ B., 4.00.

Range.-N. A. Breeds from valley of the Saskatchewan s. to N. D. (formerly to Iowa and Wisc.); winters from s. L. Calif., La., Fla., and Ga. to Guatemala and Belize; casual in Calif. in winter; in migration occurs on the Pacific coast n. to B. C., and on the Atlantic coast to the Maritime Provinces (formerly) and s. to the Lesser Antilles; accidental in Alaska.

Long Island, rare T. V., Aug. and Sept.

Eggs, 3-4, clay-color or brownish ashy, blotched, spotted, and scrawled with grayish brown, $2 \cdot 15 \times 1 \cdot 60$. Date, Minor Co., S. D., May 16 .

This is a common bird about the sloughs of Alberta prairies where its loud, frequently uttered double-noted call makes it conspicuous. It is rare on the Atlantic coast.

1907. Bent, A. C., Auk, XXIV, 160-167 (nesting).

251. Limosa hæmastica (Linn.). HudGoNIAN GodwIT. Ads. in summer.-Bill slightly curved upward. Upper tail-coverts black and white; tail black at the end, white at the hase; abowr black, rusty and grayish; below reddish brown, harred with blackish and faintly tipped with white. Juv. - Similar, but helow buffy whitish, breast grayer. Ads. and Juv. in winter.- Similar to the young below, but above brownish gray. L., 15; W., 8*2; Tar., $2 \cdot 2$; B., $3 \cdot 2$.

Range. - N. and S. A. Breeds from the lower Anderson River se. to cen. Keewatin; winters in Argentina, Patagonia, and the Falkland Islands; in migration occurs principally e. of the Great Plains, most commonly on the Atlantic coast in autumn and in the Miss. Valley in spring; casual in Alaska.

Long Island, rare T. V., Aug.-Oet. Cambridge, one record.

Eggs, 3-4, deep olive, hair-brown, or broccoli-brown (sometimes paler), usually more or less spotted with darker brown, but sometimes nearly uniform, 2.20 × 1.42 (Ridgw.). Date, Ft. Anderson, Mack., June 9.

This species is becoming one of our rarest Shore Birds. 
The Black-TAIled Godwit (252. Limosa limosa) inhabits the northern parts of the Old World and is of accidental occurrence in Greenland.

The Green-shanK (253. Glottis nebularia) is an Old World species, of which three specimens were taken by Audubon, May 28, 1832, near Cape Sable, Florida. It resembles our Greater Yellow-legs, but differs chiefly in having the lower back and rump white.

254. Totanus melanoleucus (Gmel.). Greater Yellow-legs. $A d s$. in summer. - Upperparts black, head and neck streaked and back spotted or barred with white or ashy; upper tail-coverts white, more or less barred with black; tail white or ashy, barred with black; breast heavily spotted with black; sides barred with black; middle of the belly white. Ads. and Juv. in winter. - Similar, but upperparts brownish gray, edged with whitish; sides of scapulars, tertials, and wing-coverts with blackish and whitish spots; breast only lightly streaked with blackish, and sides slightly barred. L., 14.00; W., 7·70; Tar., 2*40; B., 2*20.

Range.-N. and S. A. Breeds from Lake Iliamna, Alaska, and s. Mackenzie to s. B. C., Ungava, Lab., and Anticosti Is.; winters from s. Calif., Tex., La., and Ga. (casually N. C.) s. to Patagonia; occurs in Bermuda in migration.

Washington, rather common T. V., Apl., May; July 25-Nov. Long Island, common T. V., Apl. 10 through May; July 15 through Oct. Ossining, common T. V., to June 5;-Oct. 28. Cambridge, common T. V., Apl. 20May 20; Aug. 1-Oct. 20. N. Ohio, common T. V., Apl. 10-May 15; Sept. 1-Oct. 30. Glen Ellyn, uncommon T. V., May; Sept. 18-Oct. 24. SE. Minn., common T. V., Apl. 1; Sept. 17-Oct. 28.

Eggs, 3-4, brownish buffy, distinctly but very irregularly spotted with rich vandyke- or madder-brown, 1.43 × 1.20 (Ridgw.). Date, Ft. George, B. C., May 20.

It needs only the musical notes of the Yellow-leg to recall memories of many days passed along the shore and in the marshes. Half reclining in my blind, I see in fancy the staring decoys, pointing like weathercocks with the wind, and hear the dull booming of surf behind the brown sand-dunes.

Few birds are flying; lulled by the lap, lap of the water, I have almost fallen asleep, when from far up in the gray sky comes a soft, flutelike whistle, wheu, wheu-wheu-wheu-wheu, wheu, wheu-wheu. I respond quickly, and, lying on my back, look eagerly upward. Not a bird can be seen, but the questioning call grows stronger and is repeated more frequently. Finally I distinguish five or six black points sailing in narrow circles so high that I can scarcely believe they are the birds I hear. But no bar or shoal breaks the sound waves. The birds grow larger and on widening circles sweep earthward. Their soft whistle has a plaintive tone; their long bills turn inquiringly from side to side. The stolid decoys give no response, they repel rather than encourage, but the whistling continues, and with murmured notes of interrogation the deluded birds wheel over them and, if permitted, will alight before discovering the deception.

255. Totanus flavipes (Gmel.). Yellow-LEgs. Ads. in summer.Upperparts generally hrownish gray, head and neck streaked with black and whitr; hack, scapulars, and wing-coverts with sometimes black centers, spotted or tipped with whitish or brownish gray; upper tail-coverts white, more or less barred with black, tail varying from white to brownish gray, 
with numerous black or blackish cross-bars; breast heavily spotted or streaked and sides barred with black; belly white, legs yellow. Ads. and Juv. in winter. - Similar, but upperparts brownish gray, the sides of the feathers with whitish spots; tail-hars grayish; breast lightly streaked with ashy. L., $10 \cdot 75 ;$ W., 6*40; Tar., $2 \cdot 05 ;$ B., $1 \cdot 40$.

Remarks.-This bird closely resembles the Greater Yellow-legs in color, but may always be distinguished by its smaller size.

Range.-N. and S. A. Breeds from Kotzebue Sound, Alaska, n. Mackenzie, cen. Keewatin, and s. Ungava to the valley of the Upper Yukon, s. Sask., and n. Que.; winters in Argentina, Chile, and Patagonia, and casually in Mex., Fla., and the Bahamas; in migration occurs mainly e. of the Rocky Mts. (rare in spring on the Atlantic coast), and in the Pribilof Islands, Greenland, and Bermuda; accidental in Great Britain.

Washington, rather common T. V., Mch. to May 15; Aug.-Oct. Long Island, T. V., very rare in spring, abundant in fall; July 15-Oct. 1. Ossining, tolerably common T. V., in fall; Aug. 25-Oct. 5. Cambridge, rare T. V., May; Aug. 4-Sept. 15. N. Ohio, common T. V., Apl. 20-May 15; Sept. 1Oct. 30. Glen Ellyn, quite regular, Apl. 15-May 19; July 6-Oct. 17. SE. Minn., common T. V., Apl. 7; Aug. 23-Oct. 11.

Eggs, 3-4, buffy (variable as to shade), distinctly (sometimes broadly) spotted or blotched with dark madder-or vandyke-brown and purplish gray, 1.69 × 1.15 (Ridgw.). Date, Ft. Anderson, Mack., June 5.

This species closely resembles the preceding in notes, habits, and choice of haunts. It decoys, however, more easily, and, generally speaking, is more common.

The EUROPEAN RED-SHANK (Totanus totanus) has been once recorded from Hudson Bay (Coues, Auk, XIV, 1897, 211).

256. Helodromas solitarius solitarius (Wils.). SOLITARY SANDPIPER. Ads. in summer.-Upperparts olive-fuscous, with a slight greenish tinge; head and neck streaked and back spotted with white; upper tailcoverts fuscous, with fine whitish spots on their sides, lateral ones sometimes barred; central pair of tail-feathers fuscous, the others white, barred with black; breast streaked, and sides sometimes barred with black; belly white; axillars barred with black and white; legs greenish fuscous. Ads. and Jur. in winter. - Similar, but upperparts grayish brown; head and neck generally unstreaked, and bark only lightly spotted with buffy white; breast streaked with brownish gray. L., 8.40; W., 5.25; Tar., $1 \cdot 20$; B., $1 \cdot 15$.

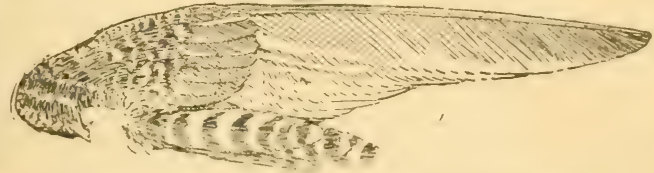

FIG. 82. Inner view of wing of Solitary Sandpiper, showing barred axillars.

Range. -N. and S. A. Summers from cen. Keewatin, n. Ungava, and N. F. s. to Nebr., Ill., Ind., Ohio, and Pa.; probably breeds regularly in the $\mathrm{n}$. part of its range, locally and casilally in the s. part; winters from the West Indies to Argentina; recorded from Greenland, Bermuda, and Great Britain.

Washington, common T. V.. Apl.-May 25; July 25-Nov. Long Island, common T. V., May; July 15-Oct. 1. Ossining, common T. V., May 3 :30; Aug. 27-Oct. 2. Cambridge, common T. V., May 12-2:3; Aug. 10 Sept. 30. N. Ohio, tolerably common in summer, Apl. 20-Sept. 15. (ilen Fillm, fairly common T. V., Apl. 8-May :31; July 16-Oct. 6. SE. Minn. ('ommon T. V., Apl. 28; July 23-Oct. 4.

Nest, lays in the abandoned nests of such tree-builcling birds as the 
Robin, Bronzed Grackle or Cedar Waxwing. Eggs, 4, "pale greenish-white, heavily blotched and spotted chiefly at the larger ends with vandyke-brown, chestnut-brown, and purplish gray," 1.36 × '98. (Raine, Ottawa Nat., 1904, 135-138; Auk, 1905, 100). Date, n. Alberta, June 9.

This is a wood Sandpiper. It is rarely found on the beaches or salt marshes near the sea, but frequents fresh-water ponds, or lakes and woodland streams, both in the lowlands and mountains. It is a quieter, more dignified bird than the Spotted Sandpiper, and as a rule only utters its tweet-tweet when flushed. The nest of this species has long been sought for, but it was not until 1903 that, like its European representative, the Green Sandpiper, it was found laying in the nests of treebuilding birds.

The Green Sandpiper (25\%. Helodromas ochropus) has been twice recorded from America (Nova Scotia and Hudson Bay, Coues Auk, XIV, $1897,210)$.

258. Catoptrophorus semipalmatus semipalmatus (Gmel.). WILLET. Ads. in summer.-Upperparts brownish gray, the head and neck streaked, and the back barred with black, and sometimes buffy, the centers of the feathers being occasionally wholly black; basal half of primaries and greater part of secondaries white; upper tail-coverts white with a few blackish bars; central tail-feathers ashy, indistinctly barred with blackish; outer ones whitish, lightly mottled with grayish; foreneck heavily streaked; breast and sides heavily barred with dark brownish gray and more or less washed with buffy; belly generally white, with sometimes a few bars. Ads, and Juv. in winter. Upperparts brownish gray, unmarked; tail gray without bars; rump and wings as in the adult; breast washed with grayish; belly white; axillars black. L., 15.00; W., 8*00; Tar., 2*30; B., 2*15.

Range.-N. and S. A. Breeds from Va. (formerly N. S.) s. to Fla. and the Bahamas; winters from the Bahamas to Brazil and Peru; accidental in Bermuda and Europe.

Washington, rare T. V., Aug. Long Island, T. V., rare in May; uncommon in Aug. and Sept. (Dutcher). Ossining, A. V. SE. Minn. rare T. V., Apl. 10.

Nest, in grassy marshes. Eggs, 3-4, clay-color or buffy, thickly spotted with chocolate, chiefly at the larger end, $2 \cdot 10 \times 1.55$. Date, Sapelo Is., Ga., Apl. 22; Cobb's Is., Va., May 16.

Willets frequent both fresh-and salt-water marshes, shores, and beaches. If you visit their haunts during the nesting season, on fluttering wings they will hover above your head or fly low over the marsh to draw you away from their home, uttering, with scarce a moment's cessation, their loudly whistled call of pilly-will-willet, pilly-willwillet. All day long, and even at night, I have heard then repeat these notes until, wearied by their persistence, one is thankful to leave them in undisturbed possession of the ground.

Јов, H. K., Wild Wings, 250 (nesting).

258a. C. s.inornatus (Brewst.). Western WILLET. Slightly larger than the preceding, and, in summer plumage, upperparts paler and less heavily marked with black; breast less heavily streaked and more suffused with buffy, middle tail-feathers without black bars. In winter plumage the two forms can he distinguished only by the slight and inconstant character of size. W., $8 \cdot 50$; Tar., $2 \cdot 50 ;$ B., $2 \cdot 40$.

Range.-W. N. Am. Breeds from cen. Ore., s. Alberta, and s. Manitoba 
s. to n. Calif., cen. Colo., s. S. D., and n. Iowa, and on the coasts of Tex. and La.; winters from cen. Calif., Tex., La., and Gulf coast of Fla. to Mex. (L. Calif., Tepic, and Guerrero); in fall migration occurs in B. C. and on the Atlantic coast from New England south.

260. Machetes pugnax (Linn.). Ruff; ReEve. Ad. $\sigma^{7}$ in summer.Very variable; above and below black with purplish reflections; or rusty barred with purplish, etc.; feathers of breast much lengthened to form a shield of rusty, black, or black and white feathers; two variously colored tufts on the hindneck. $c$ in winter.-Above grayish brown; below white; throat and breast grayish; end of tail with remains of blackish bars; ruff absent. $A d$.. .- Head, neck and underparts as in winter male; back black margined with grayish brown; inner wing-feathers barred with black and grayish brown. L., 12:50; W., 7•00; Tar., 1*70; B., 1.50.

Range.-E. Hemisphere. Breeds from the Arctic coast s. to Great Britain, Holland, Russia, and Siberia; winters throughout Africa, India, and Burma; strays occasionally to the $\mathrm{W}$. Hemisphere, from Ont. and Greenland s. to Ind., N. C., Barbados, and n. S. A.

Washington, one record, Sept. 3.

The nineteen records of the occurrence of this European species are about equally divided between spring and fall dates, and fourteen of them are from the Atlantic coast.

1905. Deane, R., Auk, XXII, 410. - 1906. Palmer, T. S., Ibid., XXIII, 98 (Am. records).

261. Bartramia longicauda (Bechst.). Upland Plover. Ads.Head and neck streaked with black and ochraceous-buff; back and wingcoverts ochraceous-buff, barred with black; tertials olive, barred with black and margined with ochraceous-buff; primaries fuscous, the outer one barred with white; inner tail-feathers brownish gray, outer ones varying from ochraceous-buff to white, all more or less barred with black; breast and sides washed with buffy and streaked or harred with black; bolly white or whitish. Juv.-Similar, but the ochraceous-buff is decper. L., 11.50; W., 6.50; Tar., $1 \cdot 90 ;$ B., $1 \cdot 15$.

Remarks. - The white bars on the outer primary will always serve to identify this species.

Range.-N. and S. A. Breeds from nw. Alaska, s. Mackenzie, cen. Keewatin, cen. Wisc., s. Mich., s. Ont., and s. Maine to s. Ore., n. Utah, cen. Okla., s. Mo., s. Ind., and n. Via.; winters on the pampas of S. A. to Argentina; in migration occurs n. to N. F. and in Europe; aceidental in Australia.

Washington, common T. V., Mch. 21-Apl. 24; June 29-Sept. Long Island, uncommon S. R., Apl.-Sept. (ambridge, T. V., not uncommon in fall; Apl. 20-May 6; July 26-Sept. 14. X. Ohio, common \&. R., II 'h 20)Sept. 20. Glen Ellyn, fairly common S. R., Apl. 10-Sept. 11. SE. Minn., S. R., formerly common, now rare, Apl. 7.

Nest, concealed in the grass. Eggs, 4, (reamy buff or white, spotted with reddish brown or chorolate, ehiefly at the larger end, 1.40 ( ) $1 \cdot 30$. Date, Haddonfield, N. J., May 6, 18s7; Holland Patent, N. Y., May 21; (ireenwood Co., Kans., May 11; se. Minn., June 17.

The Upland 'Plover' is at home on grassy plains and pastures. It is usually a shy bird, and ean rarely be successfully approached on foot. It shows no fear, however, of a man who is riding or driving, and when on horseback I have passed within a few yards of birds which regarded me with some interest but no alarm. They so closely resemble dried grass in color that it is sometimes excecdingly diffi- 
cult to distinguish them from their surroundings. One may ride over a prairie upon which, at first glance, not a Plover is visible, and find, after careful scrutiny, that dozens of birds are scattered about him feeding. This, at least was my experience near Corpus Christi, Texas, in April, 1891, but market hunters were then killing as many as sixty birds a day, and years of this kind of persecution have greatly reduced the numbers of these birds even in the thinly settled West. In the East it now breeds only locally, but Eaton states that it is increasing in Western New York.

In alighting, the birds stretch their wings to the utmost, high over their backs, as if to get the wrinkles out before gently folding them. When flushed they utter a soft, bubbling whistle. During their migrations one may clearly hear these sweet notes from birds traveling beyond the limits of human vision. Langille describes their alarm note as a

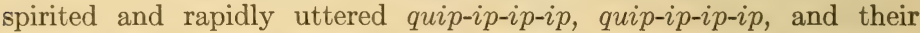

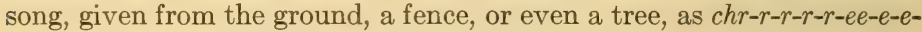
$e-e-e-00-0-0-0-0-00$. He remarks: "This prolonged, mournful, mellow whistle, more like the whistling of wind than a bird's voice, may be heard even in the night, and is one of the most weird and never-to-beforgotten sounds in Nature."

262. Tryngites subruficollis ( $V$ ieill.). BUFF-Breasted SANDPIPER. Ads.- Upperparts greenish black widely margined with pale grayish hrown; primaries fuscous, inner half of their inner webs speckled with black; longer under wing-coverts conspicuously marked and tipped with black, then white; central tail-feathers fuscous, outer ones becoming buffy, irregularly marked and tipped with black and buffy; underparts pale ochraceous-buff, tipped with whitish, and with generally concealed black markings. Juv.-Similar, but back fuscous narrowly margined or ringed with whitish. L., 8.50; W., $5 \cdot 25$; B., $\cdot 80$.

Remarks. - In any plumage this bird may be known by the peculiar speckling on the inner webs of all the primaries, and also the markings of the under wing-coverts:

Range.-N. and S. A. Breeds along the Arctic coast from n. Alaska to n. Keewatin; winters in Argentina and Uruguay; most abundant in migration in the Miss. Valley; occasional on the Atlantic coast in fall; casual on the Pacific coast n. to St. Michael, Alaska, and to ne. Siberia; straggles to Bermuda and frequently to w. Europe.

Long Island, rare T. V., Aug. and Sept. SE. Minn., uncommon T. V.

Eggs, 3-4, buffy grayish white, varying to pale olive-buff, boldly spotted longitudinally (and somewhat spirally) with dark vandyke- or madder-brown and purplish gray, 1.53 × 1.04 (Ridgw.). Date, Pt. Barrow, Alaska, June 20.

This is a rare species on the Atlantic coast. Dr. Hatch writes of it as observed by him in Minnesota: "They are an extremely active speeics when on the wing, and essentially ploverine in all respects, secking sandy, barren prairies, where they live upon grasshoppers, crickets, and insects generally, and ants and their eggs specially. I have found them repasting upon minute mollusks on the sandy shores of small and shallow ponds, where they were apparently little more suspicious than the Solitary Sandpipers are notably. The flight is in rather compact form, lipping and rising alternately, and with a dis- 



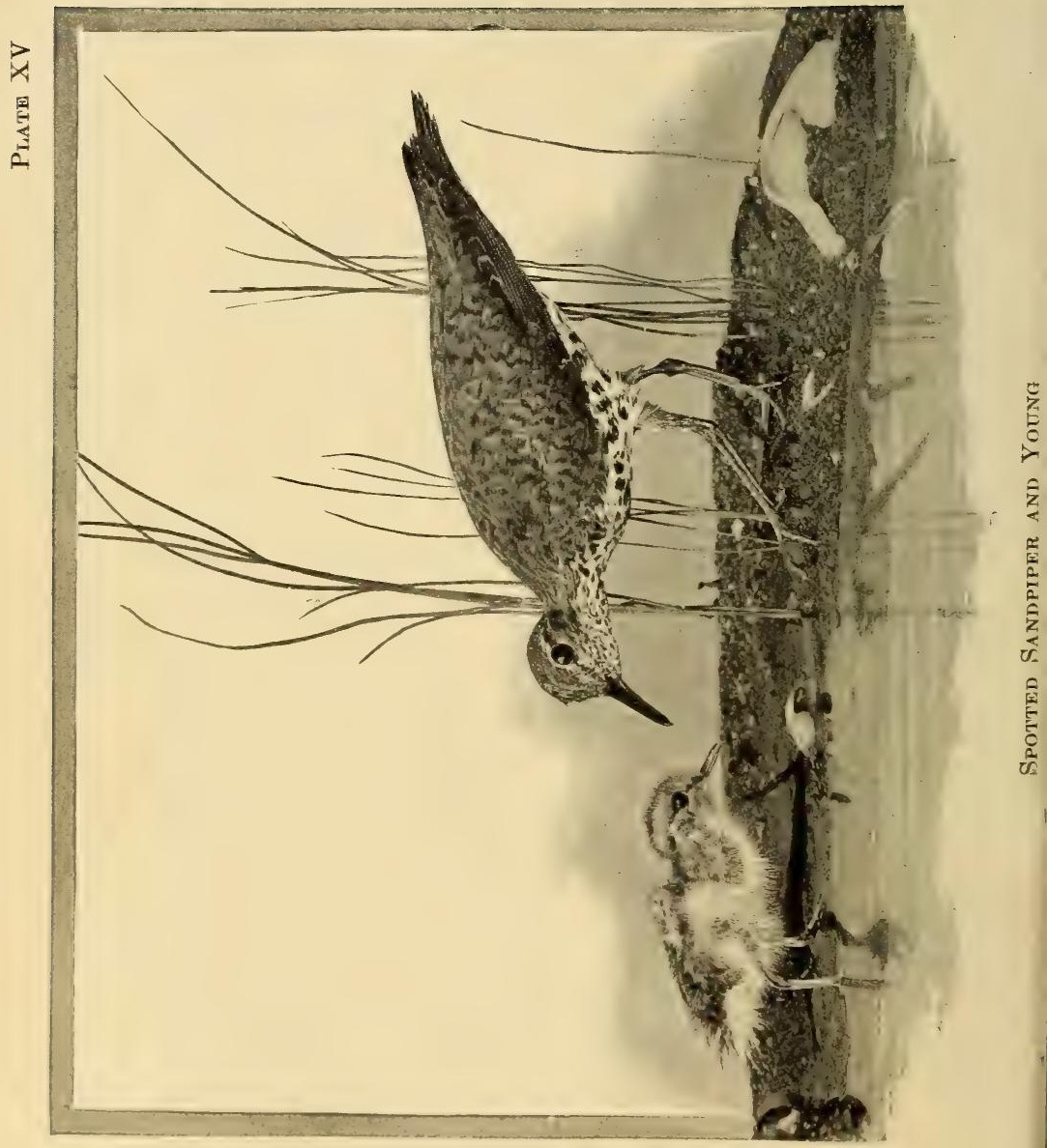


position to return again to the neighborhood of their former feedingplaces."

263. Actitis macularia (Linn.). Spotted SANdpIPER. Ads. in summer.-Upperparts brownish gray with a faint greenish luster, head and neck more or less streaked, and back barred or spotted with black; inner tailfeathers like back, outer ones white with blackish bars; underparts white; everywhere spotted with black. Juv.-Upperparts brownish gray, with a greenish tinge, back faintly and wing-coverts conspicuously barred with black and buffy; underparts pure white, unspotted, but slightly washed with grayish on breast. Ads. and Juv. in winter. - Similar, but back without bars. L., 7.50; W., 4*20; Tar., '90; B., 95 .

Range.-N. and S. A. Breeds from tree limit in nw. Alaska, n. Mackenzie, cen. Keewatin, n. Ungava, and N. F. s. to s. Calif., Ariz., s. Tex., s. La. and n. S. C.; winters from Calif., La., and S. C., to s. Brazil and cen. Peru; straggles to Great Britain and Helgoland.

Washington, common T. V., not common S. R., Apl. 2-Oct. 28. Long Island, abundant S. R., Apl. 25-Oct. Ossining, common S. R., Apl. 29Oct. 25. Cambridge, common S. R., Apl. 26-Sept. 30. N. Ohio, common S. R., Apl. 9-Oct. 15. Glen Ellyn, not very common.S. R., Apl. 19-Oct. 30. SE. Minn., common S. R., Apl. 18-Oct. 22.

Nest, on dry ground, in the grasses or weeds, or beneath a bush near fresh or salt water. Eggs, 4 , creamy buff or white, thickly spotted and speckled with chocolate, chiefly at the larger end, $1.25 \times \cdot 95$. Date, Montgomery Co., Pa., May 16; Cambridge, May 25; se. Minn., May 30.

Few Shore Birds are more generally known than this widely distributed little Sandpiper. It frequents the margins of bodies of both fresh and salt water, but is more common inland on the shores of our rivers, ponds and lakes. During the summer it is practically our only fresh-water Sandpiper, and is familiar to most of us under its common names. It runs rapidly along the beach, then pausing bobs, bows, and 'teters' in a most energetic manner. When flushed it takes wing with a sharp weet-weet weet-weet, and after a few wing-strokes scales over the water to the beach beyond. It apparently dislikes to go beyond certain limits, and after several flights makes a wide circle and returns to the starting point.

264. Numenius americanus Wils. LONG-BIlled Curlew. $A d s$. Head and neck streaked, and back barred with buffy and black; wingcoverts, inner webs of primaries, secondaries, and tail varying from buffy to pale rufous, barred or mottled with blackish; underparts ochraceousbuff, breast more or less streaked and sides sometimes barred with black; axillars rufous, generally unbarred. L., $24^{\circ} 00$; W., $10^{\circ} \cdot 50$; Tar., 3.10; B., 6.00.

Range.-N. A. Breeds from cen. 13. C., s. Sask, and Man. to ne. Calif., n. N. Mex., and nw. Tex.; winters from cen. Calif., and s. Ariz. s. to Guatemala, and on the Atlaritic coast from S. ('., to Fla., La., and Tex.; formerly a regular migrant n. to Mass. and rarely to N. F., now a straggler e. of the Miss., n. of Fla.; casual in the West Indies.

Washington, rare and irregular T. V. Long Island, casual from JulySept. (Dutcher). Ossining, A. V.

Eggs, 3-4, olive clay-color or brownish ashy, spotted or blotched with chocolate, $2.58 \times 1.85$. Date, Salt Lake Co., Utah, May 2; Crane Lake, Saskatchewan, June 1.

"These birds, as a rule, inhabit the muddy shores and moist, grassy flats and plains, but often frequent and breed upon the uplands remote 
from water. Their food consists of worms, crickets, beetles, grasshoppers, small snails, crabs and crawfish; the latter they reach for with their long bills and pull them out of their holes; and I have seen them probe for and unearth the larvæ of the beetles and other forms of life that in the spring come to or near the surface preparatory to transformation. While feeding they move about with an easy carriage.

"Their flight is not rapid but well sustained, with regular strokes of the wings, and when going a distance usually high and in a triangular form, uttering now and then their loud, prolonged whistling note, so often heard during the breeding season; before alighting, suddenly drop nearly to the ground, then gather, and with a rising sweep gracefully alight" (Goss).

265. Numenius hudsonicus Lath. HUdsontan CURLEw. Ads.Upperparts grayish brown, the sides of the feathers with buff or whitish spots; rump and tail barred with buffy and blackish; inner web of outer primaries and both webs of inner ones barred with buffy or whitish and black: underparts buffy or whitish, neck and breast streaked and sides and under wing-coverts barred with black. L., 17·00; W., 9.50; Tar., 2.20; B., 3.75.

Remarks.-Young birds often have the bill as short as in $N$. borealis from which, however, they may always be distinguished by their barred primaries.

Range.-N. and S. A. Breeds on the coast of Alaska from mouth of Yukon to Kotzebue Sound, and on the coast of n. Mackenzie; winters from L. Calif. to s. Honduras, from Ecuador to s. Chile, and from B. Guiana to mouth of the Amazon; migrates mainly along the Pacific and Atlantic coasts; rare in the interior; casual on the Pribilof Islands and in Greenland and Bermuda; accidental in Spain.

Long Island, T. V., rare Apl. 28-May 30; common from July-Oct. 1.

Eggs, 3-4, pale olive, spotted with dull brown, $2.27 \times 1.57$ (Ridgw.). Date, e. of Anderson River, Mack., July 4.

From Virginia to South Carolina, this is an abundant bird during its migrations, but it evidently travels over the sea, for it is comparatively uncommon in our North Atlantic States. During their migrations they select certain isolated islets as roosting-places and return to them night after night.

\section{Mackay, G. H., Auk, IX, 345-352 (in Mass.).}

266. Numenius borealis (Forst.). Eskimo CuRlew. Ads.-Upperparts black, margined and tipped with buffy or whitish; upper tail-coverts barred with buffy and black; tail brownish gray, edged with buffy and barred with black; primaries fuscous without bars; underparts buffy or whitish, the breast streaked, the sides and under wing-coverts barred with black. L., 13.50; W., 8.40; Tar., $1 \cdot 75$; B., $2 \cdot 40$.

Range. - N. and S. A. Breeds on the Barren Grounds of n. Mackenzie; winters in Argentina and Patagonia; now nearly extinct.

Long Island, very rare T. V., Aug.-Sept.

E'grs, :3 4, pale olive-greenish, olive, or olive-brownish, distinctly spotted, chiefly on the larger end, with deep or dark brown, $2.04 \times 1.43$ (Ridgw.). Date, e. of Anderson River, Mack., June 20.

"Most of their habits closely resemble those of the Golden Plover. In migration they fly in much the same manner, with extended and broadside and triangular lines and clusters similar to those of Ducks 
and Geese at such times. They usually fly low after landing, sweeping slowly over the ground, apparently looking it over, generally standing motionless for quite a while after alighting, which, owing to their general color approximating so closely to the withered grass, renders it difficult at times to perceive them. . . . The only note I ever heard them make is a kind of squeak, very much like one of the cries of Wilson's Tern (Sterna hirundo), only finer in tone." (Mackay, Auk, 1892, 16-21, 1893, 79; 1894, 75; 1897, 212; 1899, 180.) The Eskimo Curlew is now believed to be on the verge of extinction. The latest records appear to be Newburyport, Mass., Aug. 27, 1908 (Thayer, J. E., Auk, 1908, 77) and Waco, Nebr., Mch. 22, 1911, two females (Aug. Eiche).

A specimen of the European Corlew (Numenius arquatus) said to have been taken on Long Island in 1853, is in the New York State Museum at Albany. (Dutcher, Auk, IX, 1892, 390.)

The Whrmbrel (267. Numenius pheopus), an Old-World species, is of accidental occurrence in Greenland and has been once recorded from Nova Scotia.

\section{Family Charadridde. Plovers. (Figs. $42 c, d ; 43 e, d$. )}

The seventy-five odd species contained in this family are, as a whole, of less boreal distribution than the Snipes, and during the nesting season are distributed throughout the world. Only cight species are found in North America. Their habits in a general way resemble those of the true Snipes, but their much shorter, stouter bills are not fitted for probing, and they obtain their food from the surface. Probably for this reason several species are as frequently found on the uplands as near the shores.

I. Toes three.

KEY TO THE SPECIES

A. Back spotted or streaked with black and white, rufous, or golden yellow. . . . . . . 272. Golden Plover.

$B$. Back ashy, gray, brown, or brownish gray.

a. Rump rufous

$b$. Rump not rufous.

$b^{1}$. Bill over 50 .

$b^{2}$. A black or brownish hand on the braast. 280. Wilson's Plover.

$b^{3}$. No band on the breast; back grayish brown, margined with rufous . . . . 2 . M1. Mountain Plover.

$c^{1}$. Bill under 50 .

$c^{2}$. A black line from the eye to the bill.

II. Toes four

274. Semipalmated Plover.

277. PIPING PLOVER. 270. Black-Bellied Plover.

270. Squatarola squatarola (Limn.). BLACK-IBFIAEN PLover. (Fig. 42c, 43d.) 1ds. in summer.-Cpperparts blark, bordered with whitr:; tail white, barred with black: hasal half of inner woh of primaries white; sides of head and nerk and entire underparts, exerept white lower brelly and

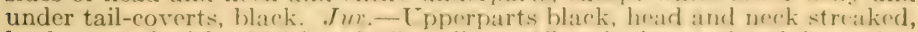
back spotted with whitish or huffy yollow; tail and wings as in arlult; underparts white, breast and sides streaked with brownish gray. Ads. and Juv. in 
winter.-Similar to the preceding, but upperparts brownish gray, lightly margined with whitish. L., $11^{\circ} 00 ;$ W., $7 \cdot 50$; Tar., 1.90; B., 1.10.

Remarks. - The rounded scales on the front of the tarsus and the presence of a fourth, although very small, toe distinguish this bird.

Range.-Nearly cosmopolitan. Breeds on the Arctic coast from Pt. Barrow to Boothia and Melville Peninsulas, and also on the Arctic coast of Russia and Siberia; winters from the Mediterranean to S. Africa, in India and Australia, and from Calif., La., and N. C. to Brazil and Peru; in migration occurs throughout the U. S., and in Greenland and Bermuda; aecidental in Hawaii.

Long Island, common T. V., May 5-June 17; Aug. 1-Nov. 4. Ossining, A. V. Glen Ellyn, two records, May and Sept. SE. Minn., now uncommon T. V., May 24.

Eggs, 3-4, light buffy olive, spotted and speckled with dark brown and brownish black or deep black, $2^{\circ} 04 \times 14^{*} 43$ (Ridgw.). Date, Pt. Barrow, Alaska, June (Thayer Coll.).

These Plovers are in a great degree tide birds, and seek a large part of their food on sand-flats left by the receding water. As the tide rises they resort to adjoining marshes or uplands, beaches, or the exposed crests of sandbars. In migrating they fly in lines and also in ranks, like Ducks and Geese. When on the ground they usually run very fast for four or five yards, then stop, elevate the head, and look around. They strike at the object they are going to pick up and eat with a very quick motion. They have two calls: one of several notes, with the accent on the second one, is mellow, clear, and far reaching; the other is low, and is uttered when they are at ease and contented.

MackaY, G. H., Auk, IX, 1892, 143-152; 300.

The LAPWING (269. Vanellus vanellus) is an Old-World species of accidental occurrence in America. The only record for eastern North America south of Greenland is based on a specimen shot at Merrick, L. I., in December, 1883 (Dutcher, Auk, III, 1886, 438).

272. Charadrius dominicus dominicus (Müll.). Golden Plover. $A d s$. in summer.-Upperparts black, spotted and margined with golden yellow; tail brownish gray, indistinctly barred; forehead, sides of head, neck, and breast white; rest of the underparts, including cheeks, black; under wing-coverts ashy. Juv.-Upperparts and tail fuscous, spotted or barred with whitish or yellow; underparts whitish, more or less streaked or barred with brownish gray. Ads. and Juv; in winter.-Similar, but less streaked below and less spotted above. L., $10 \cdot 50 ;$ W., $7 \cdot 00 ;$ Tar., $1 \cdot 60 ;$ B., 90 .

Remarks.- Immature birds are sometimes confused with those of the Black-bellied Plover, but, aside from differences of size and color, the absence of the fourth toe in the present species will always distinguish it.

Range.-N. and S. A. Breeds from Kotzebue Sound along the Arctic coast to mouth of the Mackenzie, and from Melville Island, Wellington Channel, and Melville Peninsula s. to nw. Hudson Bay; winters on the pampas of Brazil and Argentina; migrates s. across the Atlantic from N. S. and N. B.; a few pass s. through the Miss. Valley, and all migrate $\mathrm{n}$. by this route; in migration to Calif., Greenland, and Bermuda; formerly abundant, now becoming rare. (See Fig. 9.)

Washington, rare and irregular T. V. Long Island, T. V., very rare in May; common from Aug. 15-Nov. 10 (Dutcher). N. Ohio, casual T. V. Glen Fllyn, irregular T. V., Meh. 30-May 5; Sept. 6-Oct. 18. SE. Minn., now uneommon T. V., May 3; Sept. 28-Nov. 2.

Eggs, 3-4, ochraceous-t)uff or buffy white, heavily marked with chocolate, $1.85 \times 1.28$. Date, N. Alaska, May 23 . 
Golden Plovers frequent marshes, sandy hills, old fields, sand-flats exposed by the falling tide, plowed fields, and burned tracts which are free of trees and bushes. When on the ground they run rapidly and gracefully, and after alighting soon scatter. All their movements are quick, and after running a few yards they suddenly stop, hold their heads erect, and look about them. In feeding they seem to strike at an object with a motion that reminds one of a Loon or Grebe beginning to dive. When a flock is approaching decoys, every bird seems to be whistling, uttering a note like coodle, coodle, coodle. Unlike the Blackbellied Plover, the young birds are wary and more difficult to decoy than the old ones. When driven from a favorite resting- or feedingground they generally return in a short time. (MACKAY, G. H., $A u k$, $1891,17-24 ; 1892,199 ; 1893,79-82 ; 1894,75 ; 1895,78 ; 1896,80$; 1897,$212 ; 1899,180$.)

The Etropean Goldex Plover (271. Charadrius apricarius) occurs in eastern Greenland. It resembles our species, but has the under wingcoverts white instead of gray.

273. Oxyechus vociferus vociferus (Linn.). KilldeEr. Ads.-Forehead, a spot behind the eye, throat, and a ring around neck, a band on breast, lower breast, and belly white; front of crown, lores, a ring around neck, and a band on breast black; crown and back grayish brown tipped with rufous; rump and upper tail-coverts rufous; inner tail-feathers grayish brown, outer ones becoming rufous and white, all tipped with black and white. L., 10.50; W., 6.50; Tar., 1:35; B., 75 .

Range.-N. and S. A. Breeds from cen. B. C., s. Mackenzie, cen. Keewatin, and cen. Que. s. to the Gulf coast and cen. Mex.; winters from Calif., Ariz., Tex., Ind., N. J., and Bermuda s. to Venezuela and Peru; casual in N. F., Paraguay, and Chile; accidental in Great Britain.

Washington, P. R., most abundant in migrations. Long Island, not common, T. V., recorded in every month but Jan. (Dutcher). Ossining, rare T. V., in fall, Sept. 28 -Oct. 25. Cambridge, rare T. V., very rare S. R. N. Ohio, common S. R., Feb. 27-Nov. 15. Glen Ellyn, local S. R., Mch. 3-Oct. 29. SE. Minn., common S. R., Mch. 11-Oct. 10.

Nest, often far from water, a slight depression in the ground, usually scantily lined with bits of grass, ete., or stones. Egys, 4, buffy white, spotted and scrawled with chorolate chiefly at the liarerer end, $1.50 \times 1.10$. Date, Chevy Chase, Md., Apl. 6; Pewaukee, Wisc., May 15.

In localities where this bird is common it is difficult to get beyond the reach of its notes. Lakesides, meadows, pastures, and cultivated fields all attract it, but it is more numerous in the vicinity of water. It is a noisy, restless bird, running rapidly when on the ground, and when on the wing flying swiftly and sometimes pursuing a most irregular course. As a rule it is found in flocks, which scatter when feeding but unite when taking wing. At the first sign of danger it utters its half-plaintive, half-petulant kill-dee, liill-dee, and when thoroughly alarmed its outry increases until, besicle itself with frar, it reaches the limit of its voral powers. Although by no meins shy, the Killdeer never seems to gain eonfidence in man, and at his approsoch always gives voice to its fear. Even at night I have heard it cry out at some real or fancied danger.

1889. Сhadbourne, A. P., Auk, VI, 255-263 (great flight of). 
274. Agialitis semipalmata (Bonap.). Semipalmated Plover. (Figs. $42 d, 43 e$.$) . Ads. in summer.-Feathers at base of upper mandible, front$ of crown, sides of head below eye, and a band on hreast, which generally encircles the neck all around, black; rest of underparts and a ring around the neck white; back of head and back brownish gray; inner tail-feathers brownish gray, outer ones becoming gradually white; toes webbed at the base. Win-

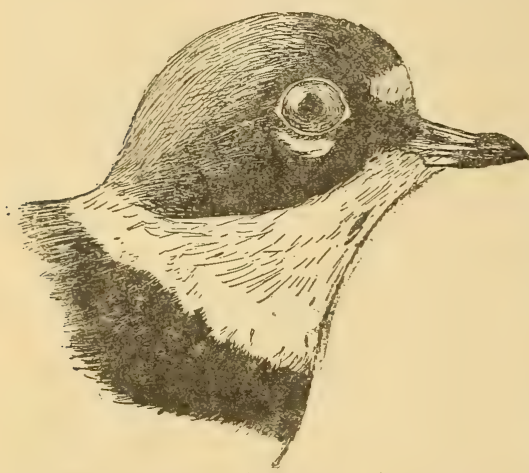

Fig. 83. Semipalmated Plover. (Natural size.) ter plumage.-Similar, but black replaced by brownish gray. L., 6.75; W., 4.80; Tar., '90; B., 50 .

Range.-N. and S. A. Breeds from Melville Island, Wellington Channel and Cumberland Sound to the valley of the Upper Yukon, s. Mackenzie, s. Keewatin, and Gulf of St. Lawrence; winters from s. L. Calif., La., and and S. C., to Patagonia, Chile, and the Galapagos; casual in Siberia, Greenland, and Bermuda.

Washington, rare T. V., May; Aug.-Sept. Long Island, abundant T. V., Apl. 29-June 4; July 15-Aug. 8. Ossining, common T. V., in fall; Aug. 23-Sept. 20. Cambridge, rare in spring; sometimes common in Aug. and Sept. N. Ohio, common T. V., May 5-25; Aug. 25-Sept. 20. SE. Minn., common T. V., May 23; Sept. 15.

Eggs, 3-4, buffy white or creamy buff, spotted with chocolate, $1.30 \times \cdot 90$. Date, Ungava Bay, Lab., June 10.

This species frequents sandy beaches, mud-flats, and marshes. It is found generally in small flocks of five or ten individuals, which, unlike the Semipalmated Sandpipers, do not feed in a compact body, but run rapidly about, independently of one another. When they take wing, however, they close ranks at once and move as though governed by one desire. Their simple, sweet, plaintive call is one of the most characteristic notes heard on our shores. At noonday, when the heat waves are dancing over the marshes and even the twittering Oxeyes are silent, one may hear the cool, pure notes of this little Plover. They may

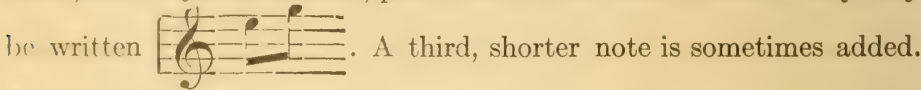

Iiven a whistled imitation of them takes me to the beaches.

277. AEgialitis meloda (Ord). PiPING Plover. Ads, in summer.Tipmerparts bale whitish ashy; forehead, underparts, and a ring around the nerek white: front of the $\mathrm{cr}^{\prime} w w_{2}$ and a bind on either side of the breast, sometimes complete, black; inner tail-feathers fuscous, outer ones becoming white. II inter mlumege.- -imilar, but black replaced by brownish gray.

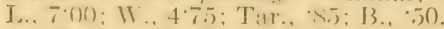

Remin .- T\%. V. Im. Brrerls locally from s. Sask., s. Ont., Magdalen Istank and . . . s. to cen. Nebr., nw. Ind., Lake Erie, N. J. (probably), and Vat, winters on the eroust of the $\mathrm{T}^{\mathrm{T}}$. S. from Tex. to Ga., and in n. Mex.; (asual in migration to N. F., the Bahamas, Greater Antilles, and Bermuda. 
Washington, casual, one record, May. Long Island, not common S. R., Mch., through Sept. Ossining, A. V. N. Ohio, breeds sparingly, May 5Sept. 20. Glen Ellyn, two records, May and Sept. SE. Minn., rare T. V., May 11-26.

Nest, a depression in the beach. Eggs, 3-4, creamy white, finely spotted or speckled with chocolate, 1.24 × 95. Date, Cape May, N. J., June 1, 1875; Shelter Is., N. Y., June 3, 1881; Minor Co., S. D., June 5.

Because of their pale colors and absence of pronounced black breast bands, Piping Plover are the most difficult to see of our small Plover. They patter over the sand or pebbles like spirit birds and disappear the moment they stop. Their liquid peep, peep, or peep-lo has a true piping quality. As a breeding bird it is now rare, and man's increasing encroachment on its haunts threatens it with extinction as a summer resident in our Atlantic States.

The Ringed Plover (275. Egialitis hiaticula), an Old-World species, is found in Greenland. It is similar to $\mathbb{E}$. semipalmata but slightly larger, the black band on the breast is wider, and there is no web between the inner and middle toes.

The Snowy Plover (278. Agialitis nivosa) of the southwestern United States and southward, is of casual occurrence in Ont., La., and Fla.

280. Ochthodromus wilsonius wilsonius (Ord.). Wilson's Plover. $A d .{ }^{7}$.- - Lores, front of crown, and a hand on the breast black; rest of underparts, forehead, and an indistinct ring on the nape white; sides of the head and nape sometimes with rufous markings; cheeks, crown, and back brownish

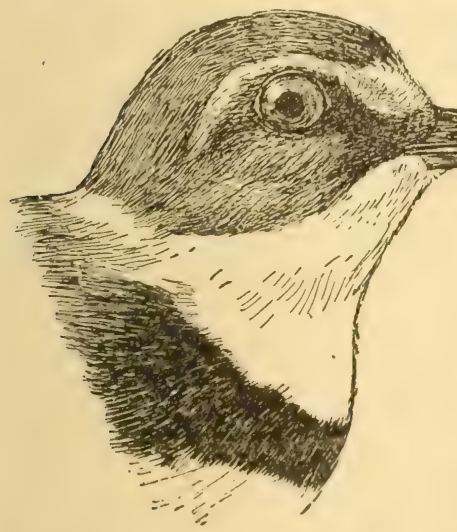

Frg. 84. Wilson's Plover. (Natural size.) gray; inner tail-feathers fuscous, outer ones becoming white. Ad. o.Similar, but black replaced by brownish gray with rusty on breast. Juv.Similar to $\%$, but upperparts margined with grayish. L., 7.50; W., 4.50; Tar., $1 \cdot 10 ; \mathrm{B} ., \cdot 80$.

Range.-S. N. Am. 'Breeds from Tex. e. along the Gulf coast, and from se. Va. (formerly N. J.) s. to the n. Bahamas; winters from s. L. Calif., Tex., and Fla. s. to s. Guatemala and probably to the West Indies; casual in N. S. and New England, and at San Diego, Calif.

Long Island, casual, five May records.

Nest, a depression in the sand. Eggs, 3, creamy white, evenly and rather finely spotted and speckled with chocolate, $1.42 \times 1.03$. Date, Sarasota, Fla., Apl. 12; Cobb's Is., Va., May 15.

This is a more strictly maritime species than the other representatives of this genus. Sandy beaches are its favorite resorts, but it is also found on mud-flats exposed by the falling tide. It is a gentle, unsuspicious bird, and when its nest is approached it runs about the intruder and begs as plainly as a bird can that he will not disturb its 
treasures. Its plaintive note is easily distinguishable from the calls of its near whlies.

The Morntarn Plover (281. Podasocys montanus), a western species, is of accidental occurrence in Florida. The upperparts are grayish brown margined with rufous, the underparts are white tinged with buffy on the breast; in adults the front of the crown and lores are black. L., about 8.75; W., 5·75; Tar., 1·50; B., '85.

\section{Family Aphrizid Ae. Surf-birds and Turnstones}

A small family of three species, all of which are found in North America, though but one of these visits our Eastern States. They are largely maritime birds, frequenting the seacoasts, where they prefer the outer beaches.

283. Arenaria interpres interpres (Linn.). TURnstone. Similar to No. 283a, A. i. morinella, but larger (W. 6.00) and, in the adult the upperparts with black prevailing. Im.-Blacker than young of morinella.

Range.-Old World. Breeds in w. Alaska from Pt. Barrow to the Yukon delta, and in w. Greenland, Scandinavia, n. Russia, Siberia, and Japan; winters on the coasts of Europe and Asia to s. Africa, Australia, and Oceanica.

283a. A. i. morinella (Linn.). Ruddy TuRnstone. Ads. in summer. - Upperparts, including wings, strikingly variegated with rufous, black and white; tail white at base, a black band near its end, and tipped with white; throat and breast black and white; belly white. Winter plumage.-Upperparts blackish, bordered with brownish gray or ashy; lower back white; longer upper tail-coverts white, shorter ones black; tail as in adult; throat white, breast black margined with white, belly white. L., 9.50; W., 6.00; Tar., 95 ; B., $1 \cdot 00$.

Range.-N. and S. A. Breeds on Arctic shores from Mackenzie River e., probably, to Melville Peninsula, and n. to Melville Is.; winters from cen. Calif., Tex., La., and S. C., to s. Brazil and cen. Chile.

Washington, rare and irregular T. V. Long Island, common T. V., May; Aug. and Sept. Ossining, A. V. N. Ohio, irregular T. V., May 5-25; Sept. 1-25. SE. Minn., rare T. V.

Eggs, 3-4, clay-color, blotched and scrawled with grayish brown, 1.60 $\times$ 1·15. Date, Mackenzie River, June 28 (Thayer Coll.).

This maritime species is found singly or in small flocks, generally on the outer beaches, where it obtains its food by turning over shells and pebbles in search of insects, crustaceans, etc.

\section{Family Hamatopodid}

The Oyster-catchers number twelve species, represented in most of the warmer parts of the globe. But three species are found in North America, and only one of these occurs in the Eastern States. They are strictly maritime birds, and resort to the outer bars and beaches in search of clams, musscls, etc., exposed by the tide. Their strong bill is used as an oyster-knife to force open the shells of these bivalves.

286. Hæmatopus palliatus $T \mathrm{emm}$. Oyster-CAtcher. Ad.-Head, neck, and upper breast glossy black, back and wing-coverts olive-brown, 
secondaries white, primaries fuscous, upper tail-coverts white, base of tail white, end fuscous, lower breast and belly white. Im.- Simil ', but head and neck blackish and upperparts more or less margined with buffy. L., $19 \cdot 00$; W., $10 \cdot 50$; Tar., $2 \cdot 40$; B., 3*40.

Range.-Coasts of N. and S. A. from Tex., La., and Va. (formerly N. J.) s. on both coasts of Mex. to the West Indies, s. Brazil, and cen. Chile; casual n. to N. B. Breeds probably throughout its range.

Long Island, A. V.

Nest, a depression in the sand. Eggs, 3, buffy white or creamy buff, rather evenly spotted and blotched with chocolate, $2.20 \times 1.55$. Date, Mouth St. John's River, Fla., Apl. 10; Coast S. C., Apl. 20; Cobb's Is., Va., May 10.

This not uncommon species from Virginia southward, is confined exclusively to the coast, and breeds usually in isolated pairs. Wayne states that in the winter it is found on the South Carolina coast in flocks of from twenty to seventy-five individuals. It agrees in habits with other members of this small family.

1905. Јов, Н. K., Wild Wings, 239 (nesting).

The EURopean Orster-Catcher (285. Hamatopus ostralegus) is of accidental occurrence in Greenland.

The Mexican JaCANa (288. Jacana spinosa) occurs in the lower Rio Grande valley of Tex., in Cuba and southward, and has been once recorded from Fla. (Lake Okeechobee, Oct. 1889; Mearns, Auk, 1902, 79).

\section{ORDER GALLINAE. GALLINACEOUS BIRDS}

\section{Family Odontophorider. American Quail. (Fig. 44.)}

The members of this family, some sixty in number, are the American representatives of the Old World Perdicido, or true Quails and Partridges, to which structurally they are closely related though differing in external appearance. Doubtless the two 'families,' as for convenience we term them, had a common origin, just as Old and New World Pigeons, or Parrots, or Spoonbills, for example, have had, and we may believe that in the later Tertiary Period, when a much warmer climate prevailed in Arctic regions, their range was doubtless continuous.

The present center of abundance of the American species is in the tropics, to which the seventeen species of Wood Quail of the genus Odontophorus are confined, only seven of the sixty members of the family crossing our southern border. This includes our Bob-white and the Masked Bob-white of northern Sonora, and formerly, at least, southern Arizona, the Scaled, Mearns' and Gambel's Quails of our Mexican border States, and the California Valley and Mountain Quails.

In eastern North America we have only one species, our familiar Bob-white, not, as we are apt to imagine it, a distinctively North American bird, but the most northern representative of a type whose stronghold is in Mexico where ten forms of the genus Colinus are known. 
Some are strikingly unlike our bird with which, however, they have been shown by Nelson to be connected by a number of intergrading races. All, so far as I am aware, have the characteristic "bob-white" call, and I have even heard this note uttered by the Black-throated Bob-white of Yucatan and Crested Bob-white of Colombia, both members of a different genus (Eupsychortyx). Voice is here, therefore, evidently more stable than color.

1897. Elliot, D. G., Gallinaceous Game-Birds of North America, 8vo, 220; plls. 46. (Francis Harper.)-1900. Dwight, J., JR., The Moult of North American Tetraonidæ, Auk, XVII, 34-51; 143-166.-1902. SANDYS, E. and VANDyke, T. S., Upland Game Birds, 8vo. 429; plls. 9 (Macmillan). -1903. Huntington, D. W., Our Feathered Game, 8vo. 396; plls. 37. -1907. RIcH, W. H., Feathered Game of the Northeast, 8vo. 430; plls. 87.

\section{KEY TO THE SPECIES}

I. Tarsi bare . • . 289. Bob-white. 289a. Florida Bob-white. II. Tarsi not bare.

1. Toes bare.

$A$. Upper third or half of tarsi feathered.

300. Ruffed Grouse. 300a. Canada Ruffed Grouse.

$B$. Tarsi entirely feathered.

a. With bunches of elongated, stiffened feathers springing from either side of the neck. 305. Prairie Hen. 306. Heath Hen.

$b$. Feathers of neck normal.

$b^{1}$. Outer web of primaries spotted with white.

308b. Prairie Sharp-tailed Grouse and subsp.

$b^{2}$. Primaries not spotted with white. SPruce Partridges.

2. Tarsi and toes entirely feathered. . . . . . Ptarmigans.

289. Colinus virginianus virginianus (Linn.). Вов-wHITE. $A d$. $\sigma^{7}$ in winter.-Upperparts varying from reddish brown to chestnut; interscapulars with broken and sometimes complete black bars; inner vane of tertials widely margined with cream-buff; rump grayish brown, finely mottled, and with a few streaks of blackish; tail ashy gray, the inner feathers finely mottled with buffy; front of crown, a band from bill to beneath eye, and a band on upper breast black; throat and a broad line from bill over eye white; sides rufous-chestnut, margined with black and white; lower breast and belly white barred with black. $A d$. o in winter. - Similar, but the throat and line over the eye, forehead, and lores pale ochraceous-buff; little or no hlack on the upper breast. Summer examples of both sexes have the crown hlacker, the buffy markings generally paler. L., $10^{\circ} 00 ;$ W., 4.50; T., 2.50 ; B. from N., 35 .

Range-Upper Sonoran and s. half of Transition zones of e. N. A. from S. D., s. Minn., s. Ont., and sw. Maine s. to e. and n. Tex., the Gulf coast, and n. Fla., w. to e. Colo: introduced in cen. Colo., N. M., Utah, Idaho, Calif., Ore., and Wash.

Washington, common P. R. Ossining, common P. R. Cambridge, P. R., sometimes abundant. N. Ohio, not common P. R. Glen Ellyn, rare P. R. SE. Minn., common P. R.

Nest, of grasses, usually arched, on the ground in bushy field borders, ete. Eggs, 10-18, white, conical, 1.20 × 95. Date, Charleston, S. C., May 22 ; Shelter Is., N. Y., June 2; Cambridge, June 20; Licking Co., Ohio., May 22; Mitchell Bay, Ont., June 5; se. Minn., June 17.

Taking the Old-World species of the genera Coturnix and Caccabis as the types respectively of Quails and Partridges, neither of these lat- 
ter names can properly be applied to our Colinus, which should therefore be known under the distinctive title Bob-white.

During the nesting season Bob-whites are distributed in pairs through clearings and cultivated fields. The members of a brood constitute a bevy or covey, though occasionally two families or broods are found in one bevy. In the fall they frequent grain fields, but as winter approaches draw in toward thickets and wooded bottom-lands, sometimes passing the coldest weather in boggy alder swamps. They roost on the ground, tail to tail, with heads pointing outward; a bunch of closely huddled forms-a living bomb whose explosion is scarcely less startling than that of dynamite manufacture.

Like most grass-inhabiting birds whose colors harmonize with their surroundings, Bob-whites rely on this protective resemblance to escape detection, and take wing only as a last resort. Sometimes they take refuge in trees, but usually they head for wooded cover, where they romain if the growth is dense, but if it is open they generally run the moment they touch the ground.

About May 1 they begin to pair, and rival males may then be seen battling for mates like diminutive gamecocks. The name "Bob-white" originated in the spring call of the male. Mounting a fence or ascending to the lower branches of a tree, he whistles the two clear musical, ringing notes $B o b$-white! Sometimes they are preceded by a lower one which can be heard only when one is near the singer. After the breeding season, when the birds are in bevies, their notes are changed to what sportsmen term "scatter calls." Not long after a bevy has been flushed and perhaps widely scattered, the members of the disunited family may be heard signaling to one another in sweet minor calls of two and three notes, when one can easily imagine them saying "Where are you?" "Where are you?" When excited they also utter low, twittering notes.

1905. JUdD, S. D., Bull. 21, Biol. Surv. (food).

289a. C. v. floridanus (Coues). Florida BoB-white. Similar to the preceding, but smaller, the plumage throughout darker, the black of the back more extensive, the rump and upper tail-coverts grayer, the black throat-band wider and sometimes rearhing down upon the breast, the rufouschestnut of the sides more extensive, the black bars of the breast and belly much wider. L., 8.50; W., 4*40; T., 2.50 .

Range.-Fla., except extreme northern part.

Nesting date, Manatee Co., Fla., Apl. 19.

A common bird throughout the pine-grown portions of the Florida peninsula. It is especially numerous on old plantations, where it frequents patches of 'cowpeas.' It resembles the northern Bob-white in habits, but is, I think, more inclined to take to the trees when flushed. I have seen a whole covey fly up into the lofty pine trees, where, squatting close to the limbs, they became almost invisible.

The European or Migratory Quail (Coturnix coturnix) has been introduced into this country on several occasions, but does not appear to have survived. 


\section{Family Tetraonides. Grouse. (Fig. 44.)}

The Grouse, numbering some twenty-five species, inhabit the northern parts of the Northern Hemisphere. Two species of Ptarmigan are found throughout the Arctic regions, while the remaining species are about equally divided between the Old World and the New. After the nesting season they commonly gather in 'coveys' or bevies. In some species, these bevies unite or 'pack,' forming large flocks. As a rule, they are terrestrial, but may take to trees when flushed, while some species habitually call and feed in trees. They are game birds par excellence, and, trusting to the concealment afforded by their protective coloration, attempt to avoid detection by hiding rather than by flying, or, in sportsman's phraseology, "lie well to a dog." Their flight is rapid and accompanied by a startling whirr, caused by the quick strokes of their concave, stiff-feathered wings. Though not, as a rule, migratory, or given to extended flights, their great weight as compared with their wing-expanse, and the necessity of getting under way at once, requires great strength, hence the exceptional development of the breast muscles which constitute most of the edible portion of these universally esteemed birds.

Many species of this family are polygamous, and their strutting, dancing or actual fighting, tootings, hootings, boomings, or drummings make them among the most interesting of birds during their periods of courtship display.

The young, as with all Gallinaceous birds, are hatched thickly covered with down, usually of a pronounced pattern, and leave the nest soon after birth, generally under the care of the female alone. Like the young of Terns, they instinctively squat at the warning note of the parent, which then flutters painfully before one, using every possible effort to draw one from the vicinity of her chicks. (For special literature, see under preceding family.)

298. Canachites canadensis canadensis (Linn.). HUDSONIAN Sprdce Partridge. Male indistinguishable from the male of C. c. canace; female similar to female of canace but less rusty.

Range.-Boreal forest region from the e. base of the Rocky Mts. w. of Edmonton, Alberta, e. to Lab. Peninsula; also a disconnected area in Alaska from Bristol Bay to Cook Inlet and Prince William Sound.

298c. C.c. canace (Linn.). Canada Spruce Partridge. Ad. $\sigma^{r}$-U Upperparts barred with black, ashy, gray, and grayish brown; tertials and wingcoverts irregularly marked with fuscous and grayish brown; tail black, tipped with rufous; black throat separated from black breast by a broken rirrular band of black and white and a band of same color as back of neck; sides mottled with black and grayish brown, ends of the feathers with white shaft strraks; rest of underparts black, broadly tipped with white, except on mirldle of lower breast; bare skin above eye bright red in life. Ad.o. Upprrparts barred with black and pale rufous and tipped with ashy gray; tail black, mottled and tipped with rufous; throat and upper breast barred with pale rufous and black; sides mottled with black and pale rufous, ends of frathers with white shaft streaks; rest of underparts black, broadly tipped 
with white and more or less washed with pale rufous. L., $15 \cdot 00 ;$ W., $6 \cdot 50$; T., $4 \cdot 75$; B. from N., $\cdot 40$.

Range.-Man., s. Ont., and N. B., s. to n. parts of Minn., Wisc., Mich., N. Y., and New England.

Nest, on the ground, sheltered by overhanging limbs. Eggs, 9-16, buffy or pale brownish, more or less speckled or spotted with deep brown, $1.71 \times$ 1.22 (Ridgw.): Date, Kentville, N. S., June 2.

The excessive tameness of this inhabitant of swampy, coniferous forests is responsible for its decrease in numbers, and it is now a rare bird in the United States. "In April and early May the males strut and drum somewhat after the manner of the Ruffed Grouse, the sound resembling the distant roll of thunder. It is usually produced when the cock is fluttering up an inclined tree trunk or a stump, and from this elevation to the ground again, or sometimes by merely springing into the air for several feet and fluttering to the ground" (Eaton).

1911. Hardy, M., Journ. Me. Orn. Soc., 47-49 (habits in Maine).

300. Bonasa umbellus umbellus (Linn.). RUFFed Grouse. (Fig. 18.) $A d . \sigma^{7}$.-Prevailing color of the upperparts rufous, much variegated with black, ochraceous, buffy, gray, and whitish; sides of the neck with large tufts of broad, glossy black feathers; tail varying from gray to rufous, irregularly barred and mottled with black, a broad black or brownish band near the end; tip gray; throat and breast ochraceous-buff, a broken blackish band on the breast; rest of the underparts white, tinged with buffy and harred with blackish or dark grayish brown, the bars indistinct on the breast and belly, stronger on the sides. Ad. o.- Similar, but with the neck tufts very' small. L., $17 \cdot 00 ;$ W., $7 \cdot 25 ; T^{\circ}, 6 \cdot 25 ;$ B. from N., ${ }^{5} 52$.

Range.-E. U. S. from Minn., Mich., s. N. Y., and s. Vt., s. to e. Kans., n. Ark., Tenn., and Va., and, in the Alleghanies, to n. Ga.

Washington, not common P. R. Ossining, common P. R. Cambridge, P. R., formerly very common. N. Ohio, rare P. R. Glen Ellyn, rare and local P. R.

Nest, a depression lined with leaves, at the base of a stump or tree, or beneath brush. E'ggs, 8-14, pale ochraceous-buff, $1.52 \times 1 \cdot 13$. Date, Chester Co., Pa., May 5; Ossining, N. Y., May 5; Portland, Conn., May 7; Cambridge, May 15; se. Minn., May 3.

Of all the characteristics of this superb game bird, its habit of drumming is perhaps the most remarkable. This loud tattoo begins with the measured thump of the big drum, then gradually changes and dies away in the rumble of the kettle-drum. It may be briefly represented thus: Thump-thump-thump-thump, thump; thump, thump-rup rup rup rup $r-r-r-r-r-r-r-r-r$. The sound is produced by the male bird beating the air with his wings as he stands firmly braced on some favorite low perch, and it is now quite woll known to be the call of the male to the female; an announeement that he is at the old rendezvous - a rendezvous that has perhaps served them for more than one season, and a place that in time becomes so fraught with delightful associations that even in autumn or winter the male, when he finds himself in the vicinity, can not resist the temptation to mount his wonted perch and vent his feelings in the rolling drum-beat that was in springtime his song of love. But now, alas! there is no ladly Grouse to come, shy but responsive, at the sound of his reverberating summons. 
There is good reason for supposing that the Ruffed Grouse is polygamous, and that the male, if he drums in vain at one place, will fly to another retreat and there seek the society of some more compliant female. The young Grouse can run about as soon as they are hatched, and can fly well when about a week old. Their mother is celebrated for the variety of expedients she puts in practice to save her brood from threatened danger, and their father has frequently been known to divide the charge with her. The young usually continue with their parents till the following spring, though it is rare at this time to see more than three or four surviving out of the original twelve or fourteen.

The food of this Grouse is largely insects and berries during the summer; in the autumn it adds seeds to the list, and when the ground is covered with snow the staples are catkins, leaves, and buds. Its toes are provided during the winter with a curious fringe of strong, horny points which act as snowshoes. In the northern part of its range this bird commonly burrows into a snowdrift to pass the night during the season of intense cold; but in summer and in the warmer region of its range it roosts habitually among the thickets of evergreen.

\section{Ernest T. Seton.}

300a. B. u. togata (Iinn.). Canada RufFed Grouse. To be distinguished from the preceding by the prevailing color of the upperparts, which are gray instead of rufous, and the more distinctly barred underparts, the bars on the breast and belly being nearly as well defined as those on the side; the tail is generally gray.

Range.-Cen. Keewatin, s. Ungava, and N. S., s. to Man., n. Mich., n. Vt., N. H., and Maine, and in the mountains of N. Y., w. Mass., and n. Conn.; birds indistinguishable from the eastern form occur from e. cen. B. C. s. to e. Ore. and cen. Idaho.

301. Lagopus lagopus lagopus (Linn.). Willow Ptarmigan. $A d$. o breeding plumage. - Throat and chest, breast and sides rich rufous, chest and sides more or less barred with black; upperparts, including tail-coverts, black thickly but irregularly barred with ochraceous or rusty; tail fuscous narrowly tipped with white (worn off in some July specimens); primaries and secondaries white; tertials like back; belly largely white. $A d$. or in fall (preliminary winter) plumage. - Similar to the preceding, but with a variable number of deep rufous feathers, vermiculated with black, on the breast, sides, and upperparts; more white in wings and belly. $A d$. o in winter. - The preliminary winter plumage is a transition dress worn chiefly in September and October, when it is gradually replaced by the full winter plumage of snowy white with a fuscous, white-tipped tail. Ad. o breeding plumage.-Upperparts, tail and wings as in the male, but with less rufous, or none, on the head and neck; throat, breast and sides ochraceous broadly burred with black; center of belly paler with broken black bars. Ad. \& in fall (preliminary winter) plumage.-Barred feathers of underparts largely replaced by rufous, more or less vermiculated feathers, which also appear in varying numbers on the upperparts. Resembles male in corresponding plumage except for the remaining feathers of the breeding plumage. $A d$. $\%$ in winter.-Similar to winter male. L., $15 \cdot 00 ;$ W., $7 \cdot 50 ;$ T., 4.40; B. from N., -42 ; depth of B. at N., 44 .

Remarks. - The seasonal plumages of the species are as confusing as they are intresting. It is not possible to treat them fully here, and the student who would pursue the matter further is referred to Dwight's paper in The Auk, 1900, 147 163. Summer males and all fall p! lumage specimens may be 
known from corresponding stages of $L$. rupestris by their rich rufous breasts and other characters. Summer females are usually deeper, but cannot always be distinguished from summer females of rupestris save by the larger bill which alone serves to separate winter specimens of the two species.

Range.-Arctic regions. In Am. breeds from n. Alaska, n. Banks Land, and cen. Greenland s. to e. Aleutian Islands, cen. Mackenzie (in the mountains to w. cen. Alberta), cen. Keewatin, James Bay, and s. Ungava; s. in winter to n. B. C., Sask. Valley, Minn., Ont., and Que., accidental in Wisc., Mich., N. Y., Maine and Mass.

Nest, on the ground. Eggs, 7-11, varying from cream-buff to rufous, heavily spotted and blotched with blackish, $175 \times 1 \cdot 20$. Date, Ft. Chimo, Lab., June 3; Ft. Anderson, Mack., June 7.

This abundant and characteristic Arctic bird does not nest south of central Labrador, but migrates southward in winter to the St. Lawrence, and has once been taken in northern New York and once in New Brunswick. An extended account of its habits will be found in "Nelson's Report on Natural History Collections made in Alaska" (p. 131). It is quoted by Captain Bendire in his "Life Histories of American Birds" (p. 70), where will be found practically all we know concerning the habits of this and the following members of this genus.

301a. L. 1. alleni Stejn. Allen's Ptarmigan. Similar to L. l. lagopus but, at all seasons, primaries usually more or less mottled with fuscous or with some fuscous along the shaft; shafts of secondaries sometimes black.

Range.-Newfoundland.

"It frequents rocky barrens, feeding on seeds and berries of the stunted plants that thrive in these exposed situations" (Merriam, Orn. and Oöl., VIII, 1883, p. 43).

302. Lagopus rupestris rupestris (Gmel.). Rock Ptarmigan. Ad. $\sigma^{7}$ breeding plumage. - Breast and sides rusty ochraceous rlosely and narrowly barred with black and more or less tipred with white; belly white; crown barred with rusty and ochrareous; back and upper tail-coverts black narrowly and irregularly but thickly barred with ochraceous and buff, and tipped with white; black predominating in the feathers of the center of the back; tail fuscous tipped with white; primaries and secondaries white, tertials like back. Ad. on in fall (rreliminary winter) plumage- - Similar to the preceding, but with the feathers of the breast, sides, back, and upperer tail-coverts finely vermiculated with blark and ochraceous in about e(pual proportions. Ads. o winter. - The preceding plumage is gradually replaceed by the winter dress of snow-white, with a fuscous, white-tipped tail and black lores. Ad. o breeding plumage. - Similar in color to the breeding female of L. l. lagopus, but rusty markings averaging paler, marticularly on underparts; edgings to feathers whiter, less buffy. $1 d$. ? fall (preliminary winter) plumage.-Resembling corresponding plumage of Arl. s, but with a varying number of the feathers of the breeding plumage remaining. $\mathrm{Ad} .2$ and $\mathrm{Im}$. winter. - Snowy white, tail-feathers fuscous, timped with white; lores sometimes black. W., 7·25; B., from N. "35; ; depth of B. at N., 332 .

Remarks. - In any plumage rupestris and its allies may be distinguished from lagopus by their smaller bill.

Range.-Aretic Am. Breeds from Melville: Is. to Melville Peninsula and s. on the Barren Grounds from Alaska to Ungava; also on alpine summits s. to cen. Yukon; s. in winter to s. Markenzie and s. Ungrava.

Nest, usually placed among the dwarf brush or sedger-covered patehes of the tundras. Eggs, 6-10, pale cream or yellowish buff, sometimes with a 
vinaceous-rufous suffusion, spotted and blotched with clove-brown or dark claret-red, 1.65 × 1.18 (Bendire). Date, n. Lab., June 16.

"In its general manners and mode of living it is said to resemble albus $[=L$. lagopus], but does not retire so far into the wooded country in the winter" (B., B., and R.).

302a. L. r. reinhardi $(B r e h m)$. Reinhardt's Ptarmigan. Ad. $\sigma^{7}$ summer. - Similar to corresponding plumage of $L$. $r$. rupestris but less heavily and regularly barred above, breast more finely barred. Ads. in fall (preliminary winter) plumage.- Similar to corresponding plumage of $L$. $r$. ru; pestris but much grayer. Ads. in winter.-Not distinguishable from $L . r$. rupestris in winter.

Range.-Northern extremity of Ungava, w. Cumberland Sound, and Greenland.

"They prefer more open ground, and rarely straggle even into the skirts of the wooded tracts. The hilltops and barrens (hence often called the Barren Ground Bird) are their favorite resorts" (Turner).

303. Lagopus welchi Brewst. Welch's Ptarmigan. Ad. ${ }^{7}$ in breeding plumage.-Upperparts black, the head and neck barred with white and ochraceous-buff, the back and wing-coverts finely and irregularly marked with wavy lines of buffy and white; tail grayish fuscous, tipped with white; throat white, foreneck like hindneck, breast and sides like back; rest of underparts white. Ads. in fall (preliminary winter) plumage.-Not seen, but back and breast doubtless with finely vermiculated black and white feathers. Ad. o breeding plumage.- Similar to corresponding plumage of rupestris. Ads. in winter. - Similar to winter ads. of rupestris. W., 7·25; B. from N., 35 ; depth of B. at N., 32 .

Remarks. - This is a much blacker and grayer bird than L.r. rupestris, and in this respect it appears most nearly to approach Rock Ptarmigan from Sitka ( $L$. $r$. dixoni? ). (For comparison with rupestris see Stejneger, The Auk, 1885, 193.)

Range.-Newfoundland.

Nest, a slight hollow in the moss, lined with a few feathers. Eggs, 8, similar to those of Lagopus rupestris. Date, N. F., June 3 (Thayer Coll.).

"According to Mr. Welch, these Ptarmigan are numerous in Newfoundland, where they are strictly confined to the bleak sides and summits of rocky hills and mountains of the interior" (Brewster).

305. Tympanuchus americanus americanus (Reich.). PraIrIE Chicken. Ad. $\sigma^{7}$--Upperparts barred with rufous and black and spotted with rufous; sides of neck with tufts generally composed of ten or more narrow, stiffened black feathers marked with buffy and rufous, their ends romended, the skin beneath these tufts bare; tail rounded, fuscous, the inner feathers somewhat mottled with ochraceous-buff, tip white; throat buffy, breast and belly white, evenly barred with black. Ad. o. - Similar, but neck tufts much smaller and tail barred with ochraceous-buff or rufous. L., 18*00; W., 9.00; T., $4 \cdot 00 ;$ B. from N., 52 .

Range. SE. Sask. and s. Man. to e. Colo., ne. Tex., Ark., w. Ky., and Ind.; probably extinct e. of Ind.; but formerly reached sw. Ont., Mich., and nw. Ohio.

Glen Fillyn, P. R., fairly plentiful locally. SE. Minn., P. R., much decreased in numbers.

Nest, on the ground. Eggs, 11-14, buffy olive, sometimes finely speckled with brownish, $1.70 \times 1 \cdot 25$. Date, Jasper Co., Iowa., May 2. 
"This familiar game bird inhabits our fertile prairies, seldom frequenting the timbered lands except during sleety storms or when the ground is covered with snow. Its flesh is dark, and it is not very highly esteemed as a table bird.

"During the early breeding season they feed largely upon grasshoppers, crickets, and other forms of insect life, but afterward chiefly upon our cultivated grains, gleaned from the stubble in autumn and the cornfields in winter; they are also fond of tender buds, berries, and fruits. They run about much like our domestic fowls; but with a more stately carriage. When flushed they rise from the ground with a less whirring sound than the Ruffed Grouse or Bob-white, and their flight is not so swift, but more protracted and with less apparent effort, flapping and sailing along, often to the distance of a mile or more. In the fall the birds collect together and remain in flocks until the warmth of spring quickens their blood and awakes the passions of love; then, as with a view to fairness and the survival of the fittest, they select a smooth open courtship ground (usually called a 'scratching ground'), where the males assemble at the early dawn to vie with each other in courage and pompous display, uttering at the same time their love call, a loud booming noise; as soon as this is heard by the hen birds desirous of mating they quietly put in an appearance, squat upon the ground, apparently indifferent observers, until claimed by victorious rivals, which they gladly accept, and receive their caresses" (Goss).

1908. Chapman, F. M., Camps and Cruises, 231-235 (display).

306. Tympanuchus cupido (Linn.). "Heath HeN. Similar to the preceding, but the scapulars broadly tipped with buffy; the neck tufts of less than ten feathers; these feathers pointed, not rounded, at the ends.

Range.-Is. of Martha's Vineyard, Mass. Formerly s. New England and parts of the Middle States.

Nest, "in oak woods, among sprouts at the base of a large stump" (Brewster). Eggs, "creamy buff in ("olor, with a slight greenish tinge," $1.73 \times 1.29$. Date, Martha's Vineyard, June 10.

In the early part of this century the Heath Hen was found locally throughout the Middle States, where, unlike its western representative, the Prairie Hen, it lived in wooded dist ricts. In New Jersey the last. Heath Hen was killed on the Barnegat Plains about 1870 (Bird-Lore, 1903, p. 50). It is now restricted to the island of Martha's Vineyard, an excellent illustration of the protection afforder by an insular habitat.

Mr. William Brewster, writing in 1890 (Forest and Stream, 188, p. 207), estimated that there were from one hundred and twenty to two hundred Heath Hens then on the island. In 1907 this number aceording to Field (Bird-Lore, IX, pp. 249-255, and 42nd. Arn. Rep. Mass. Comm.) was reduced to seventy-seven. Proper protective masures were now introduced, the birds began at once to increase, and in 1910 they were estimated to number "upwards of three hundred" (Field in epist.). Field describes the Heath Hen's call as a toot which can be "imitated by blowing gently into the neck of a two-drachm homoeopathic vial. 
Each call extends over a period of two seconds and is repeated at frequent intervals." This is evidently very unlike the emphatic boom-ahboom of the true Prairie Hen, and this pronounced difference in notes suggests that possibly the eastern and western birds are not so closely allied as their resemblance in plumage would lead one to believe.

308. Pediceetes phasianellus phasianellus (Linn.). SHARPTAIled Grouse. Similar to $P$. p. campestris but much darker and the black areas larger and more prominent than the ochraceous ones, the latter deeper, more rusty.

Range.-Cen. Alaska and nw. B. C. e. through cen. Keewatin to cen. w. Ungava, and s. to Lake Superior and the Parry Sound district, Ont.; casual e. to Saguenay River, Que.

SE. Minn., formerly present, now wanting.

308b. Pediceetes phasianellus campestris Ridgw. Prairie SharpTAILED Grouse. Ad. $o^{7}$.-Prevailing color of the upperparts ochraceousbuff, barred and irregularly marked with black; no neck tufts; outer web of the primaries spotted with white; middle tail-feathers projecting about an inch beyond the others, ochraceous-buff and black; throat buffy; breast with V-shaped marks of black; sides irregularly barred or spotted with black or buffy; middle of the belly white. $A d$. $\%$. - Similar, but smaller; the middle tail-feathers shorter. L., $17 \cdot 50$; W., 8.50; T., 4.50; B. from N., 50 .

Range.-S. Alberta and s. Man. to Wyo., Kans., and n. Ill.

Nest, on the ground. Eggs, 11-14, creamy buff or pale olive-brown, generally slightly spotted with fine, reddish brown markings, $1.65 \times 1 \cdot 22$ (Bendire). Date, Carberry, Man., June 3.

There is more or less confusion in regard to the names Prairie Hen and Prairie Chicken, but where the two species are found together I have found that the former is applied to Pediocetes and the latter to Tympanuchus. In central Nebraska, I found this species inhabiting the sand-hills while the Prairie Chicken (Tympanuchus) was nesting in immediately adjoining bushy bottom-lands. In Saskatchewan it lived among the rose-bushes near the borders of streams. When 'dancing' the male inflates a pink sac, utters a bubbling crow, rattles its tail-quills, etc. The whole performance is well described by Seton, as quoted by Bendire, and by Cameron (Auk, 1907, p. 256).

\section{Family Meleagrid 死. Turkeys}

This distinctively American family contains only two species, the Yucatan Turkey (Agriocharis ocellata) and our Wild Turkey. The former is confined to Yucatan and the adjoining portions of Guatemala and Honduras, and, except in isolated instances, has defied all attempts at domestication. The latter ranges from southern Mexico northward, and is represented by five subspecies as follows: (1) Meleagris gallopavo gallopavo of southern Mexico; (2) M. g. merriami of northern Mexico, southwestern Texas, New Mexico, Arizona and southern Colorado; (3) $M . g$. intermedia of northeastern Mexico north to middle northern Texas; (4) M. g. osceola of southern Florida, and (5) M. g. silvestris, our Wild Turkey, which, formerly, extended as far north as southern 
Maine, southern Ontario and South Dakota. It is the southern Mexico form, with white-tipped upper tail-coverts, which is the ancestor of our domesticated Turkey. It was introduced from Mexico into Europe where it had become established as early as 1530, and was later brought by colonists to Eastern North America. It breeds freely with our Wild Turkey (silvestris) and where the birds of the woods come in contact with the inhabitants of the poultry yard, evidences of such alliances are not infrequent.

310a. Meleagris gallopavo silvestris Vieill. Wild TuRkey. The Wild Turkey may be distinguished from the common domestic race chiefly by the chestnut instead of white tips to the upper tail-coverts and tail. " $\sigma^{\text {T }}$ ad. L., about 48.00-50.00; W., 21.00; T., 18.50; weight 16-40 lbs." (Ridgw.)

Range.-E. U. S. from Neb., Kans., w. Okla., and e. Tex. e. to cen. Pa., and s. to the Gulf coast; formerly n. to S. D., s. Ont. and s. Maine.

Washington, rare P. R.

Nest, on the ground, at the base of a bush or tree. Eggs, 10-14, pale cream-buff, finely and evenly speckled with grayish brown, $2.45 \times 1.95$. Date, Pipemaker Swamp, Ga., Apl. 25; Ft. Smith, Ark., Apl. 3.

This noblest of American birds is rapidly decreasing in numbers, and in comparatively few years will doubtless be found only in the parts of its range which are unfit for the habitation of man.

Except during the breeding season, Wild Turkeys are found in small flocks of six to twelve or fifteen individuals of both sexes. They roost preferably in the trees in wooded bottom-lands, returning each night to the same locality.

At the opening of the breeding season in March the male begins to gobble. As a rule, he calls only early in the morning, before leaving his roost. Later he sails to the ground and at once begins his search for breakfast, or, attracted by the plaintive piping of some female, he struts and displays his charms before her. It is at this time that battles between the males occur. They are polygamists, and the victor becomes sultan of the harem. During the period of incubation, and while the young require their mother's care, the females do not associate with the males, who then flock together.

The calls of both sexes so closely resemble those of the domestic birds that it requires a practiced ear to distinguish them. In localities where both birds might be expected to occur, I could never be sure whether I was listening to the challenge of some defiant gobbler perched in a cypress in the valley below, or to the vainglorious effort of the lord of the poultry yard.

1909. Grinnell, G. B., Forest and Stream, 852, 891, 892 (hiography).

310b. M. g. osceola Sontt. Florida Turkiy. Resembles $M . q$. silvestris, but is smaller, and the primaries, instearl of heing regularly and widely barred with white, as in that hird, have much smaller, hroken white markings. Weight, of 12-22 llss.; \& 4.75-9 lbs. (Noutt, Auk, IX, 1892, 115.)

Range.-Southern Florida.

Nesting date, St. John's River, Fla., Apl. 23.

The Florida Wild Turkey is locally common in Southern Florida. 


\section{Pheasants. Family Phasianid}

The true Pheasants, numbering about one hundred species, are found from the eastern borders of the Mediterranean through central and southern Asia to the Malayan Region.

The Ring-neck and English Ring-neck have been introduced and become naturalized in various parts of the United States.

Phasianus colchicus (Linn.). English Pheasant. Ad. $0^{7}$-- Head and neck green; no white neck-ring; rump rich bronzy red; breast bronzered; the ends of the feathers with broad greenish black bands; flanks reddish brown tipped with blue-black. Ad. ᄋ.- Above mixed, black brownish, and rusty; below brownish yellow; breast and sides with rusty and black.

The English Pheasant has been so hybridized with the Ring-necked Pheasant that it is now rare to find pure-blooded birds. Consequently either name is often equally applicable to these aviary-raised, artificially bred birds.

Nest, on the ground beneath cover. Eggs, 12-20, unmarked olive-buff, $1 \cdot 75 \times 1 \cdot 35$. Date, Gardiner's Is., L. I., May.

The so-called English Pheasant is a native of Asia Minor whence it was introduced into Europe by the Greeks, and, it is believed, by the Romans into England. The English stock remained pure until about the end of the eighteenth century when it was crossed with the Chinese Ring-necked Pheasant (Phasianus torquatus). The progeny proved fertile and continued hybridization, in which the Japanese Pheasant (Phasianus versicolor) has also been used, has left but few pure-blooded birds of the true colchicus type in England. The Pheasant introduced into this country from England is of the $P$. colchicus $\times P$. torquatus strain, in which the white neck ring is always more or less developed. It has been released and become locally established in Massachusetts, Ohio, Indiana, Iilinois, New Jersey, Vermont, Pennsylvania, and Kansas.

(See Oldys, Pheasant Raising in the United States, Farmers' Bull. No. 390, U. S. Dept. of Agric., 1910, 40.)

Phasianus torquatus ( $G m e l$.). Ring-NeCked Pheasant. Ad. $\sigma^{\pi}$.Head and neck green with strong purplish reflections; a more or less complete white neck-ring; rump gray or yellowish gray; breast bronze-red, the feathers very narrowly margined with purple-black; the end of the feathers notched and with a narrow purple black wedge; flanks buffy, tipped with blue-black. Ad. $\odot$.- Resembles adult female of $P$. colchicus.

This species has been successfully introduced in Oregon, Washington, and British Columbia; and limited numbers have been released in the Eastern United States, where, however, its hybrid with $P$. colchicus has been more frequently used for stocking purposes (see Oldys, as above).

The Gray or Hungarian Partridge (Perdix perdix) of Europe has been brought to this country in large numbers during recent years for storking purposes, nearly 50,000 having been imported between July 1. 1900 , and December 31, 1909. Thus far it does not appear to have become naturalized (See Oldys, Yearbook of Dept. of Agric. 1909, pp. 249-258). 


\section{ORDER COLUMBEE. PIGEONS AND DOVES}

\section{Family Columbidas. Pigeons and Doves. (Fig. 45.)}

The 650 odd species contained in the Order Columber are placed by Salvadori in five families as follows: (1) Treronidce or Fruit Pigeons, restricted largely to the Malayan region, 212 species; (2) Columbida, the true Pigeons, distributed throughout the world, 120 species, of which no less than 70 are contained in the genus Columba; (3) Peristerida or Doves, distributed throughout the world, but more numerous in the tropics, 312 species; (4) Gourida or Crowned Pigeons of New Guinea, 8 species, and (5) Didunculidœ, containing only the Toothed Pigeon of Samoa.

The Family Columbida of the A. O. U. Check-List contains representatives of both the Columbidae and Peristerido as grouped by Salvadori, which, in North America, number twelve species. The birds of this order differ widely in their choice of haunts. Some are strictly arboreal, others as strictly terrestrial. Some seek the forests and others prefer fields and clearings. Some nest in colonies, others in isolated pairs, but most species are found in flocks of greater or less size after the breeding season. When drinking, they do not raise the head as most birds do to swallow, but keep the bill immersed until the draught is finished. The eggs number two, rarcly one, and are white or creamy in color. Both sexes incubate, the male's daily period, so far as known, being from about 10 A.M. to 4 P.M. The young are born naked, and are fed by regurgitation on predigested food, or 'Pigeons' milk' from the crop of the parent.

1898. Whitman, C. O., Animal Behavior, Biol. Lecture M. B. L, 314 et seq. (Ginn \& Co.).-1908. Craig, W., The Voices of Pigeons Regarded as a Means of Social Control, Am. Journ. Soc., XIV, 86-100.

\section{KEY TO THE SPECIES}

A. Tail widely tipped with white or grayish white.
a. Tail pointed.
$a^{1}$. Back or rump bluish slate-color
$a^{2}$. Back olive grayish brown

b. Back olive grayish brown .

315. Passenger Pigeon. 316. Mourning Dove. $B$. Tail not tipped with white.
a. Upperparts dark slate-color .
b. Upperparts not slate color.
$b^{1}$. Upperparts rufous with purplish reflections.
$b^{2}$. Line below the eye and belly white or whitish. 322. (2uall Dove
$b^{3}$. Line under the eye and belly buffy ochraceous.

$\boldsymbol{c}^{1}$. Upperparts grayish olive-brown.

322.1. Ruddy Quall Dove $c^{2}$. Crown blue, a white line below the eye.
$c^{3}$. Crown pinkish
323. Blue-headed Quatl Dove 320). GROUND DOVE

314. Columba leucocephala $L$ inn. White-crowyen PIsifon. Ad. $0^{3}$.-Rich slate-color; crown white; back of head purplish ehestnut: barke of neck with greenish reflections, each feather with a llack border. Ad.8.- 
Similar, but paler; crown ashy, less purplish chestnut; back and sides of neck brownish ash with metallic reflections and black margins. L., 13.50; W. $7 \cdot 50 ;$ T., $5 \cdot 10 ;$ B., $\cdot 70$.

Range.-Florida Keys, the Bahamas, Greater Antilles, some of the Lesser Antilles, Yucatan, and coast of Honduras.

Nest, in low trees and bushes. Eggs, 2, glossy white, $1{ }^{*} 41 \times 1^{\circ} 02$. Date.Andros Is., Bahamas, June 15.

This Pigeon is locally common in some of the keys off southern Florida, and has been known to occur on the mainland. According to Mr. J. W. Atkins (Auk, VI, 1889, p. 246), it arrives at Key West early in May and remains until November.

A specimen of the West Indian Scaled Pigeon (314.1 Columba squamosa) was taken at Key West, Fla., Oct. 24, 1898 (Atkins, Auk, 1899, 272).

315. Ectopistes migratorius (Linn.). Passenger Pigeon. (Fig. 45.) Ad. $\sigma^{7}$-U Upperparts rich bluish slate-color; back and sides of neck with metallic reflections; middle of back and scapulars more or less washed with olive-brown; middle tail-feathers fuscous, outer ones black at the base, then slaty blue, fading into a broad, white tip; underparts deep, rich vinaceous; lower belly white; throat bluish slate-color. Ad. upperparts with less iridescence and more olive-brown; breast pale grayish brown; belly whitish. Im.-Generally similar to the $\%$, but the feathers of the upperparts and breast tipped with whitish, the primaries edged and tipped with rufous. L., $16 \cdot 29 ;$ W., $7 \cdot 82 ;$ T., $7 \cdot 53 ;$ B., $\cdot 71$.

Range.-Bred formerly from middle w. Mackenzie, cen. Keewatin, cen. Que., and N. S. s. to Kans., Miss., Pa. and N. Y.; wintered principally from Ark. and N. C. s. to cen. Tex., La., and Fla.; casual in Cuba, e. Mex. and Nev.

Washington, formerly T. V. or W. V. Ossining, formerly rare S. R., and common T. V., Apl. 15 to May 17; Aug. 21-Oct. 11; last seen Oct. 11, 1888. Cambridge, formerly abundant, now perhaps extinct. Glen Ellyn, last seen Sept. 4, 1892. SE. Minn., formerly abundant, no recent record.

Nest, a platform of sticks, in a tree. Eggs, 1, very rarely 2, white, $1.45 \times 1.09$. Date, Upton, Maine, June 15, 1872; Wisc., first week in Apl.; se. Minn., May 9, 1879.

Wilson, writing about 1808, estimated that a flock of Wild Pigeons ohserved by him near Frankfort, Kentucky, contained at least 2,230,272,000 individuals. Captain Bendire, writing in 1892, says: ". . . It looks now as if their total extermination might be accomplished within the present century. The only thing which retards their complete cxtinction is that it no longer pays to net these birds, they being too scarce for this now, at least in the more settled portions of the country, and also, perhaps, that from constant and unremitting persecution on thrir brexling-grounds they have changed their habits somewhat, the majority no longer breeding in colonies, but scattering over the country and brexling in isolated pairs" ("Life Histories of North American Birds," p. 133).

In article by William Brewster on "The Present Status of the Wild T'igron als a Bird of the United States, with some Notes on its Habits" (Aul, VI, 1889), pl). 285-291), gives much information concerning the reerent history of the hird in Michigan, one of its last strongholds. According to an informant of Mr. Brewster's, the last nesting in Michi- 
Plate XVI

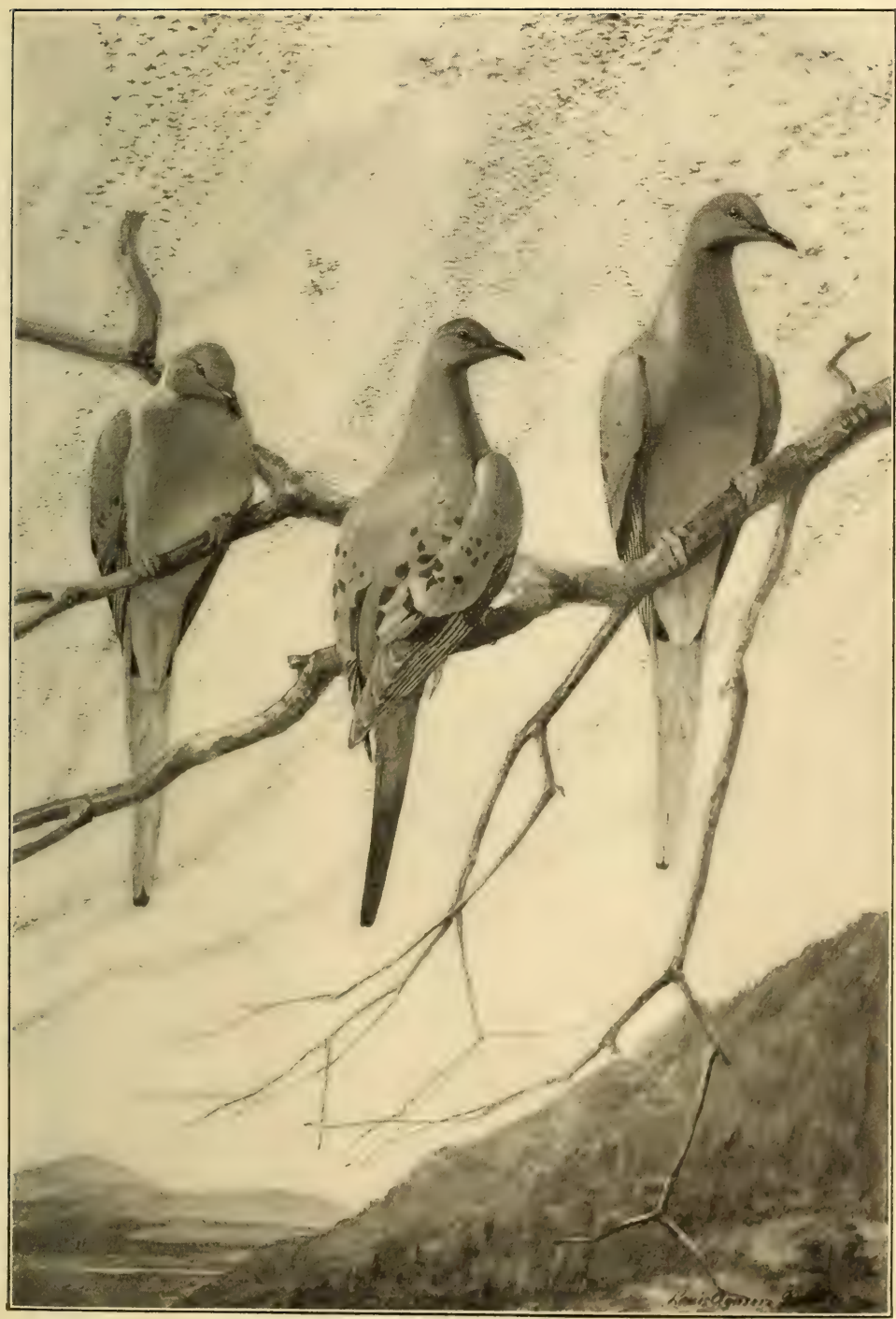

Passenger Pigeon 

gan of any importance was in 1881. "It was of only moderate sizeperhaps eight miles long." The largest known Michigan nesting occurred in 1876 or 1877 . It was twenty-eight miles long and averaged three or four miles in width.

The Passenger Pigeon is now so nearly extinct that although it has been reported as "seen" on numerous occasions, there appears to be no unquestionable record of its actual capture since 1898. Singularly enough two specimens were taken on September 14 of that year, an immature bird at Detroit, Mich. (Fleming, $A u k, 1903$, p. 66), and an adult male at Canandaigua, N. Y. (Eaton, "Birds of New York," which see also for many other records).

Through Mr. E. H. Forbush I learn that a female Passenger Pigeon is said to have been shot at Bar Harbor, Me., in the summer of 1904 . It was mounted in July of that year by J. Bert Baxter, a taxidermist of Bangor, who received it in the flesh. The present whereabouts of this specimen are unknown.

1907. Mershon, W. B., The Passenger Pigeon, 225. A Monograph (Outing Co.).-1910. Wright, A. H., Auk, XXVII, 428, 443; see also XXVIII, 53, 66; 111; 346-366.-1910. Dillen, Cassinia, 33-36 (early records).-1911. Hodge, C. F., Auk, XXVIII, 49 (present status).

316. Zenaidura macroura carolinensis (Linn.). MoURNING Dove. Ad. 8.-C - Upperparts olive gray'ish brown; forehead rinaceous; crown bluish slate-color; sides of neck with metallic reflections, a small black mark below the ear; middle tail-feathers like back, the others, seen from above, slaty gray for the basal half, then banded with black and broadly tipped with ashy and white; breast vinaceous; belly cream-buff. Ad. 9.- Similar, but with less iridescence; breast and forehead washed with grayish brown. Im.Much like o, but the feathers tipped with whitish. L., 11.85; W., 5.72; T., 5.50 ; B., ' 53 .

Remarks. - The Dove is sometimes mistaken for the Wild Pigeon, but, aside from the differences in size, may always be distinguished by its olive grayish brown instead of bluish slate-color rump, the black mark below the ear, and other characters.

Range. - N. A. Breeds chiefly in Sonoran and L. Transition zones from B. C., Sask., Man., Ont., and s. N. S. s. throughout the U. S. and Mex., and locally in L. Calif. and Guatemala; winters from s. Ore., s. Colo., the Ohio Valley, and N. C. to Panama; casual in winter in the Middle States.

Washington, P. R., common, except in mirlwinter. Ossining, common S. R., Mch. 3-Nov. 27; a few winter. Cambridge, rather rare T. V., Apl. 8-June 18; Sept. 18-Nov. 15. N. Ohio, common, S. R., Mch. 20-Oct. 25; rare W. V. Glen Ellyn, tolerably common S. R., formerly common, Mch., 12Oct. 21. SE. Minn., common S. R., Mch. 15-Dec. 25.

Nest, a flat structure of small twigs rather loosely put together, on the lower branches of a tree, generally within ten feet of the ground; rarely on the ground in the Eastern States. Egggs, 2, white, 1.07 $\times$ ' 83. Date, I). C., Apl. 18; Nazareth, Pa., Apl. 15; Ossining, N. Y., Apl. 17; ('ambridge, May 8; se. Minn., May 12.

Doves resemble Wild Pigeons, but are much smaller, and their rapid flight is aceompanied by the whistling sound of wings, while the flight of the Wild Pigeon is said to be noiseless.

During the nesting season they may be found in pairs, generally in open woodlands or tree-bordered fields. They also visit roads and 
lanes to dust themselves. The sweet, sad call of the male has won for this species its common name; it consists of several soft coos, which may be written: CoO-O-O, ah-coo- $0-0-C 00-0-0-c 00-0-0$. Under favorable circumstances these notes may be heard at a distance of at least two hundred and fifty yards; they are uttered slowly and tenderly, and with such apparent depth of feeling that one might easily imagine the bird was mourning the loss of his mate, instead of singing a lovesong to her.

At this season one or both birds may be seen performing a peculiar aërial evolution. Ascending to a height of about thirty feet, they fly for some distance in an unnatural manner, and then, after a short sail, return to their perch. When engaged in this performance they very closely resemble a Sharp-shinned Hawk.

After the nesting season Doves gather in flocks of varying size and frequent grain and cornfields. During the day they visit the nearest supply of fine gravel, which they eat in large quantities as an aid to digestion. In some localities, soon after sunset, they regularly repair in numbers to some favorite place to drink, and then retire to their roosts.

317. Zenaida zenaida (Bonap.). Znenaida Dove. Ad.-Bears a general resemblance to Zenaidura macroura, but the tail is square and tipped with ashy, and the underparts are deep, rich vinaceous. L., 10.00; W., 6*10; T., 3.50 ; B., "66.

Range.-Florida Keys, West Indies, and coast of Yucatan.

Nest, on or near the ground. Eggs, 2, glossy white, $1.22 \times \cdot 92$. Date, Bahamas, May 27.

This is a common West Indian species. Audubon found it in numbers in the keys off southern Florida, where he records it as a summer resident, arriving in April and departing in October. The few naturalists who have visited these keys since Audubon's time have not been there in the summer, and we do not therefore know whether this species still occurs there at that season. It is more terrestrial in habits than the Mourning Dove, and its notes are deeper, louder, and more solemn than the notes of that species.

The White-winged Dove (319. Melopelia asiatica asiatica) is of general distribution from the Mexican border of the United States south to Costa Rica, and it has been recorded from Cuba, Jamaica, and San Domingo. It is of accidental occurrence at Key West and Kissimmee, Florida (Ridgway, $A u k, 1897,88)$. It may he known hy the broad white margins to the wingcoverts, giving the appearance of a white wing-patch, which is conspicuous in life.

320. Chrmepelia passerina terrestris (Chapm.). Ground Dove. Ad.8.-Forchead and underparts vinaccous, centers of breast-feathers blackish; top and back of head bluish slate-color; back brownish gray; tail blackish, the outer feathers with small white tips; base of bill coral-red, tip black. Ad.s. - Similar, hut forchead and underparts pale brownish gray. Im.-Resembles f, but the feathers are tipped with whitish. L., 6.75; W., 3.60 ; T., 2.50 ; B., 50 . 
Range--Austroriparian and Floridian faunas from e. Tex. to N. C.; accidental in $\mathrm{n}$. N. Y., Pa., N. J., Md., and Va.

Washington, accidental; two records, Sept.; Oct.

Nest, on the ground or in low trees or bushes. Eggs, 2, white, ${ }^{\circ} 85 \times{ }^{\cdot} 67$. Date, San Mateo, Fla., Mch. 12.

This diminutive Pigeon frequents both pines and "hummocks," lake-shores, and old fields, and in some southern towns is a familiar bird of the quieter streets. It is by no means shy, and runs before one with quick, short steps and a graceful movement of the head. Occasionally it holds its tail upright, giving it a peculiar bantamlike appearance. Its flight is short, and when on the wing it bears an odd resemblance to a short-tailed Japanese kite.

Its favorite roosting-places are densely foliaged orange trees, and frequently when the bird is hidden in their depths one may hear its mellow, crooning coos uttered so softly that they float on the air as though born of the wind.

320b. C. p. bermudiana Bangs and Bradlee. Bermuda Ground Dove. "Size very small, smaller than C. bahamensis; bill wholly black, exceedingly small and slender (more so than in any other form of the $C$. passerina series); colors pale and ashy as in C. bahamensis and C. passerina pallescens (Baird), but even paler and grayer throughout than in either; back of $\sigma^{7}$ smoke-gray, of $q$ between smoke-gray and broccoli-brown; forehead and color of breast, in or, vinaceous pink." (Bangs and Bradlee, Auk, XIII, 1901, 25.)

Range.-Resident in the Bermudas.

322. Geotrygon chrysia (Salvad.). KeY West QUAIL-Dove. Upperparts rufous, with brilliant metallic reflections; wings rufous; a white line beneath the eye; breast vinaceous; belly white. L., 11*00; W., 6*20; T., 5*00; B., 50 .

Nest, in trees. Eggs, 2, ochraceous-white, 1.22 ×.94 (Bendire). Date, Cuba, Feb.

A West-Indian species which occurs during the summer regularly, but, so far as known, only in small numbers in the Florida Kieys.

The Quail Doves inhabit wooded districts where they live on the ground. Their flight is low and noiseless, and, according to my experience with them in Cuba, they are difficult birds to observe unless one can find some tree on the fallen fruits of which they are feeding.

The RUdDY QUaIL-Dove (322.1. Geotrygon montana) is a West Indian and Central American species, which has been once recorded from Key West (Atkins, $A u k, 1889,160$ ). It bears a general resemblanee to $G$. chrysia, but the back is more rufous and the belly is deep cream-buff.

The Blue-HEaded QuaIL-Dove (32.3. Starnarnas cyanocephala), a Cuban species, was recorded by Audubon from the Florida Kiry, hut there do not appear to be any later records. The back is olive-brown, the (rown and sides of the throat are deep grayish blue, throat black, line beneath the eye white. 


\section{ORDER RAPTORES. BIRDS OF PREY}

1893. Fisher, A. K., The Hawks and Owls of the United States in Their Relation to Agriculture, Bull. No. 3, Div. Orn. and Mam. (Biol. Surv.), Washington. 8vo. pp. 210, col. plls. 26.

\section{Family Cathartide. American Vultures. (Fig. 49.)}

A New World family of nine species, of which three are North American. Within their range Vultures are found wherever there is food. Far above the earth on firm wing they sail in broad circles, and from this outlook in the sky descend to feast upon the stricken deer in the forest or the cur lying in the gutters of a thoroughfare. It is now the generally accepted belief that Vultures find their food by the aid of their eyes alone. Except during the nesting season, they are generally found in flocks, which each night return to a regularly frequented roost. When alarmed or excited, they utter low, grunting sounds, but at other times are silent. They build no nest, but lay their one to three eggs under logs or stumps, on the ground, in caves, or similar places. The young are born naked, but are soon thickly covered with white or buff down.

325. Cathartes aura septentrionalis Wied. TURKer VULTURE. (Fig. 49.) Ads.-Head and neck naked, the skin and base of the bill bright red; plumage glossy black, edged with grayish brown. Im.-Similar, but the head covered with grayish-brown, furlike feathers. L., about $30^{\circ} 00 ; \mathrm{W}$., $22 \cdot 00$; T., $11^{\circ} 00$; B., $2 \cdot 30$.

Range.-Austral and Transition zones from s. B. C., Sask., w. Man., n. Minn., sw. Ont., w. and s. N. Y., and n. N. J. s. to s. L. Calif. and n. Mex.; winters throughout most of its regular range on the Atlantic slope but w. retires to Calif., Nebr., and the Ohio Valley; casual n. to Wisc., Mich., n. Ont., and N. B.

Washington, abundant P. R. Ossining, A. V. Cambridge, casual, two records. N. Ohio, tolerably common, S. R., Mch. 5-Oct. 30. SE. Minn., common S. R., Apl. 27.

Nest, in hollow stumps or logs, or on the ground beneath rocks, bushes or palmettos. Eggs, 1-3, dull white, generally spotted and blotched with distinct and obscure chocolate markings, but sometimes plain or but slightly spotted, $2 \cdot 80 \times 2 \cdot 00$. Date, Florida Keys, Mch. 1; Buckingham Co., Va. Apl. 3; Deer Creek, Md., Apl. 16; se. Minn., May 2, July.

One of the first birds to attract the attention of the bird student in our Southern States is the Turkey "Buzzard." Indeed, there are few moments between sunrise and sunset when these birds are not in sight. On outstretched, immovable wings they soar overhead in graceful circles, perfect pictures of "repose in motion." Without once flapping their broad pinions, they sail in spirals up the sky until they are hidden by the storm-clouds they have purposely avoided. $\Lambda$ gain, one sees them winging their way low over fields or through the streets of a town in search of food which they find chiefly, perhaps wholly, by means of sight. At times they may be seen high in the air hurrying to a distant repast, to which they are guided by the food-flight of other Buzzards. 


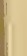


Plate XVII

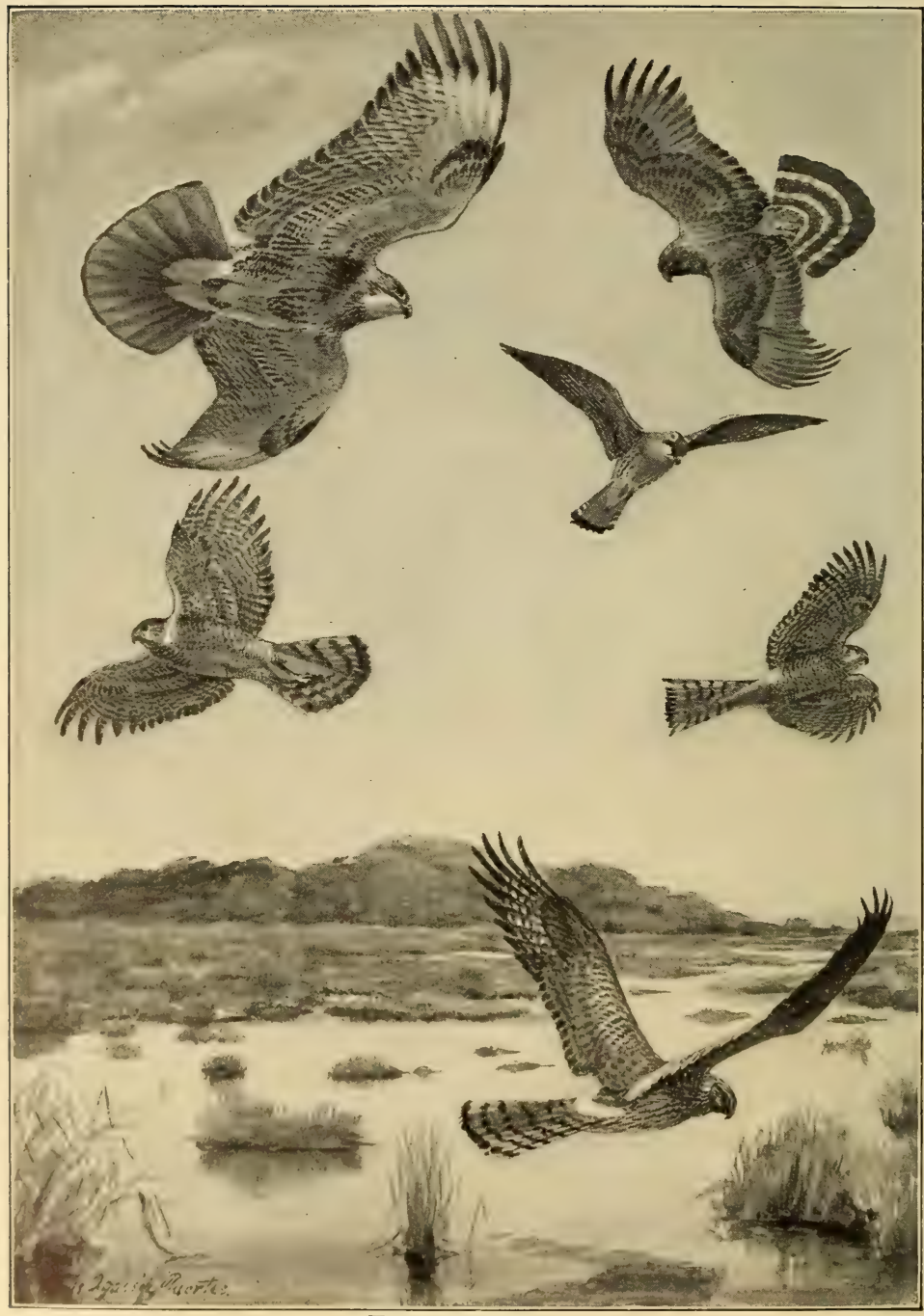

Flying Hawks

Red-tailed Hawk.

Cooper's Hawk.

Broad-winged Hawk.

Sparrow Hawk.

Sharp-shinned Hawk. 
Their services as scavengers are invaluable. The thought of burying a dead horse or cow never occurs to the southern planter. He simply drags the animal to a more or less retired place and leaves it for the Buzzards, who never fail to do justice to the repast. In some southern towns they make a self-constituted street-cleaning department, and if their efforts were seconded by a corps of goats, to dispose of the more indigestible materials, they would form an admirable branch of public service.

After a rain it is a common sight to see Buzzards perching with wings held in spread-eagle fashion as they dry their water-soaked plumage. Frequently they stand on the top of a chimney to take advantage of the heat arising with the smoke. Their only note is a low, grunting sound uttered when they are disturbed. Just after sunset Buzzards may be seen sailing to their roosting-place, generally in the upper branches of a dead tree.

326. Catharista urubu urubu (Vieill.). Black Velture. Ads.Head and neck bare, the skin and base of the bill blackish; plumage glossy black; under surface of the wings silvery. L., about $24^{\circ} 00 ;$ W., $17^{\circ} 00$; T., 8*00; B., $2 \cdot 20$.

Range.-Tropical and Lower Austral zones from w. Tex., Kans., Ill., Ind., and se. Va. s. through the s. States, Mex., and Cen. Am. to s. S. A.; casual in Ohio, Maine, Que., N. B., and N. S.; rare in the West Indies.

Washington, casual, Mch., July, Dec.

Nest, on the ground, under logs, bushes, palmettos, etc. Eggs, 1-3, pale bluish white, generally more or less spotted with distinct and obscure chocolate markings, $2.95 \times 2.00$. Date, Warrior River Swamp, Ala., Apl. 1; St. Simon's, Ga., Mch. 26.

This species is more abundant near the seacoast and less common in the interior than the preceding. It is also more often found living in towns or cities. Any one who has visited the vicinity of the market in Charleston, S. C., will testify to its abundance and semi-domestication there. Indeed, the birds have become so tame that when engaged in devouring some savory morsel they are in frequent danger of being trodden under foot.

Black Vultures are heavier birds than Turkey Buzzards, and whenever the ownership of food is in question the dispute is invariably settled in the Vulture's favor. Their stretch of wing, however, is not so great, and for this reason their flight is far less easy and graceful than that of the Buzzard. They flap their wings oftener, and this habit, in connection with their black heads, grayish primaries, and comparatively short tails, serves to identify them in the field. The only note I have ever heard from them is a low grunt uttered when they are disturbed.

35. Family Buteonide. Hawks, Eagles, Kites, Etc. (Figs. 46, 50.)

Omitting the Secretary Bird, Vultures, Ospreys, and Owls, the Order Raptores has left some four hundred and sixty species of world-wide distribution, which Ridgway places in the two families Buteonidas and 
Falconidas. Of the former, twenty-two species are North American. These present much diversity of form and habit, but our eastern species of the genera Buteo and Accipiter may, in the Northern States, at least, be seen during the migratory seasons, traveling in scattered flocks, which may take hours to pass a given point. At other times of the year, with few exceptions, they are solitary birds, having no intercourse with their kind. During the breeding season many species have definitely bounded haunts, upon which intrusion by individuals of the same species is not permitted. With much regularity they return to the same locality and even the same nest year after year, and some species are known to mate for life. Their days are an unceasing vigil. At all times they are on the alert for food. With the Buteos this consists to a large extent of small mammals and insects, birds and poultry forming a comparatively insignificant part of the diet of most species. Most Hawks are thus of great value to the agriculturist as the natural check upon the increase of the myriads of small rodents so destructive to crops.

The cries of Hawks are generally loud, startling, and characteristic of their fierce natures. They strike their prey with their feet, and use the bill to tear it into fragments.

Hawks' nests are generally bulky affairs, composed of coarse twigs and sticks. The presence of downy feathers gives evidence that they are or have been recently occupied. The young are hatched with a scanty growth of white down which soon covers the body.

To facilitate identification in the field, the Hawks of this and the following families (Falconida, Pandionidae) have been placed in one key as below.

I. Wing over $19^{\circ} 00$.

\section{KEY TO THE SPECIES}

$A$. Upper half of tarsus feathered.

a. Whole head and neck white

b. Head or neck brown or brownish.

$b^{1}$. Bill mostly yellow (Greenland). . 351. Gray Sea Eagle (Ad.).

$b^{2}$. Bill black or blackish . . . . 352. BALD EAGLE (Im.). B. Whole tarsus feathered . . . . 349. Golden Eagle. II. Wing under $19^{\circ} 00$. Placed in three sections as follows:

1. Underparts more or less streaked and spotted, without cross-bars.

2. Underparts with more or less numerous cross-bars.

3. Underparts without streaks or bars.

1. Underparts more or less streaked and spotted, without crossbars.

A. Outer primary with numerous black or blackish bars.

a. Wing under $10^{\circ} 00$.

$a^{1}$. Back bright rufous, with or without black bars.

$a^{2}$. Back bluish slate-color

360. Sparrow Hawk.

$a^{3}$. Back fuscous, second primary longest.

357. Pigeon Hawk (Ad.).

357. Pigeon Hawk (Im.).

$a^{4}$. Back fuscous, fourth primary longest, tail-feathers of nearly equal length; wing under 9.00.332. SHARP-shinNed HAwK. . (Im.)

$a^{5}$. Back fuscous, fourth primary longest, outer tail-feathers half an inch or more shorter than the middle ones; wing over $9^{\circ} 00$.

333. CoOper's Hawk (Im.). 


\section{HAWKS, EAGLES, AND KITES}

$b$. Wing over $10^{\circ} 00$.

$b^{1}$. Second primary longest.

$b^{2}$. Tail generally over $9^{\circ} 00$.

$b^{3}$. Lower tail-coverts immaculate white.

353. White Gyrfalcon.

$b^{4}$. Lower tail-coverts always more or less marked with dusky.

$c^{2}$. Tail under $9^{\circ} 00$.

354. Gray Gyrfalcon and Races.

$c^{3}$. Tarsus shorter than middle-toe without nail, upperparts blackish . . . . . . . . 356. DUCK HAwK.

$c^{4}$. Tarsus longer than middle-toe without nail, upperparts brownish . . . . . . . 355. Prairie Falcon.

$c^{1}$. Third or fourth primary longest.

$c^{2}$. Upper tail-coverts white . . . . . 331. Marsh Hawk.

$c^{3}$. Upper tail-coverts brownish . . 334. Goshawk (Im.).

$B$. Outer primary generally one color, base sometimes whitish or with a few imperfect bars.

$a$. Tarsus entirely bare, scales on its front large, rounded.

b. Tarsus not entirely bare.

$b^{1}$. Tarsus entirely feathered . - 348. Ferruginous Rodgh-Leg.

$c^{1}$. Tarsus partly feathered.

$c^{2}$. Scales on front of tarsus, small, rounded . . 364. Osprey.

$d^{2}$. Scales on tarsus not rounded, square.

$d^{3}$. Three outer primaries emarginate or "notched."*

$d^{4}$. Wing under $12^{\circ} 00$. . 343. BROAD-WINGED HAwK (Im.). $d^{5}$. Wing over $12.00 . \quad$. 342. SWaINSON's HaWK (Im.).

$e^{3}$. Four outer primaries emarginate or "notched." $\dagger$

$e^{4}$. Upper tail-coverts pure white. 331. MaRsh HaWK.

$e^{5}$. Upper tail-coverts not pure white; wing under 13.50; lesser wing-coverts conspicuously margined with rufous.

339. ReD-Shouldered HaWk (Im.).

$e^{6}$. Upper tail-coverts not pure white; wing over 13:50) lesser wing-coverts not conspicuously margined with rufous.

337. Red-tailed Hawk and races.

\section{Underparts with more or less numerous cross-bars.}

$A$. Front of tarsus with sharply defined scales.

a. Scales on front of the tarsus numerous, rounded.

$a^{1}$. Wing under 1500 . . . 356. Dचск НАwк.

$a^{2}$. Wing over 15.00 . . . . . 362. AlDLUBON'S CARACARA

b. Seales on front of the tarsus sharply defined, transverse, more or less square.

$b^{1}$. Four or five outer primaries emarginate or "notched." $\dagger$

$b^{2}$. Tail white at the base and tipped with whitish.

330. Everglade Kite.

$b^{3}$. Tail rufous, with sometimes a black band near the end.

337. Red-tailed Hawk (Ad.) and Races.

$b^{4}$. Tail black or bluckish, with four to six white or gr:iyish (rossbars. . . 339. RED-shouldered HAwk (Ad.).

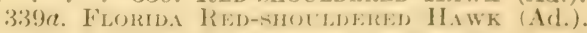

$U^{5}$. Tail 10.00 long, gray, with several indistinct blackish bands.

$c^{1}$. Three outer primaries emarginate or "notched."*

334. Goshawk.
$c^{2}$. Tail with two or three broad whitish bars.
343. BroAd-Winged HawK (Ad.).
$c^{3}$. Tail with numerous narrow, indistinct blackish bars.
342. Swainson's Hawk (Ad.).
* See Fig. 88.
† See Fig. 87. 
$B$. Front of the tarsus smooth, or with the scales not sharply defined a. Tarsus not entirely feathered.

$a^{1}$. Wing under $9^{\cdot} 00$, tail-feathers of nearly equal length.

332. SHARP-SHINNED HAwK (Ad.).

$a^{2}$. Wing over $9 \cdot 00$, outer tail-feathers half an inch shorter than the middle ones; upper tail-coverts not white.

$a^{3}$. Wing over 9.00; upper tail-coverts white.

333. COOPER'S HAWK (Ad.).

$b$. Tarsus entirely feathered.

331. Marsh Hawk (Ad.).

$b^{1}$. Legs rich rufous, heavily barred . 348. FerRuginous Rough-LEG.

$b^{2}$. Legs ochraceous-buff, more or less barred.

347a. Rovgh-LEgGed HaWK.

\section{Underparts without streaks or bars.}

$A$. Underparts white.

a. Scales on front of tarsus transverse, more or less square.

$b$. Scales on front of tarsus numerous, rounded.

334. Short-Talled Hawk.

$b^{1}$. Tail barred.

$b^{2}$. Upperparts not barred . . . . . . . 364. Osprex.

$b^{3}$. Upperparts barred . . 353. White Grrfalcon.

$c^{1}$. Tail not barred.

$c^{2}$. Tail square, white . . . . 328. White-talled Kite.

$c^{3}$. Tail forked, bluish black . 327 . Swallow-tailed Kite.

$B$. Underparts dark brown, slate, gray, or black.

a. Tarsus entirely feathered . 347a. RovGH-LEGGed HAwK.

b. Tarsus partly feathered, scales transverse, more or less square.

$b^{1}$. Wing over $13^{\circ} 00$.

$b^{2}$. Upper tail-coverts, base and tip of the tail white; two outer primaries slightly "notched" . 330. Everglade Kite.

$b^{3}$. Three outer primaries "notched"* . 342. SwaInson's Hawk. $b^{4}$. Four outer primaries "notched". . 338. Harlan's Hawk.

$c^{1}$. Wing under $13^{\circ} 00$.

$c^{2}$. Primaries more or less distinctly barred; general plumage sooty black. 344. SHORT-TAILED HAWK.

$c^{3}$. Primaries not barred; general plumage slaty blue.

329. Mississippi Kite.

327. Elanoides forficatus (Linn.). Swallow-TAILED Kite. Ads.-Head, neck, linings of wings, rump, part of tertials, and underparts white; rest of plumage glossy bluish black; tail deeply forked, outer feathers about 8.00 longer than middle ones. L., $24.00 ;$ W., $16.50 ;$ T., 13.50; B. from N., 80 .

Range.-N. and S. A. Breeds locally from se. Sask., n. Minn., s. Wisc., s. Ind., and S. C., s. through e. Mex. and Cen. Am. to Peru, Bolivia, and Paraguay; accidental w. to N. M. and Colo. and n. to n. Wisc., Ont., N. Y.. Maine, Mass., and in England; casual in the Greater Antilles; winters s. of the U.S.

Washington, three records, Aug.; Apl. SE. Minn., uncommon S. R., May 4.

Vest, in the upper branches of tall trees. Eggs, 2-3, white or buffy white, boldly spotted or blotehed, chiefly round the larger end, with hazelbrown, rhestnut, or rich madder-brown, 1.87 × 1.49 (Ridgw.). Date, San Mateo, Fla., Apl. 11; Black Hawk Co., Iowa, June 2, 1878.

The Swallow-tailed Kite winters in Central and South America, and appears in the United States in March. Its home is the air, and it is far more frequently seen on the wing than at rest. It captures 
its prey, devours it, and drinks while under way. Its flight possesses all the marvelous ease and grace of a Swallow's, made more evident, and consequently more impressive, by the bird's much greater șize.

328. Elanus leucurus (Tieill.). White-tailed Kite. Ads-- Épperparts ashy gray, whiter on the head; wing-coverts black; tail and underparts white. Im.-Very different, head streaked black and whitish; back black narrowly tipped with rusty, many of the feathers with more or less concealed white bars; tail black, central feathers barred with gray, others with white; underparts rufous with buff margins; throat white, region around eye velvety black. A later plumage has the back grayish brown edged with whitish, tail gray tipped with white; wings much as in the adult, underparts white, breast streaked with rufous. L., $15 \cdot 50 ; \mathrm{W}$., $12 \cdot 50 ;$ T., $7 \cdot 00$; B. from N., $\cdot 70$.

Range.-N. and S. A. Breeds in Lower Austral zone in Calif., Tex., Okla., S. C., and Fla.; casual in s. Ills., La., Miss., and Ala.; winters in Calif. and Fla. and s. rarely to Guatemala; resident in S. A. and Argentina and Chile to Venezuela. Accidental in Mass.

Nest, in trees. Eggs, 3-5, "handsomely marbled or clouded with various shades of rich madder-brown on a paler (sometimes whitish) ground, $1.71 \times$ 1.31" (Ridgw.). Date, Brownsville, Tex., May 11.

This species is not often found east of the Mississippi. It frequents open, marshy situations. A pair which I observed in Texas hunted by hovering over the reeds, sustaining a position facing the wind, and about forty feet from the ground, by a gentle movement of the wings.

329. Ietinia mississippiensis (Wils.). Mrssissippi Kite. Ads.Head, neck, exposed margins of the secondaries, and underparts gray; back bluish slate-color; primaries streaked or spotted with rufous-chestnut; tail black, without bars. Im.- Head streaked with black and white; back blackish, tipped with rufous or white, the concealed parts of the feathers white and with generally one blackish bar; primaries without rufous; tail with three or four broken white bars; below buffy, streaked with rufous and grayish brown. L., $14 \cdot 00$; W., $11^{*} 25$; T., $6 \cdot 50$; B. from N., 60 .

Range.-Lower Austral zone from s. Kans., Iowa, Ills., s. Ind., and S. C., s. to Tex., and Fla.; winters in Fla. and s. Tex., and s. rarely to (inatemala; accidental in Colo., S. D., Wisc., and $\mathrm{Pa}$.

Nest, in tall trees. Eggs, 1-3, dull white, sometimes with a lhuish tinge, $1.63 \times 1 \cdot 32$. Date, Lee Co., Tex., May 22 ; coast $\$$. C., May 27 , large embrjo.

This bird, like the preceding, is only a summer resilent in the United States, arriving from the south in April. It is not common east of Louisiana. It migrates in flocks, sometimes flying within gunshot, and at others so far above the earth as to be almost beyond the bounds of vision.

330. Rostrhamus sociabilis (Vicill.). Everglade Fitk. Ad.o.Dark slate-color; under, and lonerer upper tail-coverts, aud hase of the tail white, tip of the tail whitish; upper mandible much lengthenesl and hooked. $o$ and Im. - Cpperparts black, tipperd with rufous; underparts harred and mottled with rufous, black and buffy; tail as in the Ad. I., 15.100; W., 14.00; T., 7.75; B., $1 \cdot 20$.

Range.-Tropical Fla., Cuba, e. Mex., C'en. Am., and e.S. A. to Argentina; migratory in $\mathrm{n}$. Fla.

Nest, in bushes, among reeds or tall grasses. Eggss, 2-3, pale bluish white, heavily spotted, blotched, or washed with cinnamun or chocolate, $1.85 \times$ 1.47. Date, near Ft. Myers, Fla., Mch. 1. 
This species is a summer resident in southern Florida. It arrives from the south in February. Mr. W. E. D. Scott writes of it as observed at Lake Panasofkee, Florida: "Their food at this point apparently consists of a kind of large, fresh-water snail, which is very abundant, and the local name of 'Snail-Hawk' is particularly applicable to this bird as I have met with it. They fish over the shallow water, reminding one of Gulls in their motions; and having secured a snail by diving, they immediately carry it to the nearest available perch, where the animal is dexterously taken from the shell without injury to the latter." (Bull. Nutt.Orn. Club, VI, 1881, p. 16.)

331. Circus hudsonius (Linn.). Marsh Hawk. Ad. o $^{7}$--Upperparts gray or ashy; upper tail-coverts white; tail silvery gray, irregularly barred or marked with blackish; upper breast pearl-gray; the lower breast and belly white, spotted or barred with rufous. Ad. o.- Upperparts fuscous, the head and neck streaked, and the wing-coverts spotted or margined with rufnus; longer upper tail-coverts white; midd e tail-feathers barred with ashy and black, others barred with ochraceous-buff and black; underparts ochraceous-buff, widely streaked on the breast and narrowly streaked on the belly with fuscous or light umber. Im. - Similar to the o, but somewhat darker above; the underparts darker, almost rufous; the belly without streaks. or L., 19•00; W., 13·75; T., 9•00; B. from N., ‘60. ㅇ L., 22*00; W., $15^{\circ} 00 ;$ T., $10^{\circ} 00$.

Range.-N. A. Breeds from ne. Siberia, nw. Alaska, nw. Mackenzie, cen. Keewatin, n. Que., and Prince Edward Is. s. to the s. border of the U. S.; winters from s. B. C., Colo., Iowa, the Ohio Valley, and N. Y. (occasionally Mass.) s. to the Bahamas, Cuba, and Colombia.

Washington, common W. V., July-Apl. Ossining, tolerably common S. R., Mch. 6-Oct. 30; a few winter. Cambridge, common T. V., Mch. 20 -Nov. 10, one breeding record. N. Ohio, not common S. R., Mch. 5-Nov. 30. Glen Ellyn, S. R., several pairs, Apl. 4-Nov. 6. SE. Minn., common S. R., Mch. 6-Nov. 1.

Nest, on the ground, in marshes. Eggs, 4-6, dull white or pale bluish white, 1.75 $\times 1.40$. Date, New London Conn., May 18; Cambridge, June 5; Meridian, N. Y., May 12; Baxter, Iowa, May 8.

This Hawk is essentially a bird of the unwooded country, and we might as well look for a Ruffed Grouse in the open marsh as for a Harrier in the thick woods. It flies low, and may be easily identified by the large white patch on its rump. Quartering the country with slow, vacillating flight, it usually captures its living prey by surprising it away from its retreats.

The Harrier is a low-perching Hawk, and most frequently will be seen alighting on a slight elevation or in the grass. During the nesting season the male may be seen performing a number of extraordinary aërial evolutions. Sometimes he soars to a great height, then falls straight downward nearly to the ground, turning several somersaults during the descent, and uttering at the same time a reiterated sereeching. At other times he flies across the marsh in a course which would outline a gigantic saw, each of the descending parts being done in a somersault and accompanied by the screeching notes, which form the only love song within the range of his limited vocal powers. 
"Of 124 stomachs examined, 7 contained poultry, or game birds; 34 , other birds; 57 , mice; 22 , other mammals; 7 , reptiles; 2 frogs; 14, insects; 1 , indeterminate matter, and 8 were empty" (Fisher).

332. Accipiter velox (Wils.). Sharp-shinned Hawk. Ads.-Upperparts slaty gray; primaries barred with blachish; tail nearly square, ashy gray, with blackish cross-bars and a whitish tip; throat white, streaked with blackish; rest of underparts barred with white and ochraceous-buff or pale rufous. Im.-Upperparts fuscous, margined with rufous; primaries and tail much as in the ad.; underparts white or buffy white, streaked or spotted with blackish or pale rufous-brown. ơ L., 11•25; W., 6.60; T., 5.50; B. from N., "40. \& L., 13•50; W., 8•00; T., $7^{\circ} 00$.

Remarks.-This species very closely resembles Cooper's Hawk. In adult plumage the black cap characterizes that species, but immature birds may be distinguished only by size, and the difference in the shape of the tail, which in velox is nearly square, and in cooperi decidedly rounded.

Range. -N. A. Breeds nearly throughout the U.S. and Canada from nw. Alaska, nw. Mackenzie, s. Keewatin, cen. Que., and N. F. southward; winters from B. C., Colo., Iowa, n. Ohio, and Mass. s. to Panama.

Washington, common P. R. Ossining, common P. R. Cambridge, common T. V., Apl. 3-May 11; Sept. 5-Oct. 25; rare S. R., uncommon W. V. N. Ohio, not common P. R., a few winter. Gilen Ellyn, not common S. R., Mch. 19-Dec. 9. SE. Minn., common S. R., Mch. 28-Dec. 28.

Nest, in trees, 15-40 feet up. Eggs, 3-6, bluish white to pale cream-buff, distinctly spotted, heavily blotched, or even washed with chocolate or cinnamon-rufous, $1.55 \times 120$. Date, Weaverville, N. C.., May 1 ; Northampton Co., Pa., May 14; Cambridge, May 20; Knox Co., Ohio, May 11; se. Minn., May 8.

The generally misapplied names "Hen Hawk" and "Chicken Hawk" should be restricted to the birds of the genera Accipiter and Astur for they deserve the reputation commonly attributed to the large Hawks of the genus Buteo.

The Sharp-shinned Hawk differs decidedly in habits from the mouseor insect-eating species, which watch for their prey from a lookout and capture it on the ground. It is a fearless, daring, aggressive bird, and flying swiftly, rather low, either in the open or through woods, it makes sudden dashes at the frightened birds, which hurry to cover to escape its talons. One hears a eommotion among the birds; (alls of alarm, and a dark form darts through the foliage in close pursuit, or, missing its aim, alights in the center of some thickly leaved tree, there to await in silence a fresh opportunity. I have seen it follow its prey on foot through the undergrowth. Sometimes it may be seen soaring in narrow circles, when its disproportionately long tail forms a good field character.

It is usually a voiecless bird exeept during the nesting se:tson, when a too close approach to its nest causes it to utter its peculiar notes. 
"Of 159 stomachs examined, 6 contained poultry or game birds; 99 , other birds; 6 , mice; 5 , insects; and 52 were empty" (Fisher).

333. Accipiter cooperi (Bonap.). CoOPER's HAwK. Ads.-Similar to adults of the preceding, but larger and with the crown blackish. Im.Similar in color to young of $A$. velox, but larger. or L., 15.50; W., 9.50; T.,

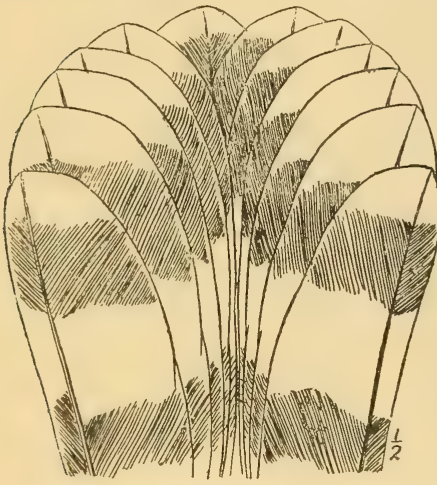

Frg. 86. Rounded tail of Cooper's Hawk. $7 \cdot 75$; B. from N., 55 . \& L., $19 \cdot 00$; W., $10.50 ;$ T., $9 \cdot 00$.

Range.-N. A. Breeds from s. B. C., s. Alberta, s. Keewatin, cen. Que., and Prince Edward Is. s. to s. border of the U. S.; winters from s. B. C., Colo., Nebr., Ohio, and Mass., s. to Costa Rica, and occasionally further $\mathrm{n}$.

Washington, common S. R., less common W. V. Ossining, tolerably common P. R. Cambridge, common T. V.; not uncommon S. R., rare W. V., Apl. 10-Oct. 20. N. Ohio, not common, Mch. 20-Nov. 1; a few winter. Glen Ellyn, local S. R., a few winter. SE. Minn., common S. R., Mch 3.

Nest, in trees, 25-50 feet up. Eggs, $3-6$, pale bluish white, sometimes lightly spotted with brownish, $1.90 \times$ 1.55. Date, Montgomery Co., Pa., Apl. 30; New London, Conn., Apl. 27; Cambridge, May 5; Herkimer Co., N. Y., May 6.

This species resembles the preceding in habits, but because of its larger size is more destructive to poultry.

"Of 133 stomachs examined, 34 contained poultry or game birds; 52 , other birds; 11 , mammals; 1 , frog; 3 , lizards; 2 , insects; and 39 were empty" (Fisher).

334. Astur atricapillus atricapillus (Wils.). Goshawk. Ads.Upperparts bluish slate-color; head blackish, a white line over and behind the eye; inner tail-feathers like the back, outer ones more fuscous, and slightly marked with blackish; tip whitish; entire underparts evenly marked with irregular, wavy bars of gray and white, the feathers of the throat and breast with darker shaft streaks. Im.-Upperparts fuscous, margined with rufous; primaries barred with black; tail brownish gray, barred with black; underparts white or buffy, streaked with black. $\sigma^{\circ} \mathrm{L} ., 22^{\circ} 00$; W., 13.00; T., 10*00; B. from N., '65. ㅇ L., 24*00; W., 13*40; T., 11'50.

Range.-N. A. Breeds in Boreal zones from nw. Alaska, nw. Mackenzie, ren. Keewatin, and n. Ungava s. to Mich., and N. H., and in the mountains s. to Pa. and N. M.; winters from Alaska and the s. Canadian Provinces s. to n. Mex., Tex., Okla., Mo., Ind., and Va.; accidental in England.

Washington, casual in winter. Ossining, rare W. V., Oct. 10-Jan. 14. ('ambridge, irregular and uncommon W. V. SE. Minn., W. R., Nov. 5-Apl. 4.

Nest, in trees. Eggs, 2-5, "white, or glaucous-white, sometimes very faintly marked with pale brownish, $231 \times 1^{\prime} 74^{\prime \prime}$ (Ridgw.). Date, Moorehouscrille, N. Y., Apl. 20; Kentville, N. S., Apl. 8; St. Croix Co., Wis., Apl. 17.

With the general habits of the two preceding species, this larger bird is much bolder than either. Dr. Fisher remarks: "This species 
is one of the most daring of all the Hawks, and while in pursuit of its prey is apparently less concerned by the presence of man than any other. It will dart down unexpectedly at the very feet of the farmer and carry off a fowl."

"Of 28 stomachs examined, 9 contained poultry or game birds; 2 , other birds; 10 , mammals; 3 , insects; 1 , centiped; and 8 were empty" (Fisher).

335. Parabuteo unicinctus harrisi $(A u d$. $)$. HARRIs's $\mathrm{H}_{A W K}$. Larger upper tail-coverts, and base of tail white; lesser and under wing-coverts rufous. $A d s$. - Above and below fuscous-brown more or less washed with rufous, especially on the rump; tail black, its base and tip white; thighs rufous, under tail-coverts white. Im.-Similar, but tail without white tip and, seen from below, with broken bars; underparts streaked or barred with white; thighs barred with white. o L., $22^{\circ} 00$; W., 14.50; T., 10.00. $\sigma^{\text {* }}$ L., $19^{\circ} 00 ;$ W., $13 \cdot 25 ;$ T., $9 \cdot 50$.

Range.-Lower Sonoran zone in se. Calif., s. Ariz., s. N. M., s. Tex., La., and Miss., s. to Cape San Lucas and Panama; accidental in Tnwa and Ills. Nest, of sticks, etc., often in 'chaparral' growth or small trees. Eggs, $2-4$, white, sometimes with small cinnamon spots, $2.08 \times 1 \cdot 70$. Date, Corpus Christi, Tex., Mch. 19.

I found this Hawk a common inhabitant of the chaparral about Corpus Christi, Texas, where it nested in the low mesquites and huisaches. Dresser observed it feeding on carrion with Caracaras and Vultures, but specimens dissected by Sennett contained mice, lizards, birds, and spermophiles. The white upper tail-coverts, as in the Marsh Hawk, make a good field mark, but Harris's Hawk lacks the light, graceful, bounding flight of that species.

337. Buteo borealis borealis $(G m e l$.). RED-TAILED HAwK. Ads.Upperparts dark grayish brown or fuscous-brown, more or less edged with rufous, ochraceous-buff, and whitish; four outer primaries "notched," the outer one not regularly barred; wing-coverts not erlged with rufous; tail rich rufous, with a narrow black band near its end and a white tip); upper breast heavily streaked with grayish brown and ochraceous-buff, lower breast lightly streaked and sometimes without streaks; upper belly streaked, spotted, or barred with black or blackish, forming a kind of brokr'n band across the belly; lower belly generally white without streaks. Im.-Cimilar, but the tail of about the same color as the back, crossed by numerous more or less distinct blackish bands; no rufous in the markings of the underparts. ${ }^{\circ}$ L., 20.00; W., 15.50; T., 9.25; B. from N., '95. ? L., 2.3.()(); W., 16.5(); T., 9.75.

Range.-E. N. Am., from Sask., Wise., and Ills., e. to cen. Kerwatin and N. F., and s. to e. Tex., ne. Mex., the Gulf crast, Flat., and the Gireater Antilles.

Washington, common W. V., rare S. R. Ossining, common P. R.; less common in winter. Cambridge, rare T. V., leseally $\mathbb{W}$. V., ()et. 10-Apl. 20. N. Ohio, common P. R. (Glen Ellyn, P. R., not common, chicfly 'T. V. SE. Minn., common S. R., Mch. 2.

Nest, in trees, 30-70 feet up. Engrs, 2-4, dull white, grenerally scantily and irregularly marked with shades of (innamon-brown, 2.11) 1:5.). Deite, San Mateo, Fla., Mch. 4; Litchfield Co., Conn., Alll. S; IRichland Co., Ill., Mch. 6; se. Minn., Apl. 23.

The Red-tailed Hawk resembles its near relative, the Recl-shouldered Hawk, in the selection of its haunts, and, to a large extent, in 
habits. It is to be distinguished in life from that species by its larger size, which, even in the field, is noticeable, and by its call. The usual note of the Red-tail is a long-drawn "squealing" whistle, which to my ear suggests the sound produced by escaping steam.

"Of 562 stomachs examined, 54 contained poultry or game birds; 51 , other birds; 278 , mice; 131 , other mammals; 37 , batrachians or reptiles; 47 , insects; 8 , crawfish; 1 , centiped; 13 , offal; and 89 were empty" (Fisher).

337a. B. b. krideri Hoopes. KrIDER's HAwK. Similar to Buteo $b$. borealis, but with much more white in the plumage; the head sometimes almost entirely white; the underparts only lightly streaked, and with the band on the belly sometimes obsolete; the tail in the ad. pale rufous, generally without a terminal black band; in the im., pale rufous, or white, washed with rufous, and with numerous blackish bars. or W., 15.00; T., 9.50.

Range.-Great Plains from Wyo., N. D., and Minn., s. to Nebr. and Mo., and in winter to Wisc., Ills., Tex., La., and Miss.

SE. Minn., uncommon S. R.

Nesting date, se. Minn., Apl. 22.

337d. B. b. harlani (Aud.). HARLAN's HAwK. Ads.-Upperparts dark sooty fuscous, bases of the feathers more or less barred with grayish or whitish and at times with some rusty; tail closely mottled with black, fuscous, rufous, and whitish; underparts varying from white more or less spotted across the belly to sooty fuscous. Im.- Similar, but the tail barred with blackish, grayish, rufous, or whitish, tipped with white. o L., about $19^{\circ} 00 ;$ W., $15^{\circ} 50 ;$ T., $8^{\circ} 25$. o L., about $21^{\circ} 00 ;$ W., $17^{\circ} 00 ;$ T., $9 \cdot 25$.

Remarks. - The status of this form has not been satisfactorily established.

Range.-Lower Miss. Valley and Gulf States, from La. to Ga. and Fla.; casual in Colo., Tex., Kans., Nebr., Iowa, Ills. and $\mathrm{Pa}$.

Dr. William L. Ralph, in Bendire's "Life Histories of North American Birds" (p. 218), reports this species as not uncommon during the winter in St. John's and Putnam Counties, Florida. He writes: "They are exactly like the Red-tailed Hawks except in color, and their callnote is the same, only being longer drawn out. The call of the latter bird, as already stated, sounds like the squealing of a pig, or 'kee-ee-e,' and that of Harlan's Hawk like 'kee-ee-ee-e-e-ee'." Illinois.

The Western Redtail (337b. B. b. calurus) has been recorded from

Outram Bangs has described the breeding Red-tailed Hawk of southern Florida, and probably of Cuba, as Buteo borealis umbrinus. It is "darker above than Buteo borealis, the throat and middle of the belly marked with broad, conspicuous striping and banding of deep chocolate-brown; tail-feathers with dark brown markings (the remains of bands) near the shafts." Owing to the lack of material the A. O. U. Committee on Classification and Nomenclature has deferred action on this proposed new race.

339. Buteo lineatus lineatus (Gmel.). (Fig. 50.) RED-SHOULdered H^wk. Ads.-Upperparts dark crayish fuscous-brown, more or less edged with rufous, ochraccous-buff, and whitish; four outer primaries "notched," all barred with black and white; lesser wing-coverts rufous, forming a conspic'uous "shoulder" patch; tail black or fuscous, with four or five white ('rosi-bars and a white tip); throat streaked with blackish; rest of underparts rufous or ochraceous-buff, everywhere barred with white or whitish. Im.Upperparts much as in the adult; basal part of the primaries mostly ochra- 
ceous-buff, fading to whitish on the inner web, with broken bars of fuscous; lesser wing-coverts conspicuously margined with rufous or rufous-chestnut; tail dark grayish brown, indistinctly barred with fuscous, and on the basal half with more or less rufous, the inner webs of the feathers with sometimes white bars; underparts white or whitish, streaked or spotted with black or blackish, the legs sometimes barred with rufous. o L., 18.30; W., 12.50; T., 8•00; B. from N., 75 . क L., $20 \cdot 35$; W., $13 \cdot 50 ;$ T., 9*00.

Remarks. - Adults of this species may always be known by the rich rufous lessar wing-coverts. Immature birds are sometimes confused with the young of the Red-tailed or Broad-winged Hawks. From the former they may be distinguished by their small size, rufous margins of the lesser wing-coverts

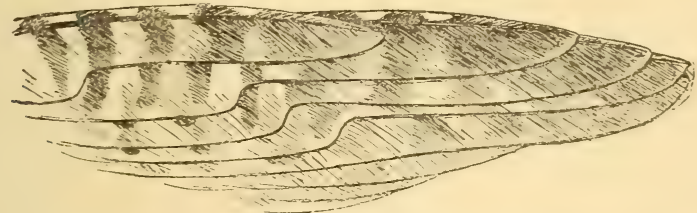

Fig. 87. Four-notched primaries of Red-shouldered Hawk. (Reduced.)

ochraceous-buff markings on the primaries, and the continuously streaked underparts; from the latter they differ in having four instead of three outer primaries "notched," in being larger, and in having ochraceous-buff on the primaries.

Range.-E. N. A. Breeds from Man., s. Keewatin, s. Que., N. S., and Prince Edward Is. s. nearly to the Gulf States and w. to edge of the Great Plains; winters s. to the Gulf coast.

Washington, common P. R. Ossining, common P. R. Cambridge, common, Apl.-Nov., less common in winter. N. Ohio, common P. R. Glen Ellyn, P. R., more common than the Red-tail; chiefly T. V.

Nest, in trees, 30-60 feet up. Eggs, 3-5, dull white, generally more or less sprinkled, spotted, or blotched with cirnamon-brown or chocolate, $2.15 \times 1.65$. Date, Iredell Co., N. C., Mch. 26; New London, Conn., Apl. 3; Cambridge, Apl. 10.

The present species and the Red-tailed Hawk are the birds to which the names Chicken Hawk and Hen Hawk are most frequently misapplied. Being both common species whose habits render them easily observed, they are often unjustly marde to suffer for the sins of their bird-killing relatives of the genera Accipiter and Astur.

The farmer sees a Hawk sailing in wide circles above him, uttering its fierce, screaming cry of kèे-you, kcè-you. While he is watching it a sly, low-flying Accipiter slips by him and makes a sudden dash into the poultry yard. The farmer does not diseriminate; a Ilawk is a Hawk, and shaking his fist at the bird in the air, he vows vengeance at the first opportunity.

The Red-shouldered Hawk is at most times of the year a bird of the woods. Particularly does it like low woods watered with small streams from which it can obtain its favorite foorl of frogs. Its note is one of the common sounds of summer, and can be heard when the bird is almost lost to sight far up in the sky. It is frequently imitated by the Blue Jay. 
"Of 220 stomachs examined, 3 contained poultry; 12 , other birds; 102, mice; 40, other mammals; 20, reptiles; 39, batrachians; 92 , insects; 16, spiders; 7 , crawfish; 1 , earthworms; 2 , offal; 3 , fish; and 14 were empty" (Fisher).

1894. Kennard, F. H., Auk, XI, 197-210, 270. (Biog.)

339a. B. 1. alleni Ridgw. Florida Red-Shodldered Hawk. Adults of this species may easily be distinguished from those of B.l. lineatus by their smaller size, grayish white head, with black shaft streaks and no rufous, the smaller fuscous tips on the scapulars and interscapulars, which do not conceal the ashy gray bases of the feathers, by the whitish or grayish cheeks and throat, and the ochraceous-buff, indistinctly barred underparts. Immature birds are very similar to those of $B$. l. lineatus, and can be distinguished only by their smaller size and darker color. ${ }^{7} \mathrm{~W}$., 11.00; T., 7.50; B., $1 \cdot 20$.

Range.-S. part of Lower Austral zone and S. Atlantic and Gulf States from S. C. through Tex. into Tamaulipas, Mex.

Nesting date, San Mateo, Fla., Feb. 22.

342. Buteo swainsoni Bonap. SwaInson's HAwK. Ad. $\sigma^{7}$.-Upperparts fuscous-brown, more or less margined with rufous or buffy; primaries unbarred, three outer ones "notched;" tail slightly grayer than the back, with numerous indistinct, blackish bars showing more plainly on the under surface; breast covered by a large, cinnamon-rufous patch; belly white or ochraceous-buff, streaked, spotted, or barred with blackish, rufous, or buff. Ad. . - Similar, but larger, the breast patch of the same color as the back. $\sigma^{7}$ and in dark or melanistic plumage. - Entire plumage fuscous, the under tail- and under wing-coverts and the tail sometimes spotted or barred. Im.Upperparts fuscous-brown, widely margined with buffy and rufous; base of the primaries grayish, and sometimes with a few broken bars; tail much as in the ad.; underparts ochraceous-buff, spotted and streaked with blackish. $0^{7}$ L., $20 \cdot 00$; W., $15{ }^{\circ} 00$; T., 8*50; B. from N., $\cdot 75$.

Remarks.-Between the light and dark phases of coloration there is every degree of intergradation, but in any plumage this Hawk may be distinguished from our other species by having only three outer primaries notched. In this respect it agrees with $B$. platypterus, from which, however, it differs decidedly both in size and color.

Range.-N. and S. A. Breeds from s. B. C., Fort Yukon, Alaska, nw. Mackenzie, and Man., s. to Chile; casual in Que., Ont., Maine, and Mass.; winters from S. D. southward. SE. Minn., S. R., Apl. 26.

Nest, in trees, 30-80 feet up. Eggs, 2-3, varying from dull bluish white to cresmy white, sometimes unmarked, but generally more or less spotted oi b lotehed with shades of cinnamon-hrown, 2:30 × 1*72. Date, Tom Green Co., Tex., Apl. 7; Dry Lake, N. D., May 12.

Swainson's Hawk is of rare occurrence east of the Mississippi. Dr. Fisher writes: "By preference it frequents the timber in the vicinity of streans, though often it is found far out on the prairie, where its only pereh is the earth mound of some mammal, or some other slightly elevated knoll."

343. Buteo platypterus platypterus (Vieill.). BROAD-WINGED HAWK. Ad. - i purpurts lark grayish lorown or fuscous, more or less margined with huffy and rufou-; three outer primaries "notched" and without ochraceoushuff markines; tail fuscous, with two hars and the tip gray-ish white; underparts herrily barrerl with lorownish ochraceous-buff. Im. - Upperparts like the precoling; tail grayish hrown, with three to five indistinct black bars and 
a narrow whitish tip; underparts white or buffy white, streaked and spotted with fuscous. ơ L., $15 \cdot 89$; W., $10 \cdot 68$; T., $6 \cdot 75$; B. from N., 70 . ㅇ L., 16.76; W., $11 \cdot 41$; T., $7 \cdot 09$.

Remarks.-Compared with the other members of this genus, the three "notched" primaries and small size are the principal characters of this Hawk.

Range.-E. N. Am. Breeds from cen.Alberta, se. Sask., n. Ont., N. B., and Cape Breton Is., s. to the Gulf coast and cen. Tex., mainly e. of the Miss.; winters from the Ohio and Delaware valleys s. to Venezuela and Peru.

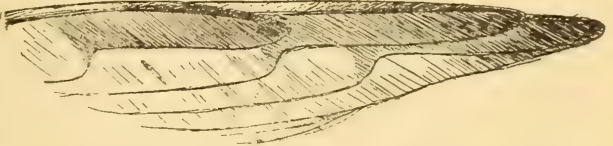

FIG. 88. Three-notched primaries of Broad-winged Hawk. (Reduced.)

Washington, uncommon P. R. Ossining, tolerably common S. R., Mch. 15-Oct. 23. Cambridge, uncommon T. V. in early fall, rare in spring and summer; Apl. 25-Sept. 30. N. Ohio, not common P. R. Glen Ellyn, not common S. R., Apl. 10-Oct. 4. SE. Minn., common S. R., Mch. 11.

Nest, in trees, 25-50 feet up. Eggs, 2-4, dull white or buffy white, spotted, blotched, or washed with ochraceous-buff or cinnamon-brown, $2 \cdot 10 \times 1{ }^{*} 60$. Date, D. C., Apl. 23; Monroe Co., Pa., May 10; Lancaster, N. H., May 11; se. Minn., May 29.

"Of all our Hawks, this species seems to be the most unsuspicious, often allowing a person to approach within a few yards of it, and, when startled, flies but a short distance before it alights again. During the early summer the Broad-winged Hawk often may be seen sitting for hours on the dead top of some high tree. At other times it is found on the smaller trees in the deep woods, along streams, or on the ground, where its food is more often procured. Although sluggish and unusually heavy in its flight, it is capable of rapid motion, and sometimes soars high in the air. One of its notes resembles quite closely that of the Wood Pewee.

"Of 65 stomachs examined, 2 contained small birds; 15 , mice; 13 , other mammals; 11 , reptiles; 13 , batrachians; 30 , insects; 2 , earthworms; 4 , crawfish; and 7 were empty" (Fisher).

344. Buteo brachyurus Vieill. Short-tanlen Hawk. Ads,Upperparts slaty gray or fuscous grayish frown; forchead whitish; tail barred with black and narrowly tipped with white, its under surfacer grayish; sides of the breast or neck with some rufous-l,rown markings: rest of the underparts pure white. Im. - Similar, but upp)(rparts browner and margined with cream-buff; underparts washed with ('ream-huff; no) ruf(ous-brown on the breast. Dark phase.-Fuscous-blark with a slight motallir luster with, in some specimens, more or less concealed white spots or hars more ("vident below; forehead whitish; tail lighter than back, barred with black, its under surface and the under surfare of the primaries grayish. I., 17.(1)(); W., 12.50; T., 7'00; Tar., 2:35; B. from N., 70 .

Range.-Peru, Bolivia, and Brazil, n. to e. Mex., and raroly Fla.

Nest, in trees. Eggs, dull white, spotterl at the larger coud with small spots and blotehes of redclish brown over alout onc-fourth ihe surface, $2 \cdot 16 \times 1 \cdot 61$ (Pennock). Date, San Mateo, Fla., Apl. 4. (Ralph).

A rare resident in Florida. According to Mr. C. J. Pennock, who found its nest at St. Marks on April 3, its call somewhat resembles 
the scream of the Red-shouldered Hawk, but is finer and more prolonged (Auk, 1890, p. 56; see also Scott, Ibid., 1889, p. 243).

The Mexican Goshawk (346. Asturina plagiata) is a tropical species which reaches the southwestern border of the United States. An individual seen by Mr. Robert Ridgway in southern Illinois, August 19, 1871, is the only known instance of its occurrence east of the Mississippi.

347a. Archibuteo lagopus saneti-johannis ( $G m e l$.). ROUGH-LEGGED HAwk. Ad., light phase.- Upperparts fuscous-brown, margined with whitish and ochraceous-buff; inner vanes of the primaries white at the base; basal half of the tail white or buffy, end with two or three grayish or whitish bars; underparts varying from white to ochraceous-buff, streaked and spotted with black, these marks uniting to form a broken band across the beily; front of tarsi entirely feathered. Im., normal phase-Similar to the ad., but the end half of the tail without bars except for the white tip, the underparts more heavily marked with black, the belly band being broad and continuous. Black phase.-Plumage more or less entirely black, the primaries and tail barred with whitish and grayish. L., 22.00; W., 16.00; T., 9550 .

Remarks.-Its feathered tarsi and heavily marked underparts characterize this species.

Range. - N. A. n. of Mex. Breeds in Hudsonian zone from the Aleutian Islands, nw. Alaska, Arctic coast, and n. Ungava s. to cen. B. C., s. Mackenzie, s. Ungava, and N. F.; winters from Ore., Colo., Minn., and n. boundary of w. U. S. s. to cen. Calif., s. N. M., Tex., La., and N. C.

Washington, rare and irregular W. V. Ossining, casual. Cambridge, T. V., not uncommon, Nov.-Dec.; Mch.-Apl. N. Ohio, not common W. V., Nov. 20-Apl. 3. Glen Ellyn, quite common W. V., Oct. 12-Apl. 30. SE. Minn., W. V., Oct. 15-Mch.

Nest, on rocky ledges or in trees. Eggs, 2-5, dull white, sometimes unmarked, but generally more or less spotted, blotched, or scrawled with cinnamon-brown or chocolate, $2 \cdot 20 \times 1 \cdot 75$. Date, Ft. Chimo, Lab., May 24 .

"The Rough-leg is one of the most nocturnal of our Hawks, and may be seen in the fading twilight watching from some low perch or beating with measured, noiseless flight over its hunting-ground. It follows two very different methods in securing its food-one by sitting on some stub or low tree and watching the ground for the appearance of its prey, as the Red-tail does; the other by beating back and forth just above the tops of the grass or bushes and dropping upon its victim, after the manner of the Marsh Hawk. . . .

"The flight of the Rough-leg is seldom rapid and often appears labored, and when on the wing this Hawk resembles the Osprey more than any other bird of prey.

"Of 49 stomachs examined, 40 contained mice; 5, other mammals; 1, lizards; 1 , insects; and 4 were empty" (Fisher).

348. Archibuteo ferrugineus (Licht.). FERruginous Rodgh-Leg. Ad, light phase. - Tpperparts mostly rufous, the centers of the feathers fusenus; tail grayish white, mareinerl with rufous; legs rufous, barred with hlark; rest of inderparts white, more or less barred with rufous on the sides and belly; tarsi fully feathered in front. Im.- Upperparts dark grayish brown, slightly viried with ochraceous-buff; tail silvery grayish brown, without hars, the base white: molorparts white, lightly spotted and streaked with fuscous. Darli phase.- Dark fuscous-h)rown, more or less varied with rufous; primaries and tail as in the ad. L., $23^{\circ} 00$; W., 17.00); T., 10.50. 
Remarks.-This species is to be distinguished from the preceding principally by its much larger bill and differently colored tail and underparts.

Range.-W. N. Am. Breeds from s. Wash., sw. Sask., and s. Man., to s. Calif., Utah, Colo., and Kans.; winters from Mont., to L. Calif. and n. Mex., and casually e. to Wisc. and Ills.

Nest, in trees or on the ground in rocky places. Eggs, 2-4, "white, or buffy white, usually more or less spotted, blotched, or clouded with brown or grayish purple (or both), $2.42 \times 1.88^{\prime \prime}$ (Ridgw.). Date, Ft. Totten, N. D., Apl. 12.

This bird is rarely found east of the Mississippi. Dr. Fisher remarks: "The Squirrel Hawk is preëminently a bird of the prairie, and, unlike the common Rough-leg, shows little partiality to the vicinity of water, though in other respects it closely resembles the latter bird in habits."

348. Aquila chrysaëtos (Linn.). Golden EAgle. Ads.-Back of the head and nape pale, buffy ochraceous; hasal two-thirds of the tail with broken grayish bars; tarsus white, entirely feathered; rest of the plumage fuscous-brown; quills fuscous. Im. - Similar, but base of the tail white; tarsus and under tail-coverts ochraceous-buff. $\sigma^{2}$ L., 30*00-35.00; Ex., 78.00-84.00; W., 23.00-24.70; T., 14.00-15.00; Tar., 3.65-3.80. ㅇ L., 35.00-40.00; Ex., 84.00-90.00; W., 25.00-27.00; T., 15*00-16.00; Tar., 4.15-4.25 (Ridgw.).

Range.-N. part of N. Hemisphere. In N. A. s. to middle L. Calif., cen. Mex., w. Tex., S. D., Man., s. Keewatin, cen. Ont., N. H., Maine, and N. S., and in the Alleghanies to sw. N. C.; less common e. of the Miss.

Washington, rare W. V. Ossining, A. V. Cambridge, 1 record. N. Ohio, rare W. V. SE. Minn., P. R.

Nest, on cliffs, rocky ledges, or in trees. Eggs, dull white, obscurely or distinctly blotched or speckled with shades of cinnamon-brown, $2.93 \times 2 \cdot 34$. Date, San Benito Co., Calif., Feb. 19; Gold Hill, Colo., Apl. 3.

"It seems to be nowhere a common species in the East, but it is much more numerous in the mountainous parts of the far West. It is confined chiefly to the mountains and more northern latitudes, where it breeds. It is able to endure intense cold, and sometimes re-

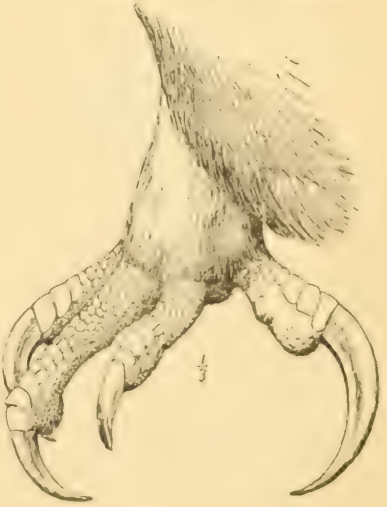

Fig. 89. Foot of Golden Eagle. mains far north in winter. In fact, its movements at that seitson are more in the form of wandering for food than regular migration to the south.

"The food consists mainly of mammals and birds, of which spermophiles, rabbits, fawns, lambs, turkeys, grouse, waterfowl, and ot her large birds form the principal part, though offal and carrion are sometimes taken. . . . Of 6 stomachs examined, 1 contained feathers; 2, mammals; 2, carrion; and 1 was empty" (Fisher).

In view of the ever-recurring story of folden Eagles bearing away children, it is well to say that Cameron shows that six pounds is about the greatest weight a Golden Eagle can carry while on the wing. 
1905. Cameron, E. S., Auk, XXII, 158-167; XXV, 251-268 (biog.).1909. MacPherson, H. B., 8vo, 1-45; plls. 1-32 (Witherby, London).

351. Haliæetus albicilla (Linn.). GRAY SEA EAgLe. Ads.-Tail white, rest of plumage varying from grayish brown to fuscous. Im.- "With plumage largely light cinnamon-brown or isabella-color. $\sigma^{\top} \mathrm{L}$., $31^{\circ} 00-34^{\circ} 00$; W., 23.00-26.00; T., 11.50-12.00" (Ridgw.).

Range.-N. part of E. Hemisphere, breeding from Scotland, n. Europe, and $\mathrm{n}$. Asia to Spitzbergen and Nova Zembla; in migration s. to Japan, China, n. India, s. Europe, and n. Africa; resident in Iceland and Greenland; recorded also from Cumberland Sd.; casual on the Aleutian Islands.

Nest, on cliffs or in trees. Eggs, 2-3, dull white, "occasionally with small, faint spots of light brown" (Davie), 3.00 × 2*35. Date, Crimea, S. Russia, Apl. 12. (Thayer Coll.)

This species breeds in southern Greenland.

352. Haliæetus leucocephalus leucocephalus (Linn.). BALD EAGLE. Ads.-Head, neck, and tail white, rest of the plumage fuscous; bill yellow; tarsus not fully feathered. Im.-Fuscous, more or less varied with white; tail fuscous, more or less mottled with white, particularly on the inner vanes of the feathers; bill black. or L., $32 \cdot 85$; Ex., $84^{*} 10$; W., $22^{\circ} 00$;

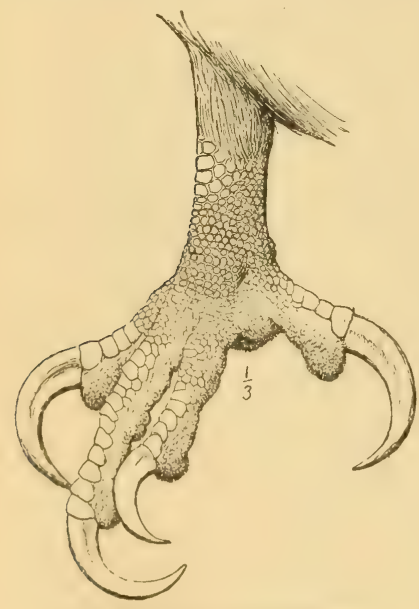

Fig. 90. Foot of Bald Eagle. T., $11 \cdot 90$; B., $2 \cdot 48$. \& L., 35.50 ; Ex., $89^{\circ} 00$; W., 24.00 ; T., $12 \cdot 25$; Weight, 12 lbs.

Remarks:-At any age the Bald Eagle may be distinguished from the Golden Eagle by its partly feathered tarsi.

Range.-U. S. to s. L. Calif. and n. Mex., breeding in suitable locations throughout its range; rare and local in Calif. and in the arid interior.

Washington, not common P. R. Ossining, common P. R. Cambridge, of irregular occurrence at all seasons. N. Ohio, tolerably common P. R. SE. Minn., P. R., becoming rare.

Nest, generally in tall trees, sometimes on cliffs. Eggs, 2-3, dull white, $2.85 \times$ 2.20. Date, Brevard Co., Fla., Nov. 25; Tampa, Fla., Dec. 3 ; coast S. C., Nov. 27, large embryos; Lancaster Co., $\mathrm{Pa}$., Feb. 11; Stone Is., Maine, Apl. 21.

Bald Eagles are seldom found far from the water. Here they may be seen soaring overhead, winging their way to and from their feeding-ground, or occupying some favorite perch, generally in an exposed position. They subsist principally upon fish. As a last resort they sometimes capture these themselves, but dead fish cast up on the shore are eagerly taken, and their habit of robbing the Fish Hawk of his well-earned booty is too well known to be commented upon. In some localities, particularly in the South during the winter, they live largely upon waterfowl which they capture themselves.

The voice of the Bald Eagle has a weird, human quality. Dr. Fisher says: "At a distance the note of the Bald Eagle is not alto- 
gether unpleasant, resembling somewhat that of Sea Gulls, but nearby it is grating and suggests a maniacal laugh." Dr. William L. Ralph writes in Bendire's 'Life Histories': "The cry of the male is a loud and clear cac-cac-cac, quite different from that of the female-so much so that I could always recognize the sex of the bird by it; the call of the latter is more harsh and often broken."

The conspicuous white head and tail of adults of this species render it easy of identification even at a considerable distance. Young birds too closely resemble Golden Eagles to be distinguished with certainty, but the rarity of that species in the east makes it probable that any Eagle observed is a Bald Eagle.

\section{Family Falconider. The Falcons, Caracaras, Etc.}

It is resemblance in structure rather than in habit which places the members of the genera Falco and Polyborus in the same family. In the former, predatory bird-life reaches its highest development; in the latter, we have birds not distantly removed from Vultures in the character of their food. From the great Arctic Gyrfalcons, nearly two feet in length, to the Indian Pygmy Falcon, no longer than a Song Sparrow, the Falcons are keen winged, dashing, fearless hunters among birds. They have not the soaring habits of the Buteos, from which they may be distinguished by their more pointed wings and more rapid wing-stroke. Their nests are less bulky than those of our buteonine Hawks, the eggs in some species being laid on the bare rock or in a hollow tree. (For Key see antea under Buteonidac.)

353. Falco islandus Brünn. White Grrfalcon. Legs, and usually under tail-coverts, always white, unmarked. Ads.-Head white, fincly streaked with black; scapulars, interscapulars, and wing-coverts white with broad bars or semi-lunes, rarely guttate spots of slaty fuscous; tail sometimes wholly white, usually broadly or narrowly barred with slaty fuscous; underparts white, with sometimes a few small grayish spots or streaks. Im. - Similar, but upperparts brownish gray with white margins and broken bars; tail barred with brownish gray; underparts more heavily, sometimes uniformly streaked. L., $22^{\circ} 00$; W., $16^{\circ} 00$; T., $10^{\circ} 00$; B. from N., $\cdot 95$.

Remarks.-The white, unmarked under tail-coverts and prevailing white color will distinguish this bird from any form or phase of $F^{\prime}$ ulco rusticolus.

Pange.-Arctic regions. Resident in Greenland; in winter casual s. to Ont., N. S., and Maine.

Nest, on rocky cliffs. Eggs, 3-4, varying from creamy white, spotted or blotched with cinnamon-brown, to uniform pale reddish brown, spotted or blotched with shades of the same color, 2*30 × 1.85. Date, Umanak, Greenland, May 26 (Thayer Coll.).

"The food consists of waterfowl and other hirds-largely of various aretic species of Grouse which are captured on the wing. All these northern Falcons were formerly esteemed for hawking, as they still are by the Mongol races; their style of flight is magnificent-much swifter than that of the Peregrine - and both are deadly 'footers' (i. e., tenacious of grip), but they lack spirit and dash" (Saunders). 
354. Falco rusticolus rusticolus (Linn.). Gray Grrfalcon. Ads.Head streaked with buffy or whitish and fuscous, in about equal amounts; upperparts grayish, slaty or brownish gray barred with white or whitish; tail barred with brownish gray and white in about equal amounts; below white with elongate spots from chin to vent; flank plumes barred, under tail-coverts barred or with shaft-streaks. Im.-Head more narrowly streaked with fuscous; upperparts browner margined with whitish and with more or less concealed spots or broken bars of whitish or buffy; underparts more heavily streaked. L., $20^{\circ} 00$; W., $15{ }^{\circ} 50$; T., $9 \cdot 50$; B. from N., 90 .

Remarks. - In any plumage the various races of rusticolus are to be distinguished from islandus by their barred, streaked, or shaft-streaked under tail-coverts. The distinctive characters of our three races of rusticolus are the broadly-streaked head of $F$. r. rusticolus, the barred or margined back and solid or comparatively unstreaked head of gyrfalco, and the black back and almost black underparts of obsoletus.

Range.-Arctic regions. Breeds in Arctic Am. from Alaska, e. to s. Greenland; in winter casual s. to B. C., Kans., Wisc., Ont., and Maine.

Nest, on cliffs or in trees. Eggs, 3-4, not distinguishable from those of the preceding, $2.37 \times 1 \cdot 72$. Date, Iceland, Apl. 15 (Thayer Coll.).

354a. F. r. gyrfalco (Linn.). Grrfalcon. Similar to $F$. r. rusticolus but darker; ad. less distinctly barred above and with the head fuscous, unstreaked. Im.-Head grayish brown, little if at all streaked or margined with buffy; back grayish brown, almost uniform, or but slightly margined or spotted with buffy.

Range.-Arctic regions. Breeds in Ellesmere Land, n. Greenland, and e. to Franz Josef Land; in winter casual s. to Minn., N. Y., R. I., Mass., and Maine.

Nesting date, Ft. Anderson, Mack., May 9.

354b. F. r. obsoletus (Gmel.). Black Grrfalcon. Head fuscous, narrowly margined with buffy, rest of upperparts uniform slaty fuscous, without bars; tail the same, without or with only broken bars; underparts of the same color as the back; the feathers with partly concealed buffy spots or margined with buffy.

Range.-Breeds in Ungava; s. in winter to N. S., Que., Ont., and Maine, and casually to N. Y., N. H., Mass., and R. I.

Nesting date, Ft. Chimo, Lab., May 22.

355. Falco mexicanus Schleg. Prairie Falcon. Ads. - Above, grayish brown; primaries and inner webs of all but the middle tail-feathers with numerous buffy bars or spots; below, white, streaked and spotted with dark grayish brown. Im.- Similar, but with the upperparts margined with ochraceous-buff or buffy. of L., $17 \cdot 00 ;$ W., $12 \cdot 20$; T., $7^{\circ} 00$.

Range.-Transition and Sonoran zones from e. border of the Great Plains and from s. B. C. and se. Sask. to s. L. Calif., and s. Mex.; casual e. to Minn. and Ills.

Nest, on cliffs, sometimes in hollow trees. Eggs, 2-5, "creamy white, vinaccous-white, or pale vinaceous-buffy, sprinkled, speckled, or irregularly syotted with madder-brown, 2.06 × 1'60" (Ridgw.). Date, Gilmer, Wyo., Mch. 25.

"The Prairie Falcon, as the names implies, is a typical plains bird, and inhabits the dry interior.

"The flight of this Hawk is swift and graceful, though in most cases it is carried on at no great distance from the ground. It is not a shy bird, except in sections where it has been persecuted and has learned that man is its worst enemy" (Fisher). 
356. Falco peregrinus anatum (Bonap.). DणCK HAwK. Ads.Upperparts dark bluish slate-color; primaries barred with ochraceous; tail indistinctly barred with blackish and tipped with white; underparts creambuff, barred and spotted with black, except on the breast. Im.-Upperparts fuscous, more or less margined with ochraceous or rufous; region below the eye black; ear-coverts buffy; wings as in the ad.; upper surface of the tail barred with grayish, under surface barred with ochraceous-buff; underparts cream-buff or ochraceous-buff, streaked, spotted or barred with black. on L., $16 \cdot 00$; W., $12 \cdot 25$; T., 6.50; B. from N., 68 . \& L., $19^{\circ} 00$; W., $14 \cdot 00 ;$ T., $7 \cdot 50$.

Range.-N. and S. A. Breeds locally (except in nw. Coast Region) from Norton Sound, Alaska, n. Mackenzie, Boothia Peninsula, and w. cen. Greenland s. to cen. L. Calif., Ariz., sw. Tex., Kans., Mo., Ind., Pa., and Conn. (in mountains to S. C.); winters from s. B. C., Colo., and N. J. (occasionally further $\mathrm{n}$.) to the West Indies and Panama; occurs also in s. S. A.

Washington, rare and irregular W. V. Ossining, casual. Cambridge, rare T. V., casual in winter. SE. Minn., uncommon S. R., Apl. 4.

Nest, on rocky cliffs and in the hollow limbs of tall trees. Eggs, 3-4, creamy white, heavily marked with cinnamon-brown, to pale reddish brown, more or less marked with shades of the same color, $2.05 \times 1.68$. Date, Wyoming Co., Pa., Apl. 18, inc. adv.; Mt. Tom, Mass., Apl. 23.

This species is the "Noble Peregrine" of falconry. It would be difficult to imagine a bird more highly endowed with qualities which make the ideal bird of prey. Its strength of wing and talon is equaled by its courage. Few birds fly more swiftly than the Duck Hawk. Even Teal-those winged bullets-can not escape it. No bird is more daring. I have had Duck Hawks dart down to rob me of wounded Snipe lying almost at my feet, nor did my ineffective shots prevent them from returning. Duck Hawks are generally found near water, where they prey largely on water birds.

"Of 20 stomachs examined, 7 contained poultry or game birds; 9, other birds; 1, mice; 2, insects; and 4 were empty" (Fisher).

The Peregrine Falcon, or Old World Duck Hawk (356. Falco peregrinus peregrinus) is of casual occurrence in Greenland.

357. Falco columbarius columbarius (Linn.). PIGEON HAwK. $A d s$. -Upperparts slaty blue, a broken buffy or rusty collar on the neck; primaries barred with white; tail with three or four distinct gravish white bars and a white tip; underparts varying from cream-buff to rleep orhraceous, streaked with blackish, exeept on the throat. Im.-Upperparts fuseous or brownish fuscous, a broken buffy collar on the nape; primaries barred with ochraceous; tail with three or four incomplete buffy bars and a whitish tip; underparts much as in the ad. L., $10 \cdot 00-13.00$; W., $8^{\circ} 00$; ' T., 5.50; $\mathrm{B}$. from N., $\cdot 45$.

Remarks.- This little Falcon bears some resemblanec to a I)uck Hawk, but is much smaller.

Range.-N. A. to n. S. A. Broeds from nw. Alaska and nw. Markonzios. in the mountains to Calif. and s. ()re. and from e'n. Keewatin, n. Ungava, and N. F. s. to n. Mich., ecn. Ont., and Maine; winters from ('alif, and the Gulf States (casually further n. ) s. to Venezuela,

Washington, not uncommon T. V. ()sining, tolerably common T. V., Apl. 1-May 11; Aug. 10-Oct. 15. Cambridere, common T. V., $\Lambda_{1} 1.25$ - May 5; Sept. 25-Oct. 20; occasional in winter. N. Ohio, rare I. R. (ilen Ellyn, regular but rare T. V., Apl. 26-May 5; Sept. 10-Oct. 16. SE. Minn., Apl. 13.

Nest, in trees, in hollow limbs, or on cliffs. Eggs, 4-5 cre:imy white, more or less heavily marked with reddish brown or chocolate, to reddish 
brown marked with shades of the same color, $1.65 \times 1$.20. Date, Bingham Co., Idaho, May 13; Lab., June 2.

"This Falcon, with the exception possibly of the Broad-winged Hawk, is the least shy of all our diurnal birds of prey, and often may be approached within a few rods. It frequents the more open country and edges of woods, and is common along the shores of large bodies of water. . . The flight is very rapid and resembles that of the Wild Pigeon quite closely; nor does the similarity end here, for while sitting on a tree the general poise is that of a Pigeon in repose, and specimens have been mistaken and shot for the latter bird. . . .

"Of 56 stomachs examined, 2 contained poultry; 41, small birds; 2 , mice; 16, insects; and 5 were empty" (Fisher).

The MerLin (358.1. Falco asalon) and the Kestrel (359.1. Falco tinnunculus), both Old World species, have each been recorded once from Greenland.

360. Falco sparverius sparverius Linn. Sparrow HAWK. Ad. $\sigma^{7} \cdot-$ Back rufous, more or less barred with black; tail rufous, a black band near its end, the tip white; head slaty blue, with generally a rufous spot on the crown; wing-coverts slaty blue, primaries barred with white; a black mark before and behind the white ear-coverts; underparts varying from cream-buff to ochraceous-buff; belly and sides spotted with black. Ad. o.-Back, tail, and wing-coverts rufous, barred with black; head as in the male; underparts more or less heavily streaked with dark ochraceous-buff. Im.-Closely resemble the adults. L., $10 \cdot 00 ; W ., 7 \cdot 30 ;$ T., $4 \cdot 80 ;$ B. from N., 45 .

Range.-N. A. e. of the Rocky Mts. Breeds from the Upper Yukon, nw. Mackenzie, s. Keewatin, and N. F. s. to Tex. and the e. Gulf States (except Fla.); winters from Kans., Ind., Ohio, and Mass. s. through e. Mex. to Costa Rica.

Washington, common W. V., rare S. R. Ossining, rather rare P. R. Cambridge, P. R., common in summer, rare in winter. N. Ohio, common P. R. Glen Ellyn, rather rare S. R., Mch. 10-Oct. 26.

Nest, in a hole in a tree, frequently in a Woodpecker's deserted nest. Eggs, 3-7, creamy white to rufous, generally finely and evenly marked with shades of the ground color, $1.40 \times 1 \cdot 12$. Date, Nazareth, Pa., Apl. 9; Cambridge, May 5 .

An old stub or branchless trunk of a dead tree standing well out in a field is the kind of perch the Sparrow Hawk most frequently chooses. From this lookout, like a Loggerhead Shrike, he awaits the appearance of game below. Generally it is a grasshopper which falls his victim. When he detects one, he flies directly over it, and poises on hovering wings until the right opportunity offers, when he drops lightly downward, clutches his prey in his talons, and then returns to his perch to devour it at leisure.

The Sparrow Hawk's call is a rather high, quickly repeated killykilly-killy-killy, which in some sections gives it the name of "Killy Hawk."

"Of 320 stomachs examined, 1 contained a game bird; 53, other birds; 89 , mice; 12 , other mammals; 12 , reptiles or batrachians; 215 insects; 29, spiders; and 29 were empty" (Fisher). 
360c. F. S. paulus (Howe). Florida Sparrow Hawk. Similar to $F$. s. sparverius but "rufous of upperparts very dark, particularly on the rectrices. Tail and wings short. Bill large and heavy." (Howe, Cont. to N. A. Orn., I, 1902, 28.)

Range.-Florida Peninsula.

Nesting date, Ft. Thompson, Fla., Apl. 1.

The Cuban Sparrow Hawk (361. Falco sparveroides) is of accidental occurrence in the Florida Keys. It has two color phases; in one, the underparts, including the under wing-coverts, are white; in the other, these parts are rufous.

362. Polyborus cheriway (Jacq.). AUdubon's CARACARA. Ads.Face bare; crown, lower back, wings, and belly black; throat buffy; nape, interscapulars, and breast barred with black and buffy; tail white, barred and tipped with black. Im.- Similar, but browner, and with few or no bars on the interscapulars and breast. L., $22^{\circ} 00$; W., $16 \cdot 00 ;$ B. from N., $1 \cdot 25$.

Range.-N. L. Calif., Ariz., Tex., and s. cen. Fla. s. to Guiana and Ecuador; accidental in Ont.

Nest, in a cabbage palmetto or on the tops of dense bushes. Eggs, 2-3, varying from cream-buff to rufous, heavily marked with shades of reddish brown and chocolate, $2.35 \times 1.85$. Date, Lake Kissimmee, Fla., Mch. 19.

Caracaras frequently associate with Vultures and feed on carrion, but they also capture their own food. This consists largely of frogs, lizards, and small snakes, which the birds find while walking about on the ground in search of them. Their flight is strong, rapid, and direct, and bears no resemblance to that of a Vulture.

\section{Family Pandionider. Ospreys. (Fig. 20.)}

The Fish Hawk or Osprey has occasioned systematists no little difficulty, and it is variously placed in its own subfamily, family, or even suborder. There is virtually but a single species which ranges throughout the world, presenting in this wide area only sufficient variation on which to base the three or four currently recognized forms. Unlike most Raptorial birds, Ospreys sometimes nest in close proximity to one another, drawn together not by sociability of temperament, but by community of interests. On Gardiner's Island, L. I., there are about two hundred Osprey nests, the protection of an insular home and an abundant food supply being the principal factors in the development of this "colony."

The firm, dense plumage, large claws, the spicules which thickly beset the grasping surface of the toes, and the reversible outer toe are all distinctive characters and the evident outcome of the Osprey's specialized feeding habits.

364. Pandion haliaëtus carolinensis (Gmel.). Osprey. (Fig. 20.)

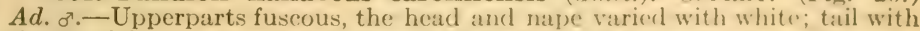
six to eight obscure bands, more distinct on the inner wet); underparts white, breast sometimes slightly spotted with grayish brown. Ad. ?.- - Cimilar, but the breast alway's spotted with grayish hrown. L., $23 \cdot 10$; W., $18 \cdot 25$ T., 8*40.

Range.-N. and S. A. Breeds from nw. Alaska, nw. Mackenzic, cen. 22 
Keewatin, s. Ungava, and N. F. s. to L. Calif., w. Mex., and the Gulf coast; winters from the s. U. S. through L. Calif. and Mex. to the West Indies and Cen. Am.; occurs also in S. A. s. to Peru and Paraguay.

Washington, uncommon S. R., Mch. 19-Nov. 30. Ossining, common T. V., rare S. R., Apl. 3-May 26; Sept. 29-Oct. 20. Cambridge, rather common T. V., Apl.-May; Sept.-Oct. N. Ohio, rare S. R., Apl. 20-Oct. Glen Ellyn, two records, May and Sept.

Nest, generally in a tree, 20-50 feet up, sometimes on rocks, rarely on the ground. Eggs, 2-4, extremely variable, sometimes dull white, unmarked, sometimes almost solid chocolate, but generally buffy white, heavily marked with chocolate, chiefly at the larger end, $2.45 \times 1.80$. Date, Bull's Mt., Md., Apl. 20; Shelter Is., N. Y., May 3; Carver's Harbor, Maine, May 8.

This species lives in colonies, and also in pairs, along our coasts, returning year after year to the same nesting-ground. Its food consists solely of fish, which, as a rule, it captures alive. Winging its way slowly over the water, it keeps a keen watch for fish which may appear near the surface. When one is observed, it pauses, hovers a moment, and then closing its wings descends with a speed and directness of aim that generally insure success. It strikes the water with great force, making a loud splash, and frequently disappears for a moment before rising with its prey grasped in its powerful talons. As a rule, it carries its food to some favorite perch, there to devour it.

The alarm-note of the Fish Hawk is a high, rapidly repeated, complaining whistle, which is sometimes varied and prolonged to the semblance of a song.

1892. Allen, C. S., Auk, IX, 313-321 (on Plum Is.).-1908. Chapman, F. M., Camps and Cruises, 47-59 (Gardiner's Is.).

\section{Family Aluconide. Barn Owls. (Fig. 47.)}

The Barn Owls, numbering some twenty-five species and subspecies, are found nearly throughout the temperate and tropical regions. They differ from other Owls in structure, but share with them the characteristic habits of the Strigidoe, the other of the two Owl families.

365. Aluco pratincola (Bonap.). BARN OwL. (Fig. 47.) Ads.Upperparts mixed with gray and ochraceous-buff, finely speckled with black and white; tail varying from white to ochraceous-buff, generally mottled with black, and sometimes with three or four narrow black bars; underparts and facial disk varying from pure white to deep ochraceous-buff, the former generally with numerous small, black, round spots, the facial disk narrowly margined by ochraccous-buff or rufous; eyes black. L., 18*00; W., 13*25; T., $5 \cdot 50 ;$ B., $1 \cdot 30$.

Range.-N. A. Breeds in Upper and Lower Austral zones from n. Sarramento Valley, Calif., Colo., Nebr., Ills., Ind., Ohio, w. N. Y., s. to the Gulf States and s. Mex., and casually to Ore., Minn., Mich., Ont., Vt., and Mass.

Washington, not rare P. R. Ossining, A. V.

Nest, in a tower or steeple, a hole in a tree or bank. Eggs, white, 5-9, 1.72 2 130. Date, D. C., Apl. 16; Delaware Co., Pa., Apl. 24.

The Barn Owl conceals itself so well during the day that, in my experience, it is a difficult bird to observe, even in localities where it is 


$$
\checkmark
$$




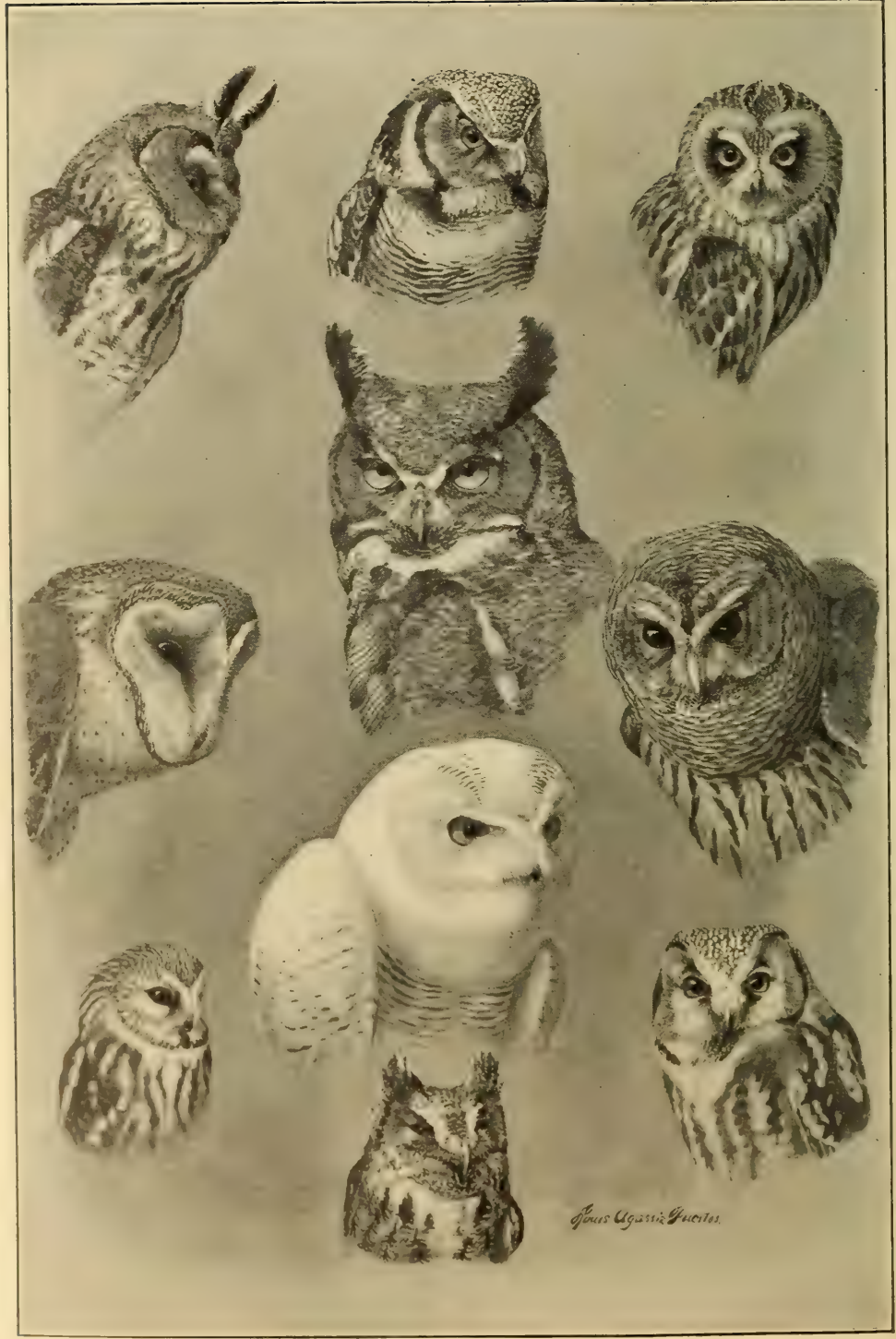

Long-eared Owl.

Barn Owl.

Saw-whet Owl.
Heads of Owls

Hawk Owl.

Great Horned Owl.

Snowy Owl.

Screech Owl.
Short-eared Owl.

Barred Owl.

Richardson's Owl 
common. For this reason the capture of one of these odd-visaged birds is frequently the cause of much excitement over the supposed discovery of an animal entirely new to science, and which, by the local press, is generally considered half bird, half monkey!

The only notes I have ever heard from the Barn Owl are a sudden wild, startling scream, a high, rapidly repeated $c r-r-r e e, c r-r$-ree, $c r-r$-ree, and, in captive birds, a hissing sound; but Bendire mentions "a feeble, querulous note like quäek-quäek, or äek-äek, sounding somewhat like the call of the Night Hawk (Chordeiles virginianus), frequently repeated, only not so loud."

"Of 29 stomachs examined, 1 contained poultry; 3, other birds; 17, mice; 17, other mammals; 4, insects; and 7 were empty" (Fisher).

39. Family Strigide. Horned Owls, Hoot Owls, Etc. (Fig. 48.)

Owls are found in all parts of the world. About two hundred and fifty species are known, of which nineteen inhabit North America. Many species respond readily to the influences of their environment and hence appear in a number of racial or subspecific forms. Of the Screech Owl, for example, there are nine North American races, and of the Horned Owls, eight. With few exceptions, Owls are woodland birds, but some species live in grassy marshes or dry plains, while others make their home in towers, steeples, or outbuildings. Owls are nocturnal birds of prey, and for this reason feed more largely on small mammalsmost of which are nocturnal - than do the diurnal birds of prey. They are therefore of even greater value to the agriculturist than Hawks. Their prey is captured with their talons, and, unless too large, is swallowed entire. The bones and hair are afterward ejected at the mouth in matted pellets.

Owls' eyes are so fixed in their sockets that they can not look from one point to another by simply "rolling" the eyclall, but are obliged to turn their hearl. The weird, almost human, roiers of ()wlis ardel not a little to the superstitious fear with which they are frequently regarded. The eggs of Owls are uniformly white, unmarked. The young are thickly covered with white down.

I. Wing over $10^{\circ} 00$.

KEY TO THE SPECIES

A. Belly without bars, striped longitudinally.

a. Upperparts with eross-bars.

$a^{1}$. Toes feathered . . . . 368. BARRED OWL. $a^{2}$. Toes nearly bare. 368a. Florida Barred OWL.

b. Upperparts striped longitudinally . . . 367. SHORT-EARED ()WL.

$B$. Belly with cross-bars.

a. With conspicuous 'horns' or 'ears.'

$a^{1}$. Wing over 13.00 . 375. Great Horned Owl and races. $a^{2}$. Wing under 1300 . . . 366. LONG-EARED OWL.

b. Without 'horns' or 'ears.'

$b^{1}$. Plumage white, more or less barred with hlark 376 . SNowy ()wL.

$b^{2}$. Plumage fuscous, mottled and barred with whitish.

370. Great Gray Owl. 
II. Wing under $10^{\circ} 00$.

$A$. Toes heavily feathered.

a. Wing more than $6^{\circ} 00$.

$a^{1}$. Tail more than 6.00 . . . . 377a. HAwK OwL. $a^{2}$. Tail less than 6.00 . . 371. Richardson's OwL.

b. Wing less than $6^{\circ} 00$. . . . . . 372. SAw-WHET OWL.

$B$. Toes thinly, if at all feathered.

a. Tarsi heavily feathered; with conspicuous 'horns.'

373. Screech Owl. 373a. Florida Screech Owl.

b. Tarsi partly bare; no 'horns' . . 378a. Florida BurRowing OwL.

366. Asio wilsonianus (Less.). LONG-EAREd OwL. Ads.-Eartufts conspicuous, an inch or more in length, black bordered by white and buffy; upperparts fuscous-brown mottled with white, the bases of the feathers ochraceous-buff; tail with six to eight fuscous cross-bars; facial disk buffy bordered by black; underparts mixed white and ochraceous-buff, the breast broadly streaked, the sides and belly irregularly barred with fuscous; eyes yellow. L., 14.80; W., 11.90; T., 6.00; B., 1.06.

Range.-Temperate N. A. Breeds from cen. B. C., s. Mackenzie, s. Keewatin, s. Que., and N. F. s. to s. Calif., n. Tex., Ark., and Va.; winters from s. Canada to Ga., La., and cen. Mex.

Washington, common P. R. Ossining, common P. R. Cambridge, rare P. R., but sometimes common in fall and winter. N. Ohio, uncommon P. R. Glen Ellyn, rare, fall records only, Nov. 7-Dec. 14.

Nest, generally in an old Crow's, Hawk's, or Squirrel's nest. Eggs, white, 3-6, 1.65 × 1.30. Date, Ossining, N. Y., Mch. 31; Cambridge, Apl. 1; se. Minn., Apl. 16.

"This species, like the Screech Owl, is nocturnal in its habits, and differs from the Short-eared Owl in never hunting during the daytime. It usually spends the day in some evergreen woods, thick willow copse, or alder swamp, although rarely it may be found in open places.

"The bird is not wild, and will allow itself to be closely approached. When conscious that its presence is recognized, it sits upright, draws the feathers close to the body, and erects the ear-tufts, resembling in appearance a piece of weather-beaten bark more than a bird.

"Like the other Owls, its flight is slow and wavering, but in common with them it is buoyant and devoid of any appearance of heaviness. The note of this Owl is said by some to resemble the noise made by kittens, while others state it is like the barking of small dogs.

"Of 107 stomachs examined, 1 contained a game bird; 15, other birds; 84 , mice; 5 , other mammals; 1 , insects; and 15 were empty" (Fisher).

367. Asio flammeus (Pont.). Short-eared Owl. Ad. o-Ear-tufts very short, difficult to distinguish in a dried skin; upperparts fuscous, the feathers margined with cream-buff or ochraceous-buff, not mottled with white; tail with ochriceous-buff and fuscous bands of about equal width; underparts whitish, the breast broadly and the belly more finely streaked with fuscous; eyes yellow. Ad. 9.- Similar, but underparts rich ochraceousbuff. L., $15 \cdot 50$; W., $12^{\circ} 75$; T., $60^{\circ} 05$; B., 1*20.

Range.-Nearly cosmopolitan. In. N. A. breeds irregularly and locally from Arctie zones s. to Calif., Colo., s. Kans., Mo., n. Ind., and Mass.; winters from Calif., Wyo., Minn., Ind., Ohio, and Mass., s. to La., Cuba, and Guatemala; common in Hawaii. 
Washington, common W. V. Ossining, casual. Cambridge, T. V., Mch. 15-Apl. 15, rare; Oct.-Nov., uncommon. N. Ohio, uncommon P. R. Glen Ellyn, rare, Dec. 11-May 15. SE. Minn., common S. R.

Nest, on the ground, in grassy marshes. Eggs, white, 4-7, 1.60 × 1.25. Date, St. Clair Flats, Mich., Apl. 20.

This species might well be named Marsh Owl, for, unlike most of our Owls, it does not frequent the woods, but lives in grassy marshes. It is not shy and does not take wing until almost stepped upon, when it arises noiselessly and flies low over the marsh. Sometimes it alights on a knoll or slight elevation, and watches the intruder in the intent, half-human manner of Owls.

During the migrations and in the winter this bird is occasionally found in flocks or colonies containing one or two hundred individuals.

"Of 101 stomachs examined, 11 contained small birds; 77, mice; 7, other mammals; 7, insects; and 14 were empty" (Fisher).

368. Strix varia varia Barton. BARRED OWL. (Fig. 48.) Ads.-No ear-tufts; upperparts grayish brown, each feather with two or three white or buffy white bars; tail with six to eight similar bars; facial disk gray, finely barred or mottled with fuscous; underparts white, more or less tinged with buffy, the breast barred, the sides and belly broadly streaked with fuscous; bill yellow; legs and feet feathered to or near the bases of the nails; eyes brownish black. L., $20 \cdot 00 ;$ W., $13 \cdot 50$; T., $9 \cdot 50 ;$ B., 1.50.

Range.-E. N. Am. Breeds from s. Keewatin, s. Que., and N. F. s. to e. Kans. and Ga., and w. to e. Wyo., and e. Colo.

Washington, not common, rare P. R. Ossining, rare P. R. Cambridge, P. R., sometimes common in Nov. and Dec. N. Ohio, common P. R. Glen Ellyn, rare and local P. R. SE. Minn., common P. R.

Nest, in a hollow tree; sometimes in an old Crow's or Hawk's nest. Eggs, white, 2-4, 2.00 × 1.65. Date, New London, Conn., Mch. 22; Black Hawk Co., Iowa, Mch. 1; se. Minn., Mch. 7.

The deep-toned, questioning voice, the absence of "horns," and the dark brown, nearly black eyes, combine to make Barred Owls appear among the most human of these strangely human birds. They inhalbit large tracts of woodland, and are generally resident in eertain localities. Their notes are uttered more or less throughout the year, but are more frequently heard during the nesting season. As a rule they call only during the first part of the night and again before sunrise, but on moonlight nights they call throughout the night, and ocrasionally they may be heard during the day. They readily respond to an imitation of their cries, and even at midday I have drawn them from their nesting-place to meet a supposed intruder on their domain. Inder favorable circumstances they may be heard at a distance of at least half a mile.

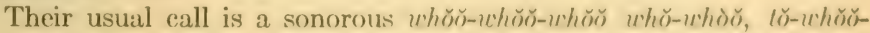
$\bar{a} h$. This is varied, both as to relative position and length of the syllables, by the same inclividuals, and is apparently the cry of gurestion and response. When two birds, perhaps rival males, enme togerther, there ensues a striking medley of whă-uhăs mingled with rolling whöo$\breve{a h s, ~ t h e ~ w h o l e ~ r e m i n d i n g ~ o n e ~ o f ~ d e e p-v o i c e d, ~ m i r t h l e s s ~ l a u g h t e r . ~ S o m e-~}$ times two birds give a concerted performance. One utters about ten 
rapid hoots, while the other, in a slightly higher tone, hoots half as fast, both performers ending together with a whōo-ăh. At times they utter a single, prolonged whōo-ăh, and more rarely a weird, gasping shriek, emphasized at its conclusion like a cry of distress.

"Of 109 stomachs examined, 5 contained poultry or game; 13, other birds; 46, mice; 18, other mammals; 4, frogs; 1, a lizard; 2, fish; 14, insects; 2 , spiders; 9 , crawfish; and 20 were empty" (Fisher).

368a. S. v. alleni Ridgw. Florida Barred Owl. Similar to the preceding, but averaging somewhat darker, and with the toes nearly naked. W., $12.50 ;$ T., $8 \cdot 50$.

Range.-Coast strip of S. Atlantic and Gulf States from e. Tex. to Fla. and S. C.

Nesting date, San Mateo, Fla., Jan. 5.

370. Scotiaptex nebulosa nebulosa (Forst.). Great Gray OWL. $A d s$.-No ear-tufts, size very large; upperparts fuscous, everywhere mottled with white, and with little or no buffy; facial disk gray, barred with black; underparts white, the breast broadly streaked, the belly and sides irregularly barred and streaked with fuscous; legs and feet heavily feathered; bill and eyes yellow. L., $27^{\circ} 00 ;$ W., $17 \cdot 50 ;$ T., $12 \cdot 00$.

Range.-Boreal N. A. Breeds in Hudsonian and upper Canadian zones from tree limit in cen. Alaska and nw. Mackenzie s. to cen. Alberta and cen. Keewatin; winters in the s. Canadian Provinces, straggling to n. Calif., Wyo., Nebr., Minn., Ind., Ohio, n. N. J., N. Y., and New England.

Cambridge, very rare and irregular W. V. SE. Minn., rare W. V.

Nest, in trees. Eggs, white, 2-4, 2.16 × 1.71. Date, Buffalo Lake, Alberta, Apl. 10 (Norris).

"Dr. Dall considers it a stupid bird, and states that sometimes it may be caught in the hands. Its great predilection for thick woods, in which it dwells doubtless to the very limit of trees, prevents it from being an inhabitant of the barren grounds or other open country in the north. . . . The note of this Owl is said to be a tremulous, vibrating sound, somewhat resembling that of the Screech Owl.

"Of 9 stomachs examined, 1 contained a small bird; 7 , mice; and 4, other mammals" (Fisher).

371. Cryptoglaux funerea richardsoni (Bonap.). RrCHARDson's OwL. Ads.-Upperparts grayish brown, both the head and back spotted with white; tail with four or five imperfect white bars; underparts white, heavily streaked with grayish brown; legs and feet heavily feathered, whitish, barred with grayish brown; eyes yellow. Im.-Upperparts dark cinnamon-brown, with a few more or less concealed white spots; tail as in the ad.; breast like the back; belly ochraccous-buff. L., $10 \cdot 00$; W., 6*75; T., 4*40.

Range.-N. N. Am. Breeds in Hudsonian and upper Canadian zones from limit of trees in cen. Alaska and $n$. cen Mackenzie s. to $n$. B. C., n. Alberta, and Magdalen Islands; s. in winter to s. Canada but rare eastward; casual s. to Ore., Colo., Nebr., Ills., Pa., and New England.

Cambridge, very rare $\mathrm{W} . \mathrm{V}$.

Nest, in holes in trees (and in old nests of other birds?). Eggs, white, 3-7, $135 \times 1$ 14. Date, Ft. Simpson, Mack., May 7.

"Richardson's Owl is nocturnal in its habits, remaining quiet during the day in the thick foliage of the trees or bushes. In fact, its vision is apparently so affected by bright light that many specimens 
have been captured alive by persons walking up and taking them in their hands. On this account the Eskimo in Alaska have given it the name of 'blind one.' "The song of this Owl, according to Dr. Merriam (Bull. Nutt. Orn. Club., VII, 1882, p. 237), is a low liquid note that resembles the sound produced by water slowly dropping from a height" (Fisher).

372. Cryptoglaux acadica acadica (Gmel.). SAw-TVHET OWL. Ads.Upperparts dark cinnamon-brown, the head finely streaked, the back spotted with white; tail with three or four imperfect white bars; underparts white, heavily streaked with cinnamon-brown or dark rufous; legs and feet feathered, buffy white, unbarred; eyes yellow. Im.- - Tpperparts as in the ad., but head and back with little or no white; breast like the back; belly ochraceous-buff. L., $8 \cdot 00 ; \pi$., $5.40 ;$ T., $2 \cdot 80 ;$ B., 60.

Remarks.-Its small size and absence of 'ears' at once distinguish this species from any $\mathrm{Owl}$ of eastern North America except $C . f$. richardsoni, from which it may be known by its lighter color, streaked instead of spotted head, and unbarred legs and feet.

Range.-N. A. Breeds from cen. and e. B. C., Alberta, Man., Que., N. B., and N.S. s. to cen. Ariz., s. Nebr., n. Ind., Pa., and MId. (in mts.); winters s. to s. Calif., La., Va. (casually to the Carolinas), and Maine; casual or accidental in Mex. and Guatemala.

Washington, rare $W$. V., Oct.-Mch. Ossining, rather rare W. V., Oct. 28-Jan. 13. Cambridge, not uncommon, IT. V., Nov-Mch. N. Ohio, rare $\mathrm{P}$. R. SE. Minn., uncommon, P. R.

Nest, in a hole in a tree; frequently a Woodpecker's, sometimes a Squirrel's deserted nest. Eggs, white, 3-5. 1.19 $\times 1.00$. Date, Trenton Falls, N. Y., Mch. 31; Farmington, Maine, May 21; se. Minn., May 9 (hatching).

"This species is not migratory, but is more or less of an irregular wanderer in its search for food during the fall and winter. It may be quite common in a locality and then not be seen again for sereral years. It is nocturnal, seldom moving about in the daytime, but passing the time in sleeping in some dark retreat. So soundly does it sleep that oftentimes it may be captured alive.

"During the day it frequents the thick evergreen woods, though sometimes it is found in comparatively open groves, but always in dense trees. . . The note of this species is peruliar and hats a rasping character, resembling the sound made when a large-toothed saw is being filed; henee the name. It is more of en heard during March and early April, though occasionally it is heard at other times of the year.

"The flight resembles that of the Worrleock very ("losely-so much so, in fact, that the writer once killed a speremen as it was flying over the alders, and not until the dog pointerl the dead hird was he aware of his mistake.

"Of 22 stomachs examined, 17 cont ained mice; 1 , a bird; 1 , an insect; and 3 were empty" (Fisher).

1911. Taverner, P. A., and Swales, B. H., Auk, XXTiII, 329-331 (migration).

373. Otus asio asio (Limn.). SсRғеси Owt. Size small; (mar-tufts mnspicuous, about an inch in length. Ads. rufous phase.- - Uperparts l, right 
rufous, finely streaked with black; underparts white, the feathers centrally streaked with black and irregularly barred with rufous; toes rather scantily feathered; eyes yellow. Gray phase.-Upperparts generally brownish gray, streaked with black and finely mottled with ochraceous-buff; underparts white, finely streaked and more finely and irregularly barred with black, more or less bordered by rufous. Nestling.-Entire plumage regularly harred with grayish or rufous and white. L., 9.40; W., 6.40; T., 3.09; B., ' 63.

Remarks. - This bird may be known by its small size and ear-tufts. Its color phases are not dependent upon age, sex, or season, and both phases are sometimes represented in the same brood. Between the two there is a complete intergradation. (See frontispiece.)

Range.-E. N. Am. from Minn., Ont., and N. B. s. to ne. Tex., and Ga., and w. to about the 100th meridian; accidental in England.

Washington, common P. R. Ossining, common P. R. Cambridge, common P. R. N. Ohio, common P. R. Glen Ellyn, common P. R. SE. Minn., common P. R.

Nest, generally in a hollow tree. Eggs, white, 4-6, 1.55 × 1.22. Date, Chevy Chase, Md., Apl. 6; Ossining, N. Y., Apl. 6; Cambridge, Apl. 15; Milton, Mass., Apl. 9; Poweshiek Co., Iowa, Apl. 9.

The Screech Owl frequently makes its home near our dwellings, and sometimes selects a convenient nook in them in which to lay its eggs. But its favorite retreat is an old apple orchard, where the hollow limbs offer it a secure refuge from the mobs of small birds which are ever ready to attack it. A search in the trees of an orchard of this kind rarely fails to result in the discovery of one or more of these feathered inhabitants who may have resided there for years. They attempt to escape capture by a show of resistance and a castanetlike cracking of the bill, but when brought from their hiding-place sit quietly, dazzled for a moment by the sudden light. They then elongate themselves and almost close their eyes, thus rendering themselves as inconspicuous as possible. How differently they appear when the western sky fades and their day begins! Is any bird more thoroughly awake than a hungry Screech Owl? With ear-tufts erected, and his great, round eyes opened to the utmost, he is the picture of alertness.

When night comes, one may hear the Screech Owl's tremulous, wailing whistle. It is a weird, melancholy call, welcomed only by those who love Nature's voice whatever be the medium through which she speaks.

"Of 255 stomachs examined, 1 contained poultry; 38, other birds; 11, mice; 11, other mammals; 2 , lizards; 4, batrachians; 1 , fish; 100 , inseets; 5 , spiders; 9 , crawfish; 7 , miscellaneous; 2 , scorpions; 2 , earthworms; and 43 were empty" (Fisher).

1893. HAsbrouck, E. M., Am. Nat., 521-533, 638-649; Allen, J. A., Auk, 3.4-351--1896. ('hadbuurne, A. P., Auk, XIII, 321-325; XIV, 3339). (dichromatism).-1911. Sherman, A., Auk, XXVIII, 155-168 (homelife).

373a. O. a. floridanus (Ridgu.), Florida Screech Owl. Much like the preceding, but smaller, with the colors deeper and markings of the underparts heavier. W., $5.95 ; \mathrm{T}, 2 \cdot 80$. The rufous phase is rare in this subspecies. 
Range.-Gulf and S. Atlantic States from se. Tex. to S. C., chiefly near the coast.

Nesting date, Archer, Fla., Mch. 31.

375. Bubo virginianus virginianus (Gmel.). GReAt Horned OwL. Ads.- Size large; car-tuits conspicuous, nearly two inches in length; upperparts mottled with varying shades of ochraceous-buff and black; facial disk ochraceous-buff; ear-tufts black and ochraceous-buff; a white patch on the throat, rest of the underparts ochraceous-buff, barred with black; legs and feet feathered; eyes ycllow. o L., $22^{\circ} 00$; W., $15^{\circ} 00$; T., 8*50; B., $1^{*} 60$.

Range.-E. N. Am. from Ont., Que., N. B., and N. F. s. to the Gulf coast and Fla.; w. to Wisc., e. Minn., Iowa, and e. Tex.

Washington, rare P. R. Ossining, tolerably common P. R. Cambridge, uncommon, autumn or winter. N. Ohio, rare P. R. SE. Minn., common P. R.

Nest, generally in an old Crow's, Hawk's or squirrel's nest. Eggs, white, 2-3, 2.20 × 1.80. Date, Merritt's Is., Fla., Dec. 17; Chester Co., Pa., Feb. 15; Cambridge, Feb. 22; Black Hawk Co., Iowa, Feb. 14; se. Minn., Feb. 21.

This "tiger among birds" is an inhabitant of heavily forested regions, and is common therefore only in the wilder, less settled portions of our country. It is the only one of our resident Owls which destroys poultry and birds in any numbers, but, in spite of its frequent visits to the farmyard, Dr. Fisher considers that in many localities it is a "beneficial species" because of its great fondness for rabbits.

Its usual call is a loud, deep-toned whōo, hoo-hoo-hoo, whōōo, whōōō. The syllables are all on the same note, and bear some resemblance to a bass-voiced dog barking in the distance.

A much rarer call is a loud, piercing scream, one of the most bloodcurdling sounds I have ever heard in the woods.

"Of 127 stomachs examined, 31 contained poultry or game birds; 8 , other birds; 13 , mice; 65 , other mammals; 1 , a scorpion; 1 , fish; 10, insects, and 17 were empty" (Fisher).

375b. B. v. subarcticus (Hoy). Arctic Horned Owl. Similar to the preceding, but much lighter in color, the ochraceous-buff markings largely replaced by gray or white.

Range.-Breeds from nw. Mackenzie and cen. Keewatin to valley of the Sask., and probably in the glacier regrion of MIt. St. Elias and Mt. Fairweather; s. in winter to $\mathrm{n}$. U. S. from Idaho to Wisc.

Cambridge, one record. SE. Minn., uncommon W. V.

375f. B. v. heterocnemis $(O h, r$. $)$. Lamirador Homnei) Owl. Similar to $B$. v. virginianus, but much darker, the prevailing color fuscous or dusky. Range.-Northern Ungava and Labrador.

376. Nyetea nyetea (Linn.). Sxowy OwL. Ad. C.-Mize large; no ear-tufts; white, more or less harred with dark grayish brown or fuscous; legs and feet heavily feathered; cyes yollow. A. - Similar, hut more heavily barred. L., $25 \cdot 00$; W., $17^{\circ} 00 ;$ T., $9 \cdot 50 ;$ B., 1.50 .

Range. - N. parts of N. Inemisphere. In N. A. breeds from Aretice regions s. to een. Markenzie, (ent. Kerwatin, and n. Cugraral; winters frem the Aretic coast s. to the s. C'madlian Provineres and .Mont., and irregularly to the Middle States and ()hio) Valley, stragrgling to ('alif., T'ex., Lat., N. (C, and Bermuda.

Washington, casual W. V. Ossining, A. V. Cambridge, rare and irregular W. V. N. Ohio, rare W. V. Gilen Ellyn, very rare W. V. SE. Minn., common W. V., Oct.-Apl. 
Nest, on the ground. Eggs, white, 3-10, 2.24 × 1.76. Date, Pt. Barrow, Alaska, June 7.

"The Snowy Owl is diurnal in its habits, but like most birds is more active in search of prey during the early morning and again toward dusk. Like many of the Hawks, it occupies a commanding perch for hours, watching what is going on about it, occasionally varying the monotony by dropping on a mouse or launching out over the broad country, soon to return to its perch. During its southern wanderings it is very partial to localities in the vicinity of water, especially the barren sand wastes along the seashore or extensive marshy flats bordering the bays and rivers.

"The flight is firm, smooth, and noiseless, and may be long protracted. It is capable of rapid flight, and, according to Audubon, is able to capture Ducks, Pigeons, and even Grouse on the wing, striking them down after the manner of the Duck Hawk.

"Of 38 stomachs examined, 2 contained game birds; 9, other birds; 18, mice; 2, other mammals; and 12 were empty" (Fisher).

1906. Deane, R., Auk, XXIII, 283-298 (flight of).

377a. Surnia ulula eaparoch (Müll.). HAwk OwL. Ads.-Size medium; no ear-tufts; upperparts dark grayish brown or fuscous; head and hindneck spotted with white; back, and especially tertials, barred with white; tail with broken whitish bars, long and rounded, the outer feathers more than an inch shorter than the middle ones; middle of the throat with a fuscous spot, and below it a white one; sides of the neck and upper breast streaked with fuscous, rest of the underparts barred with fuscous and white; legs and feet fully feathered. L., $15 \cdot 00 ; \mathrm{W}$., 8.75;T., $7 \cdot 25$.

Range.-N. N. Am. Breeds from nw. Alaska, nw. Mackenzie, and Hudson Strait to s. B. C., cen. Alberta (casually Mont.), and Ungava; winters s. to the s. Canadian Provinces, casually to Wash., Nebr., Ind., Ohio, N. Y., R. I., Mass., and Maine, occasional in England.

Cambridge, very rare in late fall. N. Ohio, rare W. V. SE. Minn., uncommon W.'V., Oct.-Mch.

Test, in coniferous trees or in the holes of dead trees or stubs. Eggs, white, 3-7, 1.50 × 1.23. Date, Red Deer, Alberta, Apl. 16 .

"The Hawk Owl is strictly diurnal, as much so as any of the Hawks, and like some of them often selects a tall stub or dead-topped tree in a comparatively open place for a perch, where it sits in the bright sunlight watching for its prey.

"Although the flight is swift and hawklike, it has nevertheless the soft, noiscless character common to the other Owls; when starting from any high place, such as the top of a tree, it usually pitches down nearly to the ground, and flies off rapidly above the tops of the bushes or high grass, abruptly arising again as it seeks another perch.

"The note is a shrill ery, which is uttered generally while the bird is on the wing" (Fisher).

378a. Speotyto cunicularia floridana Ridgu. FLORIDA BuRmowivi ()wL. Ad.- - vizo small; no ('ar-tufts; legs and feet nearly naked; upperparts grayish brown, spotted and barred with white; throat white, rest 
of the underparts barred with grayish brown and white in about equal amounts. L., 9.00; W., 6.50; T., 3.00; Tar., 1.75.

Range.-Southern Fla., chiefly in the Kissimmee 'prairie' region of Osceola, Polk, and DeSoto Counties, and also Manatee County.

Nest, in a hole in the ground excarated by the bird. Eggs, white, 5-7, $1.23 \times 11^{\circ} 03$. Date, Ft. Thompson, Fla., Mch. 26.

This diurnal Owl is locally abundant in its restricted range. Excellent accounts of its habits will be found under the following references: Rhoads, Auk, IX, 1892, 1-8; Scott, Ibid., 216-218; Palmer, Ibid, 1896, 100-108.

The Burrowrng Owl (378. Speotyto cunicularia hypogaa), is well known in the western Lnited States from the Pacific coast to Minnesota, and Louisiana, and from British Columbia, and Manitoba s. to Panama; it is migratory north of Oregon and northern Kansas; and accidental in New York and Massachusetts.

\section{ORDER PSITTACI. PARROTS, MACAWS, PAROQUETS, COCKATOOS}

\section{Fanily Psittacide. Parrots and Paroqtets. (Fig. 51.)}

The order Psittaci is divided into six families containing, in all, about five hundred and sixty species. The American species, some one hundred and ninety in number, are included in the present family which has also about two hundred and forty members in the Old World. With the exception of the Thick-billed Parrot (Rhynchopsilta pachyrhyncha), which rarely enters Arizona from Mexico, the Carolina Paroquet is the only species inhabiting the United States, and it is not found south of our boundaries. Parrots and Paroquets-the dividing line between the two can not be sharply drawn-are forest-inhabiting, fruit- and seed-eating birds. They are poor walkers, good climbers, and strong fliers, making extended flights in search of food. Their voices in Nature are harsh and diseordant; nevertheless, almost all the species possess the power of speech. Some, however, rarely learn to talk, while others invariably do. The red-tailed, graty Ifriean Parrot. (Psittacus erythacus) takes first rank for ability in this direction, while

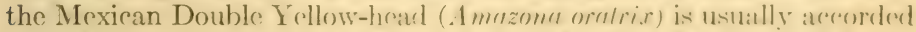
second place. Parrots are believerd to mate for life. They mest in holes, usually in trees, and lay white orges. The youmg are hatched with a covering of white down and are reared in the nest.

382. Conuropsis carolinensis (Timn.). CAROIN, P.IROQTET. (Fir.

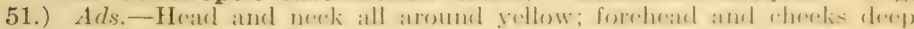
orange; bend of the wing and tilsier orange; rest of the phunatere hright meren; the inner vanes of the wing-feathers fuserons; the under surfare of the tail yellowish. Im.- Sinilar, but the head and nerek green like the barek; forehead and region in front of the eye orange: tilsiar and bend of the wing without orange. L., $12 \cdot 50 ; \mathbb{1} .7 \cdot 7 \cdot 10 ;$; ., $6 \cdot 50$.

Range.-S. Fla., ne. and e. of Lake (Okenchober; formorly from the Atlantic coast of se. L. S. w. to Tex., Oklat., and c. Colo. and n. to Nebr., 
Iowa, Wisc., and s. border of the Great Lakes, and casually to N. Y. and $\mathrm{Pa}$.

Washington, extinct, known only from specimens shot in Sept., 1865.

Nest, said to be in a hollow cypress or sycamore tree, but no authentic account of the nidification of this species has been published. Eggs (laid in captivity), white, $1 \cdot 44 \times 1 \cdot 12$. Date, probably lay in June.

The complete extermination of the Paroquet throughout the greater part of its range is due chiefly to four causes: first, it was destructive to fruit orchards, and for this reason was killed by agriculturists; second, it has been trapped and bagged in enormous numbers by professional bird-catchers; third, it has been killed in myriads for its plumage; and, fourth, it has been wantonly slaughtered by so-called sportsmen. In short, in the present century the Paroquet has always disappeared soon after its haunts were invaded by civilized man. At present it it apparently restricted to southern Florida, and there mainly if not wholly to the 'hammocks' northeast and east of Lake Okeechobee, where in April, 1904, near Taylor Creek, I saw thirteen birds.

1891. Hasbrodck, E. M., Auk, VIII, 369-379; Butler, A., Ibid., 1892, IX 49-56 (range).

\section{ORDER COCCYGES. CUCKOOS, KINGFISHERS, ETC.}

\section{Family Cuculida. Cuckoos, Anis, Etc. (Fig. 53.)}

Only thirty-five of the some one hundred and ninety known species of Cuckoos are found in the New World, and they are largely confined to the tropics.

Cuckoos, as a rule, are rather solitary birds, inhabiting wooded areas. The Anis, however, are always gregarious and live in open places. Their flight is weak, generally from tree to tree, and their feet are largely used as a means of progression. Some species hop, others walk, and one is celebrated for his speed as a runner. They are possessed of peculiar vocal powers, and their strange calls are frequently the origin of their popular names. Many species are remarkable for the irregularity of their breeding habits. The Old World Cuckoo (Cuculus canorus), like our Cowbird, places its eggs in the nests of other birds. and leaves to them the duties of incubation and rearing of the young. The Anis are communistic, and build but one nest, in which several females lay and share the task of incubation. The smaller species are insectivorous, but the larger ones add small reptiles and batrachians to their fare. The eggs of all North American species are white or bluish white, and are sometimes laid at such widely separated intervals that the same nest may contain fresh rogs and young birds. The young are hatched nakerl and the feathers of the juvenal plumage, which is the first to be acquired, remain in their sheaths until they are well-grown.

383. Crotophaga ani Linn. ANI. Ads. - Bill much compressed vertically, nearly as high as long. Black, feathers of foreparts of the body 
with irridescent margins; wings and tail with bluish reflections; tail much rounded. L., $12 \cdot 50$; T., $7 \cdot 75 ;$ W., $5 \cdot 75 ;$ B., $\cdot 95$; depth, 85 .

Range.-West Indies, Yucatan. and e. S. A. ; rare or casual in La. and S. Fla., accidental near Phila., and Edenton, N. C.

The Groove-Billed Ani (384. Crotophaga sulcirostris) of our Mexican border and southward, has been reported from Florida (Lake Worth, Jan. 1891), but it seems not improbable that the bird in question was Crotophaga ani. (Auk, 1891, 313.)

386 Coccyzus minor minor (Gmel.). Mangrove Cuckoo. Ads.Upperparts brownish gray, grayer on head, with glossy reflections; wings and middle pair of tail-feathers like back; outer tail-feathers black, broadly tipped with white; ear-coverts black; underparts ochraceous-buff, bill black, lower mandible yellow except at tip; L., $12 \cdot 50$; W., $5.40 ;$ T., 50 ; B. from N. $\cdot 80$.

Range.-Key West, Fla., West Indies (except Bahamas), and coast of Mex., and Cen. Am. to ne. S. A.

Nest, a platform of sticks, in low trees and bushes. Eggs, 3-4, greenish blue. Date, Manatee Co., Fla., May 28.

This bird is apparently a rare summer resident on the Gulf coast of Florida, but its relationships in this region to the following race appear to be unknown.

386a. C. m. maynardi Ridgw. MAYNARD's CUCKOo. Similar to the preceding, but with a slightly smaller bill and much paler underparts, the throat and breast being grayish white, very faintly washed with ochraceous, which becomes stronger on the belly. B. from N., 75 .

Range.-Florida Keys and the Bahamas.

This bird is a regular summer resident in the Florida Keys and probably adjoining Atlantic mainland (Scott, $A u k, 1889$, p. 250).

387. Coccyzus americanus americanus (Linn.). YELLOW-BILLED CucKoo. (Fig. 53.) Ads.- Cpperparts brownish gray with slight grenish gloss; most of the wing-f(rathers rufous, excerst at the tip); outer tail-feathers black, conspicuously tiuned with white, which extends down the outer vane of the outer feather; underparts dull whitish; bill black, the lower mandible yellow except at the tip. L., $12 \cdot 20$; W., 5*70; T., $6 \cdot 20 ;$ B. from N., 76 .

Remarks. - This species bears a general resemblance to the Blackbilled Cuckoo, but may always be known from that species by its yel-

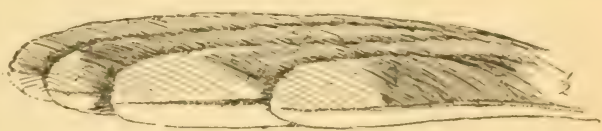

Fic. 91. T:til-feathers of Yellow-billed Cuckoo.

low lower mandible, rufous wing-feathers, and black, white-tipped tailfeathers.

Range.-Brecds mainly in Anstral zones but reaching into Transition, from N. D., Minn., s. Ont., Qur., and . V. B. s. to . Ir.x., I at., and n. Fla., and w. to S. I)., Nebr., and ()hlat; mierrates through the Wist Indies and Cen. Am.; winters s. to Argentina.

Washington, ormmon - R., MI:1 :3-Oct. 1:3. O-sining, (ommon S. R., May 4-Oct. 31. Cambrider, (rommon S. R., May 12 Sint. 15. N. Ohio, common S. R., Apl. 2()-Sept. 25. Glen Fllyn, quite common S. R., May 15Sept. 29. SE. Minn., (o)mmon \&. R., May '21-. Ing. 20).

Nest, a platform of small sticks, with a fow grassers or catkins, generally in low trees or vine-covered bushes, 4-10 fect uy. Eugs, 3-5, pale greenish 
blue, $1.22 \times \cdot 92$. Date, Gainesville, Fla., Apl. 9, laying; Buckingham Co., Va., May 13; Cambridge, May 25; Mt. Carmel, Ills., May 20.

A long, slim, dovelike bird slips noiselessly by and disappears in the depths of a neighboring tree. If you can mark his position you will find him perched motionless, and apparently slightly dazed. After a moment he recovers and begins to hop about the tree in an active search of his favorite fare of caterpillars. He is especially fond of the kind which make nests in trees, commonly known as "tent caterpillars," and if you examine the conspicuous homes of these pests you will frequently find them punctured with many holes made by the Cuckoo's bill. A Cuckoo I shot at six o'clock one September morning had the partially digested remains of forty-three of these caterpillars in his stomach.

The notes of the Cuckoo are strikingly characteristic, and while subject to much variation may be fairly represented by the syllables tut-tut, tut-tut, tut-tut, tut-tut, cl-uck-cl-uck-cl-uck, cl-uck-cl-uck, cl-uck, cow, cow, cow, cow, cow, cow. It is not usual, however, to hear the whole song given at once.

388. Coccyzus erythrophthalmus (Wils.). Black-BILled CUCKoo. Ads.-Upperparts grayish brown with a slight green gloss; wings and tail the same, the latter narrowly tipped with white; underparts dull white; bill black. L., $11 \cdot 83$; W., 5*50; T., $6 \cdot 26$; B. from N., 74 .

Remarks.-This species is to be distinguished from the Yellow-billed Cuckoo chiefly by the absence of rufous in the wings, black in the tail, and

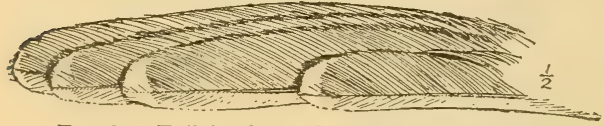

FIG. 92. Tail-feathers of Black-billed Cuckoo. yellow in the lower mandible.

Range.-N. and $\mathrm{S}$. A. Breeds mainly in the Transition zone from se. Alberta, s. Man., s. Que., and Prince Edward Is. s. to Kans., Ark., N. C., and mts. of Ga.; winters in S. A., to Peru.

Washington, rather rare S. R., May 5-Oct., 6. Ossining, common S. R., May 3-Oct. 7. Cambridge, common S. R., May 12-Sept. 20. N. Ohio, tolerably common S. R., May 1-Sept. 25. Glen Ellyn, S. R., May 5-Oct. 21. SE. Minn., common S. R., May 8-Sept. 27.

Nest, similar to that of the preceding, but more compactly built; location the same. Eggs, 2-5, greenish blue, of a deeper shade than those of the preceding species, $1.14 \times 85$. Date, Ossining, N. Y., May 28; Cambridge, May 20; Mt. Carmel, Ills., May 7; se. Minn., May 16.

This species resembles the preceding in habits. The two birds may be distinguished in life by the differences in the color of their bills and tails. William Brewster has called my attention to an easily recognizable difference in their calls. The present species has a much softer voice, and the cow, cow notes are connected.

\section{Family Alcedinid Ae. Kingfishers. (Fig. 50.)}

Kingfishers are most numerous in the Malay Archipelago, and the majority of the some one hundred and ninety known species are found 
there. There are only seven American species, all contained in the genus Ceryle, which has also five representatives in Africa and India. Our seven species are confined chiefly to the tropics, only one advancing north of southern Texas. They are solitary birds of somewhat local habit. All the American species are fish-eaters and are rarely found far from the water. Some of the Old-ITorld species, however, are forest-inhabiting and feed on small insects, mollusks, etc. Kingfishers nest in holes, usually made by themselves in a bank, and lay white eggs. The young are hatched naked, and the juvenal plumage is the first to be acquired.

390. Ceryle alcyon (Linn.). Belted Kingfisher. (Fig. 52.) Ad. $\sigma^{7}$.Upperparts bluish gray; wings with small white spots, most of the feathers tipped with white, the inner webs of the primaries white at the base; tailfeathers with numerous spots and broken bands of white; a white spot before the eye; throat white, this color passing on to the sides of the neck and nearly meeting on the back of the neck; a band across the breast, and the sides bluish gray-in immature specimens tinged with rufous -lower breast and belly white. Ad. o. - Similar to the male, but the sides and a band on the belly rufous. L., $13 \cdot 02 ;$ W., $6 \cdot 17 ;$ T., $3 \cdot 60 ;$ B., $2 \cdot 00$.

Range.-N. A. and n. S. A. Breeds from nw. Alaska, nw. Mackenzie, cen. Keewatin, n. Que., and N. F., s. to the s. border of L. S.; winters from B. C., Nebr., Ills., Ind., Ohio and Va. s. to the West Indies, Colombia, Guiana, and irregularly as far n. as Mass., N. H., and Ont.

Washington, common P. R., except in midwinter. Ossining, common S. R., Apl. 1-Nov. 23; casual in winter. Cambridge, common S. R., Apl. 10-Nov. 1; rare W. V. N. Ohio, common S. R., IIch. 20-Nor. 1; rare W. V. Glen Ellyn, isolated pairs, Apl. 1-Nov. 19. SE. Minn., common S. R., Mch. 21-Dec. 12.

Nest, in a hole in a bank, about six feet from the entrance. Eggs, 5-8, white, $1.34 \times 1.05$. Date, Shelter Is., N. Y., May 4; Cambridge, May 15; se. Minn., May 9.

The shores of wooded streams or ponds are the chosen haunts of the Kingfisher. Silently he perches on some limb overhanging the water, ever on the alert for food or foe. Paddle toward him as quietly as you please, just as you reach his danger line he drops from his perch and with loud, rattling call flies on ahead. This may be repeated several times, until finally the limits of his wanderings are reached, when he makes a wide detour and returns to the starting point.

The Kingfisher hunts after the manner of the Fish Hawk. In passing over the water it needs only the glint of a shining fin or scale: just beneath the surface to catch his watchful eye. On quickly moving wings he hovers over the place, waiting only a fair chance to plunge on the unsuspecting fish below. Emerging from the water with his prey in his bill, he shakes the spray from his plumitge, and, with an exultant rattle, flies away to some favorite perch.

1905. Herrick, F. H., Home-Life of Wild Birds, 136j-145.-1907. FinLEY, W. L., American Birds, 139-147. 


\section{ORDER PICI. WOODPECKERS, WRYNECKS, ETC.}

\section{Family Picider. Woodpeckers. (Fig. 54.)}

Woodpeckers occur in all wooded parts of the world, except in the Australian region and Madagascar. Some three hundred and seventyfive species are known, of which about one-half are confined to the New World. Twenty-four of this number are found in North America. Woodpeckers are rather solitary birds, but are sometimes found associated in scattered companies during their migrations. Above all other birds they are especially adapted to creep or climb. The peculiar structure of the foot, with its two toes directed forward and two backward (except, in North America, in one genus), assists them in clinging to an upright surface, while the pointed, stiffened tail-feathers serve as a prop. The stout, chisel-like bill of the more typical species is used to cut away wood and expose the hiding-places of grubs, etc.; then the long, distensible tongue, with its horny, spearlike tip, is thrust forward the food impaled and drawn out. The vocal powers of Woodpeckers are supplemented by the bill which is used to beat the long, rolling call forming their love-song. The eggs of Woodpeckers are uniformly white, and are placed in a hole, generally in a dead tree or limb, hollowed out by the bird.

1901. Eскstorm, F. H., The Woodpeckers (Houghton, Mifflin).

\section{KEY TO THE SPECIES}

I. No red on the head or nape.

1. Underparts not streaked or spotted.

A. Entire underparts black.

a. Wing about $10^{\circ} 00$, bill ivory-white.

392. IVORY-BILLED WOODPECKER ९.

$B$. Underparts white, without black spots or streaks.

$a$. Wing under 4.00; outer tail-feathers barred with black.

394. DOWNY WOODPECKER and races $q$.

$b$ Wing over $4 \cdot 00$, outer tail-feathers white, without black bars.

393. HAIRY WOODPECKER and races $\%$.

2. Underparts with black spots, bars, or streaks.

a. Back entirely black . 400. Arctic Three-toed Woodpecker.

b. Back black and white.

$b^{1}$. Outer tail-feathers entirely white, crown yellow or spotted with white.

401. AM. THREE-TOED WOODPECKER.

$b^{2}$. Outer tail-feathers barred with black, no black patch on the breast, ear-coverts white

395. RED-COCKADED WOODPECKER o.

$b^{3}$. Outer tail-feathers black, with generally a narrow white margin; rump white... 406. RED-HEADED WOODPECKER o.

$b^{4}$. Outer tail-feathers black and white, a large black patch on the brcast . . . 402. YelLOW-BELLIED SAPSUCKER o.

II. With red on the head or nape,

1. Whole top of head red.

A. Throat red.

a. Primaries spotted with white, belly yellowish

402. Y ELLOW-BELLIEd SAPSUCKeR $0^{7}$.

b. Primaries black, rump and belly white.

406. RED-HEADED WOODPECKER J". 
B. Throat white.
a. Breast and belly black .
405, 405a. Pileated Woodpecker ơ.
$b$. Breast black or blackish, sides streaked, belly yellowish white. 402. Yellow-Bellied Sapsucker o.
c. Underparts tinged with red, without streaks or spots.

409. RED-BELLIED WOODPECKER O $\sigma^{7}$.

2. Crown black, brown or gray, a red band across the nape, a red crest on the back of the head, or small patches of red on either side of the nape.

$A$. Underparts largely or wholly black, wing over $8 \cdot 00$.

a. Bill ivory-white . . 392. IVORY-BILLED WOODPECKER $\sigma^{\text {Th }}$ b. Bill blackish. . . 405, 405a. Pileated Woodpecker 9.

$B$. Underparts not largely black; wing under $8 \cdot 00$.

a. Underparts more or less spotted or streaked with black. $a^{1}$. A black patch on the breast, throat brown, rump white.

412, 412a. FLICKER.

$a^{2}$. Head black, ear-coverts white, a few red feathers on either side of the nape . 395. RED-COCKADED WOODPECKER o?.

b. Underparts white, or whitish, without black streaks or spots.

$b^{1}$. Crown gray, a reddish tinge on the belly.

$c^{1}$. Crown black.

409. RED-BELLIED WOODPECKER .

$c^{2}$. Outer tail-feathers barred with black.

394. DOWNY WOODPECKER and races or. $c^{3}$. Outer tail-feathers white. 393. HAIRY WOODPECKER and races $\sigma^{7}$.

392. Campephilus principalis (Linn.). IVORY-BILLED WOODPECKER. Ad. $0^{7}$.- Upperparts shining black, a large scarlet crest; a white stripe begins below the eye and, passing down the side of the neck, meets its fellow in the middle of the back; ends of the inner primaries and the end half or two-thirds of the secondaries white; outer tail-feathers very short, the central ones elongated and much stiffened; bristles over the nostrils white; bill ivory-white; underparts shining black. Ad. 9 . - Similar, but with the crest black. L., $20 \cdot 00$; W., $10^{\circ} 00$; T., 6.50 ; B., $2 \cdot 75$.

Range.-Formerly S. Atlantic and Gulf States from Tex., to N. C., n. in Miss. Valley to Okla., Mo., s. Ills., and s. Ind.; now restricted to the lower Miss. Valley and Gulf States, and of local distribution.

Nest, usually in a cypress over 40 feet up; entrance oval. Eggs, white, 3-5, "1.37 × '99" (Bendire). Date, Tarpon Springs, Fla., Mch. 17, onethird grown; Lafayette Co., Fla., Apl. 19.

The home of this magnificent Woodpecker is in the almost limitless cypress forests of our southern coasts and river valleys. Even there it is common in but few localities. In Florida it is found chiefly in the western part of the peninsula, and doubtless occurs in greatest numbers in the region between the Suwanee River and the Gulf.

The Ivory-bill is a wild, shy bird. It does not remain long in one place, and during the day ranges over an extended territory. Its call is a high, rather nasal, yap, yap-yap, sounding in the distance like the note of a penny trumpet.

1891. Hasbrodek, F. M., Auk, VIII, 174-186 (dist.).-1900. Beyer; G. G., Auk, XVII, 97-99 (nesting).

393. Dryobates villosus villosus (Linn.). HAIRY WOODPECKER. (Fig. 54a.) Ad. $0^{3}$-Upperparts black; scarlet band on the nape: miclde of the back white; wing-feathers and their "overts spotted with white; mirldle tail-feathers black, the outer ones white; a white stripe above and another below the eye; underparts white. Ad. २. - Similar, but without scarlet on the back of the neck. L., $9 \cdot 40$; W., $4 \cdot 78$; T., $3 * 30$; B., $1 * 22$. 
Range.-Transition and Upper Austral zones of ne. U. S., from Nebr., e. Colo., and Okla., e. to middle and n. parts of E. States.

Washington, rare $\mathrm{P}$. R. Ossining, rare $\mathrm{P}$. R. Cambridge, uncommon IV. V., one summer record. N. Ohio, common P. R. Glen Ellyn, fairly common P. R.

Nest, generally in a dead tree. Eggs, 4-6, white, $\cdot 95 \times \cdot 75$. Date, Nazareth, Pa., Apl. 25; Cambridge, Apl. 22; Wheatland, Ind., Apl. 30.

This species resembles the Downy Woodpecker in habits, but is less frequently observed out of the woods. Its notes are noticeably louder than the Downy's, and when one is familiar with both there is no difficulty in distinguishing the two by their voices.

In speaking of the difference which exists between the rolling tattoo of some Woodpeckers, Mr. Brewster says: "Thus, D. pubescens has a long, unbroken roll; $D$. villosus a shorter and louder one with a greater interval between each stroke; while $S$. varius, commencing with a short roll, ends very emphatically with five or six distinct disconnected taps. In this latter species I am convinced it is literally a call of recognition, as I have repeatedly seen the bird, after producing it, listen a moment when it would be answered from a distance, and its mate would shortly appear and join it" (Ann. Lyc. Nat. Hist., XI, 1875, p. 144).

393a. D. v. leucomelas (Bodd.). Northern HAIRY WoOdPECKer. Similar to $D$. v. villosus but larger and whiter. L., 10.00; W., 5.20.

Range.-Canadian zone from middle Yukon, cen. Mackenzie, cen. Keewatin, and n. Que., s. to about the n. boundary of the U. S.

393b. D. v. auduboni (Swains.). SOUthern HaIry WOOdPECKER. Similar to $D$. v. villosus, but smaller, and with somewhat less white in the plumage. L., $8 \cdot 10$; W., $4 \cdot 50$; T., $2 \cdot 80$; B., $1 \cdot 15$. Tex.

Range.-Austroriparian fauna from se. Mo., s. Ills., and s. Va. to se.

This is simply a small southern race of the preceding species. It resembles the northern forms in habits, but is much more common, being nearly as numerous as the Downy Woodpecker.

Nesting date, San Mateo, Fla., Apl. 24; Weaverville, N. C., May 3.

393g. D. v. terrænovæ Batch. NEWFOUNDLAND WOODPECKER. Similar to $D$. v. villosus, "but slightly larger, the black areas of the upperparts increased, the white areas reduced both in number and size, especially in the remiges and wing-coverts. W., $4 \cdot 90^{\circ}$ (Batchelder).

Range.-Newfoundland.

394. Dryobates pubescens pubescens (Linn.). SoUthern Downy Woodpecker. Similar to $D$. $p$. medianus but smaller, browner below and with the white markings more restricted. L., $6 \cdot 00 ;$ W., $3 \cdot 50$.

Range--Austroriparian fauna from N. C. to e. Tex.

Nesting date, St. Simons, Ga., Apl. 12.

394c. D. p. medianus (Swains.). Downy WoodPeCker. (Fig. 16a.). Ad. ${ }^{7}$.-Upperparts black, a scarlet band on the nape; middle of the back white; wing-feathers and their coverts spotted with white; middle tailfrathers black, the outer ones white, barred with black; a white stripe above and another below the eye; underparts white. Ad. 9 . - Similar, but without scarlet on the nape. L., 6.83 ; W., $3 \cdot 70$; T., 2.53 ; B., ' 68 . 
Remarks.-The Downy and Hairy Woodpeckers differ in coloration only in the markings of the outer tail-feathers, which are white, barred with black in the former, and white without bars in the latter; the difference in size between the two, however, is always diagnostic.

Range.-Canadian and Transition zones of n. and cen. parts of e. N. A. from se. Alberta, Man., and s. Ungava s. to e. Nebr., Kans., and Potomac Valley, and in mts. to N. C.

W ashington, common P. R. Ossining, common P. R. Cambridge, common P. R. N. Ohio, common P. R. Glen Ellyn, common P. R. SE. Minn., common P. R.

Nest, generally in a dead tree. Eggs, 4-6, white, $75 \times \cdot 60$. Date, Nazareth, Pa., May 9; Cambridge, May 22; Mt. Carmel, Ills., May 7.

Woodland, orchards, and the shade trees of lawns are alike frequented by this, the smallest and most familiar of our Woodpeckers. Sometimes he tells of his presence by an industrious tap, tap-tapping as he patiently digs out the grubs and larvæ which form his bill-offare. Again he hails us with a businesslike peek, peek-a note closely resembling the sound produced by a marble-quarrier's chisel, and which sometimes is prolonged into a rattling call. Like other Woodpeckers, in the spring he beats a rolling tattoo on a resonant limb, sounding a reveille which is a credit to so small a drummer.

The Downy is a sociable Woodpecker, and when the gay summer visitors have returned to their southern homes and the wind whistles drearily through the leafless trees, he joins the Chickadees and Nuthatches, and during the winter they are inseparable companions. Perhaps they share with him the snug quarters in some old trunk which he has hollowed out for a winter home.

395. Dryobates borealis (Vieill.). RED-COCKADED WOODPECKER. Ad. 8.-Crown black, a small tuft of scarlet feathers on each side of the back of the head; back barred with black and white; wings s\}rotted with black and white; middle tail-feathers black, outer ones with broken hlack hars; ear region white, separated from the white throat by a black stripe running from the bill to the shoulder; sides and under tail-erverts spetted and streaked with black; rest of the underparts white. Ad. Q.- - -imilar. but without scarlet on the head. L., 8*40; W., 4.65; T., $3 \cdot 10$; B., '80.

Range.-Austroriparian fauna n. to sw. Va., Tenn., and s. Mo., and casually to N. J.

Nest, usually well up in a living pine. Eg0s', 2-5, white, $91 \times \cdot 68$. Date, San Mateo, Fla., Apl. 29.

This species is a common inhabitant of the "piny woods." It prefers the higher branches of the trees, and frecuently hangs head downward while feeding at the extremity of a branch. Its call-note suggests the yank, yank, of the White-bellied Nuthatch, but is Iouder, hoarser, and not so distinctly enunciated.

400. Picoides areticus (Sweins.). ArCTLC THREE-TOED WOODPECKER. (Fig. 54b.) Ad. - Toes thres, two in front; micldle of the crown with a bright orange-yollow jateh; rest of the upjuerparts shining black; wing-feathers spotted with white; middle tail-feathers hlack, outer ones white, except at the base; a white line from the nostril passes below the eye; sides barred with black and white; rest of the underparts white. $A d$. 
9.- Similar, but without orange-yellow on the crown. L., 9.50; W., 5.10; T., $3 \bullet 40$; B. from N., 98 .

Range.-Canadian zone s. to the Sierra Nevada of Calif. and mts. of Nev., Idaho, Wyo., S. D. (Black Hills), Minn., Mich., n. N. Y., Vt., N. H., and Maine, casual in winter to Nebr., Ills., Ohio, Mass., and Conn.

Cambridge, one record. N. Ohio, rare W. V. SE. Minn., rare.

Nest, in a tree usually not over 15 feet up. Eggs, 4-6, white, 1.05 $\times \cdot 78$. Date, Seventh Lake, Fulton Chain, N. Y., May 27.

"It is a restless, active bird, spending its time generally on the topmost branches of the tallest trees, without, however, confining itself to pines. Although it can not be called shy, its habitual restlessness renders it difficult of approach. Its movements resemble those of the Red-cockaded Woodpecker, but it is still more petulant than that bird. . . . Its cries also somewhat resemble those of the species above mentioned, but are louder and more shrill, like those of some small quadruped suffering great pain.

"Its flight is rapid, gliding, and deeply undulating. . . . Now and then it will fly from a detached tree of a field to a considerable distance before it alights, emitting at every glide a loud, shrill note" (Audubon).

401. Picoides americanus americanus Brehm. Three-TOed WoodPECKER. Ad. $\sigma^{3}$. - Toes three, two in front; head spotted with white and with an orange-yellow patch on the crown; back barred with black and white; wing-feathers spotted with black and white; middle tail-feathers black; outer ones black and white; region below the eye mixed black and white; sides more or less barred with black and white; rest of the underparts white. Ad. o. - Similar, but crown spotted with black and white, and without yellow. L., $8 \cdot 75 ; W ., 4 \cdot 55 ;$ T., $3 \cdot 10 ;$ B. from N., 95 .

Range.-Boreal forests from cen. Ungava to n. Minn., s. Ont., n. N. Y., Maine, and N. H., casual in winter to Mass.

Nest, in a tree usually not over 12 feet up. Eggs, white, $\cdot 92 \times \cdot 70$ (Merriam, Bull. Nutt. Orn. Club., III, 1878, 200). Date, Herkimer Co., N. Y., June 4.

"It is said to greatly resemble $P$. $[=D$. $]$ villosus in habits, except that it seeks its food principally upon decaying trees of the pine tribe, in which it frequently makes holes large enough to bury itself. It is not migratory" (B., B., and R.).

402. Sphyrapicus varius varius (Linn.). Yellow-BELlied SAPsUCKER. $A d$. $\sigma^{7}$.-Crown deep scarlet, back irregularly barred with black and yellowish white; wing-feathers spotted with white, their coverts mostly white; tail black, the middle feathers with broken black bars, the outer ones with white margins; a white line from the bill passes below the eye; throat cardinal; hreast black; sides streaked with black; belly pale yellow. $A d$.. . Similar, but throat white; crown sometimes black; outer tail-feathers with broken white bars. Im. - Similar to ads., but with the crown dull blackish, the breast brownish gray barred with black, the throat whitish. L., 8*56; W., $4 \cdot 87 ;$ T., $3 \cdot 20 ;$ B., $\cdot 92$.

Range.-E. N. Am. Breeds in Canadian and upper parts of Alleghanian faunas. from sw. Mackenzic, cen. Keewatin, cen. Que., and Cape Breton Is. s. to cen. Alberta, n. Mo., n. Ind., n. Ohio, N. C. (mts.), and Mass.(mts. of n. Berkshire Co.); winters from Pa. and Ohio Valley (casually further n.) to the Gulf coast, Bahamas, Cuba, and Costa Rica; casual in Wyo.

Washington, common T. V., Mch.-May; Sept. and Oct., occasional 
in winter. Ossining, common T. V., Apl. 5-May 13; Sept. 18-Oct. 23; casual in winter. Cambridge, not uncommon T. V., Apl. and Sept. 15Nov. 1; occasional W. V. N. Ohio, common T. V., Apl. 1-May 20; Sept. 15-Oct. 20. Glen Ellyn, common T. V., Mch. 31-May 12; Sept. 14-Oct. 13. SE. Minn., common S. R., Mch. 25-Oct. 19.

Nest, about 40 feet up. Eggs, 5-7, $87 \times \cdot 67$. Date, Trenton Falls, N. Y., May 26; Goodrich, Mich., May 20; se. Minn., May 13.

As migrants, Sapsuckers are rather inconspicuous. They frequent living trees, where they are concealed by the foliage and their weak call-note is not likely to attract attention.

On reaching their summer homes in the spring their character changes, and Merriam speaks of them as "noisy, rollicking fellows; they are always chasing one another among the trees, screaming meanwhile at the tops of their voices" (Bull. Nutt. Orr. Club, IV, 1879, p. 2). Brewster describes the note of the adults at this season as "a clear, ringing cleur, repeated five or six times in succession;" while young and old utter "a low, snarling cry that bears no very distant resemblance to the mew of the Catbird" (Bull. Nutt. Orn. Club, 1876, p. 69).

The Sapsucker feeds largely on the juices of trees, which it obtains by perforating the bark. (Bolles, $A u k$, VIII, 1891, p. 256; IX, 1892, p. 110.)

405. Phlœotomus pileatus pileatus (Linn.). PILEATED WOod-

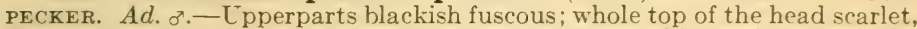
the feathers lengthened to form a crest; a narrow white stripe bordering this crest separates it from the fuscous ear-coverts; a stripe beginning at the nostril and passing down the sides of the neck to the shoulders is tinged with

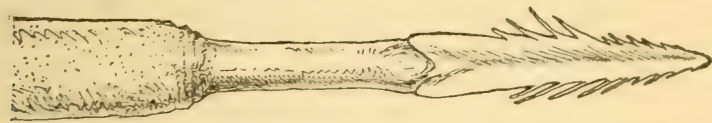

FIG. 93 Tip of tongue of Pileated Woodpecker, showing barbed, horny tip. (Much enlarged.)

yellow before the eye and is white back of the eye; it is separated from the white throat by a scarlet stripe at the hase of the lower mandib]e: hasal half of the wing-feathers white; underparts fuseous, the feathers sometimes lightly margined with white; bill horn-color. Ad. p, - Similar, but without red on the forepart of the crown or at the base of the lower mandible. I.., $17 \cdot 00$; W., 8.90; T., 6.20; B., 1.85.

Kange.-Austroriparian forests from N. C., s. and w. to middle Tex., and w. Okla.; casual in the Bahamas.

Nesting date, San Mateo, Fla., Apl. 14.

This species is common only in the wilder parts of its range. In the hummocks and cypress swamps of Florida it occurs in numbers. There, contrary to the experience of Audubon, I found it by no meins a wild bird. Indeed, Flickers were more difficult to approach. (O) the Suwance River, in March, and in Maine, in June, I have called these birds to me by simply clapping my slightly closed palms, making a sound in imitation of their tapping on a resonant limb.

The flight of this species is rather slow, but usually direct, not undulating, as in most Woodpeckers. When under way, the white 
markings of the wings show conspicuously. Their usual call-note is a sonorous cow-cow-cow, repeated rather slowly many times, suggesting a somewhat similar call of the Flicker's. Like the Flicker, they have also a wichew note uttered when two birds come together.

405a. P. p. abieticola (Bangs). Northern 'Pileated Woodpecker. Larger, bill longer, white markings more extensive. W., 9.10; T., 6.30; B., $2 \cdot 00$ (cf. Bangs, Auk, XV, 1898, 176).

Range.-Canadian and Transition zone forests of N. A. from ne. B. C., s. Mackenzie, s. Keewatin, cen. Que., and N. F. to the s. Sierra Nevada of Calif., n. N. M., and the s. Alleghanies.

Washington, rare P. R. N. Ohio, rare P. R. SE. Minn., rare P. R.

Nest, 12 to 80 feet up. Eggs, 3-5, white, $1.30 \times \cdot 94$. Date, Maine, May 11.

1901. Morrelt, C. H., Journ. Me. Orn. Soc., III, 32-35 (in Maine).

406. Melanerpes erythrocephalus (Linn.). RED-HEADED WOODPECKER. Ads.-Head, neck, throat, and upper breast deep red; upper back, primaries, bases of the secondaries, and wing-coverts bluish black; end half of the secondaries, rump, and upper tail-coverts white; tail black, the feathers more or less tipped or margined with white; lower breast and belly white, the middle of the latter generally tinged with reddish. Im.-Red head and neck of the adult replaced by mixed grayish brown and fuscous; upper back bluish black, barred with ashy; primaries and wing-coverts black; end half of the secondaries irregularly barred with black; tail black, generally tipped with white; lower breast and belly white, more or less streaked or spotted with fuscous. L., $9 \cdot 75 ;$ W., $5 \cdot 52 ;$ T., $3 \cdot 30 ;$ B., $1 \cdot 17$.

Range.-Transition and Austral zones from se. B. C., s. Alberta, Man., and Ont. s. to the Gulf coast, and from cen. Mont., cen. Colo., and cen. Tex., e. to valleys of the Hudson and Delaware; rare and local in New England; casual in Ariz., N. M., Utah, N. S., and N. B.; irregularly migratory in the $n$. parts of its range.

Washington, rather common S. R., rare W. V. Ossining, rare P. R., common in fall, Aug. 27-Oct. 12. Cambridge, irregular at all seasons; sometimes common in fall. N. Ohio, common S. R., Apl. 20-Sept. 25; occasionally winters. Glen Ellyn, common S. R., Feb. 19-Nov. 6; a few winter. SE. Minn., common S. R., Apl. 4-Sept. 17; rare in winter.

Nest, generally in a dead tree. Eggs, 4-6, white, $1 \cdot 00 \times 75$. Date, San Mateo, Fla., May 5; Chester Co., Pa., June 8; Jay Co., Ind., May 21, inc. adv.; se. Minn., May 22.

Give a bird an abundance of its favorite food, and its movements no longer seem to be governed by the calendar. Red-headed Woodpeckers were supposed to migrate southward in the fall and pass the winter south of Maryland, until Dr. Merriam, in his interesting account of the habits of this species (Bull. Nutt. Orn. Club, III, 1878, pp. 123-128), told us that in Lewis County, northern New York, their abundance in winter was in no way affected by the severity of the weather, but was entircly dependent upon the success of the erop of beechnuts which constitute their food.

Indeed, few birds seem better able to adapt themselves to their surroundings. They change their fare and habits with the season, and to the accomplishments of Woodpeckers add those of Flycatchers and fruit-eaters. We should expect, therefore, to find them very generally distributed, but in the northern States they show an evident 
choice for certain localities, and may be wanting over wide stretches of intervening territory.

They are noisy, active birds, and their loud, rolling, tree-toadlile call, ker-r-ruck, ker-r-ruck, and bright colors combine to render them conspicuous. When on the wing the white secondaries of both adult and immature birds make a striking field mark.

409. Centurus carolinus (Linn.). RED-BeLLied WoodPECKer. Ad. o.-Whole top of head and back of the neck bright scarlet; back regularly barred with black and white; primaries black at the end, white, irregularly barred with black, at the base; secondaries black, regularly spotted and barred with white; upper tail-coverts white, with streaks or arrowheads of black; outer tail-feathers and inner vanes of the middle ones irregularly marked with broken black and white bars; cheeks and underparts dull ashy white, the region about the base of the bill, the middle of the belly, and sometimes the breast, more or less tinged with red. Ad. o. - Similar, but with the crown grayish ashy, the scarlet confined to the nape and nostrils. Im.-Similar, but with the belly sometimes tinged with buffy instead of red. L., 9.50; W., 5.00; T., $3 \cdot 40 ;$ B., $1 \cdot 10$.

Range.-Lpper and Lower Austral zones of e. U. S. from se. S. D., se. Minn., sw. Ont., w. . . Y., sw. Pa., and Del., s. to cen. Tex., and the Gulf coast; casual n. to Colo., and Mass.

Washington, locally common P. R. Cambridge, A. V., one record. N. Ohio, tolerably common P. R. SE. Minn., uncommon P. R.

Vest, in dead or living trees, from 20 feet up. Eggs, 4-6, white, $1.05 \times$ 75. Date, Charleston, S. C., last of April; Black Hawk Co., Iowa, May 5; se. Minn., May 28.

This is a common bird in our Southern States. It inhabits alike coniferous and deciduous growths, but prefers the latter. It ascends a tree in a curious, jerky fashion, accompanying each upward move by . a hoarse chŭh-chŭh. It also utters a k-r-r-r-ring roll and, when matings a whicker call like that of the Flicker.

412. Colaptes auratus auratus (Limn.). Flicker. Smaller, darker, hlack dorsal bars wider than in the following form. W., 5.70; T., 3.60; B., 1:35 (cf. Bangs, Auk, XV. 1898, 177).

Range.-Austroriparian fauna from N. C., and s. Ills. to s. Fla., and cen. Tex.

Nesting date, San Mateo, Fla., Apl. 10.

412a. C. a. luteus Bangs. Jorthern Flicker. Ad. a.-Top of the head ashy gray, a bright scarlet band arosss the bark of the nerk; back, wing-coverts, and exposed part of secondaries brownish gray, harred with black; rump white; primaries black externally, the inner surfare of the wing and the shafts of the foathers yellow; upper tail-eoverts barred or streaked with blark and whitr; tail hlark alowe, yollow tipued with blark below, the outer edges of the feathers sliehtly margined or barred with white; sides of the hearl, throat, and upper loreast vinacerous; a lowad hlack stripe on each side of the throat from the hase of the lill, and a broarl blarek erescent across the breast: rest of the underparts white, more or less tinged with vinaceous, and thirkly suotted with hlark. Ad. . - Similar, hut without the black streaks on the side of the throat. L., 12.00): II., 6.0(); T., 4.00 ; B., $1 \cdot 40$.

Remarks.-Execptional spereimens have a iew red feathers in the throat stripes. A male from Louisiana has this mark entirrly red and the hearl grayisn brown, while another specimen from Toronto has half the tail orange-red. 
These unusual markings are supposed to be due to hybridization of our Flicker with the western or Red-shafted Flicker, which resembles the eastern species in pattern of coloration, but has the crown brownish gray or grayish brown, the throat stripes scarlet, the throat and breast gray, the under surface of wings and tail dull red, and lacks the red nuchal band. (See an important paper on the relationships of these birds by Dr. J. A. Allen, in the Bull. Am. Mus. Nat. Hist. IV., 1892, 21-44).

Range.-N. and e. N. Am. Breeds from tree limits in nw. Alaska, to s. Ungava, and N. F., east of the Rocky Mts., to n. edge of Austroriparian fauna; occasional on Pacific slope from Calif. northward; accidental in Greenland; migratory through most of Canada but more or less regularly resident within the U. S., except the extreme $n$. parts; $\mathbf{s}$. in winter to the Gulf coast and s. Tex.

Washington, common S. R., rare W. V. Ossining, common S. R., Mch. 25-Oct. 30; a few winter. Cambridge, very common S. R., common W. V. N. Ohio, common S. R. Mch. 10-Nov. 15; a few winter. Glen Ellyn, common S. R., Mch. 7-Dec. 24; a few winter. SE. Minn., common S. R., Mch. 21-Oct. 16.

Nest, in trees, at varying heights from the ground, frequently in orchards. Eggs, 5-9, 1*10 × 86. Date, Chester Co., Pa., May 13; D. C., May 4; Cambridge, May 10; se. Minn., Apl. 28.

The habits, notes, and colors of this well-known bird are reflected in the popular names which have been applied to it throughout its wide range. No less than 124 of these aliases have been recorded, and many have doubtless escaped the compiler.

The Flicker is a bird of character. Although a Woodpecker, he is too original to follow in the footsteps of others of his tribe. They do not frequent the ground, but that is no reason why he should not humor his own terrestrial propensities and a fondness for ants, and we may therefore frequently flush him from the earth, when, with a low chuckle, he goes bounding off through the air, his white rump showing conspicuously as he flies.

The Flicker, like other Woodpeckers, beats a rolling tattoo in the spring, but his vocal song proper is a rapidly-repeated, mellow cŭhcŭh-cŭh-cŭh-cŭh, etc., as springlike a sound as the peeping of frogs. His usual note is a vigorous, nasal kèe-yer. It recalls frosty fall mornings when the High-holes are gathering to feed on the woodbine and pepperidge berries. Approaching their feeding-grounds, one may hear the "Flicker" note. It can be closely imitated by the swishing of a willow wand: weèchew, weèchew, weèchew. I never remember hearing a bird utter this note when alone. It is accompanied by the oddest gestures, as with tails stiffly spread the birds bob and bow to each other.

1892. Allen, J. A., Bull. A. M. N. H., 21-44 (hybridism) -1900 . Burns, F. L., Wilson Bull., 1-82 (monograph).-1910. SHerman, A. R., Wilson Bull., 135-171 (home-life). 


\title{
XVI. ORDER MACROCHIRES. GOATSUCKERS, SWIFTS, HUMMINGBIRDS, ETC.
}

\begin{abstract}
44. Family Caprimulgide. Nighthawks, Whip-poor-wills, Etc. (Fig. 55.)
\end{abstract}

Goatsuckers are found in most parts of the world, but are more numerously represented in the tropics. Some one hundred species are known, of which about one-half are American, though only six reach North America. Most of the American species are forest-inhabiting, passing the day upon the leaves or perched lengthwise upon the branches of trees, where their dull, blended colors harmonize with their surroundings. The Nighthawks, however, are equally at home in treeless countries. Nighthawks feed high in the air, like Swifts, while other species frequent the borders of forests or clearings, where they feed nearer the ground. All the species capture their food of insects on the wing, their enormous mouths and the long, stiffened bristles, which in some species beset its base, especially adapting them to this mode of feeding. Many of the species are possessed of remarkable vocal powers, and their cries are among the most striking of bird-notes. They make no nest but lay their two mottled or marbled eggs on the ground. The young are hatched covered with down.

\section{KEY TO THE SPECIES}

A. A white spot in the wing.

420. Nighthawk. 420c. Florida Nighthawk. $B$. No white spot in the wing; primaries spotted with rufous.
a. Wing under $7: 50$
417. WHIP-POOR-WILL.

$b$. Wing over $7 \cdot 50$.

416. Antrostomus carolinensis (Gmel.). CHUCK-WILL's-WIDOW. $A d$. T.-Cpperparts streaked with black and finely mottled with ochraceousbuff and black; primaries black, with broken rufous bars; tail mottled with black and ochraceous-buff, the end half of all but the two middle: feathers white, more or less washed with buffy on the inner vane; underparts mottled with black, ochraceous, and cream-buff; an imperfect whitish band across the upper breast; base of the bill beset with long, stiffened bristles, the basal half of these bristles grown with hairlike branches. Ad. ९. - Similar, but with no white patches in the tail, the upper breast with an ochraceousbuff instead of white band. L., $12 \cdot 00 ; \mathrm{W} ., 8 \cdot 50 ;$ T., $6 \cdot(0) ; 3 ., 40$.

Range.-Breeds in Austroriparian fauna from Mo., Ind., s. Ohio, and s. Va. s. to cen. Tex., and Gulf States; casual in Kans. and Md., accidental in Mass. and Ont.; winters from s. Fla. to Greater Antilles and Colombia.

Washington, one record. Cambridge, A. V., one record, Dec.

Eggs, 2, laid on the ground or leaves, in woods or thickets, dull white, with delicate, obscure pale lilac markings, and a few distinct brownish gray spots, $1 \cdot 40 \times \cdot 98$. Date, San Mateo, Fla., Apl. 14 .

Generally speaking, this species resembles the Whip-poor-will in habits. Its notes are quite similar to those of that species, but are louder, less rapidly uttered, and each call has an additional syllable. Its gape is enormous, the wide-open mouth of an adult measuring 
about two inches from corner to corner. For this reason it can swallow large objects with ease, and both Hummingbirds and Sparrows have been found in the Chuck-will's-widow's stomach. Possibly they were mistaken for large moths, but Gerald Thayer records a Chuck-will's-widow which, following a steamer off the Carolina coast, was seen to pursue and catch Warblers on the wing. ( $A u k$. 1899, pp. 273-276.)

417. Antrostomus vociferus vociferus (Wils.). WHIP-POOR-WILL. Ad. $\sigma^{7}$.-Upperparts streaked with black, the head finely mottled with black and white, the back mottled with ochraceous-buff and black; primaries black, with broken rufous bars; tail irregularly barred with black and mot-

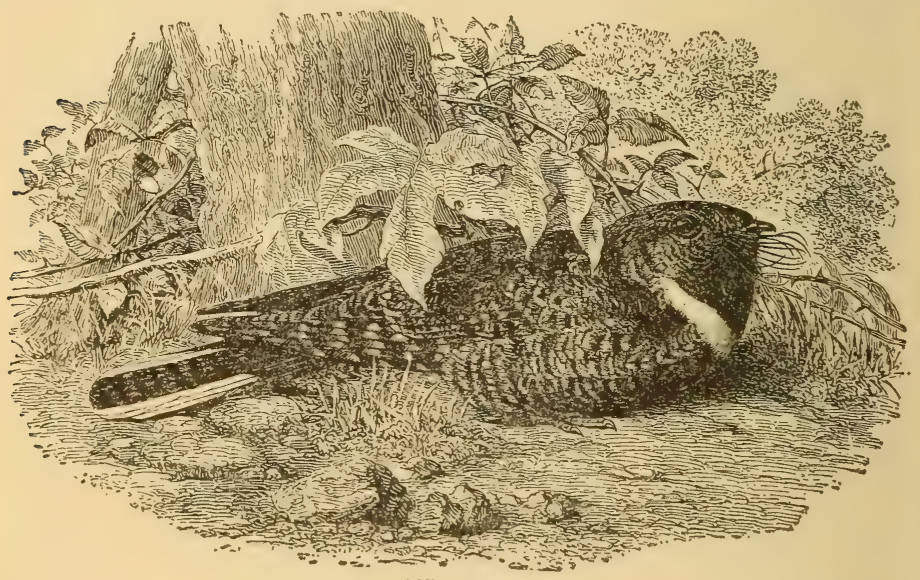

FIG. 94. Whip-poor-will.

tled with whitish or cream-buff; end half of three outer feathers white; black on the outer vane of the outer feather extending farther down than on the others; throat and breast blackish, finely mottled with cream-buff or ochraceous-buff; a narrow white band across the upper breast; belly cream-buff, irregularly barred with blackish; base of the bill beset with long, stiffened bristles, which are without hairlike branches. Ad. o. - Similar, but outer three tail-feathers narrowly tipped with ochraceous-buff; band on the throat cream-buff instead of white. L., 9.75; W., 6.08; T., $4 \cdot 65$; B., 37.

Range.-E. N. Am. Breeds from Man., s. Que., N. B., and N. S., s. to n. parts of La., Miss., and Ga., and from e. N. D., Nebr., and Kans. eastward; winters from the lowlands of S. C. and the s. parts of the Gulf States to British Honduras and Salvador.

Washington, common S. R., Apl. 13-Oct. 13. Ossining, common S. R., Apl. 19-Oct. 17. Cambridge, formerly S. R., now chiefly T. V., Apl. 30Srpt. 20. N. Ohio, lorally common S. R., Apl. 29-Sept. 15. Glen Ellyn, rare, spring records only, Apl. 19-May 21. SE. Minn., common S. R., Apl. 17-Sept. 28.

Eggs, 2, laid on the ground or leaves, in woods or thickets; dull white, with delicate, obscure lilac markings and a few distinct brownish gray spots, 
$1 \cdot 18 \times \cdot 84$. Date, Raleigh, N. C., May 2; Cambridge, May 26; Lake City, Minn., May 20; se. Minn., May 26.

In walking through rather densely grown woods I have sometimes been surprised by having a Whip-poor-will fly up from beneath my feet and disappear in the surrounding growth. I say surprised, because the bird's flight is as noiseless as a moth's, and this unusual ghostly silence is almost as startling as the whir of a Grouse.

The Whip-poor-will's day begins when the sun goes down. Then he passes out into bushy fields near his home, and, flying low, catches his supper on the wing. Between courses he rests on some low perch, and gives utterance to the notes familiar to many who have never seen their author. Whip'-poor-will', whip'-poor-will' he calls, rapidly and with unexpected snap and vigor. If one is quite near the singer, a preliminary chuck may be heard before each call. These notes are given for about two hours after sunset and for a short time before sunrise.

It is a singular fact that, in spite of the marked difference in their habits and notes, the Nighthawk and Whip-poor-will are frequently considered to be the same species. It is not the only case, however, where the notes of some species difficult of observation have been attributed to a species whose habits render it conspicuous.

420. Chordeiles virginianus virginianus (Gmel.). Nighthawk. (Fig. 55.) Ad. 3.-Upperparts black, irregularly marked with whitish, cream-buff, or ochraceous-buff; primaries fuscous, crossed in the middle by a conspicuous white har which rarely rearhes the outer vane of the first primary; tail fuscous or black, with broken bars of cream-buff and a white band near the end on all but the middle feathers; throat with a broad white band; chin and upper breast black, the feathers tipped with orhraceous-buff, cream-buff, or white; the rest of the underparts barred with black and white, sometimes tinged with buff. Ad. o. - Similar, but with no white on the tail, throat-patch ochraceous-buff, underparts more or less washed with ochraceous-buff. L., 10*00; W., 7·85; T., 4'60; B., "25.

Range.-N. and S. A. Breeds from s. Yukon, cen. Mackenzie, cen. Keewatin, n. Que., and N. F. s. to n. parts of Giulf States and w. to edge of Plains from Minn. to ne. Tex.; winters s. to Argentina.

Washington, not common S. R.; abundant T. V., Apl. 19-Oct. 8. Ossining, common S. R., May 9-Oct. 11. Cambridere, rare S. R., common T. V., May 15-Sept. 25. N. Ohio, locally eommon s. R., May 1-Sept. 20. Glen Ellyn, not common S. R., common T. V., May 1-Oct. 14. SE. Minn. common S. R., May 4-Sept. 30.

Eygs, 2, laid on the bare ground or a flat rock in open fields, rarely on the roof of a house, dull white, evenly marked with small, irregularly shaped blotches or fine specklings of grayish brown or hrownish gray, $1 \cdot 20 \times \cdot 86$. Date, Beaufort, S. (.., May 7; Chester ('o., Pa., May 2.1; New London, Ct., June 1; Cambridge, June 5; se. Minn., June 7.

In wooded regions the Nighthawk passes the day perched lengthwise on a limb, but on the plains he roosts upon the ground, where his colors harmonize with his surroundings. Soon after sunset he mounts high in the air to course for insects. Batlike he flies erratically about, and at more or less regular intervals utters a loud nasal peent, this call being followed by two or three unusually quick, flitting wing-beats. 
Iong after the light has faded from the western horizon we may hear this voice from the starlit heavens, for the Nighthawk is one of our few truly nocturnal birds. Occasionally the peents are given more rapidly, and after calling several times in close succession the bird on half-closed wings dives earthward with such speed that one fears for his safety; but just before the ground is reached he checks his rapid descent by an abrupt turn, and on leisurely wing again mounts upward to repeat this game of sky-coasting. At the moment the turn is made one may hear a rushing, booming sound, which, as writers have remarked, can be imitated in tone by blowing across the bung-hole of an empty barrel. It is made by the passage of the air through the bird's primaries.

In late summer Nighthawks gather in large flocks and begin their southward migrations. When flying the white mark on their primaries is a conspicuous character, and has the appearance of being a hole in the bird's wing.

1905. Herrick, F. H., Home-Life of Wild Birds, 129-135.

420b. C. v. chapmani Coues. Florida Nightha wr. Similar to the preceding, but smaller, and with the white and cream-buff markings of the upperparts more numerous. L., 8*60; W., 7•10; T., 4*10.

Range.-Breeds in the Gulf coast belt from eastern Tex. to Fla.; winter range unknown.

Nesting date, Volusia Co., Fla., May 8.

420c. C. v. sennetti Coues. Sennett's Nighthawk. Palest of our Nighthawks; whitish prevailing in wing coverts and scapulars; less rufous than in $C$. v. henryi; less heavily barred below than $C$. v. virginianus. W., $7 \cdot 10$.

Range.-Breeds on treeless plains from Sask. and Man. s. to cen. Nebr.; occasional in Iowa, Wisc., and Ills.; winter range unknown, probably in S. A.

\section{Family Micropodide. Swifts. (Fig. 56.)}

The ninety-odd known species of Swifts are distributed throughout the greater part of the world but are most abundant in the tropics. About one-third this number are American but only four advance north of Mexico. Some Swifts nest in colonies and most species are associated in companies, at other times of the year. Hollow trees and caves are the natural nesting- and roosting-places of many species, while others fasten their nests to the under surface of palm leaves, and the East Indian Tree Swifts attach their nest to a limb. Most Swifts appear to employ the glutinous secretion of the salivary glands in nest-construction and the edible nests of the Swifts of the genus Collocalia are composed entirely of this substance.

Swifts lay white eggs and the young are naked when hatched. They feed entirely while flying, and with their unusually long wings and small, compactly feathered bodies possess unrivaled powers of flight. Swifts are popularly confused with Swallows, but the resemblance is only superficial and exists chicfly in the similarity of flight and feeding 
habits, while the structura! differences between the two are numerous and important.

423. Chætura pelagica (Linn.). Chimnex Swift; Chimney "SwalLow." (Fig. 56.) Ads.-Entire plumage fuscous, more grayish on the throat; a sooty black spot before the eye; shafts of the tail-feathers extending beyond the vanes. L., $5 \cdot 43$; W., $4 \cdot 94 ;$ T., $1 \cdot 90 ;$ B. from N., 15.

Range.-Breeds in e. N. A. from se. Sask., Man., cen. Que., and N. F. s. to the Gulf coast, and w. to the Plains from e. Mont., to e. Tex.; winters s. of the U. S., at least to Vera Cruz and Cozumel Is. and probably in Cen. Am.; casual in s. Alberta; accidental in N. M., and Greenland.

Washington, abundant S. R., Apl. 6-Oct. 27. Ossining, common S. R., Apl. 19-Oct. 23. Cambridge, abundant S. R., Apl. 25-Sept. 20. N. Ohio, abundant S. R., Apl. 10-Oct. 20. Glen Ellyn, common S. R., Apl. 16-Sept. 29. SE. Minn., common S. R., Apl. 20-Sept. 18.

Nest, a bracketlike basket of dead twigs glued together with saliva; attached to the wall of a chimney, generally about ten feet from the top, by the gummy secretion of the bird's salivary glands. Eggs, 4-6, white, $80 \times \cdot 50$. Date, Chester Co., Pa., June 3; Ossining, N. Y., June 8; Cambridge, June 10; Petersburg, Mich., June 7.

It is unnecessary to give any aids to the identification of a bird as well known as the Chimney Swift, or, as it is more frequently called, "Chimney Swallow." It is not, however, a Swallow, but a Swift, and its structural relations are with the Hummingbirds and not with the Passerine Swallows.

Few sights in the bird-world are more familiar than the bow-andarrow-like forms of these rapidly flying birds silhouetted against the sky. They are most active early in the morning and late in the afternoon, when one may hear their rolling twitter as they course about overhead. Sometimes they sail with wings held aloft over their backs, and sometimes, it is said, they use their wings alternately. It is a common thing to see a trio of birds flying together, but it has never been ascertained that the Chimney Swift is polygamous.

In some localities Chimney Swifts congregate in large flocks, making their headquarters in a disused chimney which morning and evening they leave and return to in a body. In perching they cling to the side of the chimney, using the spine-pointed tail, as Woodpeckers do, for a support. The habit of frequenting chimneys is, of course, a recent one, and the substitution of this modern, artificial home for hollow trees, illustrates the readiness with which a bird may take advantage of a favoring change in its environment.

\section{Family Trochilide. Hummingbirds. (Fig. 57.)}

Hummingbirds are found only in the New World. About five hundred species are known. They range from Alaska to Patagonia, but are most numerous in the Andean regions of Colombia and Ecuador. Wighteen species have been found in the Uniter States; only eight of these advance beyond our Mexican border States, and but one species occurs east of the Mississippi. 
Several species inhabit the depths of dark tropical forests, but, as a rule, they are found with the flowers which bloom in the clearings, or far overhead in the sunlight. They are not gregarious, but an abundance of food sometimes brings large numbers of them together, when the air becomes animated with their rapidly moving forms. The smaller species fly so swiftly that their wings are lost in hazy circles, and it is difficult for the human eye to follow their course. The flight of the larger species is less insectlike, and each wing-beat can be detected. As a rule their voice is a weak squeak or excited chippering, but some of the tropical species have songs of decided character which they sing with much energy.

Hummingbirds feed largely on insects, which they generally capture in flowers, but many species catch insects on the wing or pick them from beneath leaves. They also feed on the juices of flowers. The nest is usually composed of plant down, bound about with spiders' webs and covered with lichens skilfully attached to a limb or leaf, and is as exquisitely dainty in appearance as its maker. All the species whose nesting habits are known lay two white eggs. The period of incubation with our Ruby-throat is fourteen days. The young are naked when hatched, but a mere breath of down precedes the growth of the juvenal plumage.

Strangely enough, these beautiful little creatures are possessed of a most unfortunate disposition, which frequently leads them to attack any bird they fancy is trespassing on their domain. They know no

- fear, and with equal courage rush at one of their kind or a passing Hawk.

1892. Ridgway, R., Rep. U. S. N. M., for 1890, 253-383. (Monographic.)

428. Archilochus colubris (Linn.). RUBy-throated HummingBird. (Fig. 57.) $A d$. $\sigma^{7}$.-Upperparts bright, shining green; wings and tail fuscous, with purplish reflections; throat beautiful metallic ruby-red, bordered on the breast by whitish; rest of the underparts dusky, washed with greenish on the sides; tail forked. Ad. o.-No ruby throat-patch; bronzy green above, whitish below; tail nearly even, outer three feathers tipped with white. Im. $\sigma^{3}$---Similar to $\%$, but throat with dusky streaks, and, in older birds, with ruby colored feathers. L., $3 \cdot 74 ;$ W., $1 \cdot 54 ;$ T., $1 \cdot 15 ;$ B., $\cdot 67$.

Range.-E. N. Am. Breeds from se. Sask., cen. Que., and Cape Breton Is. s. to Gulf coast and Fla., w. to N. D., Nebr., Kans., and cen. Tex.; winters from middle and s. Fla., and La. through s. Mex. and Cen. Am. to Panama; casual in Cuba in migration.

Washington, common S. R., Apl. 23-Oct. 18. Ossining, common S. R., Apl. 30-Oct. 3. Cambridge, very common T. V., uncommon S. R., May 10Sept. 20. N. Ohio, common S. R., May 1-Sept. 15. Glen Ellyn, rare S. R., May 1-Sept. 22. SE. Minn, common S. R., May 19-Oct. 8.

Nest, of plant down, covered externally with lichens and firmly wound with almost invisible plant fibers; generally $15-25$ feet up, saddled on a limb. Eggs, 2, white, $50 \times 35$. Date, Lafayette Co., Miss., May 6; Iredell Co., N. C., May 11; Ossining, N. Y., May 20; Cambridge, May 24.

The Ruby-throat needs no song. Its beauty gives it distinction, and its wings make music. Its only note, so far as I know, is a squeak, expressive of distrust or excitement. It has no rival in eastern North 
America, and is to be confounded with nothing but sphinx (hummingbird) moths. One hears of "Hummingbirds" seen in the evening about flower-beds. The mistake is not unnatural, and a correction is sometimes received with incredulity. The birds spend but a comparatively small part of the time upon the wing. Whoever watches a female busy about her nest will see her constantly perching here and there in certain branches of the tree, preening her plumage and looking about her. The male, at the same season, forgetful, to all appearance, of his conjugal and parental duties, may be found at home day after day on a dead twig in some tall tree, where he sits so constantly as to make the observer wonder what he can be about, and when, if ever, he takes his food. Further investigation, however, will show that he makes frequent and regular rounds of favorite feeding-places. A tall blueberry bush, for example, will be visited at short intervals as long as the observer has patience to stand beside it. The Hummingbird is curiously fearless. Sometimes one will probe a flower held in the hand, and when they fly into houses, as they pretty often do, they manifest but the smallest degree of suspicion, and will feed almost at once upon sugar held between the lips. The old bird feeds the young by regurgitationa frightful-looking act-the food consisting largely of minute insects. The young remain in the nest for some three weeks, and on leaving it are at once at home on the wing. BRadford Torrey.

\section{ORDER PASSERES. PERCHING BIRDS. (Fig. 58.)}

"Doubtless every order of birds has had its day when, if it were not a dominant type, it was at least sufficiently near it to be considered modern; and as we review what is known to us of that great series of feathered forms, from the Archæopteryx to the Thrushes, we can realize how varied has been the characteristic avifauna of each succeeding epoch from the Jurassic period to the present.

"Now has come the day of the order Passseres, the Perching Birds; here belong nur Flycatchers, Orioles, Jays, Sparrows, and Finches, Vireos, Swallows, Wrens, Thrushes, and many others. A reeent authority classifies birds in thirty-four orders, but fully one-half of the 13,000 known species are included in the single order Passeres" ("Bird-Life").

All our Passerine birds are born in an almost nakerl condition, having only a mere trace of down on the feather-tracts of the upperpiarts of the body. At its full development this natal down presents at soft, fluffy appearance over the cowering nestlings. It is pushed outward by the feathers of the juvenal plumage, to the tips of which portions of it may be seen adhoring when the young bird leaves the nest. With some passerine birds (e. g., Song Sparrow) this is at the end of only seven days (Owen, $A u k, 1899$, p. 222). Compare this surprisingly rapid development with that of a Noddy Tern, for instance, which does not 
venture to leave its home until it is two months old, and is dependent on its parents for a month more (Thompson, Bird-Lore, 1903, p. 81).

In most cases the nestling or juvenal plumage is soon followed by the first winter plumage, but some few birds $(e . g$. Seaside and Sharptailed Sparrows) wear it for two months or more. As a rule, at the postjuvenal molt, the feathers of the body and small wing-feathers are molted, while the primaries and secondaries with their coverts and the tail are retained, and it is often only by the color and appearance of these feathers that the bird of the year can be distinguished from the adult in winter, and during the former's first breeding season.

The spring molt is rarely complete; more frequently it is restricted to the body feathers, more frequently still it affects only the region about the head and throat, while some species undergo no feather renewal at that season. The post-breeding molt of the bird a year old, as well as of those older, is complete.

1900. Dwight, J., JR., Sequence of Plumages and Moults of the Passerine Birds of New York, Ann. N. Y. Acad. Sci., XIII, 173-360.

\section{Family Trrannides. Flycatchers. (Fig. 59.)}

From the systematist's standpoint, Flycatchers are songless perching birds. It does not follow that they are voiceless, or even truly songless, but that, having the voice-organ, or syrinx, less highly developed than other Passeres, they are possessed of comparatively limited vocal powers. This family is peculiar to America. The Old-World Flycatchers belong to the family Muscicapidce and are true Oscines. Of the Tyrannidoe some four hundred species are known. They are most abundant in the tropics, where their services as insect-catchers are in greatest demand. Thirty species reach the United States.

Flycatchers are found wherever there are trees. As a rule they are of sedentary and solitary disposition. Their manner of feeding is characteristic. From a favorable perch, hawklike, they await passing insects, and with an aim that rarely misses, launch forth into the air; there is a sharp, suggestive click of the broad bill, and completing their aërial circle, they return to their perch and are again en garde.

Both the nature of their food and tropical origin induce in Flycatchers highly migratory habits, the Phobe being the only eastern species to winter in the United States north of southern Florida.

I. Wing over $3 \cdot 00$.

\section{KEY TO THE SPECIES}

1. Outer tail-feather white or whitish on outer web or both webs.

A. Tail, 9.00, deeply forked, sides of breast scarlet, flanks salrnon.

443. SCISSOR-TAILEd FiYcatcher.

$B$. Tail black, not forked, outer web of outer feather, white, belly yellow, back gray

447. Arkansas Kingbird.

2. Outer tail-feather not white on outer web.

A. Tail black or blackish, sometimes tipped with white, adults with a concealed orange-red crown patch. 
a. Under wing-coverts yellowish, no white tip on the tail. 445. Gray KingBird.

b. Under wing-coverts blackish, tail tipped with white 444. KINGBIRD. $B$. Tail not tipped with white, no crown patch.

$a$. Inner vane of tail-feathers pale rufous; throat and breast grayish; belly sulphur-yellow . . . . 452. Crested Flycatcher.

b. Tail fuscous.

$b^{1}$. Entire bill black; wing rarely' more than ' 50 longer than tail; tarsus decidedly longer than bill; under tail-coverts alway's pale, yellowish white

$c^{1}$. Under mandible generally in whole or part pale brownish. wing always more than 50 longer than tail; tarsus about equal to bill; some of under tail-corerts frequently with darker centers. $c^{2}$. Wing over 3.50 ; sides and breast, except a narrow whitish line through its center, of the same color as the back.

459. Olive-sided Flycatcher.

$c^{3}$. Wing under $3 \cdot 50$; breast and sides washed with olive-gray.

II. Wing under $3^{\circ} 00$.

461. WOOD PEWEE.

$A$. Upperparts between olive-brown and dark olive-green, but with an evident brownish tinge, or lower mandible brownish.

a. Wing over 2.60 ; lower mandible flesh-color or whitish; underparts with only a very slight tinge of yellow.

466. Traill's Flycatcher. 466a. Alder Flycatcher.

b. Wing under $2 \cdot 60$; lower mandible rarely clear flesh-color, generally strongly tinged with brownish .. 467. LEAST FLYCATCHER.

$B$. Upperparts olive-green without a brownish tinge; lower mandible straw-color.

a. First primary about equal to fifth; underparts white, slightly washed with yellowish on the breast and belly; throat white.

465. Acadian Flycatcher.

b. First primary shorter than fifth; underparts sulphur-yellow; the throat and breast more or less washed with olive-green.

463. Yellow-Bellied Flycatcher.

444. Tyrannus tyrannus (Linn.). KINGBIRD. Ads.- Upperparts grayish slate-color, darker on the head and upper tail-coverts; head with a concealed orange-red crest; tail black, tipped with white; underparts white, washed with gravish on the breast. Im.- Similar, but without the crown patch, and with the plumage more or less tinged with ochraceous-buff. The male has two outer primaries deeply emarginate at the tip, the fomale usually only one, the immature bird, none. L., 8.51 ; W., 4.64 ; T., 3.55 ; B. from N., $\cdot 55$.

Range.-N. and S. A. Breeds from s. B. C., s. Markenzic, s. Keewatin, n. Ont., cen. Que., and N. F. s. to cen. Ore., n. N. M., cen. Tex., and 'en, Fla.; winters from s. Mexico to Bolivia; casual in Cuba in migration; accidental in Greenland.

Washington, common S. R., Apl. 18-Sept. 23. Ossining, common S. R., Apl. 29-Sept. 10. Cambridge, common S. R.. May 5-Sept. 1. N. Ohio, common S. R. Apl. 20-sept. 15. Glen Ellyn, fairly commons. R., Apl. 16Sept. 6. SE. Minn., common S. R., Apl. 26-Aug. 31.

Nest, compart and symmetrical, of weed-stalks, grasses, and moss, lined with plant-down, fine grasses, and rontlets, generally at the extremity of a branch 15-25 feet up. Eggs, 3-5, white, spotted with umber, $1 \cdot 00 \times \cdot 73$. Date, White Sulphur Springs, Va., May 17; (ambridge, May 30; St. Louis, Mo., May 14, inc. adv.; se. Minn., May 14.

The Kingbird is most frequently seen on a fence or dead twig on a tree, where leaves do not come in the way of his sight. He stands very upright, like a Hawk or an Owl, and, though as quiet as if he 
had nothing to do, he is keenly awake to every movement about him, and every few minutes he dashes into the air, seizes a passing insect, and returns to the spot from which he started. While his mate is sitting, he usually establishes himself near the nesting tree, and spends hour after hour in this apparently monotonous way, varying it only to relieve her by watching the nest, and thus give her an opportunity to seek food for herself. I never saw a Kingbird either assist in brooding or carry food to his mate, but his manners to her are most affectionate, and he is untiring in his labors in the feeding of the young.

This bird is accused of being quarrelsome and aggressive to other birds, and his scientific name means Tyrant Flycatcher, but in my study of his ways I have found him less aggressive than are most birds in the neighborhood of their nest. With the exception of the Crow, against whom he seems to have a special grudge, I have never seen a Kingbird take notice of any bird unless he alighted near his nest, and the meekest creature that wears feathers will try to drive away strangers who approach that sacred spot.

The calls and cries of the Kingbird are generally loud and attractive, if not particularly musical, but while his mate is sitting-and possibly at other times-he indulges in a soft and very pleasing song, which I have heard only in the very early morning.

\section{Olive Thorne Miller.}

1905. Herrick, F. H., Home-Life of Wild Birds, 49-55.

445. Tyrannus dominicensis dominicensis (Gmel.). GRAT KInGBIRD. Ads.-Above ashy gray; an orange-red crown patch; wings and tail fuscous; under wing-coverts pale sulphur-yellow; underparts white, tinged with grayish on the breast. L., $9 \cdot 00$; W., $4^{\cdot} 60$; T., $3.50 ;$ B. from N., ${ }^{\circ} 80$.

Range.-Breeds from Ga., se. S. C., Fla., and Yucatan through the Bahamas and West Indies to n. S. A.; winters from Jamaica and Haiti southward; accidental in Mass.

Nest, of grass and weeds, lined with fine grass and rootlets, in trees. Eggs, 4, deep salmon, irregularly spotted and blotched with umber and lilac, 1.00 × 75 (Maynard). Date, Little Sarasota, Fla., May 15.

The Gray Kingbird is a common summer resident of parts of our South Atlantic States, arriving early in May. It resembles the Kingbird in appearance, but lacks the white band at the end of the tail, and has quite different notes. Its usual call is a vigorous pitìri, pitirri, which, in Cuba, gives it its common name.

The Arkansas Kingbird (44\%. Tyrannus verticalis), a western species, breeds mainly in Sonoran zones, from s. B. C., s. Alberta, and s. Sask., s. to n. Lower Calif, and Chihuahua, e. to w. Minn., w. Iowa, cen. Kans., and w. Tex.; winters from w. Tex. to Guatemala; casual in Man.; accidental in Mo., Wisc., Maine, N. Y., N. J., and Md.

Washington, one record, Sept. 30.

The Fork-tailed Flycatcher (442. Muscivora tyrannus), a South American species rarely found north of southern Mexico and the southern Lesser $\Lambda$ ntilles, has been recorded from Mississippi, Kentucky, New Jersey, Maine and Bermuda. 
The Scissor-tailed Flycatcher (443. Muscivora forficata) is found in the summer as far north as southern Kansas and western Louisiana. It has occurred accidentally near Hudson Bay, in Manitoba, Ontario, New Brunswick, Connecticut, New Jersey, Virginia, and Florida. It may be known by its long, deeply forked tail and scarlet sides.

452. Myiarchus crinitus (Linn.). Crested Flycatcher. Ads.Upperparts grayish brown, washed with olive-green; outer vane of primaries margined with pale rufous; inner vane of all but the middle tail-feathers pale rufous; throat and breast pearlgray; belly sulphur-yellow. L., $9 \cdot 01$; W., $4 \cdot 14$; T., $3 \cdot 75$; B. from N. 62 .

Range.-E. N. and n. S. Am. Breeds from upper edge of Transition zone in s. Man., cen. Ont., s. Que., and N. B., s. to s. Tex., and s. Fla.; winters from e. and s. Mex. to Colombia; casual in Wyo. and Cuba.

Washington, very common S. R., Apl. 20-Sept. 29. Ossining, common S. R., May 7-Sept. 12. Cambridge, rare S. R., May 15Sept. 11. N. Ohio, common S.

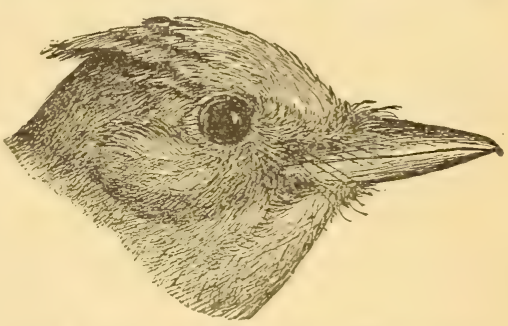

FIG. 95. Crested Flycatcher. (Natural size.) R., Apl. 25-Sept. 15. Glen Ellyn, not common S. R., May 1-Sept. 18. SE. Minn., common S. R., Apl. 25.

Nest, of grasses, twigs, and rootlets, with generally a piece of a cast snake skin, in a hole in a tree, generally less than 20 feet up. Eggs, 3-6, creamy white, streaked longitudinally with chocolate, $90 \times \cdot 68$. Date, San Mateo, Fla., May 10; Weaverville, N. C., May 20; Madison, Conn., June 2.

During the spring migration each day brings its own surprise and pleasure. The bare, silent woods where I walked alone before are now astir with flitting wings and ringing with glad music. Each morning I hurry out, full of eager anticipation, to be thrilled by the greeting of some old friend come home again.

There are red-letter days, however, even in this calendar. Hark! from the woods a loud whistle pierces far through the clearing. The Greatcrest has come!

I break away from the confusing chorus of small voices and hurry off to the woods for the first sight of the distinguished bird. Full of life and vigor, he flies about in the green tree tops, chattering to himself or calling loudly as he goes.

Not many days pass, however, before he is so taken up with domestic matters that his voice is rarely heard outside the woods. Is he engaged in his famous pursuit-hunting snake skins to line his nest? Absorbed in my daily round of nest calls, I cherish the memory of each passing glimpse of him. Now I see him liunch from a basswood top, with wings and tail spread, to sail down through the air, his tail glowing red against the light. Again, when looking for a rare Warbler, his calls arrest me. In the dead top of the highest tree in sight I find him with his mate. With crests raised, the handsome birds chase each other about the bare branches. Tired of that, they explore the old 
Woodpecker's holes in the trunk, and one of them walks out of sight down a hollow limb. A Blackbird lights in the tree, and the Greatcrest above becomes so agitated that I am convinced his mate has gone to her nest, when lo! both Flycatchers are off and away to another of the great trees that overtop the forest. Florence Merriam BaIley.

456. Sayornis phœbe (Lath.). Pнळве. (Fig. 59.) Ads.-Upperparts grayish brown with an olive-green cast; crown distinctly darker, fuscous; wings and tail fuscous, wing-bars not conspicuous; outer vane of outer tailfeather white or yellowish white, except at the tip; underparts white, more or less washed with yellowish, and tinged with brownish gray on the breast and sides; bill black. Im. and Ads. in winter.- Similar, but upperparts more olive, underparts more yellow, and wing-bars more distinct. L., 6.99; W., $3 \cdot 38$; T., 2*95; B. from N., 41 .

Remarks. - The Phœbe's principal distinguishing characters are its fuscous crown-cap, white outer vane of the outer tail-feather, and blackish lower mandible.

Range.-E. N. Am. Breeds from sw. Mackenzie, Alberta, s. Keewatin, Ont., Que., N. B., N. S., s. to ne. N. M., cen. Tex., n. Miss., and highlands of Ga.; winters in U. S. s. of lat. $37^{\circ}$ s. to s. Mex.; in migration casual w. to Colo. and Wyo., accidental in Calif. and Cuba.

Washington, common S. R., Feb. 25-Oct.; occasionally winters. Ossining, common S. R., Mch. 14-Oct. 29. Cambridge, common T. V., and not uncommon S. R., Mch. 25-Oct. 10. N. Ohio, common S. R., Mch. 14-Oct. 15. Glen Ellyn, S. R., Mch. 13-Oct. 6. SE. Minn., common S. R。, Mch. 22-Oct. 11.

Nest, bulky, largely moss and mud lined with grasses and long hairs, on a beam or rafter, under a bridge or bank. Eggs, 4-6, white, rarely with a few cinnamon-brown spots, $\cdot 78 \times{ }^{\circ} 59$. Date, Delaware Co., Pa., Apl. 18; Cambridge, Apl. 28; Galesburg, Ills., Apl. 22; se. Minn., Apl. 19.

There is something familiar, trustful, and homelike in the Phœbe's ways which has won him an undisputed place in our affections. With an assurance born of many welcomes he returns each year to his perch on the bridge-rail, barnyard gate, or piazza, and contentedly sings his humble, monotonous pewit phobe, pewit phobe-a hopelessly tuneless performance, but who that has heard it in early spring, when the 'pussy willow' seems almost to purr with soft blossoms, will not affirm that Phœbe touches chords dumb to more ambitious songsters!

Sometimes Phœbe is inspired to greater effort, and, springing into the air on fluttering wings, he utters more phobes in a few seconds than he would sing ordinarily in an hour.

Phobe is a devoted parent, and is rarely found far from home. His nest seems to be the favorite abode of an innumerable swarm of parasites which sometimes cause the death of his offspring, and when rearing a second family he changes his quarters.

Aside from a few Great-crests, no other Flycatcher winters in numbers in our Southern States, and Phœbe's notes heard in January in the heart of a Florida 'hummock' seem strangely out of place.

SAY's PhøBe (45\%. Sayornis saya), a western species, is of accidental occurrence east of the Mississippi. It has been found in northern Illinois, Wisconsin, Iowa, and, on Cape Cod, Massachusetts (Miller, Auk, VII, 1890, 228). 
459. Nuttallornis borealis (Swains.). Olive-SIded Flycatcher. Ads. - Upperparts between fuscous and dark olive; wings and tail fuscous; throat, middle of the belly, and generally a narrow line on the center of the breast white or yellowish white; rest of the underparts of nearly the same color as the back; under tail-coverts marked with dusky; a tuft of fluffy, yellowish white feathers on either flank; upper mandible black, lower mandible yellowish or pale grayish brown, the tip darker. Im. and Ads. in winter. - Similar, but with rather more olive above, more yellow below, and with the wingcoverts edged with ochraceous-buff. L., $7 \cdot 39 ;$ W., $4.05 ;$ T., $2 \cdot 70$; B. from N., 54.

Range.-N. and S. A. Breeds in Canadian and Transition zones from cen. Alaska, s. Mackenzie, s. Keewatin, cen. Que., and Cape Breton Is. s. in coniferous forests of $\mathrm{w}$. U. S. to s. Calif., Ariz., and w. Tex., and also $\mathrm{n}$. Mich., N. Y., and Mass., s. in mts. to N. C.; migrates through Mex. and Cen. Am.; winters in $\mathbf{n}$. S. A. to Peru.

Washington, casual T. V. Ossining, tolerably common T. V., May 20; Aug. 15-Sept. 16. Cambridge, rare T. V., May 20-June 6; formerly not uncommon S. R.; one Sept. record. Glen Ellyn, not common T. V., May 13June 11; Aug. 11-Sept. 15. SE. Minn., common T. V., May 10-Sept. 9.

Vest, of twigs and moss, in coniferous trees, about 25 feet up, near the extremity of a limb. Eggs, 3-5, vinaceous-white, spotted, chiefly about the larger end, with distinct and obscure rufous markings, $85 \times \cdot 62$. Date, Wareham, Mass., June 8; Kentville, N. S., June 15.

Both the Olive-side's habits and notes make it conspicuous. It perches on the topmost limb of some high tree, where, even at a distance, its stocky body and large head are evident, and calls its loud, strongly accented "come right here, come right here," in a voice that commands attention.

461. Myiochanes virens (Linn.). WOOD PeweE. Ads.-Upperparts very dark, between olive and fuscous, with sometimes a tinge of dark olivegreen, wings and tail fuscous; wing-coverts tipped with whitish, forming two more or less distinct wing-bars; underparts white or yellowish white, washed with olive-gray on sides of throat and breast, and, to a less extent, on center of breast; upper mandible black; lower mandible yellowish or brownish, the tip) frequently darker. Im.-Similar, but yellower below, wing-coverts edged with cream-buff. L., $6 \cdot 53 ; \mathrm{W} ., 3 \cdot 34 ; \mathrm{T} ., 2 \cdot 62 ; 13$. from N., $\cdot 42$.

Remarl:s. - The Wood Pewee and the Olive-sided Flycatcher differ from our other Flycatchers in having the wings decidedly longer than the tail, and in their short tarsi. From the species of the genus Empidonax they naly be known by these eharacters and their darker, more fuscous coloration.

Range.-N. and S. A. Breeds from Man., Ont., s. Que., and Prince Fdward Island to s. Tex., and cen. Fla., w. to e. Nebr.; winters from Nicarizgua to Peru; casual in Colo; in migration in Cuba.

Washington, rommon S. R., Apl. 29-Oct. 12. Ossining, common S. R., May 10-Oct. 2. Cambridge, common T. V., not uncommon S. R., May 18Sept. 15. N. Ohio, abundant S. R., May 2-Sept. 27. (ilen Filyn, fairly common S. R., May 9-Sept. 29. SE. Minn., common S. R., May 10 -Sept. 23.

Nest, compact and symmetrical, of fine grasses, rootlets, moss, etc., thickly covered with lichens, saddled on a limb, 2()-40) foet up). Eggs, 3-4, white, with a wreath of distinct and obscure umber markings about the larger end, $68 \times$ i) 4 . Date, Gainesville, Fla., May 9; Fairfax Co., Va., May 25; Ossining, N. Y., June s; ('ambridge, June 10; Mt. ('armel, Ills., May 20.

Thoroughly to anpreciate how well the Pewee's disposition is suited to his haunts and notes, we have only to imagine him taking 
the Phœbe's place and singing the Phœbe's song. He was not intended to adorn a bridge or barn, but in the darkened woods, high up in the trees, he finds a congenial home.

His pensive, gentle ways are voiced by his sad, sweet call:

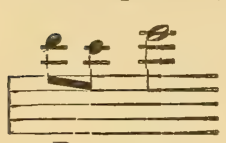

Pee-a-wee The notes are as musical and restful, as much a part of Nature's hymn, as the soft humming of a brook. All day long the Pewee sings; even when the heat of summer silences more vigorous birds, and the midday sun sends light-shafts to the ferns, the clear, sympathetic notes of the retiring songster come from the green canopy overhead, in perfect harmony with the peace and stillness of the hour.

The Western Wood Pewee (Myiochanes richardsoni richardsoni) has been recorded from Wisconsin (Cory, Birds Ills. and Wisc., 536).

463. Empidonax flaviventris Baird. Yeliow-Bellied Flycatcher. $A d s$.-Upperparts rather dark olive-green; wings and tail fuscous; greater and lesser wing-coverts tipped with white or yellowish white; underparts sulphur-yellow, the belly pure, the throat, breast, and sides more or less washed with olive-green; upper mandible black, lower mandible whitish or flesh-color; second to fourth primaries of equal length, the first shorter than the fifth. Im.-Yellow of the underparts brighter, wing-bars more yellow, and sometimes tinged with pale ochraceous-buff. L., 5.63; W., $2 \cdot 65$; T., $2 \cdot 16$; B. from N., '33.

Remarks. - This is the most yellow of our suall Flycatchers. In any plumage the entire underparts, including the throat, are sulphur-yellow or dusky yellowish. In the other eastern species of this genus the throat is white.

Range.-Breeds in Canadian zone from n. Alberta, n. Man., n. Que., and N. F., s. to N. D., n. Minn., n. Mich., n. N. Y., Pa. (mts.), and N. H.; w. in migration to the e. border of the Plains, e. Tex., and e. Mex.; winters from s. Mex. to Panama, occasional in migration in w. Fla.; accidental in Greenland.

Washington, rather common T. V., May; July 28-Oct. 6. Ossining, common T. V., May 17-June 4; Aug. 8-Sept. 20. Cambridge, T. V., sometimes rather common, May 25-June 3; Aug. 28-Sept. 8. N. Ohio, rare T. V., May 10. Glen Ellyn, rather rare T. V., May 20-June 5; Sept. 3. SE. Minn., common, T. V., May 19.

Nest, of moss, lined with grasses, on the ground, beneath the roots of a tree or imbedded in moss. Eggs, 4 , creamy white, with numerous pale cinnamon-hrown markings, chicfly about the larger end, $\cdot 68 \times{ }^{\cdot} 54$. Date, Wilmurt, N. Y., June 10; Grand Manan, N. B., June 16, inc. adv.

To see this little Flycatcher at his best, one must seek the northern evergreen forest, where, far from human habitation, its mournful notes blend with the murmur of some icy brook tumbling over mossy stones or gushing beneath the still mossier decayed logs that threaten to bar its way. Where all is green and dark and cool, in some glen overarched by crowding spruces and firs, birches and maples, there it is we find him, and in the beds of damp moss he skilfully conceals his nest. He sits erect on some low twig, and, like other Flycatchers, the snap of his bill tells of a sally after his winged prey. He glides quietly away when approached, and his occasional note of complaint may be heard as long as one remains in his vicinity. During the migration 
Plate XIX

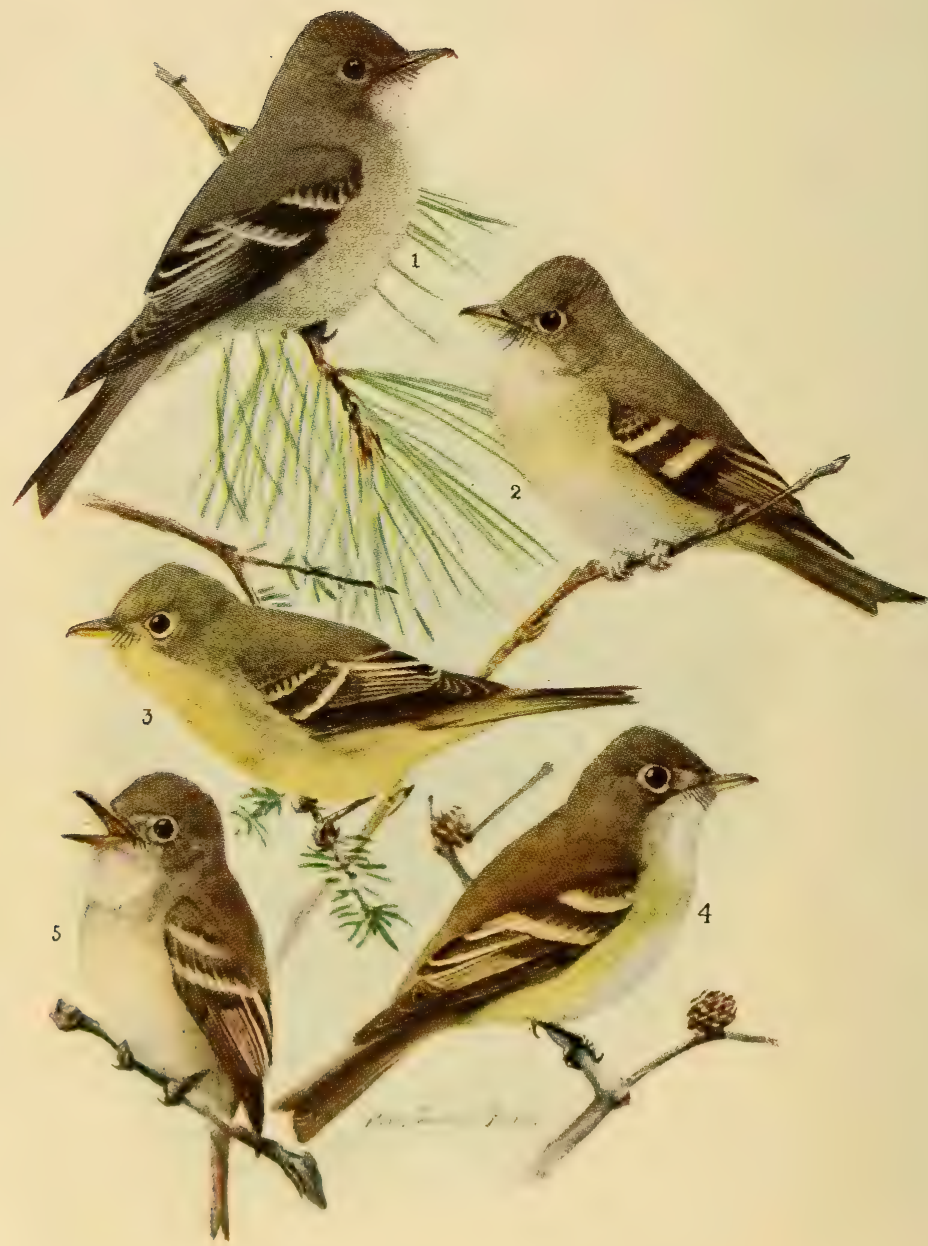

Fiycatchers

1. Wood Pewee,

3. Yellow-bellied Flycatcher.

2. Acadian Flycatcher.

4. Alder Flycatcher.

5. Least Flycatcher. 
this species is silent, and its several distinctive notes are not available for its identification, and the same thing may be said of our other small Flycatchers. Great similarity in plumage exists between them all, and without the bird in hand, identifications are at best questionable.

The song is more suggestive of a sneeze on the bird's part than of any other sound with which it may be compared. It is an abrupt psě-ě $k^{\prime}$, almost in one explosive syllable, harsh like the deeper tones of a House Wren, and less musical than the similar but longer songs of the Alder or the Acadian Flycatcher. It is hardly surprising that the birds sing very little when we see with what a convulsive jerk of the head the notes are produced. Its plaintive call is far more melodious -a soft, mournful whistle consisting of two notes, the second higher pitched and prolonged, with rising inflection, resembling in a measure $\operatorname{ch} \bar{u}-\bar{e}-\bar{e}^{\prime}-p$.

J. Dwight, JR.

465. Empidonax virescens (Vieill.). ACADIAN FlyCATCHER. Ads. -Upperparts between olive-green and dark olive-green; wings and tail fuscous; greater and lesser wing-coverts yellowish white, forming two conspicuous wing-bars; underparts white, washed with pale yellowish and slightly tinged with greenish on the breast; the throat, and frequently the middle of the belly, pure white; upper mandible black, lower mandible whitish or flesh-color; second to fourth primaries of about equal langth, the first and fifth shorter and also of equal length. Im.-Lpperparts greener; underparts more tinged with vellow; wing-hars and outer edges of the tips of the secondaries ochraccous-buff. L., 5.75; W., 2.85; T., 2.35; B. from N., 36 .

Remarks. - This species has the upperparts fully as olive-green as the Yellow-bellied Flycatcher, but the underparts are never entirely yellow, and the throat is always white.

Range.-E. N. Am. and n. S. A. Breeds from upper limit of Carolinian fauna in ne. Nebr., cen. Iowa, Mich., s. Ont., N. Y., Conn. (casually), and Mass. (one instance) s. to s. Tex., the Gulf States, and n. Fla.; migrateo through Yucatan and Cen. Arn. and winters in Colombia and Ecuador; casual in Bahamas and Cuba in migration.

Washington, common S. R., May 1-Sept. 15. Ossining, common S R., May 10-Aug. 27. N. Ohio, common S. R., May 4-Sept. 15. (ilen Ellyn, not common S. R., May 6-Aug. 27, and probably later.

Nest, shallow, of plant stems, grasses, and blossoms, generally on a fork of a beech about 8 feet up. Eggs, 2-3, creamy white, with a few cinnamonbrown spots about the larger end, $74 \% 56$. Date, Gainesville, Fla., May 12; Chatham Co., Ga., May 13; Chester Co., Pa., May 31; Ossining, N. Y., June 5.

Look for the Acarlian Flycateher in woodlands watered by small streams. It selects a low rather than a high perch, and is rarely seen more than twenty feet from the ground. The freculently uftered calls of this bird are characteristice and will enable you to identify it with more ease in the field than in the study. The most common is a single spee or peet, repeated at short intervals and acemplnied by a rapid twitching of the tail. A more peculiar noter is a louder pee-reynik. The bird seems to articulate this note with diffirulty, with bill pointed upward and wings trembling like a fledgling begging for foorl. 
Sometimes you may hear only the first call, sometimes only the second, while on other occasions the two may be uttered alternately. A rarer note may be heard when the bird makes a short, fluttering flight. It resembles the soft murmuring of whistling wings.

466. Empidonax trailli trailli (Aud.). Traill's Flycatcher. Similar to $E$. $t$. alnorum but still browner; the upperparts with little if any greenish tinge; the bill averaging narrower. Specimens from the eastern border of the range of this race are often difficult to distinguish from alnorum.

Range.-W. N. Am. Breeds from s. B. C., and Idaho to s. Calif., Ariz., N. M., and Tamaulipas, e. to Mo., Ills., and Ohio, winters in Cen. Am., s. to Colombia.

N. Ohio, common S. R., May 7-Sept. 10. Glen Ellyn, quite common S. R., May 14-Sept. 19. SE. Minn., common S. R., May 6-Aug. 10.

Nesting date, Monroe Co., Mich., June 20.

466a. E. t. alnorum Brewst. Alder Flycatcher. Upperparts between olive-green and olive or olive-brown; wings and tail fuscous; greater and lesser wing-coverts tipped with brownish ashy; underparts whitish, washed with dusky grayish on the breast and sides and pale yellowish on the belly; throat pure white; upper mandible black, lower mandible whitish or fleshcolor. Im. - Similar, but wing-bars ochraceous-buff and underparts slightly yellower. L., 6*09; W., 2*87; T., 2*33; B. from N., 35 .

Remarks. - This is the brownest of our small Flycatchers. The upperparts have an evident tinge of brown or olive-brown, a color entirely wanting in the Acadian and Yellow-bellied Flycatchers. In this respect it resembles the much smaller Least Flycatcher, from which, indeed, some specimens can be distinguished only by size.

Range.-Breeds mainly in Hudsonian and Canadian zones from cen. Alaska, nw. Mackenzie, s. Keewatin, cen. Que., and N. F., s. to e. cen. B. C., e. Mont., s. Minn., s. Ont., N. Y., n. N. J., and mts., of W. Va.; winters in Cen. Am. s. to Panama; casual in migration in s. Atlantic States.

Washington, irregularly common T. V., May 8-May 28; Aug. 16Sept. 17. Ossining, rare T. V., May 19-May 31; Aug. 29. Cambridge, rare T. V., May 28-June 6; Aug.; occasional in summer.

Nest, of coarse grasses, plant down, and plant fibers, lined with fine grasses, in the crotch of a small bush or sapling near the ground. Eggs, 3-4, creamy white, with cinnamon-brown markings about the larger end, $73 \times$ ·54. Date, Cambridge, June 15; Columbus, O., June 12.

While the Yellow-bellied Flycatcher is distinctively a bird of the deep woods, this more abundant Flycatcher in its summer home resorts to the alder patches of the open country and is seldom found far from their protecting shade. It flits restlessly about, keeping well out of sight below the waving tops of the bushes, and its presence is betrayed only by a single $p \bar{e} p$ of alarm that in no way resembles the mournful wail of the Yellow-bellied Flycatcher. It, too, is silent when migrating, and on its breeding-grounds sings but little, so that if it did not take pains to call out to every one who passes it would not be noticed among the rustling alders. The song most resembles that of the Acadian Fly-

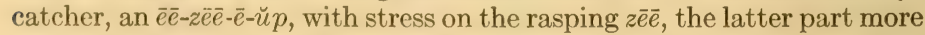
musical. The performer jerks out the notes rapidly, doubling himself up and fairly vibrating with the explosive effort. J. DwIGHT, JR.

1901. Farley, J. A., Auk, XVIII, 347-355 (in Mass.).-1902. Allen, F. H., Ibid. XIX, 84 (song). - 1910. Stanwood, C. J., Journ. Me. Orn. Soc., XII, 3-5 (nesting in Maine). 
467. Empidonax minimus W. M. and S. F. Baird. LeAst FLYCATCHER. Ads.-Lpperparts between olive-green and olive or olive-brown; wings and tail fuscous; greater and lesser wing-coverts tinged with ashy white; underparts whitish, washed with dusky grayish on the breast and sides and generally with a slight tinge of yellowish on the belly; lower mandible generally horn-color. Im.- - inderparts slightly more yellow; wingbars more buffy. L., $5 \cdot 41$; W., $2 \cdot 51$; T., $2 \cdot 21$; B. from N., 31 .

Remarks. - This is the smallest of our Flycatchers. Its size, the comparative absence of yellow on the underparts, and the generally horn-colored or brown lower mandible are its chief distinguishing characters.

Range.-Breeds in Canadian and Transition zones from w. cen. Mackenzie, s. Keewatin, Que., and Cape Breton Is., s. to cen. Mont., e. Wyo., cen. Nebr., Iowa, Ind., Pa., N. J., and in the Alleghanies to N. C.; in migration w. to e. Colo., and cen. Tex.; winters from ne. Mex. and Yucatan to Peru; casual in Grand Cayman Is., West Indies.

Washington, common T. V., Apl. 20-May 20; Aug. 13-Sept. 15. Ossining, tolerably common S. R., Apl. 25-Aug. 26. Cambridge, very common S. R., May 1-Aug. 25. N. Ohio, common T. T., Apl. 15-May 25; Aug. 25Oct. 1; rare in summer. Glen Ellym, not common S. R., chiefly T. V., May 4-Sept. 24. SE. Minn., common S. R., Apl. 30-Sept. 13.

lest, of plant down, plant fibers, rootlets, fine strips of bark, and long hairs, generally in a crotch 5-15 feet up. Eggs, 3-5, white, unmarked, -63 x 51 . Date, New York City, May 30; Cambridge, May 20; se. Minn., May 24.

When music was distributed, I believe most of our Flycatchers had back seats. It was an unfortunate circumstance, for their sedentary habits and apparently thoughtful, serious, even poetic dispositions make one believe that with proper training they might have taken high rank as musicians.

Instead of the simple melody we might expect to hear from the modest Least Flycatcher, he salutes us with a singularly inappropriate, business-like chebéc, chebéc, varying the performance by murderous sallies after passing insects. In crescendo passages he literally rises to the occasion, and on trembling wings sings an absurd chebéc tooralooral, chebéc, tooral-ooral, with an earnestness deserving better results.

The Chebec, however, possesses originality; we can not confuse his voice with that of any other bird, and young ornithologists should give him a vote of thanks for his clear enunciation.

He prefers fruit and shade trees to those of forest growth, and is therefore an inhabitant of our lawns and orchards.

The Vermiliox Flycatcher (471.1 Pyrocephalus mihinus mexicanus) of our Mexican boundary and southward, has been taken once in Florida (Tallahassee, March 25, 1901; Williams, Auk, 1901, 273).

\section{Family Alaudide. Larks. (Fig. 60.)}

Some two hundred and twenty-five species and subspecies of Larks are known, the proportion of the latter to the former being exeeptionally. large, the Horned Lark, the only American speeies, being represented in North America by no less than fourteen subspecies.

They are eminently terrestrial birds, always nest on the ground, rarely alight in trees, usually run instead of hop, 'dust' instead of 
bathe, and sing while on the wing. They are generally colored in harmony with their haunts, and, except during the nesting season, are usually found in flocks.

473. Alauda arvensis Linn. SkYLARK. Hind toe-nail as long as or longer than toe. Ads.-Above brownish ochraceous streaked with black; tail blackish, central feather margined with ochraceous buff; outer feathers more or less white; below whitish more or less washed with ochraceous buff, especially on breast, which is distinctly streaked with black. L., $7 \cdot 50$; W., $4 * 10 ;$ T., $2 * 60 ;$ B., $\cdot 45$. Bears a superficial resemblance to a Vesper Sparrow, but, aside from structural differences, is larger and more buffy.

Range.-Europe and N. Africa; accidental in Greenland and Bermuda and introduced into the U. S.

The Skylark has been introduced several times in this country. In 1887 a small colony had become established near Flatbush, Long Island, where a nest with young was found. (See Dutcher, $A u k, \mathrm{~V}, 1888$, p. 180.) After a supposed extinction a singing bird and nest were observed in July, 1895. (See Proctor, Auk, XII, 1895, p. 390.) According to Braislin (Abst. Proc. Linn. Soc. 17, 1907, p. 76) the bird is still present at Flatbush where it may be heard singing from March to October.

474. Otocoris alpestris alpestris* (Linn.). HoRnEd LARK. (Fig. 60.) $A d . \sigma^{3}$.-Forehead, line over the eye, ear region, and throat sulphuryellow; fore part of crown, a tuft of elongated feathers on either side of head, a mark from bill below eye and then downward to side of throat, and a patch on breast black; back of head and neck and rump vinaceous, more or less washed with grayish brown; back grayish brown, edged with brownish ash and tinged with vinaceous; wing-coverts deep vinaceous; tail black, outer vanes of outer feathers margined with white, middle feathers broadly margined with brownish and vinaceous; lower breast and belly white, the former more or less soiled with dusky spots; sides vinaceous. $A d$. $\%$ - Similar, but the markings, especially those of the head, less sharply defined, neck less vinaceous, etc. Im. and $A d$. in winter.- Similar, but with the black markings veiled by yellowish or whitish tips to the feathers. L., 7:75; "W., 4.27; T., 2.84; B. from N., •40" (Dwight).

Range.-E. N. Am. Breeds in Arctic zone of Canada from Boothia Peninsula s. to head of James Bay, Lab., and N. F.; winters s. to the Ohio Valley and Ga.; casual in La. and Bermuda; accidental in Greenland.

Washington, common W. V., Oct.-Apl. Ossining, casual W. V. Cambridge, not uncommon T. V., Oct. 25-Nov. 25; Mch. 25-Apl. 5; occasional W. V. N. Ohio, common W. V., Nov. 1-Apl. 1. SE. Minn., W. V.

Nest, of grasses, on the ground. Eggs, 3-4, pale, bluish or greenish white, minutely and evenly speckled with pale grayish brown, $84 \times{ }^{\circ} 60$. Date, Hebron, Lab., May 30.

These hardy birds visit us in flocks in the winter. They frequent the vicinity of the seacoast or large, flat, open tracts in the interior, and are rarely found in well-wooded regions. They are terrestrial, and may be seen running over the snow or barren ground in scattered companies. They take wing with a sharp, whistled note, and seek fresh fields, or, hesitating, finally swing about and return to near the spot from which they were flushed. They are sometimes found associated with Snow-

*See important papers on the relationships and distribution of the American representatives of this genus, by Dr. J. Dwight, Jr., in The Auk, VII, 1890, pp. 138158, and by H. C. Oberholser, Proc. U. S. N. M., XXIV, 1902, pp. 801-883. 
Buntings, and flocks may contain numbers of our resident Shore Lark, o. a. praticola.

474b. O. a. praticola Hensh. Prairie Horned Lark. Similar to the preceding, but smaller and somewhat paler, with the forehead and line over the eye white instead of yellow, the throat but slightly tinged with yellow, and sometimes entirely white. L., $7 \cdot 25$; “W., 4.08; T., 2*86; B. from N., '37" (Dwight).

Range. - NE. U. S. and Canada. Breeds chiefly in Transition zone from s. Man. and s. Que. to e. Kans., s. Mo., Ohio, W. Va., and Conn.; winters s. to Tex., Tenn., and Ga., and casually to Ariz. and Colo.

Washington, common W. V., Aug. 11-Apl. Cambridge, one record. N. Ohio, common P. R. Glen Ellyn, common P. R. SE. Minn., S. R., Mch.-Nov., a few in mild winters.

Nesting date, Buffalo, N. Y., Mch. 9; se. Minn., Mch. 10.

This is one of the birds that has

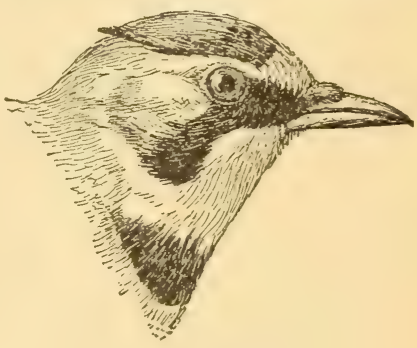

Fig. 96. Prairie Horned Lark. (Natural size.)

changed its range since the settlement of America. It is properly a species of the prairies and open barrens, but since the once-continuous forest of the older States and provinces has been broken up, it has made its appearance in the East, wherever the country is suited to its requirements.

It is strictly a ground bird, never perching on trees, though it commonly alights on the top of a fence-post or other low, level surface. When encountered on a pathway it often runs before the pedestrian after the manner of the Vesper Sparrow, from which bird, however, it may be distinguished by the black feathers in its tail, by its brown back, and by the black marks on its face; also by the fact that it runs, but does not hop, and when it flies it usually utters a whistle, whereas the Vesper Sparrow invariably flies off in silence.

Its chief song is poured forth in the air as it soars aloft, like a Skylark; but it often utters this same song while perched on some clod or stone, especially just before dawn and after sunset, as well as in the springtime, while the snow is yet on the ground.

\section{Ernest Thompson Seton.}

474k. O. a. hoyti Bishop. Hoyt's Horned Lark. "Similar to O. a. alpestris but with the upperparts generally paler and more gray, the posterior auriculars gray rather than brown, and the yellow of the head and neck replaced by white, excepting the forchearl, which is dirty grecnish white, and the throat, which is distinetly vollow, most pronouneed towird the center. . . The adult female in spring plumage differs in a similar manner from the female of alpestris, but in the female of hompli the yellow on the throat is much paler than in the male." W., 4.35. (Bishop).)

Range.-Cen. N. Am. Breeds n. of limit of trees from mouth of the Mackenzie to w. shore of Hudson Bay; winters s. to Nev., Utah, Kans., and Mich.; casual in Ohio and N. Y. 


\section{Family Corvider. Crows, Jays, Etc. (Fig. 61.)}

The Corvidoe are represented in all parts of the world except New Zealand. They number about two hundred species, of which twenty-one are found in North America. Our Crows and Jays inhabit wooded regions, and are resident throughout the year, except at the northern limits of their range. They are omnivorous feeders, taking fruits, seeds, insects, eggs, nestlings, and refuse.

Crows and Jays exhibit marked traits of character and are possessed of unusual intelligence. Some systematists place them at the top of the avian tree, and, if their mental development be taken into consideration, they have undoubted claims to this high rank.

A. Plumage black.

\section{KEY TO THE SPECIES}

a. Wing about $155^{\circ} 00$; bill over 250 . . . . . . . 486a. RAVEN b. Wing about $13^{\circ} 00^{\text {; }}$; bill about $2^{\circ} 00^{\circ}$. 488. CRow. 488 a. FlorIda Crow. c. Wing about $11^{\circ} 00$; bill about 1.50 . . . . . 490. FisH Crow. $B$. Plumage bluish or grayish.

a. Back blue; tail tipped with white; a black breast-patch.

477. Blue Jay. 477a. Florida Blue Jay.

b. Back bluish gray; tail not tipped with white; throat and breast indistinctly streaked with whitish . . . . 479. FlORIDA JAY.

c. Back gray; back of head and nape blackish; forehead whitish.

484. Canada Jay. 484c. Labrador Jay.

477. Cyanocitta cristata cristata (Linn.). BLUE JAY. (Fig. 61a.) Ads.- Upperparts grayish blue; underparts dusky whitish, whiter on the throat and belly; forehead, and a band passing across the back of the head down the sides of the neck and across the breast, black; head crested; exposed surface of wings blue, the greater wing-coverts and secondaries barred with black, and all but the middle pair broadly tipped with white, this white tip rarely less than $1^{\circ} 00$ in width on the outer feather. L., 11.74; W., 5.14; T., $5 \cdot 19 ;$ B., $1 \cdot 04$.

Range.-E. N. Am., breeding from cen. Alberta, s. Keewatin, Que., N. B., N. S., and N. F. s. to the Gulf States, except Fla., and w. to w. Nebr., e. Colo., and cen. Tex.; casual in N. M., migratory in the n. part of its range.

Washington, rather rare P. R., common T. V., Apl. 28-May 15; Sept. 15-Oct. 15. Ossining, tolerably common P. R. Cambridge, common P. R., abundant T. V., Apl. and May; Sept. and Oct. N. Ohio, common P. R. Glen Ellyn, common P. R. SE. Minn., common P. R.

Nest, of twigs, compactly interwoven, lined with rootlets generally in a tree crotch 10-20 feet up. Eggs, 4-6, pale olive-green or brownish ashy, rather thickly marked with distinct or obscure spots of varying shades of cinnamon-brown, $1 \cdot 10 \times 85$. Date, Charleston, S. C., Apl. 25; Cambridge, Apl. 28; se. Minn., May 2.

The Blue Jay, I fear, is a reprobate, but, nothwithstanding his fondness for eggs and nestlings, and his evident joy in worrying other birds, there is a dashing, reckless air about him which makes us pardon his faults and like him in spite of ourselves. Like many men, he needs the inspiration of congenial company to bring out the social side of his disposition. Household duties may perhaps absorb him, but certain it is that when at home he is very different from the noisy fellow who, with equally noisy comrades, roams the woods in the fall. How his jay, jay 
rings out on the frosty morning air! It is a signal to his companions, breakfasting in a near-by oak or chestnut, "Here, here, here's some fun!" and the poor, blinking $\mathrm{Owl}$ he has discovered looks helplessly at the blue-coated mob, whose uproar alone is terrifying. Suddenly there is absolute silence; every Jay has disappeared. One of them has seen you, and not until your silence reassures the band will they return to the sport of teasing their victim.

The Blue Jay is both a mimic and a ventriloquist. Besides an inexhaustible stock of whistles and calls of his own, he imitates the notes of other species, notably those of the Red-shouldered, Red-tail, and Sparrow Hawks.

1908. Chapman, F. M., Camps and Cruises, 5-14 (nesting).

477a. C. c. florincola Coues. Florida Blue JAX. Similar to the preceding species, but smaller, the upperparts somewhat grayer, the white tips to the feathers narrower, those on the outer pair of tail-feathers generally less than 1.00 in length. L., 10.75; W., 5.15; T., 4.80; B., 96.

Range.-Florida.

Nesting date, Archer, Fla., Apl. 4.

Blue Jays in Florida are common inhabitants of towns with liveoaks, and hop about the fences and gardens with all the domesticity of the Robins on our lawns. It has always seemed to me that the Florida birds were possessed of greater vocabularies than their northern brethren.

The MAGpIe (475. Pica pica hudsonia) inhabits western North America; stragglers have been recorded from as far east as Montreal and Illinois.

479. Aphelocoma cyanea (Vieill.). Florida JAY. Ads.-Top and sides of the head and neck, wings and tail, grayish blue; back pale brownish gray; underparts dirty white, obscurely streaked on the throat and breast; sides of the breast and faint breast-band grayish blue. L., 11.50; W., $4 \cdot 45$; T., $5 \cdot 40$; B., $\cdot 98$.

Range.-Fla., local, (hicfly along coasts, between lat. $27^{\circ}$ and $30^{\circ}$.

Nest, of sticks and roots lined with weeds and rootlets, in trees and bushes. Eggs, 4, olive-green spotted and blotehed with black, 1.17 $\times 75$ (Maynard). Date, Lantana, Fla., Apl. 6.

"The Florida Jays are noisy birds at all times, and the first intimation which one receives of their presence is a harsh scream which is given as a note of alarm. As they usually move in flocks, this cry is taken up by others, and soon the serub for many rods around will be resounding with these peculiar sounds. When undisturberd they feed on the ground or in bushes, but, upon the aprroach of an intruder, they will mount the highest point available, where they remain until driven away. They are not usually shy, and will allow one to approach them quite elosely, but when one or two are shot the survivors usually disappear. They will glide through the bushes with remarkable rapidity, never once showing themselves, or, if they have an open space to cross, dart over it, not in flocks, but singly, and, plunging into the next thicket, they will at once be lost to view" (Maynard). 
484. Perisoreus canadensis canadensis (Linn.). CANADA JAY. Ads.-Forepart of the head white, back of the head and nape sooty black, back gray; wings and tail gray, most of the feathers narrowly tipped with white; throat and sides of the neck white, rest of the underparts ashy gray. L., $12 \cdot 00 ;$ W., $5 \cdot 85$; T., $5 \cdot 80 ;$ B., $\cdot 82$.

Range.-Boreal zones of e. N. A. Breeds from limit of conifers in nw. Mackenzie and cen. Keewatin and from n. Que., s. to w. cen. Alberta, n. Minn., Mich., the Adirondacks of N. Y., n. Maine, N. H., N. B., and N. S.; casual in Nebr., Pa., and Mass.

Cambridge, A. V., one record, Oct.

Nest, of coarse twigs and strips of bark, in coniferous trees. Eggs, 4-5, white, distinctly and obscurely spotted with light olive-brown, $1 \cdot 12 \times \cdot 81$. Date, Stewiacke, N. S., Apl. 17, inc. adv.; Mahoning, Mich., Mch. 18.

While studying the habits of birds in the great coniferous forest of the north, I soon found that I was very safe in attributing any new strange shrieks or wails, whose origin I was otherwise unable to trace, to the Canada Jay. Many of the notes resemble those of the Blue Jay, but it has a number that are distinctly its own. Some of these are musical, but most of them are harsh and discordant.

In its habits it is much like its blue cousin, but it is less shy, and becomes almost tame if allowed to come unmolested about the camp for a few days in succession. In form it is like a magnified Chickadee, clad in singularly furlike, thick, puffy gray feathers; on its forehead is a white spot, the size of a dime, and its wings and tail are of a much darker gray than the other parts. This description, remembered in conjunction with the habits, will at once identify the species.

It nests early in March-that is, while deep snow still covers the ground and hard frost reigns supreme; and no satisfactory explanation of this strange habit has yet been brought forward. No doubt one or other of the parents always remains with the eggs. but still it is difficult to see how they can keep them from freezing when the surrounding air is chilled to $30^{\circ}$ below zero.

It is a non-migratory species, and it is said that in autumn it provides against the annual famine of winter by laying up a store of nuts and other food.

ERnest Thompson Seton.

1899. WARreN, O. B., Auk, XVI, 12-19 (nesting).

484c. P. c. nigricapillus Ridgw. Labrador $J_{A Y}$. Similar to the preceding, but darker, the black of the head and neck extending forward and surrounding the eye.

Range.-Northern and eastern Ungava, Lab., and N. F.

Nesting date, Lab., Apl. 16.

486. Corvus corax sinuatus (Wagl.). RAven. Similar to C. c. principalis but with a "smaller or slenderer bill, the tarsus more slender, with less of upper portion concealed by feathering of lower part of thighs." W., 16.87 ; T., 9.86 ; B., $2 \cdot 80$; depth of B., at N., 94 (Ridgw.).

Range.-Ore., Mont., S. D , s. to Honduras and e. probably to Mo., Ills., and Ind.

486a. Corvus corax principalis Ridgw. Northern Raven. Ads.Entire plumage black with steel-blue reflections; feathers on the throat 
narrow, lengthened, and pointed. "L., about ;22.00-26.50; W., 16.99; T., 9.86; B., $3^{\circ} 03$; depth of B. at N.,1 $1^{\circ} 4^{\prime \prime}$ (Ridgw.).

Remarlis. - The Raven differs from the Crow in its much greater size and in having long, pointed, instead of the usual short, rounded feathers on the throat.

Range.-NW. Naska, Melville Is., n. Ellesmere Land, and n. Greenland s. to Wash., cen. Minn., Mich., and locally to coast region of N. J. and Va., and in the higher Alleghanies to Ga. SE. Minn., uncommon W. V.

Nest, compact and symmetrical, of sticks lined with grasses, wool, etc., added to from year to year, in trees or on cliffs. "Eggs, 2-7, pale bluish green, pale olive, or olive spotted or dashed (or both) with olive-brown (sometimes nearly uniform olive from density of markings), $2{ }^{\circ} 02 \times 1 \cdot 38^{\prime \prime}$ (Ridgw.). Date, Grand Manan, Apl. 9.

"The usual note of the Raven is a hoarse, rolling $c r-r-r-c r u c k$, but he has other cries.

"Despite their difference in size and habits, I must confess that I often had difficulty in distinguishing Ravens from Crows. Every one must have noticed how the apparent size of a Crow will vary under different conditions of the atmosphere; it is the same with the Raven. At times he looks as big as an Eagle; at others scarcely larger than a Fish Crow. But when actually in company with Crows he can not be possibly mistaken, for he then appears, as he is, nearly double the size of any of them. His flight did not seem to me as characteristic as it has been described. True, he sails more than does the Crow, and there is something peculiar in his wing-strokes, but the difference is not always appreciable unless there is an opportunity for direct comparison" (Brewster, Proc. Bost. Soc. Nat. Hist., XXII, 1883, p. 378).

1910. Hartan, R. C., Cassinia 11-18 (nesting in Pa.).

488. Corvus brachyrhynchos brachyrhynchos Brehm. Crow. (Fig. 61b.) Ads.-Entire plumage black, with ster-l-blue or deep purplish reflections; the underparts duller than the upperparts; feathers on the neck normal, short, and rounded. L., 19*30; W., 12.15; T., 7.52; B., $2 \cdot() 0$.

Range.-E. N. Am. Breers from sw. Mackenzie, cen. Kerwatin, cen. Que., and N. F. s. to s. Tex., and the Gulf coast (except Fla.); winters from near the $n$. boundary of the U. S. southwarl.

Washington, abundant P. R. Oscining, common P. R. Cambridge, common P. R., ahundant T. V. N. Ohio, common P. R. Gilen Filyn, common P. R. SE. Minn., common S. R., Mch.-Nov., uncommon W. V.

Nest, bulky, of sticks lined with strips of graperine bark, grasses, moss, etc., in trees, averaging about 30 feet up). Eggs, + -6 , generally bluish green, thickly marked with shades of hrown, but sometimes light blue or even white with almost no markings, $1^{\circ}\left(5^{5}\right) \times 1 \cdot 19$. Date, Wish., D. C., Mch. 27; Delaware Co., Pa., Apl. 11; Ossining, N. Y., Apl. 14; Cambridge, Apl. 15; se. Minn., Apl. 12.

Throughout his wide range the size, color, voiec, habits, and abundance of the Crow combine to make him the most eonspiraous and consequently the best known of our birds. But in spite of his great circle of acquaintances he has few friends. An unfortunate fondness for corn has placed him under the ban of the agrieulturist; there is a price on his head; every mar:'s hand is against him. Apparently he does not mind this in the least; in fact, he serrns to rejoice in bring an outlaw. As for fear, I doubt if he knows what it means; he bas far 
too much confidence in his undoubted ability to escape his human persecutors. He laughs at their attempts to entrap him; his insolent assurance is admirable. For several centuries man has been his sworn enemy, nevertheless he appears to have held his own, accepting and adjusting himself to every new condition.

Afraid of no one, he migrates boldly by day, and in March and October we may see him with his comrades high in the air, returning to or leaving their summer homes. In winter the Crows are exceedingly abundant along our seacoasts, where they congregate to feed on mollusis, fish, and other sea food. . At this season they roost in colonies. It has been estimated that some roosts contain upward of three hundred thousand birds. Early in the morning, with regularly executed maneuvers, they start on the day's foraging, flying low, on the lookout for food. Late in the afternoon they return at a much greater height"as the Crow flies"-and, alighting at some point near the roost, wait the coming of the last stragglers. Then, at a given signal, they all rise and retire for the night. No one one who has listened to Crows will doubt that they have a language. But who can translate it?

1886. RHOADS, S. N., Am. Nat., 691-700; 777-786 (roosts).-1895. Barrows and Schwarz, Bull. 6, Biol. Surv. 1-98 (food).-1895. Burns, F. L., Wilson Bull. No. 5, 1-41 (monograph).-1897. ButLer, A. W., Proc. Ind. Acad. Sci., 175-178 (roosts).

488a. C. b. pascuus Coues. Florida Crow. Similar to the preceding, but wings and tail somewhat shorter, and bill and feet slightly larger, L., 20.00; W., 11.50-12.30 T., 7.00-7.70; B., 2.00-2.20; depth of B. at base, $75-85$; Tar., 2*40-2:50 (Ridgw.).

Range.-Peninsula of Florida.

Nesting date, San Mateo, Fla., Mch. 3.

490. Corvus ossifragus Wils. FIsH CROw. Ads.-Entire plumage black, with steel-blue or deep purplish reflections, generally more greenish on the underparts. L., $16.00 ;$ W., $11^{\circ} 00 ;$ T., $6 \cdot 40 ;$ B., 1.50 .

Remarks. - The Fish Crow may be distinguished from the common Crow (1) by its much smaller size. (2) By the uniform and somewhat richer color of the back. In brachyrhynchos the feathers of the back have dull tips; when the freshly-plumaged bird is held between the observer and the light these tips give the back a ringed or slightly scaled appearance. In ossifragus these tips are wanting, and the back is uniformly colored. (3) By the brighter color of the underparts. In brachyrhynchos the underparts are generally much duller than the upperparts; in ossifragus they are nearly as bright.

Range.-Carolinian and Austroriparian faunas of Atlantic and Gulf coasts from lower Hudson River valley and Conn. to La. and Fla.; casual in Mass.; migratory only at extreme $\mathrm{n}$. limit of range.

Washington, rather common P. R. Cambridge, A. V., one record, Mch.

Nest, of sticks, lined with strips of grapevine bark, moss, grasses, etc., generally in pines or cedars, 20-50 feet up. Eggs, 4-6, similar in color to those of the preceding species, $1.52 \times 1.06$. Date, Lake Kissimmee, Fla., Apl. 30; D. C., May 5; Seven Mile Beach, N. J., May 15.

The Fish Crow can be distinguished from the common Crow in life only by its call. Its voice is cracked and reedy, and its notes resemble those of a young common Crow. Instead of the loud, clear, open caw of adults of that species, it utters a hoarser car, as if it talked through 
its nose! The difference is perhaps not appreciable upon paper, but one who is familiar with their calls need never confuse these two birds in the field. The Fish Crow, while not confined to the coast or even the vicinity of water, is not found far inland.

The European Rook (490.1. Corvus frugilegus) and the Erropean HOODED CROw (490.2. Corvus cornix) are both of accidental occurrence in Greenland.

Clarke's Nutcracker (491. Nucifraga columbiana) of western North America is of accidental occurrence in Iowa and Wisconsin.

\section{Family Sturnide. Starlings. (Fig. 62.)}

The sixty species of true Starlings (cf. Sharpe) are distributed throughout the Old World except in Australia and New Guinea. The only American representative was introduced into this country in 1890.

493. Sturnus vulgaris Linn. StarliNG. (Fig. 62.) Ads. in summer. - Metallic purplish or greenish; feathers of the upperparts all tipped with cream-buff spots, feathers of the underparts marked only on the sides; lower belly and under tail-coverts, wings, and tail dark brownish gray, edged with cream-buff; bill yellow. Ads. and Im. in winter.-Similar, but the upperparts heavily spotted with brownish eream-buff; the entire underparts heavily spotted with white; bill blackish brown. L., 8.50; W., 5.10; T., 2.50.

Range.-W. and cen.

Europe; winters s. to Africa; accidental in Greenland ; introduced in 1890 in N. Y. City, and thence has spread as far as Springfield, Mass., Stonington, Conn., Orient, L. I., Ossining, N. Y., and Phila., Pa.

Nest, of grasses, twigs, etc., in a crevice in a building or hollow tree. Eggs, 4-6, pale bluish, $1.20 \times 86$. Date, Englewood, N. J., May 15, young on wing.

The Starling was introduced into this country by Eugene Schieffelin, who also imported one of the

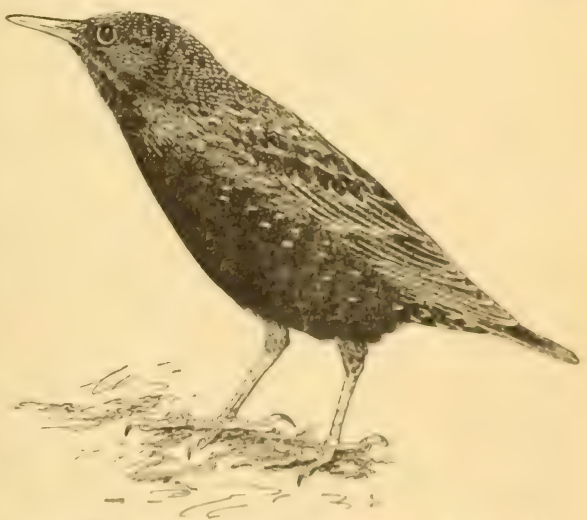

Fig. 97. Siarling; -umumer plumage. (Reduced.)

early shipments of House or 'English' Spatrows. Sixty Starlings were released in Central Park, New Jork (City, in 1890, and forty more in! 1891, and from these one hundred birds (other introductions having apparently failed) the thousands of starlings now oceupying the country for one hundred miles or more from New York ("ity have descended. In this area they are permanently resident, but there are pronounced 
local fluctuations in their numbers due to the influences of the pairing and flocking season and of the food supply. Continuous residence, as with the English Sparrow, not only implies the possession of powers of endurance and adaptability, but gives an advantage over species with which there may be conflict over the possession of a nesting-site.

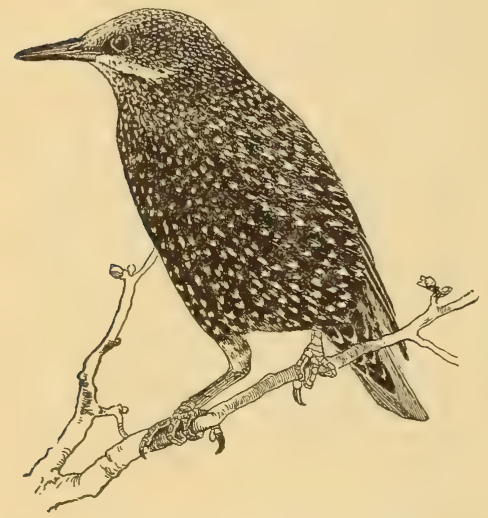

Fig. 98. Starling; winter plumage. (Reduced.)

Such conflict occurs with the English Sparrow, but the latter nests in so great a variety of places that it readily abandons one for another. With the Bluebird this is not so, and it is this species, more than any other, which is threatened by the Starling.

At the present rate of increase it is clear that within two decades the Starling will occupy the greater part of the eastern States, and unless its spread westward be prevented by the plains, it may eventually be as widely distributed as the English Sparrow. It has not as yet been decided whether, from an economic standpoint, the Starling is a desirable addition to our avifauna; but in spite of his undoubted claims to our interest, he is a distinctly foreign element in our bird-life, and seems out of place among those species with which we share the bond of a birthplace in common.

About New York City the Starling is among the first birds to nest, and the harsh, grating food-call of the young may be heard by May 15 . Here apparently but one brood is raised and young and old begin to flock the latter part of May, forming the nucleus of gatherings which in late summer and fall contain several thousand birds. Their aërial evolutions admirably demonstrate the unity of spirit which appears to control the movements of birds in flocks, and are performed with a precision which suggests long training and instant obedience.

The call of the male is a high, clear, rather long-drawn, ascending whistle, which may be easily imitated. This appears in its song, which is a choking, gasping, guttural soliloquy, with imitations of the notes of other birds interspersed. The flocking chorus is an indescribable chattering. On a number of occasions I have heard Starlings utter notes resembling those of the Wood Pewee (see page 344 ) but whether they were natural or acquired must be determined by some observer in the Old World.

Starlings are walkers, not hoppers, and aside from color, may be known by their long, pointed wings, and short, square tail. 


\section{Family Icteride. Blackbirds, Orioles, Etc. (Fig. 63.)}

This distinctively American family is most abundantly represented in the tropics, where the majority of the one hundred and fifty odd known species are found, only nineteen advancing north of Mexico. With the exception of the Orioles, they are gregarious after the nesting season, while some of the species nest in colonies and are found in flocks throughout the year. They differ markedly in habits, and are found living in ground of every nature, from dry plains and wet marshes to the densest forest growth. Some species possess marked vocal ability, while the voices of others are harsh and unmusical. They feed on fruit, seeds, grain and insects.

\section{KEY TO THE SPECIES}

I. With yellow or orange in the underparts.

II. Underparts black with or without metallie reflections.

III. Underparts grayish, slate-color, chestnut or buffy.

IV. Underparts black and white, or black, tipped or margined with rusty.

\section{With yellow or orange in the underparts.}

1. Throat or breast-crescent black.

a. Back black . . . . . . 507. Baltimore Oriole.

b. Back greenish . . . 506. Orchard Oriole (o im.).

c. A black or blackish crescent on the breast; outer tail-feathers white. 501. Meadowlark. 501a. Western Meadowlark.

2. Throat not black, no breast-crescent.

A. Entire underparts yellow, yellowish, or orange.

a. Rump and tail orange . 507. Baltimore Oriole ( $q$ and im.).

b. Underparts yellowish green 506. ORCHaRd OrIole ( $q$ and im.).

c. Upperparts brownish, streaked and spotted with black; tailfeathers pointed. . . 494. BoboLINK ( $\&$ ad. $\sigma^{7}$, fall and im.).

$B$. Throat and breast yellow or yellowish; belly black or dark grayish brown . . . . . 497. ÝlLLW-HEADED BlackBIRD.

\section{Underparts black, with or without metallic reflections.}

$A$. Outer tail-feathers 75 or more shorter than middle ones; bill 1.00 or more in length.

a. Tail over 6.00 . . . . . . 513. Boat-tailed Grackle 07.

b. Tail under $60^{\circ} 00$.

$b^{1}$. Back bronzy purple or shining, brassy bluish green, the feathers with iridescent bars . . . . . 511. Purple Grackle o?.

$b^{2}$. Back bronze, without iridescent bars.

511b. Bronzed Grackle o*.

$b^{3}$. Back bottle-green, the feathers more purple at their base, and with a narrow iridescent bar near the middle.

511a. Florida Grackle o". $b^{4}$. Back bluish black, with or without iridescent bars.

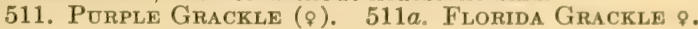

B. Outer tail-feathers little if any shorter than middle ones; bill less than $1^{\circ} 00$ in length.

a. Entire plumage bluish black, the feathers sometimes tipped with buffy or rufous. . . . 509. RUSTY BLACKBIRD ơ

b. A red and buff shoulder-patch $:$ RED-WINGED BLACKBIRDS or.

c. Head and neck all around seal-brown . . 495. COWmIRD $\sigma^{\circ}$.

d. Nape buffy, rump whitish . . . . 494. Boвolink o. 


\section{Underparts grayish, slate-color, chestnut, or buffy.}

A. Underparts grayish or slate-color.

a. Underparts grayish; bill finchlike; wing under $4^{*} 00$.

495. CowBIRD o

b. Underparts slate-color, sometimes tipped with brownish, bill thrushlike; wing over $4^{\circ} 00$. . 509. RUstr BlackBIRD ․

$B$. Underparts buffy or chestnut.

a. Underparts buffy, generally with a few black streaks.

494. BовоLINK \%.

b. Underparts buffy, without black streaks; tail about $5^{\circ} 00$.

513. Boat-tailled Grackle o.

c. Underparts chestnut; throat black. . 506. OrCHaRd OrIOLE (o ad.).

\section{Underparts black and white, or black tipped or margined with rusty.}

a. Underparts streaked black and white, or black tipped with white; shoulder generally red or reddish.

RED-WINGED BlackBIRds (\% and im.). 4

b. Upperparts and underparts tipped with rusty.

c. Nape buffy, rump whitish

509. Rusty Blackbird (im.).

494. Dolichonyx oryzivorus (Linn.). BовоLINк. Ad. o , breeding plumage.-Top and sides of the head and underparts black, the feathers more or less tipped with a narrow whitish or cream-buff fringe, which wears off as the season advances; back of the neck with a large yellowish creambuff patch; middle of back generally streaked with cream-buff; scapulars, lower back, and upper tail-coverts soiled grayish white; wings and tail black; tail-feathers with pointed tips; bill blue-black. $A d$. . - -Upperparts olive-buff, streaked with black; crown blackish, with a central stripe of olive-buff; nape finely spotted and back broadly streaked with black; wings and tail brownish fuscous: tail-feathers with pointed tips; underparts yellowish or buffy white. Ads. in fall and Im.-Similar to female, but buffier and more olivaceous throughout. L., 725 ; W., $3 \cdot 76$; T., $2 \cdot 73$; B., ${ }^{\circ} 55$.

Remarks. - The young and adults in fall plumage are known as Reedbirds. Adults acquire this plumage by a complete molt after the breeding season. The breeding plumage is regained by a complete molt in the spring, and not, as has been supposed, by a change in the color of the feathers without molting. Freshly plumaged males have the black veiled by yellow tips to the feathers; these gradually wear off, and by June have almost entirely disappeared (cf. Chapman, Auk, X, 1893, 309).

Range.-N. and S. A. Breeds mainly in Transition zone from se. B. C., cen. Alberta, cen. Sask., cen. Man., cen. Ont., cen. Que., and Cape Breton Is. s. to ne. Nev., Utah, n. Mo., Ills., Ind., cen. Ohio, W. Va., Pa., and N. J.; winters in S. A. to s. Brazil, Bolivia and Paraguay; in migration to the West Indies and e. coast of Cen. Am.; casual in Calif.; accidental in Bermuda and the Galapagos. (See Fig. 7.)

Washington, T. V., common in spring, abundant in fall; Apl. 26-May 30; July 23-Nov. 14. Ossining, tolerably common S. R., May 1-Oct. Cambridge, very common S. R., May 8-Sept. 10. N. Ohio, common S. R., Apl. 16-Oct. 10. Glen Ellyn, S. R., Apl. 27-Oct. 9. SE. Minn., common S. R., Mch. 5-Aug. 27.

Nest, of grasses, on the ground. Eggs, 4-7, grayish white, frequently tinged with the color of the numerous irregular spots and blotches of olivebrown or umber, $85 \times{ }^{\circ} 62$. Date, Ossining, N. Y., May 29; Cambridge, June 1; Erie Co., N. Y., May 15; Austin, Ills., May 20.

In June our fields and meadows echo with the Bobolink's "mad music" as, on quivering wing, he sings in ecstasy to his mate on her 


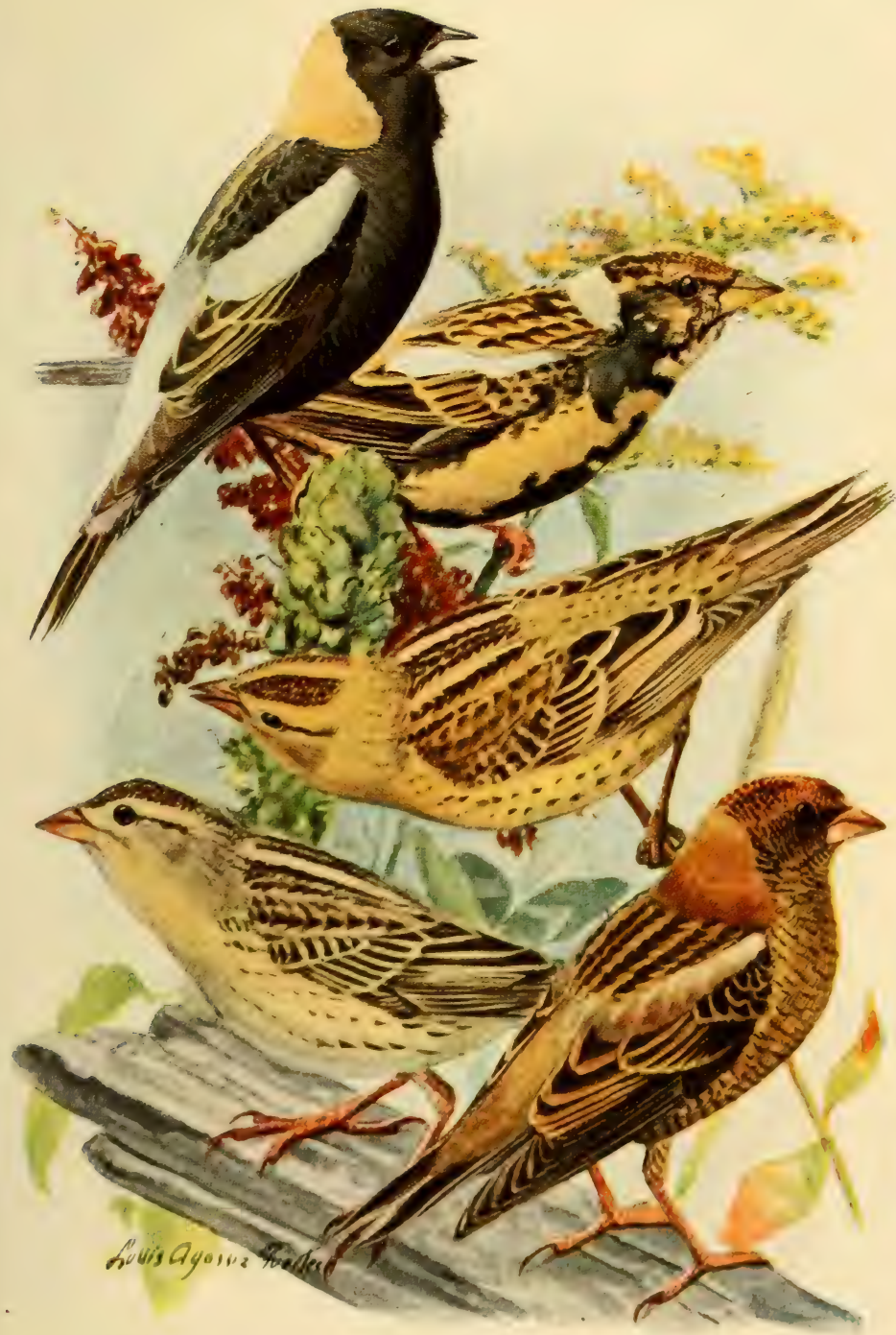

\section{Plumages of the Bobolink}

1. Adult male, summer. 2. Arlult male in post-nuptial (fill) molt. 3. Arlult male and adult female after post nuptial molt, and youne in first winter. (This is the Reredhird plumage.) 4. Adult female, summer. 5. Adult male after ermplete premuptial (spring) molt. Plumage No. 1 is then acquired by wear and fading. 

nest in the grasses below. What a wonderful song it is! An irrepressible outburst; a flood of melody from a heart overflowing with the joy of early summer.

But this glad season is soon over. Even before the tide of the year is full, the Bobolink begins to prepare for the long journey to his winter resorts. Doffing his jaunty costume of black, white, and buff, he dons the less conspicuous dress of his mate, and travels in disguise under the assumed name of Reedbird or Ricebird. His voice is hushed, save for a single call-note-a metallic chink. He travels both by day and night, and from the sky we hear his watchword as he signals his companions.

The wild-rice marshes of our coasts and rivers are the rendezvous of the countless flocks of Bobolinks, which later will invade South America, stopping en route to visit the rice, fields of South Carolina and Georgia. They pass the winter south of the Amazon, and in March or April begin their northward journey. The males, in flocks of two or three hundred, precede the females by several days. They reach Florida about April 25, and are then in full song. Only one who has heard the Bobolink sing can form an idea of the effect produced by a flock of three hundred or more singing in chorus.

495. Molothrus ater ater (Bodd.). Cowbird. Ad. $\sigma^{7}$.-Head, neck, and breast coffee-brown; rest of the plumage glossy black, with metallic bluish and greenish reflections. Ad. o. -Dark brownish gray, lighter below, especially on the throat. Juvenal plumage.-Similar to the female, but whiter below, all the feathers edged with buffy. This plumage is worn but a short time, and is then changed for that of the adult. $0^{7}$ L., $7 \cdot 92$; W., $4 \cdot 24$; T., $3.03 ;$ B., $\cdot 67$.

Range.-N. A. Breeds from s. B. C., s. Mackenzie, s. Keewatin, Ont., Que., and N. B. s. to n. Calif., Nev., n. N. M., Tex., La., and N. C.; winters from se. Calif. and the Ohio and Potomac valleys (casually further n.) to the Gulf coast and cen. Mex.

Washington, rather rare P. R., common T. V. Ossining, common S. R., Mch. 22-Nov. 11. Cambridge, common S. R., Mch. 25-Nov. 1; occasional in winter. N. Ohio, abundant S. R., Mch. 10-Nov. 15. Glen Ellyn, common S. R., Mch. 15-Sept. 10. SE. Minn., common S. R., Apl. 11-Aug. 19.

Nest, none, the eggs being laid in the nests of (some 90 recorded) other species. Eggs, white, evenly and distinctly speckled with cinnamon-brown or umber, $86 \times 65$. Date, Montgomery Co., Pa., May 10: Cambridge, May 15.

The Cowbird is an acknowledged villain, and has no standing in the bird world. English Sparrows, either because they are not aware of the customs of New World bird life, or because of a possible and not unlikely affinity, associate with him; but no self-respecting American bird should be found in his company.

As an outeast he makes the best of things, and gathers about him a band of kindred spirits who know no law. There is an air about the group which at once tells the eritical observer that their deeds are evil. No joyous song swells the throat of the male. His chicf entribution to the chorus of springtime is a gutfural bubbling producer with apparently nauseous effort. In small flocks they visit both pasture and wood- 
land, and are given to following cattle, clustering about the feet of the herd, presumably to feed on the insects found there. They build no nest, and the females, lacking every moral and maternal instinct, leave their companions only long

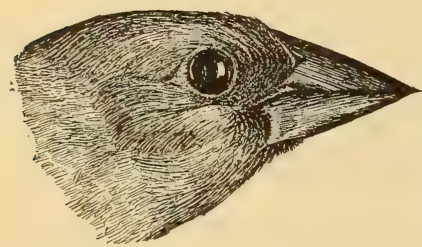

FIG. 99. Cowbird. (Natural size.) enough to deposit their eggs in the nests of other and smaller birds. I can imagine no sight more strongly suggestive of a thoroughly despicable nature than a female Cowbird sneaking through the trees or bushes in search of a victim upon whom to shift the duties of motherhood.

The ill-gotten offspring are born with the Cowbird character fully developed. They demand by far the greater share of the food, and through gluttony or mere size alone starve or crowd out the rightful occupants of the nest. They accept the attention of their foster-parents long after they could care for themselves; and when nothing more is to be gained desert them and join the growing flocks of their kind in the grainfields.

497. Xanthocephalus xanthocephalus (Bonap.). YELLOW-HEADED BlACKBIRD. $A d$. $\sigma^{7}$.- -Head, neck, throat, and breast orange-yellow; region before the eye and chin black; outer wing-coverts white, rest of the plumage black. Ad. o.- Forehead, line over the eye, sides of the head, throat, and upper breast pale, dirty yellow, more or less mixed with white; lower breast generally more or less marked with white; rest of the plumage grayish brown. L., 10.00; W., 5.50; T., 4*05; B., 85 .

Range.-W. N. Am. Breeds from s. B. C., s. Mackenzie, sw. Keewatin, and n. Minn. s. to s: Calif., Ariz., and Mex., and e. to s. Wisc., cen. Iowa, n. Ills., and Ind.; winters from sw. Calif., s. Ariz., and sw. La. s. to Mex.; accidental in Greenland and in various e. localities from Ont. and Que. to S. C., Fla., and Cuba.

Washington, A. V., one instance, Aug. Cambridge, A. V., one record, Oct. Glen Ellyn, A. V., May 21, 1898. SE. Minn., common S. R., Apl. 21.

Nest, bulky, of coarse reeds, grasses, etc., in marshes. Eggs, 4-5, grayish white, evenly and rather obscurely speckled with pale cinnamon-brown, $1 \cdot 00 \times \cdot 72$. Date, se. Minn., May 18 (first egg).

When nesting, the Yellow-head is one of the characters of the quillreed or tule marshes. Later, he joins others of his kind, forming vast flocks which frequent corn and grain fields or wherever food can be found.

"If result were commensurate with effort, the Yellow-head would be a world-famed songster; but something besides unbounded ambition and limitless muscular exertion is required to produce music. In vain the Yellow-head expands his lungs and throws out his chest, his widespread tail testifying to the carnestness of his endeavor; sound he produces in volume, but surely such a series of strained, harsh calls, whistthes like escaping steam, grunts, groans and pig-like squeals never before did duty as a song. In his youth he does far better, the note of the young 
bird being a wooden rolling call as different from the voice of the parent as is that of the young Baltimore Oriole." (Chapman, F. M., "Camps and Cruises.")

1909. Roberts, T. S., Auk, XXVI, 371-389 (home-life).

498. Agelaius phœeniceus phœniceus (Linn.). RED-WINGED BlackBIRD. Ad. $\sigma^{2}$--Lesser wing-coverts-'shoulders'-bright scarlet; middle wing-coverts varying from ochraceous-buff to buffy white; rest of the plumage black. Ad. o in winter. - Similar, but upperparts margined, with rusty. Im. $\sigma^{7}$ in winter. - Upperparts margined with rusty and buffy; underparts tipped with whitish; lesser wing-coverts dull orange-red mixed with black. Ad. . - - Head and back blackish, streaked with rusty and buffy; rump and upper tail-coverts fuscous, more or less edged with ashy; wings fuscous, edged with buffy, the lesser coverts sometimes tinged with reddish; underparts conspicuously streaked with black and white; the throat tinged with orange or yellow. of L., 9.51 ; W., $4 \cdot 72$; T., $3 \cdot 77 ;$ B., 88 , depth at base $\cdot 50$.

Range.-N. A. e. of the Great Plains, except Gulf coast and Fla. Breeds from Ont., N. S., and Que., southward; winters mainly s. of Ohio and Del. valleys, locally $\mathrm{n}$. to Mass.

Washington, common P. R., abundant in migration. Ossining, common S. R., Feb. 25-Nov. 11. Cambridge, abundant S. R., Mch. 10-Aug. 30.; a few winter. N. Ohio, abundant S. R., Mch. 1-Nov. 15. Glen Ellyn, common S. R., Mch. 5-Nov. 19. SE. Minn., common S. R., Mch. 8-Nov. 14.

Nest, of coarse grasses, weed stalks, etc., lined with finer grasses and rootlets, attached to low bushes or reeds. Eggs, 3-5, pale blue, singularly streaked, spotted or scrawled with dark purple or black, chicfly at the larger end, $1.04 \times 72$. Date, Chester Co., Pa., May 16; Cambridge, May 16; se. Minu., May 8.

A swiftly moving, compact band of silent birds, passing low through the brown orchard, suddenly wheels, and, alighting among the bare branches, with the precision of a trained choir breaks into a wild, tinkling glee. It is quite possible that in the summer this rude chorus might fail to awaken enthusiasm, but in the spring it is as weleome and inspiring a promise of the new year as the peeping of frogs or blooming of the first wild flower.

Plain, streaked Mrs. Redwing, who has been spending the winter in flocks composed only of others of her sex, soon appears, but mating is delayed until late April or early May. Then we find the old homes in the wet meadows and marshes oceupied by apparently the same birds which have dwelt there for years.

Mounting the topmost branch of a tree not far fom the nest, the male becomes an ever-vigilant sentinel. His rich "komg-quér-rēe"," which by association is so strongly suggestive of reedy marshes, is a signal that "all's well." He challenges all suspicious characters by an inquiring chŭt, chuck, and with a long, shrill alarm-note, chece-ce-e-ce-e, circles out on fluttering wings, his gorgeous crimson cpaulets showing conspicuously.

The nesting season is a short one, and in July young and old begin to gather in flocks in the marshes, where later they will be found, in countless numbers, feeding on the wild rice.

1905. Herrick, F. H., Home-Life of Wild Birds, 45-48. 
498b. A. p. bryanti Ridgw. Bahama Red-wing. Similar to $A$. p floridanus but smaller, the bill much more slender; $q$ with the underparts streaked with brownish. W., 3.70 ; T., 3.50 ; B., '90; depth of bill at nostril, $\cdot 35$.

Range.-SE. coast of Fla., Florida Keys to Key West, and the Bahamas.

498c. A. p. floridanus Mayn. FlorIdA RED-WING. Similar to $A . p$. phoeniceus but smaller, bill longer, and more slender. $0^{7} \mathrm{~W} ., 4^{\circ} 20 ; \mathrm{B} .{ }^{\circ} 90$; depth at base, $" 40$.

Range.-Fla. (except the se. coast and keys), and w. along the coast at least to Galveston, Tex.

Nesting date, Lake Flirt, Fla., Apl. 15.

498d. A. p. fortis (Ridgw.). ThICK-BILlLED RED-WING. Similar to A. p. phaniceus but larger (largest of the genus), bill shorter and proportionately thicker, $\&$ somewhat paler and browner. $\sigma^{*}$ W., $5{ }^{\circ} 00$; B., ${ }^{\circ} 80$; depth at base $\cdot 50$.

Range.-Cen. N. A. Breeds from cen. Mack. and s. Keewatin s. to ne. Colo. and $\mathrm{n}$. Texas; winters principally in the s. part of its breeding range, wandering irregularly further eastward. SE. Minn., common T. V.

501. Sturnella magna magna (Linn.). MEAdowlark. (Fig. 63b.) Ads. in summer.-Prevailing color of upperparts black, crown with a buffy line through center, back bordered and tipped with rufous and buffy; outer tail-feathers mostly white, middle ones with imperfect, connected bars, not reaching the outer edge of the feather; line from bill over eye yellow; sides of the throat and ear-coverts whitish; throat, between the lower branch of the under mandible, breast, and middle of the upper belly bright yellow; a black crescent on breast; sides and lower belly whitish, spotted or streaked with black. Ads. and Im. in winter.-Feathers all much more widely margined, the prevailing color of the upperparts rufous-brown; black breast crescent veiled with buffy; yellow of underparts duller. L., $10 \cdot 75 ;$ W., 4*76; T., 3.16; B., $1 \cdot 30$.

Remarks. - This bird is to be distinguished from the western species by its much darker upperparts, by the imperfect, confluent tail-bars, and, especially, by the absence of yellow on the sides of the throat.

Range.-E. N. Am. Breeds in Transition and Upper Austral zones from e. Minn., s. Ont., s. Que., and N. B. s. to n. Tex., Mo., and N. C., and w. to w. Iowa., e. Kans., and nw. Tex.; winters regularly from s. New England and Ohio valley s. to the Gulf States, and n. locally to the Great Lakes and s. Maine.

Washington, common P. R., less common in winter. Ossining, tolerably common S. R., Feb. 20 to Nov. 27; a few winter. Cambridge, common S. R., not common W. V. N. Ohio, abundant S. R., Mch. 5-Nov. 15; a few winter. Glen Ellyn, common S. R., Jan. 24-Nov. 15; irregular W. V. SE. Minn., common S. R., Mch. 25-Oct. 15 , rare W. V.

Nest, of grasses, usually arched, on the ground. Eggs, 4-6, white, spotted or speckled with cinnamon or reddish brown, $1 \cdot 15 \times 80$. Date, Beech Haven, N. J., May 7; Chester Co., Pa., May 9; Cambridge, May 28; Tampico, Ills., May 5; se. Minn., May 16.

In walking through grassy fields, meadows, or marshes, we sometimes flush rather large, brownish birds, which, alternately flapping and sailing, scale away with a flight that suggests a Quail's. Their white outer tail-feathers show conspicuously, and, if, instead of returning to the ground, thry alight on a fence or the outer branch of a tree, as they utter a dzil or yert and metallic twitter, they will nervously flit their tails, displaying the same white feathers. When in an exposed 
position they are wary and difficult to approach, but when walking about on the ground they trust to the long grasses for protection, and sometimes do not take wing until one is within a few feet of them.

In Cuba I noticed that a Meadowlark, closely related to ours, was very careful to conceal its brightly colored breast, with its distinctly marked crescent, and, although even perching birds were not shy, they would invariably turn their backs upon me as I drew near.

The Meadowlark's song is a clear, plaintive whistle of unusual sweetness. It is subject to much variation, both individually and geographically. The birds near my home at Englewood, N. J., generally sing:

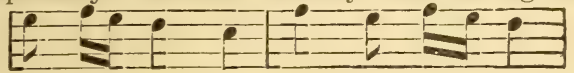

But the songs of

Florida birds are so different, I hardly recognized them by their notes.

In the fall, Meadowlarks at the north gather in flocks and resort to large marshes.

1908. Chapman, F. M., Camps and Cruises, 15 (nesting).

501c. S. m. argutula Bangs. Sotthern Meadowlark. Similar to $S$. m. magna but smaller and darker. W., 4*40.

Range.-Austroriparian and Floridian faunas from s. Ills., sw. Ind., and N. C., s. to the coast of se. Tex., La., and s. Fla.

Nesting date, San Mateo, Fla., Apl. 22.

501.1. Sturnella neglecta $A u d$. Western Meadowlark. Ads.Prevailing color of upperparts grayish brown, crown with a central buffy stripe; back black, feathers widely margined with grayish brown; rump and upper tail-coverts with narrow black bars; outer tail-feathers mostly white; middle ones brownish gray, barred with black, the hars generally not connected, and as a rule reaching the margins of the feathers; line from the bill over the eye yellow; ear-coverts grayish white; throat ycllow, this color reaching up on the sides of the throat and touching ear-coverts; breast and upper belly yellow, a black crescent on breast; sides and lower belly whitish, spotted or streaked with black. Ads. and Im. in winter.-Cpperparts more widely margined with grayish brown, these grayish brown tips with small, broken black bars; yellow of underparts duller, the black crescent veiled with whitish. W., $4^{*} 60 ;$ T., $3 \cdot 00 ;$ B., $1 * 25$.

Range.-W. N. Am. Breeds from s. B. C., cen. Alberta, and s. Man. s. to s. Calif., n. Mex., and cen. Tex.; winters from s. 13. C. and Iowa, s. to L. Calif., and Guanajuato; e. casually to Wisc., s. Mich., and n. Ill., accidental in s. Mackenzie.

SE. Minn., common S. R., Mch. 25-Oct. 15.

The Western Meadowlark resembles the eastern hird in habits, but its markedly different song and the fact that at the junction of their ranges in the Mississippi Valley both birds may be found nesting without evidence of geographical intrergradation, have finally won for the western bird the rank of a species. Just what the relations of the two forms may be in the Rio Grande Valley, and what part Sturnella magna hoopesi, of that region, plays in the problem has not yet been determined.

The call note of reglecte is a rhucki, chuck followed by a woorten rolling $b-r-r-r-r$, analogous to but very unlike the dzil or yert and metallie, twitter of magna. The song of magna is a clean-rut fifing without grace notes; that of neglecta is of mellow bubbling flute-notes. The 
flight-songs of the two birds are much alike, but, in my experience, neglecta sings much more frequently on the wing, and, in the height of the mating season, sings as often in the air as from a perch.

1890. Seton, E. T., Proc. U. S. N. M., XIII, 573-379 (biog.).-1896. Belding, L., Auk, XIII, 29, 30 (songs).

506. Icterus spurius (Linn.). Orchard OrIole. Ad. $\sigma^{\top}$ - - Head, neck, throat, and upper back black; breast, belly, lower back, and lesser wing-coverts chestnut; wings and tail fuscous, more or less edged or tipped with whitish. Ad. o.-Upperparts grayish olive-green, brighter on the head and rump; wings fuscous, middle and greater coverts tipped with whitish; tail bright olive-green; underparts dull yellow. Im. on, first winter plumage. - Similar to the ad. \&, but with the back browner. Im. or, first nuptial plumage. - Similar to the ad. $\circ$, but with the throat black and occasionally patches of chestnut on the underparts. L., $7 \cdot 32 ;$ W., $3 \cdot 18 ;$ T., $2 \cdot 92 ;$ B., .65 .

Remarks.-The interesting changes of plumage which the Orchard Oriole undergoes are well illustrated by the accompanying plate (plate xxi). The juvenal or nestling plumage (not shown) resembles, but is browner above and paler below than the first winter plumage (Fig. 6), which is acquired by molt of the body feathers and wing-coverts in July. The male in first winter plumage is indistinguishable from the female in first winter plumage; and differs only slightly from the adult female in summer plumage (Fig. 5). In first nuptial plumage, acquired by partial molt in spring, the male has the throat black, but, as a rule, is otherwise like the female (Fig. 4). The amount of black in the throat varies. Sometimes it is restricted to a few feathers, again it spreads somewhat down the breast, and such highly developed birds usually have traces of chestnut in the underparts (Fig. 3).

The postnuptial (fall) molt apparently does not occur until after the bird has left us for the South, when it passes into winter plumage (Fig. 2) which, as Dwight has said, resembles that of the adult. There is no spring molt and the adult chestnut and black breeding plumage (Fig. 1) is acquired by a wearing off of the buffy tips which fringe the winter plumage.

Range.-E. N. Am. Breeds from N. D., nw. Minn., Wisc., Mich., s. Ont., cen. N. Y., and Mass. s. to n. Fla. and the Gulf coast to s. Tex., and in Mex. to Oaxaca and Jalisco, and w. to cen. Nebr. and w. Kans.; winters from s. Mex. to n. Colombia; casual n. to Vt., N. H., Maine, and N. B., and w. to Colo.; occasional in s. Fla. and Cuba in spring migration.

Washington, common S. R., Apl. 29-Aug. 22. Ossining, common S. R., May 2-Aug. 6. Cambridge, S. R., sometimes rather common, May 15July. N. Ohio, common S. R., Apl. 28-Scpt. 5. Glen Ellyn, not common S. R., Apl. 28. SE. Minn., uncommon S. R., May 10-Aug. 26.

Nest, pensile, of grasses interwoven, near the extremity of a limb, 10-15 fect up. Eggs, 3-5, bluish white, distinctly and obscurely spotted, blotched, and scrawled with fuscous or black, $\cdot 79 \times \cdot 58$. Date, Ossining, N. Y., May 29 ; St. Louis, Mo., May 14.

Although the Orchard Oriole generally frequents apple orchards, he is entirely at home among the shade trees of our lawns.

There is an air of refinement about this bird which seems to pervade his whole life history. He dresses quietly but with excellent taste, his nest is of the choicest materials, while his song suggests the finished effort of a perfectly trained performer. His voice is indeed unusually rich and flexible, and he uses it with rare skill and expression. Words can not describe his song, but no lover of bird-music will be long in the virinity of a singing ()rchard ()riole without learning the distinguished songster's name. 


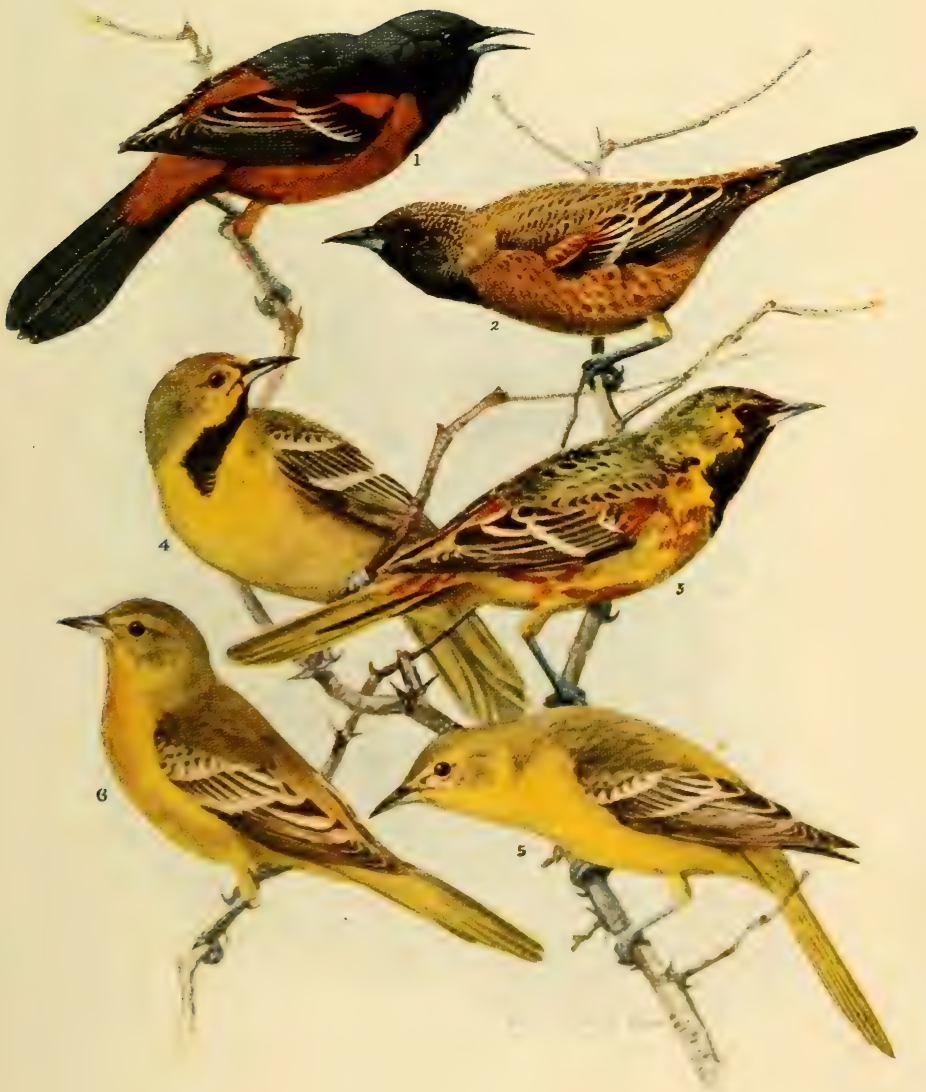

1. Adult male, summer.

2. Adult male, winter.

3. Male, first nuptial plumage

Plumages of the Orchard Oriole

4. Male, first nuptial plumage.

5. Adult female.

6. Male, first winter. 

507. Icterus galbula (Linn.). Baltimore Oriole. Ad. o.-Head, neck, throat, and upper back black; breast, belly, lower back, and lesser wing-coverts deep, rich, reddish orange; wings black, the outer margin of the greater coverts and quills edged with white; end half of middle tailfeathers black, base orange; all the others orange, crossed by a black band in the middle. Ad.. .- Upperparts brownish or grayish orange, brighter on the rump; head and back mottled with black; wings fuscous, greater and middle coverts tipped with white; tail like the rump, the middle feathers stained with black; underparts dull orange, throat sometimes spotted with black. L., $7 \cdot 53$; W., $3 \cdot 52 ;$ T., $2 \cdot 84 ;$ B., 70 .

Range.-Breeds mainly in Transition and Upper Austral zones from cen. Alberta, cen. Sask., Man., Ont., N. B., and N. S. s. to n. Tex., cen. La., and n. Ga. and w. to Mont., Wyo., and Colo. e. of the Rocky Mts.; migrates through e. Mex.; winters from s. Mex. to Colombia; accidental at York Factory, Hudson Bay, and in Cuba.

Washington, rather common S. R., Apl. 29-Aug. 26. Ossining, common S. R., May 2-Sept. 1. Cambridge, very common, S. R., May 8 through Aug. N. Ohio, common S. R., Apl. 15-Sept. 10. Glen Ellyn, common S. R., Apl. 26-Sept. 4. SE. Minn., common S. R., May 1-Sept. 1.

Nest, pensile, of grasses, bark, plant fibers, hair, strings, etc., firmly interwoven, in fruit or shade trees, near the extremity of a limb 20-40 feet up. Eggs, 4-6, white, singularly scrawled with fine, distinct or obscure black or fuscous lines, and with a few spots or blotches, $94 \times \cdot 63$. Date, D. C., May 27; Cambridge, June 1; Martin's Ferry, Ohio, May 20; se. Minn., May 22.

Sometimes Nature, as if to remind us of the richness of her stores, s?nds from the tropics a gayly attired bird which seems quite out of place among the more soberly clad inhabitants of northern climes. The genus Icterus contains nearly forty species, all more or less brightly dressed in orange, yellow, and black, but not one is more beautiful than our Baltimore Oriole. There is reason to believe that he is not unaware of his own charms; indeed, we may almost suspect him of intentionally displaying them. His splendor is not to be lost in the forest, and, whistling loudly, he flashes through our fruit and sharde trces.

He leaves to the female the task of constructing their wonderfully made nest, but he seems quite as deeply interested in the performance as if he were a skilled weaver himself; indeed, he would probably assist if he were permitted.

Young Orioles have been well named by Mrs. (Olive Thorne Miller the ery-babies of the bird world. Their ceaseless call for food is almost as much a midsummer voiee as the song of cicarlass. Long after they have left the nest we may find them in the different trees about our lawn calling out monotonously and persistently dee-dee-deredee, until one of the parents arrives and momentarily fills their mouths.

BULLOCK's ORIOLE (508. Icterus bullocki), a speries of our Western States, has been taken in New York and in Maine.

509. Euphagus carolinus (Müll.). RUsту BLA(квн1). Al. ", breeding plumage.-Entire plumage uniform glossy bluish black; tail-feathers of nearly equal length. Ad. on and Im. o in winter...-imilar, but the upperrparts widely tipped with rufous or rusty, the underparts similarly tipened with ochraceous- or eream-buff; a buffy line oxer the eye. Ad. : in hrecting plumage.-Slate-color, glossy above, duller below; wings and tail darker 
and more glossy. Ad. o and Im. o in winter.- Similar, but somewhat lighter, the upperparts widely tipped with rufous or rusty, the underparts similariy tipped with ochraceous- or cream-buff. L., 9.55; W., 4.61; T., 3.52 ; B., 80 .

Range.-E. and n. N. Am. Breeds in Boreal zone from the Kowak River, Alaska, n. Mackenzie, cen. Keewatin, and n. Ungava s. to s. Alaska, cen. Alberta, s. Keewatin, cen. Ont., N. Y., Vt., N. H., n. Maine, N. B., and N. S.; winters mainly s. of the Ohio and Delaware valleys to the Gulf coast; w. in migration to the Plains; casual in B. C., Mont., and Colo.; accidental in Calif., L. Calif., and Greenland.

Washington, common W. V., Oct. 13-Apl. 30. Ossining, common T. V., Mch. 26-May 8; Sept. 28-Nov. 27. Cambridge, very common T. V., Mch. 10-May 8; Sept. 15-Oct. 31. N. Ohio, common T. V., Mch. 5-May 10; Sept. 10-Nov. 15. Glen Ellyn, common T. V., Mch. 3-May 8; Sept. 12Nov. 15; uncommon W. V. SE. Minn., common T. V., Mch. 26-Nov. 24.

Nest, of twigs and coarse grasses lined with finer grasses, in coniferous trees or on the ground. Eggs, 4-7, grayish green to pale green, thickly blotched with light and dark brown and purple, $1^{\circ} 00 \times \cdot 76$ (Chamberlain). Date, Wilmurt, N. Y., May 7; Kings Co., N. S., May 11.

This bird is found during the migrations in small flocks on freshwater meadows or about open, bushy swamps, feeding on the ground in alder thickets or along the edges of swampy woods. It resembles, more or less, the Red-winged Blackbird in size, flight, and notes, but unlike this species, with which it sometimes associates, it is comparatively quiet and retiring. Only at times, in the spring, do we find the flocks musical centers, whence issues a confused medley of whistles, sweeter and higher-pitched than the best efforts of the Redwings. Little is known of this Blackbird in its northern home. It gathers into flocks early in the summer, and the most frequently heard note is a cluck, not in the least characteristic. Its quiet demeanor, pale yellow eye, and uniform color are its chief distinguishing characters in the field, where it may be mistaken for the Bronzed or Purple Grackle. The gray female is unlike the streaked female Redwing.

\section{J. Dwight, JR.}

BREwER'S BLACKBIRD (510. Euphagus cyanocephalus) inhabits western North America, and is of casual occurrence as far east as Illinois and Louisiana, and has been once recorded from South Carolina. It may be distinguished from $E$. carolinus by its deep violet-purple head and the comparative absence of rusty tips to the feathers.

511. Quiscalus quiscula quiscula (Linn.). Purple Grackle. (Fig. 63c.) $A d$. $\sigma^{7}$. - Head, neck, throat, and upper breast all around varying from brilliant metallic purple to bluish green or steel-blue; back and rump varying from bottle-green to metallic purple or shining brassy green, the feathers with iridescent bars; wings and tail externally metallic purple or bluish black; lower breast and belly resembling the back but duller. Ad. \&.Much duller than the male, but the feathers of the back generally showing at least traces of iridescence. $\sigma^{7}$ L., $12^{\circ} 00-13 \cdot 50$; W., 5*66; T., $5 \cdot 18$; B., $1 \cdot 18$.

Remarks.--Intermediates between this and the Bronzed Grackle are found where their ranges adjoin, but typical quiscula always has irideseent hars on the feathers of the back, rump, and belly, while in aneus these bars are wanting. (On relationships of this group see Chapman, Bull. Am. Mus. Nat. Hist., IV, 1892, 1-20.)

Range.-Middle Atlantic coast region of the U. S. Breeds in the Car- 
olinian fauna from the n. shore of L. I. Sound, rarely Mass., and the middle Hudson Valley w. to the Alleghanies and s. to the uplands of Ga., Ala., and e. Tenn.; winters mainly s. of the Delaware Valley.

Washington, common T. V. and S. R., Feb. 20; a few winter. Ossining, tolerably common S. R., Feb. 15-Nov. 8. Cambridge, rare S. R.

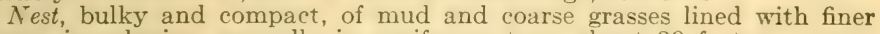
grasses, in colonies, generally in coniferous trees about 30 feet up, sometimes in bushes or holes in trees. Eggs, 3-7, very variable, generally pale bluish or bluish green, singularly spotted, blotched, or scrawled with cinnamon-brown, umber, or black, but sometimes evenly speckled with brownish, and rarely almost solid cinnamon- or rufous-brown, $1{ }^{\prime} 15 \times 82$. Date, D. C., Apl. 17; Delaware Co., Pa., Apl. 25.

When winter gives signs of retreating, there comes from the south in sable array the tried advance guard of the feathered army which is impatiently awaiting the order to march. In close rank they come, phalanx after phalanx, to retake the land which winter-once conquering, now defeated-yields to them. The air resounds with martial music; their harsh voices, united, rise in an inspiring chorus.

The campaign over, they settle in colonies on their recently acquired possessions, and these careless rovers become so attached to their homes and families that they are rarely seen far from their vicinity. Sometimes we may see them walking sedately over the lawns near their home, their glossy plumage gleaming in the light, and their yellow eyes giving them a peculiar, unbirdlike expression. But when their young are old enough to care for themselves, the old habits return, and, leading their offspring into the world, they teach them the ways of wanderers. Meeting others of their kind, they join forces, and in the fall we find them in hordes ravaging the country.

The Grackle's disposition is as gloomy as his plumage is dark. Life with him is a serious affair. He seems to utterly lack the Blue Jay's sense of humor. As a parent he is beyond reproach, and every moment is devoted to the care of his young, but it is all done in a joyless way. Eggs and nestlings form part of his fare, and I can imagine bird-mothers frightening their young into obedience by threatened visits from that ogre, the Grackle.

1892. Chapman, F. M., Bull. A. M. N. H., 1-20 (relationships).-1897. JoNes, L., Wilson Bull., No. 15, 39-56 (roosts).

511a. Q. q. aglæus (Baird). Florida Grackle. Ad. 7 $^{7}$-Head, neck, throat and upper breast all around metallic: violet-purple; back and rump rich bottle green, the feathers with more or less concealed iridescent bars; wings and tail externally metallic purple or bluish black; the wingcoverts generally with iridescent tips; lower breast and belly similar to the back but duller. Ad. Q. - Not distinguishable in color from the o of $Q$. $q$. quiscula, but differing in size. W., 5*38; T., 4.90; B., 1.25.

Range.-S. Atlantic coast from S. C. through to Fla., and w. in the s. part of the Gulf States to e. Tex.

Nesting date, San Mateo, Fla., Mch. 30.

This is a locally abundant bird, and is found in flocks throughout the year. In Florida it sometimes lives in the towns in which live-oraks grow, and it also makes its headquarters in cypress 'bays,' but its 
favorite resort is among the cabbage palmettos, upon the berries of which it feeds.

511b. Q. q. æeneus Ridgw. Bronzed Grackle. Ad. ơ--Head, neck, throat, and upper breast all around varying from brilliant metallic purple to bluish green or steel-blue; back metallic seal-bronze, the feathers without iridescent bars; wings and tail metallic purplish or bluish black; lower breast and belly similar to the back but duller. $A d$. o.-Much duller, the back and belly brownish, sometimes without metallic reflections and never with iridescent bars. W., 5•62; T., 5•04; B., 1*21.

Range.-Central and e. N. A. Breeds from Great Slave Lake, cen. Keewatin, N. S., and N. F., s. to Mont., and Colo. (e. of the Rocky Mts.) s. to San Antonio, Tex., Gulf States, cen. La., cen. Miss., cen. Ala., W. Pa, cen. N. Y., and Conn. (s. of N. Y. breeds only w. of the Alleghanies); winters mainly from the Ohio Valley s. to s. Tex.; casual in migration on the s. Atlantic coast.

Washington, rare T. V., between Feb. 20 and Apl. 17. Ossining, tolerably common T. V., Apl.; Nov. Cambridge, abundant S. R., Mch. 10Nov. 1; occasional in winter. N. Ohio, abundant S. R., Mch. 1-Nov. 15; rarely winters. Glen Ellyn, common S. R., Mch. 5-Nov. 15. SE. Minn., common S. R., Mch. 18-Nov. 1; rare in winter. Apl. 25.

Nesting date, Cambridge, May 2; Grinnell, Iowa, May 2; se. Minn.,

"The general habits of the Bronzed Grackle are in all respects identical with those of the Purple Grackle. . . .

"From an almost equal familiarity with the two birds we are able to say that their notes differ decidedly, especially those of the male during the breeding season, the 'song' of the western bird being very much louder and more musical or metallic than that of its eastern relative" (Ridgway).

513. Megaquiscalus major major (Vieill.). BoAt-tailed Grackle. Ad. $\sigma^{7}$.- Glossy bluish black; head, throat, and breast more purplish, wings and tail more blackish. Ad. o.-Much smaller, upperparts blackish brown, underparts soiled ochraceous-buff. or L., 16.00; W., 7·50; T., 7.00; B., 155.

Range.-Austroriparian fauna from Chesapeake Bay to Fla., and w. to the e. coast of Tex.

Nest, bulky and compact, of grasses, seaweed, etc., with a median layer of mud or partially decayed vegetation, in colonies in bushes. Eggs, 3-5, pale bluish white, frequently tinged with vinaceous-brown, singularly spotted, blotched, and scrawled with purplish or blackish, $1.32 \times 90$. Date, Ft. Pierce, Fla., Mch. 20; Ft. Macon, N. C., Apl. 26; Accomac Co., Va., Apl. 28.

Boat-tail Grackles are rarely if ever found far from water. Shallow lakes or marshy lagoons grown with aquatic plants are their favorite resorts. Here they may be seen in small groups, which usually contain more males than females, walking or jumping from plant to plant, sometimes springing into the air to catch a passing insect, or wading along the shore in search of food. Their usual notes are hoarse, rather forced whistles; more rarely they utter a singular rolling call, which bears a close resemblance to the sound producd by a Coot in pattering over the water. The Great-tailed Grackle, the larger southern form of this species, is uncuuestionably polygamous, but it is unknown whether the Boat-tail has more than one mate. 
52. Family Fringillide. Finches, Sparrows, Etc. (Fig. 64.)

This, the largest family of birds, contains some twelve hundred species and subspecies, which are represented in all parts of the world except the Australian region. Sparrows are plastic birds, responding so readily to environmental influences that probably not more than half the forms recognized in this family deserve standing as species, while the remaining half are climatic or geographic races. They present wide diversity of form and habit, but generally agree in possessing stout, conical bills, which are admirably adapted to crush seeds. They are thus chief among seed-eaters, and for this reason are not so migratory as insect-eating species. It is only of late years that their great economic value as the destroyers of weed-seeds has been recognized.

The brown, streaked Sparrows are, to a large extent, field- or plaininhabiting, and their neutral colors are therefore à means of protection in the exposed situations they inhabit. The brighter Grosbeaks and Finches are more arboreal. Many species take high rank as songsters, and some of our favorite cage-birds belong to this family.

The birds of this family are now generally considered to represent the most highly developed type of the Class Aves, and the anatomical reasons on which this claim is based are supported by their numerical abundance; thus the Order Passeres, beyond question the highest of avian groups, contains the greatest number of species, a distinction in turn shared by its 'highest' family.

I. Underparts with red.

\section{KEY TO THE SPECIES}

II. Underparts with no red and without distinct streaks; throat or breast sometimes with a patch or spot.

III. Underparts without red and with numerous streaks.

\section{Underparts with red.}

1. Wing-coverts plainly tipped with white or whitish, or with a white or yellow band in the wing.

A. No red in the upperparts.

a. Back black, rump whitish, throat black, breast and under wing-

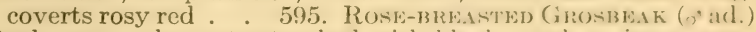

$b$. Back and underparts streaked with black; under wing-(o)verts rosy red. . . 595. Rose-breasted Grosbeak (ơ im.).

$B$. With red in the upperparts.

$a$. Red on upperparts confined to crown or forchead, and sometimes a tinge on the rump; wing under $3 \cdot 25$.

$a^{1}$. Rump and flanks generally without blackish streaks; feathers of back generally with whitish borders.

527. Greenland Redpoll. 527a. Hoary Redpoll.

$a^{2}$. Rump and flanks always streakerl; feathers of back with little white, if any, and generally with hrownish horders.

528. REDPOLL and races.

$a^{3}$. Back cinnamon-brown, unstreaked; (rown, natpe, and sides of neck black; a yellow band in the wing.

EUROPEAN GoldFinch.

b. Red or pink spread more or less over entire upperparts; wing over $3 * 25$. 


\section{$b^{1}$. Tips of mandibles crossed.}

522. White-Winged Crossbill (o⿱ ad.).

$b^{2}$. Bill stout; mandibles not crossed. 515. Pine Grosbeak (ơ ad.). 2. Wing-coverts not tipped with white.

a. Throat black or blackish; wings and tail red; body red or olive.

b. Throat and more or less of underparts red or greenish red.

$b^{1}$. Plumage blood-red, brownish red, or greenish red; tips of the mandibles crossed . . . . 521. Am. Crossbill ơ.

$b^{2}$. Plumage dull reddish; belly whitish; back indistinctly streaked, with bristly feathers over the nostrils.

$b^{3}$. Head blue; back green; rump red

517. Purple Finch (ơ ad.).

601. Painted Bunting (ơ ad.).

\section{Underparts with no red and without distinct streaks; throat or} breast sometimes with a patch or spot.

1. Tail with white spots, bars, or patches.

A. Back plain, without streaks.

a. Throat and breast black, brown, or slate-color, sharply defined from the white belly.

$a^{1}$. Breast black or brown; sides rufous . . . 587. TowheE.

$a^{2}$. Breast slate-color; sides the same, or brownish.

b. Throat and breast not black or brown.

567. Junco. 567e. Carolina Junco.

$b^{1}$. Throat and belly more or less yellow or ashy.

$b^{2}$. Wing over $4^{\circ} 00$; bill stout, greenish yellow.

514. Evening Grosbeak.

$b^{3}$. Bill small and sharp; back brown; throat yellowish.

529. GOLDFINCH (o and im.).

$b^{4}$. Body bright yellow, cap black . 529. GoldFinch (o ad.). $c^{1}$. Underparts pure white, middle of back black.

B. Back streaked with black, brown, or white.

534. SNOWFLAKE.

$a$. Bend of the wing yellow; tail under $2 \cdot 20$.

546. Grasshopper Sparrow.

b. Breast black or blackish; lesser wing-coverts reddish brown.

c. Breast buffy; belly whitish; outer tail-feathers white, next three or four more or less white with a black band at the end; secondaries not entirely white . . . 539. McCown's' Longspur o.

a. Underparts entirely light brown or buffy, only two outer tailfeathers white; no yellow on the bend of the wing.

537. SMith's LONGSPUR.

e. Underparts pure white, with a blackish spot on the center of the breast, a black stripe on the sides of the throat; sides of the crown and ear-coverts chestnut . .552. LARK SPARRow.

$f$. Wing slightly over $4^{\circ} 00$; underparts pure white or washed with rusty; head and rump white or rusty; most of secondaries white.

2. Tail without large white spots or patches.

534. SNOWFLAKE.

A. Back plain, without distinct streaks.

a. Back blue, bluish or brownish blue.

$a^{1}$. Wing over $3^{\circ} 00$; lesser wing-coverts chestnut or with broad chestnut tips . . . . . . 597. BluE Grosbeak.

$a^{2}$. Wing under $3 \cdot 00$; lesser wing-coverts blue or bluish, tipped with light brown .. . . . . 598. INDIgo BUNTING.

b. Back not blue.

$b^{1}$. Back green or greenish, or rump yellow or greenish yellow.

$b^{2}$. Mandibles not crossed.

$b^{3}$. Back greenish.

601. Painted Bunting 9. 
$b^{4}$. Back and underparts slaty gray; bill black.

515. Pine Grosbeak (o and im.).

$b^{5}$. Forehead, rump, underparts, and scapulars yellow or brownish yellow; secondaries white; bill yellow.

$c^{2}$. Mandibles crossed.

514. Evening Grosbeak ơ.

$c^{3}$. Wing-bars white . 522. White-winged Crossbill. $c^{4}$. Without white wing-bars . . . 521. AM. Crossirll.

$c^{1}$. Back brown or brownish, ashy, or slate-color.

$c^{2}$. Head and rump yellowish or reddish; wing-bars white; wing over $4^{\circ} 00$. . . . 515. Pine Grosbeak (o and im.).

$c^{3}$. Underparts brownish cream-buff; wing-coverts with broad chestnut tips; wing over $3^{\circ} 00$. . 597. Blue Grosbeak o.

$c^{4}$. Underparts whitish; wing without yellow and under $3^{\circ} 00$.

598. INDIGO BUNTING ㅇ.

$c^{5}$. Back ashy; spot before the eye and on bend of wing yellow.

B. Back distinctly streaked.

550. Seaside Sparrow.

a. Bend of the wing yellow.

$a^{1}$. Tail over $2 \cdot 20$.

$a^{2}$. A white throat-patch; breast gray; a yellowish line over the eye . . 558. White-throated Sparrow.

$a^{3}$. A black spot on the throat; breast yellow, or both.

604. Dickcissel.

$a^{4}$. No yellow over the eye; breast ashy or buffy; outer tailfeathers much the shortest.

575. Pine-woods Sparrow. 575a. Bachman's Sparrow.

$b^{1}$. Tail under $2 \cdot 20$, the feathers narrow and sharply pointed.

$b^{2}$. Crown olive-brown, a blue-gray line through its center; cheeks and breast ochraceous-buff.

549a. Nelson's Sparrow.

$b^{3}$. Crown blackish, a cream-buff line through its center.

b. Bend of the wing not yellow.

546. Grasshopper Sparrow.

$b^{1}$. Crown bright reddish brown, the feathers sometimes tipped with ashy or brownish, but without black streaks.

$b^{2}$. No white or whitish wing-bars; outer tail-feathers much shorter than middle one; lesser wing-coverts, upper tailcoverts, and margins of most of the tail-feathers rufous; wing under 2.50 . . . . 584. Swamp Sparrow.

$b^{3}$. Cheeks and throat ashy, a narrow reddish brown line from back of the eye to the nape, an indistinct black spot in the center of the breast . . . . 559. TREE SPARROW.

$b^{4}$. Eye-ring whitish, entire bill brownish flesh-color.

563. Field Sparrow.

65. Rump slaty gray; underparts generally all gratyish white; forchead black, with a narrow grayish line in its middle, a narrow black line from back of the eye to the nape.

560. Chipping Sparrow.

$c^{1}$. Crown not bright reddish brown.

$c^{2}$. Crown streaked or spotted with black or black and white.

$c^{3}$. Crown with rhestmut stroaks, and sometimess a slight ashy line through its (enter; no white or whitish wingbars; outer tail-feathers much shorter than mirldle ones.

584. SWAMP SPARROW (Im.).

$c^{4}$. Crown with reddish brown; rump ashy; wing-latrs luffy;

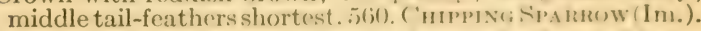

$\boldsymbol{c}^{5}$. Center of crown white; the sirles hlack; wing-hars white.

554. WhITE-CROWNED SPARROW.

$c^{6}$. Crown grayish; mandibles crossidel 5:21. A.r. ('romsilla. 
$d^{2}$. Crown mixed grayish brown and rufous, ashy, or slate-color, without black streaks.

$d^{3}$. Wing $2: 50$; bill brownish flesh-color; back rufous, streaked with black . . . . . 563. Frend SPARrow.

$d^{4}$. Wing 3.00; center of crown grayish brown, bordered by chestnut-rufous; back grayish brown, spotted with olivebrown . . . . 554. White-crowned Sparrow.

$d^{5}$. Crown slate-color; a chestnut patch behind the eye; throat black . . . . . . . English Sparrow ơ

$d^{6}$. Crown entirely dull brown; lesser wing-coverts broadly tipped with buffy. . . . . . ENGLiSH Sparrow

\section{Underparts without red and with streaks.}

1. Tail-feathers without white or yellow spots or patches.

A. Outer tail-feathers little if any shorter than the middle pair.

$a$. Head of the same general color as the back.

$a^{1}$. No yellow over the eye or on the bend of the wing or under wing-coverts.

$a^{2}$. Rump yellowish or yellowish green; mandibles crossed.

$a^{3}$. Wing-coverts tipped with white.

522. White-Winged Crossbill \&. $a^{4}$. Wing-coverts not tipped with white.

521. Red Crossbill \&.

$b^{2}$. Rump brownish or sandy or rufous; mandibles not crossed.

$b^{3}$. Back pale brownish ashy, streaked with brownish; a whitish streak over the eye; legs flesh-color; first primary as long as or longer than the second . . 541. Ipswich Sparrow.

$b^{4}$. Back and most of underparts streaked with black and reddish brown; upper and under tail-coverts streaked; first primary shorter than second; outer tail-feathers shorter than middle ones. . . . . 581. Song Sparrow.

$b^{5}$. Back distinctly streaked; a cream-buff band across the breast. . . . . . . 583. Lincoln's Sparrow.

$b^{6}$. Back grayish brown, the feathers with or without distinct streaks; first primary nearly as long as or longer than second; outer tail-feathers longer than middle pair; legs and feet blackish; with bristly feathers over the nostrils.

517. PURple Finch o.

$b^{7}$. Back without streaks; no bristly feathers over the nostrils. 598. INDIGO BUNTING o.

$b^{8}$. Upper tail-feathers and tail bright reddish brown, without black streaks; rump brighter; wing about 3.50 .

585. Fox Sparrow.

$b^{9}$. Cheeks buffy, bill pinkish; breast with a band of blackish blotches . . . 553. Harris's Sparrow Im.

$b^{1}$. A yellow mark before the eye, or on the bend of the wing, or under wing-coverts yellow.

$b^{2}$. Wing about $4^{\circ} 00$; under wing-coverts deep yellow.

595. Rose-Breasted Grosbeak 9.

$b^{3}$. Wing generally under 2.90 ; feathers of the crown black, bordered by chestnut-brown; a buffy line through the center of crown . . . 542a. SavannaH Sparrow.

$b^{4}$. Wing generally over $2 \cdot 90$; feathers of crown with small black centers bordered with cinnamon-brown and pale brownish gray . . . . . . 541. Ipswich Sparkow.

$b^{5}$. Wing about $3^{\circ} 00$; breast washed with yellow.

$b^{6}$ Wing about $3 \cdot 00$. sides brownish; 604 . DickCISSEL. from the grayish breast.

558. White-throated Sparrow. 
b. Head not the same color as the back.

$b^{1}$. A bright red crown-cap.

$b^{2}$. Rump and flanks alway's hearily streaked with blackish.

b3. Rump w28. REDPOLL and races. streaked; more or less white in the feathers of the back.

527. Greenland Redpoll. 527a. Hoary Redpoll. $c^{1}$. Crown-cap black . . . . 553. Harris's Sparrow. Ad.

B. Tail-feathers narrow and generally sharply pointed, the outer ones always much shorter than the middle pair.

a. Crown of a different color from the back, or a buffy line over the eye.

$a^{1}$. Center of crown with a more or less distinct brownish or buffy line.

$a^{2}$. Nape dull, pale olive-green, of the same color as the line over the eye, but finely streaked with black; back rufous-brown, streaked with black . . . . 547. Henslow's SParrow.

$a^{3}$. Nape bright rufous-brown, the feathers bordered by gray; the feathers of the back black, bordered by buffy whitish.

548. LeCONTE's Sparrow.

$b^{1}$. Center of crown with a more or less distinct stripe of ashy blue.

$b^{2}$. Breast and sides distinctly streaked with black or blackish.

549. Sharp-tailed Sparrow.

$b^{3}$. Breast and sides buffy or brownish, the former generally without distinct black streaks.

549a. Nelson's Sharp-Tailed Sparrow. 549b. Acadian Sharp-tailed Sparrow.

$b$. Crown of the same color as the back; no buffy line over the eye.

$a$. A yellow spot before the eye and on the bend of wing.

$a^{1}$. Upperparts very dark brown or black; the feathers edged with olive-gray or ashy, breast generally with black streaks. (Florida.) . 550a. Scott's Seaside Sparrow and races. 551. DUsky Seaside Sparrow. $a^{2}$. Back olive-gray; breast with grayish brown streaks.

b. No yellow before the eye.

550. Seaside Sparrow. $b^{1}$. Bend of wing yellow.

575. Pine-Woods Sparrow. 575a. Bachman's Sparrow.

$b^{2}$. A broad cream-buff band across the breast.

583. Lincoln's Sparrow.

$b^{3}$. No cream-buff band on the breast; streaks on the hreast tending to form a spot in its middle. 581 . SONG SPARRow,

2. Tail with white patches or base of tail yellow.

$A$. Base of the tail yellow . .533. Pine Siskin.

$B$. Outer tail-feathers with white patches.

$a$. Hind toe-nail shorter than the bill from the nostril.

$a^{1}$. Lesser wing-coverts rufous; breast streakerl with black.

540. Vesper Sparrow.

$a^{2}$. Sides of crown and ear-coverts chestnut; a black spot on the center of the breast .... 552. LARK SpArrow.

$b$. Hind toe-nail longer than bill from nostril.

$b^{1}$. Underparts cream-buff; two outer tail-feathers mostly white.

537. Smith's Longspur.

$b^{2}$. Underparts whitish; hreast streaked or spotterl with black or entirely black; second outer tail-feather with but little white.

536. LAPLAND LONGSPUR. 
A Field Key to the

Adult Male Finches and Sparrows of the Middle States (Virginia to Massachusetts) in Breeding Plumage

I. Breast with more or less yellow.

II. Breast blue.

III. Breast or throat red.

IV. Breast without either yellow, blue, or red.

I. Breast with more or less yellow.

A. Chin white, throat black; haunts grassy fields; song an unmusical effort of six or seven notes delivered with great earnestness from a low perch (rare east of the Alleghanies) . . . . 604. Dickcissel.

$B$. Underparts and breast pure yellow, crown and wings black; song a sweet canarylike warble; flight undulating, frequently accompanied by the notes chic-o-ree, per-chic-o-ree . . . 529. GoldFIncH.

\section{Breast blue.}

$A$. Length over $6{ }^{\circ} 00$; plumage deep blue, a chestnut bar across the wings (not found north of Virginia) . . . 597. BLdE GROsBeak.

$B$. Length under $6{ }^{\circ} 00$; plumage indigo-blue; haunts woody fields, scrub or second growth; song clear and musical, generally delivered from a tree-top

\section{Breast or throat red.}

1. Length over $7 \cdot 00$.

$A$. Length 8.00 ; throat and region about the base of the bill black, rest of the plumage bright vermilion-red; head with a conspicuous crest; song a rich, musical whistle; call-note an insignificant cheep; haunts thickets and bushy woodland (rare north of New York City) . . . . . . . . 593. Cardinal. $B$. Length $7 \cdot 50$; breast rose-red; belly, tip of the tail, rump, and a band in the wings white; rest of the plumage black; haunts wooded growths; song loud, clear, and highly musical; call-note a metallic peek.

2. Length under $7 \cdot 00$

$A$. Length under 6.50 ; plumage more or less heavily washed with dull reddish; haunts orchards and wooded growths; song a liquid warble; call-note a metallic chink, frequently uttered while on the wing.

517. PURPLE Finch.

$B$. Length about 6.00 ; plumage dull blood-red; mandibles crossed at the tips; generally found in small flocks in coniferous woods; utters a clicking or whistled note when on the wing (rarely found south of New England after May 1) . . . 521. Aм. Crossbill.

C. Breast white, tinged with brown; region about the bill red, a yellow band in the wings (vicinity of New York City).

EUROPEAN GOLDFINCH.

IV. Breast without either yellow, blue, or red.

1. Underparts distinctly streaked or spotted.

$A$. Outer tail-feathers white, showing conspicuously when the bird flies; haunts dry fields and roadsides; song loud and musical.

$B$. Outer tail-feathers not white.

540. Vesper Sparrow.

a. Song loud and musical; an abundant and familiar bird of general distribution; spots on the breast tending to form one larger spot in the center; crown umber, a whitish line over the eye. 581. Song Sparrow.

$b$. Song not loud and musical; short and generally unattractive haunts wet meadows or marshes; passes most of the time on the ground, rarely perching far from it, and when flushed generally returning to it. 
$b^{2}$. A buffy line over the eye and at the side of the throat, breast generally washed with buffy; haunts only salt marshes (rarely found far from the vicinity of the seashore).

549. Sharp-tailed Sparrow.

$b^{2}$. No buff on the sides of the head or breast; upperparts blackish; song tšrp-tš̌p-tš̌p'se-ee-e-s'r-r-r; rarely breeds south of New York City; haunts both salt- and fresh-water marshes. $542 a$. Savannah Sparrow.

$b^{3}$. Back reddish, head and neck buffy olive; haunts generally wet pastures; song an inconspicuous see-wick (rather rare, living in small colonies of local distribution).

2. Underparts not distinctly streaked or spotted.

547. Henslow's Sparrow,

$A$. Underparts not white or whitish, all one color.

a. Throat pure white, sharply defined from the grayish breast, a yellow spot over the eye; crown black, with a central stripe of white; haunts thickets or bushy woodlands; song a high, clear, musical whistle; call-note a sharp chink.

b. Throat not white.

558. White-throated Sparrow.

a. Throat and breast black.

$a^{1}$. Sides of the throat and belly white, crown ash, sides of the head chestnut . . . . . . House Sparrow.

$a^{2}$. Length 8.00 ; sides of the body light rufous, outer tail-feathers tipped with white; haunts thickets and bushy woodlands; call-note a vigorous towhee or chee-wink . 587. TOWHEE.

$b$. Throat and breast slate-color, like the back; belly and outer tailfeathers white; bill flesh-color (nests, in the Middle States, only on the higher parts of the Alleghanies) . . . 567. JonCO.

$B$. Underparts white or whitish, practically all one color.

a. Haunts wet marshes.

$a^{1}$. Haunts always salt marshes, generally near the sea; back grayish . . . 550. SEASIDE SPARRow.

$a^{2}$. Haunts both salt- and fresh-water marshes; back brown, streaked with black; cap and wings chestnut; song a loud, sharp, rapidly repeated weet-weet-weet, etc.

584. Swamp Sparrow.

b. Haunts dry fields, pastures, roadsides, lawns, thickets, etc.

$b^{1}$. Outer tail-feathers white, middle of the breast with a small black spot (not found east of the Alleghanies).

$c^{1}$. Outer tail-feathers not white.

552. Lark Sparrow.

$c^{2}$. Upperparts reddish brown, bill pinkish flesh-color; haunts bushy fields and pastures; song a musical, plaintive, cherwee, cher-wee, cher-wee, cheeo-dee-dee-dee-dee-dee.

563. Field Sparrow.

$c^{3}$. Bill dark brown, a buffy line through the eenter of the ground; song an insect-like pit-tùk, zee-zee-zee-zee-zee.

546. Grasshopper Sparrow.

$c^{4}$. Back streaked with black, cap chestnut, a white line over the eye, bill black; song a monotonous chippy-chipmy-chipmy, etc.

560. Chipping Sparrow.

$c^{5}$. Larger, length ahout 7.00; crown black, with a white central stripe; throat not noticeably different from the breatst; no yellow over the eye (rare; nests north of New England).

554. White-CroWNEd SPARROW.

514. Hesperiphona vespertina vespertina (W. ( $(\circ))$.). HVENiNi: Grosbeak. Ad. $\sigma^{7}$. Forehead ycllow, crown black; upperparts olivebrown, becoming dull yellow on rump; belly and scapulars yellow, wings and 
tail black; end half of the secondaries and their coverts white. Ad.. Brownish gray, lighter on the underparts more or less tinged with yellow, especially on the nape; wings black, inner primaries white at the base, secondaries edged with white; tail black, the feathers tipped with white on the inner web; upper tail-coverts black tipped with white. Ads. and Im. in winter.-Similar to ads. in summer. L., 8.00; W., 4.50; T., 3.50; B., $\cdot 72$.

Range.-Cen. N. Am. Breeds in w. Alberta; winters in the interior of N. A. s. of the Sask. and e. of the Rocky Mts. and more or less irregularly s. to Mo., Ky., and Ohio, and e. to e. Pa., N. Y., n. N. J., New England, and Que.

Glen Ellyn, one record, Dec. 11, 1889. SE. Minn., common W. V., Oct. 17-May 19.

Nest, known from but few specimens, composed of small twigs, lined with bark, hair, or rootlets, placed within twenty feet of the ground. Eggs, 3-4, greenish, blotched with pale brown (see Davie). Date, Springerville, Ariz., June 5 (H. v. montana); Las Vigas, Vera Cruz, alt. 8,000 ft., Apl. 30, young on wing (H.v. mexicana).

This distinguished inhabitant of the far Northwest is a common winter visitant in Manitoba and the contiguous parts of the bordering states. At irregular intervals it invades the northern Mississippi Valley in numbers, while still more rarely it extends its wanderings to the North Atlantic States. It travels in flocks of from six or eight to sixty individuals which by their tameness show their ignorance of man and his ways. They feed largely on the buds or seeds of treesmaple, elder, and box elder. Their notes are described by different observers as a shrill "cheepy-teet," and a "frog-like peep," while one writer remarks that "the males have a single metallic cry like the note of a trumpet, and the females a loud chattering like the large Cherry Birds (Ampelis garrulus)." Their song is given as a wandering, jerky warble, beginning low, suddenly increasing in power, and as suddenly ceasing, as though the singer were out of breath.

During the winter and early spring of 1890 there was a phenomenal incursion of Evening Grosbeaks into the Northern States, accounts of which, by Amos W. Butler, will be found in The Auk, 1892, pp. 238-247; 1893, pp. 155-157. In the winter of 1910-11 the birds again appeared in large numbers. Records of their occurrence will be found in The $A u k$ and Bird-Lore for 1911.

1910. Roberts, T. S., Bull. Minn. Acad. Sci., IV, 406-414 (habits in Minn.).-1901. Birtwell, F. J., Auk, XVIII, 388-391 (nesting).

515. Pinicola enucleator leucura (Müll.). Pine Grosbeak. (Fig. 64a.) Ad. $\sigma^{3}$ - - Slaty gray, more or less strongly washed with rose-red, strongest on the crown, rump, upper tail-coverts, and breast; wings fuscous, their coverts edged with white; tail fuscous. This plumage is acquired at the first postnuptial molt. Ad. $\circ$.- Slaty gray, crown, upper tail-coverts, and breast more or less strongly washed with olive-yellow; wings and tail as in the $\sigma^{\circ}$. Im.-Resembles the o, but is somewhat brighter. L., $9^{\circ} 08$; W., $4^{\circ} 36$; T., $3 \cdot 67 ;$ B., 54 .

Range.-E. N. Am. Breeds in Boreal forests from nw. Mackenzie (Great Brar Like), cen. Keewatin, and n. Ungava to the White Mts. of N. H., Maine, cen. N. B., s. N. S., and Cape Breton Is.; winters s. to Iowa, Ind., Pa., n. N. J., and casually to D. C. and Ky.; w. to Man., Minn., and e. Kans. 
Washington, casual in winter. Ossining, irregular W. V., Dec. 18-Apl. 12. Cambridge, irregular W. V., frequently common, sometimes abundant, Nov. 1-Mch. 25. N. Ohio, occasional W. V. Glen Ellyn, uncommon and irregular W. V., Oct. 25-? SE. Minn., uncommon W. V.

Nest, of twigs and rootlets lined with finer materials, in coniferous trees a few feet up. Eggs, "pale greenish blue, spotted and blotched with dark brown surface markings and lilac shell-spots, $1.05 \times 74$." Date, Bangor, Maine, June 5.

The Pine Grosbeak, like the Spruce Partridge and Canada Jay, may be said to find its true home in the coniferous forest or Canadian belt, which crosses the continent diagonally from Maine to Alaska.

Like many of its congeners in this inhospitable region, it nests so early in the springtime that the winter's frost and snow are still dominant among the evergreens when the eggs come to claim the attention of the pair.

Its habits at this season are but little known; but in midwinter, when it comes southward in search of food, it is a well-known frequenter, in flocks, of plantations of mountain-ash trees, or groups of sumach bushes, whose unfallen berries provide it with a bountiful supply of nourishing diet.

Its form has a general resemblance to that of the common Robin, but its very short, thick beak and its forked tail are striking differences. It is rather slow and inactive when in a tree, and when on the wing it has a loud whistle which is very characteristic and during the springtime has a prolonged and melodious song. At all times its colors, as above described, should distinguish the bird at a very considerable distance. ERnest Thompson Seton.

1895. Brewster, WM., Auk, XII, 245-256 (remarkable flight of).

517. Carpodacus purpureus purpureus (Gmel.). PLRPLE Finch. Ad. $\sigma^{7}$ - Body streaked, suffused with rose-red, strongest on the head, rump), and breast, more brownish on the back; whiter, generally white, on the belly; wings and tail brownish fuscous, the outer webs of the feathers fincly edged with rose-red; a small tuft of bristly feathers over the nostrils; outer tailfeathers longest. This plumage is accpuired at the first postmuptial molt. Ad. \%.- Very different, sparrowlike in appearance: ujperparts dark grayish brown, finely streaked with black; wings and tail dark gral ish brown; underparts white, streaked, or with wedgeshaped spots of fuscous. A whitish superciliary line. Im. o.-Similar to adult female. L., $6 \cdot 22$; W., $3 \cdot 24$; T., $2 \cdot 29$; B., 45 .

Remarks.-Females and young males bear a decided resemblance to some Sparrows, but the rounded bill, tufts of feathers over the nostrils, and forked tail are distinguishing characters.

Range.-E. N. Am. Breeds in Canadian and Transition zones from cen. B. C., ne. Alberta, n. Ont. (Moose Factory), cen. Que. (Gaspe Basin), and N. F. to s. Alberta, N. D. (Turtle Mts.), cen. Minn., n. Ills., Pa. (mts.), n. N. J., and L. I.; winters from considerably $n$. of the south-

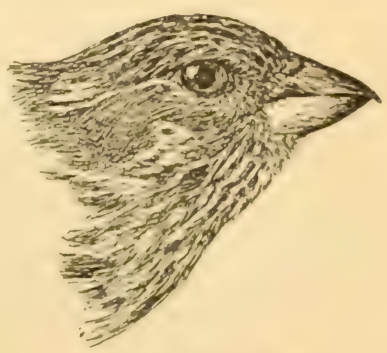

Fra. 100. Purple Finch (Natural size.) 
ern boundary of its breeding range to the Gulf coast from Tex. to Fla.; casual in Colo.

Washington, common W. V., Sept. 12-May 26, largely a migrant. Ossining, rare P. R., common T. V. Cambridge, P. R., common from Apl. to Oct.; irregular, but sometimes abundant, in winter. N. Ohio, common W. V., Sept. 1-May 20. Glen Ellyn, fairly common T. V., Mch. 8-May 15; Aug. 25-Nov. 2. SE. Minn., common T. V., Mch.-Apl., Sept.-Oct., uncommon W. V.

Nest, of twigs, grasses, and rootlets, thickly lined with long hairs, in coniferous trees, 5-30 feet up. Eggs, 4-6, blue, spotted about the larger end with fuscous, $79 \times 56$. Date, Cambridge, May 25; Holland Patent, N. Y., May 15.

During the nesting season the Purple Finch frequently takes up its abode in private grounds, even becoming a familiar garden bird, while others of its race find a congenial home in wild mountain forests, far away from the society of man. The rosy plumage of the males makes it attractively noticeable as a garden bird; but a serious offense must be charged against it-it has far too ready a taste for the blossoms of fruit trees, and is, perhaps, the most confirmed bud-eater of all our birds. It has naturally a roving disposition, and, in the autumn especially, seems ever to be impelled by some restless impulse. At this season it may often be seen descending with airy, sweeping flight into some leafless treetop, as if from a far aërial journey, its identity made known by its very characteristic utterance, a short, rather dull-sounding note, scarcely metallic - the metal pressed the instant the bell is struck.

Although the Purple Finch often essays to sing in the autumn and earliest spring, its full powers of voice belong alone to the nuptial season. Then it easily takes its place among our noteworthy song birds. Its full song is a sweet-toned, carelessly flowing warble-not too brief to miss definite character as a song, and positive enough in modulation and delivery to find ready place in the memory. At times, indeed, its singing is of a character not to be easily forgotten. The song bursts forth as if from some uncontrollable stress of gladness, and is repeated uninterruptedly over and over again, while the ecstatic bird rises high into the air, and, still singing, descends into the trees. Eugene P. Bicknell.

Passer domesticus domesticus (Linn.). HoUSE or English SPARrow. $A d$. $\sigma^{3}$. C Crown gray, bordered from the eye backward and on the nape by chestnut; lesser wing-coverts chestnut, middle coverts tipped with white; back streaked with black and chestnut; rump ashy; middle of the throat and breast black; sides of the throat white; belly whitish. $A d$. $9 .-$ Head and rump grayish brown; back streaked with black and deep ochraceous-buff; underparts dirty whitish, the breast and sides washed with pale grayish brown. L., 6*33; W., 3*01; T., 2*30; B., *48.

Range.- "Nearly the whole of Europe, but replaced in Italy by $P$. italia, extending eastward to Persia and Central Asia, India, and Ceylon" (Sharpe). Introduced and naturalized in America, Australia, New Zealand, etc.

$N e s t$, of any available material in any available place. Eggs, $4-7$, varying from plain white to almost uniform olive-brown, generally white, finely and evenly marked with olive, $1.86 \times{ }^{\circ} 62$. Date, D. C., Mch. 1 . 
This pest was first introduced into the United States at Brooklyn, New York, in $18 \tilde{1}$ and 1852. As late as 1870 it was largely confined to the cities of the Atlantic States, but since that date, partly through man's agency and partly through the bird's rapid increase in numbers and its adaptability, it has spread over most of the United States and Canada. Its harsh insistent, incessant chirp is now the dominant bird voice about our homes, where we may never again hope to hear a chorus of native bird music unmarred by the discordant chatter of this alien.

1889. Barrows, W. B., Bull. No. 1, Biological Survey, 1-405 (economic status).-1909. Townsend, C. W., Auk, XXVI, 13-19 (habits).

The Edropean Tree Sparrow (Passer montanus) has become naturalized about St. Louis, Missouri.

521. Loxia curvirostra minor (Brehm). AMr. C'rossbill. (Fig. 64d.) Ad. $\sigma^{7}$.- Tips of the mandibles crossed; body dull red, brighter on the rump, browner on the back; wings and tail fuscous. This plumage is acquired at the first postnuptial molt. Ad. o.-Dull olive-green, yellower on the rump, indistinctly mottled with blackish on the head and back, mixed with whitish on the underparts. Im. $\sigma^{7}$ - Similar to the $\%$, but mixed with red and green. L., $6 \cdot 19 ;$ W., $3 \cdot 40 ;$ T., $2 \cdot 13 ;$ B., $\cdot 66$.

Range.-N. N. Am. Breeds from cen. Alaska, n. Mackenzie, cen. Ungava, and N. F. s. to Calif. (Sierra Nevada and San Bernardino Mts.), s. Colo,, Mich., and in the Alleghanies of n. Ga. (casually in Mass., Md., and Va.); winters irregularly s. to s. Calif., N. M., n. Tex., La., and Fla.

Washington, irregular W. V., sometimes abundant. Ossining, irregular; noted in almost every month. Cambridge, of common but irregular occurrence at all seasons. N. Ohio, irregular, often common, sometimes breeds. Glen Ellyn, uncommon and irregular, Oct. 20-June 11. SE. Minn., W. V., Oct. 25.

Nest, of twigs and grasses, lined with bits of moss and rootlets, in coniferous trees, 15-30 feet up. Eggs, 3-4, "pale greenish, spotted and dotted ahout the larger end with various shades of brown and lavender shell-markings, 1.75 × 57." Date, Morehouseville, N. Y., Mch. 30 .

These parrotlike Finches are famous for their erratic wanderings. They seem to have no regard for the laws of migration which regulate the journeys of most birds, and, having no home ties, may linger in regions which offer them abundant fare without much regard to season. They nest early in the spring, sometimes when they are far south of their breeding range, but they seem quite uneoncerned by their unusual surroundings, and their young are born and raised in a foreign land. Coniferous forests form their natural surroundings, and their bills are especially adapted to aid them in forcing off the scales from the cones of these trees to obtain the seed within.

They live in flocks, and when in the trees climb about like Parrots, sometimes exhibiting as lit le fear of man as Polly on her pedestal. When feeding, they have a short, whistled call-note; they take wing in a body, and their undulating flight is accompanied by at sharp elicking or whistled note. Their song is deseribed as "varied and pleasing, but not powerful or in any respect remarkable."

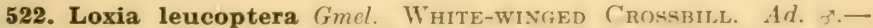
Tips of the mandibles crossed; body dull pink, brighter on the rump, more 
or less marked with black on the back; belly whitish; wings and tail black, the greater and middle wing-coverts, and sometimes tertials, tipped with white. This plumage is assumed at the first postnuptial molt. Ad. o.-D Dull olive-green, yellow on the rump, grayer on the underparts, mottled with blackish on the head and back; wings and tail as in the $0^{7}$. Im. $\sigma^{7}$. - Similar to $\%$, but plumage often with more or less pink. L., $6.05 ;$ W., 3.27 ; T., $2 \cdot 41$; B., 62 .

Range.-N. N. Am. Breeds in Boreal zones s. to s. B. C., s. Alberta, cen. Ont., N. Y. (Adirondacks), N. H. (White Mts.), s. Maine, and s. N. S.; winters in much of its breeding area and s. irregularly to $\mathbf{n}$. Ore. (Cascades), Nev., Colo., Kans., s. Ills., s. Ohio and N. C.

Washington, casual. Ossining, rare T. V., Oct. 29-Dec. 6. Cambridge, irregular W. V. N. Ohio, rare W. V. Glen Ellyn, rare, fall records only, Nov. SE. Minn., W. V., latest record Mch. 4.

Nest, of twigs and strips of birch bark, covered exteriorly with moss (Usnea), and lined with soft moss and hair, on the fork of an evergreen in deep forests. Eggs, 3 (?), pale blue, spotted and streaked near larger end with reddish brown and lilac, $80 \times \cdot 55$ (Chamberlain). Date, Wolfeville, N. S., Feb. 6 (Thayer Coll.).

Goss writes that in general habits these birds resemble the American Crossbill. Their flight is swift and undulating. While feeding and moving about they are quite noisy, almost constantly uttering a plaintive wheep or cheeping note. Their song is low, soft, and sweet, much like that of the American Goldfinch.

527. Acanthis hornemanni hornemanni (Holb.). GreenLand RedPoll. Similar to the next, but "larger (length about $5 \cdot 50-6 \cdot 50$ ), with proportionally thicker and less acute bill. o W., 3.37; T., 2.75; exposed culmen, '35; depth of B. at base, '31."

Range.-Arctic Am. and Europe. Breeds in Greenland n. to $70^{\circ}$ and in Iceland; winters in its breeding area and s. to Ungava; casual at Ft. Churchill, Hudson Bay, and Galt, Ont.

527a. A. h. exilipes (Coues). HoAry Redpoll. Ad. o7-Bill very sharply pointed, a small tuft of bristly feathers over the nostrils; crown-cap bright red; back dark grayish brown, the feathers more or less margined with white; rump white, generally unstreaked, and tinged with pink; wings and tail brownish fuscous, the feathers all more or less edged with white; middle of the throat blackish, breast tinged with pink, belly white, a few streaks on the side. Ad. + .- Similar, but with no pink on the rump or breast. Im.Similar to the o, but without the red crown-cap. L., $5 \cdot 00 ;$ W., $3 \cdot 00 ;$ T., $2 \cdot 30$; B., 30 .

Remarks.-This species is to be distinguished from Acanthis linaria and its races by the greater amount of white in its plumage, its unstreaked rump, and comparatively unstreaked underparts.

Range.-Aretic Am. and ne. Asia. Breeds from w. Alaska to Ungava, and on Chukche Peninsula, ne. Asia; winters occasionally s. to B. C., Mont., n. Minn., Mich., Ills., Ont., Maine, and Mass.

Cambridge, rare W. V.

Nest, of grass and twigs lined with feathers, in a low tree or on the ground. Eggs, 3-5, white, tinged with blue or green, spotted with reddish brown, $65 \times 50$ (Chamberlain). Date, Ft. Chimo, Lab., May 19.

528. Acanthis linaria linaria (Linn.). REDPoll. $A d$. $\sigma^{7}$--Bill very sharply pointed, a small tuft of bristly feathers over the nostrils; crown-cap bright red; lack fuscous grayish brown, the feathers margined with ochracenus-huff ; rump tinged with pink; wings and tail fuscous, the feathers more or less edged with whitish; chin and upper throat blackish, breast suffused 
Plate XXII

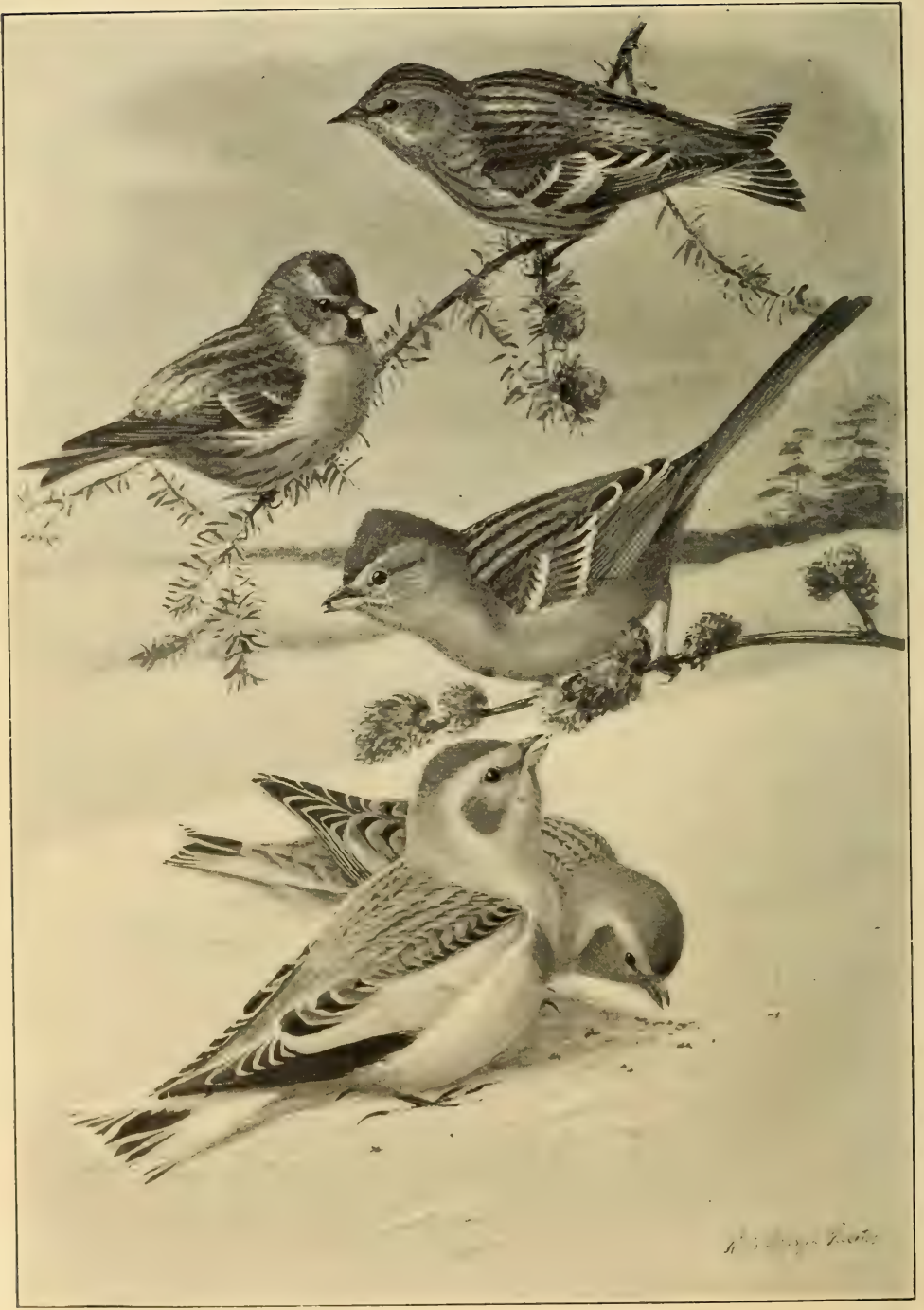

Pine Siskin

Redpoll

Tree Sparrow

Snow Bunting 
with pink, belly white, sides streaked with fuscous. This plumage is acquired at the first postnuptial molt. $A d$. $\%$. - Similar, but without pink on the rump or breast, the sides more heavily streaked. Im.- Similar to the o, but without a red crown-cap. L., $5 \cdot 32$; W., $2 \cdot 80$; T., $2 \cdot 32$; B., 36 ; depth of B. at base, $\cdot 22$.

Range.-N. parts of N. Hemisphere. Breeds in N. A. in Boreal zones from nw. Alaska, n. Mackenzie, and n. Ungava s. to n. Alberta, cen. Keewatin, and islands of Gulf of St. Lawrence; winters in more $\mathrm{n}$. parts of U. S., irregularly s. to Lassen Co., Calif., se. Ore., Colo., Kans., Ind., Ohio and Va.; casual in Ala. and Bermuda.

Washington, very rare and irregular W. V. Ossining, irregular W. V., Nov. 25-Mch. 26. Cambridge, irregular W. V., often very abundant, Oct. 25-Apl. 10. N. Ohio, rare W. V. Glen Ellyn, irregular W. V., Nov. 6-Mch. 7. SE. Minn., common W. V., Oct. 31-Apl. 7.

Nest, of dry grass and moss lined with hair, feathers, or plant down, in a low tree or tuft of

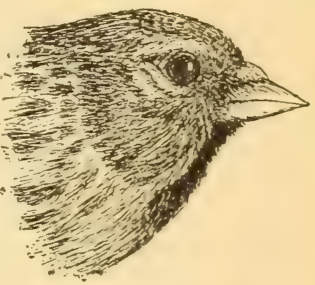

FIG. 101. Redpoll. (Natura size.) grass. Eggs, 4-6, white, tinged with green or blue, spotted with reddish brown, $.65 \times{ }^{\circ} 50$ (Chamberlain). Date, St. Michael's, Alaska, June 6.

The little Redpoll is one of those birds that are best known as winter visitors. Sometimes it comes from the north in flocks when driven from home by the annual failure of the food-supply, and speedily attracts attention by frequenting the gardens and orchards, even when these are within the limits of a town. In general habits it resembles a Goldfinch, and while with us it finds its wants supplied chiefly by the various grasses and herbs which project through the snow and still retain their seed in spite of wind and weather. It is noted for its affectionate and confiding disposition, and although it is not known to breed in captivity it has always proved an easily tamed and interesting pet.

\section{ERnest Thompson Seton.}

528a. A. 1. holbœlli (Brehm). Holbezl's Redpoll. Similar to A. l. linaria, but larger, the bill longer. W., 3.20; T., $2 \cdot 35$; I3., "38; depth of B. at base, 22 .

Range.-N. parts of N. Hemisphere. Breeds on Herschel Is.; s. in winter to Germany, Japan, and se. Siberia; occasional in migration to nw. Alaska and se. to Keewatin, Iowa, Ills., Mass., Maine, and Que.

Cambridge, very rare W. V.

This is an intermediate between A. l. linaria and A.l. rostrata, most closely approaching the former, from which it sometimes can with difficulty be distinguished. It is an exceedingly rare hird in cast ern North America, where there are but few records of its occurrence.

528b. A. 1. rostrata (Coues). Greater' Redpoll. Similar to $A$. l. linaria, but larger, the margins to the feathers of the upperparts averaging darker, the bill shorter and stouter. L., 5.50; W., 3.20; T., 2.55; $3 ., 35$; depth of B. at base, 28 .

Range.-Resident in Greenland. In winter s. through Man., Ont., Que., and Ungava to Colo., n. Ills., Mich., n. Ind., N. J., and Mass,

Ossining, A. V. Cambridge, irregular W. V., Nov.-Feb. SE. Minn., uncommon W. V. 
"The Greater Redpoll is often rather common, and in February, 1883, it occurred along the seacoast near Boston in positive abundance. As one sees them in winter in New England, the forms just mentioned, with $A$. hornemannii exilipes, do not differ appreciably in notes, habits, or general appearance. It is true that $A$. l. rostrata may be often recognized by its superior size, but the birds as a rule are so nervous and restless, and when in large flocks so constantly in motion and so likely to depart altogether at any moment, that a free use of the gun is ordinarily indispensable to positive identification" (Brewster, Minot's "Land Birds and Game Birds," 2d ed., App., p. 472).

529. Astragalinus tristis tristis (Linn.). GOLDFINCH. Ad. $0^{7}$ in summer. -Bright canary-yellow; crown, wings and tail black; wing-bars and inner vanes of tail-feathers white; longer upper tail-coverts gray; lesser wingcoverts yellow. This plumage is acquired at the second prenuptial molt. Ad. ot in winter.-Wings and tail as in summer but white edgings wider, lesser wingcoverts still yellow; back grayish brown, olive-tinged; throat and chest dull yellow, belly whitish, sides brownish buff. Im. $\sigma^{7}$ in winter. - Similar to ad. $\sigma^{7}$ in winter but lesser wing-coverts olive-green or olive-gray. Im. o $\sigma^{7}$. in summer. - Similar to ad. $\sigma^{7}$ in summer but lesser wing-coverts as in winter. Ad. 웅 summer.-No black crown-cap; upperparts yellowish brown; below dull yellow; wings and tail less black than in ad. $0^{7}$; lesser wing-coverts olivegreen. Ad. $\circ$ and Im. o in winter. - Similar to im. $\sigma^{7}$ in winter, but wings and tail less black. L., $5 \cdot 10$; W., $2 \cdot 82$; T., $1 \cdot 95$; B., 40 .

Range.-E. N. Am. Breeds in lower Canadian, Transition, and Upper Austral zones from s. Man., cen. Que., and N. F., s. to e. Colo., s. Okla., cen. Ark., and n. Ga.; winters over most of its breeding area and s. to Gulf coast.

Washington, common P. R. Ossining, common P. R. Cambridge, very common P. R. N. Ohio, common P. R. Glen Ellyn, common P. R. SE. Minn., P. R., common in summer, uncommon in winter.

Nest, externally of fine grasses, strips of bark, and moss, thickly lined with thistledown, in trees or bushes, 5-30 feet up. Eggs, 3-6, pale bluish white, $65 \times \cdot 48$.' Date, D. C., July 5; Newport, R. I., June 20; Cambridge, July 21; Ogle Co., Ills., June 30; se. Minn., July 26.

Except when nesting, Goldfinches are generally found in small flocks. Few birds seem to enjoy life more than these merry rovers. Every month brings them a change of fare, and in pursuit of fresh dainties the nesting-time is delayed almost until summer begins to wane.

Seed-bearing plants, whether in field or garden, form their larder; the old sunflowers rattle before their vigorous attack; the thistles spring into sudden blossom of black and gold as they swing from the nodding heads.

Their flight is expressive of their joyous nature, and as they bound through the air they hum a gay

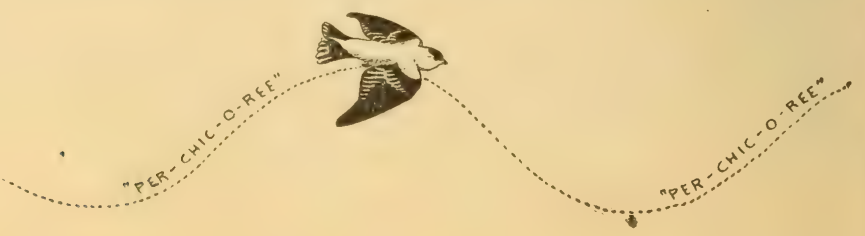


Their love song is delivered with an ecstasy and abandon which carries them off their feet, and they circle over the fields sowing the air with music. The song has a canarylike character, and while it is less varied it possesses a wild, ringing quality wanting in the cage-bound bird's best efforts.

1898. BRUCE, M. E., Auk, XV, 239-243 (home-life).

Carduelis carduelis (Linn.). European Goldfinch. Ads.-Region about the base of the bill bright red; crown, and a stripe extending from it on to the sides of the neck, black; back cinnamon-brown; wings black, crossed by a broad yellow band; tail black, inner webs of the feathers tipped with white; underparts white, sides tinged with the color of back. L., 5.50; W., $3 \cdot 00$; T., $2 \cdot 95$; B., '50.

Range.- "Europe generally, except extreme northern part" (Sharpe). Introduced near New York City and occurring also about Boston; naturalized in Bermuda.

Nest, externally, of grasses and plant down, lined with plant down, in coniferous trees. Eggs, 4-5, white, with purplish spots, $72 \times \cdot 50$. Date, Central Park, Apl. 26.

This European species was introduced into this country at Hoboken, N. J., in 1878, and descendants of the original birds probably still exist in this part of New Jersey, since I observed two at Englewood in June, 1911. In 1879 it appeared in Central Park, New York City, where it was probably also introduced, but it is now exceedingly rare in New York City. A third point of introduction is Boston, where, according to Hoffmann, "it occurs rarely." In general habits this species resembles its American cousin with which it sometimes associates.

533. Spinus pinus pinus (Wils.). Pine Siskin. Ads.-Bill sharply pointed, a small tuft of bristly feathers over the nostrils; upperparts streaked with black, the feathers margined with buffy; wings fuscous, most of the feathers margined with yellow, and yellow at the base; tail fuscous, all but the middle feathers yellow at the base; underparts white, tinged with buffy and heavily streaked with black. L., $5 \cdot 00$; W., $2 \cdot 76$; T., $1 \cdot 9() ; 13 ., \cdot 40$.

Remarks. - The yellow markings in the wings and tail of this species will always serve to distinguish it.

Range.-N. A. Breeds mainly in Canadian zone, s. through the higher mts. of w. U. S. to n. L. Calif., and s. N. M., and to n. Minn., n. Mich., N. B., N. S., and in mts. to N. C., and casually in the lower Hudson Valley and Mass.; occurs in winter over most of the U.S. s. to n. Mex.

Washington, irregularly abundant W. V., Oct. 24 May 20. Ossining, irregular P. R. Cambridge, irregular W. V., Oct. 15 May 10) sometimes very abundant; one breeding record. N. Ohio, tolcrably common W. V., Sept. 20-May 15. Glen Ellyn, irregular T. V., Apl. 8 May 2.4: Sept. 8Nov. 29. SE. Minn., uncommon T. V., and W. V. ()c.t. 2!! Ipl. 9.

Nest, of twigs and rootlets, lined with plant down and long hairs, in ('oniferous trees. Eggs, 4, pale bluish white, thinly spotted with reddish brown, .67 x 46. Date, Ossining, N. Y., May 25; Lyons Falls, N. Y., Apl. 25; Farmington, Maine, June 14.

Like some other winter birds whose movements are governed by the food-supply, the Siskin is more or less irregular in its oceurrence south of its breeding range, being abundant some years and rare or absent others.

During the summer it is an inhabitant of coniferous growths and 
its habits now resemble those of the Goldfinch. It has a flight-song, but this with its perch-song is less musical than that of its more brightly plumaged relative.

During its post-breeding wandering, it is found in closely massed flocks which move as one bird and which feed much upon the ground where they may be closely approached.

1887. Allen, J. A., Auk, IV, 284-286 (nesting).

The Black-headed Goldfinch (532. Spinus notatus), a Mexican species, is recorded by Audubon from Kentucky, where its occurrence is, of course, purely accidental.

534. Plectrophenax nivalis nivalis (Linn.). SNow Bunting. (Fig. 10.) $A d$. $\sigma^{T}$ in summer. - Whole head and neck, rump, and underparts white; back and scapulars black; outer primaries black, white basally, secondaries wholly white; outer tail-feathers white, inner ones black. Ad. of in summer. Similar, but entire upperparts streaked with black; outer primaries all fuscous; secondaries more or less tipped with fuscous. $\sigma^{7}$ in winter.--Upperparts a kind of rusty brown, almost umber on the center of the crown; back streaked with black, caused by the black bases of the feathers showing through their rusty tips; wings and tail much as in summer, but more or less edged with rusty; underparts white, the breast and sides washed with rusty. o in winter. - Similar to on, but wings as in summer o. L., 6.88; W., 4.07; T., $2 \cdot 70 ;$ B., $\cdot 42$.

Range. -N. Hemisphere. In N. A., breeds in Arctic zone from at least $83^{\circ}$ north (including Greenland) to n. parts of mainland from Alaska to Ungava; winters from Unalaska, s. Alberta, s. Keewatin, and s. Ungava s. to n. U. S. and irregularly to n. Calif., Colo., Kans., s. Ind., s. Ohio, and Fla.; casual in Bermuda.

Washington, W. V., casual, one instance. Ossining, irregular W. V., Oct. 25-Mch. 22. Cambridge, common W. V., Nov. 1-Mch. 15; abundant in migrations. N. Ohio, tolerably common W. V., Dec. 10-Mch. 15. SE. Minn., common W. V., Oct. 9-Mch. 14.

Nest, of grasses, rootlets, and moss, lined with finer grasses and feathers, on the ground. Eggs, 4-7, pale bluish white, thinly marked with umber or heavily spotted or washed with rufous-brown, $\cdot 85 \times \cdot 64$. Date, Pt. Barrow, Alaska, June 12.

The Snowflake may readily be known by the fact that it is the only one of our sparrowlike birds that has white predominating on its wings and tail, as well as on its body. It feeds exclusively on seeds, and is so much like the Shorelark in habits that the two species occasionally associate. The Snowflake is also strictly a ground bird, rarely perching on a tree, though it often does so on a house or fence. It always progresses by walking, not by hopping.

Throughout Canada and the northern tier of states this is the familiar little white bird of winter. As soon as the chill season comes on in icy rigors, the merry Snowflakes appear in great flocks, and come foraging about the barnyards when there is no bare ground left in the adjacent fields. Apparently they get but little to eat, but in reality they always find enough to keep them in health and spirits, and are as fat as butter balls. In midwinter, in the far north, when the thermometer showed thirty degrees below zero, and the chill blizzard was blowing on the plains, I have seen this brave little bird gleefully chasing his 
fellows, and pouring out as he flew his sweet, voluble song with as much spirit as ever Skylark has in the sunniest days of June. As long as the snow lasts the Snowflake stays, and as soon as the ground grows bare and there is promise of better days, this bird of winter betakes himself again to the north as far as the most northern habitation of man, and there builds his nest.

Ernest Thompson Seton.

536. Calcarius lapponicus lapponicus (Linn.). LAPLAND LONGSPUR. Hind toe-nail as long as or longer than toe. $A d$. $\sigma^{3}$ in summer.- - Head, neck, throat, and breast black; a buffy line behind the eye; nape rufous; back streaked with black and ochraceous- and cream-buff; tail fuscous, the two outer feathers with more or less white; belly white; sides streaked with black. Ad. o in summer. - Upperparts streaked with black, rufous, ochraceous- and cream-buff; nape ochraceous-buff, the color sometimes concealed by the tips of the feathers; tail fuscous, the outer one or two feathers marked with white; underparts white, the breast and sides streaked with black and ochraceous-buff. or in winter.-Similar to o in summer, but upperparts blacker, nape more rufous, breast more heavily marked with black, most of the feathers black at the base. $q$ in winter. - Similar to $q$ in summer, but upperparts duller, nape with little or no ochraceous. L., $6 \cdot 25$; W., $3 \cdot 75$; T., $2 \cdot 55 ;$ B., $\cdot 40$.

Remarks.-In some plumages this bird bears a general resemblance to certain Sparrows, but

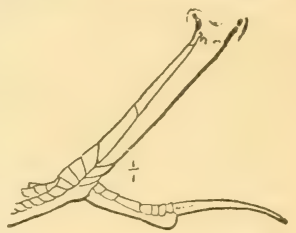

Frg. 102. Hind toe of Lapland Longspur. differs from them in having the hind toe-nail as long as or longer than the toe.

Range.-N. Hemisphere. In N. A. breeds from about lat. $73^{\circ}$ on Arctic islands, and w. Greenland, and from lat. $75^{\circ}$ in e. Greenland s. to limit of trees in Mackenzie (at least as far w. as long. $120^{\circ}$ ), (een. Keewatin, and $\mathrm{n}$. Ungava; winters from s. Que,, and n. cen. U. S. irregularly s. to the middle States and Tex., rarely Ky. and S. C.

Washington, W. V., one instance, Dec. Ossining, W. V., casual. Cambridge, one record. N. Ohio, tolerably common, W. V., Noy. 15-Apl. 25. Glen Ellyn, common W. V., Oct. 16-May 16. SE. Minn., common W. V.

Nest, of grasses and moss, lined with grasses, on the ground. Egggs, 4-6, bluish white, almost obscured by a uniform grayish brown, $\times 2 \times \cdot 60$. "Date, Pt. Barrow, Alaska, June 6.

In the east, Lapland Longspurs are generally found among flocks of Shorelarks or Snowflakes, but on the western plains they occur in great numbers. "High in the air they fly in long, straggling flockis, all singing together; a thousand voices, a tornado of whistling.

When in the fields they have a curious habit of squatting just behind some clod, and, as their colors are nearly matrehed to the soil, they are not easily observed, nor will they move until you are within a few feet; they then run a few feet and squat again. . . " (Seton).

One of the most remarkable bird tragedies of which we have any knowledge is recorded by Dr. T.S. Roberts $(A u k, 1907, p)$. 369-377) as occurring in southwestern Minnesota on March 13, 1904, when at least several million Lapland Longspurs were killed in a single night as the result of a storm in which they became exhausted and fell, or confused and struck various obstacles. 
537. Calcarius pictus (Swains.). Sмith's Longspur. Ad. or in summer. - Top and sides of the head black, a line over the eye and the ear-coverts white; back and rump streaked with black and ochraceous-buff; lesser wingcoverts black, broadly tipped with white; tail fuscous, the two outer feathers mostly white; nape and underparts ochraceous-buff. Ad. o in summer.Upperparts black, the feathers margined and tipped with pale cream-buff; two outer tail-feathers mostly white; underparts pale cream-buff; breast and sides sometimes lightly streaked with blackish. of in winter. - Similar to o in summer, but with the lesser wing-coverts black, tipped with white. L., $6 \cdot 60 ;$ W., $3 \cdot 75$; T., $2 \cdot 50 ;$ B., $\cdot 42$.

Range.-Interior of N. A. Breeds in Arctic zone on the Barren Grounds from Ft. Anderson, Mackenzie, e. to Hudson Bay (Ft. Churchill); has been taken w. to Ft. Yukon; winters from Kans. to cen. Tex.; e. in migrations to the prairies of Ills. and sw. Ind.; casual in S. C.

Nesting, similar to that of the preceding. Date, Ft. Anderson, Mack., June 12.

"Their habits are quite similar to those of $C$. lapponicus while upon the ground. . . When flushed they invariably uttered a sharp, clicking note, rapidly repeated several times. When driven from their feeding-place by my approach they would rise in a loose flock, and, after wheeling about a few times, start off in a direct line, gradually rising higher until they disappeared. After a short time their peculiar note would be heard, and, darting down from a considerable height, they would alight near the place from which they were driven" (Nelson).

The Chestnut-collared Longspur (538. Calcarius ornatus) a species of the Great Plains, has been recorded from Massachusetts, Long Island, Maryland and Maine.

McCown's Longspur (539. Rhynchophanes mccowni), a species of the Great Plains, is of casual occurrence in Illinois.

540. Poøcetes gramineus gramineus ( $G m e l$.$) . Vesper SPARrow.$ Ads.-Upperparts brownish gray, streaked with black and a little ochraceous-buff; wings fuscous, greater and middle coverts tipped with white, lesser coverts bright rufous; tail fuscous, the outer feather mostly white, the next one with much less white; underparts white; the breast and sides streaked with black and ochraceous-buff. L., $6 \cdot 12$; W., $3 \cdot 06 ;$ T., $2 \cdot 38 ;$ B., $\cdot 41$.

Remarks.-The white tail-feathers and rufous lesser wing-coverts will always distinguish this species from any other of our Sparrows.

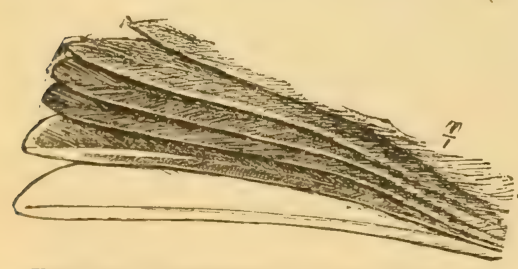

Fig. 103. Tail-feathers of Vesper Sparrow.

Range.-E. N. Am. Breeds in lower Canadian, Transition, and Upper Austral zones from sw. Keewatin, cen. Ont., cen. Que., and Cape Breton Is. s. to e. Neb., cen. Mo., Ky., Va., and N. C., w. to w. Minn.; winters from the s. part of its breeding range to the Gulf coast, w. to middle Tex.; casual in Bermuda and Yucatan.

Washington, P. R., very common T. V., less so in summer and winter. Ossining, tolerably common S. R., Apl. 2 to Nov. 4. Cambridge, common S. R., Apl. 5().t. 25. N. Ohio, abundant S. R., Mch. 20-Nov. 7. Glen Ellyn, fairly (ommon S. R., MIch. 21-Oct. 25. SE. Minn., common S. R., Apl. 1-Oct. 29. West, of rather coarse grass, lined with finer grasses, rootlets, and long 
hairs, on the ground. Eggs, 4-5, bluish white or pinkish white, speckled and spotted with rufous-brown or umber, $1.3 \times \cdot 61$. Date, Chester Co., Pa., May 5; Norwich, Conn., May 8; Cambridge, May 10; se. Minn., May 6.

In walking through dry upland fields or along dusty roadsides a rather pale, streaked Sparrow will sometimes run rapidly ahead of you, wait for you to catch up, then run ahead again. It is best to be content with what measure of his confidence and society he voluntarily grants you, for, if you quicken your steps and try to orertake him, he will rise and bound on before you or swing off to one side, showing, as he flies, the white feathers on each side of his tail.

Frequently he will alight on a fence rail or even the higher branch of a tree, for, although a field Sparrow, he is by no means a purely terrestrial one. When singing, he generally selects an elerated perch and gives himself entirely to his musical devotions. Early morning and late afternoon are his favorite hours, but he can be heard at other times. His song, which is loud, clear, and ringing, may be heard at a distance of several hundred yards. It resembles that of the Song Sparrow; but is sweeter and more plaintive. When heard in the evening it is a truly inspired and inspiring melody.

541. Passerculus princeps Mayn. Ipswich Sparrow. Ads.-Generally with a spot of sulphur-yellow before the eye and on the bend of the wing; upperparts pale brownish ashy, streaked on the head, back, and upper tail-coverts with black and cinnamon-brown; the nape and rump with few or no streaks; a white line over the eye; wings grayish brown, outer webs of greater coverts and tertials margined with pale ochraceous-buff: tail grayish brown, the outer webs of the feathers margined with brownish ashy; underparts white; breast and sides lightly streaked with blackish and ochraceous-buff. L., $6 \cdot 25 ; \mathrm{W}^{\circ}, 3 \cdot 00 ;$ T., $2 \cdot 25 ;$ B., 40 .

Range.-Breeds on Sable Is., N. S.; winters from Sable Is. s. along the Atlantic coast to Ga.

Cambridge, casual, two instances, Oct.

Nest, on the ground, in a cup-shaped hollow seratched by the birds, of weed-stalks, and coarse grasses, lined with finer grasses. Eggs, 4-, indistinguishable from those of the Savannah Syarrow but averaging a little larger (Dwight). Date, Sable Is., N. S., June 4.

Those who care to visit in winter the bleak, wind-swept sand hillocks of our Atlantic coast will find this bird much less rare than it was once supposed to be. It never strays far from the waving tufts of coarse beach-grass that scantily cover the sand-drifts, and single individuals may be found skulking among such surroundings. They seldom allow a near approach, but fly wildly away to considerable distances, and on alighting run off so rapidly that they are difficult to find a second time. The flight is rapid and irregular, and the birds maty casily be mistaken for Savannah Sparrows, with which, during the migrations, they are sometimes associated. On rare occasions a sharp (hirp is heard, but as a rule they are silent.

It is an interesting species, discovered in 1868, and at first mistaken for Baird's Sparrow of the far west, a speries, by the way, that it resembles very little. For many years nothing was known of its breeding range. In 1884 some large eggs from siable Island, Nova Scotia, sup- 
posed to be of the Savannah Sparrow, were unearthed at the National Museum, Washington, and later a summer specimen of the Ipswich Sparrow was obtained from this island. Ten years later I had the pleasure of visiting Sable Island and solving all the conjectures that had become current regarding the Ipswich Sparrow's summer home. The bird proved to much resemble the Savannah Sparrow in breeding habits, song, nest, and eggs.

J. DWIGHT, JR.

1895. Dwight, J. H., JR., Mem. No. II, Nutt. Orn. Club., 1-56 (monograph).-1902. SAunders, IT. E., Auk, XIX, 267-271 (nesting).

542a. Passerculus sandwichensis savanna (Wils.). SAVANNAH Sparrow. Ads.-A pale yellow mark over or before the eye and on the bend of the wing; general tone of the upperparts brownish black, the centers of the feathers black, margined first by rufous or ochraceous-buff, then by ashy; wings fuscous, the outer webs of the feathers margined with ochraceous-buff; tail fuscous, the outer web of the feathers margined with whitish; underparts white, heavily streaked with blachish and rufous, the breast feathers tipped with wedge-shaped marks. Ads. and Im. in vinter.-Similar, but color deeper, more suffused with ochraceous. L., 5.68; W., 2.62; T., $2 \cdot 09 ;$ B., $\cdot 40$.

Range.-E. N. Am. Breeds mainly in Boreal and Transition zones from cen. Keewatin and n. Ungava s. to n. Iowa (casually Mo.), n. Ind., mts. of $\mathrm{Pa}$., Conn., and L. I., and casually in s. . . J.; winters from s. Ind. and s. N. J. s. to ne. Mex., the Gulf coast, Bahamas, and Cuba; casual in Bermuda.

Washington, abundant T. V., Mch. 20-May 11; Sept. 21-Oct. 23; a few winter. Ossining, common T. V., Apl. 3-May 13; Aug. 28-Oct. 28. Cambridge, abundant T. V., Apl.; Oct.; breeds sparingly. N. Ohio, not common T. V., Mch. 20-May 12. Glen Ellyn, fairly plentiful S. R., Apl. 8-Oct. 20. SE. Minn., common S. R., Apl. 17-Oct. 23.

Nest, of grasses and sometimes moss, lined with finer grasses or hair, on the ground. Eggs, 4-5, bluish white, thickly marked, sometimes hearily washed, with reddish brown or cinnamon, $78 \times 56$. Date, Bolton, Mass., May 9; Cambridge, May 21; Utica, N. Y., May 19.

This is essentially a bird of the fields, and one of the most abundant species of the Maritime Provinces of Canada-in fact, characteristic of them. The roadsides abound with the birds bobbing up and down on the fence-posts and chipping vigorously at every passerby. Their boldness is tempered with a certain timidity that becomes apparent when they are followed, for, dropping into the grass, they will slip away with surprising rapidity. They have a startling way, sometimes, of springing up with a whirr of wings almost from under your very feet as you cross the fields where they have been feeding. At the southern limits of their breeding range they gather into irregularly distributed, isolated colonies frequenting wet, boggy meadows, and exhibit a shyness that is not shared by their northern brethren. In the fall, young and old gather into bands, and, joining with other species, form an important part of the large flocks of migrating Sparrows that fill the fields and hedgerows.

The song is insignificant-a weak, musical little trill following a grasshopperlike introduction, and is of such small volume that it can be heard but a few rods. It usually resembles tš $p-t s \check{\imath} p-t s \check{p} p^{\prime} s_{\bar{e}} \bar{e}^{\prime} \bar{e}-\bar{e}-s^{\prime} r-r-r$. More singing is heard toward sunset, when of a quiet evening the trilis are 
audible at greater distances. Each male seems to have a number of favorite perches, weeds or fence-posts, which are visited as inclination dictates, but he is of too restless a disposition to remain long on any of them. The most familiar note is a sharp tsip of alarm or expostulation heard during migration, but so constantly employed by both sexes in the breeding season, even on slight provocation, that one gets to think of them as veritable scolds.

They are more likely to be mistaken for the Vesper Sparrow, which they resemble even in flight, than for any other except perhaps the Ipswich and Sharp-tailed Sparrows.

J. Dwight, JR.

BaIrd's Sparrow (545. Ammodramus bairdi), a bird of the Great Plains region, has been once recorded from east of the Mississippi,--Montauk Point, L. I., Nov. 13, 1899 (Helme, Auk, 1900, 296).

546. Ammodramus savannarum australis Mayn. GrassHOPPER SPARROW. Ads.-Upperparts mixed black, rufous-brown, ashy, and cream-buff; crown blackish, a cream-buff line through its center; nape rufous-brown, each feather with a small black central spot and bordered by ashy; back black, the feathers bordered by cream-buff and with a smail central tip of rufous-brown: rump rufous-brown and ashy; an orange mark before the eye; bend of the wing yellow, lesser wing-coverts yellowish olive-green; greater coverts tipped with whitish; tailfeathers pointed, of about equal length, dark grayish brown, the centers of the feathers darker, the end half of the outer feather generally dusky whitish; underparts generally not streaked; breast and sides huffy; belly white. Nestlings have the breast spotted with blackish. L., 5*38; W., 2*38; T., $1 \cdot 79 ;$ B., $\cdot 43$.

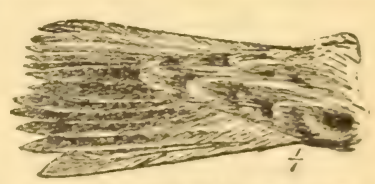

FIG. 104. Tail of Grasshopper Sparrow.

Remarks. - The yellow on the wing, unstreaked underparts, even, pointed tail, and grayish mark on the outer tail-feather are the principal characters of this species.

Range.-E. N.Am. Breeds in Austral zones (sporadically in Transition) e. of the Great Plains from $\mathrm{s}$. Wisc... s. Ont.. and s. . . H. s. to s. I.a., cen. Ala., n. Ga., and n. S. C.: winters from s. Ills, and X. C. s. to the Bahamas, Cubs, Yucatan, and the (iulf coast of II exico): (asial in IIaine.

Washington, very common S. R.. Apl. 17 . Nov. 21). ()sining. common S. R., Apl. 27-Oct. 23. Cambridge, rare - R., May 16-Sept. 1. N. Ohio, common S. R., Apl. 20-Sept. 20. (ilen Ellyn, not commons. R., May 4Sept. 13. SE. Minn., common S. R., Apl. 25-Sept. 6.

Nest, of grasses, sometimes lined with hairs, arehed. on the ground. Egys, 4-5, white, distinetly sporterd and sperekled with rufous. $73 \times 54$ Date, Hall Co., Ala., May 11; Richmond, Va., May 2.); Chester Co., Pa., May 27; se. Minn., June 6.

Few common birds may be more easily overlooked than this Sparrow. Its terrestrial habits and weak notes place it among the birds that you are not likely to find unless you know how and where to look for them. I remember once introducing this bird and its song to a visiting ornithological friend. On returning to his home, greatly to his surprise, he found it a common resident of the fields abnut his house, where, owing to his unfamiliarity with its notes and habits, its presenere had been before unsuspected. 
In the North you will generally find it in old, dry daisy or sorrel fields; in the South it inhabits the broom sedge. It will not take wing until almost stepped upon; then, if bushes are near, it takes refuge in or under them, but out in the open field it flies rapidly some distance and drops to the ground.

Its usual perch, when singing, is a fence-rail; and it does not often seek a more elevated position. Its fine, insectlike notes give it the name of Grasshopper Sparrow. They may be written pit-túck, zee-e-e-e-e$e-e-e-e$. Under favorable circumstances they can be heard by an attentive listener at a distance of two hundred and fifty feet, but the casuai observer would pass within ten feet of a singing bird and be none the wiser.

546b. A. S. floridanus (Mearns). Florida Grasshopper Sparrow. Similar to $A$. s. australis "but smaller, with larger bill, longer tarsus, and much darker coloration above, paler below; chestnut of upper surfaces much reduced in amount and replaced by black; lateral dark areas of crown almost black, interscapular region much blacker." (Mearns, Proc. U. S. Nat. Mus., XXIV, 1902, 915.)

Range.-Central Florida. (Kissimmee Prairie region.)

547. Passerherbulus henslowi henslowi (Aud.). Henslow's SparRow. Ads.-Top and sides of head and nape dull, pale olive-green, more buffy in the fall; sides of crown black; nape finely streaked with black; back rufous-brown, the feathers with narrow, central, wedge-shaped black streaks, and narrow ashy margins; bend of wing pale yellow; wing-coverts much like back; tail-feathers very narrow and sharply pointed; middle feathers rufous-brown; the outer ones much the shortest; underparts white, more or less washed with buffy and streaked with black on the breast and sides. Nestlings have no spots on the breast. L., $5{ }^{*} 00 ;$ W., $2 \cdot 20 ;$ T., $2 * 00 ;$ B., $\cdot 42$.

Remarks.-The peculiar olivaceous color of the head and nape, and the bright rufous-brown color of the back, wing-coverts, and middle tail-feathers are the best distinguishing marks of this species.

Range.-E. U.S. Breeds in Transition and Upper Austral zones from cen. Minn., Ont., N. Y., and s. N. H. s. to s. Mo., and n. Va.; winters in s. U. S. to Tex. and s. Fla.

Washington, common S. R., Apl. 10-Oct. 21. Ossining, rare T. V., Oct. 5-Oct. 10. Cambridge, very rare S. R. N. Ohio, S. R. Glen Ellyn, not common S. R., May 8-Sept. 26. SE. Minn., common S. R.

Nest, of grasses, sometimes lined with hairs, on the ground. Eggs, 4-5, grayish white, thickly and evenly speckled with pale rufous-brown, $\cdot 75 \times{ }^{\cdot} 57$. Date, Cape May Co., N. J., May 25; Richland Co., Ills., May 23.

During the summer this species seems to prefer wet meadows, but in the winter it inhabits the dry 'old fields' grown with broom sedge, which are so common in the south. It has the secretive habits of the Grasshopper and Leconte's Sparrows, and takes wing only when forced to.

P. L. Jouy writes of its song: "Besides the characteristic notes of tee-wick, they have quite a song which may be fairly represented by the syllables sis-r-r-rit-srit-srit, with the accent on the first and last parts. This song is often uttered while the bird takes a short flight upward; it then drops down again into the tangled weeds and grasses, where it is almost impossible to follow it" (Bull. Nutt. Orn. Club, VI, 1881, p. 57). 
548. Passerherbulus lecontei (Aud.). Leconte's Sparrow. Ads.No yellow before the eye or on the bend of the wing; a broad ochraceous-buff line over the eye, and a cream-buff line through the center of the blackish crown; nape rufous-brown, each feather with a small black central spot and an ashy border; back black, the feathers margined first by rufous, then creambuff and whitish; tail grayish brown, with a slight rufous tinge, darker along the shaft; the feathers narrow and sharply pointed, the outer ones much the shortest; breast and sides tinged with buffy, and more or less streaked with black; belly white. L., 5•00; W., $2 \cdot 00 ;$ T., $2 \cdot 05$; B., ' 35.

Range.-Cen. N. Am. Breeds in Canadian and Transition zones from Great Slave Lake, Mackenzie, s. Sask., and Man., s. to N. D. and s. Minn.; winters from s. Kans., and s. Mo., to Tex., Fla., and the coast of S. C., and occasionally to N. C.; casual in Ont. and N. Y.; accidental in Idaho and Colo.

Glen Ellyn, not common T. V., May 4-?; Sept. 8-Oct. 6. SE. Minn., uncommon S. R., May 1-Oct. 17.

Nest, of fine grasses, on the ground. Eggs, 3-5, delicate pink, lightly spotted with brownish and black near the larger end, $75 \times \cdot 50$ (Seton). Date, Raeburn, Man., June 6.

My experience on the coast of Texas with this elusive little Sparrow conforms with that of most observers, and the few specimens I found were in wet marshes. Mr. L. M. Loomis, however, tells us that at Chester, South Carolina, where Leconte's Sparrow is a locally common winter visitant, it shows a marked preference for dry 'old ficlds of broom sedge (Auk, II, 1885, p. 190).

Few birds are more difficult to flush. It exhibits a rail-like disinclination to take wing, and flying low and feebly, makes for the nearest cover. Ernest Thompson Seton records it as an abundant summer resident in the willow sloughs and grassy flats of Manitoba, and describes its call-notes as a thin, sharp, ventriloquial tweet, and a single, longdrawn bizz; while its song, which is delivered from some low perch a little above the grass, is a tiny, husky, double-noted reese, reese, "so thin a sound and so creaky, that I believe it is usually attributed to a. grasshopper."

1901. Peabody, P. B., Auk, XVIII, 129-134 (nesting).

549. Passerherbulus caudacutus (Gmel.). SHARp-TAILED SPARRow. Ads.-General color of the upperparts a brownish olive-green; crown olive-brown, with a blue-gray line through its center; gray ear-coverts, inclosed by ochracenus-buff lines, one of which passe's over the eye and one down the side of the throat; feathers of the hack marerined with grayish and sometimes whitish; bend of the wing yellow; tail-feathers narrow and sharply pointed, the outer foathers much the shortest; loreast and sirles washed with buffy, paler in summor, and distinctly stroaked with liack: middle of the throat and belly white or whitish. "I., $5.45 ; 11 ., 2 \cdot 30 ;$; '., 1.90; B., '50" (Dwight).

Remarks. - The chief points of differenee between this and the two forllowing birds are found in the markines of the breast and sides. In the pressent species these parts are pale orharareons-huff. distinetly streahiol with blackish; in nelsomi thry are decp ochraceous-huff, lightly if at all streaked: in subvirgatus they are cream-lunff, indistinetly strealicd with gmelish.

Range.- Salt marshes of Atlantir cosast. Breerls in Alleghanian and Carolinian faunas from Mass. to Va.; winters on salt marshes from N. J. (casually from Mass.) to Fla.

Cambridge, formerly common S. R., but occurs no longer. 
Nest, of grasses and seaweed, lined with fine grasses, on the ground. Eggs, 3-4, white or grayish white, finely speckled with cinnamon-brown, especially at the larger end, $\cdot 78 \times \cdot 57$. Date, Amityville, N. Y., May 31; Lynn, Mass., June 6.

This species is confined exclusively to the salt-water marshes of our coast, where it may be found in large numbers. It runs about among the reeds and grasses with the celerity of a mouse, and is not apt to take wing unless closely pressed. Mixed flocks of the several varieties of the Sharp-tail, together with the Seaside Sparrow, gather in the fall among the sedges, and may be observed hiding in the grass or clinging to the tall stalks of the cat-tails. In the breeding season it is usually associated with the Seaside Sparrow on the same marsh, but it prefers the drier parts, and builds its nest in the tussocks on the bank of a ditch or in the drift left by the tide, rather than in the grassier sites chosen by its neighbor.

From some bit of driftwood or a convenient stake, its infrequent song may be heard morning and evening. It is short and gasping, and only less husky than the somewhat similar performance of the Seaside Sparrow.

J. Dwight, JR.

549.1. Passerherbulus nelsoni nelsoni (Allen). NeLson's SPARRow. Similar to $P$. caudacutus, but smaller, the upperparts darker, the feathers of the back more olive-brown and more broadly margined with whitish; the throat, breast, and sides deeper ochraceous-buff, very slightly if at all streaked with blackish. "L., 5.50; W., 2.25; T., 1.90; B., '43" (Dwight).

Range.-E. N. Am. Breeds in Canadian and upper Transition zones from Great Slave Lake and w. cen. Alberta se. to sw. Man. and ne. S. D.; winters on the Atlantic and Gulf coasts from N. C. to Fla. and Tex.; n. on the Atlantic coast during migration at least to N. Y., Mass., and Maine, accidental in Calif.

Washington, rare T. V., May-Sept. Ossining, tolerably common T. V., Sept. 28-Oct. 17. Cambridge, formerly uncommon T. V. Glen Ellyn, one record, Oct. 2, 1893. SE. Minn., uncommon T. V.

Nest, on the ground, of fine grasses. Eggs, 5, grayish white ground, thickly sprinkled and clouded all over with markings of brown, thickening on the extreme butt into a dark brown zone, ${ }^{\circ} 65 \times 50$. Date, (found by E. S. Rolfe, at Devil's Lake, N. D., June 14, 1899; Auk, 1899, 356).

This interior representative of the Sharp-tailed Sparrow occurs on the Atlantic Coast only as a migrant and winter visitant when it is associated with the Sharp-tail and Acadian Sharp-tail.

549.1a. P. n. subvirgatus (Dwight). ACAdian Sharp-tailed SparRow. Similar to $P$. caudacutus, but paler above and with the throat, breast, and sides washed with cream-buff and indistinctly streaked with ashy. "L., $5 \cdot 55$; W., 2*30; T., 2*00; B., *46" (Dwight).

Range.-Marshes of the Atlantic coast. Breeds mainly in Canadian fauna from se. Que., Prince Edward Is., and Cape Breton Is. to Maine; winters on coasts of S. C., Ga., and Fla.

Ossining, rare T. V., Sept. 29-Oct. 16. Cambridge, formerly T. V., May; Sept. and Oct.; very common in fall.

Since this race was separated by me in 1887 few new facts have been developed regarding it, except that, as I anticipated, it has been found in other parts of the Maritime Provinces, and never far from salt water. 
While frequenting brackish or fresh-water marshes, where the grasses grow more luxuriantly than in the haunts of its southern relative, it prefers the more open spots or those where damp ditches make highways of escape for it afoot. It is locally abundant, particularly in the great marshes that border the Bay of Fundy, but so retiring that, save for its little song, its presence might be easily overlooked. Swaying on a tall stalk of meadow rue or squatting on a convenient fence, the males may be found at all hours of the day repeating their song a few times and then flying to some new perch or burying themselves in the grass. Occasionally toward nightfall one will mount into the air and with set wings float down, fairly gushing with song, a habit shared by the ordinary Sharp-tail and by the Seaside Sparrow as well.

With these birds they associate in autumn, and may be flushed one or two at a time from the strips of grass or reeds that are left on the salt marshes along the ditches after the hay has been cut.

The song is a husky, gasping effort, not very loud, and executed with a nod of the head. It is sung in less than a second, and resembles $k$ sh-sh-sh-ōolp, the last syllable occupying one-fifth of the time and rather musical compared with the harsh lisp that precedes it. They also have a tchĕp of alarm, but it is the exception for them to show much anxiety about their nests or young. The nest has never been taken.

J. Dwight, JR.

550. Passerherbulus maritimus maritimus (Wils.). SEASIDD Sparrow. Ads. - A yellow line before the eye and on the bend of the wirg; upperparts grayish olive-green; tail grayish brown, the outer wehs of the feathers margined with olive-greenish; a dusky line from the base of the lower mandible passes down the sides of the throat; breast more or less suffused with buffy (wanting in summer specimens), and indistinctly streaked with grayish; throat and middle of the belly white; sides grayish. L., 6.00; W., 2.50; T., $2 \cdot 20$; B., 60 .

Range. - Salt marshes of the Atlantic coast. Breeds chiefly in Carolinian fauna from s. Mass. to Va.; winters from Va. to $\mathrm{Ga}$.

Ossining, A. V.

Nest, of coarse grasses and reed stalks, lined with gratsese, on the ground. Eggs, 3-4, white or bluish white, clouded or finely speckled with rinnamon-

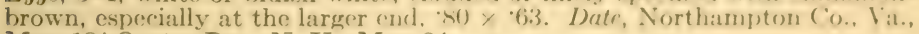
May 18; Oyster Bay, N. Y., May 24.

Like most marsh-loving birds, Seaside Sparrows are so consistent in their choice of a home that it would be fuite useless to lowk for them anywhere but in a marsh, and that a salt one, generally within somml or at least sight of the sea. The baymen rall them 'Meaulow ('hippires, and often when Snipe and Plover shooting, I have drawn numbers to mo by simply squeaking. They tipped all the reeds about my blind, chirping excitedly at the peculiar sound which aroused thrir puriosity. They pass much of their time on the ground among the reeds and grasses, but 
mount a stalk to sing their short, unattractive song of four or five notes. Sometimes they flutter into the air a few feet above the reeds and deliver their song while on the wing.

The absence of distinct streaks on the breast and lack of rufous in their olivaceous or grayish plumage will distinguish them from the Sharp-tailed, Swamp, Savannah, or Song Sparrows, the only ones which are likely to be found in their haunts.

550a. P. m. peninsulæ (Allen). Scott's Seaside Sparrow. Similar to the preceding, but much darker; prevailing color of the upperparts brownish black, the feathers margined with grayish olive-green; underparts more heavily streaked, the breast and sides streaked with black or blackish. W., $2 \cdot 30 ;$ T., $2 \cdot 00 ;$ B., $\cdot 52$.

Range.-W. coast of Fla., w. probably to Ala.

550c. P. m. fisheri (Chapm.). Louisiana Seaside Sparrow. Similar to $P$. m. peninsule but darker above, the breast and sides heavily washed with rusty buff and streaked with black.

Range. - Cen. Gulf coast. Breeds on coasts of La. and Miss.; winters sw. along the coast to Corpus Christi, Tex., and e. to Tarpon Springs, Fla.; casual at Charleston, S. C.

550d. P. m. macgillivraii ( $A u d$.). Macgillivray's Seasibe SparRow. Similar to $P . m$. fisheri but above grayer, less black; breast and flanks but faintly washed with buff and streaked with dusky grayish. Grayer above than $P . m$. peninsula and less heavily streaked below.

Range. - S. Atlantic coast. Breeds from N. C. to Ga. and n. Fla.; winters along the Gulf coast to La.

551. Passerherbulus nigrescens (Ridgw.). Dusky Seaside Sparrow. $A d s$.- Upperparts black, narrowly margined with grayish and grayish olivegreen; underparts sharply streaked with black and white in about equal proportions. "L., 5*95; W., 2*25-2*40; T., 2*10-2 50; B., '50-'60" (Ridgw.).

Range.-Marshes at $\mathrm{n}$. end of Indian River, Fla.

Nest and eggs unknown.

This Sparrow has been recorded from Salt Lake, near Titusville, Fla., but with this exception it appears to be confined to the western side of Merritt's Island on the opposite shore of Indian River. In March, 1898, I found it to be abundant near the mouth of Dummitt's Creek where it inhabited the sedge (Borrichia) bordering the water and the adjoining grassy marshes. Savannah and Swamp Sparrows were also common in these marshes. The paler color and darting, more extended flight of the former at once distinguished it from nigrescens, which, while more like the Swamp Sparrow, was soon recognized by its darker colors and shorter, more hesitating flight. The birds were not in song.

In view of the fact that this species is abundant and that the region it inhabits is in no sense isolated, but that both to the north and south there are marshes apparently similar to those it occupies, the restriction of its range to an area only a few square miles in extent make its distribution unique among North American birds.

552. Chondestes grammacus grammacus (Say). LARK Sparrow. Ads. - Sides of the crown and car-coverts chestnut, a whitish line over the 
eye and through the center of the crown; a black streak on the sides of the throat; upperparts brownish ash; back streaked with blackish; tail fuscous or black, the outer feathers tipped with white; underparts white, a small black spot in the middle of the breast. L., $6 \cdot 25 ; \mathrm{W} ., 3 \cdot 50 ;$ T., $2 \cdot 75 ;$ B., 45 .

Range.-Miss. Valley e. of the Great Plains. Breeds mainly in Austral zones from e. Nebr., nw. Minn., cen. Wisc., and s. Ont. s. to s. La. and cen. Ala. and e. to w. Pa., w. Md., and nw. W. Va.; casual in N. S., N. Y., Mass., N. J., D. C., N. C., and Fla.; winter home unknown, except in s. Miss.

Washington, A. V., Aug., two captures. N. Ohio, rare S. R., Apl. 28. Glen Ellyn, local and uncommon S. R. SE. Minn., common S. R., Apl. 20Aug. 2.

Nest, of grasses, lined with rootlets, fine grasses, and long hairs, on the ground or in low trees or bushes. Eggs, 3-5, white or pinkish white, spotted, blotched, or scrawled with purplish or black, chiefly at the larger end, $\cdot 78 \times 60$. Date, se. Minn., May 17 .

This is a common bird in the West. It frequents localities of much the same nature as those selected by the Grass Finch, and in its general habits reminds one of that species. The song is described by Ridgway ("Birds of Ills.," I, p. 262) as "composed of a series of chants, each syllable rich, loud, and clear, interspersed with emotional trills. At the beginning the song reminds one somewhat of that of the Indigo Bird (Passerina cyanea), but the notes are louder and more metallic, and their delivery more vigorous. Though seemingly hurried, it is one continued gush of sprightly music; now gay, now melodious, and then tender beyond description-the very expression of emotion. At intervals the singer falters, as if exhausted by

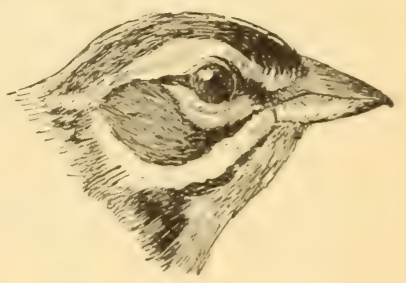

Fig. 106. Lark Sparrow. (Natural size.) exertion, and his voice becomes scarcely audible; but suddenly reviving in his joy it is resumed in all its vigor until he appears to be really overcome by the effort."

553. Zonotrichia querula (.Tutt.). HaRris's SparRow. Bill pinkish; crown and throat or breast more or less black. Ads.-Crown, throat. breast and lores glossy black, rehecks gray; above brownish gray strealied with black; rump brownish ashy, tail fuscous-gray; two white wing-hars; ludly white, sides with blackish streaks. Im.-Cimilar, but crown tipued with brownish; breast, and sometimes throat, with black streaks or lilotehes: cheeks, flanks and under tail-roverts luffy. L., 750; 11 ., 3.50; T., 3.25; B., '50.

Range-Cen. N. A. Breeds in Hudsonian zone at Fit. ('hurchill, Hudson Bay, Artillery Lake, Marekenzie, and prohably to (ireat Bear Lake and the district just s. of the Barren Grounds; in migration rangess e. to w. Ont. and e. Ills., and w. to ern. Mont. and (". Cols.; winters from n. Kans. and w. Mo. s. to s. Tex.; (asual in B. (C.; arecidental in Calif., () re., Wash., and Ohio. Glen Ellyn, one reeord, May 19, 1s97. SF. Minn., commen T. V., May 6-?; Sept. 21-Oct. 25.

Nest (found Aug. 5, 1907, hy E. T. Sroton, at Last Wornd, Cirrat Slave Lake, and the only one known), "was on the ground under a dwarf hirch, was made of grass and resembled the nest of a Whitr-throated syarrow. It (ontained three young nearly ready to fly" (Auk, 190s, 72). 
This handsome Sparrow barely enters the western limits of the region covered by the "Handbook." It there inhabits brushy undergrowths and much the same localities which White-throats frequent. Its pink or reddish bill and buff cheeks are excellent field characters. Its callnote is a sharp, metallic clink, louder than the White-throat's call, and, like that species, it utters low, chuckling, contented musical notes. Goss describes its song as composed of "pleasing, plaintive, whistling notes, in musical tone much like the White-throated Sparrow's, but delivered in a widely different song."

554. Zonotrichia leucophrys leucophrys (Forst.). WHITE-CROWNED Sparrow. Ads.-No yellow before the eye or on the bend of the wing; center of crown white bordered on either side by black stripes, no white before the eye; a white line from over the eye passes backward along the side of the head; nape gray; back dark grayish brown, margined with gray; rump dark brownish ash; greater and middle wing-coverts tipped with white; tail fuscous; underparts grayish, white on the belly, flanks and under tail-coverts cream-buff. Im. - Similar, but much browner, sides of the crown rufousbrown, center of the crown pale grayish brown; nape brownish ash; back margined with the same color. L., 6.88; W., 3.03; T., $2 \cdot 88$; B., 43.

Range.-N. A. Breeds in Hudsonian and Canadian zones of high mts. from s. Ore. to cen. Calif., and e. to Wyo. and s. N. M., and from limit of trees in cen. Keewatin and $n$. Ungava to se. Keewatin, cen. Que., and s. Greenland; winters from n. L. Calif., s. Ariz., s. Kans., and the Ohio Valley (casually from the Potomac Valley, s. to La. and Miss. and in Mex.

Washington, irregularly common W. V. and T. V., May 1-17; Oct. 7Nov. 20. Ossining, rare T. V., May 9-26; Oct. 3-30. Cambridge, uncommon T. V., May 12-22; Oct. 1-20. N. Ohio, common T. V., Apl. 22-May 20; Sept. 5-Oct. 16. Glen Ellyn, not common T. V.; chiefly spring, Apl. 24-May 31; Oct. 2-21. SE. Minn., common T. V., Apl. 30- ; Sept. 26-Oct. 14.

Nest, of grasses, on the ground or in bushes. Eggs, 4-5, pale greenish blue, speckled and spotted with bay, especially at the larger end, $90 \times \cdot 62$ (Davie). Date, Ft. Chimo, Lab., June 3.

This is one of the aristocrats of the family. Its size and its handsome markings at once distinguish it from its congeners, and are sure to attract attention. Though its season of love and music is spent in the far north, it often favors us with selections of its melodies as it rests in thickets and hedgerows while slowly passing through our country on its northward pilgrimage. Its usual song is like the latter half of the White-throat's familiar refrain, repeated a number of times with a peculiar sad cadence and in a clear, soft whistle that is characteristic of the group. It resembles its relatives also in singing its swectest songs in the woods, sometimes during the darkest hours of the night.

ERnest Thompson Seton.

554a. Z. 1. gambeli (Nutt.). Gambel's Sparrow. Similar to $Z$. $l$. leucophrys but the lores wholly gray or whitish, the white superciliary therefore reaching the bill.

Range.-W. N. Am. Breeds in Boreal zones from limit of trees in nw. Alaska and n. Mackenzic (rarely outside the mts. s. of (Great Slave Lake) s. to eren. Ore. and ren. Mont., w. to roast mts. of sw. Alaska and B. C.; winters from n. Calif. and Utah s. to San Luis Potosi, Mazatlan, L. Calif., and outlying islands; casual 2 . in migrations to Minn., Iowa, Kans., and e. Tex. SE. Minn., uncommon T. V., Apl. 30; Sept. 26-Oct. 14. 
The Golden-crowned Sparrow (55\%. Zonotrichia coronata) of the Pacific coast region is of accidental occurrence in Wisconsin (Nelson, Bull. Essex. Inst., VIII, 1876, 108).

558. Zonotrichia albicollis ( $\mathrm{Gmel}$.). White-tHROATED Sparrow. Ads.A yellow line before the eye; bend of the wing yellow; center of the crown with a white stripe bounded on either side by much wider black stripes; a white stripe from the eye passes backward along the side of the head; back rufous or rufous-brown, streaked with black and slightly margined with whitish; rump grayish brown; greater and middle wing-coverts tipped with white; tail grayish brown; underparts grayish, more so on the breast; throat with a square white patch; belly whitish; flanks and under tail-coverts tinged with grayish brown. Im. and Ads. in winter.-Yellow before the eye, and on the bend of the wing duller; crown streaks brownish ashy and mixed chestnut and black, instead of white and black; throat-patch less sharply defined and in some (Im.) specimens practically obsolete when the breast is obscurely streaked with blackish. L., $6 \cdot 74 ;$ W., $2 \cdot 89 ;$ T., $2 \cdot 86$; B., ' 44 .

Range.-E. N. Am. Breeds in Canadian and lower Hudsonian zones from n. Mackenzie (Ft. Good Hope), cen. Keewatin, and s. Ungava s. to cen. Alberta, s. Mont., cen. Minn., cen. Wisc., s. Ont., and mts. of n. Pa., N. Y., and Mass.; winters from Mo., the Ohio Valley, s. Pa., Míass. (casually Maine), s. to ne. Mex. and Fla.; casual in Ore., Calif., Utah, and ('olo.

Washington, very common $W . V$, abundant $T$. V., Mch. 1s-May; Sept. 15-Dec. 16. Ossining, common T. V., Apl. 10-May 21; Sept. 20Oct. 30; a few winter. Cambridge, very common T. V., Apl. 25-May 15; Oct. 1-Nor. 10; a few winter. N. Ohio, common T. V., Apl 1-May 21: Sept. 10-Nov. 7. Gien Ellyn, common T. V., Apl. 9-May 26; Sept. 13- Nov. 7. SE. Minn., common T. V., Apl. 8- ; Sept. 2-Nov. 13.

Nest, of coarse grasses, rootlets, moss, strips of bark, etc., lined with finer grasses, on the ground or in bushes. Eggs, 4-5, bluish white, fincly and evenly speckled or heavily and irregularly blotehed with pale rufous-brown, $.82 \times 60$. Date, Wilmurt, N. Y., May 28 ; Lancaster, N. H., June 5; Charlotte Co., N. B., June 5.

In September, when the hedgerows and woodland undergrowths begin to rustle with Sparrows, Juncos, and Towhees, I watch eagerly for the arrival of these welcome fall songssters. There are a few sweet, tremulous trials before their plaintive, sympathetic: whistle brings cheer to the

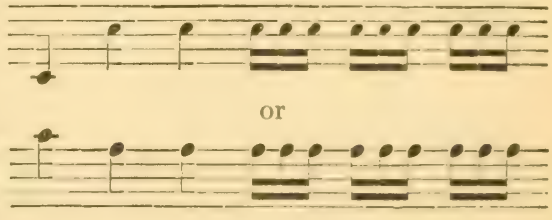
browning woods:

Few birds are more sociable than the White-throats. At this season they are always in little companies, and they frequently roost fogether in large numbers in the depths of dense thickets or clumps of exergreens. After they have retired one may hear the sharp) chiml: of their 'quarrier' chorus, and when darkness comes, with low, hrooling notes of cozy companionship they are hushed for the night.

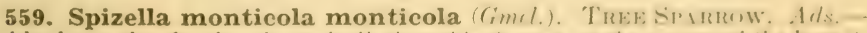
No black on the foreheadt; an incli-tine f lack spot on the cenere of the hreast: top of the head rufous-hrown, sometimes extered with ashy: a grayish lime: over the eye and a rufous-brown line hehind it back strakied with rufousbrown, black, and pale ochraccous-buff; rump, pale grayish brown; greater 
and middle wing-coverts tipped with white; outer web of the outer tailfeather whitish; breast grayish white; middle of the belly white; sides tinged with pale grayish brown; upper mandible black; lower, yellow at the base, the tip black. L., $6 \cdot 36$; W., $2 \cdot 99$; T., $2 \cdot 82$; B., 41 .

Range.-E. N. Am. Breeds in Hudsonian zone from cen. Mackenzie and n. Ungava to Great Slave Lake, cen. Keewatin, n. Que., and N. F.; winters from s. Minn., Ont., and the Maritime Provinces s. to e. Okla., cen. Ark., and S. C.

Washington, abundant W. V., Oct.-Apl. 1. Ossining, common W. V., Oct. 10-Apl. 27. Cambridge, common W. V., abundant T. V., Oct. 25Nov. 25; Mch. 20-Apl. 20. N. Ohio, abundant W. V., Oct. 24-May 3. Glen Ellyn, common W. V., Oct. 4-Apl. 28. SE. Minn., common T. V., Oct. 6May 5; a few winter.

Nest, of grasses, rootlets, and hair, on or near the ground. "Eggs, 4-5, pale green or greenish blue, spotted with reddish brown, $75 \times$ '60" (Chamberlain). Date, Ft. Chimo, Lab., June 16.

Tree Sparrows wear a small black dot on the center of their otherwise unmarked breasts, a badge which will aid in their identification. They come in flocks when the fields are beginning to look brown and dreary, but seem contented with the surroundings from which other birds have fled. They feed on the seeds of weeds and grasses, and even when the snow is deepest always find an abundance of food. I like to see them feasting on the seed-stalks above the crust, and to hear their chorus of merry, tinkling notes, like sparkling frost crystals turned to music.

Winter Chippies they are sometimes called, but at this season there is little of the Chippy's nature about them. In February or March they begin to sing a song which has been compared to that of a Canary, but is "finer, sweeter, and not so loud."

560. Spizella passerina passerina (Bech.). ChIPpINg Sparrow. Ads. -Forehead black, a short grayish line in its middle; top of the head rufous; the nape generally with a few black streaks; a grayish line over the eye and a black line behind it; back of the neck grayish, separating the rufous crown from the back; back streaked with black, a little rufous, and more pale

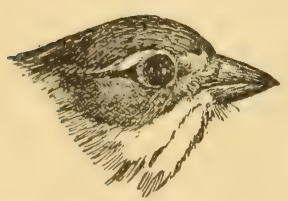

Frg. 107. Chipping Sparrow. (Natural size.)

buffy ochraceous; rump slaty gray; wing-bars not conspicuous; underparts grayish white, whiter on the throat and belly; bill entirely black. Ads. in winter and Im.--Similar, but no rufous crown-cap or black on the forehead; top of the head streaked like the back; bill brownish. Nestlings have the breast streaked with black. L., $5 \cdot 37$; W., 2.74; T., $2 \cdot 29$; B., 36 .

Remarks. - In adults the rufous crown, black forehead, gray rump, and black bill are characteristic; in winter the gray rump is a good distinguishing mark.

Range.-E. N. Am. Breeds in Canadian, Transition, and Austral zones from cen. Sask., sw. Keewatin, n. Ont., cen. Que., and Cape Breton Is. to cen. Tex., s. Miss., and cen. Ga.; winters chiefly in s. States, occasionally as far n. as Okla. and s. N. J.; casual in Cuba and ne. Mex.

Washington, common S. R., abundant T. V., Mch. 9-Nov. 11, occasionally winters. Ossining, common S. R., Apl. 9-Nov. 7. Cambridge, abundant S. R., Apl. 12-Oct. 25. N. Ohio, abundant S. R., Mch. 23 to Oct. 10. Glen Ellyn, not very common S. R., Apl. 5-Nov. 5. SE. Minn., common S. R., Apl. 8-Oct. 26. 
Nest, of grasses, fine twigs, or rootlets, thickly lined with long hairs, in trees or bushes, 5-20 feet up. Eggs, 4-5, blue or greenish blue, with cinnamonbrown or blackish markings, chiefly at the larger end, $72 \times{ }^{\circ} 51$. Date, Montgomery Co., Pa., May 8; Cambridge, May 12; se. Minn., May 16.

The Chippy is among Sparrows what the Phœebe is among Flycatchers-the humblest, most unassuming member of its family. Both show trustfulness, which, in spite of their unattractive appearance and far from pleasing voices, wins our affection. Chippy makes his nest in the vines on our piazza, and feeds on the crumbs at our doorstep, quite as though he were a member of the family; and he needs only a little encouragement to give evidence of his entire confidence in our good will by feeding from our hands. His song is a monotonous chippychippy-chippy-chippy, rather high and wiry and frequently running into an insectlike trill - by no means a musical performance.

In the fall, Chippy changes his dress, dons a streaked cap for the one of bright bay, and, with others of his kind, goes to the fields to feast on the year's harvest of seeds. He is generally found near trees and hedgerows, into which, when alarmed, he flies with his companions.

561. Spizella pallida (Swains). Clay-Colored Sparrow. Ads.With a general resemblance to immature $S$. socialis, but less rufous above, whiter below, the line over the eye white, and the rump pale grayish brown instead of slaty gray. W., $2 * 40 ;$ T., $2 * 35 ;$ B., 34 .

Range.-Interior N. A. Breeds in Canadian and Transition zones from se. B. C., s. Mackenzie, sw. Keewatin, and Isle Royale, Mich., to w. Mont., se. Colo., n. Nebr., and nw. Ills.; winters from s. Ariz., s. N. M., and s. Tex. s. to s. Mex., Guanajuato, Puebla, Oaxaca, and Chiapas; casual in Ont. and Ind. SE. Minn., common S. R., Apl. 26-Oct. 19.

Nest, of grasses, lined with hairs, on the ground or in bushes. Eggs, 3-5, similar to those of the preceding. Date, se. Minn., May 23.

"This pale Sparrow of the plains is very similar in actions to the Chipping Sparrow, but less familiar and confiding in habits" (Goss).

Brewer's Sparrow (562. Spizelle breweri), a western specie's, has been recorded once from Massachusetts. (Brewster, Am. Viat., VIII, Is74, 366.)

563. Spizella pusilla pusilla (Wils.). Field Sparrow. Bill rerddish brown. Ads.-Top of head rufous, a gray line over the eye; natpe slightly gray; back like the crown, but fincly streaked with black and narrowly edged with brownish ashy; rump brownish ashy; middle and greater wingcoverts tipped with white; underparts whitish, tinged with ochrateons-lunff on the breast and sides. Ads. in uinter and Im. - Similar, but the eolors duller, the crown edged with grayish and sometimes a faint grayish line through its center. Nestlings have the breast streaked with blark. L., 5-6x; W., 2.50; T., $2.55 ;$ B., ' 36 .

Remarks.-This bird may be known by its brightly colored back, buffy breast, and especially by its reddish bill.

Range.-E. N. Am. Breeds in Transition and Austral zones from s. Minn., s. Mich., s. Que., and s. Maine, to cen. Trx., cen. Iat., and n. Fla.; winters from Mo., Ills., s. Pa., and X. J. to the (iulf eoast, easually further n.

Washington, very common P. R. Ossining, common S. R., Apl. 22 Wov. 7. Cambridge, common S. R., Apl. 12-N(N. 1; (asual in winter. N. Ohio, abundant in summer, Mch. 6-Oct. 25. Glen Ellyn, tolerably common S. R., Mch. 27-Oct. 11. SE, Minn., common S. R., Apl, 1-Dec, 28. 
Nest, of rather coarse grasses, weed stalks, rootlets, etc., lined with fine grasses and long hairs, on the ground or in low bushes. Eggs, 3-5, white or bluish white, with numerous rufous markings, chiefly about the larger end, $\cdot 70 \times{ }^{5} 52$. Date, Raleigh, N. C., May 4; Montgomery Co., Pa., May 5; New London, Conn., May 21; Cambridge, May 25; Wheatland, Ind., Apl. 30.

Its bright rufous color, the absence of spots on its breast, and especially its flesh-colored bill, are the best field-marks of this misnamed Sparrow, for he is not a true Field Sparrow, but prefers old pastures dotted with clumps of bushes or young cedars. There is something winning in his appearance; he seems such a gentle, innocent, dovelike little bird. His song is in keeping with his character, being an unusually clear, plaintive whistle, sweeter to the lover of birds' songs than the voice of the most gifted songstress. It is subject to much variation. Not only do the same individuals sing several different songs, but two individuals in the same locality rarely sing alike. There is also much variation in the songs of birds from different regions. For this reason it is quite impossible to give a description of the song which will apply throughout the bird's range. However, an average song

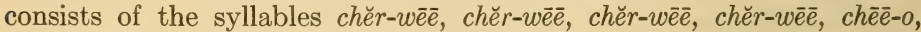
$d e-d e-d e-d e-d e$, the last notes joined in a trill.

This gives, of course, no idea of the quality of the Field Sparrow's song, but to be convinced of its rare beauty one need only hear it as the sun goes down and the hush of early evening is quieting the earth.

The Western Field Sparrow (563a. Spizella pusilla arenacea), a pale form, has been recorded from the vicinity of New Orleans.

567. Junco hyemalis hyemalis (Linn.). Slate-COLORed JUnco. Ad. $0^{7}$.- Upperparts, throat, and breast grayish slate-color; upperparts more or less washed with grayish brown; belly white, sides grayish; no wing-bars; tail fuscous, the two outer feathers and part of the third white; bill flesh-color. $A d$. o. - Similar, but the upperparts browner, throat and breast paler. Ads. in winter. - Resemble ads. in summer but are more richly washed with brownish or rusty. Nestlings, resemble the adults, but have the upperparts, throat, and breast streaked with black. L., 6.27; W., 3.03; T., $2 \cdot 71$; B., 41 .

Range.-E. and n. N. Am. Breeds in Hudsonian and Canadian zones in nw. Alaska (tree limit), n. Mackenzie (tree limit), cen. Keewatin, and cen. Ungava s. to base of Alaska Peninsula, s. Yukon, cen. Alberta, n. Minn., cen. Mich., Ont., and mts. of N. Y., Pa., and Mass.; winters throughout the e. U. S. and s. Ont. s. to the Gulf coast; casual in Calif., Ariz., and N. M.; straggles to Siberia.

Washington, abundant W. V., Sept. 26-May 12. Ossining, common W. V., Sept. 19-May 4. Cambridge, rather common W. V., abundant T. V., Sept. 20-Nov. 25; Mch. 20-Apl. 20. N. Ohio, abundant W. V., Oct. 2-May 5. Glen Ellyn, W. V., abundant spring and fall, Aug. 30-May 13. SE. Minn., common T. V., Mch. 4- ; Sept. 20-Nov. 12.

Nest, of grasses, moss and rootlets, lined with fine grasses and long hairs, on or near the ground. Eggs, 4-5, white or bluish white, finely and evenly speckled or spotted, sometimes heavily blotched at the larger end with rufous-brown, $76 \times 58$. Date, Wilmurt, N. Y., May 27; Grand Manan, N. B., May 25.

When the snow begins to fly, you will look out some gray morning to find a flock of small, plump, slate-colored birds hopping about the 
dooryard, picking up what they can find, or sitting in the bushes with an air of contentment that it is pleasant to see.

Coming, as they do, when most of the home birds have left for the south, they bring their own welcome, and soon seem like old friends. But if you would really know your gentle winter visitors, you must go back into the woods when summer comes and find them in their own homes.

Look for them in a tangle of fallen tree-tops, logs, and upturned roots. A pair I once surprised in such a place at first sat and chirped at me-with bills full of food-but soon they were flying freely back and forth to the upturned root where they had hidden their nest.

I noticed with surprise that their gray plumage toned in so well with the dark earth that they were hard to see. The sharp horizontal line across the breast where the gray turns abruptly to white added to the disguise, the straight line breaking the round form of the bird.

The 'tsip of the Junco is unmistakable and more often heard than his song, but he has both a trill and a low, sweet song as inpretentious and cheery as the friendly bird himself.

\section{Florence Merriam Batley.}

567e. J. h. carolinensis Brewst. CAROLINA JUNCO. Similar to the preceding, but slightly larger, the upperparts, throat, and breast uniform grayish slate-color without a brownish wash, bill horn-color. W., 3*26; T., $2 \cdot 85$; B., $\cdot 43$.

Range.-S. Alleghanies. Breeds in the Canadian zone (overlaipluing into the Alleghanian fauna) of mts. from w. Md., Va., and W. Va., s. to 11 . Ga.; winters in adjacent lowlands.

Nesting date, Cold Knob, W. Va., May 21.

This is a common and apparently permanent resident species in the higher parts of the southern Alleghanies.

567f. J. h. montanus Ridgw. Montana Junco, Similar to ,J. $h$. hyemalis, but head and breast blacker, the former, sharply defined from the brownish black, the sides strongly washed with brownish joinl. W., 3.15; T., $2 \cdot 60$.

Range.-N. Rocky Mts. Breeds in Canadian zone from s. Alloerta s. to n. Idaho and nw. Mont.; winters s. to Ariz., N. MI., Chihuahua, and Tex., and e. casually to Kans., Ills., Ind., Mass., and Md.

Cambridge, one record (Mch. 25, 1874).

575. Peucra restivalis restivalis (ticht.). PrNE-WoOns SPArRow. Ads. - Upperparts lightychestnut, more or less streakeel with black and margined with gray; a grayish line over the ere; bend of the wing yellow; tailfeathers narrow, grayish fuscous, the outer ones much the shortest : loreast and sides washed with pale brownish ash; loreast sometimes with a frew lalack spots; middle of the belly white. L., 5.80; W., 25.50; T., 250; B., -45.

Range.-Ga. and Fla. Breeds in Austroripatrian fauna from s. (ias. s. to cen. Fla.; winters in cen. and s. Fla.

Nest, of fine grasses, on the ground, beneath sarub palmetto. Eggls, 3-5, pure white, $72 \times{ }^{\cdot 61}$. Date, Lake Okeerhober, Fla., Apl. 14; San Maton, Fla., Apl. 23.

This is a common hird in Floricla. It winters in the southern part of the State and migrates northward in March. It is found only in 
pine woods having an undergrowth of scrub palmetto. Here it passes most of its time on the ground, and is difficult to flush.

When singing, it seeks an elevated perch. In my opinion its song is more beautiful than that of any other of our Sparrows. It is very

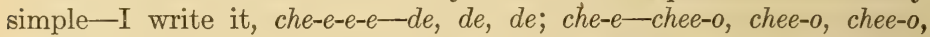
chee-o-but it possesses all the exquisite tenderness and pathos of the melody of the Hermit Thrush; indeed, in purity of tone and in execution I should consider the Sparrow the superior songster. It sings most freely very early in the morning and late in the afternoon, when the world is hushed and the pine trees breathe a soft accompaniment to its divine music.

575a. P. æ. bachmani (Aud.). Bachman's Sparrow. Similar to the preceding subspecies, but the upperparts rufous, black streaks generally confined to the back, or absent; line over the eye buffy; breast and sides brownish cream-buff without streaks.

Range. SE. U. S. Breeds in Carolinian and Austroriparian faunas in cen. Ills. (locally to se. Iowa), s. Ind., s. Ohio and cen. Va. s. to cen. Tex., and extreme nw. Fla.; winters from s. N. C. s. into Fla.; casual near Washington, D. C.

Washington, one record, Apl.

Nest, of grasses, domed and cylindrical, on the ground. Eggs, 3-4, pure white, $\cdot 74 \times \cdot 60$ (Bendire, Auk, V, 1888, 356). Date, Weaverville, N. C., May 6; Greensboro, Ala., May 8.

In Florida, where this bird is not uncommon during the winter, I have found it in pine woods undergrown with turkey oaks, and not in localities frequented by $P$. cestivalis. In South Carolina it was observed in essentially similar localities, and its song did not differ materially from that of cestivalis. Mr. Ridgway writes that in Illinois this is "emphatically a bird of open oak woods, where large white and post oaks prevail, with grass land immediately adjoining, or where the intervals between the trees consist of sward rather than undergrowth; but neglected fields, grown up to weeds, and in which dead trees are left standing, are also its favorite haunts."

He speaks of its song as reminding one somewhat of the plaintive chant of the Field Sparrow, but as far sweeter and louder; "the modulation, as nearly as can be expressed in words, resembling the syllables théééééé-thut, lut, lut, lut, the first being a rich, silvery trill, pitched in a high musical key, the other syllables also metallic, but abrupt, and lower in tone."

1888. Bendire, C. E., Auk, V, 351-356 (nesting).

581. Melospiza melodia melodia (Wils.). Song Sparrow. Ads.Crown rufous-brown, with a grayish line through its center; a grayish line over the eye; a rufous-brown line from behind the eye to the nape; feathers of the back streaked with black and margined with rufous-brown and grayish; greater wing-coverts with black spots at their tips; no white wing-bars or yellow on the wing; tail rufous grayish brown, the middle feathers darker along their shafts; outer feathers shortest; sides of the throat with black or blackish streaks; breast with wedge-shaped streaks of black and rufousbrown which tend to form one larger blotch on the center; sides washed 
with brownish and streaked with black and rufous-brown; middle of the belly white. L., $6 \cdot 30$; W., $2 \cdot 52$; T., $2 * 62$; B., 449 .

Range.-N. A. e. of the Rocky Mts. Breeds in Canadian, Transition, and Upper Austral zones from s. Mackenzie (Great Slave Lake), cen. Keewatin, n. Ont., cen. Que., and Cape Breton Is. s. to s. Nebr., cen. Mo., Ky., s. Va., and s. N. C. (mts.), and w. to the Rocky Mts. of Alberta; winters from Neb., Ills., Mass. (locally), and N. J., s. to the Gulf coast, and sporadically $\mathrm{n}$. to Mich., and N. S.

Washington, common P. R., abundant T. V., Mch. and Oct. Ossining, common P. R. Cambridge, very abundant S. R., Mch. 10-Nov. 1; locally common W. V. N. Ohio, P. R., abundant in summer, common in winter. Glen Ellyn, common S. R., Feb. 12-Nov. 2. SE. Minn., common S. R., Mch. 16-Nov. 11.

Nest, of coarse grasses, rootlets, dead leaves, strips of bark, etc., lined with finer grasses and sometimes long hairs, on the ground, sometimes in bushes. Eggs, 4-5, white or bluish white, with numerous rufous-brown markings which sometimes nearly conceal the ground color, $76 \times{ }^{\circ} 60$. Date, Montgomery Co., Pa., Apl. 27; Cambridge, Apl. 30; se. Minn., Apl. 27.

The Song Sparrow's vast range in a dozen varying climates, its readiness to adapt itself to the different conditions in each of the regions it inhabits, its numerical abundance and steady increase while some of its family are dying out, its freedom from disease and vermin, and its perennial cheerfulness, evidenced by its never-failing music-all proclaim that it is indeed one of Nature's successes.

Its irrepressible vivacity and good spirits in spite of all circumstances are aptly illustrated by the fact that its song may be heard in every month of the year and in all weathers; also by night as well as by day-for nothing is more common in the darkest nights than to hear its sweet chant in half-conscious answer to the hooting of the Owl or even the report of a gun.

It is never seen far from water, and when it is alarmed it flies downward or along-never upward-into some low thicket, pumping its tail as it flies.

Its alarm note is a simple metallic chip, which is very distinctive when once learned. But its merry chant-which has won for it the name of "Song Sparrow" - is its best-known note. It is a voluble and uninterrupted but short refrain, and is, perhaps, the sweetest of the familiar voices of the meadow lands. The song that it occasionally utters while on the wing is of quite a different character, being more prolonged and varied.

Though so abundant, it can not be styled a sociable species. Fven during the migrations it is never seen in compact flocks like the Rerlpoll or Snowflake; at most it will be found forming a part of a long, scattered migrating train that usually includes a number of different but nearly related species.

Ernest Thompson Sieton.

1899. Owen, D. E., Auk, XVI, 221-225 (growth of young).

583. Melospiza lincolni lincolni (Aud.). LinColN's SPARIROW. Ads.-Upperparts streaked with black, brownish gray, and grayish brown: tail-feathers narrow and rather pointed, the outer one's shortest; underparts white, rather finely streaked with black, a broad crcam-buff band 
across the breast, a cream-buff stripe on either side of the throat; sides tinged with cream-buff. L., $5 \cdot 75 ;$ W., $2.50 ;$ T., $2 \cdot 40 ;$ B., $\cdot 41$.

Remarks. - The cream-buff band on the breast is distinctive of this species.

Range.-N. A. Breeds in Boreal zones from Alaska and n. Ungava s. to n. Minn., cen. Ont., n. N. Y., N. B., and N. S. and s. in the Cascade, Sierra Nevada, and Rocky Mts. to s. Calif. and n. N. M.; winters from San Jacinto Mts., Calif., s. Okla., and n. Miss. to Guatemala; casual only e. of the Alleghany Mts. s. of Washington, D. C.

Washington, rare T. V., May 8-21; Sept. 30-Oct. 1. Ossining, rare T. V., Sept. 29-Oct. 16. Cambridge, not uncommon, T. V., May 15-May 25; Sept. 14-Oct. 10. N. Ohio, tolerably common T. V., Apl. 25-May 25. Glen Ellyn, not common T. V., fall records only, Sept. 11-Oct. 9. SE. Minn., common T. V., Apl. 17- ; Sept. 10-Oct. 30.

Nest, generally similar to that of the Song Sparrow, on the ground. "Eggs, 4-5, pale green or buffish, sometimes almost white, thickly spotted and blotched with reddish brown and lilac, $80 \times 60$ " (Chamberlain). Date, Wilmurt, N. Y., June 10; Racine, Wisc., June 6.

The most striking characteristic about the Lincoln's Sparrow is its shyness, whether migrating in the lavish abundance of the West, straying casually through the states of the Atlantic seaboard, or settled for the summer in a chosen spot of the northern evergreen woods. Scampering like a mouse along some tumble-down stone wall half buried in poison ivy, sumach, and all the tangled growth that goes to make up an old hedgerow, or peering out from a clump of low-spreading bushes, this little bird may sometimes be detected; but as he hurries northward late in the migration, when all the woods and fields are ringing with bird music, our attention is seldom directed toward the silent straggler, while in the autumn he is lost in the waves of Sparrows that flood the country.

If we follow him northward, we find him irregularly distributed in small colonies or single pairs in damp clearings, perhaps along brooks or ponds, but avoiding almost entirely the wetter, more open localities, where the Swamp Sparrow is at home. Attracted by a sharp chirp which, at times reduplicated, resembles that of a young Chipping Sparrow, we may succeed in catching a glimpse of him as he lurks beneath a little spruce perhaps no bigger than an umbrella.

Sometimes venturing timidly to the outer boughs of a spruce, he surprises the hearer with a most unsparrowlike song. It is not loud, and suggests the bubbling, guttural notes of the House Wren, combined with the sweet rippling music of the Purple Finch, and when you think the song is done there is an unexpected aftermath. The birds sing very little and at long intervals, and are seldom heard during the later hours of the day, ceasing at once if anybody approaches.

\section{J. Dwight, JR.}

584. Melospiza georgiana (Lath.). Swamp Sparrow. Ads. in summer.-Crown chestnut-rufous; forehead black; a grayish line over the eye; a blackish line behind the eye; nape slaty gray with a few black streaks; feathers of the back broadly streaked with black and margined with rufous and cream-buff or ashy buff; wing-coverts rufous, the greater ones with black spots at their tips; rump rufous grayish brown, sometimes streaked 
with black; tail rufous grayish brown, the middle feathers darker along their shafts; throat and middle of the belly white, breast grayish, sides washed with pale grayish brown. Ads. in winter and $I m$. - Similar, but the top of the head streaked with black, rufous-brown, and grayish; nape less gray; breast washed with brownish. L., 5.89; W., $2 \cdot 34$; T., $2 \cdot 32$; B., 46.

Remarks. - The underparts resemble those of some immature Whitethroated Sparrows, but the wing-bars and the yellow bend of the wing will always distinguish the latter.

Range.-N. A. e. of Great Plains. Breeds in Canadian, Transition, and part of Upper Austral zones from w. cen. Alberta, cen. Mackenzie, cen. Keewatin, cen. Que., and N. F. s. to n. Nebr., n. Mo., n. Ills., W. Va. (mts.) and N. J.; winters from Nebr., Ohio Valley, and Mass. (rarely) s. to the Gulf coast from cen. Fla. to Mex.; accidental in Utah and Colo.

Washington, very common T. V., Apl. 12-May 19; Sept. 28-Oct. 29; a few winter. Ossining, tolerably common S. R., Apl. 4-Dec. 2; a few winter. Cambridge, abundant S. R., Apl. 12-Nov. 10; a few winter. N. Ohio, common T. V., Mch. 23-May 20. Glen Ellyn, tolerably common T. V., Apl. 2-May 26; Sept. 2-Oct. 24; possibly S. R. SE. Minn., common S. R., Apl. 5-Nov. 18.

Nest, generally similar to that of the Song Sparrow, on the ground. Eggs, 4-5, similar in color to those of the Song Sparrow, but the markings generally more confluent, $76 \times 57$. Date, Cambridge, May 13; New Canada, N. S., May 19; Pewaukee, Wisc., May 23; se. Minn., May 25.

While wintering in the South, Swamp Sparrows frequently belie their name, and I have often found numbers of them in dry 'old fields' of broom sedge; but at the north they are more consistent, and one rarely sees them beyond the confines of a wet meadow, or, more preferably, a large grassy marsh with reed-bordered streams.

Swamp Sparrows may be distinguished from their cousins, the Song Sparrows, by their unstreaked breast, much darker upperparts, and totally different notes. Their usual call-note is a sharp cheep, not unlike that of the White-throated Sparrow, and quite different from the rather nasal chimp of the Song Sparrow. Their song is a simple, sweet, but somewhat monotonous tweet-tweet-tweet, repeated many times, all on one note, and sometimes running into a trill.

585. Passerella iliaca iliaca (Merr.). Fox Sparrow. Ads.-Upperparts rufous-brown, the feathers margined by cinnamon-brown and without black; upper tail-coverts and tail bright rufous; wings margined with rufous; underparts heavily streaked and spotted with rufous-brown and blackish; middle of the belly white; lower mandible yellowish. L., 7.26; $11 ., 3 \cdot 39$; T., $2 \cdot 85$; B., '50.

Range.-N. A. Breeds in Boreal zones from tree limit in ne. Alaska, and $n$. Ungava s. to cen. Alberta, $n$. Man., s. Keewatin, Magdalen Islands, and N. F.; winters from lower Ohio and Potomac valleys (occasionally further n.) to cen. Tex. and n. Fla.; casual on the coast of s. Alaska and in Calif.

Washington, very abundant T. V., Mch. 13-May 11; Oct. 23-Nov. 15; a few winter. Ossining, tolerably common T. V., Mch. 4-Apl. 20; Oct. 14Nov. 28. Cambridge, abundant T. V.,

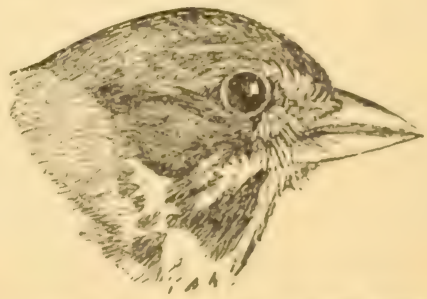

Fia. 108. Fox sporrow. (Natural size.) 
Mch. 15-Apl. 12; Oct. 20-Nov. 15; occasional in winter. N. Ohio, common T. V., Mch. 12-Apl. 23; Oct. 1-Nov. 16. Glen Ellyn, fairly common T. V., Mch. 11-Apl. 28; Sept. 22-Nov. 8. SE. Minn., common T. V., Mch. 12- ; Sept. 17-Nov. 12.

Nest, of coarse grasses, lined with finer grasses, hair, moss, and feathers, on the ground, and in low trees and bushes. Eggs, 4-5, pale bluish, evenly speckled or heavily blotched with umber or vinaceous-brown, ${ }^{\circ} 80 \times{ }^{\circ} 63$ (see Bendire, Auk, VI, 1889, 108). Date, Ft. Resolution, Mack., June 1.

In the early spring the Fox Sparrow is seen mostly about damp thickets and roadside shrubbery; later it takes more to woodsides, foraging on leaf-strewn slopes where there is little or no undergrowth, often associated with small parties of Juncos. On its return in the autumn it again becomes a common denizen of hedgerows and thickets, and also invades the weedy grainfields, rarely, however, straying far from some thickety cover. Sometimes large numbers congregate among withered growths of tall weeds, whence they emerge with a loud whirring of wings as their retreat is invaded, and hie away in tawny clouds, flock after flock. It is a great scratcher among dead leaves, and can make the wood rubbish fly in a way which, in proportion to its size, a barnyard fowl could scarcely excel.

The usual note of the Fox Sparrow is a feeble tseep. A note of excitement is louder and sharper in tone. Its song is not surpassed by that of any of our Sparrows. It is a revelation to hear it at sundown on some vernally softened evening of early springtime; little swarms of gnats hover in the balmy air; from the twilight meadows comes the welcome, half-doubtful piping of the first hylas-no other sound. Then perhaps from some dusky thicket a bird's song! An emotional outburst rising full-toned and clear, and passing all too quickly to a closing cadence, which seems to linger in the silent air. It is the song of the Fox Sparrow with that fuller power and richness of tone which come into it, or seem to, at the sunset hour. It breaks forth as if inspired from pure joy in the awakened season, though with some vague undertone, scarcely of sadness, rather of some lower tone of joy.

Eugene P. Bicknell.

1889. Bendire, C. E., Auk, VI, 107-116 (nesting).

587. Pipilo erythrophthalmus erythrophthalmus (Linn.). TowHEE. Ad. $\sigma^{7}$.-Upperparts black, sometimes margined with rufous; throat and breast black, belly white, sides rufous; outer web of primaries with white; tail black, the three outer feathers tipped with white; outer web of the outer feather entirely white; iris red. Ad. \&.-Upperparts, wings, throat, and breast bright grayish brown; tail fuscous-brown the three outer feathers tipped with white; sides rufous, middle of the belly white. Nestlings have the back and underparts streaked with black. L., 8*35; W., 3.34; T., $3 \cdot 68 ;$ B., 55 .

Range.-E. N. Am. Breeds in Alleghanian and Carolinian faunas from se. Sask., s. Man., s. Ont., and s. Maine s. to cen. Kans. and n. Ga.; winters from se. Nebr., the Ohio and Potomac valleys (casually New England) to cen. Tex., the Gulf coast, and s. Fla.

Washington, common S. R., very common T. V., Apl. 5-Oct. 21; a few winter. Ossining, common S. R., Apl. 21-Oct. 31. Cambridge, common S. R., Apl. 25-Óct. 15. N. Ohio, common S. R., Mch. 10-Oct. 25. Glen 
Ellyn, not common S. R., Mch. 30-Nor. 18. SE. Minn., common S. R., Apl. 11-Nov. 8.

Nest, externally of dead leaves and strips of bark, lined with fine grasses, on or near the ground. Eggs, 4-5, white, finely and evenly speckled with shades of rufous, sometimes blotched at the larger end, $96 \times \cdot 71$. Date, Fairfax Co., Va., May 8; Montgomery Co., Pa., May 17; Cambridge, May 20; Rosetta, Ill., May 2; Wheatland, Ind., May 6.

There is a vigorousness about the Towhee's notes and actions which suggests both a bustling, energetic disposition and a good constitution. He entirely dominates the thicket or bushy undergrowth in which he makes his home. The dead leaves fly before his attack; his white-tipped tail-feathers flash in the gloom of his haunts. He greets all passers with a brisk, inquiring chewink, towhee, and if you pause to reply, with a fluff-fluff of his short, rounded wings he flies to a nearby limb to better inspect you.

It is only when singing that the Towhee is fully at rest. Then a change comes over him; he is in love, and, mounting a low branch, he gives voice to his passion in song. I have long tried to express the Towhee's song in words, but nerer succeeded as well as Ernest Thompson Seton when he wrote it chuch-burr, pill-a-uill-a-uill-a.

587a. P. e. alleni Coues. WHITE-EYED TOWHEE. Similar to the preceding, but with less white on the wings and tail; only two outer tail-feathers tipped with white; iris yellowish or white. L., 8.00 ; W., 3*20; T., 3*60; B., 52 .

Range.-Coast region from about Charleston, S. C., s. through Fla. Nesting date, San Mateo, Fla., Apl. 18.

This southern race of the Towhee does not associate with the northern bird, which is abundant in the south in the winter.

The latter selects haunts of much the same nature as those in which it passes the summer, while the southern bird lives in heavy growths of scrub palmetto. The notes of alleni differ from those of erythrophthalmus; its towhee is much higher, and its song, as Dr. Allen pointed out years ago, is shorter. It is also a shyer bird than its northern cousin.

The Arctic Towhee (.588. Pipilo maculatus arcticus) of the Creat Plains and Rocky Mountain region, is of rasual onceurrenre in Illinois and Wisconsin. It bears a general resemblanes to $P$ '.. . rythrophthalmus, hut hats more white in the tail and the scapulars and back are marked with white.

The Green-tailed Towhee, (5.92.1. Orospiza chlorura) of the western United States is of accidental occurrence in Virginia.

593. Cardinalis cardinalis cardinalis ( $\mathrm{i}$ imn.). (IRIN.AL. A $l$. . Throat and regions at beut the biase of the bill black: rest of the plumater

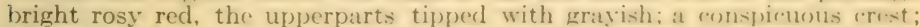
bill red. Ad. o. - Throat and region ahout the liase of lill grayish blarek; erest, wings, and tail dull red: upperparts olive brownish ash: underparts buffy ochraceous, lighter on the hrlly, and sometimes tinerel with red on the breast. L., $8 \cdot 25 ; \mathrm{W} ., 3 \cdot 75 ;$ T., $4.00 ;$ B., 64 .

Range.-Carolinian and Austroriparian faunas from so. S. D., s. Inwa, n. Ind., n. Ohio, s. Ont. (locally), se. and sw. Pa., and s. Hudson Valley s. 
to the Gulf States; casual in Minn., Wisc., Mich., N. B., Mass., and Conn.; resident in Bermuda.

Washington, common P. R.; less common than formerly. Ossining, A. V. Cambridge, irregular but not very infrequent at all seasons. N. Ohio, common P. R. Glen Ellyn, rare S. R. SE. Minn., rare.

Nest, of twigs, rootlets, and strips of bark, lined with grasses and rootlets, in bushes. Eggs, 3-4, white or bluish white, speckled or spotted with grayish brown, cinnamon-brown, or umber, $1.00 \times 70$. Date, D. C., Apl. 15; Chester Co., Pa., Apl. 30; Central Park, New York City, May 5.

One's first impression of the Cardinal Grosbeak will usually be that he is rather a clumsy fellow. His body appears to be stiff, as if it were made of wood, different in every way from the pliant, lithe body of the Catbird, for example. He hops about on the ground with tail held well up out of harm's way, and comes heavily down upon his feet, as if his body were really very solid. In fact, he is not at all a graceful bird.

$\mathrm{He}$ is a famous singer, his song being a loud, clear whistle, into which usually enters quite frequently the sound of $q ! q ! q !$ and a peculiar long-drawn-out $e-\bar{e}$ ! sometimes syllabled as "three cheers!" He is a favorite cage-bird. The female Cardinal is herself a charming singer, more pleasing to many than her mate, her music being softer in tone and otherwise different from his. The common call-note of both is a sharp, abrupt tsip! easily recognized after being once heard.

As the head of a family the Cardinal is admirable, not only in his attentions to his lovely dove-colored mate, but in singing to her by the hour, and in protecting her from intrusion or danger. To the young in the nest he is an untiring provider of worms and grubs, and thus most useful in a garden. Nothing can be more comical than his behavior when he first conducts his young family out into the world while his mate is engaged with her second sitting. He is as fussy as any young mother, hopping about in great excitement, and appearing to think the whole world thirsting for the life of his pretty little ones.

The Cardinal mother shows the restless manners and anxious spirit of her mate, taking one's intrusion upon her domestic affairs greatly to heart, and being so much disturbed that there is more pain than pleasure in making acquaintance with her nestlings.

\section{Olive Thorne Miller.}

593d. C. c. floridanus Ridgw. Florida CARDINAL. Similar to C. $c$. cardinalis but smaller, male averaging deeper red; female darker ana richer in color, particularly on breast. W., $3 \cdot 40$.

Range.-Florida.

Nesting date, San Mateo, Fla., Apl. 12.

595. Zamelodia Iudoviciana (Linn.). Rose-breasted Grosbeak. Ad. $\sigma^{7}$. in summer -Head, throat, and back black; breast and under wingcoverts bright rose-red, this color sometimes extending down the center of the white belly; rump white, tipped with black; wings black; primaries white at the base; tail black, the outer feathers tipped with white on the inner weh. Ad. o in winter.- Similar but upperparts and breast margined with brown; throat rose; superciliary whitish, sides with black spots. Im. $\sigma^{7}$ in winter.-Resembles the $\%$, but under wing-coverts rose-red; breast 
tinged with rose. Im. $\sigma^{\text {in }}$ summer.--Similar to ad. $\sigma^{\text {n }}$ in summer but wingquills and some tail-feathers brownish as in $\%$. The ad. winter plumage is acquired at the next (first postnuptial) molt, and the ad. summer the following spring. $A d$. o.- Upperparts grayish brown, margined with creambuff and pale grayish brown; a buffy line through the center of the crown, and a conspicuous whitish line over the eye; wings and tail dark grayish brown; wing-coverts tipped with white; under wing-coverts orange; underparts buffy, streaked with dark grayish brown. L., 8.12; W., 4.02; T., $2 \cdot 99$; B., 69 .

Range.-E. N. Am. and n. S. A. Breeds in lower Canadian and Transition zones from s. cen. Mackenzie, n. Man., cen. Ont., s. Que. and Cape Breton Is. s. to cen. Kans., cen. Mo., cen. Ohio, cen. N. J., and in mts. to $\mathrm{n}$. Ga.; winters from.s. Mex. to Ecuador; casual in migration in Cuba, Jamaica, and the Bahamas; accidental in Ariz., Colo., and Calif.

Washington, rather common T. V., May 1-30; Aug. 29-Oct 6. Ossining, tolerably common S. R., May 3-Oct. 1. Cambridge, very common S. R., May 10-Sept. 10. N. Ohio, common S. R., Apl. 27-Sept. 15. Glen Ellyn, fairly common S. R., common T. V., Apl. 27-Sept. 28. SE. Minn., common S. R., Apl. 27-Sept. 23.

Nest, of fine twigs, weed stalks, and rootlets, in bushes or trees, 5-20 feet up. Eggs, 4-5, pale blue, with numerous olive-brown or rufous-brown markings, $90 \times \cdot 69$. Date, Carmel, N. J., May 20; Cambridge, May 25; se. Minn., May 21.

Sometimes in passing through young second growths, and more rarely densely undergrown woodland, I hear a singular kind of questioning call-note, not loud, but distinct-a steely peek, peek. It is a signal to me to pause and look for its author; even a glimpse of him is worth several minutes' waiting and watching. There is no mistaking his black, white, and rose costume; but the identity of his more modestly attired mate may long remain an open question. So little does she resemble him that she might pass for an overgrown Sparrow with a rather conspicuous whitish stripe over her eye.

The song of the Rose-breasted Grosbeak is generally compared to that of the Robin, and musical annotation would doubtless show that the comparison is not misleading. But the similarity is largoly one of form; in expression there is no more resemblance in their voices than there is between the birds themselves. There is an exquisite purity in the joyous carol of the Grosbeak; his song tells of all the glizdness of a May morning; I have heard few happier strains of bird music. With those who are deaf to its message of good cheer I can only sympathize, pitying the man whose heart does not leap with enthusiasm at the sight of rival males dashing through the woods like winged meteors, leaving in their wake a train of sparkling notes.

The Black-headed Grosbeak (5.96. Zamelodia melanocephaln), a western species, has been recorded from Michigan.

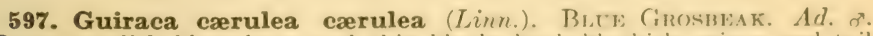
-Deep purplish blue; lores and chin black; hark blarkish; wings and tail black, slightly edged with blue; middle wing-eoverts widely, and greater coverts narrowly tipped with chestnut-rufous. Ad. in 11nim.-Similar. but widely margined with rusty brown, particularly on lark. Im. ; in winter.-Resembles the o. Im. or in summer.-Plumage meftled brown and blue. The ad. winter plumage is acquired at the next (first postnuptial) 
molt, and the ad. summer by wearing off of brown margins the following spring. $A d$.. .-Upperparts grayish brown; in some specimens more or less blue about the head and rump and lesser wing-coverts; rump inclined to ashy; wings fuscous, the greater and middle coverts tipped with ochraceousbuff; tail fuscous, slightly margined with bluish gray; underparts brownish cream-buff, the feathers of the breast sometimes blue at the base. L., $7 \cdot 00$; W., 3.50; T., $2 \cdot 75$; B., 65.

Range.-E. N. Am. Breeds in Carolinian and Austroriparian faunas from Mo., s. Ills., and Md. s. to e. Tex., and n. Fla.; winters in Yucatan and Honduras; casual in s. Ind. and s. Pa.; accidental in Wisc., New England, the Maritime Provinces, and Cuba.

Washington, very uncommon S. R., May 1-Sept. 20. Cambridge, A. V., one instance, May.

Nest, of grasses, in bushes or high weedy growths. Eggs, 3-4, pale bluish white, $84 \times \cdot 65$. Date, Chatham Co., Ga., May 14; Raleigh, N. C., June 8.

"Unless seen under the most favorable circumstances the adult male does not appear to be blue, but of an ill-defined, dusky color, and may easily be mistaken for a Cow Blackbird (Molothrus ater), unless most carefully watched; besides, they usually sit motionless, in a watchful attitude, for a considerable length of time, and thus easily escape observation.

"The Blue Grosbeak frequents much the same localities as those selected by the Indigo Bird and Field Sparrow, viz., the thickets of shrubs, briers, and tall weeds lining a stream flowing across a meadow or bordering a field, or the similar growth which has sprung up in an old clearing. The usual note is a strong, harsh ptchick, and the song of the male is a very beautiful, though rather feeble, warble, somewhat like that of the Purple Finch, but bearing a slight resemblance also to that of the Rose-breasted Grosbeak" (Ridgway).

598. Passerina cyanea (Linn.). Indigo Bunting. Ad. o in summer.Rich blue, deeper on the head, brighter on the back; lores blackish; wings and tail black, margined with blue. $A d$. o in winter.-Resembles the o, but has more or less blue in the plumage. Ad. $\circ$.- Upperparts uniform grayish brown without streaks; wings and tail fuscous, sometimes lightly margined with bluish; wing-coverts margined with grayish brown; underparts whitish, washed with grayish brown and indistinctly streaked with darker; belly whiter. Im.-Resembles the o, but is darker. L., 5.59; W., $2 \cdot 58$; T., $2 \cdot 11$; B., 41 .

Remarks. - The female of this species is rather a puzzling bird, and may be mistaken for a Sparrow. Its unstreaked back and the slight tinge of blue generally present on the outer web of the wing-and tail-feathers should serve to distinguish it.

Range-E. N. Am. Breeds chiefly in Alleghanian and Carolinian faunas e. of the Great Plains from e. cen. N. D., cen. Minn., nw. Mich., s. Ont., s. Que., and s. N. B. s. to cen. Tex., s. La., cen. Ala., and cen. Ga.; winters from s. Mex., and Cuba to Panama; casual in e. Colo., s. Sask., and s. Man.

Washington, common S. R., Apl. 29-Oct. 9. Ossining, common S. R., May 4-Oct. 17. Cambridge, common S. R., May 15-Oct. 1. N. Ohio, common S. R., Apl. 26-Oct. 10. Glen Ellyn, fairly common S. R., May 1Sept. 22. SE. Minn., common S. R., Apl. 28-Oct. 2.

Nest, of grasses, hits of dead leaves, and strips of bark, lined with fine grasses, rootlets, and long hairs, generally in the crotch of a bush. Eggs, 3-4, pale bluish white, $\cdot 73 \times \cdot 57$. Date, Richmond, Va., May 28; Chester Co., Pa., May 26; Canbridge, June 4; Brooklyn, Ind., May 21. 
In walking among clumps of bushes in clearings or old pastures, look sharp if a small brown bird flies before you, especially if she calls cheep and twitches her tail nervously from side to side. Though she be a sparrowy-looking bird, look well to her shoulders and tail. If you discover a glint of blue and her cries call her mate, you will ever after be a more trustworthy observer-for his brilliant coat is unmistakable.

Having made sure of your birds, watch them to their nest-a compactly made cup-too cleverly hidden in the dense green thicket to be easily discovered. The color of the eggs will again test your accuracy of observation; in varying lights they look green, blue, and white.

The female Indigo is so suspicious that it is not hard to be vexed with her, but the primary virtues of an observer are conscientiousness and patience; so take your hard cases as a means of grace.

However distrustful the poor mother bird is, her mate's cheery song makes up for it all. After most birds have stopped singing for the year, his merry voice still gladdens the long August days.

I well remember watching one Indigo-bird, who, day after day, used to fly to the lowest limb of a high tree and sing his way up from branch to branch, bursting into jubilant song when he reached the topmost bough. I watched him climb as high into the air as he could, when, against a background of blue sky and rolling white clouds, the blessed little songster broke out into the blithest round that ever bubbled up from a glad heart.

Florence Merriam Bailey.

The Varied Bunting (600. Passerina versicolor versicolor), a species of our Mexican border, has been once recorded from Michigan.

601. Passerina ciris (Linn.). Painted Bunting; Nonpareil. Ad. $\sigma^{7}$. - Head and sides of the neck indigo-blue; back golden green; rump dull red; underparts bright red; wings and tail tinged with dull red; greater wingcoverts green. Im. $\sigma^{7}$.-Resembles the $\%$. Ad. ?.- Upperparts bright olivegreen; underparts white, washed with greenish yellow; wings and tail fuscous, margined with olive-green. L., 5.25 ; W., 2.7(); T., 2.15; B., 42.

Range.-SE. U. S. Breeds in Austroriparian fauna from s. Kans., cen. Ark., n. Miss., and se. N. C. s. to se. N. M., Tex., and the Gulf coast ; casual in s. Ariz., and s. Ills.; winters in the Bahamas, (uba, and from een. Mex. to Panama; occasional in winter in s. La. and cen. Fla.

Nest, similar to that of $P$. cyaner, in bushes or low trees. Eggs, 3-1, white or bluish white, with numerous chestrut or rufous-brown markings, $\cdot 78 \times{ }^{\circ} 56$. Date, Chatham Co., Ga., May 16.

Mr. Maynard found this species in southern Florida in January, but it does not migrate northward until about May 1 . He writes that it "is always shy and retiring, seldom appearing in the open, but remaining in the dense, thorny undergrowth which covers all waste plicess in Florida, especially if the soil has been cultivaterl. Whenever the birds perceive an intruder they retire into the depths of these fast nesses, : and it requires considerable beating to drive them out, when they at once dart into the nearest cover. The adult males are esperially shy, and seldom show themselves. Even while singing they remained concealed, and, although we were thus furnished with a clew to their whereabouts, it was with the utmost difficulty that we caught sight of the authors 
of the harmonious strains which nearly always greeted our ears when we were in the vicinity of their homes" ("Birds of Eastern North America").

"Their notes very much resemble those of the Indigo-bird, but lack their energy and are more feeble and concise" (B., B., and R.).

The Grassquit (603. Tiaris bicolor) of the Bahamas has been once recorded from Miami, Florida.

The Melodious Grassquit (603.1. Tiaris canora) of Cuba, has been once recorded from Sombrero Key, Florida.

604. Spiza americana (Gmel.). Dickcissel. Ad. o in summer.-Head and sides of the neck ashy gray; forehead tinged with yellow; a yellow line over the eye and one on the side of the throat; a black patch on the throat; chin white; breast yellow, spreading down on to the white belly; back streaked with black and pale grayish brown; rump brownish ash; lesser wingcoverts rufous; wings and tail fuscous. Ad. o in winter.-Has less yellow and a more or less concealed throat-patch. Im. $\sigma^{7-R e s e m b l e s ~ ㅇ . ~ A d . ~ ․ ․-~}$ Similar, but the head grayish brown, streaked with blackish, and with no black patch on the throat and less yellow on the breast, which is sometimes lightly streaked with black. L., $6 \cdot 00 ;$ W., $3 \cdot 20 ;$ T., $2 \cdot 35 ;$ B., $\cdot 55$.

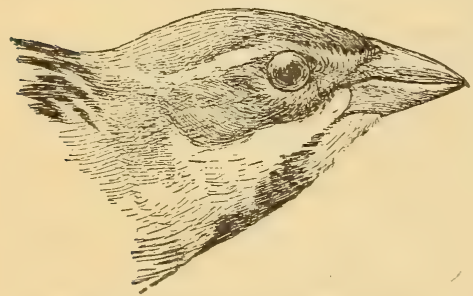

Fig. 109. Dickcissel. (Natural size.)

Range.-E. N. Am., and n. S. Am. Breeds chiefly in Austral zones from ne. Wyo., nw. N. D., nw. Minn., s. Mich., and s. Ont., s. to s. Tex., and s. Miss.; formerly bred on the Atlantic coastal plain from Mass. (casually wandering to Maine), to S. C., but now extremely rare e. of the Alleghanies; winters in $\mathbf{n}$. S. A. ; accidental in L. Calif., Ariz., Man., N. S., and Jamaica.

Washington, formerly "very abundant," now seen only occasionally, May-Aug. Cambridge, casual, found nesting at Medford, June 9, 1877, where several birds were observed; not uncommon in 1833-34 (see Bull. Nutt. Orn. Club, III, 1878, 45, 190). N. Ohio, rare S. R., May 1. Glen Ellyn, rather rare and local S. R., formerly common, May 3-Sept. 5. SE. Minn., common S. R., May 11-Aug. 20.

Nest, bulky, of coarse grasses and leaves, lined with finer grasses and sometimes long hairs, on the ground or in low trees or bushes. Eggs, 4-5, pale blue, $80 \times 60$. Date, St. Louis, Mo., May 23; Avondale, Ohio, May 14; Powesheik Co., Iowa, May 28.

Prior to 1880 these birds were more or less common in the middle Atlantic States, but they are now of rare occurrence east of the Alleghanies. In Texas I have seen them migrating in closely massed flocks of several hundred individuals, all silent, except for an occasional cack. They alight on the prairie to feed; birds in the rear are constantly arising and passing to the front; there is ceaseless motion.

In the summer Dickcissel makes his home in grassy fields and pastures, and from a weed stalk or bordering fence, with uplifted head, he announces his presence as though life itself depended on his vocal exertions. It is a poor song from a musical standpoint, but pleasing because of the singer's earnestness. 
1903. RhoAds, S. N., Cassinia, 17-28 (historical).-1904. Miller, W. DE W., Auk, XXI, 487 (nesting in N. J.).

The LARK BUNTING (605. Calamospiza melanocorys), a western species, has been recorded from Massachusetts, Long Island, and South Carolina.

\section{Family Tangaridere. Tanagers. (Fig. 65.)}

Although a distinctively American family, the Tanagers are so elosely related to the Finches that it is not clear to which family certain genera should be referred. About three hundred and fifty species are known, most of them being confined to the tropics, and only four species, all migratory, reach the United States. They are remarkable, as a whole, for the brilliancy of their plumage, as well as for their marked sexual differences in color, and our Scarlet Tanager is, therefore, no exception to the rule.

They are arboreal and for the most part forest-inhabiting birds, feeding on flowers, fruit, and insects. The tropical species are of a roving disposition, and wander through the forests in search of certain trees bearing ripe fruit, near which they may always be found in numbers. As a rule, they are not musical. A few species, including ours, have more or less pleasing songs, but the voices of the majority are weak and squeaky.

\section{KEY TO THE SPECIES}

A. With red in the plumage.

a. Wings and tail black . . . . 608. Scarlet TANAger $\sigma^{*}$. $b$. Wings and tail like the body . . . 610. Summer Tanager ơ. $B$. Without red in the plumage.

a. Underparts, including under wing-coverts, dull buffy yellow.

610. SUMMER TANAGER ㅇ

b. Underparts greenish yellow, under wing-coverts white.

608. Scarlet Tanager $\%$

608. Piranga erythromelas Vicill. Scarlet TANAGER. (Fig. 65.) Ad. or in summer. - Bright scarlet, wings and tail black, under wing-('overts white. Ad. o in winter.- Similar to the ?, lut wings and tail blatek. Im. o in winter. - Similar to o, but wing-coverts black. Im. o in summer. - Similar to ad. o in summer, but primaries and secondaries as in winter. The adult summer plumage is accuired at the second spring (prenuptial) molt. Ad. o.-Upperparts light olive-green; wings and tail fuscoms, lightly margined with olive-green; underparts greenish yellow. L., 7.25; $\mathbb{W}$., 3.75; T., $2 \cdot 09 ;$ B. from N., 46 .

Range.-E. N. Am. and n..S. Am. Breeds matinly in Alleghanian and Carolinian faunas from se. Sask., cen. Man., ('en. ()nt.., s. Que., N. B., and N. S. s. to s. Kans., n. Ark., Tenn., n. (ia., and mits, of lis. and S. ('. ; winters from Colombia to Peru; migrates through ('uha, Jamaira, and Yuratan, and along the e. coast of ('on. Am.; casual in mieration in Wyo., ('olo., the? Bahamas, and Lesser Antilles.

Washington, common T. V., less (e)mmon S. R., Apl. 17 (O). 15. ()xsining, common S. R., May 4-Oct. 9. ('ambridere, rather common \&. R., May 12-Oct. 1. N. Ohio, ('ommon S. R., Apl. 24 ()et. 2. (ilen Ellym, net enmmon S. R., Apl. 30-Sept. 29. SE. Minn., ('ommon S. R., Apl. 2! Sept. 11.

Nest, of fine twigs and weed-stalks, lined with vine tendrils and hlossom stems, generally near the end of a horizontal limb, $7 \ldots 2$ ) fort up. Eggs, 3-4, 
pale bluish white or greenish blue, with numerous rufous or rufous-brown markings, $\cdot 88 \times \cdot 68$. Date, Delaware Co., Pa., May 28; New London, Conn., May 31; Cambridge, June 7; Black Hawk Co., Iowa, May 23; se. Minn., May 21.

In watching birds, there are certain sights and sounds that make a day memorable much as a beautiful sunset does. I say to myself, "I have seen a Scarlet Tanager today!" or, "I have listened to a Hermit Thrush this evening."

High among the tree-tops of the cool green woods the Tanager sings through the summer days. Hidden by the network of leaves above us, we often pass him by; but once discovered he seems to illuminate the forest. We marvel at his color. He is like a Bird of Paradise in our northern landscape.

We are first guided to him by his call and song. They are peculiar, and both have a rare woods flavor. The call is a distinctly uttered chip-chirr. The song is a loud, cheery, rhythmical carol, suggesting the song of the Robin.

Inside the green woods the Tanager spends the summer, flying down to visit his nest in the fresh young undergrowth or to bathe in the still forest pools, and hunting and singing in the tree-tops high overhead.

\section{Florence Merriam Bailey.}

610. Piranga rubra rubra (Linn.). Summer Tanager. Ad. red, brighter below; wings fuscous, margined with rose-red. Im. $\sigma^{7}$ in winter. - Similar to the o, but with more or less of a reddish tinge throughout the plumage. Im. $\sigma^{7}$ in summer. - Variable; sometimes a mixture of ad. $\sigma^{\text {Th }}$ and $q$ plumages, at others like the ad. $\sigma^{7}$, but wing-quills as in $\%$. The ad. $\sigma^{7}$ plumage is acquired at the first postnuptial molt and retained thereafter at all seasons. Ad. . - Upperparts orange olive-green; underparts yellowish orange. L., $7 \cdot 50$; W., $3 \cdot 75$; T., $2 \cdot 90$; B. from N., $\cdot 55$.

Range.-SE. U. S. and n. S. Am. Breeds in Carolinian and Austroriparian faunas from se. Nebr., s. Iowa, se. Wisc., cen. Ind., s. Ohio, Md. (formerly N. J.), and Del. s. to ne. Mex. and cen. Fla.; winters from cen. Mex. to Peru and Guiana; straggles n. to N. B., Que., N. S., Maine, and Ont.; migrant in w. Cuba.

Washington, uncommon S. R., Apl. 18-Sept. 19. Cambridge, one record.

Nest, of leaves, strips of bark, etc., generally near the extremity of a limb, about 20 feet up. Eggs, 3-4, bluish white or greenish blue, with numerous cinnamon- or olive-brown markings, $96 \times 68$. Date, San Mateo, Fla., May 9; Mt. Pleasant, S. C., May 12; Mt. Carmel, Ills., May 28.

This is a common summer resident of our Southern States, arriving in Florida early in April. It frequents open, rather than dense woods, and is particularly numerous in pineries having an undergrowth of oaks. It may be easily identified, not alone by its color but by its unicque call-note-a clearly enunciated chicky-tucky-tuck. Its song bears a general resemblance to that of the Scarlet Tanager, but to my ear is much sweeter and less forced.

The Western Tanager (6n\%. Piranga ludoviciana), a species of our Western States, has been reeorded from Wisconsin, Maine, Massachusetts, Connecticut, New York, Louisiana and Wisconsin. 
54. Family Hirdxdinid.e. Swallows. (Fig. 66.)

The some one hundred known species of Swallows are distributed throughout the world, but are most poorly represented in the Australian region, where only three species occur. About thirty-five species are American, and nine of these are found north of Mexico. In their long, powerful wings and small, weak feet, Swallows present an excellent illustration of the effects of use and disuse. The greater part of their day is passed on the wing, and in alighting they select a perch which they can grasp with ease. Swallows live almost exclusively upon inserts, which they capture on the wing, their large mouths, as in the case of the Swifts and Goatsuckers, being especially adapted to this mode of feeding.

They nest both in pairs and colonies, and during their migrations, associate, in countless numbers, at regularly frequented roosting-places

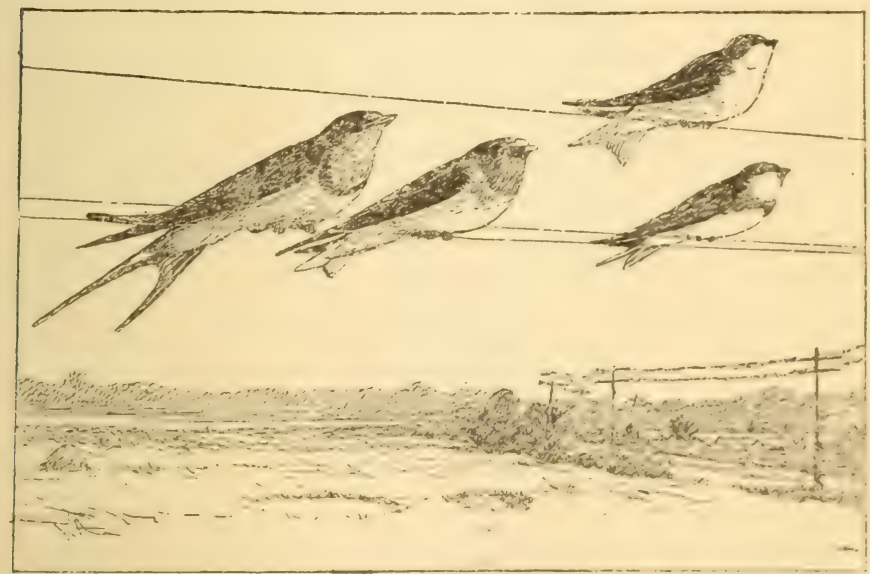

Fia. 110. Barn Swallow. Cliff Swallow.

Tree Swallow.

Bank swallow.

or migration stations. These are sometimes in trees, but more often in marshes, and to them the swallows regularly returm each night. They migrate, as far as known, moredy hy day, their womlerful power of

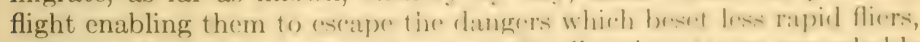
and to make journeys of great extrnt. Swallows meste are remarkathle for their wide diversity of architreture, as well as for the skill shown by these small-billed, weak-footed birds in their const ruetion, and complarison of the mud dwelling of the ('liff Swallow with the tunnelled home of the Bank Swallow, illustrates how small the relation may he betwen the structure of the bird and the charaeter of its mest. 


\section{KEY TO THE SPECIES}

1. Upperparts with metallic reflections.

A. Underparts steel-blue.

a. Feathers on the belly fuscous at the base

$b$. Feathers on the belly white at the base .

611. Purple Martin o7.

$B$. Underparts not steel-blue.

a. Throat chestnut, rufous, or brownish.

$a^{1}$. Upper tail-coverts the same as the back; tail with white spots.

$a^{2}$. Upper tail-coverts rufous or buffy; no white in the tail.

613. Barn Swallow.

612. Cliff Swallow.

b. Throat gray or white.

$b^{1}$. Entire underparts white . . . . 614. Tree Swallow.

$b^{2}$. Throat and breast brownish gray . 611. Purple Martin .

$b^{3}$. Throat, breast, and sides sooty brownish gray.

2. Upperparts without metallic reflections.

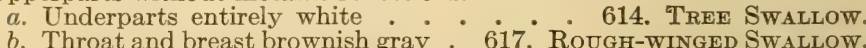

611.1 CUBan Martin o.

c. Throat and belly white; a brownish gray band across the breast. 616. BanK SWaLlow.

611. Progne subis subis (Linn.). Purple Martin. Ad. o.-Shining blue-black; wings and tail duller. $I m . \sigma^{7}$ in winter.-Resembles the $\circ$. Im. $\sigma^{7}$ in summer. - Similar to $\circ$, but bluer above and with a number of adult blue feathers scattered through underparts. The ad. $\sigma^{\top}$ plumage is acquired at the first postnuptial molt. Ad. o.-Upperparts glossy bluish black, duller than in the $\sigma^{\text {* }}$; wings and tail black; throat, breast, and sides brownish gray, more or less tipped with white; belly white. L., $8 \cdot 00$; W., 5.80; T., 2.90; B. from N., 32 .

Range.-N. and S. A., except the Pacific coast region. Breeds from w. cen. Alberta, s. Sask., cen. Man., nw. Ont., N. B., and N. S., w. to Mont. and Idaho, and s. to the Gulf coast, Fla., Vera Cruz and Jalisco; winters in Brazil; accidental in Bermuda and the British Isles.

Washington, rather common S. R., Apl. 1-Sept. 14. Ossining, tolerably common S. R., Apl. 27-Sept. 11. Cambridge, formerly locally common S. R., Apl. 20-Aug. 25. N. Ohio, common S. R., Apl. 1-Sept. 5. Glen Ellyn, local S. R., Mch. 23-Sept. 10. SE. Minn., common S. R., Apl. 1-Sept. 9.

Nest, of straws, twigs, etc., in houses or gourds erected for the purpose. Eggs, 4-5, white, 1.00 × 73. Date, Tarboro, N. C., May 19; Cambridge, May 30 ; St. Louis, Mo., May 21.

The Purple Martin is very common throughout the south, and breeds wherever gourds or boxes are erected for its occupation. In the Northern States it is a comparatively rare bird of local distribution.

In Forest and Stream, Vol. XXII, 1884, p. 484, Mr. Otto Widmann, of ()ld Orchard, Missouri, presents an interesting table showing how often young Martins are fed. He watched a colony of sixteen pairs of birds from 4 A.M. to 8 P.M., during which time the parents visited their offspring 3,277 times, or an average of 205 times for each pair. The males made 1,454 , the females 1,823 visits.

1903. JACoBs, J. W. (Waynesburg, Pa.), The Story of a Martin Colony (methods of attracting, etc.).-1906. TAverner, P. A., Wilson Bull., XVIII, 87-92 (roost).

611.1. Progne cryptoleuca Baird. Cuban Martin. Ad. ơ.-"Similar to $l$ 'subis, but feathers of ventral region marked beneath surface, with 
a broad spot or bar of white." $A d$. \& and $i m$. $\sigma^{7}$ - Similar to those of $P$. subis, but "whole under portion and sides of head and neck, chest, sides and flanks uniform sooty grayish brown, in marked contrast with pure white of belly, anal region, and under tail-coverts. L., 7.60 ; W., 5.50; T., 3•10" (Ridgw.).

Range.-Cuba; occasional or accidental in s. Florida.

612. Petrochelidon lunifrons lunifrons (Say). Cliff Swallow. (Fig. 110.) Ads.-Forehead whitish, crown steel-blue, throat and sides of the head chestnut; a brownish gray ring around the neck; breast brownish gray, tinged with rufous and with a steel blue patch in its center; belly white; back steel-blue, lightly streaked with white; shorter upper tailcoverts pale rufous; tail fuscous, the feathers of nearly equal length. Im.Similar, but upperparts duller; throat black, sometimes mottled with white. L., 6.01; W., 4.34; T., $2 \cdot 01$; B. from N., $\cdot 20$.

Remarks. - The Cliff Swallow may be known from our other Swallows by its rufous upper tail-coverts.

Range.-N. A. Breeds from lower edge of the Arctic to Lower Austral Zone from cen. Alaska, n. cen. Mackenzic, s. Keewatin, n. Ont., cen. Que., Anticosti Island, and Cape Breton Is. s. over nearly all of the $L$. s. except Fla. and the Rio Grande Valley (casual as a breeder s. of lat. 3 $3^{\circ}$, e. of long. $97^{\circ}$ ); probably winters in Brazil and Argentina.

Washington, rare S. R., Apl. 10-Sept.-? Ossining, common S. R., May 1-Sept. 12. Cambridge, S. R., much less common than formerly, Apl. 28-Aug. 25. N. Ohio, tolerably common S. R., Apl. (j-segnt. 25. Glen Ellyn, not common, local, S. R., Apl. 25-Sept. 16. SE. Minn., common S. R., Apl. 13-Sept. 12.

Nest, of mud, generally retort-or pocket-shaped, beneath cliffs or the eaves of a barn or other building. Eggs, 4-5, white, with numerous spots of cinnamon-, olive-, or rufous-brown, $81 \times 5.5$. Date, shelter Is., N. Y., May 29; Cambridge, June 5; se. Minn., May 19.

During the nesting season these Swallows are of very local distribution. They will return year after year to thoir rows of mud tonements beneath the eaves of some barn or outbuilding, and, although familiar birds to residents of the immediate vicinity, they may be entire strangers to those who have never had a colony of these birch settled near them. Like Barn Swallows, they are masons, and they may be seen on muddy shores rolling the little pellets of claty which enter into the construction of their nest. In the fall they are found in flocks with other Swallows, but at all times they mat be readily indentified by their pale rufous upper tail-coverts, which make a conspicums field-mark.

The Cuban Cliff Stwallow (fi1?.1. Petrochelider fulma) has been once recorded from the Dry Tortugats, Florida (Aontt, Auli, VII, 1S!30, 2(i.5). It resembles lunifrons but has the forchead and rump) chestnut and no black on the throat.

613. Hirundo erythrogaster (Borld.). B.InN Siwallow. (Fig. 110.) Ad. $\sigma^{2}$-Forehead, throat, and unper breast chestumf-rufous; rest of the underparts washed with the same color: upperparts sterl-hlue: tail dewply forkerl, all but the middle feathers with whitr.sentson their inner wols. .1d. :- Similar, but underparts usually paler and outer tail-feat hers sherter. Im. Piperparts mixed with dusky, foreheacl and throat paler: outer tail-feathers shorter. L., 6.95; W., 4.67; T., 3.30; B. from N., 21.

Range.-N. A. Breeds from nw. Mlaska, n. Markenzir, s. Man., and s. Ungava s. to s. Calif., s. Tex. (w. of loug. $\left.97^{\circ}\right)$, $\mu$. Ark., and N. ( ., and in 
Mex. s. to Tepic; winters from s. Mex. to n. Argentina, and cen. Chile; accidental in the Galapagos, Bermuda, and Greenland.

Washington, common S. R., more abundant T. V., Mch. 30-Sept. 17. Ossining, common S. R., Apl. 15-Sept. 22. Cambridge, common S. R., but fast decreasing, Apl. 20-Sept. 10. N. Ohio, abundant S. R., Mch. 30-Sept. 22. Glen Ellyn, S. R., fairly common and increasing, Apl. 7-Sept. 1. SE. Minn., common S. R., Apl. 28-Aug. 31.

Nest, of mud and grasses, lined with grasses and feathers, generally on the rafter of a barn or other building. Eggs, 4-6, white, with numerous spots of cinnamon-, olive-, or rufous-brown, generally smaller than those on the eggs of P. lunifrons, $77 \times{ }^{\circ} 54$. Date, Chester Co., Pa., May 19; Portsmouth, R. I., May 18; Cambridge, May 25.

Barn Swallows nest both in pairs and colonies, and during the breeding season are more generally distributed than any other of our Swallows. Almost every old-fashioned barn with its great doors hospitably opened is cheered by their sweet call-notes and happy twittering song as they dart in and out on their errands of love.

Barn Swallows take first rank among a family of birds famous for their power of flight. While their relatives are circling about feeding on insects in the air above, they capture their prey nearer the ground, skimming low over the fields, turning quickly to right or left, up or down, and pursuing their erratic course with marvelous ease and grace.

The European Swallow (613.1. Hirundo rustica) is of accidental occurrence in Greenland.

614. Iridoprocne bicolor (Vieill.). Tree Swallow. (Figs. 13, 110.) $A d s$.- Upperparts steel-blue or steel-green; underparts pure white; outer tail-feathers somewhat longer than the middle ones. Nestling.-Upperparts dull brownish gray; underparts pure white, with sometimes a dusky breastband. L., $5 \cdot 90$; W., $4 \cdot 70$; T., $2 \cdot 35$; B. from N., $\cdot 22$.

Range.-N. A. Breeds in Canadian, Transition, and Upper Austral zones from nw. Alaska, s. and w. Mackenzie, s. Keewatin, and n. Ungava to s. Calif., Colo., Kans., Mo., and Va.; winters from cen. Calif., s. Tex., s. parts of the Gulf States, and se. N. C. (casually N. J.) s. over the greater part of Mex. to Guatemala and Cuba; occasional in Bermuda in migration; accidental in the British Isles.

Washington, common T. V., Mch. 26-May 26; July 8-Oct. 14. Ossining, common T. V., Apl. 4-May 26; Aug. 4-Oct. 16. Cambridge, S. R., formerly common, now common only as a migrant, Apl. 5-Oct. 8. N. Ohio, common S. R., Apl. 10-Sept. 20. Glen Ellyn, not common T. V., rare S. R., Apl. 21-Sept. 8. SE. Minn., common S. R., Mch. 30-Aug. 31.

Nest, of coarse grasses and feathers, in a hollow tree or bird-box. Eggs, 4-7, white, $74 \times 55$. Date, Saybrook, Conn., May 13; Cambridge, May 20; Jackson Co., Mich., May 15; se. Minn., May 26.

While our eastern Barn and Cliff Swallows have abandoned their primitive methods of nesting in caves or beneath cliffs, and the Bank Swallows still adhere to the customs of their ancestors, Tree Swallows are passing through a transition period in their history. Some accept the houses or boxes erected by man as substitutes for the holes in trees or stumps which others still use.

Near New York City they are the first birds to flock after the nesting season, and they begin to gather in our marshes as early as July 1. Their numbers rapidly increase, and the maximum of abundance 
is reached about August 15, when they outnumber all other Swallows together by at least three to one. They return to their roosts in the reeds with great regularity every night, and early in the morning fly out over the country to feed. Their flight in the evening is comparatively low, at an average height of thirty to forty feet. They sail about in circles more than other Swallows, and many pause to rest on telegraph wires, where their pure white breasts easily distinguish them from the Swallows which may be associated with them. In the morning their flight is much higher and more direct. They migrate by day, leaving their roosting-ground in flocks, which sometimes contain myriads, and, after attaining a great height, pursue their journey to the south. When migrating along the coast they sometimes collect in large numbers in bayberry bushes (Myrica) and feed on their fruit.

1900. Chapman, F. M., Bird Studies with a Camera, 89-105 (roosting).

The Bahama Swallow (615.1. Callichelidon cyaneoviridis) has been once recorded from the Dry Tortugas and Tarpon Springs, Florida, and may occur more or less regularly in the Key's off southeastern Florida (Scott, Auk, VII, 1890, 265). It is satiny white below, dull bottle-green above; wings and tail bluer, the outer tail-feathers an inch longer than the middle ones.

The European Martin (615.2. Chelidonaria urbica) is of accidental occurrence in Greenland.

616. Riparia riparia (Linn.). BANK Swallow. (Fig. 110.) Ads.Upperparts brownish gray; throat white; a brownish gray band on the breast; outer vane of first primary without recurved hooklets; a small tuft of feathers above the hind-toe. L., 5.20; W., 3.95; T., 2.00) I3. from N., '18.

Range.-N. Hemisphere. In N. A. breeds in Boreal, Transition, and Austral zones from near limit of trees in n. Alaska and n. Cngava s. to s. Calif., Ariz., Tex., La., and Va.; migrate's through Mex. and C'm. An. (casually West Indies), and probably winters in S. A. to Brazil and P(ru.

Washington, common S. R., more common T. V., Apl. 13. Sept. 19. Ossining, common S. R., Apl. 18-()et. 1. Cambridge, formerly common S. R., Apl. 28-Sept. 1; common T. V. N. Ohio, common S. R., Apl. 6-Sept. 20. Glen Ellyn, fairly common T. V.; a few S. R., Apl. 22-Sept. 3. SE. Minn., common S. R., Apl. 10-Sept. 25.

Nest, of grasses and feathers, in a hole in a sand-bank, 2-3 feet from the entrance. Eggs, 4-6, white, "6x $\%{ }^{\circ} 4 \times$. Date, ('hester Co., P'a., May 10; Ossining, N. Y., May 20); Cambrirlge, May 2x; se. Minn., June 1.

This is a locally distributerl species, breeding in colonies only where sand-banks offer it a favorable nesting-site. Probubly for the reason that such banks are more frequently found bordering streams than inland, the hirds are more numerous in the vicinity of water.

Bank Swallows may be readily known from other Swallows, exeepting the Rough-winged, by their nesting habits, small size, and absence of metallic coloring.

From the Rough-wing they differ in having the underparts white, with a conspicuous band arross the breast, and in their somewhat quicker movements.

617. Stelgidopteryx serripennis (Aud.). Rotin-WINGEn SWALLow. Ads.-Upperparts brownish gray; throat and breast pale brownish 
gray; belly white; outer web of first primary with a series of recurved hooklets (sometimes absent in o); no tuft of feathers above the hind-toe. Im.- Similar, but without recurved hooklets on the first primary; throat and breast more or less washed and wing-coverts edged with rufous. L., 5.75; W., $4 \cdot 35$; T., $2 \cdot 10$; B. from N., $\cdot 19$.

Range.-N. A. Breeds in Transition, Austral, and Tropical zones from s. B. C., Mont., N. D., Minn., s. Wisc., Ont., s. N. Y., cen. w. Mass., and Conn. s. to s. U. S. from s. Calif. to n. Fla., and to Vera Cruz and Jalisco; winters from sen. Mex. s. to Costa Rica; casual in Man.

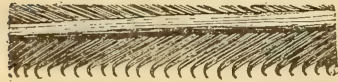

FIG. 111. Section of outer primary of adult Rough-winged Swallow. (Enlarged.)

Eggs, 4-8, white, $\cdot 72 \times \cdot 51$.

Washington, common S. R., Apl. 2-Sept.

3. Ossining, common S. R., Apl. 17-Aug. 12 . N. Ohio, common S. R., Apl. 15-Sept. 20. SE. Minn., common S. R., Apl. 14-Aug. 26. Nest, of coarse grasses and feathers, under bridges, in stone walls, or in a hole in a bank.
Date, D. C., May 17; se. Minn., May 21 .

Rough-winged Swallows resemble Bank Swallows both in habits and appearance. They do not, however, always nest in holes in banks, but are sometimes found nesting about bridges, railway trestles and their abutments.

With the Bank Swallow this bird differs from our other Swallows in the absence of metallic colors, while from the Bank Swallow it is to be distinguished by its plain, pale brownish gray, uniformly colored throat and breast, and somewhat slower, less erratic flight.

\section{Family Bombycillide. Waxwings. (Fig. 67.)}

Of the three known species of Waxwings, one (Bombycilla garrula) is common to the northern parts of both the Old and New Worlds; one (B. cedrorum) is found only in America, and one (B. japonica) is restricted to eastern Asia. Our Waxwings are notable for the irregularity of their migrations or wanderings, and B. cedrorum for the lateness of its nesting season. Their voice is doubtless the least developed in the group of so-called singing-birds.

618. Bombycilla garrula (Linn.). Bohemian Waxwing. Ads.Forchead, chin, and line through the eye velvety black; a conspicuous crest; front of crown chestnut-rufous; upperparts rich grayish brown; upper tailcoverts, wings, and tail grayish; primary coverts and secondaries tipped with white, the latter with small, red, seed-shaped sealing-wax-like tips; all but the outer primaries tipped with yellow or white on the outer web; end of tail with a yellow band; breast like the back, grayer on the belly; under tailcoverts chestnut-rufous. L., 8.00; W., 4*60; T., $2 \cdot 60 ;$ B. from N., 29.

Range.-Boreal zones of N. Hemisphere. In N. A. breeds from n. Alaska, n. Mackenzie, and cen. Keewatin s. to s. B. C. and s. Alberta; winters e. to N. S. and s. irregularly to e. Calif., Colo., Kans., s. Ills., Ind., Ohio, Pa., and Conn.; casual in Ariz.

Glen Ëllyn, one record, Jan. 22, 1908. SE. Minn., irregular W. V., until Apl. 1.

Nest, of twigs, roots, moss, etc., in trees. Eggs, similar in color to those of B. cedrorum, $92 \times 65$. Date, Cariboo, B. C., June 15 .

The distribution of this bird in the United States is not unlike that of the Evening Grosbeak. It is exceedingly rare and irregular in the 
Atlantic States, but occurs with some frequency in the northern Mississippi Valley. In notes and habits it is said to resemble its small cousin, the Cedar Waxwing.

1909. ANderson, R. M., Auk, XXVI, 10-12 (nesting).

619. Bombycilla cedrorum Vieill. CEDAR WAXWING. (Fig. 67.) $A d s .-F o r e h e a d$, chin, and a line through the eye relvety black; a conspicuous crest; upperparts rich grayish brown; upper tail-corerts, wings, and tail gray; secondaries often, tail rarely, with small, red, seed-shaped, sealingwax-like tips; tail with a yellow band at its end; breast like the back, changing gradually into yellowish on the belly; under tail-coverts white. The absence of the red tips is doubtless an indication of immaturity. The nestling is streaked below. L., $7 \cdot 19 ;$ W., $3 \cdot 70 ;$ T., $2 * 37$; B. from N., 26.

Range.-N. A. Breeds in Canadian, Transition, and Upper Austral zones from cen. B. C., cen. Alberta, s. Keewatin, n. Ont., nw. Que., and Cape Breton Is. s. to s. Ore., n. N. M., Kans., n. Ark., and N. C.; winters throughout nearly all of the U. S. and s. to Cuba, Mex., and Panama; accidental in the Bahamas, Bermuda, Jamaica, and British Isles.

Washington, very common P. R., less so in winter. Ossining, common P. R. Cambridge, not common P. R., common S. R., abundant T. V. in spring, Feb. 1-Apl. 25. N. Ohio, irregularly common in summer. Glen Ellyn, S. R., Jan. 21-Sept. 24; occasional W. V. SE. Minn., common S. R., Feb. 25-Sept. 28.

Nest, bulky, of strips of bark, leaves, grasses, twigs, rootlets, moss and sometimes mud, lined with finer materials of the same nature, often in fruit or shade trees, 5-20 feet up. Eggs, 3-5, pale bluish gray or putty color, distinctly and obscurely spotted with black or umber, ${ }^{\circ} 88 \times{ }^{6} 62$. Date, Weaverville, N. C., May 30; Cambridge, June 6; se. Minn., June 10.

When the spring migration is over and the home birds have gone to nest-building, small flocks of Goldfinches and Waxwings-two peculiarly gentle, attractive birds-may still be seen wandering about the country. The squads of Cedar-birds fly evenly, on a level with the tree-tops, in close ranks, often of five, seven, or nine. Frequently, when under full headway, they suddenly wheel and dive down to an apple tree for a meal of canker-worms.

In following the heautiful Waxwings about one listens in vain for a song, but soon comes to relish their two geculiar calls-at hushed whistle and the subdued call Thoreau describes as their "beady note," a succession of short notes strung together-for they both seem to harmonize with the quiet reserve of the delicately tinted birds.

In July, when the wandering flocks are: no longer seen, a walk through the neighboring orehards may show where both tardy builders have at last gone to nesting, and few bird homes afford pictures of such human tenderness and devotion. If there is an evergreen in the vicinity, the Cedar-bird mounts guard upon its tip, but oceasionally relieves the monotony of his watch by flying up in the air for light luncheons of passing insects.

The strong individuality of the Waxwings makes them interesting birds to the field student. The use of their crests in expressing emotion, and the protective attitudes they assume when watehed at their nests, throw much light upon bird psychology.

To the bird-lover, however, the Cedar-birds have their own attrac- 
tion; their proverbially gentle, refined ways make them seem superior creatures of the air to whom he can but yield his affection.

I shall never forget a pair that I once found by a clear mountain lake. They were perched upon two evergreen spires that guarded a silent bay, whose dark water was gilded by the lingering light of the setting sun.

Florence Merriam Bailey.

1905. Herrick, F. H., Home Life of Wild Birds, 36-38; 86-102.-1911. SaUnders, A. A., Auk, XXVIII, 323-329 (nesting).

\section{Family Lanidder Shrikes. (Fig. 68.)}

The number of species ascribed to this family by different authors varies widely, few agreeing as to exactly what subfamilies should be admitted. The true Shrikes, however, of the subfamily Laniinox, numbering seventy-seven species, are a well-defined group, of which only two occur in the New World. Their habits, in the main, conform to those of our species.

621. Lanius borealis Vieill. Northern Shrike. Ads.-Upperparts gray; wings and tail black; primaries white at the base, secondaries tipped with white or grayish; outer, sometimes all, the tail-feathers tipped with white, the outer feather mostly white; forehead whitish; lores grayish black; ear-coverts black; underparts white, generally finely barred with black; bill hooked and hawklike. Im. - Similar, but entire plumage more or less heavily barred or washed with grayish brown. L., 10*32; W., 4.55; T., 4.00; B. from N., $\cdot 55$.

Range.- N. N. Am. Breeds in the Hudsonian zone and locally in the Canadian from NW. Alaska, n. Mackenzie, and n. Ungava to the base of the Alaska Peninsula, cen. Sask., s. Ont., and s. Que.; winters s. to cen. Calif., Ariz., N. M., Tex., Ky., and Va.

Washington, rare and irregular W. V., Oct.-Feb. Ossining, tolerably common W. V., Oct. 26-Apl. 17. Cambridge, common W. V., Nov. 1-Apl. 1. N. Ohio, not common W. V., Nov. 6-Apl. 3. Glen Ellyn, not common W. V., Oct. 24.-June 5. SE. Minn., common W. V., Oct. 17-Mch. 28.

Nest, of twigs, grasses, etc., in low trees or bushes. Eggs, similar in color to those of $L$. ludovicianus, $1 \cdot 05 \times 76$. Date, Ft. Anderson, Mack., June 11 .

This bird may be known at once by his colors-gray, black, and white,-by the consternation his appearance causes among the Sparrows, and by his peculiar flight, which is steady and straightforward, with much flapping, and close to the ground till he nears his intended perch, which is reached at the last moment by a sudden upward turn.

$\mathrm{He}$ is so well known as a bird of hawklike, sanguinary character that most students are astonished when they find out that toward springtime he develops into a vocalist of no mean powers. Often in the warm days of March he may be heard singing on the top of some tall tree, a song that would do credit to a Catbird-indeed, it recalls strongly that loquacious songster. He is, I think, a better singer than his southern cousin, but resembles him in habitually impaling his prey on a thorn, a fence barb, or a forked twig. His food consists chiefly 
of mice, noxious insects, and the equally noxious English Sparrow, so that the Shrike is a bird worthy of al': protection.

\section{Ernest Thompson Seton.}

622. Lanius ludovicianus ludovicianus Linn. LOGGERHEAD SHRIKe. (Fig. 68.) Ads.-Upperparts gray, wings and tail black, primaries white at the base, secondaries tipped with white; outer, sometimes all, the tailfeathers tipped with white; the outer feather mostly white; lores black, connected by a narrow black line on the forehead at the base of the bill; ear-coverts black; underparts white, sometimes tinged with gray. L., 9.00; W., 3.82 ; T., 3.87 ; B. from N., 48 ; depth of B. at N., 35 (average of nine Florida specimens).

Range.-Austroriparian fauna from s. N. C. to s. Fla., and w. to La.

Nest, of strips of bark, small twigs, and vegetable fibers, lined with grasses, in thorny hedges or low trees, about 7 feet up. Eggs, 3-5, dull white or creamy white, thickly marked with cinnamon-brown and lavender, $\cdot 98 \times$ 78. Date, Archer, Fla., Mch. 10.

Like some of the Hawks and Flycatchers, the Loggerhead does not search for his prey, but waits for it to come within striking distance. It is of importance, therefore, that his perch should command an uninterrupted view of his surroundings. For this reason one rarely or never sees a Shrike in a tree, but always on its outermost or highest branches. He will fly directly toward its center, but just as he reaches it swing up and light on its top. He also selects telegraph wires, peaks of houses, and especially the apex of a lightning-rod or weather-vane.

From his point of vantage he maintains a constant outlook for any unsuspecting grasshopper, small snake, or lizard which may appear below. The distance at which he can detect these gives evidence of his power of sight. I have seen Shrikes fly fifty yards with the evident object of capturing a grasshopper which they undoubtedly saw before starting.

Like the Butcher-bird, the Loggerhead frequently impales its prey on a convenient thorn or spike. Doubtless this habit aids him in dissecting his food, but I do not think that he does it for this reason alone. The bird's vigilance, like that of the waiting Hawk, is probithly atfended by varying results. One hour may yield excellent returns, the next, may be fruitless. But under any cireumstances he camnot resist taking advantage of an opportunity to secure food. Sometimes the opportunities exceed the demands of his stomach, and then, after capturing his unfortunate vietim, he simply impales and leaves it.

If perservance deserved success, the Logererhead would take high rank as a songster. But his notes are harsh and unmusieal. Thery onsist of a series of guttural gurgles, squeaky whistles, and shrill pipes, some of which might be attributed to the ereaking weather-vanes he so often chooses as a perch.

622e. L. 1. migrans Pelmer. MrgnaNT SHrrke. Similar to $L$. $l$. ludovicianus but palcr abowe and somewhat grayer below; the bill smaller, the wing longer, $3^{*} 90$.

Range-E. N. Im. Brocels rhiofly in Transition and Upper Austral zones from n. Minn., Wisc., Mich., s. Ont., s. Que., Maine, and N. B. s. to 
e. Kans., s. Ills., Ky., w. N. C., and interior of Va. (locally in the East); winters from the Middle States and s. New England to Tex., La., and Miss.

Washington, rare W. V., Aug. 11-Apl. 6; may summer. Ossining, casual. Cambridge, one record, (Nov. 9, 1892). N. Ohio, tolerably common S. R., Mch. 10-Nov. 1. Glen Ellyn, fairly common S. R., Mch. 2-Sept. 29. SE. Minn., common S. R. Mch. 15-Oct. 28.

Nesting date, Auburn, N. Y., May 11; se. Minn., Apl. 7.

\section{Family Vireonides. Vireos. (Fig. 69.)}

The Vireos, numbering about one hundred species and subspecies, are peculiar to America. Most of them are confined to tropical America, only eleven species reaching the United States where, except along our southern boundaries, they are migratory.

Vireos are for the most part arboreal, though several species haunt the lower, rather than the higher growth. For small, insect-eating birds they are rather slow in their movements. We do not see them darting out after insects as do the Flycatchers, nor do they flit through the foliage after the manner of many Warblers, but patiently glean their food from the under surfaces of leaves, crevices in the bark, etc. They are more musical than the small Warblers; all our species have pleasing songs, and some of them are especially gifted. Their nests are neatly constructed cups suspended from the arms of a forked branch.

\section{KEY TO THE SPECIES}

$A$. With distinct white or yellowish white wing-bars.

a. Eye-ring, or line from eye to bill, yellow.

$a^{1}$. Throat and breast bright yellow; rump gray.

628. YELLOW-THROATED VIREO.

$a^{2}$. Underparts white or whitish; sides and sometimes breast washed with greenish yellow; rump olive-green.

631. White-eyed Vireo. 631a. Key West Vireo.

$b$. Eye-ring and line from eye to bill white.

$b^{1}$. Head lead-blue; wing over 2:50.

629. Blue-headed Vireo. 629a. Modntain Vireo.

$b^{2}$. Head grayish, nearly like back; wing under $2 \cdot 50$.

$B$. Without white wing-bars.

633. BeLL's VIREo (Illinois).

a. Underparts yellowish; first primary as long as fifth.

626. Philadelphia Vireo.

$b$. Underparts white; sides washed with yellowish; first primary 75 long. 627. WARBLING VIREO.

c. Underparts white, with little if any yellowish on sides; head with a lead-gray cap, bordered by narrow black lines over the eye.

624. RED-EYED ViREO. 623. BLACK-WHiskered Vireo.

623. Vireosylva calidris barbatula ( $C a b$.). BLACK-WHISKERED VIREO. Ads.- Similar to the next species, but somewhat duller above and with a fuscous streak on either side of the throat.

Range.-S. Fla. (as far n. as Anclote Keys), Key West, Dry Tortugas, Cuba, Little Cayman, and the Bahamas.

Nest, pensile, of dry grasses shreds of bark, cotton, lichens, and spiders' wobs, lined with soft, cottonlike fibers, suspended from a forked branch, 5-20 feet up. Eggs, 3-4, white, with a pinkish hue, speckled and spotted, 
chiefly at the larger end, with reddish brown, $78 \times \cdot 55$. Date, British Honduras, Apl. 23 (Thayer Coll.).

This is a not uncommon summer resident in southern Florida, arriving from its winter home in Central America early in May. Its song resembles that of the Red-eyed Vireo, but is somewhat more hesitating and emphatic.

624. Vireosylva olivacea (Linn.). RED-EYED VIREO. Ads.-Crown slaty gray, bordered on either side by blackish; a conspicuous white line over the eye; rest of the upperparts, wings, and tail light olive-green; no wingbars; underparts pure white. Iris red in ad., brown in im. L., 6.23; W., $3 \cdot 20$; T., $2 \cdot 20 ;$ B. from N., $\cdot 40$.

Remarks. - The well-defined slaty gray cap, bordered by narrow black lines, are the best distinguishing marks of this species.

Range.-N. and S. Am. Breeds in Canadian, Transition, and Austral zones from cen. B. C., s. Mackenzie, s. Keewatin, n. Ont., Anticosti Is., and Cape Breton Is. s. to se. Wash., s. Mont., e. Wyo., e. Colo., w. Tex., n. Coahuila, and cen. Fla.; winters in S. A.

Washington, very common S. R., Apl. 21-Oct. 17. Ossining, common S R., Apl. 29-Oct. 19. Cambridge, abundant S. R., May $10-$ Sept. 10. N. Ohio, abundant S. R., Apl. 27-Oct. 1. Glen Ellyn, common S. R., May 5Oct. 5. SE. Minn., common S. R., May 5-Sept. 15.

Nest, pensile, of strips of bark, bits of dead wood, paper, and plant-down, firmly and smoothly interwoven, lined

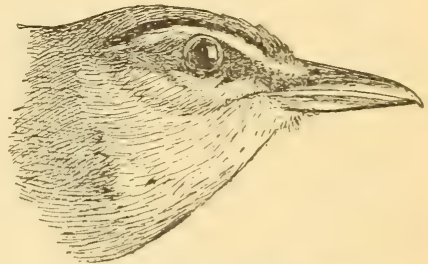

Fig. 112. Red-eyed Vireo.

(Natural size.)

with finer strips of bark and vine tendrils, suspended from a forked branch, 5-40 feet up. Eggs, 3-4, white, with a few black or umber specks or spots about the larger end, $\cdot 85 \times \cdot 55$. Date, D. C., May 26; Cambridge, May 28; Mt. Carmel, Ills., May 23; se. Minn., May 29.

This, the most common and generally distributed of our Vireos, is found alike in the shade trees of our lawns, in orchards, or woodlands. The conspicuous white line over the eye, with its black border, and the bird's red eye, and its frequently uttered, complaining note, a nasal whang, are good characters by which to distinguish it from its relatives.

Wilson Flagg's description of the Red-eye to my mind exactly reflects the character of the bird and its song: "The Preacher is more generally known by his note, because he is incessant in his song, and particularly vocal during the heat of our long summer days, when only a few birds are singing. His style of preaching is not declamation. Though constantly talking, he takes the part of a deliberative orator, who explains his subject in a few words and then makes a pause for his hearers to reflect upon it. We might suppose him to be repeating moderately, with a pause between each sentence, 'You see it-you know it-do you hear me?-do you believe it?' All these strains are delivered with a rising inflection at the close, and with a pause, as if waiting for an answer."

1905. Herrick, F. H., Home-Life of Wild Birds, 103-114. 
The Yellow-GReen Vireo (625. Vireosylva flavoviridis flavoviridis), a. Mexican and Central American species, has been once recorded from Godbout, Province of Quebec.

626. Vireosylva philadelphica Cass. Philadelphia Vireo. Ads.Upperparts light olive-green; the crown sometimes grayish; a whitish line over the eye; wings and tail edged with olive-green; no wing-bars; first primary nearly as long as second; entire underparts nearly uniform pale, greenish yellow. L., 4.75; W., $2 \cdot 60 ;$ T., $1 \cdot 95 ;$ B. from N., 26.

Remarks. - The pale, greenish yellow color spread almost uniformly over the entire underparts distinguishes this bird from our other Vireos.

Range.-E. N. Am. Breeds in Canadian zone from n. and cen. Alberta, n. Man., n. Ont., N. B., and Maine, to n. Mich. and N. H.; winters from Cozumel Is. and Guatemala to Veragua.

Washington, very rare T. V., May; Sept. Ossining, rare T. V., Sept. 20-Oct. 20. Cambridge, rare T. V. Glen Ellyn, rather rare T. V., May 14, 15; Aug. 21-Sept. 30. SE. Minn., uncommon T. V., May 9.

Nest, pensile, of fine grass and birch bark, suspended from a forked branch about eight feet from the ground. Eggs, 4, similar in color to those of $V$. olivacea (Seton). Date, Duck Mt., Man., June 4.

This species resembles the Red-eyed Vireo in habits, and Mr. Brewster writes that its song is so nearly identical with the song of that species "that the most critical ear will, in many cases, find great difficulty in distinguishing between the two. The notes of philadelphicus are generally pitched a little higher in the scale, while many of the utterances are feebler and the whole strain is a trifle more disconnected. But these differences are of a very subtile character, and, like most comparative ones, they are not to be depended upon unless the two species can be heard together. The Philadelphia Vireo has, however, one note which seems to be peculiarly its own, a very abrupt, doublesyllabled utterance with a rising inflection, which comes in with the general song at irregular but not infrequent intervals. I have also on one or two occasions heard the male when in pursuit of his mate utter a soft pseuo, similar to that sometimes used by Vireo olivaceus, and both sexes when excited or angry have a harsh, petulant note exactly like that of V. gilvus" (Bull. Nutt. Orn. Club., V, 1880, p. 5).

1897. Dwight, J. D., Jr., Auk, XIV, 259-272 (biography).

627. Vireosylva gilva gilva ( $V$ ieill.). W ARbLING Vireo. Ads.-Upperparts ashy olive-green; no wing-bars; wings and tail edged with the color of the back; first primary very short, not more than $1^{\circ} 00$ in length; underparts white slightly washed with yellowish. L., $5 \cdot 80 ;$ W., $2 \cdot 85 ;$ T., $2 \cdot 14 ;$ B. from N., $\cdot 30$.

Range.-E. N. Am. Breeds in Transition and Austral zones from se. Alberta, n. Man., cen. Ont., and N. S. s. to nw. Tex., s. La., N. C., and Va.; winter home unknown, but s. of the U. S.

Washington, rather common S. R., Apl. 21-Sept. 12. Ossining, tolerably common, S. R., May 3Sept. 18. Cambridge, lo-

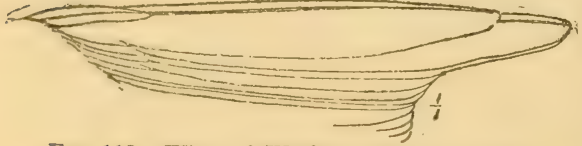

Fig. 113. Wing of Warbling Vireo, to show short first primary. cally common S. R., May 5-Sept. 15. N. Ohio, abundant S. R., Apl. 17-Oct. 10. Glen Ellyn, not common S. R., May 1-Sept. 15. SE. Minn., common S. R., May 3-Sept. 15. 
Nest, pensile, of grasses and plant fibers, firmly and smoothly interwoven, lined with fine grasses, suspended from a forked branch 8-40 feet up. Eggs, 3-4, white, with a few specks or spots of black, umber, or rufousbrown, chiefly about the larger end, $76 \times 55$. Date, Cambridge, May 30; Holland Patent, N. Y., May 27; se. Minn., May 24.

Unlike its cousin, the Preacher, the Warbling Vireo is not generally distributed, but shows a decided preference for rows of shade trees, particularly rows of elms. It passes the greater part of its time in the upper branches, and is more often heard than seen.

Although resembling the Red-eye in general appearance, its song is so different that singing birds need never be mistaken for that species. Instead of the Red-eye's broken, rambling recitative, the song of the Warbling Vireo is a firm, rich, continuous warble with a singular alto undertone.

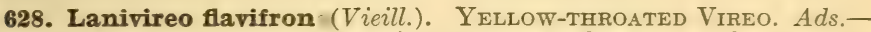
Upperparts bright olive-green, changing to gray on the rump and upper tailcoverts; greater and middle wing-coverts tipped with whitc, forming two distinct wing-bars; outer web of tertials edged with white; eye-ring, throat and breast bright yellow; belly white. L., 5.95; W., 3.05; T., $2 \cdot 10$; B. from N., 36.

Range.-E. N. Am. Breeds in Transition and Austral zones from se. Sask., s. Man., s. Ont., s. Que., and Maine s. to cen. Tex., cen. La., and cen. Fla.; winters from Yucatan and s. Mex. to Colombia; casual in winter in Cuba and the Bahamas.

Washington, common S. R., Apl. 19-Sept. 29. Ossining, tolerably common S. R., Apl. 30-Sept. 7. Cambridge, common S. R., May 6-Sept. 10. N. Ohio, common S. R., Apl. 25-Sept. 25. Glen Ellyn, not common S. R., May 2-Sept. 26. SE. Minn., common S. R., Apl. 27-Sept. 15.

$N$ est, pensile, of strips of bark, plant fibers, etc., interwoven, lined with fipe grasses and covered externally with lichens, suspended from a forked branch 10-30 feet up. Eggs, 3-4, white, with a few specks or spots of black, umber, or rufous-brown, chiefly about the larger ends, $80 \times \cdot 60$. Date, New London, Conn., May 21; Cambridge, May 26; Holland Patent, N. Y., May 24.

The Yellow-throated Vireo is a dweller in tree tops, and whether in woodland, orchard, or lawn, he seldom comes below the upper story of his home. But even at a distance his bright yellow breast is a conspicuous mark, at once distinguishing him from other members of his family.

If the Red-eyed Vireo is a soprano, the Yollow-throat is a contralto. He sings much the same tune, but his notes are decper and richer, while they are uttered more deliberately and with greater expression than those of his somewhat ton voluble cousin. "Sce me; I'm here; where are you?" he calls, and at intrrvals rrpeats his question in varying forms. Sometimes he astonishes us by an intricate liquid trill which suggests the wonderful song of the Ruby Kinglet, but which unfortunately is sometimes marred by the scolding notes that preeerle or follow it.

629. Lanivireo solitarius solitarius (Wils.). BLEE-HEADEI) TIRE(). Ads.-Top and sides of the head bluish gray; eye-ring and lores white: hack olive-green; greater and middle wing-coverts tipped with white, forming 
two distinct wing-bars; outer web of tertials edged with whitish; underparts white; sides washed with greenish yellow. L., $5.61 ;$ W., $2 \cdot 96 ;$ T., $2 \cdot 15$; B. from N., 28 .

Remarks. - This species may be known by its white lores and eye-ring, and bluish gray cheeks and crown.

Range.-E. N. Am. Breeds in Canadian and Transition zones from cen. Alberta, s. Mackenzie, s. Keewatin, cen. Ont., s. Que., and Cape Breton Is. s. to n. N. D., cen. Minn., Mich., mts. of s. Pa. and R. I.; winters from Gulf States to Guatemala.

Washington, common T. V., Apl. 6-May 18; Sept. 6-Nov. 3. Ossining, tolerably common T. V., Apl. 23-May 14; Sept. 8-Oct. 20. Cambridge, common T. V., rare S. R., Apl. 20-May 8; Sept. 15-Oct. 5. N. Ohio, common T. V., Apl. 17-May 20; Sept. 1-30. Glen Ellyn, not common T. V., May 919; Aug. 11-Oct. 9. SE. Minn., common T. V., May 3-Sept. 28.

Nest, pensile, of pine needles, plant-down, etc., firmly interwoven, suspended from a forked branch 5-10 feet up. Eggs, 3-4, white, with a few specks or spots of black, umber, or rufous-brown, chiefly at the larger end, $.80 \times$ 53. Date, Taunton, Mass., May 21; Cambridge, May 28; Webster, N. H., May 29.

This large and handsome Vireo-a bird of the woods-is the first of its family to reach the Northern States in the spring and the last to depart in the autumn. Like its congeners, but unlike birds in general, it sings at its work. In form its music resembles the Red-eye's, the Philadelphia's, and the Yellow-throat's; but to me it is more varied and beautiful than any of these, though some listeners may prefer the Yellow-throat for the richness and fullness of its "organ tone." The Solitary's song is matchless for the tenderness of its cadence, while in peculiarly happy moments the bird indulges in a continuous warble that is really enchanting. It has, too, in common with the Yellowthroat, a musical chatter-suggestive of the Baltimore Oriole's-and a pretty trilled whistle. Its most winning trait is its tameness. Wood bird as it is, it will sometimes permit the greatest familiarities. Two birds I have seen which allowed themselves to be stroked in the freest manner while sitting on the eggs, and which ate from my hand as readily as any pet canary; but I have seen others that complained loudly whenever I approached their tree. Perhaps they had had sad experiences.

BRADFORD TORREY.

629c. L. S. alticola Brewst. Mountain Solitary Vireo. Similar to the preceding, but with a much larger bill, and the back generally with more or less slaty blue. W., $3{ }^{*} 15$; T., $2 \cdot 25$; B. from N., 35 ; depth of B. at N., 20.

Range.-Breeds in Canadian and Alleghanian faunas in the Alleghanies from w. Md. to e. Tenn. and n. Ga.; winters in lowlands from S. Car. to Fla. Nesting date, Iredell Co., N. C., Apl. 9.

This race of the Blue-headed Vireo is a common summer resident in the southern Alleghanies (see Loomis, $A u k, 1891$, p. 329).

A single specimen of the Plumbeous Vireo (629b. L. s. plumbeus), a western species, has been taken at Peterboro, N. Y. (Miller, Auk, XI, 1894, 79).

631. Vireo griseus griseus (Bodd.). White-Eyed ViREo. $A d s$. Upperparts, including upper tail-coverts, bright olive-green, more or less 
washed with grayish; greater and middle wing-coverts tipped with yellowish white, forming two distinct wing-bars; outer web of tertials edged with whitish; lores and eye-ring yellow; throat white or whitish; belly white; breast and sides washed with greenish yellow; iris white, hazel in the young. L., 5*27; W., $2 \cdot 37$; T., 1·95; B. from N., '29.

Range.-E. U. S. Breeds chiefly in Austral zones from se. Nebr., s. Wisc., N. Y., and Mass. to cen. Tex. and cen. Fla.; winters from Tex., Ga., Fla., and S. C. through e. Mex. to Yucatan and Guatemala; casual n. to Vt., Ont., N. B., and in Cuba.

Washington, common S. R., Apl. 18-Oct. 19. Ossining, common S. R., Apl. 29-Oct. 3. Cambridge, rare S. R., May 8-Sept. 20; formerly common. Glen Ellyn, rare, spring only, May 24-June 5.

Nest, generally similar to that of $V$. olivaceus, suspended from a forked branch in thickets. Eggs, 3-4, white, with a few specks of black, umber, or rufous-brown at the larger end, $75 \times \cdot 55$. Date, Chatham Co., Ga., Apl. 22; Ossining, N. Y., May 27; Cambridge, June 1; Mt. Carmel, Ills., May 11.

If birds are ever impertinent, I believe this term might with truth be applied to that most original, independent dweller in thickety undergrowths, the White-eyed Vireo. Both his voice and manner say that he doesn't in the least care what you think of him; and, if attracted by his peculiar notes or actions, you pause near his haunts, he jerks out an abrupt "Who are you, eh?" in a way which plainly indicates that your presence can be dispensed with. If this hint is insufficient, he follows it by a harsh scolding, and one can fancy that in his singular white eye there is an unmistakable gleam of disapproval.

I have always regretted that the manners of this Vireo have been a bar to our better acquaintance, for he is a bird of marked character and with unusual vocal talents. He is a capital mimic, and in the retirement of his home sometimes amuses himself by combining the songs of other birds in an intricate potpourri.

631a. V. g. maynardi Brewst. KeY West Vireo. Scarcely distinguishable in color from the preceding, but averaging somewhat paler and less yellow below, and with a larger bill. L., 5.12; W., 2*40; T., 2.12; B, from N., 35 .

Range.-Fla., from Tarpon Springs and Anastasia Is. s. on the coast and keys to Key West.

631b. V. g. bermudianus (Bangs and Bradlee). Bermoda WhiteEYED VIREO. Similar to $V$. g. griseus but wing averaging shorter, tarsus longer, general coloration grayer, less yellow and olivaccous. (The $A$ uk, 1901, 252).

Range.-Bermuda.

"Not a very satisfactory subspecies" (Ridgway).

633. Vireo belli belli $A u d$. Bell's VIREO. Ads.-Crown ashy gray, changing to olive-green on the rump; greater and middle wing-(")verts narrowly tipped with white; lores and eye-ring whitish; underparts white, breast and sides washed with greenish yellow. L., 4.75 ; W., 2.20; T., $1 \times 60$; B. from N., 28 .

Range.-Breeds in Austral zones from ne. Colo., s. S. D., n. Ills., and nw. Ind. to e. Tex. and Tamaulipas; winters in Mex. and Guatemala; accidental in N. H.

Nest, pensile, of strips of bark and plant fibers firmly and smoothly interwoven, lined with finer grasses, etc., in bushes or low trees. Eggs, 4-6, white, 
with a few specks of black, umber, or rufous-brown at the larger end, $\cdot 66 \times$ •50. Date, Corpus Christi, Tex., Apl. 24; Mercer Co., Ills., May 25.

This is a common bird in its range, and is locally not uncommon as far east as Illinois. "In their food, habits, and actions they are very similar to the White-eyed. Their call- and alarm-notes are not quite so harsh, and their song is delivered in a less emphatic manner; an indescribable sputtering, that does not rank it high in the musical scale" (Goss).

1901. Carr, M., Proc. Neb. Orn. Un., 46-48 (habits).

The Bahama Honey Creeper (695. Careba bahamensis) was found by Dr. Würdemann in January, 1858, on Indian Key, southeastern Florida, but has not, to my knowledge, been taken by subsequent observers. The upper parts are sooty black, the rump and middle of the underparts yellow, and a line over the eye, the throat, and the lower belly are white or whitish; length about 4.50 .

\section{Family Mniotiltide. Wood Warblers. (Fig. 70.)}

The Wood Warblers are found only in America. About one hundred and fifty-five species are known, of which fifty-five visit the United States, there being nearly twice as many in the Eastern as in the Western States. With three or four exceptions, they are inhabitants of woodland, but, during their migrations, may be found in the trees of lawns or orchards. They feed almost exclusively upon insects, and are thus highly migratory, thousands of miles frequently separating their summer and winter homes.

The majority are among the last of the spring arrivals; their coming caps the climax of the migration, and the first severe frost leaves but few with us. They migrate by night, and are chief among the victims of lighthouses and electric-light towers. When migrating, they are generally found in straggling companies composed of a number of species, which during the day travel slowly through the woods from tree to tree.

They capture their insect food in a variety of ways. Some species flit actively from branch to branch, taking their prey from the more exposed parts of the twigs and leaves; others are gleaners, and carefully explore the under surfaces of leaves or crevices in the bark; while several, iike Flycatchers, capture a large part of their food on the wing. As a rule, they are arboreal, but many are thicket-haunting, and some are terrestrial.

Several species have remarkable vocal ability, but, generally speaking, they have rather weak voices, and take low rank as songsters.

Warblers are at once the delight and the despair of field students. To the uninitiated, their existence is unknown, and when search reveals the before unsuspected fact that our woods are thronged with birds as exquisitely colored as the daintiest tropical forms, we feel as though a new world were opened to us. Entering an apparently deserted bit of woods, we hear faint voices, lisping tseeps, and soon discover that the tree tops are animated with flitting forms. What limitless possibilities 
there are in a flock of Warblers! Who can say what rare species may be among them?-perhaps the bird we have long vainly looked for; perhaps a stranger from another clime!

1907. Chapman, F. M., and others. The Warblers of North America, 8vo., col. plls. 24; pp. 306 (Appleton).

\section{KEY TO THE SPECIES}

\section{First Group.-Throat yellow, yellowish, or orange.}

I. Underparts without streaks or spots.

II. With black or brown streaks on the breast or sides, or (in one species) a blackish brown band across the throat, or (in one species) a black patch on the breast.

\section{Second Group.-Throat black, gray, ashy, white, whitish, brown, or buffy.}

I. Throat and upper breast one color, black, gray, ashy, or brown, very different from the white or yellow belly.

II. Throat white or whitish, with or without streaks or spots; rest of underparts streaked or spotted with black, bluish, chestnut, or yellow.

III. Underparts white, whitish, or buffy, without streaks, spots, or patches.

\section{FIRST GROUP}

\section{Underparts without streaks or spots.}

1. Tail with conspicuous white spots or patches.

A. Wings with white wing-bars.

a. Underparts entirely pure yellow.

$a^{1}$. Forehead yellow; a black line through the eye; rump same as back . . . . . . 641. Blue-Winged Warbler. $a^{2}$. Crown ashy; rump yellow . 657. Magnolia Warbler (Im.).

b. Underparts not entirely pure yellow.

$b^{1}$. Throat bright yellow; belly white or whitish.

$b^{2}$. Back olive-greenish . . . . 671. Pine Warbler.

$b^{3}$. Back bluish, with a yellowish patch in the middle.

648. Parula Warbler (Im.).

$c^{1}$. Underparts pale yellowish white or buffy; throat not brighter than belly. .

$c^{2}$. Back olive-green, slightly streaked with black.

$c^{3}$. Underparts pale cream-buff, stronger on the flanks.

660. BAY-BREASTED WARBLER (Im.).

$c^{4}$. Underparts pale yellowish white.

661. Black-poll Warbler (Im.).

$d^{2}$. Back not streaked.

$d^{3}$. Back olive-green, without streaks . 671. Pine IVARnLer o. $d^{4}$. Back with a bluish tinge and without streaks.

$B$. Without white wing-bars.

658. Cerulean Warbler (Im.).

a. Underparts bright orange or orange-ycllow; wings, tail-eoverts, and tail bluish gray . . . 637. Prothonotary Warbler.

b. Underparts pure yellow; wings, rump, and tail greenish; head sometimes blackish; inner web of outer tail-feathers white.

684. HoOded Warbler ( 8 and im.).

c. Underparts pale yellowish; hrad ashy; rump olive-green; small white tail-spots, not reaching to ends of feathers.

640. Bachman's Warbler ( $\$$ and im.).

d. Underparts pale yellowish; entire upperparts olive-green; a white spot at the base of the primaries.

654. Black-throated Blue Warbler 9. 
2. Tail without white spots or patches; wings without white wing-bars. A. Cap, or forehead, or cheeks black or blackish.

a. Cap black; forehead and cheeks yellow.

685. Wilson's WARBLER.

$b$. Band on the forehead and cheeks black or blackish; no yellow line over the eye . .681. Maryland Yellow-Throat ot.

681b. Florida YelLOW-THROAT or.

c. Forehead or crown and cheeks black or blackish; a clear yellow line over the eye . . . . .677. KentuCKy WARbler.

$B$. No black on forehead.

a. Crown ashy, of a very different color from the olive-green back, or with the bases of the crown feathers rufous-brown or chocolate.

$a^{1}$. Crown plain ashy; under tail-coverts white.

640. BaCHMAN'S WARBLER.

$a^{2}$. Crown ashy; bases of feathers chestnut; eye-ring distinctly white; most of underparts and under tail-coverts bright yellow . . . . . 645. NASHVILLE WARBLER.

$a^{3}$. Crown of nearly the same color as the back; the feathers with rufous-brown bases; underparts dull greenish yellow.

646. ORANGE-CROWNED WARBLER.

$b$. Crown of the same color as the back; forehead the same, or yellowish, or brownish.

$b^{1}$. Underparts uniform yellow or yellowish.

$b^{2}$. Underparts bright yellow.

$b^{3}$. Upperparts bright olive-green; forehead yellowish; short bristles at base of bill; tail greenish brown.

685. WILSON's WARBLER (Im.).

$b^{4}$. Upperparts bright greenish yellow; inner web of tailfeathers yellow ... 652. Yellow WARBLER $\circ$.

$b^{5}$. Upperparts ashy greenish; eye-ring white.

645. NashVILle Warbler (Im.).

$c^{2}$. Underparts dull yellow or yellowish.

$c^{3}$. Underparts dull greenish yellow, obscurely streaked with dusky; back ashy greenish.

646. Orange-crowned Warbler (Im.).

$c^{4}$. Underparts yellowish or buffy yellowish; outer tail-feathers decidedly shortest; legs flesh-color.

681. Maryland Yellow-throat $\%$.

681b. FloRida YelLOW-THROAT $ᄋ$.

$c^{5}$. Breast somewhat yellower than rest of underparts; flanks brownish; legs blackish; tail-feathers of same length.

645. NAShVille WARBLer (Im.).

$c^{6}$. Inner margins of tail-feathers yellow.

652. YelLOW WARBLer i.

$c^{7}$. Back bright olive-green; under tail-coverts white.

647. Tennessee Warbler (Im.).

$c^{8}$. A small white spot at the base of the primaries.

654. Black-throated Blue Warbler.

$c^{1}$. Throat and breast yellow; belly white or whitish.

$c^{2}$. A black spot before the eye and a white line over it; wing $3{ }^{\circ} 00$. 683. Yellow-BREAsted Chat.

$c^{3}$. Legs flesh-color; outer tail-feathers shortest; forehead sometimes brownish . 681. Maryland Yellow-throat $q$.

681b. Florida YelLOW-THROAT $\%$.

$c^{4}$. Legs blackish; tail-feathers even; wing under $3^{\circ} 00$.

645. NAShVille WARBLer (Im.). 


\section{With black or brown streaks on the breast or sides, or (in one species) a blackish brown band across the throat, or (in one species) a black patch on the breast.}

I. Underparts streaked or spotted.

1. Underparts streaked with rufous-brown.

A. Crown chestnut.

a. Entire underparts rich yellow 672a. Yellow Palm WArbler.

$b$. Throat and breast bright yellow; belly yellowish white.

$B$. No chestnut crown-cap.

672. Palm Warbler.

a. Underparts yellowish white; eye-ring yellowish.

672. Palm Warbler (Im.).

b. Underparts yellow, washed with brownish; eye-ring yellowish. 672a. Yellow Palm Warbler (Im.).

c. Underparts bright yellow; forehead yellow; inner webs of tailfeathers yellow . . . 652. Yellow Warbler (Ad.).

2. Underparts streaked or spotted with black.

a. Back unspotted, the same as the head, olive-green or olive-brown. $a^{1}$. Underparts pale sulphur-yellow, streaked with black; no wingbars; wing $3^{\circ} 00$ or over.

675. Water-Thrush. 675a. Grinnell's Water-Thrush.

$a^{2}$. Underparts bright yellow; no black streaks on the flanks; wing nearly $3^{\circ} 00$. . . . 671. Pine Warbler.

$a^{3}$. Underparts bright yellow; sides streaked with black; wing about 2.00 . 673. Prairie Warbler ( 9 and im.).

$a^{4}$. Throat pale yellow, indistinctly spotted or streaked; belly whitish; cheeks bright yellow; outer web of outer tail-feather white at the base.

667. Black-throated Green Warbler (Im.).

$a^{5}$. Throat and breast yellow, distinctly spotted; median wingcoverts white . . . 650. CAPE MAY WARBLER (o and im.).

b. Head not olive-green or olive-brown.

$b^{1}$. Back black or streaked with black, or center of crown orange.

$b^{2}$. Underparts pale yellow; black spots confined to sides; no white wing-bars . 670. KirTLAND's WarBLER.

$b^{3}$. Underparts pale yellow, indistinctly streaked with blackish; two white or whitish wing-bars.

661. Black-poll Warbler (Im.).

$b^{4}$. Throat orange or yellow, without streaks; car-coverts gray or black; center of crown yellowish or orange.

662. BLACKBURNIAN WARBLER.

$b^{5}$. Underparts streaked with black; car-cov'rerts rufous; ('ap) black.

650. Cape May Warbler.

$b^{6}$. Head bluish gray or ashy; rump bright yollow: eye-ring white; white tail-spots not reaching to ends of feathers.

657. Magnolia Warbler.

$c^{1}$. Back not black.

$c^{2}$. Back ashy gray.

$c^{3}$. Throat yellow; belly white; wing-hars and tail-spots white.

$c^{4}$. A yellow line from the bill to the eye.

663. Yellow-THROATED WARBLER.

$c^{5}$. A white line from the bill to and over the eye.

663a. Sycamore Warbler.

$d^{3}$. Entire underparts yellow; breast with a necklaee of black spots; no wing-bars or tail-spots

686. Canadian Warbler.

$d^{2}$. Center of back brick-red; underparts yellow; sides streaked with black ....... 673. Prairie Warbler. 
II. Underparts not streaked.

A. Throat yellow; breast with a band of copper or blackish chestnut; upperparts blue; center of back greenish yellow.

648. Parula Warbler.

$B$. Throat and forehead yellow; breast and crown-cap black.

640. Bachman's WaRBLER.

\section{SECOND GROUP}

\section{Throat and upper breast one color, black, gray, ashy, or brown,} very different from the white or yellow belly.

A. Belly white or whitish.

a. Back gray or greenish gray, crown yellow, cheeks black or g:ay, wing-bars yellow *. 642. Golden-WINGed WARBLER.

b. Back and crown bright olive-green, cheeks yellow, wing-bars white . . . . 667. Black-throated Green Warbler.

c. Back and crown dark blue, a white spot at the base of the primaries.

654. Black-throated Blue Warbler ơ.

d. Back streaked with gray and black; cap, throat, and sides chestnut. 660. BAY-BREASTED WARBLER $\sigma^{7}$.

$e$. Back streaked with black and white, a white line through the center of the crown . . 636. Black AND White Warbler o7.

$f$. Back black; sides, center of wings, and base of tail salmon-red.

B. Belly yellow.

687. Redstart ơ.

a. Throat black.

$a^{1}$. Cheeks bright yellow, black crown-cap connected with black throat by a black line, end half of inner web of outer tail-feathers white ... . 684. HOODED WARBLER.

$a^{2}$. Cheeks dull greenish yellow, black crown-cap not connected with black throat, white tail-spots not reaching to the ends of feathers . . . . 640. BACHMAN's WARBLER.

$a^{3}$. A black streak through the eye, wing-bars white.

$b$. Throat bluish gray, ashy, or brownish.

$b^{1}$. A white eye-ring . . . 678. ConNecticut WARBLer. $b^{2}$. No white eye-ring $\because \therefore$ 679. Modrning Warbler.

II. Throat white or whitish, with or without streaks or spots; rest of the underparts spotted or streaked with black, bluish, chestnut, or yellow.

A. Back streaked with black.

a. With chestnut streaks on the sides, under tail-coverts white.

$a^{1}$. Wing over $2 \cdot 50$, head with chestnut or black streaks or spots, wing-bars white

660. Bay-BREASTEd Warbler ${ }^{\circ}$. $a^{2}$. Wing under $2 \cdot 50$, crown and wing-bars yellow or yellowish.

b. With black or bluish streaks 659. CHESTNUT-SiDEd WARBLER. $b^{1}$. Cap solid black 661 . Black-poll Warbler $\sigma^{7}$. $b^{2}$. Crown, rump, and sides of the breast with a yellow patch or spot.

$b^{3}$. Cap black, with a white streak through the center.

636. Black and White Warbler 9 . $b^{4}$. Crown olive-green, with small black streaks.

661. BLACK-POLL WARBLER .

$b^{5}$. Crown blue, a bluish black band across the breast.

$b^{6}$. Crown brownish, under tail-coverts yellow.

658. Cerulean Warbler o?.

672. Palm Warbler (Im.). 
$B$. Back without streaks or spots.

a. With white or yellow spots in the tail.

$a^{1}$. Wing-bars white, cheeks yellow, back greenish.

667. Black-throated Green Warbler (Im.).

$a^{2}$. Wing-bars, cheeks, and back grayish, under tail-coverts white. 650. Cape May Warbler (o and im.). $a^{3}$. Back brownish, under tail-coverts yellow.

672. Palm Warbler (Im.).

$a^{4}$. Sides of breast, band in wings, and base of tail yellow.

b. Without white or yellow spots in the tail.

687. Redstart (\% and im.).

$b^{1}$. A pale rufous streak bordered by black through the center of the crown ............ 674. Oven-BIRD.

$b^{2}$. A white line over the eye, throat generally without spots, wing over $3^{\circ} 00$, bill over 50 . . 676. LoUisiana WATER-THRUSH.

$b^{3}$. A buffy line over the eye, throat with small black spots, wing under $3^{\circ} 00$, bill under 50 . . . 675. WATER-THRUSH.

675a. Grinnell's Water-Thrush.

\section{Underparts white, whitish, or buffy, without streaks, spots, or patches.}

A. Tail with white or yellow spots or patches

a. Wing-bars white or grayish.

$a^{1}$. Underparts pure white, back greenish yellow, cheeks gray, wing under 2:50 . 659. Chestnut-sided Warbler (Im.).

$a^{2}$. Underparts tinged with buffy, back and cheeks olive-green, with generally distinct black streaks, wing over $2{ }^{\circ} 50$.

660. BAY-BREASTED WARBLER (Im.).

$a^{3}$. Underparts soiled whitish, back brownish or grayish green, eyering white, wing-bars grayish, wing over $2 \cdot 50$.

671. Pine Warbler (o and im.). $a^{4}$. Underparts white, back streaked with pure black and white. 636. Black and White Warbler \%.

b. Wing-bars yellowish, greenish, or absent.

$b^{1}$. Back and head bright greenish yellow, cheeks gray, underparts pure white . 659. Chestnut-sided Warbler (Im.).

$b^{2}$. Back, head, and cheeks yellowish green, underparts yellowish, inner margins of tail-feathers yellow . 652. YelLow WARBLER (Im.).

$b^{3}$. Back gray or grayish, a black line through the eye.

$641+642$. Brewster's Warbler.

$b^{4}$. Back and head brownish, wings and base of tail with a yellow band . . . . . 687. Redstart (\% and im.).

$b^{5}$. Back bright green, head and cheeks grayish, a small black spot in front of the eye... 647. Tennessee Warbler o?.

$B$. Tail without white or yellow spots or patches.

a. Under tail-coverts yellow.

$a^{1}$. Back olive-green, outer tail-feathers shortest, legrs flesh-eolor. 681. Martland Yellow-throat (o and im.).

681b. Florida Yellow-throat.

$a^{2}$. Back grayish olive-green, tail-feathers of equal length, legs blackish

646. ORANGE-CROWNED WARBLER.

b. Under tail-coverts white or whitish.

$b^{1}$. Head plain brown, a whitish line from the fill over the eye.

638. SWAINSON'S WARBLER.

$b^{2}$. Center of crown and line from the bill over the eye buffy, hordered by black stripes . . 639. Worm-EAtiNa WARBIEr.

$b^{3}$. Crown greenish, a small white spot at the base of the primaries almost concealed by wing-coverts.

654. Black-throated Blue Warbler (\$ and im.).

$b^{4}$. Crown grayish, bend of the wing yellow. 


\section{A Field Key to the}

\section{Adult Male Warblers of Eastern North America in} Spring and Summer Plumage.

I. Throat yellow, white, or whitish; underparts without streaks or patches.

II. Throat black, brown, or slate-color.

III. Throat yellow or orange, underparts with streaks. (In one species a blackish brown band across the breast.)

IV. Throat white or whitish, with streaks or spots on the underparts. (In two species a yellow patch on the sides of the breast.)

\section{Throat yellow, white, or whitish; underparts without streaks or patches.}

1. Throat yellow.

$A$. Length over $6^{\circ} 00$, the largest of the Warblers; haunts dense thickets in second growth; song, a peculiar mixture of whistles, chucks, and crow-calls, delivered from the undergrowth, from the trees above, or on the wing, when the bird resembles a bunch of falling leaves . . . . . 683. Yellow-Breasted Chat.

$B$. Length under $6^{\circ} 00$.

a. Head and neck bright golden yellow like the breast; tail-feathers white, except at the tip; haunts near the water; especially low bushes and willows hanging over streams and ponds; call, a sharp peek; range, from Virginia and s. Minnesota southward.

637. PROTHONOTARY WARBLER.

b. Forehead and cheeks black, a yellow line over the eye; song, a loud whistled call of five to seven notes; haunts near the ground; range from lower Hudson valley southward.

677. KentucKY WARBLER.

c. Forehead and cheeks black, bordered by grayish; no line over the eye; haunts undergrowth; call, a frequently repeated chack; song, a loud, rapid I beseech you, I beseech you, I beseech you, or witch-e-weè-o, witch-e-weè-o, witch-e-weè-o; movements restless; abundant . . . . 681. MARYLAND YELLOW-THROAT.

$681 b$. FLORIDA YELLOW-THROAT.

$d$. Head and back olive-green; wings with two white bars; outer tail-feathers with white; haunts pine woods; song, a musical trill.

671. Pine Warbler.

e. Crown bluish ash, eye-ring white; call-note sometimes like the sound produced by striking two pebbles together.

645. NAShVille WARBLer.

$f$. Forehead yellow, a small black mark in front of the eye; wings with two white bars; outer tail-feathers with white; song, swēe-echee,

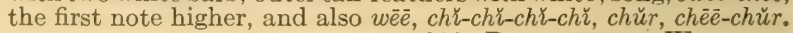
641. BLUE-WINGED WARBLER.

g. Forehead yellow; crown-cap black; cheeks yellow; wings and tail unmarked; rather rare . . 685. WILsON's WARBLER.

2. Throat white or whitish.

A. Length $5 \cdot 00$; crown brown or with blackish and buffy stripes.

a. A conspicuous whitish line through the center of the crown, bordered by black lines; not common.

639. WORM-EATING WARBLER.

b. Crown plain brown; range, Virginia and southward.

$B$. Length 4:50; crown ashy or forehead yellow.

638. SWAINSON's Warbler.

a. Forehead yellow.

$a^{1}$. Breast white, with a barely perceptible tinge of yellow; wingbars white or yellow, a black mark in front of the eye; rare. $641 \times 642$. BREWSTER'S WARBLER。 
b. Forehead not yellow.

$b^{1}$. Breast white, crown plain bluish ashy, clearly defined from the bright olive-green back . . 647. TENNESSEE WARBLER.

$b^{2}$. Breast whitish, tinged with yellow and indistinctly streaked with dusky; crown dull ashy, not clearly defined from the back and with a partly concealed patch of rufous-brown; rare in the Atlantic States north of South Carolina.

\section{Throat black, brown, or slate-color.}

646. Orange-crowned Warbler.

1. Belly white.

a. Back blue, a white spot near the outer edge of the wing; common.

654. Black-throated BlUE Warbler.

b. Back green, cheeks yellow; song, a buzzlike zee repeated five or six times, the next to last note the highest; common.

667. Black-throated Green Warbler.

c. Back grayish, forehead yellow, a black mark through the eye and a white line below it; a large patch of yellow on the wings; song, $z e e-z e e-z e e-z e e$, all on the same note; not common.

642. Golden-winged Warbler.

$d$. Back black; sides of the breast, middle of the wing, and base of the tail-feathers reddish orange; movements active, tail frequently spread, the reddish color showing conspicuously; abundant.

687. Redstart.

e. Back streaked with black and white; song fine and wiry; movements like those of a Creeper; common.

636. Black and White Warbler.

f. Back streaked with buffy and black; forehead and cheeks black; crown-cap, throat, upper part of the breast, and sides chestnut; rather rare . . . . 660. BAY-BREASTED WARBLER.

2. Belly yellow.

$A$. Throat slate-color; haunts near the ground.

a. Breast showing traces of black, no white eye-ring; rare in most places . . . . . 679. Mourning Warbler.

b. Breast with no traces of black, a white eye-ring; call a sharp peek; very rare in the spring . . . 678. CONNECTICUT WARBLER.

B. Throat black.

a. Forehead and crown yellow, wings with white bars, a black line through the eye; very rare. orehead and cheeks yellow, rest of the head and sides of the neck black; outer tail-feathers almost entirely white; haunts near the ground, generally in wet woods; movements artive, the white tail-feathers showing conspicuously in flight; lower Hudson valley southward; common . . 684. Hooded Warbler.

c. Forehead yellow, a small black patch on the crown, white patches on the tail not reaching to the ends of the feathers; range, South Carolina southward . . . 640. BACHMAN's WARBLER.

\section{Throat yellow or orange, underparts with streaks. (In one species a blackish brown band across the breast.)}

1. Belly white, with or without black streaks.

a. Throat rich orange; back black, streaked with white; tolerably common . . . 662. Blackiburnian Warbler.

$b$. Throat bright yellow, back grayish; range, Virginia and southern Wisconsin southward; abundant.

663. Yellow-throated Warbler.

663a. SYCAMORE WARBLER.

c. Throat yellow, with a blackish band crossing the upperpart of the breast; abundant . . 648-648a. PARULA WARBlers.

2. Belly yellow, with streaks or spots on the breast or sides. 
A. With black streaks or spots on the underparts.

a. Back grayish, unstreaked; a necklace of black spots on the breast; no streaks on the sides nor white on the wings or tail; common.

686. Canadian Warbler.

b. Back black, crown grayish, a black stripe through the eye; breast and sides streaked with black; end of tail black, a white band across its middle; common . . 657. MAGNoliA Warbler.

c. Back streaked with white, center of the crown and line over the eye orange . . . . 662. Blackburnian Warbler.

d. Back greenish, streaked with black; crown black, a rufous earpatch, a white patch on the wings, rump yellow; rather rare.

650. CAPE MaY Warbler.

e. Back greenish, with a patch of rufous-brown; haunts second growths and old bush-grown pastures; common in some places.

673. Pratrie Warbler.

f. Back grayish, streaked with black; crown bluish; no conspicuous white marking on the wings; very rare.

$B$. Underparts with rufous-brown streaks.

670. Kirtland's Warbler.

a. Crown yellow, back greenish, inner border of tail-feathers yellow; general appearance that of a yellow bird; haunts lawns, orchards, and second growths; rarely seen in deep woods; abundant. 652. YELLOW WARBLER.

b. Crown chestnut, back brownish, outer tail-feathers tipped with white; haunts near the ground, frequently seen along roadsides and in old fields; movements leisurely, constantly wags its tail; common. 672. Palm Warbler. 672a. Yellow Palm Warbler.

\section{Throat white or whitish, with streaks or spots on the underparts. (In two species a yellow patch on the sides of the breast.)}

1. A patch of yellow on the sides of the breast.

a. Back grayish, streaked with black; rump and a partly concealed crown-patch yellow; note, a loud tchip, generally uttered during flight; abundant . . . . . 655. MYrTLE WARbler.

b. Back brown, breast more or less spotted with black; a yellow band across the middle of wings and tail; movements active, tail frequently spread, the yellow band showing conspicuously; abundant.

2. No yellow patch on the sides of the breast.

687. REDSTART (Im.).

$A$. With wing-bars; back streaked with black; haunts in trees.

a. Back bright blue; very rare near the Atlantic coast.

658. Cerulean Warbler.

b. Back grayish, crown black; movements slow; abundant.

661. BLACK-POLL WARBLer.

c. Back greenish yellow, crown bright yellow, sides chestnut; common . 659. CHESTNUT-SIDED WARBLER.

$B$. Without wing-bars; back not streaked; haunts on or near the ground; walkers, not hoppers.

a. Crown pale rufous, bordered by black streaks; song, a loud teacher, repeated eight or nine times and increasing in volume; common. 674. OVENBIRD.

$b$. Crown like the back, breast with a tinge of sulphur-yellow, an inconspicuous buffy line over the eye; bill less than $\cdot 50$ in length; common

c. Crown like the back, breast and particularly flanks tinged with buffy, a conspicuous white line over the eye; bill nearly 75 in length; a far shyer bird than the preceding; song loud and ringing . . . . . 676. Louisiana Water-Thrush.

636. Mniotilta varia (Linn.). Black AND White Warbler. (Fig. 114.) Ad. o.-No yellow anywhere; upperparts streaked with black and 
white; ear-coverts black; inner webs of outer tail-feathers with white patches; wing-coverts black, tipped with white; throat and upper breast black or black and white; sides streaked with black and white; middle of the belly white. Ad. o.--Similar, but the underparts with fewer black streaks; sides washed with brownish. Im. $\sigma^{7}$.- Similar to the $q$, but with more streaks on the underparts. L., $5 \cdot 30 ;$ W., $2 \cdot 73 ;$ T., $2 \cdot 02 ;$ B. from N., $\cdot 37$.

Range.-E. N. Am. Breeds in Canadian, Transition, and Austral zones from cen. Mackenzie, s. Keewatin, n. Ont., N. F., N. S., and N. B. to e. Tex., La., cen. Ala., and n. Ga., w. to S. D. and casually to Wyo., and Colo.; winters from Florida southward.

Washington, abundant T. V., less common S. R., Apl. 8-Oct. 18. Ossining, common S. R., Apl. 18-Oct. 1. Cambridge, very common S. R., Apl. 25-Sept. 5. N. Ohio, common T. V., a few S. R., Apl. 22-Sept. 26. Glen Ellyn, common T. V., Apl. 28-May 28; Aug. 11-Sept. 27. SE. Minn., common T. V., uncommon S. R., Apl. 23-Oct. 12.

Nest, of strips of bark, grasses, etc., lined with rootlets or long hairs, on the ground at the base of a stump, log, or rock. Eggs, 4-5, white, spotted and speckled with cinnamon-brown to umber, chiefly in a wreath at the larger end, $66 \times{ }^{5} 54$. Date, Iredell Co., N. C., Apl. 18; New York City, May 18; Cambridge, May 18.

None of our Warblers can be more readily identified than this conspicuously marked creeper. It is generally distributed throughout woodland, and climbs with even more agility than a true Creeper, hanging from the the under surface of branches and twigs, and flitting actively from tree to tree after apparently the most superficial examination. Its alarm note is a sharp pit, sometimes rapidly repeated. The usual song is a thin, wiry, see-see-see-see.

1910. Stanwood, C. J., Journ. Me. Orn. Soc., XII, 61-66 (nesting).

637. Protonotaria citrea (Bodd.). Prothonotary Warbler. Ad. 8.-Whole head, neck, and underparts rich orange, lighter on the belly; back greenish yellow, changing to bluish gray on the rump; wings and tail ashy; inner webs of all but middle tail-feathers white, except at tip; no wing-bars. Ad. .- Similar, but yellow paler, belly with more white. L., 5.50 ; W., 2.90 ; T., 1.85 ; B. from N., 42 .

Range.-E. N. Am. Breeds in Austroriparian fauna and along river bottoms of Carolinian fauna from ne. Nebr., se. Minn., s. Wisc., s. Mich., Ohio, cen. Del., and e. Md. s. to e. Tex., and n. Fla.; winters from Nicaragua to Colombia; casual n. to N. Y., New England, Ont., and N. B., and w. to Ariz.

Washington, of irregular oceurrence in May. N. Ohio, one record, May 9. Glen Ellyn, rare, spring only, May 13-15. SE. Minn., common S. R. of Mississippi bottoms, May 7-Aug. 16.

Nest, of rootlets, fine twigs, and moss, plant-rlown or feathers, in a hole in a stub or stump, generally of a willow tree. Eggs: 5-7, white, thickly and rather coarsely marked distinctly and olscurcly with cinnamon-hrown, chestnut, or rufous-brown, $69 \times \cdot 56$. Date, (tharleston, S. ('., May; 3 ; Lewis Co., Mo., May 20; Mt. Carmel, Ills., May $x$; Pieree ('o., Wisc., May 31 ; se. Minn., June 1.

This exquisite Warbler frequents bushes and low trees-particularly willow trees-hanging over the water. Its ("all-note so closely resembles that of a Water-Thrush (Seiurus), I have sometimes mistaken it for that species. Its usual song, as Mr. Browstrer remarks in his admirable biography of this species, "sounds at a distance like the call of the Solitary Sandpiper, with a syllable or two added-a 
simple peet, tweet, tweet, tweet, given on the same key throughout. Nearer at hand, however, the resemblance is lost, and a ringing, penetrating quality becomes apparent in the Warbler's song." (Bull. Nutt. Orn. Club, III, 1878, pp. 153-162.)

Thoroughly to appreciate the Prothonotary's radiant beauty, one should float quietly in a canoe past its haunts. Its color shows to best advantage against the dark background of its home, and its every movement is a delight to the eye.

638. Helinaia swainsoni (Aud.). SwaInson's WARBLer. Ads.Crown cinnamon-brown; a whitish line over the eye; back, rump, wings, and tail olive grayish brown without white; underparts soiled yellowish white, grayer on the sides. L., $5 \cdot 00$; W., $2 \cdot 75$; T., $1.90 ;$ B. from N., ' 46.

Range. - S. E. U. S. Breeds in Austroriparian fauna from se. Mo., s. Ills., s. Ind., and se. Va. (Warwick Co.), s. to La. and n. Fla.; winters in Jamaica; migrates through Cuba and Bahamas; casual in Nebr., Tex., and Vera Cruz.

Nest, externally of leaves, lined with pine needles and rootlets, in bushes, canes, palmettos, and clumps of vines, from three to ten feet above the ground or surface of the water. Eggs, 3-4, white, with a faint bluish tinge, $\cdot 75 \times \cdot 54$. Date, Charleston, S. C., May 7.

The history of Swainson's Warbler is very similar to that of Bachman's Warbler. It was discovered by Dr. Bachman near Charleston, South Carolina, in 1832, and for somewhat over fifty years was practically a lost species, but proves now to be a common bird in some parts of its range. Its rediscovery near Charleston by Mr. A. T. Wayne and Mr. Brewster is recounted by the latter in an article which adequately portrays the bird, its habits and haunts. It lives on and near the ground, and, according to Mr. Brewster's experience, four things seem indispensable to its existence- "water, tangled thickets, patches of cane, and a rank growth of semi-aquatic plants." Its song, which is highly ventriloquial, is described by the same author as "a series of clear, ringing whistles, the first four uttered rather slowly, and in the same key, the remaining five or six given more rapidly, and in an evenly descending scale. . . . In general effect it recalls the song of the Water Thrush (Seiurus noveboracensis). It is very loud, very rich, very beautiful, while it has an indescribable tender quality that thrills the senses after the sound has ceased." The Auk, 1885, pp. 65-80; see also Ibid., pp. 346-348, and also Perry, Orn. and Oöl., 1886, p.188; 1887, p. 141.

639. Helmitheros vermivorus (Gmel.). WORM-EATING WARBLER. (Fig. 115.) Ads.-A black line from the eye to the nape, and two on the crown from either nostril; an olive-buffy line over either eye, and a third through the center of the crown; back, wings, and tail olive-green without white; underparts whitish cream-buff, whiter on the throat and belly. L., $5 \cdot 51 ;$ W., 2.78; T., 2.05; B. from N., 39 .

Range.-E. N. Am. Breeds mainly in the Carolinian fauna from s. Iowa, n. Ills., e. and w. Penn., and the Hudson and Conn. River valleys s. to s. Mo., Tenn., Va., and mts. of S. C. (casually further south); winters from Chiapas to Panama, in Cuba and the Bahamas, and casually in Fla.; in migration casually to Mass., Vt., w. N. Y., s. Ont., and s. Wisc.

Washington, quite common S. R., Apl. 28-Sept. 15. Ossining, common S. R., May 7-Aug. 23. Cambridge, A. V., one instance, Sept. 
Plate XXIII

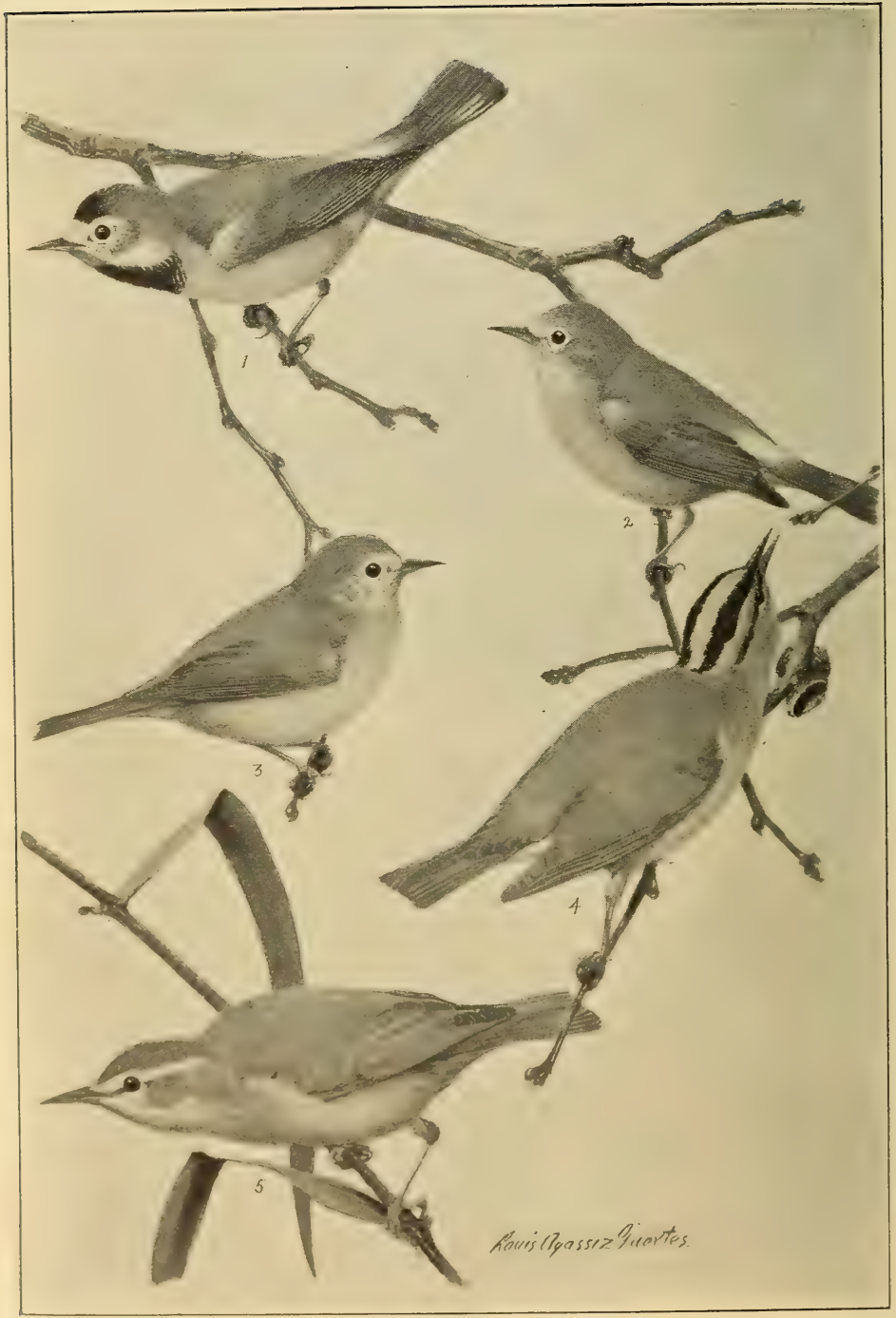

1, 2,3. Bachman's Warbler

5. Swatnson's Warbler

4. Worm-Eating Warbler (From "Warblers of North America.") 
Nest, of rootlets, leaves, and bark, on the ground. Eggs, 4-6, white, speckled, spotted, or blotched with cinnamon- or rufous-brown, ${ }^{\circ} 68 \times \cdot 54$. Date, Iredell Co., N. C., May 10; Waynesburg, Pa., May 16; New Haven, Conn., May 25.

This comparatively rare, retiring Warbler may be found on dry wooded slopes, hillsides, and ravines, generally where there is a rather dense undergrowth, but occasionally where the ground is quite clear and open. It lives on or near the ground, and in its slow, deliberate actions resembles a Vireo more than the usually active Warblers. Its call-note is a sharp chip, while its song, as all observers agree, closely resembles that of the Chipping Sparrow, but is somewhat weaker.

640. Vermivora bachmani (Aud.). BachMan's Warbler. Ad. $\sigma^{7}$ - Forehead yellow, bordered by a black patch on the crown; back of the head bluish gray; back and rump bright olive-green; lesser wing-coverts yellow; tail grayish, all but the middle feathers with white patches on their inner web near the tip; throat and belly yellow, a large black patch on the breast. Im. $\sigma^{7}$ - Throat-patch smaller than in ad. $\sigma^{7}$; less black or none on head. Ad. .-Crown grayish; forchead yellowish; back, wings, and tail as in the $\sigma^{\pi}$; underparts whitish, washed with yellow on the throat and breast; bend of the wing yellow. Im. o.- Similar, but with less yellow; back grayer. L., $4 \cdot 25 ;$ W., $2 * 40 ;$ T., $1 \cdot 80 ;$ B. from N., 32 .

Range. S. E. U. S. Breeds in Austroriparian fauna in se. Mo., ne. Ark., w. Ky., and near Charleston, S. C., and probably in s. Ind. and N. C.; winters in Cuba; in migration occurs in La., Miss., Ala., and Fla.; casual in Va. and the Bahamas.

Nest, chiefly of fine grasses, cane leaves, skeletonized leaves and ocrasionally Tillandsia (Wayne); in low bushes, 1-3 fret up. Eggs, 3-4, pure, glossy white, $63 \times \cdot 49$. Date, Charleston, S. C., Apl. 17; Dunklin Co., Mo., May 13; Logan Co., Ky., May 14.

Bachman's Warbler was described by Audubon from a pair of birds taken by Dr. Bachman at Charleston, South Carolina, in July, 1833. Several specimens were subsequently taken in the West Indies during the winter, but over fifty years passed before the speries was again found in the United States. It proves now to be a common bird in parts of its range, and has been found in large numbers near New Orleans, and on the Suwance River in Florida in March and April, and at Key West in late July and August. The nest remained undiscovered until 1897, when it was found by Widmann in Missouri, and it has since been found by Embody in Kentucky and Wayne in touth Carolina.

Mr. Brewster and myself had exeellent opportunities to study its habits on the Suwance River, and in The Auli for 1S!91, pp. 149-157, will be found a detailed account of our observations written hy Mr. Brewster. It was migrating with other II:arhlers, and kept to the topps of the highest trees, but in its breceling haunts it proves to be a lowranging bird like most of the members of this genus. Its moxements are rather leisurely, and resemble those of $V$. primss or $V$. colale. Its song is described by Brewster as resembling that of the Parula $W$ arbler.

641. Vermivora pinus (Limn.). BLte-WIN(Fen WarnLer. (Fig. 116.) Ad. $\sigma^{7}$.-Crown and entire underparts bright yollow, a black line through the 
eye; back and rump bright olive-green; wings and tail bluish gray; greater and middle wing-coverts tipped with white or yellowish white; outer three tail-feathers with large white patches on their inner webs, fourth feather with a much smaller patch. Ad. o.- Similar, but yellow on the head confined to the forehead; underparts duller. L., $4 \cdot 80$; W., $2 \cdot 40$; T., $1 \cdot 80$; B. from N., 33 .

Remarks. - The only variation of note in the plumage of otherwise typical specimens of this species occurs in the color of the wing-bars, which in some specimens are tinged with yellow. A specimen in Mr. Brewster's collection (No. 25,511, Seymour, Conn., June 11, 1889, E. A. Eames) shows this variation carried to an extreme, and has the wing-bars as broadly yellow as in $V$. chrysoptera, though in every other respect it is typical pinus. Between this species and $V$. chrysoptera there exists a complete set of intergrades; which are variously called $V$. leucobronchialis and $V$. lawrencei. They are generally considered to be hybrids, and it has also been suggested that dichromatism may aid in producing their coloration. Their relationships will be found discussed under the following references: Brewster, Bull. Nutt. Orn. Club, 1881, 218; Ridgway, Auk, 1885, 359; Manual N. A. Birds, 486; Chapman, Warblers of N. A., 74; Faxon, Memoirs Mus. Comp. Zoöl., 1911, No. 2.

Range.-E. N. Am. Breeds from se. Minn., s. Mich., w. N. Y., Mass. (rarely), and s. Conn. s. to ne. Kans., cen. Mo., Ky. Md., and Del. (casually further s.); winters from s. Mex. casually to Colombia; very rare migrant in se. U. S. s. of Va. and e. of La.; occasional in s. Ont.

Washington, rather uncommon T. V., Apl. 26-May 22; Aug. 13-Sept. 2; a few breed. Ossining, common S. R., May 4-Sept. 7. N. Ohio, common S. R., Apl. 27-Sept. 15. Glen Ellyn, irregular, possibly S. R., May 1-Sept. 15. SE. Minn., uncommon S. R., Apl. 30-Sept. 1.

Nest, of bark and leaves, lined with fine strips of bark and tendrils, and firmly wrapped with numerous leaves, whose stems point upward, on the ground, generally in or at the border of second growth. Eggs, 4-6, white, thinly speckled with rufous, cinnamon-brown, or rufous-brown, ${ }^{\cdot} 62 \times \cdot 50$. Date, Chester Co., Pa., May 22; New Haven, Conn., May 20; Oberlin, Ohio, May 10; se. Minn., May 16 (nest finished).

This species may be found in scrubby second growths, woodland borders, or even the lower trees of dense woods. Its movements are rather slow and leisurely, and, like a Chickadee, it may sometimes be seen hanging head downward while searching for food.

It is a times a rather persistent songster, and its peculiar song is not likely to be mistaken for that of any other Warbler. As a rule, it consists of the two drawled, wheezy notes swēe-chee; the first inhaled, the second exhaled. A less common song, uttered later in the season, is $w \bar{e} \bar{e}, \operatorname{ch} \grave{\imath}-\operatorname{ch} \breve{\imath}-\operatorname{ch} \grave{\imath}-\operatorname{ch} \bar{\imath}, \operatorname{ch} \bar{u} r, \operatorname{ch} \bar{e} \bar{e}-\operatorname{ch} \bar{u} r$, and is sometimes accompanied by peculiar kik notes.

1909. Wright, H. W., Auk, XXVI, 337-345 (nesting in Mass.).

Vermivora leucobronchialis (Brewst.). BREWSTER's WARBLER. $A d$. $\sigma^{3}$.-Forehead and forepart of the crown yellow, a black line from the bill through the eye; rest of the upperparts bluish gray; wing-bars broadly yellow; tail like the back, three to four outer feathers marked with white; underparts pure white, faintly washed with yellow on the breast. Fall specimens are more heavily washed with yellow, and the upperparts are margined with olive-green. Ad. $\%$.- Similar, but wing-bars white, and crown not so bright.

Remarlss.-The descriptions are from typical specimens of the puzzling bird known as Vermivora leucobronchialis. Between it and $V$. pinus there are specimens showing every degree of intergradation. Typical examples are comparatively rare, and the most common form has the breast heavily washed with yellow, the back tinged with olive-green, and the white wing- 
bars washed with yellow; in other words, about intermediate between typical leucobronchialis and typical pinus.

This hybrid between pinus and chrysoptera or color phase of pinus, has been found in Louisiana, from Virginia northward to Connecticut, and as far west as Michigan, Its breeding range apparently coincides with the northern portion of that of pinus. Upward of one hundred and fifty specimens, representing typical leucobronchialis and various phases of its intergradation with pinus are known, and in the Connecticut River Valley the bird is stated to be more frequent than chrysoptera. In general habits it resembles both pinus and chrysoptera. Some individuals sing like the former, some like the latter, while others have notes of their own. The significant facts in the bird's interesting and puzzling history are given in the Warblers of North America, pp. 72-77, and by Faxon in the Memoirs Mus. Comp. Zoöl., 1910, XL, pp. $57-78$.

Vermivora lawrencei (Herrich). LAWRENCE's WARBLEk. Ad. o - Forehead and forepart of the crown yellow, rest of the upperparts bright olive-green; wing-bars white; tail bluish gray, the three to four outer feathers marked with white; a black patch on the check divided by a yellow line from the black patch on the throat and upper breast; lower breast and belly yellow, under tail-coverts white. $A d$. o.-Forchead dingy yellow, rest of the upperparts bright olive-green; wing-bars white, tinged with yellow; tail as in the $\sigma^{7}$, black patches of the $\sigma^{7}$ replaced by dusky olive-green.

Remarks. - This bird combines the characters of pinus and chrysoptera; it has the black cheek-patches and breast-patch of the latter, but in other respects resembles the former, and is doubtless a hybrid between the two. Its history and a discussion of its relationships will be found under the references given above. It is a much rarer bird than Brewster's Warbler, and less than a score of specimens have been recorded.

The bird resembles Brewster's Warbler in haunts and habits, and, like that puzzling bird, it sings like both pinus and chrysoptera.

642. Vermivora chrysoptera (Linn.). Golden-WINGED WARBler. (Fig. 117.) $A d$. $\sigma^{7}$-Crown bright yellow; rest of the upjerparts bluish gray, sometimes washed with greenish; a large black patch about the eye, separated from another on the throat by a white stripe; a white line over the eye; wings and tail bluish gray; tips of middle wing-coverts and outer werbs of greater ones bright yellow, forming a large yellow patch on the wing; outer three tail-feathers with laree white patches on thrir inner wets at the tip, fourth feather with a smaller pateh; lower breast and belly white; sirles grayish. Ad. 9.- Similar, but the crown and upperparts duller, the pateh on the sides of the head and throat grayish instearl of hlark. L., 5.10; W., $2 \cdot 46$; T., 1.94 ; B. from N., 34 .

Range.-E. N. Am. Breeds in Alleghanian falna from een. Minn., s. Ont., and Mass. s. to s. Iowa, n. Ills., n. Ind., n. N. J., and n. (ia.; winters from Guatemala to Colombia, and risually in s. Mex.; very rare in Fla., and s. Ga.; accidental in Man.

Washington, uncommon T. V., May 1 30); Aug. \& 21. Osiniug, rare S. R., May 8-Aug. 25. ('ambringe, rather common \&. R., May 12 . Iug. 25. N. Ohio, rare T. V. Gilen Ellyn, irregular, not common T. V., May 4 18; Aug. 16-Sept. 24. SE. Minn., common S. R., May is Sept. ?).

Nest, much like that of $V$. pirus, on or near the ground, in second growths or bushy ficlds. Eggs, 4-i), white, sperekled and spotterd, chiefly about the larger end, with cinnamon-brown, chestuut, or umber, $62 \times{ }^{\circ} 50$. 
Date, Buncombe Co., N. C., May 16; Bethel, Conn., May 29; Monroe Co., Mich., May 17.

In their actions and choice of haunts the Golden-winged resemble the Blue-winged Warblers. Their song is of much the same quality, but the notes are all of the same kind and length, and the bird utters a rather lazy zee-zee-zee-zee, at once distinguishable from the song of pinus.

645. Vermivora rubricapilla rubricapilla (Wils.). NASHVILLE WARBLER. Ads.-Top and sides of the head bluish gray, a partially concealed chestnut patch in the center of the crown; back and rump bright olive-green; wings and tail edged with the same and without white; underparts bright yellow, whiter on the belly. Im.-Upperparts dull olive-green, more or less washed with brownish; crown-patch often absent; rump brighter; wings and tail as in the ad.; sides of the head brownish ashy, eye-ring white; underparts yellowish, brighter on the breast; sides brownish. L., $4 \cdot 77$; W., $2 \cdot 33$; T., $1 \cdot 81 ;$ B. from N., 28 .

Range.-E. N. Am. Breeds in Canadian and Transition zones from s. Sask., n. Ont., cen. Que., and Cape Breton Is. s. to Nebr., n. Ills., n. Pa., n. N. J., and Conn.; winters from Vera Cruz to Guatemala; very rare on the Atlantic slope s. of Chesapeake Bay.

Washington, uncommon T. V., Apl. 28-May 19; Sept. 5-Oct. 2. Ossining, tolerably common T. V., May 7-27; Aug. 11-Oct. 4; may breed. Cambridge, rather common S. R., May 5-Sept. 15 ; abundant T. V. N. Ohio, common T. V., Apl. 28-May 27; Sept. 1-Oct. 16. Glen Ellyn, regular T. V., Apl. 27-May 25; Aug. 20-Oct. 19. SE. Minn., common S. R., May 1Sept. 29.

Nest, of grasses and moss, lined with finer grasses and fine, hairlike rootlets, on the ground, in partial clearings or tree-grown pastures. Eggs, 4-5, white, thickly speckled, chiefly at the larger end, with rufous or cinnamonbrown, $61 \times \cdot 48$. Date, Cambridge, May 25; Lancaster, N. H., May 25; Bangor, Maine, June 3; Detroit, Minn., May 30.

This Warbler is an inhabitant of rather open woodland, young second growth, or tree-bordered fields. In addition to the usual chip, it has a sharp, characteristic call-note, while its song is about as likely to attract attention as that of the Chestnut-sided Warbler. Thayer ("Warblers of North America") writes: "The Nashville has at least two perch-songs and a flight-song, all subject to a good deal of variation.

Its commoner perch-song consists of a string of six or eight or more, lively, rapid notes suddenly congested into a pleasant, rolling twitter. . . In the other perch-song, the notes of what correspond to the rolling twitter are separate and richer, and the second part of the song is longer and more noticeable than the first whose notes are few and slurred, while the whole is more languidly delivered. . . . The flight-song, a fairly common performance in late summer, is sung from the height of five to forty feet above the (usually low) tree tops. It is like the commoner perch-songs, but more hurried, and slightly elaboraated,- - often with a few chippings added at both ends."

1910. Stanwood, C. J., Jour. Me. Orn. Soc. XII, 28-33 (nesting).

646. Vermivora celata celata (Say). ORANGE-CROWNED WARBLER. Ads.-Upperparts rather ashy olive-green; feathers of the crown orangerufous at the base; wings and tail edged with olive-green and without white; 


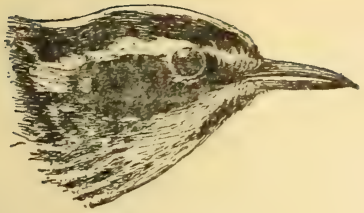

FIG. 114. Black and White Warbler.

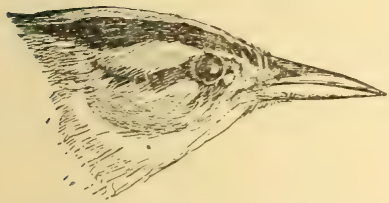

Frg. 115. Worm-eating Warbler.

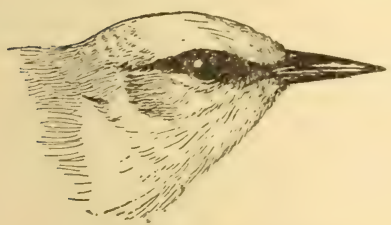

Frg. 116. Blue-winged Warbler.

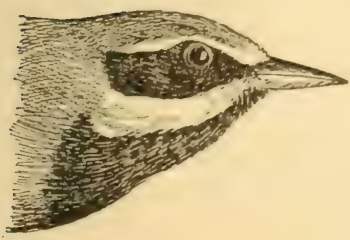

Fig. 117. Golden-winged Warbler.

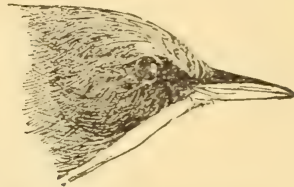

FIG. 118. Parula Warbler.

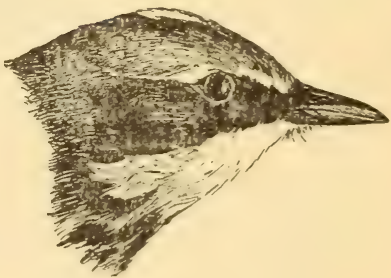

FIG. 119. Myrtle Warbler.

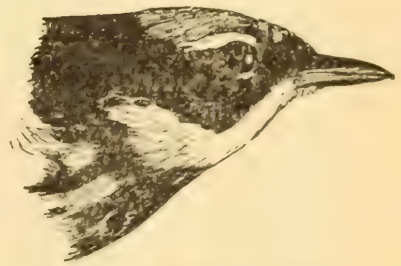

FIg. 120. Magnolia Warbler.

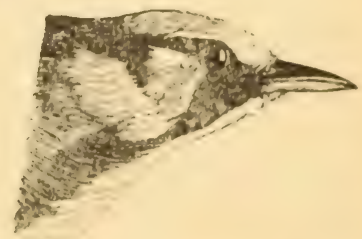

Fig. 121. Clyestmut-sided Warbler.

Figs. 114-121. Heads of Warbiers. (Natural size.) 
eye-ring yellow; underparts greenish yellow, obscurely streaked with dusky on the breast. Im.- Similar, but without orange-rufous in the crown; upperparts more ashy; underparts duller; eye-ring white. L., 5•00; W., 2.50; T., $1 \cdot 95$; B., from N., 31 .

Range.-Cen. N. Am. Breeds in lower Hudsonian and Canadian zones from Kowak River, Alaska, se. to cen. Keewatin and Man., and s. locally in the Rocky Mts. to N. M.; winters in the Gulf and S. Atlantic States to S. C., and s. through Mex. to Mt. Orizaba; rare in migration along the Atlantic slope from New Hampshire southward.

Washington, casual T. V., two records, Oct. Ossining, A. V. Cambridge, rare T. V., in fall, Oct. 5-Nov. 15. N. Ohio, rare T. V., Apl. $27-$ May 21. Glen Ellyn, not common T. V., May 1-21; July 28-Oct. 7. SE. Minn., common T. V., Apl. 25- ; Aug. 18-Oct. 16.

Nest, of leaves and fine grasses, on or near the ground. Eggs, 4-5, white, with specks or spots of cinnamon-brown or rufous, more numerous at the larger end, ‘63 × 49 . Date, St. John's, N. B., June 9 (Thayer Coll.).

Orange-crowned Warblers are rare in the Atlantic States north of South Carolina. In Florida, where they are common in the winter, they evidently prefer the densely foliaged live and water oaks. Their sharp chip is sufficiently characteristic to be recognized after one has become thoroughly familiar with it. Their song, which I have never heard, is described by Colonel Goss as consisting of "a few sweet trills uttered in a spirited manner, and abruptly ending on a rising scale."

647. Vermivora peregrina (Wils.). TenNessee WARBLER. (Fig. 70a.) $A d$. $\sigma^{x}$. - Top and sides of the head bluish gray, sharply defined from the bright olive-green back and rump; wings and tail edged with olivegreen; no white wing-bars; inner margin of inner vane of outer tail-feathers generally white at the tip; underparts white, sometimes tinged with yellow. Ad. ․- Similar, but crown tinged with greenish and underparts washed with yellowish. Im.-Upperparts uniform olive-green; underparts washed with yellowish; under tail-coverts white. L., 5.00; W., 2.63; T., 1.69; B. from N., '32.

Remarks. - The adults of this and the two preceding species may be distinguished with ease; immature birds, however, are frequently confused. The Nashville is distinctly yellow on the breast and under tail-coverts; the Orange-crowned is pale greenish yellow, with dusky streaks and yellow under tail-coverts; the Tennessee is pale greenish yellow, without streaks, and with the under tail-coverts white.

Range.-E. N. Am. Breeds in Canadian zone from upper Yukon Valley, s. Mackenzie, cen. Keewatin, s. Ungava, and Anticosti Is. s. to s. B. C., s. Alberta, Man., n. Minn., Ont., N. Y. (Adirondacks), n. Maine, and N. H.; winters from Oaxaca to Venezuela; in migration occurs mainly in the Miss. Valley, rare on the Atlantic slope; occasional in Fla. and Cuba.

Washington, T. V., rare in May; occasionally common, Aug. 31-Nov. 30. Ossining, rare T. V., May 22-27; Aug. 22-Oct. 2. Cambridge, rare T. V., May 15-25; Sept. N. Ohio, common T. V., May 4-25; Sept. 10-Oct. 10. Glen Ellyn, common T. V., Apl. 30-June 6; July 29-Oct. 9. SE. Minn., common T. V., Apl. 30 - ; Sept. 30 - .

Nest, of fine hempen fibers, grasses, and moss, lined with hair, in low bushes near the ground. Eggs, pearly white, with a circle of brown and purplish spots about the larger end, $60 \times{ }^{5} 50$ (B., B., and R.). Date, S. Lewiston, Maine, June 4.

"The Tennessee is easily discovered and identified by its peculiar song-a twittering, semi-trilled, rather prolonged utterance of three parts, not very unlike the weaker and buzzier strains of the American 
Goldfinch's song" (Thayer in "Warblers of North America"). Bradford Torrey says the Tennessee's song "is more suggestive of the Nashville's than of any other, but so decidedly different as never for a moment to be confounded with it," and adds a detailed description ("The Footpath Way," p. 8).

648. Compsothlypis americana americana (Linn.). PARULA $W_{A R-}$ BLER. Similar to $C$. a. usnece but with less black about the lores, throat in $\sigma^{7}$ with more yellow, the blackish throat band very narrow or poorly defined. o not distinguishable from $\%$ of usnea. Smaller than specimens of usnece from the northern Atlantic States; larger than specimens of usnece from the lower Mississippi valley. W., $2 * 25$; T., 1.60 ; B., 38 ("Warblers of North America").

Range.-SE. U. S. Breeds in Austral zones from the Dist. of Col. s. to Ala. and Fla.; winters probably in Fla. and n. West Indies.

Washington, T. V., and a few breed, Apl. 19-Oct. 16.

Nest, generally in bunches of Tillandsia. Eggs, 4-5, white, with rufous markings, chiefly in a wreath about the larger end, $66 \times \cdot 47$. Date, Mt. Pleasant, S. C., Apl. 15; Iredell Co., N. C., May 11.

In Florida the Parula's notes mark the beginning of a new ornithological year, and its song is associated in my mind with the beauties of a southern spring when the cypresses are enveloped in a haze of lacelike blossoms, and the woods are fragrant with the delicious odor of yellow jasmine. Then the dreamy softness of the air is voiced by the Parula's quaint, drowsy, little gurgling sizzle, chip-er, chip-er, chip-er, chee-ee-ee-ee. The abundance of the Tillandsia 'moss' furnishes the Parula with unlimited nesting-sites, and the bird is proportionately common.

648a. C. a. usneæ Brewst. Northern Pardla Warbler. (Fig. 118.)

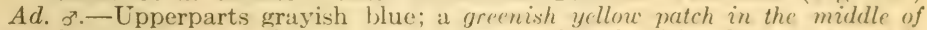
the back; greater and lesser wing-coverts tipped with white; outer tailfeathers with a white patch near the end; throat and hreast yellow, more or less marked with pale rufous, a bluck, or bluish black, or rufous band across the breast; belly white; sides sometimes marked with rufous. Ad. p.Similar, but the rufous color and band on the breast sometimes absent. Im.-Resembling the o. L., 4.7:3; W., 2.40; T., $1 \cdot 76$; 13 . from N., 32.

Range.-E. U. S. Breeds mainly in Transition and Austral zones from e. Nebr., n. Minn., cen. Ont., Anticrsti Is. and Cajpe Breton Is. s. to cen. s. Tex., s. La., Ala., Va., and Md.; winters probably in the Bahamas and West Indies, and from Vera Cruz to Nicaragua.

Washington, T. V., but dates not distinguishable from those of americana. Ossining, common T. V., May 2-24; Fept. 21-Oet. 7. Cambridge, common T. V., May 1-2x; Sept. 10-30. N. Ohis, not common T. V.. May 1-18. Glen Ellyn, not common T. V., May 3-2x; Aug. 25-0)t. 1. SE. Minn., common T. V., May 5-Sept. 9.

Nest, in a bunch of Usner 'moss.' Eggs, similar to those of the preceding. Date, New Haven, May 1s; Lancister, N. H., May 31; Ann Arbor, Mich., May 12.

This slightly differentiated form of the Parula Warbler resembles the southern race in song and habits. During its migrations it is gonerally distributed, preferring, however, deciluous to coniferous growths, but when nesting it selects only localities where is found the Lisnea moss in which it builds. 
650. Dendroica tigrina (Gmel.). CAPE MAY WARBler. (Fig. 4.) Ad. $0^{7}$.-Crown black, slightly tipped with greenish; ear-coverts rufous, bounded behind by a large yellow patch on the side of the neck; back olivegreen, broadly streaked with black; rump yellow or greenish yellow; a large white patch on the wing-coverts; outer tail-feathers with a large white patch on their inner webs, near the tip; underparts yellow, heavily streaked with black; lower belly and under tail-coverts whitish. Ad. o.- Upperparts grayish olive-green; crown with more or less concealed black; rump yellowish; a yellow line over the eye; middle wing-coverts with narrow white tips; outer tail-feathers with a white patch on their inner webs near the tip; underparts yellow, streaked with black; belly and under tail-coverts whiter. $I m$. $\sigma^{7}$.- Resembles the $q$, but the wing-coverts have more white. Im. $q .-$ Similar to ad. $\%$, but with little or no yellow on the underparts; upperparts duller, and more uniform in color. L., 5.00 ; W., $2 \cdot 61$; T., $1.88 ;$ B. from N., $\cdot 30$.

Range.-E. N. Am. Breeds in Canadian zone from s. Mackenzie, $\mathbf{n}$. Ont., N. B., and N. S. s. to Man., n. Maine, and N. H., and in Jamaica (?); winters in the Bahamas and the West Indies to Tobago.

Washington, sometimes very common, usually uncommon T. V.; May 120; Aug. 4-Oct. 17. Ossining, tolerably common T. V., Aug. 20-Oct. 1. Cambridge, rare T. V., May 15-25; Aug. 25. N. Ohio, not common T. V., May 4-18. Glen Ellyn, irregular T. V., Apl. 30-May 21; Sept. 8-15. SE. Minn., common T. V., May 8.

Nest, partially pensile, of twigs and grass fastened with spiders' webbing, lined with horsehair, on a low branch of a small tree in pasture or open woodland. Eggs, 3-4, dull white or buffy, slightly speckled, and wreathed around the larger end with spots of brown and lilac, $\cdot 70 \times \cdot 50$ (Chamberlain). Date, St. John's, N. B., June 16.

During its migrations this generally rare Warbler may be found associated with its wood-inhabiting congeners and it also frequents the coniferous trees of our lawns. In the summer it haunts the higher branches of coniferous trees. Gerald Thayer (in "Warblers of North America") writes of its song: "The whole utterance, in tone phrasing and accentuation, strongly suggests the Black and White Warbler's shorter song. . . . On the other hand, the Cape May's singing is near akin to the Blackpoll's."

652. Dendroica æstiva æstiva $\left(G m e l\right.$.). Yellow WARBLER. Ad. $\sigma^{7}$.Upperparts bright greenish yellow, brighter on the crown; wings edged with yellow; tail fuscous, the inner vanes of the feathers yellow; underparts bright yellow, streaked with rufous. $A d$.. .- Upperparts uniform yellowish olivegreen; tail as in the $\sigma^{7}$; wings fuscous, edged with yellow; underparts bright yellow, slightly, if at all, streaked with rufous on the breast and sides. Im. $\sigma^{\text {. }}$. - Similar to the o. Im. \%.-Upperparts light olive-green; tail fuscous, the inner margins of the inner vanes of the tail-feathers yellow; underparts uniform dusky yellowish. L., $5 \cdot 10 ;$ W., $2 \cdot 40 ;$ T., $1 \cdot 89 ;$ B. from N., 33 .

Remarks.- In any plumage this bird may be known by the yellow on the inner vanes of the tail-feathers.

Range.-N. A. Breeds from Hudsonian through Upper Austral zone in N. A. e. of Alaska and Pacific slope from tree limit s. to Nev., n. N. M., s. Mo., and n. S. C.; winters from Yucatan to Guiana, Brazil, and Peru.

Washington, common S. R., abundant T. V., Apl. 4-Sept. 28. Ossining, common S. R., Apl. 30-Sept. 27. Cambridge, abundant S. R., May 1-Sept. 15. N. Ohio, abundant S. R., Apl. 14-Sept. 10. Glen Ellyn, not very common S. R., Apl. 30-Sept. 6. SE. Minn., common S. R., Apl. 28-Sept. 10.

Nest, of fine grasses and hempen fibers, with a conspicuous amount of plant-down, lined with plant-down, fine grasses, and sometimes long hairs, in the shrubs or trees of lawns or orchards, about water, etc. Eggs, 4-5, bluish 
white, thickly marked with cinnamon- and olive-brown, with frequently a wreath about the larger end, $70 \times \cdot 50$. Date, Waynesburg, Pa., May 14; New Haven, Conn., May 20; Cambridge, May 23; Lancaster, N. H., June 7; Black Hawk Co., Iowa, May 19; se. Minn., May 24.

When any one tells me he has seen a "Wild Canary," I feel reasonably sure he refers to the Yellow Warbler, for the casual observer at once betrays his inexperience by entirely overlooking the bird's streaked breast and slender bill. It has, it is true, the general appearance of a yellow bird, and its bright colors and preference for gardens, orchards, the shrubbery of our lawns or bushy brooksides, instead of the woods, frequently bring it to the attention of those to whom most birds are strangers. It is an active bird, and its song-wee-chee, chee, chee, cherwee-though simple, has a pleasing, happy ring.

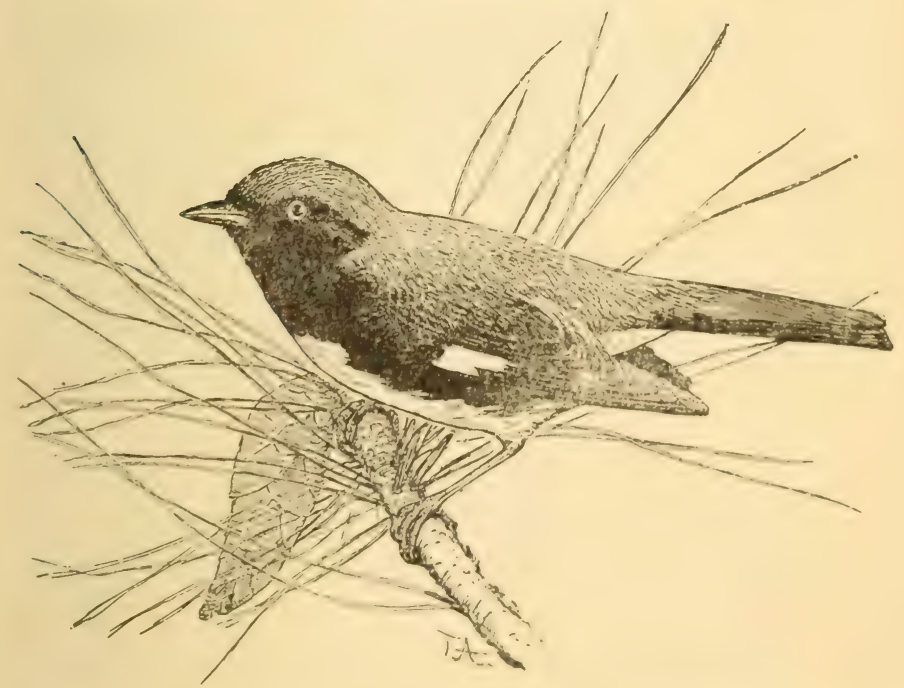

Fic. 122. Black-throated Blue Warbler. (Reduced.)

654. Dendroica eærulescens carulescens (GMil.). IBLACK-THROATFI)

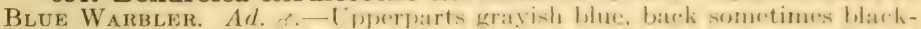
ish; wings and tail erlerel with hlue; besse of ller mrimarirs while, forming : white spot on the wing at the end of the primary erverts; inmer vitures of outer tail-feathers with a white patch near their tips; sides of the head and throat black: sides mixed hlark and whife: hreast and belly white. Ad. . Upperparts uniform olive-gresn; tail generally with a faint bluish tinge, the white pateh on the outer feathers seareely distinguishable: white at the base of the primaries much redured and sometimes enneealed by the primary coverts: ear-coverts dusky gray: underparts soiled buffy yellowish. Im. o- - Similar to ad. 3, but the nuperparts washed with gresnish, the throat tipped with white, and less hlark on the sirles. Im. 2.- cimilar to ad. $\%$, but somewhat yellower. L., $5 \cdot 2 x$; W., $2 \cdot 52 ;$ T., $2 \cdot 06$; B. from N., 29 . 
Remarks.-The white spot at the base of the primaries is the distinguishing mark of this species.

Range.-E. N. Am. Breeds in Canadian and Transition zones, from $\mathbf{n}$. Minn., cen. Ont., and ne. Que. s. to cen. Minn., s. Mich., s. Ont., Pa. (mts.), and n. Conn.; winters from Key West, Fla., southward; in migration casually to N. D., Nebr., Kans., Colo., and N. M.; accidental on the Farallon Islands.

Washington, very common T. V., Apl. 19-May 30; Aug. 4-Oct. 9. Ossining, common T. V., Apl. 25-May 28; Aug. 26-Oct. 10. Cambridge, rather common T. V., May 10-25; Sept. 20-Oct. 10. N. Ohio, common T. V., Apl. 27-May 29; Sept. 5-Oct. 16. Glen Ellyn, common T. V., Apl. 29-May 29; Aug. 25-Oct. 10. SE. Minn., uncommon T. V., May 11.

Nest, of strips of bark, fine grasses, and pine needles, lined with hairlike black rootlets, in the heavier undergrowth of dense woods, usually within two feet of the ground. Eggs, 3-5, grayish white, with distinct and obscure olive-brown markings, chiefly about the larger ends, ${ }^{\circ} 68 \times{ }^{\circ} 50$. Date, Litchfield, Conn., June 8; Lancaster, N. H., June 19; Kalamazoo Co., Mich., May 29.

Where the range of this species reaches the Canadian zone, it nests in coniferous forests, but southward its summer home is in deciduous woods, always, however, with a dense undergrowth. Its call-note is a sharp, recognizable chip, its common song may be written zwee-zweezwee, but it is subject to much variation, indeed Thayer (in "Warblers of North America") describes three additional songs.

The male Black-throated Blue Warbler can be identified at sight, but his obscurely colored mate has been the cause of many a field student's neckache. When flitting about with other Warblers it is difficult to observe any positive character by which to distinguish her; but the white spot at the base of the primaries is an unmistakable mark, if one can see it clearly.

654a. D. c. cairnsi Coues. CaIrn's WArbler. Similar to D. c. carulescens but or with the back always more or less spotted with black, sometimes the center of the back being entirely black. Ad. $\&$ generally darker than of carulescens. While specimens of true ccrulescens not infrequently show more or less black in the back, cairnsi is very rarely without this character.

Range.-Breeds in Canadian and Alleghanian faunas in the Alleghanies from Md. to Ga.; winters in the. West Indies.

655. Dendroica coronata (Linn.). Myrtle Warbler. (Fig. 119.) Ad. $0^{3}$. - A yellow patch on the crown, rump, and each side of the breast; upperparts bluish gray, streaked with black; two white wing-bars; outer tail-feathers with white spots on their inner vanes near the tip; throat white; breast and upper belly heavily marked with black; lower belly white. $A d$. 9.- Similar, but with less black below; breast simply streaked with black; upperparts browner. Im. and ads. in winter.-Yellow crown-patch more or less conecaled by brownish tips to the feathers; rump bright yellow; yellow on the sides of the breast much reduced; upperparts grayish brown, streaked with black; wing-hars grayish; tail with white patches; underparts soiled white, streaked with black. L., $5 \cdot 65$; W., $2 \cdot 85$; T., $2 \cdot 25$; B. from N., " 29 .

Remarks. - The vellow patches on the crown, rump, and sides of the breast are characteristic of this species.

Range.-N. A. except w. U. S. Breeds in Hudsonian and Canadian zones from tree limit in nw. Alaska, n. Mackenzie, cen. Keewatin, and cen. Ungava s. to n. B. C., s. Alberta, n. Minn., n. Mich., cen. Ont., N. H., and Maine, and mts. of N. Y., Vt. and Mass.; winters from Kans., Ohio Val- 
ley, and N. J. (locally s. New England) s. to the Greater Antilles, Mex., and Panama, and on the Pacific coast from cen. Ore. to s. Calif.; accidental in Greenland and e. Siberia.

Washington, abundant W. V., Aug. 7-May 23. Ossining, common T. V., Apl. 13-May 28; Aug. 16-Nor. 11; a few winter. Cambridge, abundant T. V., Apl. 12-May 20; Sept. 1-Yor. 1; a few winter. N. Ohio, common T. V., Apl. 12-May 20; Sept. 15-Nor. 3. Glen Ellyn, common T. V., Apl. 8-May 28; Sept. 25-Dec. 29. SE. Minn., common T. V., Apl. 6- ; Sept. 9-Oct. 28.

Nest, of vegetable fibers lined with grasses, in coniferous trees 5-10 feet up. Eggs, 4-5, white or grayish white, distinctly and obscurely spotted and speckled or blotched with olive-brown or rufous-brown, $70 \times \cdot 52$. Date, Bangor, Maine, May 30; Kentville, N. S., May 29.

These strong, hardy Warblers leave their cousins of the woods and in loose companies forage in old fields and scrubby growths among the bayberry or myrtle (Myrica) bushes, which bear their favorite food. So fond are they of these berries that their movements are largely governed by the success or failure of the bayberry crop. Near my home at Englewood, N. J., Myrtle WTarblers are always common during the winter if there is an abundance of bayberries and always absent when the berries are wanting.

No Warbler is more easily identified than this bird with its four distinct patches of yellow. The yellow rump is conspicuous in life, and, in connection with the bird's characteristic tchep, forms an excellent field-mark. It begins to sing on its spring migrations a bright, cheery trill suggesting the song of the Junco.

Audubon's Warbler (656. Dendroica auduboni auduboni), a species of the Western States, has been recorded once from Massachusetts and once from Pennsylvania.

657. Dendroica magnolia (Wils.). Magnolia Warbler. (Fig. 120.)

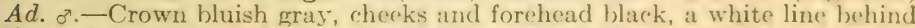
the eye; back black, bordered with olive-green, a large white patch on the wing-eoverts; rump yellow, tail black, inner vanes of all but the central feathers with white patches on their middle, the end third of the feather being entirely bleck; throat yollow, breast and sides heavily streaked with black. Ad. o. - Similar, but with the colors duller and less sharply defined; back greener. Ads. foll and im. -Top and sides of the head ashy; hatek olive-green, with nearly concealed black spots: two narrow wing-bars; rump yellow, tail as in the adults; underparts yollow; whiter on the belly; sides with black streaks. Im. 2.- Cimilar, but no black streaks abowe, those on sides barely evident. L., 5.12: W., 2.30; T., 2.(0); I3. from ..., 30.

Remarks. - In any plumage this bird may be known by the white patehes on the tail being near the middle insteatl of at the tip of the feathers.

Range.-E. N. Am. Breeds in C'anarlian and upper Transition zones from sw. Mackenzie (casually (ireat Bear Lake), s. Kerewatin, n. (une, and N. F. s. to cen. Alberta, s. Sask., Minn., n. Mird., and n. Mass., and in the mts. of W. Va., MIrl., Pa., and N. Y': winters from s. Mex. to P'anama.

Washington, common T. V., Apl. 22-May 30) Aug. 15-Oct. 6. ()ssining, common T. V., May 9-28; Aug. 13-0et. 11. (ambridge, T. V., rather common, May 12-25; not uneommon, siept. 10-25. N. (ohio, common T. V Apl. 28-May 27; Sept. 1-Oct. 10. (ilen Eillyn, common T. V., May 3-June 5; Aug. 12-Oct. 9. sE. Minn., common T. V., Mity 6; ; Aug. 12 sept. 9.

Nest, of fine twigs, leaf stems, etc., linerd with hairlike rontlets, in enniforous trees, usually 3-6 feet up. Eggs, 3-5, white, marked with cinnamon- and 
olive-brown, chiefly in a wreath about the larger end, $66 \times 48$. Date, Branchport, N. Y., June 2; Lancaster, N. H., May 24.

Adult Magnolia Warblers are so distinctly marked that ordinarily they may be identified at sight. Immature birds are less strikingly colored, but in any plumage the species may be known by having the white tail-spots nearer the middle than the ends of the feathers. Seen from below, the birds thus appear to have a white tail broadly banded with black.

The Magnolia's summer home is among the spruces and hemlocks. Its typical song, which is of somewhat the same character as that of the Yellow Warbler, is described by Thayer (in "Warblers of North America") as a "peculiar and easily remembered: weeto weeto weeeétee-eet,or witchi, witchi, whichi tit, 一the first four notes deliberate and even and comparatively low in tone, the last three hurried and higher pitched, with decided emphasis on the antepenult weet or witch."

1910. Stanwood, C. J., Auk, XXVII, 384-389 (nesting).

658. Dendroica cerulea (Wils.). Cerdlean Warbler. Ad. $\sigma^{7}$.Upperparts bright cerulean blue, the sides of head and back streaked with black; wings and tail edged with blue; two white wing-bars; inner vanes of all but the central tail-feathers with white patches at their tips; underparts white, a bluish black band across the breast; sides streaked with bluish black. Ad. \%.-Upperparts bluish olive-green; wings and tail much as in the $\sigma^{7}$; underparts white, generally more or less tinged with pale yellow. Im.-Similar to ad. o, but yellower. L., $4 \cdot 50 ;$ W., $2 \cdot 65 ;$ B. from N., 31 .

Range.-E. N. Am. Breeds mainly in Austral zones from se. Nebr., se. Minn., s. Mich., s. Ont., w. N. Y., w. Pa., and W. Va. s. to ne. Tex., La., and cen. Ala. and locally in w. N. C., w. Va., e. Md., and cen. Del.; winters from Panama to Peru; in migration straggles to N. Mex.; Colo., R. I., Conn., N. J., and e. Pa.

Washington, several records in May, one in fall. N. Ohio, common S. R., Apl. 29-Sept. 20. Glen Ellyn, not common, local S. R., May 8-Aug. 19. SE. Minn., rare S. R.

Nest, of fine grasses bound with spiders' silk, lined with strips of bark and fine grasses and with a few lichens attached to its outer surface, in a tree, 25-50 feet from the ground. Eggs, 3-4, creamy white, thickly covered with rather heavy blotches of reddish brown, $60 \times 47$ (Allen, Bull. Nutt. Orn. Club, IV, 1879, 26). Date, Oberlin, Ohio, May 15; Ann Arbor, Mich., May 20.

In writing of this species as observed by him in Ritchie County, West Virginia, Mr. Brewster says:

"Decidedly the most abundant of the genus here. The first specimen taken May 5. They inhabit exclusively the tops of the highest forest trees, in this respect showing an affinity with $D$. blackburnia. In actions they most resemble $D$. pensylvanica, carrying the tail rather high and having the same 'smart bantamlike appearance.' Were it not for these prominent characteristics they would be very difficult to distinguish in the tree tops from Parula $[=$ Compsothlypis $]$ americana, the songs are so precisely alike. That of the latter bird has, however, at least two regular variations: in one, beginning low down, he rolls his guttural little trill quickly and evenly up the scale, ending apparently only when he can get no higher; in the other the commence- 
ment of this trill is broken or divided into syllables, like zee, zee, zee, $z e-e e-e e-e e p$. This latter variation is the one used by $D$. caerulea, and I could detect little or no difference in the songs of dozens of individuals. At best it is a modest little strain and far from deserving the encomium bestowed upon it by Audubon, who describes it as 'extremely sweet and mellow;' decidedly it is neither of these, and he must have confounded with it some other species. In addition to the song they utter the almost universal Dendroicine lisp and also the characteristic tchep of $D$. coronata, which I had previously supposed entirely peculiar to that bird."

659. Dendroica pensylvanica (Linn.). CHestnut-sided WARBLER. (Fig. 121.) $A d$. $\sigma^{3}$.-Crown bright yellow, a black line behind the eye; front part of the cheeks black; ear-coverts white; back streaked with black and margined with bright olive-green; wing-bars yellowish white; tail black, the outer feathers with white patches on their inner vanes at the tip; underparts white, the sides chestnut. Ad. o.- Similar, but somewhat duller in color. Ad. in fall and im.-Very different; upperparts bright yellowish olive-green, back sometimes streaked with black; wing-bars yellowish white; underparts pure, silky white, the sides in ads. with spots or patches of chestnut. L., 5*14; W., $2 \cdot 45 ;$ T., $2 \cdot 00$; B. from N., 29.

Range.-E. N. Am. Breeds mainly in the Transition zone from cen. Sask., nw. Man., cen. Ont., and N. F., s. to e. Nebr., Ills., Ind., n. Ohio, n. N. J., and R. I., and s. in the Alleghanies to Tenn., and S. C., and casually in s. Mo. and the Wabash Valley; winters from Guatemala to Panama; in migration casual in Fla., the Bahamas, and s. Mex.

Washington, abundant T. V., Apl. 19-May 30; Aug. 10-Oct. 14. Ossining, tolerably common S. R., May 2-Sept. 24. Cambridge, abundant S. R., May 5-Sept. 10. N. Ohio, T. V., May 2-25. Glen Ellyn, rare S. R., common T. V., May 1-Sept. 26. SE. Minn., common S. R., May 3-Sept. 15.

Nest, of strips of bark, leaf stems, etc., lined with tendrils and rootlets, in bushes, about 3 feet up. Eggs, 4-5, white, with numerous distinet and obscure cinnamon-and olive-brown markings, chiefly in a wreath about the larger end, $69 \times 50$. Date, New Haven, Conn., May 2:3; Cambridge, May 26; Ann Arbor, Mich., May 20; se. Minn., May 29.

When settled for the summer, Chestnut-sided Warblers may be found in second growths, scrubby clearings, or the bushy borders of woodlands. There is a suggestion in their movements of the restless activity of the Redstart, as with drooped wings and slightly raised tail they flit among the lower growth. They have two songs, both of which closely resemble those of the Yellow Warbler, though a practiced ear can at once recognize the song of either.

Adults of this species are too conspicuously marked to be mistaken for any other Warbler, but in the fall have a care in identifying the very differently colored young.

660. Dendroica castanea (Wils.). Bay-BREasten Warblerr. $A d . \sigma^{*}$. -Forehead and checks black, a cream-buff patch on the sides of the nerk; crown chestnut; throat, upper breast, and sides chestnut-rufous; bark hrownish ashy, streaked with black; two white wing-bars, inner vanes of outer tailfeathers with white patches at their tips; lower breast and belly buffy white. Ad. o.-Crown olive-green, streaked with black and with generally some chestnut; rest of upperparts as in the $\sigma^{7}$; underparts buffy white; breast and sides more or less stained with rufous. Ad. in fall and im.-Upperparts bright olive-green, indistinctly streaked with black; wings and tail much as 
in the ads.; underparts white, tinged with cream-buff, especially on the flanks; ads. usually have some concealed chestnut in crown and traces of chestnut on sides. L., $5 \cdot 63 ;$ W., $2 \cdot 95 ;$ T., $2 \cdot 12 ;$ B. from N., $\cdot 30$.

Range.-E. N. Am. Breeds in Canadian zone from nw. Alberta, s. Keewatin, s. Ungava, and N. F. s. to s. Man., n. Maine, and mts. of N. H.; winters in Panama and Colombia; casual in migrations to Mont., S. D., and Tex.; irregular on the Atlantic slope and rare s. of Va.

Washington, sometimes abundant, usually uncommon T. V., May 227; Aug. 29-Nov. Ossining, tolerably common T. V., May 14-28; Aug. 5Sept. 26. Cambridge, rather rare T. V., May 15-25; Sept. 12-28. N. Ohio, common T. V., May 4-23; Sept. 7-Oct. 10. Glen Ellyn, tolerably common T. V., May 8-June 5; Aug. 13-Oct. 4. SE. Minn., uncommon T. V., May 13- ; Aug. 18-Sept. 15.

Nest, of grasses and plant fibers, lined with plant-down and long hairs, in coniferous trees, 5-20 feet up. Eggs, 4-5, white, finely marked, chiefly at the larger end, distinctly and obscurely with cinnamon-, olive-, or rufousbrown, $72 \times \cdot 52$. Date, Bangor, Maine, June 15 .

During its migrations this tastefully marked Warbler is generally uncommon enough to be considered somewhat of a prize, though at irregular intervals it becomes comparatively common. It is said to be much rarer in fall than in spring, but at this season Bay-breasts so closely resemble Black-polls, that it is sometimes difficult to determine specimens, while, in immature plumage, many birds cannot possibly be distinguished in nature.

In the summer the Bay-breasts inhabit the northern coniferous forests, living, it is said, in the tree tops. "In a grouping based on songs, the Bay-breast should stand in a quintette with the Blackburnian, the Black-poll, the Black and White, and the Cape May. . . . The Baybreast's singing, in the spring at least, is the most liquid and inarticulate of the lot and sometimes the loudest" (Thayer in "Warblers of North America").

1909. Stanwood, C. J., Journ. Me. Orn. Soc., 103-110 (nesting).

661. Dendroica striata (Forst.). Black-POLL WARBLER. (Fig. 123.) $A d . \sigma^{7}$-Crown black; ear-coverts white; nape streaked, black and white; back and rump ashy, streaked with black; two white wing-bars; inner vanes of outer tail-feathers with white patches at their tips; underparts white, streaked with black, the streaks most numerous on the sides, and wanting on the middle of the breast and belly. Ad. $\%$-Upperparts olive-green, distinctly streaked with black; wings and tail as in the or; underparts white, tinged with yellow, the breast and sides distinctly streaked with black. Ads. fall and im. Similar to o, but the upperparts are brighter and not distinctly streaked, the underparts yellower and not distinctly streaked. L., $5 \cdot 56 ;$ W., $2 \cdot 92 ;$ T., $2 \cdot 05 ;$ B. from N., 30 .

Remarks. - No two of our Warblers more closely resemble each other than do immature and fall examples of this and the preceding species. There is no difference in the color of the upperparts, but castanea has the underparts tinged with delicate cream-buff, strongest on the flanks, while striata is distinctly yellowish below.

Range.-N. A. Breeds in Hudsonian and Canadian zones from limit of trees in nw. Alaska, to N. F., s. to cen. B. C., Man., Mich., n. Maine, and mts. of Vt. and $\mathrm{N}$. H.; winters from Venezuela to Brazil; migrates through the Bahamas and West Indies. (See Fig. 5.)

Washington, abundant T. V., Apl. 28-June 16; Aug. 31-Oct. 20. Ossining, common T. V., May 7-June 6; Aug. 30-Oct. 16. Cambridge, abundant 
T. V., May 12-June 5; Sept. 8-Oct. 20. N. Ohio, common T. V., May 6June 2; Sept. 1-Oct. 16. Glen Ellyn, common T. V., May 2-June 8; Aug. 23-Sept. 27. SE. Minn., common T. V., May 8- ; Aug. 27- .

Nest, of twigs, moss, rootlets, etc., lined with fine grasses and tendrils, generally in spruce trees, about 6 feet up. Eggs, 4-5, white, more or less speckled and spotted, and generally heavily blotched at the larger end with cinnamon-, olive-, or rufous-brown, $70 \times{ }^{\circ} 54$. Date, Grand Menan, N. B., June 11.

The Black-poll is not the last Warbler to reach us in the spring, but it is usually the last of the transients to leave us, the length of its stay and its abundance making its passage one of the features of the spring migration. In the fall it is even more abundant. Adults and young are now alike in plumage, but they are to be confused only with the much rarer Bay-breasts.

Gerald Thayer (in "Warblers of North America") describes the Black-poll's main song, from which there are many variations, as "a string of six to twelve or more, short, equal and equally-divided sibilant notes, cobweb-thin and glassy-clear,-uttered rather fast; the whole song smoothly swelling in volume to the middle, or the second third, and then smoothly falling off."

662. Dendroica fusca (Müll.). Blackburnian Warbler. Ad. o.Center of the black crown, a line over the eye, patch behind the black ear-coverts, throat, and breast beautiful rich orange; back black, streaked with whitish; wing-coverts white, forming a large white patch on the wing; inner vane of most of the tail-feathers almost entircly white, exeept at the tip; the outer vane of the outer feather white at the base; belly tinged with orange, sides streaked with black. Ad. o.- Resembles the o" but the orange markings are paler, the upperparts are ashy olive-green streaked with black and whitish; the white on the wings and tail is less extensire. $I m . \sigma^{x}$ Resembles the $q$, but has the orange markings dull yellow, the crown-j)atch nearly absent. Im. \%. - Similar to the im. ot, but the yellow markings much paler, nearly buffy, the back browner. L., $5 \cdot 25$; W., $2 \cdot 71$; T., 1.96 ; I3. from N., 31 .

Remarks.-In connection with other markings, the large amount of white in the tail, appearing on even the outer vane of the outer feather, is characteristic of this species.

Range.-E. N. Am. Breeds in lower Canadian and upper Transition zones from Man. and Cape Breton Is. to e'n. Minn., Wisc., n. Mir.h., Mass., and Conn., and in the Alleghanies from Pa. to (ia.; winters from (o)lombia to cen. Peru.

Washington, common T. V., Apl. 30-Junc 3; Aug. 14-Oet. 7. ()ssining, common T. V., May 10-29; Aug. 15-()ct. 15. ('ambridge, T. V., unrommon, May 12-22; rare, Sept. 15-30. N. ()hio, (ommon T. V., Apl. 27 Maty 25; Sept. 1-25. Glen Ellyn, fairly common T. V., May 4-June s; Aug. 12 Sept. 22. SE. Minn., common T. V., May 3- ; Sept. 4.

Nest, of fine twigs and grasses, linerl with grasses and tendrils, in coniforous trees, $10-40$ fert up. Egygs, 4, gravish white or bluish white, distinctly and obscurely spotterd, specekled, and hlotehed with cinnamon-horewn or olive-brown, $68 \times 50$. Date, Branchport, N. Y., May 21 ; Lancaster, N. H., June 4; Kalamazoo Co., Mich., June 2.

The Blackburnian is uncommon enough to make us appreciate his unusual beauty. Coming in May, before the woorls are fully relarl, he seems like some bright-plumaged tropiral bird who has lost his way and wandered to northern climes. The summer is passed among the 
higher branches in coniferous forests, and in the early fall the bird returns to surroundings which seem more in keeping with its attire.

Mr. Minot describes its summer song as resembling the syllables wee-seé-wee-seé-wee-seé (wee-seé-ick), while in the spring its notes may be likened to wee-see-wee-see, tsee-tsee, tsee, tsee, tsee-tsee, tsee, tsee, the latter syllables being on ascending scale, the very last shrill and fine.

663. Dendroica dominica dominica (Linn.). YELLOW-THROATED WARBLER. $A d . \sigma^{7}$. - A yellow line in front of the eye and a white line over it; upperparts gray, forehead blackish; wings and tail edged with grayish, two white wing-bars; outer tail-feathers with white patches near their tips; cheeks and sides of the throat black; a white patch on the side of the neck; throat and breast yellow, belly white, sides streaked with black. $A d$. $\%$. Similar, but with less black on the head, throat and neck. L., $5 \cdot 25 ;$ W., $2 \cdot 60$; T., $2 \cdot 01 ;$ B., 49 .

Range.-E. N. Am. Breeds mainly in Austroriparian fauna from s. Md. and cen. Del. to middle Fla.; winters in s. Fla., Bahamas, and Greater Antilles, and also casually n. to S. C. and in the Lesser Antilles; in migration casually to N. Y., Mass., and Conn.

Washington, rare S. R., rather common in late July and Aug.; Apl. 19-Sept. 4.

Nest, of twigs, strips of bark, and Tillandsia 'moss,' lined with vegetable down, 30-40 feet from the ground, in pines or live-oaks, sometimes in a bunch of Tillandsia 'moss.' Eggs, 4-5, white or grayish white, with numerous distinct and obscure cinnamon- or olive-brown markings, sometimes evenly distributed, sometimes in a wreath at the larger end, $74 \times \cdot 52$. Date, Charleston, S. C., Apl. 2; Raleigh, N. C., Apl. 22.

Some birds are so characteristic of certain places that wherever heard or seen they recall their accustomed haunts. I have only to remember the song of the Yellow-throated Warbler to give form to a mental picture of some tree-bordered stream or bayou in the South. The song bears some resemblance to that of the Indigo Bunting, but has a wilder, more ringing quality. In this respect it suggests the song of Seiurus motacilla. It may be written ching-ching-ching, chicker, cherwee. It is to some extent ventriloquial, and this in connection with the rather deliberate movements of the birds, and the fact that they resort to the upper branches, makes it sometimes difficult to locate the singer.

663a. D. d. albilora Ridgw. Sycamore Warbler. Similar to the preceding, but with a smaller bill and the line in front of the eye white instead of yellow. W., $2{ }^{\circ} 60 ;$ T., $2{ }^{*} 00 ;$ B., ${ }^{\circ} 45$.

Range.-E. cen. U. S. Breeds in Upper and Lower Austral zones of Miss. Valley from se. Nebr., s. Wisc., s. Mich., Ohio, W. Va., and s. N. C. s. to e. Tex. and La.; winters from Puebla, Mex., to Costa Rica; in migration occasional e. to S. C.

"The Sycamore Warbler is a common summer resident in the bottom-lands [of Illinois], where, according to the writer's experience, it lives chiefly in the large sycamore trees along or near the water-courses. On this account it is a difficult bird to obtain during the breeding season, the male usually keeping in the topmost branches of the tallest trees, out of gunshot and often, practically, out of sight, although its presence is betrayed by its loud, very unwarblerlike song" (Ridgway). 
667. Dendroica virens (Gmel.). Black-throated Green WarBLER. $A d$. $\sigma^{x}$ - - Upperparts bright olive-green, back sometimes spotted with black; line over the eye and cheeks bright yellow, ear-coverts dusky; two white wing-bars; inner vanes of outer tail-feathers entirely white, outer web white at the base; throat and breast black; belly white, sometimes tinged with yellow; sides streaked with black. $-A d$. $\circ$. - Similar, but the black of throat and breast more or less mixed with yellowish. Ad. $\sigma^{\circ}$ in fall and im. $\sigma^{\text {? }}$. - Similar to the o, but with more yellow on the chest, the black sometimes being almost entirely hidden or wanting. Im. $\%$.- Similar to ad o, but duller above, black on chest sometimes entirely absent. L., 5.10; W., $2 \cdot 46$; T., 1.99; B. from N., '25.

Remarks. - The bright yellow cheeks of this species, in connection with the large amount of white in the tail, will serve to distinguish it in any plumage.

Range.-N. A. Breeds in lower Canadian and Transition zones from w. cen. and ne. Alberta, s. Man., cen. Ont., ne. Que., and N. F., s. to s. Minn., s. Wisc., n. Ohio, n. N. J., Conn., and L. I., N. Y., and in the Alleghanies s. to S. C. and Ga.; in migration w. to e. Tex.; winters from Mex. to Panama.

Washington, very common T. V., Apl. 22-May 30; Aug. 26-Oct. 21. Ossining, common T. V., Apl. 30-June 3; Sept. 1-Oct. 26; a few breed. Cambridge, abundant, S. R., May 1-Oct. 15. N. Ohio, common T. V., Apl. 25-May 24; Sept. 1-Oct. 16; a few breed. Glen Ellyn, common T. V., Apl. 29-June 6; Aug. 22-Oct. 12. SE. Minn., common T. V., uncommon S. R., Apl. 29-Sept. 22.

Nest, of small twigs and moss, lined with rootlets, fine grasses, and tendrils, in coniferous trees, 15-50 feet from the ground. Eggs, 4, white, distinctly and obscurely spotted and speckled with olive-brown or umber, chiefly at the larger end, $65 \times 46$. Date, New Haven, Conn., May 21; Cambridge, June 5; Grand Menan, N. B., June 14.

When migrating this species joins the ranks of the Warbler army and visits wooded land of almost any kind. When nesting it prefers coniferous forests, where it is a dweller among the tree-tops.

While resembling its congeners in general habits, the song of the Black-throated Green is so unlike their generally humble ditties that the bird seems possessed of more character than they impress us with having. Mr. Burroughs graphically represents its notes by straight lines: - $-\mathrm{V} \longrightarrow$; a novel method of musical annotation, but which nevertheless will aid one in recognizing the bird's song. There is a quality about it like the droning of bees; it seems to voice the restfulness of a midsummer day.

1910. Stanwood, C. J., Auk, XXVII, 289-294 (nesting).

Townsend's Warfler (ffis. Dendroica townsendi), a species of western North America, has been once recorded from Pennsylvania.

670. Dendroica kirtlandi (Baird). Krrtlann's Warmler. Ad. o7.Head bluish gray, sometime's spotted with black; lores and sides of the throat black; back brownish ashy, spotted with black; no white wing-bars; outer tail-feathers with white patehes on their inner webs at the tips; underparts pale yellow; sides streaked and spotted with blark. Ad. ?. - Similar, but lores and cheoks grayish, black streaks less pronemuncerl. Fall sperimens of both sexes are much browner. I., 5.75; W., $2 \cdot 75 ; \mathrm{T} ., 2 \cdot 3() ; \mathrm{I}$. from N., 332 .

Range.-E. N. Am. Breeds in Transition zone in ()scoda, ('rawford, and Poscommon counties, Mich.; winters in the Bahamas as far s. at least as the Caicos Islands; in migration recorded from Minn., Wisc., Ont., Ohio, Ills., Ind., Mo., Va., S. C., Ga.. and Fla. 
Washington, one record, Sept. 25, 1887. N. Ohio, rare T. V., May 9 and 11. Glen Ellyn, one record, May 7, 1894. SE. Minn., one record, Minneapolis, May 13.

Nest, on the ground at the foot of a pine or oak, of soft bark, strips of vegetable fiber, grass, etc., lined with fine grass, pine needles, and hair. Eggs, 3-5, white, speckled with umber, wreathed at the larger end, $\cdot 71 \times \cdot 54$. Date, Oscoda Co., Mich., June 6. (See Wood, Warblers of N. A., 206-209.)

During the summer this, the rarest of North American Warblers, is known only from north central Michigan, while during the winter it appears to be restricted to the Bahamas. In the intervening region it has been reported about thirty-five times; it reaches Florida about April 20 and Michigan about May 15. The return journey is made between August and November.

Aside from its size and color, Kirtland's Warbler may be known by its habit of tail-wagging in which it rivals the Palm Warbler. When migrating it frequents the lower growth and when nesting lives only in high, sandy jack-pine plains. According to Wood (in "Warblers of North America") this Warbler has several distinct songs, "all of which belong to the whistling type and have the clear, ringing quality of the Oriole's."

671. Dendroica vigorsi vigorsi (Aud.). PINE WARBLER. (Fig. 70b.) Ad. $\sigma^{7}$--Upperparts bright olive-green, sometimes washed with ashy; two whitish wing-bars; outer tail-feathers with white patches on their inner vanes near the tip; underparts bright yellow, more or less washed with ashy, turning to white on the lower belly and under tail-coverts; sides sometimes with a few black streaks. Ad. o.- Similar, but upperparts brownish olive-green; underparts soiled whitish; breast tinged with yellow. L., 5:52; W., $2 \cdot 81 ;$ T., $2 \cdot 25 ;$ B. from N., 33 .

Range-E. N. Am. Breeds in Transition and Austral zones from n. Man., n. Mich., s. Ont., s. Que., and N. B. s. to e. cen. Tex., the Gulf States, and Fla.; winters from s. Ills. and coast of Va. to Fla., e. Tex., and Tamaulipas, and casually $\mathrm{n}$. to Mass.

Washington, quite uncommon S. R., Mch. 20-Oct. 29; abundant in fall. Ossining, casual. Cambridge, locally common S. R., Apl. 10-Oct. 20; occasional W. V. N. Ohio, rare T. V.; Apl. 29-May 15. Glen Ellyn, not common T. V., spring records only, Apl. 17-May 24. SE. Minn., common T. V., Apl. 26-.

Nest, of strips of bark, leaves, plant fibers, etc., in pines $10-80$ feet up. Eggs, 4-5, white or grayish white, with numerous distinct and obscure cinnamon-brown to umber markings, chiefly in a wreath or band at the larger end, $70 \times 52$. Date, Raleigh, N. C., Mch. 24; Cambridge, May 20.

True to its name, the Pine Warbler is rarely found outside of pine woods. In the South, where pineries may extend over half a state, it is an abundant and generally distributed bird; in the more northern part of its range it is, from force of circumstances, a local species, occurring only with the pines.

In the winter it is found in small flocks, which may contain a few Myrtle or Palm Warblers, and at this season it lives on or near the ground. In the summer it is more arboreal. Its habit of clinging to the trunk of a tree, or hopping along a limb while searching for insects in crevices in the bark, has given it the misnomer of Pine Creeping 
Warbler. Its song which, in Florida, is often heard in the winter, is a clear, sweet, even trill.

672. Dendroica palmarum palmarum (Gmel.). PALM WARBLer. Ads.-Crown chestnut; back olive grayish brown, indistinctly streaked; rump olive-green; no wing-bars; tail black, the outer feathers with white patches on their inner vanes at the tips: a yellow line over the eve; throat and breast bright yellow; belly soiled whitish, tinged with yellow; sides of the throat, the breast, and sides streaked with chestnut-rufous; under tailcoverts yellow. Ad. in winter and Im.-Crown-cap partly concealed by brownish tips to the feathers and sometimes wanting: line over the eye and eye-ring white; underparts soiled whitish, more or less tinged with yellow; breast streaked with dusky. L., 5*25; W., $2 \cdot 64$; T., $2 \cdot 10$; B. from X., '32.

Range.-Interior N. A. Breeds in Canadian zone from s. Mackenzie (Ft. Simpson) and cen. Keewatin s. and se. to n. Minn.; winters from s. Fla. and the Bahamas to the Greater Antilles and Yucatan; occurs in migration on the Atlantic slope.

Washington, rare T. V., Apl. 22-May 18; Sept. 18-Oct. 11. Ossining, T. V., Apl. 29; Sept. 30-Oct. 12. Cambridge, uncommon T. T.. in fall, Sept."15-Oct. 10. $\mathrm{X}$. Ohio, tolerably common T. V., Apl. 24-iray 20; Sept. 10 to Oct. 16. Glen Ellyn, common T. V., Apl. 23-1Iay 19; Sept. 4Oct. 18. SE. Minn., common T. V. Apl. 23- ; Sept. 17-Oct. 3.

Nesting date, Ft. Resolution, Mack., June 18.

This interior race of the Yellow Palm Warbler is occasionally met with in the North Atlantic States, while in Florida it is much more common than the eastern form. Sometimes the two birds may be seen in the same flock, when the brighter colors of hypochrysea are usually apparent.

672a. D. p. hypochrysea Ridgw. Yellow Palm Warbler. Ads.Crown chestnut; back brownish olive-green: rump olive-green: no white wing-bars; secondaries sometimes tingerd with chestnut; tail edged with olive-green, the outer feathers with white spots on their inner vanes near the tips; line over the eye and eye-ring yollow: underparts entirely hright yellow: sides of the throat, the breast, and sides streakerd with chestmutrufous. Ad. in winter and Im. - ('rown-cap) partly concealed by the brownish tips to the feathers and sometimes wanting: line over the eye and eye-ring yellowish; entire underparts uniform yellow; watherd with ashy: the sides of the throat, the breast, and sides streakerl with chestnut-rufous or dusky. L., $5 \cdot 43$; W., $2 \cdot 61$; T., $2 \cdot 10$; B. from N., 31 .

Remarks.-In any plumage this hirrl nay be distinguished from the preceding by its uniform yellow underparts.

Range.-Atlantie slope of $\mathbf{X}$. A. Breeds in Canadian zome from Ont., n. Que., and N. F., s. to s. . S. X. B., and Maine: winters from Lat, to n. Fla., casually to $\mathrm{X}$. C. and Pa.; arecidental in Ohio, ('uha, Jamaica and Bermuda.

Washington, T. V., enmmon, Mch. 31-Apl. 29: Sept. 4 Oct. 2h. Osining, tolerably common T. V.. Apl. 11-.Iay 5; Aept. 20 vos. 4 . Cambridge, usually emmon, sometimes abundant, T. Y. . 1, l. 15 .12ay 5; ()et. 1-15.

Nest, of rather enarse grasses lined with finer grasses. on or near the ground. Eggs, 4-5, white or buffy white, with some distinet and obsecure? cinnamon-or olive-brown markings, chiefly at the lareer (end, $6.5,51$. Date, Dartmouth, N. S., May 26.

This species is a renegade Dendroica. He has no liking for the woods, and even trees in the open do not seem to attract him. His tastes bring him to fields and roadsides, where he lives on or near the 
ground, but is ever active and much on the move. During the winter, in the south, he is a common bird in the streets and gardens of towns, and like a Chippy hops familiarly about piazzas.

He has the same nervous peculiarity, which, irrespective of family, seems to affect some birds, and, as though life were a matter of beating time, never ceases to wag his tail. His fine chip is recognizable after one has become familiar with it, while his two songs are described by Gerald Thayer (in "Warblers of North America") as "chiefly trills, one slower and fuller-toned, the other much quicker and thinner."

673. Dendroica discolor (Vieill.). Pratrie Warbler. (Fig. 124.) $A d$. $\sigma^{7}$.-Upperparts bright olive-green; back spotted with chestnut-rufous; wing-bars yellowish; outer tail-feathers with large white patches at their tips, the outer vane of the outer feather white at the base; a yellow line over the eye; lores and a crescent below the eye black; underparts bright yellow; sides heavily streaked with black. $A d$. o. - Similar, but with less, and sometimes no chestnut-rufous in the back. Im. o.-Upperparts uniform ashy olive-green; no apparent wing-bars; outer tail-feathers with white on their inner webs at the tips; ear-coverts ashy; underparts yellow; sides indistinctly streaked with blackish. L., $4 \cdot 75 ;$ W., $2 \cdot 20 ;$ T., $1 \cdot 95 ;$ B. from N., $\cdot 28$.

Remarks. - The chestnut-rufous patch in the back at once identifies the adults; but the young females are puzzling birds to be known chiefly by their small size, absence of wing-bars and streaks on the sides.

Range.-E. U. S. Breeds chiefly in Carolinian and Austroriparian faunas from se. Nebr., e. Kans., s. Ohio, sw. Pa., s. N. J., and (along the coast) from Mass. s. to sw. Mo., n. Miss., nw. Ga., Fla., and the Bahamas, and n. locally to cen. Mich., s. Ont., and N. H.; breeds rarely and locally in the Gulf States; winters from cen. Fla. through the Bahamas and the West Indies.

Washington, very common S. R., Apl. 12-Sept. 20. Ossining, rare S. R., May 2-Sept. 14. Cambridge, locally common S. R., May 8-Sept. 15. N. Ohio, rare, Apl. 29, May 9 and 14.

Nest, of plant fibers and plant-down, lined with rootlets and long hairs, in briary bushes. Eggs, 4-5, white, spotted distinctly and obscurely with cinnamon- or olive-brown, or chestnut, chiefly in a wreath at the larger end, $\cdot 64 \times \cdot 48$. Date, Savannah, Ga., Apl. 25; Raleigh, N. C., May 14; Cambridge, May 28; Ottawa Co., Mich., May 26.

The Yellow, Palm, and Prairie Warblers are the three "Wood Warblers" that are rarely found in the woods. The latter, however, differs decidedly in habits from either of the former. It is a rather retiring inhabitant of scrubby clearings, bushy fields, and pastures, or thickets of young pines and cedars. But while the Prairie, if silent, might readily escape observation, no one with an ear for bird music will pass within sound of a singing bird without at least trying to solve the mystery of its peculiar notes, a series of six or seven quickly repeated zees, the next to the last one the highest.

674. Seiurus aurocapillus (Linn.). OVEN-BIRD. (Fig.125.) Ads.Center of the crown pale rufous or ochraceous-buff, bordered on either side by black lines; rest of the upperparts, wings, and tail brownish olive-green; no wing-bars or tail-patches, underparts white; the sides of the throat, the breast, and sides streaked with black. L., 6.17; W., 3.00; T., 2.15; B. from N., 35 .

Range.-N. A. Brecds in Canadian, Transition, and Upper Austral 
zones from sw. Mackenzie (casually the lower Yukon Valley), to N. F. s. to cen. Alberta, Colo., Kans., s. Mo., Ohio Valley, Va., in mts. to Ga. and S. C., and e. to the Atlantic coast from N. S. to Va.; winters from cen. Fla. (casually S. C.) and islands on the La. coast through the Bahamas to Colombia.

Washington, very common S. R., Apl. 10 to Oct. 17. Ossining, common S. R., Apl. 27-Oct. 10. Cambridge, very common S. R., May 6-Sept. 15. N. Ohio, abundant S. R., Apl. 22-Oct. 1. Glen Ellyn, not common S. R., common T. V., Apl. 28-Sept. 30. SE. Minn., common S. R., Apl. 27Sept. 22.

Nest, bulky, covered, the entrance at one side, of coarse grasses, weed stalks, leaves, and rootlets, on the ground. Eggs, 4-5, white, spcckled or spotted with cinnamon- or rufous-brown markings, sometimes finely distributed, sometimes confluent about the larger end, $80 \times \cdot 60$. Date, Weaverville, N. C., May 7; Chester Co., Pa., May 22; Cambridge, May 25; se. Minn., May 19.

During the nesting season Oren-birds are among our commonest woodland birds. We hear them everywhere; one singer scarcely ceases before another begins. But when the song period has passed how comparatively rare they become! The reason is not hard to find. At most times the Oven-bird is somewhat of a recluse. He passes much of his time on or near the ground, generally where the woods are more or less undergrown. Only the practised ear will detect his sharp, weak cheep.

If there be such a thing as inspiration, I believe the Oven-bird sings under its influence. Not that his usual song is in the least remarkable, but because the bird is so obviously moved by a spirit which demands utterance. Watch him now as he is about to sing. Flying up from the ground, how cautiously he hops from branch to branch, and, with crest slightly erect, walks carefully along a limb, when, suddenly overcome by the music in his soul, he throws fear to the winds and lifts up his voice in a crescendo chant which vibrates through the woods. Teacher, teacher, TEACHER, TEACHER, TEACHER, Mr. Burroughs writes it, and the description is difficult to improve upon.

The bird fairly quivers with the violence of his effort. The result seems inadequate; we foel that he is striving for something better, and, in truth, as Mr. Bicknell says, he sometimes breaks the bonds that ordinarily beset his expression, and "bursts forth with a wild outpouring of intricate and melodious song," the very force of which carries him up into the air among the tree tops.

1911. Stanwood, C. J., Journ. Me. Orn. Soc., XIII, 18-20 (nesting).

675. Seiurus noveboracensis noveboracensis ( fmel.). WATERThrUsh. Ads.-Upperparts, wings, and tail uniform olive; no wing-bars or tail-patches; a buffy line over the eye; underparts white, tinged with pale sulphur-ycllow, (richer in fall) and rerywhere-including throat-streaked with black. L., 6.04; W., 2.99; T., $2 \cdot 11$; B. from N., "36.

Range.-E. N. Am. Breeds chiefly in Camarlian zone from n. Ont., n. Ungava, and N. F. s. to cen. Ont., nw. N. Y., and u. New Funland (casually s. New England), and in mis. s. to W. Vat; winters from the Valley of M(exico to British Guiana, and throughout West Indies.

Washington, common 'T. V., I[1. 22 June 2; July 21-Oct. 6. Ossining, 


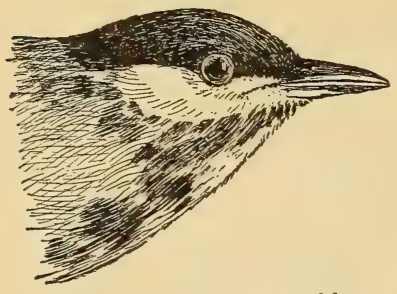

FIG. 123. Black-poll Warbler.

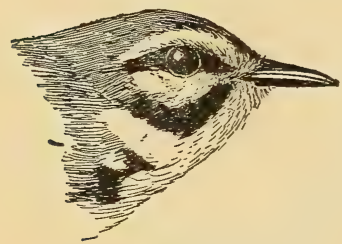

FIG. 124. Prairie Warbler.

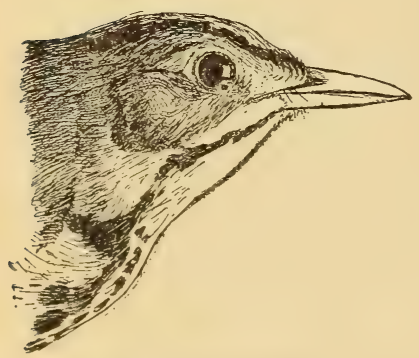

FIG. 125. Oven-bird.

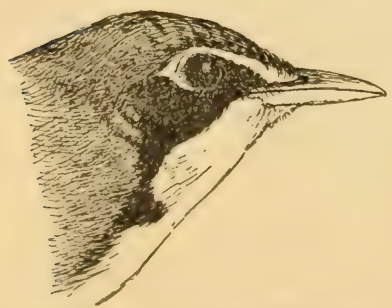

Fig. 126. Kentucky Warbler.

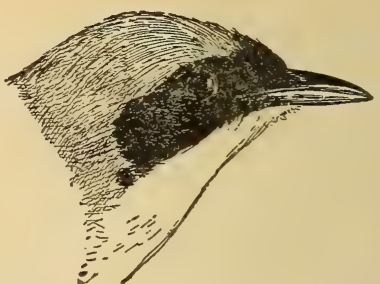

Fig. 127. Maryland Yellow-throat.

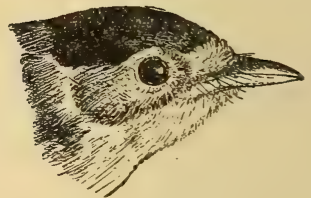

FIG. 128. Wilson's Warbler.

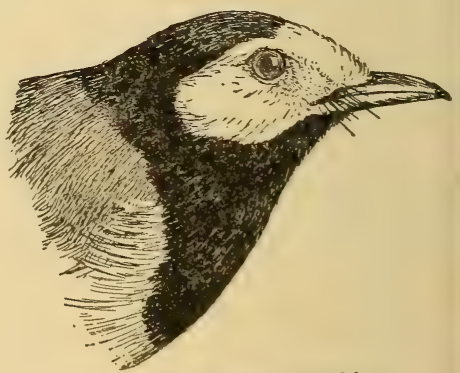

FIG. 129. Hooded Warbler.

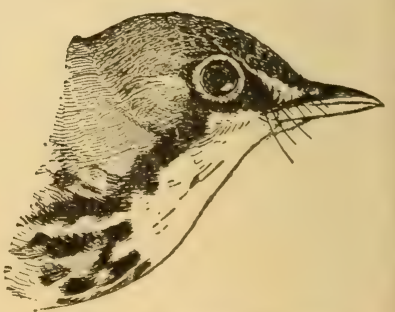

Frg. 130. Canadian Warbler.

Frgs. 123-130. Heads of Warblers. (Natural size.) 
tolerably common T. V., May 11-21; July 28-Oct. 3. Cambridge, abundant T. V., May 8-June 1; Aug. 10-Oct. 10. N. Ohio, common T. V., Apl. 26May 25; Sept. 1-15.

Nest, of moss, lined with tendrils and fine rootlets, in a mossy bank or under the roots of a fallen tree. Eggs, 4-5, white, or buffy white, with numerous cinnamon-brown markings, chiefly about the larger end, $76 \times 59$. Date, Branchport, N. Y., May 18; Pittsfield, Maine, May 28.

In general habits this bird resembles its southern relative, the Louisiana Water-Thrush, but during its migrations it is frequently found some distance from water, and I have known birds to spend several days beneath evergreen trees on a lawn a quarter of a mile from the woods. It is, too, much less shy than motacilla, and one can generally approach closely enough to take note of the characters which distinguish it from that species-a smaller bill, more sharply defined and darker streaks, and yellower underparts.

The sharp, steely alarm note, clink, is not so penetrating as that of motacilla, and the loud, ringing song, while lacking in the wild quality which so characterizes the notes of that species, is nevertheless more musical.

675a. S. n. notabilis Ridgw. Grinnell's WATER-Throsh. Similar to the preceding, but slightly larger, upperparts darker, underparts and line over the eye whiter. W., $3 \cdot 10 ;$ T., $2 \cdot 20 ;$ B. from N., 37 .

Range.-W. N. Am. Breeds chiefly in Boreal zones from limit of trees in nw. Alaska, n. Yukon, nw. and cen. Mackenzic, and cen. Keewatin s. to s. B. C., cen. Mont., nw. Nebr., n. Minn., and nw. Mich.; winters in Cuba and the Bahamas and from Mex. to n. S. A.; migrates throughout the Miss. Valley, and along the Atlantic coast from S. C. southward; casual in N. J.

Washington, casual, two instances, May. Glen Ellyn, fairly common T. V., Apl. 14-June 5; Aug. 17-Oct. 6. SE. Minn., common T. V., Apl. 30- ; Sept. 24.

676. Seiurus motacilla (Vieill.). Loursiana Water-Thrush. (Fig. 70d.) Ads.-A conspicuous white line over the eye; upperparts, wings, and tail olive; no wing-bars or tail-patches; underparts white, tingerl with (reambuft, especially on the flanks, and streaked with blackish, exrept on the throat

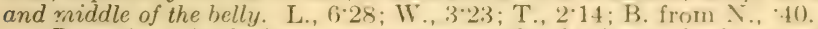

Remarks.-Aside from its larger size, this bird may lo known from the preceding species by the whiter, more conspicuous line over the eye, huffy instead of yellowish tinge on the underparts, and absence of suots on the throat.

Range.-E. U. S. Breeds mainly in Carolinian fauna from se. Nelor., se. Minn., and the s. parts of Mirh., Ont., N. Y., and Now England s. to ne. Tex., n. Ga., and cen. S. C.; winters from n. Mrex. to ('olombia, and in the West Indies.

Washington, rare S. R., Apl. 2-Serpt. 14. Ossining, rommon S. R., Apl. 9-Aug. 24. N. Ohio, tolerably common si. R., Mch. 2S Sept. 15. SE. Minn., uncommon S. R., Apl. 17-Aug. 26.

Nest, of leaves, twigs, and rontlets, under a bank or the upturned roots of a fallen tree. Eggs, 4-6, white, evenly sperekled or spotterl, distinetly and obscurely, with cinnamon- or rufous-brown, $75 \times$ (i). Date, Ireileil Co., N. C., Apl. 21; Wayneshurg, Pa., May 5, hatching; New Haven, Conn., May 6; Petersburg, Mich., May 5.

Few birds are more particular in their choice of homes than this Water-Thrush. He lives where dashing brooks leap down wooded 
hillsides, or where quieter streams flow through the lowland forests. $\mathrm{He}$ is a wild, shy bird, and his never-ceasing alertness suggests the watchfulness of the savage. Approach as quietly as you will, the WaterThrush knows of your coming. With a tilting motion he walks on ahead, springs from rock to rock, or with a sharp, metallic clink of alarm takes wing and darts through the woods so low you scarcely get a glimpse of him. From a distant limb near the ground he watches you, constantly teetering his body as though even when resting he must find some outlet for his surplus nervous energy.

As a songster the Water-Thrush is without a rival. His song is not to be compared with the clear-voiced carol of the Rose-breasted Grosbeak, the plaintive chant of the Field Sparrow, or the hymnlike melody of the true Thrushes; it is of a different kind. It is the untamable spirit of the bird rendered in music. There is an almost fierce wildness in its ringing notes. On rare occasions he is inspired to voice his passion in a flight-song, which so far exceeds his usual performance that even the memory of it is thrilling.

677. Oporornis formosus (Wils.). KentuCKy Warbler. Ad. $\sigma^{7}$.(Fig. 126.) A yellow line from the bill passes over and around the back of the eye; crown, region below the eye, and the side of the throat black, the crown tipped with gray; rest of the upperparts, wings, and tail olive-green; no wing-bars or tail-patches; underparts bright yellow. Ad. o. - Similar, but the black areas more grayish and less clearly defined. L., 5*40; W., $2 \cdot 60$; T., $1.90 ;$ B. from N., ' 32 .

Range.-E. U. S. to n. S. A. Breeds in Carolinian and Austroriparian faunas from se. Nebr., s. Wisc., se. and sw. Pa., and the Hudson Valley s. to e. Tex., La.; Ala., and n. Ga.; winters from Tabasco to Colombia; accidental in Vt.

Washington, not very uncommon S. R., Apl. 29-Sept. 2. Ossining, common S. R., May 2-Aug. 27. N. Ohio, rare, Apl. 27 and May 12.

Nest, bulky, of twigs and rootlets, firmly wrapped with several thicknesses of leaves, lined with fine rootlets, on or near the ground. Eggs, 4-5, whité or grayish white, finely and evenly speckled or coarsely blotched with rufous to umber, $\cdot 72 \times \cdot 58$. Date, Buncombe, N. C., May 23 ; West Chester, Pa., May 27; Dunklin Co., Mo., May 15.

The Kentucky Warbler frequents rather densely grown, wellwatered woods. Here he may be found, on or near the ground, hopping from limb to limb or walking about searching for food. When singing, he generally mounts to the lower branches of the higher trees. His song is entirely unlike that of any other Warbler. It is a loud, clearly whistled performance of five, six, or seven notes-tur-dle,turdle, tur-dle-resembling in tone some of the calls of the Carolina Wren. Even in the woods it may be heard at a distance of about one hundred and fifty yards.

In the height of the breeding season this Warbler is a most persistent singer. On one occasion, at Englewood, N. J., I watched a male for three hours. During this period, with the exception of five interruptions of less than forty-five seconds each, he sang with the greatest regularity once every twelve seconds. Thus, allowing for the brief intervals of silence, he sang about 875 times, or some 5,250 
notes. I found him singing, and when I departed he showed no signs of ceasing.

678. Oporornis agilis (Wils.). CoNNecticut Warbler. $A d . \sigma^{7}$. Head, neck, and breast bluish gray, lighter on the throat; crown in the fall tipped with olive-green; eye-ring white; rest of upperparts, wings, and tail olive-green; no wing-bars or tail-patches; belly yellow; sides washed with olive-green. Ad. o and Im.- Similar to the $\sigma^{7}$, but upperparts uniform olivegreen; throat and breast pale grayish brown; belly pale yellow. L., 5*40; W., 2:90; T., $1 \cdot 90 ;$ B. from N., 32 .

Range.-E. N. Am. Breeds in Canadian zone from Man. to cen. Minn., and n. Mich.; winters in n. S. A.; migrates through Fla. and the Bahamas; in spring rare e. of Alleghanies but common in the Miss. Valley; in autumn rare in the Miss. Valley but common e. of the Alleghanies; casual ne. of Mass. and in Ont.

Washington, T. V., very rare in spring, May 24-30; common from Aug. 28-Oct. 24. Ossining, rare T. V., Aug. 26-Oct. 9. Cambridge, fall T. V., sometimes locally abundant, Sept. 10-30. N. Ohio, tolerably common T. V., May 7-24. Glen Ellyn, fairly common T. V., May 12-June 28; Aug. 14-Sept. 22. SE. Minn., uncommon T. V., June 1.- .

Nest, of dry grasses, on the ground. Eggs, 4, white, with a few spots of lilac-purple, brown, and black about the larger end, $75 \times \cdot 60$. (Seton, $A u k$, I, 1884, 192.) Date, Carberry, Man., June 21.

"Connecticut Warbler" is an unfortunate misnomer for this species. 'Swamp' or 'Tamarack Warbler,' or 'Bog Black-throat,' would have been much more truly descriptive.

Ir: the vold, boggy tamarack swamps of Manitoba, where I found it breeding, it was the only one of the family, and almost the only bird, whose voice broke the silence of those gray wastes. Its loud song was much like the "teacher, teacher" chant of the Oven-bird, but it also uttered another, which I can recall to mind by the aid of the sylables "free-chapple, free-chapple, free-chapple, whorт."

The nest was placed on the ground, or, rather, in the moss which everywhere covered the ground to a depth of a foot or two, and was composed of fine vegetable fibers.

This species has somewhat the manners of the Viress, but is much more active and sprightly in its movements. During the migrations it is generally found on or near the ground, in the undergrowth of low, damp woods, and also in bordering, weedy fields, where it sometimes announces its presence by a sharp peek. Eirvert THIMPSON SETon.

679. Oporornis philadelphia (Ti7s.). Mnerwivi Warmerer. Ad. $\gamma^{7}$.

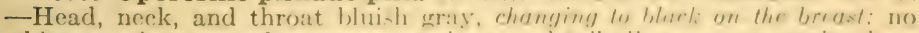
white eye-ring; rest of upperparts, wings, and tail olive-greent; no wing-bars or tail-patches; belly yollow. Ad. and $\mathrm{Jm}$.-Similar, but upperparts olivegreen, slightly grayer on the hearl; breast grayish, throat whiter. L., 5.63; W., $2 \cdot 56$; T., $2 \cdot 13$; B. from N., 32 .

Remarks. - This species bears a general resemblanee to the preceding, but may be distinguished from it by the abeenee of at white eyr-ring.

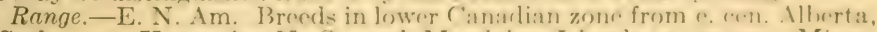
s. Sask., sw. Keewatin, N. S., and Magrlalen Islands, s. to (')!. Minn., Mich., cen. Ont., and mts. of $\mathrm{X}$. Y.. Pia.. Mass., and W. Ya.: winters from Nicaragua to Ecuador; in migration from (c. Tex. to the llleghatnies; rare e. of the Alleghanies and from N. ( $\therefore$. w. to Miss. (See ligr (j.) 
Washington, very rare T. V., May 6-30; Aug. 17-Oct. 1. Ossining, rare T. V., May 28-29; Aug. 18-Oct. 1. Cambridge, rare T. V., May 22-June 5; Sept. 12-25. N. Ohio, tolerably common T. V., May 5-28. Glen Ellyn, rather rare T. V., May 18-June 8; Aug. 17- . SE. Minn., uncommon T. V., May 13- ; Aug. 1-Sept. 10.

Nest, of strips of bark and other fibrous materials, lined with hair, on or near the ground. Eggs, 4, white, sprinkled with reddish dots near the larger end, $\cdot 71 \times \cdot 54$. Date, Orleans Co., N. Y., May 31; Listowel, Ont., June 3 ; Kalkuska Co., Mich., June 7.

The Mourning Warbler inhabits the undergrowth, choosing situations not unlike those selected by the Maryland Yellow-throat.

"Its common song consists of a simple, clear, warbling whistle, resembling the syllables 'trúe, 'trúe, 'trúe, 'trú, 'toó, the voice rising on the first three syllables and falling on the last two.

"Sometimes, when otherwise occupied, the first, or first two, syllables are omitted. All through the breeding season, and till late in July, they have a very characteristic habit of perching, at frequent intervals during the day, on some branch, generally a dead one, and commonly ten or fifteen feet from the ground, and singing for half an hour at a time." (Merriam, "Birds of Connecticut," 24.)

681. Geothlypis trichas trichas (Linn.). MARYLAND YellowTHROAT. (Fig. 127.) $A d$. o.-A broad band across the forehead, and on the cheeks and ear-coverts black, bordered behind by grayish; rest of the upperparts, wings, and tail olive-green, sometimes tinged with brownish; no wing-bars or tail-patches; throat and breast bright yellow, changing to whitish on the belly; sides washed with brownish; under tail-coverts yellow. Ad. o in fall.- - Similar, but browner above; black mask tipped with grayish; belly more yellow; sides browner. Im. o - Similar, but the black mask more concealed, sometimes merely indicated by a dusky area. Ad. ..No black mask; upperparts, wings and tail olive-green, the forehead sometimes tinged with rufous; throat and breast yellowish, changing to whitish on the belly; under tail-coverts yellow; sides brownish. L., 5.33; W., 2.20; T., $2 \cdot 04 ;$ B., $\cdot 42$.

Range.-E. N. Am. Breeds in Canadian, Transition, and Upper Austral zones from N. D., n. Minn., n. Ont., and s. Lab. s. to cen. Tex., n. parts of the Gulf States, and Va.; winters from N. C. and La. to Fla., the Bahamas, Cuba, Jamaica, Guatemala, and Costa Rica.

Washington, abundant S. R., Apl 13-Oct. 21. Ossining, common S. R., Apl. 28-Oct. 23. Cambridge, abundant S. R., May 5-Oct. 20; occasional in winter. N. Ohio, abundant S. R., Apl. 25-Sept. 25. Glen Ellyn, common S. R., May 2-Oct. 2. SE. Minn., common S. R.

Nest, bulky, of strips of bark, coarse grasses, and dead leaves, lined with fine grasses, tendrils, and rootlets, on or near the ground. Eggs, 3-5, white, rather thinly speckled and spotted with rufous to umber, chiefly-sometimes entirely - at the larger end, $\cdot 70 \times \cdot 53$. Date, Chester Co., Pa., May 19; Cambridge, May 25; Lancaster, N. H., June 2; Melbourne, Iowa, May 24.

Doubtless one of the first acquaintances you will make, among the Warblers, will be this black-masked inhabitant of thickets and bushes. Indeed, you have only to pause near his home, when he will meet you halfway. He announces his coming by an impatient, quickly repeated chack, varying to chit, pit, quit, as, hopping from twig to twig, he finally appears for a moment and then darts back into the cover of his haunts.

His song is characteristic of his active, nervous nature, and is deliv- 
ered with much force and energy. It varies greatly with locality, a fact which may account for the quite different descriptions given of it by authors. Sometimes it is written wichity, wichity, wichity, wichity; again, rapity, rapity, etc.; but the birds near New York City seem to me to say $I$ beseech you, I beseech you, I beseech you, I beseech you; though, to be sure, the tone is far from pleading.

They sing throughout the summer, and include a flight-song in their repertoire. This is usually uttered toward evening, when the bird springs several feet into the air, hovers for a second, and then drops back to the bushes.

681b. G. t. ignota Chapm. Florida Yellow-throat. Similar to the preceding, but with longer tarsus, tail, and bill; yellow of underparts of a deeper shade and of greater extent; flanks of a much darker color; upperparts browner; black mask wider, its ashy border (in summer specimens) slightly paler and of greater extent; first primary shorter, equaling the eighth instead of the sixth. W., $2 \cdot 17$; T., $2 \cdot 18$; B., $\cdot 47$.

Range.-SE. U. S. Breeds in Austroriparian fauna from the Dismal Swamp, Va., s. to Fla. and along the Gulf coast at least to La.; winters from the coast of S. C. to se. Tex. and Cuba.

Nesting date, Charleston, S. C., May 9.

In Florida this southern representative of the Maryland Yellowthroat is usually found in dense growths of scrub palmetto. Its song differs recognizably from that of the northern bird.

683. Icteria virens virens (Linn.). Yellow-BREASTed Chat. Ads.Largest of the Warblers; upperparts, wings and tail olive-green; line from the eye to the bill, one on the side of the throat, and eye-ring white; throat, breast, and upper belly bright yellow; lower belly white; sides grayish. L., 7•44; W., $3{ }^{*} 00 ;$ T., $3 \cdot 07 ;$ B. from N., ${ }^{\circ} 41$.

Range.-E. N. Am. Breeds mainly in Upper and Lower Austral zones from s. Minn., Wisc., Mich., Ont., cen. N. Y., and s. New England s. to se. Tex., s. parts of Gulf States, and n. Fla.; winters from Puebla, Vera Cruz, to Costa Rica; casual in Maine.

Washington, common S. R., Apl. 16-Sept. 28. Ossining, common S. R., Apl. 28-Aug. 29. ('imbridge, rather rare and irregular S. R., May 15-Sept. N. Ohio, common S. R., May 1-Sept.

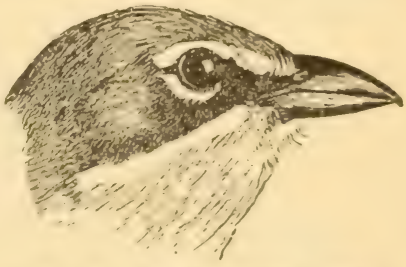

Fig. 131. Yollow-brensted Chat. (Nutural size.)

15. Glen Ellyn, local, not common, May 10-Aug. 16. SE. Minn., rare S. R. (?).

Nest, rather bulky, of coarse grisses, leaves, and strips of hark well interwoven, lined with finer grasses, in is croteh, neat the ground. Eygls, $3-5$, white, rather evenly speckled and spotterd with rufous-brown, 90 × Date, Chatham Co., Ga., May 7; Wayneshurg, Pa., May 10; New Haven, Conn., May 22; Oberlin, Ohio, May 15.

Bushy undergrowths or thickets in partial elearings form the home of the Chat. After an acquaintance of many years I frankly confess that his true character is a mystery to me. While listening to his strange medley and watching his peculiar actions, we are certainly justified 
in calling him eccentric, but that there is method in his madness no one who studies him closely can doubt.

Is the odd jumble of whistles, chucks, and caws uttered by one bird in that copse yonder, or by half a dozen different birds in as many places? Approach cautiously, and perhaps you may see him in the air-a bunch of feathers twitched downward by the queer, jerky notes which animate it. One might suppose so peculiar a performance would occupy his entire attention, but nevertheless he has seen you; in an instant his manner changes, and the happy-go-lucky clown, who a moment before was turning aërial somersaults, has become a shy, suspicious haunter of the depths of the thicket, whence will come his querulous chŭt, chŭc as long as your presence annoys him.

684. Wilsonia citrina ( $\mathrm{Gmel}$.). Hooded WARBLer. (Fig. 129.) $A d$. o. $^{3}$.-Forehead and cheeks bright yellow; crown black, connected behind with the black throat; upperparts, wings, and tail olive-green; outer tailfeathers with inner vane mostly white; breast and belly yellow; bill with evident bristles at its base. Ad. 9 . - Similar, but with the black hood usually developed as a narrow line on the nape and crown, and a blackish wash on the throat or chest. Im. $\sigma^{3}$. - Similar to ad. $\sigma^{7}$, but the black feathers with yellow tips. Im. o. - Similar to ad. $\%$, but with no black on the head or breast. L., $5 \cdot 67$; W., $2 \cdot 58$; T., $2 \cdot 30$; B. from N., 31 .

Range.-E. U. S. Breeds in Carolinian and Austroriparian faunas from se. Nebr., s. Iowa, sw. Mich., cen. N. Y., and the lower Conn. Valley s. to La., Ala., and Ga.; winters from Vera Cruz to Panama; occasional in the Bahamas, Cuba, and Jamaica; casual n. to Wisc., Mich., Ont., and Mass.

Washington, locally common S. R., Apl. 19-Oct. 1. Ossining, rare S. R., to Sept. 1. N. Ohio, rare, May 8, 9, 12 and 22.

Nest, of leaves, strips of bark, and rootlets, lined with fine grasses and rootlets, in the crotch of a bush or sapling, about four feet up. Eggs, 4-5, white or creamy white, rather thinly speckled or spotted with rufous or rufous-brown, generally in a wreath at the larger end, $71 \times \cdot 53$. Date, Charleston, S. C., Apl: 30, inc. adv.; Saybrook, Conn., May 26; Kalamazoo Co., Mich., June 10.

This beautiful bird is a lover of well-watered, rather densely grown woods. It is a bird of the lower growth rather than the trees, but is not a thicket-haunter, and its habit of flitting restlessly from bush to bush renders it easily observed. When on the wing its white outer tail-feathers are conspicuously displayed, and, with the striking markings of the head, make an excellent field-mark.

The song of the Hooded Warbler is sweet and graceful. It is subject to much variation, but as a rule consists of eight or nine notes. To my ear the bird seems to say, "You must come to the woods, or you won't see me." Its call-note is a sharp, characteristic cheep, frefrequently uttered when the bird is anxious for the safety of its nest or young, and accompanied by a flit of the tail, which reveals the white outer tail-feathers.

685. Wilsonia pusilla pusilla (Wils.). Wilson's Warbler. (Fig. 128.) $A d$. ${ }^{\prime}$.-Forehead yellow, crown black; rest of the upperparts, wings and tail bright olive-green; no wing-bars nor tail-patches; underparts bright 
yellow; bill with bristles at its base. $A d$. o.---Similar, but generally without the black cap. Im. + . -Similar, but without black cap. L., 5.00; W., 2*21; T., $2 \cdot 03$; B. from N., 25 .

Range.-E. N. Am. Breeds in Boreal zones from tree limit in $\mathrm{nw}$. Mackenzie, and N. F., s. to s. Sask., n. Minn., cen. Ont., N. H., Maine, and N. S.; winters in e. Cen. Am.; migrates mainly along the Alleghanies; practically unknown in the Austroriparian fauna from Va. to La.

Washington, rather common T. V., May 1-26; Aug. 27-Oct. 6. Ossining, tolerably common T. V., May 9-30; Aug. 10-Sept. 9. Cambridge, common T. V., May 12-25; uncommon, Sept. 5-20. N. Ohio, tolerably common T. V., May 5-June 2; Sept. 5-15. Glen Ellyn, not common T. V., May 7June 26; Aug. 16-Sept. 21. SE. Minn., common T. V., May 2- ; Aug. 23Sept. 27.

Nest, on the ground, almost wholly of fine, dry grass, lined with a few hairs, deeply cupped and quite substantial for a Warbler. Eggs, 4, white, with or without light brown splashes and with a small wreath of dark specks at the larger end, $\cdot 59 \times{ }^{*} 48$. Date, Bangor, Maine, June 1. (See "Warblers of North America," 277.)

The Black-cap frequents the lower woodland or bushy growths. Like other members of this genus, it has decided talents as a fly-catcher and captures much of its prey on the wing, darting out into the air, but does not, like a true Flycatcher, return to the same perch. It is an alert little bird and its motions of wings, tail or crest suggest a certain pertness of manner.

"The song has much of the ringing clarity of the Canada's and Hooded's songs. The commonest form of it, a rapid bubbling warble of two nearly equal parts, the second lower-toned and sometimes diminuendo, has always reminded me of a Northern Water-Thrush's song" (Thayer in "Warblers of North America").

686. Wilsonia canadensis (Linn.). CANADIAN WARBLER. (Fig. 130.) Ad. $\sigma^{7}$-Upperparts, wings, and tail gray; no wing-bars or tail-patches; crown spotted with black; line from the bill to the eye and und(ry)arts yellow; sides of the neck black; a necklace of black spots across the lrewst; under tailcoverts white; bill with evident bristle at its base. $A d$. ? and Im. o.-_imilar, rut with no black on the head or sides of the throat; nereklare indienated by dusky spots. Im. o. - Similar, but with breast spots fainter or wanting. L., 5.61 ; W., 2.53 ; T., $2 \cdot 23$; B. from N., "31.

Range.-E. N. Am. Breeds in the Canadian zone and carually in tho Transition from cen. Alberta, s. to N. F., s. to cen. Minn., cen. Mich., s. Ont., cen. N. Y., and Mass., and along the Alleghanies to N. C. and Tenn.; winters in Ecuador and Peru and casually in (xuatemala.

Washington, very eommon T. V., May 5-June 2; July 31-Sept. 25. Ossining, eommon T. V., May 6-June 2; Aug. 10 O)et. 11. Cambridge, common, May 12-30, rare, Sept. 1-15; rare S. R. N. Ohio, common T. V., Apl. 28-May 27; Sept. 1-1x. Glen Ellyn, common T. V., May J-June 6; Aug. 15-Sept. 22. SE. Minn., (ommon T. V., May 8 ; Aug. 1s-S'rpt. 5.

Nest, of strips of bark, bits of dead wood, and moss wrapperd in lraves, and lined with fine rootlets, in mossy banks or under roots. E'ygs, 4-5, white, speckled and spotted, chirfly at the lareer end, with rufous or rufousbrown, $66 \times 51$. Date, Lancaster, N. H., June 9; Bay City, Mich., June 2.

Although when associated with other migrating Warblers this hird may be found in woodland of varied character, it prefers low, wet woods, in which, like Wilson's Warbler, it frequents the lower growth. Like that bird also it is an expert fly-catcher. 
Its song is sweet, loud, and spirited. Fuertes writes "it suggests to me the unfinished song of a Goldfinch more than that of a Warbler. It is very broken and energetic and also possesses a large quality" ("Warblers of North America").

687. Setophaga ruticilla (Linn.). REDsTART. (Fig. 70c.) Ad. $\sigma^{7}$ Upperparts, throat; and breast shining black; basal half of the wing-feathers salmon, end half and wing-coverts black; basal two-thirds of all but the middle tail-feathers salmon, end third and middle feathers black; sides of the breast and flanks deep reddish salmon; belly white, tinged with salmon; bill with prominent bristles at its base. $A d$. + . - Salmon of the $\sigma^{7}$ replaced by dull yellow; head grayish; back ashy, with a greenish tinge; underparts, except where marked with yellow, white. Im.-Resemble the $\%$; the $\sigma^{\prime}$ acquires his full plumage at the end of his first breeding season during which he resembles the $\%$, but is more or less mottled with black. L., 5*41; W., $2 \cdot 57$; T., $2 \cdot 27$; B. from N., $\cdot 27$

Range.-N. A. Breeds in Canadian, Transition, and Upper Austral zones from cen. B. C. to N. F., s. to Wash., n. Utah, Colo., cen. Okla., Ark., and N. C.; rarely breeds in the se. U. S. s. of lat. $35^{\circ}$; casual in migration in Ore., Calif., L. Calif., Ariz., and n. Ungava; winters in the West Indies and from cen. Mex. to Ecuador and B. Guiana. (See Fig. 8.)

Washington, very abundant T. V., Apl. 15-May; Aug. 19-Sept. 30; a few breed. Ossining, common S. R., May 1-Oct. 3. Cambridge, abundant S. R., May 5-Sept. 20. N. Ohio, common S. R., Apl. 27-Sept. 20. Glen Ellyn, not common S. R., common T. V., May 3-Oct. 5. SE. Minn., common S. R., May 2-Sept. 22.

Nest, of fine strips of bark, leaf stalks, and plant-down, firmly interwoven, lined with tendrils and fine rootlets, in the crotch of a sapling, 5-20 feet up. Eggs, 4-5, grayish white or bluish white, spotted and blotched, chiefly at the larger end, with cinnamon- or olive-brown, $68 \times 50$. Date, Raleigh, N. C., May 12; Waynesburg, Pa., May 19; New Haven, Conn., May 20; Cambridge, June 2.

If this active, brilliantly colored inhabitant of woodlands were as rare as he is beautiful, we would consider a meeting with him an event demanding at least a page in our journals. In Cuba most of our Wood Warblers are known simply as 'Mariposas'-butterflies; but the Redstart's bright plumage has won for him the name 'Candelita'the little torch that flashes in the gloomy depths of tropical forests.

Ching, ching, chee; ser-wee, swee, swe-e-e he sings, and with wings and tail outspread whirls about, dancing from limb to limb, darting upward, floating downward, blown hither and thither like a leaf in the breeze. But the gnats dancing in the sunlight and the caterpillars feeding in the shade of the leaves know to their sorrow that his erratic course is guided by a purpose.

\section{Family Motacilidde. Wagtails and Pipits. (Fig. 71.)}

Of the one hundred species included in this family only ten are American, the remaining ninety being distributed throughout the Old World. Of Wagtails, a single species (Budytes flavus alascensis) reaches western Alaska, while our nine species of Pipits are scattered from the Arctic zone to Patagonia, oniy two being known from north of the Rio Grande. 
Wagtails are found about the borders of streams and where there is more or less vegetation, while the Pipits are more larklike and usually inhabit an open, treeless country. Both Wagtails and Pipits are eminently terrestrial. They walk or run, instead of hop, rarely (with one or two exceptions) if ever alight in trees, sing on the wing, the Pipits ascending much the higher, and nest on the ground, and both have in a highly dereloped form the habit of tail-wagging.

697. Anthus rubescens (Tunstall). AMerican Pipit. (Fig. 71.) Ads. in winter.-Outer tail-feather largely white, next one or two white-tipped. Above warm grayish brown; wing-coverts tipped with whitish or buffy; longest tertial longer than fifth primary; a whitish or buffy line over eye; below buffy (whitish just before spring molt) breast and sides streaked with fuscous; hind toe-nail longest, as long as or longer than its toe. After spring molt upperparts grayer, underparts more pinkish buff, but these colors fade as breeding season advances. L., 6*38; W., 3.50; T., 2.69; B., 47.

Range.-Breeds in Arctic zone from ne. Siberia, n. Alaska, and lat. $70^{\circ}$ on w. coast of Greenland s. to Great Slave Lake, cen. Keewatin, n. Que., and S. F., and on high mts. s. to Calif., Colo., and N. M. ; winters from s. Calif., and the Ohio and lower Del. valleys to Guatemala.

Washington, W. V., sometimes abundant, Oct. 2-May 12. Ossining. common T. V., Mch. 26-(?); Sept. 21-Nor. 16. Cambridge, T. V., abundant Sept. 20- Kor. 10; rare Apl. 10-May 20. \. Ohio, common T. V., Apl. 6-May 26; Oct. 19. Glen Ellyn, not common T. V., Apl. 15- ; Sept. 30Oct. 18. SE. Minn., common T. V., May 4 - ; Oct.

Nest, of grasses, on the ground. Eggs, 4-6, bluish white or grayish white, thickly and erenly sperkled with cinnamon- or vinaceous-brown, $\cdot 78 \times \cdot 57$. Date, Whale River, Lab., June 20.

Large, open tracts in the vicinity of the coast are the localities in which Titlarks are most common, but they are also found in numbers in old fields, meadows, and pastures inland. A recently burned or newly plowed field is a good place in which to look for them. Once seen, there is little difficulty in identifying these graceful walliers, as they run on before you, or with constantly wagging tail await your approach. The individuals of a flock are generally seattered over a varying space while feeding, but when flushed they rise together and, with a soft dee-lee, dee-dee, mount high in the air as though bound for parts unknown, but often, after hovering above you for several seconds in an undecided way, they will return to or near the place from which they rose. Their flight is light and airy, and in loose companies they undulate gently through the air without apparent effort, uttering their faint dee-lee as they fly.

The Pipit's song is delivered in the air both as he mounts to and descends from a height of as much as two hundred feet. To me it sounds like the ringing of a little bell. Townsend " Along the Labrador Coast," p. 52) describes it as "che-whée, che-whée, with a vibratory resonance on the whee."

700. Anthus spraguei $(A u r)$. SPRArre's PIPIT. Hind tor-nail longer than its claw. Ads.-Above eravish brown widly margined with buffy or ashy: tail fusenus, twe nuter foathers lareely whitr, wings browner with two indistinet hars; bolnw white. buff-tinged, a band of streakis arross the breast. L., $6 \cdot 25$; W., $3 \cdot 30$; T., $2 \cdot 40$; B., 50 . 
Range.-Interior plains of N. A. Breeds in Transition zone from sw. Sask. and s. Man. s. to w. Mont., and N. D.; winters from Tex., s. La., and s. Miss., to s. Mex.

Nest, of grasses on the ground. Eggs, 3-5, grayish white, thickly and finely speckled with blackish and purplish.

This species appears to be of rare but more or less regular occurrence on the coast of South Carolina and Georgia. In general habits it resembles the Pipit, but its song appears to be far more noteworthy than the vocal effort of that species. Seton ("Birds of Manitoba") writes that the song, which is delivered from a height of five hundred feet or more, is loud and ventriloquial. "At the beginning it is much like that of the English Skylark, and the notes are uttered deliberately but continuously, and soon increase in rapidity and force till in a few seconds the climax is reached, after which they fade away in a veery-like strain, and then suddenly stop."

The European White Wagtail (694. Motacilla alba) and European Meadow Pipit (698. Anthus pratensis) have been recorded as of accidental occurrence in Greenland.

\section{Family Mimides. Thrashers, Mockingbirds, Etc. (Fig. 72a, b.)}

Most of the sixty-odd species contained in this distinctively American family are restricted to the tropics, only eleven being found north of Mexico. Generally speaking, they frequent scrubby growths and bushy borders of wooded land. When singing they take a more or less exposed perch and devote themselves seriously and exclusively to the delivery of their musical message. As a rule they are possessed of exceptional vocal ability, and the Mockingbirds, of which there are some twenty species, some quite as talented as ours, are conceded first rank among American song birds, so far as variety of expression and execution are concerned.

\section{KEY TO THE SPECIES}

A. Back slate-color; cap black; under tail-coverts rufous-brown.

A. Back slate-color, cap black, under tail-coverts rufous-brown. 704. CatBird.

$B$. Back and crown grayish; underparts whitish; outer tail-feathers white. 703. MOCKINGBIRD.

C. Back rufous; underparts streaked with black . 705. BRown THRAsher.

703. Mimus polyglottos polyglottos (Linn.). MockingBIRD. Ads. Above ashy; wings and tail fuscous; primary coverts white, centrally, black at end, primaries basally white, showing conspicuously in flight; outer tailfeather white, next two or three with a decreasing amount; below soiled white. L., $10 \cdot 50$; W., $4 \cdot 50$; T., $4 \cdot 90$; B., $\cdot 70$.

Remarks. - The sexes can not be certainly distinguished in color, but in the female the white areas average slightly smaller. Nestlings are grayish brown above, white, spotted with fuscous below.

Range.-SE. U. S., chiefly in Austral zones, from e. Nebr., s. Iowa, Ills., Ind., Ohio, and Md., s. to e. Tex., s. Fla., and the Bahamas, and sparingly to N. Y. and Mass.; accidental in Wisc., Ont., Maine, and N. S.; introduced in Bermuda. 
Washington, uncommon P. R., less numerous in winter. Cambridge, rare S. R., Mch. to Nov.

Nest, of coarse twigs, weed stalks, etc., lined with rootlets, cotton, etc., in thickets, orange trees, etc. Eggs, 4-6, pale greenish blue or bluish white, sometimes with a brownish tinge, rather heavily spotted and blotched, chiefly at the larger end, with cinnamon- or rufous-brown, $1.00 \times 72$. Date, Gainesville, Fla., Apl. 1; Raleigh, N. C., May 9.

The Mockingbird might be called our national song bird; his remarkable vocal powers have made him famous the world over, while our more retiring Thrushes are scarcely to be found mentioned outside the literature of ornithology. He is a good citizen, and courting rather than shunning public life, shows an evident interest in the affairs of the day. He lives in our gardens, parks, and squares, and even in the streets of the town, and is always alert and on the qui vive; a selfappointed guardian, whose sharp alarm-note is passed from bird to bird like the signals of watchmen.

In Florida, Mockingbirds begin to sing in February, and by March 1 the air rings with music. The heat of midday is insufficient to quell their ardor, and on moonlight nights many birds sing throughout the night. It is customary to consider the Mockingbird a musician possessed of marvelous technique, but with comparatively little depth of feeling. $\mathrm{He}$ is said to create intense admiration without reaching the soul. But listen to him when the world is hushed, when the air is heavy with the rich fragrance of orange blossoms and the dewy leaves glisten in the moonlight, and if his song does not thrill you then confess yourself deaf to Nature's voices.

It must not be supposed that every Mockingbird is a mocker; there is much variation in their imitative gifts. Mr. L. M. Loomis tells me of a Mockingbird he once heard singing in South Carolina which imitated the notes of no less than thirty-two different species of birds found in the same locality, and this during ten minutes' continuous singing! This was a phenomenal performance, one I have never heard approached, for in my experience many Mockinghirds have no notes besides their own, and good mockers are exceptional.

1902. Daniels, J. W., Wilson Bull., 68-71 (nesting).

704. Dumetella carolinensis (Linn.). ('AтвrRD. Ads.-Crown and tail black; under tail-coverts chestmut, sometimes spotted with slaty, and rarely largely slaty; rest of the plumage slaty gray. L., 89.4; W., 354; T., $3 \cdot 65 ;$ B., 60 .

Range-E. N. Am. Broeds mainly in Transition and Austral zones from cen. B. C., cen. Alberta, cen. Sitsk., s. Man., cen. ()nt., s. (Jue., and N. S. s. to ne. Ore.. n. Ttah, ne. N. M., c. Tex., and n. Fla.; resident in Bermuda; winters from s. States to the Bahamas and ("uba and through Mex. to Panama; casual in winter $\mathrm{n}$. to the Middle States.

Washington, abundant S. R., Apl. 24 (), 11 ; oreasionally winters.

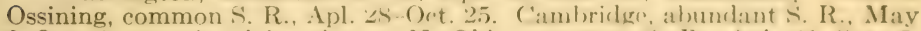
6-Oct. 1; occasional in winter. N. Ohio, (r)mmonn \&. R., Apl. 21-0)t. 5. Glen Ellyn, common S. R., Api. 29-Oct. 6. SE. Minn., common S. R., Apl. 30-Oct. 6.

Nest, of twigs, grasses, and leaves, lined with rontlets, in thickets or 
densely foliaged trees. Eggs, 3-5, rich greenish blue, $994 \times 67$. Date, D. C., May 17; Cambridge, May 22; Utica, N. Y., May 21; se. Minn., May 18.

The Catbird is one of the most intelligent birds in North America. $\mathrm{He}$ is inclined to be very friendly to man, and where he is well treated and his confidence won he likes to nest near our homes, showing himself delightfully familiar, coming around the doorsteps, answering one's calls and talk, and singing by the hour for our entertainment. In the garden and orchard he is as useful as he is enchanting, for he is an untiring devourer of insects, and his value in preserving our fruits can hardly be overrated. In this way he earns his full share of the fruit protected, and it should not be grudged to him when he proceeds to take it, as he surely will.

It is not generally known that the Catbird is a charming singer, for the reason, probably, that his song is rarely loud, and is preferably given from the depths of the thickest shrub he can find. One more often hears than sees him sing, and will miss even the hearing unless quite near, and gifted with a listening ear, ever open to bird notes.

The Catbird mother is one of the most anxious and devoted. If her nest is discovered, she exhibits so much distress that one sympathetic to bird griefs has no heart to pursue investigations.

The Catbird is generous and helpful to others of his kind in trouble of any sort, feeding and caring for deserted or orphaned young ones of any species, and always ready to aid distracted parents in the defense of their home and little ones.

$\mathrm{He}$ is of a lively and restless temperament, entirely lacking the serene repose of his near relatives, the Thrushes. He is always tossing upward or spreading his tail, jerking his lithe body about, now crouching like a cat ready to spring, then straightening himself up very tall; one moment puffing his feathers out till he looks like a ball, and the next holding them closely against his body. He is very playful, full of droll pranks and quaint performances. I know of no bird better worth cherishing and cultivating than the Catbird.

\section{Olive Thorne Miller.}

1905. Herrick, F. H., Home-Life of Wild Birds, 122-128.

705. Toxostoma rufum (Linn.). Brown Thrasher. (Fig. 72a.) Ads.-Upperparts, wings, and tail rufous; wing-coverts tipped with whitish; underparts white (buffy in fall), heavily streaked with black or cinnamon, except on throat and middle of belly. L., 11.42; W., 4.06; T., 5.03; B., $\cdot 96$.

Range.-E. U. S. Breeds mainly in Transition and Austral zones from s. Alberta, s. Man., n. Mich., s. Ont., s. Que., and n. Maine, s. to e. La., Miss., Ala., and n. Fla., and from base of the Rocky Mts. in Mont., Wyo., and Colo. eastward; winters from se. Mo. and N. C. to s. cen. Tex., s. Fla., and casually further $n$.

Washington, very common S. R., Apl. 8-Oct.; occasionally winters. Ossining, common S. R., Apl. 22-Oct. 28. Cambridge, common S. R., Apl. 26-Oct. 20. N. Ohio, common S. R., Apl. 6-Oct. 15. Glen Ellyn, common S. R., Apl. 9-Oct. 11. SE. Minn., common S. R., Apl. 15-Oct. 7.

Nest, of twigs, coarse rooilets, and leaves, lined with finer rootlets, in bushes, thickets, or on the ground. Eggs, 3-6, bluish white or grayish white, thickly, evenly, and minutely speckled with cinnamon- or rufous-brown, 
1.08 × 80. Date, D. C., May 7; Montgomery Co., Pa., May 15; Cambridge, May 21; Wheatland, Ind., May 7 ; se. Minn., May 11.

Hedgerows, shrubbery about the borders of woods, scrubby growth, or thickets in dry fields, are alike frequented by the Thrasher. Generally speaking he is an inhabitant of the undergrowth, where he passes much time on the ground foraging among the fallen leaves. He is an active, suspicious bird, who does not like to be watched, and expresses his annoyance with an unpleasant kissing note or sharply whistled whè̀u.

Like many thicket-haunting birds, who ordinarily shun observation, he seeks an exposed position when singing. Morning and evening he mounts to a favorite perch-generally in the upper branches of a tree-and deliberately gives his entire attention to his song. This is repeated many times, the bird singing almost continuously for an extended interval. He is a finished musician, and, although his repertoire is limited to one air, he rivals the Mockingbird in the richness of his tones and execution. I never listen to the Thrasher's song without involuntarily exclaiming, "What a magnificent performance!" Nevertheless, there is a certain consciousness and lack of spontaneity about it which makes it appeal to the mind rather than to the heart.

\section{Family Troglodytide. Wrens. (Fig. $72 c, d$.)}

The Wrens are one of the few families of birds represented in both hemispheres, in which there is a larger number in the New World than in the Old; only thirty-odd of the some two hundred and sixty known forms occurring in the Old World, while the remainder are American. In this country they are most abundant in the tropies, only fourteen species advancing beyond Mexico. Wrens, as a rule, are haunters of the undergrowth in well-thicketed places, but some species are marsh-inhabiting and others live among rocks. They are active, nervous little creatures, whose usually up-cocked tail is an index to their excitable dispositions. Their notes of alarm or displeasure are loud, harsh and insistent, but the songs of most species are marked by sweetness and brilliancy of execution. Their irrepressible energy finds expression in nests of great size or complex structure as well as in exceptionally large sets of eggs.

KEY TO THE SPECIES

A. Upperparts bright rufous, a long, conspieurus whitish line ower the eye;

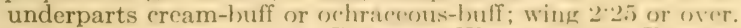

718. Carolina Wren. 718a. Florida Wren.

$B$. Upperparts not bright rufous.

a. Upperparts uniform dark, redclish olive-lorown; lack without whito streaks.

$a^{1}$. Underparts whitish; primaries fincly harred; ur white line over the? eye 721. Horse When. 721\%. Western Hotse Wran. $a^{2}$. Underparts whitish; primaries not barred; a white line over the reve. 719. BEWICK'S WREN. $\boldsymbol{a}^{3}$. Underparts brownish, finely barred with black. 722. W INTER Wien. 
b. Back with white streaks.

$b^{1}$. White streaks confined to the center of the back; a white line over the eye . 725. LONG-BILLed MARSH WRen and races.

$b^{2}$. Crown, back, and wing-coverts streaked with white.

724. Short-Billed Marsh Wren.

718. Thryothorus ludovicianus ludovicianus (Lath.). CAROLINA Wren. (Fig. 72c.) Ads.-Above bright rufous or rufous-brown without bars or streaks; feathers of rump with concealed downy white spots; a long, conspicuous whitish or buffy line over eye;' wings and tail rufous-brown, finely barred with black; underparts ochraceous-buff or cream-buff, whiter on the throat; flanks sometimes with a few blackish bars. Worn breeding plumage is dingier above and whiter below. The largest of our Wrens. L., $5 \cdot 50$; W., $2 \cdot 30$; T., $2 \cdot 00 ;$ B., ${ }^{\circ} 60$.

Range.-E. U. S. Breeds in Carolinian and Austroriparian faunas from se. Nebr., s. Iowa, Ohio, s. Pa., and lower Hudson and Conn. valleys s. to cen. Tex., Gulf States, and n. Fla.; casual n. to Wisc., Mich., Ont., Mass., N. H., and Maine.

Washington, common P. R. Cambridge, rare or casual. N. Ohio, tolerably common P. R.

Nest, bulky, of grasses, feathers, leaves, etc., lined with finer grasses, long hairs, etc., in holes in trees or stumps, nooks and crevices about buildings, etc. Eggs, 4-6, white or creamy white, with numerous cinnamon-, rufous-brown, and lavender markings, sometimes wreathed about the larger end, ' $75 \times{ }^{\circ} 58$. Date, Weaverville, N. C., Apl. 20 .

The cozy nooks and corners about the home of man which prove so attractive to the House Wren are less commonly chosen by this bird. His wild nature more often demands the freedom of the forests, and he shows no disposition to adapt himself to new conditions. Undergrowths near water, fallen tree tops, brush heaps, and rocky places in the woods where he can dodge in and out and in a twinkling appear or disappear like a feathered Jack-in-the-box, are the resorts he chooses.

The nervous activity so characteristic of all Wrens reaches in him its highest development. Whatever he may be when alone, he is never at rest so long as he imagines himself observed. Now he is on this side of us, now on that; a moment later, on a stump before us, bobbing up and down and gesticulating wildly with his expressive tail; but as a rule he is seldom in sight more than a second at a time. Of course, so excitable a nature must find other than physical outlet for its irrepressible energy, and the bird accompanies his movements by more or less appropriate notes: scolding cacks, clinking, metallic rattles, musical trills, tree-toadlike krrrings - in fact, he possesses an almost endless vocabulary. He is sometimes called Mocking Wren, but the hundreds of birds I have heard were all too original to borrow from others. In addition to his peculiar calls he possesses a variety of loud, ringing whistles, somewhat similar in tone to those of the Tufted Titmouse or Cardinal, and fully as loud as, if not louder than, the notes of the latter. The more common ones resemble the syllables whee-udel, whee-udel, whee-udel, and tea-kettle, tea-kettle, tea-kettle.

1909. Townsend, C. W., Auk, XXVI, 263-269 (in N. E.).

718a. T. 1. miamensis Rilgw. FlORIDA WREN. Similar to the preceding, but larger; above darker; below more deeply colored. W., $2 \cdot 46$; T., $2 \cdot 19 ;$ B., ·70. 
Range.-Florida s. of the Suwanee River, Gainesville, and Palatka. Nesting date, San Mateo, Fla., Apl. 6.

719. Thryomanes bewicki bewicki (Aud.). Bewick's Wren. Ads.Above dark cinnamon-brown without bars or streaks; feathers of rump with concealed, downy white spots; outer vane of primaries little if at all barred; central tail-feathers grayish-brown, barred, at least on sides, with black; outer ones black, tipped with grayish; the outer one or two with more or less bars on the outer vane; a white or buffy line over eye, underparts grayish white; flanks brownish. L., $5 \cdot 00$; W., $2 \cdot 30$; T., $2 \cdot 10$; B., 50 .

Range.-E. U. S. Breeds chiefly in Carolinian fauna from se. Nebr., n. Ills., s. Mich., and s. cen. Pa. s. to cen. Ark., n. Miss., cen. Ala., and along the Alleghanian highlands to $\mathrm{n}$. S. C.; winters from near n. limit of its range s. to Gulf coast and Fla.; accidental in Ont., and N. H.

Washington, rare and local T. V., Mch. 26-July- ; may winter, Nov. 24-Dec. 22.

Nest, resembles that of T. aëdon; location the same. Eggs, 4-6, white, speckled with cinnamon-, rufous-brown, or lavender, evenly, or in a wreath at the larger end, $66 \times \cdot 50$. Date, Buncombe Co., N. C., Apl. 14; Old Orchard, Maine, Apl. 20.

"No bird more deserves the protection of man than Bewick's Wren. He does not need man's encouragement, for he comes of his own accord and installs himself as a member of the community wherever it suits his taste. He is found about the cow-shed and barn along with the Pewce and Barn Swallow; he investigates the pig-sty, then explores the garden fence, and finally mounts to the roof and pours forth one of the sweetest songs that ever was heard. Not . . . like the House Wren's merry roundelay, but a fine, clear, bold song, uttered as the singer sits with head thrown back and long tail pendent-a song which may be heard a quarter of a mile or more, and in comparison with which the faint chant of the Song Sparrow sinks into insignificance. The ordinary note is a soft, low plit, uttered as the bird hops about, its long tail carried erect or even leaning forward, and jerked to one side at short intervals. In its movements it is altogether more deliberate than either $T$. ludovicianus or T. aërlon, but nothing can excel it in quickness when it is pursued" (Ridgway).

721. Troglodytes aëdon aëdon (Vicill.). Hotse Wren. Ads-Above cinnamon olive-brown, more rufous on the rump and tril; back generally with indistinet bars; feathers of the rump with concealed, downy white spots; wings and tail fincly barred; below grayish white, flankis rusty, sides and flanks usually, breast rarely, under tail-enverts always barred with blackish. L., 5•00; W., 1.97; T., 1·71; B., $\cdot 50$.

Range.-E. N. Am. Breeds chiofly in Transition and Upper Austral zones from e. Wisc., Mirh., cen. Ont., s. Que., and N. B. s. to Ky. and Va.; winters in e. Tex. and Tamaulipas, and in the S. Atlantir and Gulf States.

Washington, common S. R., Apl. 13-O).t. 11. ()ssining, (ommon S. R., Apl. 23-Oet. 14. Cambridge, formerly abundant S. R., Apl. 24 siput. 25; now rare and local. N. Ohio, common s. R., lpl. 17 () e.t. 5. (ilen Eillyn, S. R. in isolated pairs; $A p l .26$-Oct. 13. SE. AIImm., common S. R., Apl, 27Sept. 18.

Nest, of twigs lined with gr'tsses, feathers, ete., generally filling the hole in a tree, bird-box, crevice, etc., in which it is placerl. Eimgs, 68 , vinacenus, uniform, or minutely speckled, with generally a wreath of a deeper shade 
at the larger end, $65 \times \cdot 51$. Date, White Sulphur Springs, Va., Apl. 27; D. C., May 1; Cambridge, May 25; se. Minn., May 19.

It has been claimed that the name House Wren is a misnomer, because in the South during the winter these birds are found in the forests miles from the nearest habitation. This, however, is owing to circumstances over which the House Wren has no control. He is just as much of a House Wren in the south as he is in the north; you will find a pair in possession of every suitable dwelling. The difficulty is that in the winter there are more House Wrens than there are houses, and, being of a somewhat irritable disposition, the House Wren will not share his quarters with others of his kind. Late comers, therefore, who can not get a snug nook about a house or outbuilding, are forced to resort to the woods.

In the summer, when they are spread over a much greater area, House Wrens are very particular in their choice of haunts, and for this reason are locally distributed. Having selected a nesting-site, they become much attached to it, and return to the same place year after year. It may be a bird-box, a crevice in a building, a hollow in an apple tree, or hole in a fence rail; wherever it is, it is theirs, and they will fight for it against all comers.

The song of the House Wren is delivered with characteristic energya sudden outpouring of music which completely dominates the singer, who with raised head and drooped tail trembles with the violence of his effort.

1905. Herrick, F. H., Home Life of Wild Birds, 38-44.

721a. T. ä. parkmani (Aud.). Western Hodse WRen. Similar to $T$. aëdon aëdon but grayer, bars above usually more distinct; black bars of tail usually more or less margined posteriorly with grayish or buffy; flanks less rusty.

Range.-W. N. Am. Breeds in lower Canadian and Transition zones from s. B. C., n. Alberta, cen. Sask., and s. Man., s. to L. Calif., s. Ariz., sw. Tex., s. Mo., and s. Ills.; winters from Calif. and Tex. southward to Mex.

SE. Minn., common T. V., Apl. 26-Sept. 18.

722. Nannus hiemalis hiemalis (Vieill.). WINTER WREN. Ads.Tail very short; a cinnamon-buff line over eye; upperparts dark, nearly uniform cinnamon-brown; back indistinctly barred; feathers of the rump with concealed, downy white spots; wings and tail barred; underparts cinnamon-buff; flanks and belly heavily barred with black. L., $4^{*} 06 ;$ W., 1*89; T., $1 \cdot 24 ;$ B., $\cdot 35$.

Range.-E. N. Am. Breeds in Canadian zone from cen. Alberta, s. Man., n. Ont., n. Que., and N. F., s. to cen. Minn., n. Wisc., cen. Mich., and Mass., and through the Alleghanies to N. C.; winters from about its s. breeding limit to Tex. and n. Fla.

Washington, rather common W. V., Aug. 10-May 1. Ossining, tolerably common W. V., Sept. 18-Apl. 27. Cambridge, T. V., uncommon, Sept. 20 Nov. 25; rare, Apl. 10-25; a very few winter. N. Ohio, tolerably common W. V., Sept. 14-May 17. Glen Ellyn, fairly common, T. V., Apl. 1-May 10; Sept. 9-Nov. 7. SE. Minn., common T. V., rare W. V., Sept. 22-Apl. 3.

Nest, of small twigs and moss, lined with feathers, in the roots of a tree, brush-heap, or similar place. "Eggs, 5-7, white or creamy white, finely but 
rather sparingly speckled with reddish brown, sometimes nearly immaculate, '69 × '50" (Ridgw.). Date, Upton, Maine, June 11.

When looking for a Winter Wren during the fall migration I go to an old raspberry patch, and in the woods watch the stumps and fallen trees. In the shadow of the woods it is easy to overlook the small dark bird creeping under a log or clambering over an old stump. But often, when sitting alone in the deserted patch, my heart has been warmed by the sudden apparition of the plump little Nren atilt of a dry goldenrod stalk close beside me, his tail standing straight over his back and his head cocked on one side. He would bow to me with a droll bobbing motion, but his hearty quip-quap and the frank look of interest in his bright eyes showed that he was quite ready to make friends. Many a dull morning has been gladdened by such an encounter.

Perhaps my choicest memories, however, are of a Wren who left his usual home in the dark coniferous forest for our brighter woodlands of maple and beech. He built his nest in an upturned root on the edge of a bit of marshy land, helping himself to some feathers the Scarlet Tanager had left at his bath in the swamp behind.

I had never before had a chance to listen to his famous song, and it was the event of the summer in the woods. Full of trills, runs, and grace notes, it was a tinkling, rippling roundelay. It made me think of the song of the Ruby-crowned Kinglet, the volume and ringing quality of both being startling from birds of their size. But while the Kinglet's may be less hampered by considerations of tune, the Wren's song has a more appealing human character. It is like the bird himself. The dark swamps are made glad by the joyous, wonderful song.

Florence Merriam Bailey.

724. Cistothorus stellaris (Licht.). Short-Billed Marsh Wren. Ads.-Entire upperparts strcated with white, black, and ochraceous-buff; wings and tail barred; underparts unbarred, white; under tail-coverts, flanks, and a more or less 'broken band across breast ochraceous-buff. L., 4*00; W., 1•75; T., 1*41.

Range.-E. N. Am. Breeds in Transition and Upper Austral zones from se. Sask., s. Keewatin, s. Ont., and s. Maine, s. to e. Kans., cen. Mo., cen. Ind., and n. Del.; winters from s. Ills., and s. N. J. to s. Tex., La., and Fla.; accidental in Colo.

Washington, very rare $T$. V., two instances, May. Ossining, rare S. R., to Oct. 16. Cambridge, formerly locally common S. R., May 12-Sept. 25; now chiefly T.V. N. Ohio, rare, May $12,14,16$

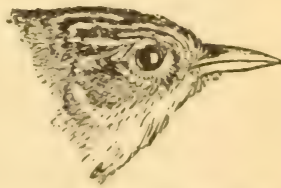

FIG. 132. Short-billed Marsh Wren. (Natural size.) and 19. Glen Ellyn, fairly common S. R., May 8 -Oct. 17. SE. Minn., (ommmon S. R., May 13-Sept. 19.

Nest, globular, the entrance on one side, of grasses, lined with plantdown, on or near the ground, in a tussock of tall grass. E!ygs, fi-s, pure white, rarely with a few lavender spots, $62 \times{ }^{4} 47$. Date, Cambridge, May 25.

This bustling, energetic little creature will much more often he heard than seen. Its ordinary call-note, like the sound of two pebbles 
struck together, may be heard in a dozen directions for a quarter of an hour before one of the birds comes in view, so careful are they to keep concealed among the protecting sedge. The ordinary song of the species has much the same timbre as the call-note; it resembles the syllables chap_chap-chap-chap, chap chap-chap-chap-p-p-rrrr; but during the height of the love season it vents its feelings in a much more ambitious refrain, one which, while it is everywhere varied and in parts very musical, is still conspicuous for the amount of chappering that enters into its composition. While singing, it is usually seen clinging to the side of some tall swaying reed with its tail bent forward so far as almost to touch the head, thus exhibiting in an exaggerated manner a characteristic attitude of all the Wrens.

This is less a species of the deep-water marshes than is the longbilled member of the genus, and often it will be found in places that are little more than damp meadows. It is remarkably mouselike in its habits and movements, and can be flushed only with extreme difficulty.

Ernest Thompson Seton.

725. Telmatodytes palustris palustris (Wils.). LONG-BILLED MARSH WREN. Crown unstreaked, its sides black, its center olive-brown, a white line over eye; middle of back black broadly streaked with white; rest of back cinnamon-brown; middle tail-feathers narrowly, outer tailfeathers broadly barred; below white, the sides and flanks pale cinnamonbrown sometimes extending to breast; under tail-coverts rarely barred. Specimens in worn

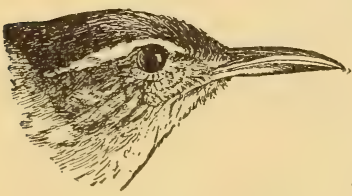

FIg. 133. Long-billed Marsh Wren. (Natural size.) breeding plumage are grayer.

Range.-E. U. S. Breeds in Transition and Upper Austral zones from s. Ont. and s. Que. s. to the Potomac Valley and coast of Va.; winters from s. N. J. to S. C. and casually to Fla.; casual in N. B.

Washington, very numerous S. R., Apl. 15-Nov. 1. Ossining, common S. R., May 10Oct. 28. Cambridge, locally abundant S. R., May 15-Oct. 1; sometimes a few winter. N. Ohio, common S. R., Apl. 21-Sept. 20. Glen Ellyn, fairly common S. R., May 16-Oct. 10.

Nest, globular, the entrance at one side, of coarse grasses, reed stalks, etc., lined with fine grasses, attached to reeds or bushes. Eggs, 5-9, uniform chocolate or minutely speckled or thickly marked with cinnamon- or olive-brown, ${ }^{\circ} 65 \times{ }^{*} 49$. Date, D. C., June 4; Cambridge, June 12 .

If you would make the acquaintance of this Marsh Wren, you have only to visit his home in the cattails and tall, reedy grasses bordering rivers, creeks, and sloughs. It will be unnecessary to announce yourself; he will know of your presence long before you know of his, and from the inner chambers of his dwelling will proceed certain scolding, cacking notes before this nervous, excitable bit of feathered life appears on his threshold. With many flourishes of the tail and much bobbing and attitudinizing, he inquires your business, but before you have had time enough to inspect him he has darted back into his damp retreats, and you can tell of his frequently changing position only by his scolding, grumbling notes. 
All this time his neighbors-and he generally has numbers of themhave doubtless been charming you with their rippling, bubbling, gurgling song. It is quite beyond their control ${ }_{4}^{\text {t }}$ hey seem filled to overflowing with an inexhaustible supply of music. Sometimes, like a mine of melody, it explodes within them and lifts them from the dark recesses of the flags up into the air above.

725b. T. p. griseus (Breust.). Worthiygton's Marsh Wren. Grayest of the Marsh Wrens. Ads.-Above olive-gray; sides of crown narrowly blackish, black of back much reduced in extent, white streaks less conspicuous than in other races; helow white, the sides grayish, bars, if present, indistinct; under tail-coierts barred, in this respect resemhling $T$. p. mariance from which it may be readily distinguished by its much grayer color. W., 1.80 ; T., $1.52 ;$ B., $\cdot 53$.

Range.-S. Atlantic coast region from S. C. to n. Fla.

725d. T. p. iliacus Ridgu. Pratrie MARsh Wren. "Similar to T. $p$. palustris, but slightly larger and with the coloration much more rufescent, the brown of the upperparts russet-brown to cinnamon-brown or russet, the flanks conspicuously deep cinnamon-buff or cinnamon" (Ridgw.).

Range.-Plains and Prairies of cen. N. A. Breeds in Transition and Upper Austral zones from cen. Alberta and sw. Keewatin s. to cen. Miss. Valley and e. to Ind.; winters s. along the Gulf coast to w. Fla. and s. to Mex. SE. Minn., common S. R., May 5-Sept. 9.

Nesting da e, se. Minn., June 3 (nest, no eggs).

725e. T. p. marianæ (Scott). Marian's Marsh Wren. Similar to T. $p$. palustris, but smaller, with the upperparts darker, the sides and flanks more heavily washed and of abrut the same color as rump: the under tail-coverts, and sometimes sides and breast barred or spotted with black. W., $1 \cdot 80 ;$ T., $1.50 ;$ B., 52 .

Remarks. - The amount of blark above is variable and the general tone of color in some specimens closely approaches that of T.p. pulustris, from which, however, the heavily barred under tail-coverts separate this race.

Range.-Coast of S. Atlantic States. Breeds on coast of N. C.; winters s. to S. C. and w. coast of Fla.

Nesting date, Matanzas Inlet, Fla., May 24.

\section{Family Certhimde. Creepers. (Fig. 73.)}

This is an Old World family, numbering about twelve species, of which only one is found in America where, represented by five subspecies, it ranges as far south as the southern extremity of the Mexiran tableland. It is a true tree-creeper, and, like a Woodpecker, uses its tail as a prop in climbing.

726. Certhia familiaris americana (BOnap.). BROWN (REEPER.

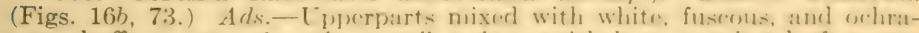
ceous-buff; rump pale rufous: tail pale grayish lorown; a hand of ereambuff through all but outer wing-feathers; bill enrwerl: tail-feathers stiffened and sharply pointed; underparts white. L., 5.66; W., 2.56; T., 2.65; B., 63.

Range.-E. N. Am. Breeds mainly in C'anarlian and Trancition zones from s. Man., cen. Ont., s. Que., and ... F. s. to e. Vebr.. n. Ind., n. N. Y., and Mass., and s. along the Alleghanies to X. C., and casually in se. Mo.; 
winters over a large part of its breeding range and s. to cen. Tex. and $\mathrm{n}$. Fla.

Washington, common W. V., Sept. 22-May 1. Ossining, tolerably common W. V., Sept. 20-May 7. Cambridge, common T. V., rather common W. V., Sept. 25-May 1; one summer record. N. Ohio, common W. V., Oct. 1-May 9. Glen Ellyn, tolerably common W. V., Sept. 15-May 19. SE. Minn., common T. V., uncommon W. V., Sept. 25-Mch. 30.

Nest, of twigs, strips of bark, bits of dead wood, moss, etc., placed behind the loose bark of a tree. Eggs, 5-8, white, spotted and speckled with cinnamon- or rufous-brown and lavender, chiefly in a wreath at the larger end, $62 \times \cdot 47$ (Brewster, Bull. Nutt. Orn. Club., IV, 1879, 199). Date, Holland Patent, N. Y., May 20.

The facts in the case will doubtless show that the patient, plodding Brown Creeper is searching for the insects, eggs, and larvæ which are hidden in crevices in the bark; but after watching him for several minutes one becomes impressed with the thought that he has lost the only thing in the world he ever cared for, and that his one object in life is to find it. Ignoring you completely, with scarcely a pause, he winds his way in a preoccupied, near-sighted manner up a tree trunk. Having finally reached the top of his spiral staircase, one might suppose he would rest long enough to survey his surroundings, but like a bit of loosened bark he drops off to the base of the nearest tree and resumes his never-ending task.

He has no time to waste in words, but occasionally, without stopping in his rounds, he utters a few screeping, squeaky notes, which are about as likely to attract attention as he is himself. As for song, one would say it was quite out of the question; but Mr. Brewster, in his biography of this bird, tells us that in its summer home, amid the northern spruces and firs, it has an exquisitely pure, tender song of four notes, "the first of moderate pitch, the second lower and less emphatic, the third rising again, and the last abruptly falling, but dying away in an indescribably plaintive cadence, like the soft sigh of the wind among the pine boughs."

1879. Brewster, W., Bull. Nutt. Orn. Club, IV, 199-209 (Biog.). -1895. Widmann, O., Auk, XII, 350-355 (nesting in Mo.).-1905. Chadbourne, A. P., Auk, XXII, 179-183; Kennard, F. H. and McKechnie, F. B., 183-193 (nesting in Mass.).

\section{Family Sittide. Nuthatches. (Fig. 74a.)}

The Nuthatches, numbering some seventy species, are mainly restricted to the northern parts of the Northern Hemisphere, four species occurring in the New World. Although expert creepers, they receive no support from the tail while climbing, nor does their foot conform to the usual Woodpecker type of two toes in front and two behind. Both their toes and toe-nails are, however, well developed, and the birds run up or down a tree trunk with equal ease. Their notes are pronounced, characteristic, and freely uttered, but their singing powers are limited. They rest in holes in trees, but, contrary to the 
rule that birds which nest in such situations lay white unmarked eggs, their eggs are spotted. Their name is derived from the habit of wedging a nut in a crevice of the bark and then attempting to 'hatch' or 'hack' it by repeated strokes with the bill.

\section{KEY TO THE SPECIES}

A. Underparts more or less washed with rufous; a black or gray streak through the eye . . . 728. RED-BREASTED NUTHATCH.

$B$. Underparts white or whitish; under tail-coverts more or less rufous; tail with white spots. 727 . White-Breasted Nuthatch. 727b. Florida Nuthatch.

C. Whole top of the head brown . . . 729. Brown-headed Nuthatch.

727. Sitta carolinensis carolinensis Lath. WHITE-BREASTED Nuthatch. (Fig. 74a.) Ad. $\sigma^{7}$.-Top of head shining black; rest of upperparts bluish gray; inner secondaries bluish gray, marked with black; wingcoverts and quills tipped with whitish; outer tail-feathers black, with white patches near their tips; middle ones bluish gray; sides of head and underparts white; lower belly and under tail-coverts mixed with rufous. Ad.. . Similar, but black of head veiled by bluish gray. L., $6 \cdot 07 ;$ T., $1 \cdot 92 ;$ B., 70 .

Range. -N. Am. e. of the Plains. Breeds in Canadian, Transition, and Upper Austral zones from n. Minn., cen. Ont., s. Que., and N. F., s. to the n. parts of the Gulf States; casual in Keewatin.

Washington, common T. V., and W. V., less common S. R. Ossining, common P. R. Cambridge, P. R., rare in summer, uncommon in winter, common in migrations; most numerous in Oct. and Nov. N. Ohio, common P. R. Glen Ellyn, fairly common P. R. SE. Minn., common P. R.

Nest, of feathers, leaves, etc., in a hole in a tree or stump. Eggs, 5-8, white or creamy white, thickly and rather evenly spotted and sperkled with rufous and lavender, $75 \times 57$. Date, Cambridge, Apl. 19; se. Minn., Apl. 7.

When the cares of a family devolve upon him, the Nuthatch eschews all society and rarely ventures far from his forest home. But in the winter I believe even the birds are affected by the oppressive loneliness; the strangers of summer become for a time boon companions, and we find Downy Woodpeckers, Chickadees, and Nuthatches wandering about the woods or visiting the orchards on apparently the best of terms.

Few birds are easier to identify: the Woodpecker pecks, the Chickadee calls chickadee, while the Nuthatch, rumning up and down the tree trunks, assumes attitudes no bird outside his fumily would think of attempting. His powers of speech are in nowise disturbed by his often inverted position, and he aceompanies his erratic clamberings by a conversational twitter or oecasionally a lourl, nasial yonk, yank, which frequently tells us of his presence hefore we see him.

He is not too absorbed in his business to have a mild interest in yours, and he may pause a moment to look you over in a calm kind of way, which somehow makes one feel that perhaps, after all, Nuthat ches are of as much importance as we. But his curiosity is soon satisfied; affairs are evidently pressing, and with a yank, yank, he resumes his search for certain tidbits in the shape of grubs or insects' eggs hidelen in the bark. 
There is such a lack of sentiment in the Nuthatch's character, he seems so matter-of-fact in all his ways, that it is difficult to imagine him indulging in anything like song. But even he can not withstand the all-conquering influences of spring, and at that season he raises his voice in a peculiar monotone-a tenor hah-hah-hah-hah-hah-sounding strangely like mirthless laughter.

727b. S. c. atkinsi Scott. Florida White-Breasted NUthatch. Similar to the preceding, but somewhat smaller, the wing-coverts and quills but slightly or not at all tipped with whitish, the female with the top of the head and nape black, as in the male. W., $3 \cdot 32$; T., $1 \cdot 80 ;$ B., $\cdot 70$.

Range.-Breeds in Austroriparian fauna from Miss. e. along the coast to Fla., and n. to S. C.

Nesting date, San Mateo, Fla., Mch. 16.

728. Sitta canadensis Linn. Red-Breasted Nuthatch. Ad. o.Top of head and a wide stripe through eye to nape shining black; a white line over eye; upperparts bluish gray, no black marks on secondaries, or tips to wing-coverts; outer tail-feathers black, with white patches near their tips; middle ones bluish gray; throat white; rest of underparts ochraceousbuff. Ad. o. - Similar, but top of head and stripe through the eye bluish

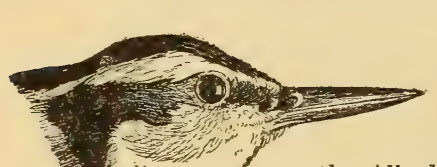
gray, like the back; underparts paler. L., $4 \cdot 62$; W., $2 \cdot 66$; T., $1 \cdot 58$; B., $\cdot 50$.

Range.-N. A. Breeds in Canadian zone from the upper Yukon Valley, and N. F., s. to n. Minn., Mich., and Mass., and s. in the Sierra Nevada and Rocky Mts. to Calif., Ariz., and N. M., and in the Alleghanies to N. C.; winters from s. Canada s. to L. Calif., and the Gulf States.

Washington, irregularly abundant W. V., sometimes rare, Sept. 15-May 10. Ossining, irregular W. V., Aug. 8-May 8. Cambridge, irregular T. V. Fig. 134. Red - breasted Nuthatch. (Natural size.) and W. V., Aug. 15-Nov. 25; Nov. 25-Apl. 15. N. Ohio, tolerably common W. V., Sept. 4-May 22. Glen Ellyn, irregular T. V., Apl. 24-May 21; Aug. 19-Dec. 12. SE. Minn., common T. V., uncommon W. V., Sept. 24Apl. 21.

Nest, of grasses, in a hole in a tree or stump. Eggs, 4-7, white or creamy white, speckled with cinnamon-, rufous-brown, and lavender, $60 \times{ }^{\circ} 47$. Date, Calais, Maine, May 7.

While resembling the White-breasted Nuthatch, this more northern species differs from it sufficiently both in notes and appearance to be easily distinguished. Its black face-stripe is a noticeable character, while to the trained ear its higher, finer, more nasal, slightly drawled, penny-trumpet-like yna, yna is quite unlike the White-breast's vigorous yank, yank. The Red-breast has an evident partiality for pine trees, and may be seen hovering about the cones while looking for a foothold from which to extract their seeds.

729. Sitta pusilla Lath. Brown-headed Nuthatch. Ads.-Top and back of head grayish brown, sometimes tipped with pale ashy; a whitish patch on nape; no white over eye; rest of upperparts bluish gray; outer tailfeathers black, tipped with grayish, middle ones bluish gray; underparts grayish white; the breast, particularly in the fall, with a tinge of buff; sides gray. L., $4 \cdot 50$; W., $2 \cdot 60$; T., $1 \cdot 25 ;$ B., 52 . 
Range.-SE. U. S. Breeds in Austroriparian fauna from s. Mo., and s. Del. s. to e. Tex. and s. Fla.; casual in s. Mich., Ohio, N. Y., and the Bahamas.

Nest, of feathers, grasses, etc., generally near the ground, in a hole in a tree or stump. Eggs, 5-6, white or creamy white, heavily spotted or blotched with cinnamon- or olive-brown, $56 \times \cdot 46$. Date, San Mateo, Fla., Mch. 4; Charleston, S. C., Mch. 12; Edgecombe Co., N. C., Mch. 28.

This little Nuthatch, the Red-cockaded Woodpecker, and Pine Warbler, are characteristic birds of the great pineries in our Southern States. Frequently they are found associated. The Woodpeckers generally keep to the tree tops, the Warblers live on or near the ground, while the Nuthatches scramble about from the base of the trunk to the terminal twigs, but feed chiefly among the smaller branches, actively and spirally, getting food which they take to the main trunk to wedge behind the large bark scales. They are talkative sprites, and, like a group of school children, each one chatters away without paying the slightest attention to what his companions are saying. When feeding they utter a liquid, conversational pit-pit, a note which is accelerated and emphasized as the birds take wing. At intervals, even when the individuals of a troop are quite widely separated, they all suddenly break out into a thin, metallic dee-dee-dee or tnee-tnee-tnee.

\section{Family Paride. Titmice. (Fig. 74b.)}

Like the Nuthatches, with which, after the nesting season, they are often associated, the Titmice are largely restricted to the more northern parts of the world. Of the two hundred and forty-one known species, fifteen are North American, where they range to the southern border of the Mexican tableland. They inhabit wooded countries, where their destructiveness to insects, their eggs and larva, is of incalculable value. Their nests vary widely in character. The true Titmice (P'ntheste's) excavate holes in dead trees; Egithalus builds a felted, purse-shaped structure of plant-down with the entrance near the top; Auripurus a not dissimilar but more globular home which is eovered with thorny twigs, and Psaltriparus a long, loosely-woven bag of plant-down, covered with lichens. They are migratory at the northern limit of their range and, except when nesting, are usually found in small troops.

KEY TO THE SPECIES

A. Crown brown; sides chestnut

740a. Acamian Chickadez.

B. Crown black; outer margin of greater wing-eoverts, distinctly whitish;

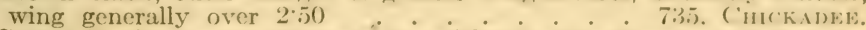

$C$. Crown black; greater wing-eoverts without white margins; wing under $2 \cdot 50$.

D. Crown gray, crested

736. Carolina Chickadee.

731. TEFTED Titmotse.

731. Breolophus bicolor (Linn.). TUFTED TiTMorse. Ads.-Irrad crested. Forehead black; rest of upperparts, wings, and tail gray; hack in winter tinged with olive-brown; underparts whitish; sides washed with rufous. L., $6 \cdot 00 ;$ W., $3 \cdot 10 ;$ T., $2 \cdot 70 ;$ B., 45 . 
Range.-Carolinian and Austroriparian faunas from Nebr., Iowa, Ills., Ind., Ohio, Pa., and N. J. s. to cen. Tex., the Gulf coast, and Fla.; casual in s. parts of Wisc., Mich., N. Y., and Conn.

Washington, very common P. R., more so in winter. N. Ohio, common P. R. Glen Ellyn, only two records, Apl. 4 and Nov. 19.

Nest, of leaves, moss, strips of bark, feathers, etc., in Woodpeckers' deserted holes, stumps, etc. Eggs, 5-8, white or creamy white, rather coarsely

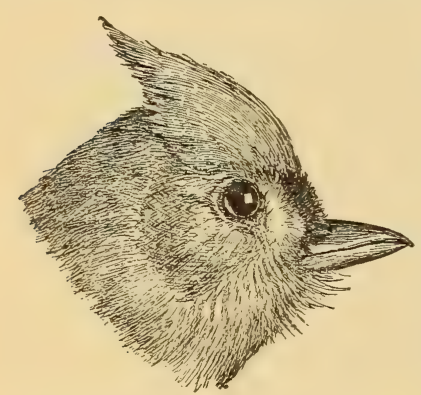

Frg. 135. Tufted Titmouse. (Natural size.) and evenly marked with rufous-brown, ' $71 \times$ '55. Date, Mt. Pleasant, S. C., Apl. 21; Weaverville, N. C., Apl. 8; Brookville, Ind., Apl. 22.

The Tufted Titmouse is a bird of very general distribution in woodlands, where its presence is always made known by its notes. Its common call is a loud, clearly whistled peto, peto, peto, peto, which may be repeated by the same individual for hours at a time. Occasionally the key is changed, and at first the notes are decidedly pleasing, but the bird finally wearies one by its monotonous repetition. It utters also other whistled calls, and a de-de-de-de, much like the notes of the Chickadee, though somewhat louder and hoarser. The Tufted Tit is not a shy bird and may be approached with ease. Its conspicuous crest is an excellent field-mark.

735. Penthestes atricapillus atricapillus (Linn.). ChICKAdEe. (Fig. 74b.) Ads.-Top of the head, nape, and throat shining black; sides of the head and neck white; back ashy; outer vanes of greater wing-coverts distinctly margined with white; wing and tail-feathers margined with whitish; breast white; belly and sides washed with cream-buff. L., $5 \cdot 27$; W., $2 \cdot 53$; T., $2 \cdot 43 ;$ B., 37 .

Range.-Canadian and Transition zones of e. N. A. from se. Keewatin, and N. F. s. to cen. Mo., Ills., n. Ind., Ohio, Pa., n. N. J., and in the Alleghanies s. to N. C.; somewhat further s. in winter.

Washington, rare and irregular W. V., Oct. 19-Apl. 19. Ossining, tolerably common P. R. Cambridge, common P. R., more numerous in fall and winter. N. Ohio, common P. R. Glen Ellyn, fairly common P. R. SE. Minn., common P. R.

Nest, of moss, grasses, feathers, and plant-down, in old stumps, holes in trees, etc., not more than 15 feet up. Eggs, 5-9, white, spotted and speckled, chiefly at the larger end, with cinnamon- or rufous-brown, $60 \times \cdot 48$. Date, Saybrook, Conn., May 6; Cambridge, May 10; Holland Patent, N. Y., May 15; Brookville, Ind., Apl. 22; se. Minn., May 11.

When most birds were strangers to me, I remember thinking what a blessing it would be if every one spoke his name as plainly as does this animated bunch of black and white feathers. No need of a text-book to discover his name; with winning confidence he introduced himself, and probably for this reason he has always been my best friend among birds. I never hear his voice in the woods without answering him:

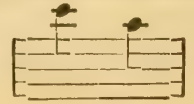

or

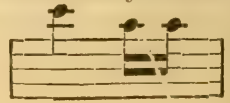


This is the so-called 'Phœbe' note, which, it may be added, is uttered by both sexes. Soon he comes to me, mildly inquisitive at first, looking about for the friend or foe whose call has attracted him. In an unconcerned way he hops from limb to limb, whistling softly the while, picking an insect's egg from beneath a leaf here or larva from a crevice in the bark there, all the time performing acrobatic feats of which an accomplished gymnast might be proud. Finally his curiosity becomes aroused, he ceases feeding, and gives his entire attention to the discovery of the bird who so regularly replies to him. Hopping down to a limb within three feet of my head, he regards me with puzzled intentness; his little black eyes twinkle with intelligence, he changes his call, and questions me with a series of chick- $\breve{a}$-dēees, liquid gurgles, and odd chuckling notes which it is beyond my power to answer, and finally, becoming discouraged, he refuses to renew our whistled conversation and retreats to the woods.

On several occasions Chickadees have flown down and perched upon my hand. During the few seconds they remained there I became rigid with the emotion of this novel experience. It was a mark of confidence which seemed to initiate me into the ranks of woodland dwellers.

1900. Chapman, F. M., Bird Studies with a Camera, 147-61 (nesting). 1911. Stanwood, C. J., Journ. Me. Orn. Soc., XIII, 25-32 (nesting).

736. Penthestes carolinensis carolinensis ( $A u d$.). CARolina ChICKADEE.- Similar to the preceding species, but smaller; greater wing-coverts not margined with whitish; wing and tail-feathers with less white on their outer vanes. L., 4.06-4.75; W., $2 \cdot 20-2 \cdot 48$; T., $1 \cdot 88-2 \cdot 12$; B., $30-32$.

Range.-SE. U. S. Breeds in Carolinian and Austroriparian faunas from cen. Mo., Ind., cen. Ohio, Pa. (sparingly), and cen. N. J., s. to se. La., the Gulf coast, and $\mathrm{n}$. Fla.

Washington, very common P. R., particularly in winter.

Nest, of grasses, fine strips of bark, feathers, hair, etc., in holes in trees, stumps, etc. Eggs, 5-8, similar in color to those of $I^{\prime}$. atricapillus. Date, Mt. Pleasant, S. C., Mch. 23; Iredell Co., N. C., Apl. 13; D. C., Apl. 24.

My experience with this southern Chickarlee has been confined largely to Florida. There I found it a comparatively shy bird, with notes quite unlike those of $P$. atricapillus. Instead of the two elear whistles which atricapillus in New Jersey utters, the Floridat hird repeates four rather tremulous notes, and there is also a substantial difference in its other calls, one of which resembles the words my watcher key, my watcher key.

Dr. C. W. Richmond writes me that at Washington the chick-řl-dēe call of carolinensis is higher pitched and more hurriedly given than that of atricapillus, and that the whistle ensists of three notes, but in New Jersey, Mr. WV. DeIV. MFiller tolls me that it consists of four.

Writing from the mountains of North Carolina, where both species occur together, Mrr. Brewster says: "In one place a male of each speciess was singing in the same tree the low, plainitive, tswee-dee-turseretlee of the $P$. carolinensis, contrasting sharply with the ringing te-derry of its more northern cousin" (The Auk, 1886, p. 177). 
736b. P. c. impiger (Bangs). Florida ChickadeE.-Similar to $P$. c. carolinensis, but smaller (except bill) and darker above.

Range.-Southern half of Florida.

740. Penthestes hudsonicus hudsonicus (Forst.). HudsonIAN ChICKADEe. Ads.-Crown dull, dark brownish gray; back brownish ashy; wings and tail grayish; throat black; ear-coverts, sides of the neck, breast, and belly white; sides rufous.

Range.-N. N. Am. Breeds in Hudsonian and Canadian zones from Kowak Valley, Alaska, and tree limit in cen. Mackenzie and cen. Keewatin s. to s. B. C., cen. Alberta (casually Mont.), n. Man., cen. Ont., and Ungava; s. in winter casually to $\mathrm{n}$. Ills.

740a. P. h. littoralis (Bryant). Acadian CHICKadeE.-Similar to $P$. $h$. hudsonicus, but smaller and browner.

Range.-NE. N. Am. Breeds in Boreal zones from n. Que., and N. F., s. to the Adirondacks of N. Y. and mts. of n. Vt. and cen. N. H.; migrating casually to Mass., R. I., and Conn.

Cambridge, rare, perhaps only casual, W. V., Nov. 1-Apl. 1.

Nest, of moss and felted fur, in holes in trees and stumps. Eggs, 6-7, not distinguishable from those of $P$. atricapillus, $\cdot 61 \times \cdot 50$. Date, Stewiacke, N. S., May 25.

The general habits of this northern Chickadee resemble those of atricapillus, but its notes are recognizably different. Wright (Auk, 1890, p. 407) speaks of its "sweet, warbling song," and Clark (Journ. Me. Orn. Soc., 1906, p. 27) writes of "a sweet, little song of three or four notes," but Brewster ("Birds of the Cambridge Region," p. 379) says "besides low, chattering, conversational sounds-difficult of description but far from musical in character-which the birds occasionally make while feeding, I have heard them utter only a low chip much like that of the common Chickadee, but rather feebler, an abrupt, explosive tch-tchip, and a nasal drawling tchick, chee-day-day. In the call last mentioned the intervals between the doubled middle note and the single notes which precede and follow it are very pronounced, and the accented notes are very strongly emphasized - characteristics which serve at once to distinguish these sounds from any that the Black-capped Chickadee ever produces."

1910. Allen, F. H., The Auk, XXVII, 86 (song).

\section{Family Sylvidde. Old-World Warblers, Kinglets, and Gnatcatchers. (Fig. 75.)}

No generally accepted classification of the birds of this family has as yet been proposed, but for our present purposes they may be divided into three subfamilies: (1) The Sylviince, or Old-World Warblers, numbering some five hundred species, confined exclusively to the Old-World, with the exception of one species found in Alaska; (2) the Regulince, or Kinglets, of which two of the seven known species are found in the New World; (3) the Polioptilince, or Gnatcatchers, an American group containing about fifteen species, three of which are found in the United States. 
The Old-World Warblers are generally dull, olivaceous birds with ten, instead of the nine, primaries of our Mniotiltida, with which, indeed, they have no close relationship. Many of the species are highly musical, whence the origin of the family name, a misfit when applied to the NewWorld Warblers, to which it was given because of their superficial resemblance to the Old-World forms, rather than for their musical endowments. The Kinglets and Gnatcatchers are typically represented by the species described below.

\section{KEY TO THE SPECIES}

A. With a bright-colored crest.
a. Crest ruby, without black
$b$. Crest yellow, or orange and yellow, bordered by black.

B. Without a colored crest.

748. Golden-Crowned Kinglet.

a. Back ashy blue; outer tail-feathers white.

751. Blue-gray Gnatcatcher.

b. Back olive-green; no white in tail. RUBY-CROWNED KINGLE' (q and im.).

748. Regulus satrapa satrapa Licht. Golden-Crowned Kinglet. $A d$. $\sigma^{7}$.-Center of crown bright reddish orange, bordered by yellow and black; a whitish line over the eye; rest of upperparts olive-green; wings and tail fuscous, margined with olive-green; tail slightly forked; underparts soiled whitish. Ad. o. - Similar, but crown without orange, its center bright yellow, bordered on each side by black. L., 4.07; W., $2 \cdot 14$; T., $1 \cdot 75$; B., '28.

Range.-E. N. Am. Breeds in Boreal zones from n. Alberta, s. Keewatin, s. Ungava, and Cape Breton Is. s. in Rocky Mts. to n. Ariz. and N. M., and to Mich., N. Y., and mts. of Mass., and in the higher Alleghanies s. to N. C.; winters from Iowa (casually Minn.), Ont., and N. B. to n. Fla. and Mex.

Washington, abundant W. V., Sept. 30-Apl. 27. Ossining, common W. V., Sept. 20-Apl. 28. Cambridge, very common $T$. V., not uncommon

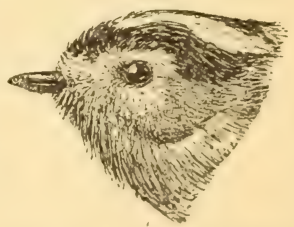

FIG. 136. Golden-crowned Kinglet. (Natural size.)

W. V., Sept. 25-Apl. 20. N. Ohio, common W. V., Sept. 26-May 4. Glen Ellyn, common T. V., irregular W. V., Sept. 19-May 8. SE. Minn., common T. V., Mch. 30- ; Sept. 21-Dec. 1.

Nest, generally pensile, of green mosses, lined with fine strips of soft inner bark, fine black rootlets, and feathers, in coniferous trees, 6-60 fert from the ground. Eggs, 9-10, creamy white to muddy eream-color, speckled and blotched with pale wood-brown, and rarely, faint lavender, $5.5 \times 44$. (See Brewster, Auk, V, 1888, 337.) Date, Grand Menan, N. B., May 24.

This Kinglet resembles in habits its ruby-crowned cousin, with which during the migrations it is frequently associated. It.s notes, however, are quite unlike those of that species, its usual call-note bring a fine, high $t i-t i$, audible only to practiced ears. In his extended account of the nesting habits of this species, as observed by him in Worecster County, Mass. (Auk.l. c.), Mr. Brewster writes that its song "begins with a succession of five or six fine, shrill, high-pitched, somewhat faltering notes, and ends with a short, rapid, rather explosive warble. The opening notes are given in a rising key, but the song falls rapidly 
at the end. The whole may be expressed as follows: tzee, tzee, tzee, tzee, $t i, t i$, ter, $t i$-ti-ti-ti."

Muffled in its thick coat of feathers, the diminutive Goldcrest braves our severest winters, living evidence that, given an abundance of food, temperature is a secondary factor in a bird's existence.

749. Regulus calendula calendula (Linn.). RUBY-CROWNED KINGLET. (Fig. $75 a$.) $A d .0^{7}$.-Crown with a partly concealed crest of bright red; rest of upperparts grayish olive-green, brighter on the rump; wings and tail fuscous, edged with olive-green; two whitish wing-bars; tail slightly forked, the middle feathers shortest; underparts soiled whitish, more or less tinged with buffy. Ad. \& and Im. - Similar, but without the red crown-patch. L., $4 \cdot 41$; W., $2 \cdot 24$; T., $1 \cdot 73$; B., $\cdot 29$.

Remarks.-Females and young are warblerlike in general appearance, but note the short first primary, barely one inch in length.

Range.-N. N. Am. Breeds in Boreal zones from nw. Alaska, and w. cen. Ungava s. in mts. to s. Calif., s. Ariz., cen. N. M., n. Ont., N. B., and N. S. (casually Maine); winters from s. B. C., Iowa, and Va. (casually further n.) s. to Guatemala.

Washington, abundant T. V., Apl. 12-May 15; Sept. 25-Nov. 1; occasionally winters. Ossining, common T. V., Apl. 8-May 13; Sept. 16-Nov. 3. Cambridge, rather commion T. V., Apl. 12-May 5; Oct. 10-30. N. Ohio, common T. V., Apl. 1-May 23; Sept. 9-Nov. 3. Glen Ellyn, fairly common T. V., Mch. 22-May 19; Sept. 9-Oct. 27. SE. Minn., Mch. 12- ; Sept. 18Oct. 24 .

Nest, usually semipensile, of moss and fine strips of bark, neatly interwoven, lined with feathers, in coniferous trees, 12-30 feet from the ground. Eggs, 5-9, dull whitish or pale buffy, faintly speckled or spotted with pale brown, chiefly at the larger end, $55 \times{ }^{\circ} 43$ (Davie). Date, Boulder Co., Colo., June 3.

When the leaves begin to turn you will notice numerous very small, olive-green birds flitting about the terminal twigs of the trees and lower growth, in the woods, orchards, or hedgerows. They resemble Warblers, but are much tamer-you can almost touch them-and have a habit of nervously flitting their wings every few seconds, perhaps accompanying the action by a wrenlike, scolding note. You will not often hear them sing at this season, and there is little in their voice or appearance to tell you that they are among the most famous of feathered songsters.

The May morning when first I heard this Kinglet's song is among the most memorable of my early ornithological experiences. The bird was in the tree-tops in the most impassable bit of woods near my home. The longer and more eagerly I followed the unseen singer the greater the mystery became. It seemed impossible that a bird which I supposed was at least as large as a Bluebird could escape observation in the partly leaved trees. The song was mellow and flutelike, and loud enough to be heard several hundred yards; an intricate warble past imitation or description, and rendered so admirably that I never hear it now without feeling an impulse to applaud. The bird is so small, the song so rich and full, that one is reminded of a chorister with the voice of an adult soprano. To extend the comparison, one watches this gifted but unconscious musician flitting about the trees with somewhat 
the feeling that one observes the choir-boy doffing his surplice and joining his comrades for a game of tag.

751. Polioptila cærulea cærulea (Linn.). Blde-gray Gnatcatcher. (Fig. 75b.) $A d$. $\sigma^{3}$-- Upperparts bluish gray; forehead and front of the head narrowly bordered by black; wings edged with grayish, the secondaries bordered with whitish; outer tail-feathers white, changing gradually until the middle ones are black; underparts dull grayish white. $A d$. o.-Similar, but without the black on the head. L., $4 \cdot 50$; W., $2 \cdot 05$; T., $2 \cdot 00$; B., $\cdot 40$.

Range.-SE. U. S. Breeds in Austroriparian and Carolinian faunas from e. Nebr., and s. parts of Wisc., Mich., and Ont., and sw. Pa., MId., and s. N. J. s. to s. Tex. and cen. Fla.; winters from s. Tex., Gulf States, and n. Fla. to the West Indies and Cen. Am.; casual n. to se. Minn., New England, and N. Y.

W ashington, rather common S. R., Mch. 30-Nov. 23. N. Ohio, common S. R., Apl. 20-Sept. 15. Glen Ellyn, not common, S. R., Apl. 22-Aug. 20; possibly later. SE. Minn., rare S. R.

Nest, of tendrils, fine strips of bark, and fine grasses firmly interwoven and covered externally with lichens, on a horizontal branch or in a crotch, 10-60, usually 30 feet up. Eggs, 4-5, bluish white, thickly spotted and speckled with cinnamon-, rufous-brown, or umber, $56 \times \cdot 46$. Date, Mt. Pleasant, S. C., Apl. 17; Iredell Co., N. C., May 6.

The Blue-gray Gnatcatcher frequents rather densely foliaged trees, generally in the woods, showing a preference for the upper branches. He is a bird of strong character, and always seems to me like a miniature Mockingbird with some of the habits of Kinglets. His exquisitely finished song is quite as remarkable as the ordinary performance of his large prototype, but is possessed of so little volume as to be inaudible unless one is quite near the singer. His characteristic call-note-a rather sudden ting, like the twang of a banjo string - can be heard at a greater distance.

66. Family Turdide. Thrushes, Bluebirds, Etc. (Fig. 76.)

The some six hundred species included in this large family are placed by systematists in several subfamilies. About two hundred and forty are true Thrushes belonging in the subfamily Turdiure, the juvernal plumage of which is always more or less spotted. These are dist ributed throughout the world, eighty inhabiting the New Horld, twelve of which are found north of Mexico. Thrushes inhabit woolded regions; our species are migratory, and gregarious or socialshe fo a greater or less extent during their migrations and in winter. As songsters, they are inferior to some of our birds in power of exerution, but their voices are possessed of greater sweetness and expression, and they are conceded first rank among song birds by all true lovers of bird inusice.

KEY TO THE SPECIES

I. Tail blue, back blue or bluish

760. BLUEBird.

II. Tail not blue.

1. Tail with white.

$A$. Tail black, outer feathers tipped with whito. 761 . 76 ilh, Romis. $B$. Tail white tipped with black . . 765a. Greenland Whitear. 
2. No white in tail; which is olive-brown or rufous.

A. Tail not brighter than back.

a. Upperparts cinnamon-rufous.

$a^{1}$. Entire underparts, including sides, more or less heavily marked with round, black spots; back brighter than tail.

755. WoOD Thrush.

$a^{2}$. Throat and upper breast pale buffy, with small, cinnamonbrown, wedge-shaped spots; belly pure white; sides with a b. Upperparts olive.

barely perceptible grayish wash . . 756. WiLson's Thrush.

$b^{1}$. Throat, breast, cheeks, eye-ring, and lores deep cream-buff.

758a. Olive-BACKed Thrush.

$b^{2}$. Throat, and breast, white, with only a very slight buffy tinge; eye-ring whitish, lores grayish.

757. Gray-Cheeked Thrush. 757a. Bicknell's Thrush.

B. Tail brighter than back.

a. Upperparts olive-brown, sometimes inclining to cinnamon; upper tail-coverts and tail rufous . . . 759b. Hermit Thrush.

755. Hylocichla mustelina (Gmel.). Wood Thrush. Ads.-Upperparts bright cinnamon-brown, brightest on the head, and changing gradually to pale olive-brown on the upper tail-coverts and tail; underparts white, thickly marked with large, round black spots except on the throat and middle of the belly. L., $8 \cdot 29$; W., $4 \cdot 44$; T., $2 \cdot 92$; B., ${ }^{\circ} 65$.

Remarks. - The Wood Thrush may be distinguished from our other Thrushes (1) by its larger size; (2) by its brighter, more rufous color above; and (3) especially by the numerous large, round black spots on its underparts. These cover not only the breast, but are equally numerous on the sides, where they extend well up under the wings.

Range.-E. N. Am. Breeds in Alleghanian and Carolinian faunas from s. S. D., cen. Minn., cen. Wisc., s. Ont., and s. N. H. s. to e. Tex., La., and n. Fla.; winters from s. Mex., to Costa Rica; casual in Maine.

Washington, common S. R., Apl. 19-Oct. 10. Ossining, common S. R., Apl. 30-Oct. 2. Cambridge, locally common S. R., May 10-Sept. 15. N. Ohio, common S. R., Apl. 20-Oct. 1. Glen Ellyn, fairly common S. R., Apl. 30-Sept. 29. SE. Minn., common S. R., May 1-Sept. 19.

Nest, of leaves, rootlets, fine twigs, and weed stalks, firmly interwoven, with an inner wall of mud and lining of fine rootlets, generally in saplings, about 8 feet up. Eggs, 3-5, greenish blue, lighter and with less green than those of the Catbird, averaging lighter, but not certainly distinguishable in color from those of the Robin, 1.05 x:76. Date, Yemassee, S. C., May 12; D. C., May 1; Chester Co., Pa., May 17; Cambridg, May 26; se. Minn., May 26.

The Wood Thrush is not so distinctively a bird of the woods as the Veery. Well-shaded lawns are sometimes graced by its presence, and at all times it is more familiar and easier to observe than its retiring relative. Large size, bright cinnamon upperparts, and especially a conspicuously spotted breast and sides, are its most striking field characters.

The Wood Thrush's call-notes are a liquid quirt and a sharp pit-pit. The latter is the more characteristic and is often heard after nightfall. When the bird is alarmed or imagines its young in danger, its loud and rapid utterance of this call, resembling the sound producedby striking large pebbles together, gives painful evidence of its fear and anxiety.

The songs of the Wood and Hermit Thrushes are of the same char- 


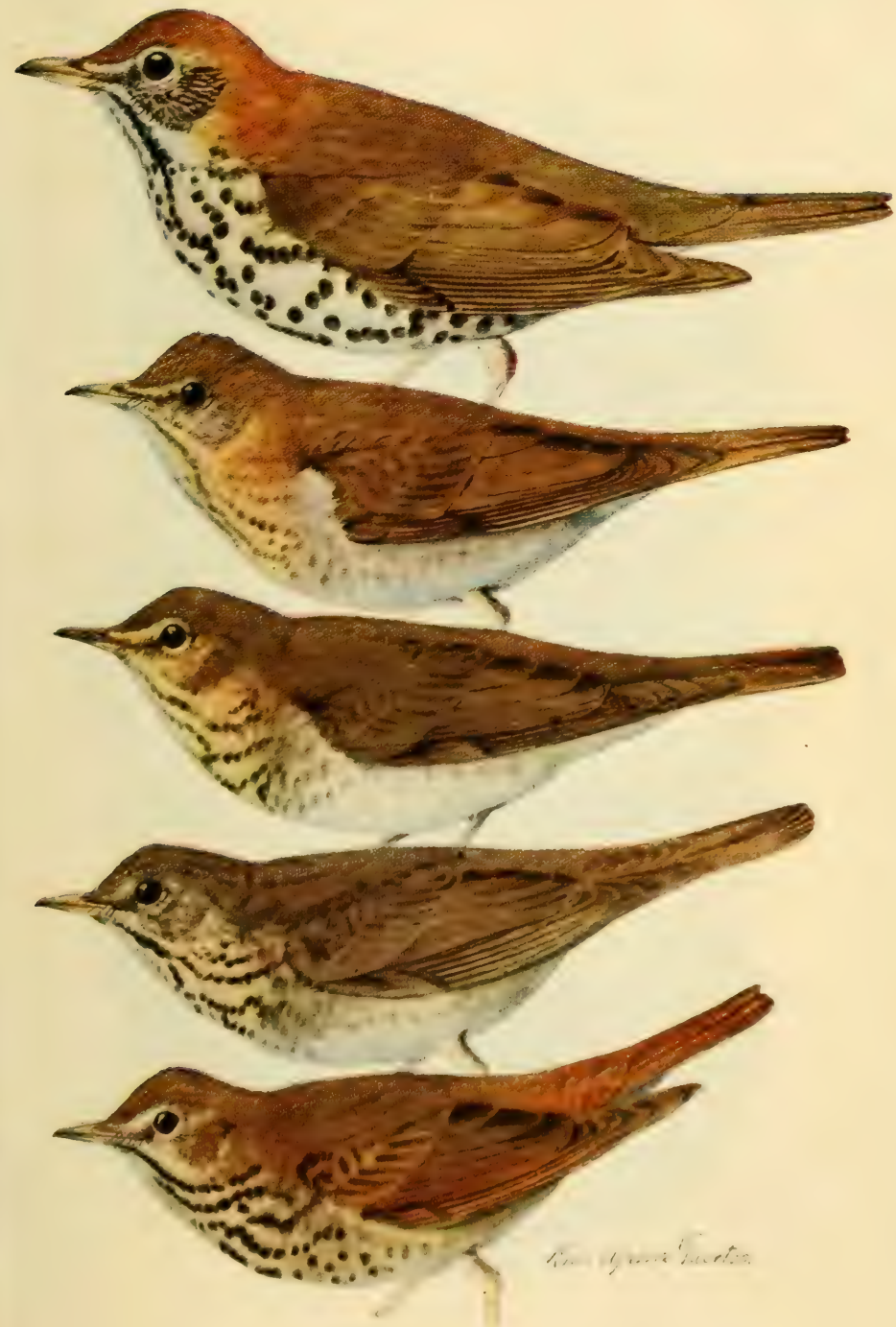

Thrushes of the Gents Hylocichla

1. Wood Thrush.

2. Veery.
3. Olive-backed Thrush.

4. Gray-cheeked Thrush.

5. Hermit Thrush. 

acter, but, while the Hermit is the more gifted performer, the Wood Thrush does not suffer by the comparison. His calm, restful song rings through the woods like a hymn of praise rising pure and clear from a thankful heart. It is a message of hope and good cheer in the morning, a benediction at the close of day:

The flutelike opening notes are an invitation to his haunts; a call from Nature to yield ourselves to the ennobling influences of the forest.

1910. Weygandt, C., Cassinia, 21-27 (biography).

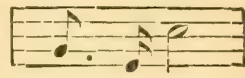

Come to me.

756. Hylocichla fuscescens fuscescens (Steph.). VEERY. Ads.Upperparts, wings, and tail nearly uniform cinnamon-brown, not so bright as in the Wood Thrush; center of the throat white; sides of the throat and breast with a delicate tinge of cream-buff, spotted with small wedge-shaped spots of nearly the same color as the back; belly white; sides white, with only a faint tinge of grayish. L., $7 \cdot 52$; W., $3 \cdot 84 ;$ T., $2 \cdot 87$; B., 53.

Remarks. - The Veery's distinguishing characters are (1) its uniform cinnamon-brown upperparts; (2) its delicately marked breast ; and (3) particularly its almost white sides. The Wood Thrush has the sides heavily spotted, and the other Thrushes have this part more or less strongly washed with grayish or brownish.

Range.-E. N. Am. Breeds in lower Canadian and Alleghanian faunas from n. Mich., cen. Ont., Anticosti, and $N$. F., s. to n. Ills., n. Ind., n. Ohio, and $\mathrm{n}$. N. J., and in the Alleghanies to N. C. and $\mathrm{n}$. Gia.; winters in $\mathrm{n}$. S. A.

Washington, common T. V., Apl. 26-Juno 2. Aug. 18 . Ápt. 25. (Ossining, common S. R., Apl. 29-Sept. 5. Cambridere, locally abundant S. R., May 8-Sept. 5. N. Ohio, common S. R., Apl. 20-Oct. 1. Gilen Ellyn, tolerably common, T. V., Apl. 24-May 29; Aug. 26-Sept. 3.

Nest, of strips of bark, rootlets, and leaves, wrapped with leares and lined with rootlets, on or near the ground. Eggys, 3-5, greenish blue, of the same shade as those of the Wood Thrush, six $\times \cdot(j ;$.$) Date, ()ssining, \mathrm{N}$. Y., May 26; Cambridge, May 28; Farmington, Maine, June 2.

The Veery's home is in low, wet, rather denscly undergrown woodlands. He is a more retiring bird than the Wood Thrush; he lives nearer the ground and is less likely to leave the cover of his haunts. For this reason, even in localities where both are equally common, the Wood Thrush is more frequently observed.

The Veery's call-notes are a clearly whistled whereo or whe'-you, the first note the higher, and a somewhat softor loo-wher or trueri, with the first note lower, all of which can be rescely imitated. His song is at weird, ringing monotone of blended alto and soprano tones. Neither notes nor letters can toll one of its peruliar qutiality; it has neither break nor pause, and seems to (rmanate from no one plater. If youl ("an imagine the syllables vec-r-r-hu repeated eight or nine times around a series of intertwining circles, the description may (mable you to recognize the Veery's song.

The Veery has a double persomality, or he may repeat the motes of some less vocally developerl aneestor, for on oceasions he gires ulterance to an entirely uncharactoristic scries of rorling notes, and even mounts high in the trer to sing a hesitating molley of the same unmusical cacks, broken whistlert calls, and atfomptal trills. Fortunately, this performance is comparatively uncommon, and to most of us the 
Veery is known only by his own strange, unearthly song. His notes touch chords which no other bird's song reaches. The Water-Thrush is inspiring, the Wood and Hermit Thrushes "serenely exalt the spirit," but the Veery appeals to even higher feelings; all the wondrous mysteries of the woods find a voice in his song; he thrills us with emotions we can not express.

756a. H. f. salicicola Ridgw. Willow Thrush. Similar to the preceding, but with the upperparts slightly darker. Miss.

Range.-W. N. Am., eastward in migration to Wisc., Ills., Ind., and

Glen Ellyn, tolerably common T. V., May 3-June 4; Aug. 26-Sept. 17. SE. Minn., common S. R., May 5.

Nesting date, se. Minn., May 24.

75\%. Hylocichla aliciæe aliciæ (Baird). Gray-cheeked Thrush. Ad.-Upperparts uniform olive, practically no difference between the colors of the back and tail; eye-ring whitish, lores grayish; middle of the throat and middle of the belly white; sides of the throat and breast with a very faint tinge of cream-buff (richer in the fall); the feathers of the sides of the throat spotted with wedge-shaped marks, those of the breast with halfround black marks; sides brownish gray or brownish ashy. L., 7·58; W., 4.09; T., 2*96; B., '55.

Remarks.-The uniform olive of the upperparts of this species at once separates it from our other eastern Thrushes except its subspecies bicknelli and the Olive-backed Thrush. From the latter it may be known by the comparative absence of buff on the breast and sides of the throat, by its whitish eye-ring and grayish lores.

Range.-N. A. Breeds in Hudsonian zone in a narrow belt just s. of tree limit from ne. Siberia to cen. Ungava, and N. F.; winters in S. A.

Washington, rather common T. V., May 8-31; Sept. 15-Oct. 20. Ossining, tolerably common T. V., May 15-June 1; Sept. 20-Oct. 17. Cambridge, uncommon T. V., May 18-28; Sept. 15-Oct. 9. N. Ohio, not common T. V., Apl. 29-May 23. Glen Ellyn, common T. V., May 1-June 4; Aug. 26-Oct. 9. SE. Minn., common T. V., May 7- ; Sept. 8.

Nest, of grasses, leaves, strips of fine bark, etc., lined with fine grasses, in low trees or bushes. Eggs, 4, greenish blue, spotted with rusty brown, $\cdot 92 \times$ *67. Date, Ft. Yukon, Alaska, June 9 .

The Gray-cheeked and Bicknell's Thrushes differ more widely in name than in anything else. As a matter of fact, they are representatives of one and the same species which, in the northern parts of its range, is somewhat larger than it is in the southern parts of its range. But here the difference stops: the northern bird (alicia) resembling the southern bird (bicknelli) in notes and habits; while the difference between them in size is so slight that during their migrations, where both might be expected to occur together, it would be impossible to say which bird was under observation. During the nesting season, however, it will be safe to call any olive-backed, gray-cheeked Thrush found south of the St. Lawrence, Bicknell's and all to the north of that river the Gray-cheeked.

The Olive-backed Thrush (swainsoni) may be distinguished in life from the gray-cheeked bird (alicio and bicknelli) by its buff cheeks and eye-ring; but the identification should be made under favorable conditions and by one familiar with specimens of the birds. 
757a. H. a. bicknelli Ridgu. BiCKNeLL's ThRESH. Similar to the preceding, but smaller. L., $6 \cdot 25-7 \cdot 25$; W., $3 \cdot 40-3 \cdot 80$; T., $2 \cdot 60-2 \cdot 70$; B., $\cdot 50-52$ (Ridgw.).

Range.-E. N. Am. Breeds in Hudsonian and upper Canadian zones in N. S., mts. of n. Jew England, the Catskills and Adirondack of N. Y., and probably mts. of $w$. Mass.; migrates through se. L. S. and the Bahamas; winters in Haiti and probably n. S. A.

Washington, apparently rare T. V., May 1t-23; Oct. 3. Cambridge, rather common T. V., May 2-May 30; Sept. 25-Oct. 5.

Nest, essentially like that of $H$. u. surainsoni, both in construction and position. Eggs, greener and more finely spotted than those of swainsoni (Brewster, Minot's Land Birds and Game Birds, 2d ed., appendix, 468). Date, Seal Island, N. S., June 13 (Thayer Coll.).

"In northern New England Bicknell's Thrush breeds from an altitude of about three thousand feet (scattered pairs may be found lower than this) to the extreme upper limits of tree growth, but most abundantly among the dwarfed, densely matted spruces and balsams which cover such extensive areas on the upper slopes and ridges of our higher mountains. Here, in an atmosphere always cool and ordinarily saturated with moisture from passing clouds, it spends the summer in company with such birds as Swainson's Thrushes, Winter Wrens, Yellow-rumped and Black-poll Warblers, Juncos, White-throated Sparrows, and Yellow-bellied Flycatchers. In riany places it is quite as numerous as any of these species, and in certain farored localities it probably outnumbers them all put together. Nevertheless one may spend hours in its chosen haunts without getting a fair view of a single individual, for, despite (or perhaps really because of) the fact that these solitudes are rarely invaded by man, Bicknell's Thrush is, while breeding, one of the very shyest of our smaller birds.

"The song is exceedingly like that of the Veery, having the same ringing, flutelike quality; but it is more interrupted, and it ends differently - the next to the last note dropping a half tone, and the final one rising abruptly and having a sharp emphasis. The ordinary (ails are a whistled phen practically identimal with that of $I I$. fuscescens, a harsh note which recalls the cry of the Night Hawk, a low cluck much like that of the Hormit Thrush, and a pip or peenli similar to that of Swainson's [ = Olive-backed] Thrush. The last is rarely heard" (Brew'ster, Minot's Land and Game Birds, p. 467).

1882. Bicknell, E. P., Bull. Nutt. Orn. Cluh, VII, 152-159.-1883. Brewster, W., Ibid, VIII, 12-17 (biographical).

758a. Hylocichla ustulata swainsoni (Tschudi). OLIVE-BA('KED Thrush. Ad. Upperparts uniform olite; back and tail practically the same color; eye-ring deep cream-bubf, lores the same; whole throat and breast with a strong tinge of deep cream-buff or even ochrareous-buff: the feathers of the sides of the throat with wedge-shaped hlackspots at their tips, these of the breast with rounded black spots at their tips: mirldle of the belly white;

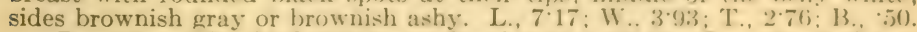
Remarks. - This bird will be confused only with the Ciray-reherked and Bicknell's Thrushes, from which it differs in the murch stronger suffusion of buff on the throat and breast, its buff eye-ring and lores.

Range.-N. A. Breeds in lower Hudsonian and (anathian zone's from 
nw. Alaska, to s. Ungava, and N. F., s. to Kenai Peninsula, Alaska, e. Ore., Nev., Utah, Colo., n. Mich., N. Y., and in mts. from Mass. to Pa., and W. Va.; winters from s. Mex. to S. A.

Washington, common T. V., Apl. 19-June 2; Sept. 2-Nov. 1. Ossining, tolerably common T. V., May 2-30; Sept. 19-Oct. 22. Cambridge, common T. V., May 12-28; Sept. 15-Oct. 5. N. Ohio, common T. V., Apl. 22-June 13; Sept. 2-Oct. 24. Glen Ellyn, common T. V., Apl. 23-June 6; Aug. 16Oct. 24. SE. Minn., common T. V., May 1- ; Sept. 25- .

Nest, of coarse grasses, moss, rootlets, leaves and bark, lined with rootlets and grasses, in bushes or small trees, about 4 feet up. Eggs, 3-4, greenish blue, more or less spotted and speckled with cinnamon-brown or rufous, '90 × 64. Date, Upton, Maine, June 4.

Passing northward in the spring, in small, silent bands, scattered through the woodland undergrowth, whence they quietly slip away, if disturbed, often to the higher branches of the trees, these birds easily escape observation. In late September or early October their loud, metallic call-notes may be recognized overhead at night, and during the day the birds themselves may be iound on the edges of the woods or along tangled hedgerows, associated with Sparrows and other migrants. Their summer home is in the coniferous forest of the North, although they do not confine themselves strictly to the evergreen woods, and, avoiding its depths, seek rather the vicinity of clearings well grown up with firs and spruces. Here, day after day, the same musician may be seen pouring forth his ringing song from some commanding elevation-preferably a dead tree top. If approached, he promptly dives down into the underbrush, where he is very likely joined by his mate, and both proceed to scold, in a mild way, the chance intruder. Little is ever seen of these shy birds, but fortunately their notes are quite characteristic, and the sole obstacle in distinguishing them from those of the Hermit Thrush, a bird frequenting the same localities, lies in the difficulty of tracing them to their source.

The effect of its loud and beautiful song is much enhanced by the evening hush in which it is most often heard. It lacks the leisurely sweetness of the Hermit Thrush's outpourings, nor is there pause, but in lower key and with greater energy it bubbles on rapidly to a close rather than fading out with the soft melody of its renowned rival. There are also a variety of other notes, the most frequent being a $p \breve{k} k$ of alarm, pitched higher than a corresponding cluck of the Hermit Thrush.

J. Dwight, JR.

759b. Hylocichla guttata pallasi ( $C a b$.). Hermit Thrush. Ad.Upperparts olive-brown, sometimes cinnamon-brown; tail pale rufous, of a distinctly different color from the back; throat and breast with a slight buffy tinge; feathers of the sides of the throat with wedge-shaped black spots at their tips; those of the breast with large, rounded spots; middle of the belly white; sides brownish gray or brownish ashy. L., $7 \cdot 17$; W., 3.56; T., $2 \cdot 74 ;$ B., $\cdot 51$.

Remarks. - The Hermit Thrush may always be easily identified by its rufous tail. It is the only one of our Thrushes which has the tail brighter than the back.

Range.-N. and e. N. A. Breeds in Canadian and Transition zones from s. Yukon, to n. Que., s. to cen. Alberta, s. Sask., cen. Minn., n. Mich., 
Ont., Mass., Conn., L. I. (locally), and mts. of Pa. and Md.; winters from Mass. (locally) and the lower Del. and Ohio valleys to Tex., Fla., and Cuba.

Washington, very common T. V., sometimes not uncommon W. V., Apl. 6-May 17; Sept. 18-Nov. 12. Ossining, common T. V., Apl. 5-May 9; Oct. 18-Nov. 26. Cambridge, very common T. V., Apl. 15-May 5; Oct. 5 -Nov. 15; occasionally one or two may winter; one summer record. N. Ohio, common T. V., Mích. 21-May 10; Oct. 2-28. Glen Ellyn, common T. V., Mch. 18-May 11; Sept. 14-Nov. 1. SE. Minn., common T. V., Apl. 1- ; Sept. 13-Oct. 26.

Nest, of moss, coarse grasses, and leaves, lined with rootlets and pine needles, on the ground. Eggs, 3-4, greenish blue, of a slightly lighter tint than those of the Wood Thrush, $88 \times \cdot 69$. Date, Holland Patent, N.Y.,May 23; Grand Menan, N. B., May 26.

This Thrush comes to us in the spring, when the woods are still bare, and lingers in the autumn until they are again leafless-the earliest as it is the latest of our Thrushes. It is common on its migrations, but attracts little notice, for, though not really a shy bird, its disposition is retiring, and it is most at home in secluded woodland and thickety retreats. Still, it often finds seclusion enough along shrubby roadsides, and may so far doff its hermit traits as to approach dwellings, where its attractive lightness of motion and ease of manner may be observed from indoors. It frequently descends to the ground, but is soon back again in the branches, making short flights from perch to perch, often with long, quiet pauses in the intervals. It may be known at sight by its habit of lifting its tail slightly; especially after alighting. This action is usually accompanied by the bird's customary note - a low chuck, which sounds seareely thrushlike.

The Hermit Thrush bears high distinction among our song birds. Its notes are not remarkable for variety or volumo, but in purity and sweetness of tone and exquisite modulation they are unequaled. Some, indeed, have deemed the Wood Thrush not inforior; but though the Wood Thrush at its best seems sometimes to touch the very highest chords of bird music, the strains of its wilder cousin, in trancquil clearness of tone and exalted serenity of expression, go beyond any woods music we ever hear.

While traveling, the Hermit Thrush is not in full voice, and he who would know its song must follow it to the mossy forests, which are its summer home.

Eugene P. Bicknell.

1910. McClintock, N., Auk, XXVII, 409-41s (nesting).

Townsend's Soltatre ( $\% 5$;. Myrulestes townsendi) of western North America, is of accidental occurrence in Illinois and New York.

The Red-winged Thresh ( $\tilde{g}$ n. Turdus musicus), a Furopran species, is of accidental occurrence in Greenland.

761. Planesticus migratorius migratorius ( $/$ imu.). Rorm 76a.) Ads.-Top and sides of the head hlack, a white spot alonve and helow the eye; rest of the upperparts grayish slate-color; marrins of wings slightly lighter; tail hlarkish, the outer feathers with white spots at their tips: throst white, streaks? with hlack; rest of the undorparts rufous (tipped with white in the fall), becoming white on the middle of the lower belly; bill yellow, 
brownish in fall. Im. females average paler below and with less black on the head, but fully adult birds are as richly colored as the brightest males. Nestling.-Back and underparts spotted with black. L., 10.00; W., 4.96; T., $3 \cdot 87$; B., $\cdot 84$.

Range.-N. A. Breeds from limit of trees in nw. Alaska, to n. Ungava, and N. F. s. to Cook Inlet, Alaska, cen. Alberta, se. Wyo., Kans., Ills., Ind., Ohio, Pa., N. J., and in the Alleghanies to N. C.; winters from cen. Kans., Ohio valley, and N. J. (irregularly further n.) to the Gulf coast and Fla., and to Nuevo Leon, Mex.; accidental in Bermuda and Cuba.

Washington, rather common S. R., abundant T. V., from Feb.-Apl.; irregularly common W. V. Ossining, common S. R., Mch. 4-Oct. 30; a few winter. Cambridge, very abundant S. R., common but irregular W. V. N. Ohio, abundant S. R., Feb. 26-Nov. 30; a few winter. Glen Ellyn, very common S. R., rare W. V., Jan. 25-Nov. 19. SE. Minn., common S. R., rare W. V., Mch. 8-Nov. 11.

Nest, of coarse grasses, leaves, rootlets, etc., with an inner wall of mud and lining of fine grasses, most frequently in fruit or shade trees, 5-30 feet up. Eggs, 3-5, greenish blue, very rarely with brownish markings, $1 \cdot 14 \times \cdot 80$. Date, New York City, Apl. 20; Cambridge, Apl. 25; se. Minn., Apl. 28.

While the few Robins that have the courage to winter with us are seeking protection from chilling winds in the depths of friendly evergreens, their comrades who extended their journey to the south are holding carnival under sunny skies. In Florida, during the winter, Robins may be found in enormous flocks, feeding on the berries of the China tree, holly, and mistletoe. Occasionally they give voice to a half-suppressed chorus, as though rehearsing for the approaching season of song.

Robins migrate in flocks, and the arrival of the advance guard makes the dreariest March day seem bright. It is a question whether these pioneers are summer residents or transients en route to a more northern summer home, but in my experience they make the sunny side of some woods their headquarters and remain there until paired. They are then in full song, and we see them in their accustomed haunts about our lawns and orchards.

Toward the last of June the young of the first brood, with the old males, resort in numbers nightly to a roosting-place. These roosts are generally in deciduous second growths, usually in low, but sometimes on high ground. The females are now occupied with the cares of a second family, and the males are said to return each day to assist them in their duties.

Early in September, when the nesting season is over, Robins gather in large flocks, and from this time until their departure for the south, roam about the country in search of food, taking in turn wild cherries, dogwood and cedar berries.

The songs and call-notes of the Robin, while well known to every one, are in reality understood by no one, and offer excellent subjects for the student of bird language. Its notes express interrogation, suspicion, alarm, caution, and it signals to its companions to take wing; indeed, few of our birds have a more extended vocabulary.

1890. Brewster, W., Auk, X, 360-373 (summer roosts).-1892. Torrey, B., Foot-path Way, 153-175 (summer roosts).-1895. Widmann, O., 
Auk, XII, 1-11, also 274 (winter roosts).-1898. Howe, R. H., JR., Auk, XV, 162-167 (nesting).-1905. Herrick, F. H., Home Life of Wild Birds, $72-85$.

761b. P. m. achrusterus (Batch.). Southern Robin. Smaller than P. m. migratorius, colors in general much lighter and duller. W., 4.80; T., $3 \cdot 60$.

Range.-SE. U. S. Breeds in s. part of Carolinian fauna from s. Ill. and Md. to n. Miss., n. Ga., and S. C.

The VARIED THRUSH (763. Ixoreus nævius nævius), a species of western North America, has been recorded from Quebec, Massachusetts, Long Island, and New Jersey.

765a. Saxicola œnanthe leucorhoa (Gmel.). GreEnland Wheatear. 4d. o.-Upperparts light gray; forehead and upper tail-coverts white; cheeks and wings black; the basal two-thirds of the tail white, the end black; underparts whitish, more or less washed with buffy. Ad. $\%$.-Similar, but duller, the black grayer, the white parts more buffy. Ad. in winter and Im. - Upperparts cinnamon-brown, wings edged with lighter; upper tailcoverts and hase of the tail white; end of the tail black, tipped with buffy; underparts ochriccous-buff. L., $6 \cdot 25 ;$ W., $4 \cdot 00 ;$ T., $2 \cdot 20 ;$ B., 50 .

Range-NE. Arctic Am. Breeds in Arctic zone from Ellesmere Land and Boothia Penninsula e. to Greenland and Iceland, and s. to n. Ungava; winters in w. Africa, migrating through the British Isles and France; casual in migration to Keewatin, Ont., N. B., Que., N. Y., Bermuda, La., and Cuba.

Nest, of moss and grasses, usually in crevices among rocks. Eggs, 4-7, bluish white, $81 \times 59$. Date, Holsteinborg, Greenland, June 8.

This European species is a common summer resident in Greenland. It has been found nesting in Labrador, and there is evidence of its having bred at Godbout, Province of Quebec (Merriam, Auk, 1885, p. 305; Comeau, ibid., 1890, p. 294). South of these points it is of accidental occurrence.

Mr. Saunders writes: "From early spring onward the Wheatear is to be seen, jerking its white tail as it flits along, uttering its sharp chack, chack, on open downs, warrens, and the poorer land; ascending the mountains almost to the highest summits.

"The song of the male is rathor pretty, and the bird also displays considerable powers of imitating other species."

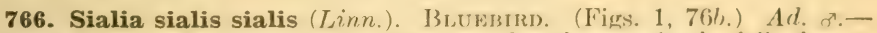
Upperparts, wings, and tail bright blue, tipperl with rusty in the fall; throat, breast, and sides dull cinnamon-rufous; lerlly whitr. Ad. P.-Upperparts with a grayish tinge; throat, loreast, and sirles paler. Veslling-Batek spotted with whitish; the breast fouthers marnined with fuscous. L., $7 \cdot() 1$; W., 3.93; T., $2.58 ; B_{.,} 47$.

Range.-E. N. Am. Breeds from lower Canadian to Lower Austral zone from s. Man., n. Ont., s. (uee, and N. F., s. to s. Tox., the Gulf eoast, and s. Fla.; casually w. to base of the Rorky Mits. in Mont., Wyo., and (colo.; winters from s. Ills., and s. N. Y., southward.

Washington, common S. R., and W. V. ()sining, common P. R. Cambridge, common S. R., Mch. 6-Nov. 1; more numerous during migrations, in Mch. and Nov. N. Ohio, common S. R., Feh. 17-Nox. 14: a few wintrer. Glen Ellyn, fairly common S. R., Feb. 19-Nov. 18. SE. Minn., common S. R., Mch. 16-Oct. 31.

Nest, of grasses, in hollow trees or bird-houses. Eggs, $4-6$, bluish white, 
sometimes plain white, $\cdot 85 \times \cdot 65$. Date, Ft. Pierce, Fla., Mch. 17; Mt. Pleasant, S. C., Mch. 26, small embryos; Cambridge, Apl. 15; se. Minn., Apl. 16.

A bird so familiar as the Bluebird needs no introduction; in fact, he seems so at home in our orchards and gardens or about our dwellings that one wonders what he did for a home before the white man came.

In the winter, it is true, Bluebirds are greater rovers, and one may see them in the Southern States whirling through the woods in large flocks or feeding on the berries of the mistletoe. But the warmth of returning spring reminds them of cozy bird-boxes or hospitable pear or apple trees, and soon we see them inspecting last summer's home, evidently planning repairs and alterations.

The Bluebird's disposition is typical of all that is sweet and amiable. His song breathes of love; even his fall call-note-tùr-wee, tùrwee-is soft and gentle. So associated is his voice with the birth and death of the seasons that to me his song is freighted with all the gladness of springtime, while the sad notes of the birds passing southward tell me more plainly than the falling leaves that the year is dying.

1905. Herrick, F. H., Home Life of Wild Birds, 115-121. 


\section{BIBLIOGRAPHICAL APPENDIX}

The appended titles of general and local ornithological publications have been selected from the great mass of literature relating to American birds, in part with regard to their historic importance, but mainly on the basis of their present working value. They include chiefly systematic and faunal works, references to special books and papers being given in their proper connection in the body of the book.

It is hoped that the section devoted to 'local lists,' as they are commonly termed, will be of much assistance to the faunal naturalist and particularly to students of the bird-life of the regions to which, respectively, they refer. Unfortunately many of these papers are now out of print, but the Librarian of the American Museum of Natural History may be consulted with a view to securing, at cost, type-written copies of those not otherwise available, and which are of sufficient importance to warrant the expense involved.

\section{THE WORLD}

1875-1895. Sharpe, B. and others. Catalogue of Birds in the British Museum. 27 vols. with descriptions of the birds of the world, ills. $-\mathbf{1 8 8 5}$. Stejneger, L., and others. Riverside Natural History. Vol. IV, Birds, 4to, 558 pp., ills. (Houghton, Miffin). Classification, structure, habits, distribution.-1893-1896. NEWTON, A., and others. A Dictionary of Birds. Pop. Ed., 8vo, 1088 pp., ills. (Macmillan).-1894-95. LYDEKKER, R., and others. Royal Nat. Hist., Birds, 4to, Vols. III, 584 pp., and IV, 576 pp., ills., General account.-1899. Evans, A. H., Birds. Vol. IX, Cambridge Natural History (Macmillan), 8vo, 63.5 pp., ills. Classification, habits, distribution.-1899-1909. ShaRPE, B. A Hand-List of the (ienera and Species of Birds. 8vo, 5 vols. Published by British Museum. Names and Ranges.-1909. Knowlton, F. H., and others. Birds of the World, sm. 4 to, 873 pp., ills. (Holt). Habits, distribution.

\section{NOR'TH AMERICA}

1808-14. Wilson, A. American Ornithology. 9 vols., 4to. Many subsequent editions, the last, in one volume, by Porter \& Coate's, Philadelphia, is crude, but at least places Wilson's text within reach of every onc.-1831-39. Addubon, J. J. Ornithological Biograyphy. 5 vols., 8 vo of text to acerompiny the 4 elephant folios of plates (1827-38). Republished in 8 vols., s\%o, 1, 10 - 44 and later editions. The elephant folios with the 5 volumes of text sell for $\$ 2.5(10)$ $-\$ 3000$; the text ean sometimes be purchased at $\$ 5$ per volume; the first sio edition brings about \$350.-1832-34. NetTale, T. Manual of the (Ornithology of the United States and Canada. 2 vols. Several later editions, the last revised by Montague Chamberlain (Little, Brown \& ('o.), 190:3, 22 vols. in one, 473 and $431 \mathrm{pp} . \mathbf{1 8 7 2}$. Coues, E. Key to North Ameriman Bircls. 1903,5 th and last ed., 2 vols., roy. 8 vo, $1152 \mathrm{pp}$. The introduction, of 2.33 pages, treats of general ornithology and the anatomy of bircls--1874-1884. BaIRd, S. F., Brewer, T. M., and Ridiway, R. History of North American Birds. Land birds, 3 vols.; water birds, 2 vols., 4 to. The volumes on land birds republished in Svo size but from same plates, 1905, 596, 590, 5(60) 
pp. 'Little, Brown \& Co).-1886. American Ornithologists' Union Check-List of North American Birds. New York, Rev. Ed. 1910, 8vo, 430 pp.-1887. Ridgway, R. A Manual of North American Birds. 2d Ed. 1896, 653 pp. (Lippincott).-1892-5. Bendire, C. Life Histories of North American Birds. I, 414 pp., Gallinaceous birds, Pigeons, Hawks, and Owls; II, 1895, 508 pp., Parrots, Cuckoos, Trogons, Kingfishers, Woodpeckers, Goatsuckers, Swifts, Hummingbirds, Cotingas, Flycatchers, Larks, Crows and Jays, Blackbirds and Orioles. (Pub. by U. S. Nat. Mus.)-1893. NeHRLING, H. Our Native Birds of Song and Beauty. Vol. I, 371 pp.; Vol. II, 1896, 452 pp. Biographical.-1898. Davie, O. Nests and Eggs of North American Birds. 5th Ed., 8vo, 509 pp. (Columbus, Ohio).-1901-1911. RIDGWAy, R. The Birds of North and Middle America. Bull. 50, U. S. Nat. Mus. Part I, 1901, Fringlllidæ; Part II, 1902, Tanagridæ, Icteridæ Cœrebidæ, Mniotiltidæ; Part III, 1904, Motacillidæ, Hirundinidæ, Ampelidæ, Ptilogonatidæ, Dulidæ, Vireonidæ, Laniidæ, Corvidæ, Paridæ, Sittidæ, Certhiidæ, Troglodytidæ, Cinclidæ, Chameidæ, Sylviidæ; Part IV, 1907, Turdidæ, Zeledoniidæ, Mimidæ, Sturnidæ, Ploceidæ, Alaudidæ, Oxyruncidæ, Tyrannidæ, Pipridæ, Cotingidæ. Other volumes to follow. The standard work.-1903. Chapman, F. M. Color Key to North American Birds. 312 pp., upward 800 col. ills.-1904. ReEd, C. S. North American Birds' Eggs. 356 pp., many ills.-1910. American Ornithologists' Union Alcridged Check-List of North American Birds. Pocket Edition, 77 printed +77 blank pp. (New York.)

\section{EASTERN NORTH AMERICA}

1872-1881. Marnard, C. J. Birds of Eastern North America; 1896, Rev. Ed., 4to, 721 pp., ills. (West Newton, Mass.).-1884. Langille, J. H. Our Birds in Their Haunts. $12 \mathrm{mo}, 624 \mathrm{pp}$. (Cassino).-1889. Merriam, F. A. Birds Through an Opera-glass. $12 \mathrm{mo}, 223 \mathrm{pp}$. (Houghton).-1895. Wright, M. O. Birderaft, $12 \mathrm{mo}, 317$ pp., ills. (Macmillan).-1895. ChapMAN, F. M. Handbook of the Birds of Eastern North America, 421 pp., ills.; 1912, Rev. Ed. (Appleton's).-1897. C Chapman, F. M. Bird-Life. A Guide to the Study of our Common Birds. 12mo, 269 pp. 75 plls.; 1901, Rev. Ed., with col. plls. (Appleton's).-1897. Wright, M. O., and Coues, E. Citizen Bird, 12mo, 430 pp., ills. (Macmillan).-1898. Blanchan, N. Bird Neighbors, 234 pp., col. plls. (Doubleday).-1898. Merriam, F. A. Birds of Village and Field. $12 \mathrm{mo}, 406 \mathrm{pp}$., ills. (Houghton).-1898. Scotr, W. E. D. Bird Studies, an Account of the Land Birds of Eastern North America. 4to, 363 pp. Many half-tones (Putnam's).-1898. Apgar, A. C. Birds of the United States East of the Rockies. 12mo, 415 pp., ills. (Am. Book Co.).-1899. Cory, C. B. The Birds of Eastern North America. 8vo, 387 pp., ills. (Field Museum).-1905-6. Reed, C. A. Bird-Guide. Oblong, 32mo, Part I, 254 pp.; Part II, 197 pp.; many ills. (Doubleday).

\section{GREENLAND}

1861. Reinhardt, J. List of Birds Hitherto Observed in Greenland; Ibis, III, pp. 1-19, 118 species. 1875. Newton, A. Notes on Birds Which Have Been Found in Greenland, . London, 8vo pamphlet, pp. 94-115 (Author's extra from Man. Nat. Hist. Greenland). $63+62$ species; bibliography.-1889. HageruP, A. Some Account of the Birds of Southern Greenland, from the MSS. of A. Hagerup, edited by Montague Chamberlain. Auk, VI, pp. 211-218, 291-297, 39 species.-1891. HAgerUP, A. T. The Birds of Greenland, translated from the Danish by Fremann B. Arngrimson, edited by Montague Chamberlain. Boston (Little, Brown \& Co), 8vo, 62 pp.; 139 species.-1892. Stone, W. Birds Collected by the West Greenland Expedition. Proc. Acad. Nat. Sci., Phila., 1892, pp. 145-152; 147 species.1895. Stone, W. List of Birds Collected by the Peary Expd. Proc. Acad. Nat. Sci., Phila., 1895 , pp. 502-505; 28 species.-1895. Schalow, H. voN. Ueber eine Vogelsammlung aus Westgrönland. Jour. für Orn., 1895, pp. 
457-481; 35 species.-1899. Chapman, F. M. Report on Birds Received Through the Peary Expeditions to Greenland. Bull. Am. Mus. Nat. Hist., XII, pp. 219-244: 48 species.-1904. Sch.low, H. Die Vögel der Arktis, Band IV, Leiferung, I, pp. 81-288; Gustav Fischer, Jena. A detailed synopsis of Arctic bird-life.

\section{BRITISH POSSESSIONS}

\section{BERMUDA}

1859. Jones, J. M., Tedderbern, J. W., and Hurdis, J. L. The Naturalist in Bermuda. Birds, pp. 23-97-1884. Reid, S. G. List of the Birds of Bermuda. Bull. L. S. Nat. Mus., No. 25., pp. 165-279; $1>6$ species. (See also, Merriam, C. H., Ibid., 28:3, 284.)-1901. Bangs, O. and BradLEE, T. S. The Resident Land Birds of Bermuda. Auk, XVIII, pp. 249-257; 10 species.

\section{Canada}

1909. MACOCN, J. and J. M. Catalogue of Canadian Birds. 8ro, xviii +761 pp. Government Ptg. Bureau, Ottawa. Distribution and nesting; important.-1908. Preble, E. A. A Biological Investigation of the Athabaska-Mackenzie Region. N. A. Fauna, No. 27, 574 pp. Birds, pp. 251-500; 296 species, bibliography.

\section{KEEWATIN}

1902. Preble, E. A. Birds of Kecwatin. N. A. Fauna, No. 22, pp. 75$131 ; 260$ species.

\section{LABRADOR}

1861. Coues, E. Notes on the Ornithology of Lahrador. Proc. Acad. Nat. Sci., Phila., XIII, pp. 215-257; 82 species.-1885. 'Terner, L. M. List of the Birds of Labrador, including L ngava, East Main, Moose, and Gulf Districts of the Hudson Bay Company, together with the Istand of Anticosti. Proc. L. S. Nat. Mus., VIII, pp. 233-254; 207 species. (See also Packard, A. S. The Labrador ('oast, 1891).-1887. Friz.ir, M. A. An Ornithologist's Summer in Lahrador. Orn. and Oöl., XII, I)|, 1 3, 17 20, 3:335; 62 speries. - 1902. BI(GELow, H. B. Jirds of the Northe:astern Coast of Labrador. Auk, XIX, 1902, rpr. 24-31; 8.5 speries.-1907. Tow isexp, C. W., and Allen, (x. M. Birds of Labrador. Prore. Bost. Sore. Nat. Hist., XXXXII, pp. 277-42x, map); 213 spercies. (See also ToWNikxd, C. W., and Bent, A. C. The Auk, 1910, pp. 1-18; 93 species.)

\section{ManitoBa}

1886. Seton, E. T. The Birds of Western Manitolua. Auk, III, pp. 145-156, 320-329, 453; 258 species-1891. SETox, F. T. The Birds of Manitoba. Proc. U. S. Nat. Mus., XIII, py). 457-643, 1 pl.; 2fiti sivecies. (See also 14 additions, Auk, 1893, p. 49.)-1909. SETox, E. T. Fauna of Manitoba. British Asse. Handlook. Winnipeg, py). 147; $27: 3$ species.

\section{New Brunswick}

1857. Bryant, H. A List of Birls Obserred at Grand Mrman and at Yarmouth, N. S., from June 16 to July $九$. Proc. Bost. Sor Sit. Mist.. VI, pp. 114-123; 55 species.-1873. Herrick, H. A Partial ('atalogue of the Birds of Grand Menan, N. 13., Bull. Essex. Inst., V. p). 24-11: 194 species.1879. Pearsall, R. F. (irand Menan Notes; Summers of 1477 and 1474 . Forest and Stream, XIII, p. $524 ; 43$ species.-1882. Batcheldr, C. F. 
Notes on the Summer Birds of the Upper St. John. Bull. N. O. C., VII, pp. 106-111, 147-152; 105 species.-1882. Chamberlain, M. A Catalogue of the Birds of New Brunswick. Bull. Nat. Hist. Soc. New Brunswick, No. 1, pp. 23-68; 269 species.

\section{NEWFOUNDLAND}

1869. ReEKs, H. Notes on the Zoölogy of Newfoundland. Zoölogist, 2nd ser., IV, pp. 1609-1614, 1689-1695, 1741-1759, 1849-1858; 212 species. See also Canad. Nat. and Quart. Journ. Sci., V, 1870-71, pp. 38-47, 151159, 289-304, 406-416; and Harver, M. Forest and Stream, III, pp. 53, 196, 341.-1900. Porter, L. H. Newfoundland Notes. Auk, XVII, pp. 7173; 50 species summer birds.

\section{Nova Scotia}

1857. Bryant, H. (See New Brunswick.)-1858. Blakiston, R. A., Bland, R. E., and Willis, J. R. List of Birds of Nova Scotia. Thirteenth Ann. Rep. Smiths. Inst., pp. 280-286; 206 species.-1879. Jones, J. MATTHEW. List of the Birds of Nova Scotia-Land Birds. Forest and Stream, XII, pp. $65,66,105,106,205,245 ; 128$ species.-1887. Dwight, J., JR. Summer Birds of the Bras d'Or Region of Cape Breton Island, Nova Scotia. Auk, IV, 1887, pp. 13-16; 59 species. (See also Allen, F. H., Ibid., 1891.)1888. Downs, A. Birds of Nova Scotia, edited by Harry Piers. Proc. and Trans. Nova Scotia Inst. Nat. Sci., VII, ii, pp. 142-178; 240 species.

\section{ONTARIO}

1860. MCILwraith, T. List of Birds Observed in the Vicinity of Hamilton. Canad. Journ. V, pp. 387-396. (See also Proc. Essex. Inst., V, 1866, pp. 79-96), 241 species.-1882. Morden, J. A., and SaUnders, W. E. List of the Birds of Western Ontario. Canad. Sportsm. and Nat. II, pp. 183-187, 192-194, also III, pp. 218, 219, 243; 236 species.-1891. FARLEY, F. L A List of the Birds of Elgin County, Ontario. The Oölogist, VIII, pp. 81-87; 190 species.-1891. Ottawa Field Nat. Club. The Birds of Ottawa. Ottawa Nat. V, pp. 31-47;224 species.-1894. McIlwrarth, T. The Birds of Ontario, 8 vo, $\mathrm{x}+426 \mathrm{pp}$. Wm. Briggs, Toronto; 317 species.-1897-8. NAsH, C. W. Birds of Ontario in Relation to Agriculture. Rep. Farmers' Inst. of Ont. 8vo, 32 pp.-1900. Nash, C. W. Check List of the Birds of Ontario. Warwick Bros. and Rutter, Toronto. 8vo, 58 pp.; 302 species.-1901. Fleming, J. H. A list of the Birds of the Districts of Parry Sound and Muskoka, Ont. Auk, XVIII, 1901, pp. 33-45; 196 species. (See also Ibid., XIX, p. 403.) 1905. NAsh, C. W. Check List of the Birds of Ontario. L. K. Cameron, Printer, Toronto, Ont. 82 pp.; 324 species.-1906. Swales, B. H., and Taverner, P. A. Remarks on the Summer Birds of Lake Muskoka, Ont. Wilson Bull., XVIII, pp. 60-68; 59 species.-1906-7. Fleming, J. H. Birds of Toronto, Ont. Auk, XXIII, pp. 437-453; XXIV, pp. 71-89; 290 species. 1907. Hubel, F. C. Preliminary List of the Summer Birds of the Cobalt Mining Region, Nipissing District, Ont. Auk, XXIV, pp. 48-52; 76 species. -1907-8. Taverner, P. A. and Swales, B. H. The Birds of Point Pelee, Wilson Bull. XIX, pp. 37-53; 82-99, 133-153; XX, pp. 79-96, 107-129; 209 species. See also Wood, N. A., Ibid., 1910, pp. 63-78.-1910. EIfrig, G. A Winter of Rare Birds at Ottawa. Auk, XXVII, pp. 53-59.

\section{QUEBEC}

1878. Cory, C. B. A Naturalist in the Magdalen Islands (Boston). Part II, pp. 33-83, list of birds; 109 species.-1882. Wintle, E. D. Ornithology of the Island of Montreal. Canad. Sportsm. and Nat., II, pp. 108110, 116, 117; 168 species.-1882-5. Merriam, C. H. List of Birds Ascertained to Occur within Ten Miles of Point des Monts, Province of Quebec, 
Canada; based chiefly upon the notes of Napoleon A. Comeau. Bull. N. O. C., VII, pp. 233-242, and Addenda; VIII, pp. 244, 245; Auk, I, 1884 p. 295; II, 1885 , pp. 113,$315 ; 180$ species.-1884. Brewster, W. Notes on the Birds Observed During a Summer Cruise on the Gulf of St. Lawrence. Proc. Bost. Soc. Nat. Hist., XXII, pp. 364-412; 92 species.-1889. Bishop, L. B. Notes on the Birds of the Magdalen Islands. Auk, VI, pp. 144-150; 66 species.-1889. Dionne, C. E. Catalogue des Oiseaux de la Province de Quebec avec des Notes sur leur Distribution Geographique. . . . Quebec des Presses a Vapeur de J. Dussault, Port Dauphin, 8vo, 119 pp.; 273 species.-1891. Palmer, William. Notes on the Birds Observed During the Cruise of the United States Fish Commission Schooner Grampus in the Summer of 1887. Proc. U. S. Nat. Mus., XIII, 1890, pp. 249-265; 78 species.-1893. Dwight, J., Jr. Summer Birds of Prince Edward Island. Auk, X, 1893, pp. 1-15;81 species.-1896. Wintle, E. D. The Birds of Montreal. W. Drysdale \& Co., Montreal. 8vo, xiv +181 pp.; 254 species.1908. MacSwain, J. A Catalogue of the Birds of Prince Edward Island. Proc. and Trans. Nova Scotia Inst. of Science. XI, pp. 570-592; 220 species.

\section{UNITED STATES}

\section{Mississippi VaLLEY}

1888. Cooke, W. W. Report on Bird Migration in the Mississippi Valley in the years 1884 and 1885 . Edited and revised by C. Hart Merriam. Bull. No. 2, Div. Economic Ornithology [= Biological Survey]. 313 pp., 1 map.

\section{New ENGLAND}

1877. Minot, H. D. The Land and Game Birds of New England. Second Ed., edited by Wm. Brewster, $1 \times 95,492$ pp. (IIoughton).-1881-3. Stenrns, W. A. and Coues, E. New England Bird-Life. 2 rols., pp. 324-409-1904. Hoffmann, R. A Guide to the Birds of New Eingland and Eascern New York. 350 pp. (Houghton).-1909. Alikn, (i. M. Birds of New England. Occ. Papers Bost. Soc. Nat. Hist., VII, pp. 1-230, Annotated list of 402 species.

\section{Alabama}

1878-9. Brown, N. C. A List of Birds Observed at Coosada, Central Alabama. Bull. N. O. C., III, p). 165-174; IV, 1)1, $7-13 ; 119$ speceies. 1890-1. Avery, W. C. Birds ()hserved in Alabama. Am. Ficld, XXXil.

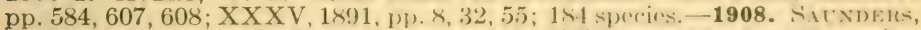
A. A. Some Birds of Central Alabama. Auk, XXV, p1), 413-424; 129) spercies.

\section{Connecticut}

1843. Linsley, J, H. A Catalogue of the Bircls of Comecetient. Am. Journ. Sci. and Arts, XLIV, pl). 24927.4, 302.2 spereies. Fier also Ihid., XLVI, 1844, pp. 50, 51.-1877. Mrreram, ('. II. A Review of the Birds of Connecticut, with Remarks on their Inabits. Trans. of the ('onn.

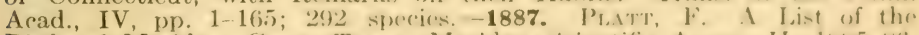

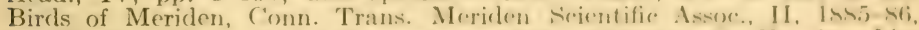
pp. 30-53; III, p. 41; 116 speries -1892. Avernth, ('. K.. JR. List

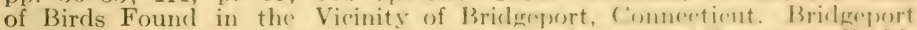
Scientific Society, 8vo, pr). 1-i9; 2216 speries-1906. ('mapMa. F. M. (see New York).-1908. Commete. A List of the Birels of the New Haven Region. Bull. No. 1, New Haven Bird Club. pl). 1-32; 217 species. 


\section{Delaware}

1905. RhoAds, S. N. and Pennock, C. J. Birds of Delaware: A Preliminary List. Auk, XXII, 1905, pp. 194-205; 211 species. (See also Auk, XXV, 1908, pp. 282-288.)-1897-1908. Stone, W., Editor. Numerous Notes on Delaware Birds. Proc. Del. Valley Orn. Club, Phila.

\section{District of Columbia}

1883. Coues, E. and Prentiss, D. W. Avifauna Columbiana, Second Edition. Bull. U. S. Natl. Mus. No. 26, 8vo, pp. 1-133, many woodcuts, 4 maps, 248 species.-1888. Richmond. C. W. An Annotated List of Birds Breeding in the District of Columbia. Auk, V, pp. 18-25; 100 species.1888. Smith, Hugh M., and Palmer, William. Additions to the Avifauna of Washington, D. C., and Vicinity. Auk, V, pp. 147, 148. Adds 12 species to Coues' and Prentiss' list of 1883.

\section{FLORIDA}

1871. Aluen, J. A. On the Mammals and Winter Birds of East Florida. Bull. Mus. Comp. Zoöl., II, pp. 161-450, pll. ix-xiii; 181 species.--1888. Chapman, F. M. A List of Birds Observed at Gainesville, Florida. Auk, V, pp. 267-277; 149 species.-1888-90. Scotw, W. E. D. A Summary of Observations on the Birds of the Gulf Coast of Florida. Auk, V, pp. 373-379; VI, pp. 13-18, 152-160, 245-252, 318-326; VII, pp. 14-22, 114-120; 262 species.1890. Sсотт, W. E. D. On Birds Observed at the Dry Tortugas, Florida, during parts of March and April, 1890. Auk, VII, pp. 301-314; 80 species.1891. Brewster, W. and Chapman, F. M. Notes on the Birds of the Lower Suwanee River. Auk, VIII, pp. 125-138; 116 species. (See also Brewster, Ibid., pp. 149-157.)-1892. Sсотт, W. E. D. Notes on the Birds of the Caloosahatchie Region of Florida. Auk, IX, pp. 209-218. 259 species.-1895. Wayne, A. T. Notes on the Birds of the Wacissa and Aucilla River Regions of Florida. Auk, XII, 1895, pp. 362-367; 161 species.-1896. Cory, C. B. Hunting and Fishing in Florida with a Key to the Water Birds of the State.1904. Williams, R. W., Jr. A Preliminary List of the Birds of Leon County, Florida. Auk, XXI, 1904, pp. 449-462; 156 species. (See also Ibid., XXIII, pp. 153-161; XXIV, pp. 158, 159.)-1906. Fowler, H. W. Birds Observed in June in the Florida Keys. Auk, XXIII, pp. 396-400; 33 species.

\section{Georgia}

1883. Barley, H. B. Memoranda of a Collection of Eggs from Georgia. Bull. N. O. C., VIII, pp. 37-43; 104 species.-1903. Smith, R. S. Birds of Kirkwood, De Kalb Co., Ga. Wilson Bull., XV, pp. 49-59; 125 species.1909. Howell, A. H. Notes on the Summer Birds of Northern Georgia. Auk, XXVI, pp. 129-137; 76 species.

\section{ILLINOIS}

1855. Kennicott, R. Catalogue of Animals Observed in Cook County, Illinois. Trans. Ill. State Agric. Soc. for 1853-54, I, Birds, pp. 580-589; 187 species.-1868. Allen, J. A. (See Iowa.)-1874. Ridgway, R. Catalogue of the Birds Ascertained to Occur in Illinois. Ann. Lyc. Nat. Hist. N. Y., X, pp. 364-394; 311 species.-1876. Nelson, E. W. Birds of Northeastern Illinois. Bull. Essex Inst., VIII, pp. 90-155; 316 species.-1877. Nelson, E. W. Notes upon Birds Observed in Southern Illinois, between July 17 and September 4, 1875. Bull. Essex. Inst., IX, pp. 32-65; 133 species. 1881. Ridgway, R. A Revised Catalogue of the Birds Ascertained to Occur in Illinois. Ills. State Lab. Nat. Hist., Bull. No. 4, pp. 161-208; 352 species. -1884. Coоke, W. W. Bird Migration in the Mississippi Valley, Southern 
Illinois. Forest and Stream, XXIII, pp. 444, 445, 463 464; 144 species based on Ridgway's list of 1881 and observations of Cyrus W. Butler in the vicinity of Anna, Ills., during December 1882, and January 1883.-1887. RIDGWAY, R. List of the Birds Found Breeding within the Corporate Limits of Mt. Carmel, Illinois. Bull. No. 2, Ridgway Orn. Club, pp. 26-35; 85 species.1890-1895. Ridgway, R. The Ornithology of Illinois. Roy. 8vo, Vol. I, 1890, 520 pp., 32 plls. Land-birds to Gallinæ; Vol. II, 1895, 282 pp., 33 plls. Gallinæ and Water-birds; 363 species.-1891. Loucks, W. E. List of Birds Found Breeding in the Vicinity of Peoria, Illinois. The Oölogist, VIII, pp. 224-226; 80 species.-1904. Walter, H. E. and A. W. Wild Birds in City Parks. Rev. Ed., Chicago, 16mo, 66 pp.; 145 species.-190\%. WoodRUfF, F. M. The Birds of the Chicago Area. Chicago Acad. Sci. Bull. VI, Nat. Hist. Surv., 221 pp., 12 plls.; 318 species.-1909. CoRy, C. B. Birds of Illinois and Wisconsin. Field Museum, Zoöl. Ser. IX, 8vo, 764 pp., many ills.; 398 species.-1910. Hess, I. E. One Hundred Breeding Birds of an Illinois Ten-Mile Radius. Auk, XXVII, pp. 19-32.

\section{INDIANA}

1869. Haymond, R. Birds of Franklin County, Indiana. Cox's Geol. Surv. Indiana, Rep. for 1869 , pp. 209-235; 163 species.-1888-89. EverMANN, B. W. Birds of Carroll County, Indiana. Auk, V. pr), 344-351; VI, pp. 22-30; 203 species.-1891. Butler, A. W. The Birds of Indiana, with Illustrations of Many of the Species. Prepared for the Indiana Horticultural Society, and Originally Published in its Transactions for 1890. 8vo, 135 pp.; 305 species.-1905. McAtee, W. L. Ecological Notes on the Birds Occurring within a Radius of Five Miles of the Indiana University Campus. Proc. Ind. Acad. Sci., pp. 65-202, 32 ills.; 225 species.

\section{Iow A}

1868. Allen, J. A. Notes on Birds Observed in Western Iowa, in the Months of July, August, and September; also on Birds Observed in Northern Illinois, in May and June, and at Richmond, Wayne Co., Indiana, between June third and tenth. Mem. Bost. Soc. Nat. Hist., I, pt. IV, p). $488-526$. Ogle County, Ills., 84 species; Cook County, Ills., 94 species; Richmond, Ind., 72 species; Western Iowa, 108 species.-1873. Trippe, F. M. Notes on the Birds of Southern Iowa. Proc. Bost. Soc: Nat. Hist., XV, 1)p. 229-242; 162 species.-1888. Keyes, Charles R. amd Williams, H. S. A Preliminary Annotated Catalogue of the Birds of Iowa. Pror. Davenport Acad. Nat. Sci., V, 8vo, 49 pp.; 260 species.-1890. ('o()NE, JoHn V. Summer Residents of Buena Vista County, Iowa. The ()ölogist, VII, pp. 45 47; 52 species.-1895. Jones, Lynds. Bird Migration at (irinnell, Iowa. Auk, XII, 1895, pp. 117-134, 231-237.-1897. ANI)RS(oN, R. M. An Annotated List of the Birds of Winnebago and Hancork ('ounties, Iowat. Pub. by Author, Forest City, Iowa. $16 \mathrm{mo}, 19$ pr).; $21 \times$ speries.-1906. Wilson, B. H. Birds of Scott Co., Iowa. Wilson Bull., XVIII, pp) $1-11 ; 16(i$ spereses.1907. Anderson, R. M. The Birds of Iowa. Proc. Davenport Acad. Sci., XI, pp. $125-417 ; 355$ species.

\section{KANSAS}

1875. Snow, F. H. A Catalogue of the Bircls of Kansas. Contributed to the Kansas Academy of Scienee. $8 v 0,14$ pl). Third Erlition. 2(95) speecies.1886. Goss, N. S. A Revised ('atalogue of the Bircls of Kansas, with Descriptive Notes of the Nests and Egges of the Birds Kmown to Broed in the State. Topeka. 8vo, vi 76 pl).; 335) spereies. (her also review in Auk, III, 1886, p. 399.)-1891. Goss, N. S. History of the Birds of Kansis. Illustrating 529 Birds. Topeka, Kansas. Geo. W. ('rane \& ('o., Royal swo, 69)2 pp., 35 photogravure plates; 343 species.-1899. IANT\%, 1). E. A R(יview of Kansas Ornithology. Trans. Kans. Acad. Sci., 1896-7, pp. 224-276; 
351 species.-1903. Snow, F. H. A Catalogue of the Birds of Kansas. Fifth Edition. Trans. Kans. Acad. Sciences, XVIII, 23 pp.; 342 species.

\section{KeNTUCKY}

1883. Beскнам, C. W. A List of the Birds of Bardstown, Nelson County, Kentucky. Journ. Cinc. Soc. Nat. Hist., VI, pp. 136-147; 167 species.-1885. BeckHAM, C. W. List of the Birds of Nelson County. Kentucky. Geol. Surv., John R. Proctor, Director. Author's Edition, 4to, pp. 1-58; 171 species.-1887. Pindar, L. O. List of the Birds of Fulton County, Kentucky. Orn. and Oöl., XII, pp. 54, 55, 84, 85; 122 species.1889. Pindar, L. O. List of the Birds of Fulton County, Kentucky. Auk, VI, pp. 310-316; 183 species.-1910. Howel, A. H., Notes on the Summer Birds of Kentucky and Tennessee. Auk, XXVII pp. 295-304. Kentucky, 80 species.

\section{LOUISIANA}

1900. Beyer, G. E. The Avifauna of Louisiana. Proc. La. Soc. Nat., 45 pp.; 323 species.-1904. Allison, A. The Birds of West Baton Rouge Parish, Louisiana. Auk, XXI, 1904, pp. 472-484; 130 species.-1906. Beyer, G. E., Allison, A., Kopman, H. H. List of the Birds of Louisiana. Auk, XXIII, 1906, pp. 1-15, 275-282, XXIV, 314-321; XXV, 173-180; 339-448. 128 species to Pici. 1908. HowelL, A. H. Notes on the Winter Birds of Northern Louisiana. Proc. Biol. Soc. Washington, XXI, 119-124 pp.; 70 species.

\section{MAINE}

1862. Boardman, G. A. Catalogue of the Birds Found in the Vicinity of Calais, Maine, and about the Islands at the Mouth of the Bay of Fundy. Edited by A. E. Verrill. Proc. Bost. Soc. Nat. Hist., IX, pp. 122-132; $236+4$ species. (For 12 additions see Verrill, Ibid., pp. 233, 234.)-1862. Verrill, A. E. Catalogue of the Birds Found at Norway, Oxford Co., Maine. Proc. Essex. Inst., III, pp. 136-160; 159 species.-1872. MAYNARD, C. J. A Catalogue of the Birds of Coos Co., N. H., and Oxford Co., Maine. With notes by Wm. Brewster, Proc. Bost. Soc. Nat. Hist., XIV, 1871, pp. 356-385; 164 species.-1882. Brown, N. C. A Catalogue of the Birds Known to Occur in Portland, Maine. Proc. Portl. Soc. Nat. Hist., Dec. 14, 1882, pp. 1-37; 250 species. (See also Proc. Portl. Soc. Nat. Hist., 1889, pp. 37-40.)-1900. Howe, R. H., JR. Summer Birds near Isleboro and the Fox Islands. Journ. Maine Orn. Soc. II, pp. 28-32; III, pp. 14, 15; IV, p. $18 ; 100$ species.-1908. KNight, O. W. TThe Birds of Maine. Pub. by Author, Bangor. 8vo, 693 pp., 30 ills.; 327 species.

\section{MARYLAND}

1895. Kirkwood, F. C. A List of the Birds of Maryland. Trans. Md. Acad. Sci., 1895, pp. 241-382; 290 species.-1900. Merriam, C. H., and Preble, E. A. The Summer Birds of Western Maryland. Maryland Geol. Surv.; pp. 291-307; 100 species.-1904. Erfrig, G. Birds of Allegany and Garrett Counties, Western Maryland. Auk, XXI, 1904, pp. 234-250; 180 species.

\section{Massachusetts}

1870. Maynard, C. J. Catalogue of the Birds of Eastern Massachusetts. The Naturalist's Guide, Part II, pp. 81-170; 299 species.-1886. Allen, J. A. A Revised List of the Birds of Massachusetts. Bull. Am. Mus. Nat. Hist., I, pp. 221-271; 349 species. 1887. ClarK, H. L. The Birds of Amherst and Vicinity, Including Nearly the Whole of Hampshire County, Mass. 8vo, 55 pp.; 177 species.-1888. Brewster, W. Notes on the Birds 
of Winchendon, Worcester Co. Auk, V, pp. 386-393; 82 species.-1889. FAxos, W. On the Summer Birds of Berkshire County, Mass. Auk, VI, pp. 39-46, 99-107. Southern Berkshire, 76 species; Graylock Mountain, 80 species.-1889. Ingalls, C. E. Birds of Templeton and the Adjoining Towns. Gardner News, XX, June; 155 species. Not seen; title from Howe and Allen.-1891. Colburn, W. W., and Morris, R. O. The Birds of the Connecticut Valley in Massachusetts. $16 \mathrm{mo}, 24 \mathrm{pp}$. Springfield. Published by the Authors. 212 species.-1891. WAkefield, J. R. A List of the Birds of Dedham. Dedham Hist. Reg., II, pp. 70-74; 181 species. Not seen; title from Howe and Allen.-1897. Morse, A. P. Birds of Wellesley. Published by Author. Wellesley. 16mo, 56 pp.; 224 species.-1900. FAxoN, W., and Hoffmann, R. The Birds of Berkshire Co. Coll. Berkshire Hist. and Sci. Soc., III. pp. 109-166; 200 species.-1901. Howe, R. H. JR., and Allex, G. M. The Birds of Massachusetts. Published by the Authors. 8ro, 154 pp.;362 species.-1901. Morris, R. O. The Birds of Springfield, Mass. and Vicinity. H. R. Johnson, Springfield. 8vo, 54 pp.; 255 species.-1905. Townsend, C. W. The Birds of Essex County, Massachusetts. Memoirs Nutt. Orn. Club. 4to, 3.52 pp. Frontispiece and Map; 319 species.-1906. Brewster, W. The Birds of the Cambridge Region of Massachusetts. Memoirs Nutt. Orn. Club, IV, 426 pp., plls. 7; 249 species.-1909. Wright, H. W. Birds of the Boston Public Garden. (Houghton, Mifflin), 16mo, 238 pp.; 116 species.

\section{MichigaN}

1857. Kneeland, S. On the Birds of Keeweenan Point, Lake Superior. Proc. Bost. Soc. Nat. Hist., VI, 231-241 pp.; 147 species.-1875. Bores, A. H. Catalogue of the Birds Ascertained to Occur in Southern Michigan. 8vo, 12 pp.; 211 species.-1876. Covert, A. B. Birds of Lower Michigan. Forest and Stream, VI, pp. 99, 132, 163, 214, 266, 318, 354, 402; VII, pp. 147, 164, 276. (See also VI, p. 197.) 213 species.-1879. GibBs, M. Annotated List of the Birds of Michigan. Bull. U. S. Geol. and Geograph. Survey of the Territories, V, 3, pp. 481-497; 310 species.-1880. STEERE, J. B. A List of the Mammals and Birds of Ann Arbor and Vicinity. 8vo, 8 pp.; 111 species of birds. - 1884. Atkiss, H. A. Summer Birds of Locke, Michigan. Orn. and Oöl., IX, pp. 43-45; 80 species.-1884. Atkins, H. A. Winter Birds of Locke, Michigan. Orn. and Oöl., IX, pp. 31, 32; 31 speries.-1885. Atrins, H. A. Summer Birds of Lorke, Michigan. Orn. and Oöl., X, p. 3; 82 species.-1885. GibBs, M. A Catalogue of the Birds of Kalamazoo County, Michigan. Orn. and Oöl.. X, p). 6, 7, 38, 39, 54, 5.5, 68-70, 86, 87, 118, 119, 13.3-135, 149-151,166, 167, 1х9, 19(); 230 species.-1885-7. Gгввя, M. The Birds of Michigan. Forest and Stream, XXIII, pp. 48:3, 45. XXIV, pp. $5,6,26,27,44,45,65,84,104,105,124,125,144,145,144,224$, $267,268,288,289,307,347,387,388,427 ; \mathrm{XV}$, pl). 4, 5, 3(1). 305, 365, 366; XXVI, pp. 305, 306; XXVII, pp. 123, 124, 22.3, 224; 6. species.-1890. White, T. G. Birds of Mackinas Island, Michigan. The Oölogist, VII, pp. 48, 49; 101 speciés.-1893. ('оOK, А. J. Birrls of Mich-

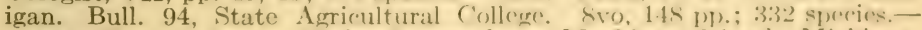
1893. White, S. E. Birds ()hserved on Markinar Island, Mirhieran, During the Summers of $1889,189()$, and 189)1. The Iuk, X, p1, 2.21 2:30; $14: 3$ species.-1897. Bores, A. H. Birls of Nochish Island, Mt. Mary's River, Michigan. Bull. Mich. Orn. ('luh, I, pr). 17 20, 27-2!); 149 specice-1903. Swales, B. H. Notes on the Winter Birds of Wayme ('o.. Mirehigan. Wilson Bull., XIV, pp. 20-24; XV, 19()., p. $82 ; 71$; A List of the Land Birds of Southeastern Miehieran. Bull. Mich. ()ru. ('lub,

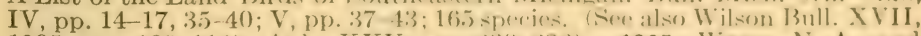
1905, pp. 108-114); Auk, XXV, pr. 23() 232). 1905 Wonn, N. 1.. and Frothingham, E. H. Notes on the Birrls of the An sialble Valley, Miehigan. Auk, XXII, 190.5, pp. 39-54; 1033 speries.-1906. WoOd, ․ A., I'Eet, M. M., and McCreary, O. Annotated List of the Birls of Porrujuine Mountains 189 species] and Isle Royale [ 81 species], Mich. Rep. Geol. Surv. 
Mich., 1905, pp. 113-127. See also McCreary, Ibid., pp. 56-67.-1909. BlackWELder, E. Summer Birds of Iron County. Auk, XXVI, pp. 363370; 80 species.-1910. Wood, J. Claire. Some Winter Birds of the Season 1908-9 in Wayne County. Auk. XXVII, pp. 36-41.-1910. Wood, N. A., and Tinker, A. D. Notes on Some of the Rarer Birds of Washtenaw County. Auk, XXVII, pp. 129-141; 34 species.-1910. Chaney, R. W. Summer and Fall Birds of the Hamlin Lake Region, Mason County. Auk, XXVII, pp. 271-279; 119 species.-1911. WoOd, N. A. Expedition to Charity Islands, Lake Huron. Wilson Bull., XXIII, pp. 78-112; 162 species.

\section{MinNesota}

1871. Trippe, T. M. Notes on the Birds of Minnesota. Proc. Essex Inst., VI, pp. 113-119; 138 species.-1874. НАтсH, P. L. Report on the Birds of Minnesota. Bull. Minn. Acad. Nat. Sci., pp. 43-68; 230 species.1876. Roberts, T. S. A List of Some Birds Observed in the Vicinity of Minneapolis, Minn., not Enumerated in Dr. Hatch's List. The Scientific Monthly (Toledo, Ohio), I, 5, p. 231.-1880. RoBerts, T. S., and Benner, F. A Contribution to the Ornithology of Minnesota. Bull. N. O. C., V, pp. 11-20; 86 species.-1881. Haтch, P. L. A List of the Birds of Minnesota. Ninth Ann. Rep. Geol. and Nat. Hist. Surv. Minn., for 1880, 1881, pp. 361-372; 281 species.-1881. Roberts, T. S. The Winter Birds of Minnesota. 9th Ann. Rep. Geol. and N. H. Surv. Minn., for 1880-1881, pp. 373-383; 52 species.-1883. Brackett, F. H., Ornithological Notes from Minnesota. Quart. Journ. Bost. Zoöl. Soc., II, pp. 47-49; III, pp. 7-16; 134 species.1890. Cantwell, G. C. A List of the Birds of Minnesota. Orn. and Oöl., XV, p. 129-139. (See also p. 156 and XVI, p. 157); 295 species.-1892. Hatch, P. L. Notes on the Birds of Minnesota. Geol. and Nat. Hist. Survey of Minn. 8vo, 487 pp.; 302 species.-1904. Currier, E. S. Summer Birds of the Leech Lake Region, Minn. Auk, XXI, pp. 29-44; 117 species.1907. Roberts, T. S. List of Birds of Becker Co., Minn., Pioneer Hist. of Becker Co. (Pioneer Press, St. Paul). pp. 159-190;262 species.

\section{MISSISSIPPI}

1905. Stockard, C. R. Nesting Habits of Birds in Mississippi. Auk, XXII, 1905, pp. 146-158, 273-285; 83 species.-1906. Allison, A. Notes on the Winter Birds of Hancock Co., Miss., Auk, XXIII, 1906, pp. 44-47; 61 species. Also, Ibid., p. 232.-1907. Allison, A. Notes on the Spring Birds of Tishomingo County, Miss. Auk, XXIV, pp. 12-25.

\section{Missouri}

1879. Scotт, W. E. D. Notes on Birds Observed During the Spring Migration in Western Missouri. Bull. N. O. C., IV, pp. 139-147; 148 species. -1884. Hurter, J. List of Birds Collected in the Neighborhood of St. Louis, Mo. Orn. and Oöl., IX, pp. 85-87, 95-97 (see also p. 128); 265 species.-1896. Widmann, O. The Peninsula of Missouri as a Winter Home for Birds. Auk, XIII, 1896, pp. 216-222.-1907. WidmanN, O. A Preliminary Catalogue of the Birds of Missouri. Trans. Acad. Sci., St. Louis, XVIII, pp. 1-288; 383 species.-1908. Woodruff, E. S. Birds of Shannon and Carter Counties, Missouri. Auk, XXV, pp. 191-213; 172 species.

\section{NeBraska}

1878. Aughey, S. Notes on the Nature of the Food of the Birds of Nebraska. First Ann. Rep. U. S. Ent. Com. for the year 1877. Appendix II, pp. 13-62; 252 species.-1883. Hall, A. Spring Birds of Nebraska. Forest and Stream, XX, pp. 265, 266, 284; 114 species.-1888. TAYLOR, W. Edgar. A Catalogue of Nebraska Birds . . Ann. Rep. Nebr. State Board 
of Agric. for the year 1887, pp. 111-118; 314 species.-1888-89. TAYLOR, E. W., and Van Vleet, A. H. Notes on Nebraska Birds. Orn. and Oöl., XIII, pp. 49-51, 169-172; XIV, pp. 163-165; 137 species.-1896. BRUNER, L. Notes on Nebraska Birds. Rep. Neb. State Hort. Soc., 1896, pp. 48-178; 415 species. -1901. Brener, L. Birds that Nest in Nebraska. Proc. Nebr. Orn. Union, 1901, pp. 48-61; 212 species.-1904. BRUNer, L., WaLcott, R. H., and Swenk, M. H. A Preliminary Review of the Birds of Nebraska, 1-116+5 p.; 406 species. Klopp and Bartlett, Omaha, Nebr.-1909. WALсотт, R. H. An Analysis of Nebraska's Bird Fauna. Proc. Neb. Orn. Union, IV, pp. 25-55.

\section{New HAMPShire}

1877. Goodhue, C. F. The Birds of Webster and Adjoining Towns. Forest and Stream, VIII, pp. 33, 49, 96, 113, 146; 151 species.-1872. MAYnard, C. J. See Maine.-1887. Chadbocrne, A. P. A List of the Summer Birds of the Presidential Range of the White Mountains, N. H. Auk, IV, pp. 100-108; 47 species.-1888. FAxON, W., and AlleN, J. A. Notes on the Summer Birds of Holderness [65 species], Bethlehem [50 species], and Franconia, N. H. [87 species]. Auk, V, pp. 149-155.-1889. Allen, F. H. Summer Birds at Bridgewater, N. H. Auk, VI, pp. 76-79.-1882. Knowlton, F. H. A Revised List of the Birds of Brandon, Vt. The Brandon Union, February 10, 1882; 149 species.-1898. DEARBORN, N. Preliminary List of the Birds of Belknap and Merrimack Counties, N. H. New Hampshire College, Durham, 8vo, 34 pp.; 175 species.-1900. Batchelder, F. W. and FoGG, E. H. Preliminary List of Birds . . . . of Manchester, N. H. Proc. Manchester Inst. Arts and Sci., I, pp. 123-138; 132 species. (See also Proc. for 1901, 1902.)-1900. DearborN, N. The Birds of I urham and Vicinity. Cont. Zoöl. Lab. N. H. College Agric. and Mech. Arts, VI, 121 pp., map.-1904. Allen, G. M. The Birds of New Hampshire. Proc. Manchester Inst. Arts and Sciences, IV, pp, 23-222; 28:3 speries.-1904. Comer, A. C. A Partial List of the Summer Birds of Holderness, N. H. Wilson Bull., XVI, 5-9 pp.; 94 species.

\section{NEW JeRsey}

1885. Barrell, H. F. Birds of the Upper Passaic Valley, New Jersey. Orn. and Oöl., X, pp. 21-23, 42, 43; 149 species.-1887. Tirurber, E. A List of Birds of Morris County, New Jersey. True Democratic Banner (newspaper), Morristown, N. J., Nov. 10, 17, 24; 205 speries.-1894. NTone, IV. The Birds of Eastern Pennsylvania and New Jorsey. Svo, 18.5 p). I) Valley Orn. Club, Phila.; 346 species.-1894. STone, W. Summer Birds of the Pir e Barrens of New Jersey. Auk, XI, 189)4, [) . 13:3-1.1(); (9) spereies.- \$897-1910. STone, WV., Editor. Numerous Notes on Bircls of ('hiefly Southern New Jersery. Pros. Del. Valley Orn. Club, Phila.-1901. Bansion, W. A. the Pirds of Princeton, N. J. Bull. Bircl ('lul), Princerton Iniv. I, pp. '7-82; 230) species.-1906. ('mapMas, F'. M. ('ice New York.)-1907. Holmes, L. K. Birds Found within a Radius of 12 Miles of summit, N. J. Wilson Bull. XIX, pr). 21-27: 201 spereies. Sue also list of summer Birrls. Ibid., XVII, pp. \&-12; and Hamm, List of summit 13irds, Ihid., pl). 117 1'22. -1909. Stone, W. The Bircls of New Jersey. Ann. Rep). N. J. Nitate Museum for 1908, p). 11-347, 109 419; plls. 1 \&..-1909. BAH, . W. L. Breeding Birds of Passaic and Sussex ('ountios. ('assinia, pu). 29)-36; 94 species.

\section{NEW YoRK}

1844. Giraud, J. P., Jr. The Birds of Long Island . . . New York. 1 vol., 8vo, 397 pp.; 286 speries. 1844. DEKAY, JAMES F. Zö̈logy

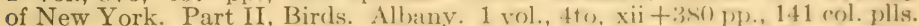
-1876. Fowler, H. G. Birds of Central New York. Forest and Stream, VI, 
pp. 180, 233, 284, 337, 402; VII, pp. 36, 52, 84, 230. Also Additions Ibid., p. $180 ; 170$ species.-187\%. Roosevelt, T., JR., and Minot, H. D. The Summer Birds of the Adirondacks in Franklin County, N. Y. 8vo, 4 pp.; 97 species.-1879. RathbUn, Frank R. A Revised List of Birds of Central New York. (Cayuga, Onondaga, Seneca, Wayne, and Yates Counties, Auburn, N. Y.) 47 pp. See also Orn. and Oöl., VII, 1882, pp. 132, 133. 14 additions.-1879-80. Mearns, E. A. A List of the Birds of the Hudson Highlands. Bull. Essex. Inst., X, pp. 166-179; XI, pp. 43-52, 154-168, 189204; XII, pp. 11-25, 109-128; XIII, pp. 75-93. (See also Auk, VII, 1890, pp. $55,56) ; 214$ species. 1880. GREGG, W. H. Revised Catalogue of the Birds of Chemung County, New York. Elmira, N. Y., O. H. Wheeler; 217 species.1881-84. Merriam, C. H. Preliminary List of Birds Ascertained to Occur in the Adirondack Region, Northeastern New York. Bull. N. O. C., VI, pp. 225-235; and Addenda VII, 1882, pp. 128, 256, 257. Auk, I, 1884, pp. 58, 59; 211 species.-1882. Bicknell, E. P. A Review of the Summer Birds of a part of the Catskill Mountains, with prefatory remarks on the faunal and floral features of the region. Trans. of the Linn. Soc. of New York, I, pp. 115-168; 90 species.-1885. Hollick, A. Preliminary List of the Birds Known to Breed on Staten Island. Proc. Nat. Sci. Assc. Staten Island. Extra No. 4, December. 67 species.-1886. BARNuM, M. K. A Preliminary List of the Birds of Onondaga County, N. Y, Bull. of the Biol. Lab. of Syracuse University. 8vo, pp. 1-34; 204 species.1886. RALPH, W. L., and BAGG, E. An Annotated List of the Birds of Oneida County, N. Y., and Its Immediate Vicinity. Trans. Oneida Hist. Soc., III, pp. 101-147; 224 species. (See also Ibid., VII, 1890, pp. 2, 29-232.) Orn. and Col. XIII, 1888, pp. 58, 59. Auk, XI, 1894, pp. 162-164. 1886. Woodruff, L. B., and Parne, A. G., Jr. Birds of Central Park, New York City. A Preliminary List. Forest and Stream, XXVI, pp. 386, 387, 487; 121 species.-1889. Bergtold, W. H. A List of the Birds of Buffalo and Vicinity. Bull. Buffalo Nat. Field Club, I, 7, pp. 1-21; 237 species._1889. Davison, J. L. Birds of Niagara County, New York, Forest and Stream, XXXIII, pp. 164, 183, 303; 190 species.-1892. Clute, W. N. The Avifauna of Broome Co., N. Y. Wilson Quart., pp. 59-64; 106 species.-1896. Short, E. H. Birds of Western New York. F. H. Lattin, Albion, N, Y. 20 pp.; 229 species.-1901. EAton, E. H. Birds of Western New York. Proc. Roch. Acad. IV, 64 pp.; 299 species.-1901. Embody, G. C. Birds of Madison County, N. Y. Bull. Dep't. Geol. and Nat. Hist., Colgate University, Hamilton, N. Y. 8vo, 36 pp.; 191 species. (See also Maxon, Auk, XX, p.263.)-1904. Chapman, F. M. An Annotated List of the Birds Known to Breed within 50 Miles of New York City. Guide Leaflet, No. 14, Am. Mus. Nat. Hist., 31 pp., 13 ills.-1906. Chapman, F. M. The Birds of the Vicinity of New York City. Am. Mus. Nat. Hist., Guide Leaflet, No. 22, Rev. Ed., 96 pp. Numerous ills.; 353 species.-1907. Braislin, W. C., A List of the Birds of Long Island, N. Y. Abst. Proc. Linnæan Society, N. Y., 1907, pp. 31-123; 364 species. (See also Auk, 1909, pp. 314-316.)-1910. ReED, H. D., and Wright, A. H. Vertebrates of the Cayuga Lake Basin. Proc. Am. Philos. Soc., XLVIII, pp. 370-459; 257 species.-1910. Wright, A. H. and Allen, A. A. The Increase of Austral Birds at Ithaca. Auk, XXVII, pp. 63-66.-1910. EAton, E. H. Birds of New York. I, Water and Game Birds. 4to, pp. 1-501, col. plls. [by Fuertes] 42.

\section{North Carolina}

1871. Coues, E. Notes on the Natural History of Fort Macon, N. C. and Vicinity. Proc. Acad. Nat. Sci. Phila., XXIII, Birds, pp. 18-47. Also Ibid., 1878 , pp. $22-24 ; 133$ species.-1885. Brimley, H. H. and C. S. Summer Birds of Raleigh, N. C. Orn. and Oöl., X, pp. 143, 144; 82 species.1885. Brimley, H. H. and C. S. Winter Birds of Raleigh, N. C. Orn. and Oöl., X, p. 128; 72 species.-1886. Brewster, W. An Ornithological Reconnaissance in Western North Carolina. Auk, III, pp. 94-112, 173- 
179; 102 species.-1886. Batchelder, C. F. The North Carolina Mountains in Winter. Auk, III, pp. 307-314; 40 species.-1887. Atkixson, G. F. Preliminary Catalogue of the Birds of North Carolina. Journ. Elisha Mitchell Society, 1887, Part 2, pp. 44-87; 255 species. A compilation with some errors. 1887. Calrns, J. S. A List of Birds of Buncombe Co., North Carolina. Orn. and Oöl., XII, pp. 3-6; 169 species.-1887. Sexietr, G. B. Observations in Western North Carolina Mountains in 1886 . Auk, IV, pp. 240-245; 29 species.-1888. Brimley, C. S. A List of Birds Known to Breed at Raleigh, N. C. Orn. and Oöl., XIII, pp. 42, 43; 54 species. (See also Ibid., p. 187. Auk, XIV, p. 165.)-1889. CAIrxs, J. S. The Summer Birds of Buncombe County, North Carolina. Orn. and Oöl., XIV, pp. 17-22; 123 species.-1893. Brimex, C. S. Some Additions to the Avifauna of North Carolina, with Notes on Some Other Species. Auk, X, 1893, pp. 241-244; 48 species.-1897. Smrthwick, J. W. P. Ornithology of North Carolina. Bull. 144, N. C. Agric. Exp. Sta., pp. 193-228; 303 species.1899. Pearson, T. G. Preliminary List of Birds of Chapel Hill, N. C. Journ. Elisha Mitchell Sci. Soc., XVI, pp. 33-51; 132 species. 1901. Bishop, L. B. The Winter Birds of Pea Island, N. C. Auk, XVIII, pp. 260-268; 42 species.-1905. Oberholser, H. C. Notes on the Mammals and Summer Birds of Western North Carolina. Published by Biltmore Forest School. Birds pp. 11-24; 136 species.-1910. Philipp, P. B. (see S. C.).

\section{OHIO}

1877. LaNGDON, F. W. A Catalogue of the Birds of the Vicinity of Cincinnati. 8vo, 18 pp. Salem, Mass.; 279 species.-1879. Langdon, F. W. A Revised List of Cincinnati Birds. Journ. (in. Soc. Nat. Hist., I, 4, pp. 167-193. (See also Ibid., III, pp 121-127; V, 1882, p. 186; VI, 1883, pI). 1231; 256 species.) - 1882. WheA tov, J. M. Report on the Birds of Ohio. Report of the Geological Survey of Ohio, IV, I, pp. 1s $8-62 x ; 298$ species.-1891. Smith, R. W. A List of the Birds of Warren ('ounty, Ohio. Journ. ('in. Soc. Nat. Hist., XIV, pp. 105-133; 189 species-1896. Orerholser, H. C. A Preliminary List of the Birds of Wayne Co. Bull. Ohio Agric. Exp. Sta. I, 4, pp. 243-354; 183 speries.-1902. Hexinger, W. F. A Preliminary List of the Birds of Midclle southern ()hio. Wilson Bulletin, IX, pp. 77-93; 209 species. (See also Il,id., pl). 133()-132; XII, 19(0), pp. 6993).-1902. Jones, L. Bird Studies in Lorain Co., Ohio. Wilson Bull., IX, pp. 37-58; also pp. 94-100.-1903. DAwson, W. L. The Birds of (Ohio, 4 to $x l y+671$ pp. Many illus. Columbus, Wheaton Pub). ('o.-1903. Finud, A. I. Birds of Lecking Co., Ohio. Bull. Sci. Lab. Denison Univ., XV; 203 species. -1903. Jones, L. The Birds of ()hio. A Revised ('atalogue. Ohio State Acad. of S'ci., Sperial Papers No. 6, 141 pl) 1 map; 318 speries. -1906. Heninger, W. F. A Preliminary List of Birds of Rinceat ('o., Ohio. Wilson Bull., XVIII, pp. 47-60; 205 sperie-1909-10. JoNr.s, I. The Birds of Cedar Point and Vicinity. Wilson Bull., XXI, pI). 5i 76, 115-131, 187-202; XXII, pp. 25-41.97-115, 172-182. Note-Livery issue of the Wilson Bulletin (Oberlin, Ohio) contains matter of special interest to bird students in Ohio and the adjoining states.

\section{Pennsylvania}

1844. BAIRD, W. M. and S. F. List of Birds Found in the Virinity of Carlisle, Cumberland ('ounty, Pa. Am. Journ. Siri. and Arts, XLVI, pr). 261-273.; 201 species.-1845. BAIR1), S. F. ('atalogue of Birds Found in the Neighborhood of Carlisle. (umberland ('ounty, Pa. Lit. Ree. and Journ. Linn. Assoc. of Penna. College, I, pp. 249-257; 203 spories-1861. BARNARD, V. A. A Catalogue of the Bircls of Chester County. Pa. Times of

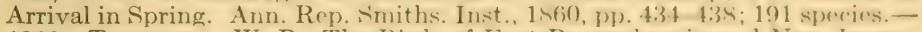
1869. Turnbell, W. P. The Birds of East Pennsylvania and New Jersey. 
. 1 vol. roy. 8vo, and also 4 to, xii +62 pp.; 342 species.-1880. WARren, H. B. The Birds of Chester County, Pa. Forest and Stream, XIII, pp.1024, 1025; XIV, pp. 6, 25; 218 species.-1886. PARker, H. G. List of Birds near Philadelphia with the Dates That Sets of Eggs Were Taken. Orn. and Oöl. XI, pp. 70, 71; 76 species.-1887. PennOCK, C.J. Birds of Chester County, Pa. The Oölogist. IV, pp. 1-10; 234 species.-1889. Ressel, C. B. Birds of Chester County, Pa. Orn. and Oöl., XIV, 97-101, pp. 112-116, 129, 130; 199 species. -1890. Warren, B. H. Report on the Birds of Pennsylvania. With Special Reference to the Food Habits. Second Edition. Harrisburg. 8vo, xiv +434 pp.; 100 col. plls.-1891. STONe, W. The Summer Birds of Harvey's Lake, Luzerne Co., Pennsylvania, with Remarks on the Faunal Position of the Region. Proc. Acad. Nat. Sci. Phila. 1891, pp. 431-438; 54 species.1892. Dwight, J., JR. Summer Birds of the Crest of the Pennsylvania Alleghanies. Auk, IX, pp. 129-141; 84 species.-1893. JAcoBs, J. W. Summer Birds of Greene Co., Pa. 8vo, 15 pages; 90 species. Published by Author, Waynesburg, Pa.-1893. TODD, W. E. C. Summer Birds of Indiana $[65$ species] and Clearfield [55 species] Counties, Pa. Auk, X, 1893, pp. 35-46.-1894. Stone, W. The Birds of Eastern Pennsylvania and New Jersey. 8vo, vii + 185 pp. Del. Valley Orn. Club, Phila. 346 species.-1895. Rotzeld, W. E. Birds of Narbeth,Pa., and Vicinity. The Citizen, June 22 and 29, and reprinted in pamphlet, 8 pp.; 108 species.-1896. BAILY, W. L. Summer Birds of Northern Elk Co. Auk, XIII, pp. 289-297; 69 species.-1896. Young, R. T. Summer Birds of Anthracite Coal Regions of Pennsylvania. Auk, XIII, 1896, pp. 278-285; 69 species.-1897. Montgomery, T. H., JR. A List of the Birds of the Vicinity of West Chester, Chester Co., Pa. Am. Nat., 1897, pp. 622-628, 812-814, 907-911; 145 species.-1897-1910. Stone, W. Editor. Numerous Notes on and Short Lists of Eastern Pennsylvania Birds. Proc. Del. Valley Orn. Club, Phila.-1899. Rhoads, S. N. Notes on Some of the Rarer Birds of Western Pennsylvania. Auk, XVI, pp. 308-313; 65 species.-1901. Burns, F. L. A Sectional Bird Census, at Berwyn, Pa. Wilson Bull. No. 36, pp. 84-103; 62 species.-1904. Todd, W. E. C. The Birds of Erie and Presque Isle, Erie Co., Pa. Annals Carnegie Museum, II, pp. 481-596, 4 plates; 237 species.-1904. Todd, W. E. C. The Mammal and Bird Fauna of Beaver County, Pa. Bausman's History of Beaver County, II, 1904, pp. 1195-1202; 178 species.

\section{RHODE ISLAND}

1899. Howe, R. H., Jr., and Sturtevant, E. The Birds of Rhode Island. Published by Authors. 8vo, 111 pp; 291 species.-1908. Commissioners of Birds. A Check-List of Rhode Island Nesting Birds, pp. 1-26; 104 species.

\section{South Carolina}

1868. Coues, E. Synopsis of the Birds of South Carolina. Proc. Bost. Soc. Nat. Hist., XII, pp. 104-127; 294 species.-1879. Loomis, L. M. A Partial List of the Birds of Chester County, S. C. Bull. N. O. C., IV, pp. 209-218; 140 species. (See also additions and notes. Auk., II, 1885, pp. 188-193; VIII, 1891 , pp. 49-59, 167-173; IX, 1892; pp. 28-39; XI, 1894. pp. 26-39, 94-117.)-1885. Hoxie, W. Notes on the Birds of the Sea Islands. Orn. and Oöl., X, pp. 13-27, 29, 44-46, 62, 63. (Also Corrections and Additions, Ibid., XI, 1886 , pp. 33, 34) 238 species-1890. Loomis, L. M. Observations on Some of the Summer Birds of the Mountain Portions of Pickens County. Auk, VII, pp. 30-39, 124-130; 76 species.-1891. Loomis, L. M. June Birds of Cæesar's Head, S. C. Auk, VIII, pp. 323-333; 52 species. -1910. Philipp, P. B. List of Birds Observed [in the Carolinas]. Auk, XXVII, pp. 312-322. (See also Wayne, Ibid., p. 464.)-1910. Wayne, A. T. Bircls of South Carolina. Cont. from Charleston Museum, I, 8vo, xxi tpp. $254 ; 337$ species. 


\section{Tennesseé}

1886. Fox, T. H. List of Birds Found in Roane County. Tennessee, During April, 1884, and March and April, 1885. Auk, III, pp. 315-320; 114 species.-1895. Rhodds. S. N. Cont. Zoöl. Tenn., Pror. Acad. Nat. Sci., Phila., 1895. pp. 463-501. Also Auk, XIII, 1>96, p. 181; 22.3 species.1910. Howell, A. H. Notes on the Birds of Kentucky and Tenuessee. Auk, XXVII, pp. 295-304. Tenn,; 162 species.

\section{VERMONT}

1901. Howell, A. H. Preliminary List of Summer Birds of Mount Mansfield, Vt. Auk, XVIII, pp. 337-347; 86 species.-1902. PerkiNs, G. H. A Preliminary List of the Birds Found in Vermont. 21st Ann. Rep. Vt. State Bd. Agric., pp. ১5-118; 261 species. See also Howe, R. H., JR., Cont. N. A. Orn. II, pp. 5-22.-1903. Davexport, E. B. Birds Ohserved on Mt. Mansfield and the West End of Stowe Valley at the Base of the Mountain, in the Summer of 1902 . Wilson Bull., Xi, pp. $77-86 ; 7 t$ species.1907. Davenport, E. B. Birds of Windham and Bennington Counties. Bull. No. 2, Vermont Bird Club (Burlington, Vt.), pp. 5-14,; 176 species.1908. Allen, F. H. Summer Birds of Southern Termonit. Auk, XXV, pp. $56-64 ; 86$ species.

\section{VIRGINIA}

1890. Rrves, Wr. C., M. D. A Catalogue of the Birds of the Virginias. Proc. Newport Nat. Hist. Soc., Document VII, Newport R. I. Svo, 100 pp.; 305 species.-1902. Daxiels, J. W. Summer Birds of the Great Dismal Swamp. Auk XIX, 15-18 pp,; 41 species.-1910. Emвony, G. C. A List of Birds Observed at Ashland, Via. Auk, XXVII, pp. 169-177; 114 species.

\section{West Virginia *}

1873. Sсотт, W. E. D. Partial List of the Summer Birds of Kanawha County, West Virginia, with Annotations. Proc. Bost. Soce. Hist., XV, pp. 219-227; 86 species-1875. BREWSTER, W. Some Observations on the Birds of Ritchie county, West Virginia. Annals of the Lye Nat. Hist., N. Y., XI, pp. 129-146; 100 speeries-1888. Do.1. W. D. Birch of lliest Virginia. Bull 3, Agric. Exp. Sta., Morgantown; 200 speries-1889. SirzIBER, T. Birds of Greenbriar Connty, Ifest Via. The IIawkeye Orne and Oöl. (E. B. Webster, ('reseno. Iowa), II, p\}), 2-4 13-15, 2!) :32: 121 speeries. -1890. Rrves, W. C. (Sef Virginia.)-1898. Rivis, IV. C. Summer Birds of the West Virginia Suruere Belt. Ank, XV. pu. 1:31-1:37; 4ti speeres. 1909. Brooks, E. A. West Virginia Birds in State Bonrd of Agrieulture. Report W. Va. State Board Agric.., for 199(1), p1). 3-62; 19:3 speries.

\section{WISCONSIN}

1853. Hor, P. R. Notes on the Ornitholegry of Wisconsin. Proc. Aradl.

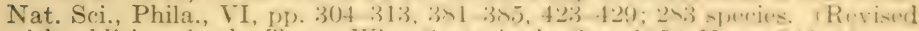

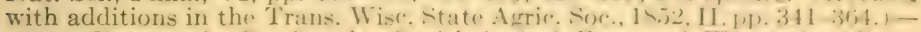

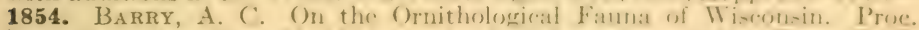

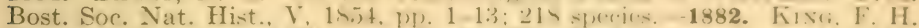

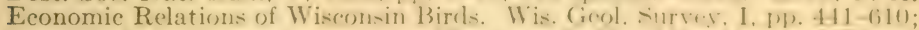

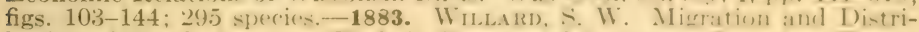
bution of North American Birds in Brown and (nutgamie. Connties. Trans.

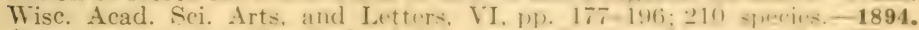

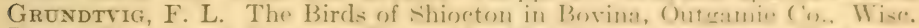
Trans. Wisc. Acad. Sciences, X, pp. 73-15s: 1.3 speries-1903. Ki MLIEN, L. and Hollister, N. The Birels of Wisenusin. IBull. Wire: Nat. Hist. Soc., III (N. S.), pp. 1-143, s half-tones; 357 species.-1909. (i)RY, C. B. (See Ills.) 



\section{INDEX}

Acanthis hornemanni exilipes, 380 . hornemanni hornemanni, 380.

linaria holbœlli, 381.

linaria linaria, 380.

linaria rostrata, 381

Accipiter cooperi, 294. velox, 293.

Actitis macularia, 261.

Echmophorus occidentalis, 139.

AEgialitis hiaticula, 267. meloda, 266.

nivosa, 276

semipalmata, 266.

Estrelata gularis, 176. hasitata, 176. scalaris, 176.

Agelaius phœniceus bryanti, 361 . phœniceus floridanus, 362 . phœniceus fortis, 362 . phœeniceus phœniceus, 361 .

Aix sponsa, 197.

Ajaja ajaja, 217.

Alauda arvensis, 348.

Alaudidæ, figured, 128 .

Albatross, Wandering, 173.

Yellow-nosed, 173.

Albinism, 96.

Alca torda, 148.

Alcedinidæ, 320; figured, 127.

Alcidæ, 145; figured, 118.

Alle alle, 149.

Alleghanian fauna, 30 .

Altricial birds, 75 .

Aluco pratincola, 308.

Aluconidæ, 308; figured, 125.

American Ornithologists' Union, 23. Committee of, 8 .

Ammodramus bairdi, 389 . savannarum australis, 389 . savannarum floridanus, 390.

Anas fulvigula, 193. platyrhynchos, 191. rubripes rubripes, 192. rubripes tristis, 192.

Anatidæ, 186.

Anatinæ, 190; figured, 121.

Anhinga anhinga, 181.

Anhingidæ, 181; figured, 120.

Ani, $70,318$.

Groove-billed, 319 .

Anoüs stolidus, 171.

Anser albifrons albifrons, 212. albifrons gambeli, 212. brachyrhynchos, 213. fabalis, 213.

Anseres, 186; figured, 121.

Anserinæ, 121, 210.

Anthrenus, 21.

Anthus pratensis, 472, rubescens, 471 .

spraguei, 471.
Antrostomus carolinensis, 331. vociferus vociferus, 332 .

Aphelocoma cyanea, 351 .

Aphrizidæ, 268.

April, birds of, 34, 38 .

Aquila chrysaëtos, 301.

Aramidæ, 230; figured, 123.

Aramus vociferus, 230.

Archibuteo ferrugineus, 300 .

lagopus sancti-johannis, 300 .

Archilochus colubris, 336 .

Arctic zone, 29.

Ardea cinerea, 224.

herodias herodias, 223.

herodias wardi, 224.

occidentalis, 223.

wuerdmanni, 223

Ardeidæ, 219; figured, 122.

Arenaria interpres interpres, 268.

interpres morinella, 268.

Arquatella maritima maritima, 249.

Asio flammeus, 310 .

wilsonianus, 310 .

Astragalinus tristis tristis, 382 .

Astur atricapillus atricapillus, 382 .

Asturina plagiata, 300 .

Audubon Societies, National Association of, 24 .

August, birds of, 35, 39 .

Auk, Great, 149.

Little. See Dovekie.

Razor-billed, 148.

Auk, The, 24 .

Austral Region, 29.

Austroriparian fauna, 30

Auxiliary barrel, 14.

Avocet, American, 241; figured, 105.

Bæolophus bicolor, 485 .

Baldpate, 194.

Banding birds, 73 .

Banner marks, 95.

Bartramia longicauda, 259.

Beach-bird. See Sanderling.

Beretle-heral. So, Plower, Black-bellied.

Bendire, C. E., 22.

Bill, uses of, 104.

Bird, young, condition of, 79 .

defense of, 81.

feeding of, 80,81 .

food of, 80 .

Bird-Lore, 24.

Birds and insects, 99.

and $\operatorname{man}, 114$

and rodents, 100.

and weeds, 100.

as scavengers, 101.

care of, in the field, 16.

collecting, 15.

distribution of, 27.

economic value of, 98,100 . 
Birds, food of, 98.

how named, 5.

how to find, 3 .

how to identify, 4 ,

intelligence of, 11.

migration of, 32 .

relation of, to $\operatorname{man}, \mathbf{1}, 2$.

senses of, 109.

sexual organs of, 20.

skinning, 16.

study of, in nature, 60 .

voice of, 60 .

why we should study, 1, 2 .

Birdskins, 15, 16.

Bittern, American, 221.

Cory's Least, 222.

Least, 222.

Blackbird, Bahama Red-wing, 362.

Cow. See Cowbird.

Crow. See Grackles, Purple and Bronzed.

Florida Red-wing, 362.

Red-winged, 72,361 .

Rusty, 365.

Skunk. See Bobolink.

Thick-billed Redwing, 362.

Yellow-headed, 360.

Black-cap, Wilson's. See Warbler, Wilson's.

Black-head. See Duck, Scaup.

Black Jack. See Scaup, Lesser.

Blind, umbrella, 11.

Bluebill. See Duck, Scaup.

Greater. See Scaup, Duck, Greater.

Small. See Scaup, Lesser.

Bluebird, 115, 499.

Blue Peter. See Coot.

Blue Stocking. See Avocet.

Bobolink, 358; map of migration of, 44.

Bob-white, 100, 270.

Florida, 271.

Bog-sucker. See Woodcock.

Bombycilla cedrorum, 421. garrula, 420.

Bombycillidæ, 420; figured, 130.

Bonasa umbellus togata, 274. umbellus umbellus, 273.

Booby, 179.

Blue-faced, 180.

Red-footed, 180.

Boreal Region, 28.

Botaurus lentiginosus, 221.

Brant, 214.

Black, 214.

White. See Goose, Snow.

Branta bernicla glaucogastra, 214.

canadensis canadensis, 213.

- canadensis hutchinsi, 213.

canadensis minima, 213.

leucopsis, 214. nigricans, 214.

Brant-bird. See Turnstone.

Brent. See Brant.

Broadbill. See Ducks, Scaup and Shovel ler.

Brooding, 79.

Broods, number of, 68 .

Brown-Back. See Dowitcher.

Bubo virginianus heterocnemis, 315 .

virginianus subarcticus, 315 .

virginianus virginianus, 315 .
Bufflehead, 204.

Bull-bat. See Nighthawks.

Bulweria bulweri, 176.

Bunting, Bay-winged. See Sparrow, Ves* per.

Black-throated. See Dickcissel.

Indigo, 410.

Lark, 413.

Painted, 411.

Snow, 384.

Varied, 411.

Burgomaster. See Gull, Glaucous.

Butcher-bird. See Shrike, Northern.

Buteo borealis borealis, 295.

borealis calurus, 296 .

borealis harlani, 296.

borealis krideri, 296.

borealis umbrinus, 296.

brachyurus, 299.

lineatus alleni, 298.

lineatus lineatus, 296.

platypterus platypterus, 298.

swainsoni, 298.

Buteonidæ, 287; figured, 126.

Butorides virescens virescens, 227.

Butter-ball. See Bufflehead.

Buzzard, 'Turkey, 286.

Cahow. See Shearwater, Audubon's.

Calamospiza melanocorys, 413 .

Calcarius lapponicus lapponicus, 385 . ornatus, 386. pictus, 386 .

Calico-back. See Turnstone.

Calidris leucophæa, 254.

Call, location, 60 .

Call-notes, 60.

Callichelidon cyaneoviridis, 419 .

Calls of præcocial birds, 60, 61 .

Camera, 13.

Campephilus principalis, 323.

Camptorhynchus labradorius, 206.

Canachites canadensis canace, 272. canadensis canadensis, 272.

Canadian zone, 28.

Canary, Wild. See Goldfinch.

Canvasback, 201.

Caprimulgidæ, 331; figured, 127.

Caracara, Audubon's, 307.

Cardinal, 407.

Florida, 408.

Kentucky. See Cardinal.

Cardinalis cardinalis cardinalis, 407. cardinalis floridanus, 408.

Carduelis carduelis, 383.

Carolinian fauna, 30.

Carpodacus purpureus purpureus, 377.

Casarca ferruginea, 196.

Cataloguing birdskins, 20 .

Catbird, 473.

Catharista urubu urubu, 287.

Cathartes aura septentrionalis, 286.

Cathartidæ, 286; figured, 126.

Catoptrophorus semipalmatus inornatus: 258.

semipalmatus semipalmatus, 258.

Cedar-bird. See Waxwing, Cedar.

Centurus carolinus, 329.

Cepphus grylle, 146.

mandti, 147.

Certhia familiaris americana, 481. 
Certhiidæ, 481; figured, 131.

Ceryle alcyon, 321 .

Chæmepelia passerina bermudiana, 285. passerina terrestris, 284.

Chætura pelagica, 335.

Chalk-line. See Heron, Little Green.

Charadriidæ, 124.

Charadrius apricarius, 265. dominicus dominicus, 264.

Charitonetta albeola, 204.

Chat, Yellow-breasted, 467.

Chaulelasmus streperus, 193.

Chebec. See Flycatcher, Least.

Chelidonaria urbica, 419.

Chen cærulescens, 212. hyperboreus hyperboreus, 211. hyperboreus nivalis, 211.

Cherry-bird. See Waxwing, Cedar.

Chewink: See Towhee.

Chickadee, 100, 486.

Acadian, 488.

Carolina, 487.

Florida, 488.

Hudsonian, 488.

Chicken, Mother Carey's. See Petrel, Wilson's.

Prairie, 276.

Chippy. See Sparrow, Chipping.

Winter. See Sparrow, Tree.

Chondestes grammacus grammacus, 394

Chordeiles virginianus chapmani, 334. virginianus sennetti, 334 . virginianus virginianus, 333 .

Chuck-will's-widow, 331.

Ciconiidæ, 219.

Circus hudsonius, 292.

Cistothorus stellaris, 479.

Civilization, effects of, on birds, 113.

Clangula clangula americana, 203. islandica, 204.

Clape. See Flicker.

Climate, 27.

Cobb. See Gull, Great Black-backed.

Coccyges, 318; figured, 126.

Coccyzus americanus americanus, 319. erythrophthalmus, 320 . minor maynardi, 319. minor minor, 319.

Cockawee. See Old-Squaw.

Cœreba bahamensis, 430 .

Colaptes auratus auratus, 329. auratus luteus, 329.

Colinus virginianus floridanus, 271. virginianus virginianus, 270 .

Collection, care of, 21.

Collector, outfit of, 14.

Colonial birds, nesting habits of, 71 .

Color and age, 87. and climate, 89. and concealment, 91. and habit, 95. and season, 87 . and sex, 87 .

Columbæ, 281; figured, 125.

Columba leucocephala, 281. squamosa, 282 .

Colymbidæ, 138; figured, 118.

Colymbus auritus, 140 . holbœelli, 140. nigricollis californicus, 141 .

Compsothlypis americana americana, 447.
Compsothlypis americana usneæ, 447 .

Condor, The, 23.

Conuropsis carolinensis, 317.

Cooper Ornithological Club, 24.

Coot, American, 237; figured, 109.

Bumblebee. See Duck Ruddy.

Butter-billed. See Scoter, American.

Ivory-billed. See Coot, American.

Patch-head. See Scoter, Surf.

White-winged. See Scoter, Whitewinged.

Corvidæ, 350; figured, 128 .

Corvus brachyrynchos brachyrhynchos, 353.

brachyrhynchos pascuus, 354 .

corax principalis, 352.

corax sinuatus, 352 .

frugilegus, 355 .

ossifragus, 354 .

Coturnincops noveboracensis, 235.

Coturnix coturnix, 271.

Counter-shading, 93

Courlan. See Limpkin.

Courlans, 230.

Courtship, 70.

Cowbird, 70, 77, 359.

Crake, Corn, 236.

Spotted, 235.

Crane, Blue. See Heron, Great Blue.

Brown. See Crane, Sandhill.

Little Brown, 229.

Sandbill, 229.

White. See Crane, Whooping.

Whooping, 229

Creciscus jamaicensis, 235.

Creeper, Black and White. See Warbler, Black and White.

Brown, 481; figured, 107.

Crex crex, 236.

Crossbill, American, 379.

White-winged, 379.

Crotophaga ani, 318.

sulcirostris, 319 .

Crow, 110, 111, 353.

Carrion. See Vulture, Black.

European Hooded, 355.

Fish, 354.

Florida, 354

Crow-Duck. See Coot.

Crying-bird. See Limpkin.

Cryptoglaux acadica acadica, 313

funerea richardsoni, 312

Cuckoo, 100.

Black-billed, 320 .

Mangrove, 319.

Maynard's, 319.

Yellow-billed, 319.

Cuculidæ, 318; figured, 127.

Curlew, Eskimo, 262.

European, 263.

Hudsonian, 262.

Jack. See Curlew, Hudsonian.

Long-billed, 261.

Pink. See Spoonbill, Roseate.

Spanish. See Ibis, White.

Cut-water. See Skimmer, Black.

Cyanocitta cristata cristata, 350 . cristata florincola, 351.

Cygninæ, 121, 215.

Dabchick. See Grebe, Pied-billed. 
Dafila acuta, 197.

Daption capense, 174.

Darter, Little Blue. See Hawk, Sharpshinned.

Big Blue. See Hawk, Cooper's.

Darters, 181.

December, birds of, 36 .

Decoration of nest, 74 .

Delaware Valley Ornithological Club, 23.

Dendrocygna bicolor, 215.

Dendroica æstiva æstiva, 448.

auduboni auduboni, 451 .

cærulescens cærulescens, 449.

cærulescens cairnsi, 450.

castanea, 453.

cerulea, 452 .

coronata, 450 .

discolor, 460.

dominica albilora, 456 .

dominica dominica, 456 .

fusca, 455 .

kirtlandi, 457.

magnolia, 451.

palmarum hypochrysea, 459 .

palmarum palmarum, 459 .

pensylvanica, 453 .

striata, 454 .

tigrina, 448.

townsendi, 457.

vigorsi vigorsi, 458.

virens, 457 .

Dermestes, 21.

Dichromanassa rufescens, 225.

Dichromatism, 96.

Diedapper. See Grebe, Pied-billed.

Diomedea exulans, 173.

Diomedeidæ, 172; figured, 119.

Distribution and food, 98 .

factors influencing, 27.

factors governing local, 104.

Diver, Great Northern. See Loon. Hell. See Grebe, Horned.

Diving Birds, 138.

Dolichonyx oryzivorus, 358.

Dough-bird. See Curlew, Eskimo.

Dove, Bermuda Ground, 285.

Carolina. See Dove, Mourning.

Ground, 284.

Mourning, 100, 283.

Turtle. See Dove, Mourning.

White-winged, 284.

Zenaida, 284.

Dovekie, 149.

Dowitcher, 247.

Long-billed, 247.

Dryobates borealis, 325 .

pubescens medianus, 325 .

pubescens pubescens, 325 .

villosus auduboni, 324 .

villosus leucomelas, 324 .

villosus terrænovæ, 324 .

villosus villosus, 323 .

Duck, Black, 192.

Black-head. See Duck, Scaup.

Blue-bill. See Duck, Scaup.

Bridal. See Duck, Wood.

Broad-bill. See Ducks, Scaup and Shoveller.

Brown-legged Black, 192.

Butter. See Bufflehead.

Crow. See Coot.
Duck, Dipper. See Bufflehead.

Dusky. See Duck, Black.

English. See Mallard.

Florida, 193.

Gray. See Gadwall.

Greater Scaup, 202.

Harlequin, 206.

Labrador, 206.

Lesser Scaup, 202.

Long-tailed. See Old-squaw.

Masked, 210.

Pied. See Duck, Labrador.

Raft. See Scaup, Lesser.

Red-legged Black, 192.

Ring-bill. See Duck, Ring-necked.

Ring-necked, 203.

Ruddy, 210.

Rufous-crested, 198.

Scaup, 202.

Spoonbill. See Shoveller.

Spirit. See Bufflehead.

Summer. See Duck, Wood.

Surf. See Scoter, Surf.

Wood, 186, 197.

Ducks, Molt of, 86.

Dumetella carolinensis, 473 .

Dunlin, 253.

Eagle, Bald, 302.

Caracara. See Caracara.

Golden, 301.

Gray Sea, 302.

Economic Value of Birds, 98.

Ectopistes migratorius, 282.

Eggs, collecting and preserving, 21.

colors of, 78.

number of, laid, 77.

shape of, 78 .

size of, 78.

variations of, 78,79

Egret, 224.

Peale's. See Egret, Reddish.

Reddish, 225.

Snowy, 225.

White, 110.

Egretta candidissima candidissima, 225.

Eider, American, 207.

King, 208.

Northern, 207.

Steller's, 207.

Elanus leucurus, 291.

Empidonax flaviventris, 344.

trailli alnorum, 346.

trailli trailli, 346.

virescens, 345 .

Enemies of nesting birds, 71 .

Environment as mold for habit, 73

Ereunetes mauri, 254.

pusillus, 253.

Erismatura jamaicensis, 210.

Erolia ferruginea, 253.

Erythrism, 96.

Euphagus carolinus, 365.

Falco æsalon, 306.

columbarius columbarius, 305.

islandus, 303.

mexicanus, 304 .

peregrinus anatum, 305 .

peregrinus peregrinus, 305 .

rusticolus gyrfalco, 304 . 
Falco rusticolus obsoletus, 304. rusticolus rusticolus, 304 . sparverius paulus, 307 . sparverius sparverius, 307. sparveroides, 307. tinnunculus, 306.

Falcon, Peregrine, 305. Prairie, 304.

Falconidæ, 303.

Faunal areas, 28.

February, birds of, 34, 38 .

Feet, uses of, 107.

Field-glass, 5, 9.

Finch, Grass. See Sparrow, Vesper. Lark. See Sparrow, Lark.

Pine. See Siskin, Pine.

Purple, 377.

Summer, See Sparrow, Bachman's.

Firebird. See Oriole, Baltimore.

Flamingo, 216; figured, 108.

Flicker, 77, 100, 329. Northern, 329.

Flight-song, 64 .

Flinthead. See Ibis, Wood.

Florida cærulea cærulea, 226.

Floridian fauna, 31 .

Flycatcher, Acadian, 74, 345.

Alder, 346.

Crested, 74, 341.

Fork-tailed, 340 .

Great-crested. See Flycatcher, Crested. Green-crested. See Flycatcher, Acadian. Least, 347.

Olive-sided, 343.

Scissor-tailed, 341.

Traill's, 346.

Vermilion, 347.

Yellow-bellied, 344.

Fly-up-the-creek. See Heron, Little Green.

Food of birds, 98.

Fratercula arctica arctica, 145. arctica naumanni, 146.

Fregata aquila, 186.

Fregatidæ, 185; figured, 120.

Fregetta grallaria, 178.

Frigate-bird, 185.

Fringillidæ, 369; figured, 129.

Frost-bird. See Plover, Golden.

Fulica americana, 237. atra, 237.

Fuligulinæ, 198; figured, 121.

Fulmarus glacialis glacialis, 174.

Fute. See Curlew, Eskimo.

Gadwall, 193.

Gallinæ 269; figured, 125.

Gallinago delicata, 245. gallinago, 247.

media, 247.

Gallinula galeata, 236.

Gallinule, Florida, 236. Purple, 236.

Gannet, 180. Gannet. See Ibis, Wood.

Gare-fowl. See Auk, Great,

Garrot. See Golden-eyes.

Gavia adamsi, 144.

arctica, 144.

immer, 143.

stellata, 144.
Gaviidæ, 142

Gelochelidon nilotica, 164 .

Geothlypis trichas trichas, 466 . trichas ignota, 467 .

Geotrygon chrysia, 285. montana, 285.

Glacial period, 56 .

Glottis nebularia, 256.

Gnatcatcher, Blue-gray, 491.

Godwit, Black-tailed, 256.

Hudsonian, 255.

Marbled, 255.

Golden-eye, American, 203.

Barrow's, 204.

Goldfinch, 85, 88, 382.

European, 383.

Black-headed, 384.

Goggle-nose. See Scoter, Surf.

Goosander. See Merganser, American.

Goose, Barnacle, 214.

Bean, 213.

Blue, 212.

Brant. See Brant.

Cackling, 213.

Canada, 213.

European White-fronted, 212.

Greater, Snow, 211.

Hutchins's, 213.

Laughing, See Goose, White-fronted.

Lesser Snow, 211.

Nigger. See Cormorant, Doublecrested.

Pink-footed, 213.

Sea. See Phalaropes, Red and Northern.

Solan. See Gannet.

White-fronted, 212.

Goshawk, 294.

Mexican, 300.

Grackle, Boat-tailed, 368 .

Bronzed, 368.

Florida, 367.

Purple, 68, 366.

Grassbird. See Sandpiper, Pectoral.

Grassquit, 412.

Melodious, 412.

Gray-Back. See Knot.

Grebe, Eared, 141.

Holboell's, 140.

Horned, 140

Pied-billed, 141.

Western, 139.

Greenback. See Plover, American Golden.

Greenhead. See Mallard.

Greenshank, 256.

Grosbeak, Black-headed, 409.

Blue, 409.

Cardinal. See Cardinal.

Evening, 375.

Pine, 376.

Rose-breasted, 408.

Grouse, Black. See Partridge, Canada Spruce.

Canada. See Partridge, Spruce.

Canada Ruffed. 274.

Pinnated. See Chicken. Prairie.

Prairie Sharp-tailed, 278.

Ruffed, 273; figured, 108.

Sharp-tailed, 278.

Spruce. See Partridge, Canada Spruce. 
Grouse, Willow. See Ptarmigan, Willow. Gruidæ, 229; figured 123.

Grus americana, 229. canadensis, 229. mexicana, 229.

Guara alba, 218. rubra, 218.

Guillemot, Black, 146.

Common. See Murre.

Mandt's, 147.

Thick-billed. See Murre, Brünnich's. Guiraca cærulea cærulea, 409.

Gull, Black-headed. See Gull, Laughing. Bonaparte's, 160.

Flood. See Skimmer, Black.

Fork-tailed. See Gull, Sabine's.

Franklin's, 160.

Glaucous, 155.

Great Black-backed, 157.

Herring, 157.

Iceland, 156.

Ivory, 154.

Kumlien's, 156.

Laughing, 159.

Little, 161.

Mackerel. See Tern, Common.

Mew, 159.

Ring-billed, 158.

Ross's, 161.

Sabine's, 162.

Short-billed, 159.

Siberian, 159

Summer. See Tern, Common.

White-winged. See Gull, Iceland.

Gulls, as scavengers, 102.

Gun for collecting, 14.

Gyrfalcon, 304.

Black, 304.

Gray, 304.

White, 303.

Habit and Structure, 104.

Habitat, 103.

Hæmatopodidæ, 268.

Hæmatopus ostralegus, 269. palliatus, 268.

Hagdon, See Shearwater, Greater. Black. See Shearwater, Sooty.

Hair-bird. See Sparrow, Chipping.

Haliæetus leucocephalus leucocephalus, 302.

Hang-nest. See Oriole, Baltimore.

Harelda hyemalis, 205.

Harrier. See Hawk, Marsh.

Hawk, Black. See Hawk, Rough-legged.

Blue Hen. See Goshawk.

Broad-winged, 298.

Chicken. See Hawks, Red-shoulderecl and Red-tailed.

Cooper's, 296.

Cuban Sparrow, 307.

Duck, 305.

Fish, 73, 307.

Florida Red-shouldered, 298.

Florida Sparrow, 307.

Harlan's, 296.

Harris's, 295.

Hen. See Hawks, Red-shouldered and Red-tailed.

Killy. See Hawk, Sparrow.

Krider's, 296.
Hawk, Little Black. See Hawk, Shorttailed!

Marsh, 72, 292

Pigeon, 305.

Red-shouldered, 296.

Red-tailed, 295.

Rough-legged, 300.

Sharp-shinned, 293.

Short-tailed, 299.

Snail. See Kite, Everglade.

Sparrow, 306.

Squirrel, 301.

Swainson's, 298.

Hawks, economic value of, 100 .

Hearing, sense of, 109.

Helinaia swainsoni, 440.

Hell-Diver. See Grebe, Pied-billed.

Helmitheros vermivorus, 440.

Helodromas ocrophus, 258.

solitarius solitarius, 257.

Hen, Heath, 276.

Indian. See Bittern, American.

Meadow. See Coot, American and Rail, Clapper.

Mud. See Rail, Clapper and Coot, American.

Prairie. See Chicken, Prairie.

Herodias egretta, 224.

Herodiones, 217; figured, 122.

Heron, Black-crowned Night, 228.

European, 224.

Great Blue, 72, 223.

Great White, 223.

Iittle Blue, 226.

Little Green, 227.

Louisiana, 226.

Night, 74.

Snowy. See Egret, Snowy.

Ward's, 224.

Yellow-crowned Night, 228.

Hesperiphona vespertina vespertina, 375 .

High-hole. See Flicker.

Himantopus mexicanus, 242 ,

Hirundinidæ, 415; figured, 130.

Hirundo erythrogaster, 417. rustica, 418.

Histrionicus histrionicus, 206.

Honey Creeper, Bahama, 430.

Horse-head. See Scoter, Surf.

Hudsonian zone, 28.

Hummingbird, Ruby-throated, 336.

Hydranassa tricolor ruficollis, 226.

Hydrochelidon leucoptera, 171. nigra surinamensis, 170 .

Hylocichla aliciæ aliciæ, 494. aliciæ bicknelli, 495 .

fuscescens fuscescens, 493 . fuscescens salicicolus, 494 . guttata pallasi, 496 .

mustelina, 492.

ustulata swainsoni, 495 .

Ibididæ, 218; figured, 122.

Ibis, Glossy, 218.

Scarlet, 218.

White, 218.

White-faced Glossy, 219.

Wood, 219.

Ice Age, 57.

Icteria virens virens, 467 . 
Icteridæ, 357; figured, 129.

Icterus galbula, 365 . spurius, 364 .

Ictinia mississippiensis, 291.

Incubation, 68, 79. period of, 79 .

Indigo-bird. See Bunting, Indigo.

Inheritance of nesting habit, 76 .

Insects, loss caused by, 99. taste of, to birds, 109 .

Intelligence of birds, 111.

Ionornis martinicus, 236.

Iridoprocene bicolor, 418.

Ixobrychus exilis, 222. neoxenus, 222.

Ixoreus nævius nævius, 499.

Jacana, Mexican, 269. spinosa, 269.

Jackdaw. See Grackle, Boat-tailed.

Jaeger, Long-tailed, 152.

Parasitic, 151.

Pomarine, 150.

January, birds of, 33 .

Jay, Blue, 113, 350 .

Canada, 352.

Florida, 352.

Florida Blue, 351.

Labrador, 352.

Joree. See Towhees.

Journal Maine Ornithological Society, 24.

Journals, 9.

Junco, Carolina, 401.

hyemalis carolinensis, 401.

hyemalis hyemalis, 400 .

hyemalis montanus, 401.

Montana, 401.

Slate-colored, 400.

July, birds of, 35 .

June, birds of, 35 .

Kestrel, 306.

Key, field, to common birds, 133. to orders and families, 118.

Kildee. See Killdeer.

Killdeer, 265.

Kingbird, 339.

Arkansas, 340 .

Gray, 340 .

Kingfisher, Belted, 321.

Kinglet, Golden-crowned, 489. Ruby-crowned, 490.

Kite, Blue. See Kite, Mississippi. Everglade, 291.

Fork-tailed. See Kite, Swallow-tailed. Hook-bill. See Kite, Everglade.

Mississippi, 291.

White-tailed, 291.

Kittiwake, 155.

Knot, 248.

Labeling birdskins, 20.

Lagopus lagopus alleni, 275. lagopus lagopus, 274. rupestris reinhardi, 276. rupestris rupestris, 275 . welchi, 276.

Lamellirostral swimmers, 186.

Laniidæ, 422; figured, 130.

Lanius borealis, 422 . ludovicianus ludovicianus, 423.
Lanius ludovicianus migrans, 423.

Lanivireo flavifrons, 427 .

solitarius solitarius, 427 .

solitarius alticola, 428 .

Lapwing, 264.

Larinæ, 152; figured, 119.

Lark, Field. See Meadowlark. Horned. 348.

Hoyt's Horned, 349.

Prairie. See Meadowlark.

Prairie Horned, 349.

Shore. See Lark, Horned.

Larus affinis, 157.

argentatus, 157.

atricilla, 159 .

brachyrhynchos, 159.

canus, 159.

delawarensis, 158.

franklini, 160 .

hyperboreus, 155.

kumlieni, 156.

leucopterus, 156.

marinus, 157.

minutus, 161.

philadelphia, 160.

Leadback. See Sandpiper, Red-backed.'

Lens, photographic, 13.

Leptoptilos crumeniferus, 219. dubius, 219.

Limicolæ, 238; figured, 124.

Limosa fedoa, 255.

hæmastica, 255.

limosa, 256.

Limpkin, 230.

Linnet. See Finch, Purple.

Pine. See Siskin, Pine.

Redpoll. See Redpoll.

Lobipes lobatus, 240.

Log-cock. See Woodpecker, Pileated.

Longipennes, 150; figured, 118.

Longspur, Chestnut-collared, 386. Lapland, 385.

MeCown's, 386.

Smith's, 385.

Loon, 143.

Black. See Cormorant, Double-crestad.

Black-throated, 144.

Red-throated, 144.

Yellow-billed, 144.

Lophodytes cucullatus, 189.

Lord and Lady. See Duck, Harlequin.

Loxia curvirostra minor, 379.

leucoptera, 379.

Lunda cirrhata, 146.

Machetes pugnax, 259.

Machrochires, 331; figured, 127.

Macrorhamphus griseus griseus, 247. griseus scolopaceus, 247.

Magazines, ornithological, 24.

Maine Ornithological Society, 24.

Mallard, 191.

Black. See Duck, Black.

Man-o'-war-bird, 186; figured, 106.

Marabou, 219.

March, birds of, 34, 38 .

Mareca americana, 194. penelope, 194.

Marila affinis, 202. americana, 200. collaris, 203. 
Marila marila, 202.

valisineria, 201.

Marlin, Brown. See Godwit, Marbled. Ring-tailed. See Godwit, Hudsonian.

Marsh-Hen. See Rail, Clapper.

Martin, Bee. See Kingbird. Cuban, 416.

- European, 419. Purple, 416.

Mating, 70.

Maybird. See Bobolink.

May, birds of, 34,38 .

Meadowlark, 362.

Southern, 363.

Western, 363.

Megalestris skua, 150.

Megaquiscalus major major, 368 .

Melanerpes erythrocephalus, 328.

Melanism, 96.

Meleagridæ, 278.

Meleagris gallopavo osceola, 279. gallopavo silvestris, 279 .

Melopelia asiatica asiatica, 284.

Melospiza georgiana, 404 .

lincolni lincolni, 403 .

melodia melodia, 402 .

Memory of birds, 113.

Merganser, American, 188. Hooded, 189.

Red-breasted, 188.

Mergellus albellus, 190.

Merginæ, 187; figured, 121.

Mergus americanus, 188. serrator, 188.

Merlin, 306.

Micropalama himantopus, 248.

Micropodidæ, 334; figured, 127.

Migration, at night, 50 .

extent of, 40 .

height of, 51.

how performed, 48 .

of western birds, 40 .

routes of, 41.

speed of, 51,52 .

times of, 32 .

why performed, 55 .

Mimidæ, 472; figured, 131.

Mimus polyglottos polyglottos, 472 .

Mniotilta varia, 438 .

Mniotiltidæ, 430; figured, 130.

Mockingbird, 65, 472.

Finch. See Shrike, Loggerhead.

Mollimoke, 174.

Molothrus ater ater, 359.

Molt, 85 .

Motacilla alba,

Motacillidæ, 470; figured, 131

Mother Carey's Chicken, 173, 178.

Moose-bird. See Jay, Canada.

Mud-Hen. See Coot.

White-billed. See Coot.

Murre, 147.

Brünnich's, 148.

Murrelet, Ancient, 146.

Muscivora forficata, 341 . tyrannus, 340 .

Myadestes towndsendi, 497.

Mycteria americana, 219 .

Myiarchus crinitus, 341.

Myiochanes richardsoni richardsoni, 344. virens, 343.
Names of birds, 6 .

Nannus hiemalis hiemalis, 478.

Nesting dates, 69 . season, date of, 66-68. site, 71 .

Nests, 70 . character of, 75 . collecting and preserving of, 21. construction of, 74 .

exercises in, 81 .

material for, 73 .

sanitation of, 81 .

Netta rufina, 198.

Nettion carolinense, 195. crecca, 195.

Nighthawk, 33, 100.

Florida, 334.

Sennett's, 334

Noddy, 54, 171.

Noddy. See Fulmar.

Nomenclature system of, 6 .

Nomonyx dominicus, 210.

Nonpareil. See Bunting, Painted.

Note-books, 9.

Notes, recognition of, 61 .

November, birds of, $36,39,40$.

Numenius americanus, 261 .

arcuatus, 263.

borealis, 262 .

hudsonicus, 262.

phæopus, 263.

Nuthatch, Brown-headed, 484

Florida White-breasted, 484.

Red-breasted, 484.

White-breasted, 483.

Nuttallornis borealis, 343 .

Nyctanassa violacea, 228 .

Nyctea nyctea, 315 .

Nycticorax nycticorax nævius, 228.

Oceanites oceanicus, 177.

Oceanodroma castro, 177.

leucorhoa, 177.

Ochthodromus wilsonius wilsonius, 367.

October, birds of, 36, 39, 40.

Odontoglossæ, 216; figured, 122.

Odontophoridæ, 269

Oidemia americana, 208.

deglandi, 209.

fusca, 209.

perspicillata, 209.

Old-squaw, 205.

Old-wife. See Old-squaw.

Olor buccinator, 216.

columbianus, 215.

cygnus, 216.

Oölogist, The, 25.

Opera-glass, 5, 9.

Oporornis agilis, 465 .

formosus, 464 .

philadelphia, 465 .

Oreospiza chlorura, 407.

Orientation, power of, 53 .

Oriole, Baltimore, 65, 74, 365. Orchard, 364.

Oscines, 62.

Osprey, 307. foot of, 108.

Otocoris alpestris alpestris, 348 . alpestris hoyti, 349.

alpestris praticola, 349 . 
Otus asio asio, 313. asio floridanus, 314 .

Oven-bird, 460.

Owl, Acadian. See Owl, Saw-whet.

Barn, 309.

Barred, 109, 110, 311.

Burrowing, 317.

Cat. See Owl, Screech.

Day. See Owl, Hawk.

Florida Barred, 312.

Florida Burrowing, 316.

Florida Screech, 314.

Great Gray, 312.

Great Horned, 315.

Hawk, 316.

Hoot. See Owl, Barred.

Labrador Horned, 315.

Long-eared, 310.

Marsh, 311.

Monkey-faced. See Owl, Barn.

Mottled. See Owl, Screech.

Richardson's, 312.

Saw-whet, 313.

Screech, 313.

Short-eared, 310.

Snowy, 315.

Owls, economic value of, 101 .

Oxeye, Meadow. See Sandpiper, Least. Sand. See Sandpiper, Semipalmated. Oxyechus vociferus vociferus, 265.

Oyster-catcher, 268.

European, 269.

Pandion haliaëtus carolinensis, 307 .

Pagophila alba, 154.

Palmetto-bird. See Yellow-throat, Florida.

Paludicolæ, 229; figured, 123.

Pandionidæ, 307.

Parabuteo unicinctus harrisi, 295.

Parasitism, 76.

Paridæ, 485; figured, 131

Faroquet, Carolina, 317.

Parrakeet. See Paroquet, Carolina.

Parrot, Sea. See Puffin.

Partridge. See Grouse, Ruffed, and Bobwhite.

Birch. See Grouse, Ruffed.

Canada Spruce, 272.

Hudsonian Spruce, 272.

Hungarian, 280.

- Swamp. See Grouse, Canada Spruce.

Passer domesticus domesticus, 378. montanus, 379.

Passerculus princeps, 387. sandwichensis savanna, 388 .

Passerella iliaca iliaca, 405.

Passeres, 337; figured, 128.

Passerherbulus caudacutus, 391 henslowi henslowi, 390.

lecontei, 391.

maritimus fisheri, 394.

maritimus macgillivrai, 394.

maritimus maritimus, 393.

maritimus peninsulæ, 394.

nelsoni nelsoni, 392.

nelsoni subvirgatus, 392.

nigrescens, 395.

Passerina ciris, 411.

cyanea, 410.

versicolor versicolor, 411.
Peabody-bird. See Sparrow, Whitethroated.

Pediceetes phasianellus campestris, 278. phasianellus phasianellus, 278.

Peep. See Sandpipers, Least and Semipalmated.

Peet-weet. See Sandpiper, Spotted.

Pelagodroma marina, 178.

Pelecanidæ, 183; figured, 120.

Pelecanus erythrorhynchus, 184. occidentalis, 184.

Pelican, 56.

Brown, 184.

Frigate. See Man-o'-war-bird. White, 27, 57, 184.

Pelidna alpina alpina, 253. alpina sakhalina, 252.

Perdix perdix, 280.

Penthestes atricapillus atricapillus, 486. carolinensis carolinensis, 487. carolinensis impiger, 488. hudsonicus hudsonicus, 488 . hudsonicus littoralis, 488.

Peregrine. See Hawk, Duck.

Perisoreus canadensis canadensis, 352. canadensis nigricapillus, 352 .

Permanent residents, $32,37$.

Petrel, Black-capped, 176.

Bulwer's, 176.

Hawaiian, 177.

Leach's, 177.

Peale's, 176.

Pintado, 174.

Scaled, 176 .

Storm, 176.

White-bellied, 178 .

White-faced, 178.

Wilson's, 177.

Petrochelidon fulva, 417.

lunifrons lunifrons, 417.

Peucæa æstivalis æstivalis, 401. æstivalis bachmani, 402.

Pewee, Wood, 343.

Pewit. See Phœbe.

Phaëthon æthereus, 179. flavirostris, 178.

Phaëthontidæ, 178; figured, 120.

Phalacrocoracidæ, 182; figured, 120.

Phalacrororax auritus auritus, 182. auritus floridanus, 183. carbo, 182. vigua mexicanus, 183.

Phalarope, Northern, 240. Red, 239.

Wilson's, 241.

Phalaropodidæ, 239; figured, 124.

Phalaropus fulicarius, 239.

Phasianidæ, 280.

Phasianus colchicus, 280. torquatus, 280.

Pheasant. See Grouse, Ruffed. English, 280.

Ring-necked, 280.

Pheugopedius rutilus, 62.

Philohela minor, 244.

Phløeotomus pileatus abieticola, 328. pileatus pileatus, 327 .

Phœbe, 342. Say's, 342.

Phœnicopteridæ, 216; figured, 122.

Phœnicopterus ruber, 216. 
Photographic outfit, 13.

Pici, figured, 127.

Picidæ, figured, 127.

Picoides americanus americanus, 326 arcticus, 325 .

Pigeon, Homing, 53.

Passenger, 282.

Prairie. See Plover, Upland.

West Indian Scaled, 282.

White-crowned, 281.

Wild, 282.

Pintail, 197.

Pipilo erythrophthalmus alleni, 407. erythrophthalmus erythrophthalmus 406. maculatus arcticus, 407.

Pipit, American, 471.

European Meadow, Sprague's, 471.

Piranga erythromelas, 413.

ludoviciana, 414. rubra rubra, 414.

Pisobia bairdi, 251

fuscicollis, 250.

maculata, 249 .

minutilla, 251 .

Planesticus migratorius achrusterus, 8, 499.

migratorius migratorius, $7,8,497$.

migratorius propinquus, 8 .

Plataleidæ, 217; figured, 122.

Plautus impennis, figured, 149.

Plectrophenax nivalis nivalis, 384 .

Plegadis autumnalis, 218. guarauna, 219

Plover, Black-bellied, 263.

Chicken. See Turnstone.

European Golden, 265.

Field. See Plover, Upland.

Golden, 264.

map of, 47.

migration of, 46 .

Grass. See Plover, Unland.

Mountain, 268.

Piping, 266.

Ringed, 267.

Semipalmated, 266.

Snowy, 267.

Upland, 94, 259.

Wilson's, 267.

Plumage, 84.

colors of, 87.

color of and climate, 90 .

color of and concealment, 92.

color of and season, 88.

color of and sex, 88 .

wear, 86.

Podasocys montanus, 268.

Podilymbus podiceps, 141.

Poisoning collections, 21.

Polioptila cærulea cærulea, 491.

Polyborus cheriway, 307 .

Polygamy, 70.

Polysticta stelleri, 207.

Poøectes gramineus gramineus, 386.

Porzana carolina, 234. porzana, 235.

Præcocial birds, 75.

Prairie-Pigeon. See Gull, Franklin's.

Preacher. See Vireo, Red-eyed.

Procellariidæ, 173; figured, 119.
Progne cryptoleuca, 416.

subis subis, 416.

Protonotaria citrea, 439.

Psittaci, 126, 317.

Psittacidæ, 317.

Ptarmigan, Allen's, 275.

Greenland. See Ptarmigan, Reinhardt's.

Ptarmigan, molt of, 86.

Reinhardt's, 276.

Rock, 275.

Welch's, 276.

Willow, 274.

Puffin, 145

Large-billed, 146.

Tufted, 146.

Puffinus assimilis, 176.

borealis, 175 .

gravis, 175 .

griseus, 176.

lherminieri, 175 .

puffinus, 175

Pygopodes, 138; figured, 118.

Pyrocephalus rubinus mexicanus, 347.

Qua-bird. See Heron, Black-crowned Night.

Quail. See Bob-white.

Migratory, 271.

Quail-Dove, Blue-headed, 285.

Key West, 285.

Ruddy, 285.

Quawk. See Heion, Black-crowned Night.

Querquedula cyanoptera, 196. discors, 195.

Quiscalus quiscula æneus, 368.

quiscula aglæus, 367 .

quiscula quiscula, 366 .

Rail, Carolina. See Sora.

Clapper, 232.

Florida Clapper, 232.

King, 231.

Little Black, 235; figured, 105.

Louisiana, 232.

Virginia, 233.

Yellow, 235.

Rain-crow. See Cuckoos.

Rallidæ, 230; figured, 123.

Rallus erepitans crepitans, 232. crepitans saturatus, 232. crepitans scotti, 232.

crepitans waynei, 233.

elegans, 231.

virginianus, 233.

Range, 103.

Raptores, 286; figured, 125.

Raven, 352.

Northern, 352.

Reason, definition of, 111, 112 .

Recurvirostra americana, 241.

Recurvirostridæ, 241.

Red-bird. See Cardinal.

Red-head, 200, 201.

Redpoll, 380.

Greater, 381.

Greenland, 380

Hoary, 380 .

Holboell's, 381.

Mealy. See Redpoll, Hoary. 
Red-shank, 257.

Redstart, 470 ; map of migration of, 45 .

Red-tail, Western, 296.

Reed-bird. See Bobolink.

Reeve, 259.

Regulus calendula calendula, 490 . satrapa satrapa, 489 .

Rhodostethia rosea, 161.

Rhyncophanes mecowni, 386.

Ricebird. See Bobolink.

Ring-neck. See Plover, Semipalmated.

Riparia riparia, 419.

Rissa tridactyla tridactyla, 155.

Robin, 7, 68, 73, 74, 114, 497.

Golden. See Oriole, Baltimore.

Ground. See Towhee.

Southern, 499.

Swamp. See Thrush, Hermit.

Rocker. See Ptarmigan, Rock.

Rockweed Bird. See Sandpiper, Purple.

Rook, European, 355.

Rostrhamus sociabilis, 291.

Rough-leg, Ferruginous, 300.

Ruff, 259.

Rynchopidæ, 172; figured, 119.

Rynchops nigra, 172 .

Saddle-back. See Gull, Great Blackbacked.

Sanderling, 254.

Sandpiper, Baird's, 251.

Bartramian. See Plover, Upland.

Black-bellied. See Dunlin.

Buff-breasted, 260.

Curlew, 253.

Green, 258.

Least, 251.

Pectoral, 249.

Purple, 249.

Red-backed, 252.

Red-breasted. See Knot.

Semipalmated, 253.

Solitary, 257.

Spotted, 261.

Stilt, 248.

Western, 254.

White-rumped, 250.

Sanitation of nest, 81 .

Sapsucker, Yellow-bellied, 326.

Saw-bill. See Merganser, American.

Saxicola œenanthe leucorhos, 499.

Sayornis, phœebe, 342 . saya, 342 .

Scalp Act in Pennsylvania, 101.

Scissor-bill. See Skimmer, Black.

Scolopacidæ, figured, 124.

Scolopax rusticola, 245.

Scoter, American, 208.

Surf, 209.

Velvet, 209.

White-winged, 209.

Scotiaptex nebulosa nebulosa, 312 .

Sea-Dove. See Dovekie.

Sea-Parrot. See Puffin.

Sea-Pigeon. See Guillemot, Black.

Sea-Swallow. See Tern, Common.

Sedge-hen. See Rail, Clapper.

Seiurus aurocapillus, 460.

noveboracensis notabilis, 463 .

noveboracensis noveboracensis, 461

motacilla, 463 .
Senses of birds, 109.

September, birds of, 36,39 .

Setophaga ruticilla, 470 .

Sexing Birds, 20.

Sexual characters, 89.

Shag. See Cormorant.

Shearwater, Allied, 176.

Audubon's, 175.

Cory's, 175.

Dark-bodied, 49.

Greater, 175 .

Manx, 175.

Sooty, 176 .

Shelldrake. See Merganser, American and Red-breasted.

Pond. See Merganser, American.

Ruddy, 196.

Shells, for collecting, 14 .

Shore-birds, 238.

Shoveller, 196.

Shrike, Loggerhead, 423.

Migrant, 423.

Northern, 422

Sialia sialis sialis, 499 .

Sickle-bird. See Curlew, Long-billed.

Sight, sense of, 110.

Siskin, Pine, 383.

Sitta canadensis, 484.

carolinensis atkinsi, 484 .

carolinensis carolinensis, 483.

pusilla, 484

Sittidæ, 482; figured, 131.

Skimmer, Black, 172.

Skua, 150 .

Skunk-head. See Scoter, Surf.

Skylark, 348.

Smell, sense of, 109 .

Smew, 190.

Snail-Hawk. See Kite, Everglade.

Snake-bird, 181.

Snipe, American. See Snipe, Wilson's. Brown. See Dowitcher.

English. See Snipe, Wilson's.

European, 247.

Grass. See Sandpiper, Pectoral.

Gray. See Knot and Dowitcher.

Great, 247.

Jack. See Snipe, Wilson's.

Red-breasted. See. Dowitcher, and Knot.

Robin. See Knot and Dowitcher

Rock. See Sandpiper, Purple.

Surf. See Sanderling.

Wilson's, 94, 245.

Winter. See Sandpiper, Purple

Snowbird. See Junco, Slate-colored.

White. See Snow Bunting.

Snow Bunting, 86, 100.

Snowflake. See Bunting, Snow.

Societies, Ornithological, 23.

Solitaire, Townsend's, 497.

Somateria dresseri, 207.

molissima borealis, 207.

spectabilis, 208.

Song, 62 .

functions of, 62 .

geographical variations of, 64 .

imitation of, 65 .

inheritance of, 64 .

Sora, 234.

South-southerly. See Old-squaw. 
Sparrow. Acadian Sharp-tailed, 392.

Aleutian Song, 90.

Bachman's, 402.

Baird's, 389.

Brewer's, 399.

Bush. See Sparrow, Field.

Chipping, 398.

Clay-colored, 399.

Desert Song, 90.

Dusky Seaside, 394.

English, 378.

European Tree, 379.

Field, 399.

Florida Grasshopper, 390.

Fox, 405.

Gambel's, 406.

Grasshopper, 389.

Harris's, 395.

Henslow's, 390.

House, 54, 68, 70, 114, 116, 378.

Ipswich, 387.

Lark, 394.

Leconte's, 391.

Lincoln's, 403.

Louisiana Seaside, 394.

Macgillivray's Seaside, 394 .

Mexican Song, 90.

Nelson's, 392.

Pine-woods, 401.

Savannah, 388.

Scott's Seaside, 393.

Seaside, 85, 393.

Sharp-tailed, 85, 391.

Song, $68,80,402$; climatic races of, 90-92.

Sooty Song, 90.

Swamp, 404.

Tree, 100, 397.

Vesper, 386.

Western Field, 400.

White-crowned, 396.

White-throated, 397.

Yellow-winged. See Sparrow, Grasshopper.

Spatula clypeata, 196.

Species, life of, 115 . status of, 113.

Speckle-belly. See Goose, American White-fronted.

Speed of birds, 51 .

Speotyto cunicularia floridana, 316. cunicularia hypogæa, 317.

Sphyrapicus varius varius, 326 .

Spine-tail. See Duck, Ruddy.

Spinus notatus, 384 pinus pinus, 383 .

Spiza americana, 412.

Spizella breweri, 399 .

monticola monticola, 397.

pallida, 399 .

passerina passerina, 398.

pusilla arenacea, 400 .

pusilla pusilla, 399 .

Spoonbill. See Shoveller.

Roseate, 110, 217.

Sprigtail, See Pintail.

Squatarola squatarola, 263.

Stake-driver, See Bittern, American.

Starling, 98, 355.

Starnœenas cyanocephala, 285.

Steganopodes, 178; figured, 120.
Steganopus tricolor, 241.

Stelgidopteryx serripennis, 419.

Stercorariidæ, 150; figurej, 119.

Stercorarius longicaudus, 150.

parasiticus, 151.

pomarinus, 150.

Sterna anæthetus, 170. antillarum, 169. caspia, 165 .

dougalli, 168.

forsteri, 166 .

fuscata, 170 .

hirundo, 167.

maxima, 165.

paradisea, 168.

sandvicensis acuflavida, 166. trudeaui, 166.

Sterninæ, 162; figured, 119.

Stiff Tail. See Duck, Ruddy.

Stilt, Black-necked, 242.

Stone-chat. See Wheatear.

Storks, 219.

Wood. See Ibis, Wood.

Strigidæ, 309; figured, 125.

Striker, Little. See Tern, Least.

Strix varia alleni, 312 .

varia varia, 311 .

Sturnella magna argutula, 363 . magna magna, 362 .

neglecta, 363 .

Sturnidæ, 355; figured, 129.

Sturnus vulgaris, 355 .

Sula bassana, 180. cyanops, 180.

Sula leucogastra, 179. piscator, 180.

Sulidæ, 179; figured, 120 .

Summer residents, 32 . visitants, 33 .

Surina ulula caparoch, 316.

Swallow, Bahama, 419.

Bank, 419.

Barn, 417.

Chimney, 335.

Cliff, 417.

Cuban Cliff, 417.

Eaves. See Swallow Cliff.

European, 418.

Rough-winged, 419.

Tree, 45, 76, 418; figured, 105 .

White-bellied. See Swallow, Tree.

Swan, Trumpeter, 216.

Whistling, 215.

Whooping, 216.

Swift, Chimney, 335.

Sylviidæ, 488; figured, 132.

Synthliboramphus antiquus, 146.

Tail, uses of, 106.

Tanager, Scarlet, 85, 88, 94, 100, 413.

Summer, 414.

Western, 414.

Tangaridæ, figured, 129.

Taste, sense of, 109.

Tattler. See Yellow-legs, Greater.

Teal, Blue-wing, 195.

Cinnamon, 196.

European, 195.

Green-winged, 195.

Summer. See Teal, Blue-wing.

Winter. See Teal, Green-wing. 
See Sandpiper, Spotted. See Yellow-legs, Greater. tes palustris griseus, 481 . 3 iliacus, 481.

is marianæ, 481.

is palustris, 480 .

nent of birds, 114 .

ure control, laws of, 28.

tic, 168.

46,170 .

d, 170 .

s, 166.

2, 165.

n, 167.

3, 166.

ed, 164.

69 .

. See Tern, Gull-billed.

-wstate, 168.

Royal, 165.

Sandwich. See Tern, Cabot's.

Short-tailed. See Tern, Black.

Sooty, 54, 170.

Trudeau's, 166.

White-winged Black, 171.

Wilson's. See Tern, Common.

Tertiary period, 57 .

Tetraonidæ, 272.

Thalassidroma pelagica, 176.

Thalassogeron culminatus, 173 .

Thayer, A. H., researches of, 93.

Thistle-bird. See Goldfinch.

Thrasher, Brown, 474.

Thrush, Alice's. See Thrush, Gray cheeked.

Bicknell's, 495.

Brown. See Thrasher, Brown.

Golden-crowned. See Oven-bird.

Gray-cheeked, 494.

Hermit, 496.

Olive-backed, 495.

Red-winged, 497.

Swainson's. See Thrush, Olive-backed.

Tawny. See Veery.

Varied, 499.

Willow, 494.

Wood, 492.

Thryomanes bewicki bewicki, 477 .

Thryothorus ludovicianus ludovicianus, 476.

ludovicianus miamensis, 476.

Thunder-pumper. See Bittern, American.

Tiaris bicolor, 412 .

canora, 412.

Timberdoodle. See Woodcock.

Tinea, 21.

Tinker. See Auk, Razor-billed.

Tip-up. See Sandpiper, Spotted.

Titlark. See Pipit, American.

Titmouse, Tufted, 485.

Totanus flavipes, 256.

melanoleucus, 256.

totanus, 257.

Towhee, 406 .

Aretic, 407.

Green-tailed, 407.

White-eyed, 407.

Toxostoma rufum, 474.

Transient visitants, 33 .

Tree-duck, Fulvous, 215.

Tringa canutus, 248.
Trinomials, 7 .

Trochilidæ, 335; figured, 127.

Troglodytes aëdon aëdon, 477 . aëdon parkmani, 478 .

Troglodytidæ, 475; figured, 131.

Tropic-birds, Red-billed, 179. Yellow-billed, 178, 179.

Tryngites subruficollis, 260.

Tube-nosed Swimmers, 172.

Tubinares, 72; figured, 119.

Turdidæ, 491; figured, 132.

Turdus iliacus. musicus, 497.

Turkey, Florida, 279. Wild, 279.

Turnstone, 46. 268. Ruddy, 268.

Tympanuchus americanus americanus, 276.

cupido, 277.

Tyrannidæ, 338; figured, 128.

Tyrannus dominicensis dominicensis, 340 . tyrannus, 339. verticalis, 340 .

Uria lomvia lomvia, 148. ringvia, 147. troile troile, 147.

Vanellus vanellus, 264.

Veery, 493.

Vermivora bachmani, 441. celata celata, 444 .

chrysoptera, 443.

lawrencei, 443.

leucobronchialis, 442.

peregrinus, 446.

pinus, 441.

rubricapilla rubricapilla, 444.

Vireo belli belli, 429 .

Bell's, 429.

Bermuda, White-eyed, 429.

bermudianus, 429 .

Black-whiskered, 424.

Blue-headed, 427.

griseus griseus, 428.

griseus maynardi, 429.

Key West, 429.

Mountain Solitary, 428.

Philadelphia, 426.

Red-eyed, 425.

Solitary. See Vireo, Blue-headed.

Warbling, 426.

White-eyed, 428.

Yellow-throated, 427.

Vireonidæ, 424; figured, 130.

Vireosylva calidris barbatula, 424. gilva gilva, 426 .

olivacea, 425 .

philadelphica, 426 .

Vulture, Black, 287.

Turkey, 287.

Vultures, as scavengers, 101.

Wagtail, European White, 472.

Warbler, Audubon's, 451.

Bachman's, 441.

Bay-breasted, 453.

Black and White, 438.

Black and Yellow. See Warbler, Magnolia.

Blackburnian, 455. 
Black-throated Blue, 449.

Black-throated Green, 457.

Blackpoll, 454 ; map of migration of, 42 .

Blue-winged, 441.

Blue Yellow-backed. See Warblers.

Brewster's, 442.

Cairnss, 450.

Canadian, 469.

Cape May, 448.

Cerulean, 452.

Chestnut-sided, 453.

Connecticut, 465 .

Golden-winged, 443.

Hooded, 468.

Kentucky, 464.

Kirtland's, 457.

Lawrence's, 443.

Magnolia, 451.

Mourning, 465; map of migration of, 43.

Myrtle, 450.

Nashville, 444.

Northern Parula, 447.

Orange-crowned, 444.

Palm, 459.

Parula, 447.

Pine, 458.

Prairie, 460.

Prothonotary, 439.

Red-poll. See Warblers, Palm and Yellow Palm.

Summer. See Warbler, Yellow.

Swainson's 440.

Sycamore, 456.

Tennessee, 446.

Townsend's 457.

Wilson's, 468.

Worm-eating, 440.

Yellow, 65, 448.

Yellow Palm, 459.

Yellow-rumped. See Warbler, Myrtle.

Yellow-throated, 456.

Warblers, migration of, 41.

Water-Thrush, 461.

Grinnell's, 463 .

Louisiana, 463.

Water-Turkey, 181.

Water-witch. See Grebe, Pied-billed.

Wave, bird. o2.

Wavey. See Goose, Snow.

Blue. See Goose, Blue.

Wraxwing, Bohemian, 420 .

Cedar, 80, 99, 421.

Whale bird. See Phalarope, Red.

Wheatear, Greenland, 499.

Whimbrel, $2 \mathrm{f}^{\prime} 3$.

Whip-poor-wili, 72,332

Whiskey-Jfck. See Jay, Canada.

Whistler. See Golden-eyes.

Widgeon, See Baldpate.

European, 194.

Willet, 258.

Western, 258.

Wilson Bulletin, 25.

Wilson Ornithological Club, 23.

Wilsonia eanadensis, 469. citrina, 468. pusilla pusilla, 468 .

Wing, uses of, 105.

Winter residents, $33,37$.

Woodcock, 94; American figured, 104, 106. American, 244.
Woodcock, Black, See Wc Pileated.

European, 245.

Woodpecker, American T?

Arctic Three-toed, 325.

Black-backed. See Wor Three-toed.

Downy, 325; figured, 11

Golden-winged. See Fl

Hairy, 323.

Ivory-billed, 323.

Ladder-backed. See

American Three-toe

Newfoundland, 324.

Northern Hairy, 324.

Northern Pileated, $32 \delta$

Pigeon. See Flicker.

Pileated, 327.

Red-bellied, 329.

Red-cockaded, 325.

Red-headed, 328.

Southern Downy, 324 .

Southern Hairy, 324.

Yellow-bellied. See Sapsucker, Yellow. bellied.

Wren, Bewick's, 477.

Carolina, 476 .

Florida, 476

House, 477.

Long-billed Marsh, 480.

Marian's Marsh, 481.

Mocking. See Wren, Carolina.

Prairie Marsh, 481.

Short-billed Marsh, 479.

Western House, 478.

Winter, 478.

Worthington's Marsh, 481.

Wood. See Wren, House.

Xanthocephalus xanthocephalus, 360 .

Xanthochroism, 96.

Xema sabini, 162.

Yellow-bird. See Goldfinch.

Summer. See Warbler, Yellow.

Yellow-hammer. See Flicker.

Yellow-legs, 256

Greater, 256

Summer. See Yellow-legs.

Winter. See Yellow-legs, Greater.

Yellow-throat, Florida, 467.

Maryland, 65, 100, 466.

Northern, 466.

Young birds, colors of, 95.

condition of, at birth, 79 .

defense of, 81 .

exercises of, 81.

fear in, 81 .

foeding of, 80 .

flight of, 82 .

growth of, 80.

voice of, 81 .

Yucker. See Flicker.

Zamelodia ludoviciana, 408.

Zebra-bird. See Woodpecker. Red bellied.

Zenaida zenaida, 284.

Zenaidura macroura caroiinensis, 283

Zonotrichia albicollis, 397.

leucophrys gambeli, 396.

leucophrys leucophrys, 396.

querula, 395. 






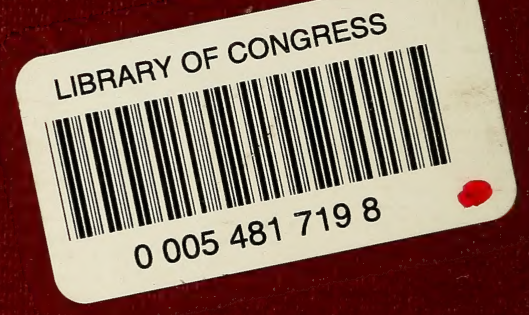

